



\section{Proceedings - The Tenth International Symposium GRID 2020 \\ EDITION:}

INTERNATIONAL SYMPOSIUM ON GRAPHIC ENGINEERING AND DESIGN

PUBLISHER:

UNIVERSITY OF NOVI SAD

FACULTY OF TECHNICAL SCIENCES

DEPARTMENT OF GRAPHIC ENGINEERING AND DESIGN

21000 Novi Sad, Trg Dositeja Obradovića 6

\section{EDITORIAL COMMITTEE: \\ PhD Nemanja Kašiković \\ PhD Dragoljub Novaković \\ PhD Živko Pavlović \\ PhD Sandra Dedijer}

TECHNICAL SECRETARY:

PhD Bojan Banjanin

EDITOR:

PhD Sandra Dedijer

LAYOUT AND PRODUCTION:

GRID team

PRINT:

Grafički centar GRID, Trg Dositeja Obradovića 6, Novi Sad

CIRCULATION:

150 copies

СIP - Каталогизација у публикацији

Библиотеке Матице српске, Нови Сад

$655(082)$

7.05:655(082)

INTERNATIONAL Symposium on Graphic Engineering and Design GRID (10 ; 2020 ; Novi Sad)

Proceedings [Elektronski izvor] / 10th International Symposium on Graphic Engineering and Design GRID 2020, November 12-14th, 2020, Novi Sad ; [editor Sandra Dedijer]. - Novi Sad : Faculty of Technical Sciences, Department of Graphic Engineering and Design, 2020. - (International Symposium on Graphic Engineering and Design GRID, ISSN 2620-1437)

Način pristupa (URL): https://www.grid.uns.ac.rs/symposium/download/2020/ proceedings grid 2020.pdf. - Opis zasnovan na stanju na dan 13.11.2020. - Nasl. s naslovnog ekrana. - Bibliografija uz svaki rad. - Registar.

ISBN 978-86-6022-303-8

a) Графичка индустрија - Зборници б) Графички дизајн - Зборници COBISS.SR-ID 25675017 


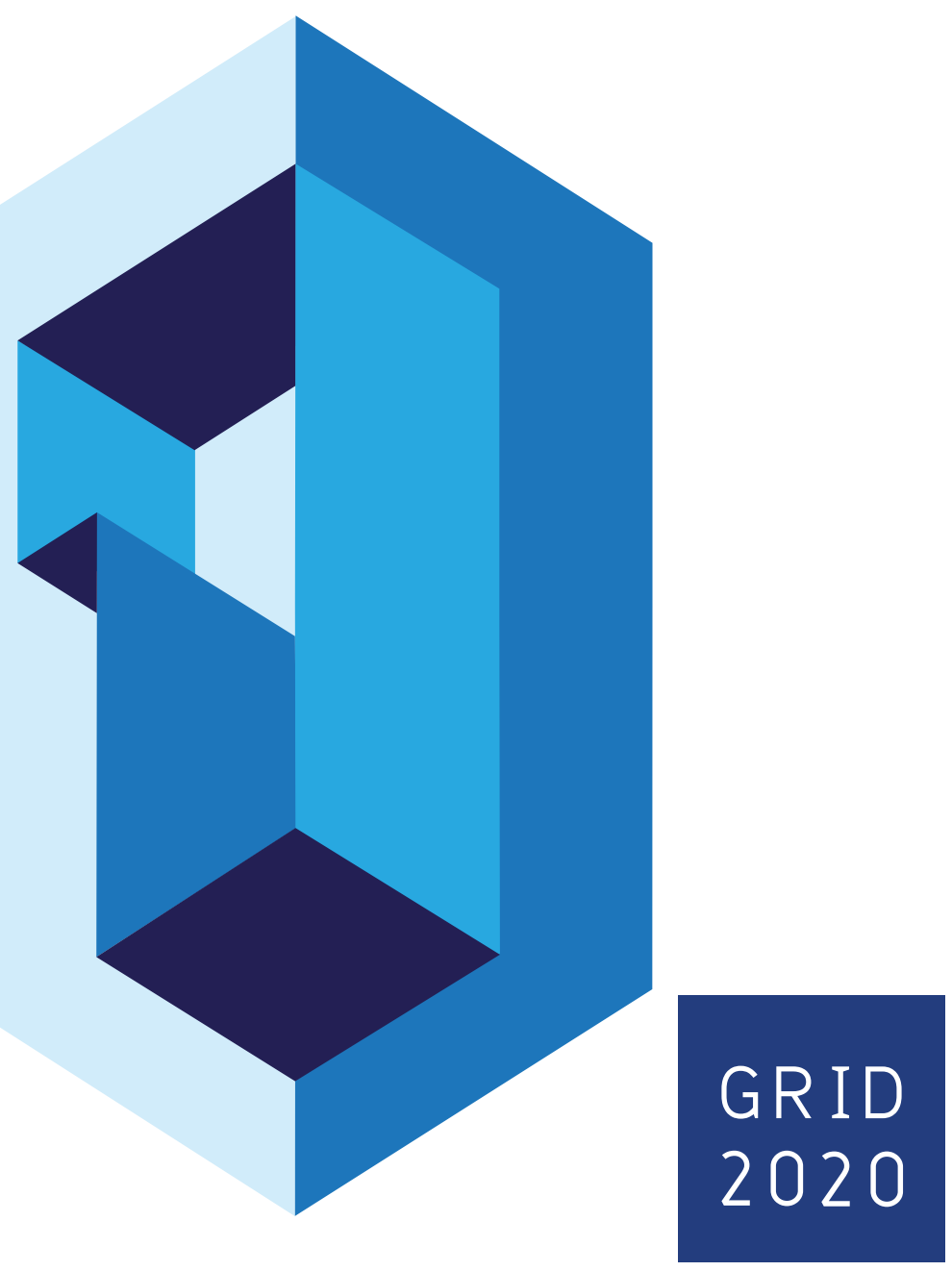

PROCEEDINGS

$\bigcap \begin{aligned} & \text { TH } \\ & \text { INTERNATIONAL SYMPOSIUM ON } \\ & \text { GRAPHIC ENGINEERING AND DESIGN }\end{aligned}$

UNIVERSITY OF NOVI SAD

FACULTY OF TECHNICAL SCIENCES

DEPARTMENT OF GRAPHIC ENGINEERING AND DESIGN 



\section{SCIENTIFIC COMMITTEE}

Dragoljub Novaković, University of Novi Sad, Faculty of Technical Sciences, Novi Sad, (president) (SRB)

Thomas Hoffman-Walbeck, Stuttgart Media University, Stutgart (DEU)

Lidija Mandić, University of Zagreb, Faculty of Graphic Arts, Zagreb (HRV)

Igor Majnarić, University of Zagreb, Faculty of Graphic Arts, Zagreb (HRV)

Sanja Mahović Poljaček, University of Zagreb, Faculty of Graphic Arts, Zagreb (HRV)

Diana Gregor-Svetec, University of Ljubljana, Faculty of Natural Sciences and Engineering, Ljubljana (SVN)

Aleš Hladnik, University of Ljubljana, Faculty of Natural Sciences and Engineering, Ljubljana (SVN)

Tadeja Muck, University of Ljubljana, Faculty of Natural Sciences and Engineering, Ljubljana (SVN)

Raša Urbas, University of Ljubljana, Faculty of Natural Sciences and Engineering, Ljubljana (SVN)

Urška Stankovič Elesini, University of Ljubljana, Faculty of Natural Sciences and Engineering, Ljubljana (SVN)

Tomáš Syrový, University of Pardubice, Faculty of Chemical Technology, Pardubice (CZE)

Michal Veselý, Brno University of Technology, Faculty of Chemistry, Brno (CZE)

Petr Nemec, University of Pardubice, Faculty of Chemical Technology, Pardubice (CZE)

Michal Ceppan, Slovak University of Technology in Bratislava,

Faculty of Chemical and Food Technology, Bratislava (SVK)

Joanna Ewa Izdebska, Warsaw University of Technology, Faculty of Production Engineering, Warsaw (POL)

Sabu Thomas, Mahatma Gandhi University, Kottayam (IND)

Csaba Horváth, Obuda University, Faculty of Light Industry and Environmental Engineering, Budapest (HUN)

Ákos Borbély, Obuda University, Faculty of Light Industry and Environmental Engineering, Budapest (HUN)

László Koltai, Obuda University, Faculty of Light Industry and Environmental Engineering, Budapest (HUN)

Rafael Huertas, University of Granada, Faculty of Science, Granada (ESP)

Anastasios Politis, Technological Educational Institute of Athens, Athens (GRC)

Branko Milosavljević, University of Novi Sad, Faculty of Technical Sciences, Novi Sad (SRB)

Iskren Spiridonov, University of Chemical Technology and Metallurgy, Sofia (BGR)

Mladen Stančić, University of Banja Luka, Faculty of Technology, Banja Luka (BIH)

Miljana Prica, University of Novi Sad, Faculty of Technical Sciences, Novi Sad (SRB)

Nemanja Kašiković, University of Novi Sad, Faculty of Technical Sciences, Novi Sad (SRB)

Gojko Vladić, University of Novi Sad, Faculty of Technical Sciences, Novi Sad (SRB)

Živko Pavlović, University of Novi Sad, Faculty of Technical Sciences, Novi Sad (SRB)

Jonas Malinauskas, Vilnius College of Technologies and Design, Vilnius (LTU)

Roberto Pašić, St. Clement of Ohrid University of Bitola, Bitola (MKD)

Vladan Končar, Ecole Nationale Supérieure des Arts et Industries Textiles, Roubaix (FRA]

Arif Özcan, Marmara University, School of Applied Sciences, Printing Technologies, Istanbul (TUR)

Catarina Silva, Polytechnic Institute of Cávado and Ave, Barcelos (POR)

Tim C. Claypole, Swansea University, Welsh Centre for Printing and Coating, Swansea (GBR]

Alexandra Pekarovicova, Western Michigen University, Department of Chemical and Paper Engineering, Kalamazoo (USA)

\section{ORGANIZATIONAL COMMITTEE}

Dragoljub Novaković, University of Novi Sad, Faculty of Technical Sciences, Novi Sad (SRB)

Živko Pavlović, University of Novi Sad, Faculty of Technical Sciences, Novi Sad (SRB)

Miljana Prica, University of Novi Sad, Faculty of Technical Sciences, Novi Sad (SRB)

Nemanja Kašiković, University of Novi Sad, Faculty of Technical Sciences, Novi Sad (SRB)

Sandra Dedijer, University of Novi Sad, Faculty of Technical Sciences, Novi Sad (SRB)

Gojko Vladić, University of Novi Sad, Faculty of Technical Sciences, Novi Sad (SRB)

Magdolna Pál, University of Novi Sad, Faculty of Technical Sciences, Novi Sad (SRB)

Uroš Nedeljković, University of Novi Sad, Faculty of Technical Sciences, Novi Sad (SRB)

Željko Zeljković, University of Novi Sad, Faculty of Technical Sciences, Novi Sad (SRB)

Ivan Pinćjer, University of Novi Sad, Faculty of Technical Sciences, Novi Sad (SRB)

Neda Milić Keresteš, University of Novi Sad, Faculty of Technical Sciences, Novi Sad (SRB) 
Ivana Tomić, University of Novi Sad, Faculty of Technical Sciences, Novi Sad (SRB) Ivana Jurič, University of Novi Sad, Faculty of Technical Sciences, Novi Sad (SRB) Vladimir Dimovski, University of Novi Sad, Faculty of Technical Sciences, Novi Sad (SRB) Bojan Banjanin, University of Novi Sad, Faculty of Technical Sciences, Novi Sad (SRB) Rastko Milošević, University of Novi Sad, Faculty of Technical Sciences, Novi Sad (SRB) Stefan Đurđević, University of Novi Sad, Faculty of Technical Sciences, Novi Sad (SRB) Jelena Vladušić, University of Novi Sad, Faculty of Technical Sciences, Novi Sad (SRB) Savka Adamović, University of Novi Sad, Faculty of Technical Sciences, Novi Sad (SRB) Vladimir Zorić, University of Novi Sad, Faculty of Technical Sciences, Novi Sad (SRB) Jelena Novaković, University of Novi Sad, Faculty of Technical Sciences, Novi Sad (SRB) Vesna Gvoić, University of Novi Sad, Faculty of Technical Sciences, Novi Sad (SRB) Saša Petrović, University of Novi Sad, Faculty of Technical Sciences, Novi Sad (SRB) Gordana Bošnjaković, University of Novi Sad, Faculty of Technical Sciences, Novi Sad (SRB] Dunja Branovački, University of Novi Sad, Faculty of Technical Sciences, Novi Sad (SRB) Predrag Ubović, University of Novi Sad, Faculty of Technical Sciences, Novi Sad (SRB) Ana Lilić, University of Novi Sad, Faculty of Technical Sciences, Novi Sad (SRB) Nada Miketić, University of Novi Sad, Faculty of Technical Sciences, Novi Sad [SRB] Petar Vasilić, University of Novi Sad, Faculty of Technical Sciences, Novi Sad (SRB)

\section{CHAIR OF ORGANIZATIONAL COMMITTEE}

Sandra Dedijer, University of Novi Sad, Faculty of Technical Sciences, Novi Sad (SRB)

\section{TECHNICAL SECRETARY}

Bojan Banjanin, University of Novi Sad, Faculty of Technical Sciences, Novi Sad (SRB)

\section{REVIEWING COMMITTEE}

Tomislav Cigula, University of Zagreb, Faculty of Graphic Arts, Zagreb (HRV) Igor Majnarić, University of Zagreb, Faculty of Graphic Arts, Zagreb (HRV) Sanja Mahović Poljaček, University of Zagreb, Faculty of Graphic Arts, Zagreb (HRV) Csaba Horváth, Obuda University, Faculty of Light Industry and Environmental Engineering, Budapest (HUN) László Koltai, Obuda University, Faculty of Light Industry and Environmental Engineering, Budapest (HUN)

Erzsébet Novotny, Obuda University, Faculty of Light Industry and Environmental Engineering, Budapest (HUN)

Raša Urbas, University of Ljubljana, Faculty of Natural Sciences and Engineering, Ljubljana (SVN) Klementina Možina, University of Ljubljana, Faculty of Natural Sciences and Engineering, Ljubljana (SVN) Dragoljub Novaković, University of Novi Sad, Faculty of Technical Sciences, Novi Sad (SRB) Iskren Spiridonov, University of Chemical Technology and Metallurgy, Sofia (BGR) Rafael Huertas, University of Granada, Faculty of Science, Granada (ESP) Ondrej Panak, University of Pardubice, Faculty of Chemical Technology, Pardubice (CZE) Markéta Držková, University of Pardubice, Faculty of Chemical Technology, Pardubice (CZE) Bohumil Jašúrek, University of Pardubice, Faculty of Chemical Technology, Pardubice (CZE) Petr Dzik, Brno University of Technology, Faculty of Chemistry, Brno (CZE) Viera Jančovičová, Slovak University of Technology in Bratislava, Faculty of Chemical and Food Technology, Bratislava (SVK) Pavol Gemeiner, Slovak University of Technology in Bratislava, Faculty of Chemical and Food Technology, Bratislava (SVK) Miljana Prica, University of Novi Sad, Faculty of Technical Sciences, Novi Sad (SRB) Sandra Dedijer, University of Novi Sad, Faculty of Technical Sciences, Novi Sad (SRB) Živko Pavlović, University of Novi Sad, Faculty of Technical Sciences, Novi Sad (SRB) Nemanja Kašiković, University of Novi Sad, Faculty of Technical Sciences, Novi Sad (SRB) 
Magdolna Pál, University of Novi Sad, Faculty of Technical Sciences, Novi Sad (SRB) Gojko Vladić, University of Novi Sad, Faculty of Technical Sciences, Novi Sad (SRB) Uroš Nedeljković, University of Novi Sad, Faculty of Technical Sciences, Novi Sad (SRB) Ivan Pinćjer, University of Novi Sad, Faculty of Technical Sciences, Novi Sad (SRB) Mladen Stančić, University of Banja Luka, Faculty of Technology, Banja Luka (BIH) Thomas Hoffman-Walbeck, Stuttgart Media University, Stutgart (DEU) Joanna Ewa Izdebska, Warsaw University of Technology, Faculty of Production Engineering, Warsaw (POL) Anastasios Politis, Technological Educational Institute of Athens, Athens (GRC) Zuzanna Żołek-Tryznowska, Warsaw University of Technology, Faculty of Production Engineering, Warsaw (POL) Thomas Sabu, Mahatma Gandhi University, School of Chemical Sciences, Kottayam (IND) Jonas Malinauskas, Vilnius College of Technologies and Design, Vilnius (LTU) Roberto Pašić, St. Clement of Ohrid University of Bitola, Bitola (MKD) Vladan Končar, Ecole Nationale Supérieure des Arts et Industries Textiles, Roubaix (FRA) Arif Özcan, Marmara University, School of Applied Sciences, Printing Technologies, Istanbul (TUR) Catarina Silva, Polytechnic Institute of Cávado and Ave, Barcelos (POR)

Tim C. Claypole, Swansea University, Welsh Centre for Printing and Coating, Swansea (GBR] Alexandra Pekarovicova, Western Michigen University, Department of Chemical and Paper Engineering, Kalamazoo (USA) 


\section{WITH SUPPORT OF:}

Ministry of Education, Science and Technological Development, Republic of Serbia

University of Novi Sad, Faculty of Technical Sciences, Novi Sad,

Republic of Serbia

CIII-RS-0704-09-2021

CIII-RS-1311-03-2021

\section{CO - ORGANISER:}

University of Zagreb, Faculty of Graphic Arts,

Zagreb, Republic of Croatia

Obuda University, Faculty of Light Industry and Environmental Engineering, Budapest, Hungary

University of Ljubljana, Faculty of Natural Sciences and Engineering,

Ljubljana, Republic of Slovenia

\section{SPONSORS:}

Alfa Digital, Belgrade, Serbia

Centropapir, Sremski Karlovci, Serbia

Futura, Novi Sad, Serbia

Mojić d.o.o., Bijeljina, Bosnia and Herzegovina

Pre-Print, Novi Sad, Serbia 


\section{TABLE OF CONTENTS}

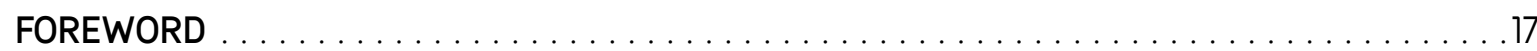

\section{INTRODUCTORY INVITED LECTURES}

1. Ozcan A.:

NEW APPROACHES IN SMART PACKAGING TECHNOLOGIES . . . . . . . . . . . . . . 21

2. Karlovits I:

LIGNOCELLULOSIC BIO-REFINERY DOWNSTREAM PRODUCTS

IN FUTURE PACKAGING APPLICATIONS

\section{PRINTING ADDED VALUE}

3. Plazonić I., Bates I., Džimbeg-Malčić V., Zember D.:

COLORIMETRIC CHANGES OF WATERBASED FLEXOGRAPHIC INK

PRINTED ON HEMP-BASED PAPERS EXPOSED TO ARTIFICIAL AGEING . . . . . . . . 57

4. Tomić I., Pinćjer I., Miketić N.:

THE INFLUENCE OF TOTAL BASE INK COVERAGE ON THE UNIFORMITY

OF DIGITAL PRINTS OVERPRINTED WITH PEARLESCENT INKS

5. Vrabič Brodnjak U., Todorova D.:

INVESTIGATION OF THE OPTICAL PROPERTIES OF CHITOSAN AND RICE STARCH

BLENDS, AS A FILLER IN PAPER OR AS A FILM FOR PACKAGING APPLICATIONS . . . . .69

6. Todorova D., Pavlova N.:

INVESTIGATION ON THE PRINTABILITY OF SPECIALTY

PAPERS FOR LUXURY LABELS

7. Durnyak B., Lutskiv M., Buben V., Shepita P., Petriaszwili G., Żołek-Tryznowska Z.:

MATHEMATICAL MODELLING OF OPTICAL DENSITY ON

THE EXAMPLE OF PRODUCING RASTERIZED FILMS.

8. Cigula T., Hudika T., Katana M., Golik Krizmanić M., Tomašegović T.:

THE INFLUENCE OF PCL-ZNO COATING COMPOSITION

ON COATED OFFSET CARDBOARD PRINTS

9. Jamnicki Hanzer S., Kulčar R., Vukoje M., Širol P.: MECHANICAL AND CHEMICAL RESISTANCE

OF THERMOCHROMIC PACKAGING PRINTS.

10. Hudika T., Cigula T., Žličarić M., Strižić Jakovljević M.: PCL-TIO ${ }_{2}$ NANOCOMPOSITE TO IMPROVE AGEING OF OFFSET PRINTS . . . . . . . . . . . 119

11. Jurič I., Novaković D., Kašiković N., Dedijer S.:

INFLUENCE OF DIGITIZATION INPUT DEVICE ON CALCULATION OF

PRINT (NON)UNIFORMITY VALUE OF PRINTS USING ISO 13660 METHOD

12. Milošević R., Kašiković N., Pavlović Ž., Petrović S., Kukuruzović D., Urbas R.:

THE EFFECTS OF FRAGRANCED MICROCAPSULES APPLICATION ON THE

PHYSICAL AND PRINT QUALITY CHARACTERISTICS OF THE PRINTS

\section{PAPER AS A SUBSTRATE}

13. Czene T., Koltai L:

THE EFFECT OF THE VIRGIN FIBERS TO THE

PROPERTIES OF DIFFERENT PAPER PRODUCTS. 
14. Yilan G., Ozcan A., Caglar T.:

SUSTAINABLE CARDBOARD LABEL PRODUCTION . . . . . . . . . . . . . . . . . . . . . . 153

15. Kulčar R., Vukoje M., Krajnović I., Rožić M.:

INFLUENCE OF RECYCLED FIBRES IN PAPER ON

THE UV STABILITY OF THERMOCHROMIC PRINTS.

16. Birtane $\mathrm{H}$ :

THE PRODUCTION OF FLAME RETARDANT PAPER WITH DOPO . . . . . . . . . . . . . 169

17. Karlovits I., Lavrič G.:

PAPER SURFACE EFFICIENCY AND INKJET COLOUR

REPRODUCTION ON INVASIVE AND AGRO RESIDUE PAPERS . . . . . . . . . . . 177

18. Żołek-Tryznowska Z., Więcek M.:

MEASUREMENTS OF SURFACE FREE ENERGY AS A TOOL TO ASSES

THE EFFECT OF VARNISHING AND PRINTING OF THE PAPER SUBSTRATES . . . . . . . . 185

19. Šumiga B., Karlovits I., Šumiga B.:

ADHESION STRENGTH OF TEMPERATURE VARIED NANOCELLULOSE

ENHANCED WATER BASED PAPER AND CARDBOARD ADHESIVES.

\section{GRAPHIC MATERIALS AND PROCESSES EFFICIENCY}

20. Adamović S., Pinćjer I., Banjanin B., Đurđević S., Miketić N.:

THE EVALUATION OF THE ORGANIC LOAD OF THE WASTE

OFFSET DEVELOPER WITH EXTRACTION METHODS

21. Kulić Mandić A., Bečelić-Tomin M., Kerkez Đ., Pucar Milidrag G., Pešić V., Prica M.:

A MINI REVIEW: OPTIMAL DYE REMOVAL BY

FENTON PROCESS CATALYSED WITH WASTE MATERIALS.

22. Vrabič Brodnjak U., Trematerra P.:

PASTA PACKAGING WITH BIO-BASED BARRIER TO PREVENT INSECT INFESTATION . . 213

23. Arman Kandirmaz E., Bunyamin Zelzele O.:

THE PRODUCTION OF ECOFRIENDLY BIOFILM

WITH NATURAL OIL FOR FOOD PACKAGING

24. Petriaszwili G., Janicki P., Komarov S.:

INVESTIGATIONS ON BOOK CUTTING BY CIRCULAR

KNIFE WITH ECCENTRIC BLADE MOVEMENT

25. Gvoić V., Prica M., Kerkez Đ., Lužanin O., Kulić Mandić A.,

Bečelić-Tomin M., Tomašević Pilipović D.:

FENTON-LIKE OXIDATION OF FLEXOGRAPHIC WATER-BASED KEY

(BLACK) DYE: A DEFINITIVE SCREENING DESIGN OPTIMIZATION

26. Prica M., Tubić A., Lončarski M., Gvoić V., Vasiljević S., Pavlović Ž., Agbaba J.:

APPLICATION OF ADVANCED OXIDATION PROCESS FOR THE REMOVAL OF SYNTHETIC WATER-BASED PRINTING DYE AND MICROPLASTICS FROM AQUEOUS SOLUTION . . . 243

27. Vukoje M., Bolanča Mirković I., Bešlić M., Petković G.:

THE INFLUENCE OF ARTIFICIAL AGING ON RECYCLABILITY

AND MECHANICAL STABILITY OF PHARMACEUTICAL PACKAGING

28. Pinćjer I., Miketić N., Tomić I., Adamović S.:

EXPLORING THE VARIOUS PARAMETERS OF

$\mathrm{CO}_{2}$ LASER IN THE CUTTING OF PAPER.

29. Pál M., Banjanin B., Dedijer S., Vladić G., Bošnjaković G.:

PRELIMINARY ANALYSIS OF IMAGE PROCESSING-BASED

EVALUATION OF EMBOSSING OUALITY. . 
30. Dedijer S., Pál M., Tomić I., Poljak S., Pavlović Ž., Jurič I., Milić Keresteš N.: STATISTICAL ANALYSIS OF THE INFLUENCE OF PRINT RUN ON SURFACE ROUGHNESS OF DIGITAL FLEXO PRINTING PLATES' SOLID TONE AREAS . .

31. Kerkez Đ., Bečelić-Tomin M., Pucar Milidrag G., Gvoić V.,

Kulić Mandić A., Leovac Maćerak A., Tomašević Pilipović D.:

TREATMENT OF WASTEWATER CONTAINING PRINTING DYES:

SUMMARY AND PERSPECTIVES

\section{PACKAGING ADDED VALUE}

32. Bota J., Petković G.:

EVALUATION OF ZIPPER TEAR STRIP DESIGN

STRUCTURE FOR PAPERBOARD PACKAGING

33. Gregor-Svetec D., Šumrada T.:

PACKAGING PAPER COATED WITH PLA

34. Gegeckiene L., Venyte I.:

ECO-FRIENDLY MATERIAL FOR PACKAGING.

35. Pibernik J., Tomašegović T., Mahović Poljaček S., Madžar A.:

CONSUMER'S EXPERIENCE OF TEA PACKAGING AS ENVIRONMENT-FRIENDLY . . . . . 317

36. Klančar K., Vrabič Brodnjak U.:

PROMOTIONAL PACKAGING FROM CARTON OF INVASIVE ALIENT PLANT

37. Bošnjaković G., Vladić G:

RESEARCH METHODOLOGIES FOR ASSESSING

THE ERGONOMICS OF PACKAGING PRODUCTS - A REVIEW

38. Franken G.:

PACKAGING DESIGN AND TESTING BY EYE TRACKING

39. S. Hussein M.A., Attia M., Mohamed N.:

CHILD-RESISTANT FEATURES OF PHARMACEUTICAL PACKAGING

IN THE EGYPTIAN AND GLOBAL MARKET; A COMPARATIVE STUDY

40. Beyler Çigil A::

BIOBASED INTELLIGENT PACKAGING APPLICATION

\section{PRINTING QUALITY}

41. Pukhova E., Vereshchagin V.:

COMPENSATION OF DEFECTS IN PRINTING PROCESS WITH HISTOGRAM METHODS . . 373

42. Durnyak B., Lutskiv M., Petriaszwili G., Shepita P.:

ANALYSIS OF RASTER IMPRINTS PARAMETERS ON

THE BASIS OF MODELS AND EXPERIMENTAL RESEARCH

43. Ozcan A., Arman Kandirmaz E., Bunyamin Zelzele O.:

THE EFFECT OF DEINKING AND BINDER TYPE ON INKJET PRINT OUALITY

44. Trochoutsos C., Politis A.:

DEVELOPMENTS IN DIGITAL PRINT STANDARDIZATION

45. Vereshchagin V., Pukhova E., Khokhlova M.:

COMBINATION OF AM AND FM SCREENING AS SECURITY PRINTED FEATURE

46. Horváth C., Koltai L., Maňúrová K.:

PROSPECTS FOR THE FUTURE OF COMMERCIAL PRINTING.

47. Mustač S., Majnarić I., Bauk S., Miloš S.:

COLOUR QUALITY TESTING OF CYAN OFFSET PRINTS DEPENDING

ON PIGMENT CONCENTRATION AND DIFFERENT CTP SCREENING MODE. . . 
48. Spiridonov I., Yordanov S., Boeva R., Milkov A.:

INVESTIGATION OF PROCESS COLOURS VARIATIONS OF

ELECTROPHOTOGRAPHY COLOUR PRODUCTION PRESSES

49. Stančić M., Ružičić B., Vujčić Đ., Grujić D., Dragić M., Janković B.:

INFLUENCE OF INKJET PRINT PARAMETERS ON

THERMAL RESISTANCE OF PRINTED KNITWEARS.

50. Petrović S., Kašiković N., Zeljković Ž., Milošević R.:

FACTORS INFLUENCING MECHANICAL PROPERTIES OF

POLYURETHANE FOAMS USED IN COMPRESSIBLE FLEXOGRAPHIC SLEEVES

\section{EDUCATION}

51. Banjanin B., Pál M., Dimovski V., Adamović S., Lilić A.:

3D PRINTING IN THE EDUCATION OF

GRAPHIC ENGINEERING AND DESIGN STUDENTS.

52. Šafranj J., Katić M., Zivlak J.:

CLASSIFICATION IN SCIENTIFIC AND TECHNICAL WRITING

53. Lošonc A., Ivanišević A., Katić I.:

ECONOMIC DISCOURSE AND VISUAL CONFIGURATION

\section{NOVEL TECHNOLOGIES}

54. Iskra A., Gabrijelčič Tomc H.:

ANALYSIS OF OBSERVING AND RECOGNITION PROFILE

FACIAL IMAGES USING EYE TRACKING SYSTEM.

55. Iskra A.:

EYE TRACKING STUDY OF FRONTAL AND

PROFILE FACE IMAGE OBSERVATION AND RECOGNITION

56. Čuk M., Bizjak M., Muck D., Nuša Kočevar T.:

3D PRINTING AND FUNCTIONALIZATION OF TEXTILES

57. Košak K., Muck D., Čuk M., Nuša Kočevar T.:

3D PRINTED JEWELLERY DESIGN PROCESS BASED ON SCULPTURE INSPIRATION . . . 507

58. Pivar M., Muck D.:

STUDY OF 4D PRIMITIVES' SELF-TRANSFORMATION . . . . . . . . . . . . . . . 515

59. Asrizal Razali M., Ismail N., Hassim N.:

IMMERSIVE INTERCULTURAL EXPERIENCE FOR

GRAPHIC COMMUNICATION STUDIES THROUGH VIRTUAL REALITY

60. Efkolidis N., Minaoglou P., Aidinli K., Kyratsis P.:

COMPUTATIONAL DESIGN USED FOR JEWELRY . . . . . . . . . . . . . . . . . . 531

61. Đurđević S., Novaković D., Zeljković Ž.:

DEVELOPMENT OF PRODUCTS STATE IDENTIFICATION APPLICATION

\section{DESIGN}

62. Dujmović A., Pušnik N.:

ADVERTISING ON CITY BUSES.

63. Gabrijelčič Tomc H., Nuša Kočevar T.:

OBSERVATION ON CREATIVITY AND SPATIAL

VISUALISATION SKILLS OF GRAPHIC ARTS' STUDENTS. 
64. Kovačević D., Brozović M., Banić D.:

APPLYING GRAPHIC DESIGN PRINCIPLES ON TEA PACKAGING . . . . . . . . . . . . . . 571

65. Khloud Khaled A::

THE POWER OF COMMEMORATIVE BANKNOTE DESIGN

TO SUPPORT GLOBAL AND LOCAL EVENTS . . . . . . . . . . . . . . . . . . . . . . . . . . . 577

66. Lakićević M., Simić I., Kolarov R.:

DESIGNING PARTERRES ON THE MAIN CITY SOUARES

67. Manavis A., Nazlidou I., Spahiu T., Kyratsis P.:

JEWELLERY DESIGN AND WEARABLE APPLICATIONS:

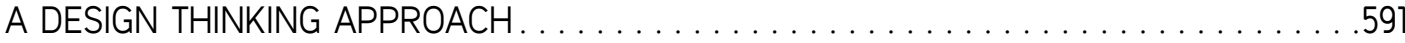

68. Rackov M., Knežević I., Čavić M., Penčić M., Čavić D., Kuzmanović S.:

DESIGN SOLUTIONS OVERVIEW OF UNIVERSAL

MOTOR GEAR DRIVES WITH HELICAL GEARS

69. Beris Y., Gülaçti I. E.:

INFLUENCES OF JAPANESE PRINTS ON EUROPEAN PRINTMAKING

(IN THE CASE OF DEGAS-MANZI PARTNERSHIP). .

\section{DIGITAL MEDIA}

70. Hoffman-Walbeck T., Adams II R.:

VISUALIZATION OF THE PROCESS-RESOURCE MODEL FOR WORKFLOWS

71. Mauzner F., Mandić L., Agić A., Pibernik J.:

DEVELOPMENT OF CHILDREN'S COGNITIVE ABILITIES

THROUGH INTERACTIVE APPLICATIONS

72. Roudný P., Držková M.:

USE OF PREPRESS AUTOMATION IN THE CZECH REPUBLIC AND

EXAMPLES OF AUTOMATED PROCESSING FOR SELECTED PREPRESS TASKS

73. Učakar A., Selič P., Urbas R.:

USE OF CODECS IN VIDEO UPLOADS . . . . . . . . . . . . . . . . . . . . . . . . . 643

74. Mitrović K., Jakšić A., Spajić J.:

THE ANALYSIS OF GRAPHIC DESIGN PLATFORMS

USED IN SOCIAL MEDIA MARKETING

75. Plot M., Roškar S., Gabrijelčič Tomc H.:

EVALUATION OF THE IMPACT OF AN AWARENESS-BASED ANIMATION

ON STUDENTS' KNOWLEDGE ABOUT MENTAL ILLNESS . .

76. Vladić G., Mijatović S., Bošnjaković G., Jurič I., Dimovski V.:

ANALYSIS OF THE LOADING ANIMATION

PERFORMANCE AND VIEWER PERCEPTION

77. Güner A., Gülaçti I. E.:

THE RELATIONSHIP BETWEEN SOCIAL ROLES OF

CONTEMPORARY ART MUSEUMS AND DIGITALIZATION. .

78. Zeljković Ž., Novaković D., Petrović S., Milić Keresteš N., Đurđević S.:

ELECTRONIC PUBLISHING AS A GRAPHIC PRODUCT

\section{TYPOGRAPHY}

79. Jovančić K., Milić Keresteš N., Nedeljković U.:

INFLUENCE OF WHITE SPACE ON TEXT SCANNING 
80. Žarko J., Nedeljković U.:

THE EFFECT OF CONTROLLING THE WEIGHT VARIABLE

ON THE TYPEFACE ATTRIBUTE ASSESSMENT . .

81. Stanić Loknar N., Bratić D., Agić A.:

KINETIC TYPOGRAPHY - FIGURATION AND TECHNOLOGY

82. Bratić D., Stanić Loknar N.:

AI DRIVEN OCR: RESOLVING HANDWRITTEN FONTS RECOGNIZABILITY PROBLEMS. . . 725 




\section{Foreword}

Dear readers,

It is my great pleasure to introduce You the research papers of the Tenth Symposium on Graphic Engineering and Design. With this proceeding we continue the works of previous symposiums which have been held biennial since year 2002.

We're delighted that this international symposium has again a great number of the papers and participants coming from many countries.

The papers include the achievements of researches in the field of technology and scientific areas relevant to graphic technology and graphic design. Through the work of the symposium GRID we continued significant scientific cooperation with educational institutions all over the world. With them we are continuing good cooperation which is the driving force for the creation and display of new developments, both individual and common. I want to thank everyone who participated with their paper and presentation in the Symposium. Your contribution is significant for the improvement of the Symposium on Graphic Engineering and Design GRID 20. The research achievements here presented are also valuable to the scientific and professional community and are highly appreciated. 



\section{INTRODUCTORY INVITED LECTURES}





\title{
NEW APPROACHES IN SMART PACKAGING TECHNOLOGIES
}

\author{
Arif Ozcan \\ Marmara University, School of Applied Sciences, Printing Technologies, Istanbul, Turkey
}

\begin{abstract}
Customer expectations have changed due to the developing technology and changing and improving product variety. This has led the printing industry, the packaging sector in particular, to grow considerably. The food industry along with the increasing need to preserve food long periods of time have led to the need to develop methods that preserve the freshness and safety of food products during their shelf-life. For this reason, attention was paid to packaging systems to facilitate food processing, preserve food quality, extend shelf-life, and prevent the food from spoiling. Thanks to these systems, packaging went beyond being a simple barrier outside the food, and has also taken upon roles of releasing protective agents or removing unwanted matter. Microbial growth is one of the most important factors that cause food to spoil. Although the problem has previously been tried to be solved by heating, drying, fermentation, freezing and adding antimicrobial agents, there are limitations, especially when used with fresh food. Today, a new generation of technologies have been introduced to monitor the condition of products with a tiny sensor or label placed onto the packaging. Smart packaging is a packaging material that not only improves the basic functions of a product, but also responds to stimuli around this product. Smart packaging in general, has two main categories, namely intelligent packaging and active packaging. This study will examine the concept of smart packaging that has emerged due to increased competitiveness, digital interaction and consumer awareness, changes in consumer behaviour and expectations, and improved interest in product safety. As a result, it is obvious that state-of-the-art smart packaging, which can connect to the Internet and has many channels of interaction, will bring about new business models and create new customer experiences and will replace conventional packaging, which has no interactions, in the near future.
\end{abstract}

Keywords: Packaging, smart packaging, active packaging, intelligent packaging

\section{INTRODUCTION}

The historical development of packaging began with the most basic need for preservation and today (Lydekaityte and Tambo, 2020), it has become an integral part of the business models of product-based companies (Chan et al, 2006). The main functions of packaging are to contain food, protect it from the adverse external affects and damage from shipping, facilitate storing and communicate with customers by offering information about its content (Robertson, 2016). Today, aside from being wrapped around a product, packaging plays a major role in attracting the interest of customers by differentiating a product from its alternatives and increasing its visibility by means of shape and design (Wells et al, 2007). Packaging makes it easier for consumers to prepare and store food at home.

The main function of food packaging is to ensure the quality and safety of food during storage and transportation and to extend shelf-life by preventing chemical contamination, contact with oxygen, humidity, light and physical force and spoilage caused by microorganisms (Caon et al, 2017). Convenience food is reliable only if it does not pose a danger or risk to consumer health throughout the process of "from field to fork". Food security is safeguarded by national and international regulations and standards. To ensure food security, related policies must prevent unfair competition by means of an effective control network encompassing the entire food chain and protect the health and interests of consumers (Aytekin et al, 2015).

Despite the enormous contribution conventional food packaging techniques have made to the development of food delivery systems until recently, it is no longer possible for these techniques to meet the growing demands of consumers. Conventional packaging systems have some limitations, especially in terms of extending shelf-life and ensuring food safety. Increasing industrial use and technology development have led to an increase in consumer demands and changed the trends of the food industry in the same direction (Priyanka and Parag, 2013). While manufacturers' aim is to make sure that the packaging material keep the food fresh for as long as possible, customers want to see the freshness of the food for themselves without opening the packaging (Sürengil and Kılınç, 2011). In parallel with the increasing product variety, consumers are more meticulous about what they want. They pay attention to whether the production process is sanitary and hygienic. Active and intelligent packaging systems have 
been developed to meet growing consumer demands and industrial production trends (Lagaron et al, 2004). In recent years, rapid industrialization, population growth and changing lifestyles have led to increased demand for processed and packaged food (Pal et al, 2019). This, in turn, has led the packaging sector to develop along with the food sector.

The developing food industry and growing demand for long-term storage and preservation of food are have generated the need to develop methods that can easily monitor and preserve the freshness and safety of the food throughout its shelf-life (production, storage, transportation and consumption). Smart sensors and labels that can be added onto the packaging represent the next generation of technology that will help monitor the condition of products (Mustafa and Andreescu, 2018). Smart packaging in general, has two main categories, namely intelligent packaging and active packaging (Loucanova et al, 2017; Schaefer and Cheung, 2018).

As mentioned above, this study will examine a new generation of packaging that has emerged due to increased competitiveness, digital interaction and consumer awareness, changes in consumer behaviour and expectations, and improved interest in product safety. It will also explore the need to develop more innovative and smart approaches to packaging and its environmental impact. The study will investigate the functions of "containment-preservation-communication-facilitation" of new-generation packaging systems that go beyond the basic functions of protection and transportation. As a result, it is obvious that state-of-the-art smart packaging, which can connect to the Internet and has many channels of interaction, will bring about new business models and create new customer experiences and will replace passive packaging, which has no interactions, in the near future (Kontominas, 2015).

\section{SMART PACKAGING CONCEPT}

There are many definitions of smart packaging in literature. It can be defined as a packaging that is produced by adding new functions to passive packaging (Brockgreitens and Abbas, 2016) and a material that does not only improve basic functions but can also respond to external stimuli (Priyanka and Parag, 2013). Smart packaging is described as an active or intelligent technique that involves interactions between package and food (package content) or internal gas atmosphere and fulfils with consumer expectations for high quality, fresh, and safe products (Labuza and Breene, 1989). Active packaging prevents the growth of pathogens and destructive microorganisms, prevents the transport of pollutants, and extends the shelf-life while preserving the safety and quality of the product (Ozdemir and Floros, 2004). In other words, the produced packaging has interactive properties. Smart packaging has the ability to communicate with its environment in the supply chain or with the consumer. This is achieved through at least one of the electronic, mechanical, chemical, electrical or online technologies. These systems are focused on improving packaging functions to meet growing consumer demands, increasing regulatory requirements, and growing interest in safety. Smart packaging can have a variety of features or uses but overall, it has two categories, namely active packaging and intelligent packaging (Figure 1).

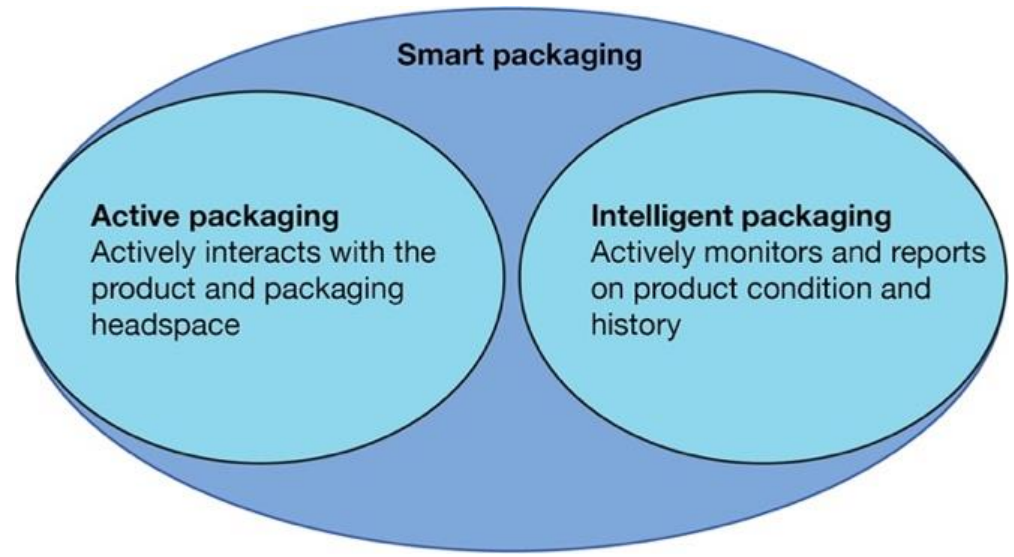

Figure 1: Smart packaging types (Young et al, 2020) 


\section{ACTIVE PACKAGING}

Active packaging involves packaging systems that relate with food in a way that they deliberately incorporate components that would release or absorb substances into or from the packaged food or the environment surrounding the food (European Commission, 2009). Active packaging offers innovative approaches to maintain or extend the shelf-life of a product, as well as to preserve the quality, safety and integrity of food products. Active packaging systems can be divided into active scavenging systems (absorbers) and active-releasing systems (emitters). Whereas the former remove undesired compounds from the food or its environment, for example, moisture, carbon dioxide, oxygen, ethylene, or odor, the latter add compounds to the packaged food or into the headspace, such as antioxidants, antimicrobial compounds, flavours, carbon dioxide, ethylene, or ethanol. Table 1 provides an overview of active packaging systems for food application and Figure 2 shows active agents for active packaging.

Table 1: Active packaging types for food applications (Yildirim et al, 2018)

\begin{tabular}{|c|c|c|}
\hline $\begin{array}{l}\text { Active } \\
\text { packaging } \\
\text { type }\end{array}$ & Food type & Expectation \\
\hline \multicolumn{3}{|c|}{ Active scavenging systems (absorber) } \\
\hline \multirow{4}{*}{$\begin{array}{l}\text { Oxygen } \\
\text { scavenger }\end{array}$} & Cooked meat products & Prevention of discoloration \\
\hline & Grated cheese, bakery products & Prevention of mold growth \\
\hline & Fruit and vegetable juices & $\begin{array}{l}\text { Retention of vitamin C content, prevention of } \\
\text { browning }\end{array}$ \\
\hline & $\begin{array}{l}\text { Seeds, nuts and oils; fat-containing instant } \\
\text { powders, fried snacks; dried meat products }\end{array}$ & Prevention of rancidity \\
\hline $\begin{array}{l}\text { Moisture } \\
\text { scavenger }\end{array}$ & $\begin{array}{l}\text { Mushrooms, tomatoes, strawberries, } \\
\text { maize, grains, seeds, fresh fish and meat }\end{array}$ & $\begin{array}{l}\text { Extension of shelf life through maintaining } \\
\text { moisture content, decrease in moisture } \\
\text { condensation in the packaging, positive impact on } \\
\text { the appearance, reduction in browning or } \\
\text { discoloratiion }\end{array}$ \\
\hline $\begin{array}{l}\text { Ethylene } \\
\text { absorber }\end{array}$ & Climacteric fruits and vegetables & $\begin{array}{l}\text { Reduction in ripening and senescence, theraby } \\
\text { enhancing quality and prolonging shelf-life }\end{array}$ \\
\hline \multicolumn{3}{|c|}{ Active releasing systems (emitter) } \\
\hline $\begin{array}{l}\text { Antioxidant } \\
\text { releaser }\end{array}$ & $\begin{array}{l}\text { Fresh fatty fish and meat; fat-containing } \\
\text { instant powders; seeds, nuts and oils; fried } \\
\text { products }\end{array}$ & Improvement of oxidative stability \\
\hline $\begin{array}{l}\text { Carbon } \\
\text { dioxide } \\
\text { emitter }\end{array}$ & Fresh fish and meat & $\begin{array}{l}\text { Extension of microbiological shelf life, reduction } \\
\text { in head space volume of modified atmosphere } \\
\text { packaging }\end{array}$ \\
\hline $\begin{array}{l}\text { Antimicrobial } \\
\text { packaging } \\
\text { systems }\end{array}$ & $\begin{array}{l}\text { Fresh and processed meat, fresh and } \\
\text { smoked fish, fresh seafood, dairy products, } \\
\text { fresh and processed fruits and vegetables, } \\
\text { grain, cereals and bakery products, ready- } \\
\text { to-eat meals }\end{array}$ & $\begin{array}{l}\text { Inhibition or retardation of bacterial growth, } \\
\text { extension of the shelf-life }\end{array}$ \\
\hline
\end{tabular}




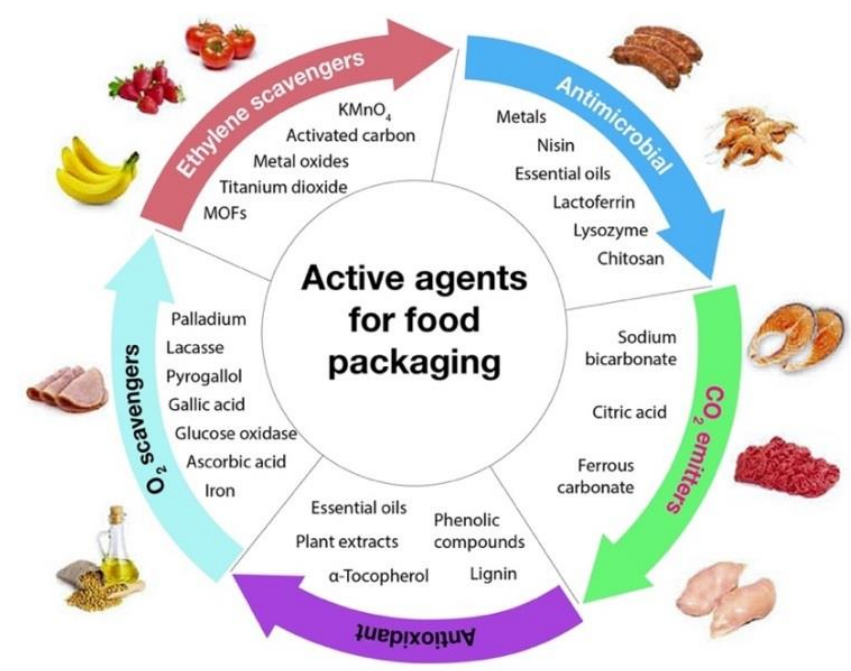

Figure 2: Active agents for active food packaging (Vilela et al, 2018)

\subsection{Oxygen Scavengers}

High levels of oxygen in food packaging can facilitate microbial growth, odor formation, colour change and nutrient loss, which considerably reduce shelf-life of products. Therefore, it is highly important to control the oxygen level in food products to limit food spoilage and degradation. Oxygen scavenging systems offer an alternative to vacuum or gas-flushing packaging and improve product quality and shelflife. Moreover, they are more cost-effective as they reduce packaging costs and increase profitability.

Typical oxygen absorption systems are based on the removal of oxygen through chemical oxidation of iron powder or the use of enzymes. In the first case, iron placed in a small sachet is oxidized to iron oxide. For the sake of effectiveness, the material used to make the sachet is highly permeable to oxygen and in some cases to water vapour. This system, known as Ageless and developed by Mitsubishi Gas Chemical Company, is very widespread and the first one to be used in food packaging. The type and amount of absorbent to be used is determined by the initial oxygen level in the package, the amount of dissolved oxygen in the food, the permeability of the packaging material, its size, shape, weight and the water activity of the food. Iron-based oxygen absorbing systems have the ability to scavenge oxygen in many foods, including high, medium or low-moist foods and lipid-containing foods (Smith, 1995). They can also work in chilled and frozen storage conditions and can be used as effective oxygen scavengers even in microwave-safe food products. In enzymatic oxygen scavenging systems, an enzyme reacts with a substrate to remove oxygen (Figure 3). These systems are more expensive than iron-based systems due to the cost of enzymes used for oxygen removal. Enzymatic oxidation systems are also very sensitive to temperature, $\mathrm{pH}$, water activity, and solvents included in the sachet, which limit their widespread use (Ozdemir and Floros, 2004).

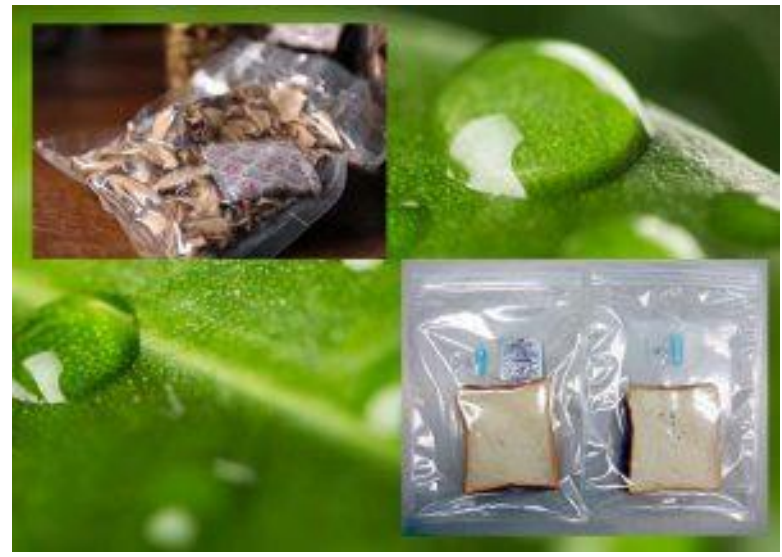

Figure 3: Enzymatic oxygen cleaning systems for food packaging 
Oxygen scavenging sachets are not suitable for liquid foods as the direct contact of the liquid with the sachet may cause its contents to spill. Also, the sachets may accidentally be consumed along with the food or may be swallowed by children. For this reason, the U.S. Food and Drug Administration mandates that oxygen scavenging sachets sold in the United States must be labeled with "do not eat" (Figure 4).

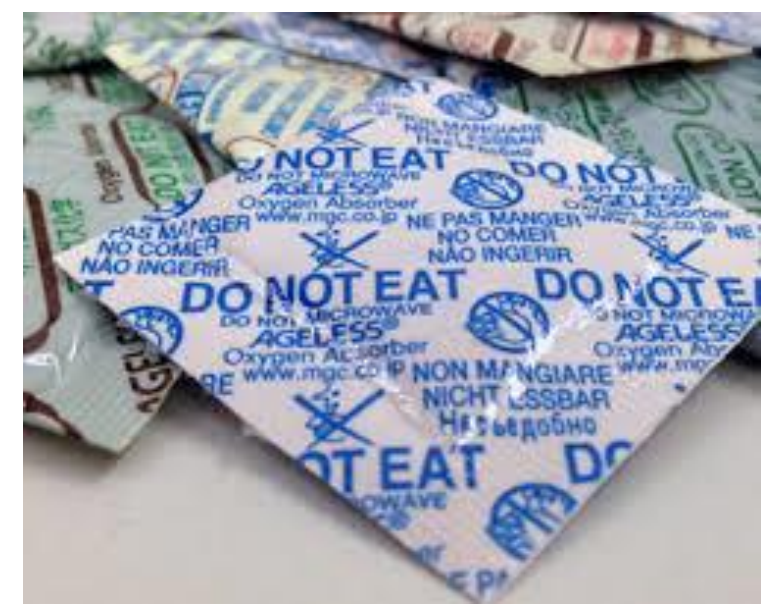

Figure 4: Oxygen scavenger bag for food packaging

\subsection{Moisture Scavengers}

Controlling excess moisture in food packaging is important to suppress microbial growth and prevent foggy film formation. If the packaging has poor water vapour permeability, the accumulation of water inside the packaging will be more pronounced. Excess water formation inside a food packaging is usually caused by inhalation by fresh produce, temperature fluctuations, or dripping of tissue liquid from freshcut meat. Excess water accumulation inside the packaging promotes the formation of bacteria and mold, resulting in reduced quality and shelf-life. Moisture scavengers physically absorb and hold onto water molecules from the surrounding environment. Drying agents absorb the moisture in the environment through both physical and chemical adsorption, and thus reduce relative humidity in the headspace (Gaikwad et al, 2019). The most effective way to control excess water accumulation in food packaging with a high barrier against water vapour is to use moisture scavengers such as silica gel (Figure 5), molecular sieves, natural clay, calcium oxide, calcium chloride and modified starch. Silica gel is the most widely used moisture scavenger, as it is both non-toxic and non-corrosive. Moisture absorption by silica gel is an example of physical moisture adsorption, while moisture absorption by calcium chloride is an example of a chemical reaction. In general, moisture scavengers are most commonly used in food packaging applications (Wilson, 2017). Table 2 lists the moisture scavengers used in food packaging.
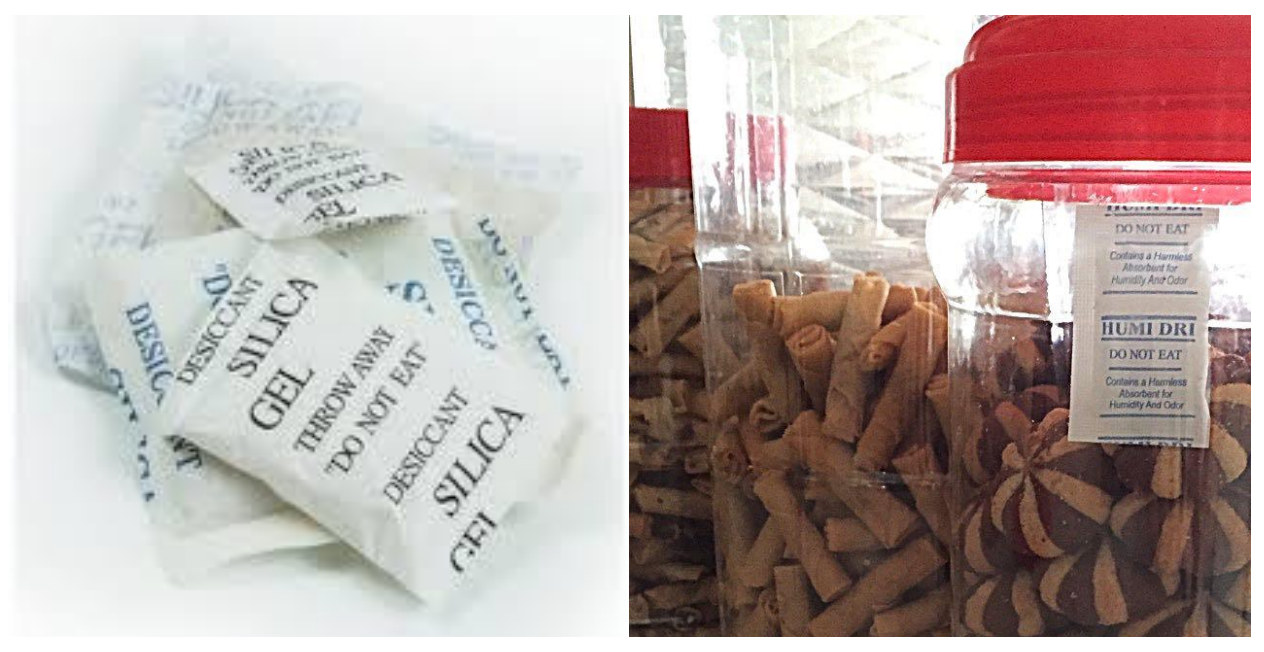

Figure 5: Silica gel for moisture scavenger 


\begin{tabular}{|l|l|}
\hline Classification & Moisture absorbing materials \\
\hline Inorganic & $\begin{array}{l}\text { Silica gel, natural clay (monotomorillonite, zeolite), calcium chloride, magnesium chloride, } \\
\text { aluminium chloride, lithium chloride, potassium acetate, calcium bromide, calcium nitrate, } \\
\text { zinc chloride, phosphorus pentoxide, activated alumina, calcium oxide, barium oxide, sodium } \\
\text { chloride, potassium chloride, potassium carbonate, ammonium nitrate, bentonite, sodium } \\
\text { hexametaphosphate }\end{array}$ \\
\hline Organic & $\begin{array}{l}\text { Sorbitol, xylitol, fructose, cellulose and their derivatives (sodium carboxymethyl cellulose, } \\
\text { potassium carboxymethyl cellulose, ammonium carboxymethyl cellulose, monoethanolamine } \\
\text { carboxymethylcellulose), diethanolamine or triethanolamine }\end{array}$ \\
\hline $\begin{array}{l}\text { Polymer- } \\
\text { based }\end{array}$ & $\begin{array}{l}\text { Starch copolymers, polyvinyl alcohol, absorbent resin } \\
\text { Starch-grafted sodium polyacrylate, acrylamide synthesis attapulgite, diatomaceous earth }\end{array}$ \\
\hline
\end{tabular}

\subsection{Ethylene Absorbers}

Ethylene is a growth-stimulating hormone accelerating ripening and senescence through increasing the respiration rate of fruits and vegetables, thus shortening the shelf-life. Ethylene also accelerates chlorophyll degradation rates in leafy products. For these reasons, the removal of ethylene from the headspace slows senescence, thereby prolonging shelf-life.

The best-known, inexpensive and widely used ethylene absorption system is potassium permanganate in silica. Silica absorbs ethylene and potassium permanganate oxidizes it to ethylene glycol. Silica is kept in a highly permeable sachet or can be incorporated into a packaging film. With that being said, potassium permanganate is not integrated into the surface of packaging films that contact food due to its toxicity. The surface area of the substrate and the amount of potassium permanganate affect the performance of these systems. Another system for ethylene adsorption is based on impregnating zeolite with potassium permanganate, followed by coating the impregnated zeolite with a quaternary ammonium cation. This system not only absorbs ethylene from the environment, but can also absorb other organic compounds such as benzene, toluene and xylene (Sacharow, 1998; Zagory, 1995). An example of an ethylenescavenger used in food packaging is shown in Figure 6.

Ethylene released from fruits and vegetables directly affects growth and ripening processes (Dan et al, 2018; Sun et al, 2018). The role of ethylene in the growth of plants often varies based on the nature of fruits, the stage of ripeness and the degree of exposure to ethylene (Pathak et al, 2017). In addition to accelerating fruit ripening, ethylene often leads to over-ripening and even rotting, which shortens shelflife and causes losses. There is also an increasing demand for long-term preservation of food quality and minimization of food spoilage for both health and economic reasons (Wei et al, 2020). Therefore, making use of ethylene synthesis inhibitors or scavengers to slow the ripening of fruits and vegetables is critically important in post-harvest preservation (Pathak, 2019). 


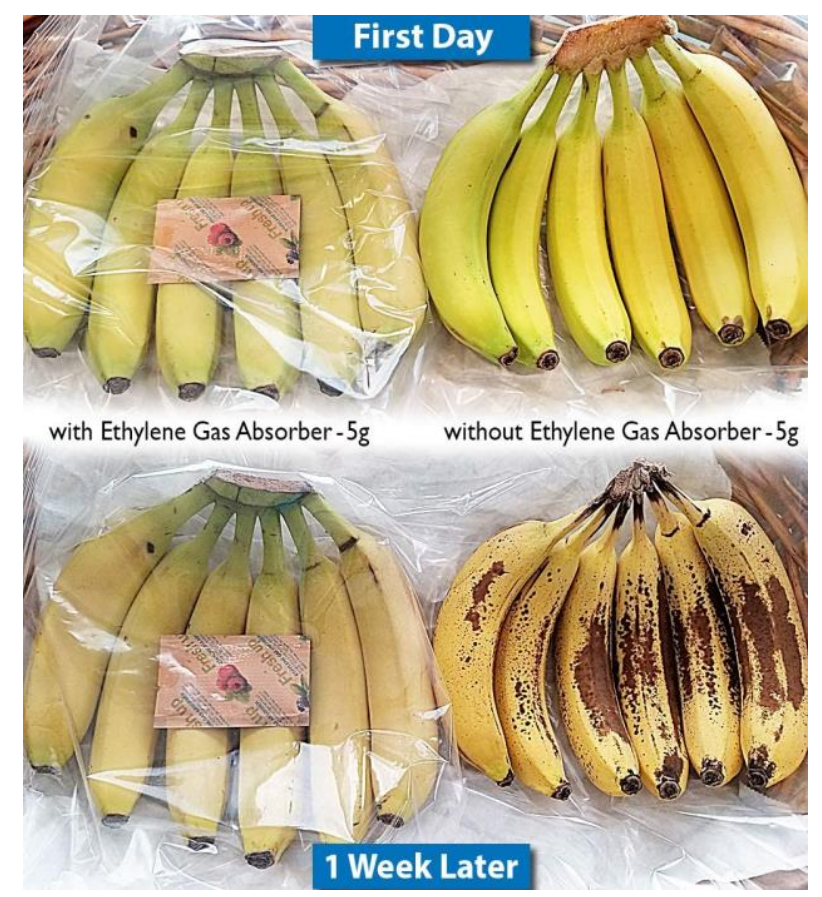

Figure 6: Ethylene gas absorber for food packaging

\subsection{Antioxidant releaser}

Significant interest has also been placed on antioxidant agents because of their capability to increase the stability of oxidation-sensitive food products. Oxidative degradation is the major cause of food spoilage after microbial growth (Gómez-Estaca et al, 2014). Oxidative reactions are responsible for reducing the nutritional value of food affected by the degradation of essential fatty acids, proteins and lipid soluble vitamins, producing off-flavours and odors, and colour change due to pigment degradation (Bastarrachea et al, 2015; Sanches-Silva et al, 2014). There are studies focusing on the inclusion of antioxidant agents in packaging and on natural antioxidants currently applied in active food packaging. In addition, edible and active films and coatings (chitosan, cellulose derivatives, gelatin, galactomannans, alginate,) are used as carriers of natural antioxidants for lipid foods (Ganiari et al, 2017). The advantage of enclosing antioxidants within the packaging material surpasses the beneficial of their direct inclusion in food formulations. So, most of the antioxidant systems are manufactured in the form of sachets, pads or labels, or incorporated into the packaging monolayer or multilayer materials (Vilela et al, 2018). Classification of antioxidant compounds according to their mechanism of action is shown in Figure 7.

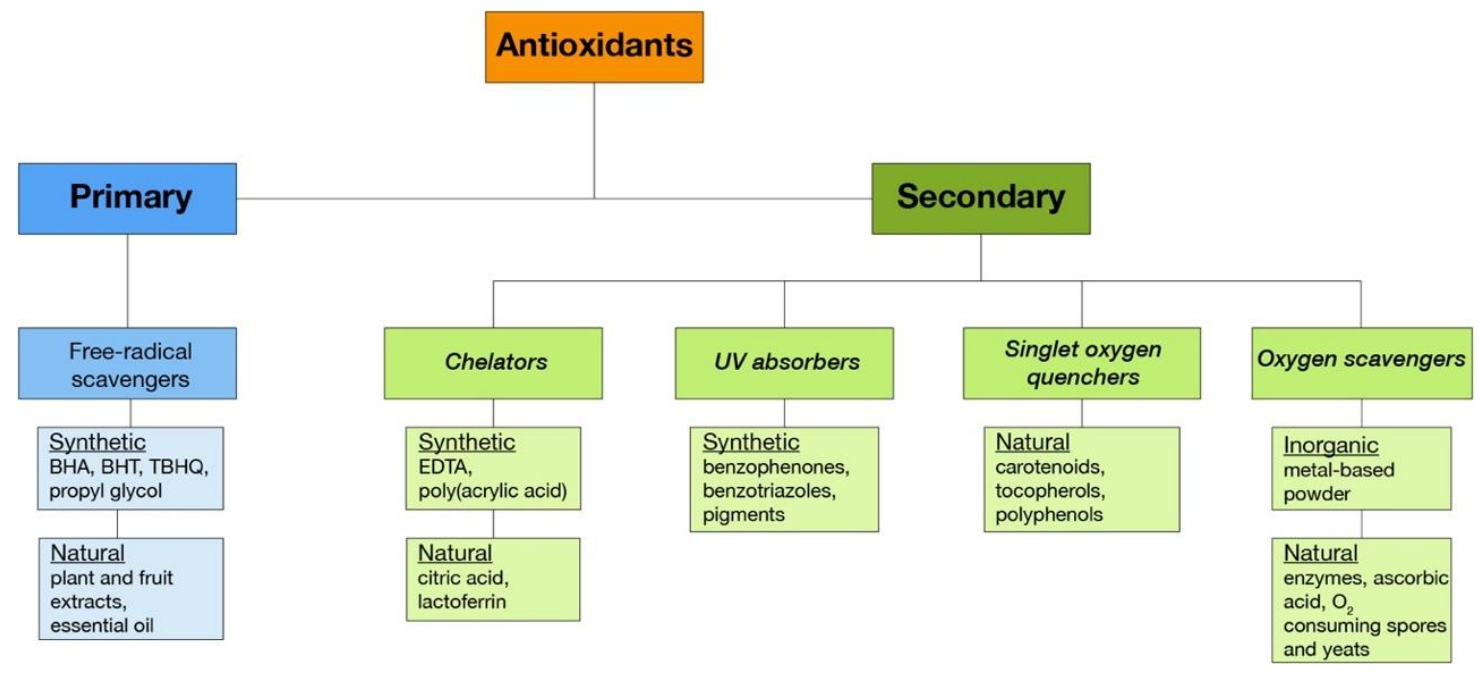

Figure 7: Listing of antioxidant compounds according to their mechanism of action (Tian et al, 2013). 


\subsection{Carbon dioxide emitter}

Carbon dioxide $\left(\mathrm{CO}_{2}\right)$ is formed in some foods due to spoilage and respiratory reactions. This $\mathrm{CO}_{2}$ must be removed from the packaging to prevent the product from spoiling and the packaging from damage. For example, roasted coffee can contain $15 \mathrm{~atm}$ of dissolved $\mathrm{CO}_{2}$ due to the Strecker decomposition reaction taking place between sugars and amines. In such a case, $\mathrm{CO}_{2}$ scavengers can be of use. $\mathrm{O}_{2}$ and $\mathrm{CO}_{2}$ scavenging bags are used to delay flavour changes due to oxidation and to absorb $\mathrm{CO}_{2}$ (Floros et al, 1997). An example of carbon dioxide emitter in food packaging is seen in Figure 8.

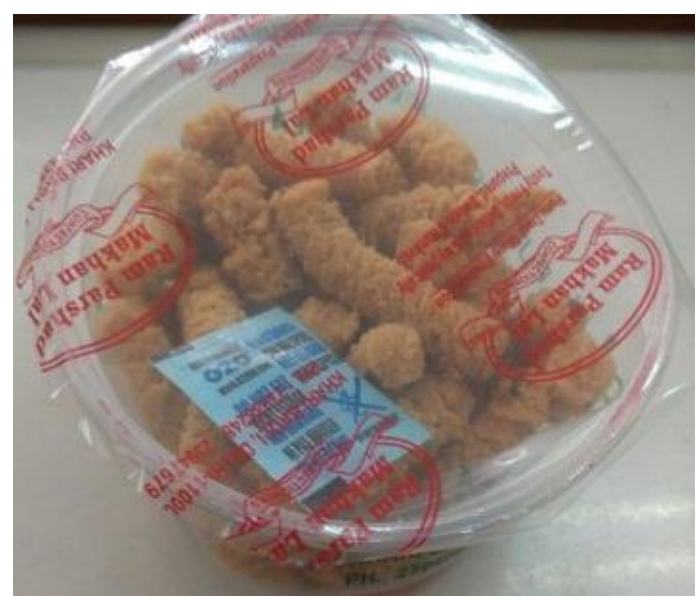

Figure 8: Carbon dioxide emitter in food packaging

In some plastic films, $\mathrm{CO}_{2}$ permeability is 3 to 5 times higher than oxygen permeability. In such cases, $\mathrm{CO}_{2}$ must be produced continuously to maintain the desired concentration in the packaging. For this purpose, $\mathrm{CO}_{2}$ producing systems are used in the packaging of products such as fresh meat, poultry, fish and cheese. In some food products where the volume and appearance of the packaging is critical, $\mathrm{O}_{2}$ scavengers and $\mathrm{CO}_{2}$ emitters are used together to prevent the packaging to collapse due to $\mathrm{O}_{2}$ absorption (Mane, 2016).

However, in some cases, high $\mathrm{CO}_{2}$ levels are desirable for food such as meat and poultry as this prevents microbial growth on the surface and therefore extends shelf-life. Fresh meat, poultry, fish and cheese can benefit from packaging with a high concentration of $\mathrm{CO}_{2}$. Commercially available $\mathrm{CO}_{2}$-scavengers are listed in Table 3.

Table 3: $\mathrm{CO}_{2}$-scavengers in commercial use (Vermeiren et al, 1999)

\begin{tabular}{|l|l|l|}
\hline Trade name & Company & Substances and actions \\
\hline Freshlock or Ageless E & Mitsubishi Gas Chemical (Japan) & $\begin{array}{l}\mathrm{CO}_{2} \text {-scavenging }\left(\mathrm{Ca}\left(\mathrm{OH}_{2}\right) / \mathrm{O}_{2} \text {-scavenging (iron }\right. \\
\text { powder) }\end{array}$ \\
\hline Ageless G & Mitsubishi Gas Chemical (Japan) & $\mathrm{CO}_{2}$-generating (ascorbic acid)/ ${ }_{2}$-scavenging \\
\hline Freshilizer CV & Toppan Printing Co (Japan) & $\mathrm{CO}_{2}$-and $\mathrm{O}_{2}$-scavenging (non-ferrous metal) \\
\hline Freshilizer C and CW & Toppan Printing Co (Japan) & $\mathrm{CO}_{2}$-generating/ $\mathrm{O}_{2}$-scavenging \\
\hline Freshpax M & Multisorb technologies (USA) & $\mathrm{CO}_{2}$-generating/ ${ }_{2}$-scavenging \\
\hline Verifrais & S.A.R.L. Codimer (France) & $\mathrm{CO}_{2}$-generating \\
\hline Vitalon G & Toagosei Chem. Ind. Co. (Japan) & $\mathrm{CO}_{2}$-generating/ $\mathrm{O}_{2}$-scavenging \\
\hline
\end{tabular}




\subsection{Antimicrobial packaging systems}

There is increasing interest in the use of packaging materials containing antimicrobial substances due to increasing sensitivity towards health. Consumers demand minimally processed, preservative-free food products with longer shelf-life (Irkin and Esmer, 2015). Packaging materials, edible films and coatings can be reinforced with antimicrobials to form a protective barrier to prevent and delay such microbial growth. Packaging materials serve as carriers of antimicrobials that are effectively released into the food to extend the shelf-life, and improve the quality and safety of the food (Corrales et al, 2014). This allows packaging to provide an additional and final barrier to prevent the growth of foodborne pathogens (Guarda et al, 2011). In addition, most natural antimicrobial agents are biodegradable and easily decompose. Antimicrobial packaging can be produced by incorporating antimicrobial substances directly in packaging films, coating packaging films with these antimicrobial substances and producing packaging materials made from polymers. In general, antimicrobial packaging systems can either migrate or not migrate into the food based on their interaction with the antimicrobial substance used and with the packaging and food matrix (Muriel-Galet et al, 2012). Antimicrobial packaging has been proven to improve the shelf-life, safety and quality of many food products due to its potential to reduce or minimize microbial growth in food (Jung et al, 2018; Kandirmaz and Ozcan, 2019). Natural antimicrobial agents and biopolymers are listed in Table 4.

Table 4: Samples of potential natural antimicrobial agents and biopolymers for food packaging (Tang et al, 2012; Imran et al, 2010)

\begin{tabular}{|l|l|}
\hline \multirow{2}{*}{ Classification } & Antimicrobial agents and biopolymers \\
\hline \multirow{2}{*}{$\begin{array}{l}\text { Plant volatiles and } \\
\text { plant/spice extracts }\end{array}$} & $\begin{array}{l}\text { Allyl-isothiocyanate, cinnamaldehyde, eugenol, linalool, terpienol, thymol, carvacrol, } \\
\text { pinene, allicin }\end{array}$ \\
\cline { 2 - 2 } & $\begin{array}{l}\text { Grapefruit seed extract, grape seed extract, hop beta acid, Brassica erucic acid oil, } \\
\text { rosemary oil, oregano oil, basil oil, other essential oils }\end{array}$ \\
\hline \multirow{2}{*}{$\begin{array}{l}\text { Polysaccharides and } \\
\text { derivatives }\end{array}$} & Starch, chitosan, pullalan, natural gums \\
\cline { 2 - 2 } & Cellulose based paper, fatty acids, alginate, carrageenan, chitosan \\
\hline \multirow{2}{*}{$\begin{array}{l}\text { Proteins/enzymes/ } \\
\text { bacteriocins }\end{array}$} & $\begin{array}{l}\text { Corn-zein, soy-protein isolate, whey-protein isolates, wheat-gluten, peanut-protein, } \\
\text { milk-proteins, collagen/gelatin }\end{array}$ \\
\cline { 2 - 2 } & Lysozyme, glucose-oxidase, lactopeoxidase \\
\cline { 2 - 2 } & Nisin, pediocin, subtilin, lacticin (EDTA) \\
\hline \multirow{2}{*}{ Lipid based coatings } & Beeswax, carnauba wax, sugar cane wax, rice bran wax, bay berry wax \\
\hline Chelating agents & Ethylenediaminetetraacetic acid \\
\hline
\end{tabular}

\section{INTELLIGENT PACKAGING}

Intelligent packaging is one type of smart packaging that's normally used for food, beverage, and pharmaceutical products. Although intelligent packaging is related to the food industry, it has no direct effect on the product. The European Food Safety Authority (EFSA) defines intelligent packaging as "materials and items that monitor the state of packaged food or the environment around the food" (EFSA, 2009). They have the ability to communicate the conditions of the packaged product, but do not interact with the product. The goal is to monitor the product and offer information to the customer (Figure 9). This information can be about the contents of the packaging, as well as terms of use and storage (Müller and Schmid, 2019). Another definition for intelligent packaging is about the fact that they monitor the condition of packaged products or the environment surrounding the packaging to inform the 
customer about any changes to the product or about the current situation of the product (Biji et al, 2015). In more detail, intelligent packaging is a system that fulfills smart functions such as detecting, sensing, recording, tracing, communicating and applying scientific logic to prolong shelf-life, improve quality and safety, and facilitate decision-making, and alerts customers about possible problems (Loucanova et al, 2017).

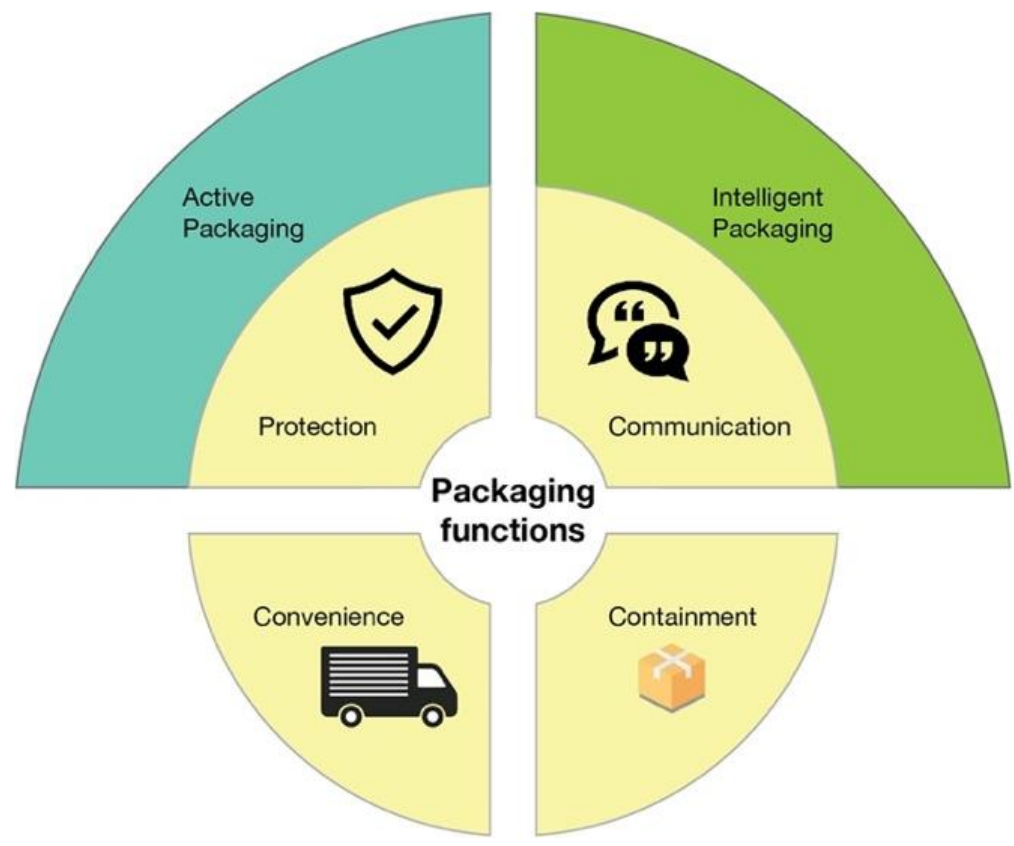

Figure 9: Packaging functions

As seen from the figure, smart packaging systems have added advanced features to two functions of packaging in particular. These are the improvement of protective properties thanks to active packaging and of information function thanks to intelligent packaging. There are three main intelligent packaging systems, which are indicators, sensors and radio frequency identification (RFID) tags (Ghaani et al, 2016). Time-temperature indicators, oxygen and carbon dioxide indicators, colour temperature indicators, pathogen indicators and refraction indicators are some of these systems.

\subsection{Indicators}

Indicators communicate the necessary information to the consumer. This information can be about presence or absence of a substance, as well as about the reaction between two or more substances. Usually, such information is indicated by instantaneous visual changes, such as, different colour densities or diffusion of the dye across the indicator geometry. A distinctive feature of indicators is the type of relevant information that is qualitative or semi-quantitative by nature. There is a wide variety of indicators, which can be reduced to three categories, namely, time-temperature indicators, freshness indicators and gas indicators. These indicators improve product quality and value (Hogan and Kerry, 2008; Robertson, 2016).

\subsubsection{Time-temperature Indicators}

Temperature indicators show whether a product is heated above or cooled below a threshold temperature and warn customers about the possible survival of microorganisms and protein denaturation when freezing or defrosting. It is also possible to monitor temperature throughout the supply chain. Temperature indicators are based on chemical, electrochemical, mechanical, enzymatic or microbiological change and they produce a visible reaction such as a mechanical deformation, colour formation or change of colour. Due to the role of both time and temperature in physical and chemical degradation, TTIs have taken on a crucial task in obtaining information about the history of temperature of a packaged food over a given time. TTIs are usually small self-adhesive labels and are also user-friendly thanks to being easy to understand (Taoukis and Labuza, 2003; Biegańska, 2017). Different timetemperature indicators are shown in Figure 10. 


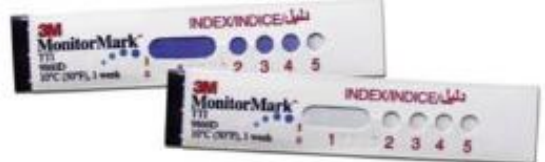

b
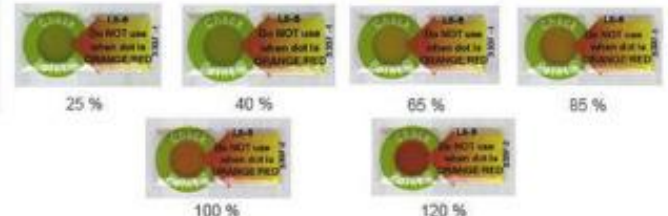

C

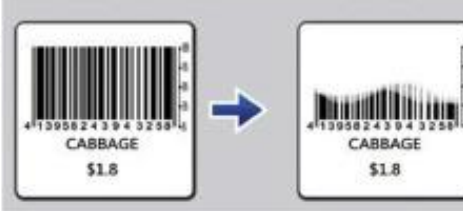

$100 \%$

$120 \%$

e
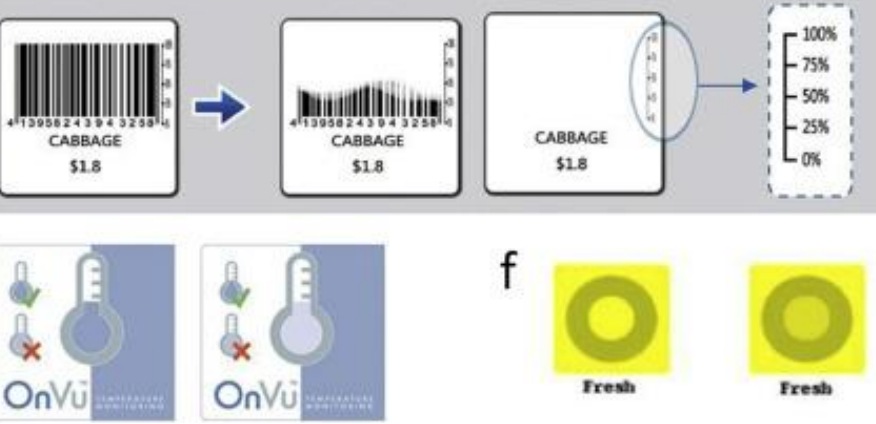

d

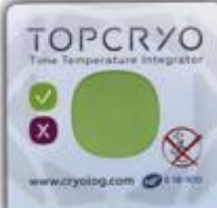

f
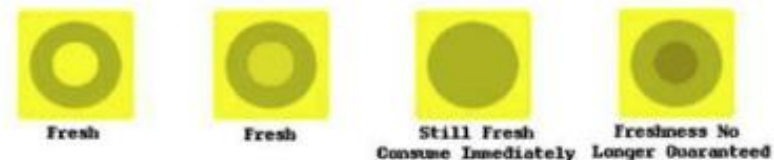

Figure 10: Time-temperature indicators (a) 3M Monitor Mark, b) VITSAB, c) FreshCode, d) TopCryo, e) OnVu, f) FreshCheck) (Poyatos-Racionero et al, 2018)

\subsubsection{Freshness Indicators}

These indicators allow the quality of food products to be monitored during storage and transportation. Loss of freshness may be due to exposure to harmful conditions or exceeding shelf-life. Freshness indicators offer direct information about a product's quality based on microbial growth or chemical changes. It does so by detecting volatile amines, which are produced when a food product spoils, by conductometric or $\mathrm{pH}$ change or similar methods. Freshness indicators work on the principle that the organic acid, carbon dioxide and volatile nitrogen compounds that occur as a result of the microbial growth in the structure of the food that loses its freshness, change the chemical structure of the dye in the indicator. The dye usually changes colour as a result of the reaction between the dye and its degradation metabolites. In this way, visible, easily detectable freshness measuring systems can be created. Hydrogen sulfide, ethanol, diacetyl and carbon dioxide are some examples of freshness indicators. Freshness indicator sample can be seen in Figure 11.

\section{Freh-Check Fresh-Check $^{*}$ self-adhesive time temperature indicator}

As the Fresh-Check indicator is exposed to heat, it gradually

changes color to alert the consumer of optimal freshness.

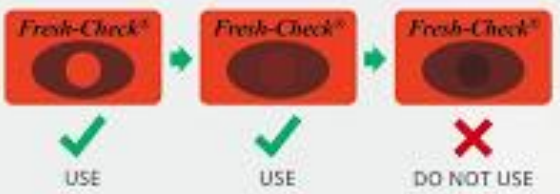

Figure 11: Freshness indicator (Fresh-Check, 2018)

\subsubsection{Gas Indicators}

These label-shaped indicators are placed in the package and monitor changes in the inner atmosphere due to microorganism metabolism and enzymatic or chemical reactions on the food matrix. It can also be used to monitor the situation of active packaging such as $\mathrm{O}_{2}$ and $\mathrm{CO}_{2}$ scavengers. Since they are placed inside the packaging, they must be non-water-soluble and must have a certificate of food contact compliance (Fuertes et al, 2016). A gas indicator sample can be seen Figure 12. 


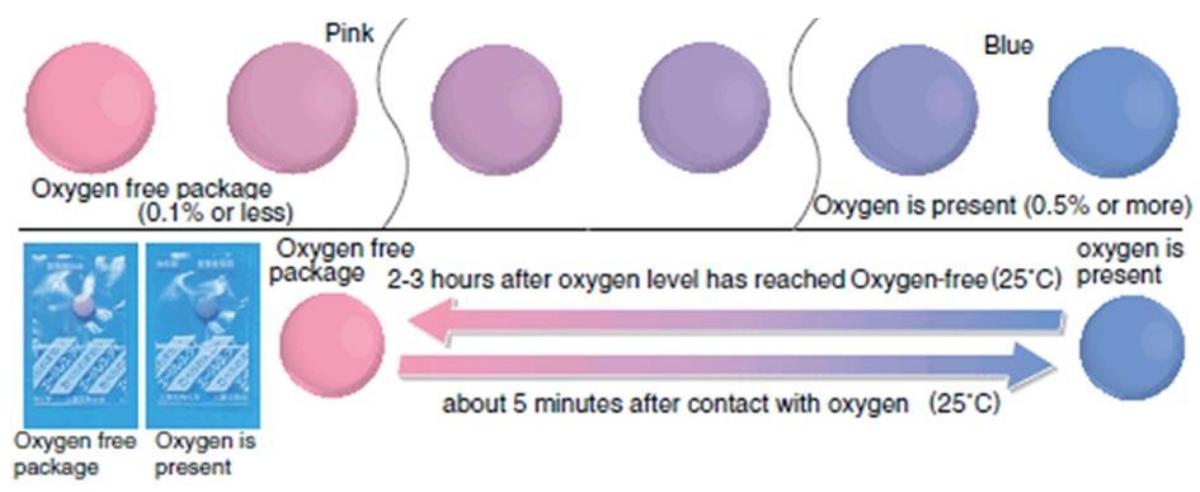

Figure 12: Gas indicator - Ageless Eye (MITSUBISHI GAS CHEMICAL, n.d.)

\subsection{Barcodes and RFID Tags}

These devices, which perform automatic identification, not only provide information flow within the food supply chain, but also increase efficiency in terms of food quality and safety. The task of these labels, which are also called data carriers, is to provide automation, traceability, protection from theft or counterfeiting, rather than providing information about the condition of the food. They are usually placed on an outer packaging (box, parcel, pallet, etc.) other than the product's packaging. The most commonly used systems are barcode labels and RFID labels.

Barcodes are widely used in retailers and stores for inventory check and stock tracking due to their low cost and ease of use. A barcode is made up of parallel spaces and bars arranged to represent a 12-digit data. The encoded information is read by an optical barcode scanner, which sends the information to a system where it is stored and processed. RFID tags are an advanced example of a data carrier tag. An RFID system has three main elements: a) a tag consisting of a microchip connected to a small antenna, b) a reader emitting radio waves and receiving responses from the tag in return, and c) a middleware communicating with the RFID through a local network or web server. Sample RFID tag can be seen Figure 13.

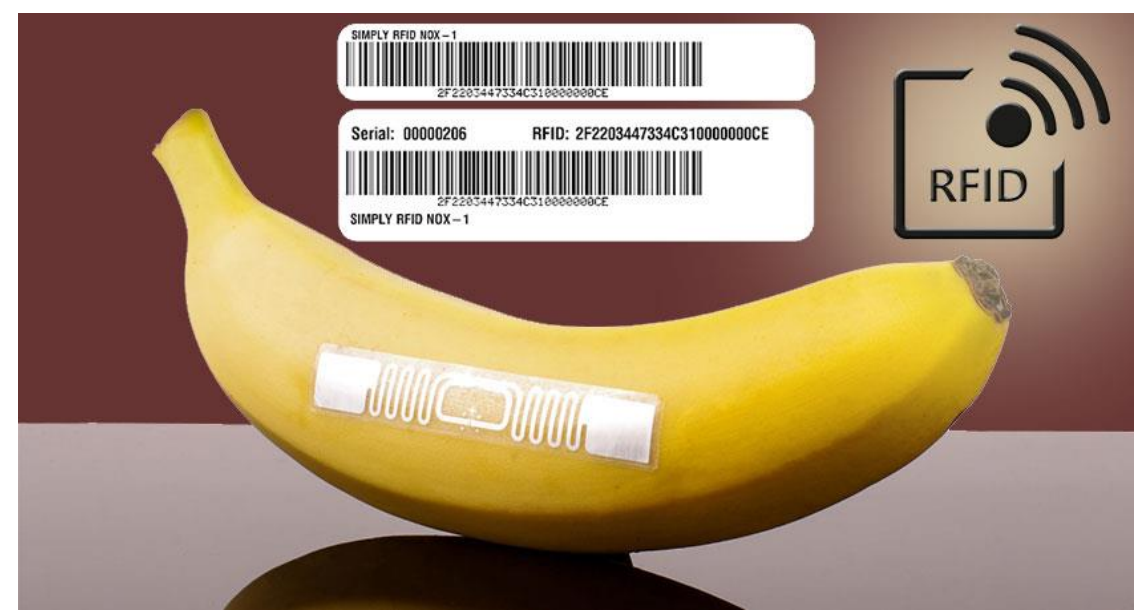

Figure 13: RFID tag (The Silicon Review, 2018)

\subsection{Sensors}

Sensors are electronic devices that detect one form of signal and convert it to another. Depending on the type of converter, sensors can be active or passive. Biosensors and gas sensors are used as intelligent packaging tools for common analytes such as $\mathrm{pH}$, humidity, colour and biological species.

The pectin-based edible sensor was developed by the combination of the calorimetric exchange principle of anthocyanins and variations in total volatile basic nitrogen that cause the degradation of meat-based products. Similarly, membrane film sensors have been developed for maintaining the freshness of pomfret fish. Edible sensors are a new approach to food packaging as they are a harmless method for detecting deterioration (Mahalik and Nambiar, 2010; Dudnyk et al, 2018). 


\subsubsection{Biosensors}

Biosensors are sensors with biological analyte in which the change in the product is detected and then converted into an electrical signal using a transducer. Biological analyte-interactive biosensors for monitoring quality and see changes in colour during deterioration for beef and chicken fillet and electrochemical biosensors based on nylon- 6 nano fiber membrane operationalized by glucose oxidase to detect glucose in various beverages are some examples for biosensors (Fang et al, 2017; Scampicchio et al, 2010). Schematic diagram of biosensor is shown in Figure 14.

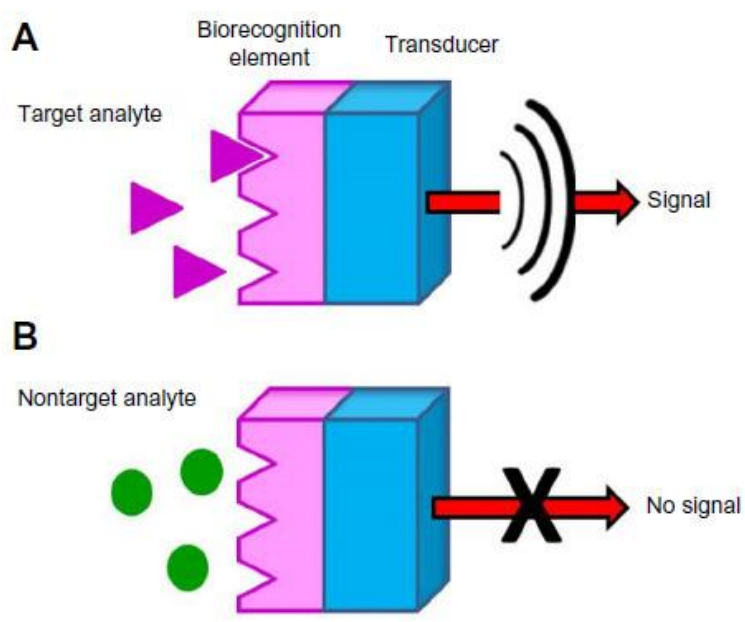

Figure 14: Schematic diagram of biosensor with target analyte (A) and nontarget analyte (B) (Krejcova et al, 2015)

\subsubsection{Gas sensors}

Gas sensors are designed to detect gaseous or volatile compounds such as carbon dioxide, oxygen, volatile amines and certain other gases. For example, a carbon dioxide sensor is used to detect accurate carbon dioxide levels using indicator paint and $\alpha$-naphtholphthalein. These sensors are also characterized by toxicity caused by the displacement of dyes (Pereira et al, 2015; Kalpana et al, 2019). Gas Sensoroptochemical sensor, gas sensor-based on sol gel, gas sensor-based on colorimetric sensing, gas sensorbased on photoluminescence and gas sensor-based on colorimetric sensing are common gas sensors. A schematic of gas sensor is shown in Figure 15.

(a)

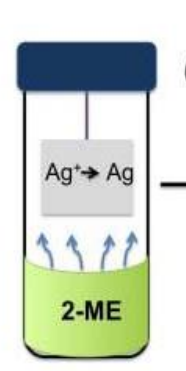

(e)

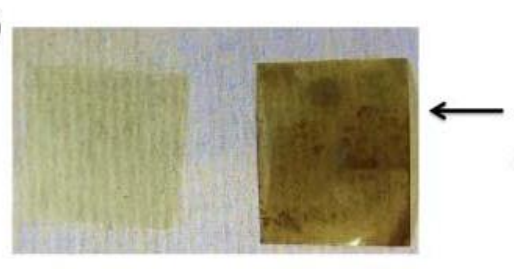

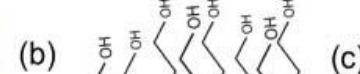

(c)
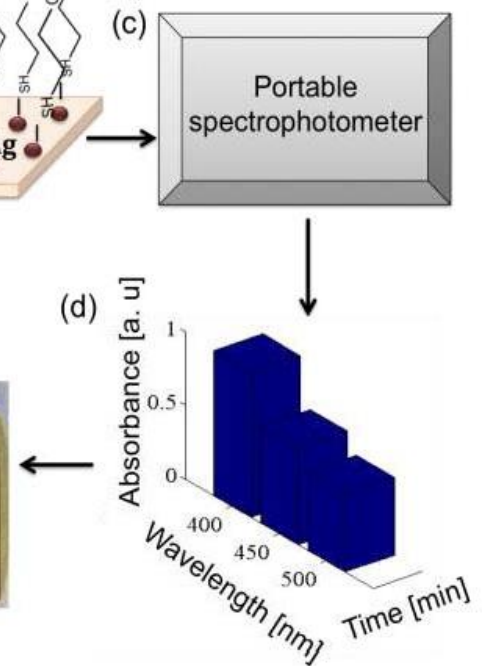

Figure 15: A schematic of the sensor set up showing (a) a flask tube with PEI/Ag film exposed to 2-ME vapours, (b) chemisorption of thiols to Ag+ prepared on PEI film, (c) a portable spectrophotometer, (d) expected absorbance results; $€$ a photograph of the colour change of PEI/Ag film from transparent to yellow-brown after 2-ME exposure (Rvspayeva et al, 2018) 


\section{CONCLUSIONS}

In a changing and developing world, demand for food has been increasing due to growing population, which has also attached great importance to issues such as food security, freshness, shelf-life, traceability and supply chain. For these functions to be fulfilled, packaging has to offer more than conventional packaging. Packaging has now undertaken intelligent tasks far beyond its conventional functions. Protecting the product from external conditions, transporting and storing it are not enough for today's demands. Smart packaging can be used in a wide range of applications, from meat products to liquids and fruits and vegetables.

With an active packaging, type of which is chosen based on the product's features, conditions preferred and reactions to stimuli, the product quality will be preserved and the growing of pathogens and microorganisms will be prevented, which will be directly reflected onto the shelf-life of that product. Smart packaging has the ability to communicate with its environment in the supply chain or with the consumer.

In addition to the improvements made on the food itself, intelligent packaging systems, which are applied only on the outer surface or on the packaging, both improve product traceability and safety and inform the customer. These can be smart devices in the form of labels. Or they may contain points or ink that perform various functions. Although the potential advantages of smart packaging technologies have been widely studied and proven, there is still not enough application in the market. Studies need to be conducted on their cost so that these systems can be commercially applicable.

\section{REFERENCES}

[1] Aytekin, N. D., Coşkun, S., Uzmanı, A.: “AB Gıda Güvenilirliğinde Risk Illetişimi, Kamuoyunun Bilgilendirilmesi ve Türkiye'nin Durumu”, AB Uzmanlık Lisans Tezi, TC Gıda Tarım Ve Hayvancılık Bakanlığı, 2015.

[2] Bastarrachea, L. J., Wong, D. E., Roman, M. J., Lin, Z., Goddard, J. M.: "Active packaging coatings", Coatings 5(4), 771-791, 2015. doi: 10.3390/coatings5040771.

[3] Biegańska, M.: "Shelf-life monitoring of food using time-temperature indicators (TTI) for application in intelligent packaging" Towaroznawcze Problemy Jakości (2), 75-85, 2017.

[4] Biji, K. B., Ravishankar, C. N., Mohan, C. O., Gopal, T. S.: "Smart packaging systems for food applications: a review", Journal of food science and technology 52(10), 6125-6135, 2015. doi: 10.1007/s13197-015-1766-7.

[5] Brockgreitens, J., Abbas, A.: "Responsive food packaging: Recent progress and technological prospects", Comprehensive Reviews in Food Science and Food Safety 15(1), 3-15, 2016. doi: 10.1111/1541-4337.12174.

[6] Caon, T., Martelli, S. M., Fakhouri, F. M.: "New trends in the food industry: application of nanosensors in food packaging", In: Nanobiosensors, (Academic Press, Cambridge MA, 2017.), pages 773-804. doi: 10.1016/B978-0-12-804301-1.00018-7.

[7] Chan, F. T. S., Chan, H. K., Choy, K. L.: "A systematic approach to manufacturing packaging logistics", The International Journal of Advanced Manufacturing Technology 29(9-10), 1088-1101, 2006. doi: 10.1007/s00170-005-2609-x.

[8] Corrales, M., Fernandez, A., Han, J. H.: "Antimicrobial packaging systems", In: Innovations in food packaging, (Academic Press, Cambridge MA, 2014.), pages 133-170. doi: 10.1016/B978-0-12394601-0.00007-2.

[9] Dan, M., Huang, M., Liao, F., Qin, R., Liang, X., Zhang, E., Huang, M., Huang, Z., He, Q.: “Identification of ethylene responsive mirnas and their targets from newly harvested banana fruits using highthroughput sequencing", Journal of agricultural and food chemistry 66(40), 10628-10639, 2018. doi: 10.1021/acs.jafc.8b01844.

[10] Dudnyk, I., Janeček, E. R., Vaucher-Joset, J., Stellacci, F.: “Edible sensors for meat and seafood freshness", Sensors and Actuators B: Chemical 259, 1108-1112, 2018. doi: 10.1016/j.snb.2017.12.057.

[11] European Commission.: "EU Guidance to the Commission Regulation (EC) No 450/2009 of 29 May 2009 on active and intelligent materials and articles intended to come into the contact with food (version 1.0)", 2009. 
[12] European Food Safety Authority (EFSA).: "Guidelines on submission of a dossier for safety evaluation by the EFSA of active or intelligent substances present in active and intelligent materials and articles intended to come into contact with food", EFSA Journal 7(8), 1208, 2009. doi: 10.2903/j.efsa.2009.1208.

[13] Fang, Z., Zhao, Y., Warner, R. D., Johnson, S. K.: "Active and intelligent packaging in meat industry", Trends in Food Science \& Technology 61, 60-71, 2017. doi: 10.1016/j.tifs.2017.01.002.

[14] Floros, J. D., Dock, L. L., Han, J. H.: "Active packaging technologies and applications", Food Cosmetics and Drug Packaging 20(1), 10-17, 1997.

[15] Fresh-Check: "Visual Temperature Assurance On Every Package”, URL http://fresh-check.com/ (last request: 2020-11-09).

[16] Fuertes, G., Soto, I., Carrasco, R., Vargas, M., Sabattin, J., Lagos, C.: “Intelligent packaging systems: sensors and nanosensors to monitor food quality and safety", Journal of Sensors, 2016. doi: 10.1155/2016/4046061.

[17] Gaikwad, K. K., Singh, S., Ajji, A.: "Moisture absorbers for food packaging applications", Environmental Chemistry Letters 17(2), 609-628, 2019. doi: 10.1007/s10311-018-0810-z.

[18] Ganiari, S., Choulitoudi, E., Oreopoulou, V.: "Edible and active films and coatings as carriers of natural antioxidants for lipid food", Trends in Food Science \& Technology 68, 70-82, 2017. doi: 10.1016/j.tifs.2017.08.009.

[19] Ghaani, M., Cozzolino, C. A., Castelli, G., Farris, S.: "An overview of the intelligent packaging technologies in the food sector", Trends in Food Science \& Technology 51, 1-11, 2016. doi: 10.1016/j.tifs.2016.02.008.

[20] Gómez-Estaca, J., López-de-Dicastillo, C., Hernández-Muñoz, P., Catalá, R., Gavara, R.: “Advances in antioxidant active food packaging", Trends in Food Science \& Technology 35(1), 42-51, 2014. doi: 10.1016/j.tifs.2013.10.008.

[21] Guarda, A., Rubilar, J. F., Miltz, J., Galotto, M. J.: "The antimicrobial activity of microencapsulated thymol and carvacrol", International journal of food microbiology 146(2), 144-150, 2011. doi: 10.1016/j.ijfoodmicro.2011.02.011.

[22] Hogan, S. A., Kerry, J. P.: "Smart packaging technologies for fast moving consumer goods", (John Wiley \& Sons Ltd, 2008.) pages 33-54.

[23] Imran, M., Revol-Junelles, A. M., Martyn, A., Tehrany, E. A., Jacquot, M., Linder, M., Desobry, S.: "Active food packaging evolution: transformation from micro-to nanotechnology", Critical reviews in food science and nutrition 50(9), 799-821, 2010. doi: 10.1080/10408398.2010.503694.

[24] Irkin, R., Esmer, O. K.: "Novel food packaging systems with natural antimicrobial agents", Journal of food science and technology 52(10), 6095-6111, 2015. doi: 10.1007/s13197-015-1780-9.

[25] Jung, J., Raghavendra, G. M., Kim, D., Seo, J.: “One-step synthesis of starch-silver nanoparticle solution and its application to antibacterial paper coating", International journal of biological macromolecules 107, 2285-2290, 2018. doi: 10.1016/j.ijbiomac.2017.10.108.

[26] Kalpana, S., Priyadarshini, S. R., Leena, M. M., Moses, J. A., Anandharamakrishnan, C.: "Intelligent packaging: Trends and applications in food systems", Trends in Food Science \& Technology 93, 145157, 2019. doi: 10.1016/j.tifs.2019.09.008.

[27] Kandirmaz, E. A., Ozcan, A.: "Antibacterial effect of Ag nanoparticles into the paper coatings", Nordic Pulp \& Paper Research Journal 34(4), 507-515, 2019. doi: 10.1515/npprj-2019-0034.

[28] Kontominas, M.: "Bioactive Food Packaging: Strategies, Quality, Safety", (DEStech Publications, Inc, 2015.).

[29] Krejcova, L., Michalek, P., Rodrigo, M. M., Heger, Z., Krizkova, S., Vaculovicova, M., Hynek, D., Adam, V., Kizek, R.: "Nanoscale virus biosensors: state of the art", Nanobiosensors in Disease Diagnosis 4, 47-66, 2015. doi: 10.2147/NDD.S56771.

[30] Labuza, T. P., Breene, W. M.: "Applications of "active packaging" for improvement of shelf-life and nutritional quality of fresh and extended shelf-life foods", Journal of food processing and preservation 13(1), 1-69, 1989. doi: 10.1111/j.1745-4549.1989.tb00090.x.

[31] Lagaron, J. M., Catalá, R., Gavara, R.: "Structural characteristics defining high barrier properties in polymeric materials", Materials Science and Technology 20(1), 1-7, 2004. doi: 10.1179/026708304225010442.

[32] Loucanova, E., Kalamarova, M., Parobek, J.: "The innovative approaches to packaging-comparison analysis of intelligent and active packaging perceptions in Slovakia”, Studia Universitatis „Vasile Goldis" Arad-Economics Series 27(2), 33-44, 2017. doi: 10.1515/sues-2017-0007. 
[33] Lydekaityte, J., Tambo, T.: "Smart packaging: definitions, models and packaging as an intermediator between digital and physical product management", The International Review of Retail, Distribution and Consumer Research 1-34, 2020. doi: 10.1080/09593969.2020.1724555.

[34] Mahalik, N. P., Nambiar, A. N.: "Trends in food packaging and manufacturing systems and technology", Trends in food science \& technology 21(3), 117-128, 2010. doi: 10.1016/j.tifs.2009.12.006.

[35] Mane, K. A.: "A review on active packaging: an innovation in food packaging", International Journal of Environment, Agriculture and Biotechnology 1(3), 2016. doi: 10.22161/ijeab/1.3.35.

[36] MITSUBISHI GAS CHEMICAL: “AGELESS EYE, Oxygen Indicator", URL https://www.mgc.co.jp/eng/products/sc/ageless-eye.html (last request: 2020-11-09).

[37] Muriel-Galet, V., López-Carballo, G., Gavara, R., Hernández-Muñoz, P.: “Antimicrobial food packaging film based on the release of LAE from EVOH", International Journal of Food Microbiology 157(2), 239-244, 2012. doi: 10.1016/j.ijfoodmicro.2012.05.009.

[38] Mustafa, F., Andreescu, S.: "Chemical and biological sensors for food-quality monitoring and smart packaging", Foods 7(10), 168, 2018. doi: 10.3390/foods7100168.

[39] Müller, P., Schmid, M.: "Intelligent packaging in the food sector: A brief overview", Foods 8(1), 16, 2019. doi: 10.3390/foods8010016.

[40] Ozdemir, M., Floros, J. D.: "Active food packaging technologies", Critical reviews in food science and nutrition 44(3), 185-193, 2004. doi: 10.1080/10408690490441578.

[41] Pal, M., Devrani, M., Hadush, A.: "Recent developments in food packaging technologies", Beverage \& Food World 46(1), 21-25, 2019.

[42] Pathak, N.: "Photocatalysis and vacuum ultraviolet light photolysis as ethylene removal techniques for potential application in fruit storage", Ph.D. Thesis, Technische Universität Berlin, 2019.

[43] Pathak, N., Caleb, O. J., Geyer, M., Herppich, W. B., Rauh, C., Mahajan, P. V.: "Photocatalytic and photochemical oxidation of ethylene: Potential for storage of fresh produce-A review", Food and Bioprocess Technology 10(6), 982-1001, 2017. doi: 10.1007/s11947-017-1889-0.

[44] Pereira Jr, V. A., de Arruda, I. N. Q., Stefani, R.: "Active chitosan/PVA films with anthocyanins from Brassica oleraceae (Red Cabbage) as Time-Temperature Indicators for application in intelligent food packaging", Food Hydrocolloids 43, 180-188, 2015. doi: 10.1016/j.foodhyd.2014.05.014.

[45] Poyatos-Racionero, E., Ros-Lis, J. V., Vivancos, J. L., Martínez-Máñez, R.: "Recent advances on intelligent packaging as tools to reduce food waste", Journal of Cleaner Production 172, 3398-3409, 2018. doi: 10.1016/j.jclepro.2017.11.075.

[46] Priyanka, C. N., Parag, D. N.: "Intelligent and active packaging", International Journal of Engineering and Management Sciences 4(4), 417-418, 2013.

[47] Robertson, G. L.: "Food packaging: principles and practice”, (CRC press, 2016.).

[48] Rvspayeva, A., Jones, T. D., Hughes, P. A., Esfahani, M. N., Shuttleworth, M. P., Harris, R. A., Kay, R.W., Desmulliez, M.P.Y., Marques-Hueso, J.: "PEI/Ag as an optical gas nano-sensor for intelligent food packaging", 18th International Conference on Nanotechnology 2018, (IEEE-NANO, 2018), pages 1-4. doi: 10.1109/NANO.2018.8626269.

[49] Sacharow, S.: "Freshness enhancers: the control in controlled atmosphere packaging", Preserved Foods 157(5), 121-122, 1998.

[50] Sanches-Silva, A., Costa, D., Albuquerque, T. G., Buonocore, G. G., Ramos, F., Castilho, M. C., Machado A.V., Costa, H.S.: "Trends in the use of natural antioxidants in active food packaging: a review", Food Additives \& Contaminants: Part A 31(3), 374-395, 2014. doi: 10.1080/19440049.2013.879215.

[51] Scampicchio, M., Arecchi, A., Lawrence, N. S., Mannino, S.: "Nylon nanofibrous membrane for mediated glucose biosensing", Sensors and Actuators B: Chemical 145(1), 394-397, 2010. doi: 10.1016/j.snb.2009.12.042.

[52] Schaefer, D., Cheung, W. M.: "Smart packaging: opportunities and challenges", Procedia CIRP 72, 1022-1027, 2018. doi: 10.1016/j.procir.2018.03.240.

[53] Smith, J. P.: "Principles of Modified-Atmosphere and Sous Vide Product Packaging", (Routledge, New York, 1995.), page 287.

[54] Sun, M., Yang, X., Zhang, Y., Wang, S., Wong, M. W., Ni, R., Huang, D.: "Rapid and visual detection and quantitation of ethylene released from ripening fruits: the new use of Grubbs catalyst", Journal of agricultural and food chemistry 67(1), 507-513, 2018. doi: 10.1021/acs.jafc.8b05874. 
[55] Sürengil, G., Kılınç, B.: “Gıda-ambalaj sektöründe nanoteknolojik uygulamalar ve su ürünleri açısından önemi", Journal of FisheriesSciences.com 5(4), 317-325, 2011. doi: 10.3153/jfscom.2011036.

[56] Tang, X. Z., Kumar, P., Alavi, S., Sandeep, K. P.: "Recent advances in biopolymers and biopolymerbased nanocomposites for food packaging materials", Critical reviews in food science and nutrition 52(5), 426-442, 2012. doi: 10.1080/10408398.2010.500508.

[57] Taoukis, P. S., Labuza, T. P.: "Time-temperature indicators (TTIs)", Novel food packaging techniques, 103-126, 2003. doi: 10.1016/B978-1-85573-675-7.50010-9.

[58] The Silicon Review: "Now it is easier to detect contaminated food with RFID stickers", URL https://thesiliconreview.com/2018/11/rfid-stickers-could-signal-contaminated-food (last request: 2020-11-09).

[59] Tian, F., Decker, E. A., Goddard, J. M.: "Controlling lipid oxidation of food by active packaging technologies", Food \& function 4(5), 669-680, 2013. doi: 10.1039/c3fo30360h.

[60] Vermeiren, L., Devlieghere, F., van Beest, M., de Kruijf, N., Debevere, J.: "Developments in the active packaging of foods", Trends in food science \& technology 10(3), 77-86, 1999. doi: 10.1016/S09242244(99)00032-1.

[61] Vilela, C., Kurek, M., Hayouka, Z., Röcker, B., Yildirim, S., Antunes, M. D. C., Nilsen-Nygaard, J., Pettersen, M.K., Freire, C.S.R.: "A concise guide to active agents for active food packaging", Trends in Food Science \& Technology 80, 212-222, 2018. doi: https://doi.org/10.1016/j.tifs.2018.08.006.

[62] Wei, H., Seidi, F., Zhang, T., Jin, Y., Xiao, H.: "Ethylene scavengers for the preservation of fruits and vegetables: A review", Food Chemistry 337, 2020. doi: 10.1016/j.foodchem.2020.127750.

[63] Wells, L. E., Farley, H., Armstrong, G. A.: "The importance of packaging design for own-label food brands", International Journal of Retail \& Distribution Management 35(9), 2007. doi: 10.1108/09590550710773237.

[64] Wilson, C.: "Influences of modified atmosphere packaging and drip absorbents on the quality, safety, and acceptability of fresh-cut cantaloupe", MSc thesis, Michigan State University, 2017.

[65] Yildirim, S., Röcker, B., Pettersen, M. K., Nilsen-Nygaard, J., Ayhan, Z., Rutkaite, R., Radusin, T., Suminska, P., Marcos, B., Coma, V.: "Active packaging applications for food", Comprehensive Reviews in Food Science and Food Safety 17(1), 165-199, 2018. doi: 10.1111/1541-4337.12322.

[66] Young, E., Mirosa, M., Bremer, P.: "A Systematic Review of Consumer Perceptions of Smart Packaging Technologies for Food", Frontiers in Sustainable Food Systems 4, 2020. doi: 10.3389/fsufs.2020.00063.

[67] Zagory, D.: “Active food packaging", (Springer, Boston, MA, 1995.), pages 38-54.

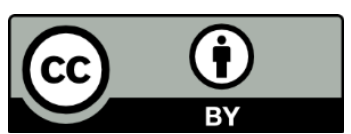

(C) 2020 Authors. Published by the University of Novi Sad, Faculty of Technical Sciences, Department of Graphic Engineering and Design. This article is an open access article distributed under the terms and conditions of the Creative Commons Attribution license 3.0 Serbia (http://creativecommons.org/licenses/by/3.0/rs/). 



\title{
LIGNOCELLULOSIC BIO-REFINERY DOWNSTREAM PRODUCTS IN FUTURE PACKAGING APPLICATIONS
}

\author{
Igor Karlovits (i) \\ Pulp and Paper Institute, Ljubljana, Slovenia
}

\begin{abstract}
The concept of efficient utilisation of renewable bio-based materials (biomass feedstock) is the driving force in the green transformation to a more sustainable and circular society. Biorefineries or biochemical platforms convert and utilise different sources of biomass into fuels and other beneficial derivates like fibres and other bio-based chemicals. These can be used as building blocks for many potentially useful applications. In this review, we shall describe the current state of the art and trends in the conversion of lignocellulosic feedstock into materials which can be primarily used in packaging applications. The three main constituents (cellulose, hemicellulose and lignin) are being re-engineered into new products with higher added value. The main goal of all these downstream products is that they do not compete with animal feed and food applications. The main downstream products of different kind of transformations are different natural fibres which can be further processed into micro or nano fibrillated state and used for a broad application of fields from ink, adhesive and packaging materials. Also, fibres and its derivates can be bonded successfully into bio-composites or fibre-based foams applications for the protective packaging applications. Hemicellulose, as a second most abundant component, has been researched for applications in adhesives and paper and paperboard coatings. Lignin which is currently utilised as an energy source for the paper industry, has been recently actively researched. Lignin-based biopolymers have a potential to be used in many different applications from additives in the barrier coatings on the packaging to active packaging and even as lignin-based foams. All these applications are currently in the development stages and cover niche market segments, but are expected to grow and to be used in future markets.
\end{abstract}

Keywords: biorefinery, fibres, lignin, packaging, fibre-based foams

\section{INTRODUCTION}

Packaging with its multiple functions and sometimes conflicting requirements throughout the life cycle of a product makes a vital building block for all societies from the old ages to contemporary modern societies. With steady continual grow at $2.8 \%$ and soaring market values of $\$ 1.05$ trillion in 2024 (from $\$ 917$ billion in 2020) according to Smither Pira study (Pira, 2019) packaging market is significant for all countries. This trend of the growing market is similar to all continents, but trends in structure and future perspectives differ for continents. The E.U.S the recent administrative and legislative decisions like the Directive 2008/98/EC on waste and connected specific Directives (E.U., 2008), Directive 94/62/EC on packaging and packaging waste (E.U., 1994) and the most recent Green Deal (E.U., 2020) puts the E.U. trailing to be the first climate-neutral continent. The European Green Deal is an action plan to:

- boost the efficient use of resources by moving to a clean, circular economy

- restore biodiversity and cut pollution

A part of the European Green Deal is also the new Circular Economy Action Plan (E.U., 2020) which presents new initiatives along the entire life cycle of products in modernising the E.U. economy while protecting the environment. Inside this Action plan for packaging, there are several ways the E.U. wants to tackle the packaging waste problems. Single-use products will be phased out wherever possible and replaced by durable products for multiple uses. New legislative initiatives on reuse to substitute singleuse packaging, tableware and cutlery by reusable products in food services, as well as targets for reducing packaging waste, will be proposed. Measures will be introduced for waste prevention and reduction, increasing recycled content, minimising waste exports outside E.U. Another action plan the Farm to Fork targets the agricultural sector where more natural production and resource efficiency is promoted with an emphasis on sustainable production. If we take a step back and rethink these goals and which resource is renewable and also has some additional benefits, the solution is the lignocellulosic biomass. Photosynthesis removes carbon dioxide from the air to produce sugars. A large part of carbon is built into these sugars, and the rest of the oxygen goes into the air. The sugar is converted into other organic compounds that are useful to the plant. A surprisingly wide range of compounds is produced, including 
starches, fats, proteins, and many other classes of molecules. However, a very high percentage of the sugar is simply converted into cellulose - or in the case of woody plants, cellulose and lignin. Because all biomass consists of carbon-rich compounds - and the carbon in these compounds originated as atmospheric $\mathrm{CO}_{2}$ captured by green plants to create sugar - forests can be viewed as a significant carbon sink. A "carbon sink" is anything that absorbs large amounts of carbon dioxide from the atmosphere, retaining the carbon in one form or another (Bouchard, 2018). One of the major consumers of wood is, of course, the pulp and paper industry, with over $40 \%$ of all industrially traded wood (W.W.F., 2020). Other consumers are mainly (industrial Roundwood, pellets, sawn wood, and wood-based panels (F.A.O., 2018). These sectors are mainly mechanically processing the wood and retaining the sunk sugars carbon and fibres in the structure. So, the pulp and paper industry have a long tradition in chemically modifying the lignocellulosic biomass, it has some side streams which have also been tried in the past to be utilised, but until now the market product was pulp and natural fibre which are converted to paper and boards. There are other industrial facilities which are using lignocellulosic biomass - not wood-based, but another kind of crops and agro-residues to produce energy or animal feedstock. So, the concept of these facilities were the founding stones of the biorefineries. The bioeconomy encompasses the production of renewable biological resources and their conversion into food, feed, bio-based products and bioenergy via innovative and efficient technologies and feedstocks come from agriculture, forestry, landscape conservation and side streams from food production. The bioeconomy concept was further upgraded to the Circular Economy concept. The Ellen McArthur Foundation, which is one of the leading promoters of the sustainable society, defines the circular economy as an economy which aims to redefine growth, focusing on positive society-wide benefits. It entails gradually decoupling economic activity from the consumption of finite resources and designing waste out of the system. Underpinned by a transition to renewable energy sources, the circular model builds economic, natural, and social capital. It is based on three principles (Ellen MacArthur Foundation, 2020):

- Design out waste and pollution

- Keep products and materials in use

- Regenerate natural system

\section{BIOREFINERY CONCEPTS}

Lignocellulosic biomass fulfils all of the requirements, and the missing element is the total efficient utilisation of all compounds in the carbon sink. The circular economy is complementary to the renewable character of the bioeconomy and must facilitate the recycling of carbon after efficient uses. One of the possible solutions for this are the biorefineries. The definition of biorefining in the circular economy by the IEA Bioenergy Task 42 (IEA, 2018) is that it is "Sustainable processing of biomass into a portfolio of marketable biobased products (food and feed ingredients, chemicals, materials, fuels, energy, minerals, $\mathrm{CO}_{2}$ ) and bioenergy (fuels, power, heat) «. The concept is presented in Figure 1, while the bio refination of biomass concept is presented in Figure 2 .

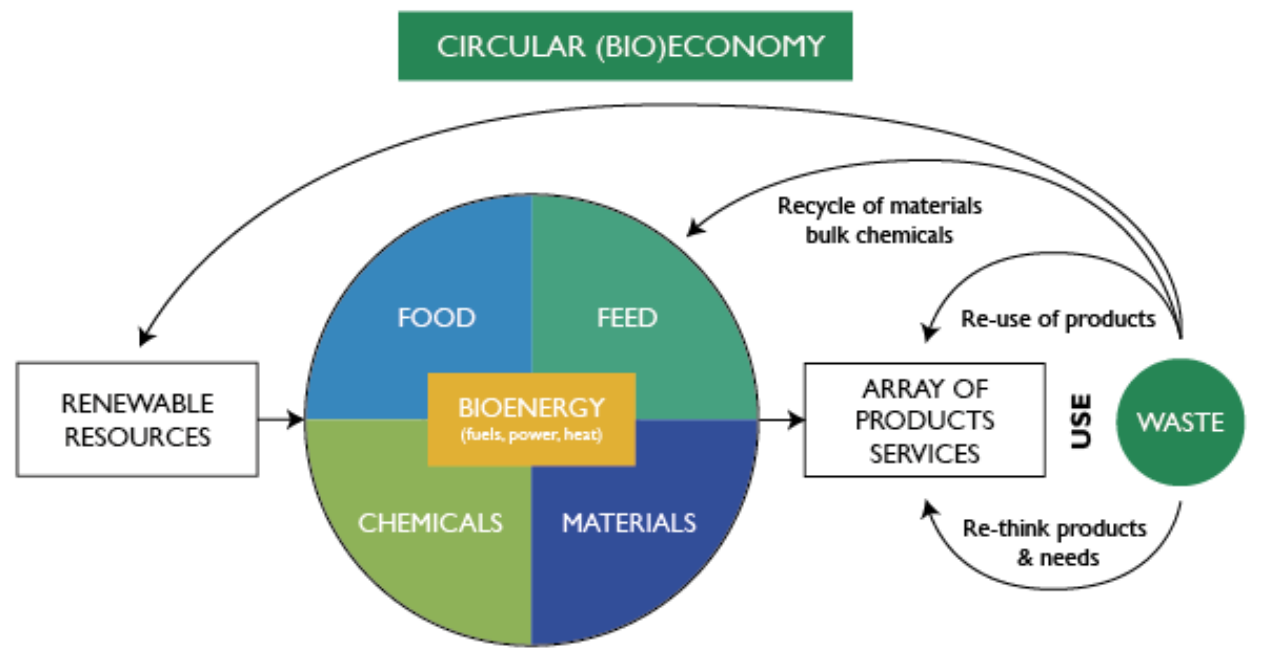

Figure 1: Circular Bioeconomy concept (Adapted from Wenger J. et al, 2018) 


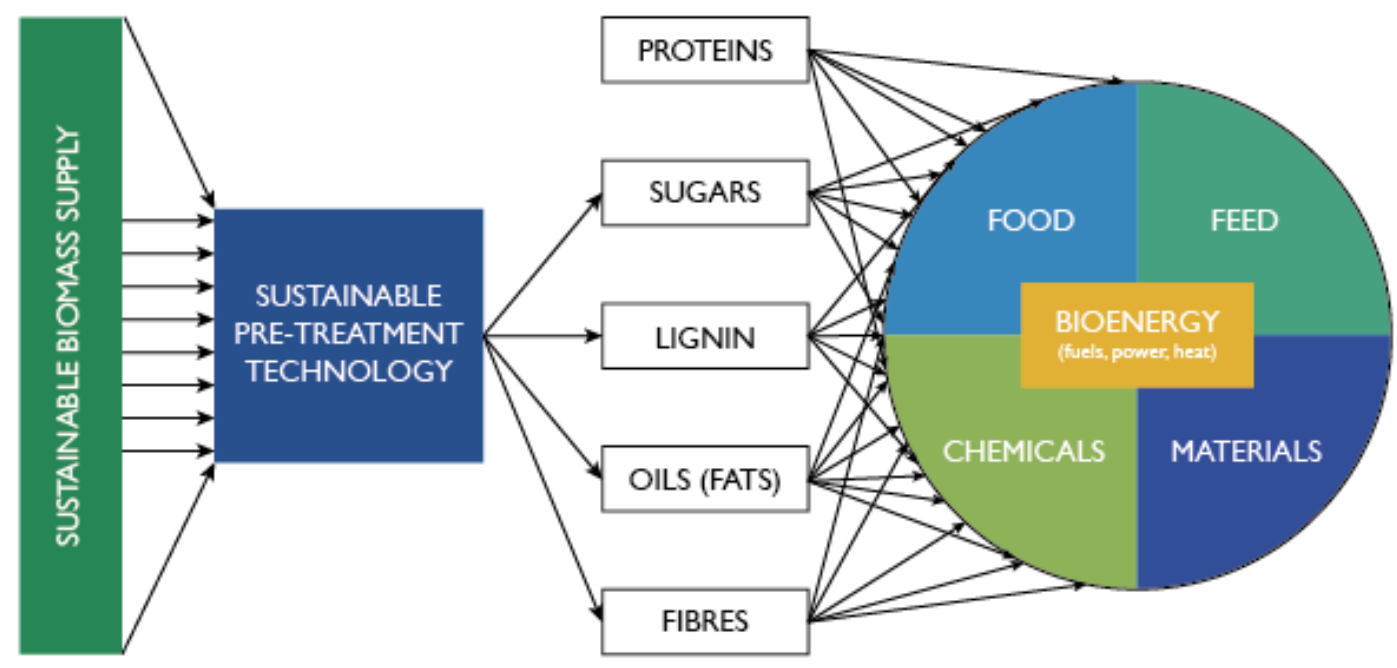

Figure 2: Biomass rafination (Adapted from Wenger J. et al, 2018)

The classification of biorefineries is complex and are sometimes broad and generic, but one which describes the complexity of the system grouping is presented in (Cherubini et al, 2009):

- The lignocellulosic feedstock biorefinery - uses nature dry raw material, such as cellulosecontaining biomass and wastes.

- The whole crop biorefinery - uses raw materials, such as cereals or maize.

- The green biorefinery - uses nature-wet biomasses, such as green grass, alfalfa, clover or immature cereal.

- The two-platform concept biorefinery - includes the sugar and the syngas platforms.

- The conventional biorefinery-based on existing industries, such as the sugar and starch industry.

- The thermochemical biorefinery - based on a mix of several technologies.

- The marine biorefinery - based on marine biomass. 8. The liquid-phase catalytic processing biorefinery - based on the production of functionalised hydrocarbons from biomass-derived intermediates.

- The forest-based biorefinery - based on the full integration of biomass and other feedstocks (including energy), for simultaneous production of pulp, (paper) fibres, chemicals and energy

Due to limitations and scope of this paper, we shall give an overview of the side streams and possible uses of biorefinery products from the lignocellulosic feedstock biorefinery (which also encompasses the forest-based biorefinery). The biochemical and biomaterial side streams and derivates (fibres, hemicellulose, lignin) which will be presented will cover only the packaging sector (thus they can also be used in other industries like pharmaceuticals, cosmetics and food industry).

The lignocellulosic-feedstock biorefinery uses lignocellulosic biomass as feedstock with the advantages of high availability, moderate cost, no direct competition with food and feed production, and has a "good position of conversion products on the traditional Petro-chemical and future biobased product market" (Kamm et al, 2016). The components (mainly cellulose, lignin and hemicellulose) are separated by several available procedures before being further processed into various products and bioenergy; however, certain technologies (e.g., separation, lignin utilisation) still need to be further developed. The pulp and paper industry serves as an example of this specific biorefinery type as it has placed an increasing focus on "value-added coproducts from underutilised streams and waste materials »since the 1980s (De Jong et al, 2015). With its main fibrous products and "value-added coproducts, including, e.g., tall oil, acetic acid, furfural, and lignosulfonates," the pulp and paper industry can also be considered as an early non-foodcrop industrial biorefinery (De Jong et al, 2015). For instance, lignin has mainly been burned as black liquor up until now, and the chemical recovery processes are used for energy (heat, electricity) production; however, lignin is also said to have great potential for use to create products in the future, such as renewable polymers or materials. Further perspectives on lignocellulosic biorefineries can be found in (Hassan et al, 2019), Saini et al (2019), (Konwar et al, 2018) and (de Jong and Gosselink, 2014). 


\section{FIBER (CELLULOSE AND NANOCELLULOSE) APPLICATIONS}

Cellulose $\left[\left(\mathrm{C}_{6} \mathrm{H}_{10} \mathrm{O}_{5}\right) \mathrm{n}\right]$ is an organic compound and the most abundant biopolymer on Earth. It is a complex carbohydrate or polysaccharide consisting of hundreds to thousands of glucose molecules, linked together to form a chain. An overview of cellulose structure can be found in (leoleovich, 2008). The principal commercial use for cellulose is paper manufacturing, where the kraft process is used to separate cellulose from lignin. Cellulose fibres can be also be utilised in the textile industry, while microcrystalline cellulose and powdered cellulose are used as drug fillers and as food thickeners, emulsifiers, and stabilisers. An illustration of fibre-relevant aspects in lignocellulosic-feedstock biorefineries appears in Figure 3, while an in-depth review of the fibre applications can be found in (Wenger et al, 2018).

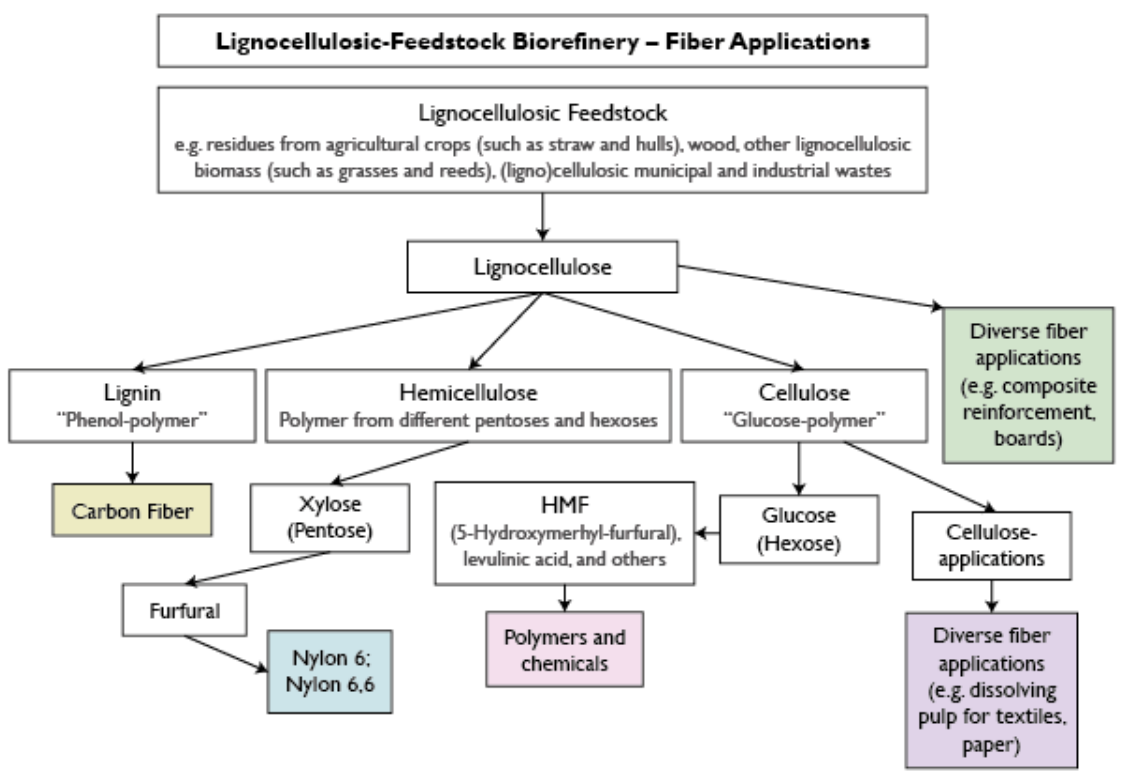

Figure 3: Fibre applications in lignocellulosic-feedstock Biorefinery (Adapted from Wenger J. et al, 2018)

From Figure 3. We can see that regarding cellulose we can take two routes: the bio-chemicals through glucose as a building block for polymer solutions or more fibre-based cellulose applications. The application routed is, of course, dependent on the market value of the selected fibre applications and in Figure 4. a scheme is presented which shows approximate bandwidths and relations between prices and volumes in different applications fields.

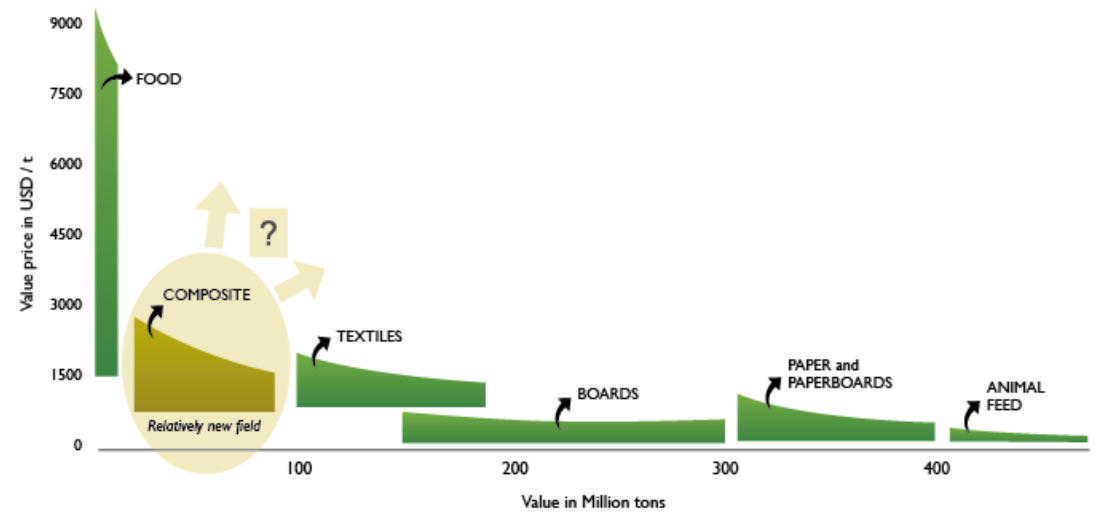

Figure 4: Market value and volumes of fibre-based solutions

From Figure 4. We can see that the highest potential market value has a recently developing filed of composites and technical textiles while the paper and board applications with specialised packaging solutions can mitigate the stagnation of classic printing and writing papers. Solutions which can be 
directly be applied to the packaging via composites and paper and boards are micro-fibrillated cellulose (M.F.C.) and nano-cellulose applications, fibre-based foams and fibre-based composites.

\subsection{Micro-fibrillated cellulose (M.F.C.) and nano-cellulose}

In addition to conventional fibres, micro- and nanoscale cellulose are promising materials. They can be grouped into three main types: micro-fibrillated cellulose (M.F.C.), nanocrystalline cellulose (N.C.C.) and bacterial nano-cellulose (BNC), which can be distinguished according to their dimensions, functions and preparation methods. Table 1, taken from Klemm et al (2011), gives a brief summary of M.F.C., N.C.C. and BNC (sources, formation and average size).

Table 1: Parameters and speed (Klemm, 2011)

\begin{tabular}{|c|c|c|c|}
\hline Type of nanocellulose & $\begin{array}{l}\text { Selected } \\
\text { references and } \\
\text { synonyms }\end{array}$ & Typical sources & Formation and average size \\
\hline $\begin{array}{l}\text { Micro-fibrillated } \\
\text { cellulose (M.F.C.) }\end{array}$ & $\begin{array}{l}\text { Micro-fibrillated } \\
\text { cellulose, } \\
\text { nanofibrils, } \\
\text { nano-fibrillated } \\
\text { cellulose }\end{array}$ & $\begin{array}{l}\text { Wood, sugar } \\
\text { beet, potato } \\
\text { tuber, hemp, } \\
\text { flax, invasive } \\
\text { plants }\end{array}$ & $\begin{array}{l}\text { Delamination of wood pulp by } \\
\text { mechanical pressure before } \\
\text { and after chemical or } \\
\text { enzymatic treatment; diameter } \\
\text { 5-60 nm; length; several } \\
\text { micrometres }\end{array}$ \\
\hline $\begin{array}{l}\text { Nano-crystalline } \\
\text { cellulose (N.C.C.) }\end{array}$ & $\begin{array}{l}\text { Cellulose } \\
\text { nanocrystals, } \\
\text { crystallites, } \\
\text { whiskers, rod- } \\
\text { like cellulose } \\
\text { microcrystals }\end{array}$ & $\begin{array}{l}\text { Wood, cotton, } \\
\text { hemp, flax, } \\
\text { wheat straw, } \\
\text { mulberry bark, } \\
\text { ramie, Avicel, } \\
\text { tunicin, cellulose } \\
\text { from algae and } \\
\text { bacteria }\end{array}$ & $\begin{array}{l}\text { Acid hydrolysis of cellulose } \\
\text { from many sources; } \\
\text { diameter:5-70 nm; length:100- } \\
250 \mathrm{~nm} \text { (from plant cellulose); } \\
10 \mathrm{~nm} \text { to several micrometres } \\
\text { (from the cellulose of } \\
\text { tunicates, algae, bacteria) }\end{array}$ \\
\hline Bacterial nano-cellulose & $\begin{array}{l}\text { Bacterial } \\
\text { cellulose, } \\
\text { microbial } \\
\text { cellulose, bio- } \\
\text { cellulose }\end{array}$ & $\begin{array}{l}\text { Low-molecular- } \\
\text { weight sugars } \\
\text { and alcohols }\end{array}$ & $\begin{array}{l}\text { Bacterial synthesis; diameter } \\
\text { 20-100 nm; different types of } \\
\text { nanofiber networks }\end{array}$ \\
\hline
\end{tabular}

Nano-cellulose has an extensive range of potential applications, with the highest demand for composites (35\% of the total nano-cellulose demand), pulp and paper (15\%), paints, films and coatings (15\%). The use of nanocellulose in packaging applications can be grouped into biocomposites where we blend the nanocellulose with other biopolymers. It can be utilized as an agent for achieving better barrier properties on packaging material with additional active packaging functionalities like antioxidant and aroma-active agents for controlled release. Both multi-functional bio-based composites and tailor-made nano papers have shown improved mechanical properties and excellent functional properties, such as transparency, biodegradability, and specific surface properties to add new functionalities like gas barrier enhancement and heat sealability (Johansson et al, 2012). Nanocelluloses (nanofibers and whiskers) form a remarkable useful group of naturally obtained nanomaterials because of their extraordinary mechanical properties, combining high stiffness and strength with lightweight character. For example, cellulose crystals can exhibit Young's modulus of up to ca. $134 \mathrm{GPa}$ and their tensile strength is expected to be in the range of a few GPa (Nishino et al, 1995). These properties mean that nanocellulosics can be placed at the top of high-performance natural materials. However, to apply it into different biocomposite matrix, optimal material and physical properties need to be achieved for the reinforcement's physical dimension and the nature of the interface between reinforcement and matrix. Very different cellulosic materialsbacterial, microcrystalline, microfibrillated or nanocrystalline-can cause distinctly different reinforcement (Miao and Hamad, 2013). For example in (Lavrič et al, 2020) applications of B.F.C. in the 
paper industry is presented, while many more studies demonstrated the usefulness of N.F.C. and B.F.C. mixture with different bio-based polymers such as chitosan or PLA. (Fernandes et al, 2010; Li et al, 2009; Nakagaito et al, 2009; Okubo et al, 2009), PHB (Zhang et al, 2019) or even bio-based epoxies (Nair et al, 2019) and in so-called nano papers. Nano paper produced by nano fibrillated cellulose is an exciting packaging material due to its high toughness and high effectiveness as an oxygen barrier (Henriksson et al, 2008; Nogi et al, 2009). Other reviews of using nanocellulose in food packaging can be found in (Souza et al, 2020; Ferrer et al 2017; Azeredo et al, 2017; Vilarinho et al, 2018) where they confirmed nanocellulose could contribute to the strength of biocomposite barrier films. Biocomposite films compromised of nano cellulose can effectively resist oxygen permeation, and water vapour and moisture resistance are critical areas of challenge. The barrier properties of interesting for paper and paperboard packaging are usually focused on oxygen, water vapour, and aroma permeability. The aforementioned properties are essential to extend the shelf life of fresh foods as well as for other biodegradable or watersensitive products. For a similar reason, grease resistance and hydrophobicity are of importance for many applications of paper and paperboard packaging and are commonly measured to define the general characteristics and potentialities of new materials (Johansson et al, 2012). Properties of nanocellulose films compared with other polymers can be found in (Nair et al, 2014), while one of the most detailed research on permeability properties of cellulose-based films can be found in (Wang et al, 2018) and the application limits are presented in Figure 5.
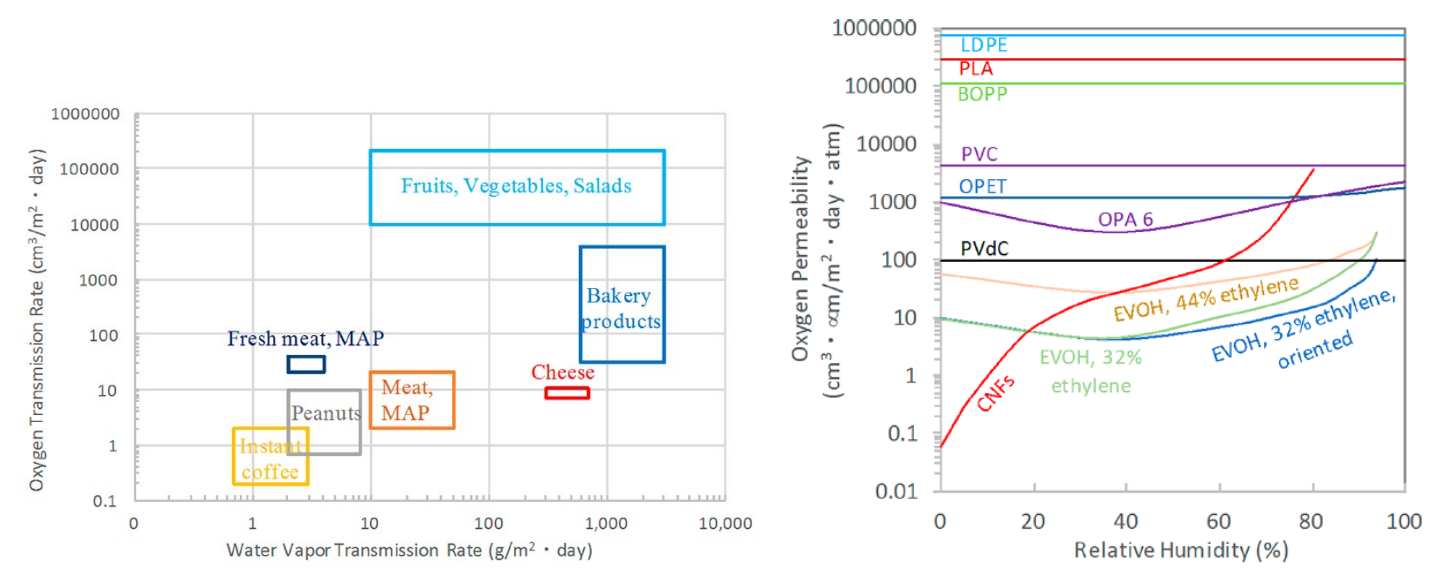

Figure 5: Oxygen Transmission rate of nano cellulosic and commercial polymers (Wang et al, 2018)

In (Brodin et al, 2014), a detailed study is presented on challenges and applications of N.F.C. and M.F.C. in paper coatings. N.F.C. and M.F.C. can as mentioned to be used to surface finish paper and to improve its properties (Havimo et al, 2011; Aulin et al, 2010; Hult et al, 2010; Belbekhouche et al, 2011; Minelli et al, 2010; Syverud and Stenius, 2009; Sothornvit, 2009). Among the different materials, nano-fibrillated cellulose (N.F.C.), has shown exciting barrier properties (Hult et al, 2010; Plackett et al, 2010, Syverud and Stenius, 2009; Sothornvit, 2009) and has been used in different studies related to paper coating (Aulin et al, 2011; Hult et al, 2010; Syverud and Stenius, 2009). In particular, it was shown that carboxymethylated N.F.C. could lead to remarkably high barrier properties, provided that it completely covers the paper surface. Indeed, tested papers coated with a few grams of N.F.C. per square meter showed a decrease of up to six orders of magnitude in air permeability and also showed increased grease resistance (Hult et al, 2010). Of course, the printability of such materials are also essential, and some studies like (Karlovits et al, 2018) showed that the addition of M.F.C. and N.F.C. provided same flexo printing quality as reference papers. Comparison of cellulose and nanocellulose papers were also studied from the morphological, structural and barrier properties by (Djafari et al, 2019). Nevertheless, another promising application is using nanocellulose as an enhancer of starch glues in the corrugated board production where an increase of board production up to $45 \%$ for the BC II was reported by adding nanocellulose based solution (Holtan S., 2020). The market entry into the flexible pouches markets could also be paved by the development of enzymatic fibrillation of cellulose (HefCel) technology which enables refining nanocellulose is in the consistency of $15-25 \%$ when traditional nanocellulose production methods result in 1-3\% consistency. With these properties, it enables production of densely packed structure of nanocellulose films and coatings with outstanding oxygen, grease and mineral oil barrier properties (V.T.T., 2020). An example of this solution is presented in Figure 6, and a commercial solution from Arjowiggins for flexible pouches. 

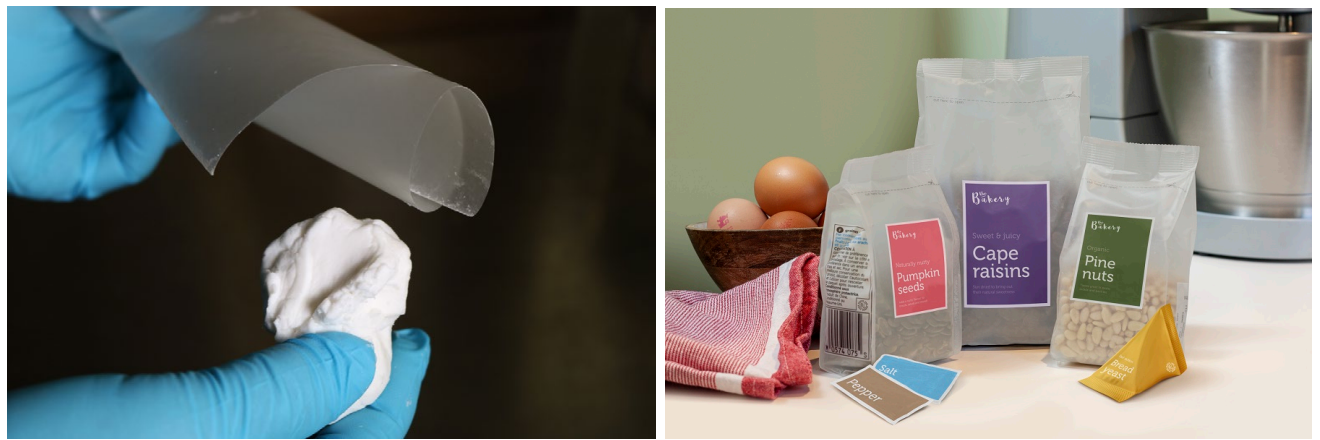

Figure 6: Hefcel nanocellulose (V.T.T.) and nanocellulose based flexible pouches by Arjowiggins

\subsection{Fibre-based cellulose bio foams as packaging material}

One of the most potential technologies beyond paper and board manufacturing is foam forming technology, where water is replaced with aqueous foam. In foam forming technology aqueous foam instead of water is used as a carrier medium in the manufacturing process of fibre-based products. By adding air bubbles in water, the properties of the carrier fluid are changed fundamentally. This new and versatile technology will radically widen the product property window and the variety of raw materials that can be utilised in the manufacturing process. Foam enables utilisation of longer fibres than in traditional water-based process, improved control of web structure and manufacturing of structures having low density compared to paper and board (densities less than $100 \mathrm{~kg} / \mathrm{m}^{3}$ can be obtained) (Pääkkönen, 2020). The current solutions for replacing some forms of EPS packaging are polylactide (PLA) foams, for example, made from corn, and corrugated board and moulded fibre products made from wood pulp; all have benefits and drawbacks. PLA has good water resistance and offers similar performance to EPS, but its price and recycling in current infrastructure hamper its usage. Fiber and fibre moulded solutions, on the other hand, are inferior regarding thermal and cushioning properties. Foamformed cellulose-based materials offer key technical benefits compared with the current alternatives. For example, the foam-forming technology allows short and long fibres to be combined to improve the mechanical performance of the foam, providing better protection. In addition, cellulose fibres can be combined with polymer or biopolymer fibres. Other elements can be incorporated into the foam, for example, a cellulose-PLA foam composite for delicate applications that require a material with excellent cushioning performance. The thermal stability of cellulose-based foams is also better than PLA foams, which means they can be used in hot environments, or to pack products that are still warm from production. Depending on the application, cellulose-based foams can even be produced with existing paper infrastructure to create products such as bio-based board, cushioning materials, nonwoven web, and insulation (Pääkkönen, 2020). An example of a fibre-based foaming structure is presented in Figure 7.

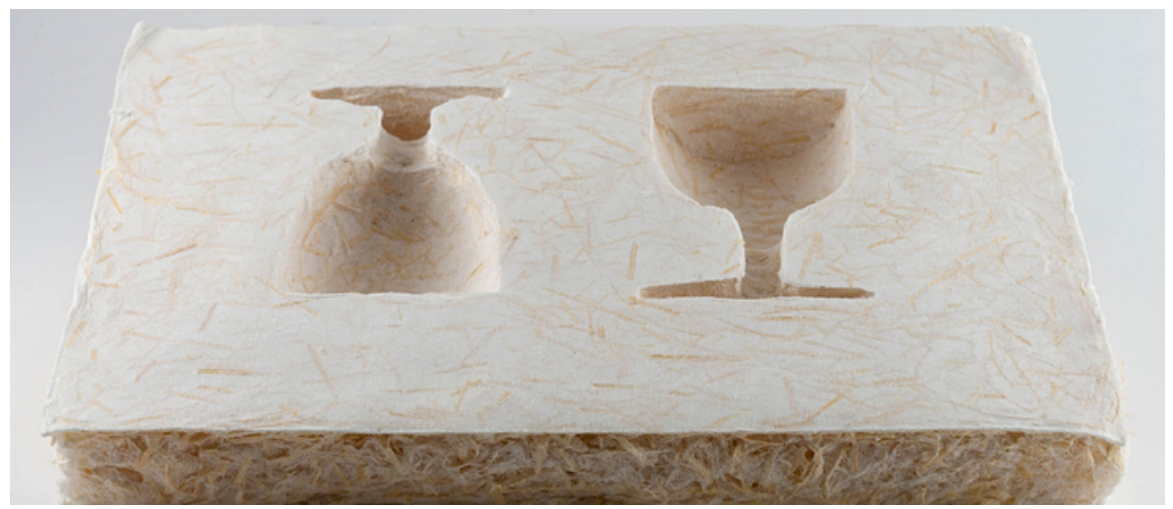

Figure 7: Fibre foam packaging structure (Pääkkönen, 2020).

A study by (Hellen et al, 2013) proved that fibre-based foaming solutions (where fibres and other furnish components are mixed with foam instead of water, and where air content is between 50-70\%) are viable solutions for different applications in packaging. They claim that significant resource savings are expected for foam forming technology in the form of: 
- The most significant advantage through fibre savings

- Less drying energy due to a decreased basis weight

- Chemical costs are lower due to reduced basis weight and improved retention

- Clear improvement in resource-efficiency and benefits in adding value to fibre-based products.

In his PhD study (Al-qararah, 2015) an aqueous foam was used as the carrier phase in the deposition of fibre networks, but on laboratory scales without complications caused by product-specific industrial processes like foam production, wet pressing and drying. His main finding was that in axial mixing, the bubble size and its distribution could be affected by several factors such as the rotation speed, air content and surface tension. The mean bubble size became smaller for natural than regenerated fibres, and the bubble size distribution became narrower for natural fibres. The reasons behind this behaviour were likely to be the rough surfaces of the natural fibres and the related fraction of fine particles, which were absent for regenerated fibres. The microscopic pore structure of foam-formed sheets and water-formed sheets at a roughly equal density were significantly different. The pore size distribution of the foamformed sheets was much more comprehensive than the corresponding distribution of the water-formed sheets. In a paper by (Paunonnen et al, 2018) they enhance the strength of lightweight cellulose fibre foams by combining fines of different length scales and adding polymer (natural rubber). This addition improved the network structure to recover after compression. Forming and subsequent water removal and drying methods have a profound effect on the sheet structure (Timofeev et al, 2016; Haffner et al, 2017). Foam-formed fibre networks can have a much lower density (Madani et al, 2014), improved and tailored pore size distribution (Al-Qararah et al, 2015), and more diverse fibre orientation (Alimadadi and Uesaka, 2016) compared with similar water-formed materials. Foam-formed three- dimensional wood fibre networks (3DFNs) have structural similarities with sheet materials, such as paper. The load-bearing elements in both are the same: fibres, joints, and a connected network.

Paper exhibits three types of deformation: linear and non-linear elastic strain, visco-elastic timedependent recoverable creep, and plastic non-recoverable deformation (Brezinski, 1956; Alava and Niskanen, 2006). Alimadadi and Uesaka (2016) reported the same phases for foam-formed 3DFNs made from pure thermomechanical (T.M.P.) reject pulp. However, the fibre network structure of 3DFNs is very different from that of sheets. The number of bonds a fibre makes with neighbouring fibres at low densities is different from that for thin sheets. 3DFNs also retain their integrity more easily than sheets (Alimadadi and Uesaka, 2016).

Moreover, 3DFNs show a unique and much higher deformation recovery compared with paper and some nonwoven sheets. In addition to the number of bonds (determined by the material density) (Borodulina et al, 2016), the stress and strain distribution in a material is affected by several other factors, such as the fiber length and stiffness. Also, properties like bond compliance and the elastic and viscoelastic creep recovery of foam-formed 3DFNs and extend their use to application areas where highly flexible and elastic materials are preferred.

Besides using fibre-based foams, other solution includes bio-based foams based on starch derivates. In their paper, Su et al (2018) gave an overview of biobased packaging alternatives where different solutions (pure biopolymer foams and fibre-reinforced solutions were presented). The main technical challenges with starch bio-foam are low elasticity, high stiffness, high brittleness, and high water absorption (Shogren et al, 2002; Svagan et al, 2011; Phaodee et al, 2015). In order to improve the strength and water resistance, researchers have added mineral fillers, wood fibres, resin, or coating with wax and other materials (Andersen et al, 1999; Fang and Hanna, 2001). Thanks to their excellent mechanical properties, cellulose fibres can be used as additives to the starch matrix to increase the strength properties, such as tensile strength, stress performance, and toughness (Salgado et al, 2008; Bénézet et al, 2012; Li et al, 2014). Besides that, fibres together with components such as chitosan or natural latex can create synergistic effects to improve further the functional properties of the bio-foam (Kaisangsri et al, 2012; Phaodee et al, 2015). The fibre foaming technology is matured, and the first installation of small production scale facility was launched this year in Finland.

\section{HEMICELLULOSE APPLICATIONS}

Hemicellulose was mainly treated as a waste product in the pulp and paper industry and together with lignin was washed out together with lignin and used as an energy source. Due to is the lower amount in the biomass feedstock (around 20-30\%) and a smaller polymer structure from the cellulose (unlike 
cellulose, hemicellulose consists of shorter chains 500 - 3000 sugar units as opposed to 7000 - 15,000 glucose molecules per polymer), is not a primary choice for reinforcement applications. Nevertheless, it has been investigated in applications like gels and films and was shown to be suitable as in emulsions and stabilisers. Several papers have an overview of the current state of the art on hemicellulose-based hydrogels (Hu et al, 2018), and in Konge et al (2018). In their research (Farhat et al, 2017) have used alkaline treatment for hemicellulose extraction from hardwood pulp and partly delignified switchgrass. Their results showed that loading stress required to break hemicellulose based adhesive connection between two paper surfaces rose after adding 8\% of A.Z.C. crosslinker in the hemicellulose, which increased the adhesive behaviour of the material. The hemicellulose and cellulose modifications (especially wood-based xylan) were routed out for coating and packaging - including films, barrier materials and coating binders - from bleached birch kraft pulp, as well extracted pulp in Laine (2012). The research team had test xylan, for example as binders in pigment - coatings applications for offset grade paper. Good surface strength of coated paper could be demonstrated with butylated and allylated xylan (X-BA2), and it performed almost as well in the tests as the reference latex. The performance of hydroxy propylated xylan (HPX2) was not as good as that of X-BA2. Some development is needed as, e.g., shear viscosities of the coating colours with xylan derivative binders were generally considerably higher than those of the latex colour. In another study by Talja et al (2011), cellulose fatty acid esters were synthesised and characterised from chemical pulps, with different hemicellulose contents. Paper coatings were prepared and analysed. The coatings were hydrophobic, and the barrier properties importantly were found not to vary significantly at all between the cellulose substituents and the degrees of substitution. Water contact angle values were over $90^{\circ}$. Hydrophobicity was also confirmed by low water absorption into the coated boards; the values being similar to those of commercial ones. The best water vapour barrier properties, i.e. the lowest water vapour transmission rates (WVTR) were obtained for the coatings prepared from the palmitoyl esters of the low hemicellulose content pulp cellulose.

One recent research in the utilisation of hemicellulose as a holistic recovery of agricultural residues was presented in (Jahn et al, 2020). In their research, they have tested different sources of hemicellulose (wheat straw, oat husks) and have tested it as a paper additive, flame retardant and floating agent. Their research found that hemicelluloses are also suitable as an additive for increasing the strength of recycling paper. By adding 1 or $2 \mathrm{wt} \%$ hemicellulose the static as well as the dynamic strength increased by more than $10 \%$. The flame-retardant applications were also satisfying, and they achieved in the application of the flame retardants onto fibre-insulating material and to get the same fire protection class as well as a better smouldering performance like conventional flame retardants. This finding can be easily applied to archival boxes and packaging application where fire protection of the packaging container is important. The use as a flotation agent, whereby the digestion method plays an important role, and further research is needed as well that that delignification is not suitable for isolation of foaming agents. One exciting route of reusing materials for a new type of application was described in (Albertson et al, 2010) where they had used the soluble waste from Masonite production. After fractionation, the hemicellulose rich fraction was used to form a cross-linked hydrogel. This hydrogel was further used as a coating on seeds for the temporary inhibition of germination. This concept can be transferred to other coating applications in the print and packaging sector. One direct application of hemicellulose films was made in a dissertation by (Ma, 2018) was screen printed moisture sensor was applied to hemicellulose-based bio-films, and their application for smart packaging was investigated. In this study, the hemicellulose-based barrier coating was applied on to the backside of the commercial S.B.S. board, and on top of it was screen printed moisture sensor. The hemicellulose-based biofilm shows good capability in terms of its mechanical strength and printability to be applied as packaging material. Due to the influence of moisture on barrier properties, the hemicellulose-based biofilm was successfully modified with citric acid. It was found that compared to the sensor printed on uncoated S.B.S. board, the sensor printed on barrier coated S.B.S. board has a significant delay of impedance increase with the increasing R.H. This behaviour shows that the hemicellulose-based barrier coating is capable of blocking out the moisture vapour and can be potentially used for packaging applications. The public research of hemicelluloses as dispersants and texture modifiers in other dispersion applications than foods and cosmetics is however still in early phases. The current status of hemicellulose commercialisation and utilisation is assumed to change for a few reasons. First, there is increased knowledge and (economical) motivation to create biopolymer-based materials and surfactants. Secondly, the availability of non-food hemicelluloses is increasing steadily as the increased valorisation of the non-food biomass and development of the biorefinery concepts. There is commercial and economic interest and demand to make valuable products of all the components of lignocellulose and not just cellulose (Ebringerova and Heinze, 2000). 


\section{LIGNIN APPLICATIONS}

Lignin is not a homogeneous, monodisperse polymer, but rather a complex mixture of polymers that may exhibit a diverse range of molar masses (e.g., polydispersity). There are significant differences in structures between polymers (monomer abundance, interunit linkages), and potential diverse distributions of various functional groups (e.g., primary, secondary, and phenolic hydroxyl and carboxylate groups) between polymer chains. Lignin has been incorporated into many biopolymers, such as starch, protein, cellulose, P.L.A. and PHB, to form bioplastics solutions. Based on the overview of multiple lignin solutions and fibre applications in bioplastics (Yang et al, 2019) conclude that the lignin as reinforcements can produce bioplastics with high performance. Lignin can function as a plasticiser, stabiliser, or bio-compatibiliser in bioplastics, which will produce different properties on bioplastics. Besides, lignin is modified to enhance its miscibility with biopolymers considerably by functionalisation of hydroxyl groups. However, due to its complex structure, the ability to obtain technical lignin of a reduced degree of association is presently a very tough challenge for promoting the use of lignin in bioplastic. Nevertheless, recent research on cellulose-lignin and lignin-containing cellulosic fibre-reinforced bioplastics are desirable and meaningful. The scheme for the possible combination technologies and applications is presented in Figure 8.

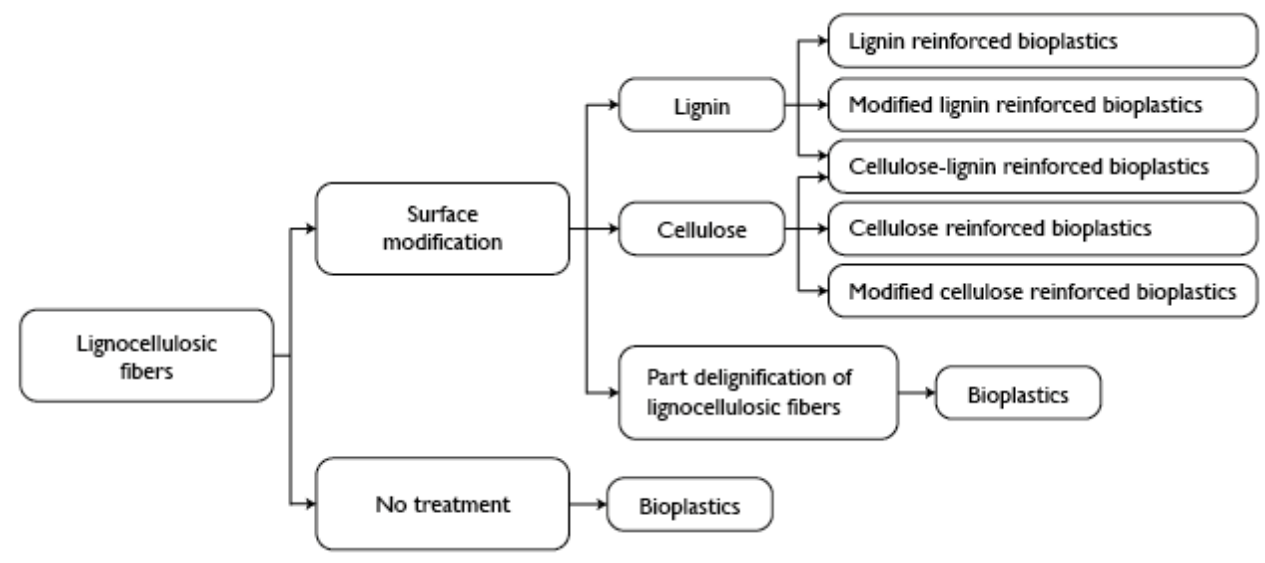

Figure 8: Global scheme of the uses of lignocellulosic fibres and lignin in bioplastics.

Many companies are interested in replacing bisphenol A (commonly known as B.P.A.) with lignin in epoxies, incorporating lignin into polyurethane, and creating biobased foams and coatings. For polyurethane applications, the type, abundance, and accessibility of hydroxyl groups in the lignin are critical. Notably, the relative abundance and distribution of these alcohol groups are strongly dependent on the biomass source and processing history (Alijenad et al, 2019). Kraft softwood lignin has been used to replace 10-30\% (by weight) of the polyol in flexible foam formulations and reported that the developed foam had viscoelastic behaviour similar to the control foams]. The foam produced with $100 \%$ replacement of the polyol with sodium lignosulfonate lignin was dense, brittle, and mechanically weak and was more like a rigid foam than flexible foam. Overall, the prepared foams using kraft lignins and lignosulfonates were reported to have better compressive strength viscoelastic properties], and dimensional and thermal stability relative to the control foams using conventional fossil-derived polyols (Carriço et al, 2016); (Chang et al, 2014) and (Wysocka et al, 2016).

In their work (Tondi et al, 2016) makes formulations, with various lignin/furanic ratios, blowing agents, and catalyst concentrations obtained by the copolymerisation of furanics with the spent liquor from the magnefite wood pulping process. Their research showed that lignin foams could be prepared with various densities as low as $185 \mathrm{~kg} \mathrm{~m}^{-3}$. The lignin foams exhibited typical characteristics of porous materials, i.e., the compression resistances and thermal conductivities were directly proportional to the density. These properties show a similar trend to the previously observed characteristics of tannin foams. These results that these type of lignin-based foams may have the potential to serve as an environmentally-friendly alternative for materials, such as polystyrene and polyurethane. 


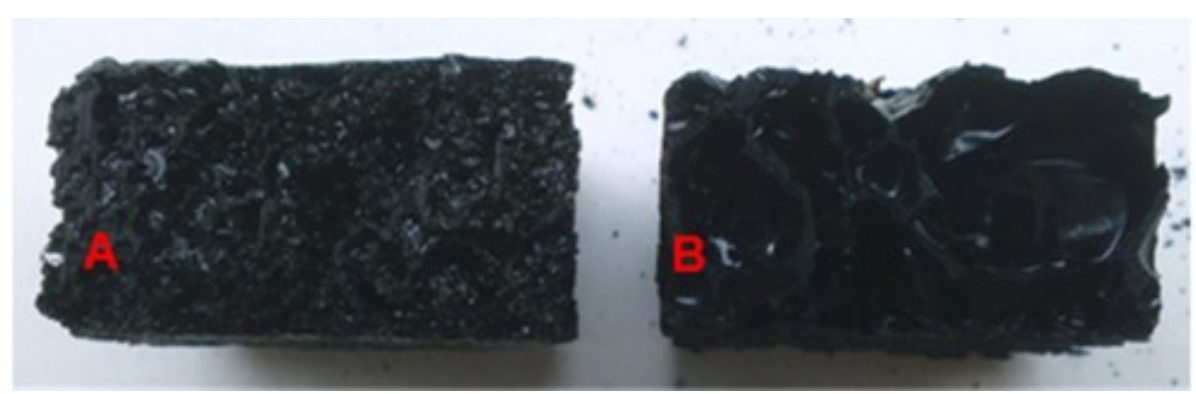

Figure 9: Lignin based foams with and without wood particles (Tondi et al, 2016)

Due to their polyphenolic structure lignins bear several interesting functional properties, such as antioxidant activity. Natural antioxidants are very much looked for in the aim of protection of light or oxygen-sensitive goods and are being used in active packaging. In research conducted by (Domenek et al, 2013) PLA lignin films were prepared by twin-screw extrusion followed by thermo-compression using two different commercial sources of alkali lignins obtained from gramineous plants. Their results show that lignins do not impair the mechanical and barrier performance of the polymer and the plastics processing even allows for the generation of active substances.

In his MSc thesis, Borenius (2019) researched the use of lignin and hemicellulose in dispersions as surfactants and functional materials. During his research that alkali $\mathrm{O}_{2}$ oxidised (LigniOx) lignins showed to have potential as dispersants, especially in carbon black dispersions and to an extent in the titan dioxide dispersions. This type of lignins could be used as dispersants in paint, coating, ink, plastic and other dispersion-related applications. A very detailed study of using lignin in biopolymeric packaging films was done by (Zadeh et al, 2018), where lignin was investigated for use in sustainable biopolymeric packaging film. Alkali lignin and lignosulfonate were added to enzymatically modified soy protein isolate biopolymeric film with different concentrations to improve the film physical and functional properties. As a raw material, alkali lignin (A.L.) and lignosulfonate (L.S.S.) showed significant radical scavenging activity compared to commercial BHT, which carry strong potentials in use for active packaging structure. Films containing A.L. showed strong UV-blocking ability induced by the natural colour of lignin. Mechanical properties and thermal stability of films containing lignin were significantly changed compared to the control films without lignin. This implies that the typical limitations of the biopolymeric film in packagings, such as low mechanical properties and poor thermal properties, may be minimised or solved by utilising lignin and enzymatic treatment, while offering an additional potential in functionality, such as antioxidant activity derived from lignin.

\section{CONCLUSION}

The lignocellulosic biorefinery concept provides future places for packaging material building blocks production. Sustainable and circular uses of bio-based resources demand to meet society needs will be dependent on the production of a variety of products like food, feed, materials, chemicals and energy from limited resources. Nanocellulose and lignin as fillers, reinforcement agents and potential antimicrobial materials open up numerous possibilities in the packaging applications. Nanocellulose already is on the brink of broader commercialisation with numerous applications (mainly around the "old" pulp and paper mills), while hemicellulose and lignin are in the early rising stage of development. The biopolymer composites as it seems are in the ambiguous phase as part of the polymer industry, is pushing the chemical recycling of petroleum-based polymers instead of natural-based ones. The demand from the customers is crucial as this will increase the development of smart bio-based circular packaging solutions. It is up to policymakers and the market to recognise that quality lignocellulosic materials are still widely used for energy production or lower value-added products (commodity papers), and a change has to be made. The success in the specialised markets can open up the necessary demand for scaling up, which can provide products of higher, more efficient volumes of biobased renewable products which do not pollute the environment. Another challenge in areas with decentralised biomass availability (unlike the refurbished pulp and paper mills near large forest areas) is in small scale but flexible biorefineries and logistics optimisation where contemporary I.T. solutions like artificial intelligence can be used. This would thoroughly connect the two fibre worlds (the natural and the digital optic one). 


\section{REFERENCES}

[1] Alava, M., Niskanen, K.: "The physics of paper", Reports on Progress in Physics 69 (3), 669-723, 2006. doi: 10.1088/0034-4885/69/3/R03

[2] Albertsson, A., Voepel, J., Edlund, U., Dahlman, O. and Söderqvist-Lindblad, M.: "Design of Renewable Hydrogel Release Systems from Fiberboard Mill Wastewater", Biomacromolecules 11 (5), 1406-1411, 2010. doi: 10.1021/bm100253e

[3] Alimadadi, M., Uesaka, T.: "3D-oriented fibre networks made by foam forming", Cellulose 23 (1), 661-671, 2016. doi: 10.1007/s10570-015-0811-z

[4] Al-Qararah M. A.: "Aqueous foam as the carrier phase in the deposition of fibre networks", PhD thesis, University of Jyväskylä, 2015.

[5] Al-Qararah, A., Ekman, A., Hjelt, T., Ketoja, J., Kiiskinen, H., Koponen, A., Timonen, J.: “A unique microstructure of the fibre networks deposited from foam-fibre suspensions", Colloids and Surfaces A: Physicochemical and Engineering Aspects 482, 544-553, 2015. doi: 10.1016/j.colsurfa.2015.07.010

[6] Aulin, C., Gällstedt, M., Lindström, T.: "Oxygen and oil barrier properties of microfibrillated cellulose films and coatings", Cellulose 17, 559-574, 2010. doi: 10.1007/s10570-009-9393-y

[7] Aulin, C., Johansson, E., Wågberg, L., Lindström, T.: "Self-organized films from cellulose nanofibrils using the layer-by-layer technique", Biomacromolecules 11 (4), 872-882, 2010. doi: 10.1021/bm100075e

[8] Azeredo, H., Rosa, M., Mattoso, L.: "Nanocellulose in bio-based food packaging applications", Industrial Crops and Products 97, 664-671, 2017. doi: 10.1016/j.indcrop.2016.03.013

[9] Belbekhouche, S., Bras, J., Siqueira, G.: "Water sorption behavior and gas barrier properties of cellulose whiskers and microfibrils films", Carbohydrate Polymers 83 (4), 1740-1748, 2011. doi: 10.1016/j.carbpol.2010.10.036

[10] Bénézet, J. C., Stanojlovic-Davidovic, A., Bergeret, A., Ferry, L., Crespy, A.: "Mechanical and physical properties of expanded starch, reinforced by natural fibres", Industrial Crops and Products 37 (1), 435-440, 2012. doi: 10.1016/j.indcrop.2011.07.001

[11] Borenius, P.: "Lignin and Hemicellulose in Dispersions - as Surfactants and Functional Materials", MSc thesis, Tampere University, 2019.

[12] Borodulina, S., Motamedian, H. R., Kulachenko, A.: "Effect of fibre and bond strength variations on the tensile stiffness and strength of fibre networks", International Jorunal of Solids and Structures 154, 19-32, 2016. doi: 10.1016/j.ijsolstr.2016.12.013

[13] Bouchard, P. "Trees And Carbon Dioxide: What Is The True Connection?", URL: https://medium.com/the-philipendium/trees-and-carbon-dioxide-what-is-the-truth-c7f8c9d12602 (last request: 2020-10-17), 2018.

[14] Brezinski, J. P.: "The creep properties of paper", Tappi Journal 39 (2), 116-128, 1956.

[15] Brodin, F., Gregersen, $\varnothing$., Syverud, K.: "Cellulose nanofibrils: Challenges and possibilities as a paper additive or coating material - A review", Nordic Pulp \& Paper Research Journal 29 (1), 156-166, 2014. doi: 10.3183/npprj-2014-29-01-p156-166

[16] Carriço, C. S., Fraga, T., Pasa, V. M. D.: "Production and characterisation of polyurethane foams from a simple mixture of castor oil, crude glycerol and untreated lignin as bio-based polyols", European Polymer Journal 85, 53-61, 2016. doi: 10.1016/j.eurpolymj.2016.10.012

[17] Chang, L., Sain, M., Kortschot, M.: "Improvement in Compressive Behavior of Alkali-treated Wood Polyurethane Foams", Cellular Polymers 33 (3), 139-158, 2014. doi: 10.1177/026248931403300302

[18] Cherubini, F., Jungmeier, G., Wellisch, M., Willke, T., Skiadas, I., Van Ree, R., de Jong, E.: "Toward a common classification approach for biorefinery systems", Biofuels, Bioproducts and Biorefining 3 (5), 534-546, 2009.

[19] De Jong, E., Gosselink, R.: "Lignocellulose-Based Chemical Products", Bioenergy Research: Advances and Applications, 277-313, 2014. doi: 10.1016/B978-0-444-59561-4.00017-6

[20] De Jong, E., Jungmeier, G.: "Biorefinery Concepts in Comparison to Petrochemical Refineries", Industrial Biorefineries \& White Biotechnology, 3-33, 2015. doi: 10.1016/B978-0-444-63453-5.00001-X

[21] Djafari Petroudy, S., Rahmani, N., Rasooly Garmaroody, E., Rudi, H., Ramezani, O.: "Comparative study of cellulose and lignocellulose nano papers prepared from hardwood pulps: Morphological, structural and barrier properties", International Journal of Biological Macromolecules 135, 512-520, 2019. doi: 10.1016/j.jjbiomac.2019.05.212 
[22] Domenek, S., Louaifi, A., Guinault, A.: "Potential of Lignins as Antioxidant Additive in Active Biodegradable Packaging Materials", Journal of Polymers and the Environment 21, 692-701, 2013. doi: 10.1007/s10924-013-0570-6

[23] Ebringerova A., Heinze T.: "Xylan and xylan derivatives - Biopolymers with valuable properties, 1 Naturally occurring xylans structures, procedures 88 and properties", Macromolecular Rapid Communications 21 (9), 542-556, 2000. doi: 10.1002/1521-3927(20000601)21:9<542::AIDMARC542>3.0.CO;2-7

[24] Ellen McArthur Foundation: "What Is A Circular Economy?" URL: https://www.ellenmacarthurfoundation.org/circular-economy/concept (last request: 2020-10-14), 2020.

[25] EUR-Lex: "Directive 2008/98/EC on waste and repealing certain", URL: https://eurlex.europa.eu/legal-content/EN/TXT/?uri=celex\%3A32008L0098 (last request: 2020-10-14), 2008.

[26] EUR-Lex: "Directive 94/62/EC on packaging and packaging waste", URL: https://eurlex.europa.eu/legal-content/en/TXT/?uri=CELEX:31994L0062 (last request: 2020-10-14), 1994.

[27] FAO: "Forest Product Statistics", URL: http://www.fao.org/forestry/statistics/80938@180723/en/ (last request: 2020-10-18), 2018.

[28] Farhat, W., Venditti, R., Quick, A., Taha, M., Mignard, N., Becquart, F., Ayoub, A.: "Hemicellulose extraction and characterisation for applications in paper coatings and adhesives", Industrial Crops and Products 107, 370-377, 2017. doi: 10.1016/j.indcrop.2017.05.055

[29] Ferrer, A., Pal, L., Hubbe, M.: “Nanocellulose in packaging: Advances in barrier layer technologies", Industrial Crops and Products 95, 574-582, 2017. doi: 10.1016/j.indcrop.2016.11.012

[30] Hassan, S., Williams, G., Jaiswal, A.: "Lignocellulosic Biorefineries in Europe: Current State and Prospects", Trends in Biotechnology 37 (3), 231-234, 2019. doi: 10.1016/j.tibtech.2018.07.002

[31] Havimo, M., Jalomäki, J., Granström, M., Rissanen, A., livanainen, T., Kemell, M., Heikkilä, M., Sipi, M., Kilpeläinen, I.: "Mechanical strength and water resistance of paperboard coated with long chain cellulose esters", Packaging Technology and Science 24 (4), 249-258, 2011. doi: 10.1002/pts.932

[32] Holtan, S.: "Boost Your corrugator productivity with Exilva Microfibrillated cellulose", URL: https://www.exilva.com/blog/boost-your-corrugator-productivity-with-exilva-microfibrillatedcellulose (last request: 2020-10-13), 2020.

[33] Hu, L., Du, M., Zhang, J.: "Hemicellulose-Based Hydrogels Present Status and Application Prospects: A Brief Review", Open Journal of Forestry 08 (01), 15-28, 2018. doi: 10.4236/ojf.2018.81002

[34] Hult, E.-L., lotti, M., Lenes, M.: "Efficient approach to high barrier packaging using microfibrillar cellulose and shellac", Cellulose 17 (3), 575-586, 2010.

[35] Johansson, C., Bras, J., Mondragon, I., Nechita, P., Plackett, D., Šimon, P., Svetec, D. G., Virtanen, S., Baschetti, M. G., Breen, C., Clegg, F., Aucejo, S.: "Renewable fibres and bio-based materials for packaging applications - A review of recent developments", Bioresources 7 (2), 2506-2552, 2012. doi: 10.15376/biores.7.2.2506-2552

[36] Kaisangsri, N., Kerdchoechuen, O., Laohakunjit, N.: "Biodegradable foam tray from cassava starch blended with natural fiber and chitosan", Industrial Crops and Products 37 (1), 542-546, 2012. doi: 10.1016/j.indcrop.2011.07.034

[37] Kamm, B., Gruber, P. R., Kamm, M.: "Biorefineries-Industrial Processes and Products", In: Ullmann's Encyclopedia of Industrial Chemistry, (Wiley-VCH Verlag, Berlin, 2016.), pages 1-38. doi: 10.1002/14356007.104_101.pub2

[38] Karlovits, I., Lavrič, G., Pleša, T., Kavčič, U.: "The influence of M.F.C. and N.F.C. addition in an uncoated paper on flexography optical print quality", Paper technology and industry 59 (1), 14-18, 2018.

[39] Kong, W., Dai, Q., Gao, C., Ren, J., Liu, C., Sun, R.: “Hemicellulose-Based Hydrogels and Their Potential Application”, In: Polymer Gels. Gels Horizons: From Science to Smart Materials, (Springer, Singapore, 2018). doi: 10.1007/978-981-10-6086-1_3

[40] Konwar,L. J., Mikkola, J.-P., Bordoloi, N., Saikia, R., Chutia, R. S., Kataki, R.: "Sidestreams From Bioenergy and Biorefinery Complexes as a Resource for Circular Bioeconomy", In: Waste Biorefinery, (Elsevier, Amsterdam, 2018.), pages 85-125, doi: 10.1016/B978-0-444-63992-9.00003-3

[41] Lavrič, G., Medvešček, D., Skočaj, M.: "Papermaking properties of bacterial nanocellulose produced from mother of vinegar, a waste product after classical vinegar production", Tappi journal 19 (4), 197-203, 2020. doi: 10.32964/TJ19.4.197 
[42] Li, F., Guan, K., Liu, P., Li, G., Li, J.: "Ingredient of biomass packaging material and compare study on cushion properties", International Journal of Polymer Science 2014, 2014. doi: 10.1155/2014/146509

[43] Madani, A., Zeinoddini, S., Varahmi, S., Turnbull, H., Phillion, A. B., Olson, J. A., Martinez, D. M.: "Ultra-lightweight paper foams: Processing and properties", Cellulose 21 (3), 2023-2031, 2014. doi: 10.1007/s10570-014-0197-3

[44] Miao, C., Hamad, W. Y.: "Cellulose reinforced polymer composites and nanocomposites: a critical review", Cellulose 20, 2221-2262, 2013. doi: 10.1007/s10570-013-0007-3

[45] [45] Nair, S., Dartiailh, C., Levin, D. Yan, N.: "Highly Toughened and Transparent Biobased Epoxy Composites Reinforced with Cellulose Nanofibrils", Polymers 11 (4), 612, 2019. doi: 10.3390/polym11040612

[46] Nair, S. S., Zhu, J., Deng, Y., Ragauskas, A. J.: "High-performance green barriers based on nanocellulose", Sustainable Chemical Processes 2 (23), 2014. doi: 10.1186/s40508-014-0023-0

[47] Packaging Insights: "V.T.T. Develops Lightweight 100\% Bio-Based Stand-Up Pouches", URL: https://www.packaginginsights.com/news/VTT-Develops-Lightweight-100-Bio-Based-Stand-UpPouches.html (last request: 2020-10-18), 2017.

[48] Pääkkönen, E.: “Bio-Based Packaging”, URL: https://makingoftomorrow.com/bio-based-packaging/ (last request: 2020-10-16), 2020.

[49] Phaodee, P., Tangjaroensirirat, N., Sakdaronnarong, C.: "Biobased polystyrene foam-like material from crosslinked cassava starch and nanocellulose from sugarcane bagasse", BioResources 10 (1), 348-368, 2015.

[50] Pira, S.: "Strategic Forecasts For Global Packaging To 2024 - Smithers", URL: https://www.smithers.com/resources/2020/mar/smithers-forecasts-global-packaging-market-togrow (last request: 2020-10-12), 2020.

[51] Ruoxi, M.: "Screen Printed Moisture Sensor On Barrier Coated S.B.S. Board: The Characterisations of the Hemicellulose-Based Biofilms and Their Applications for Smart Packaging", PhD thesis, Western Michigan University, 2018.

[52] Saini J. K., Gupta, R., Hemansi, Verma, A., Gaur, P., Saini, R., Shukla. R., Kuhad, R. C. "Integrated Lignocellulosic Biorefinery for Sustainable Bio-Based Economy", In: Sustainable Approaches for Biofuels Production Technologies, (Springer, Cham, 2019.), doi: 10.1007/978-3-319-94797-6_2

[53] Salgado, P. R., Schmidt, V. C., Molina Ortiz, S. E., Mauri, A. N., Laurindo, J. B.: "Biodegradable foams based on cassava starch, sunflower proteins and cellulose fibers obtained by a baking process", Journal of Food Engineering 85 (3), 435-443, 2008. doi: 10.1016/j.jfoodeng.2007.08.005

[54] Sothornvit, R.: "Effect of hydroxypropyl methylcellulose and lipid on mechanical properties and water vapor permeability of coated paper", Food Research International 42 (2), 307-311, 2009. doi: 10.1016/j.foodres.2008.12.003

[55] Souza, E., Gottschalk, L., Freitas-Silva, O.: “Overview of Nanocellulose in Food Packaging", Recent Patents on Food, Nutrition \& Agriculture, 11 (2), 154-167, 2019. doi: 10.2174/2212798410666190715153715

[56] [56] Syverud K., Stenius, P.: "Strength and barrier properties of MFC films", Cellulose 19, 75-85, 2009. doi: 10.1021/bm700624p

[57] Talja, R. A., Kulomaa, T. P. S., Labafzadeh, S., Kyllönen, L. E., King, A. W. T., Kilpeläinen, I., PoppiusLevlin, K.: "Cellulose esters from birch kraft pulp - new biomaterials for barrier coating", Proceedings of 16th International Symposium on Wood, Fibre and Pulping Chemistry (Tianjin, China, 2011), pages 1394-1398.

[58] Timofeev, O., Jetsu, P., Kiiskinen, H., Keränen, J. T.: "Drying of foam-formed mats from virgin pine fibres", Drying Technology 34 (10), 1210-1218, 2016. doi: 10.1080/07373937.2015.1103254

[59] Tondi, G., Link, M., Kolbitsch, C., Gavino, J., Luckeneder, P., Petutschnigg, A., Herchl, R., Van Doorslaer, C.: "Lignin-based foams: Production process and characterisation", BioResources 11 (2), 2972-2986, 2016.

[60] Vilarinho, F., Sanches Silva, A., Vaz, M. F., \& Farinha, J. P.: "Nanocellulose in green food packaging", Critical reviews in food science and nutrition 58 (9), 1526-1537, 2018. doi: 10.1080/10408398.2016.1270254

[61] Wang, J., Gardner, D. J., Stark, N. M., Bousfield, D. W., Tajvidi, M., Cai, Z.: "Moisture and Oxygen Barrier Properties of Cellulose Nanomaterial-Based Films", ACS Sustainable Chemistry \& Engineering 6 (1), 49-70, 2017. doi: 10.1021/acssuschemeng.7b03523 
[62] Wenger, J., Stern, T., Schöggl, J., van Ree, R., De Corato, U., De Bari, I., Bell, G., Stichnothe, H.: "Natural Fibers And Fiber-Based Materials In Biorefineries Status Report 2018", URL: http://task42.ieabioenergy.com/wp-content/uploads/2018/12/IEA-Bioenergy-Task42-FibresReport_FINAL_181214JW.pdf (last request: 2020-10-12), 2018.

[63] W.W.F.: "Pulp and Paper", URL: https://www.worldwildlife.org/industries/pulp-and-paper (last request: 2020-10-15), 2020.

[64] Wysocka, K., Szymona, K., McDonald, A. G., Mamiński, M. Ł.: "Characterisation of Thermal and Mechanical Properties of Lignosulfonate- and Hydrolyzed Lignosulfonate-based Polyurethane Foams", BioResources, 11, 7355-7364, 2016.

[65] Yang, J., Ching, Y. C., Chuah, H. C.: "Applications of Lignocellulosic Fibers and Lignin in Bioplastics: A Review", Polymers 11 (5), 751, 2019. doi: 10.3390/polym11050751

[66] Zadeh, E., O'Keefe, S., Kim, Y.: "Utilization of Lignin in Biopolymeric Packaging Films", A.C.S. Omega 3 (7), 7388-7398, 2018. doi: 10.1021/acsomega.7b01341

[67] Zhang, B., Huang, C., Zhao, H., Wang, J., Yin, C., Zhang, L., Zhao, Y.: "Effects of Cellulose Nanocrystals and Cellulose Nanofibers on the Structure and Properties of Polyhydroxybutyrate Nanocomposites", Polymers 11 (12), 2063, 2019. doi: 10.3390/polym11122063

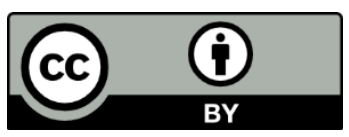

(C) 2020 Authors. Published by the University of Novi Sad, Faculty of Technical Sciences, Department of Graphic Engineering and Design. This article is an open access article distributed under the terms and conditions of the Creative Commons Attribution license 3.0 Serbia (http://creativecommons.org/licenses/by/3.0/rs/). 

PRINTING ADDED VALUE 



\title{
COLORIMETRIC CHANGES OF WATERBASED FLEXOGRAPHIC INK PRINTED ON HEMP-BASED PAPERS EXPOSED TO ARTIFICIAL AGEING
}

\author{
Ivana Plazonić (iD), Irena Bates (iD), Vesna Džimbeg-Malčić (iD), Davor Zember \\ University of Zagreb, Faculty of Graphic Arts, Zagreb, Croatia
}

\begin{abstract}
The objective of the research was to investigate colorimetric changes of the waterbased flexographic ink printed on hemp-based papers subjected to artificial ageing. Three types of commercially available hemp office papers were used as printing substrate and by Esiproof instrument were printed manually in full tone with process waterbased flexographic inks. Both, papers and prints were exposed to artificial ageing in the Suntest XLS+ test chamber according ASTM D 6789-2 standard. The $L^{*}, a^{*}, b^{*}$ colour coordinates were measured and $\Delta E_{00}$ colour difference was calculated for different stages of light exposure in order to determine the change from the original color value. In total exposure time was $96 \mathrm{~h}$. The results have shown how the paper optical stability is dependent upon manufacturing process and that bleached hemp fibers provides better optical stability of papers than unbleached hemp fibers. Further, stability of prints made on hemp-based papers is for the most part defined by ink color, while the impact of the printing substrate is less pronounced. Generally, it was noticed how the most stable among prints were prints covered with the black ink, while prints with the yellow ink had the greatest changes in color under the influence of light.
\end{abstract}

Key words: artificial ageing, colorimetric changes, flexographic prints, hemp-based papers

\section{INTRODUCTION}

During past years, the worldwide capacity for production of non-wood plant fiber pulps has increased dramatically. These plants with widely differing characteristics, such as bagasse, wheat and rice straws, bamboo, hemp and kenaf are being used as a raw material in the manufacture of pulp and paper all over the world (Ashori, 2006; Krgović et al, 2004). Many of them are used still only on experimentally bases, while some of them are used in commercial paper mills. However, still the highest percentage up to $92 \%$ of world paper production is based on wood plant fibers (Fahmy et al, 2017). From the moment of production, the paper is subject to the natural ageing process which can be defined as a sum of all irreversible chemical and physical processes which occurs in organic materials slowly during time. It can be characterized as material with high sensitivity to temperature and light that are the most common degradation factors (Izdebska, 2016). Depending on its source (wood or different plants as cotton, flax, bamboo, wheat and hemp), each type of cellulose has particular characteristics that influence the properties and the stability of paper (Princi et al, 2008). But regardless of the origin of the cellulose fibers in paper structure, they contain to a greater or lesser extent cellulose, hemicellulose and lignin (Cocca et al, 2011). Generally, in lower-quality papers cellulose is embedded in a hemicellulose and lignin matrix. Pure cellulose during the natural process of paper ageing does not absorb visible light (over $400 \mathrm{~nm}$ ), but strongly absorb UV (under $200 \mathrm{~nm}$ ). Hemicellulose has similar behavior as cellulose, while lignin strongly absorbs in the UV and the visible region (Zervos, 2010). As paper is a multi-component material which can also include additives as starch, minerals, and synthetic polymers this component can also play a significant role in paper degradation due ageing (Area and Cheradame, 2011). After light absorption, the paper as printing substrate may generate chromospheres (as formaldehyde, furan, methoxy quinone and stilbene) in acid and alkaline hydrolysis and photo-oxidation degradation which results in paper discoloration (Xiaomeng and Guangxue, 2011). Printability of each substrate greatly depends on the interactions between the surface of printing substrate and used printing ink at the given printing process variables. The printing inks are a complex mixture of different components, which are classified by their function in ink matrix, and the composition of ink colorants is significantly dependent on the printing technology (Karlovits and Gregor-Svetac, 2011). Therefore, in addition to the paper change, the ink will also experience a change due to exposure to external factors as light, heat, humidity and air quality. All these natural processes of deterioration start as soon as ink is printed (Debeljak and Gregor-Svetac, 2010; Bates et al, 2012). So unquestionably the analysis of the colorimetric changes of prints must be perceived by two factors: the ageing of paper and ink. As the flexography is the fastest growing global analog print method which can be performed on a wide range of materials and substrates (absorbent and nonabsorbent) and with substantially improvement in quality due years (Izdebska, 2016), it is evident why 
the prints made by this printing technique are the subject of our research. Therefore, in this study, experiment was carried out in conditions of artificial aging where the ageing phenomenon of flexographic prints was analyzed through spectrophotometric changes of prints obtained on papers containing hemp fibers.

\section{METHODS}

\subsection{Printing substrates}

In this research three types of hemp-based office papers with approximately the same nominal grammage $\left(90 \mathrm{~g} / \mathrm{m}^{2}\right)$ were used as printing substrates (Table 1 ).

Table 1: Description of papers used as printing substrates

\begin{tabular}{|c|c|c|}
\hline \multicolumn{3}{|c|}{ Hemp-based office papers } \\
\hline Type 1 & Type 2 & Type 3 \\
\hline $\begin{array}{c}\text { unbleached, uncoated } \\
\text { handmade sustainable paper } \\
\text { made from } 100 \% \text { hemp plant } \\
\text { fiber }\end{array}$ & $\begin{array}{c}\text { non-chlorine bleached, uncoated } \\
\text { handmade sustainable paper } \\
\text { made from } 100 \% \text { hemp plant } \\
\text { fiber }\end{array}$ & $\begin{array}{c}\text { natural, unbleached white } \\
\text { industrial paper made from } 25 \% \\
\text { hemp and } 75 \% \text { post-consumer } \\
\text { waste fibers }\end{array}$ \\
\hline
\end{tabular}

\subsection{Full tone flexographic prints}

Hemp-based office papers were cut in dimensions $190 \mathrm{~mm} \times 40 \mathrm{~mm}$ and subjected to manual printing using a print tester Esiproof (RK print). The prints in cyan, magenta, yellow and black was made in full tone by Iroflex 917, waterbased flexographic inks manufactured by Sun Chemical. Prints were obtained using a ceramic anilox roller with $40 \mathrm{lin} / \mathrm{cm}, 60^{\circ}$ spread angle and a cell volume of $39.10 \mathrm{~cm}^{3} / \mathrm{m}^{2}$. The printing process was carried out at a temperature of $23^{\circ} \mathrm{C}$ and a relative humidity of $50 \%$.

\subsection{Artificial ageing}

Papers and prints were cut into strips $60 \mathrm{~mm} \times 90 \mathrm{~mm}$ and placed side by side in Suntest XLS+ test chamber, supplied with a daylight filter, which emit the UV radiation of wavelength in range of $290 \mathrm{~nm}-$ $800 \mathrm{~nm}$. The procedure of artificial ageing was carried out according to ASTM D 6789-02, during which the level of light intensity was $765 \pm 50 \mathrm{~W} / \mathrm{m}^{2}$, the temperature was kept at $22.6^{\circ} \mathrm{C}$ and relative humidity was $50 \%$. Exposure to the UV radiation was performed in two cycles for 48 hours. Approximately one hour of treatment under a xenon lamp corresponding to one day in nature (Debeljak and Gregor-Svetac, 2010; Izdebska et al, 2013).

The colorimetric values of papers as printing substrates and prints were determined using a spectrophotometer X-Rite SpectroEye. Color data were measured under illuminant D65, $2^{\circ}$ standard observers. On the basis of those measurements, the colorimetric difference $\left(\Delta \mathrm{E}_{00}{ }^{*}\right)$, which appeared after ageing, were calculated with the following equation (Luo et al, 2001), using the corresponding unaged paper or print as reference:

$$
\Delta E_{00}=\sqrt{\left(\frac{\Delta L^{I}}{k_{L} S_{L}}\right)^{2}+\left(\frac{\Delta C^{I}}{k_{C} S_{C}}\right)^{2}+\left(\frac{\Delta H^{I}}{k_{H} S_{H}}\right)^{2}+R_{T}\left(\frac{\Delta C^{J}}{k_{C} S_{C}}\right)\left(\frac{\Delta H^{I}}{k_{H} S_{H}}\right)}
$$

The results reported are the average of ten measurements from each sample.

\section{RESULTS AND DISCUSSION}

The analyzed papers and flexographic prints behaved differently during artificial ageing.

\subsection{Colorimetric changes of hemp-based office paper as printing substrate}

In the first stage of the study, the optical properties of papers used as printing substrates were analyzed and the changes in the color $\left(\Delta \mathrm{E}_{00^{*}}\right)$ in relation to the artificial aging time are shown in Figure 1. 


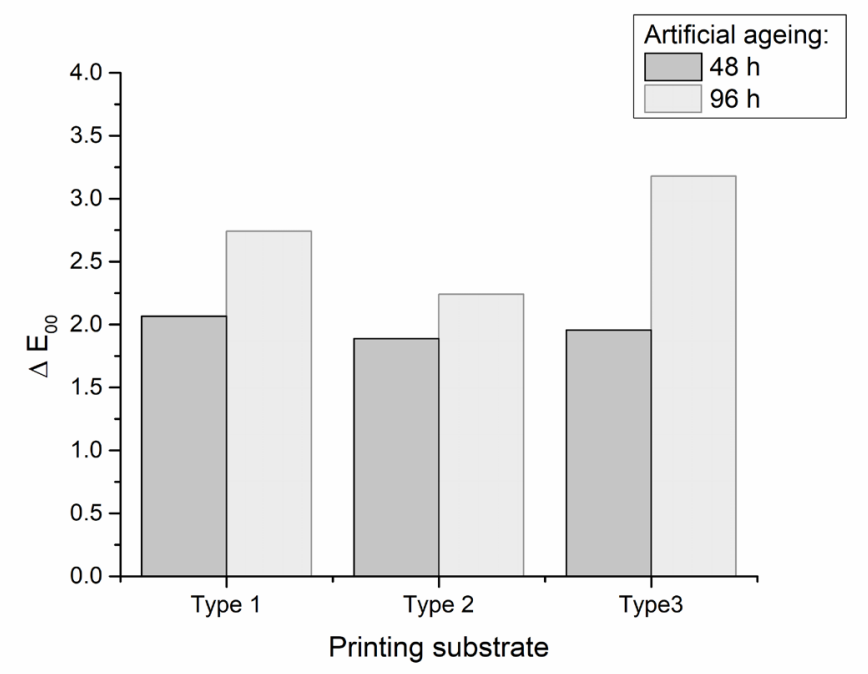

Figure 1: Color difference of tree types of paper used as printing substrate during artificial ageing

The influence of UV radiation treatment on initial color of all printing substrates types was more pronounced with longer ageing treatment period. It was noticed that the most stabile paper type is Type 2 (made from bleached virgin hemp fibers), while the color change during ageing treatment of 96 hours is the most progressive at the paper Type 3 (made form admixture of hemp fibers and post-consumer waste fibers). In previous researches it is proven how process of bleaching fibers used for paper production is significant stage in paper production which ensures optical stability of paper during different ageing treatments (Plazonić et al, 2018; Plazonić et al, 2020).

\subsection{Colorimetric changes of prints}

The calculated differences in color $\left(\Delta \mathrm{E}_{00}{ }^{*}\right)$ of prints on all three types of paper after 48 and 96 hours of ageing treatment are presented in Figures $2 \mathrm{a}-2 \mathrm{~d}$. It was noticed that light effect on prints strongly depends on the particular ink type. Cyan, magenta, yellow and black inks have not the same stability on light. Generally, it was noticed how the most stable among prints was the black ink, while the yellow ink under the influence of light had the greatest changes in color. From the $\Delta E_{00} *$ results calculated for prints it was observed how the ink plays a greater role in the stability of the print than the printing substrate. Generally all prints, regardless of the type of ink and printing substrates, after first 48 hours of ageing treatment show very small noticeable difference for standard observer $\left(\Delta \mathrm{E}_{00} * \leq 2\right)$, while further exposure to UV radiation treatment have the strongest impact on yellow ink prints $\left(\Delta \mathrm{E}_{00} *>2\right)$.

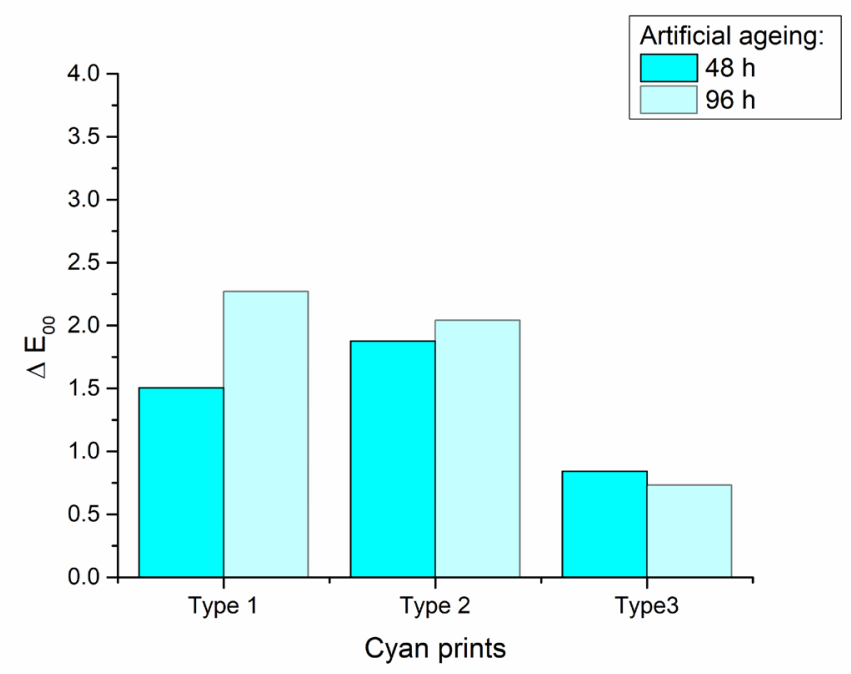

Figure 2a: Color difference of cyan prints on papers during artificial ageing 
From the results shown in Figure $2 \mathrm{a}$ it is evident how the smallest color difference occurs on cyan prints made on paper Type 3 which have shown the smallest stability on light above all analyzed printing substrates. Cyan prints on paper Type 3 have a negligee color difference to observer after 48h and $96 \mathrm{~h}$ of ageing treatment $\left(\Delta \mathrm{E}_{00} *\right.$ after $48 \mathrm{~h}$ and after $96 \mathrm{~h}$ is $\left.<1.0\right)$. On the other hand, cyan prints on printing substrates made only from hemp fibers show similar stability to the influence of UV radiation as the substrate on which they are printed.

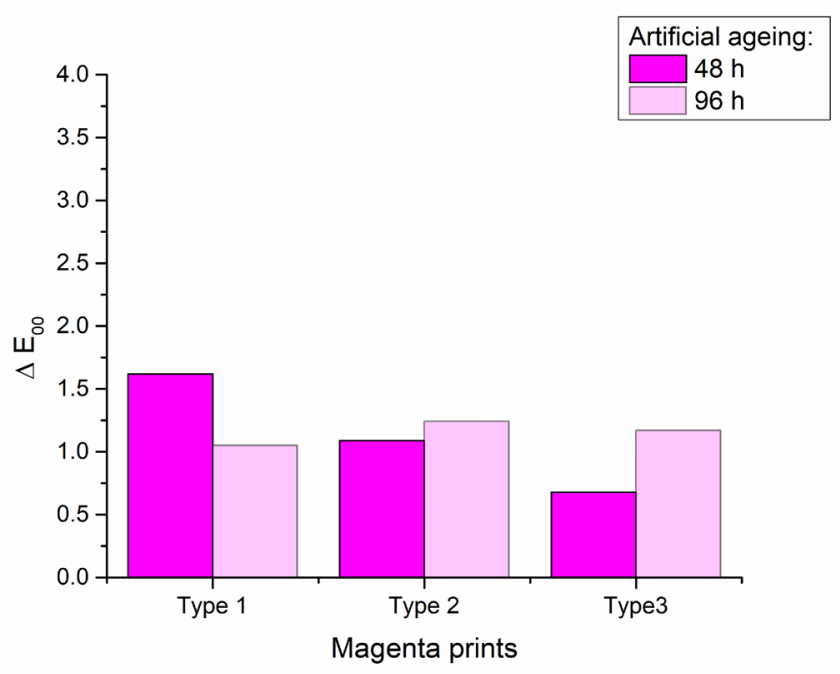

Figure 2b: Color difference of magenta prints on papers during artificial ageing

From Figure $2 \mathrm{~b}$ it is visible how magenta prints have similar stability on UV radiation treatment regardless on which printing substrate is printed. It is noticed how in the first 48 hours of treatment all the changes in magenta color occurs and with further treatment not significant changes in color were noticed.

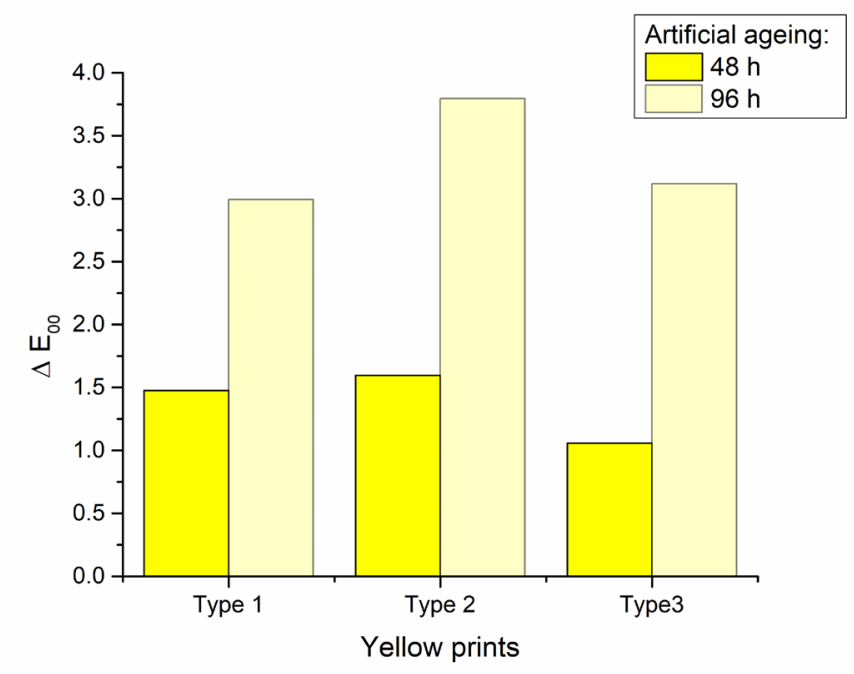

Figure 2c: Color difference of yellow prints on papers during artificial ageing

As shown in Figure 2c with increasing treatment time the color difference of yellow prints increases exponential at all three analyzed printing substrates. After first 48 hours of ageing treatment the change in yellow color for all prints was in range from 1.1 to 1.6, while with the additional 48 hours of ageing treatment these changes were become noticeable ( $\Delta \mathrm{E}_{00} *$ is in range from 3.0 to 3.8). The highest color difference was observed on the paper Type 2 especially more significant after $96 \mathrm{~h}$ of ageing treatment. 


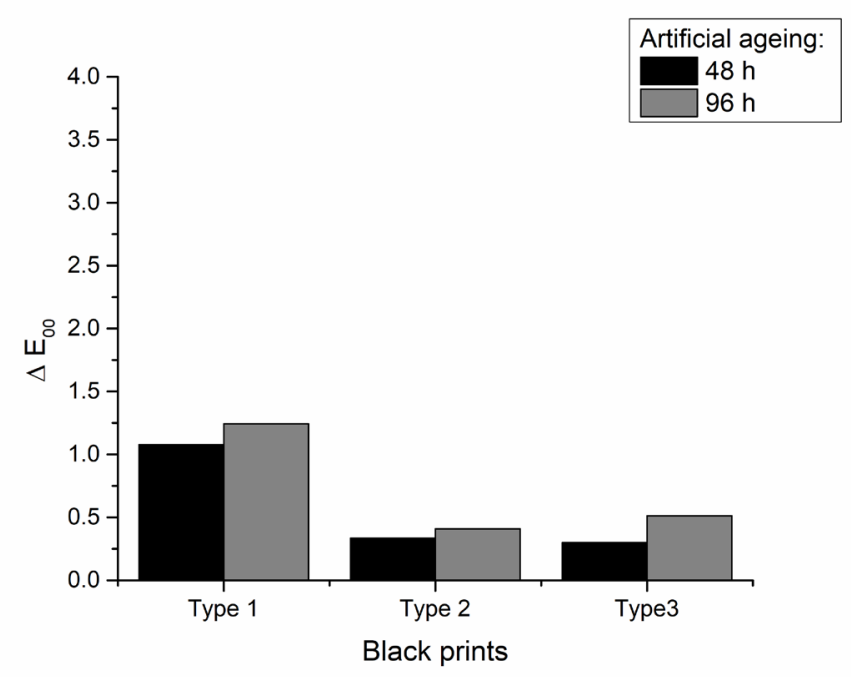

Figure 2d: Color difference of black prints on papers during artificial ageing

From the Figure $2 d$ it is clearly visible that the color differences of black prints at all analyzed printing substrates are exceptionally low $\left(\Delta \mathrm{E}_{00} * \leq 1.0\right)$. Exceedingly small color changes of black ink prints occur within the first 48 hours of aging, while with additional $48 \mathrm{~h}$ of ageing the changes in color are negligible. However, among all observed prints the most stable black print is the one made on printing substrate Type 2, while the print with the highest change in color is the one made on Type 1 (unbleached 100\% hemp based paper).

\section{CONCLUSIONS}

The aim of this study was to investigate colorimetric changes of printed office hemp-based papers subjected to artificial ageing. The results have shown that the lowest impact of UV radiation treatment was on paper made only from bleached hemp fibers. However, this office paper as printing substrate has not provided the best stability of prints under UV radiation treatment for all flexographic inks. From all results it could be concluded how color stability of prints are mainly defined by the type of pigment and ink, but also by the ink interaction with the printing substrate. Once again it was proven how the most stable are prints with the black ink, while prints with the yellow ink under the influence of light had the greatest changes in color.

\section{ACKNOWLEDGMENTS}

This work has been supported by the University of Zagreb.

\section{REFERENCES}

[1] Area, M.-C., Cheradame, H.: "Paper aging and degradation: recent findings and research methods", BioResources 6 (4), 5307-5337, 2011.

[2] Ashori, A.: "Nonwood Fibers- A Potential Source of Raw Material in Papermaking", Polymer-Plastics Technology and Engineering 45 (10), 1133-1136, 2006. doi:10.1080/03602550600728976.

[3] Bates, I., Džimbeg-Malčić, V., Itrić, K.: "Optical deterioration of samples printed with basic Pantone inks", Acta Graphica 23 (3-4), 79-90, 2012.

[4] Cocca, M., D'Arienzo, L., D'Orazio, L.: "Effects of Different Artificial Agings on Structure and Properties of Whatman Paper Samples", International Scholarly Research Notices 2011 (7), 2011. doi:10.5402/2011/863083.

[5] Debeljak, M., Gregor-Svetec, D.: "Optical and Color Stability of Aged Specialty Papers and Ultraviolet Cured Ink Jet Prints", Journal of Imaging Science and Technology ${ }^{\circledR} 54$ (6), 060402-1060402-9, 2010. doi: 10.2352/J.ImagingSci.Technol.2010.54.6.060402. 
[6] Fahmy, Y., Fahmy, T. Y. A., Mobarak, F., El-Sakhawy, M., Fadl, M.H.: “Agricultural Residues (Wastes) for Manufacture of Paper, Board, and Miscellaneous Products: Background Overview and Future Prospects", International Journal of ChemTech Research 10 (2), 424-448, 2017. doi:10.5281/zenodo.546735.

[7] Izdebska, J., Żołek-Tryznowska, U., Książek, T.: "Influence of artificial aging on cellulose film. The optical properties of printed and non-printed biodegradable film bases", Agro FOOD Industry Hi Tech, 24 (5), 52-56, 2013.

[8] Izdebska, J.: "Aging and Degradation of Printed Materials", In book: "Printing on Polymers: Fundamentals and Applications, Chapter: 22", (Elsevier, Chadds Ford, USA, 2016), page 353-370. doi:10.1016/B978-0-323-37468-2.00022-1.

[9] Izdebska, J.: "Flexographic Printing", In book: "Printing on Polymers: Fundamentals and Applications, Chapter: 11", (Elsevier, Chadds Ford, USA, 2016), page 179-197. doi:10.1016/B978-0-323-374682.00022-1.

[10] Karlovits, M., Gregor-Svetec D.: “Comparison Of Durability Between Uv Inkjet And Conventional Offset Prints Exposed To Accelerated Ageing", Journal of Graphic Engineering and Design 2 (2), 10 15, 2011.

[11] Krgović, M., Mijatović, B., Nikolić, S., Nadežda, B.: “Hemp as a raw material for fiber and paper production", Hemijska industrija 58 (5), 213-216, 2004. doi:10.2298/HEMIND0405213K.

[12] Luo, M. R., Cui, G., Rigg, B.: "The development of the CIE 2000 colour-difference formula: CIEDE2000", Color Research \& Application 26 (5), 340 - 350, 2001. doi: 10.1002/col.1049.

[13] Plazonić, I., Malnar, L., Džimbeg-Malčić, V., Barbarić-Mikočević, Ž., Bates, I.: “Changes in the optical properties of hemp office papers due to accelerated ageing", Proceedings of 9th international symposium on graphic engineering and design 2018, (Grafički centar GRID:, Novi Sad, 2018), pages 121-127.

[14] Plazonić, I., Džimbeg-Malčić, V., Bates, I., Barbarić-Mikočević, Ž.: "Effects of Photo-oxidation on the Properties of Hemp Office Papers", International Journal of Technology 11(2), 215-224, 2020. doi: 10.14716/ijtech.v11i2.3196.

[15] Princi, E., Vicini, S., Marsano, E., Trefiletti, V..: "Influence of the artificial weathering on thermal stability of paper-based materials", Thermochimica Acta 468, 27-34, 2008. doi:10.1016/j.tca.2007.11.019.

[16] Xiaomeng, C., Guangxue C.: "Study on Photoaging Phenomenon of Digital Inkjet Presswork", Advanced Materials Research 174, 219-222, 2011. doi:10.4028/www.scientific.net/AMR.174.219.

[17] Zervos, S.: "Natural and Accelerated Ageing of Cellulose and Paper: A Literature Review", In book: "Cellulose: Structure and Properties, Derivatives and Industrial Uses, Chapter: 5", (Nova Science Publishers, Inc.,UK, 2010).

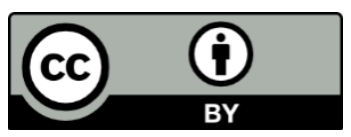

(C) 2020 Authors. Published by the University of Novi Sad, Faculty of Technical Sciences, Department of Graphic Engineering and Design. This article is an open access article distributed under the terms and conditions of the Creative Commons Attribution license 3.0 Serbia (http://creativecommons.org/licenses/by/3.0/rs/). 


\title{
THE INFLUENCE OF TOTAL BASE INK COVERAGE ON THE UNIFORMITY OF DIGITAL PRINTS OVERPRINTED WITH PEARLESCENT INKS
}

\author{
Ivana Tomić (iD), Ivan Pinćjer (D), Nada Miketić \\ University of Novi Sad, Faculty of Technical Sciences, \\ Department of Graphic Engineering and Design, Novi Sad, Serbia
}

\begin{abstract}
Print uniformity is an important parameter that can determine perceived quality of a printed product. If the product is of low print uniformity, its quality is often regarded as non-satisfactory. In this work we were interested in the uniformity of electrophotography prints overprinted with inks containing pearlescent pigments. Our goal was to determine whether the overall print uniformity was influenced by the total base ink coverage i.e. the ink coverage of the printing substrate before pigments were applied to it. Hence, three scenarios were considered: when pearlescent inks were printed over the unprinted paper, previously printed grey, and black colour patch. Nine different types of pearlescent pigments, dispersed in a transparent ink vehicle, were screen printed over the paper and the previously printed patches of grey and black colour. The base colours were printed in electrophotography. The uniformity of prints obtained in such a manner was determined by calculating GLCM parameters that were shown to correlate well with human perception of uniformity. It was shown that overprinting the electrophotography prints with pearlescent inks significantly decreased the uniformity of prints with black base colour and slightly improved the uniformity of those with grey colour. When pearlescent inks were printed over the paper, the uniformity did not change significantly. Observing the print uniformity of overprinted samples, the best results were obtained when pearlescent inks were printed directly to the paper, following the cases when they were printed over the grey and black prints. It is therefore concluded that the total base ink coverage has significant effect on the uniformity of electrophotography prints overprinted with pearlescent inks. The results indicate poor adhesion of the ink vehicle used as a carrier for pearlescent pigments to electrophotographic toner.
\end{abstract}

Key words: print uniformity, electrophotography, pearlescent pigments

\section{INTRODUCTION}

Together with colour and sharpness, print uniformity is one of the most important parameter influencing perception of a printed product (Jurič, 2018). If there is a variation in density in the areas that are expected to be uniform (areas of one colour) the print is perceived as non-uniform and is rated as being of lower quality. The non-uniformity can be micro and macro (ISO/IEC, 2017), while the variations in density can be random or systematic (Christoffersson, 2002).

The non-uniformity depends on the printing process, paper and the ink used, as well as their interaction (Jurič, 2018; Sadovnikov et al, 2005). It is often a problem in electrophotography, due to the nature of the printing process (Jurič, 2018; Sipi, 2002). In this work we were interested whether the non-uniformity of electrophotography prints can be improved by overprinting, where we considered using inks with pearlescent pigments. These types of pigments are often used in packaging for achieving the effect of subtle, pearl shine, as well as the colour travel effect (change of a colour with the change of the angle of viewing/illuminating). Pearlescent pigments are described by their interference colour, which is a colour observed near the specular angle of reflection (Klein, 2010). They consist of a substrate which is almost always natural or synthetic muscovite - mica, and the layers of different materials. It is their structure that enables abovementioned optical effects, and determine the size and the shape of pigment flakes (which further influence the uniformity of prints if those pigments are used in printing inks).

In this work we place a focus on the interaction of electrophotography ink and pearlescent inks. The goal was to test whether print uniformity of overprinted samples depends on the amount of the electrophotography toner on the printing surface. So, three options were considered - pearlescent inks were printed over the unprinted paper, as well as the previously printed grey and black ink. In this manner we tested how the electrophotography ink layer interacts with pearlescent ink and whether the uniformity of overprinted sample is actually influenced by the total base ink coverage. 


\section{METHOD}

For this study we used nine pearlescent pigments that differed in their composition and, therefore, the interference colour. Almost all the pigments have muscovite mica as a carrier and a different number of additional layers (Table 1). For brevity, in the rest of the paper we will name the pigments by their interference colours.

Table 1: Pigments used in the study

\begin{tabular}{|l|l|c|l|}
\hline Pigment & $\begin{array}{l}\text { Interference } \\
\text { colour (name) }\end{array}$ & $\begin{array}{l}\text { Number of } \\
\text { components }\end{array}$ & Composition \\
\hline 504 Red & Red & 2 & Mica coated with: ferric oxide \\
\hline 221 Rutile Fine Blue & Pearl-gold & 3 & $\begin{array}{l}\text { Mica coated with: titanium dioxide, ferric } \\
\text { oxide }\end{array}$ \\
\hline 231 Rutile Fine Green & Green & 3 & $\begin{array}{l}\text { Mica coated with: titanium dioxide, tin } \\
\text { oxide }\end{array}$ \\
\hline 223 Rutile Fine Lilac & Lilac & $\begin{array}{l}\text { Mica coated with: titanium dioxide, tin } \\
\text { oxide }\end{array}$ \\
\hline 325 Solar gold satin & Gold & 3 & $\begin{array}{l}\text { Mica coated with: titanium dioxide, tin } \\
\text { oxide }\end{array}$ \\
\hline Blue-shade silver SW 9605 & Blue-silver & 4 & $\begin{array}{l}\text { Mica coated with: titanium dioxide, ferric } \\
\text { oxide, silicon dioxide }\end{array}$ \\
\hline T20-03 WNT Tropic sunrise & $\begin{array}{l}\text { Green- } \\
\text { orange* }\end{array}$ & 5 & $\begin{array}{l}\text { Silicon dioxide coated with: titanium } \\
\text { dioxide, tin oxide, zirconium oxide, } \\
\text { auxiliaries }\end{array}$ \\
\hline GP Rutile Blue Green WNT & Turquoise & 7 & $\begin{array}{l}\text { Mica coated with: titanium dioxide, cobalt } \\
\text { titanate, zirconium oxide, aluminium oxide, } \\
\text { tin oxide, auxiliaries }\end{array}$ \\
\hline
\end{tabular}

*Interference colour for the selected pigment is green, but it is named differently in order not to be confused with the 231 Rutile Fine Green. Orange was chosen since the pigment provides green through silver, red and orange colour flop

As a printing substrate we used matte art paper grammage of $300 \mathrm{~g} / \mathrm{m} 2$. The grey and black patches ( $\mathrm{K}$ of $50 \%$ and $100 \%$ ) size of $10 \times 10 \mathrm{~cm}$ were printed on Xerox DocuColor 252 digital printer. After printing and drying they were overprinted with the pearlescent pigments dispersed in the aqueous ink vehicle. Pigments' concentration in the vehicle was 15\%. Overprinting was done in screen printing in order to increase the thickness of the pearlescent inks' layer. We used screen with the mesh count of $43 \mathrm{l} / \mathrm{cm}$. Two layers were deposited over the paper and previously printed patches, after which the prints were dried in the temperature of $140^{\circ}$ during 1 minute.

Prints were further digitized by Canon CanoScan $5600 \mathrm{~F}$ scanner. All the samples (paper, prints without and with pearlescent inks' layer) were scanned in the resolution of $600 \mathrm{ppi}$. Prior scanning, all the automatic options for colour and image correction were turned off in order not to change the initial data. Scanned images were saved as non-tagged TIFF files. The area of $2000 \times 2000$ px of the scanned images were used for subsequent processing.

To determine print uniformity, we used Haralik's method based on the second order statistical measurements through the Grey-Level Co-occurrence Matrix (GLCM) (Gebeješ et al, 2012; Jurič et al, 2016). Of all the parameters that can be obtained from GLCM we choose two that were shown to correlate well with human perception of uniformity - Homogeneity and Entropy (Gebeješ et al, 2013; Gebeješ et al, 2016). Homogeneity measures the uniformity of the non-zero entries in GLCM (Clausi, 2002) and it ranges from 0-1, where 1 indicates completely uniform surface. Entropy is a measure of spatial disorder (Gebeješ et al, 2012), where entropy value of 0 indicates solid colour image. Higher entropy would mean more random distribution of the pixel values.

Calculation of the parameters was performed in Matlab R2016a. All the parameters were calculated from the lightness channel ( $L^{*}$ in CIELAB colour space). We used the distance of $5 \mathrm{px}$ (Tomić, 2016) and the calculation was performed in all directions (horizontal, vertical, $-45^{\circ}$ and $45^{\circ}$ ). The mean value of the parameter calculated in all four directions was taken into account for further analysis. 


\section{RESULTS}

Homogeneity and Entropy values for samples where pearlescent inks are printed over the paper are shown in Figure 1. As a reference, each graph contains the corresponding parameters for unprinted paper.

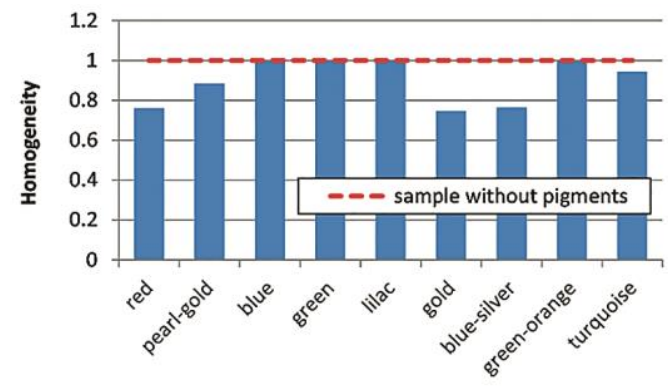

Pigments used for overprinting

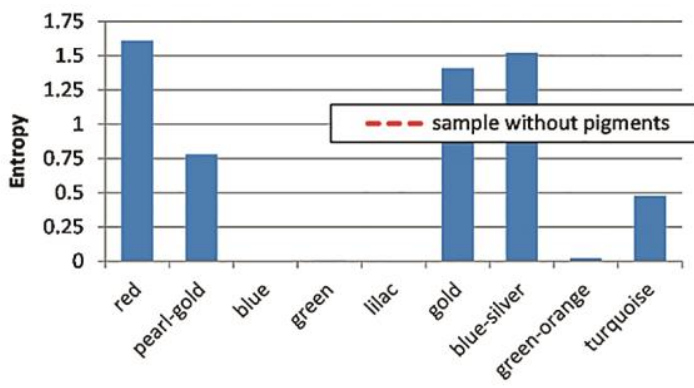

Pigments used for overprinting

Figure 1: Homogeneity and Entropy values of paper printed with pearlescent inks

Unprinted paper used in the experiment had the most uniform surface (Homogeneity was 1, while the Entropy was 0). Adding the pearlescent inks did not change the uniformity in case of ink with Blue, Green, Lilac and Green-Orange pigment - Homogeneity of those prints was very close to 1, while Entropy was quite close to $0(0.005,0.006,0.004$ and 0.025 , respectively) and hence could not be represented well in Figure $1 \mathrm{~b}$. Since all the above-mentioned pigments are (semi)transparent the obtained result can be explained by their optical properties. Namely, pearlescent pigments often consists of more than two layers of different materials. Different refraction indexes of those layers leads to constructive interference, which allows the change of the perceived colour with the change of the angle of light incidence or viewing. When (semi)transparent pigments are printed over the white background, the light of complementary colour is transmitted through the pigment and reflected back in the specular angle. That means that the colour detected in the specular angle is the combination of the interference colour and its complementary colour i.e. white. During scanning the detector was positioned in the specular angle, so what it detected was white, uniform colour.

The rest of the pigments are not transparent, hence the reflected light has different colour. In these cases the uniformity decreased. The smallest change were seen for Turquoise pigment. This pigment dissolved very well in the vehicle, so its spread over the paper was better in comparison to the rest of the pigments used.

Figure 2 shows the Homogeneity and Entropy values for prints where pearlescent inks were printed over grey colour.

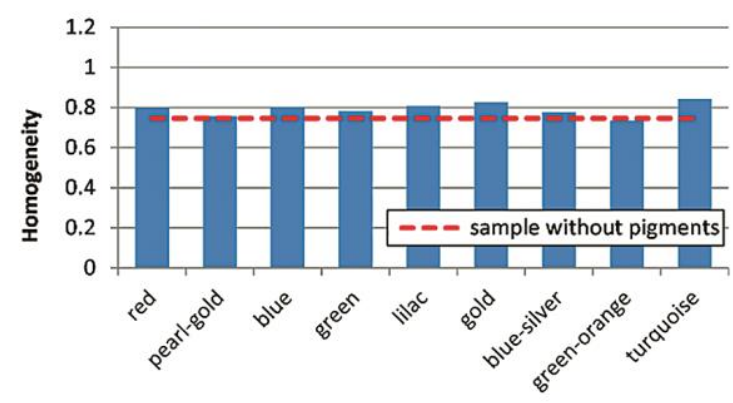

Pigments used for overprinting

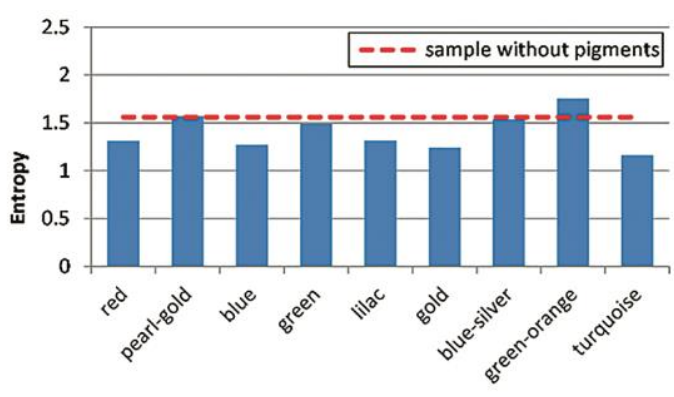

Pigments used for overprinting

Figure 2: Homogeneity and Entropy of prints with grey base colour

Grey patch printed in electrophotography had lower Homogeneity and higher Entropy in comparison to the unprinted paper. This means that it was less uniform than both white and black (see Figures 1-3) colour. In electrophotography the reasons for non-uniformity are mostly related to the process of the printing (Sipi, 2002) where random variations are dominant. 
When pearlescent inks were printed over the grey patch the Homogeneity was the same or even better for all the pigments. Furthermore, the uniformity expressed through this parameter seems not to change much regardless of the pigment used. Entropy was only higher in the case of Green-Orange pigment, while in the rest of the cases it slightly decreased or stayed unchanged. This means that overprinting the grey patch with pearlescent inks slightly increased its print uniformity, lowering the errors caused by the printing process.

Homogeneity and Entropy values for black samples overprinted with pearlescent inks are shown in Figure 3.
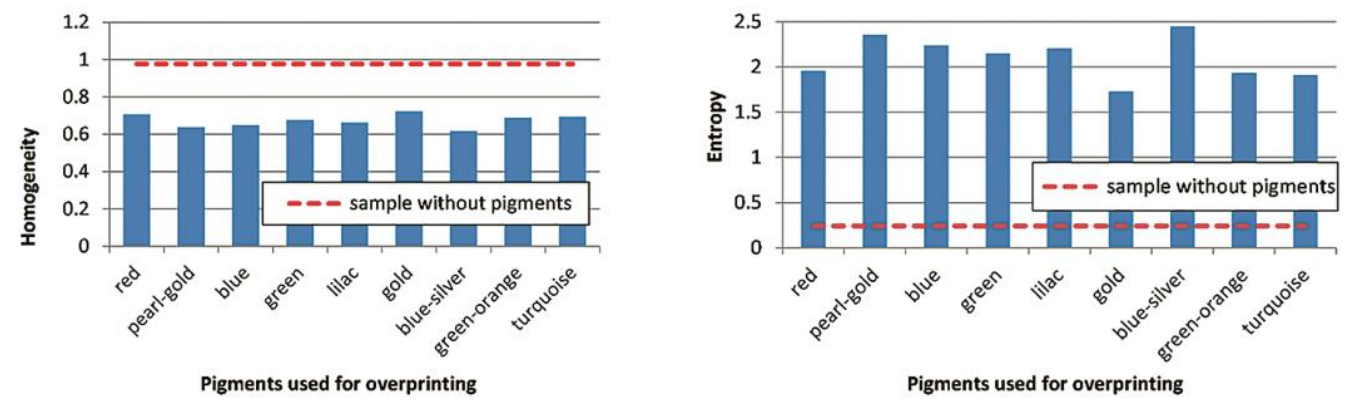

Figure 3. Homogeneity and Entropy of prints with black base colour

Black patch had almost perfect uniformity with Homogeneity quite close to 1 and Entropy of just 0.24. This is understandable since black ink is completely covering the paper. Adding the pearlescent inks in this case reduced uniformity which can be seen in lower Homogeneity and drastic increase in Entropy (Figure 3). By observing the scanned images it was noticed that in all the cases parts of the prints were uncovered by pigments (holes in the pearlescent pigment layer can be clearly seen in images on the left, Figure 4). This was not the case when pigments were applied over the grey colour, where pearlescent ink penetrates to the parts of the patch that was not covered by the toner (see Figure 4, images on the right). Lower uniformity of black patch may indicate poor interaction of aqueous ink vehicle and the electrophotography toner.

(a)

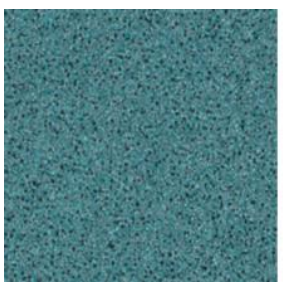

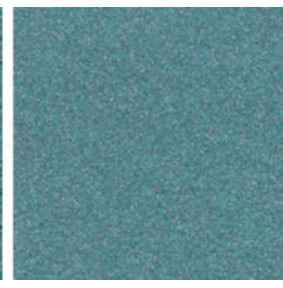

(b)
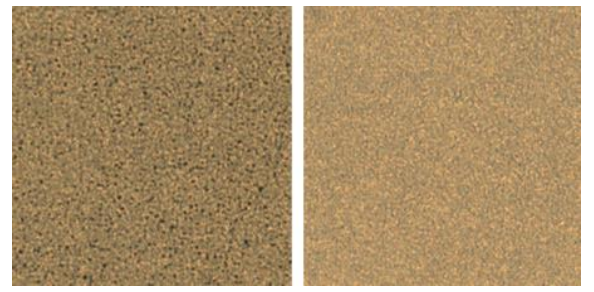

Figure 4. Part of the scanned image of (a) black and grey patch overprinted with Blue-silver pigment, (b) black and grey patch overprinted with Pearl-gold pigment

The Homogeneity and Entropy of overprinted samples with respect to the base colour are shown in Figure 5 and Figure 6.

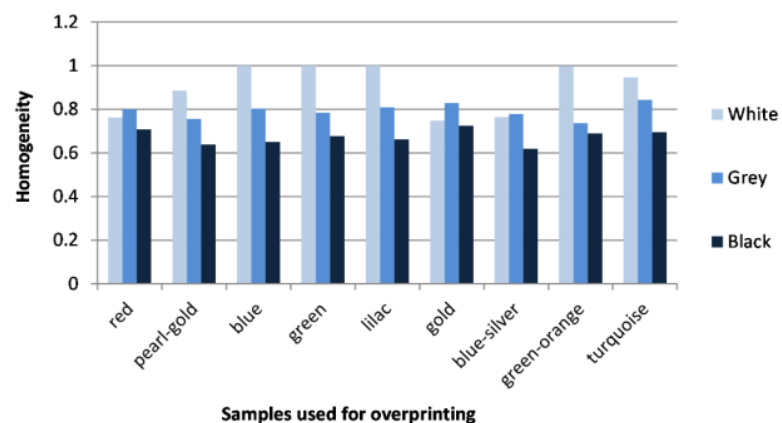

Figure 5. Comparative view of print Homogeneity with respect to the base colour 


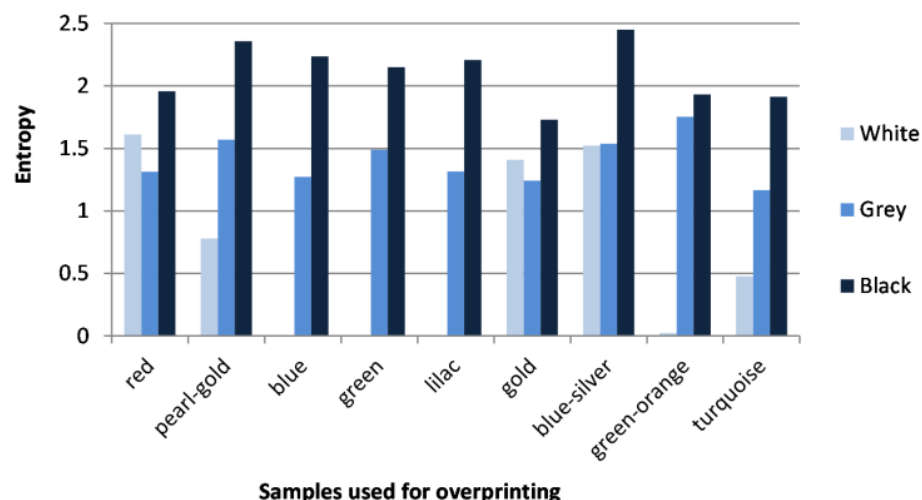

Figure 6. Comparative view of print Entropy with respect to the base colour

From the comparative view it is evident that print uniformity was the best when pigments were printed directly to the paper (in almost all the cases Homogeneity was the highest and Entropy lowest), then grey and finally black ink. Gold and Red pigment are the only two exceptions where samples with grey base colour has slightly better uniformity in comparison to white.

\section{CONCLUSIONS}

Pearlescent pigments are used in printing in order to achieve special visual effects, such as the effect of a pearl shine and colour travel effect. In this work we evaluated print uniformity of the electrophotography prints overprinted with inks containing pearlescent pigments. The goal was to determine the interaction of the electrophotography toner and the pearlescent pigments and to assess how the overall print uniformity is influenced by the amount of the base ink in the printing surface.

The results showed that the uniformity of electrophotography prints without pearlescent pigments was the highest for black and white base colour. The grey patch was quite non-uniform which can be attributed to the nature of the printing process. Adding the pearlescent pigments' layer significantly decreased the uniformity of prints with black base colour and slightly improved the uniformity of grey prints. When pigments were printed over the paper, the uniformity did not change in five cases, while in the rest four it was somewhat lower.

The best results in print uniformity of overprinted samples were obtained when pigments were printed directly to the paper, following the cases when they were printed over the grey and black prints. Therefore, it is concluded that the total base ink coverage significantly influences the uniformity of electrophotography prints overprinted with pearlescent inks. Such results can be explained by the lower capacity of electrophotography toner to attract aqueous ink vehicle in which pearlescent pigments were dispersed. Hence, if the pearlescent pigments are to be printed over the solid colour patch printed in electrophotography alternative options for ink carriers should be considered.

\section{ACKNOWLEDGMENTS}

This research (paper) has been supported by the Ministry of Education, Science and Technological Development through the project no. 451-03-68/2020-14/200156: "Innovative scientific and artistic research from the FTS (activity) domain".

\section{REFERENCES}

[1] Clausi, D.-A.: "An analysis of co-occurrence texture statistics as a function of grey level quantization", Canadian Journal of Remote Sensing, 28 (1), 45-62, 2002. doi: 10.5589/m02-004

[2] Christoffersson, J.: "Evaluation of Systematic \& Colour Print Mottle", MSc thesis, Linkoping University, 2002.

[3] Gebeješ, A., Tomić, I., Huertas, R., Stepanić, M.: “A preliminary perceptual scale for texture feature parameters", 6. International Symposium on Graphic Engineering and Design, (Faculty of Technical Sciences: Novi Sad, Serbia, 2012), pages 195-201. 
[4] Gebeješ, A., Huertas, R., Tomić, I., Stepanić, M.: "Selection of optimal features for texture characterization and perception", 1. Colour and Visual Computing Symposium - CVCS, (The Colour and Visual Computing Laboratory at NTNU: Gjovik, Norway, 2013), pages 1-5. doi: 10.1109/CVCS.2013.6626278

[5] Gebeješ, A., Huertas, R., Tremeau, A., Tomić, I., Biswas, P., Fraza, C., Hauta-Kasari, M.: "Texture Characterization by Grey-Level Co-occurrence Matrix from a Perceptual Approach", 24th Color Imaging Conference - CIC24, (Society for Imaging Science and Technology: San Diego, USA, 2016), pages 271-277. doi: 10.2352/ISSN.2169-2629.2017.32.271

[6] ISO/IEC: "ISO/IEC 24790:2017 - Information technology - Office equipment - Measurement of image quality attributes for hardcopy output - Monochrome text and graphic images", URL: https://www.iso.org/standard/69796.html (last request: 2020-08-05), 2017.

[7] Jurič, I., Karlović, I., Novaković, D., Tomić, I.: "Comparative study of different methods for the assessment of print mottle", Color Research and Application 41 (5), pages 493-499, 2016. doi: 10.1002/col.21984

[8] Jurič, I. "Print uniformity model for digital prints", PhD thesis, University of Novi Sad, 2018.

[9] Klein, G. A.: "Industrial Color Physics", (Springer, London, 2010.)

[10] Sadovnikov, A., Salmela, P., Lensu, L., Kamarainen, J-K., Kälviäinen, H.: "Mottling Assessment of Solid Printed Areas and Its Correlation to Perceived Uniformity", 14th Scandinavian Conference on Image Analysis, (SCIA: Joensuu, Finland, 2005), pages 409-418.

[11] Sipi, K.: "Toner-paper interactions induced by the fixing process in electrophotographic printing", Licentiate's thesis, Helsinki University of Technology, 2002.

[12] Tomić, I., Dedijer, S., Jurič, I., Pál, M.: "The Effect of Scanning Resolution and Displacement Value on the GLCM-Based Features for Paper Texture Characterization", 8. International Symposium on Graphic Engineering and Design, (Faculty of Technical Sciences: Novi Sad, Serbia, 2016), pages 263-271.

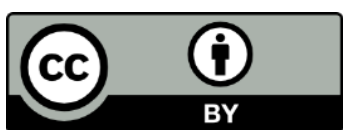

(C) 2020 Authors. Published by the University of Novi Sad, Faculty of Technical Sciences, Department of Graphic Engineering and Design. This article is an open access article distributed under the terms and conditions of the Creative Commons Attribution license 3.0 Serbia (http://creativecommons.org/licenses/by/3.0/rs/). 


\title{
INVESTIGATION OF THE OPTICAL PROPERTIES OF CHITOSAN AND RICE STARCH BLENDS, AS A FILLER IN PAPER OR AS A FILM FOR PACKAGING APPLICATIONS
}

\author{
Urška Vrabič Brodnjak ${ }^{1}$ (D), Dimitrina Todorova ${ }^{2}$ (i) \\ ${ }^{1}$ University of Ljubljana, Faculty of Natural Sciences and engineering, Department of Textiles, \\ Graphic Arts and Design, Ljubljana, Slovenia \\ ${ }^{2}$ University of Chemical Technology and Metallurgy, Department of Pulp, Paper and \\ Printing Art, Sofia, Bulgaria
}

\begin{abstract}
Bio based materials fall under the broad category of bio-products or bio-based products, which includes materials, chemicals and energy derived from renewable biological resources. This research shows the preparation of both, paper sheets with blend fillers of chitosan and rice starch and chitosan and rice starch films, which could be used as packaging material for a variety of applications. In this research, we used a blend mixture, different concentrations of chitosan and rice starch both in paper production and in films to investigate the optical properties of the obtained materials with a combination of ultrasonic treatment during the film formation. The research showed that the optical properties of the obtained packaging materials improved. It also showed that blend fillers of chitosan and rice starch are effective paper fillers in the preparation of cellulose mixture for bio based packaging materials and the optical properties are with slight changes. The investigation on the optical properties of the obtained paper samples during accelerated thermal showed that the ageing of paper with addition of chitosan and chitosan and rice starch blends had the same behaviour through the 72 hours of ageing. The ultrasonic treatment of the films improved transparency. The surface at untreated blend film was more uneven compared to chitosan and rice starch films, which improved after the treatment.
\end{abstract}

Key words: bio based polymers, fillers, packaging, properties, analysis.

\section{INTRODUCTION}

In the last decade, interest in biodegradable polymers has been focused on packaging materials derived from renewable resources (Ten and Vermerris, 2013). Such polymers include chitosan and starch, which have already been produced in many applications (Puvvada et al, 2012; Mendes et al, 2016; Aghazadeh et al, 2018). Consequently, wood-fibre paper is a rather heterogeneous material containing cellulose fibres, consisting of lignin, hemicellulose and other substances such as ash, dust, etc. Cellulose is a semicrystalline polysaccharide composed of cyclically recurring monomer units of glucose, which form long parallel linear chains of cellulose. The linear macromolecules of cellulose form strong crystallites and weak non-crystalline (amorphous) domains through hydrogen bonds formed between the lateral hydrogen atoms of one chain and the hydroxyl groups of the glucose units of the adjacent chain (lolovich, 2016; Li et al, 2015; Lindh et al, 2016). They also occur between hydroxyl groups of adjacent glucose units within the macromolecule. Due to transverse hydrogen bonds between macromolecules of glucose units, the macromolecules are close together. This prevents the interaction of glucose units with water, which identifies cellulose as partially crystalline, as already mentioned. On a structural level, paper can be regarded as a dense network of cellulose fibres consisting of cellulose microfibrils embedded in a matrix of lignin and hemicellulose. Chitosan is a polymer which is used as an additive in many areas, not only in paper production (Khalil et al, 2016). Its chemical structure is very similar to the glucose unit of cellulose, but the amino group is located at the site of the hydroxyl group. Chitosan acts as an antibacterial agent and, as a water barrier, influences the water resistance of the paper, which can be found in a number of literary sources (Maitra and Singh, 2018; Tang et al, 2016; Amirabad et al, 2018; Jung et al, 2018; Zarayneh et al, 2018). It is very poorly soluble in water (Flores-Hernández et al, 2018; López-Mata, 2018; Sabbah et al, 2019). Namely, it achieves water resistance by combining its amino groups with hydroxyl groups of cellulose, thereby forming strong hydrogen bonds that prevent water from binding to the cellulose molecule (Zarayneh et al, 2018; Phan et al, 2019).

Rice starch also consists of glucose units, which, in contrast to cellulose and chitosan, are linked together to form a more branched structure. Most types of starch contain two types of glucose polymers: a linear chain molecule, i.e. amylase, and a branched polymer glucose, i.e. amylopectin (Bourtoom and Chinnan, 
2008; Woggum et al, 2015; Thakur et al, 2016). In general, the positive cationic starch molecules are linked to the negatively charged cellulose molecules, which can increase the strength of the paper. The use in paper should be handled with care, especially with the higher quantities; the elasticity can be negatively affected (Bourtoom and Chinnan, 2009; Ashwar et al, 2015; Romani et al, 2017). Rice starch is insoluble in cold water and becomes water-soluble when heated (Mathew et al, 2018). In the manufacture of paper, rice starch has been used as an additional component in films that form blends with other biopolymers (Vrabič Brodnjak, 2017). In general, rice starch is used as a binder for various coatings (Bourtoom and Chinnan, 2008; Ashwar et al, 2015; Shah, 2016; Ogunsona, 2018; Hoyos-Leyva, 2018). The mechanical properties of paper are primarily determined by the cellulose fiber properties, the fire network structure and the properties of the added non-fibrous materials and in some cases also by the adhesive forces between the individual fibers, microfibres and molecular chains. This research also shows the preparation, characterisation and ultrasonic treatment of the blend chitosan-rice starch films. The aim of the research was also to improve the mechanical, moisture and optical properties of chitosan, rice starch and composite chitosan-rice starch film using ultrasonic treatment.

The production of improved paper with improved tensile properties using biodegradable macromolecules is quite limited. Therefore, the primary objective of this research was to determine the influence of different paper fillers, i.e. chitosan and rice starch, together with their different concentrations, on the optical, moisture and mechanical properties and thermal ageing. Optical, mechanical and surface properties were analysed. The result of this research is paper with added chitosan and rice starch, which can be used to produce packaging materials for different purposes.

\section{MATERIALS AND METHODS}

\subsection{Materials}

In this research paper, filler solutions with different amounts of chitosan and rice starch were applied into paper pulp suspension and then the paper was produced as described in the previous research (Brodnjak and Todorova, 2017). At the same time chitosan and rice starch films as packaging material has been manufactured separately and properties were determined.

Chitosan, with the molecular weight lower than $20 \mathrm{kDa}$ and deacetylation degree higher than 85\%, was purchased from Sigma Aldrich (Austria). Acetic acid (99\%) was purchased from Sigma Aldrich (Austria). Rice starch was obtained from Farmalabor Srl (Italy) and had 14\% of moisture content, 1\% of proteins and $0.6 \%$ of ashes. Modified cationic polyacrylamide was delivered by Kemira, Finland and is with Molecular Weight of $11.10^{6} \mathrm{~g} / \mathrm{mol}$, Charge Density of $1,05 \mathrm{meq} / \mathrm{g}$, Viscosity (Brookfield) $700 \mathrm{cP}\left(0,5 \%, 25^{\circ} \mathrm{C}\right)$ and Conductivity $66,6 \mu \mathrm{S}_{(0,5 \%)}$. Glycerol, obtained from Sigma Aldrich (Austria), was also used as a plasticiser at films.

\subsubsection{Paper}

Paper suspensions were prepared using 6 combinations of pulp suspensions, bio polymers (chitosan and rice starch) and retention additive.

The procedure of mixing pulp and other additives was as followed: firstly $23,5 \mathrm{~g}$ o.d.f. were stirred in tap water $(2000 \mathrm{ml})$, then the chitosan and rice starch were added. The mixing proceeded and after that the retention additive was added.

The preparation was followed with mixtures:

1. Only pulp (P)

2. Pulp and $0,05 \%$ retention additive (PR)

3. Pulp, $5 \%$ chitosan, $0,05 \%$ retention additive $(5 \% \mathrm{CH})$

4. Pulp, $5 \%$ of rice starch and chitosan, $0,05 \%$ retention additive ( $5 \% \mathrm{CHR})$

5. Pulp, $7.5 \%$ chitosan, $0,05 \%$ retention additive $(7.5 \% \mathrm{CH})$

6. Pulp, $7.5 \%$ of rice starch and chitosan, $0,05 \%$ retention additive $(7.5 \% \mathrm{CHR})$

\subsubsection{Films}

The rice starch dispersion was prepared by dissolving $2 \mathrm{~g}$ of rice starch in $100 \mathrm{ml}$ of distilled water and glycerol $(40 \% \mathrm{w} / \mathrm{w})$ was added as a plasticiser. The solution was mixed until it gelatinised $\left(85^{\circ} \mathrm{C}\right.$ for 20 $\min$ ) and then cooled to room temperature. 
The chitosan solution was prepared by dissolving $2 \mathrm{~g}$ of chitosan in $100 \mathrm{ml}(2 \% \mathrm{w} / \mathrm{w})$ malic acid and glycerol $(40 \% \mathrm{w} / \mathrm{w})$ was added as a plasticiser. The solution was mixed at $90{ }^{\circ} \mathrm{C}$ for 5 minutes until chitosan was not dispersed and after that cooled to room temperature. Before cooling down, the film solution was filtered through a polyester screen (mesh no. 140 with mesh opening $160 \mu \mathrm{m}$ ) with aspiration to remove small lumps in the solution.

The rice starch-chitosan film was prepared by mixing $100 \mathrm{ml}$ of $2 \%$ rice starch solution with $100 \mathrm{ml}$ of $2 \%$ chitosan solution. After that, $40 \%$ of glycerol as a plasticiser (w/w; of total solid weight in solution) was added into the mixed solution. The total solution for blend film was mixed at $800 \mathrm{rpm}$ for 5 minutes at room temperature and then filtered through a polyester screen with the same mesh opening as at the chitosan solution. The aspiration was performed in order to remove small lumps in the solution.

After the aspiration, the solutions (for chitosan, rice starch film and blend film) were placed into an ultrasonic bath (Asonic, Ultrasonic bath), using constant $35 \mathrm{kHz}$ frequency for 15 minutes.

After aspiration and treatment, the mixtures (untreated and treated) were poured onto Petri dishes (50 $\mathrm{ml}$ ), spread thinly and evenly and dried at $55{ }^{\circ} \mathrm{C}$ for 10 hours. After the films had been peeled off the trays, they were cooled at room temperature $\left(23^{\circ} \mathrm{C} ; 55 \% \mathrm{RH}\right)$. $\mathrm{RH}$ For further investigations the films were stored in desiccators at $60 \%$.

\subsection{Methods}

\subsubsection{Grammage, density, specific surface, thickness}

Grammage of all samples was determined in accordance with the ISO 536 standard. Density and specific surface volume were calculated form grammage and thickness, as described in the standard method ISO 534.

\subsubsection{Colour of the films}

The film colour was determined using CIE colorimeter $X$-rite. The CIE Lab scale was used to determine $L^{*}$, $a^{*}$ and $b^{*}$ colour values. A standard plate was used as the standard $\left(L^{*}=92.82, a^{*}=-1.24, b^{*}=0.5\right)$. Six measurements for each specimen at different locations on samples were made. Before the colour measurements, the samples were conditioned at $55 \% \mathrm{RH}$ and $25 \pm 2{ }^{\circ} \mathrm{C}$ for $72 \mathrm{~h}$.

\subsubsection{Smoothness and air permeability}

Smoothness and air permeability were determined according to standard TAPPI T460 and ISO 8791-2.

\subsubsection{Surface (SEM)}

The SEM micrographs of paper and film surfaces were taken with a scanning electron microscope (JSM$6060 \mathrm{LV})$. The instrument operated at $10 \mathrm{kV}$ and at the magnification 1000x.

\subsubsection{Printing quality of papers}

\section{a) Colour values and gloss}

The colour of sample papers was determined with a CIE colorimeter X-rite. The CIE Lab scale was used to determine the $L^{*}, a^{*}$ and $b^{*}$ colour values. The plate was used as a standard $\left(L^{*}=92.82, a^{*}=-1.24, b^{*}=\right.$ 0.5). For each sample, ten measurements were made at different locations on the surface. Before the colour measurements, the samples were conditioned at $60 \% \mathrm{RH}$ and $27 \pm 2{ }^{\circ} \mathrm{C}$ for $72 \mathrm{~h}$.

Gloss was determined as the specularly and diffusely reflected light component determination against the known standard and was measured at $60^{\circ}$ angle. The measurements and determination were conducted by using the standard ISO 8254 method and ten measurements on each sample has been made.

b) Abrasion resistance

The abrasion resistance of all samples-printed papers were made on rub tester Labthink (China), according to TAPPI T830 standard. The test was proceeded on dry samples and two of each paper samples were tested. The procedure was carried out on dual stations with arc movement. In our research two stroke (Rubbing Times) were determined: 25 and 50 cycles, at rubbing speed $106 \mathrm{cpm}$ and rub pressure $8.9 \mathrm{~N}$. For determination of print abrasion, optical density was measured before and after rubbing.

\subsubsection{Thermal aging of papers}

The accelerated thermal ageing of the investigated paper samples was conducted according to ISO 56301:2014 in closed chamber at $105{ }^{\circ} \mathrm{C}$ and air circulation for standard humidity of $50 \%$ with duration of 
72 hours, because from the literature review is known that $72 \mathrm{~h}$ of thermal ageing corresponds to 25 years of natural ageing of paper.

For measuring the optical properties of the paper samples - whiteness CIE, whiteness CIE - UV, ISO brightness, ISO brightness - UV, fluorescense CIE, fluorescense ISO brightness (ISO 2470: 2016) was used Konica Minolta spectrophotometer.

\section{RESULTS AND DISCUSSION}

\subsection{Basic properties of papers and films}

To evaluate the influence and effect of bio based components onto paper, it was essential to establish and make samples with the same grammage. Therefore, the paper sheets were prepared with the grammage $80 \mathrm{~g} / \mathrm{m}^{2}$. The beating degree of a pulp, hardwood fibres, dimensions of the fibres and addition of the fillers have influence on thickness of the paper. This plays an important role at end usage, especially at printing papers. As expected, the thickness of the samples had mostly the same values (Table 1). Paper with only pulp, combination of softwood and hardwood fibres with no additives, had the lowest thickness $(0.0084 \mathrm{~mm})$. With addition of the retention additive and fillers, the thickness at all other paper sheets increased respectively. The changes were also detected at specific surface and density, where sample $\mathrm{P}$, with only pulp and no additives, had the highest density, compared to other tested papers.

Table 1: Basic properties (grammage, thickness, specific surface and density) of all paper samples

\begin{tabular}{|l|c|c|c|c|c|c|}
\hline \multirow{2}{*}{ Anlysis } & \multicolumn{6}{|c|}{ Samples } \\
\cline { 2 - 7 } & $\mathrm{P}$ & $\mathrm{PR}$ & $5 \% \mathrm{CH}$ & $5 \% \mathrm{CHR}$ & $7.5 \% \mathrm{CH}$ & $7.5 \mathrm{CHR}$ \\
\hline $\begin{array}{l}\text { Grammage } \\
\left(\mathrm{g} / \mathrm{m}^{2}\right)\end{array}$ & 80 & 80 & 80 & 80 & 80 & 80 \\
\hline $\begin{array}{l}\text { Thickness } \\
(\mathrm{mm})\end{array}$ & 0.084 & 0.095 & 0.091 & 0.090 & 0.095 & 0.096 \\
\hline $\begin{array}{l}\text { Specific } \\
\text { surface } \\
\left(\mathrm{m}^{3} / \mathrm{g}\right)\end{array}$ & 0.0011 & 0.0012 & 0.0011 & 0.0011 & 0.0012 & 0.0012 \\
\hline $\begin{array}{l}\text { Density } \\
\left(\mathrm{g} / \mathrm{m}^{3}\right)\end{array}$ & 952.38 & 842.11 & 879.12 & 888.89 & 842.11 & 833.33 \\
\hline
\end{tabular}

In this study, an ultrasonic treatment of the film solution was used in order to increase the solubility of composition components, which influenced many film properties (strength, elongation, moisture and colour). Generally, colour is an important factor of the appearance of packaging materials. The total colour difference, chroma and hue angle were calculated from the colour values. The untreated chitosan films were more coloured than rice starch and blend films. It is known that chitosan has more yellowness compared to other tested samples in the research. From the $L^{*}$ values, which indicate lightness, it can be seen that the treated samples became less coloured, are lighter, especially the rice starch film. The a* and $b^{*}$ values vary significantly between the untreated and treated samples. All films include a plasticiser, which also affected the colour. The hue angle was not significantly different among all sample films. The results of calculated chroma showed that the untreated samples have more yellowness than the treated ones.

Table 2: Thickness and colour values of the sample films

\begin{tabular}{|l|l|c|c|c|c|c|c|c|}
\cline { 2 - 8 } \multicolumn{1}{c|}{} & Sample & $\begin{array}{c}\text { Thickness } \\
(\mu \mathrm{m})\end{array}$ & $\mathrm{L}^{*}$ & $\mathrm{a}^{*}$ & $\mathrm{~b}^{*}$ & $\Delta \mathrm{E}$ & $\mathrm{C}$ & $\mathrm{H}$ \\
\hline \multirow{3}{*}{ Untreated } & Chitosan film & 210 & 84.06 & -3.19 & 10.36 & 3.56 & 10.84 & 178.75 \\
\cline { 2 - 9 } & Rice starch film & 205 & 86.65 & -4.07 & 9.88 & 6.28 & 10.67 & 178.89 \\
\cline { 2 - 9 } & Blend film & 215 & 88.92 & -3.00 & 11.35 & 5.92 & 11.73 & 178.75 \\
\hline \multirow{2}{*}{$\begin{array}{l}\text { Treated with } \\
\text { ultrasound }\end{array}$} & Chitosan film & 207 & 85.78 & -2.05 & 9.22 & 2.36 & 9.45 & 178.68 \\
\cline { 2 - 9 } & Rice starch film & 203 & 91.66 & -4.89 & 7.30 & 5.69 & 8.79 & 179.21 \\
\cline { 2 - 9 } & Blend film & 216 & 90.45 & -2.78 & 9.07 & 5.50 & 9.49 & 178.75 \\
\hline
\end{tabular}




\subsection{Smoothness and air permeability of papers}

Paper is a highly porous material consisting of a matted fibre layer, and the additives could cause the variation of many properties such as smoothness and air permeability. The open surface of paper sheets decreased with increasing amounts of the above-mentioned polymers. Smoothness was better in samples with chitosan and rice starch. The smoothness also improved with increasing amounts of bio-polymers. As expected and shown in Figure 1, the air permeability was worst for paper containing only pulp. With the addition of bio-polymers and retention additive, the structure of the paper became more uniform and filled, improving the properties. The best air permeability was achieved by paper with $7.5 \% \mathrm{KHR}$, where only $1186 \mathrm{mml} / \mathrm{min}$ was measured.

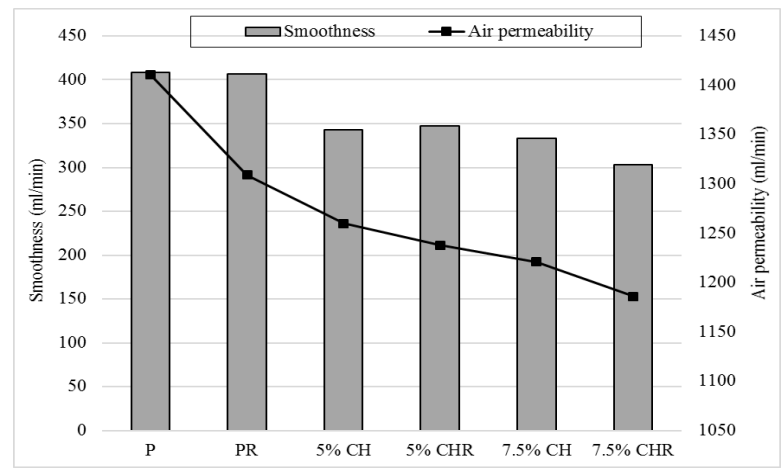

Figure 1: Smoothness and air permeability

\subsection{SEM of papers and films}

With scanning electron microscope (SEM) the evaluation of the distribution of chitosan and rice starch onto the paper sheets has been evaluated.

These micrographs (Figure 2) show that the fillers covered the fibres and closed the pores and open areas in the base paper. The surface of the sample papers showed a smoother and more uniform surface for papers with fillers (Figure 7-5\% CH, 5\% CHR, 7.5\% CH and 7.5\% CHR) compared to the samples without fillers (P and PR).

A comparison between paper sheets with used fillers but different concentrations proved their effect, which is consistent with improved mechanical, grease and water barrier properties. The absorption, thickness, moisture and roughness of the papers with fillers have a great influence on the properties of the chemical structures, types of fillers. If the fillers are unevenly distributed in the fibre paper composition, many properties can deteriorate afterwards and this can also influence the printing process (uneven printing image and mottling).
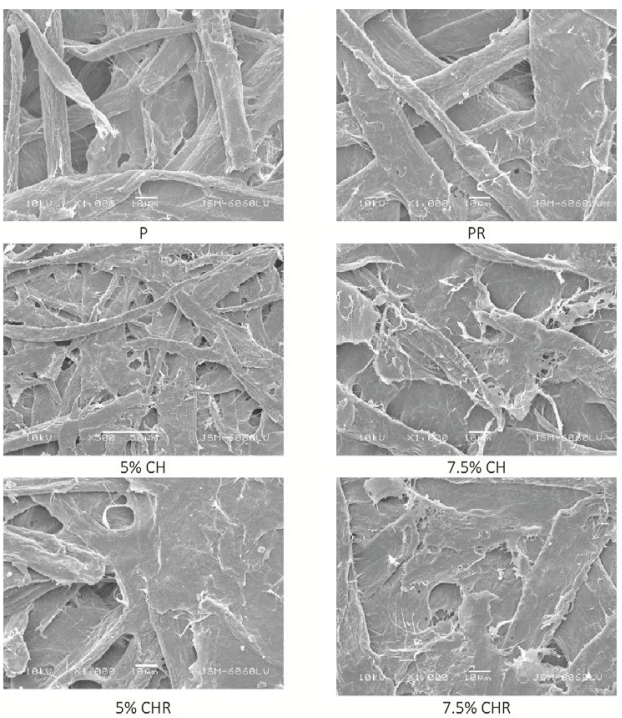

Figure 2: SEM micrographs of all samples taken at 1000x magnification and operating at 10kV voltage 
The surface micrographs showed a smoother, more even surface on all treated films. As can be seen in Figure $3 a$, the untreated chitosan film is less smooth and not as uniform as the ultrasonically treated film (Figure $3 b$ ). The same trend can be seen in Figures $3 c$ and $3 d$, where the SEM micrographs of rice starch are shown. Figure $3 c$ shows that the untreated rice starch film has a more irregular surface than the chitosan film. The untreated chitosan rice starch film had a less uniform, smooth and dense structure (Figures $3 e$ and $3 f$ ). The ultrasonic treatment caused a homogeneity of the surface and is a good indicator for better structural and mechanical properties compared to the untreated film. In general, the ultrasonic treatment helps to obtain a smoother and more homogeneous surface.

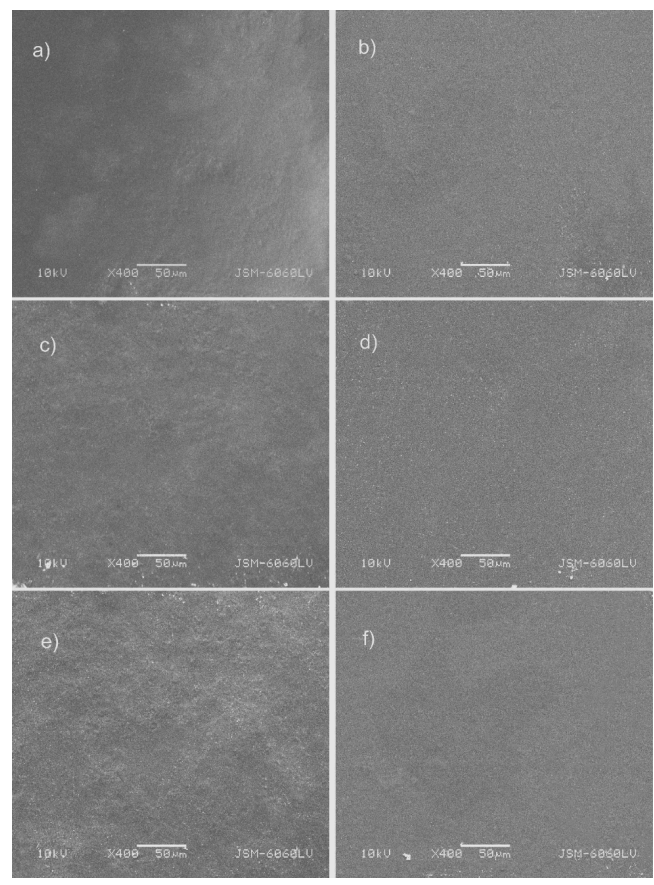

Figure 3: SEM micrographs of untreated and ultrasound treated films: a) untreated chitosan film, b) treated chitosan film, (c) untreated rice starch film, d) treated rice starch film, e) untreated blend chitosan-rice starch film, f) treated blend chitosan-rice starch film

\subsection{Printing quality of papers}

With papers, colour is important for future finishing and printing processes. It determines the quality of the light reflected by the paper, which is described by hue, saturation and darkness or lightness. The base paper determines the optical properties, whereby the brightness should be as close as possible to the brightness of the sample paper. In the investigation, the paper used was not bright white, it was slightly brown, and the fillers with chitosan did not have the same effect as on white paper. Chitosan powder is naturally yellowish, but rice starch is white, so the fillers on paper did not cause any major colour changes, as can be seen from Table 3. The colour difference was calculated from the results of the printed colours $(\Delta E)$.

Table 3: Colour values $\left(L^{*} a^{*} b^{*}\right)$, colour difference $(\Delta E)$ and gloss of all sample papers

\begin{tabular}{|c|c|c|c|c|c|}
\hline \multirow[b]{2}{*}{ Samples } & \multicolumn{3}{|c|}{ Colour values } & \multirow{2}{*}{$\begin{array}{l}\Delta \mathrm{E} \\
(/)\end{array}$} & \multirow{2}{*}{$\begin{array}{c}\text { Gloss at } 75^{\circ} \\
(/)\end{array}$} \\
\hline & $\mathrm{L}^{*}$ & $a^{*}$ & $b^{*}$ & & \\
\hline$P$ & -0.601 & 2.80 & 1.29 & / & 4.2 \\
\hline $\mathrm{PH}$ & -0.603 & 2.81 & 0.90 & 0.39 & 4.4 \\
\hline $5 \% \mathrm{CH}$ & -0.606 & 2.84 & 2.56 & 1.27 & 5.6 \\
\hline $5 \% \mathrm{CHR}$ & -0.605 & 2.82 & 2.15 & 0.86 & 5.3 \\
\hline $7.5 \% \mathrm{CH}$ & -0.605 & 2.84 & 3.18 & 1.89 & 5.8 \\
\hline $7.5 \%$ CHR & -0.605 & 2.82 & 2.84 & 1.55 & 5.6 \\
\hline
\end{tabular}


The colour difference was calculated according to the sample, including only pulp (P). As expected, the higher difference occurred in samples where chitosan and rice starch were added. For $5 \%$ chitosan and rice starch, the colour difference due to the addition of rice starch was less than for $5 \%$ chitosan. The same value was $7.5 \%$, with the largest colour difference calculated only for chitosan $(\Delta E=1.89)$, but in combination with rice starch it was smaller (1.55).

Colour is not one of the main properties of this packaging material, and this type of mixed filler does not have a significant effect on the printing properties, e.g. the colours, and could therefore be used in this area.

The gloss is related to the surface morphology and is achieved during drying. Due to the additives and fillers in the paper sheets it is known that they also improve the gloss values. The gloss of filled papers increased, even more so for papers where a higher proportion of fillers was used, especially with $7.5 \%$ chitosan (around 5.8). For low gloss papers, rice starch was added, but the difference is small. This is in line with the results of previous studies where fillers were reported to also improve surface smoothness, making the surface glossier after application.

Abrasion resistance was used to evaluate the resistance of printed surfaces to frictional abrasion. Failure or damage to paper is related to substrate ink adhesion, paper additives, thickness and internal stress. It should be noted that there are several methods that can characterise other aspects of imaging material degradation as a result of frictional contact with different surfaces under different conditions. Therefore, the application of specific methods depends on the end-user applications, such as the type of packaging materials and coatings, barrier properties requirements of the packaging paper, etc. In our study, the TAPPI standard was used as the standard method for determining the print quality of reamed sample papers.

In our research, dry friction test and two-cycle (Rubbing Times) were determined: 25 and 50 cycles, at a friction speed of $106 \mathrm{cpm}$. As shown in Figure 4, the dry rubbing test showed that all paper samples with bio-polymers gave better results (optical density) compared to paper with pulp and retention additive only.

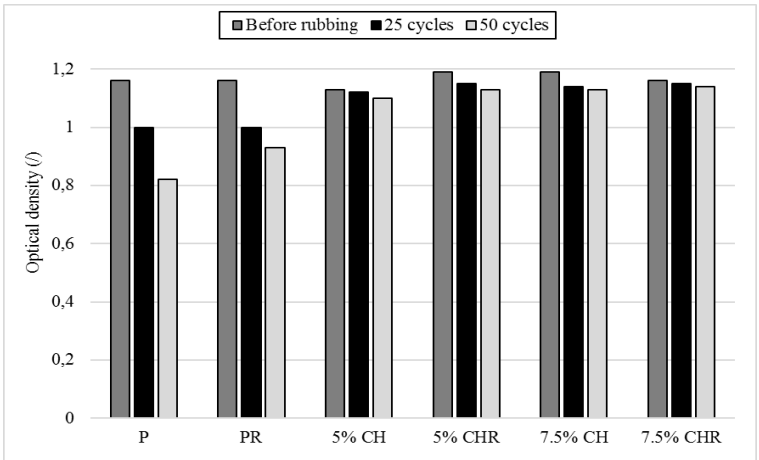

Figure 4: Optical density of all paper samples before and after rubbing 25 and 50 cycles

After 25 cycles (Figure 4) papers, where chitosan and/or rice starch was included, achieved better quality, according to other papers. Before rubbing, the highest optical density (1.19) had papers with $5 \%$ chitosan and $7.5 \%$ of chitosan and rice starch. At paper, where the highest amount of fillers was used (7.5\%) the smallest decrease after rubbing (25 and 50 cycles) of optical density was detected. Paper, where only chitosan was used, the optical density after rubbing, was almost the same as at paper with added rice starch. The highest the concentration of the fillers was, the most stable colour resistance was after rubbing 50 cycles. As expected, fillers increased colour stability, compared to paper sheet, where the fillers were not used. From this part is can be concluded that rice starch and chitosan had great influence on more stable and durable printing properties.

\subsection{Thermal aging of papers}

Table 3 shows the results for the optical properties of the investigated paper samples with and without addition of different amount of chitosan and hitosan and rice starch blends.

The results for the Whiteness CIE, Whiteness CIE - UV, ISO Brightness, ISO Brightness - UV, Fluorescense $\mathrm{CIE}$ and Fluoresense ISO Brightness shows that paper samples with only pulp (P) have the highest optical properties, followed by the samples from pulp and retention additive (PR). Adding the blends in the 
cellulose suspension in different ratios cause yellowing of the paper colour, visible to the human eye. But the differences between the Whiteness CIE, Whiteness CIE - UV, ISO Brightness, ISO Brightness - UV of the paper samples with $5 \%$ and $7,5 \%$ bled fillers are insignificant to the human eye, which the spectrophotometer shows by a difference in the range of 1-2 units.

Table 3: Optical properties of paper samples during 72 hours of accelerated thermal ageing

\begin{tabular}{|c|c|c|c|c|c|}
\hline \multirow[t]{2}{*}{$\begin{array}{l}\text { Optical } \\
\text { parameter }\end{array}$} & \multirow[t]{2}{*}{$\begin{array}{l}\text { Paper } \\
\text { samples }\end{array}$} & \multicolumn{4}{|c|}{ Hours of thermal ageing } \\
\hline & & 0 & 24 & 48 & 72 \\
\hline \multirow[t]{6}{*}{ Whiteness CIE } & $P$ & 52,74 & 39,71 & 31,27 & 24,86 \\
\hline & $P R$ & 45,99 & 32,96 & 25,2 & 19,9 \\
\hline & $5 \% \mathrm{CH}$ & 29,65 & 9,9 & $-1,41$ & $-9,99$ \\
\hline & $5 \% \mathrm{CHR}$ & 34,26 & 14,42 & 2,95 & $-5,21$ \\
\hline & $7,5 \% \mathrm{CH}$ & 35,86 & 16,9 & 5,75 & $-2,17$ \\
\hline & $7,5 \% \mathrm{CHR}$ & 34,55 & 13,65 & 1,38 & $-7,4$ \\
\hline \multirow{6}{*}{$\begin{array}{c}\text { Whiteness CIE } \\
- \text { UV }\end{array}$} & $P$ & 52,48 & 39,47 & 30,98 & 24,53 \\
\hline & PR & 45,85 & 32,74 & 24,97 & 19,6 \\
\hline & $5 \% \mathrm{CH}$ & 29,58 & 9,9 & $-1,32$ & $-10,03$ \\
\hline & $5 \% \mathrm{CHR}$ & 34,17 & 14,34 & 2,92 & $-5,33$ \\
\hline & $7,5 \% \mathrm{CH}$ & 35,8 & 16,9 & 5,75 & $-2,26$ \\
\hline & $7,5 \% \mathrm{CHR}$ & 34,46 & 13,67 & 1,41 & $-7,5$ \\
\hline \multirow{6}{*}{$\begin{array}{c}\text { ISO } \\
\text { Brightness }\end{array}$} & $P$ & 75,85 & 71,25 & 68,09 & 65,94 \\
\hline & $P R$ & 72,78 & 68,1 & 65,13 & 63,28 \\
\hline & $5 \% \mathrm{CH}$ & 67,82 & 61,38 & 57,56 & 54,87 \\
\hline & $5 \% \mathrm{CHR}$ & 69,48 & 62,93 & 59,03 & 56,43 \\
\hline & $7,5 \% \mathrm{CH}$ & 70,18 & 63,79 & 59,95 & 57,42 \\
\hline & $7,5 \% \mathrm{CHR}$ & 70,27 & 63,5 & 59,33 & 56,6 \\
\hline \multirow{6}{*}{$\begin{array}{c}\text { ISO } \\
\text { Brightness - } \\
\text { UV }\end{array}$} & $P$ & 75,84 & 71,21 & 68,04 & 65,9 \\
\hline & $P R$ & 72,75 & 68,08 & 65,09 & 63,23 \\
\hline & $5 \% \mathrm{CH}$ & 67,82 & 61,38 & 57,57 & 54,85 \\
\hline & $5 \% \mathrm{CHR}$ & 69,48 & 62,9 & 59,02 & 56,42 \\
\hline & $7,5 \% \mathrm{CH}$ & 70,18 & 63,78 & 59,94 & 57,4 \\
\hline & $7,5 \% \mathrm{CHR}$ & 70,27 & 63,49 & 59,34 & 56,56 \\
\hline \multirow{6}{*}{$\begin{array}{c}\text { Fluorescence } \\
\text { CIE }\end{array}$} & $P$ & 0,26 & 0,24 & 0,29 & 0,33 \\
\hline & PR & 0,14 & 0,21 & 0,23 & 0,3 \\
\hline & $5 \% \mathrm{CH}$ & 0,07 & 0 & $-0,1$ & 0,04 \\
\hline & $5 \% \mathrm{CHR}$ & 0,09 & 0,08 & 0,03 & 0,12 \\
\hline & $7,5 \% \mathrm{CH}$ & 0,06 & 0,01 & 0,01 & 0,1 \\
\hline & $7,5 \%$ CHR & 0,09 & $-0,02$ & $-0,03$ & 0,09 \\
\hline \multirow{6}{*}{$\begin{array}{c}\text { Fluorescence } \\
\text { ISO } \\
\text { Brightness }\end{array}$} & $P$ & 0,01 & 0,04 & 0,05 & 0,04 \\
\hline & $P R$ & 0,02 & 0,02 & 0,04 & 0,05 \\
\hline & $5 \% \mathrm{CH}$ & 0 & 0 & $-0,01$ & 0,01 \\
\hline & $5 \% \mathrm{CHR}$ & 0,01 & 0,03 & 0,01 & 0,01 \\
\hline & $7,5 \% \mathrm{CH}$ & $-0,01$ & 0,01 & 0 & 0,02 \\
\hline & $7,5 \%$ CHR & 0 & 0 & $-0,01$ & 0,03 \\
\hline
\end{tabular}


The investigation on the optical properties of the obtained paper samples during accelerated thermal shows that the ageing of paper with addition of chitosan and chitosan and rice starch blends have the same behaviour through the 72 hours of ageing. The largest change is observed in the first studied parameter - Whiteness CIE (Figure 5), which after the end of the accelerated thermal aging has decreased by approximately $50 \%$.

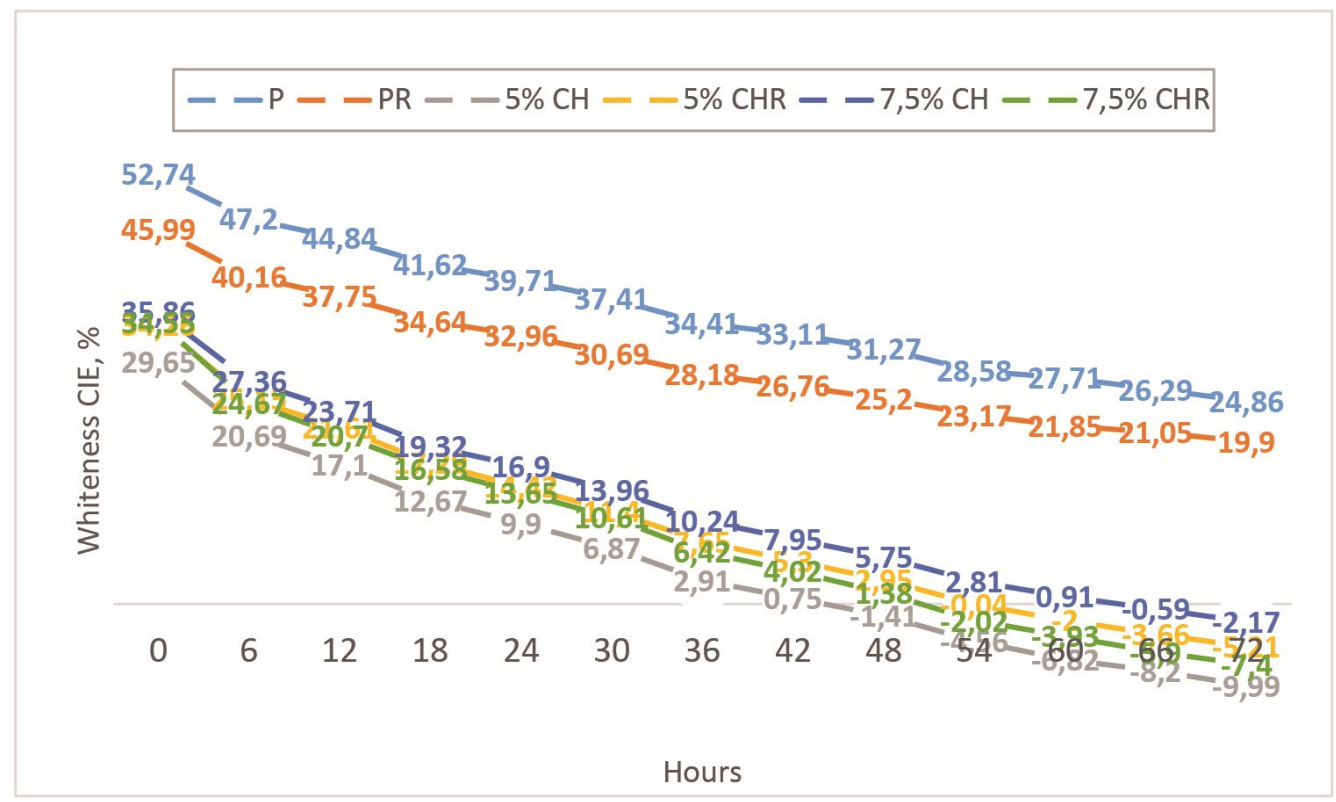

Figure 5: Whiteness CIE, \% of the tested paper samples during thermal aging

For the second parameter ISO Brightness (Figure 6) the decrease is in the range of 10 units, and again the nature of the change during ageing for all paper samples is similar.

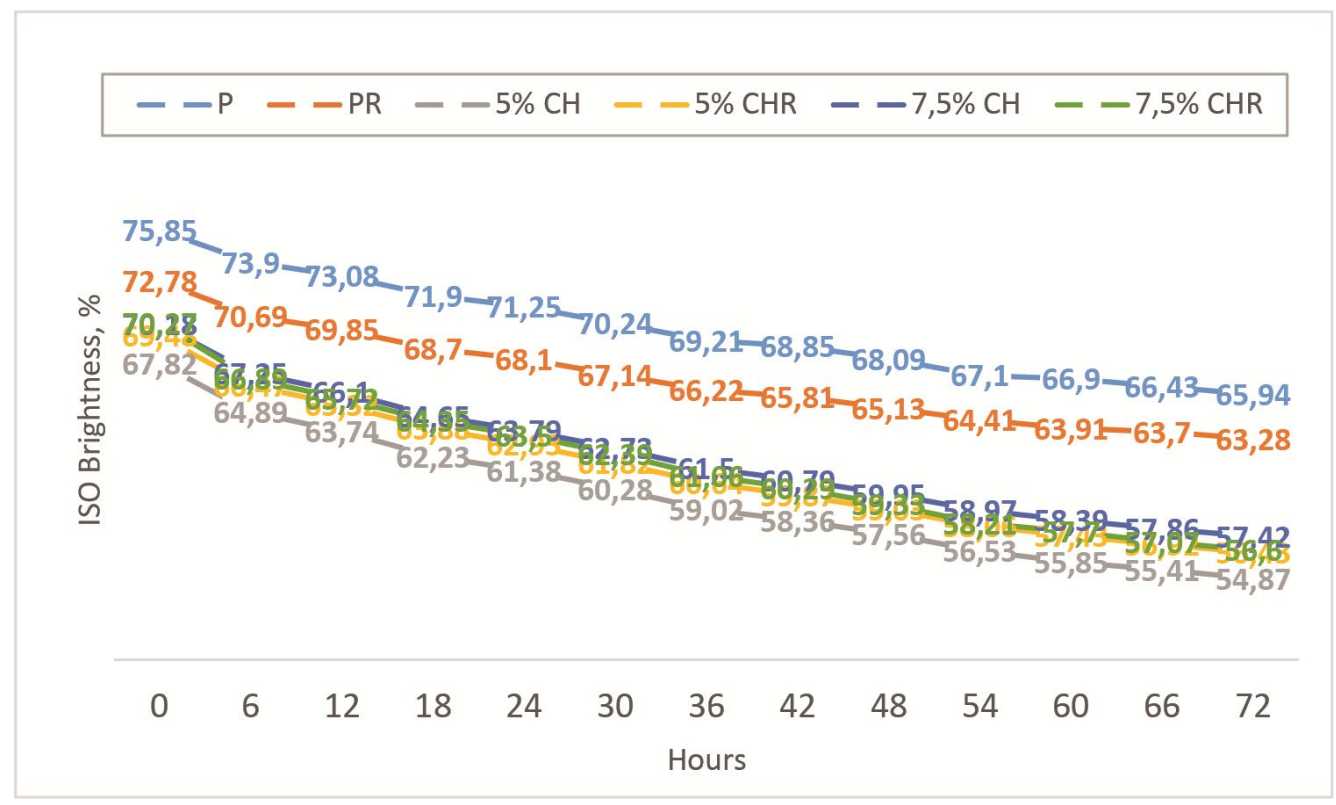

Figure 6: ISO brightness, \% of the tested paper samples during thermal aging

Large fluctuations are observed for the third examined parameter - Fluorescence CIE (Figure 7), which may be due to the low values of this indicator and the accuracy range of the used measuring device. All three graphs show that paper samples with $7.5 \%$ chitosan $(7.5 \% \mathrm{CH})$ has the closest optical properties to the zero paper sample. 


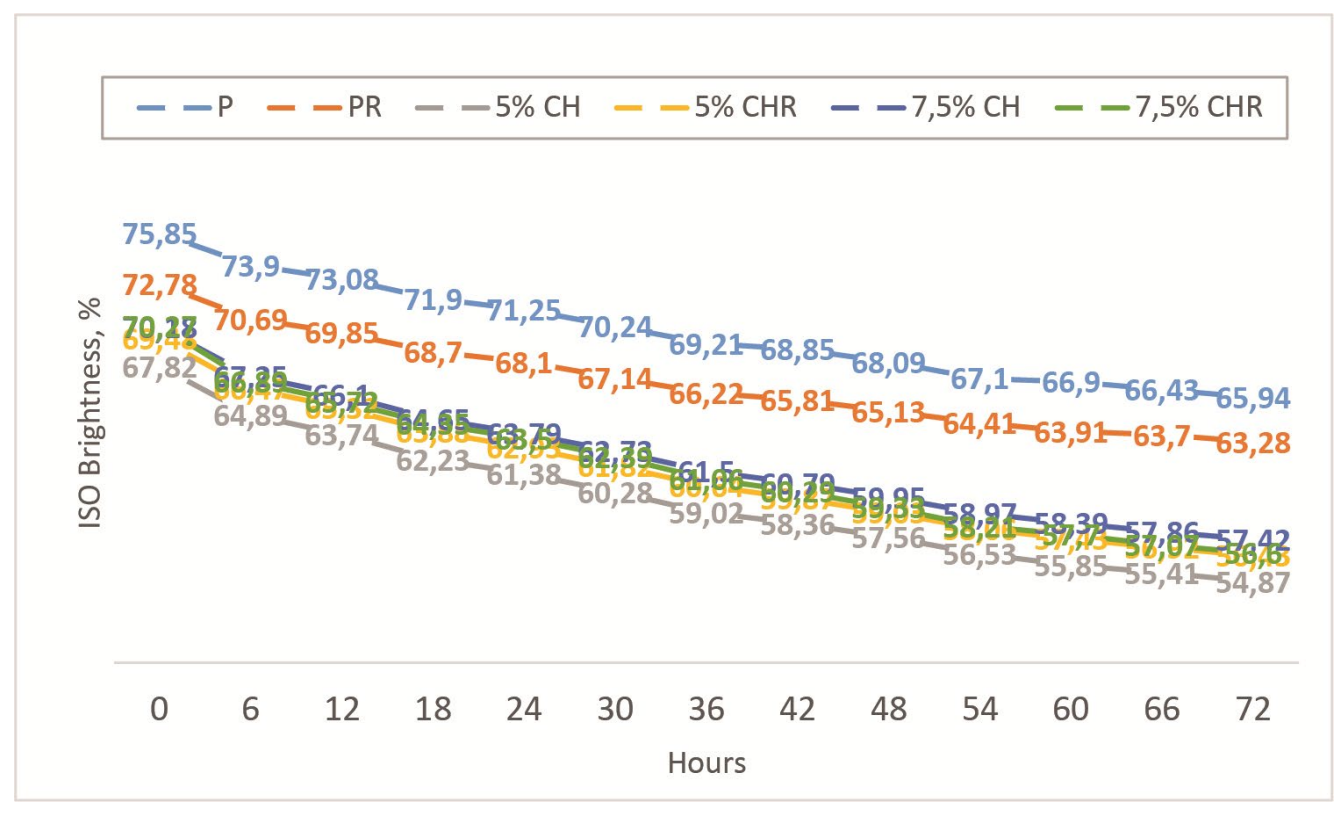

Figure 7: Fluorescence CIE, \% of the tested paper samples during thermal aging

\section{CONCLUSIONS}

Certain fillers in the paper can make their functionality and the end use of the paper possible. From previous and our research, it has been proven that the fillers can offer many advantages, such as improved printing, surface and many barrier properties. For packaging paper, print quality is an important factor among other properties. Research has shown that paper samples with bio-based fillers improved abrasion resistance and at the same time, no major colour differences occurred compared to paper without fillers. The ageing of paper with the addition of chitosan and chitosan and rice starch blends has shown that they show the same behaviour over the 72 hours of ageing. Further, to improve the barrier properties of packaging paper, this type of bio-based paper could be associated with additional additives and concentrations of polymers and additives presented in our study.

\section{REFERENCES}

[1] Aghazadeh, M., Karim, R., Sultan, M. T., Paykary, M., Johnson, S. K., Shekarforoush, E.: "Comparison of starch films and effect of different rice starch-based coating formulations on physical properties of walnut during storage time at accelerated temperature", Journal of Food Processing Engineering 41, e12607, 2018. doi: 10.1111/jfpe.12607

[2] Amirabad, L. M., Jonoobi, M., Mousavi, N. S., Oksman, K., Kaboorani, A., Yousefi, H.: "Improved antifungal activity and stability of chitosan nanofibers using cellulose nanocrystal on banknote papers", Carbohydrate Polymers 189, 229-237, 2018. doi: 10.1016/j.carbpol.2018.02.041

[3] Ashwar, B. A., Shah, A., Gani, A., Shah, U., Gani, A., Wani, I.A., Masoodi, F. A.: "Rice starch active packaging films loaded with antioxidants-development and characterization", Starch-Stärke 67, 294-302, 2015. doi: 10.1002/star.201400193

[4] Bourtoom, T., Chinnan, M. S.: "Preparation and properties of rice starch - chitosan blend film", Food Science and Technology 41, 1633-1641, 2008. doi: 10.1016/j.Iwt.2007.10.014

[5] Bourtoom, T., Chinnan, M. S.: "Improvement of water barrier property of rice starch-chitosan composite film incorporated with lipids", Food Science and Technology International 15, 149-158, 2009. doi: 10.1177/1082013208105993

[6] Brodnjak, U. V., Todorova, D.: "Novel Packaging Paper Made from Blend Fillers of Chitosan and Rice Starch", Journal of Polymer and Textile Engineering, 33-43, 2017. doi: 10.9790/019X-04033343

[7] Flores-Hernández, C. G., Colin-Cruz, A., Velasco-Santos, C., Castaño, V. M., Almendarez-Camarillo, A., Olivas-Armendariz, I., Martínez-Hernández, A. L.: "Chitosan-starch-keratin composites: improving thermo-mechanical and degradation properties through chemical modification", Journal of Polymer Environment 26, 2182-2191, 2018. doi: 10.1007/s10924-017-1115-1 
[8] Hoyos-Leyva, J. D., Bello-Pérez, L. A., Alvarez-Ramirez, J., Garcia, H. S.: "Microencapsulation using starch as wall material: A review", Food Review International 34, 148-161, 2018. doi: 10.1080/87559129.2016.1261298

[9] Iolovich, M.: "Isophase Transitions of Cellulose - A Short Review", Athens Journal of Sciences 3, 309 322, 2016. doi: 10.30958/ajs.3-4-4

[10] Jung, J., Raghavendra, G. M., Kim, D., Seo, J.: "One-step synthesis of starch-silver nanoparticle solution and its application to antibacterial paper coating", International Journal of Biological Macromolecules 107, 2285-2290, 2018. doi: 10.1016/j.ijbiomac.2017.10.108

[11] Khalil, A. H. P. S., Saurabh C. K., Adnan, A. S., Fazita, M. N., Syakir, M. I., Davoudpour, Y., Dungani, R.: "A review on chitosan-cellulose blends and nanocellulose reinforced chitosan biocomposites: Properties and their applications", Carbohydrate Polymers 150, 216-226, 2016. doi: 10.1016/j.carbpol.2016.05.028

[12] Li, H., Meng, B., Mahurin, S.M., Chai, S. H., Nelson, K. M., Baker, D. C., Dai, S.: "Carbohydrate based hyper-crosslinked organic polymers with-OH functional groups for CO 2 separation", Journal of Materials Chemistry A 3, 20913-20918, 2015. doi: 10.1039/c5ta03213j

[13] Lindh, E. L., Bergenstråhle-Wohlert, M., Terenzi, C., Salmén, L., Furó, I.: "Non-exchanging hydroxyl groups on the surface of cellulose fibrils: the role of interaction with water", Carbohydrate Research 434, 136-142, 2016. doi: 10.1016/j.carres.2016.09.006

[14] López-Mata, M. A., Ruiz-Cruz, S., de Jesús Ornelas-Paz, J., Del Toro-Sánchez, C. L., Márquez-Ríos, E., Silva-Beltrán, N. P., Burruel-Ibarra, S. E.: "Mechanical, barrier and antioxidant properties of chitosan films incorporating cinnamaldehyde", Journal of Polymer Environment 26, 452-461, 2018.

[15] Maitra, J., Singh, N.: "Starch-Chitosan Blend Cross-Linked with Calcium Chloride", Advances in Polymer Sciences and Technology, 133-145, 2018. doi: 10.1007/978-981-13-2568-7_13

[16] Mathew, S., Snigdha, S., Mathew, J., Radhakrishnan, E. K.: "Poly (vinyl alcohol): Montmorillonite: Boiled rice water (starch) blend film reinforced with silver nanoparticles; characterization and antibacterial properties", Applied Clay Science 161, 464-473, 2018. doi: 10.1016/j.clay.2018.05.009

[17] Mendes, J. F., Paschoalin, R. T-, Carmona, V. B., Neto, A. R. S., Marques, A. C. P., Marconcini, J. M., Oliveira, J. E.: "Biodegradable polymer blends based on corn starch and thermoplastic chitosan processed by extrusion", Carbohydrate Polymers 137, 452-458, 2016. doi: 10.1016/j.carbpol.2015.10.093

[18] Ogunsona, E., Ojogbo, E., Mekonnen, T.: "Advanced material applications of starch and its derivatives", European Polymer Journal 108, 570-581, 2018. doi: 10.1016/j.eurpolymj.2018.09.039

[19] Phan, D. N., Lee, H., Huang, B., Mukai, Y., Kim, I. S.: "Fabrication of electrospun chitosan/cellulose nanofibers having adsorption property with enhanced mechanical property", Cellulose 26, 17811793, 2019.

[20] Puvvada, Y. S., Vankayalapati, S., Sukhavasi, S.: "Extraction of chitin from chitosan from exoskeleton of shrimp for application in the pharmaceutical industry", International Current Pharmaceutical Journal 1, 258-263, 2012. doi: 10.3329/icpj.v1i9.11616

[21] Romani, V. P., Prentice-Hernández. C., Martins. V. G.: "Active and sustainable materials from rice starch, fish protein and oregano essential oil for food packaging", Industrial Crop and Products 97, 268-274, 2017. doi: 10.1016/j.indcrop.2016.12.026

[22] Sabbah, M., Di Pierro, P., Dell'Olmo, E., Arciello, A., Porta, R.: "Improved shelf-life of Nabulsi cheese wrapped with hydrocolloid films", Food Hydrocolloids 96, 29-35, 2019. doi: 10.1016/j.foodhyd.2019.05.010

[23] Shah, U., Naqash, F., Gani A., Masoodi, F. A.: "Art and science behind modified starch edible films and coatings: a review", Comprehensive Reviews in Food Science and Food safety 15, 568-580, 2016. doi: 10.1111/1541-4337.12197

[24] Tang, Y., Hu, X., Zhang, X., Guo, D., Zhang, J., Kong, F.: "Chitosan/titanium dioxide nanocomposite coatings: Rheological behavior and surface application to cellulosic paper", Carbohydrate Polymers 151, 752-759, 2016. doi: 10.1016/j.carbpol.2016.06.023

[25] Ten, E., Vermerris, W.: "Functionalized polymers from lignocellulosic biomass: State of the art", Polymers 5, 600-642, 2013. doi: 10.3390/polym5020600

[26] Thakur, R., Saberi, B., Pristijono, P., Golding, J., Stathopoulos, C., Scarlett, C., Vuong, Q.: "Characterization of rice starch-ı-carrageenan biodegradable edible film. Effect of stearic acid on the film properties", International Journal of Biological Macromolecules 93, 952-960, 2016. doi: 10.1016/j.jibiomac.2016.09.053 
[27] Vrabič Brodnjak, U.: "Infuence of ultrasonic treatment on properties of bio-based coated paper", Progress in organic coatings 103, 93-100, 2017. doi: 10.1016/j.porgcoat.2016.10.023

[28] Woggum, T., Sirivongpaisal, P., Wittaya, T. "Characteristics and properties of hydroxypropylated rice starch based biodegradable films", Food Hydrocolloids 50, 54-64, 2015. doi: 10.1016/j.foodhyd.2015.04.010

[29] Zarayneh, S., Sepahi, A. A., Jonoobi, M., Rasouli, H.: "Comparative antibacterial effects of cellulose nanofiber, chitosan nanofiber, chitosan/cellulose combination and chitosan alone against bacterial contamination of Iranian banknotes", International Journal of Biological Macromolecules 118, 10451054, 2018. doi: 10.1016/j.ijbiomac.2018.06.160

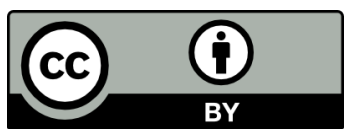

(C) 2020 Authors. Published by the University of Novi Sad, Faculty of Technical Sciences, Department of Graphic Engineering and Design. This article is an open access article distributed under the terms and conditions of the Creative Commons Attribution license 3.0 Serbia (http://creativecommons.org/licenses/by/3.0/rs/). 


\title{
INVESTIGATION ON THE PRINTABILITY OF SPECIALTY PAPERS FOR LUXURY LABELS
}

\author{
Dimitrina Todorova $^{1}$ (D), Nevena Pavlova ${ }^{2}$ \\ ${ }^{1}$ University of Chemical Technology and Metallurgy, Department of Pulp, Paper and \\ Printing art, Sofia, Bulgaria \\ ${ }^{2}$ Rotoprint, Industrialna zona, Ravno pole, Bulgaria
}

\begin{abstract}
Specialty luxury label papers mainly are results from the search for all that stimulates our creativity and senses. They are from papers that awaken the desire to create, as a magnificent mix of texture and colours that elevates luxury packaging to the category of art and a brilliant collection that ultimately shows that luxury packaging really is. In order to achieve the desired complex effect on the customer with its combined impact through the texture, colour of the paper and graphic design for each manufacturer of luxury labels, it is undoubtedly essential to be familiar with the printability of the paper used.

The aim of the present work was to study the main properties of the commonly used papers for printing of self-adhesive labels, in view of their printability. It is especially important for the production, as well as for the awareness of the designers working in this field, to know the specifics of these papers, to know the main indicators influencing their printability, to know all the facts allowing the right choice of printing technology and finishing processes. To achieve this goal, various properties of five types of paper have been determined: structural-dimensional, physical-mechanical, capillary-hygroscopic and optical. In addition, with all paper analysis, a printing sample have been made with different types of printing (offset UV, flexo UV, screen, cold foil, hot foil, silk foil) and converting (emboss, laser cutting, laser engraving) techniques. Based on the obtained results, new designer labels for wine have been printed. The results show that there is a clear dependence between the paper composition, its main and specific properties and the quality of the different printing and finishing processes, as well as the overall appearance of the produced labels. The printing and finishing processes have been carried out in Rotoprint Printing House, Bulgaria and the obtained results could give a valuable information not only for the particular printing house, but for other specialists in the field of labels production.
\end{abstract}

Key words: specialty papers, printability, self-adhesive labels, strength properties, printing, converting

\section{INTRODUCTION}

Predecessors of modern labels are the brands that the producers of beverages (mainly wines) put on amphora, bottles and other clay dishes. The advent of paper in Europe has had a major impact on the appearance of labels. By 1820, wine labels began to resemble those that exist today, but are characterized by a strict and compact style. Initially, they have a simple rectangular or oval shape. Over the time, all kinds of ornaments and coats of arms, angels, saints, monks, folk scenes and picturesque landscapes, etc. enter the production of labels. In those days there were no official rules for the content of labels: they usually contained only information on the geographical origin, the producer and the place of production. In 1834, winemakers began to put on labels and information about the year of harvest. For the period from 1820 to 1920, the production of champagne increased from 2 to 20 million bottles per year, and last but not least, the label played a big role in its 10-fold increase. The small piece of paper becomes a powerful engine of trade and a means of information for customers. The first official rules for labeling wines appeared in the early 20th century. Since then, more and more attention has been paid to labels: such famous artists as Salvador Dali, Marc Chagall, Pablo Picasso and Andy Warhol are working on their design. The pioneer in this field is the Bordeaux area, with the famous example of Mouton-Rothschild, which in 1924 started to ask an artist to create the label for each vintage of its wine (Obis, 2018; Franson, 2006).

Paper is almost as old as communication itself. Plus, it is as versatile and technologically advanced as any electronic chip. Most of the paper producers work hard to provide high quality and value-added papers, with striking surfaces and textures, vivid colours and papers, that can be printed in every possible way. Label papers are highly functional papers, that can catch our eye or remain discreetly in the background. Luxury label papers are not just a means of communication - they are simply art in the field of: olive oils, red, white and sparkling wines, spirits and liqueurs, gourmet, beers and others (Franson, 2006; UPM Raflatac, n.d.; EUR-Lex, 2015; Labels \& Labeling, 2010). 
Labels for packaged products can come in a variety of sizes and shapes. They range from those without an adhesive layer, which are glued with glue, In-mold labelling - IML (which are built into the package when casting it) to self-adhesive, which can be sensitive to pressure, heat (self-adhesive thermocouple).

Self-adhesive labels are made on the basis of paper and synthetic film coatings. Surface coating is applied to improve the properties of the label paper. Modern technologies allow the production of surface-coated paper using a base, both from cellulose and with the participation of secondary fibrous material. The use of surface-coated paper allows to significantly increase the quality of the print and the artistic layout. The advantage of surface-coated paper is the smooth flat surface, which has better printing properties than the uncoated one. As a result of different calendaring techniques, the paper acquires gloss or matt. Excessive gloss is not always desirable, as the matte surface is better for reading. Of particular importance for surfaceenhanced printing paper is its "dusting and lintting" resistance.

For the production of labels, one-sided coated paper is used, suitable for further processing, which must be resistant to twisting and moisture. Coated papers should contain an increased amount of binder to prevent ink from passing through. With continuous application of printing inks on the paper, no additional measures are required to ensure varnish impermeability, because they themselves give the paper the necessary barrier properties. Among the advantages of surface-coated paper is its density and the high degree of surface uniformity in the absorption of printing inks. The additional requirements for this type of paper in terms of hydrophobicity are due to the wetting of its surface during the offset printing process and the end-user's application.

Self-adhesive labels refer to adhesive materials, the adhesive ability of which does not require activation by wetting or temperature exposure. The gluing of this type of labels is carried out by joining them to heterogeneous surfaces and their subsequent pressing or smoothing. They are most common in:

- labels for packaging of various goods;

- $\quad$ sticking to food prices;

- $\quad$ self-adhesive labels on electronic scales;

- $\quad$ high quality full colour advertising production on white, coloured, fluorescent, metallized paper;

- labels of wine and alcoholic beverages;

- $\quad$ postage stamps, envelopes, folders, cassettes;

- $\quad$ transport and production marking for different purposes.

The properties of the paper depend on the properties of the source fibrous materials, their morphological structure and chemical composition, the degree and nature of grinding, the presence of fillers, sizing agents and other chemical additives, as well as the technological conditions of production.

Each type of paper is characterized by a certain combination and level of quality indicators, due to the specificity of the conditions in which it is used. The variety of areas of application of the paper determines the diversity in the properties required by it (Holik, 2006; Thorn and On Au, 2009).

The aim of the present work is to study the main properties of the commonly used papers for printing of self-adhesive labels, in view of their printability. It is especially important for the production, as well as for the awareness of the designers working in this field, to know the specifics of these papers, to know the main indicators influencing their printability, to know all the facts allowing the right choice of printing technology and finishing processes. To achieve this goal, various properties of five types of paper have been determined: structural-dimensional, physical-mechanical, capillary-hygroscopic and optical. In addition, with all paper analysis, a printing sample have been made with different types of printing (offset UV, flexo UV, screen, cold foil, hot foil, silk foil) and converting (emboss, laser die-cutting, laser engraving) techniques. Based on the obtained results, new designer labels for wine have been printed.

\section{MATERIALS AND METHODS}

Self-adhesive wine label papers are a special type of papers characterized by a variety of fiber compositions, chemical additives, production technology and properties. Due to this feature, very often the product characteristics of the papers from different manufacturers are different, incomplete, insufficient or completely missing. Therefore, the complete characterization of the papers used in the printing house is essential for the optimization of the production processes and leads to the successful realization of the produced products. In the present work five types of papers for self-adhesive luxury wine labels have been used: Pure Cotton, Symphonie, Blizzard, Organdie and Velin Caviar, delivered from Rotoprint printing house. 


\subsection{Microscopic analyses}

The microscopic analyses of cellulose and paper materials, is a specific analysis generally used to determine the fiber composition of the paper and to study the structure and size of the source fibers. Small amount of test fibers (pre-milled mechanically) is placed in a porcelain pounder with a few drops of $1 \% \mathrm{NaOH}$. This is followed by rinsing the sample several times with distilled water on a fine metal mesh. Three samples of fibers have to be placed on a glass slide, distribute well with the help of pins, and remove excess water with the help of filter paper. A drop of Herzberg's reagent (Cl - Zn - J) (ISO 9184-3:1990) is dropped on each of the samples and again very carefully the fibers should be distributed. Finally, the samples are dried at about $60^{\circ} \mathrm{C}$ with a lamp. After cooling down to room temperature, each sample is covered with a thin glass slide, so the fiber samples to be evenly distributed, free of accumulations and air bubbles. Stained fiber samples are ready to be observed under a microscope at different magnifications (Ivanova et al, 2009).

To determine the type of fibers, the peculiarities of their structure are studied - shape and size (whether they are flat or cylindrical); presence of tubules - size and shape; appearance of their ends; size, type and location of the pores, as well as the size and shape of the cells. The colour and morphological features of the fibers determine the type of raw material from which the paper sample is obtained. The Herzberg reagent stains the fibrous materials in the following ways (Ivanova et al, 2009): Cotton, linen and hemp pale to intense pink - red; Cellulose - blue to violet colour, while the sulphite cellulose is coloured more intensely, and the sulphate - paler and darker with brownish hues; Wood pulp and semi-cellulose - from light yellow to yellow-brown colour depending on the yield; Wool - pale yellow colour; Artificial fibers - blue colour; Acetate fibers - yellow colour; Synthetic fibers - with no colour.

For the microscopic characterization of the natural fibers according to their morphological features, the following three characteristics are examined: general appearance of the fibers (size and configuration); fiber marking (type, size and location of pores, presence of channel, nature of the ends), accompanying structural elements (core rays, cells and vessels).

\subsection{Paper Properties}

According to ISO 187: 1990, the conditioning and subsequent testing of paper samples was performed under the following conditions: Relative humidity - $50 \pm 2 \%$; Temperature $-23 \pm 1{ }^{\circ} \mathrm{C}$, the required time for conditioning the paper before the test is at least $4 \mathrm{~h}$.

Studies have been conducted to determine:

- Composition - type of fibrous materials;

- Structural and dimensional properties - basic weight - ISO 536: 1998; thickness - ISO 534: 2006; density - ISO 534: 2006; porosity; Bekk smoothness (ISO 5627 / A1: 2004);

- Hygroscopic properties - water absorption Cobb60 (ISO 535:2014);

- Strength properties - tensile index - ISO 1924-2: 2000; burst index - ISO 2758: 2005, tear index ISO 1974:2012

- Optical properties - whiteness CIE, whiteness CIE - UV, ISO brightness, ISO brightness - UV, fluorescense CIE, fluorescense ISO brightness (ISO 2470: 2016); colour coordinates - L*, a*, b* (ISO 5631-3:2008).

\subsection{Printing of samples on the tested papers}

Printed sample, presented in Figure 1, was applied to all five tested types of paper. The figure shows the main types of printing and converting processes in the production of self-adhesive labels, in the conditions of Rotoprint printing house. The used printing and converting machines are:

Gallus EM 280 - UV flexographic printing and rotary screen printing, hot foil embossing and cold foil printing. Possibility to print in 8 colours; width of the material from $120 \mathrm{~mm}$ to $270 \mathrm{~mm}$; maximum size of the printed product $440 \mathrm{~mm} \times 250 \mathrm{~mm}$; average printing speed about $80 \mathrm{~m} / \mathrm{min}$.

Gallus TCS 250 - combines a wide range of printing, processing and finishing options. Modular seven offset press including finishing processes such as screen printing, hot foil embossing, varnishing and relief embossing, lamination section, flexo section for complete and partial varnishing, embossing, 3D embossing and flat punching. Printing with UV offset inks and varnishes with maximum format of the printed product $254 \mathrm{~mm} \times 254 \mathrm{~mm}$; maximum paper width $260 \mathrm{~mm}$; average machine speed 7500 stroke/hour; suitable for short runs with complex designs requiring the use of special types of paper and perfect quality.

Cartes GT 364 HSDL - machine for finishing operations with section for flat hot stamping, printing of two different foils at the same time, section for flat screen, Silk foil, embossing, flat bed die-cutting, laser die- 
cutting, different types of perforations, engraving, perforation of individual sections, numbering and custom information, disc knives for splitting and trimming the material with average machine speed 5000 stroke/hour; maximum width of the material $360 \mathrm{~mm}$; maximum area of the printed field $250 \mathrm{~mm} \times$ $360 \mathrm{~mm}$.

The printability of each paper sample was visually evaluated on the basis of the reproduced printed elements. In Rotoprint to maintain an excellent print quality a spectrophotometric calibration is done periodically (on every six months) by which a calibration curves are constructed for each sample and the results are embedded in the prepress software.

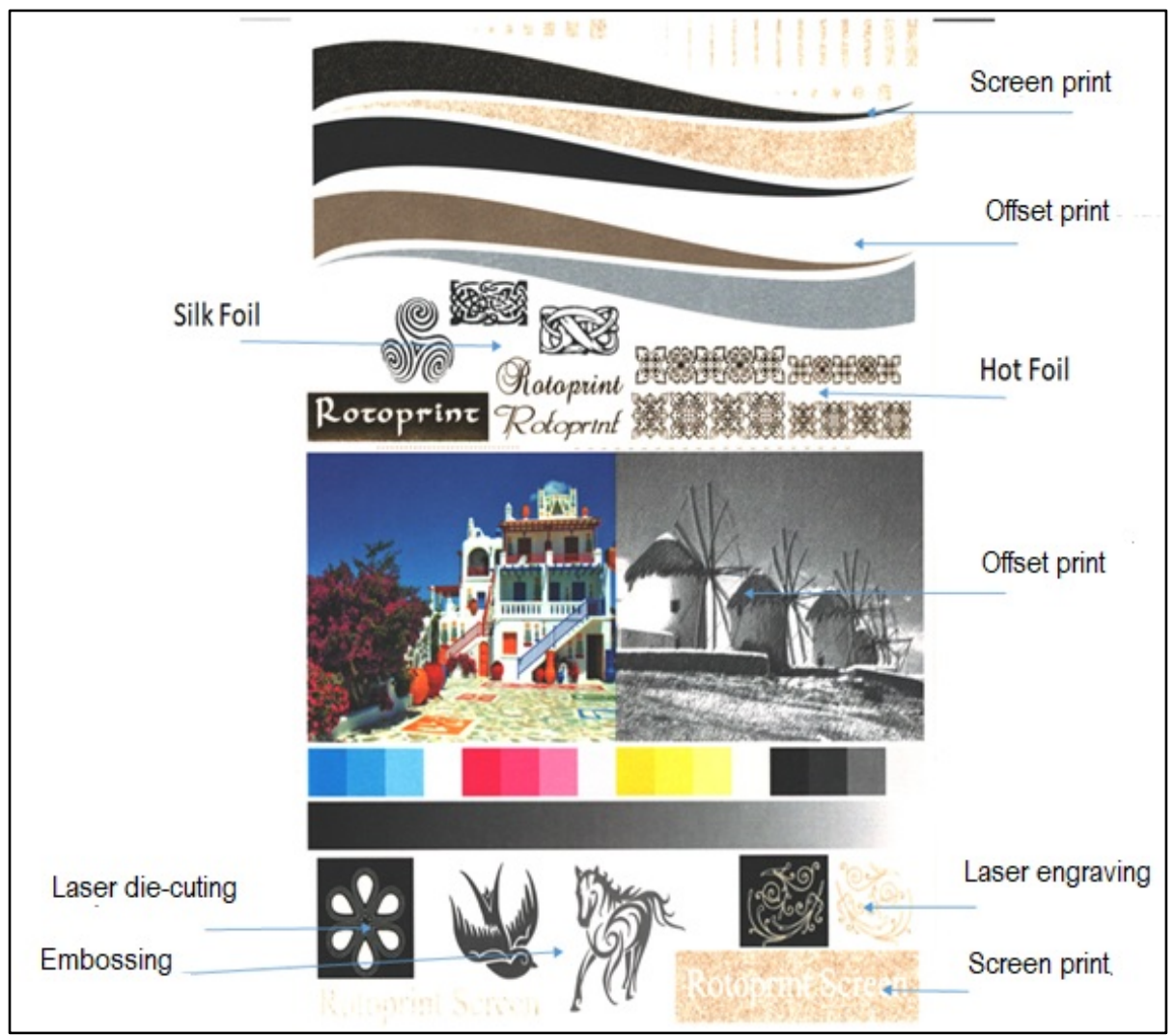

Figure 1: Printed sample

\section{RESULTS AND DISCUSSIONS}

For the extensive characterization of the studied five types of papers for self-adhesive labels, a variety of laboratory analyzes were performed followed by printing samples, on the basis of which the connection between the properties of the papers and their printability was considered. Based on the conclusions of the research, new designer wine labels have been made, which have been printed and processed using various printing and finishing techniques.

\subsection{Investigation on the fiber content of the papers}

Figure 2 shows the microscopic analysis of Pure Cotton paper. It is visible that this type of paper contains $100 \%$ natural cotton fibers, which under the "Cl-Zn-J" indicator are stained in pale to intense pink-red colour and have the typical natural cotton morphology: long fibers, tape-shaped, without pointed edges with thin walls and in the center passes a wide channel (up to 2/3 of the width), with no pores and thickenings. 


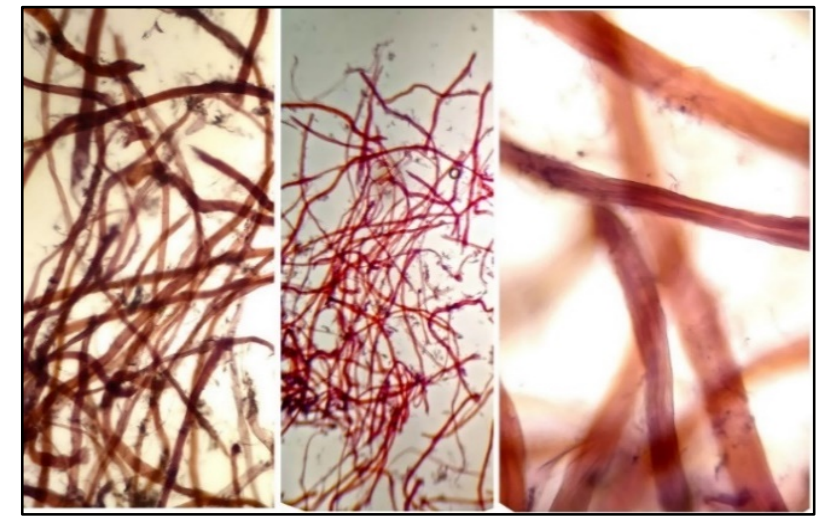

Figure 2: Microscopic analysis of Pure Cotton paper

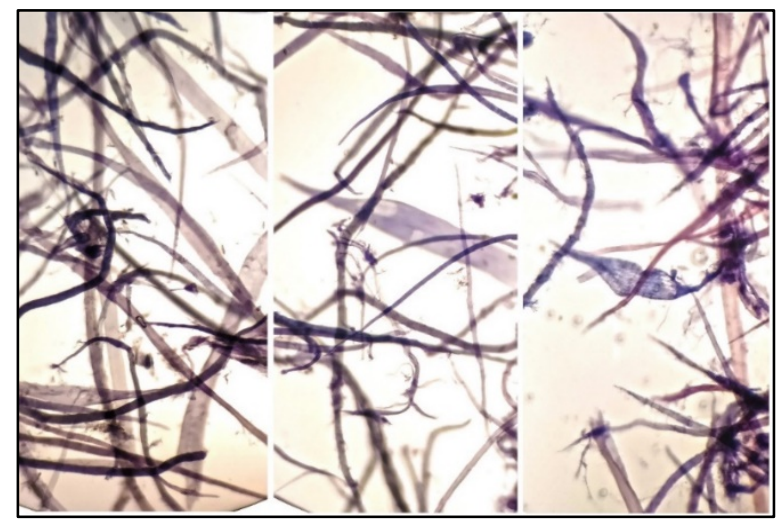

Figure 3: Microscopic analysis of Symphonie paper

The results of the microscopic analysis of Symphonie paper are presented in Figure 3. The fibers of this type of paper have the typical for bleached fibrous materials, of coniferous and deciduous wood species, blue to violet colouring under "Cl-Zn-J" indicator. Therefore, the paper consists of $100 \%$ bleached cellulose with a lignin content less than $9 \%$. Regarding the specific tree species, the figure shows that the Symphonie paper contains of bleached softwood cellulose from spruce wood and bleached hardwood cellulose from poplar wood.

The composition of Blizzard paper is multicomponent, which is clearly outlined by the heterogeneous picture presented in Figure 4. This paper consists of not more than 5\% natural cotton fibers, softwood cellulose from spruce wood and two types of hardwood cellulose - from poplar and beech wood. Predominant in the composition of the paper is the cellulose from poplar wood, in the range of $50 \%$.

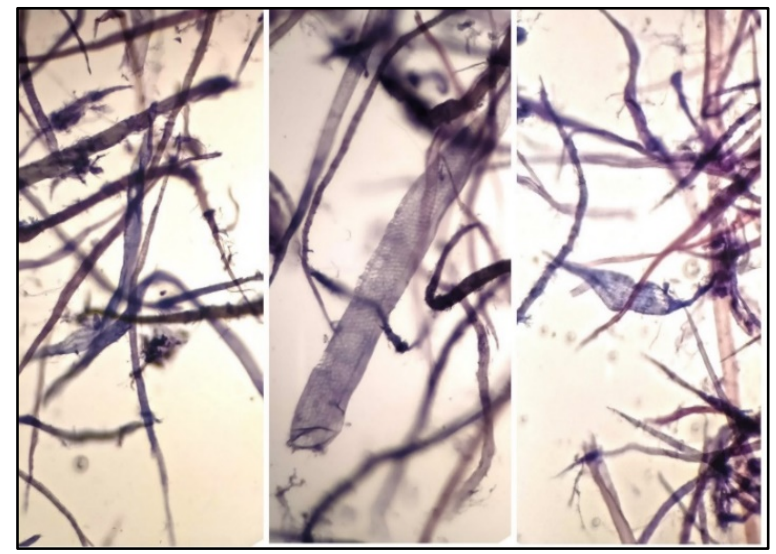

Figure 4: Microscopic analysis of Blizzard paper 


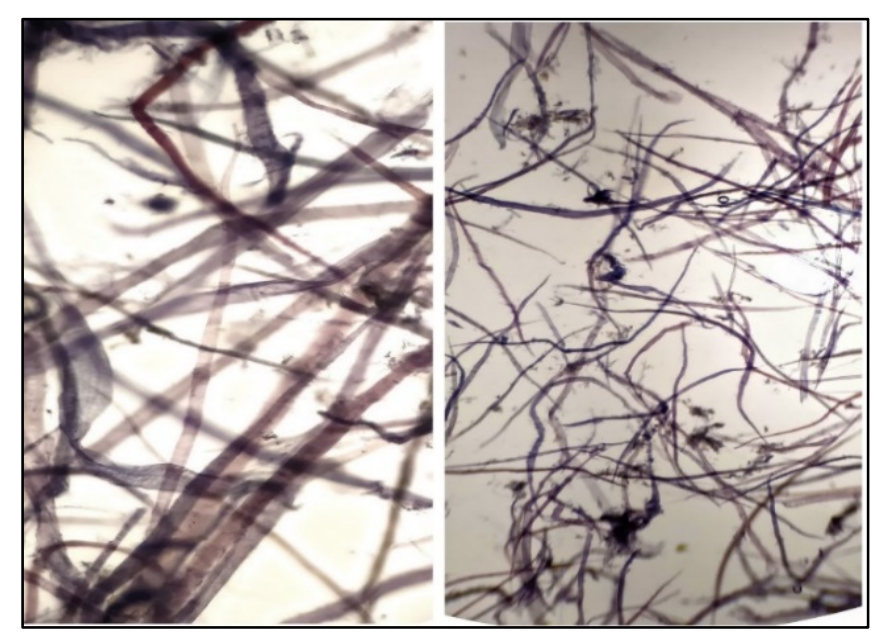

Figure 5: Microscopic analysis of Organdie paper

The microscopic analysis of the fourth type of paper - Organdie is presented in Figure 5. This paper consists of small amount of natural cotton fibers, not more than $10 \%$ and bleached softwood cellulose from spruce wood and bleached hardwood cellulose from beech wood, with the predominant cellulose content of the coniferous specie.

Figure 6 shows the microscopic analysis of Velin Caviar paper. This is the paper with the largest variety of types of cellulose fibrous materials used. It consists of about $10 \%$ natural cotton cellulose, $40 \%$ softwood cellulose of two wood types - spruce and pine, in a ratio of 1:1 and hardwood cellulose from two species of wood - poplar and beech wood, again in a ratio of 1:1, with a total content of $50 \%$.

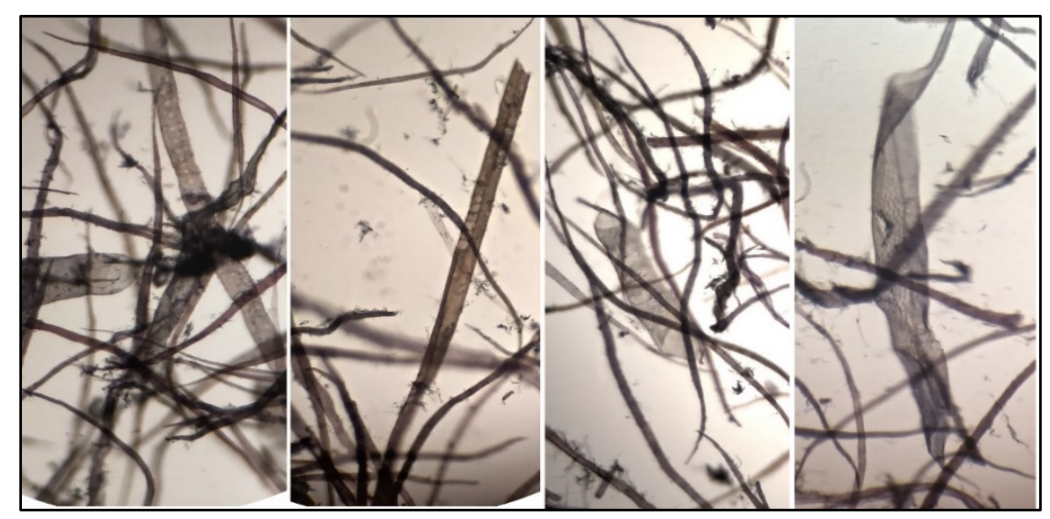

Figure 6: Microscopic analysis of Velin Caviar paper

\subsection{Paper properties investigation}

The results from the analysis of the investigated structural and dimensional properties, hygroscopic, strength and optical properties of the studied papers are presented in Table 1.

The investigated papers are with a basic weight in the range of $90-100 \mathrm{~g} / \mathrm{m}^{2}$ and thickness between 0,09 - $016 \mathrm{~mm}$, but most interesting are the results for the density and porosity of the papers, because they have bigger deviation which means that even at similar basic weight papers probably will have different ability of emboss and engraving during the converting processes. The smoothness of the paper is the most important characteristic of the paper for the engraving printing, which means that most suitable could be Blizzard paper. From the Cobb analysis is seen that Blizzard paper has the optimal for the offset printing Cobb values $\sim 22 \mathrm{~g} / \mathrm{m}^{2}$ and we could expect excellent offset printability, followed by Pure Cotton with $\sim 20$ $\mathrm{g} / \mathrm{m} 2$. The strength properties are in dependence to the nature type of the fiber material and to the variety of the fiber content of the paper - more cotton fibers means enhance strength while bigger fiber variety ensures closed and evenly formed paper structure and fiber distribution. From the optical properties is seen that paper Blizzard and Organdie are more or less the same and they could be used for a similar labelling purposes. 
Table 1: Investigated characteristics of the studied papers

\begin{tabular}{|c|c|c|c|c|c|c|c|c|c|c|c|c|c|c|c|c|}
\hline \multirow[b]{2}{*}{ Properties } & \multicolumn{16}{|c|}{ Investigated papers } \\
\hline & $\begin{array}{l}\text { Dimensi } \\
\text { on }\end{array}$ & \multicolumn{3}{|c|}{$\begin{array}{l}\text { 1. Pure } \\
\text { Cotton }\end{array}$} & \multicolumn{3}{|c|}{ 2.Symphonie } & \multicolumn{3}{|c|}{ 3. Blizzard } & \multicolumn{3}{|c|}{ 4. Organdie } & \multicolumn{3}{|c|}{$\begin{array}{l}\text { 5. Velin } \\
\text { Caviar }\end{array}$} \\
\hline \multicolumn{17}{|c|}{ Structural and dimensional properties } \\
\hline I.1. Basic weight & $\mathrm{g} / \mathrm{m}^{2}$ & \multicolumn{3}{|c|}{100} & \multicolumn{3}{|c|}{90} & \multicolumn{3}{|c|}{90} & \multicolumn{3}{|c|}{95} & \multicolumn{3}{|c|}{90} \\
\hline I.2. Thickness & $\mathrm{mm}$ & \multicolumn{3}{|c|}{0,16} & \multicolumn{3}{|c|}{0,14} & \multicolumn{3}{|c|}{0,1} & \multicolumn{3}{|c|}{0,14} & \multicolumn{3}{|c|}{0,09} \\
\hline I.3. Density & $\mathrm{kg} / \mathrm{m}^{3}$ & \multicolumn{3}{|c|}{625} & \multicolumn{3}{|c|}{643} & \multicolumn{3}{|c|}{900} & \multicolumn{3}{|c|}{864} & \multicolumn{3}{|c|}{1000} \\
\hline I.4. Porosity & $\mathrm{m}^{3} / \mathrm{kg}$ & \multicolumn{3}{|c|}{0,0016} & \multicolumn{3}{|c|}{0,0015} & \multicolumn{3}{|c|}{0,0011} & \multicolumn{3}{|c|}{0,0012} & & 0,001 & \\
\hline Porosity & $\%$ & & 58,33 & & & 57,13 & & & 40 & & & 42,4 & & & 33,33 & \\
\hline $\begin{array}{l}\text { l.5. Smoothness } \\
\text { (Bekk), TS (top } \\
\text { side) }\end{array}$ & & & 1,4 & & & 2,06 & & & 24,93 & & & 3,55 & & & 18 & \\
\hline $\begin{array}{l}\text { Smoothness } \\
\text { (Bekk), BS (bottom } \\
\text { side) }\end{array}$ & S & & 1,35 & & & 1,52 & & & 24,33 & & & 3,22 & & & 18,33 & \\
\hline II. $\quad$ Hygrosco & c properti & & & & & & & & & & & & & & & \\
\hline $\begin{array}{l}\text { II.1. Water } \\
\text { absorption Cobb } 60 \text {, } \\
\text { TS }\end{array}$ & $a^{2}$ & & 19,67 & & & 17,28 & & & 21,95 & & & 16,42 & & & 25,9 & \\
\hline $\begin{array}{l}\quad \text { Water } \\
\text { absorption Cobb } 60 \text {, } \\
\text { BS }\end{array}$ & $\mathrm{g} / \mathrm{m}^{2}$ & & 20,68 & & & 18,56 & & & 20,92 & & & 16,79 & & & 25,25 & \\
\hline III. Strength & operties & & & & & & & & & & & & & & & \\
\hline $\begin{array}{l}\text { III.1. Tensile Index, } \\
\text { MD (machine } \\
\text { direction) }\end{array}$ & $\mathrm{N} m / \sigma$ & & 38,17 & & & 64,44 & & & 50,37 & & & 60,53 & & & 59,81 & \\
\hline $\begin{array}{l}\text { Tensile Index, } \\
\text { CD (cross } \\
\text { direction) }\end{array}$ & N.m/g & & 25,17 & & & 41,48 & & & 26,17 & & & 30,88 & & & 35,56 & \\
\hline III.2. Burst Index & $\begin{array}{c}\mathrm{kPa} \cdot \mathrm{m}^{2} / \\
\mathrm{g}\end{array}$ & & 180 & & & 267 & & & 222 & & & 268 & & & 258 & \\
\hline $\begin{array}{l}\text { III.3. Tear Index, } \\
\text { MD }\end{array}$ & $\mathrm{mN} \cdot \mathrm{m}^{2} /$ & & 5,8 & & & 6 & & & 6,89 & & & 5,47 & & & 5,78 & \\
\hline $\begin{array}{ll} & \text { Tear Index, } \\
\text { CD } & \end{array}$ & & & 6,2 & & & 6,44 & & & 6,89 & & & 6,32 & & & 5,78 & \\
\hline IV. Optical pr & perties & & & & & & & & & & & & & & & \\
\hline $\begin{array}{l}\text { IV.1. Whiteness } \\
\text { CIE }\end{array}$ & $\%$ & & 132,97 & & & 63,51 & & & 145,29 & & & 143,03 & & & $-0,60$ & \\
\hline $\begin{array}{l}\text { Whiteness } \\
\text { CIE - UV }\end{array}$ & $\%$ & & 75,13 & & & 62,35 & & & 87,64 & & & 90,95 & & & 0,09 & \\
\hline $\begin{array}{l}\text { IV.2. ISO } \\
\text { Brightness }\end{array}$ & $\%$ & & 95,45 & & & 78,30 & & & 93,75 & & & 94,25 & & & 4,02 & \\
\hline $\begin{array}{c}\text { ISO } \\
\text { Brightness - UV }\end{array}$ & $\%$ & & 85,29 & & & 78,16 & & & 83,68 & & & 85,26 & & & 4,04 & \\
\hline $\begin{array}{l}\text { IV.3. Fluorescense } \\
\text { CIE }\end{array}$ & & & 57,85 & & & 1,16 & & & 57,65 & & & 52,08 & & & $-0,69$ & \\
\hline $\begin{array}{l}\text { Fluoresense } \\
\text { ISO Brightness }\end{array}$ & $\%$ & & 10,15 & & & 0,14 & & & 10,07 & & & 8,98 & & & $-0,02$ & \\
\hline IV.4. Color coordina & & $L^{*}$ & $a^{*}$ & $b^{*}$ & $L^{*}$ & $a^{*}$ & $b^{*}$ & $L^{*}$ & $a^{*}$ & $b^{*}$ & $L^{*}$ & $a^{*}$ & $b^{*}$ & $L^{*}$ & $a^{*}$ & $b^{*}$ \\
\hline & D65_10 & $\begin{array}{l}6 \\
\text { है } \\
\sigma\end{array}$ & ֻn & $\frac{m}{\tilde{p}_{i}}$ & 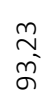 & 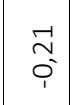 & $\stackrel{\infty}{\underset{\sigma}{\sigma}}$ & 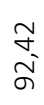 & خิ & $\underset{\substack{N \\
\stackrel{n}{r}}}{\stackrel{0}{1}}$ & $\begin{array}{l}\text { ó } \\
\text { ñ }\end{array}$ & $\stackrel{\infty}{\infty}$ & $\underset{\substack{n\\
}}{\stackrel{\infty}{1}}$ & $\begin{array}{l}\text { Oे } \\
\text { さ্ঠ }\end{array}$ & $\hat{n}$ & 守 \\
\hline
\end{tabular}




\subsection{Investigation on the printability of the papers}

Pure Cotton is suitable for full colour offset printing, featuring that the colour density provided by the technology itself is not maximum. This is mainly due to the fact that one of the studied properties, namely the water absorption capacity of Cobb60, which for Pure Cotton is about $20 \mathrm{~g} / \mathrm{m}^{2}$, which is slightly below the optimal values of the offset printing index. It also has an exceptional effect on the reproduction of elements and strokes with screen printing. The absorbency of this paper combined with its porosity is so great that in fact highly pigmented inks, such as silver and gold bronze, are almost absorbed in depth and are poorly reproduced.

This paper has an exceptional pleasant to be touched texture, which is actually evident from the measurement of its smoothness (the lowest smoothness of all tested papers) considering its basic weight $-100 \mathrm{~g} / \mathrm{m}^{2}$. This quality makes it suitable for wine labels with clean designs. At first glance, the paper itself gives elegance and luxury to wine labels. And this is what attracts most designers and their desire to work with it.

From the samples made, it was found that the perception of the Hot foil is excellent, even the thin jewellery inscriptions and serifs are reproduced with high quality. The newly introduced technology in the world of Silk foil labels reproduces very well, behaved stable throughout printing.

From the printed samples was found out that at minimal pressure of the working section, the paper is easily torn, even the substrate is slightly cracked. This makes the paper not very suitable for embossing technology, not only for the production in Rotoprint, but also for many other productions, which is proved by the strength properties, showing lower values of tensile, tear and burst resistance. The quality of embossing could be judged by other indicators, such as porosity. Pure Cotton is the most porous of all the papers investigated - 58\%, which in combination with its weak strength properties can lead to problems in embossing irregularly shaped labels.

As a result of the research carried out, in Rotoprint two exemplary design of wine labels were created, which were produced with the printing and finishing techniques and technologies in accordance with the research and the end products are shown on Figure 7.

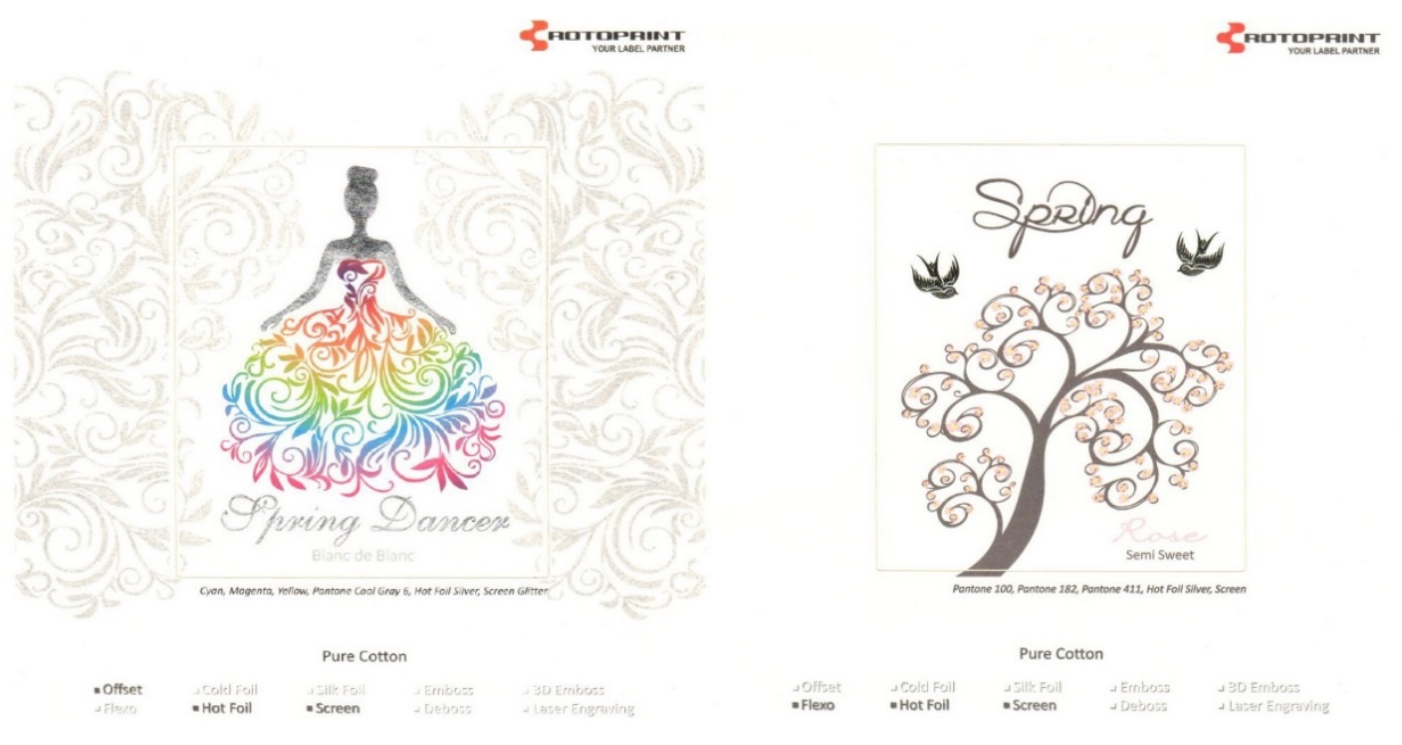

Figure 7: New designed labels on Pure Cotton paper

Excellent reproduction of the full-colour offset printing was established from the printed samples made on Symphonie paper. When printing on this paper, the colour density is higher, which might be due to its slight yellowness, but mostly is proven both visually and by measuring the optical properties of the tested papers (see Table 1). The established water absorption capacity of this type of paper is not very high compared to other papers, about $18 \mathrm{~g} / \mathrm{m}^{2}$ and the inks manage to fix on its surface very well.

A disadvantage is the reproduction of slightly torn and sometimes slightly jagged strokes in screen printing, which is largely due to the roughness of the paper - smoothness of the top side about $2 \mathrm{~s}$ was measured. The reproduction of very thin elements with the Silk and Hot foil technologies is very good, but there is a difference in the dense areas, where the texture of the material can be seen. This his is not always negative, in fact it can actually be a desired effect by a designer. 
Upon careful evaluation of the printed and converted samples we concluded that with this type of paper, the embossing is of an excellent quality, which is predictable from the results of the examined parameters, noted in the above table, due to its high porosity - $57 \%$ and very good strength properties. It is well known that when the porosity of the paper is high and is with higher plasticity it is a prerequisite for excellent embossing. Symphonie paper also has the highest values of resistance of tensile and burst, which is due not only to the high-quality fibrous material from which the paper is made (bleached cellulose from hard and softwood), but also to its excellent structural distribution, given by the fiber ratio (60:40\%) and its ability to form evenly distributed hydrogen bonds, even thou the paper is anisotropic, responsible for the strength of the paper. This is extremely important not only for the embossing technology, but also for the embossing of irregularly shaped labels, which produce a cutout of different width and shape. The produced designed wine labels on Symphonie paper, based on the research carried out are shown on Figure 8.

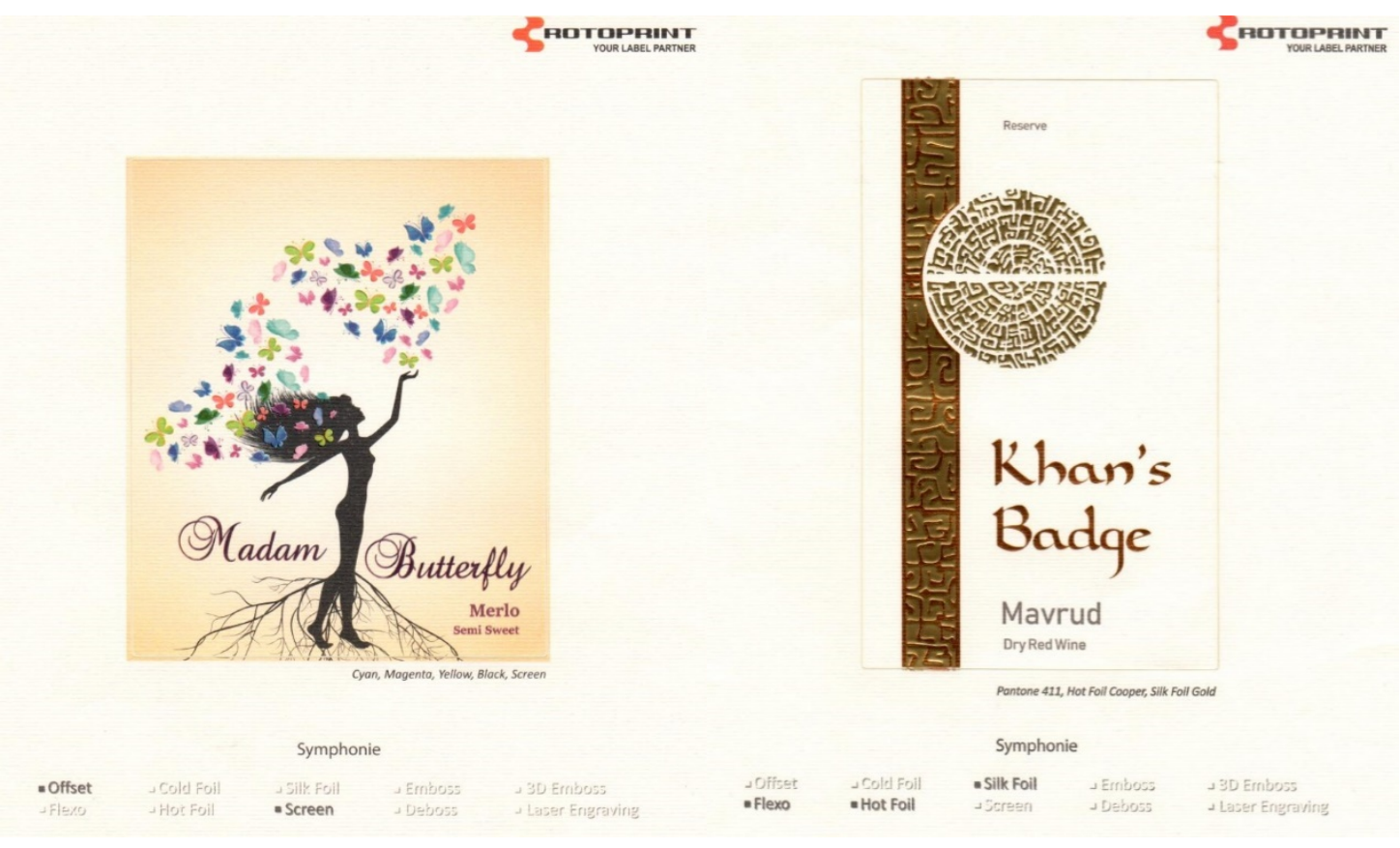

Figure 8: New designed labels on Symphonie paper

At first glance, Blizzard is a typical offset paper, with fine-feeling surface touch, with a very good printability, which makes it widely used in the label industry. This paper is preferred not only by wine label producers, but also for many other products in the food industry. From the printed samples the exceptional quality of the full-colour offset and flexo printing was established, with high optical density and well-fixed colours, even overflow and very good screen printing. Reproduction of thin, even jewellery elements, as well as dense areas with Silk foil and Hot stamping technologies are flawless. All these properties are due to the excellent combination of properties that this paper has, due to the variety of fibrous materials in its composition and the uniform structure of the paper sheet, both on the surface and in the core. Blizzard is characterized by high smoothness - about $25 \mathrm{~s}$ and compared to other types of paper studied, with the highest whiteness, optimal strength and hydrophobicity, medium to low porosity and relatively high density.

It is noteworthy that it has the highest tear resistance $-6.9 \mathrm{mN} . \mathrm{m}^{2} / \mathrm{g}$., and it depends primarily on the strength and nature of the fibers in the paper, but also from the structure. This is evidenced by microscopic analysis, which confirms the content of cotton fibers and spruce fibers in combination with two types of hardwood cellulose, which makes this paper with a closed structure, suitable for almost all printing and finishing processes. The produced wine labels on Blizzard paper, based on the research carried out are shown on Figure 9. 


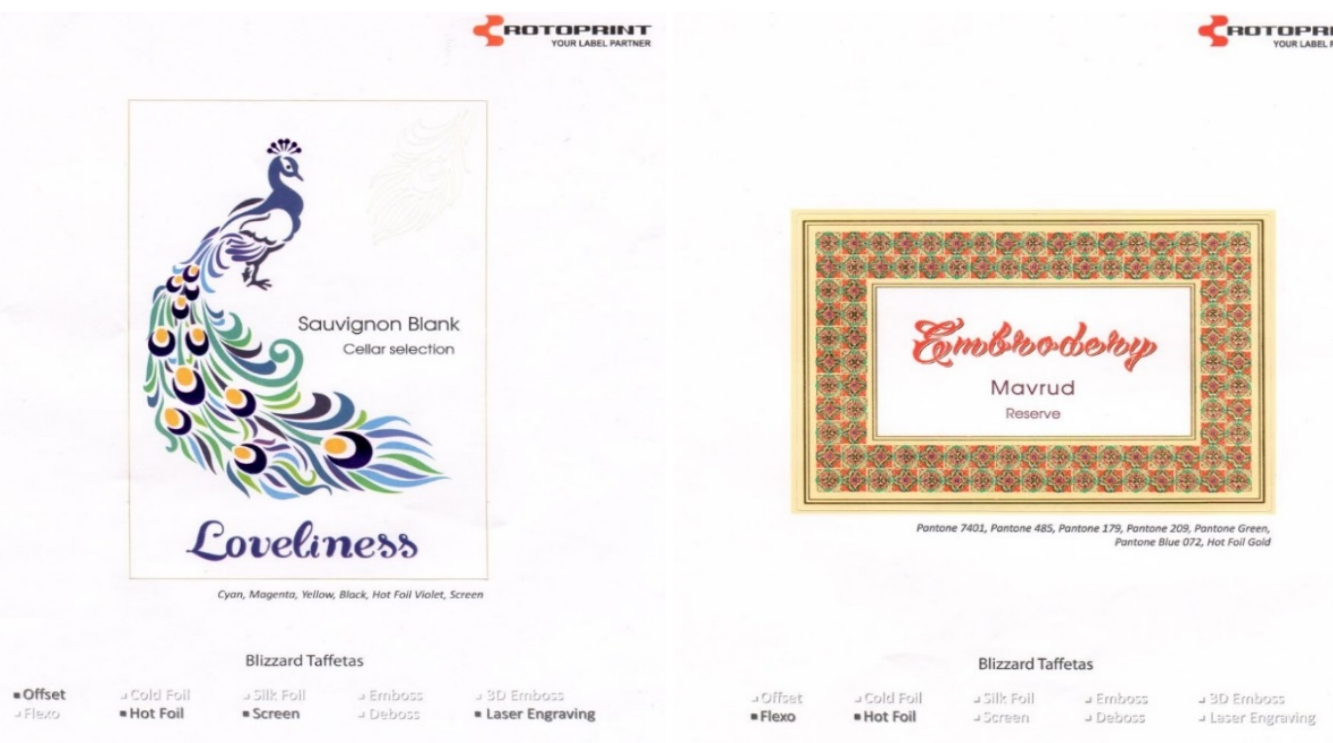

Figure 9: New designed labels on Blizzard paper

Organdie paper differs from the other studied papers with a special rough surface structure (resembling orange peel), characterized by low smoothness, about 3s, but on the other hand with good strength properties. This uneven surface has a negative effect on the printing of dense and very fine areas. Although it does not have a high water absorption capacity - about $16.5 \mathrm{~g} / \mathrm{m}^{2}$, the printing of strokes with screen printing technic is uneven, there is no sharpness of the elements. A similar problem occurs with dense areas with hot stamping. There is a "lintting" of the foil elements as a result of micro-irregularities on the surface of the paper. Also preferred for Silk Foil technology are elements of medium size, because the very thin ones are torn. In general, the reproduced colours are with high density due to the optical properties of Organdie - the paper has a high whiteness, thanks to the optical brightener. The samples made in Rotoprint show that the emboss is optimal due to the good physical and mechanical properties of the paper, despite the low porosity. Organdie paper could be widely used in the label industry, as it is suitable for clean designs, those that involve mainly finishing rather than printing processes. The produced wine labels on Organdie paper, based on the research carried out are shown on Figure 10.

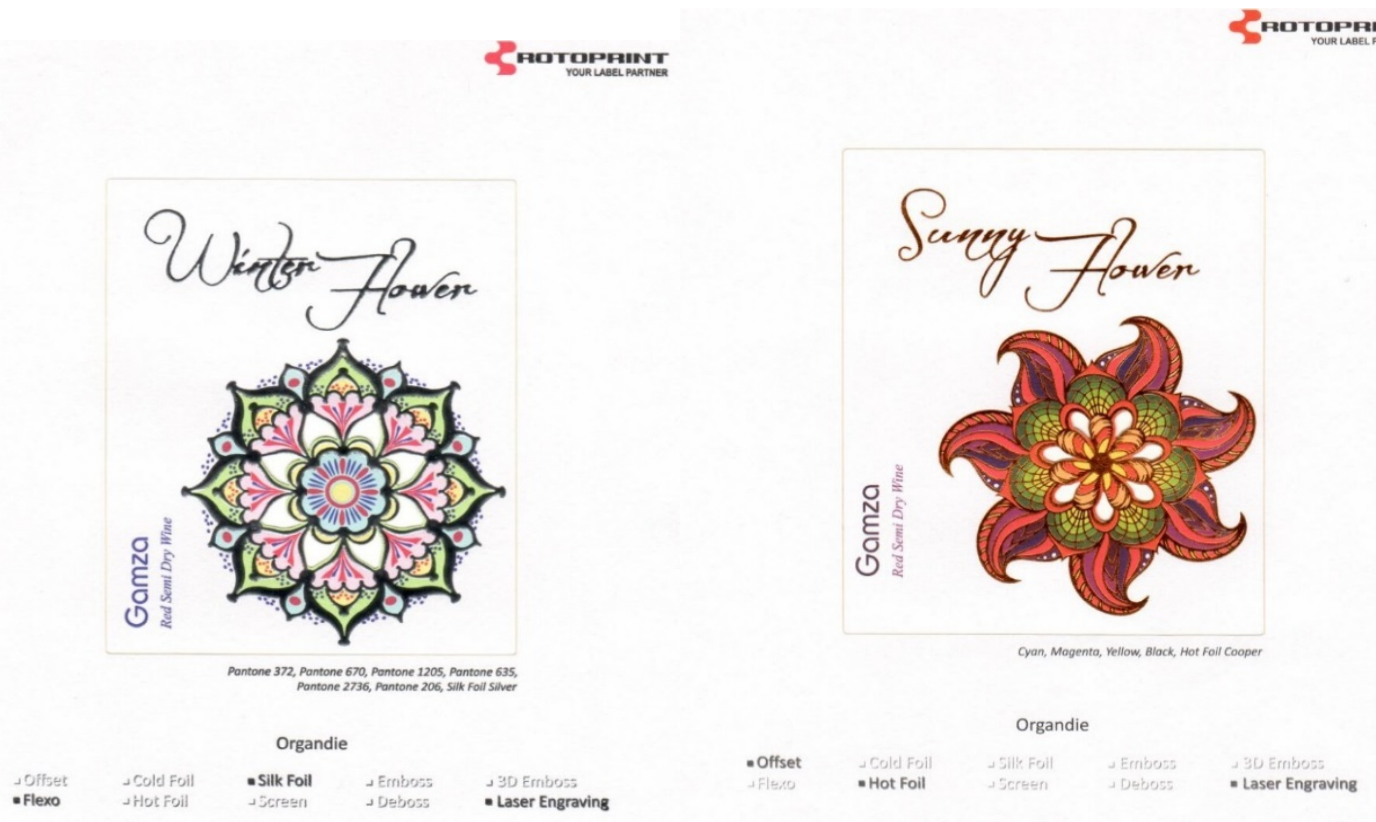

Figure 10: New designed labels on Organdie paper 
Velin Caviar paper differs significantly in colour from all the papers examined so far - it is coloured in suspension in deep black, which was established by microscopic analysis, and subsequently by engraving and laser perforation. The measured whiteness is as low as possible - ISO Brightness - 4.02\%.

This paper, like Blizzard, is attractive to designers because of its high smoothness and the velvety feeling of material when touched. It is characterized by the highest density of the investigated papers $-1000 \mathrm{~kg} / \mathrm{m}^{3}$, and has relatively good strength together with a good embossing. These properties are as a result of the balanced fibrous material composition of the paper, including cotton fibers and spruce wood fibers.

From the printed samples made it is clear that this paper is not suitable for full colour printing. Its absorbency is so high (just over $25 \mathrm{~g} / \mathrm{m}^{2}$ ) that even highly coating inks such as screen inks absorb into it. The only seal that is obtained is with highly pigmented gold and silver bronze, as well as screen varnish with glitter particles. All other processes such as Silk foil and Hot stamping and finishing are reproduced in high quality.

For this reason, the application of this paper is more limited and label designs could rely mainly on finishing processes. The produced designed wine labels on Velin Caviar paper, based on the research carried out are shown on Figure 11.

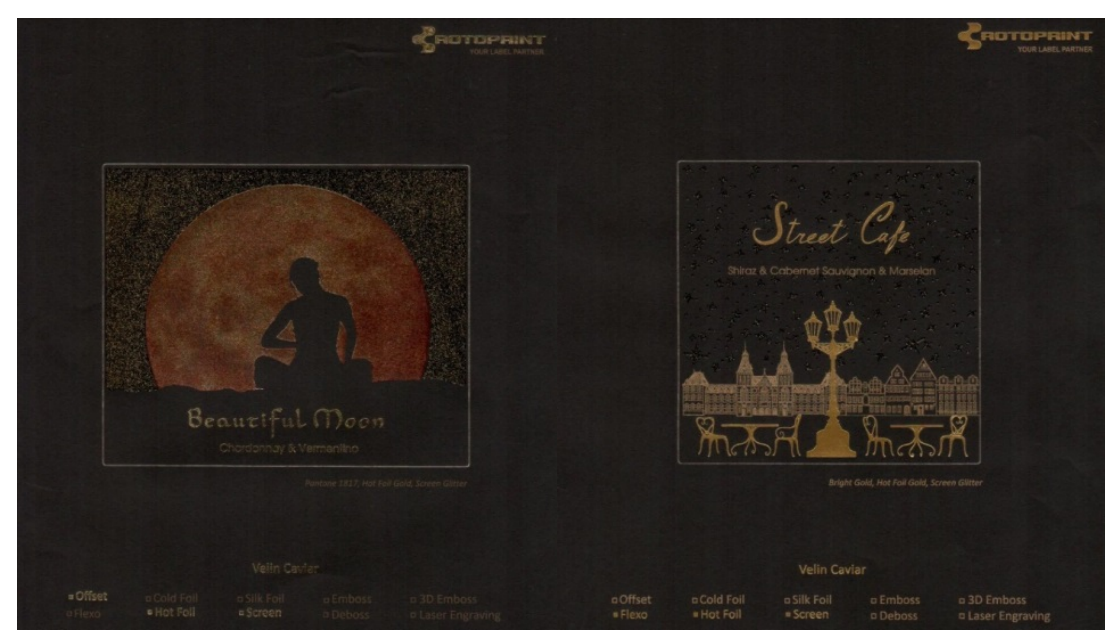

Figure 11: New designed labels on Velin Caviar paper

\section{CONCLUSION}

The conclusions of this scientific work could be summarized as follows:

- Paper from $100 \%$ natural cotton cellulose with high porosity and low strength properties could be used for the production of wine labels with clear designs through various printing techniques without finishing processes.

- Paper from 100\% natural bleached cellulose from softwood and hardwood species with high porosity and strength could be suitable for the production of wine labels through various printing techniques with variety of finishing processes.

- Paper with various fiber composition, including more than three wood materials, also cotton fibers with high density, low porosity and middle water absorption properties could be suitable for the production of wine labels through almost all printing and finishing processes.

- Paper with various fiber composition, including more than three wood materials, also cotton fibers with high density, low porosity and water absorption properties could be suitable for the production of wine labels with clean designs that involve mainly finishing rather than printing processes.

- Deeply dyed paper with various fiber composition, including more than three wood materials, also cotton fibers with very high density, low porosity and high water absorption capacity could be suitable for the production of wine labels that involve mainly finishing rather than printing processes.

- $\quad$ Papers with highly developed macrostructure of the surface (produced through marking felt) are characterized with a risk for dusting and lintting through the printing and finishing processes. 


\section{REFERENCES}

[1] EUR Lex: “Етикетиране на храните”, URL:

http://europa.eu/legislation_summaries/consumers/product_labelling_and_packaging/co0019_bg.h tm (last request: 2015-11-23).

[2] Franson, P.: "Labels Gone Wild", URL: https://www.winemag.com/2006/03/01/labels-gone-wild/ (last request: 2017-12-24).

[3] Holik, H.: "Handbook of Paper and Board", (Wiley-VCH, Weinheim, 2006.)

[4] Ivanova, N., Bencheva, S., Todorova, D.: "Handbook for exercises in chemistry, technology and properties of paper", (UCTM, Sofia, 2009.)

[5] Labels \& Labeling: "Printability testing of digitally printed labels", URL:

https://www.labelsandlabeling.com/news/latest/printability-testing-digitally-printed-labels (last request: 2010-07-07).

[6] Obis, E.: "Wine labels and consumer culture in the United States", InMedia:The French Journal of Media Studies, 2018. doi:https://doi.org/10.4000/inmedia.1029.

[7] Thorn, I., On Au, C.: „Applications of Wet-End Paper Chemistry”, (Springer, Berlin, 2009.)

[8] UPM Raflatac: "Paper Label Materials", URL: https://www.upmraflatac.com/products-andservices/label-products/paper-labels/ (last request: 2020-09-22).

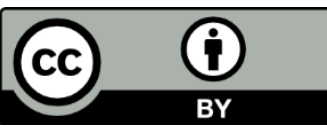

(C) 2020 Authors. Published by the University of Novi Sad, Faculty of Technical Sciences, Department of Graphic Engineering and Design. This article is an open access article distributed under the terms and conditions of the Creative Commons Attribution license 3.0 Serbia (http://creativecommons.org/licenses/by/3.0/rs/). 


\title{
MATHEMATICAL MODELLING OF OPTICAL DENSITY ON THE EXAMPLE OF PRODUCING RASTERIZED FILMS
}

\author{
Bohdan Durnyak ${ }^{1}$, Mikola Lutskiv ${ }^{1}$, Vitalij Buben ${ }^{1}$, Petro Shepita ${ }^{1}$, Georgij Petriaszwili ${ }^{2}$ (D), \\ Zuzanna Żołek-Tryznowska ${ }^{2}$ ii \\ ${ }^{1}$ Ukrainian Academy of Printing, Lviv, Ukraine \\ ${ }^{2}$ Warsaw University of Technology, Institute of Mechanics and Printing, Warsaw, Poland
}

\begin{abstract}
A mathematical model of optical density of rasterized films has been improved, which has significantly increased the calculation accuracy of the optical density, especially at low intensities of the light areas of the image of 0-5\%. The results of the simulation have been presented in the form of graphs of the optical densities characteristics for various parameters and their properties have been analysed.
\end{abstract}

Key words: optical density, rasterized film, simulation model, mathematical modelling.

\section{PREFACE}

Modern production of printing forms is characterized by a high degree of digitization. However, there are examples of using photographic films to perform various tasks. The quality of printing products is determined by the factors that lead to the information changes in reproduction. The factors are associated with the reproduction technological conditions and the nature of the elements that make the information, the manufacture of rasterized printing plates and the printing process in the presence of various effects. Therefore, to improve the quality of the finished products at each stage of the technological chain of the manufacturing process of printed matter, it is necessary to monitor and evaluate certain parameters. Each technological stage is performed on a specific equipment, the less we have the control checks of the parameters, the harder it is to detect various influences, distortions, the waste origin, and it is difficult to optimize certain processes (Baranovskyj et al, 2013; Blanter, 1999; Predko, 2009). One of the most important and complicated process is the process of making films and preparing for direct recording on a plate, changing the size of raster elements in the process of reproduction, increasing (dot gain) of the raster elements area of the image when manufacturing the plates (copying), on the imprint at the contact area of the plate or offset canvas with the paper. The dot gain of the ink layer during the printing process is significant and could be 10-20\% (Nazar et al, 2011; O'Kvin, 2001; Pashulja, 2011; Predko, 2009).

The complexity of the problem is that far not all operations of printing plate manufacturing are controlled. For example, it is now possible only to have a visual supervision of the development of printing plates during their manufacturing. Printing plates are controlled at the end of the process. Instrumentally, the quality of the films is estimated predominantly by a densitometer in the transmitted light at the stage of its withdrawal from the development unit (Nazar et al, 2011; Pashulja, 2011; Predko, 2009). In simple densitometers, there is the problem of the accuracy of determining the optical density of the films in percent, especially in light and dark shades. There is a problem of determining and quantifying the quality of films at the stage of preparation for lighting and recording. Therefore, modelling, calculating and evaluating the quality of raster plates is an urgent task when preparing images for printing.

\section{BACKGRAUNDS}

Modern densitometers are devices for measuring the intensity of reflected or transmitted light, on the basis of which one can determine the optical density, relative area of the printing elements, their geometric dimensions, the optical density of the film or plate in percent, etc. (Blanter, 1999; Pashulja, 2011). Manufacturers of densitometers (the Netherlands, Germany, etc.) for some reason do not provide the algorithms for calculating individual parameters based on the measured intensity of the reflected or transmitted light. Therefore, one should highlight the specific problem of the method for determining the optical density of the film in percent in the transmitted light by separate densitometers, especially in light and dark shades, the measurement error may be tangible (Nazar et al, 2011; Pashulja, 2011; Predko, 2009). 
In the process of manufacturing films and the printing plates, the received imprints, one is constantly dealing with the concept of optical density and other related concepts, whose indicators are defined in Ukrainian standard DSTU 4334-2004, as well as in other sources (Pashulja, 2011). The non-transparent (transparent) areas of the photo films (negative, slide) are estimated by their optical densities measured in the transmitted light. The shade parameters on a raster photo-plate are determined by the relative area of the raster elements in percent of the photo films area, occupied by raster elements on the basis of the measured integral optical density of the image and they are converted into the value of the relative area by the Murray-David formula (Pashulja, 2011). The minimum and maximum optical densities of the photo films are intended for the production of offset plates in accordance with DSTU ISO12647-2 $D_{\min } \leq$ $0,15, a D_{\max } \geq 3,5$. The optical density of transmittance of the raster element should not exceed 0.1 of the density of the photo film background and should not be greater than 0.15 (Nazar et al, 2011; Pashulja, 2011; Predko, 2009).

In most cases, in the printing industry they use digital images that are processed by computer graphics packages, and their quality is evaluated visually, and therefore objectively. The transformation of digital images into a raster photo film and the manufacture of a printing plate is carried out using CtP technology (Kuznetzov, 2002; Lutskiv, 2012; Predko, 2009). The existing methods of digital image processing operate the levels (gradation) of grey that are within [0.255] and operate with arrays of numbers (Gonsales, 2012). Instead, the printing image is much more complex, it has a raster structure, the information carrier is the area of raster elements that have a given shape and linearity (Baranovskyj et al, 2013; Havrysh et al, 2016; Kuznetzov, 2002; O'Kvin, 2001). Therefore, the existing diverse methods for processing digital images (Gonsales, 2012) cannot be directly applied for the analysis and evaluation of raster plates. In the available sources, the light transmittance is determined by the logarithmic expression of the inverse value of the transmittance coefficient for calculating the optical density, instead, based on the measured integral optical density, the images are converted into the values of the relative area according to the Murray-Davis formula which help evaluate the quality of the plates (Kuznetzov, 2002; Pashulja, 2011). However, these formulas are rarely used to calculate, design and analyse the graphic characteristics of raster plates.

The purpose of the work is to improve the existing formulas to determine the gradation characteristics of raster plates, to develop a simulator to calculate and analyse their properties at different effects.

\section{MATEMATICAL MODELLING AND RESEARCHES}

Initially, the term "densitometry" had been used for the notion "measurement of the blackening degree"; it was lately significantly expanded due to various studies of objects and the use of this measuring technique. The degree of blackening is being measured on negatives and positives, black and white, transparent and opaque originals, and on photographic materials and coloured imprints. Objects of measurement can be multi-coloured or raster. Modern densitometers are devices for measuring the intensity of reflected or transmitted light, on the basis of which the optical density, the relative area of printed elements, linear raster and other parameters are determined (Pashulja, 2011). However, not all printers and technologists have enough knowledge concerning the producing qualities of densitometers' analyses, evaluating and controlling the quality of individual technological steps of preprinting and printing processes.

Let one briefly consider the work of the reflecting densitometer, which serves to measure the reflected light, which is most often used by printers to measure on the printed imprints when adjusting the colour apparatus and controlling the imprints quality (Blanter, 1999; Pashulja, 2011). The measurement is based on the difference between incident light on the measuring surface and the amount of reflected light, which depends on the ink layer thickness. Mathematically, we are dealing with the ratio of the incident light and reflected light. Here is a simple example. The amount of incident light on the measured object is taken as 1 . Only the 10th part was reflected, and the rest was absorbed. The next calculation is $1 / 0.10=$ 10. The absorption rate is 10 . However, the densitometer does not indicate the degree of absorption, but only the part of the colour, which is determined and calculated by the decimal logarithm of the absorption rate. The basis of the application of the logarithm is the Weber-Fechner psychophysical law, which states that the visual sense of a person chooses the tone's impression in a logarithmic form (Baranovskyj et al, 2013; Blanter, 1999; Pashulja, 2011). The logarithm calculator is simple and understandable. In number 1 , it is equal to 0 , at $10=1$, at $100=2$, at $1000=3$, and so on.

Non-transparent (transparent) areas of photo-films (negatives, slides) are being evaluated for their optical densities in transmitted light using densitometers. The optical transmittance density in the 
incident light of a photo film is usually determined by the expression (Blanter, 1999; Kuznetzov, 2002; Pashulja, 2011):

$D_{0}=\lg \frac{1}{T}$, or $D_{0}=\lg \frac{F_{0}}{F}$.

where $F_{0}$ - is the flux (intensity) of incident light on the object of measurement, $F$ - is the light flux transmitted to the object of measurement.

T-factor - is the ratio of global fluxes that is transmitted through the measuring sample to the light streams given as a sample. As it has been already mentioned, in simple densitometers, there is the problem of the accuracy of determining the optical density of the photomicrograph at light and dark areas. From the expression (1), it is clear that at low values of light flux $F$ the optical density will increase significantly. For the convenience of calculations, the intensity of light fluxes in percent $\left(F_{0}=100 \%\right)$ is used. To increase the accuracy of calculations, the initial value of $F$ flux is increased by $1 \%$. With such assumptions, the expression (1) for calculating the optical density will look as:

$D_{0}=\lg \left(\frac{100}{F \%}+1\right)$

On the basis of expressions (1) and (2), the optical density of the photo-film in incident light for the small values of intensity has been calculated (Figure 1).

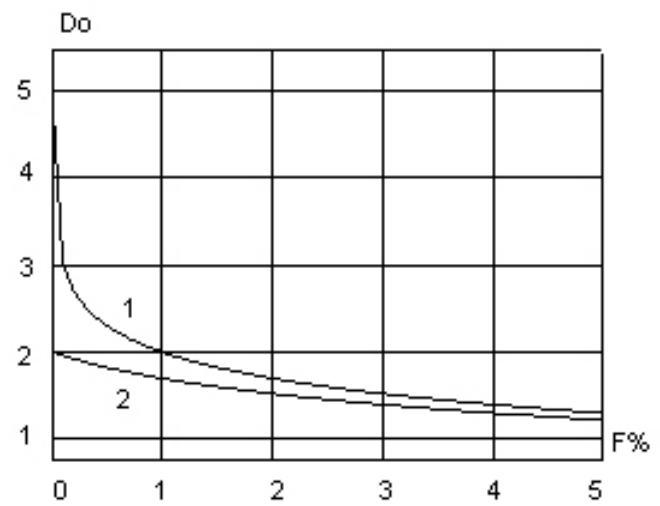

Figure 1: The optical density of the photo-film at the small values of the light intensity 1 - is calculated by the formula (1), 2 - by the expression (2)

The calculated initial value of optical density (1) is more than 30 , which is rounded to 5 for convenience of comparison. At the flux intensity $F=0,5 \%$, the absolute error of optical density is 0,481 , and at $F=1 \%$, the error is 0,21 units. Consequently, the initial flux of the displacement of the intensity of the flux increases the accuracy of the calculation of the optical density at small fluxes. Similarly to expression (2), we present here the formula for the negative:

$D_{0}=\lg \left(\frac{100}{100+F \%}+1\right)$

As an example, the calculated characteristics of the optical density for positive and negative are presented in Figure 2. 


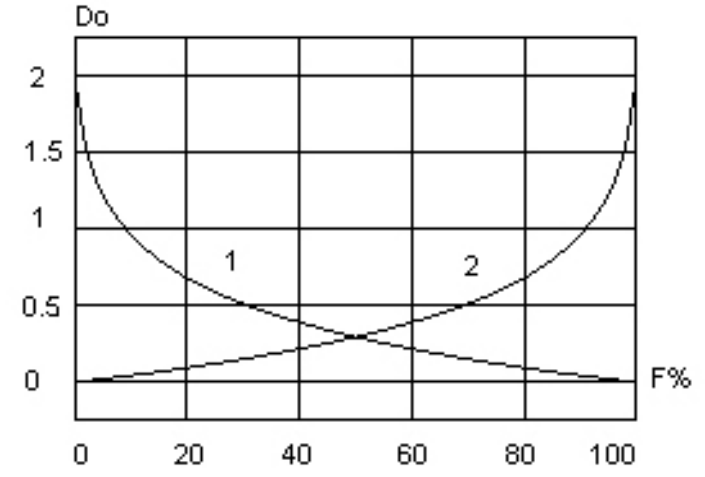

Figure 2: The optical density of the photo-film 1 - positive, 2 - negative

Characteristics of the optical densities of the films for positive and negative are symmetrical, and this confirms the validity of the suggested expressions for the calculation of the optical density. The influence of the change in the intensity of the light flux on the optical density has been studied. The film optical density depends on its properties, for example, the photo-film background and other influences. The effect of decreasing the light flux intensity on the optical density has been researched. The results of calculations are presented in the form of a complex of characteristics of the optical density of the gradual decrease in the flux intensity F0 by 0.9; 0.8; 0.7; 0.6; (Figure 3).

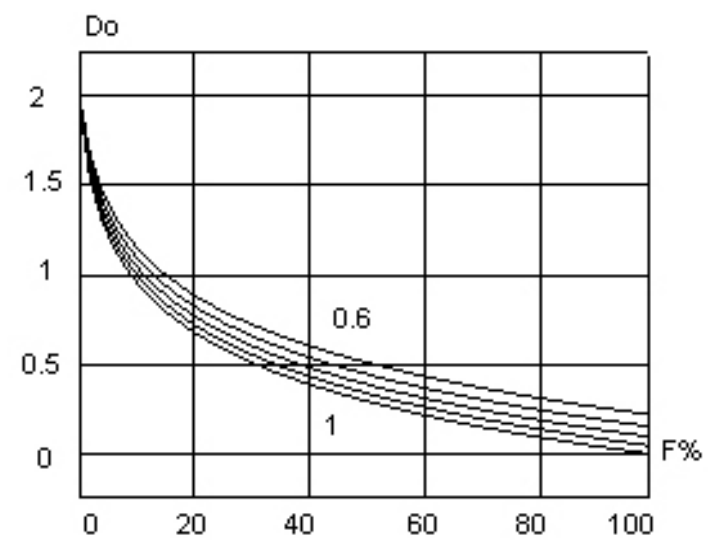

Figure 3: A set of characteristics of photo-plates optical densities at decrease of a light flux intensity

The initial value of the plate optical density does not depend on the intensity of the light flux and is $D_{0}=2$. Nominal intensity of the light flux is F0 $=100 \%$, the characteristic of the optical density is located below, gradually decreases and in the end goes to zero. With a decrease in the light flux intensity, the characteristics are shifted upwards, and the optical density variation from zero is $0.045 ; 0.0968 ; 0.153$; and 0.219 with a tolerance of 0.15 . Consequently, the calculation of the optical density of the photo-film in expression (3) is not very sensitive to the change in the intensity of the light flux, which is its advantage. The analysis of the optical density properties of the plate has been carried out under the condition that the plate substance is homogeneous on the whole surface, and transmittance coefficient changes linearly within $[0 \leq \mathrm{F} \leq$ of $100 \%]$. However, during the stage of image screening the correction is made, due to this the transmittance coefficient, in most cases, is nonlinear. Therefore, the researches of the film optical density at a nonlinear transmittance coefficient are of considerable practical interest. A block diagram has been worked out with the simulator in the package of Simulink, that on the basis of the expression (2) calculates and defines the characteristics of the plate optical density for nonlinear transmittance coefficient (Figure 4): 


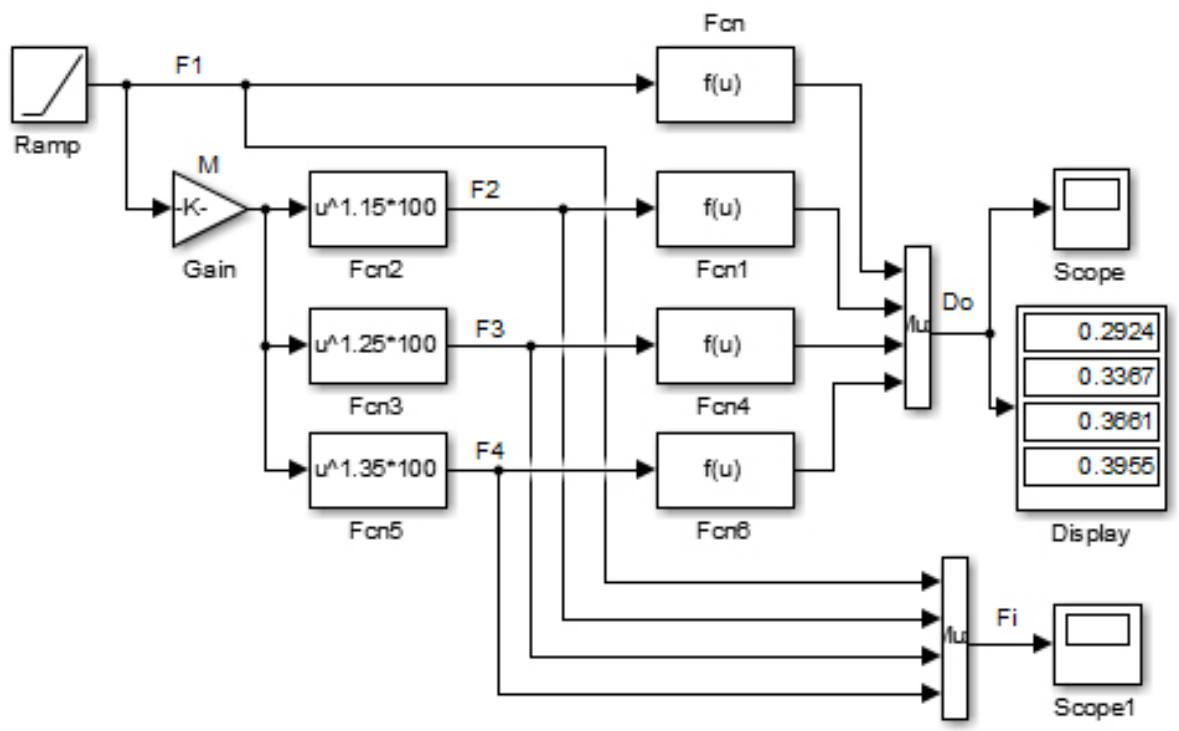

Figure 4: A block diagram of the simulator to define characteristics of the plate optical density for nonlinear transmittance coefficient

The Ramp block generates the linearly increasing Fo light flux, that is scaled by the Gain block. In the first row of math functions blocks Fcn, there are programs that form rated nonlinear coefficients of reduction by the expression $T=U^{v}$, which, after de normalizing, turn into nonlinear light fluxes of $F_{2}, F_{3}, F_{4}$, that are visualized by the Scope 1 block and simultaneously supplied to the output of the second row of math functions blocks Fcn, that calculate films optical density for nonlinear transmittance coefficients, visualized by the Scope block. More sufficient data of separate blocks parameters are shown in Figure4. The results of simulation of nonlinear light fluxes are shown in Figure 5:

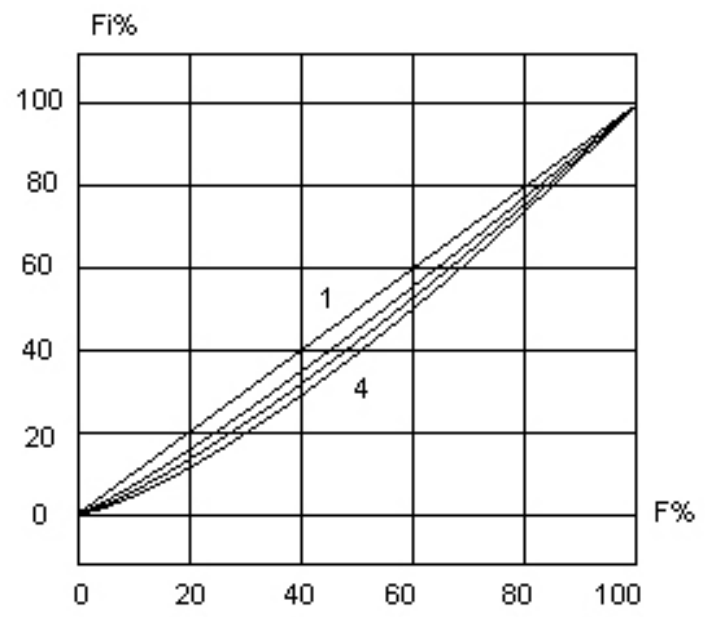

Figure 5: Parameters of nonlinear light fluxes

Upper parameter is linear. Nonlinear parameters of fluxes are placed lower in the form of the curved graphics. Maximal parameters deviations from the linear is on the middle fluxes and constitute 5.2; 8,2; $11,0 \%$, that is quite small in general. Physically non-linearity of the transmittance coefficients causes the distortion of raster elements sizes (expending) during the process of reproduction of the photo-film contamination production, as well as copying from a photo-film or direct record on the film. The results of simulation of nonlinear transmittance coefficient influence on the film optical density are shown in Figure 6 in the form of the set of parameters: 


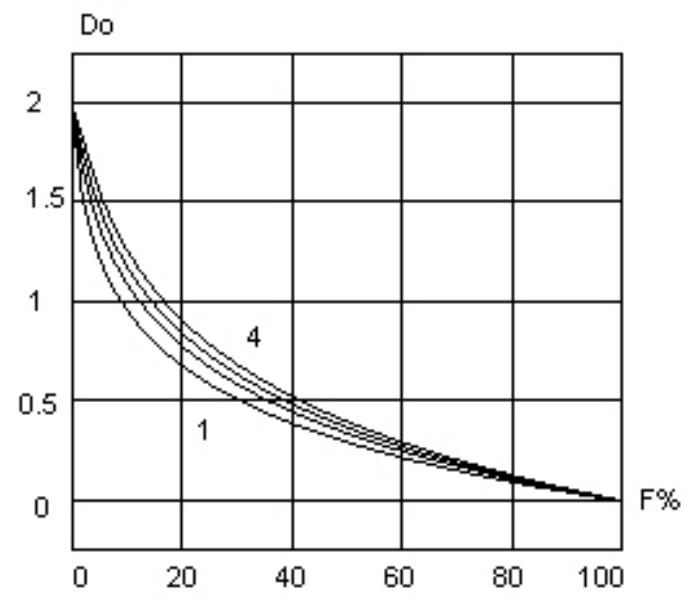

Figure 6: A set of parameters of the plate optical densities for nonlinear transmittance coefficients

Slight deviation of light fluxes from linearity $(5,2 ; 8,20 ; 11,0 \%)$ considerably shifts the parameters of the film optical densities to the right. It is offered to assess the influence of non-linearity of transmittance coefficient on the optical density by the maximal deviation in the parameter from the first one $\left(E=D_{i}-D_{0}\right)$. The results of simulation of the deviation of the film optical density from the nominal one for different light fluxes are shown in Figure 7:

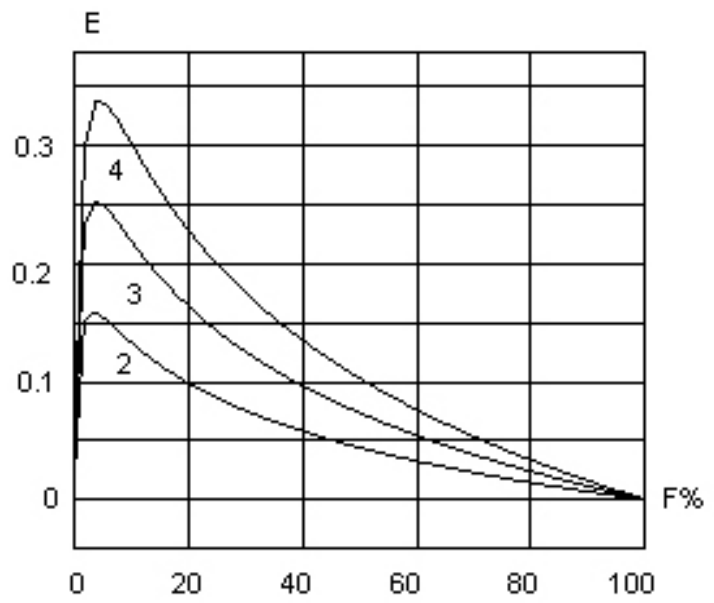

Figure 7: Deviation of the photo-film optical density from the nominal one for light fluxes variation

Slight deviation of light fluxes from the linearity $(5,2 ; 8,20 ; 11,0 \%)$ causes large deviations of the optical density on small fluxes ( $F=5-100 \%$ ). Their maximal values are 0,$34 ; 0,25$ and 0,16 units at tolerance of not more than 0,15 units. Thus, the film optical density is most sensible to expanding on light tones. The increase of plate optical density at non-linearity of transmittance coefficient must be taken into account as distortions of raster elements during the process of reproduction, the so-called expanding, i.e. an increase of area (sizes) during the production of rasterized films, as well as copying from a photo-film or direct record on a plate in the CtP systems, though it is often ignored. To control the expansion of a photo-film, it is possible to use a densitometer by measuring the density of the controlled scale instead of the area.

\section{CONCLUSIONS}

A mathematical model of optical density of rasterized films has been improved, which has significantly increased the calculation accuracy of the optical density, especially at low intensities of the light flux of 0$5 \%$. The results of the simulation have been presented in the form of graphs of the optical densities characteristics for various parameters and their properties have been analysed. 
The block diagram of the simulator Simulink in the Matlab package has been worked out, which provides an opportunity to calculate and design a family of the optical densities characteristics for various parameters, analyses, and practical application. The results of the simulation of the linear reduction influence of the light flux intensity in the form of a set of the optical densities characteristics of a photofilm have been presented and it has been found out that even double reduction of a flux has little effect on the optical density, the finite deviation of the optical density is 0,219 at tolerance of 0,15 units. Thus, plate optical density is quite insensitive to the linear changes of the flux intensity.

The influence of the nonlinearity of the transmittance coefficient has been studied, caused by distortions of the geometric dimensions of raster elements (expanding) in the reproduction process of the plate contamination production, as well as copying from a photo-film or direct record on a plate. It has been found out that slight deviation of the transmittance coefficient, with its maximal values of 5,$2 ; 8,2 ; 11,0 \%$, causes significant deviation of the optical density on small fluxes ( $F=5-10 \%$ ), their maximum values are $0.34,0.25$ and 0.16 units at tolerance of not more than 0.15 units, so the expanding (the increase of the area of the raster elements) must be taken into account while raster plate production, which is often ignored. To control the expansion of a photo-film, it is possible to use a densitometer by measuring the density of the controlled scale instead of the area. The obtained results of the research can be used for preparing images for screening, as well as for photo-films production and control.

\section{REFERENCES}

[1] Baranovskyj V., Lutskiv M., Fil L., Chernozubova G.: "Construction and analysis of screening characteristics", Journal Naukovi zapysky UAP 4, 131-138, 2013.

[2] Blanter D.: "Scanning and screening images", (ECOM, Moscow, 1999.)

[3] Gonsales R., Vuds R.: "Digital image processing", (Tekhnosfera, Moscow, 2012.)

[4] Havrysh B., Durniak B., Tymchenko O., Yushchyk O.: "Vidtvorennia zobrazhen rastrovymy skanuiuchymy prystroiamy", (UAD, Lviv, 2016.)

[5] Kuznetzov J.: "Technology for image information processing", (Petersburg Institute of Printing, St. Petersburg, 2002.)

[6] Lutskiv M., Buben V.: "Construction of the characteristics of demodulation linear tint chart", Journal Computer printing technology 2 (40), 109-115, 2018.

[7] Lutskiv M.: "Digital printing technology", (Ukrainian Academy of Printing, Lviv, 2012.)

[8] Nazar I., Lazarenko E., Jakutsevych S.: "Offset printing options: management and influence factors", (UAP, Lviv, 2011.)

[9] O’Kvin D.: "Dopechatnaja podgotovka. Rukovodstvo dizajnera", (Vil'jams, Moscow, 2001.)

[10] Pashulja P.: "Standardization, metrology, compliance, printing quality", (UAP, Lviv, 2011.)

[11] Predko L.: "Prepress Process Design: tutorial", (UAP, Lviv, 2009.)

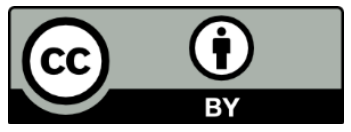

(C) 2020 Authors. Published by the University of Novi Sad, Faculty of Technical Sciences, Department of Graphic Engineering and Design. This article is an open access article distributed under the terms and conditions of the Creative Commons Attribution license 3.0 Serbia (http://creativecommons.org/licenses/by/3.0/rs/). 



\title{
THE INFLUENCE OF PCL-ZNO COATING COMPOSITION ON COATED OFFSET CARDBOARD PRINTS
}

\author{
Tomislav Cigula (D), Tomislav Hudika (D), Mihael Katana, \\ Marina Golik Krizmanić, Tamara Tomašegović (D) \\ University of Zagreb, Faculty of Graphic Arts, Zagreb, Croatia
}

\begin{abstract}
The most significant printing branch in these days is packaging printing. Packaging must primarily preserve the product from damaging, but at the same time must attract the consumers to be picked up from the shelf in the store. To ensure protective and aesthetic role of the packaging the prints are commonly coated with varnishes which will improve visual, mechanical, surface, and optical properties. In this paper a coating composed of polycaprolactone (PCL) and nanoscale $\mathrm{ZnO}$ was used to coat the offset prints on the cardboard.

The coatings were prepared by adding various weight amounts of the $\mathrm{ZnO}$ nanoparticles (weight ratios of $0.1,0.5$ and $1 \%$ ) into the mixture of PCL and ethyl-acetate. The coatings were applied onto prepared offset prints. The prints were evaluated before and after coating process by determining colour coordinates, print gloss, water vapour permeability and by calculating colour difference.

The results showed that on the uncoated paper coating with prepared OVPS did not affect the colour reproduction outside acceptable tolerance levels, except for magenta coated with $w(\mathrm{ZnO})=0.5$ and $1 \%$. The coating with prepared coatings caused almost none change of print gloss on uncoated paper, but increased the print gloss on coated paper. The water-vapor permeability was lowered on both investigated paper types but on the uncoated paper the addition of $\mathrm{ZnO}$ nanoparticles decreased barrier properties in comparison to the coating composed of only PCL. Increasing the mass of added ZnO increases barrier properties of the print on both investigated cardboards.

To conclude, this research has proved applicability of the PCL-ZnO coatings as a OVP on cardboard offset prints as it did not highly influenced colour reproduction but had decreased water vapour transmission rate. On the coated paper/cardboard one must take into account the increased colour difference of magenta and chose the ink to be closer to the target values at the beginning. In addition, to further investigate applicability in the packaging printing, further research should include investigation of resistance to ink fading in the ageing process, bending tests, adhesion etc.
\end{abstract}

Keywords: Offset printing, coating, PCL, surface free energy, colour difference, nano ZnO

\section{INTRODUCTION}

Despite the negative forecasts that entire printing industry will be declining in growth or even reduce its turnover on annual level, packaging is one of many printing branches that are growing continuously (Smithers, 2017). The main idea of packing is to preserve the product from any form of damage while maintaining the aesthetics as well to be as user friendly as possible (Kipphan, 2001). To ensure that, it is common that printed packaging is varnished with some sort of overprint varnish (OVP). Those varnishes ensure that packaging will have better mechanical, surface, optical properties and to improve the visual component like glossy effect. On the other hand, the OVP could influence the colour of the print. Another downside with existing OVPs is the lack of eco-friendly properties (Van Der Walle et al, 1999). In order to improve the "green" component of the packaging, OVPs have to be replaced (Kovačević et al, 2019; Makower, 2015; Kiphan, 2001). Biodegradable materials such as biopolymers could be used as the base for coating materials (Lavoine et al, 2016). In order to further improve functionality of the biopolymer coating, nanoparticles in designated weight ratios could be added to form a nanocomposite overprint varnish (Rastogi and Samyn, 2015). Nanoparticles have the possibility to improve wettability, strength, print gloss or resistance to UVA/UVB radiation - colour fading (Bota, 2017). Problem with commonly used OVPs is their lack of antibacterial properties specially when dealing with food items (Lavoine et al, 2016). For this paper, PCL will be used as OVP's base while nanoparticle $\mathrm{ZnO}$ will be used to improve its properties. ZnO was chosen because it is known for its antibacterial properties when dealing with human skin or in contact with food (Rastogi and Samyn, 2015). In addition, research of ZnO in nanoscale was conducted to determine its hydrophobics and resistance to UV (Ghule et al, 2006; Bota et al, 2018). In 
this paper, investigation of the optical and physical properties was conducted to evaluate applicability of the proposed coatings as an OVP.

\section{MATERIALS AND METHODS}

To investigate the influence of the $\mathrm{ZnO}$ weight ratio in the nanocomposite on the printed samples, uncoated Tauro offset paper $300 \mathrm{~g} / \mathrm{m}^{2}$ (further denominated as uncoated paper) and UMP Finesse Gloss paper (further denominated as coated paper) were chosen as the common packing substrates. The CMYK printing was conducted on sheetfed printing press KBA Rapida 105 PRO. The ink used to print the samples were quickset process commercial inks (Novavit Supreme Bio, Flintgroup) The printing process was conducted in compliance with the ISO 12647-2:2013, i.e. Fogra PSO (Sharma et al, 2005). This was done in order to ensure the ink's colorimetrical accuracy and possibility to compared measured results prior and after coating with the actual standard. The printed sample's colour properties were determined by Techkon SpectroDens spectrophotometer (Techkon, 2020).

Print gloss was determined before and after coating by means of Elcometer 407, a statistical gloss meter according to TAPPI/ANSI T 480 om-15 at 60 (Elcometer, 2010). The intensity of light depends on the measured sample and the angle of illumination. Measured angle mimics the angle of human eye and the viewed sample. The remaining part of the light penetrates into sample and is absorbed or diffused (Van Der Walle et al, 1999). At the angle of $60^{\circ}$ the surface gloss can be separated into low (<10 GU), middle (10-70 GU) and high (>70 GU) (Hunter, 2008).

The biopolymer used was the PCL (polycaprolactone) as the base of the proposed OVP. The PCL is a biodegradable polymer with a low melting point of $60^{\circ}$ Celsius. It has high level of applications and compatibility with other materials such as nanoparticles (Uglešić, 2015). The PCL (6800 Capa) was dissolved in ethyl acetate on heated magnetic stirrer in an air-tight container for approx. 120 minutes.

$\mathrm{ZnO}$ (Alfa Aesar) in the form of nanoparticle was added and homogenized into mixture with ultrasound dispenser Hirrlscher UP100H for 10 minutes at 100 amplitude and 100\% power. The weight ratios of the $\mathrm{ZnO}$ nanoparticles were $0.1 \%, 0.5 \%$ and $1 \%$. Nanocomposite OVPs were applied to printed samples using K202 Control Coater in controlled conditions defined by the ISO 187:1990 while the wet OVP's thickness was around $24 \mu \mathrm{m}$, as defined by the coating bar standard for the bar 3 (Wu and Baghdachi, 2015).

After coating, the prints were characterized as before coating process. From the acquired $L^{*} a * b^{*}$ coordinates colour difference was calculated for $\Delta \mathrm{E}_{00}$ and $\Delta \mathrm{E}_{\mathrm{ab}}$ (Sharma et al, 2015). Print gloss was also measured and compared as well.

Water-vapor permeability was determined using gravimetric cup method (water method). In this type of test the samples act as a water-vapor barrier where water is inside of the glass and this represents $100 \%$ humidity on the test start (American Society for Testing and Materials, 2016). In this research, amount of the water was $100 \mathrm{ml}$ while samples are at the distance of approx. $10 \mathrm{~mm}$ from the water surface. Samples were weighted at $0 \mathrm{~h}, 24 \mathrm{~h}$ and $48 \mathrm{~h}$. This way, the given results represents the weight change of the lost water in a given time interval. The water vapor transmission rate (WVTR) was calculated using equation (1). The results are presented in $g /$ day $^{*} \mathrm{~m}^{2}$ :

WVTR $=m_{0}-\frac{m_{2}+m_{g}}{2}$

where mo represents the sample mass at the beginning, $\mathrm{m}_{2}$ and $\mathrm{m}_{3}$ are sample mass after 24 and $48 \mathrm{~h}$, respectively. Only one ink was measured due to the fact that all OVPs should act as an impregnation overtop layer regardless of the ink bellow (Bota et al, 2018).

\section{RESULTS}

With measured $L^{*} a^{*} b^{*}$ values it was possible to detect the colour change and dependence of the colour to the increasement of the nanoparticle weight ration. Furthermore, by calculating colour difference $\Delta E_{00}$ and $\Delta \mathrm{E}_{\mathrm{ab}}$ (Mokrzycki and Tatol, 2011) which were used to determine colour difference between samples and compliance of the coated prints to the Fogra PSO $\left(\Delta \mathrm{E}_{\mathrm{ab}}<5\right)$ (Sharma et al, 2005) .

In Figure 1. one can see $\Delta E_{a b}$ diagram for prints on the uncoated paper. The colour difference was calculated between predefined colour coordinates (Fogra PSO) and average colour coordinates measured on samples. On the $\mathrm{x}$ axe samples are denominated to the weight ratio of the $\mathrm{ZnO}$ in a coating, while Printed sample means print without the OVP. 
It can be noticed that $\Delta \mathrm{E}_{\mathrm{ab}}$ on uncoated paper type remained under 5 for all samples after varnishing. The values of $\Delta \mathrm{E}_{\mathrm{ab}}$ on printed samples after initial varnishing (PCL $0 \%$ ) for cyan, yellow and black decreased while magenta experienced increase, with the exception of the sample coated with PCL-1\% ZnO. Generally, colour coordinates of magenta experiences smallest change while black experiences largest. It can be also noted that the increase of nanoparticles concentration did not influenced the colour significantly. As the uncoated paper is rough and absorptive it absorbs prepared coating reducing its influence on the optical properties of the print.

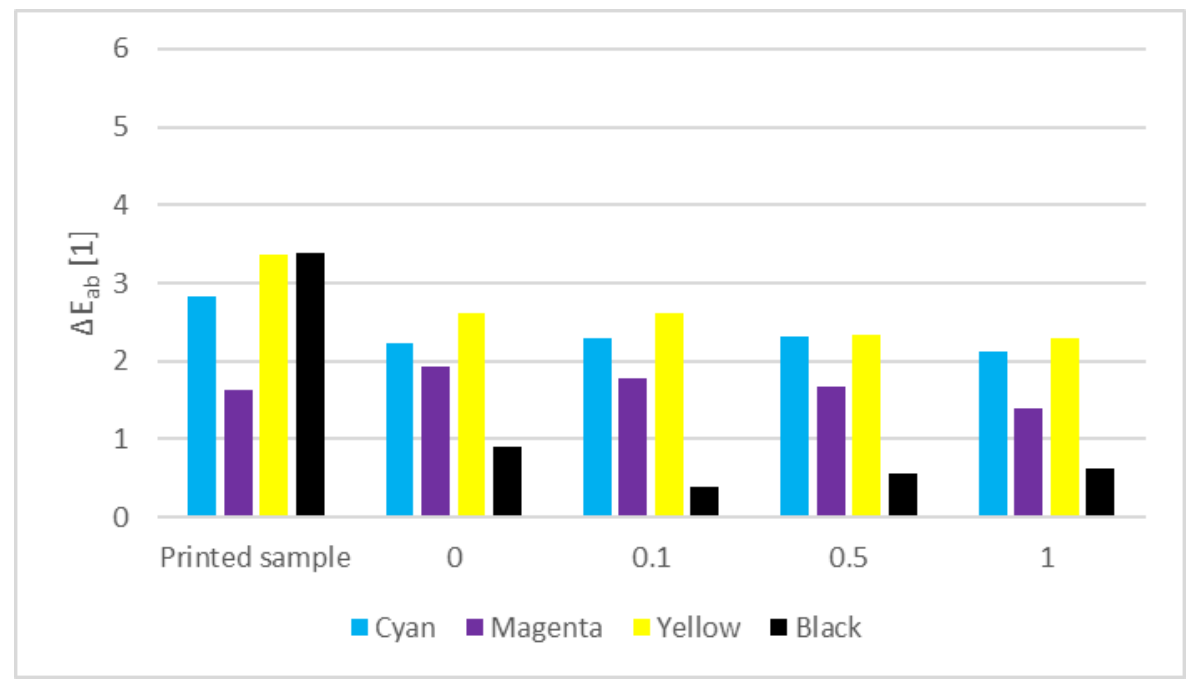

Figure 1: Colour difference $\Delta E_{a b}$ to the Fogra PSO predefined values on the uncoated paper

The difference between samples was determined by calculating $\Delta \mathrm{E}_{00}$, a formula developed to be more in compliance to human visual experience of colour difference. The calculations are made between printed sample (without OVP) and coated samples. As it can be seen in Figure 2, the added nanoparticles do affect the colour reproduction but in very small scale. The results of the difference $\Delta \mathrm{E}_{00}$ show that adding $\mathrm{ZnO}$ nanoparticles decrease the colour difference in comparison to the printed sample coated only by $\mathrm{PCL}$ coating. The only colour which is highly influenced by coating process is black with differences over 2, while differences by all other colours are under 1. Previous research (Golik Krizmanić, 2020) showed that PCL itself causes darkening of the print and therefore achromatic, black, colour is more influenced by this fact. Furthermore, as previously mentioned, uncoated paper is absorptive and less coating stays on the top of the printed sample.

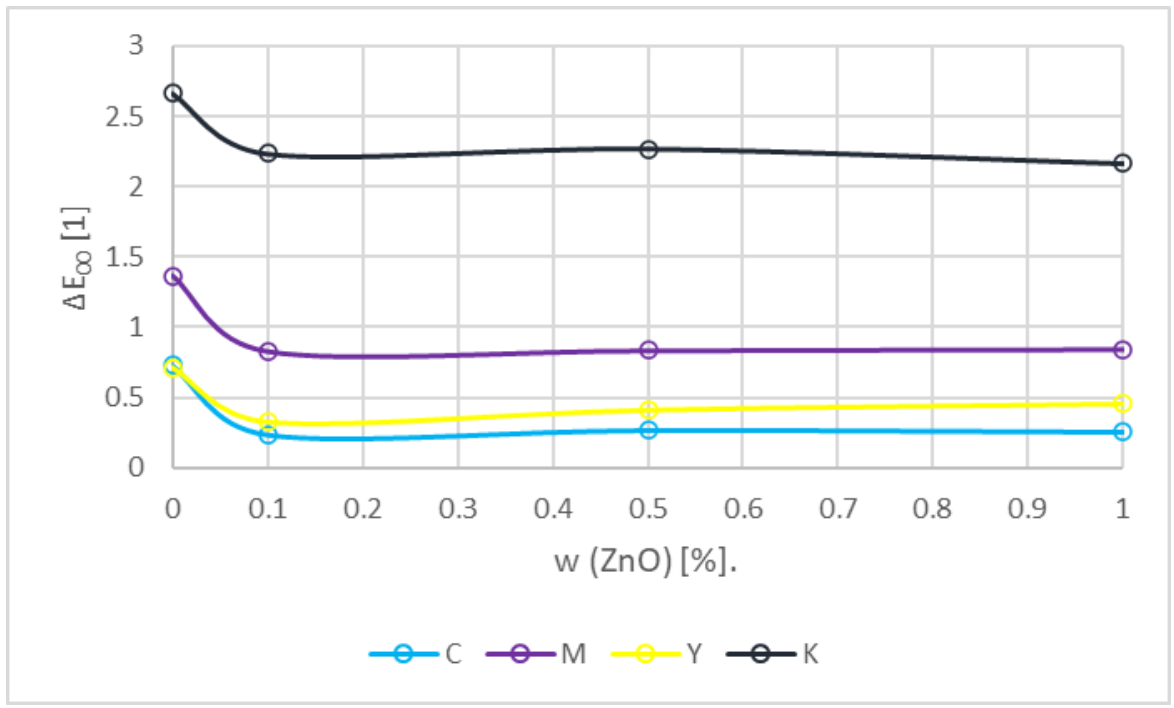

Figure 2: Colour difference $\Delta E_{00}$ to the print without coating on the uncoated paper 


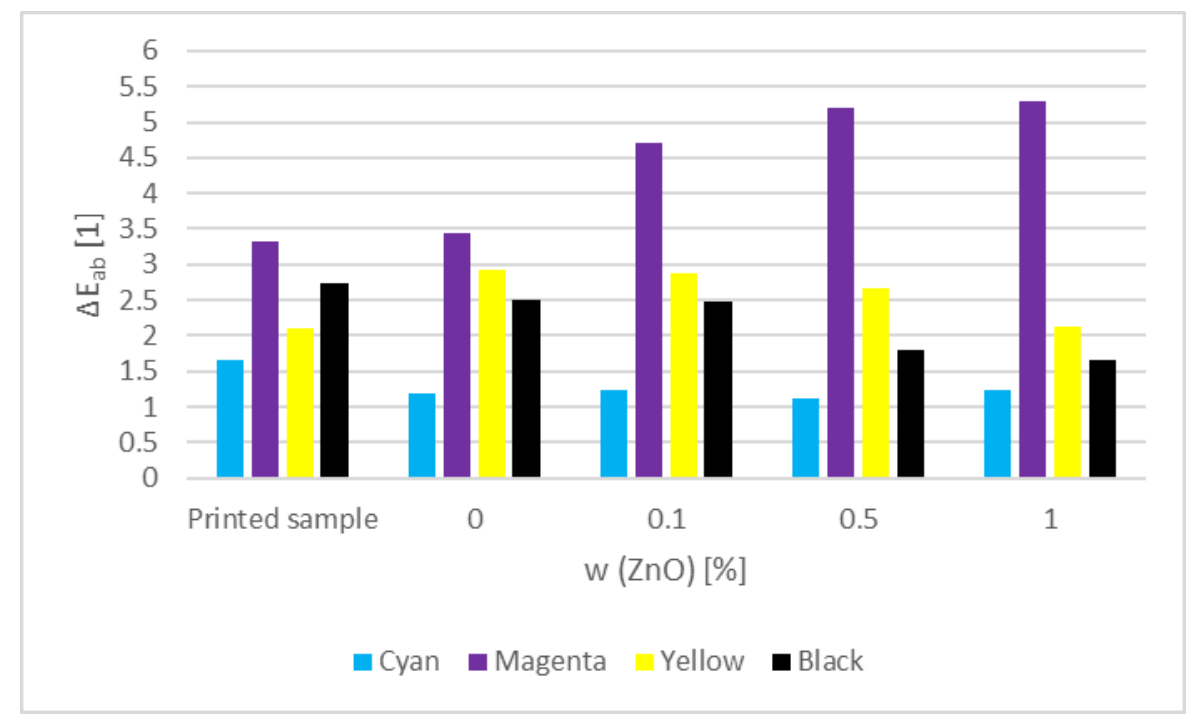

Figure 3: Colour difference $\triangle E_{a b}$ to the Fogra PSO predefined values on the coated paper

In Figure 3 diagram for $\Delta \mathrm{E}_{\mathrm{ab}}$ on coated paper can be observed. The initial printed samples have all $\Delta \mathrm{E}_{\mathrm{ab}}$ under 5 (in compliance to the Fogra PSO) while it can be seen that magenta coated with composite where nanoparticle weight ratio is $<0.5 \%$ experiences $\Delta \mathrm{E}_{\mathrm{ab}}$ over 5 which leaves it outside the defined tolerance. While observing the measured $L^{*} a^{*} b^{*}$ after varnishing one can see that magenta had primarily changed in the $b^{*}$ coordinate (target values $L^{*} a^{*} b^{*}=47,74,-5$; printed sample $L^{*} a^{*} b^{*}=46.87,74.01,-1.82$; sample coated with $\left.w(Z n O)=1 L^{*} a^{*} b^{*}=47.25,73.98,0.28\right)$. This means that original ink is moving magenta colour in $b^{*}$ coordinate which is only "improved" by the increasing ZnO weight ratio.

Although the differences to the standard are larger than the ones on the uncoated paper, observing Figure 4 one could see that colour difference between uncoated sample and the ones coated with prepared composites are smaller. The largest difference is by black while cyan and yellow are under 0.5 . It could also be noticed that increasing $\mathrm{ZnO}$ weight ratio is decreasing colour difference $\Delta \mathrm{E}_{00}$ of black, but increasing the difference of magenta. The $\mathrm{ZnO}$ influences the $\mathrm{L}^{*}$ coordinate of the black ink the most therefore increasing the lightness, i.e. compensates darkening of the image by the PCL coating. On the other side, coatings with the increase of the $\mathrm{ZnO}$ weight increase $\mathrm{b}^{*}$ coordinate of the magenta, increasing the colour difference.

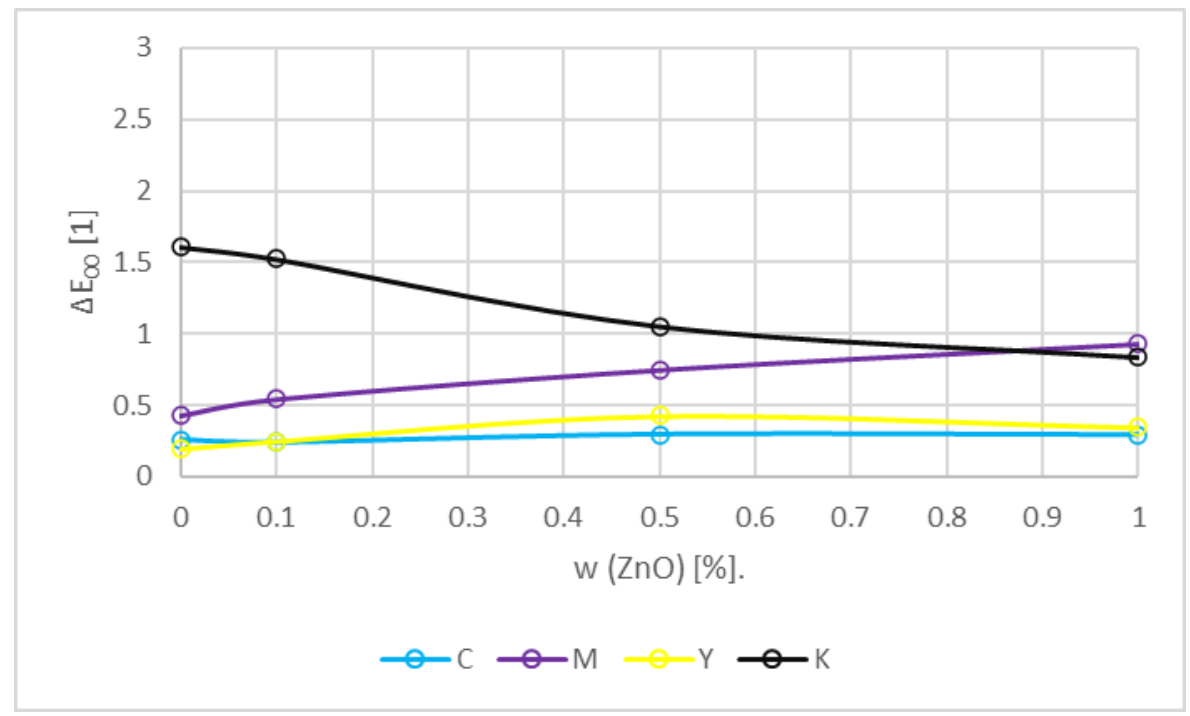

Figure 4: Colour difference $\Delta E_{00}$ to the print without coating on the coated paper

Figures 5 and 6 show difference of print gloss $(\Delta G$, equation 2$)$ on investigated samples. The initial value of gloss on uncoated paper is very low $(\approx 5 \mathrm{GU})$ while on the coated paper is cca. $60 \mathrm{GU}$. 
$\Delta G=\frac{G_{P S}}{G_{O V P}}$

where Gps is gloss of the printed sample and Govp is gloss of the coated samples.

On diagram presented in Figure 5 it can be seen that print gloss on the uncoated paper is unchanged regardless of the composition of the coating. As seen on the colour change, the uncoated paper's absorption means less coating stays on the surface of the print and therefore has lower influence on the surface properties. On the other hand, on the coated paper the increased concentration of the added $\mathrm{ZnO}$ particles leads to the increase of the print gloss on samples (Figure 6). The increase is highest on the magenta while on the cyan it is the same or slightly increased with the coating in which $w(Z n O)=1 \%$. This can be attributed to the already glossy surface and saturation of polymer matrix with increase of the nanoparticle weight ratio (Bota, 2017).

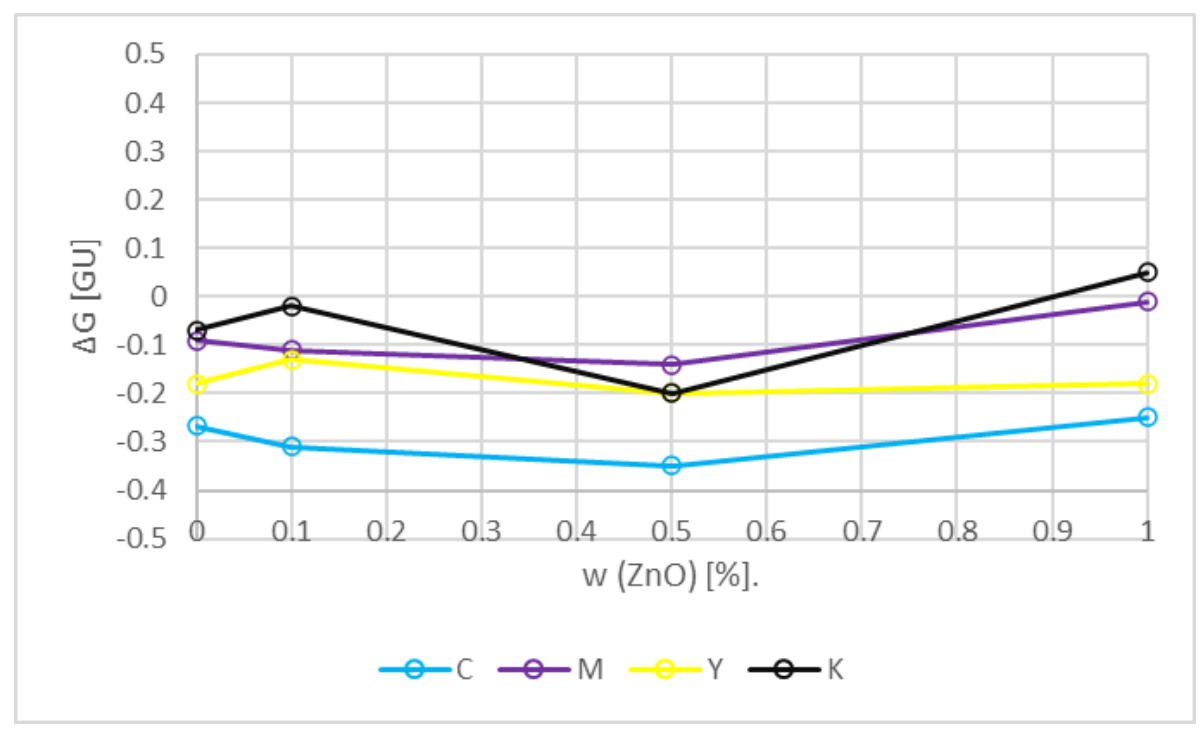

Figure 5: Difference of print gloss between print with and without coating on the uncoated paper

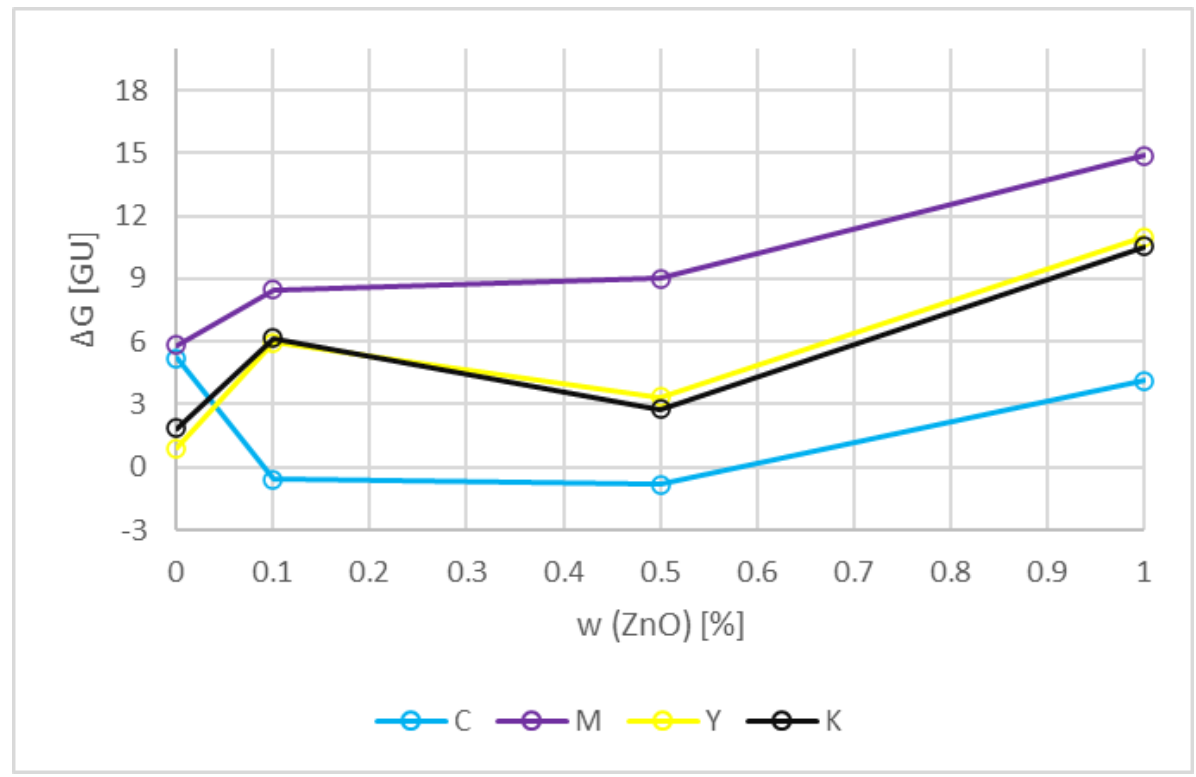

Figure 6: Difference of print gloss between print with and without coating on the coated paper

Water-vapor permeability is one of the ways to measure the quality and efficiency of the packaging material. The samples were weighed at the beginning of the test, and then after $24 \mathrm{~h}$ and $48 \mathrm{~h}$. Diagrams in Figures 7 and 8 show water vapour permeability of prepared sample, where on the $x$-axe are samples 
denominated as printed sample means uncoated print, while 0 means print coated with PCL, $0.1,0.5$ and 1 mean prints coated with composites of $\mathrm{PCL}$ with various weight ratio of $\mathrm{ZnO}(0.1,0.5$ and $1 \%)$.

In Figure 7 one can see that the permeability decreases with the nanocomposite application on uncoated paper. The printed uncoated sample has very high wettability level as well as very high permeability to water-vapor due to its surface properties. The nanocomposite impregnates the surface in some amount and the best result, i.e. the lowest water vapour permeability is achieved by PCL coating. Addition of the $\mathrm{ZnO}$ at the lowest weight ratio decreased barrier property of the print, but it could be seen that increasing the weight ratio increases the barrier properties. This is probably the consequence of nanoparticle penetration in the sample surface, where it weakens the polymer matrix. With the increase of nanoparticle concentration this effect is compensated, as it can be seen on $0.5 \%$ and $1 \%$ of the concentration.

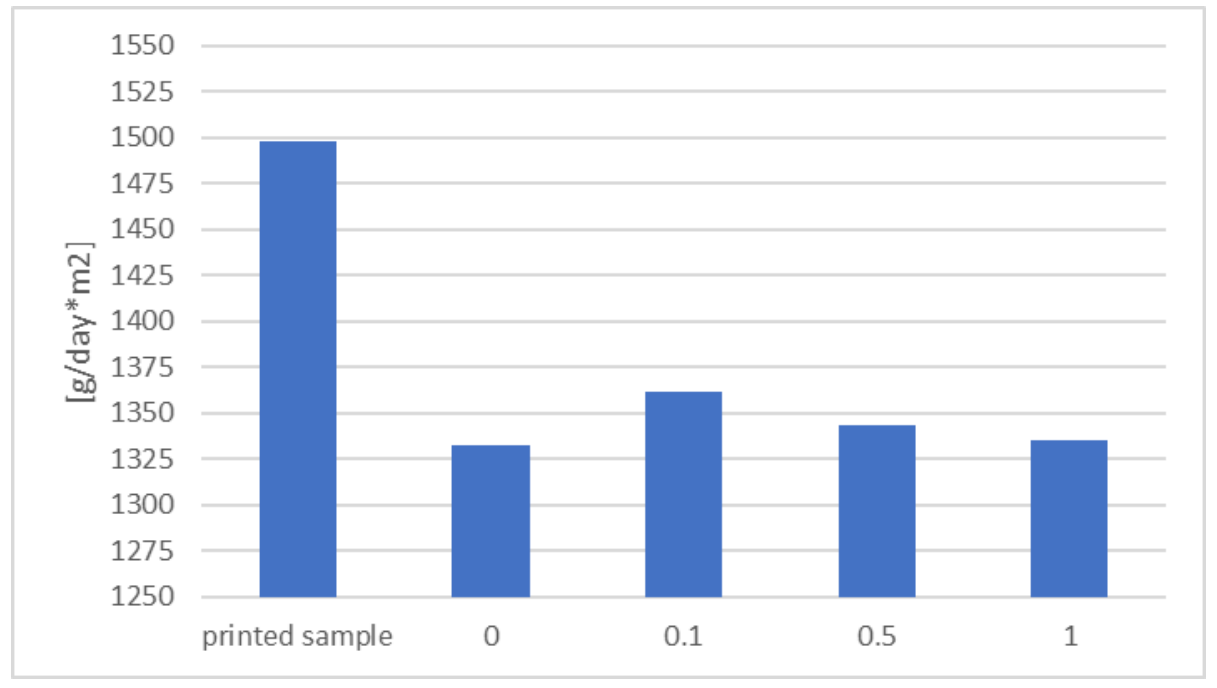

Figure 7: Water vapour transmission rate of prints on the uncoated paper

On the coated paper, similar trend could be noticed when it comes to permeability after varnishing, i.e. the PCL coating shows lower permeability than the coating which has $w(Z n O)=0.1 \%$ particles, but increasing weight ratio of $\mathrm{ZnO}$ decreases permeability to water vapour (Figure 8). It could be seen on both papers that the reduction of the transmission rate is almost the same $\left(\approx 165 \mathrm{~g} / \mathrm{daym}^{2}\right)$ which shows much higher effectiveness on the coated paper as the initial value is much lower.

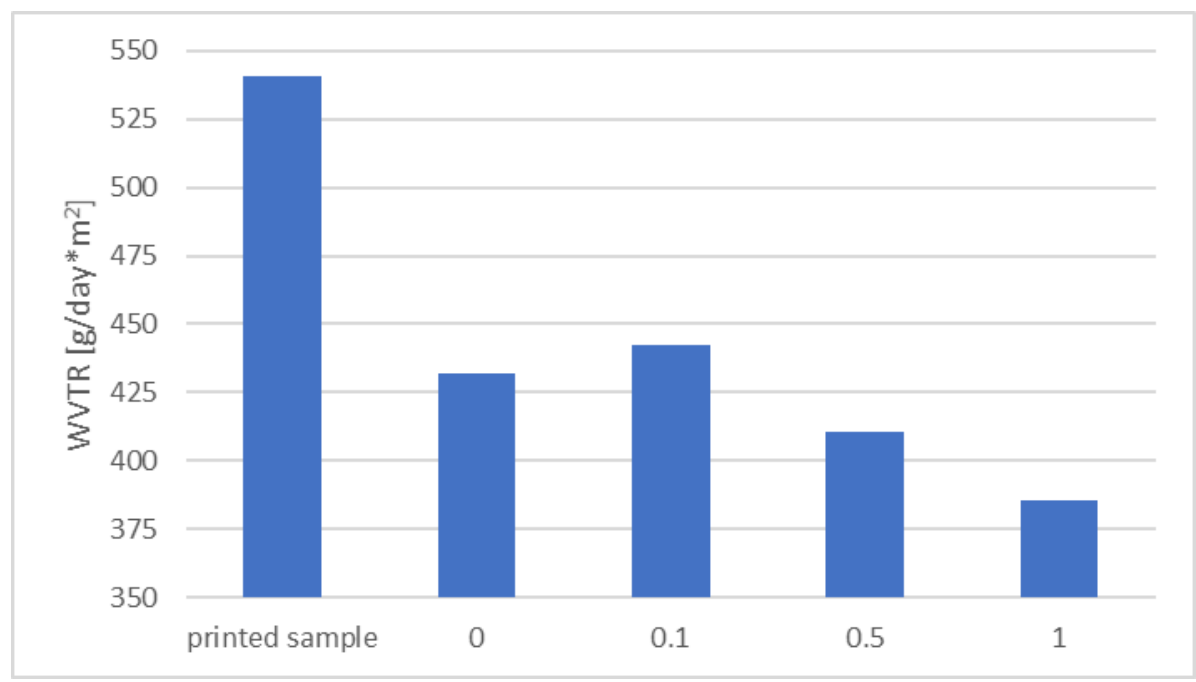

Figure 8: Water vapour transmission rate of prints on the coated paper 


\section{CONCLUSION}

The aim of this paper was to assess the influence of nanocomposite PCL-ZnO in different composition (by varying weight ratio of $\mathrm{ZnO}$ nanoparticles) on printed sample's properties. To conduct this experiment, uncoated offset paper and gloss coated paper were chosen as they are used as the common packaging material. The samples were printed via offset printing technique on KBA Rapida 105 PRO printing machine in ordinance with ISO 12647-2:2013, i.e. Fogra PSO. The samples were coated with prepared nanocomposite OVPs (PCL-ZnO).

The results showed that on the uncoated paper coating with prepared OVPs did not affect the colour reproduction outside acceptable tolerance levels. On the coated paper the coatings in which weight ratio of $\mathrm{ZnO}$ was 0.5 and 1\% caused magenta to be outside acceptable tolerance level. On the other hand, it could be seen that weight ratio of $\mathrm{ZnO}$ causes lower colour differences to the original print on coated paper.

Applying the prepared coatings caused almost none change of print gloss on uncoated paper, but increased the print gloss on coated paper

The water-vapor permeability was lowered on both investigated paper types but on the uncoated paper adding ZnO nanoparticles decreased barrier properties in comparison to the coating composed of PCL only. Increasing the mass of added ZnO increases barrier properties of the print on both investigated cardboards.

This research has proved applicability of the PCL-ZnO coatings as a OVP on cardboard offset prints as it did not highly influenced colour reproduction but has decreased water vapour transmission rate. On the coated paper/cardboard one must take into account increased colour difference of magenta and chose the ink which will be reproduced closer to the standardized colorimetric values or add lower concentration of the nanoparticles without decreasing their role in the coating. In addition, to further investigate the applicability in the packaging printing, further research should include investigation of resistance to ink fading in the ageing process, bending tests, adhesion etc.

\section{ACKNOWLEDGMENTS}

This research is part of the project UIP-2017-05-4081, "Development of the model for production efficiency increase and functionality of packaging", supported by Croatian Science Foundation. It is also supported by University of Zagreb short term funding "Development and modification of composite coatings on packaging printing substrates".

\section{REFERENCES}

[1] American Society for Testing and Materials, ASTM E96/E96M-16 Standard Test Methods for Water Vapor Transmission of Materials, ASTM International, 2016. doi: 10.1520/E0096_E0096M-16.

[2] Bota, J., Vukoje, M., Brozovic, M., Hrnjak-Murgic, Z.: "Reduced water permeability of biodegradable PCL nanocomposite coated paperboard packaging", Chemical and Biochemical Engineering Quarterly 31, 417-424, 2018. doi: 10.15255/CABEQ.2017.1126.

[3] Bota, J.: "Optimisation of Coated Paperboard Packaging Properties According to Design", PhD thesis, University of Zagreb Faculty of Graphic Arts, 2017.

[4] Elcometer: "Elcometer 407 operating manual", URL: https://www.elcometer.com/images/stories/PDFs/InstructionBooks/407.pdf (last request: 2020-0918), 2010.

[5] Ghule, K., Ghule, V., Chen, J., Ling, C.: "Preparation and characterization of ZnO nanoparticles coated paper and its antibacterial activity study", Green Chemistry 8, 1034-41, 2018. doi: 10.1039/B605623G.

[6] Golik Krizmanić, M.: "Functional PCL coating with the addition of $\mathrm{ZnO}$ nanoparticles as print protection", BSc thesis, University of Zagreb Faculty of Graphic Arts, 2020.

[7] Hunter, R.: "Methods of determining gloss", Journal of Research of the National Institute of Standards and Technology 18, 14-16, 2008.

[8] Kipphan, H.: "Handbook of Print Media", (Springer-Verlag, Berlin, 2001.), pages 206-224. doi: 10.1007/978-3-540-29900-4. 
[9] Kovačević, D., Brozović, M., Itrić Ivanda, K.: "Eco-mark on product packaging and its effect on the perception of quality", Journal of Graphic Engineering and Design 10 (2), 17-24, 2019. doi: 10.24867/JGED-2019-2-017.

[10] Lavoine, N., Guillard, V., Desloges, I., Gontard, N., Bras, J.: “Active bio-based food-packaging: Diffusion and release of active substances through and from cellulose nanofiber coating toward food-packaging design", Carbohydrate Polymer Technologies and Applications 149, 40-50, 2016. doi: 10.1016/j.carbpol.2016.04.048.

[11] Makower, J.: "How green printing can make a good impression", URL: https://grist.org/article/printing/ (last request: 2020-09-20), 2006.

[12] Mokrzycki, W., Tatol, M.: "Color difference Delta E-A survey Colour difference $\Delta E-A$ survey", Machine Vision and Applications 1, 14-18, 2014.

[13] Rastogi, V., Samyn, P.: "Bio-based coatings for paper applications", Coatings 5, 887-930, 2015. doi: 10.3390/coatings5040887.

[14] Sharma, G., Wu, W., Dalal, E.: "The CIEDE2000 color-difference formula: Implementation notes, supplementary test data, and mathematical observations", Color Research and Application 30, 2130, 2005. doi: 10.1002/col.20070.

[15] Smithers: "Inkjet printing builds towards $\$ 100$ billion market", URL: https://www.smithers.com/resources/2018/oct/inkjet-printing-builds-towards-\$100-billion-market (last request: 2020-06-20), 2017.

[16] Techkon: "Spectro-Densitometer SpectroDens", URL: https://www.techkon.com/files/downloads/prospekte/SpectroDens\%20Manual\%20Web.pdf (last request: 2020-09-17), 2020.

[17] Uglešić, P.: "Biodegradable polymers and their application", BSc thesis, University of Zagreb Faculty of Chemical Engineering, 2015.

[18] Van Der Walle, G., Buisman, H., Weusthuis, A., Eggink, G.: "Development of environmentally friendly coatings and paints using medium-chain-length poly(3-hydroxyalkanoates) as the polymer binder", International Journal of Biological Macromolecules 25, 123-8, 1999. doi: 10.1016/S01418130(99)00025-2.

[19] Wu, L., Baghdachi, J.: "Functional Polymer Coatings: Principles, Methods, and Applications", Wiley, Hoboken NJ, 2015.), pages 134-155. doi: 10.1002/9781118883051.

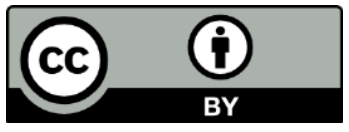

(C) 2020 Authors. Published by the University of Novi Sad, Faculty of Technical Sciences, Department of Graphic Engineering and Design. This article is an open access article distributed under the terms and conditions of the Creative Commons Attribution license 3.0 Serbia (http://creativecommons.org/licenses/by/3.0/rs/). 


\title{
MECHANICAL AND CHEMICAL RESISTANCE OF THERMOCHROMIC PACKAGING PRINTS
}

\author{
Sonja Jamnicki Hanzer (D), Rahela Kulčar (D), Marina Vukoje (D), Petra Širol \\ University of Zagreb, Faculty of Graphic Arts, Zagreb, Croatia
}

\begin{abstract}
Thermochromic inks are temperature-sensitive materials that change colour due to a temperature change. These inks are mostly printed on smart packaging applications where they are used in a form of temperature indicators. The colorants in these inks are microencapsulated which makes the prints obtained with these inks more sensitive to abrasion in comparison to the prints obtained with conventional inks. Thermochromic prints are also very sensitive to adverse environmental conditions, such as exposure to UV light, heat and certain chemicals and solvents.

Abrasion and chemical resistance of thermochromic prints obtained on metallized label papers are discussed in this paper. For that purpose, two thermochromic UV screen inks were printed on two types of metalized papers that are commonly used as food packaging labels. The prints thus obtained were then subjected to a rub test in accordance with standard method BS 3110. Rub test was performed using Hanatek RT4 Rub and Abrasion Tester. The degree of rubbing was assessed by visual inspection and by detection of the colorimetric changes on the prints after their exposure to rubbing. Assessment of prints' resistance to various liquid agents (water, ethanol and citric acid) was done in accordance to standard method ISO 2836. Evaluation of chemical degradation on prints was done by the spectrophotometric measurements.

The results of conducted research showed good rub resistance of these inks, as no rubbing was detected, but poor resistance to all liquid agents they were exposed to. Exposure to ethanol, particularly, caused severe damage to the prints. The bleeding of the colorants from the prints was also detected. However, even though the prints were not able to completely withstand exposure to specific liquid agents which was demonstrated by their optical deterioration, the thermochromic effect was still present in them after resistance tests were conducted.
\end{abstract}

Key words: thermochromic inks, metallized label paper, rub resistance, chemical resistance

\section{INTRODUCTION}

Thermochromic (TC) inks are temperature sensitive inks that exhibit colour changes in response to temperature fluctuations. There are two primary types of TC inks: liquid crystals and leuco dyes. Leuco dye-based inks are being used more often, especially in smart packaging applications. TC inks can go from colourful to colourless, colourless to colourful, or can change from one colour to another. Moreover, the change of colour may be irreversible or reversible. In case of irreversible inks, a colour change is permanent, while reversible inks exhibit a temporary colour change i.e. the original colour is restored upon cooling. Each thermochromic colorant has a fixed temperature range over which its colour change takes place. This temperature range is called the activation temperature $\left(T_{A}\right)$ or activation point (Bäckman, 2017; Kulčar et al, 2010; Lam Po Tang and Stylios, 2006; Seeboth and Lotzsch, 2013).

TC inks based on leuco dyes generally consist of an encapsulated three-part system which includes a dye that changes colour, a compound that acts as a colour developer and a solvent. At temperatures below the activation point, the solvent is in solid state enabling the dye and colour developer to form a colour, resulting in a full colour effect. When the temperature reaches the activation point, the solvent becomes liquid, keeping colour developer and the leuco dye apart (WRAP, 2013).

Depending on the application, TC inks can be applied with many printing processes, including offset lithography, flexography, gravure, and screen printing (Homola, 2008). The formulation of TC inks includes a mixture of TC microcapsules dispersed in ink's vehicles. The sizes of microcapsules used in printing inks are in the range of 3 to $5 \mu \mathrm{m}$ which makes them at least ten times larger than the average size of the colorants used in the formulation of conventional printing inks. The main disadvantage of microencapsulated TC systems is their limited lightfastness and resistance to different atmospheric conditions (Seeboth and Lotzsch, 2008). Moreover, the microencapsulation of TC colorants makes TC inks significantly more susceptible to abrasion than conventional printing inks.

In recent years, applications for TC inks have expanded. They have found their main application in the food industry as indicators printed on smart packaging, where are used to enhance labels, give warnings 
or the advice of correct consumption temperature (Đurđević et al, 2015). They can also be found in security printing, where are used on checks, tickets, medication recipes, etc. Recently, such inks are gaining their roles in commercial purposes - decorations, design solutions, promotional materials etc.

During the shipping or handling process, printed products are often exposed to a degree of abrasion to its surface. This abrasion can result in a significant degradation in the appearance of the prints i.e. a print defect could appear in form of scuffed, rubbed off or scratched surface. Rub resistance, in particular, describes the ability of printed product to withstand marking, scuffing or smudging during handling in conversion, packaging, distribution and use (Bozhkova et al, 2017). A good rub resistance is expected for prints applied on labels and packaging, but also for prints applied on the covers of books, magazines, notebooks or folders. The main factors influencing on ink rub resistance are the basic properties of paper (smoothness, absorption ability, etc.), the composition of the ink, printing conditions and ink drying properties (Zhou et al, 2011). Alongside to abrasion that could negatively affect packaging prints also certain chemicals can cause print's alterations: either by direct degradation of the print in contact with the product or by the migration of an ingredient into the ink. A print is considered to be resistant to a chemical substance when no alteration occurs when it is brought into contact with it, i.e. when no change in colour, no leaching, no reduction in the abrasion or scratch resistance of printed film is observed (Brancher, 2020).

This research aimed to analyze mechanical and chemical resistance of UV cured thermochromic inks applied on metallized label papers. For that reason, the prints were subjected to a standard rub test and they were also treated with three liquid agents to prove the prints' resistance to liquids and chemicals. The degree of rubbing was assessed by visual inspection and by detection of the colorimetric changes on the prints after their exposure to rubbing. Chemical resistance of prints was observed based on optical deterioration of prints after treatments with liquid agents compared against untreated prints.

\section{MATERIALS AND METHODS}

\subsection{Printing substrates}

As printing substrates two metallized label papers were selected, one of which had embossed metallized surface (Alukett Spezial Fashion by B\&B), and another which had more uniform and radiant surface (Alukett Spezial by B\&B). Both metallized papers had a functional coating on the reverse side as they were designed to be used as beer labels. The characteristics of metallized label papers given by the producer are presented in Table 1.

Table 1: Characteristics of metallized label papers

\begin{tabular}{|c|c|c|c|c|c|}
\hline Paper grade & \multicolumn{5}{|c|}{ Property } \\
\hline & $\begin{array}{c}\text { Basis weight } \\
\mathrm{g} / \mathrm{m}^{2} \\
(\text { ISO 536) }\end{array}$ & $\begin{array}{c}\text { Caliper } \\
\mu \mathrm{m} \\
\text { (ISO 534) }\end{array}$ & $\begin{array}{c}\text { Gloss Novogloss } \\
\text { (coated side) } \\
\%\end{array}$ & $\begin{array}{c}\text { Smoothness Bekk } \\
\text { (reverse side) } \\
\text { Bekk Sec. } \\
(\text { ISO 5627) }\end{array}$ & $\begin{array}{c}\text { Cobb 60" } \\
\text { (reverse side) } \\
\mathrm{g} / \mathrm{m}^{2} \\
(\text { ISO 535) }\end{array}$ \\
\hline Alukett Spezial & 71 & 64 & 35 & 250 & 17 \\
\hline $\begin{array}{c}\text { Alukett Spezial } \\
\text { Fashion }\end{array}$ & 71 & 65 & - & 150 & 17 \\
\hline
\end{tabular}

\subsection{Printing inks}

Two thermochromic UV screen inks manufactured by commercial producer were chosen for printing on metallized substrates. These inks were coloured below a specific temperature and changed to another lighter colour as they were heated. One ink was coloured in orange below its activation temperature $\left(\mathrm{T}_{\mathrm{A}}=12^{\circ} \mathrm{C}\right)$ and changed to yellow above it (hereinafter $\left.\mathrm{OY}_{12}\right)$. Another ink was coloured in purple below its activation temperature $\left(T_{A}=31^{\circ} \mathrm{C}\right)$ and changed to pink above it (hereinafter $\mathrm{PP}_{31}$ ). Both inks were type of reversible inks i.e., the original colour was restored upon cooling (Figure 1). These inks consisted of two types of colorants: thermochromic leuco dyes and conventional pigments (Homola, 2008). We can assume that orange $\left(\mathrm{OY}_{12}\right.$ ) ink was made by addition of red leuco dyes to conventional yellow pigments, while purple $\left(\mathrm{PP}_{31}\right)$ ink was made by combination of conventional pink pigments with blue leuco dyes. 


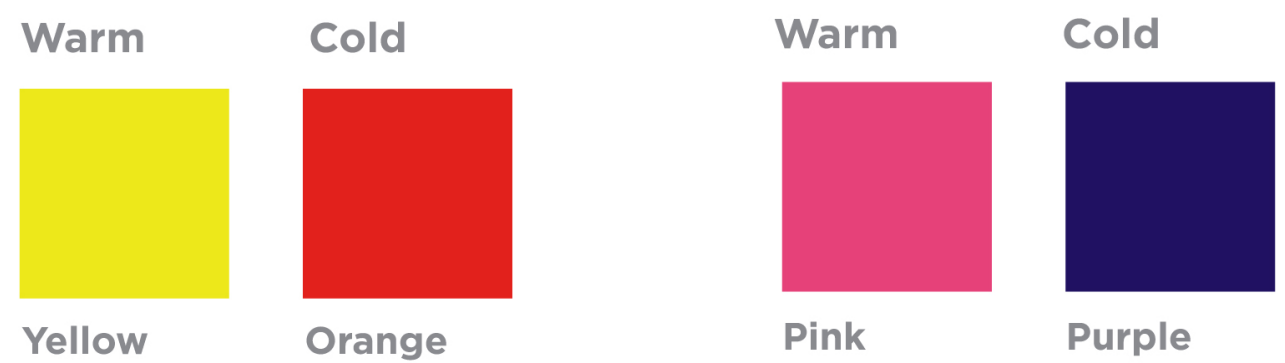

Figure 1: The colour of used thermochromic inks in their warm (above $T_{A}$ ) and cold state (below $T_{A}$ )

Printing was conducted in laboratory conditions by semi-automatic screen printing device Siebdruckgeräte von Holzschuher KG., Wuppertal, using a mesh of 62-64 lin/cm. The prints were printed in full tone. After printing, they were cured in a Technigraf Aktiprint L 10-1 UV dryer (30 W/cm). The characteristics of inks given by the producer are presented in Table 2.

Table 2: Characteristics of thermochromic UV screen inks

\begin{tabular}{|c|c|}
\hline UV thermochromic ink & D12-Flatbed \\
\hline Viscosity at $25^{\circ} \mathrm{C}$ & $65-110$ poise \\
\hline Density (Approx.) & $8.0 \mathrm{lb} . /$ gal \\
\hline Appearance & Viscous Liquid \\
\hline Percent Solids (Approx.) & $99 \%$ \\
\hline Percent Volatiles (Approx.) & $<1.5 \%$ \\
\hline
\end{tabular}

\subsection{Rub test trials}

A Hanatek RT4 Rub and Abrasion Tester was used for testing the rub resistance of the printed samples. The testing was done in accordance to British Standard BS 3110:1959 (British Standards Institution, 1959). The rub resistance was determined on a dry print in terms of removal of a layer of ink due to friction, created by rubbing the examined print against white uncoated paper $\left(80 \mathrm{~g} / \mathrm{m}^{2}\right)$. The white uncoated paper was used to clearly see the ink transference. Powered by an electric motor, the disc with the facedown attached printed sample and the disc with the white paper substrate rotated at an identical speed of $1 \mathrm{rev} / \mathrm{sec}$ under the constant rubbing pressure. The pressure between discs was regulated by different weights placed on the upper disk. Tests were performed at two varying pressures: 3.6 and 6.9 $\mathrm{kPa}$. A number of rubs (revolutions) was set to 50 for each tested sample. For each sample (ink/substrate combination), three tests were performed. The degree of surface rub was assessed by visual inspection (the degree of dry ink transfer onto a white uncoated paper) and by detection of the colorimetric changes on the prints.

\subsection{Assessment of prints' resistance to various chemical agents}

Assessment of prints' resistance to various chemical agents (water, ethanol and citric acid) was done in accordance to standard method ISO 2836:2004. International Standard ISO 2836:2004 in the field of printing industry defines methods of assessing the resistance of prints to liquid and solid agents, solvents, varnishes and acids (International Organization for Standardization, 2004). Water, ethanol and citric acid were chosen as test agents because laboratory prints were made on metallized beverage labels, so the selected agents simulated water, alcohol and juice of citrus fruits.

For assessment of prints' resistance to water, four strips of filter paper were immersed into distilled water and then drained until no water drops were dripping off filter paper. Two saturated strips of filter paper were then placed on the lower glass plate; the printed test piece was placed on the top of them and was covered with other two strips of saturated filter papers. The top glass plate was then placed covering filter papers and load of $1 \mathrm{~kg}$ mass on top of that all. The package was left for 24 hours at ambient temperature. After the treatment, the laboratory prints were dried in an oven for 30 minutes at a temperature of $40{ }^{\circ} \mathrm{C}$. The assessment was made of any changes in the print and in the receptor (filter paper) surface which has been in the contact with print. 
The method of testing resistance of prints to ethanol was performed in a test tube, which was half-filled with denatured ethanol (96\%). The printed test piece was submerged in the solvent and was left in it for 5 minutes. The test temperature was $23^{\circ} \mathrm{C}$. After exposure time was over, the laboratory prints were dried in an oven for 10 minutes at a temperature of $40{ }^{\circ} \mathrm{C}$. The colour change of the solvent and discoloration and any change of the test piece (print) were noted and reported.

For assessment of prints' resistance to citric acid, two strips of filter paper were immersed in the $5 \%$ citric acid and then drained until there were no solution drops dripping off filter paper. One saturated strip of filter paper was then placed on the lower glass plate with the laboratory print placed on it. That same print was then covered with another saturated filter paper and the second glass was placed on top of everything. The whole was placed in a moisture-tight wrapper. Also, $1 \mathrm{~kg}$ of load was placed on top of it all to provide pressure. The exposure time was set to 1 hour, at a temperature of $23^{\circ} \mathrm{C}$. After exposure was over, the print was rinsed in deionized water and was left to dry in the oven at $50{ }^{\circ} \mathrm{C}$ for 30 minutes. An assessment was made of any change to the print and any bleeding of the colour onto the filter paper. Summarized details of test conditions for conducted chemical resistance test methods are presented in Table 3.

Table 3: Test conditions for used liquid agents

\begin{tabular}{|c|c|c|c|c|}
\hline Test agent & Receptor surface & Temperature ${ }^{\circ} \mathrm{C}$ & Test duration & Contact condition \\
\hline Water (distilled) & filter paper & $23 \pm 2$ & $24 \mathrm{~h}$ & $1 \mathrm{~kg} \mathrm{on} 54 \mathrm{~cm}^{2}$ \\
\hline Ethanol $(\mathrm{v} / \mathrm{v}=96 \%)$ & test tube & $23 \pm 2$ & $5 \mathrm{~min}$ & liquid \\
\hline Citric acid $(\mathrm{w} / \mathrm{v}=5 \%)$ & filter paper & $23 \pm 2$ & $1 \mathrm{~h}$ & $1 \mathrm{~kg}$ on $54 \mathrm{~cm}^{2}$ \\
\hline
\end{tabular}

\subsection{Spectrophotometric measurements}

Evaluation of mechanical and chemical degradation on prints was done by the spectrophotometric measurements. Spectrophotometric measurements were conducted on laboratory prints before and after their exposure to mechanical and chemical treatments. Temperature-dependent spectral reflectance of the samples was measured (spectral region 430-700 nm, $1 \mathrm{~nm}$ step) by fiber-based USB 2000 spectrometer (Ocean Optics, USA) using $30 \mathrm{~mm}$ wide integrating sphere (ISP-30-6-R) with $\left(8^{\circ}:\right.$ di) measuring geometry and $6 \mathrm{~mm}$ sampling port diameter. OceanView software by Ocean Optics was used to calculate the CIELAB $L^{*}, a^{*}, b^{*}$ values taking into account the D50 illuminant and $2^{\circ}$ standard observer. The samples were heated on the surface of a water block (EK Water Blocks; EKWB d.o.o., Slovenia).

For evaluation of mechanical and chemical degradation, the colour difference between the prints before and after conducted treatments was calculated using the formula CIEDE2000 (CIE, 2004). Each printed sample was measured 3 times at 3 different positions on the print area.

For evaluation of prints' rub resistance properties, spectroscopic measurements were done at constant temperature of $20^{\circ} \mathrm{C}$ for both inks, while in case of evaluation of prints' optical deterioration caused by liquid agents, spectroscopic measurements were done at two fixed temperatures for each TC print: one below its $T_{A}$, and another above its $T_{A}$. For that reason, prints made with $O Y_{12}$ ink were measured at $8^{\circ} \mathrm{C}$ and $20^{\circ} \mathrm{C}$, while prints made with $\mathrm{PP}_{31}$ ink were measured at $20^{\circ} \mathrm{C}$ and $40^{\circ} \mathrm{C}$, respectively.

Interpretation of measured colour-difference parameter $\triangle \mathrm{E}$ from the CIEDE2000 formula was done in relation to subjective visual perception. If the calculated CIEDE2000 results are below 1 , then the average eye of the observer cannot perceive the difference between two colours. A very small difference between colours can be perceived when the results are between 1 and 2 , but it is tolerated, that is, the colour difference up to 2 is acceptable (Rudolf et al, 2020).

\section{RESULTS AND DISCUSSION}

\subsection{Results of rub resistance measurements}

After series of rub tests performed on TC prints, samples of white paper were then visually inspected to determine if the rub resistances of prints were satisfactory. The results showed that all printed samples had high rub resistance, at all tested conditions, as no transfer of dry ink onto the white uncoated paper was observed. Alongside to that, the colour difference CIEDE2000 between printed samples before and after conducted rub tests was determined and the results are presented in Figure 2 and Figure 3. 


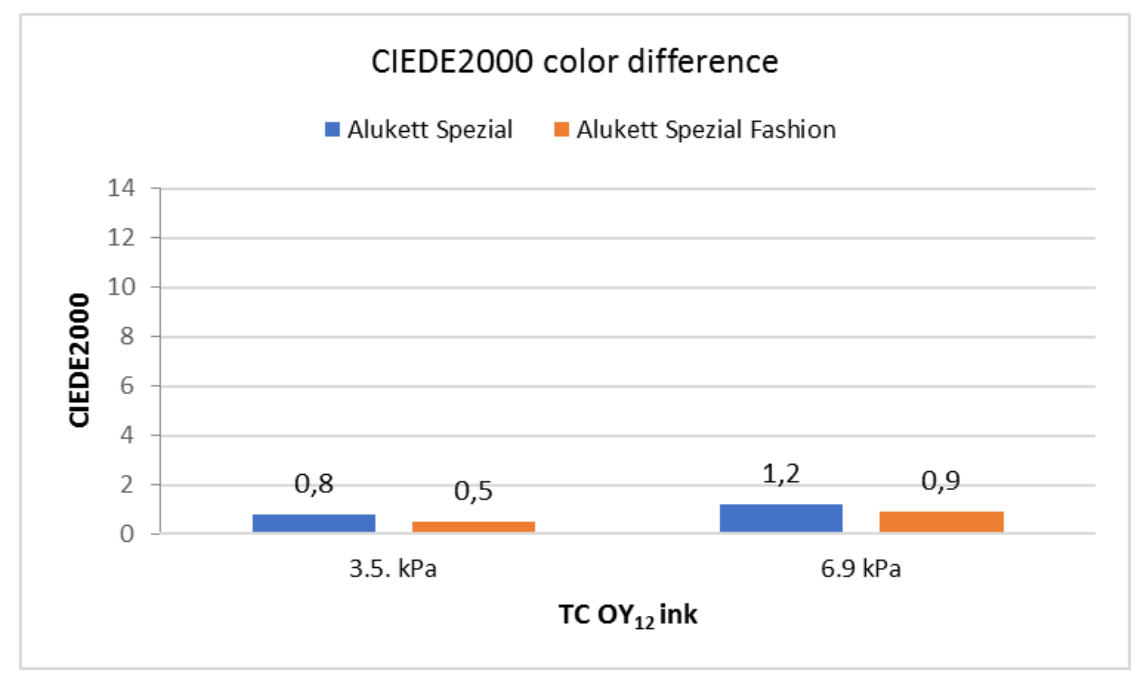

Figure 2: Colour difference measured on the $\mathrm{TCOY}_{12}$ prints after their exposure to rubbing

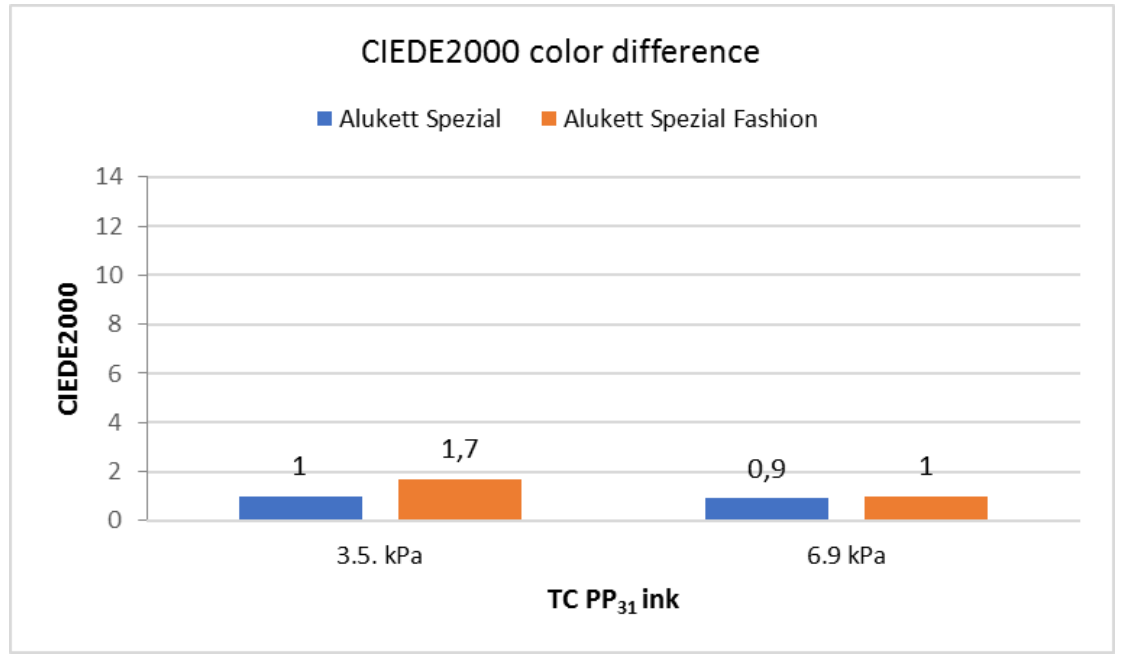

Figure 3: Colour difference measured on the TC $P P_{31}$ prints after their exposure to rubbing

The results show that both tested inks applied on both substrates, under all testing conditions, showed minimal optical deterioration on their prints, as all measured CIEDE2000 results were below 2 (which is considered as an acceptable colour difference). These results correspond well to the results of previously conducted visual assessment. However, if we further compare the results obtained between two thermochromic inks, the $\mathrm{OY}_{12}$ ink showed slightly better results than $\mathrm{PP}_{31}$ ink, especially when printed on an embossed metallized substrate (Alukett Spezial Fashion), where measured colour difference was under 1 , which means that the average eye of the observer couldn't perceive the difference between two colours. The results of rub tests for both inks applied on both substrates are satisfactory.

\subsection{Results of prints' chemical resistance}

Assessment of the prints' resistance to chemical agents was done based on any colour changes in the prints and in the receptor (filter paper or testing solvent). After treatment with water, for both tested metallized label papers, a moderate bleeding was noticed in case of $\mathrm{PP}_{31}$ prints (filter papers that were in direct contact with prints were lightly coloured in pink at their contact surface), but in case of OY 12 prints no bleeding was visually inspected. In case of prints' exposition to ethanol, the remaining solvent in the test tube was highly coloured in yellow and in pink as severe bleeding from $\mathrm{OY}_{12}$ and $\mathrm{PP}_{31}$ prints from both label papers was noticed. Moreover, exposure to ethanol caused severe damage to the prints which can be seen in Figure 4. Discoloration of the print surface was noticed, and some areas of the prints were completely peeled off the metallized label paper surfaces. This would mean that ethanol destroys the attractive forces between the TC ink and paper, affecting the ink adhesion onto the paper. 

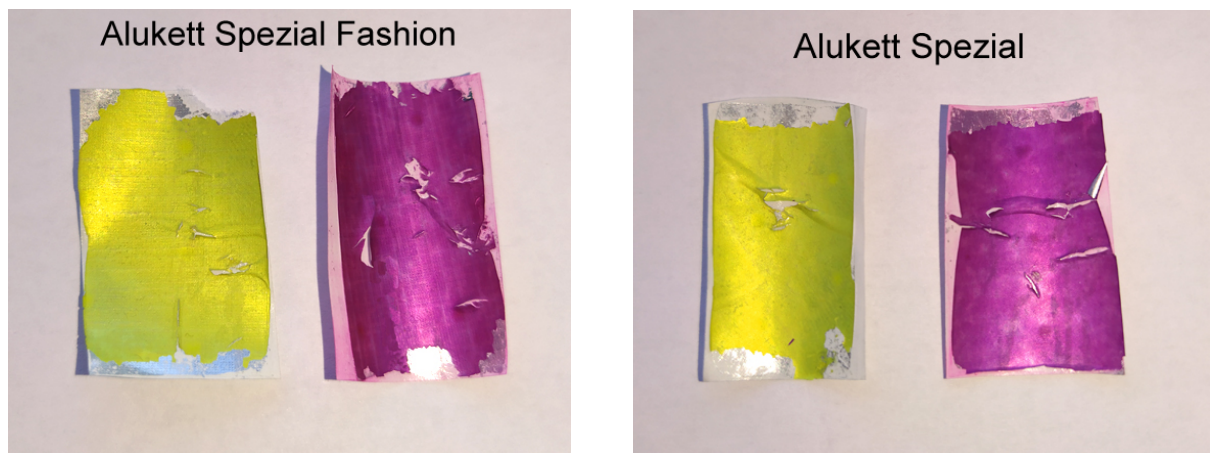

Figure 4: Appearance of the prints after treatment with ethanol

In addition, after treatment with citric acid, for both tested metallized label papers, quite high bleeding of colorants into the filter papers was detected in case of $\mathrm{PP}_{31}$ inks, while the only slight indication of bleeding was detected from $\mathrm{OY}_{12}$ ink printed on Alukett Spezial label paper, and in case of the same ink printed on embossed Alukett Spezial Fashion label paper, no bleeding was detected.

Figures 5-8 present the CIEDE2000 colour difference of the prints measured at temperatures below and above TC inks' $T_{A}$.

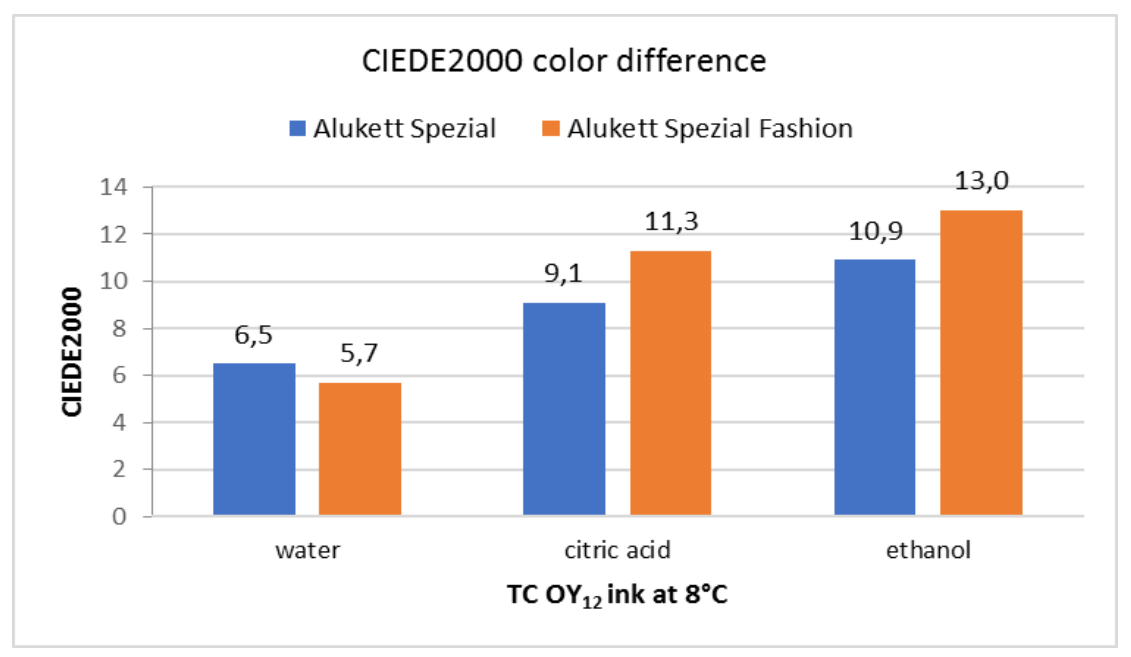

Figure 5: CIEDE2000 colour differences measured on OY 12 TC prints below inks' $T_{A}$ after treatments with chemical agents

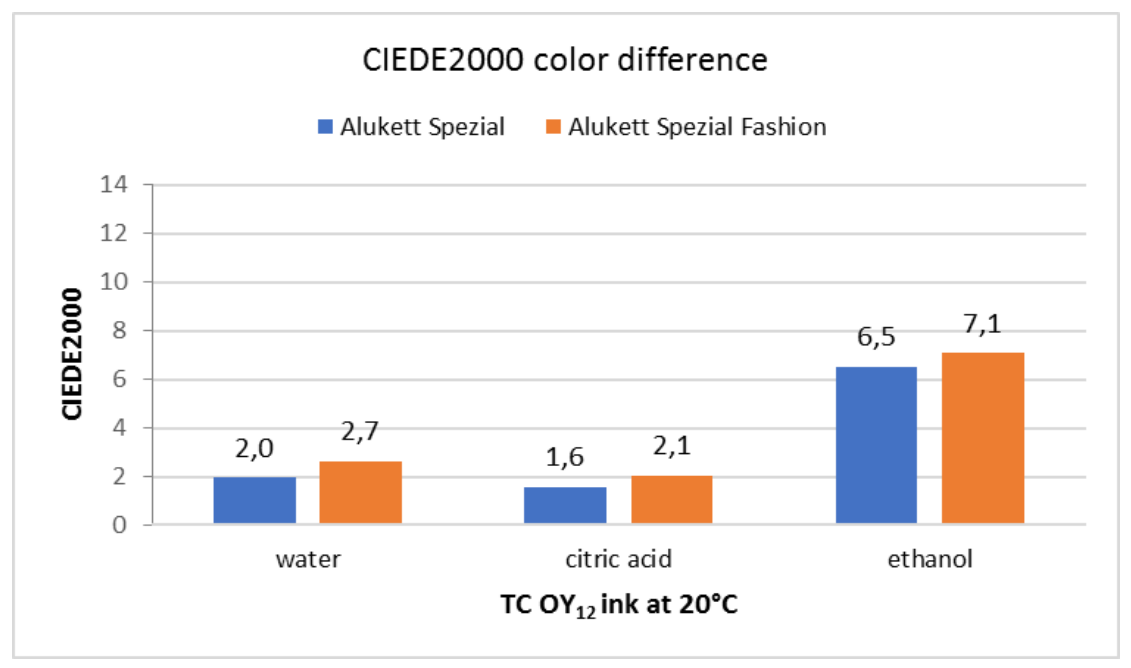

Figure 6: CIEDE2000 colour differences measured on OY 12 TC prints above inks' $T_{A}$ after treatments with chemical agents 


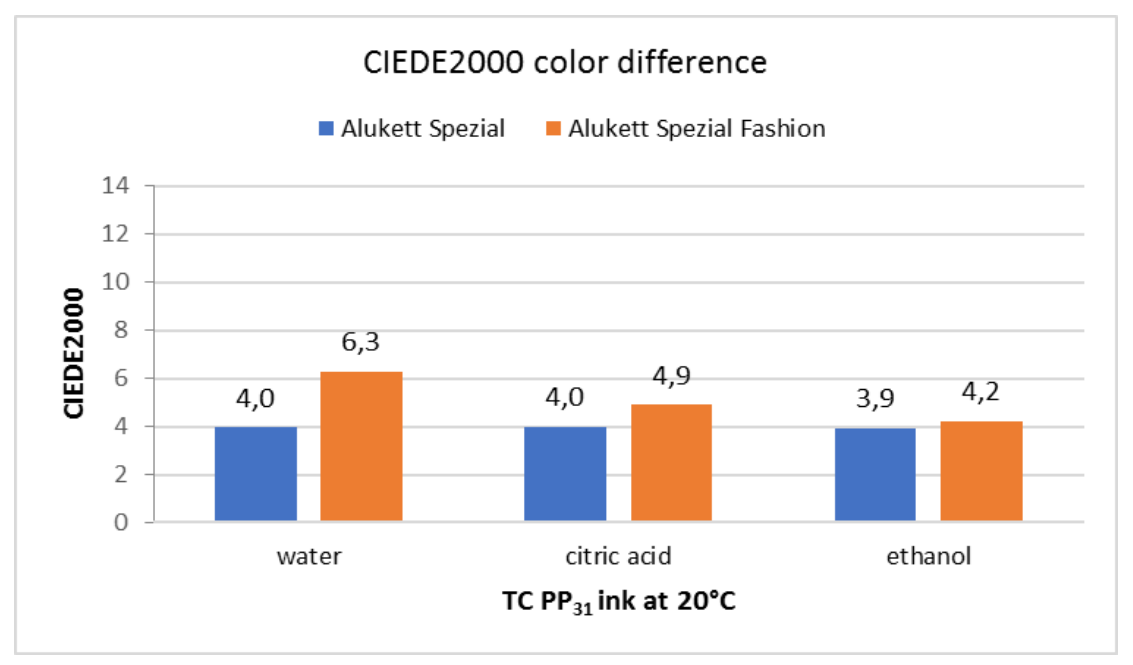

Figure 7: CIEDE2000 colour differences measured on PP 31 TC prints below inks' $T_{A}$ after treatments with chemical agents

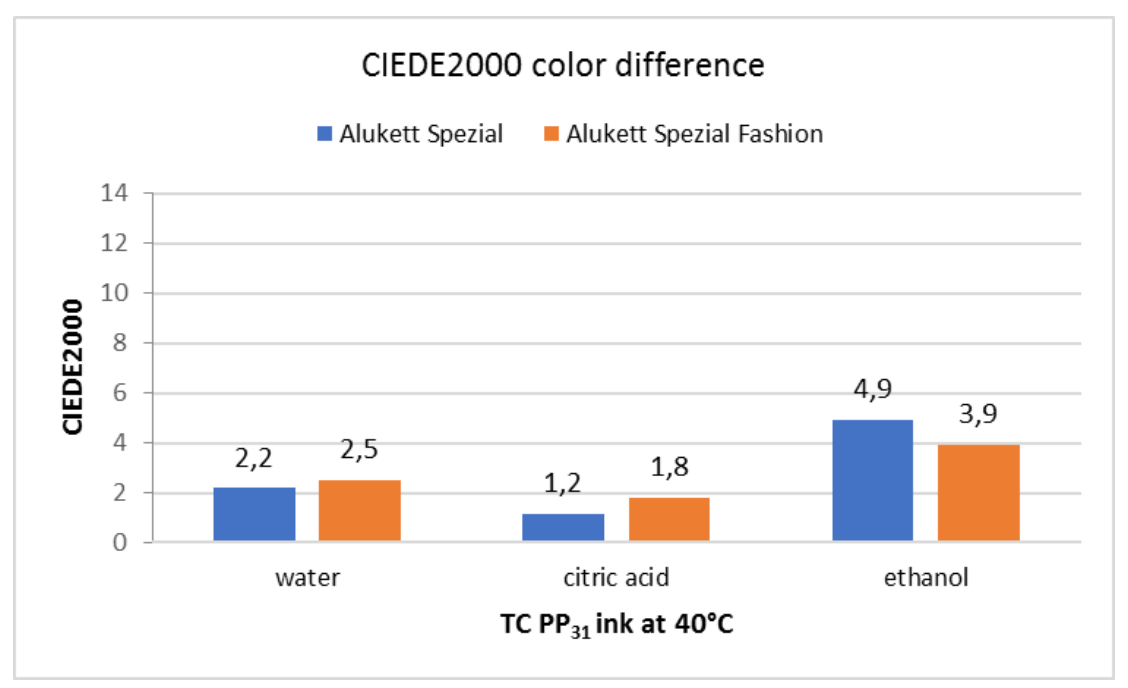

Figure 8: CIEDE2000 colour differences measured on $P P_{31} T C$ prints above inks' $T_{A}$ after treatments with chemical agents

If we compare CIEDE2000 colour differences measured on TC prints, for both inks, at all testing conditions, we can see the greatest effect of all liquid agents on the prints when thermochromic microcapsules are active, at $8{ }^{\circ} \mathrm{C}$ for $\mathrm{OY}_{12}$ ink and at $20^{\circ} \mathrm{C}$ for $\mathrm{PP}_{31}$ ink. It is also evident from the results that the prints made with $\mathrm{OY}_{12}$ ink were affected more by selected liquid agents that those printed with $\mathrm{PP}_{31}$ ink. One possible explanation of differences in results obtained between $\mathrm{OY}_{12}$ and $\mathrm{PP}_{31}$ prints can be the different chemical structure of the TC ink used, i.e. different composition of the TC ink binder formulation. Depending on the structure of the binder and colorants (presence of polar or non-polar groups within the structure), different reactions (dispersion, polar or hydrogen) will occur between the prints and the liquid agents used i.e. one material will dissolve in another, if they have similar behaviour or if they react in a similar way (Rožić et al, 2017)). In this case, the liquid agents used did not affect equally the $\mathrm{OY}_{12}$ and $\mathrm{PP}_{31}$ prints, therefore a different chemical structure of the used TC inks can be assumed.

Results further show a pattern of prints coloration change due to different polarity of the solvents. Polarity increases in a row: ethanol < citric acid < water. Ethanol as a strong solvent, by the action of its polar and hydrogen interactions with the print, creates greater differences in the colour of the print in contrast to the other two liquid agents used.

Moreover, there is as well, the influence of paper topography evident. If we compare the obtained results from the aspect of the printing substrates, inks printed on the embossed metallized substrate (Alukett Spezial Fashion), in most cases, were slightly less resistant to liquid chemical agents. Or, it is maybe 
possible that on rougher surface, where deposited ink adheres to the irregularities of the embossed surface, the change in colour caused by treatment with the liquid agents, becomes more prominent than on smoother surface where ink is deposited in more uniform layer.

Also, it should be noted that, even though the prints were not able to completely withstand exposure to specific liquid agents which was demonstrated by their optical deterioration, the thermochromic effect was still present in them after resistance tests were conducted.

Figures 9-11 show reflectance spectra for tested TC prints on both substrates before and after treatment with each specific liquid.
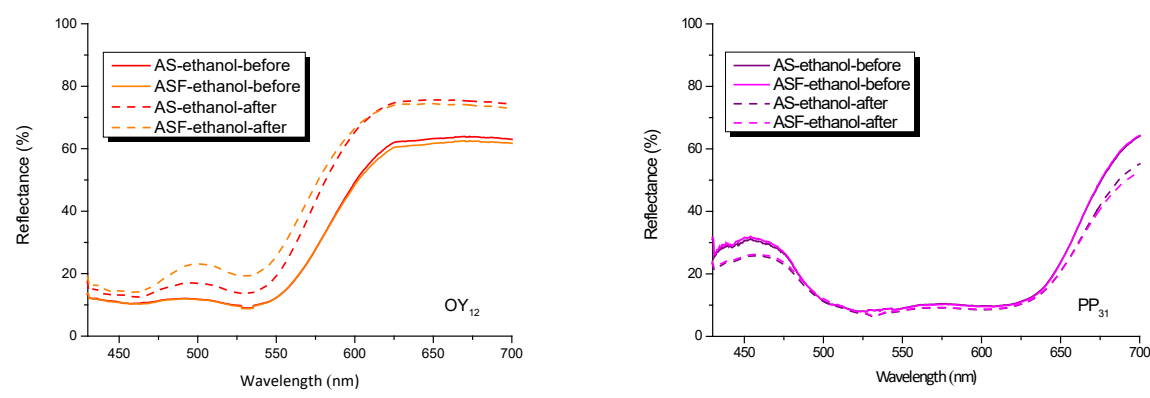

Figure 9: Spectral reflectance curves for the $\mathrm{OY}_{12}$ and $P P_{31}$ samples on two papers (AS - Alukett Spezial, ASF - Alukett Spezial Fashion), before and after treatment with ethanol
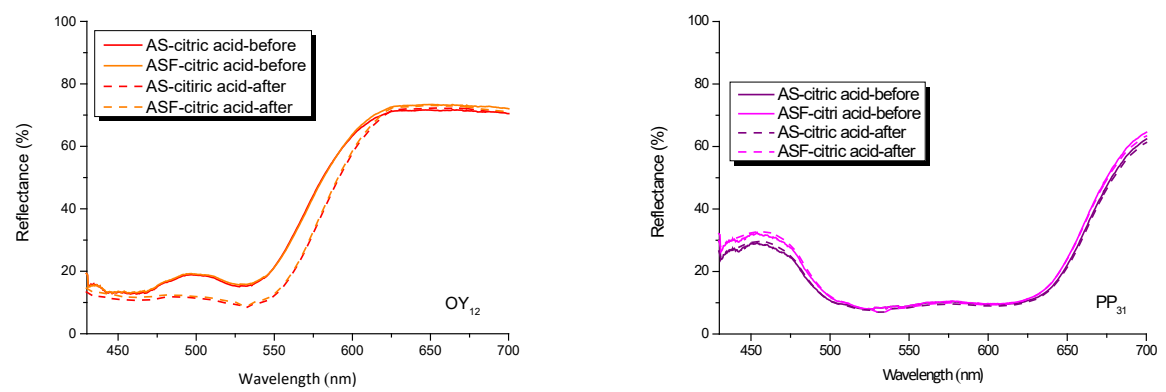

Figure 10: Spectral reflectance curves for the $O Y_{12}$ and $P P_{31}$ samples on two papers (AS - Alukett Spezial, ASF - Alukett Spezial Fashion), before and after treatment with citric acid
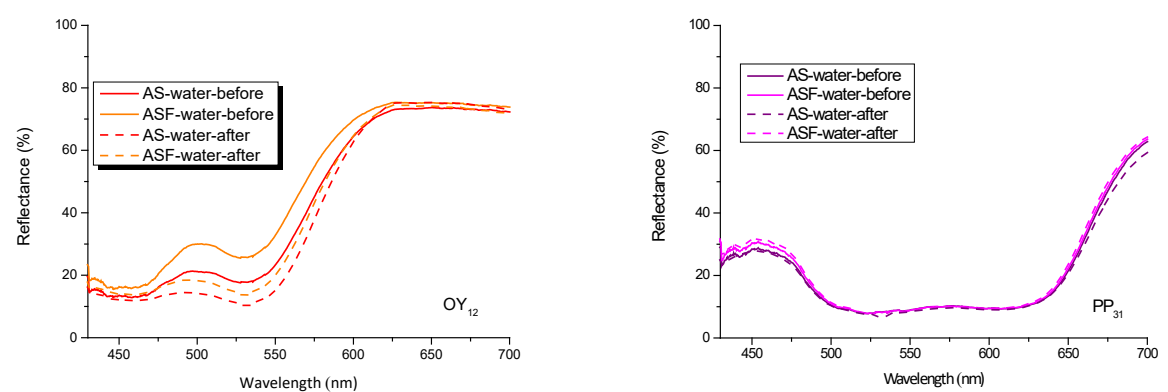

Figure 11: Spectral reflectance curves for the $O Y_{12}$ and $P P_{31}$ samples on two papers (AS - Alukett Spezial, ASF - Alukett Spezial Fashion), before and after treatment with water

At temperatures at which TC microcapsules are active $\left(\mathrm{OY}_{12}\right.$ at $8^{\circ} \mathrm{C}$ and $\mathrm{PP}_{31}$ at $20^{\circ} \mathrm{C}$ ), spectral reflectance curves in the range of 430 to $700 \mathrm{~nm}$ were read. Larger deviations are evident from the curves on the $\mathrm{OY}_{12}$ sample than on $\mathrm{PP}_{31}$. On the $\mathrm{PP}_{31}$ sample, the largest deviation is visible after ethanol treatment, although this difference is smaller than on $\mathrm{OY}_{12}$ sample. The results correlate with the measured dE2000 values and show that the degradation on $\mathrm{OY}_{12}$ is higher on both media than on $\mathrm{PP}_{31}$ indicating poorer stability of that TC ink. 


\section{CONCLUSIONS}

After assessment of TC inks' resistance to rub and to selected liquid agents the following could be concluded.

Thermochromic UV inks showed good rub resistance as no rub was detected either by visual inspection or by spectrophotometric evaluation of colorimetric changes of the prints.

All tested TC prints showed low resistance to liquid chemical agents, especially to the ethanol, which as a strong solvent degraded the prints at the highest extent.

Higher bleeding of colorants was visually inspected from $\mathrm{PP}_{31}$ prints than form $\mathrm{OY}_{12}$ prints, while at the same time, spectrophotometric evaluation showed that prints made with $\mathrm{OY}_{12}$ inks had a lower resistance to all liquid agents in comparison to $\mathrm{PP}_{31}$ prints.

Highest colour differences were noticed when prints were in their "cold state", i.e. below their $\mathrm{T}_{\mathrm{A}}$ when thermochromic microcapsules were active.

The metallized label paper with a rougher surface was slightly more affected by the liquid agents than the one with smoother and radiant surface.

However, even though the prints were not able to completely withstand exposure to specific chemical agents which was demonstrated by their optical deterioration, the thermochromic effect was still present in them after the resistance tests were conducted.

\section{ACKNOWLEDGMENTS}

The authors are grateful for the financial support of the University of Zagreb (Financial support for research in 2020).

\section{REFERENCES}

[1] Bäckman, M.: "Feasibility study of thermochromic inks for the packaging industry", URL: https://lup.lub.lu.se/student-papers/search/publication/8905340 (last request: 2020-20-09), 2017.

[2] Bozhkova, T. T., Boeva, R., Spridonov, I., Sapkota, J., Nedelchev, Y. V., Kašiković, N., Dedijer, S., Pal, M.: "Improvement of physical-mechanical and optical properties of the packaging production through coating with aqueous polymer dispersions in accordance with the environmental protection requirements", Bulgarian Chemical Communications 49, 169-173, 2017.

[3] Brancher: "Fastness of inks: Chemical resistance", URL: http://www.brancher.com/-Resistance-auxagents-chimiques-.html?lang=en (last request: 2020-20-09), 2020.

[4] British Standards Institution, BS 3110(1959):1959 Methods for measuring the rub resistance of print, British Standards Institution, 1959.

[5] CIE: "Colorimetry, 3rd Edition", (CIE, Vienna, 2004.)

[6] Đurđević, S., Novaković, D., Vladić, G., Kašiković, N.: "The development of novel smart packaging labels and mobile application for protection, information and identification of product shelf life", Acta Graphica: Journal for Printing Science and Graphic Communications 26, 35-41, 2015.

[7] Homola, T. J.: "Color-changing inks", (McGraw-Hill Global Education Holdings, New York NY, 2008.). doi: 10.1036/1097-8542.YB080620

[8] International Organization for Standardization, ISO 2836:2004 Graphic Technology- Prints and printing inks- Assessments of resistance to various agents, International Organization for Standardization, 2004.

[9] Kulčar, R., Friskovec, M., Hauptman, N., Vesel, A., Klanjšek Gunde, M.: "Colorimetric properties of reversible thermochromic printing inks", Dyes and Pigments 86, 271-277, 2010. doi: 10.1016/j.dyepig.2010.01.014.

[10] Lam Po Tang, S., Stylios, G. K.: "An overview of smart technologies for clothing design and engineering", International Journal of Clothing Science and Technology 18, 108-128, 2006. doi: 10.1108/09556220610645766.

[11] Rožić, M., Vukoje, M., Kapović, D., Marošević, L.: "Solvents interactions with thermochromic print", Journal of Graphic Engineering and Design 8, 19-25, 2017. doi: 10.24867/JGED-2017-2-019.

[12] Rudolf, M., Plazonić, I., Petrić Maretić, K., Bates, I., Radić Seleš, V.: "Rub resistance of ink jet prints on laboratory substrates with wheat pulp", Printing\&Design 2020, (Fotosoft d.o.o.: Zagreb, Croatia, 2020) pages 126-131, 2020. 
[13] Seeboth, A., Lotzsch, D.: "Thermochromic and thermotropic materials", (CRC Press, Boca Raton FL, 2013.)

[14] Seeboth, A., Lotzsch, D.: "Thermochromic Phenomena in Polymers", (Smithers Rapra Technology Limited, Shropshire UK, 2008.)

[15] WRAP: "Using thermochromic inks to reduce household food waste", URL: http://www.wrap.org.uk/content/using-thermochromic-inks-reduce-household-food-waste-0 (last request: 2020-20-09), 2013.

[16] Zhou, W. H., He, B. H., Zhang, C. X., Han, Y.: "Analysis on Ink Layer Rub Resistance for Coated Paper Prints", Advanced Materials Research 380, 173-178, 2011. doi:

10.4028/www.scientific.net/AMR.380.173.

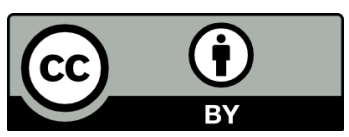

(C) 2020 Authors. Published by the University of Novi Sad, Faculty of Technical Sciences, Department of Graphic Engineering and Design. This article is an open access article distributed under the terms and conditions of the Creative Commons Attribution license 3.0 Serbia (http://creativecommons.org/licenses/by/3.0/rs/). 


\title{
PCL-TIO 2 NANOCOMPOSITE TO IMPROVE AGEING OF OFFSET PRINTS
}

\author{
Tomislav Hudika (D), Tomislav Cigula (D), Mihaela Žličarić (D), Maja Strižić Jakovljević (iD) \\ University of Zagreb, Faculty of Graphic Arts, Zagreb, Croatia
}

\begin{abstract}
UV radiation or sunlight can affect the printed sample by fading the ink surface and therefore the product losses it's decorative purpose and becomes less desirable to the customer. To create the efficient protective coating, titanium dioxide $\left(\mathrm{TiO}_{2}\right)$ will be used as a well-known compound that should lower the effects of UV radiation. $\mathrm{TiO}_{2}$ should lower the colour fade after UV radiation and this will be determined by densitometric and colorimetric (CIE $L^{*} a^{*} b^{*}$ ) measurements. In addition, measurement of print gloss will also be conducted to evaluate visual appearance of the sample. Biopolymer Polycaprolactone (PCL) was the base of the $\mathrm{PCL}^{-\mathrm{TiO}_{2}}$ composite in which $\mathrm{TiO}_{2}$ nano sized. To determine influence of the amount of $\mathrm{TiO}_{2}$, three composites were prepared by adding different weight ratio of the $\mathrm{TiO}_{2}$. The prepared nanocomposites were then applied onto the offset prints on gloss art print paper and on the uncoated paper. The results have shown that $\mathrm{TiO}_{2}$ coating does affect ink's density, colorimetric properties and print gloss after initial coating. The change in chroma due to the accelerated ageing is most visible on yellow ink, cyan and magenta proved to be the more stable. Accelerated ageing caused change in the $\mathrm{L}^{*}$ of black. On all colours, increase of the $\mathrm{TiO}_{2}$ weight ratio improved resistance of colour to change. Coated gloss paper was more resistant to density change where uncoated had lower change in chroma. It could be concluded that $\mathrm{TiO}_{2}$ has the ability to protect the prints in the measured time interval but it has to be noted that concentration of the $\mathrm{TiO}_{2}$ particles also causes colour difference and must be observed when defining composure of the nanocomposite.
\end{abstract}

Keywords: Nanocomposite, offset, coating, biopolymer, $\mathrm{PCL}, \mathrm{TiO}_{2}$

\section{INTRODUCTION}

Cardboard packaging has a vast share in the packaging industry. Regardless of the general opinion, the packaging industry is supposed to grow in the period of 2018 - 2022 up to $3.1 \%$ annually, according to Smithers-Pira (Smithers-Pira, 2018.) Industries are faced with the new trends, such as eco-friendly and "green" industry development and packing is no exception (Kovačević et al, 2019). Nevertheless, application of these concepts must not degenerate its basic purpose and requirements which are product protection and aesthetics (Makower, 2006).

Paperboard itself has some weak points and therefore usage of synthetic materials is growing in general use but those materials do have some disadvantages in terms of recyclability and biodegradation (Vukoje, 2018). Paper based materials are more suitable to meet those environmental-friendly requirements but they lack the good barrier properties, resistance to colour fading when exposed to UV radiation, tensile strength and more (Bota et al, 2018). One of solutions is to coat with overprint varnishes (OVPs) in order to improve their downsides. A number of currently used OVPs are not eco-friendly, which leads to the research of substitute materials (Bota, 2017).

Biodegradable materials such as biopolymers are increasingly applied as coating materials (Rastogi et al, 2015). The surface of the paper can be coated with polymer layer that contains nanoparticles which could fulfil the requirements of the OVP (Uglesic, 2015). The surface properties such as wettability, strength, water-vapor permeability as well as the optical properties (colour resistance to colour fading, ink density and print gloss (Afsharpour et al, 2017).

To improve properties of the biodegradable material one usually adds some chemical compounds. Recently, nanomaterials are widely used in composition of these materials (Fithriyah et al, 2015). Mechanical and optical properties are largely dependent on the nanoparticle's degree of dispersion in the biopolymer solution. Depending on the weight ratio of nanoparticles in the mixture, nanocomposites can display different properties as well.

In order to lower degradation of prints due to the UV radiation or general sunlight titanium-dioxide $\left(\mathrm{TiO}_{2}\right)$ nanoparticles could be used (Miklečić et al, 2015). Titanium dioxide, also called titania $\left(\mathrm{TiO}_{2}\right)$ is a white, opaque, naturally occurring mineral which exists in the number of crystalline forms. Its most important and useable forms are rutile and anatase. The most important function in the powder form is the pigment used for whiteness and opacity. Titanium-dioxide is also used to protect materials from UV radiation (ex. 
inks from fading) due to its ability to absorb ultraviolent light. In this paper $\mathrm{PCL}-\mathrm{TiO}_{2}$ composites will be investigated to determine its usability as an OVP.

\section{MATERIALS AND METHODS}

For the purpose of this research, the most common paper types, coated and uncoated, were chosen gloss art print paper (coated) with production name UPM Finesse gloss paper and offset paper (uncoated) with production name Tauro offset, both of $300 \mathrm{~g} / \mathrm{m}^{2}$. The samples were printed by means of sheetfed offset printing press KBA Rapida 105 with quickset process inks (Novavit Supreme Bio, Flintgroup) in compliance with the Fogra PSO 2016 printing process (Kipphan, 2001).

The nanocomposites were prepared by dissolving PCL (6800 Capa) in ethyl acetate with heated magnetic stirrer in air-tight container for 120 minutes, $\mathrm{TiO}_{2}$ nanoparticles (Sigma Aldrich rutile) were added with weight ratios of $0.10 \%, 0.25 \%$ and $0.50 \%$, samples designated as Ti010, Ti025, Ti050 while sample where coating process was not conducted is designated as ORG. The nanoparticles were homogenized into PCL solution with ultrasound dispenser Hirrlscher UP100H for 10 minutes at $100 \%$ amplitude and $100 \%$ power.

The polycaprolactone or PCL is a biodegradable polymer with a low melting point around 60 degrees Celsius. Its common use is as an additive to resins, modelling via 3D printer and with its high level of compatibility with other materials also as a base for primers or coatings (Rastogi et al, 2015).

Nanocomposites were applied to printed samples using K202 Control Coater in controlled conditions defined by the ISO 187:1990 while the wet OVP's thickness was approx. $24 \mu \mathrm{m}$, as defined by the coating bar standard bar 3.

After drying and characterization, the varnished samples were placed into Cofomegra Solarbox 300 Xenon Test chamber (Cofomegra, 2020). The samples were subjected to indoor exposure (sunlight through a glass window, ATSM 3424-11 2011). Exposure in the test chamber was divided into intervals of 2 (0 - 10 hours) and 5 hours (10 - 25 hours).

The prepared samples were analysed by measuring colorimetric coordinates in compliance with $\mathrm{CIE}$ $L^{*} a * b *$ colour space and relative print density (D). The results were obtained by Techkon SpectroDens spectrophotometer (Techkon Spectrodensitometer, 2020).

The instrument settings for colorimetric measurements were light source D50, standardized observer $2^{\circ}$, no polarization filter, filter $\mathrm{M} 1$ and calibrated on absolute white. Densitometric measurements' settings were density filter status E, light source D50, polarization filter included, calibrated on paper sample. In addition, after measuring $\mathrm{CIE} \mathrm{L}^{*} \mathrm{a}^{*} \mathrm{~b}^{*}$ coordinates, colour difference $\Delta \mathrm{E}_{\mathrm{ab}}$ was calculated (Mokrzycki et al, 2014). Although there are newer colour difference formulas, the $\Delta E^{*}$ ab is an important feature for graphic reproduction. It is still used to evaluate compliance to the international standard (ISO 12647$2: 2013)$, which provides tolerances in the reproduction of process colours $\left(\Delta \mathrm{E}^{*} \mathrm{ab}<5\right)$ (Sharma et al, 2005). Measurements were conducted in every of 2 (0 - 10 hours) and 5 hours (10 - 25 hours) of accelerated ageing.

The print gloss was measured with the use of Elcometer 407 statistical gloss meter at the angle of 60 degrees (Elcometer n.d.). The intensity of the light depends on the measured material and the angle of illumination. In the case of non-metals (coating, plastics), the amount of reflected light increases with increased angle of illumination which mimics the human eye (Hunter, 2012). The remaining part of the light penetrates into the material and is absorbed or diffused (Van der Walle et al, 1999).

\section{RESULTS}

The relative density measurement is more used in process control on the printing machine, but could provide us information about ink layer, indirectly to the strength of a process colour. In this research ink density could give a quick response about ink fading. Fading as phenomena can be explained as a change in ink's density measured via reflectiveness (Wang et al, 2018).

\subsection{Ink density on coated paper}

In Table 1 one could see that ink density is generally decreasing for all four inks when increasing weight ratio of $\mathrm{TiO}_{2}$ in coating. 
Table 1: Density for all four inks with and without nanocomposite coating before ageing process

\begin{tabular}{|c|c|c|c|c|}
\hline & ORG & Ti010 & Ti025 & Ti050 \\
\hline Cyan & 1.43 & 1.41 & 1.44 & 1.39 \\
\hline Magenta & 1.51 & 1.52 & 1.49 & 1.46 \\
\hline Yellow & 1.33 & 1.32 & 1.30 & 1.24 \\
\hline Black & 1.77 & 1.74 & 1.70 & 1.66 \\
\hline
\end{tabular}

Decrease of the density value is largest on the black (achromatic colour) and lowest on the cyan. As the $\mathrm{TiO}_{2}$ is a white powder increases reflection of the light from the surface and therefore causing decrease of the ink film density on a substrate (Kumar et al, 2012). In Figure 1, one can diagrams for density change $\left(D^{\prime}\right)$ of the cyan and magenta ink during accelerated ageing process. Density change ( $\left.D^{\prime}\right)$ is calculated using Equation (1).

$D^{\prime}=\frac{D_{0}}{D_{i}}$

where $D_{0}$ is the initial density value before ageing process and $D_{i}$ is the density value after certain period (i) of the accelerated ageing process.

Observing Figures 1 and 2 one could see that density change of cyan and black are almost none while on magenta and yellow one could see increasing trend of density change over accelerated ageing change.
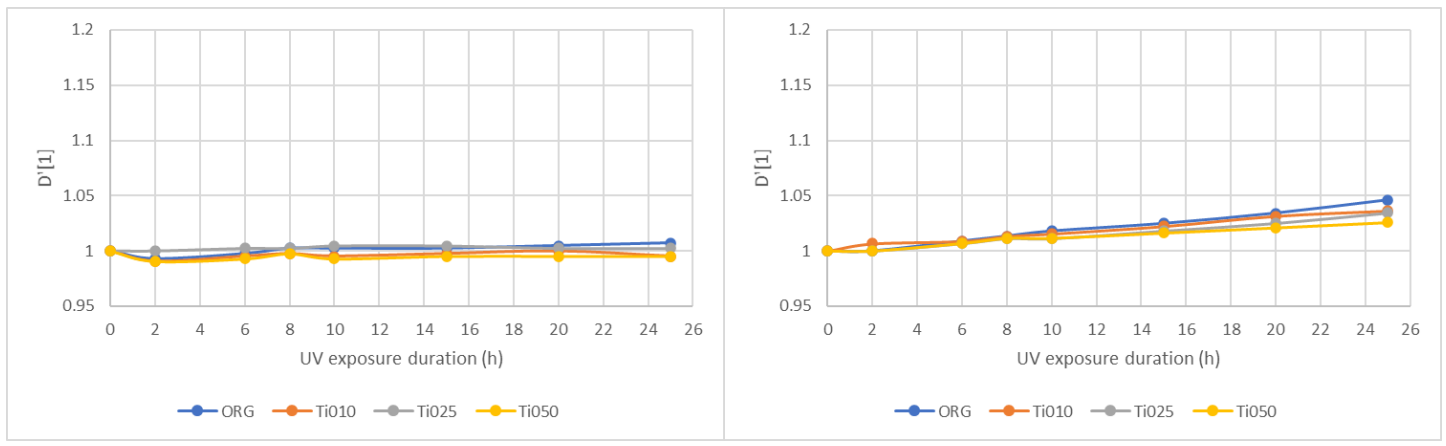

Figure 1: Ink density change ( $\left.D^{\prime}\right)$ - cyan (left) and magenta (right)

Although less visible on black and cyan, on all printed samples is the protection by the nanocomposite noticed. Furthermore, increasing the weight ratio of the $\mathrm{TiO} 2$ in a nanocomposite increases protective role to the ink film over time. This behavior is most likely a consequence of the UV light absorbance of the TiO2 (Hongying et al, 2004) which then disables degradation of the colour under the nanocomposite layer.
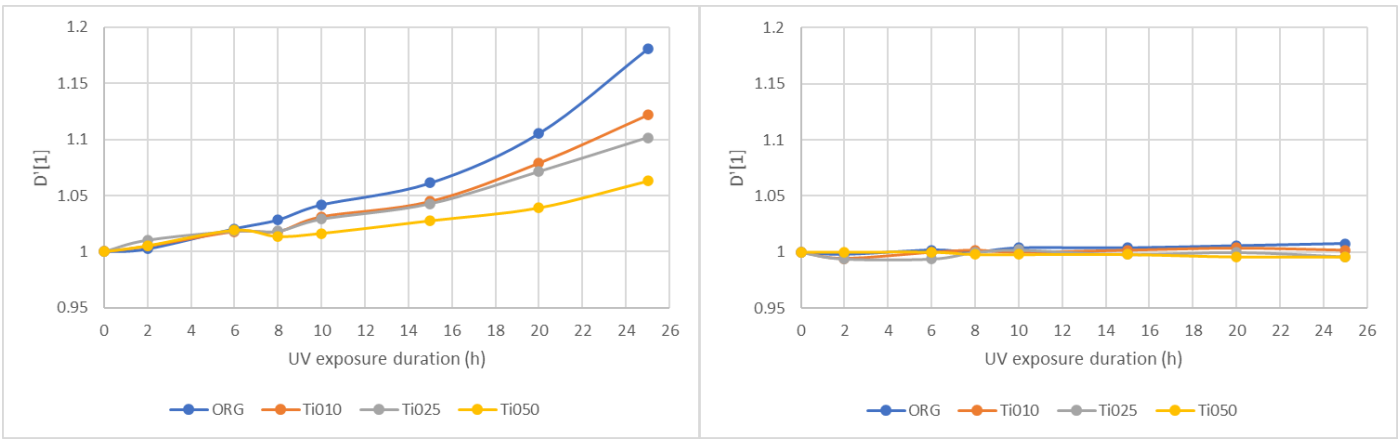

Figure 2: Ink density change ( $\left.D^{\prime}\right)$ - yellow (left) and black (right)

\subsection{Ink density on uncoated paper}

Ink density on uncoated substrates is lower from the one found on gloss substrates. In Table 2 one could see the ink's density of printed samples before the ageing process. As mentioned before, fading as 
phenomena can be explained as a change in ink's density measured via reflectiveness which in this case due to surface properties is very low as the substrate itself is matte (Kappel et al, 2008).

Table 2: Density for all four inks and concentration before ageing process

\begin{tabular}{|c|c|c|c|c|}
\hline & ORG & Ti010 & Ti025 & Ti050 \\
\hline Cyan & 0.97 & 0.95 & 0.98 & 0.96 \\
\hline Magenta & 0.98 & 0.99 & 1.00 & 1.01 \\
\hline Yellow & 0.91 & 0.90 & 0.91 & 0.91 \\
\hline Black & 1.27 & 1.24 & 1.26 & 1.25 \\
\hline
\end{tabular}

On diagrams in Figure 3, cyan and magenta are presented in entire tested accelerated aging period. The density change of cyan is increasing, i.e. the ink is lowering the density value, but in a very small amount regardless on application of nanocomposite coating. Magenta's results do show that ink is decreasing density faster than observed at cyan.
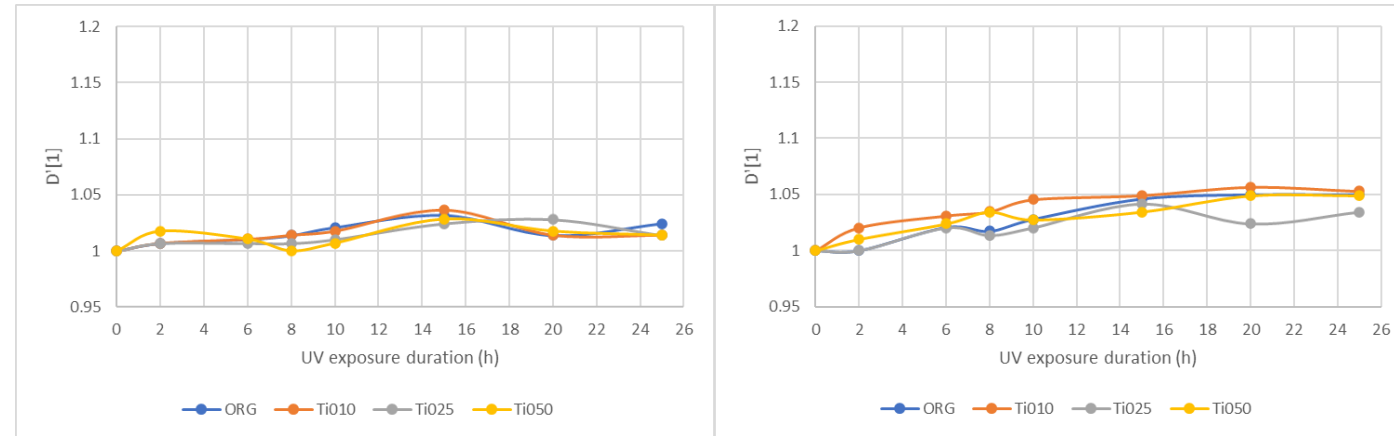

Figure 3: Ink density change ( $\left.D^{\prime}\right)$ - cyan (left) and magenta (right)

The biggest density decay has occurred on original yellow samples on uncoated samples and most stable ink in this accelerated ageing process was black (Figure 4). On both inks it is clearly visible that nanocomposite protects them from change in density. Different to the coated paper, on the uncoated paper protection role of the nanocomposite coating is not so connected with the weight ratio of the $\mathrm{TiO}_{2}$ in it as smallest density change on yellow is obtained by the nanocomposite with $0.25 \% \mathrm{TiO}_{2}$, on black this is achieved by nanocomposite with $0.10 \% \mathrm{TiO}_{2}$.
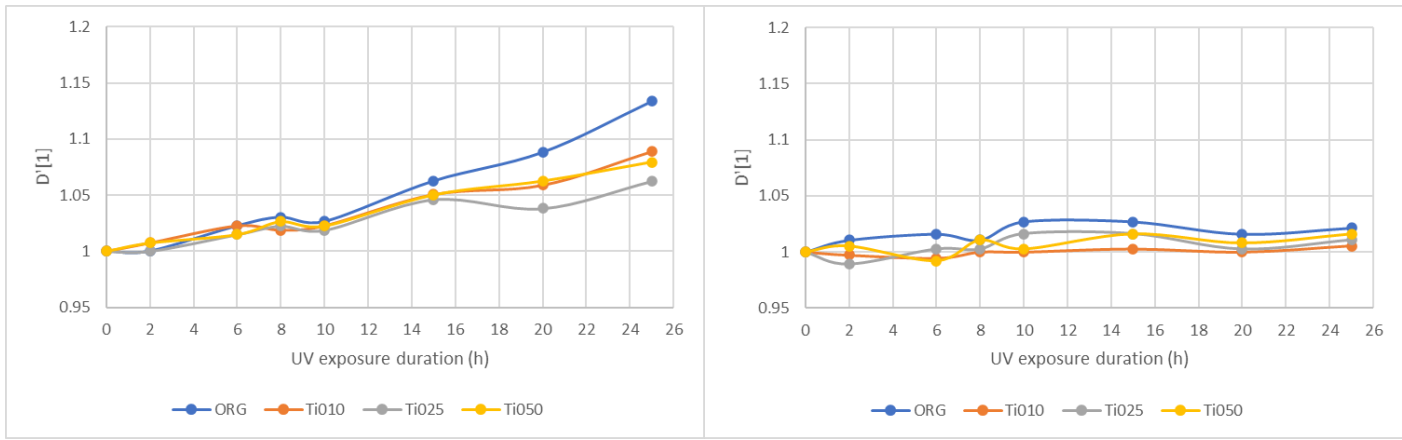

Figure 4: Ink density change ( $\left.D^{\prime}\right)$ - yellow (left) and black (right)

The different effect of prepared nanocomposites on the print's protection during accelerated ageing is most probably due to the absorption of the uncoated paper in comparison to the coated paper. The micro-unevenness on the uncoated paper causes the absorption of the nanocomposite in the coating process leaving nanoparticles trapped in the paper and disabling them to absorb part of the light, i.e. disable fading of the inks. 


\subsection{Colorimetric analysis on coated paper}

In this paragraph colorimetric measurements are presented. The colour difference is presented between average measured colour coordinates in the CIE L*a*b* colour space and colour coordinates provided by Fogra PSO 2016.

In Table 3, are presented colour differences $\Delta \mathrm{E}_{\mathrm{ab}}$ before accelerated ageing. It can be seen that all the printed inks on the original (before coating) are in compliance to the Fogra PSO, but magenta is very close to the allowed tolerance $\left(\Delta \mathrm{E}_{\mathrm{ab}}<5\right)$. The colour difference of the coated samples are out of the allowed difference on magenta samples and black coated with nanocomposite in which weight ratio of $\mathrm{TiO}_{2}$ is $0.5 \%$. The used magenta ink has a bit high $b^{*}$ coordinate $\left(b^{*}=-1\right)$ than defined by the standard $\left(b^{*}=-5\right)$ which even increases with coating, On the other hand, increasing the amount of the $\mathrm{TiO}_{2}$ particles will lead to the increase of lightness of the sample, which influences black most.

Table 3: $\Delta E_{a b}$ for all four inks and concentration before ageing process

\begin{tabular}{|c|c|c|c|c|}
\hline & ORG & Ti010 & Ti025 & Ti050 \\
\hline Cyan & 1.61 & 1.98 & 1.38 & 1.92 \\
\hline Magenta & 4.17 & 6.65 & 7.24 & 7.58 \\
\hline Yellow & 2.56 & 3.43 & 1.77 & 1.52 \\
\hline Black & 3.18 & 2.05 & 2.67 & 5.91 \\
\hline
\end{tabular}

As previously investigated (Havlínová et al, 2002) the ageing process highly influences lightness of black and chromatic components of other process colours. Therefore, to determine influence of the accelerated ageing on the prepared samples, calculation of the chroma $(C)$ and chroma change $\left(C^{\prime}\right)$ was performed for the cyan, magenta and yellow and lightness change ( $\left.L^{\prime}\right)$ for black. The chroma change was calculated by the following Formula (2):

$C^{\prime}=\frac{C_{0}}{C_{i}}$

Where $C_{0}$ is chroma before the accelerated ageing and the $C_{i}$ is chroma on the sample after certain period (i) of the accelerated ageing process.

In the Figures 5 and 6 are presented values of calculated chroma change on the samples printed on coated paper. If the chroma change $\left(C^{\prime}\right)$ is lower than 1 means that the chroma of the sample increased and $C^{\prime}$ higher than 1 means that chroma of the sample is lower than on the beginning.
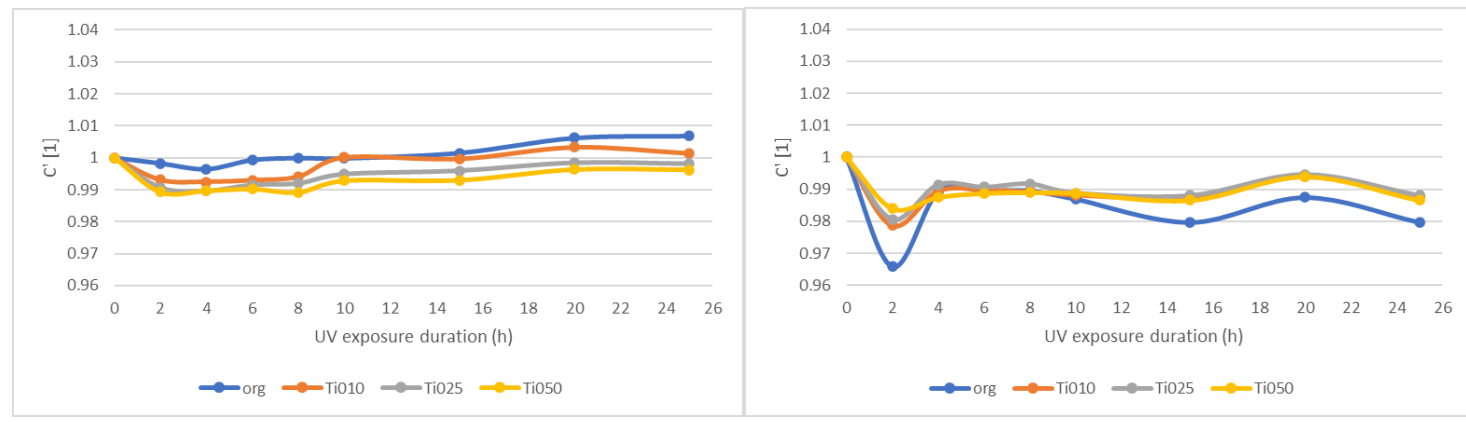

Figure 5: Chroma change - cyan (left) and magenta (right)

As seen in the Figure 5, the chroma of the magenta ink is stable regardless on the accelerated ageing time and nanocomposite used. On the other hand, on cyan and yellow ink it is clearly seen decrease of the chroma with the duration of the accelerated ageing process (Figure 6). In addition, on both inks there is visible trend that chroma change is lower with the increase of the added $\mathrm{TiO}_{2}$ particles in the nanocomposite proving the positive effect of the added nanoparticles. 


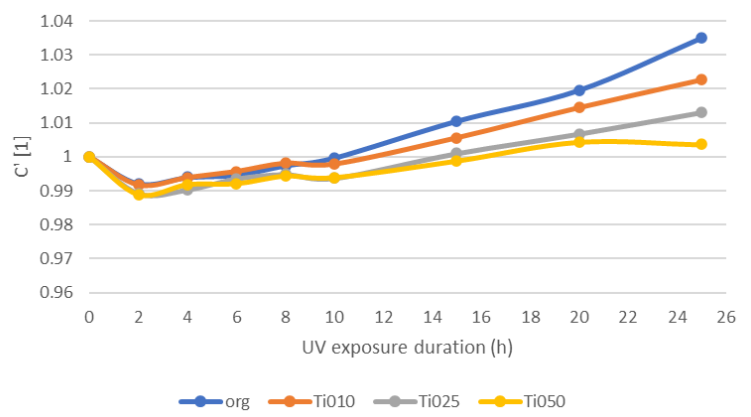

Figure 6: Chroma change - yellow

The $\mathrm{TiO}_{2}$ as a nanoparticle has various application among others is ability to absorb UV light and therefore could be used as part of the protective coating (Khitab et al, 2018). The changes that occurred with the black ink were tracked via $L^{*}$ coordinate as to black being achromatic and therefore the change in a* and $b^{*}$ coordinate is less relevant. The diagram in Figure 6 shows the lightness change $\left(L^{\prime}\right)$. The lightness change ( $\left.L^{\prime}\right)$ was calculated using the following Formula (3):

$L^{t}=\frac{L_{0}}{L_{i}}$

where $L_{0}$ is chromatic value at the beginning and $L_{i}$ is lightness of the colours after defined (i) accelerated ageing period.

Same as the chroma change, results in the Figure 7 mean that lightness of the sample is lower than initial if the $L^{\prime}$ is higher than 1 and lower than initial if $L^{\prime}$ is higher than 1 . As with the chroma of the cyan and yellow it is visible that increasing weight ratio of the $\mathrm{TiO}_{2}$ in composite provides better protection of the sample colour and reduces change of the lightness of the black ink ( $L^{\prime}$ nearer to 1 ). Although it was expected that black ink without protection would get lighter, results show opposite, the $L^{*}$ is decreasing during accelerated ageing process. This change is low and is close to the instrument repeatability (SpectroDens, 2020), but the trend could be noticed.

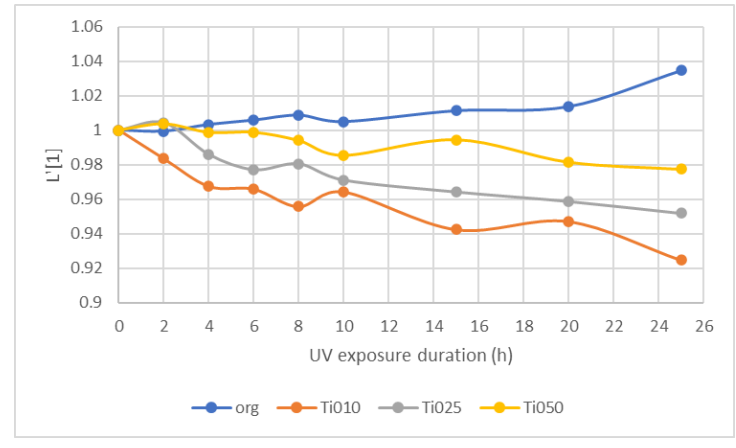

Figure 7: Lightness change - black

\subsection{Colorimetric analysis on uncoated paper}

The uncoated paper is more resistant to colour change after varnishing as to its counterpart - coated gloss paper. This phenomena is linked to the uncoated paper's surface which is more rough and absorptive, leading to the lower ink densities which are present through reflectiveness (Kappel et al, 2008). The colour difference is presented between average measured colour coordinates in the CIE $L^{*} a^{*} b^{*}$ colour space and colour coordinates provided by Fogra PSO 2016. In Table 4, are presented colour differences $\Delta \mathrm{E}_{\mathrm{ab}}$ before accelerated ageing. It can be seen that all the printed inks on the original (before coating) are in compliance to the Fogra PSO. Moreover, $\mathrm{TiO}_{2}$ coating did lower the $\Delta \mathrm{E}_{\mathrm{ab}}$ on magenta, yellow and black which is because PCL coating itself lowers lightness of the colours (Golik, 2020). 
Table 4: $\Delta E_{a b}$ for all four inks and concentration before ageing process

\begin{tabular}{|c|c|c|c|c|}
\hline & ORG & Ti010 & Ti025 & Ti050 \\
\hline Cyan & 3.62 & 3.256 & 2.33 & 3.05 \\
\hline Magenta & 1.71 & 1.08 & 1.45 & 1.79 \\
\hline Yellow & 3.56 & 3.09 & 2.18 & 2.54 \\
\hline Black & 3.85 & 1.64 & 0.75 & 1.69 \\
\hline
\end{tabular}

On diagram in the Figure 8, one can see that cyan had very low change in chroma change during the tested and measured period of time. If the chroma change $\left(C^{\prime}\right)$ is lower than 1 means that the chroma of the sample increased and $C^{\prime}$ higher than 1 means that chroma of the sample is lower than on the beginning.

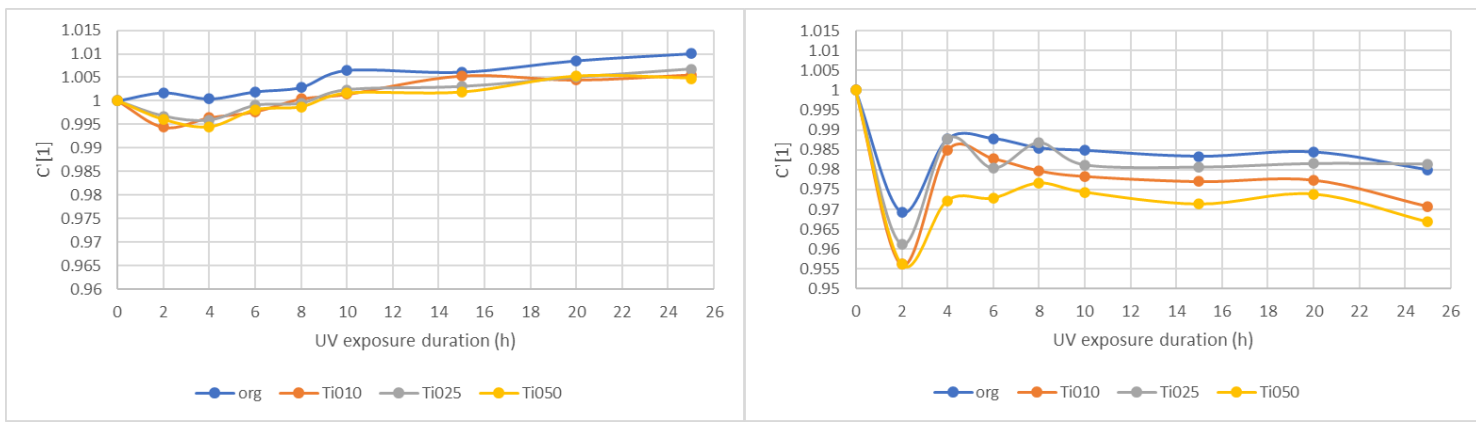

Figure 8: Chroma change - cyan (left) and magenta (right)

Observing Figures 8 and 9 one could see that accelerated ageing influences prints on the uncoated paper differently to the ones on the coated paper. Only cyan is decreasing chroma by exposed to the light in the accelerated ageing process, but the decrease is lower on the samples coated with nanocomposites (Figure 7). Magenta and yellow increase chroma, with yellow being less affected by nanocomposite coating, i.e. chroma change of all yellow samples are similar to the 10 hours of accelerated ageing. The yellow and magenta are inks with predominant chromatic coordinates in CIE L*a*b* colour space with magenta dominant in $+a^{*}$ and yellow with dominant $+b^{*}$. The opposite coordinate $\left(b^{*}\right.$ by magenta and $a^{*}$ by yellow) is of low value and with having in mind lower ink film on rough and absorptive uncoated paper, the varnishing and/or ageing process causes changes in coordinates which could compensate the chroma change. In this research, magenta decreases slightly $a^{*}$ coordinate, but increases $b^{*}$, while by yellow was the opposite (the change itself was small $\approx 1$ ).

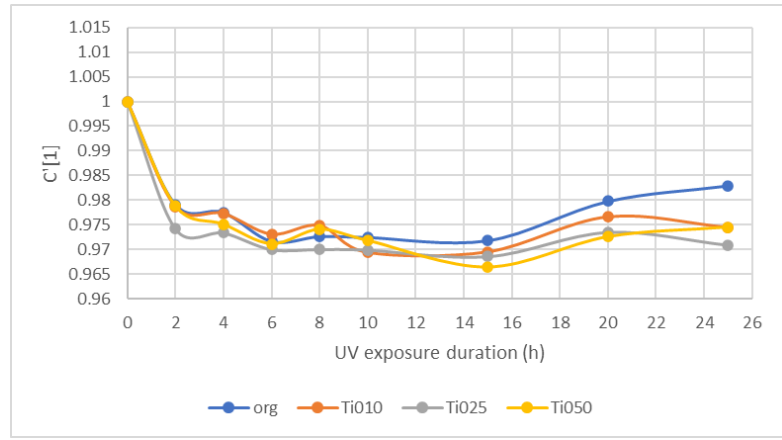

Figure 9: Chroma change - yellow

Same as the chroma change, results in the Figure 10 mean that lightness of the sample is lower than initial if the $L^{\prime}$ is lower than 1 and higher than initial if $L^{\prime}$ is higher than 1 . Although it was expected that only the black ink without protection would get lighter, results do show the opposite. All measured results are scattered throughout the diagram meaning that $\mathrm{TiO}_{2}$ was probably soaked into the substrate as there is no trend. Black did undergo the biggest colour change ( $\left.\Delta \mathrm{E}_{\mathrm{ab}}\right)$ in the initial measurement provided in the Table 4 above and this both phenomena can be linked. 


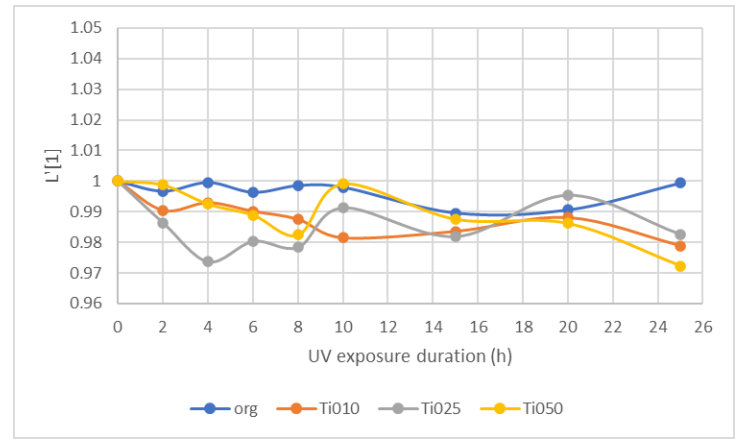

Figure 10: Lightness change - black

\subsection{Print gloss analysis on coated paper}

Print gloss as an important visual aspect was measured to see the dependence of the gloss to the accelerated ageing process. In Figure 11, cyan and magenta gloss unit diagrams are shown. The print gloss values are expressed in gloss units (GU) measured by means of previously mentioned glossmeter (Landy, 2007). It can be noted that gloss is widely effected by the weight ratio of $\mathrm{TiO}_{2}$. The uncoated, cyan printed sample has $71.1 \mathrm{GUs}$ at the beginning while the value goes down in an almost linear with increase of weight ratio of $\mathrm{TiO}_{2}$. The accelerated ageing impacts the overall print gloss of the uncoated sample the most, while samples protected by nanocomposites deteriorate less. Magenta had lower GU value at the beginning, compared to the cyan. The nanocomposite coating also lowered the initial gloss.
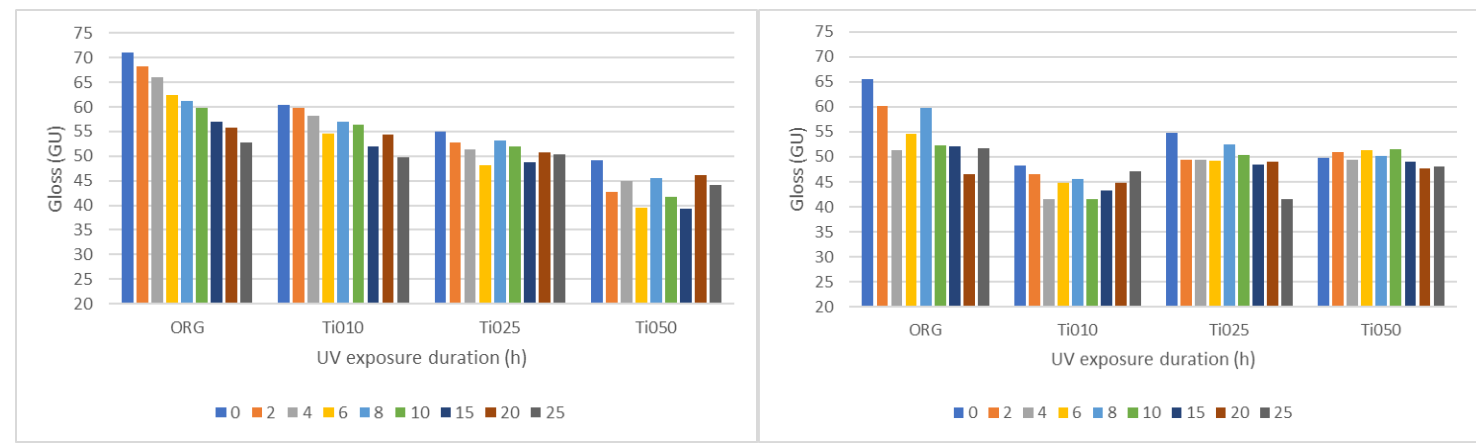

Figure 11: Print gloss - cyan (left) and magenta (right)

On yellow and black one can see similar behaviour with nanocomposites lowering the initial gloss and stabilizing it throughout the entire ageing interval (Figure 12). One can see from this diagrams that the bigger the nanoparticle concentration, lower the gloss units. Black sample's ink gloss was most affected by the $0,5 \%$ concentration where initial gloss was lowered in a substantial amount. This could be the consequence of agglomeration of the particles leading to the more uneven surface of the print sample.

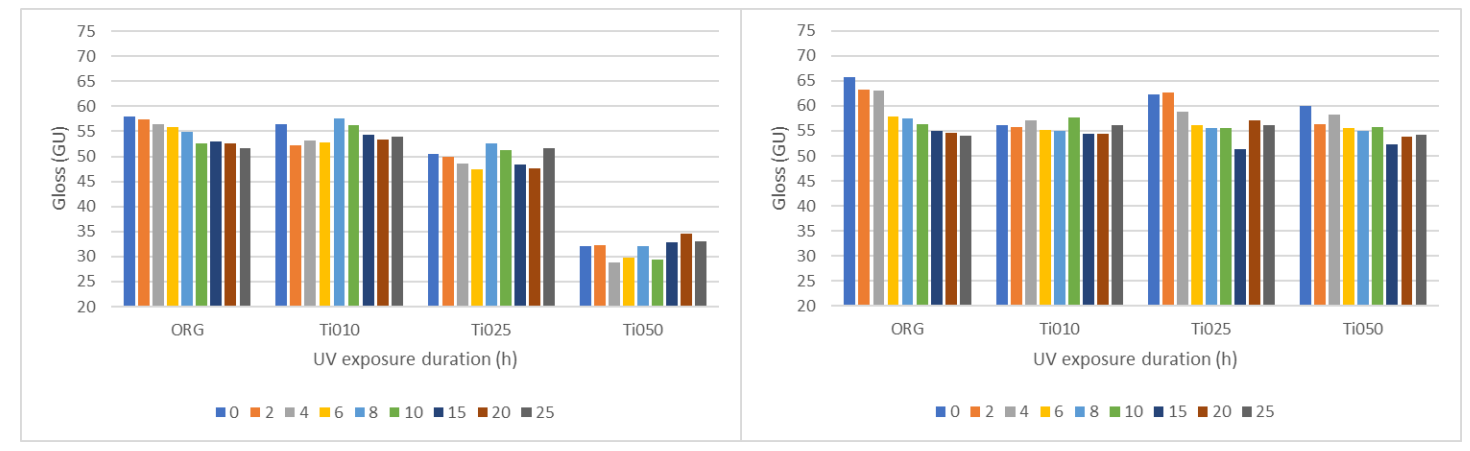

Figure 12: Print gloss - yellow (left) and black (right) 


\subsection{Print gloss analysis on uncoated paper}

Print gloss measured on the uncoated offset paper is very low due to the substrate surface properties. According to the ISO 2813 all measured values under 10 are considered matte while over 3 GU difference on very matte surface is visible to human eye (Landy, 2007). On Figure 13 and 14, diagrams for print gloss on uncoated paper can be seen. The change on all measured inks are barely visible and therefore irrelevant on macro scale. On micro scale one can notice that UV radiation does not influence the ink or the coating in the terms of print gloss on uncoated paper.

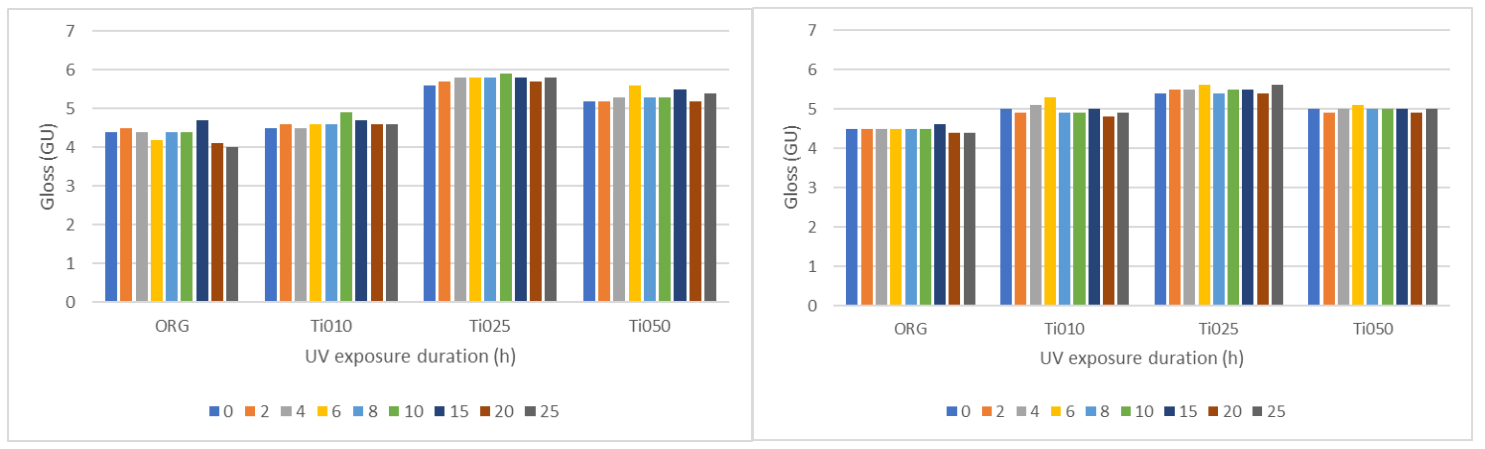

Figure 13 Print gloss - cyan (left) and magenta (right)

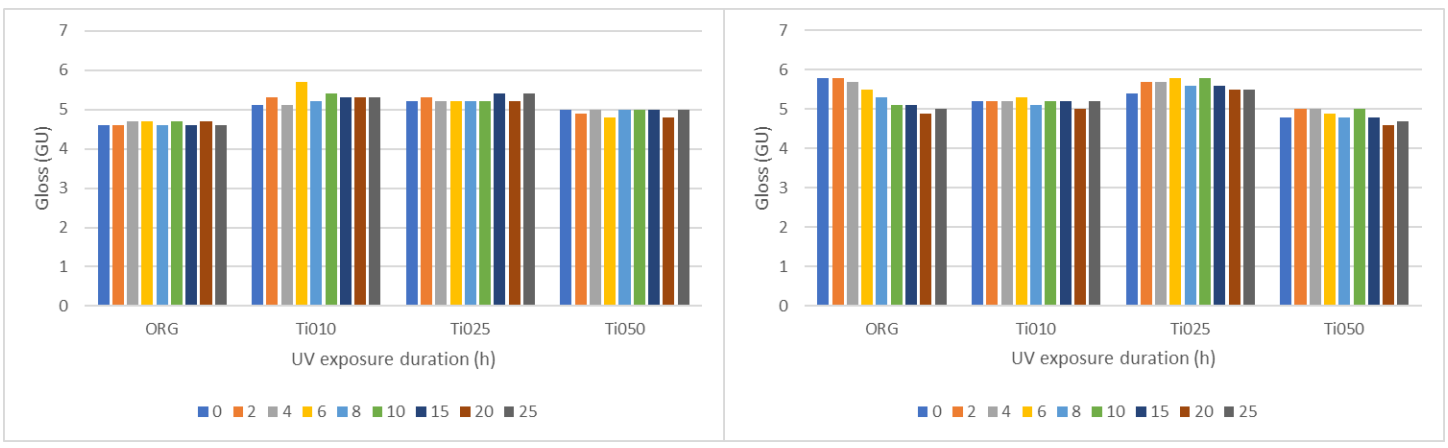

Figure 14: Print gloss - yellow (left) and black (right)

\section{CONCLUSION}

The change in the appearance of the graphics is a problem to battle when producing items made to be used or stored for a longer period of time. The aim of this paper was to determine if a PCL-TiO2 nanocomposite can be used to protect the offset prints in a simulated ageing.

For the purpose of this research samples of process colours were prepared on coated and uncoated papers. The prepared samples were then coated by PCL-TiO2 nanocomposites in which weight ratio of nanoparticles (TiO2) was changed. The samples were then exposed to the accelerated ageing for 25 hours. Investigation of the changes included optical measurements (print gloss) and determining optical density and color coordinates in $\mathrm{CIE} \mathrm{L*a*b*} \mathrm{colour} \mathrm{space.}$

The results of the research showed that accelerated ageing caused significant change in optical density of the yellow ink on both papers while cyan and black experienced almost no change in optical density. Nanocomposites proved their role in preserving inks, which is more visible on coated papers. The increase in weight ratio of $\mathrm{TiO} 2$ improves the protective effect, which can clearly be seen on coated paper, a bit less on uncoated paper. When determining colour difference to the standardized values, it could be seen that nanocomposite do not cause colours to be outside the allowed tolerances on uncoated paper, but shift the magenta outside the tolerance on coated paper. Although the change between samples is not high, magenta was close to the tolerance before coating process. Similar to the optical density, chroma of the yellow ink on coated paper decreased most by the ageing process. Results of the print gloss determination showed that print gloss decreases by coating with nanocomposites, but in the ageing process all concentrations of the $\mathrm{TIO} 2$ stabilize the print gloss to the initial value after coating process. 
This research proved the protective role of the nanocomposite in the investigated accelerated ageing process, but showed the need for better colour control of the initial printing, especially magenta. The protection role is higher with more nanoparticles in coating so there must be further researched. e.g. SEM to detect possible agglomeration and absorption on the papers and FTIR to detect influence of the $\mathrm{TiO}_{2}$ changes by UV irradiation, to achieve optimal concentration.

\section{ACKNOWLEDGMENTS}

This research is part of the project UIP-2017-05-4081, "Development of the model for production efficiency increase and functionality of packaging", supported by Croatian Science Foundation. It is also supported by University of Zagreb short term funding "Development and modification of composite coatings on packaging printing substrates".

\section{REFERENCES}

[1] Afsharpour, M., Imani, S.: "Preventive protection of paper works by using nanocomposite coating of zinc oxide", Journal of Cultural Heritage 25,142-148, 2017. doi: 10.1016/j.culher.2016.12.007.

[2] Bota, J., "Optimisation of Coated Paperboard Packaging Properties According to Design", PhD thesis, University of Zagreb, 2017.

[3] Bota, J., Vukoje, M., Brozovic, M., Hrnjak-Murgic, Z.: "Reduced water permeability of biodegradable PCL nanocomposite coated paperboard packaging", Chemical and Biochemical Engineering Quarterly 31, 417-424, 2018. doi: 10.15255/CABEQ.2017.1126.

[4] Cofomegra, Solarbox, A family of two sizes and four models tabletop xenon test chambers,

[5] URL: https://cofomegra.it/download/SOLARBOX\%20XENOTEST\%20depliant\%20eng.pdf (last request: 2020-09-18).

[6] Fithriyah, N., Erdawati, M.: "Influence of nanoparticles coating on paper durability", Journal of Engineering Science and Technology 10(10), 1-11, 2015.

[7] Golik M.: "Functional PCL coating with the addition of ZnO nanoparticles as print protection", Bachelor thesis, University of Zagreb, 2020.

[8] Havlínová, B., Babiaková, D., Brezová, V., Ďurovič, M., Novotná, M., Belányi, F.: "The stability of offset inks on paper upon ageing", Dye Pigment 54, 173-188, 2002. doi: 10.1016/S01437208(02)00045-1.

[9] Hunter, R.: "Methods of determining gloss", Journal of Research of the National Institute of Standards and Technology 18, 14-16, 2012.

[10] Hongying, Y., Sukang, Z., Ning, P.: "Studying the mechanisms of titanium dioxide as ultravioletblocking additive for films and fabrics by an improved scheme", Journal of applied polymer science 92, 5-10, 2004. doi: 10.1002/app.20327.

[11] Kappel, C., Hirn, U., Donoser, M., Bauer, W.: "Measurement of Printing Ink Penetration in Uncoated Papers and Its Influence on Print Quality", 94th Annual Meeting of Pulp and Paper Technical Association Canada 94, 539-542, 2008.

[12] Khitab, A., Ahmad, S., Munir, M., Kazmi, S., Arshad, T., Khushnood, R.: "Synthesis and applications of nano titania particles", Reviews on advanced materials science 53, 90-105, 2018. doi: 10.1515/rams2018-0007.

[13] Kipphan, H.: "Handbook of Print Media", (Heidlberg publication, 2001), pages 206-224.

[14] Kovačević, D., Brozović, M., Itric Ivanda, K.: "Eco-mark on product packaging and its effect on the perception of quality", Journal of Graphic Engineering and Design 10, 17-24, 2019. doi: 10.24867/JGED-2019-2-017.

[15] Kumar, S., Verma, K., Singla, M.: "Size dependent reflective properties of TiO2 nanoparticles and reflectors made thereof", Digest Journal of Nanomaterials and Biostructures 7, 607-619, 2012.

[16] Landy, M.: "Visual perception: A gloss on surface properties". Nature 447, 158-159, 2007. doi: 10.1038/nature05714.

[17] Makower, J.: "How green printing can make a good impression", 2006,

[18] URL: https://grist.org/article/printing/ (last request: 2020-09-20).

[19] Miklečić, J., Blagojević, S., Petrić, M., Jirous-Rajković, V.: "Influence of TiO2 and ZnO nanoparticles on properties of waterborne polyacrylate coating exposed to outdoor conditions", Progress in Organic Coatings 89, 67-74, 2015. doi: doi.org/10.1016/j.porgcoat.2015.07.016. 
[20] Mokrzycki, W., Tatol, M.: "Color difference Delta E-A survey Colour difference $\Delta E-A$ survey", Machine Vision and Applications 1, 14-18, 2014.

[21] Rastogi, V., Samyn, P.: "Bio-based coatings for paper applications", Coatings 5, 887-930, 2015. doi: 10.3390/coatings5040887.

[22] Sharma, G., Wu, W., Dalal E.: "The CIEDE2000 color-difference formula: Implementation notes, supplementary test data, and mathematical observations", Color Research and Application 30, 2130, 2005. doi: 10.1002/col.20070.

[23] Smithers-Pira, Inkjet printing builds towards $\$ 100$ billion market, URL: https://www.smithers.com/resources/2018/oct/inkjet-printing-builds-towards-\$100-billionmarket (last request: 2020-06-15).

[24] Techkon Spectrodenistometer, URL: https://www.techkon.com/files/downloads/prospekte/SpectroDens\%20Manual\%20Web.pdf (last request: 2020-09-17).

[25] Uglesic, P.: "Biodegradable Polymers and application", Bachelor thesis, University of Zagreb, 2015.

[26] Vukoje, M.: "The influence of adhesion parameters on material and organic recycling of thermochromic prints", PhD thesis, University of Zagreb, 2018.

[27] Van der Walle, G., Buisman, H., Weusthuis, A., Eggink, G.: "Development of environmentally friendly coatings and paints using medium-chain-length poly(3-hydroxyalkanoates) as the polymer binder", International Journal of Biological Macromolecules 25, 123-128, 1999. doi: 10.1016/S01418130(99)00025-2.

[28] Wang, Z, Elsayed, E.: "Degradation Modeling and Prediction of Ink Fading and Diffusion of Printed Images", IEEE Transactions on Reliability 67, 184-195, 2018. doi: 10.1109/TR.2017.2780170.

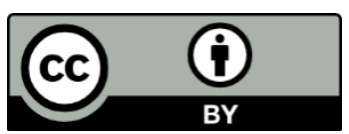

(C) 2020 Authors. Published by the University of Novi Sad, Faculty of Technical Sciences, Department of Graphic Engineering and Design. This article is an open access article distributed under the terms and conditions of the Creative Commons Attribution license 3.0 Serbia (http://creativecommons.org/licenses/by/3.0/rs/). 



\title{
INFLUENCE OF DIGITIZATION INPUT DEVICE ON CALCULATION OF PRINT (NON)UNIFORMITY VALUE OF PRINTS USING ISO 13660 METHOD
}

\author{
Ivana Jurič (D), Dragoljub Novaković (i), Nemanja Kašiković (iD), Sandra Dedijer \\ University of Novi Sad, Faculty of Technical Sciences, \\ Department of Graphic Engineering and Design, Novi Sad, Serbia
}

\begin{abstract}
This paper examines the influence of the digitization input device on the print nonuniformity value when using the ISO 13660 method. This method belongs to the group of techniques called Image Analysis Method (IAM), so the basis for calculating the quality attributes is a digitized print. We selected six different devices: three flatbed scanners and three mobile phones. All settings were constant, such as the scan resolution (600 spi) and light source (D50). To have controlled prints, they were simulated using the MATLAB code - Macro Uniformity Toolbox and printed using the Epson Stylus PRO 7800 InkJet machine. We simulated random print nonuniformity know as small-scaled (graininess) and large-scaled (mottle). The calculated values differ drastically by changing the digitization device, while the values within the same group of devices are strongly correlated. The obtained results indicate the need to expand the standard and define more precise settings for input devices.
\end{abstract}

Keywords: print (non)uniformity, ISO 13660 method, scanner-based system, camera-based system

\section{INTRODUCTION}

There are developed various methods for print quality control, starting from densitometry until spectrophotometry. Recently, one new way has also been introduced for evaluating the print quality of lines, text, print uniformity, registration, etc. It is still underdeveloped but is undoubtedly used for print quality control. The new method is called Image Quality Analysis by some authors (Briggs and Tse, 2005), and it is based on an analysis of the acquired images (i.e., printed samples). We adjusted the name and called it the Image Analysis Method (IAM) because it closely describes the quality control of the prints. Schematic representation of the method is presented in Figure 1. From the original to the numerical values, we need to go through a few steps. The technique can be incorporated into one device (such as QEA Personal IAS or vipFLEX), or the steps could be performed independently.

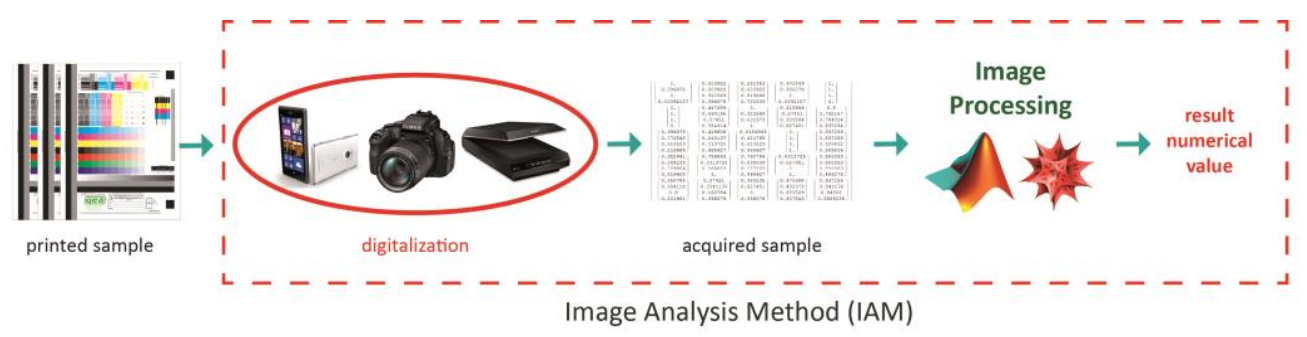

Figure 1: Schematic representation of Image Analysis Method (IAM)

The first international standard that defines procedures and methodology for quantifying essential print quality attributes is ISO 13660:2001 (International Organization for Standardization 13660, 2001; Dhopade, 2009). The standard is device-independent; we can analyze digital, flexo, offset or any other prints (Briggs et al, 1999). According to the standard, the image to be analyzed needs to be digitized using any input device as long as it is capable of sampling the image at a minimum resolution of $600 \mathrm{ppi}$ (International Organization for Standardization 13660, 2001). Responding to the needs of the new standard, instrumentation manufacturers developed a class of devices called image analyzers (Briggs and Tse, 2005). In such a device, the print is acquired with a camera and analyzed (processed) to quantify attributes such as dot gain, line, and text quality, or print nonuniformity such as graininess and mottle. Beside image analyzer, that way of control could be accomplished by using several devices, which together form a system for quality control, called Image Analysis System (Briggs and Tse, 2005). We also adjust this name as Image Analysis Method (IAM). 
Image Analysis System or Image Analysis Method (IAM) includes a light source and some kind of the photodetector in a defined geometric arrangement. In this case, photodetector could be CCD or CMOS sensor. Hence, IAM could be developed in two main styles: the camera-based or flatbed scanner-based system (Briggs and Tse, 2005). Each method has its advantages and disadvantages.

The advantages of the scanner-based system are low cost, and it can easily acquire the entire page area, which can facilitate many print quality analyzes (Briggs and Tse, 2005). The scanner also has built-in illumination, and we can define an area of interest during scanning, that reduces the time of later image processing. On the other hand, this system is time-consuming at high resolutions, and it is a contact method, which leads to the unnaturalness of the scanned sample.

The camera-based system offers higher resolution and very accurate position measurement (Briggs and Tse, 2005). This type of system can be installed directly on the printing machine and provide inline control during printing. It also allows us to upgrade the system by adding other devices such as densitometers and colourimeters. The additional strength of this system is the light source which is away from the sample, so we get a more natural digital sample, as opposed to scanning. The light source is not embedded; therefore, this system is more expensive than the scanner-based one. Also, the camera-based system typically captures only a small section of the printed page at a time, so we need some vacuum table for placing the sample.

Using IAM, we can evaluate print quality according to a large number of attributes. One of the most frequently used attributes is print (non)uniformity (Dhopade, 2009; Lindberg and Fahlcrantz, 2005; Dalal et al, 1998; Petersson, 2005). In the reviewed literature (Petersson, 2005; Christoffersson, 2004; Fahlcratz, 2005; Sadovnikov et al, 2007; Weingerl, 2014; Rasmussen et al, 2006), there are several different definitions of print (non)uniformity. The general physical description would be that the print nonuniformity is an unwanted variation of optical density (reflected light) from the print. Different types of print nonuniformity are presented in Figure 2. Two main groups are random and systematic nonuniformity.
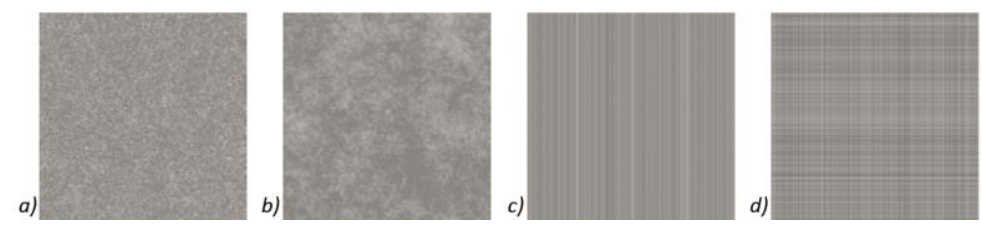

Figure 2: Different types of print nonuniformity: a) small-scale (graininess), b) large-scale (print mottle) random nonuniformity, c) stripes and d) wire mark texture - as systematic nonuniformity (Christoffersson, 2004)

In this paper, we only analyzed random nonuniformity - graininess and print mottle. Print nonuniformity could be quantified using different methods: NU index (Rilovski, 2012), GLCM method (Hladnik and Mihael, 2011; Jurič et al, 2015), standard ISO 13660, method by (Christoffersson, 2004), etc. Common to all methods is that they are based on the IAM method. All methods use the digitized sample for obtaining the numerical value of a print quality attribute which is evaluated. The only difference between them is in the processing of the digitized sample; some of them use the gray level of pixels, some Fast Fourier Transform, etc.

In this paper, we used the method proposed by ISO standard 13660:2001. According to the standard, print mottle is aperiodic fluctuations of density at a spatial frequency less than 0,4 cycles per millimetre in all directions (International Organization for Standardization 13660, 2001). The patch for analyzing print mottle is divided into 100 equal tiles (as shown in Figure 3). Optical density is measured across each tile $i$ several times, and $m_{i}$ is the average of density measurement. The measure of print mottle across the entire patch is the standard deviation of all $m_{i}$ (Weingerl, 2014):

$$
\text { ISO_M }=\sqrt{\frac{1}{n-1} \sum_{i=1}^{n}\left(m_{i}-\left(\frac{1}{n} \sum_{i=1}^{n} m_{i}\right)\right)^{2}}
$$

Where $m_{i}$ is the average density measurement of tile $i, n$ is the total number of tiles.

Graininess is defined as aperiodic fluctuations of density at a spatial frequency greater than 0,4 cycles per millimetre in all directions:

ISO_G $=\sqrt{\frac{\sum_{i=\perp}^{n} \sigma_{i}^{2}}{n}}$ 
where $\sigma_{i}$ is the standard deviation of tile $i, n$ is the total number of tiles.

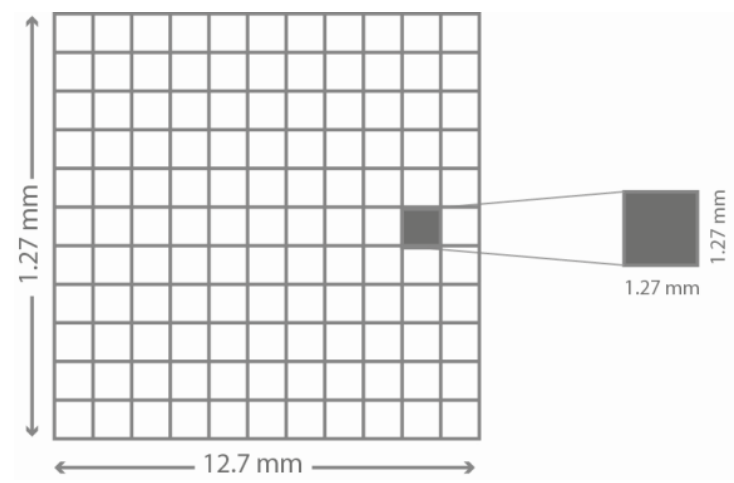

Figure 3: ROI divided into 100 equal parts (tiles), inside which is calculated optical density

The standard ISO 13660:2001 defines the procedures and methodology of various print quality attributes measurement but has its drawbacks. One major drawback of this standard is the lack of reference values. There are no defined acceptance criteria; the user explains it. Once print quality measurements have been made, it is up to those involved to determine if the print quality is acceptable.

In this study, we analyzed the effect of using different devices for digitizing prints on the final value of print quality, measuring graininess and print mottle. As it is shown in Figure 1, we can use the camera, scanner or any other device that has a sufficiently high-quality image sensor, such as a mobile device.

\section{METHODS}

The samples for the experiment were generated using the MATLAB software and plugin Macro Uniformity Toolbook (Rawashdeh, 2006), which is intended to simulate surface nonuniformities in print (Rasmussen et al, 2006). In the mentioned sample generation plugin, it is possible to vary several parameters. For the research, it was chosen to vary the minimum size $\left(p_{\min }\right)$ of the blotch. On all samples, the background color is neutral gray (0.5) (Fahlcrantz, 2005; Lindberg and Fahlcrantz, 2005), and the size of digital samples is $\mathrm{N}=2048 \mathrm{px}$. The parameters for generating all samples are given in Table 1 .

Table 1: Parameters used for generating the samples

\begin{tabular}{|l|l|l|}
\hline Function & Constant parameters & Varied parameter \\
\hline & color $=0.5$ & \\
RN & $p_{\max }=100$ & $p_{\min }=0,0.4,0.6,0.95,2.5,4.5,6.5,9$, \\
(Random Noise) & $\mathrm{A}=0.04$ & $11.5,15.5,21,25.5,29.5,33.5,38,43$, \\
& $\mathrm{N}=2048 \mathrm{px}$ & $48,53.5,58,65,80,94.5$ \\
& Resolution $=300 \mathrm{dpi}$ & \\
\hline
\end{tabular}

Generated samples were printed on IQ Selection whiteboard $\left(250 \mathrm{~g} / \mathrm{m}^{2}\right)$ with inkjet printing machine Epson Stylus PRO 7800. Size of the patch was $160 \times 160 \mathrm{~mm}$ (Jurič, 2018). After print, samples need to be digitized. For this research, we used two different systems: scanner-based and camera-based system. When scanning samples, all automatic corrections were turned off for all devices. Scanning was done in color, 8 bits for each RGB channel. Samples were stored exclusively as TIF format, without compression and without added profile. The standard and previous research papers applying the standard (Briggs et al, 1999; International Organization for Standardization 13660, 2001; Tomić et al, 2016) recommend a scan resolution of 600 spi, which was also used in this paper. Samples were scanned using Adobe Photoshop software and the ScanGear accessory for the Epson Perfection V370 (scanner 1) and CanoScan LIDE 210 (scanner 2) scanners. In contrast, the original manufacturer's software was used for the HP ScanJet 4010 (scanner 3) scanner. The scanners were cleaned with alcohol before use to avoid any unwanted dots from the scanning surface.

Unlike scanning, during digitization of samples with a mobile phone, it is necessary to define the conditions of digitization and device parameters to avoid variations during the experiment. These devices must be positioned and fixed during digitization, so for the purposes of the experiment, it is necessary to 
use the stand. The mobile phone was at a distance of $30 \mathrm{~cm}$ from the sample, and the D50, which simulates daylight, was chosen as the light source. The aperture, shutter speed and ISO value for the mobile phones used in the experiment are listed in Table 2.

Table 2: The aperture, shutter speed and ISO value for the mobile phones used in the experiment

\begin{tabular}{|l|l|l|l|}
\hline Mobile phone & Aperture f & $\begin{array}{l}\text { Shutter } \\
\text { speed [s] }\end{array}$ & ISO \\
\hline $\begin{array}{l}\text { Samsung J5 } \\
\text { (mobile 1) }\end{array}$ & 1.9 & $\begin{array}{l}1 / 50 \\
1 / 100\end{array}$ & $\begin{array}{l}80 \\
125\end{array}$ \\
\hline $\begin{array}{l}\text { Nokia Lumia 630 } \\
\text { (mobile 2) }\end{array}$ & 2.4 & $1 / 35$ & $\begin{array}{l}320 \\
400 \\
500\end{array}$ \\
\hline $\begin{array}{l}\text { iPhone 5 } \\
\text { (mobile 3) }\end{array}$ & 2.4 & $1 / 35$ & 65 \\
\hline
\end{tabular}

After digitization, the samples required necessary processing, which implies only two operations: cutting and rotation. Depending on the resolution of the digitization input device, the fields for later processing are of different dimensions in pixels, and constant dimensions expressed in $\mathrm{cm}$. To avoid blurred edges and the appearance of vignettes, the $16 \times 16 \mathrm{~cm}$ sample was cut to $15.5 \times 15.5 \mathrm{~cm}$. Table 4 shows the field values of $15.5 \times 15.5 \mathrm{~cm}$ expressed in pixels $(\mathrm{px})$ for each device used and each scan resolution.

Table 4: Field size (px) after digitization depending on the input device

\begin{tabular}{|c|c|c|c|c|c|c|}
\hline $\begin{array}{c}\text { Input } \\
\text { device }\end{array}$ & $\begin{array}{c}\text { CanoScan } \\
\text { LIDE 210 }\end{array}$ & $\begin{array}{c}\text { Epson } \\
\text { Perfection } \\
\text { V370 }\end{array}$ & $\begin{array}{c}\text { HP ScanJet } \\
4010\end{array}$ & Samsung J5 & $\begin{array}{c}\text { Nokia } \\
\text { Lumia 630 }\end{array}$ & iPhone 5 \\
\hline $\begin{array}{c}\text { Size of } \\
\text { cropped } \\
\text { patch [px] }\end{array}$ & 3661 & 1700 & 1100 & 1500 \\
\hline Resolution & \multicolumn{3}{|c|}{$600 \mathrm{spi}$} & \multicolumn{3}{|c|}{$72 \mathrm{ppi}$} \\
\hline
\end{tabular}

In Introduction, we mentioned different methods for print (non)uniformity quantification and described the procedure and methodology of ISO 13660 method, which was used in the experiment. For faster calculation, we made MATLAB add-in for quantifying print mottle and graininess based on the methodology described in the standard.

The add-in contained the following steps:

1. import of acquired patch (RGB image),

2. conversation into gray image using built-in Matlab function rgb2gray ( gray $=0.2989 * R+$ $0.5870 * G+0.1140 * B)$,

3. cropping the patch at 100 same tiles,

4. calculation of optical density into one tile (optical density is calculated by the value of the gray level of each pixel) and

5. calculation of print mottle according to standard ISO 13660.

\section{RESULTS AND DISCUSSIONS}

Based on the obtained results of print nonuniformity (Figure 4 and 5), using the ISO method, the samples can be clearly grouped into two sets: micro (graininess) and macro (print mottle) nonuniformity. Regardless of the size of the blotch (spot), some of the samples can be grouped as graininess and some as mottling. The ISO Graininess value increases to sample V4 and then decreases slightly, while the ISO Mottling value slowly rises from the first sample and continues to grow after sample V4. A spot size of $p_{\min }=0.95$ for this sample confirms the definition of the ISO standard 13660, that in mottling the maximum spot frequency is less than $0.4 \mathrm{cy} / \mathrm{mm}$ (ISO, 2001) which corresponds to a spot size $p_{\min }$ of 2.5 taken for sample V5. The maximum frequency for sample V4 is: $f_{\max }=1 / p_{\min }=1.05 \mathrm{cy} / \mathrm{mm}$. Therefore, it can be concluded that samples from V0 to V4 belong to the group of micro nonuniformity. The slope of 
the curve in sample V21, which is most pronounced when using a scanner, confirms that the sample is the same as sample VO - uniform. By enlarging the spot size, a uniform print is obtained again.

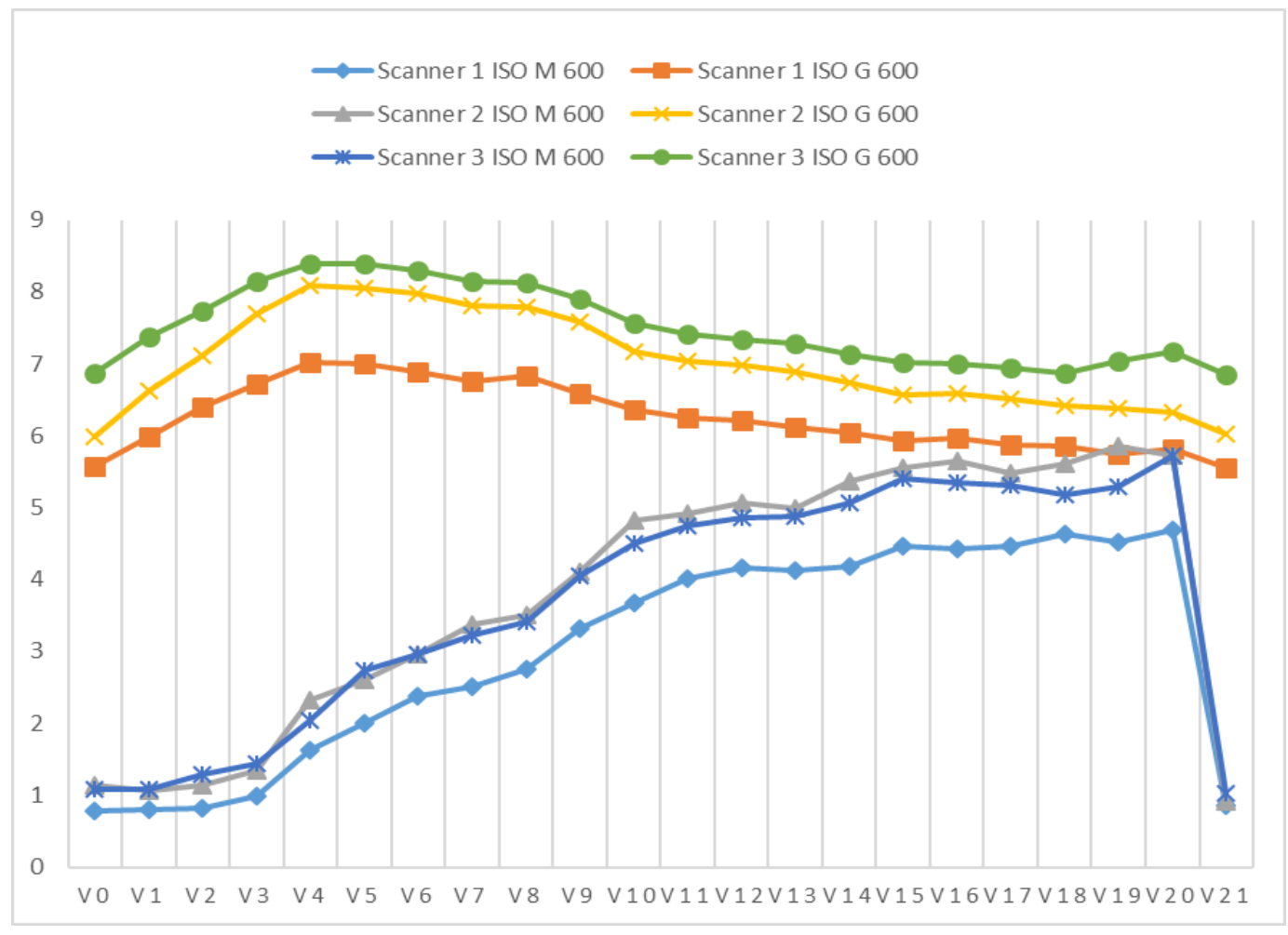

Figure 4: Results of graininess and print mottle using scanners as input device

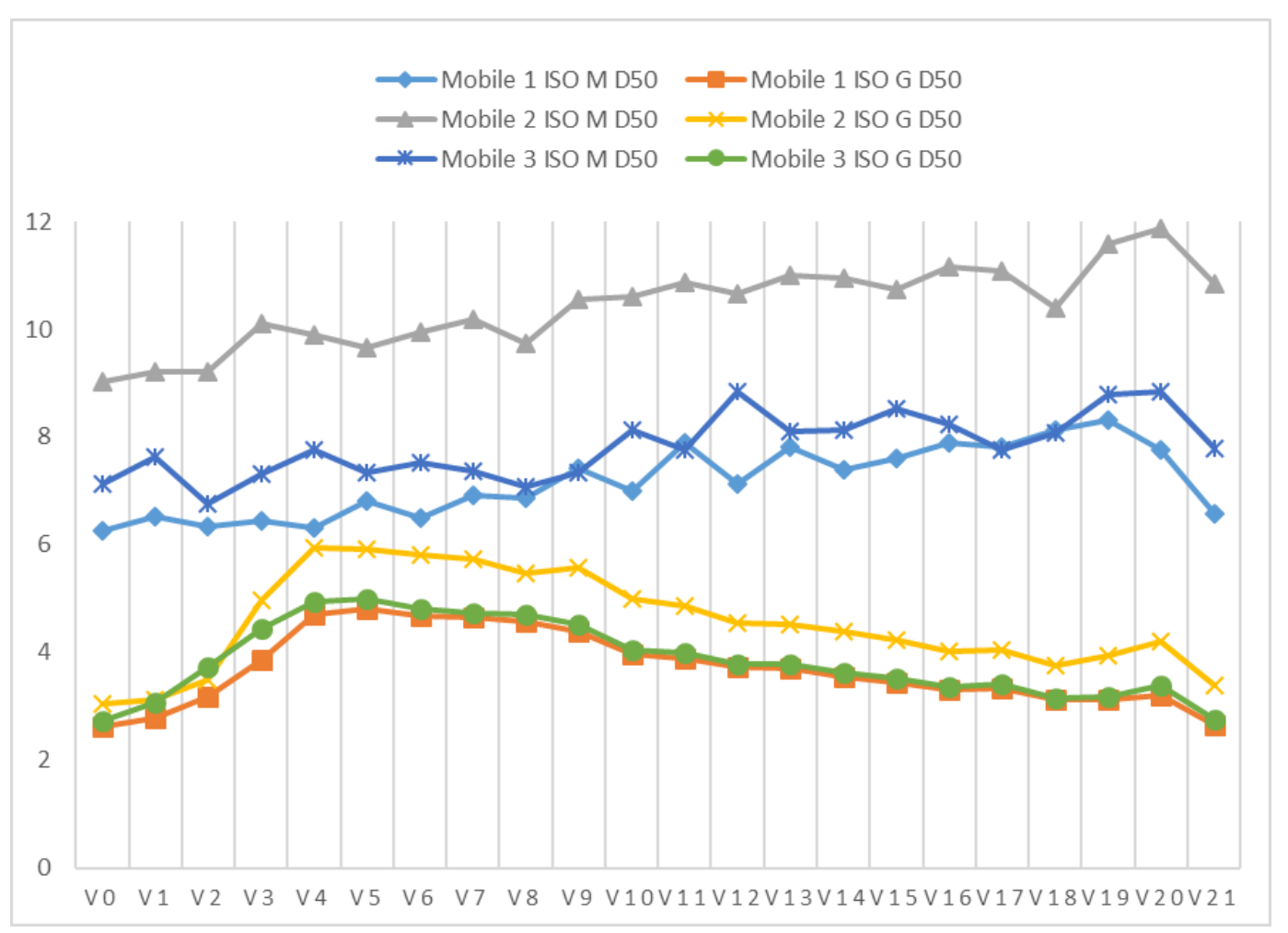

Figure 5: Results of graininess and print mottle using mobile phones as input device 
Based on the graphs, it can be clearly seen that the values obtained using different scanners correlate well, which confirms the value of the correlation coefficient that is above 0.9. However, this is not the same case when looking at mottling values when using mobile phone as input device. The shape of the curve is drastically different, and the correlation is much weaker (0.6 - 0.8). When using a mobile phone, signal noise occurs, which directly affects the calculation of the print mottle, but does not affect the graininess value.

\section{CONCLUSIONS}

Print quality analysis is a crucial part of the printing process and should be conducted in controlled and well-defined conditions. The ISO 13660: 2001 standard has defined new attributes for quality analysis, but is incomplete in terms of methodology. In this paper, the influence of the input device for digitization on the obtained value of print nonuniformity (mottle and graininess) is examined. Based on the results, a clear difference in mottle and graininess values can be seen when different devices are used for digitizing the same samples. The most considerable deviations from the set, initial values appear when measuring mottling when using a mobile phone. The scanner proved to be a more stable and accurate device to use.

\section{ACKNOWLEDGMENTS}

This research (paper) has been supported by the Ministry of Education, Science and Technological Development through the project no. 451-03-68/2020-14/200156: "Innovative scientific and artistic research from the FTS (activity) domain".

\section{REFERENCES}

[1] Briggs, J. C., Forrest, D. J., Klein, A. H., Tse, M. K.: "Living with ISO-13660: Pleasures and perils", International Conference Digital Print Technology, 421-425, 1999. URL:

http://www.qea.com/upload/files/products/Paper_1999\%20IS\%26T-NIP\%20Living\%20with\%20ISO136602.pdf (last request: 2020-10-10).

[2] Briggs, J. C., Tse, M.K.: "Objective Print Quality Analysis and The Portable Personal IAS Image Analysis System", 44, 2005. doi: 10.11370/isj.44.505.

[3] Christoffersson, J.: "Evaluation of Systematic \& Colour Print Mottle", Linkopings Universitet, Sweden, 2004, URL: https://www.diva-portal.org/smash/get/diva2:20130/FULLTEXT01.pdf (last request: 2020-10-10).

[4] Dalal, E. N., Rasmussen, D. R., Nakaya, F., Crean, P. A., Sato, M, Corporation, X.: "Evaluating the Overall Image Quality of Hardcopy Output",169-173, 1998, URL:

https://www.researchgate.net/publication/220865074_Evaluating_the_Overall_Image_Quality_of_ Hardcopy_Output (last request: 2020-10-10).

[5] Dhopade, A.: "Image Quality Assessment According To ISO 13660 and ISO 19751", Test Targe 9, 4350, 2009.

[6] Fahlcrantz, C. M.: "On the evaluation of print mottle", PhD thesis, KTH School of Computer Science and Communication Stockholm, ISBN 91-7178-205-2, 2005.

[7] Hladnik, A., Mihael, L.: "Paper physics: Paper and board surface roughness characterization using laser profilometry and gray level cooccurrence matrix", Nordic Pulp \& Paper Research Journal 26, 99-105, 2011. doi:10.3183/NPPRJ-2011-26-01-p099-105.

[8] International Organization for Standardization, ISO13660 Information Technology - Office Equipment - Measurement of image quality attributes - Binary Monochrome text and graphic images, International Organization for Standardization, 2001.

[9] Jurič, I., Karlović, I., Novaković, D., Tomić, I.: “Comparative study of different methods for the assessment of print mottle", Color Research and Application, 2015. doi:10.1002/col.21984.

[10] Jurič, I.: "Model za kontrolu kvaliteta površinske uniformnosti digitalnih otisaka", PhD thesis, University of Novi Sad, Faculty of Technical Sciences, Department of Graphic Engineering and Design, 2018.

[11] Lindberg, S., Fahlcrantz, C. M.: "Perceptual assessment of simulated print noise with random and periodic structure", Journal of Vision Communication and Image Representation 16, 271-287, 2005. doi:10.1016/j.jvcir.2004.11.002. 
[12] Petersson, J.: "A Review of Perceptual Image Quality", BSc thesis, Department of Science and Technology, Linköpings Universitet, 2005. URL: https://www.divaportal.org/smash/get/diva2:20240/FULLTEXT01.pdf (last request: 2020-10-10).

[13] Rasmussen, D. R., Donohue, K. D., Ng, Y. S., Kress, W. C., Gaykema, F., Zoltner, S.: "ISO 19751 macrouniformity", Proceedings Volume 6059 Image Quality and System Performance III 2006, (SPIE 6059: San Jose, California, 2006). doi:10.1117/12.648086.

[14] Rawashdeh, N.: "Macro Uniformity Toolbox (v2)", URL:

https://www.mathworks.com/matlabcentral/fileexchange/9882-macro-uniformity-toolbox--v2?requestedDomain=true (last request: 2020-10-10).

[15] Rilovski, I.: "Influence of paper surface properties and toner type on digital print mottle", Celuloza Si Hartie 61, 4-9, 2012.

[16] Sadovnikov, A., Lensu, L., Kälviäinen, H.: “Automated Mottling Assessment of Colored Printed Areas", Proceedings of15th Scandinavian Conference 2007, (SCIA:Aalborg, Denmark, 2007), pages 621-630.

[17] Tomić, I., Dedijer, S., Jurič, I., Pál, M.: "The effect of scanning resolution and displacement value on the GLCM-based features for paper texture characterization", Proceedings of the 8th International Symposium on Graphic Engineering and Design 2016, (Department of Graphic Engineering and Design, Faculty of Technical Sciences, University of Novi Sad, 2016), pages, 263-271, URL: http://www.grid.uns.ac.rs/symposium/download/grid16.zip (last request: 2020-10-08).

[18] Weingerl, P.: "Objective methods for print inhomogeneity evaluation and their correlation with visual perception", MSc thesis, Univerza v Ljubljani, 2014.

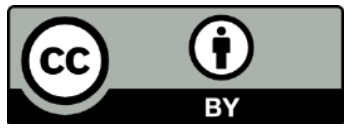

(C) 2020 Authors. Published by the University of Novi Sad, Faculty of Technical Sciences, Department of Graphic Engineering and Design. This article is an open access article distributed under the terms and conditions of the Creative Commons Attribution license 3.0 Serbia (http://creativecommons.org/licenses/by/3.0/rs/). 



\title{
THE EFFECTS OF FRAGRANCED MICROCAPSULES APPLICATION ON THE PHYSICAL AND PRINT QUALITY CHARACTERISTICS OF THE PRINTS
}

\author{
Rastko Milošević ${ }^{1}$ (D), Nemanja Kašiković ${ }^{1}$ (D), Živko Pavlović ${ }^{1}$ (D), Saša Petrović ${ }^{1}$ (D), \\ Dragan Kukuruzović ${ }^{2}$ (D), Raša Urbas ${ }^{3}$ (D) \\ ${ }^{1}$ University of Novi Sad, Faculty of Technical Sciences, Department of Graphic Engineering and \\ Design, Novi Sad, Serbia \\ ${ }^{2}$ University of Novi Sad, Faculty of Technical Sciences, Department for Production Engineering, \\ Novi Sad, Serbia \\ ${ }^{3}$ University of Ljubljana, Faculty of Natural Sciences and Engineering, Department of Textiles, \\ Graphic Arts and Design, Ljubljana, Slovenia
}

\begin{abstract}
Today, various coatings are used in the printing industry, which give the printed product various additional features such as functional, decorative and protective properties. As a coating, fragrant microcapsules can be applied in combination with a printing ink or varnish to provide printed products with added value. The functionality of the applied fragranced microcapsules is initiated and achieved by rubbing the applied coating surface, whereby the microcapsules burst open and release the encapsulated active ingredient, the fragrance. In this paper the effects of the applied fragrance microcapsules (in the form of coating) on the print quality and the physical properties of the coated prints are investigated. Performed AFM and print quality analyses of the functional coatings produced showed that the applied fragrance microcapsules and their different concentrations significantly influence both the physical and print quality properties of the prints.
\end{abstract}

Keywords: fragranced microcapsules, functional coatings, print gloss, surface roughness

\section{INTRODUCTION}

The printing industry faces immense challenges and a demand for new, innovative and value-added print products that can deliver both customer benefits and higher profits for printers. One of the ways to create innovative, value-added printed products is the use of scents using fragranced microcapsules (Milošević, 2019; American Inks and Coatings, n.d.). In order to decorate, protect or give a new functionality to the printed product, different types of coatings are used today, which may contain different materials that enable certain properties, e.g. fragrant microcapsules (Milošević, 2019; Ghosh, 2006). Microcapsules are tiny particles that have a very regular, spherical shape and usually consist of two main parts: the core encapsulated active material, and the shell - an outer part that protects the core (Ghosh, 2006). The fragrant microcapsules encapsulating scents, are mechanically activated by a frictional movement (ie. rubbing motion, application of pressure and shear force) under which the shell of the microcapsules bursts and releases the encapsulated fragrance. Numerous types of microcapsules encapsulate different active ingredients (ie. agents) and have different functionalities and can be incorporated into printing substrates or applied to their surface by various printing or non-printing techniques (Milošević, 2019; Rodrigues et al, 2009; Goetzendorf-Grabowska et al 2004; Goetzendorf-Grabowska et al, 2008; Urbas et al, 2017). Coated prints with fragrant microcapsules have a new functionality, but as a negative effect, the applied coating layer changes its important physical and optical properties, resulting in higher surface roughness and thickness of the prints and a change in print quality characteristics. For this reason, it is important to analyze the physical and optical properties of the coated prints with different fragranced microcapsules mass concentrations, and to determine the extent to which they differ from the original prints (uncoated samples) (Milošević, 2019, Urbas et al, 2017).

This research aims to investigate the influence of applied coatings with fragrant microcapsules on surface roughness as a physical property and the print gloss characteristics of the prints. Performed AFM and print gloss analyses of the produced functional coatings (using an automated coating technique and different mass concentrations of the fragrant microcapsules) showed that the coating process significantly influences both the surface roughness and the print gloss characteristics of the prints. 


\section{METHODS}

For substrate material that was to be printed and coated in the experiment, a matt coated paper (GardaMatt Art, Lecta, Spain) with the following basic properties was used: base weight $130 \mathrm{~g} / \mathrm{m}^{2}$, specific volume $0.85 \mathrm{~cm}^{3} / \mathrm{g}$, thickness $111 \mu \mathrm{m}$ and CIE whiteness 121.3. First, selected substrates were printed with cyan process ink (Diatone ${ }^{\circledR}$ PREMIUM+, Sakata inx, Japan) using sheetfed offset technology (Performa 74, KBA, Germany). The printed samples were coated only with water-based varnish and a mixture of varnish and various mass concentrations of fragrant microcapsules in water suspension. The fragranced microcapsules used were monocore microcapsules produced by a modified "in situ" polymerization method, in which a combination of several essential oils was encapsulated with the fragrances of rosemary, lavender and sage, while the microcapsule shell consisted of partially methylated trimethylol melamine (Melamin, Slovenia) (Šumiga, 2013; Milošević et al, 2017). Water-based printing varnish selected for the coating process of the prints was made of an acrylic emulsion (without the polyethylene wax) and is generally used to protect the prints (Cinkarna Celje, Slovenia). Fragranced microcapsules were premixed with the water-based varnish in three different mass concentrations of $0 \%, 1 \%, 7 \%$. For the coating process the automatic coating technique (K303 Multi Coater, RK PrintCoat Instruments Ltd, UK) with the following process parameter settings was used: coating rod 2 (wet printing thickness $12 \mu \mathrm{m}$ ), diameter of wire for coating rod $0.15 \mathrm{~mm}$ and coating speed $8 \mathrm{~m} / \mathrm{min}$. Coated prints were then air dried for 24 hours at room temperature $\left(25^{\circ} \mathrm{C}, 55 \% \mathrm{RH}\right.$; LED Termohigrometar, RWT-291B, Realwayto, China).

The characterization of the fragrance microcapsules (size/volume distribution calculations) was based on a SEM analysis (scanning electron microscopy; JSM 6060 LV, Jeol, Japan) and subsequent image analysis (500 measurements; ImageJ software) (ImageJ, n.d.). The characterization of the surface properties of the coated prints was performed by atomic force microscopy (AFM, VeeCO di CP II, Digital Instruments, USA) and scanning probe microscopy software (SPIP, Denmark). For the analysis of the surface roughness properties of the coated samples the standard surface roughness parameter was used (Root-Mean-Square roughness $-\mathrm{S}_{\mathrm{q}}$ ). The optical properties, i.e. the print gloss of the coated prints was measured using the Elcometer 407 Statistical Glossmeter (X-Rite, USA) in accordance with ASTM D523-89 standard (ASTM D523-89, 1999).

\section{RESULTS}

Figure 1a shows the morphology of the fragranced microcapsules in water suspension, which were used in the coating process in combination with the water-based varnish. The fragrance microcapsules used had a particularly regular, spherical shape and a smooth surface of the shell.

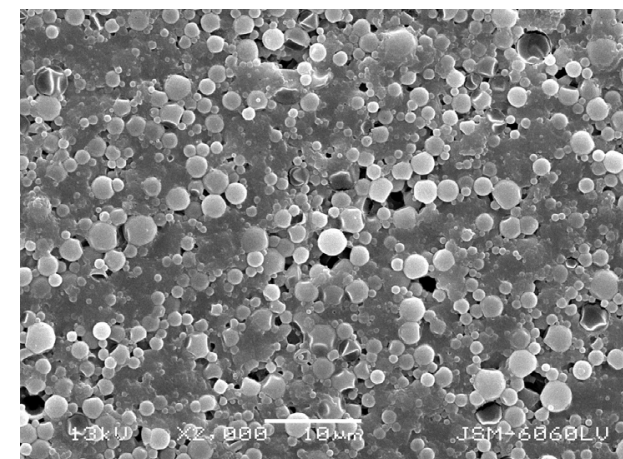

a.

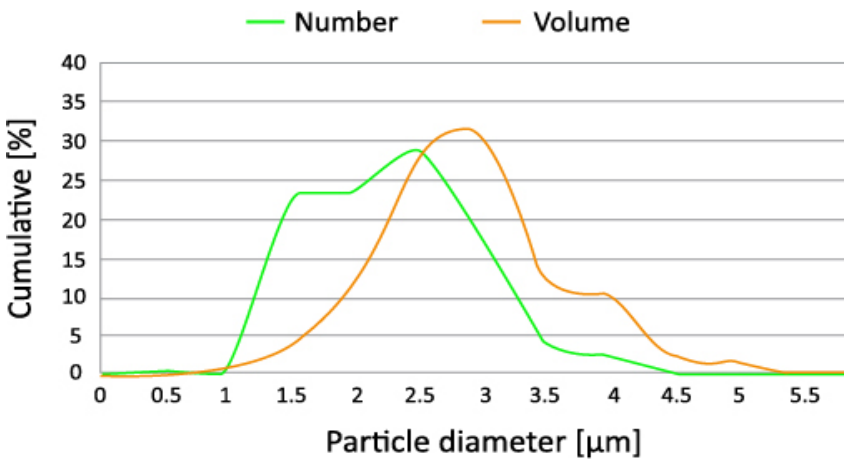

b.

Figure 1: Morphology of fragrance microcapsules in water suspension (a) (SEM; 1.000x magnification) and their size and volume distributions (b)

As Figure $1 b$ shows, the sizes of the fragrance microcapsules are relatively uniform. The distribution of microcapsules diameter sizes was relatively narrow, positively skewed (green curve, Figure $1 \mathrm{~b}$ ), with the vast majority of the microcapsules studied having diameter sizes between 1 and $3 \mu \mathrm{m}$ (92.08\%). The mean diameter size of the sampled fragrant microcapsules is $2.08 \mu \mathrm{m}$ (standard deviation $0.63 \mu \mathrm{m}$ ), while the minimum and maximum diameter sizes are $1.06 \mu \mathrm{m}$ and $4.60 \mu \mathrm{m}$ respectively. The volume distribution of the microcapsules (orange curve, Figure 1b) was nearly symmetrical (normal distribution), with $17.62 \%$ of 
all sampled microcapsules (with diameters between 2.5 and $3 \mu \mathrm{m}$ ) representing $30.36 \%$ of the total volume of the microcapsules. No agglomeration of the microcapsules was observed.

Table 1 shows the results of the surface roughness characteristics of the samples (Root-Mean-Square roughness $-S_{q}$ ) for a solid tone patch (only printed, uncoated), a coated sample with the only varnish without microcapsules (0\%), a coated sample with varnish and fragrant microcapsules in the mass concentration of $1 \%$, and a coated sample with the varnish and microcapsules in the mass concentration of $7 \%$. Figure 2 shows 3D renderings of the AFM data for the same four sample groups.

Table 1: Root-Mean-Square surface roughness values of the tested samples

\begin{tabular}{|c|c|c|c|c|}
\hline Sample & Solid tone & $0 \%$ & $1 \%$ & $7 \%$ \\
\hline $\mathrm{S}_{\mathrm{q}}[\mathrm{nm}]$ & $56.21 \pm 3.49$ & $19.40 \pm 5.20$ & $22.70 \pm 6.23$ & $53.06 \pm 7.15$ \\
\hline
\end{tabular}

From the data presented, it can be seen that only the printed sample (solid tone patch) has the highest surface roughness $\left(\mathrm{S}_{\mathrm{q}}\right)$ compared to other samples (Table 1 and Figure $2 \mathrm{a}$ ). The coating process without fragranced microcapsules drastically reduced the value of the surface roughness (to $19.40 \mathrm{~nm}$ ) and enabled a very uniform and flat surface structure (Figure $2 b$ ). The subsequent addition and increase of the mass concentrations of the fragrant microcapsules in the varnish coating layer ( $1 \%$ and $7 \%$ ) resulted in a significant increase in the surface roughness values $\left(\mathrm{S}_{\mathrm{q}}\right)$, Table 1 . Higher concentrations of the fragrant microcapsules in the coating layer caused more pronounced changes in the surfaces of the coated samples, which resulted in the generation of the numerous new peaks (Figures $2 \mathrm{c}$ and $2 \mathrm{~d}$ ).

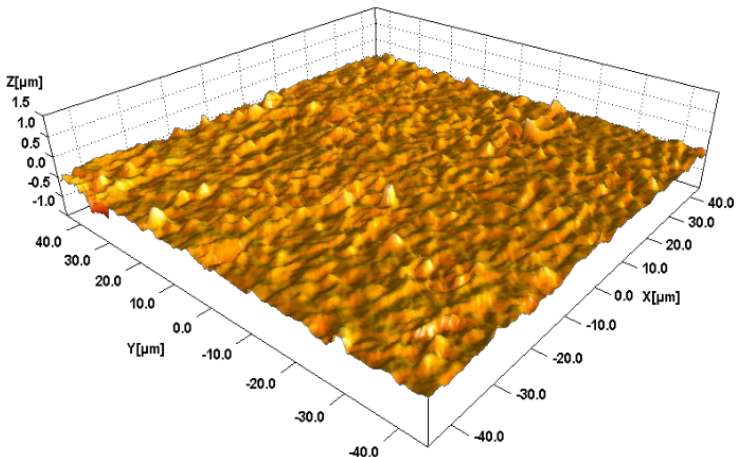

a.

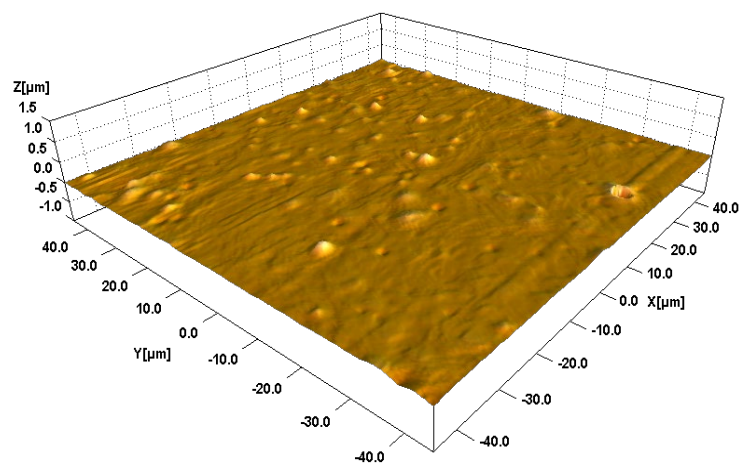

C.

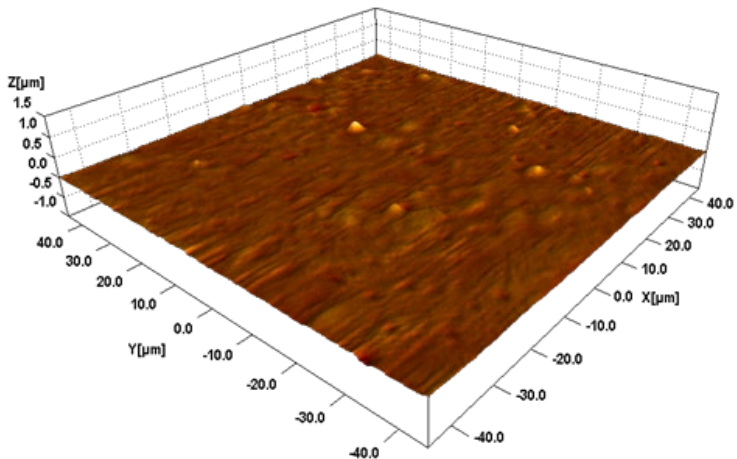

b.

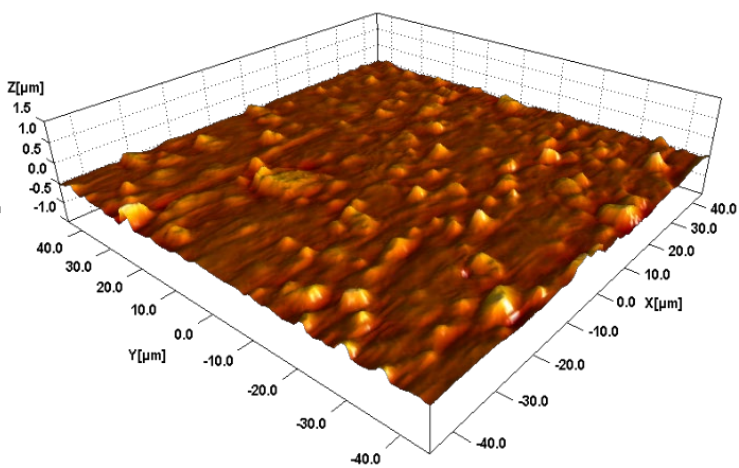

d.

Figure 2: 3D renderings of the acquired AFM data: (a) only printed sample, (b) $0 \%$ sample, (c) $1 \%$ sample, (d) $7 \%$ sample (AFM; $90 \times 90 \mu \mathrm{m})$

The use of the fragrant microcapsules not only increases the value of the final printed product, but also changes the basic print quality properties. Figure 3 shows the measured print gloss values of the tested samples. It can be seen that the sample printed without varnish (cyan solid tone patch) has the lowest print gloss value. The coating applied only with the varnish enabled the highest print gloss value. The addition of fragrant microcapsules, however, led to the generation of many surface irregularities, which affected the reflective properties of the samples, i.e. reduced the print gloss values. With increasing mass concentration 
of the fragrant microcapsules (from $1 \%$ to $7 \%$ ), the print gloss decreased, which is consistent with the previously analyzed surface roughness data.

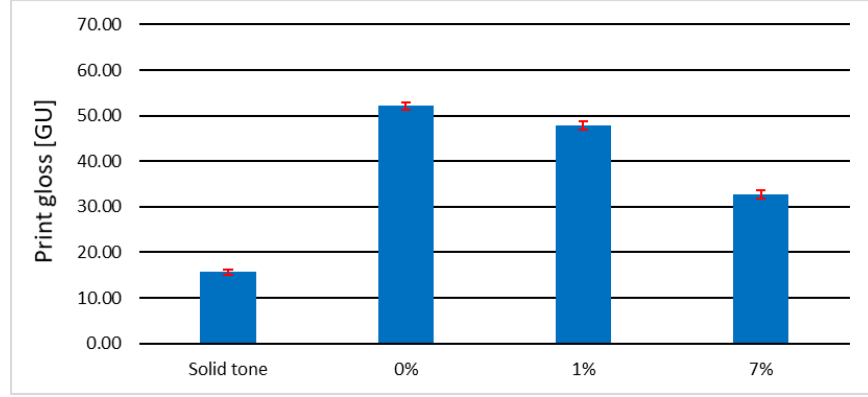

Figure 3: Print gloss data of the analyzed samples $\left(60^{\circ}\right.$ angle)

\section{CONCLUSIONS}

The fragrance microcapsules used in the coating process of the prints had a particularly regular, spherical shape and a smooth surface of the shell. Their diameter sizes were relatively uniform, resulting in a relatively narrow diameter size distribution. The volume distribution of the microcapsules was almost symmetrical, while no agglomeration of the microcapsules was observed.

From the AFM and print gloss analyses presented, it can be concluded that the coating process performed with only varnish, without the fragrant microcapsules, resulted in a uniform, non-porous surface structure with only a few isolated peaks. The resulting surface was much smoother (lower surface roughness value) than the reference sample (only printed solid cyan tone), which in turn enabled the highest print gloss. The use of fragrant microcapsules in the coating process resulted in rougher surfaces with more irregularities, changing the original flat surface of the only coated sample without fragrant microcapsules. The higher concentration of the fragrant microcapsules in the coating layer (7\%) resulted in a higher surface irregularity of the surface, resulting in a significant increase in the surface roughness value $\left(\mathrm{S}_{q}\right)$ and a decrease in print gloss.

\section{ACKNOWLEDGMENTS}

This research was supported by the Ministry of Education, Science and Technological Development through project no. 451-03-68/2020-14/200156: "Innovative scientific and artistic research from the FTS (activity) domain", and by Cinkarna Celje, Slovenia, which provided materials for the experiment.

\section{REFERENCES}

[1] American Inks and Coatings, URL: http://www.americaninks.com/files/AIC\%20pH\%20Technical\%20Bulletin.pdf (last request: 2020-1017).

[2] American Society for Testing and Materials: ASTM D523-89. "Standard test method for specular gloss", American Society for Testing and Materials, 1999. doi: 10.1520/D0523-14R18.

[3] Goetzendorf-Grabowska, B., Krolikowska, H., Gadzinowski, M.: "Polymer Microspheres as Carriers of Antibacterial Properties of Textiles: A preliminary Study", Fibres \& Textiles in Eastern Europe 12 (4), 62-64, 2004.

[4] Goetzendorf-Grabowska, B., Królikowska, H., Bąk P., Gadzinovski, M., Brycki, B., Szwajca, A.: "Triclosan Encapsulated in Poli (L,L-lactide) as a Carrier of Antibacterial Properties of Textiles", Fibres \& Textiles in Eastern Europe 16 (3), 102-107, 2008.

[5] Gosh., K.: "Functional coatings by Polymer Microencapsulation", (Wiley-VCH, Weinheim, 2006.), pages $3 ; 153 ; 177 ; 235$.

[6] ImageJ: "Download", URL: https://imagej.nih.gov/ij/download.html (last request: 2019-08-14).

[7] Milošević, R., Kašiković, N., Cigula, T., Stanković Elesini U., Urbas, R.: "The characterization of microcapsules printed by screen printing and coating technology", Journal of Graphic Engineering and Design 8 (1), 45-56, 2017. doi: 10.24867/JGED-2017-1-045. 
[8] Milošević, R.: "Characterization of coated prints with microcapsules", PhD Thesis, Department of Graphic Engineering and Design, Faculty of Technical Sciences, University of Novi Sad, Serbia, 2019.

[9] Rodrigues, S., Martins, I., Fernandes, I., Gomes, P., Mata, V., Barreiro, M., Rodrigues, A.: "Scentfashion ${ }^{\circledR}$ : Microencapsulated perfumes for textile application", Chemical Engineering Journal 149 (1-3), 463-472, 2009. doi: 10.1016/j.cej.2009.02.021.

[10] Šumiga, B.: "Informational approaches in the design of chemical microencapsulation processes", PhD thesis, Faculty of Natural Sciences and Engineering, University of Ljubljana, Slovenia, 2013.

[11] Urbas, R., Milošević, R., Kašiković, N., Pavlović, Ž., Stankovič Elesini, U.: “Microcapsules application in graphic arts industry: a review on the state-of-the-art", Iranian Polymer Journal 26 (7), 541-561, 2017. doi: 10.1007/s13726-017-0541-1.

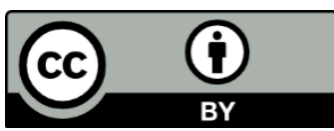

(C) 2020 Authors. Published by the University of Novi Sad, Faculty of Technical Sciences, Department of Graphic Engineering and Design. This article is an open access article distributed under the terms and conditions of the Creative Commons Attribution license 3.0 Serbia (http://creativecommons.org/licenses/by/3.0/rs/). 

PAPER AS A SUBSTRATE 



\title{
THE EFFECT OF THE VIRGIN FIBERS TO THE PROPERTIES OF DIFFERENT PAPER PRODUCTS
}

\author{
Tibor Czene ${ }^{1}$ (i) , László Koltai $^{2}$ (iD) \\ ${ }^{1}$ Óbuda University, Doctoral School on Materials Sciences and Technologies, \\ Budapest, Hungary \\ ${ }^{2}$ Óbuda University, Rejtő Sándor Faculty of Light Industry and Environmental Engineering, \\ Budapest, Hungary
}

\begin{abstract}
The products from paper are widely used materials with several benefits. The corrugated paper keeps items protected through long-distance logistic processes and constant shipping and handling. The corrugated boxboards are ideal options for any industry's shipping, packaging and storage needs. Papers and cardboards are quite low cost and also provide environmental-friendly solutions, using recyclable materials such as used corrugated cartons and old newspapers.

Recycling offers a reduction in environmental impact in densely populated regions and a large production of paper and board products. Generally, the use of recycled fiber produces paper with poorer mechanical properties due to the decrease in the interfiber bonding. The recycled pulp must be treated to restore its bonding strength, for which there are six methods possible: mechanical treatment, chemical additives, chemical treatment, fractionation, papermaking process modification and blending with virgin fiber. Although some mills produce 100\% recycled paper, the majority augment their used pulp with some virgin fiber. Paper properties can be tailored within some ranges by modifying the properties of fibers, but the influence of fine quality on structure, strength and optical properties of paper can be even greater.

The properties of papers are essentially determined by their raw materials. Most of these raw materials are made from $100 \%$ recycled fiber, but as the quality of the waste fiber varies, different chemicals must be used to provide the desired or expected properties. From an environmental and economic point of view, the use of primary fibers can be an alternative.
\end{abstract}

Key words: virgin fiber, specific volume, tensile force, tensile strength, tearing strength

\section{INTRODUCTION}

Recycling has emerged as one of several possible solutions for environmental protection, and this includes waste papers, which can be collected and treated for reuse. However, a key issue for waste paper reprocessing is to preserve the optical and physical properties in the reprocessed waste paper fibers. It has been reported that sodium hydroxide $(\mathrm{NaOH})$, a conventional deinking agent, turns the reprocessed paper yellow, and reduces strength of the reprocessed paper sufficiently thus an additional treatment is necessary (Zeyer et al, 1994).

The characteristic of the paper can be customized within some ranges by changing the properties of fibers, but the effect of particles quality on structure, strength and optical properties of paper can be even higher. Fibrillary particles improve bonding between fibers, and thus also tensile index of paper, while flake-like particles promote a light-scattering coefficient of paper. In the texture of paper, the fines fragments may act as small fibers, fill space between fibers, block fiber-fiber bonding, help in assembling fiber-fiber bonds, or simple stand on free fiber surfaces (De Silveira et al, 1996; Karnis et al, 1996; Peel, 1999). Fibrillary mechanical pulp particles are shown to gain strength properties, while flake-like elements are positive for the light-scattering coefficient of paper when mixed into a fines-free mechanical pulp with virgin fibers (De Silveira et al, 1996; Luukko, 1999).

Cellulosic fibers are negatively charged due to the presence of acidic groups (carboxyl, sulfonic acid, phenolic or hydroxyl groups), which either originate from cell wall constituents or being introduced during pulping or bleaching of fibers. Filler retention by a direct route affects optical characteristics of paper like brightness, whiteness, specific-scattering coefficient, which in turn directly influence printing characteristics (Tyagi et al, 2010). A paper-based product in most cases contains $90-99 \%$ cellulose fibers, which are the main structural part and the most important integrant influencing the final properties. A network of self-bonding cellulose fibers within network structure affects chemical and physical characteristics of the paper products. However, the chemical structure of cellulose is now well established and consists of $\beta$-anhydroglucose units with dominant hydroxyl groups, which are appropriate 
groups for reactions. These are mainly due to the one primary and two secondary hydroxyl groups in each monomer unit in polymer structure (Fengel and Wegener, 1984; Sjostrom, 1994). Because paper network is composed from randomly laid fibrous (cellulose) and non-fibrous (fillers) materials, it contains a complicated set of cavity pore channels with a variety of capillary dimensions. Hence, it is readily permeable to liquids. However, the structure of paper can be modified during the contact of liquids because it disrupts hydrogen bonds, relaxes fibers, and produces dimensional modifications in pores and capillaries.

Binders or adhesives are among several matters generally added to the pulp slurry before paper sheet formation. Binders belong to the class of macromolecular substances. For example, high molecular weight compounds are mostly hydrophilic colloid parts. The main point of the binder adding is to improve the strength of paper products. However, other paper properties may be affected by binder addition. Other additives used in papermaking are fillers, sizing agents, etc.

\section{EXPERIMENTAL WORK}

\subsection{Materials and methods}

Tests were conducted with unbleached sulphite pine cellulose and recycled corrugated board. The materials were disintegrated with laboratory pulp mixer with water. Using these two types of suspensions, we prepared different mixed-pulps according to the ratio of cellulose and corrugated waste papers. Based on the dry matter content of the raw materials it was calculated the proportion of fibrous materials and the required mass values. To study the mechanical and physical properties of the mixed pulps, we produced sample-paper sheets using laboratory Erntst Haage sheet former.

\subsubsection{Disintegration with laboratory pulp mixer}

We disintegrated separate the cellulose and the paper waste in the laboratory pulp mixer. The glass jar of it is 10 I volume. The RPM of the mixer was $3000 / \mathrm{sec}$. We plucked the known weight waste paper into $3 \times 3 \mathrm{~cm}$ pieces, then the material was soaked for 24 hours in $20 \mathrm{OC}$ water. Then we disintegrated them for 20 minutes on 3000 RPM. We prepared the cellulose similarly to our method.

\subsection{Sheet formation}

The dry matter of the suspension in the mixer is known. Without the dilution we can calculate how much suspension we need for the sheet forming with $314 \mathrm{~cm} 2$ sheet size for a given grammage (basis weight). We produced sample-paper sheets with $80 \mathrm{~g} / \mathrm{m} 2$ grammage using laboratory Erntst Haage sheet former. The sample sheets were stored in airtight plastic case until further examination.

\subsection{Mechanical tests}

To study the mechanical and physical properties of the different sample-paper sheets we used the most important methods and standards, like the bursting test, the tearing test, the tensile test and the capillary rise test of paper.

\subsubsection{The burst test of the sample-papers}

The burst test is frequently used as a general guide to the strength of paper products, like sheets, solid board and corrugated board. Measures the pressure required to puncture a sheet of paper or paperboard as an indicator of its load carrying capacity under specific conditions (unit: $\mathrm{kPa}$ ). Based on the measured values were calculated the following parameter. Burst index means the bursting strength in kilopascals, divided by the basis weight in $\mathrm{g} / \mathrm{m} 2$. On the other hand the burst factor can be calculated with the bursting strength in gram per centimetre squire, divided by the basis weight in $\mathrm{g} / \mathrm{m} 2$ (kPa.m2/g). The burst test was performed according to the ISO 2758:2001 standard using Mullen system burst tester.

\subsubsection{Tear test of the sample-papers}

The tear strength of paper means the resistance of a paper sheet to tearing force (in $\mathrm{mN}$ ) that it is subjected to. It is another important basic physical property of paper and paperboard. Also known as the Elmendorf test, the tearing test has been performed in the paper industry for many decades in order to measure the mean internal resistance of cellulose or papers to the propagation of a deliberately initiated 
tear. Based on the measured values were calculated the tear index which means: tearing strength/grammage, quoted in mN.m2/g. The tear test was performed according to the ISO 1974:2012 standard using Elmendorf Tear Tester.

\subsubsection{Tensile strength test of the sample-papers}

The tensile strength is the maximum stress to break a strip of paper sheet. It is one of the most important basic physical properties of paper and paperboard. The strength, length and bonding of fiber, degree of fiber refining and the direction of the fiber are the main sources of the tensile strength of paper. It is also depends on the quality and quantity of fillers used. It is a significant factor for many applications as like printing, converter and packaging papers. The tensile strength test of paper sheet is like to the other materials test, but the method of expressing is different. It is calculated with the force per unit width and express as $\mathrm{N} / \mathrm{m}$. It is also important to measure the stretch at break value. Stretch at break is a ratio (in \%) of the elongation of a test piece, over its initial length, at the moment when the maximum tensile force is reached during a tensile test.

Based on the measured values were calculated the tensile index which index is defined with tensile strength divided by basis weight and express as $\mathrm{Nm} / \mathrm{g}$.

The tensile test was performed according to the ISO 1924-1/3 standard using L\&W Tensile Tester.

\subsubsection{Capillary rise of the sample-papers}

For unsized papers such as blotting papers and other papers having relatively high water absorbency the Klemm method for determining water absorbency is used. Test pieces are immersed to a set depth in water and the height of the water rise is measure after a set time.

The capillary rise test was performed according to the ISO 8787:1986 standard using Klemm Absorbency Tester.

\section{RESULTS AND DISCUSSION}

\subsection{Unblended Paper Properties}

The properties of the papers made from $100 \%$ sulphite pine pulp and $100 \%$ recycled paper are shown in Table 1. Compared to sulphite pine papers, the recycled papers have a lower mechanical property values and a lower apparent density because mechanical properties are indicative of the strength derived from factors such as fiber strength, fiber length, and bonding.

The apparent density is a mediate scale of the elasticity of the pulp. Apparent density is simply calculated from weight, area and thickness of paper sample. A resilient pulp has a higher apparent density as its fibers are more lightly compressed into the holes of the paper sheet. Recycled fibers are more inflexible and not so lightly compressible (Minot et al, 1993; Ellis and Sedlachek, 1993). The different is 19\%. The capillary rise value of $100 \%$ sulphite pine paper is $12 \mathrm{~mm}$ lower than $100 \%$ recycled paper (old carton paper). The different is $37 \%$, because the fluid transport in paper depends on the fiber types, the refining, and the other materials of the paper (filers, sizing materials), and the recycled papers contains lot of different other components. The reused papers also had a nether tensile strength and tensile index, burst index and tearing values due to some loss in the interfiber bonding (Alince et al, 2001) from wreckage of the polysaccharide macromolecules as an outcome of dehydration (Minor et al, 1993). The grade of fiber bonding in the paper sheet can be mediate measured by burst test. The $100 \%$ sulphite pine sheet have a $168 \%$ higher burst value than, the $100 \%$ old carton paper and sign lower bonding areas in their recycled papers (Rushdan, 2015). 
Table 1: Mechanical and physical properties of papers

\begin{tabular}{|c|c|c|c|c|c|}
\hline & $\begin{array}{c}\text { 100\% recycled paper } \\
\text { (old carton paper) }\end{array}$ & $\begin{array}{c}94 \% \text { recyc/ } \\
6 \% \text { sulph. }\end{array}$ & $\begin{array}{c}88 \% \text { recyc/ } \\
12 \% \text { sulph. }\end{array}$ & $\begin{array}{c}85 \% \text { recyc/ } \\
15 \% \text { sulph. }\end{array}$ & $\begin{array}{c}100 \% \text { sulphite } \\
\text { pine paper }\end{array}$ \\
\hline apparent density [g/cm3] & 0.65 & 0.63 & 0.64 & 0.64 & 0.81 \\
\hline tensile strength [kN/m] & 3.104 & 3.473 & 3.554 & 3.873 & 6.610 \\
\hline stretch [\%] & 2.07 & 1.72 & 1.66 & 1.72 & 1.62 \\
\hline tensile index [Nm/g] & 30.18 & 34.08 & 35.66 & 39.11 & 68.51 \\
\hline bursting [lb/in'] & 18.60 & 23.7 & 25.4 & 30.1 & 49.8 \\
\hline bursting index & 1.34 & 1.66 & 1.74 & 1.98 & 3.52 \\
\hline tearing force [mN] & 649.91 & 760.28 & 738.69 & 744.58 & 668.39 \\
\hline capillary rise [mm] & 24.0 & 24.5 & 25.5 & 28 & 12.0 \\
\hline
\end{tabular}

\subsection{Blended Paper Properties}

The properties of the papers made from mixtures of the sulphite pine pulp and recycled papers are shown in Table 1. The paper properties were highly affected by the sulphite pine pulp incorporated, with the changes suspended on the extraordinary property, percentage of mixing and the type of recycled paper used. The sulphite pine pulp improved the structural and mechanical properties. The mix of $15 \%$ sulphite paper produced the biggest changes in the structural and mechanical properties and the mix of 6 $\%$ the lowest changes.

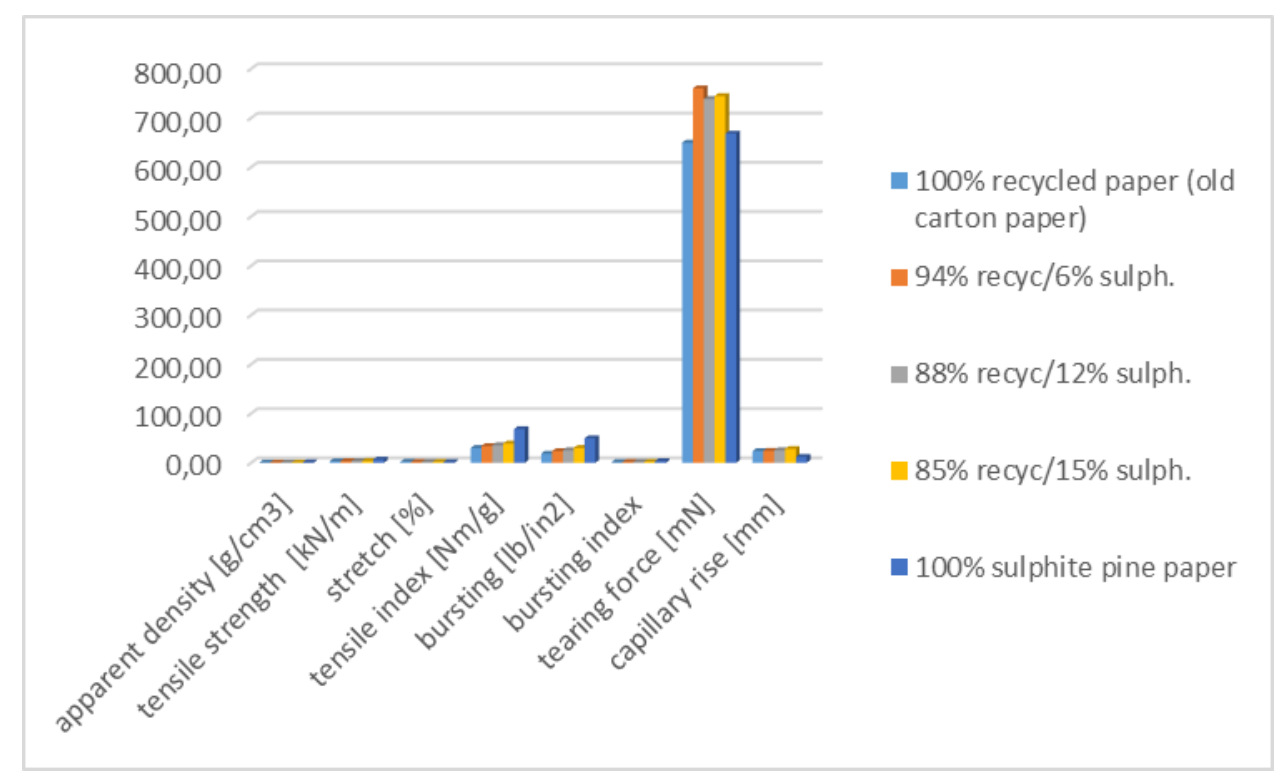

Figure 1: The properties of the papers

The addition of sulphite pine pulp increased the apparent density, tensile index, burst index of the recycled paper. Density is among the important structural properties of paper (Levlin, 1999). Structural properties deal with the placing of containing materials within the paper sheet (Peel, 1999). The results are explained the stability of a paper with randomly oriented fiber is impendent on the strength of the individual fibers and the stability and number of bonds between them (Kallmes and Perez, 1965; Page, 1969; Van Den Akker, 1958).

The strength properties of the blended recycled papers were not linearly related to those of the sulphite pine paper (Table 1 and Figure 1).

As it can be seen from the data, the value of the apparent density changed only in a little degree with the blending of the primer fiber. The increase of the tensile properties was in proportion to the degree of the added sulphite fiber, similarly to the tensile volume. The degree of the changes, that is the increase of the mechanical parameters can be analysed by the percentage of the fiber material correlation. See Table 2. 
Table 2. The correlation between material composition and properties

\begin{tabular}{|c|c|}
\hline properties & correlation \\
\hline apparent density $[\mathrm{g} / \mathrm{cm} 3]$ & 0.98 \\
\hline tensile strength $[\mathrm{kN} / \mathrm{m}]$ & 1 \\
\hline stretch $[\%]$ & -0.5 \\
\hline tensile index $[\mathrm{Nm} / \mathrm{g}]$ & 1 \\
\hline bursting $[\mathrm{lb} / \mathrm{in} 2]$ & 0.97 \\
\hline bursting index & 0.98 \\
\hline tearing force $[\mathrm{mN}]$ & -0.4 \\
\hline capillary rise $[\mathrm{mm}]$ & -0.7 \\
\hline
\end{tabular}

\section{CONCLUSION}

The properties of recycled paper were affected by the addition of sulphite pine virgin pulp with high correlations. The changes on the properties diverse, impend on the particular property, percentage of blending. The blended recycled paper properties were not linearly related to the sulphite pine paper properties. The changes in the paper properties originate from the properties of the sulphite pine pulp its elasticity, potential bonding area and other materials.

In conclusion, it can be said, that the sulphite fibers added to the recycled papers significantly increased the mechanical parameters of the product. Analysing the correlation values, it can be established there is very strong relationship between the volume of the mass of fiber and the measured properties. Except the capillary rise, whose correlation volume showed a weak relationship. The possible reason for this is that in the case of paper the water absorption and the capillary properties are dependent on the volume of added materials a larger degree than the strength and shape of the fibers and the number of bonds.

\section{REFERENCES}

[1] Alince, B., Porubska, J., Van De Ven, T.G.M: „Effect of model and fractionated TMP fines od sheer properties", Proceeding of the 12th Fundamental Research Symposium 2001, (FRC Symposium: Oxford, United Kingdom, 2001), pages 1343-1355.

[2] De Silveira, G., Zhang, X., Berry, R., Wood, J.R.: „Location of fines in mechanical pul handsheets using scanning electron microsopy", Journal of pulp and paper science 22 (9), 315-320, 1996.

[3] Ellis, R.C., Sedlachek, K.M.:"Recycled versus virgin-fibre characteristics: A comparions in secondary fiber recycling", Tappi Journal 76, 143-146, 1993.

[4] Fengel, D., Wegener, G.:" Wood Chemistry Ultrastructure Reactions" (Walter de Gruyter, Berlin, 1984.)

[5] Görres, J., Amiri, R., Wood, J.R., Karnis, A.: „Mechanical pulp fines and sheet structure“, Proceedings of the International paper physics conference 1995, (Niagara on the Lake, Canada, 1995), pages 37-48.

[6] Kallmes, O. J., Perez, M.: "A new theory for load/elongation properties of paper", Proceedings of the $3^{\text {rd }}$ Fundamental Research Symposium - Consolidation of paper 1965, (Cambridge, United Kingdom, 1965), pages 779-800.

[7] Levlin, J.: "General physical properties of paper and board”, In: Papermaking science and technology, (Fapet Oy, Helsinki Finland, 1999.), pages 136-161.

[8] Luukko, K.: „Characterization And Properties Of Mechanical Pulp Fines“ , PhD thesis, University Of Technology, Helsinki, Finland, 1999.

[9] Minor, J. M., Scott, C. T., Atalla, R. H.:" Restoring Bonding Strength To Recycled Fibres", Proceedings of the TAPPI Recycling symposium 1994, (Atlanta, Georgia, 1994), pages 379-385.

[10] Page, D. H.: "The Theory for Tensile Strength Of Paper", Tappi Journal 52 (4), 674-681, 1969.

[11] Peel, J. D.: "Paper Science and Paper Manufacture", (Angus Wilde Publication Inc., Vancouver, 1999.), page 272. 
[12] Rushdan, I.: "The Effect of Initial Processing on the Bonding Index of Acacia Mangium recycled paper", Proceedings of the International Pulp and Paper Conference 1998, (Sarawak, Malaysia, 1998), pages $57-65$.

[13] Sjostrom, E.: „Wood Chemistry“, (Academic Press, New York NY, 1993.)

[14] Sood, Y.V., Tyagi, R., Tyagi, S., Pande, P.C., Tondon, R.: „Surface charge of different papermaking raw materials and its influenceon paper properties", Journal of scientific and industrial research 69 (4), 2010.

[15] Van Den Akker, J. A.: "Importance of fibre strength to sheet strength", Tappi Journal 41 (8), 416-425, 1958.

[16] Zeyer, C., Joyce, T.W., Heitmann, J.A., Rucker, J.W.: „Factors influencing enzyme deinking of recycled fiber", Tappi Journal 77 (10), 169-177, 1994.

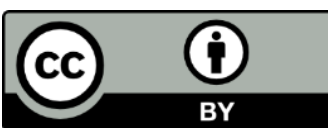

(C) 2020 Authors. Published by the University of Novi Sad, Faculty of Technical Sciences, Department of Graphic Engineering and Design. This article is an open access article distributed under the terms and conditions of the Creative Commons Attribution license 3.0 Serbia

(http://creativecommons.org/licenses/by/3.0/rs/). 


\title{
SUSTAINABLE CARDBOARD LABEL PRODUCTION
}

\author{
Gulsah Yilan ${ }^{1}$ (D), Arif Ozcan $^{2}$ (D), Tanju Caglar ${ }^{3}$ \\ ${ }^{1}$ Marmara University, Faculty of Engineering, Chemical Engineering, Istanbul, Turkey \\ ${ }^{2}$ Marmara University, School of Applied Sciences, Printing Technologies, Istanbul, Turkey \\ ${ }^{3}$ Marmara University, Institute of Pure and Applied Sciences, Printing Technologies, \\ Istanbul, Turkey
}

\begin{abstract}
Recently, all industrial sectors have shown significantly increasing attention in reaching the sustainability goals regarding economic, environmental, social, and also technological aspects not only at the regional level but also nationwide and even global scale. Aside from being an economically popular concept, sustainability is strictly related to effective resource use and efficient waste disposal. Thus, it functions as a complementary issue to be considered in various production activities. The sustainable production approach includes reducing or (if possible) eliminating the negative impacts on the human health and environment, reducing the waste generated, increasing the recycling rate, and developing energy and material saving processes. The printing industry is one of the most important industries in reaching sustainable production goals. The need for the printed products, which is the focus of this study, is increasing in parallel with the changing consumer expectations and technological developments. However, from the point of the printing industry view, a solid sustainability consensus is not settled among the practitioners, yet. This study aims to evaluate the sustainability of the cardboard label production considering several combinations of raw materials such as paper, ink, and surface coating additives via appropriate MultiCriteria Decision Analysis (MCDA) methods. The most frequently used paper and ink types are considered with three alternatives for each. To indicate the sustainability scores economic, environmental, and social evaluation criteria are selected. By applying the Multi-Attribute Utility Theory (MAUT), the sustainability score of each label is calculated to determine the optimum alternative in terms of the production process and also the material used. This evaluation provides detailed information to the producer and also to the consumer about the alternative production routes to use less energy and raw material, and also to decrease the environmental impacts while sustaining the economic feasibility. Besides, alternative solutions are offered to reach sustainability goals by considering the economic and environmental life cycle impacts of these materials. Hence, an increase in awareness about the printing industry and service channels is expected. Moreover, this study is also important in presenting the applicability of sustainability assessments in the printing industry.
\end{abstract}

Keywords: Sustainability, Printing Industry, Label Production, Multi-Criteria Decision Analysis, Case Study

\section{INTRODUCTION}

Global warming and climate change issues have been the biggest challenges of the 21st century, so far. Companies struggle with not only how to reduce their expenses but also how to sustain the balance of nature concerning technological developments. Impacts on the environment are threatening both today's and tomorrow's populations. Thus, a comprehensive perspective is required to handle global warming, industrialization, overexploitation of the natural resources, and environmental pollution issues together for offering a sustainable pathway for future generations. When the sustainability issue is discussed, one can only imagine the environmental aspects. However, sustainable development includes all related topics such as quality and quantity of goods and services produced and used by communities, perceptions of consumers and producers, poverty, environmental sensitivity, and so on. If economic and ecological balance are considered complementary aspects, then more realistic sustainability goals can be achieved to enhance the well-being of the society from social, economic, and cultural points of view (Akdoğan and Hicyorulmaz, 2015). The companies principally focus on the materials that have significant impacts on natural ecosystems when transformed or consumed. While depleting the raw materials directly or indirectly, almost all producers generate and release a variety of waste types to the environment that in turn threaten the survival of our species and also our planet. The consequences of our acts on the environment today will determine the world the next generations will be living in. The mutual thinking of creating a sustainable world continues to unite humankind (Wondemu, 2011).

Sustainability covers reducing (and if possible eliminating) the impacts of production activities on humanity and the environment, decreasing the amount of waste generated during production, increasing the 
recyclability of products, and developing production processes that aim material and energy savings. Nonetheless, sustainable development is defined as the "development that meets the needs of the present without compromising the ability of future generations to meet their own needs" (Dresner, 2008).

Fundamentally, three main goals of sustainability are reducing, reusing, and recycling waste streams. One of the most important industries in reaching sustainability goals is the printing industry that contributes significantly to the economic growth of countries (Hami et al, 2018). Considering the printing industry, the reduction in the number of waste streams results in a decrease in the raw material supply. Besides, the increased amount of reuse results in lower levels of recycling activities. The main raw materials of this market are paper, cardboard, and ink. Despite the developments in digital technologies and emerging digital communication alternatives, the demand for printed products continues increasing with changing consumer expectations. In the light of technological developments in the printing industry, the production efficiency is increasing and wastage rates are decreasing. In addition, the supply chain system - including the raw material supply, the fair use of resources, paper recycling, acquisition of raw materials for ink, and ink production - is getting more attention currently.

Cardboard label production is one of the main branches of the printing industry. The volume of production, the range of application areas, and the currency of the cardboard label production are in an increasing trend. Cardboard label produced via offset printing is one of the products with the highest market share in the label sector. It has a vital role especially in the textile sector, functioning in strengthening the image of the firm, and informing the consumers. Cardboard label designs are products with wide circulation in printing activities. The printing sector brings together the companies of raw material suppliers, cardboard label producers, and textile firms using cardboard labels in their products. Considering the limited availability of the earth's resources, it is important to prefer using environmentally friendly alternatives for the basic raw materials of paper and ink during the production activities. Nevertheless, from environmental and economic points of view, this perspective holds the keys to reduce the raw material and energy demand, to decrease the costs of raw materials, and even to open a window of opportunity for new employment possibilities in the recycling sector.

Moreover, the printing ink producers are also making a great effort in using raw materials with low (and none if possible) environmental impacts during the production of pigments, colorants, solvents, and other additives. Recently, the amounts of petroleum-based mineral oils are decreasing in response to the increase in vegetable oils. Similarly, an increasing effort is made for reducing (and eliminating if possible) the volatile organic compounds (VOCs) emissions in the solvents, drying agents, cleaning solvents, and other chemicals used in different stages of printing. A significant development is achieved in reducing and eliminating the use of IPA in the offset printing dampening solution (Ozcan, 2017).

For sustainable development, the production rate of paper and cardboard from industrial woods is increasing progressively. Additionally, there are some other approaches of sustainability such as preventing the cutting down of forests via paper production from alternative plants, naturally growing herbs, agricultural and industrial residuals (Karlovits et al, 2020), and also acid and chlorine-free bleaching process in the paper production (Masod and Abdullah, 2015). Especially Scandinavian countries are the pioneers of green technologies with low-chlorine pulp, elemental chlorine-free (ECF), and total chlorine free (TCF) bleaching techniques (Bergquist and Söderholm, 2015; Söderholm et al, 2017). Furthermore, the use of paper and paper products with chlorine is proved to create some health issues, and accordingly, the use of these products in food packaging and hygiene products is not recommended (Shoham et al, 1992).

Some printing houses in the printing industry aim to increase awareness with their individual activities employing sustainable alternatives. Small improvements in the basic principles such as product design, graphic design, paper selection, ink choosing, and even the number of colors may result in significant variations in terms of sustainability. In the process of the selection of the type of paper, ink, and coating materials to be used in the cardboard label production, proposing an alternative production route considering environmental aspects and ecological limits along with the costs may create a significant impact on the perception of consumer and producer (Monteiro et al, 2019). Thus, a transition to more sustainable production models (e.g. less deforestation, less environmental impacts, lower carbon and water footprint, lower energy demand) may be provided. The increase in efficiency as an obvious result of sustainable practices may also encourage the other stakeholders to shift from their conventional production activities to more sustainable ones.

When performing a sustainability analysis, it is vital to plot the 'big picture' i.e. rather than focusing on a single parameter, one should consider a variety of parameters simultaneously. For example, the term "water-based" is accepted as an environmentally friendly alternative, and similarly, "vegetable oil-based systems" may be considered favorable owing to the renewable source content. Nonetheless, vegetable oil- 
based products sometimes need significantly more energy to dry than alternative materials. In reality, no single technology or printing process provides the best solution. The most appropriate option can only be identified by considering all stakeholders involved in a particular process or product, taking all the relevant factors into account (Eupia, 2013).

Several modeling approaches may be used to propose a sustainability assessment. The most used methodologies are Life Cycle Assessment (LCA), Cost-Benefit Analysis (CBA), and Multi-Criteria Decision Analysis (MCDA). Especially, MCDA is the most popular method since it allows the practitioners to evaluate economic, technical, environmental, and social aspects simultaneously (Strantzali and Aravossis, 2016; Yilan et al, 2020).

In this study, an application of MCDA methodology is conducted in the label printing industry. At first, the raw materials are selected for printing as paper and ink. Then evaluation criteria are determined and valuated. The next step is to normalize the criteria so that they have the same order. A final weighting step via Multi-Attribute Utility Theory (MAUT) is applied to reach the final representative sustainability scores.

\section{METHODS}

The aim of this study is to conduct a sustainability analysis of cardboard label production with offset printing systems. In this study, several combinations of raw materials, especially paper and ink, are examined via appropriate MCDA methods. The paper and ink types are considered with three alternatives for each resulting in a number of 9 label combinations. The technical properties of the selected paper and ink types are given in tables 1 and 2, respectively.

Table 1: Physical and optical characteristics of the paper types used in the study

\begin{tabular}{|c|c|c|c|c|c|}
\hline & & & $\begin{array}{l}\text { Paper } 1 \\
\text { (0\% Recycled) }\end{array}$ & $\begin{array}{l}\text { Paper } 2 \\
\text { (25\% Recycled) }\end{array}$ & $\begin{array}{l}\text { Paper } 3 \\
\text { (50\% Recycled) }\end{array}$ \\
\hline \multicolumn{2}{|c|}{ Basis Weight $\left(\mathrm{g} / \mathrm{m}^{2}\right)$} & ISO 536:2012 & 300 & 300 & 300 \\
\hline \multicolumn{2}{|c|}{ ISO Brightness D65 (\%) } & ISO 2470-2:2008 & 105 & 104 & 104 \\
\hline \multicolumn{2}{|c|}{ Opacity (\%) } & ISO 2471:2008 & 99.8 & 99.7 & 99.9 \\
\hline \multicolumn{2}{|c|}{$\begin{array}{l}\text { Roughness Bendtsen } \\
\text { (ml/min) }\end{array}$} & ISO 8791-2:2013 & 250 & 250 & 249 \\
\hline \multicolumn{2}{|c|}{ Thickness $(\mu \mathrm{m})$} & ISO 534:2005 & 328 & 327 & 328 \\
\hline & $\mathrm{L}^{*}$ & \multirow{3}{*}{$\begin{array}{l}\text { ISO 5631-3:2014 } \\
\text { (D50/2 })\end{array}$} & 94.1 & 94.6 & 94.3 \\
\hline & $a^{*}$ & & 2.5 & 2.7 & 2.3 \\
\hline & $\mathrm{b}^{*}$ & & -7.0 & -6.7 & -7.1 \\
\hline \multicolumn{3}{|c|}{ CIE Whiteness (\%) } & 149 & 148 & 148 \\
\hline
\end{tabular}

Table 2: Physico-chemical composition of ink types used in the study

\begin{tabular}{|c|c|c|c|}
\hline & $\begin{array}{c}\text { Ink 1 (Soy } \\
\text { oil-based) }\end{array}$ & $\begin{array}{c}\text { Ink 2 (Mineral } \\
\text { oil-based) }\end{array}$ & $\begin{array}{c}\text { Ink 3 (UV } \\
\text { curable ink) }\end{array}$ \\
\hline Pigment & 20 & 20 & 20 \\
\hline Resin & 30 & 30 & 0 \\
\hline Mineral oils & 0 & 0 & 0 \\
\hline Vegetable oils & 40 & 40 & 0 \\
\hline Dryers & 5 & 5 & 0 \\
\hline Additives & 5 & 5 & 5 \\
\hline Oligomer & 0 & 0 & 50 \\
\hline Monomer & 0 & 0 & 20 \\
\hline Photoinitiator & 0 & 0 & 5 \\
\hline
\end{tabular}


The widely accepted methodology for conducting a sustainability analysis is the MCDA technique. In this study, a techno-economic and eco-social parameter are selected as cost and volatile organic compounds (VOCs), respectively. No extra technical parameter is required since the recyclable content of the paper is considered in the cost and VOC calculations.

As usual, techno-economic parameters have always been the main drivers of decision-makers. However, as environmental awareness is increased in response to the sustainability debate, the need for additional parameters emerged for decision-making. In this respect, the VOCs parameter is selected as an eco-social parameter. VOCs have several negative environmental effects and have been tied to adverse health effects for those with prolonged exposure. Traditional inks are petroleum-based and are known to release high amounts of VOCs while vegetable-based inks, usually made with soy, are more sustainable and release no VOCs (Merritt, 2020).

It is reported that petroleum-based inks emit approximately $25 \%$ to $40 \%$ of VOCs while drying, while the emissions levels of vegetable inks (such as soy, flax, canola, or safflower) can be as low as $2 \%$ to $4 \%$, even some brands of ink releasing none at all. Current regulations limit the allowed VOCs release rates for petroleum inks to be no more than 30 percent VOC, and this is where the new vegetable-based inks can be an effective green alternative (Moore, 2013; Stone, 2008).

\section{RESULTS AND DISCUSSION}

The calculation results of the selected paper and ink types are given in table 3. Paper types are based on the widely used coated freesheet paper differentiating in the recycled content from 0 to $50 \%$. Ink types are selected as UV curable ink, soy-based ink, and mineral-based ink. The techno-economic criterion, cost of paper and ink types, is evaluated directly from the sales department of a private company. The eco-social criterion is evaluated with an online calculator (Environmental Paper Network's Paper Calculator) (https://c.environmentalpaper.org/) for the paper types and from literature for the ink types.

Table 3: Evaluation criteria used in the study

\begin{tabular}{|c|c|c|}
\hline & $\begin{array}{c}\text { Techno-Economic } \\
\text { Cost }(\boldsymbol{\epsilon} / \mathrm{kg})\end{array}$ & $\begin{array}{c}\text { Eco-social } \\
\text { VOC (kg/ton) }\end{array}$ \\
\hline Paper types & & \\
\hline P1 (Coated freesheet, recycled content: 0\%) & 3.0 & $4.05 \mathrm{E}-02$ \\
\hline P2 (Coated freesheet, recycled content: $25 \%)$ & 2.7 & $3.87 \mathrm{E}-02$ \\
\hline P3 (Coated freesheet, recycled content: 50\%) & 2.5 & $3.69 \mathrm{E}-02$ \\
\hline Ink types & & \\
\hline I1 (UV curable ink) & 10 & $0.00 \mathrm{E}+00$ \\
\hline I2 (Soy-based ink) & 4.5 & $4.00 \mathrm{E}-02$ \\
\hline I3 (Mineral-based) & 4.0 & $3.00 \mathrm{E}-01$ \\
\hline
\end{tabular}

According to the different paper and ink types, a combination of 9 labels (see Figure 1 for label content) is compared from a sustainable point of view with an MCDA technique. At first, the total cost and total VOCs are calculated considering $98 \%$ of the label is made of paper and the rest $2 \%$ is made up of ink. While the paper and ink types are varying, we choose a constant type of varnish for fixing the number of labels to 9. Since all labels have the same varnish, the effects related to varnish do not make a difference across different alternatives. For this reason, the effects of varnish are not included in the analysis. After calculating the total values of cost and VOCs, the normalization process is evaluated in such a way that the values differ from 0 (the worst option) to 1 (the best option). The normalization step is especially important in setting a common basis for parameters with different numerical values and also units. After normalization, the parameters can be combined to reach a final sustainability score. In this study, an equal weighting is preferred for techno-economic and eco-social parameters to calculate a representative score in the application of MAUT. 


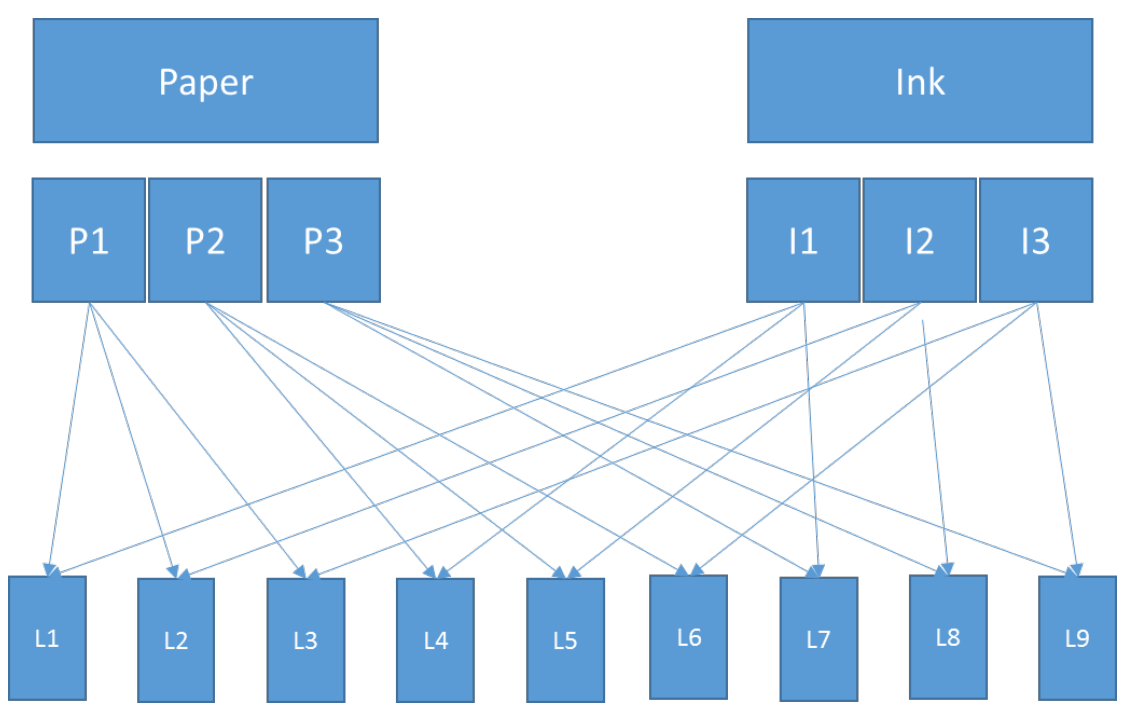

Figure 1: Combinations of paper and ink types used in the study

The normalized values of cost and VOCs along with the sustainability scores are given in Figure 2. Orange and grey bars represent the normalized values of cost and VOCs, respectively. As mentioned before, the higher the normalized values, the better the sustainability scores. Blue bars represent the cumulative scores with the equal weight (50\% cost and 50\% VOCs), and finally indicate sustainability. As seen in the figure, L9 has the lowest cost (meaning the highest normalized value) while L7 has the lowest VOCs.

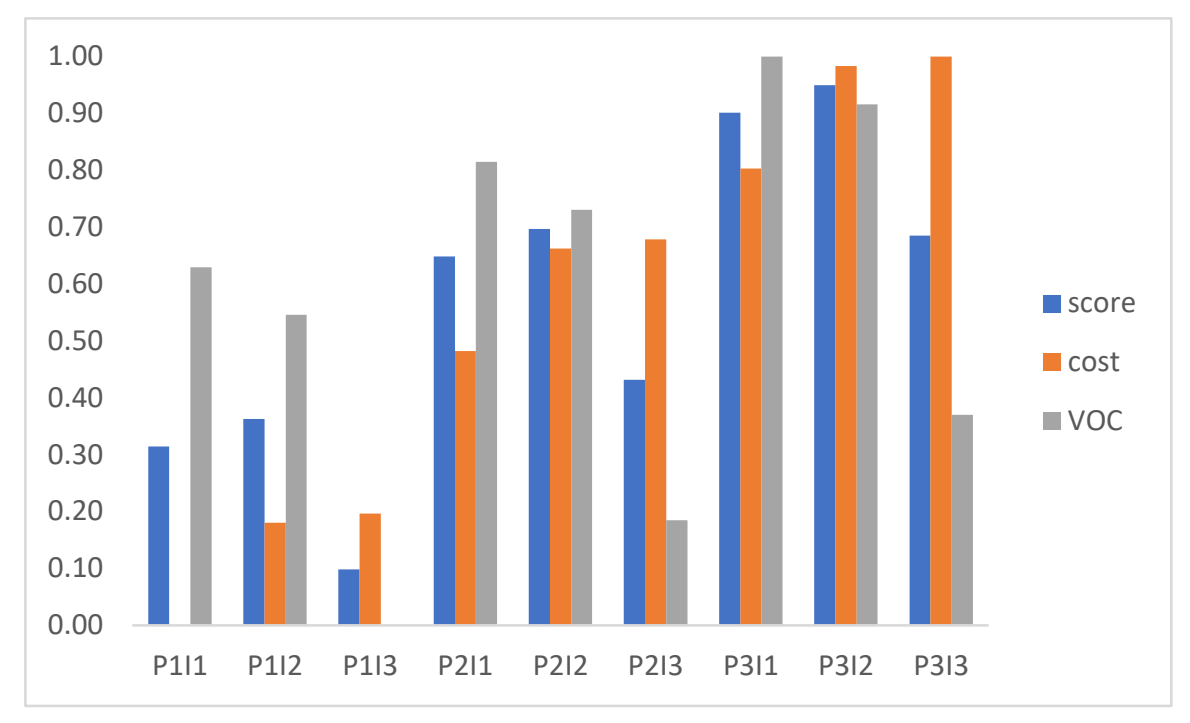

Figure 2: Sustainability scores of each label used in this study

A final ranking of the sustainability scores in decreasing order from the best to the worst option is given in table 4 . The highest cumulative score in terms of sustainability is gathered for $L 8$ indicating the best option where $L 3$ is the worst option. The results clearly show that the decision-makers require a broader perspective to select the most sustainable option among different alternatives rather than evaluating single aspects.

Table 4: A final ranking of the sustainability score of each label used in this study

\begin{tabular}{|l|c|c|c|c|c|c|c|c|c|}
\hline Ranking & 1 (Best) & 2 & 3 & 4 & 5 & 6 & 7 & 8 & 9 (Worst) \\
\hline Label & L8 & L7 & L5 & L9 & L4 & L6 & L2 & L1 & L3 \\
\hline Content & P3I2 & P3I1 & P2I2 & P3I3 & P2I1 & P2I3 & P1I2 & P1I1 & P1I3 \\
\hline
\end{tabular}




\section{CONCLUSIONS}

The printing industry is one of the most important industries in reaching sustainable production goals. However, a solid sustainability consensus is not settled among the practitioners, yet. In this study, the sustainability scores of a total number of 9 labels are calculated to determine the optimum alternative via MCDA methodology. The evaluation criteria are selected as cost and VOCs. The optimum results acquired with neither the cheapest (L9) nor the environmentally friendly (L7) alternative, rather a distinct label (L8) has the highest score indicating the need for a broader perspective to offer a sustainable alternative among the similar options.

\section{ACKNOWLEDGMENTS}

The study is held as a part of the Master Thesis entitled as "Sustainability in Printing Industry: A Study on Cardboard Label Production", to be submitted to Marmara University, the Institute of Pure and Applied Sciences.

\section{REFERENCES}

[1] Akdoğan, H., Hicyorulmaz, E.: "The importance of the sustainability of environmental accounting", Journal of Economic Development, Environment and People 4 (2), 6-20, 2015. doi: 10.26458/jedep.v4i2.104

[2] Bergquist, A. K., Söderholm, K.: "Transition to greener pulp: regulation, industry responses and path dependency", Business History 57 (6), 862-884, 2015. doi: 10.1080/00076791.2014.986105

[3] Dresner, S.: "The principles of sustainability" (Earthscan, Sterling VA, 2008.)

[4] Eupia, "Information note: Environmental impact of printing ink", URL: https://www.eupia.org/fileadmin/FilesAndTradExtx_edm/2013-0305_EuPIA_Environmental_Impact_of_Printing_Inks_01.pdf (last request: 2020-09-30), 2013.

[5] Hami, N., Mat Yamin, F., Mohd Shafie, S., Muhamad, M. R.: "Implementing sustainable manufacturing practices in a printing company: A case study", The $2^{\text {nd }}$ Conference on Technology \& Operations Management $2{ }^{\text {nd }}$ CTOM (University of Science, Pulau Pinang, Malaysia, 2018.)

[6] Karlovits, I., Kavcic, U., Lavric, G., Sinkovec, A., Zoric, V.: "Digital printability of papers made from invasive plants and agro-industrial residues", Cellulose Chemistry and Technology 54 (5-6), 523-529. 2020. doi: 10.35812/CelluloseChemTechnol.2020.54.53

[7] Masod, M. Y. B., Abdullah, H.: "Practicing Environmental Protection in Printing Industry", Journal of Printing Science and Technology 52 (6), 497-499, 2015. doi: 10.11413/nig.52.497

[8] Merritt.: "4 Best Green Solutions for Sustainability in the Printing Industry", URL: https://www.josephmerritt.com/marketing-media/articles/4-best-green-solutions-for-sustainabilityin-the-printing-industry (last request 2020-09-30), 2020.

[9] Monteiro, J., Silva, F. J. G., Ramos, S. F., Campilho, R. D. S. G., Fonseca, A. M.: “Eco-Design and Sustainability in Packaging: A Survey", Procedia Manufacturing 38, 1741-1749, 2019. doi: 10.1016/j.promfg.2020.01.097

[10] Moore, V.: "Benefits Of Eco Solvent Inks", URL: https://www.sustainablebusinesstoolkit.com/benefits-of-eco-solventinks/ (last request 2020-09-30), 2013

[11] Ozcan, A.: "Examination of printability parameters of iPa free offset printing", Journal of Graphic Engineering and Design 8 (1), 29. 2017. doi: 10.24867/JGED-2017-1-029

[12] Shoham, Y., Schwartz, Z., Khasin, A., Gat, O., Zosim, Z., Rosenberg, E.: "Delignification of wood pulp by a thermostable xylanase from Bacillus stearothermophilus strain T-6", In Microorganisms to Combat Pollution, (Springer, Dordrecht, 1992.), pages 83-94. doi: 10.1007/BF00129084

[13] Söderholm, K., Bergquist, A. K., Söderholm, P.: "The transition to chlorine free pulp revisited: Nordic heterogeneity in environmental regulation and R\&D collaboration", Journal of Cleaner Production 165, 1328-1339, 2017. doi: 10.1016/j.jclepro.2017.07.190

[14] Stone, T.: "Eco-friendly inks", URL: https://creativepro.com/eco-friendly-inks/ (last request 2020-0930), 2008.

[15] Strantzali, E., Aravossis, K.: "Decision making in renewable energy investments: A review", Renewable and Sustainable Energy Reviews 55, 885-898. 2016. doi: 10.1016/j.rser.2015.11.021 
[16] Wondemu, E.: "Ink and paper saving for sustainable printing", BSc thesis, Helsinki Metropolia University of Applied Sciences Degree Programme in Media Engineering, 5-41, 2011.

[17] Yilan, G., Kadirgan, M. N., Çiftçioğlu, G. A.: "Analysis of electricity generation options for sustainable energy decision making: The case of Turkey", Renewable Energy 146, 519-529, 2020. doi: 10.1016/j.renene.2019.06.164

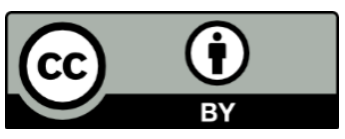

(C) 2020 Authors. Published by the University of Novi Sad, Faculty of Technical Sciences, Department of Graphic Engineering and Design. This article is an open access article distributed under the terms and conditions of the Creative Commons Attribution license 3.0 Serbia (http://creativecommons.org/licenses/by/3.0/rs/). 



\title{
INFLUENCE OF RECYCLED FIBRES IN PAPER ON THE UV STABILITY OF THERMOCHROMIC PRINTS
}

\author{
Rahela Kulčar (D), Marina Vukoje (iD), Ivana Krajnović (D), Mirela Rožić (iD) \\ University of Zagreb, Faculty of Graphic Arts, Zagreb, Croatia
}

\begin{abstract}
Recycled paper for environmentally conscious consumers can positively influence product selection. Thermochromic inks printed on such materials can give the product a special effect and increase its market competitiveness. During recycling, the paper is subjected to the action of various processes and chemicals, which later can have an impact on its stability, structural and optical properties. As is already known, the optical properties of paper affect the quality of the print. Thus, the goal of this study is to determine whether environmentally friendly substrates containing recycled fibres can be of the same quality as non-recycled substrates for the printing of thermochromic inks. For the research purposes, two commercially available thermochromic inks were printed on papers with a certain percentage of recycled fibres (33\% and 100\%). The results will show whether the percentage of fibres affects the colorimetic properties, dynamic characteristics of thermochromic inks and the UV stability during accelerated ageing of thermochromic prints.
\end{abstract}

Key words: thermochromic inks, UV stability, recycled fibres

\section{INTRODUCTION}

Today, many different types of inks and printing processes are used. To satisfy the market innovations, there is a greater demand for traditional and functional printing inks, such as thermochromic (TC) printing inks. Thermochromism in the graphics industry has a wide range of applications and their development is still in progress (Gunde et al, 2011). Also, today's graphic designers try to use environmentally friendly substrates. Recycled paper for eco-conscious consumers can have a positive reaction during product selection. TC inks printed on such materials can give the product a special effect. In 2016, $72.5 \%$ of all paper consumed in Europe was recycled. Recovered paper is today the most important raw material for the production of paper, paperboard and corrugated board (CEPI, 2017). The quality of paper made from recycled fibres is generally lower than that of the virgin fibres due to a shorter fibre length which in the end affects the tensile strength (Coppola et al, 2018). When it comes to printing, the printing quality is strongly influenced by the structural (topography and porosity) and chemical properties of the paper surface, being one of the most important factors concerning costumer's evaluation (Koivula et al, 2008; Moutinho et al, 2011). One of the main functions of printing inks is to adhere the printing substrate and remain there for the whole lifespan of print. Adhesion of inks to paper plays an important role in many industrial applications (Awaja et al, 2009). Kibirkštis et al (2013) showed in their research that geometrical accuracy of small elements printed on recycled paper, in comparison to pictures printed on paper produced from virgin fibres, is almost the same.

Leuco dye-based thermochromic inks are today commercially available in all major ink types (such as water-based, solvent-borne and photocuring inks) for application on different substrates. Most TC organic composites are mixtures consisting of colour former (leuco dye), a developer and solvent. TC printing inks are normally protected in polymer capsules and dispersed in the resinous medium. Offset TC inks have different rheological properties to conventional ones (Kulčar et al, 2010; Friškovec et al, 2013; Panák et al, 2015). The colorimetric properties of TC inks are only retained for a rather short period. The quite short pot life and poor stability of TC colour are related to the chemical stability of the ink formulation. Attention should also be given to the substrates used since the printing substrate can dynamic properties during heating and cooling process of thermochromic ink as shown in previous research (Vukoje et al, 2018a).

The objective of this work is to determine the influence of UV stability on the dynamic properties of TC inks printed on an environmentally friendly paper substrate, but in order not to lose its quality. Also, the TC inks with different chemical compositions on such substrate will suggest a more acceptable option with an emphasis on greater lightfastness stability. 


\section{EXPERIMENTAL}

Two recycled papers with different proportions of recycled fibers (RF), 33\% (33RF) and 100\% (100RF), were used as a substrate in printing trials.

Also, two commercially available offset thermochromic (TC) inks were used for printing. TC27 offset ink was coloured in blue below its activation temperature $\left(T_{A}=27^{\circ} \mathrm{C}\right)$ and changed to colourless when was heated above the activation point. TC45 ink was coloured in green below its activation temperature $\left(T_{A}=45^{\circ} \mathrm{C}\right)$ and changed to yellow above the activation point. The solvent in the TC27 ink was a mineral spirit and TC45 ink were vegetable-based. The colour changes of both inks were reversible, i.e. original colour was restored upon cooling. Ink producers recommended printing these inks onto uncoated, absorbent papers to achieve the best print quality.

The printing trials were carried out using the Prüfbau Multipurpose Printability Tester. The quantity of 1.5 $\mathrm{cm}^{3}$ of ink was applied on the distribution rollers while printing was carried out with the printing force of $600 \mathrm{~N}$. The samples were printed in full tone.

For accelerated ageing of the prints, Solarbox 1500e device (CO.FO.ME.GRA) was used. This device enables the simulation of environmental conditions in an open or closed space and ensures the control of temperature and radiation. All the samples were exposed to filtered xenon light for a period of 6 and 12 hours at a BST temperature of $60{ }^{\circ} \mathrm{C}$, at irradiation of $550 \mathrm{~W} / \mathrm{m}^{2}$. The indoor filter was used for the simulation of conditions of internal exposure (equivalent to sun rays filtered through a windowpane). The UV filter was used to change the xenon spectral curve into the ultraviolet range.

Spectral reflectance was measured by using Ocean Optics USB2000+ spectrometer using $50 \mathrm{~mm}$ wide integrating sphere under (8: di) measuring geometry (diffuse geometry, a specular component included). The printed samples were heated/cooled on the full-cover water block (EK Water Blocks, EKWB d.o.o. Slovenia). Its temperature was varied by thermostatically controlled water block. Reflectance spectra were measured in one heating/cooling cycle. The measurements were performed in the steps of $1 \mathrm{~nm}$ for the spectral region from 430 to $750 \mathrm{~nm}$. Ocean Optics SpectraSuite software was used for the calculation of the CIELAB values from measured reflectance. The D50 illuminant and $2^{\circ}$ standard observer were applied in these calculations.

\section{RESULTS AND DISCUSSION}

The samples were measured at estimated temperatures of each thermochromic colour, and spectral curves ranging from 430 to $750 \mathrm{~nm}$ were read through the measurement to give a visual representation of the colour change at different temperatures.

Figures 1 - 3 show the spectral reflectance curves of a sample printed with TC27 printing ink, which at an activation temperature of $27^{\circ} \mathrm{C}$ goes from light blue to transparent and spectral reflections of the printing substrate on which the ink is printed. Measurements were made from $15^{\circ} \mathrm{C}-55^{\circ} \mathrm{C}$ in both directions. The results show that the effect of UV radiation leaves consequences on all samples in a relatively short time. Spectral reflectance curves additionally show the differences int the paper structures, i.e. the reflectance in the blue part of the 33RF paper spectrum indicate the presence of optical brighteners in the paper, while in the case of 100RF paper this is absent.

The results show that the decolorization of TC27 sample is not complete even at the highest temperatures applied in the experiment, which are far above the activation temperature. Also based on the spectral reflection curves, it is clearly observed that the thermochromic effect of color change with a longer time of UV aging is significantly reduced. Moreover, the paper itself is subject to change during UV aging as can be seen from the reflection curves, whose intensities decrease during exposure to UV irradiation.

Figures 4-6 show spectral reflectance curves of a sample printed with the TC45 thermochromic printing ink, which at the activation temperature of $45^{\circ} \mathrm{C}$ turns from green to yellow. Measurements were made from $10^{\circ} \mathrm{C}-60^{\circ} \mathrm{C}$ in both directions. 

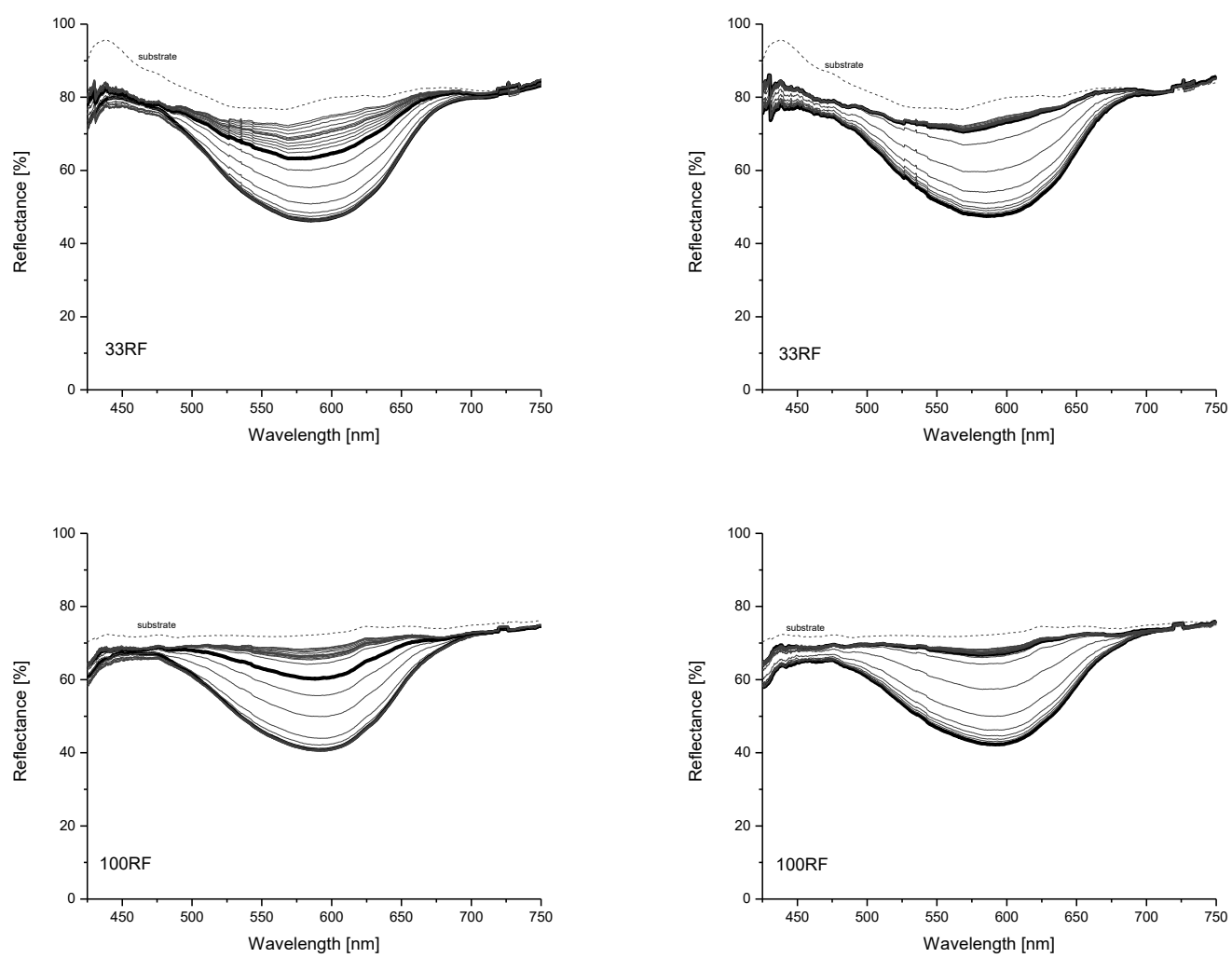

Figure 1: Spectral reflectance curves for the TC27 sample measured at heating (left) and cooling (right) on 33RF and 100RF papers
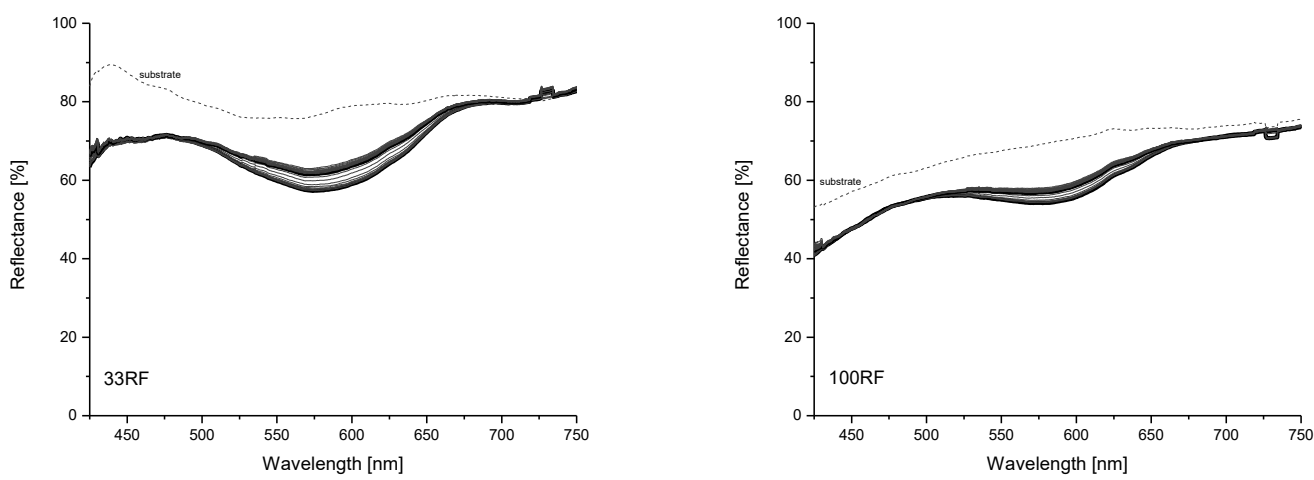

Figure 2: Spectral reflectance curves for the TC27 sample exposed to light for 6 hours (measured at heating) on different papers
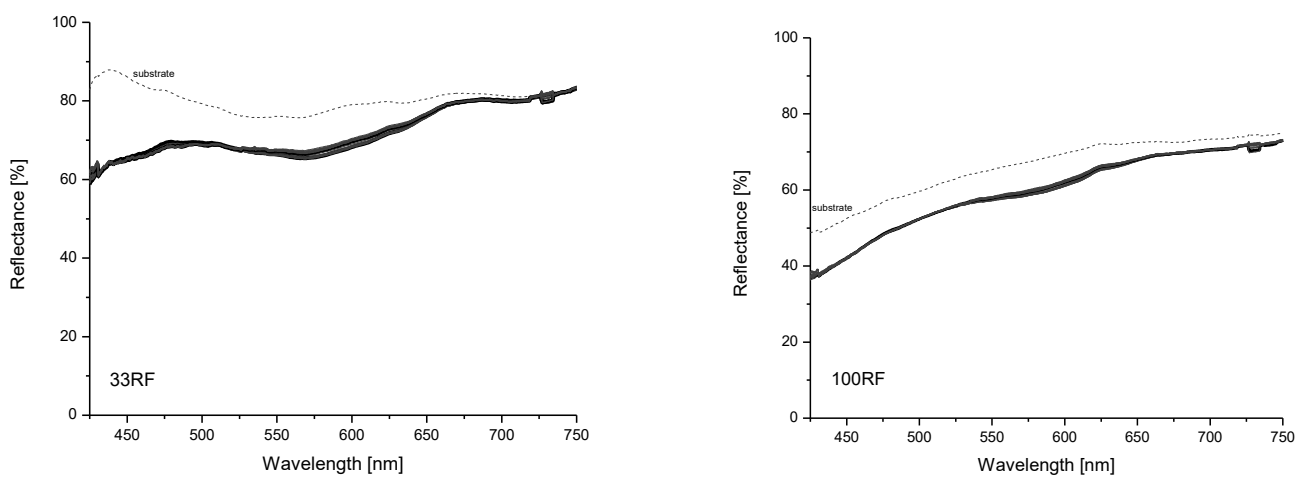

Figure 3: Spectral reflectance curves for the TC27 sample exposed to light for 12 hours (measured at heating) on different papers 

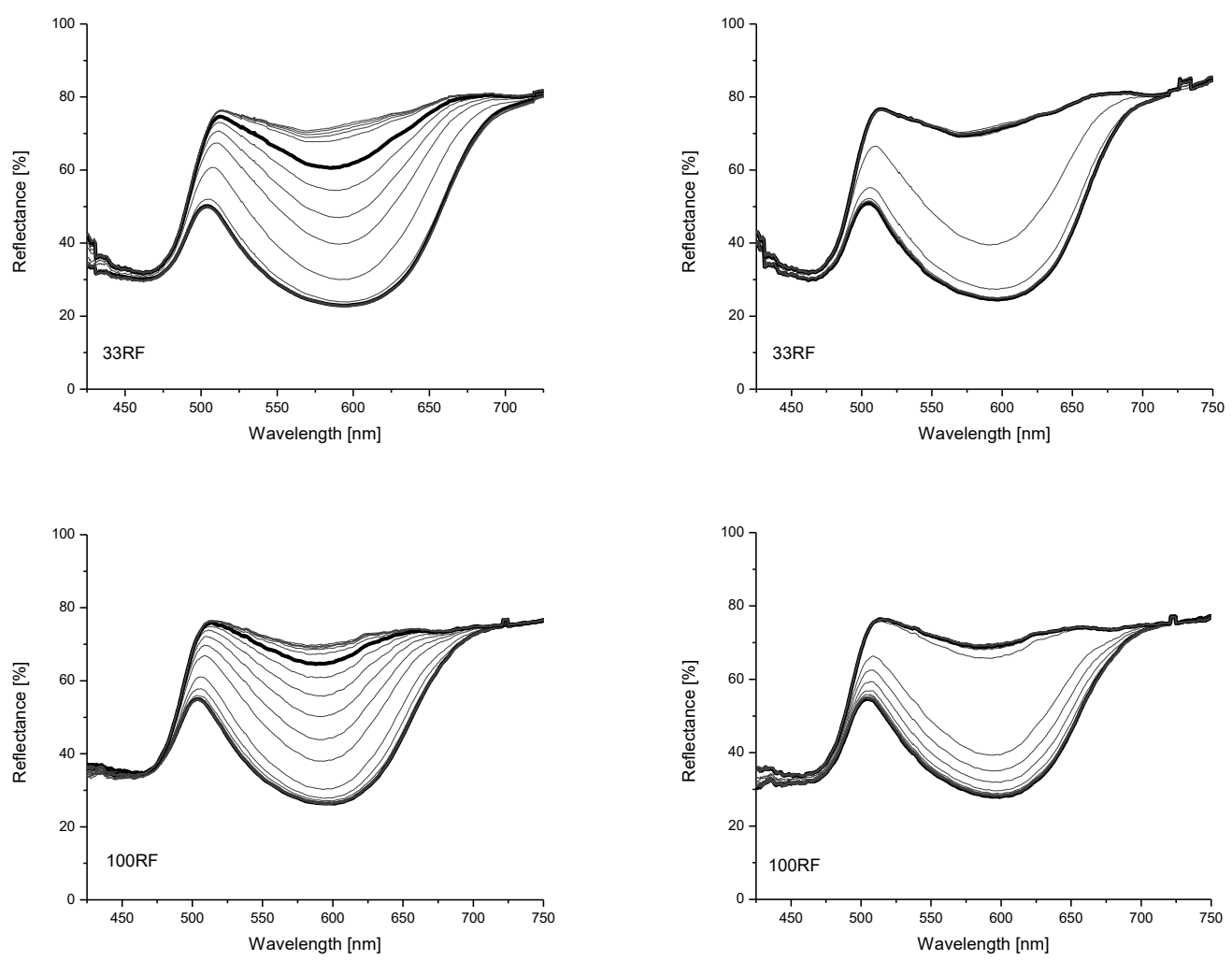

Figure 4: Spectral reflectance curves for the TC45 sample measured at heating (left) and cooling (right) on different papers
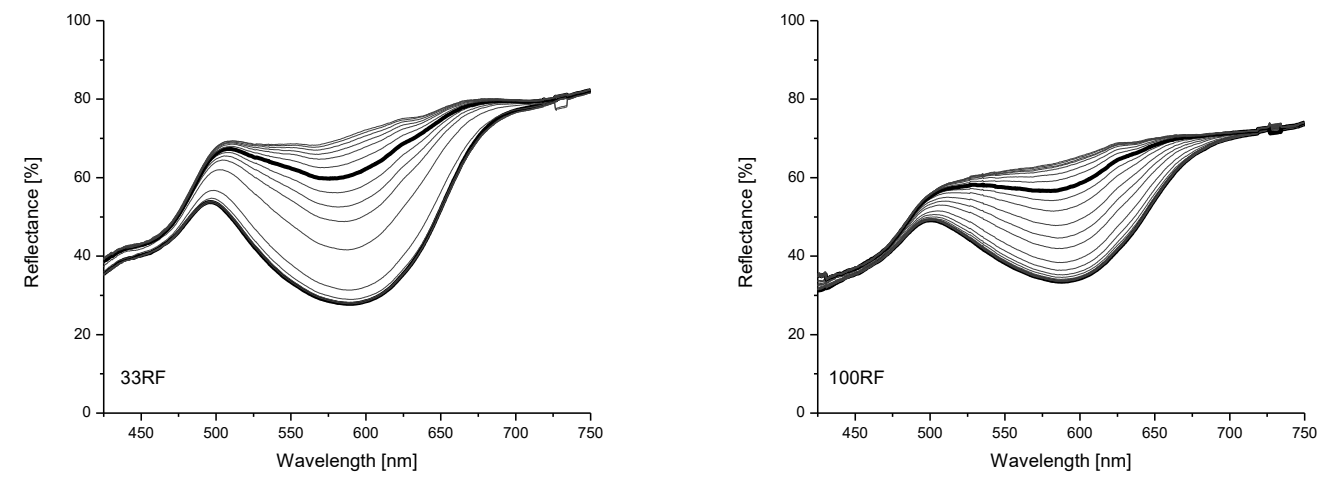

Figure 5: Spectral reflectance curves for the TC45 sample exposed to light for 6 hours (measured at heating) on different papers
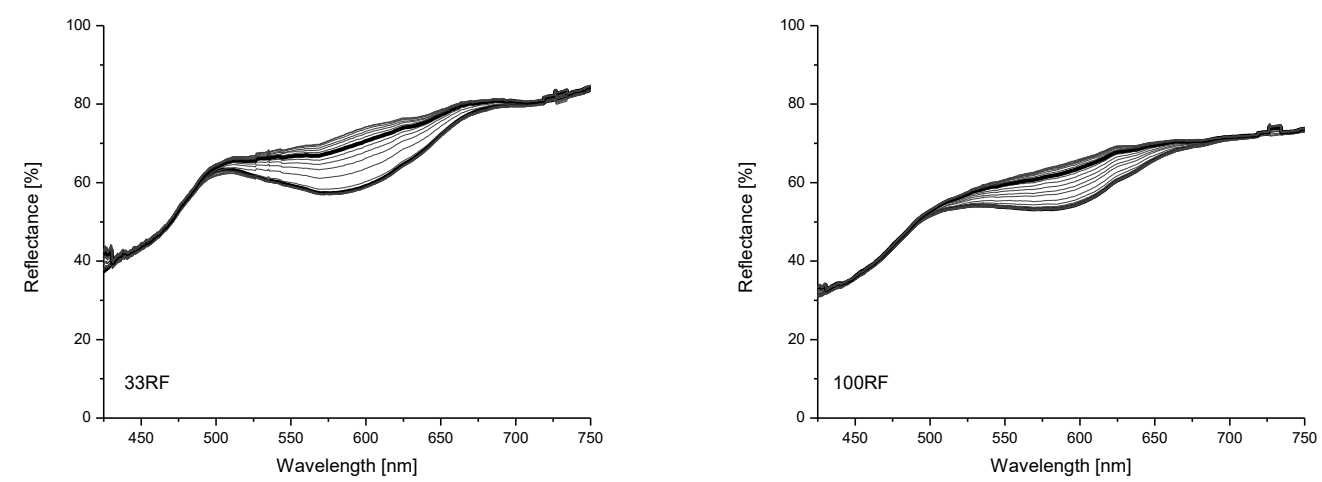

Figure 6: Spectral reflectance curves for the TC45 sample exposed to light for 12 hours (measured at heating) on different papers 
From the measured spectral reflectance curves (Figure 1-6), it can be seen that the colour change is gradual and continuous and that the spectral curves of all the samples differ when the samples are heated and cooled at the same temperature. Color degradation is approximately the same on both recycled papers. After 6 hours of ageing, only slightly changes occurred on TC45 sample on both papers while on TC27 the colour degradation is greater. Ageing decreases the dynamics of discolouration, and after 12 hours of ageing, the thermochromic effect of TC27 sample is completely lost, while on TC45 colour change is still present, which indicates that TC45 ink is more stable compared to TC27 regardless of the paper used.

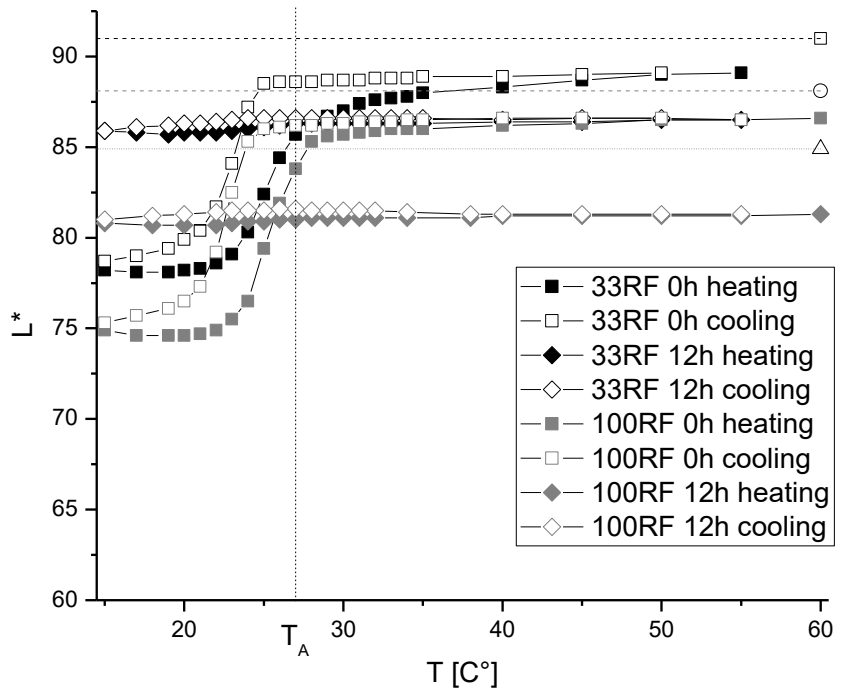

Figure 7: Hysteresis loops of TC27 ink printed on two different papers (original and exposed to UV light for 12h)

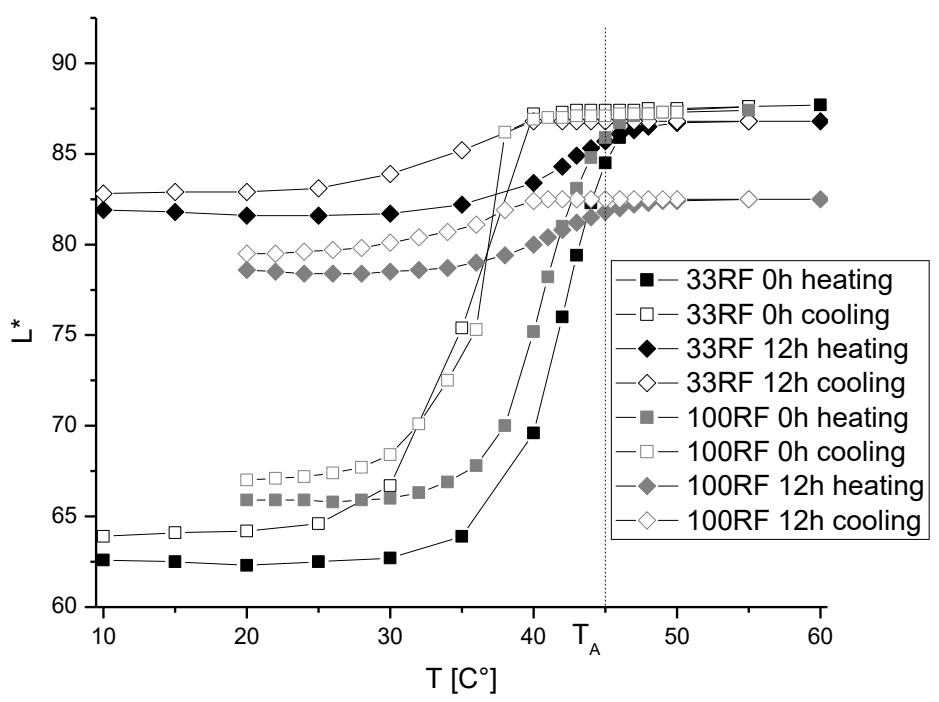

Figure 8: Hysteresis loops of TC45 ink printed on two different papers (original and exposed to UV light for 12h) (open signs).

Figure 7 and 8 shows colour hysteresis of prints on 33RF and 100RF before and after exposed to UV light for 12 hours. These two samples appear differently during the two reversible thermochromic reactions. UV radiation has a great effect on the hysteresis loop. With longer ageing, the hysteresis loop decreases and disappears a bit completely, which means that in this way the dynamic effect of thermochromic inks completely disappears.

Figures 9 and 10 shows the transitons of prints colour from blue to colourless (Figure 9) and from green to yellow (Figure 10). The $a^{*}$ and $b^{*}$ values of prints after 12 hours of ageing are smaller than the initial values. The color change pathway was significantly reduced especially in the TC27 sample on both papers. 


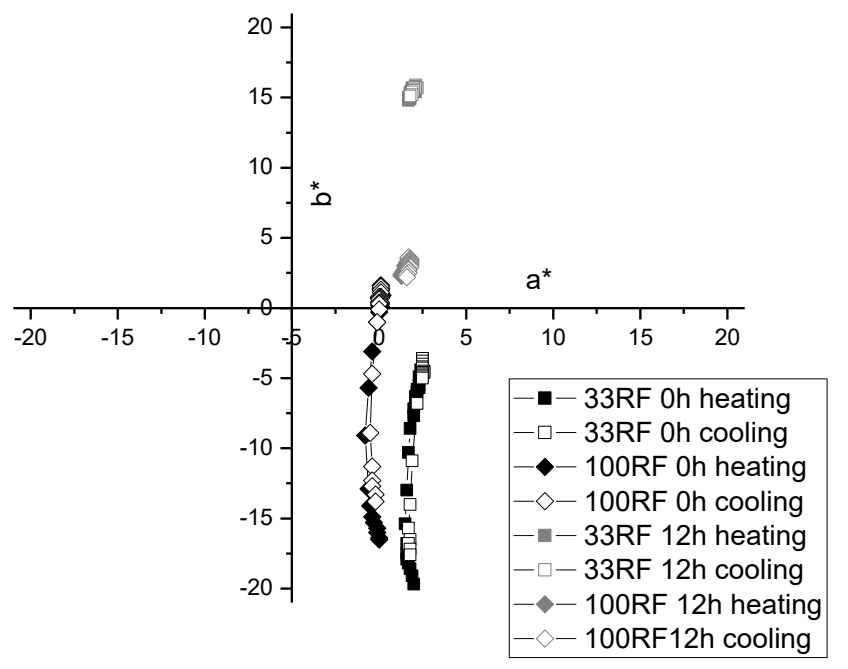

Figure 9: Changing of CIELAB values of TC27 sample in tbe ( $\left.a^{*}, b^{*}\right)$ plane during (solid signs) and cooling (open signs).

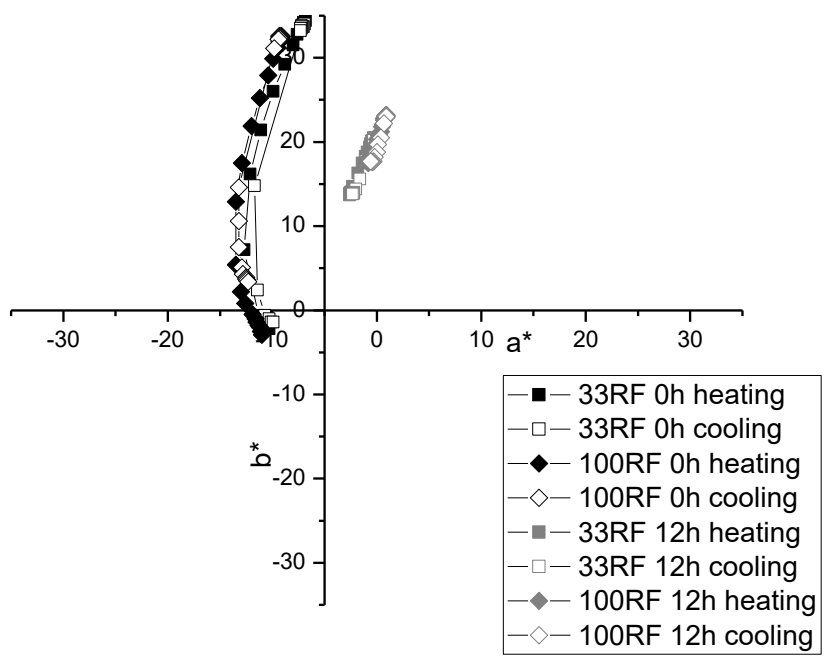

Figure 10: Changing of CIELAB values of TC45 sample in tbe $\left(a^{*}, b^{*}\right)$ plane during heating (solid signs) and cooling

It can be seen from Figure 7 and 9 that the exposure of the sample to accelerated ageing changes the dynamics of discolouration, especially in the thermochromic colour TC27, in which after 12 hours of accelerated ageing the chromism disappears almost completely.

The TC45 sample gave better results than TC27 in terms of accelerated aging, which can be determined from the hysteresis surface in Figure 8 and the CIELAB representation (Figure 10), where it can be observed that the dynamics of color change is present even after 12 hours, although significantly reduced.

Offset inks generally consist of the colorant, the binder, and the additives (catalytic dryers, antioxidants, wax particles and other). The colorant is a hydrophobic organic pigment and the binder consists of alkyd and hard resins. Ink oils can be classified into mineral (mixture of hydrocarbons from petroleum distillates) and vegetable oils (esters) (Pykönen et al, 2018). The mineral oil based inks dries mainly by the absorption into the paper structure while an oxygen-induced free-radical polymerization of unsaturated ink components can occur if the inks contain drying oils or alkyds, resulting in the ink matrix polymerization and crosslinking, while under the influence of oxygen can partly solidify. After printing, the mineral oil-based inks slowly absorb into the pore structure of the paper and it is desired that the oil 
separates from the pigments encapsulated by the binders to obtain sufficient print quality. However, if the ink contains drying oils or alkyds, such as alkyd resin as the binder and vegetable oil as the carrier, oxygen-induced polymerization and cross-linking reactions with unsaturated offset ink components will harden the structure of the ink and strongly bind the ink to the fibers by chemical /or physical means (Kemppainen et al, 2015). Additionally, polar vegetable oils also were found to be less mobile than the non-polar mineral oils (Koivula et al, 2008). Vegetable oils have typically better stability due to higher boiling point when comparing to mineral oils (Pykönen et al, 2018).

Recycled paper is absorbent and ink can penetrate into its structure. while in the case of non absorbent papers (coated, synthetic) the ink binder stays on te paper surface (Vukoje et al, 2017; Vukoje et al, 2018b).

Taking into account all the above menioned facts, it can be concluded that the TC27 ink binder after printing, absorbs into the paper structure, and separates from the TC microcapules, leaving them more "unprotected" to UV irradiation. In the case od TC45, after printing the process of oxipolymerization occurs, forming the polymerized matrix on the top of the paper, making the TC microcapsules more secrue. This results in better stability of TC45 to UV ageing than TC7.
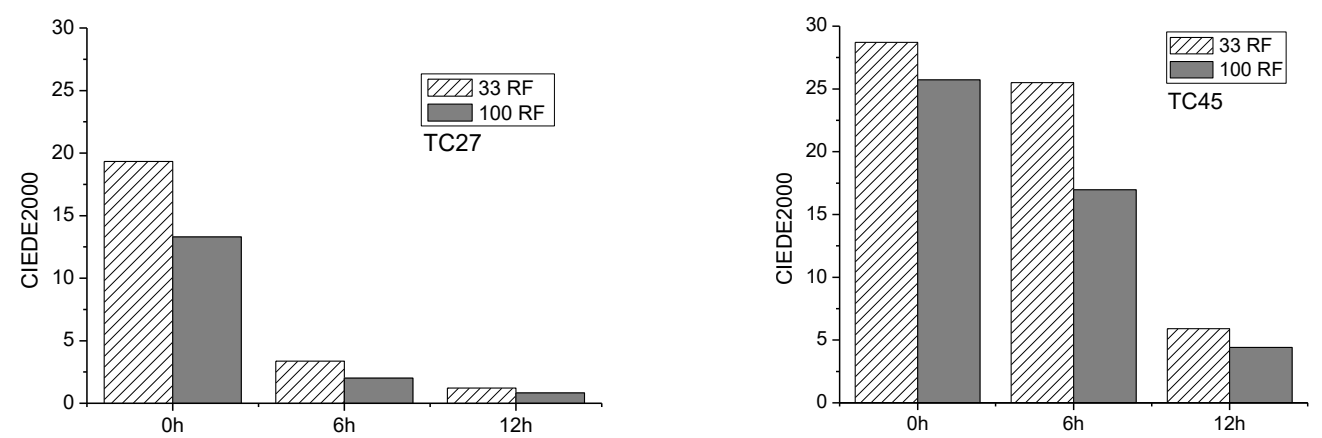

Figure 11: Total colour difference (CIEDE2000) between the lowest and the highest measured temperatures

Figure 11 shows the CIEDE2000 colour difference between the lowest and the highest temperatures to highlight the overall color contrast. A higher CIEDE2000 value represents a larger color change due to the thermochromic reaction. From this, it is evident that thermochromic properties depend more on ink properties and ageing than on the characteristics of the used recycled papers.

\section{CONCLUSION}

In this paper, measurements were performed on two offsets reversible thermochromic printing inks based on leuco dyes of different activation temperatures on papers with $33 \%$ and $100 \%$ of recycled fibre content. UV treatments showed negative effects on the stability and reversibility of the coloured samples. Exposure to UV radiation on the samples shows a decrease in the dynamics of discolouration. The destruction of the thermochromic effect on ageing is greater on TC27 sample. The binder in TC27 inks is mineral oil-based while the binder in TC45 is vegetable-based. This parameter in the ink composition may affect the degree of UV stability. The substrate used in this study showed similar results to studies on some other non-recycled media, indicating that more environmentally friendly substrates can be used as well, in printing with thermochromic inks.

\section{REFERENCES}

[1] Awaja, F., Gilbert, M., Kelly, G., Fox, B., Pigram, P.J.: "Adhesion of polymers”, Progress in Polymer Science 34, 948-968, 2009. doi: 10.1016/j.progpolymsci.2009.04.007.

[2] CEPI, Key Statistics 2016. Brussels, 2017.

[3] Coppola, F., Modelli, A., Strlič, M., Andretta, M., Scagnolari, F.: "Kinetics of degradation of nonrecycled and recycled contemporary paper", Cellulose 25, 5337-5347, 2018. doi: 10.1007/s10570018-1951-8 
[4] Friškovec, M., Kulčar, R., Klanjšek Gunde, M.: "Light fastness and high-temperature stability of thermochromic printing inks", Coloration Technology 129, 214-222, 2013. doi: 10.1111/cote.12020

[5] Gunde, M.K., Friškovec, M., Kulčar, R., Hauptman, N., Kaplanova, M., Panak, O., Vesel, A.: "Functional properties of the leuco dye-based thermochromic printing inks", Proceedings of the Technical Association of the Graphic Arts 2011, (TAGA, USA, 2011), pages 5 -21.

[6] Kemppainen, K., Upola, H., Körkkö, M.: "Ink and dirt behavior in repulping after artificial aging of coldset offset-printed newspapers at different temperatures", Nordic Pulp and Paper Research Journal 30, 527-534, 2015. doi: 10.3183/npprj-2015-30-03-p527-534.

[7] Kibirkštis, E., Kabelkaite, A., Markowski, L., Miliunas, V.: "Microscopic analysis of recycled paper effect on print quality parameters", Microscopy Research and Technique 76, 890-892, 2013. doi: 10.1002/jemt.22243

[8] Koivula, H., Preston, J.S., Heard, P.J., Toivakka, M.: "Visualisation of the distribution of offset ink components printed onto coated paper", Colloids and Surfaces A: Physicochemical and Engineering Aspects 317, 557-567, 2008. doi: 10.1016/j.colsurfa.2007.11.043.

[9] Kulčar, R., Friskovec, M., Hauptman, N., Vesel, A., Klanjšek Gunde, M.: "Colorimetric properties of reversible thermochromic printing inks", Dyes and Pigments 86, 271-277, 2010. doi: 10.1016/j.dyepig.2010.01.014.

[10] Moutinho, M.T., Ferreira, P.J.T., Figueiredo, M.L.: "Paper surface chemistry as a tool to improve inkjet printing quality", BioResources 6, 4259-4270, 2011.

[11] Panák, O., Držková, M., Kaplanová, M.: "Insight into the evaluation of colour changes of leuco dye based thermochromic systems as a function of temperature", Dyes and Pigments 120, 279-287, 2015. doi: 10.1016/j.dyepig.2015.04.022

[12] Pykönen, M., Silvaani, H., Preston, J., Fardim, P., Toivakka, M.: "Influence of plasma activation on absorption of offset ink components into pigment-coated paper", Nordic Pulp and Paper Research Journal 25, 93-99, 2018. doi: 10.3183/npprj-2010-25-01-p093-099.

[13] Vukoje, M., Glibo, R., Kulčar, R., Rožić, M., Vukoje, M., Glibo, R., Kulčar, R., Rožić, M.: "The influence of printing substrate on colorimetric properties of thermochromic offset prints", Acta Graphica 29, 7-14, 2018a. doi: 10.25027/agj2017.28.v29i3.161

[14] Vukoje, M., Miljanić, S., Hrenović, J., Rožić, M.: "Thermochromic ink-paper interactions and their role in biodegradation of UV curable prints", Cellulose 25, 6121-6138, 2018b. doi: 10.1007/s10570018-1970-5.

[15] Vukoje, M., Rožić, M., Miljanić, S., Pasanec Preprotić, S.: "Biodegradation of thermochromic offset prints", Nordic Pulp \& Paper Research Journal 32, 289-298, 2017. doi: 10.3183/NPPRJ-2017-32-02p289-298.

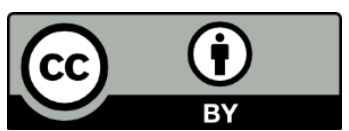

(C) 2020 Authors. Published by the University of Novi Sad, Faculty of Technical Sciences, Department of Graphic Engineering and Design. This article is an open access article distributed under the terms and conditions of the Creative Commons Attribution license 3.0 Serbia (http://creativecommons.org/licenses/by/3.0/rs/). 


\title{
THE PRODUCTION OF FLAME RETARDANT PAPER WITH DOPO
}

\author{
Hatice Birtane iD \\ Marmara University, Faculty of Arts and Sciences, Department of Chemistry, Istanbul, Turkey
}

\begin{abstract}
Flame retardant property to paper increases the use of paper and the value of paper products. The flame retardant property was achieved by the addition of an organophosphorus agent to the paper. A great deal of research has been done on 9,10-Dihydro-9-oxa-10-phosphaphenanthrene-10-oxide (DOPO) derivatives as flame retardants. To apply the flame retardant property in condensed phase, DOPO derivative materials are generally used as an acid source for intumescent flame retardants to promote dehydration and carbonization of the charring agent to form a continuous layer of carbon. In this study, In order to prepare a flame retardant paper coating, DOPO derivative was synthesized with 3-aminophenyl sulfone, and benzaldehyde reaction and the chemical structure of DOPO is illuminated by ATR-FTIR then paper was coating with a flame retardant coating formulation ingredient with DOPO. The paper's properties were investigated. Surface energy of coated papers and contact angles were determined with goniometer. Printability parameters such as color, gloss, surface tension were examined. The results the study DOPO added paper coatings improve the paper flame retardancy.
\end{abstract}

Key words: Flame retardant, Coating, DOPO, Printability

\section{INTRODUCTION}

Flame retardant materials represented to provide fire resistance to prevent or suppress the combustion process or to allow slow combustion in materials (Bernava and Strazds, 2015) were rare and required special handling methods. In the past, halogenated flame retardants have been widely applied to improve the flame retardancy of the coated material. These compounds have been limited due to the potential health and environmental hazards associated with the use of these compounds (Velencoso et al, 2018; Wang et al, 2019). Therefore, recently halogen-free flame retardants have been used as an alternative to halogenated flame retardants. Halogen-free flame retardants are phosphorus- (Wang et al, 2019; Wang et al, 2018; Zhang et al, 2017), nitrogen- (Wang et al, 2019; Huang et al, 2017), silicon- (Wang et al, 2019; Zhang et al, 2011; Liu et al, 2016) based compounds and nano flame retardants (Wang et al, 2019; Shabestari et al, 2017; Zhou et al, 2018; Qiu et al, 2017; Zhang et al, 2018; Vahabi et al, 2018).

Flame-retardant coatings prevent or delay the ignition of valuable documents (checks, money, valuable books) or printed papers (wallpapers, laminate parks, etc.) by providing an extinguishing time or prevent the spread of fire. (checks, money, valuable books) or printed papers (wallpapers, laminate parks, etc.) to provide an extinguishing time or prevent the spread of fire (Arman Kandırmaz, 2020).

In this study, it is aimed to obtain a flame reterdant coating and to examine the flame reterdancy performance of the coating. In this context, DOPO derivative was synthesized with 3-aminophenyl sulfone, and benzaldehyde reaction. In addition, there are trimethylolpropane triacrylate (TMPTA), 2Hydroxyethyl methacrylate (HEMA) and Poly(ethylene glycol) diacrylate (PEGDA) in the coating formulation. The synthesized DOPO derivative in certain proportions was added into the formulation and paper was coating.

\section{MATERIALS AND METHODS}

\subsection{Materials}

Trimethylolpropane triacrylate (TMPTA), 2-hydroxyethyl methacrylate (HEMA), poly(ethylene glycol) diacrylate (PEGDA), benzaldehyde, 3-aminophenyl sulfone and tetrahydrofuran were all purchased from Sigma Aldrich. 9,10-dihydro-9-oxa-10-phosphaphenanthrene-10-oxide (DOPO) and Darocur 1173 were obtained from Ciba Specialty Chemicals. 


\subsection{Synthesis of DOPO containing compounnd}

DOPO containing compound, as Ai et al. (Ai et al, 2019) suggested, prepared. The compounds DOPO $(13,78 \mathrm{~g}, 64 \mathrm{mmol}), 3$-aminophenyl sulfone $(7.95 \mathrm{~g}, 0.032 \mathrm{~mol})$, and benzaldehyde $(6.79 \mathrm{~g}, 64 \mathrm{mmol})$ were dissolved in tetrahydrofuran $(120 \mathrm{~mL})$. The mixture was stirred at $30{ }^{\circ} \mathrm{C}$ for 24 hours under a $\mathrm{N}_{2}$ atmosphere. The mixture was filtered and then white product was obtained. Subsequently, the crude product was added to a tetrahydrofuran solution and stirred; the solid was filtered and then precipitate was washed repeatedly with tetrahydrofuran. The synthesis scheme of the DOPO-derivate compound is given in Figure 1.
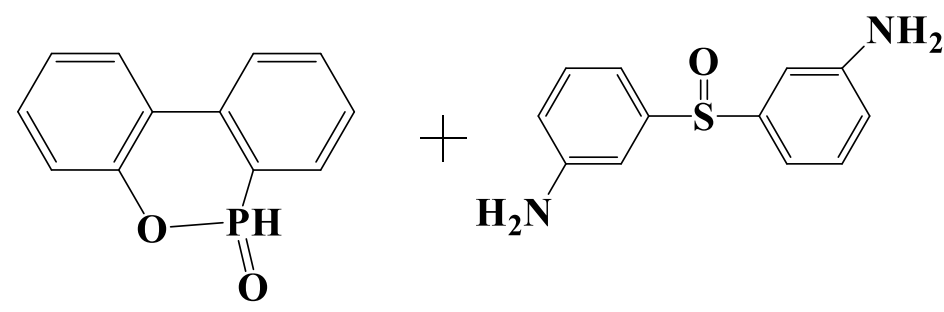<smiles>O=Cc1ccccc1</smiles>

\section{THF}

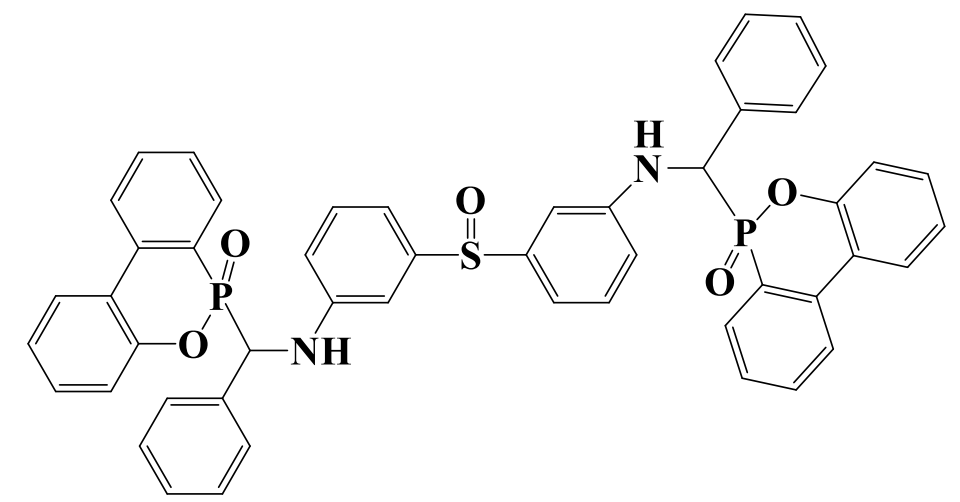

DOPO containing compound

Figure 1: Synthesis of DOPO containing compound

\subsection{Preparation of paper coating}

The base formulation is composed of trimethylolpropane triacrylate (TMPTA), 2-hydroxyethyl methacrylate (HEMA) and poly(ethylene glycol) diacrylate (PEGDA). The synthesized DOPO derivative in $1 \%, 3 \%$ and $\% 5$ proportions was added into the formulation and paper was coating. And then the coated papers were cured under UV-irridation. The formulation of coatings is given in Table 1. 


\begin{tabular}{|c|c|c|c|c|c|}
\hline & $\begin{array}{c}\text { PEGDA } \\
(\%)\end{array}$ & $\begin{array}{c}\text { TMPTA } \\
(\%)\end{array}$ & $\begin{array}{c}\text { HEMA } \\
(\%)\end{array}$ & $\begin{array}{c}\text { Daracure } \\
1137 \\
(\%)\end{array}$ & $\begin{array}{c}\text { DOPO } \\
(\%)\end{array}$ \\
\hline FO & 20 & 60 & 18 & 3 & 0 \\
\hline F1 & 20 & 60 & 18 & 3 & 1 \\
\hline F3 & 20 & 60 & 18 & 3 & 3 \\
\hline F5 & 20 & 60 & 18 & 3 & 5 \\
\hline
\end{tabular}

\subsection{Characterization}

\subsubsection{ATR-FTIR}

The chemical composition and functional groups, of paper and coated papers that we prepared, were made by Perkin Elmer Spectrum100 ATR-FTIR in the wavelength range $4000-400 \mathrm{~cm}^{-1}$.

\subsubsection{Contact angle}

The wettability characteristics of the coatings were determined on a Kruss (Easy DropbDSA-2) tensiometer. The contact angles $(\theta)$ were measured by means of sessile drop test method in which drops were created by using a syringe. Measurements were made using 3-5 $\mu$ d drops of distilled water. For each sample, at least five measurements were made, and the average was taken.

\subsubsection{TGA}

The thermal stability of the paper, base formulation coated paper and DOPO containing coated papers was determined in the temperature range of 30 to $750{ }^{\circ} \mathrm{C}$ at a heating rate of $10{ }^{\circ} \mathrm{C} / \mathrm{min}$ under a nitrogen atmosphere (TGA, Pyris America).

\subsubsection{LOI measurements}

The flammability characteristics of the paper coatings were determined by the LOI test. The LOI values of the coating materials were measured by using a FTT (Fire Testing Technology) type instrument, on the test specimen bar of $120 \times 10 \times 3 \mathrm{~mm}$ according to ASTM D2863.

\section{RESULTS AND DISCUSSIONS}

\subsection{Characterization of coatings}

\subsubsection{ATR-FTIR}

DOPO containing paper coatings were characterized via FTIR spectroscopy and TGA. The FTIR spectra of paper, F0, F1, F3 and F5 are given in Figure 2. The bands at 1637 and $1581 \mathrm{~cm}^{-1}$ in FTIR spectra of F1, F3 and F5 are due to -P-Ph stretching vibrations (Oktay and Çakmakçı, 2017). The peak at $1155 \mathrm{~cm}^{-1}$ is attributed to the $-\mathrm{P}=\mathrm{O}$ stretching (Oktay and Çakmakçı, 2017).- $\mathrm{S}=\mathrm{O}$ peak is shown at $1405 \mathrm{~cm}^{-1}$. 


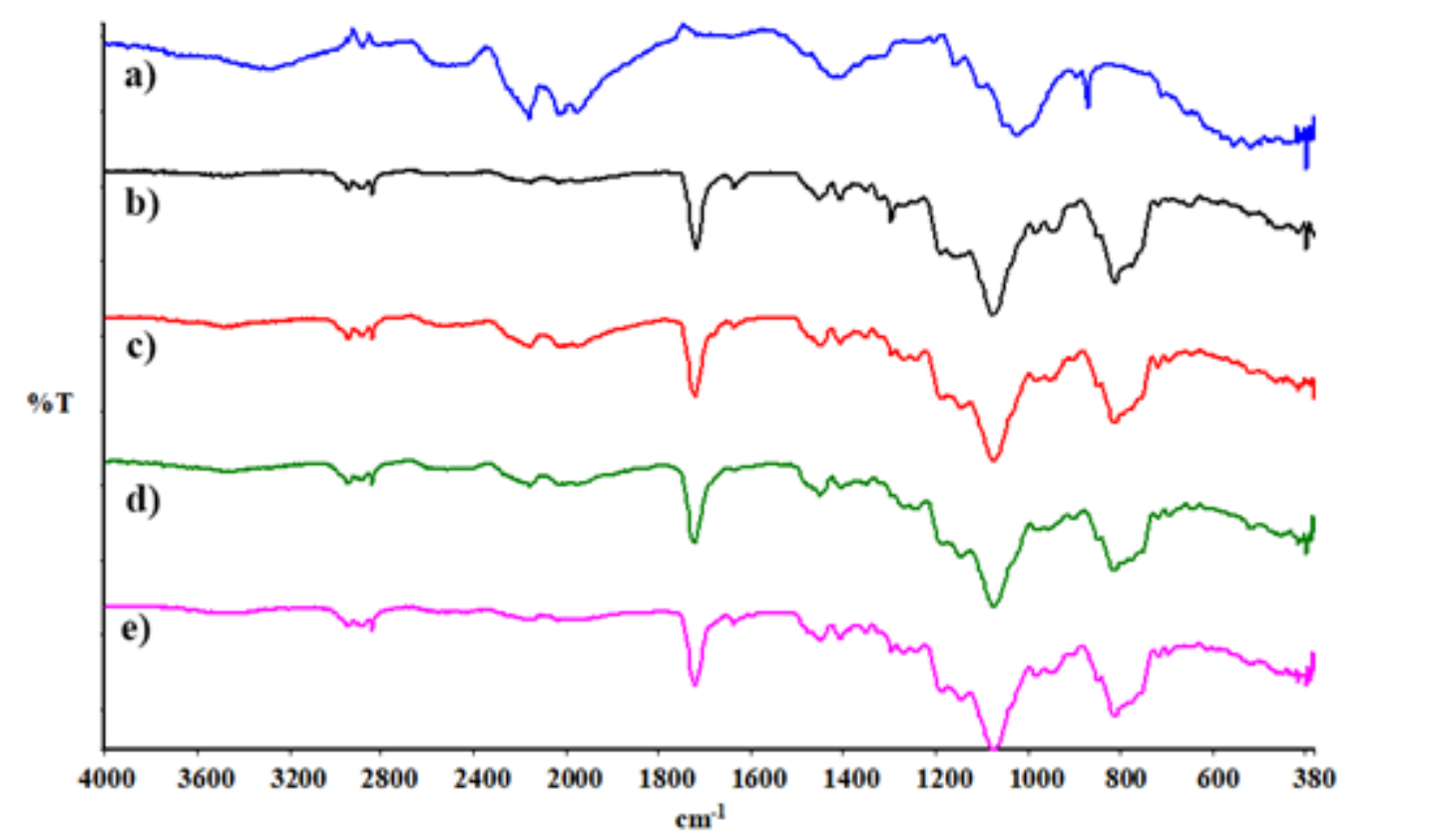

Figure 2: ATR-FTIR spectra of a) uncoated paper b) coated paper without DOPO compound c) coating with 1\% DOPO compound d) coating with 3\% DOPO compound e) coating with 5\% DOPO compound

FTIR results showed that DOPO containing paper coatings were prepared successfully.

\subsubsection{Thermal stability of coated papers}

The thermal stability of uncoated paper and paper coatings were evaluated with TGA under nitrogen atmosphere. Fig. 4 shows TGA thermograms of paper, F1, F3 and F5 formulations. Under nitrogen atmosphere, with the increased DOPO containing compound percentage, $T_{5}$ and $T_{\max }$ were increased. The maximum weight loss temperatures and the residual masses increased with increasing amount of DOPO containing compound. From this results its concluded that the addition of DOPO containing compound improved the thermostability of coated papers. In previous reports, it was also shown that the thermal stability improves when DOPO containing compound is incorporated into paper coatings.

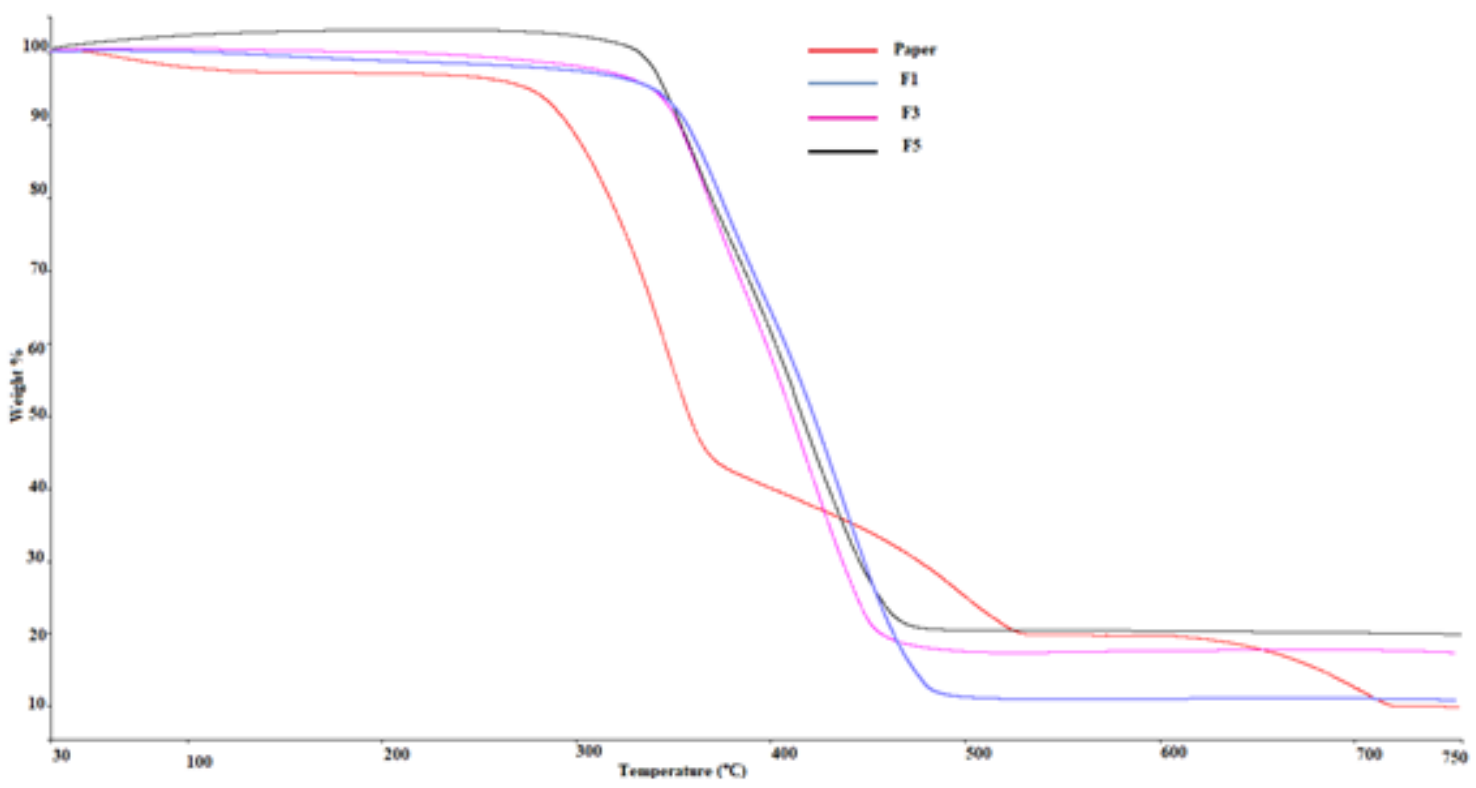

Figure 4: Thermogravimetric analysis of paper coatings 


\subsubsection{Wettability feature}

The contact angle values of all coatings are given in Table 2 . The water contact angle of paper without any coating was measured as $82^{\circ}$. When $3 \%$ DOPO containing was added to coating formulation (F3), the contact angle decreased to 34.9. On the other hand, the contact angle value of the DOPO containing papers descreased, this is due to the presence the hydrophilic groups in DOPO containing compound.

Table 2: Total surface energy and Contact Angle values of films

\begin{tabular}{|c|c|c|}
\hline Formulation Name & $\begin{array}{c}\text { Surface Energy } \\
\left(\mathrm{mJ} / \mathrm{m}^{2}\right)\end{array}$ & Contact Angle \\
\hline Uncoated paper & 35.4 & 82.0 \\
\hline F0 & 35.6 & 81.4 \\
\hline F1 & 40.1 & 69.1 \\
\hline F3 & 52.4 & 34.9 \\
\hline F5 & 58.0 & 19.4 \\
\hline
\end{tabular}

\subsubsection{Color and gloss properties of coatings}

The color values of the coated and uncoated papers are given in Table 3. Color differences were calculated by delta $E$ of substrates (F0, F1, F3, F5) how it differs from based paper. When the table is examined, the most changing parameter of the color is $\mathrm{L}$. This shows that the lightness has become darker, not the color. In other words, the color of the paper has not changed much, only the lightness of the color has changed. When the color differences are examined, the color difference caused by the change in the $L$ value is too high. However, the difference is not much in the visual inspection. When the gloss value was examined, it was determined that all coatings were very glossy compared to the base paper. Because the polymeric coating formulation filled the voids on the paper surface and reduced the diffuse reflection. Thus, the smooth reflection and gloss increased. However, with the addition of DOPO to the formulation, the roughness increased a little, so the gloss decreased. However, it still has a glossy surface than base paper. The gloss decreased as the amount of DOPO increased.

Table 3: Color and gloss properties of coatings

\begin{tabular}{|c|c|c|c|c|c|c|}
\hline Formulation No & $\mathrm{L}^{*}$ & $\mathrm{a}^{*}$ & $\mathrm{~b}^{*}$ & Image (acid) & $\Delta \mathrm{E}_{00}$ & Gloss \\
\hline Base paper & 80 & 0 & -3 & & Ref. & 6 \\
\hline F0 & 74 & -1 & -4 & & 4.59 & 28 \\
\hline F1 & 72 & -2 & -5 & & 6.58 & 26 \\
\hline F3 & 67 & -3 & -1 & & 10.67 & 22 \\
\hline F5 & 65 & -5 & 1 & & 13.54 & 20 \\
\hline
\end{tabular}




\subsubsection{Flame retardancy properties}

The flame retardancy properties of DOPO containing paper coatings were examined with LOI measurements. LOI values of coated and uncoated papers are given in figure 5. As can be seen from figure 5, when the LOI results are examined, it is seen that all the coatings on the base paper increase the $\mathrm{LOI}$ and make it difficult for the paper to ignite. However, this increase was effectively increased with the addition of DOPO to the coating formulation. In other words, it is more difficult to ignite in coatings with DOPO added. In addition, as the amount of DOPO increases, the LOI value increases slightly. Compared to the base paper, the F5 coating that gives the best LOI result, the LOI value increases by $30.2 \%$.

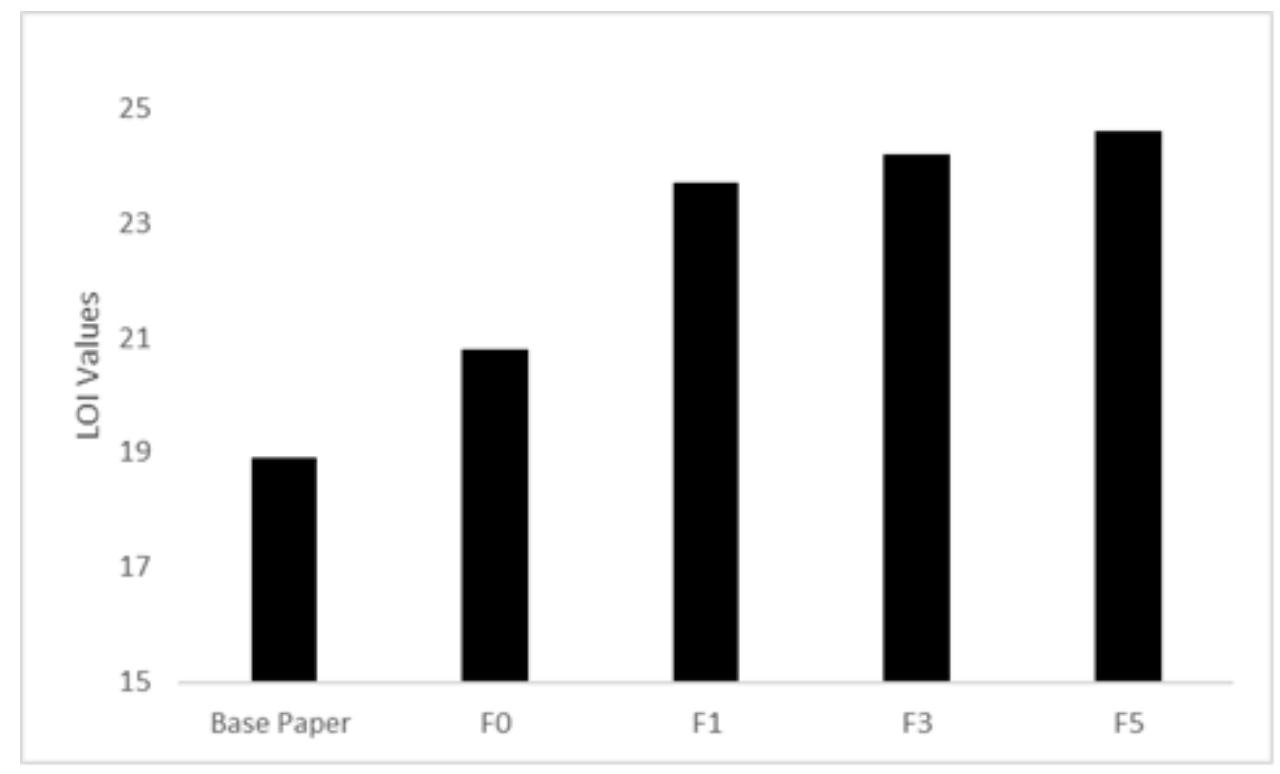

Figure 5: LOI values of coatings

\section{CONCLUSIONS}

According to ATR-FTIR results DOPO containing paper coatings were prepared successfully and DOPO coating paper has been given flame reterdancy property. TGA thermograms was also shown that the thermal stability improves when DOPO containing compound is incorporated into paper coatings.

When the results were examined, it was determined that DOPO increased the LOI value and made it difficult to ignite. According to the obtained LOI results, it is concluded that there will be more time to save printed products in a possible fire.

\section{REFERENCES}

[1] Ai, L., Yang, Z., Hu, J., Chen, S., Zeng, J., Liu, P.: "Synergistic Flame Retardant Effect of Organic Phosphorus-Nitrogen and Inorganic Boron Flame Retardant on Polyethylene", Polymer Engineering and Science 60, 414-422, 2020. doi: 10.1002/pen.25296.

[2] Arman Kandırmaz, E.: "Flame Retardant Hybrid Paper Coatings with PVA - Melamine / Zinc Borat" Journal of Graphic Engineering and Design 11 (1), 47-52, 2020. doi: 10.24867/JGED-2020-1-047.

[3] Bernava, A., Strazds, G.: "The Flame Retardant Coating of Linen Fabrics", Advanced Materials Research 1117, 219-222, 2015. doi: 10.4028/www.scientific.net/AMR.1117.219.

[4] Huang, H., Zhang, K., Jiang, J., Li, J., Liu, H.: "Highly dispersed melamine cyanurate flame-retardant epoxy resin composites", Polymer International 66, 85-91, 2017. doi: 10.1002/pi.5244.

[5] Liu, C., Chen, T., Yuan, C., Song, F., Chang, Chen, G., Xu, Y., Dai, L.: “Modification of epoxy resin through the self-assembly of a surfactant-like multielement flame retardant", Journal of Material Chemistry A 4, 3462-3470, 2016. doi: 10.1039/c5ta07115a.

[6] Oktay, B., Çakmakçı, E.: "DOPO tethered Diels Alder clickable reactive silica nanoparticles for bismaleimide containing flame retardant thiol-ene nanocomposite coatings", Polymer 131, 132-142, 2017. doi: 10.1016/j.polymer.2017.10.043 
[7] Qiu, S. L., Xing, W. Y., Feng, X. M., Yu, B., Mu, X. W., Yuen, R. K. K., Hu, Y.: "Self-standing cuprous oxide nanoparticles on silica@ polyphosphazene nanospheres: 3D nanostructure for enhancing the flame retardancy and toxic effluents elimination of epoxy resins via synergistic catalytic effect", Chemical Engineering Journal 309, 802-814, 2017. doi: 10.1016/j.cej.2016.10.100.

[8] Shabestari, M. E., Kalali, E. N., Gonzalez, V. J., Wang, D. Y., Fernandez Blazquez, J. P., Baselga, J., Martin, O.: "Effect of nitrogen and oxygen doped carbon nanotubes on flammability of epoxy nanocomposites", Carbon 121, 193-200, 2017. doi: 10.1016/j.carbon.2017.05.087.

[9] Vahabi, H., Saeb, M. R., Formela, K., Cuesta, M. L.: "Flame retardant epoxy/halloysite nanotubes nanocomposite coatings: exploring low-concentration threshold for flammability compared to expandable graphite as superior fire retardant", Progress in Organic Coating 119, 8-14, 2018. doi: 10.1016/j.porgcoat.2018.02.005.

[10] Velencoso, M. M., Battig, A., Markwart, J. C., Schartel, B., Wurm, F. R.: "Molecular firefighting-How modern phosphorus chemistry can help solve the flame retardancy task", Angewandte Chemie International Edition 130, 10608-10626, 2018. doi: 10.1002/anie.201711735.

[11] Wang, J., Ma, C., Wang, P., Qiu, S., Cai, W., Hu, Y.: "Ultra-low phosphorus loading to achieve the superior flame retardancy of epoxy resin", Polymer Degradation and Stability 149, 119-128, 2018. doi: 10.1016/j.polymdegradstab.2018.01.024.

[12] Wang, P., Chen, L., Xiao, H.: "Flame retardant effect and mechanism of a novel DOPO based tetrazole derivative on epoxy resin", Journal of Analytical and Applied Pyrolysis 139, 104-113, 2019. doi: 10.1016/j.jaap.2019.01.015.

[13] Zhang, C., Guo, X. D., Ma, S. M., Liu, X. R., Xu, J. Z., Ma, H. Y.: "Synthesis of an organicinorganic hybrid strontium hydroxystannate nanorod and application as novel flame retardant", Materials Letters 229, 297-300, 2018. doi: 10.1016/j.matlet.2018.07.047.

[14] Zhou, K. Q., Tang, G., Gao, R., Jiang, S. D.: "In situ growth of OD silica nanospheres on 2D molybdenum disulfide nanosheets: towards reducing fire hazards of epoxy resin", Journal of Hazardous Materials 344, 1078-1089, 2018. doi: 10.1016/j.jhazmat.2017.11.059.

[15] Zhang, W., Li, X., Yang, R.: "Pyrolysis and fire behaviour of epoxy resin composites based on a phosphorus-containing polyhedral oligomeric silsesquioxane (DOPO-POSS)", Polymer Degradation and Stability 96, 1821-1832, 2011. doi: 10.1016/j.polymdegradstab.2011.07.014.

[16] Zhang, Y., Yu, B., Wang, B., Liew, K. L., Song, L., Wang, C., Hu, Y.: "Highly effective P-P synergy of a novel DOPO-based flame retardant for epoxy resin", Industrial and Engineering Chemistry Research 56, 1245-1255, 2017. doi: 10.1021/acs.iecr.6b04292.

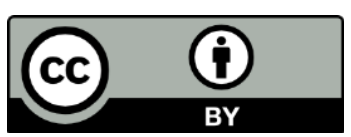

(C) 2020 Authors. Published by the University of Novi Sad, Faculty of Technical Sciences, Department of Graphic Engineering and Design. This article is an open access article distributed under the terms and conditions of the Creative Commons Attribution license 3.0 Serbia (http://creativecommons.org/licenses/by/3.0/rs/). 



\title{
PAPER SURFACE EFFICIENCY AND INKJET COLOUR REPRODUCTION ON INVASIVE AND AGRO RESIDUE PAPERS
}

\author{
Igor Karlovits (D), Gregor Lavrič \\ Pulp and Paper Institute, Ljubljana, Slovenia
}

\begin{abstract}
Paper surface efficiency was developed by Preucil and was intended to define the colourimetry and geometrical part of the light reflection with paper surface values. The surface characteristics of paper, primarily its roughness and absorptivity affect colour reproduction beside the ink pigments or dye. Rougher paper surfaces scatter the light in a more non-uniform manner while paper absorption may cause ink vehicle absorption and thus decreasing gloss, or it may absorb both vehicles and pigment-producing an unexpected colour shift. The formula was upgraded with paper whiteness values as the basic formula did not explain the whole phenomena. These paper properties were the foundation of the paper standardisation for standardised printing. On the other hand, during inkjet printing, a limited amount of liquid is deposited onto a paper surface. When the droplet hits the surface, it starts to spread and wet the surface depending on the ink and paper properties and had different colourant deposition from the formulas used mainly for offset printing inks. In this paper, we have researched the modified surface efficiency formula applied to inkjet printing (HP PageWide Pro 477dw) on invasive and agro-residue papers with specific non-white paper shades. We have measured the dynamic liquid penetration using ultrasound measurement to model the surface behaviour of the inks and measured CIE LCH values of the samples and calculated the CIE $\triangle E_{00}$ colour differences and the influence of paper surface efficiency and paper shade influence on the colour reproduction. The results indicate that using recalculated Cobb Absorption values gives good negative linear correlation with the original formula regarding the magnitude of colour difference.
\end{abstract}

Keywords: paper surface efficiency, colour reproduction, invasive plant paper, agro-residue paper, inkjet

\section{INTRODUCTION}

In defining paper properties and their influence on colour, reproduction one has to take in care of different paper properties. An excellent overview of surface and optical properties of paper can be found in (Farnood, 2009). Several research papers (Jurič et al, 2013; Tutak, 2014) showed the influence of paper properties on the colour reproduction values and visual evaluation by observers. In inkjet printing like in all printing technologies, the measured and the observed colour is the result of ink/surface interaction, and as (Pauler et al, 2009) found that in-home and office inkjet printing Large colour gamut is governed by low ink penetration, a low light scattering of the substrate and small dot size. The non-ideal property of process inks and the continuous tone character of colour reproduction of the studied desktop inkjets explained the observed convex shape of the colour gamut. For plain paper, dye-based and pigment-based inks were shown to follow different mechanisms, with lower penetration of the pigment-based ink. Colour gamut could be increased by a surface treatment that further reduced the penetration, but this treatment worked only for the pigment-based inks. Internal sizing of plain paper had only a minimal influence on colour gamut for dye-based ink, even though the ink penetration was reduced. In their research (Parales et al, 2008) found that the colour gamut of papers printed in inkjet has an excellent linear correlation between lightness and gamut volume especially on glossy coated papers and indicate that the surface finish and grammage influence the colour gamut. Similar research was carried out by Lowell (2006) and Lundberg (2011). To test the influence of whiteness values of inkjet prints (Hu et al, 2017) tested papers with dyes without changing the surface properties. Their results indicate that the colourimetric print values (lightness and chroma values) increased with increasing paper whiteness up to a certain level, after which the paper whiteness did not have a noticeable impact on its print lightness and chroma values. The print colour ( $a^{*}$ and $b^{*}$ values) was affected by its corresponding paper colour. On the other hand in another study by (Fernandez-Reche et al, 2003) by testing 29 paper found no systematic correlation between colour reproduction and specific colourimetric properties of the types of paper: and proposed search for other physical (not just colourimetric) properties (for instance, gloss or ink absorption capacity). Many times, in inkjet printing, mainly coated papers are investigated due to better optical print quality, but also some research can be found regarding uncoated samples. For example, in their research ( $\mathrm{Li}$ et al, 2015) investigated the impact on ink penetration of the 
microstructure and hydrophilicity of the uncoated papers. Their experimental results indicated that paper specimens with the sizing agent were resistant to the ink, resulting in slow and shallow ink penetration. Paper containing filler had a more hydrophilic surface and porous structure, leading to faster and deeper ink penetration. However, the calendering operation could make the paper structure more compact and reduce the porosity and penetration depth. When an appropriate combination of sizing agent, filler content, and the calendering process was utilised, a more stable hue could be produced with improvements in optical density, saturation, and colour.

All these researches regarding the interaction of inks, paper surfaces were an underlying foundation in the development of printing standards like the ISO 12647-2. The "standardised" paper types were developed by the PaperDam Group which has used the so-called surface index two which was based on PPS roughness and gloss in correlation with whiteness to specify the paper types used in print standardisation (Martilla et al, 2011). These metrics provided a good foundation for white and near white papers, but what about non-white papers with very distinctive paper shades, where no bleaching, coating pigments or optical brighteners are used and are not part of the standardised paper groups? How to evaluate them with a standard metric which includes the paper properties and colour values? Invasive plant papers and agro-residue papers are papers which utilise fibres from different sources (agro residues, dedicated crops or industrial waste). They provide alternative fibre sourcing beside the standard wood pulp solutions. Due to their specific fibres which are not bleached, and no extra whitening is used to retain as much as possible the sustainable and circular nature of these paper. Due to these properties, they need another approach regarding investigating their influence on their colour reproduction.

One of the solutions is to use the paper surface efficiency formula. During the first phase of the colour reproduction control development, Preucil (1963) proposed the paper surface efficiency formula (PSE), which defines the colour reproduction values after ink-paper interaction. The formula includes (geometrical reflection - gloss) and ink absorbency in (\%) but no other optical property is included, and this formula was based on densitometric measurements which were used at that time:

$\mathrm{PSE}=(100-\mathrm{A})+\mathrm{G} / 2$

Where PSE - is paper surface efficiency in \%

A- is ink absorbency of paper in \%

$\mathrm{G}$ - is paper gloss measured with $75^{\circ}$ angle gloss meter

This formula was also tested by (Charoenpholphibool, 1989) using offset inks on coated and uncoated papers. The densitometric values were changed for colourimetric, and results indicate that as the PSE increased, hue error and greyness decreased. The research found that the correlations were significant and were used to predict the colourimetric responses $\left(C^{*}, L^{*}\right)$ of ink when printed on papers having different PSE.

In another study by (Jeng-Rung Ho, 1991) the formula was extended by surface roughness measurements and was tested for predicting solid inking and printing gloss of offset printing. From the correlation matrix analysis, the new PSE equation yielded a higher correlation coefficient than the old PSE equation to predict better printed SID and print gloss. The formula they propose is:

NEW PSE $=0.6 / \mathrm{R} \times 100 \%+\mathrm{G} / 2$

Where $\mathrm{R}$ is the Print Parker Surface Roughness in $\mu \mathrm{m}$

As they have omitted the absorption factor to surface roughness factor, this would be more useful for offset printing where the pigment is on the paper surface, while in inkjet the dye goes into the paper surface, so this formula should be tested regarding different printing techniques.

In their paper (Yang et al, 2013) based on the research by (Yang et al, 2010) proposed a modified formula where they have included the whiteness factor (and weighted gloss to a lower number):

PSE $($ modified $)=100+0.8 \mathrm{G}+0.2 \mathrm{~W}-\mathrm{A} / 2$

Where the $\mathrm{W}$ - is the paper whiteness measurement in \%

The new formula was tested with laboratory offset test and using the Preucil procedure (KN Ink Absorbency). The results indicate the modified PSE formula can be used to predict ink colour effect effectively with hue error of magenta ink and greyscale of cyan ink on the paper, which provides data reference for paper make-ready, colour correction, and printing quality control. These results should help when lacking paper during printing to proceed with a paper substitute, which has close PSE values, rather than whiteness or another optical property. For example, in ISO 12647-2:2017 for offset printing (for 
other printing technologies no specific paper parameters are applied) pure optical properties (paper whiteness, gloss, paper CIE L*a*b* and fluorescence) are defined but no absorption value. Absorption value influences the optical density, CIE Lab and gloss values due to ink levelling and ink vehicle and pigment separation processes. So, this parameter is more or less »hidden « from the printers as paper mills can change formulations to fulfil the optical requirements. However, a slight change in pigment coating orientation (more precisely the imbibition process of ink vehicle draining in the porous structure) can influence the speed and ratio of absorbency and thus influence the optical properties. The paper mills traditionally check the paper absorption more often with the Cobb method, which is a static approach and expresses information about the water absorption capacity of paper samples. Based on this information, the sizing ratio is determined. The KN ink staining test can be used (just like in the original Preucil method), but some researchers did not find a high correlation between KN ink test and real ink behaviour on the press. This variation is due to the different nature of some $\mathrm{KN}$ or other staining inks used in paper and printing research. In their paper (Cigula et al, 2019) emphasise additional paper properties which are not in basic defined paper properties like smoothness and surface free energy which also have influencing factor on the ink - paper interaction and finally on the colourimetric values.

Our research aim was to try to modify and test the surface efficiency formula for inkjet printing and test the applicability on invasive and agro-residue papers which have brown shades and cannot be classified in "standardised" paper types. The modification involves the measurement of the absorption by using ultrasound methods previously also used by (Sharma, 2005) which found a strong correlation of ultrasound response with inkjet print quality parameters, dot area and print density, for photographic quality papers.

\section{METHODS AND MATERIALS}

All the papers were produced at the Pulp and Paper Institute in Ljubljana, Slovenia on a pilot paper machine. The traditional softwood and hardwood fibres were combined with different alternative fibres. The alternative fibres were from invasive plant's species obtained in urban harvesting and from planned to harvest plants miscanthus and tomato stems as agro-waste. At the same time, the jute bags from coffee transport were upcycled as a fibre source for papermaking. All the alternative (invasive and agrowaste fibres) were delignified and processed for the appropriate papermaking. Cationic starch, surface sizing and some fillers were added to gain basic printability properties. The primary material properties of the tested papers are presented in Table 1.

Table 1: The primary material properties of the invasive and agro-based papers

\begin{tabular}{|c|c|c|c|c|c|c|}
\hline Parameter & Jute & Miscanthus & $\begin{array}{c}\text { Canadian } \\
\text { Goldenrod }\end{array}$ & $\begin{array}{c}\text { Black } \\
\text { Locust }\end{array}$ & $\begin{array}{c}\text { Tomato } \\
\text { stem }\end{array}$ & $\begin{array}{c}\text { Japanese } \\
\text { Knotweed }\end{array}$ \\
\hline Grammage (g/m²) & 85 & 125 & 105 & 120 & 115 & 110 \\
\hline Alternative fibers (\%) & 35 & 67 & 45 & 40 & 20 & 40 \\
\hline Cationic starch (\%) & 1 & 0,75 & 1 & 1 & 1 & 1 \\
\hline Fillers (\%) & 10 & 0 & 10 & 10 & 5 & 10 \\
\hline Surface sizing (\%) & 3 & 2 & 3,5 & 3,5 & 4 & 3 \\
\hline
\end{tabular}

The prints were made by HP PageWide Pro $477 \mathrm{dw}$ inkjet printer which uses dye-based inks. All the paper samples were printed with a cyan colour patch in $100 \%$ ink value. The colourimetry values of the printed patches were measured following ISO 13655:2017 standard by using i1Pro2 spectrophotometer, which uses directional geometry and D50/2 ${ }^{\circ}$ setup using standard white backing. The paper values (CIE Lab and D65 whiteness) were measured using Datacolor Elrepho spherical spectrophotometer using d/0 geometry using $\mathrm{D} 65 / 10^{\circ}$ values. To define the absorption rate of the paper and the ink penetration, we have used additional measurements, as the liquid penetration dynamics, for what ultrasound measurements with Emtec PDA C.02 measuring device was applied. 16\% isopropanol mixture was the working fluid to define and simulate dye penetration ratio into the substrate. The original and modified surface efficiency formula uses Absorption value in \%, obtained from a staining test. This type of the oil/varnish component absorption rate cannot be used for inkjet printing due to different ink/dye composition and ink adhesion behaviour. For ultrasound measurements which are signal intensity/time values, we have chosen the t95 parameter and the A30 (internally recalculated Cobb water absorption value) which defines when the 
intensity drops to $95 \%$ of its original values. The paper gloss was measured using the $75^{\circ}$ angles with Lehman gloss meter.

\section{RESULTS}

The results of the samples basic properties needed for the calculation are presented in Table 2 . The values for the surface efficiency were calculated according to the original formula provided by Preucil, modified with 2 absorption values. In formulas, we have changed the A \% value to t95 value as both are dimensionless and multiplicated by 100 because of the small number for more straightforward calculation, and used calculated A30 value which is the approximation of the Cobb value. The resulting curves from the absorption measurement are presented in Figure 1. The results indicate differences in the critical region of the first few second when the inkjet inks are absorbed.

Table 2: Paper properties and surface efficiency calculation

\begin{tabular}{|c|c|c|c|c|c|c|c|}
\hline Paper sample & $\begin{array}{c}\text { W D65 } \\
(\%)\end{array}$ & Gloss (\%) & $\begin{array}{c}\text { A- } \\
\text { t95\% }\end{array}$ & A30 & $\begin{array}{c}\text { PSE 1-t95 } \\
(\%)\end{array}$ & $\begin{array}{c}\text { PSE 1- } \\
\text { A30* }\end{array}$ & $\begin{array}{l}\text { PSE 2** } \\
(\%)\end{array}$ \\
\hline Jute & 52,58 & $5,48 \pm 0,39$ & 35,6 & 27,8 & 29,46 & 33,36 & 43,55 \\
\hline Miscanthus & 31,13 & $3,6 \pm 0,31$ & 18,6 & 26,5 & 38,9 & 34,95 & 41,32 \\
\hline $\begin{array}{c}\text { Canadian } \\
\text { Goldenrod }\end{array}$ & 37,90 & $6,01 \pm 0,57$ & 15,5 & 25,1 & 39,24 & 34,45 & 43,64 \\
\hline Black Locust & 27,56 & $2,88 \pm 0,1$ & 13,3 & 22,1 & 41,91 & 37,51 & 42,86 \\
\hline Tomato stem & 43,17 & $4,1 \pm 0,52$ & 5,8 & 27,8 & 45,05 & 34,05 & 42,05 \\
\hline $\begin{array}{c}\text { Japanese } \\
\text { Knotweed }\end{array}$ & 31,08 & $3,03 \pm 0,08$ & 5,4 & 24,4 & 45,78 & 36,3 & 42,11 \\
\hline
\end{tabular}

*Original Preucil formula modified by us (KN absorption - changed to A30 from PDA measurements)

**modified formula based on the work by (Yang et al, 2010)

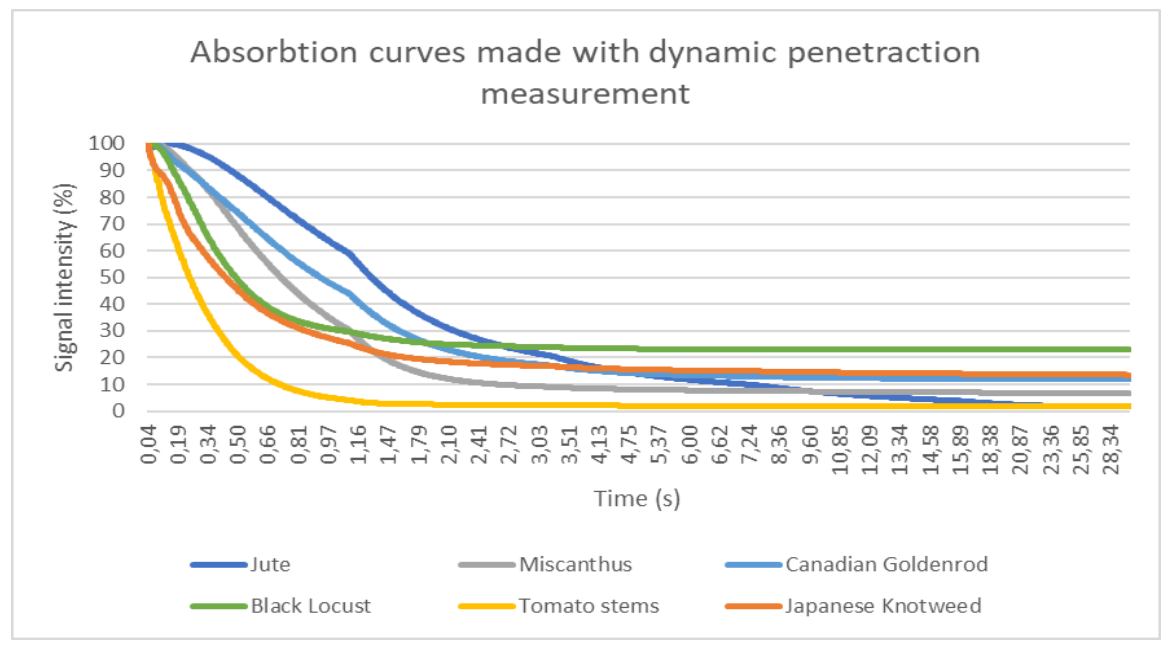

Figure 1: Absorption curves of different papers

From Figure 1. we can observe that the quickest absorption in the first few seconds had the Tomato stem, Japanese knotweed and Black Locust paper while the paper made from jute bags, Canadian Goldenrod and Miscanthus had lower absorption in the first 2-3 seconds. After the 3 seconds, more or less, all paper had similar absorption curves. The changes in the first 2-3 seconds, which can be differentiated by the t95 value had no value for the paper surface efficiency value but the whole curve calculation during the $30 \mathrm{~s}$ period. These results indicate that the overall absorption is more important than the first contact effects in the calculation of colour reproduction and colourimetric changes. The colourimetric changes of printed ink (100\% cyan) patch are presented in Table 3. 
Table 3: Colourimetric values of the $100 \%$ Cyan patch (CIE Lab of ideal cyan was taken as $L=57, a=-40, b=-52$ )

\begin{tabular}{|c|c|c|c|c|}
\hline Samples & Cyan D & CIE Lab & CH & $\Delta \mathrm{E} 00$ \\
\hline Jute & 0.82 & $56,29 /-16,50 /-23,87$ & $29,02 / 235,34$ & 12,24 \\
\hline Miscanthus & 0.86 & $51,91 /-17,29 /-10,73$ & $20,35 / 211,79$ & 18,12 \\
\hline $\begin{array}{c}\text { Canadian } \\
\text { Goldenrod }\end{array}$ & 0.86 & $53,54 /-20,23 /-11,81$ & $23,43 / 210,26$ & 16,82 \\
\hline Black Locust & 0.88 & $49,86 /-13,66 /-10,06$ & $16,97 / 216,34$ & 19,41 \\
\hline Tomato stem & 0.85 & $54,41 /-17,49 /-18,65$ & $25,58 / 226,80$ & 13,83 \\
\hline $\begin{array}{c}\text { Japanese } \\
\text { Knotweed }\end{array}$ & 0.86 & $51,28 /-14,44 /-11,91$ & $18,72 / 219,51$ & 18,05 \\
\hline
\end{tabular}

From Table 2., it is evident that the colour difference is very high (in comparison with "ideal" cyan ink taken from widest available CMYK gamut) as we used papers with distinctive shades and inkjet printing which is absorbent especially in papers which are not coated.

To see the usefulness of our modified Absorption value in the two paper surface efficiency formulas we calculated both $\mathrm{t} 95$ and $\mathrm{A} 30$ factor with $\Delta \mathrm{E}_{00}$ values as a reference for colour quality reproduction, where the $A 30$ value produced a better coefficient of determination $R^{2}$ for linear correlation 0,75 ( $r$ Pearson coefficient of 0,86 ); (the t95 factor had only $r=0,28$ ). So here the surface efficiency value is negatively linear to good print quality (lower PSE values gives smaller colour difference values from the referent colour). The low PSE value comes from high gloss and high A30 value.

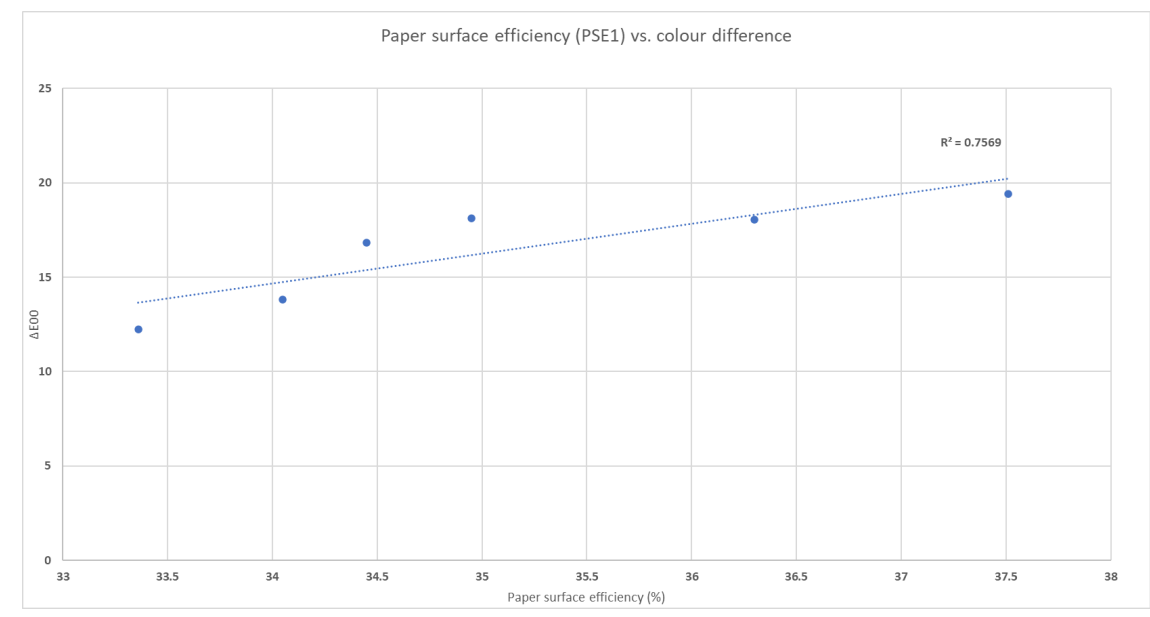

Figure 2: Correlation between Paper surface efficiency PSE1 and colour difference $\left(\Delta E_{00}\right)$

When comparing the two-surface efficiency formula with the changed absorption values, the second one which uses coefficients for gloss and whiteness did not show the correlation between colour difference. The calculated values indicate that the papers used in this study with very low whiteness cannot use the whiteness modified formula without further adjustments for water-based inkjet prints.

\section{CONCLUSION}

Any printer which confronts printability problems regarding achieving standardised values has to rely on the required optical properties and the »black box « knowledge of the paper mills that they will find a solution for achieving the desired colourimetric values. On the other hand, with agro-residue or invasive plant papers which are uncoated and do not contain optical brighteners, the usual paper properties used for print evaluation based on whiteness cannot be used. The whiteness formulas were developed for the characterisation of white and blue shades of white papers. For paper which are uncoated and non-white papers, the surface efficiency formula can be used to predict print quality. To use it for inkjet printing, the change of absorption component is needed (originally developed for $\mathrm{KN}$ inks which mimic the offset 
printing) to digitally calculated A30 absorption values. The changed formula provided excellent linear correlation with $r=0,86$, when used with the original Preucil formula developed in the 60 s of the previous century. The results show that with these measurements, we can "predict" the size of colour difference from ideal ink. As these papers have very distinctive shades, future research will include besides paper whiteness values also paper shade values in the calculation, as the human observer is differently sensitive to lightness, chroma and hue. The use of modified paper surface efficiency formula (adjusted for inkjet printing) can be beneficial in future colourimetric measurement research due to non -existent standardisation of these kinds of papers. Also, the results can be useful for paper production to optimise the alternative fibre content of papers as these are more variable than in large scale wood pulp production.

\section{ACKNOWLEDGEMENTS}

We want to thank Tea Kapun and the project APPLAUSE "From harmful to useful with citizen's led activities", co-financed by the European Union under the European Regional Development Fund, through the initiative Urban Innovative Actions, for providing alien plant species papers.

\section{REFERENCES}

[1] Charoenpholphibool, W.: "The Study of paper surface efficiency", MSc thesis, Rochester Institute of Technology, New York, 1989.

[2] Cigula, T., Tomašegović, T., Hudika, T.: "Effect of the paper surface properties on the ink transfer parameters in offset printing", Nordic Pulp \& Paper Research Journal 34(4), 540-549, 2019. doi: 10.1515/npprj-2019-0018.

[3] Farnood, R.: "Review: Optical properties of paper: theory and practice", (In Advances in Pulp and Paper Research, Oxford 2009), pages 273-352.

[4] Hu, G., Fu, S., Chu, F., Lin, M.: "Relationship between Paper Whiteness and Color Reproduction in Inkjet Printing”, Bio Resources 12(3), 4854-4866, 2017. doi: 10.15376/biores.12.3.4854-4866.

[5] Jurič, I., Karlović, I., Tomić, I., Novaković, D.: “Optical paper properties and their influence on colour reproduction and perceived print quality", Nordic Pulp \& Paper Research Journal 28(2), 264-273, 2013.

[6] Li, R., Zhang, Y., Cao, Y., Liu, Z.: "Ink Penetration of Uncoated Inkjet Paper and Impact on Printing Quality", Bio Resources 10(4), 8135-8147, 2015.

[7] Lowell, V.: "Ink-Jet Inks and Substrates - Novel Approaches for Their Physical and Optical Properties Characterisation", Graduate thesis, Western Michigan University, Michigan, 2006.

[8] Lundberg, A.: "Ink-paper interactions and effect on print quality in inkjet printing", MSc thesis, Mid Sweden University, Sudsvall, 2011.

[9] Martilla, J., Carl, G., Lanat, L.: "Standardisation Update and Paperdam Group", PPA's Paper Profile working group, 2011

URL: http://www.paperdam.org/cms/upload/P_PPA_London_2011/JM_Paperdam_status_126472_2011_02.pdf> (last request 2020-09-03.).

[10] Pauler, N., Norberg, O., Edström, P.: "Mechanism involved in the optical interaction between the ink and substrate for Home \& Office inkjet printing", Proceedings of $36^{\text {th }}$ International Research Conference of larigai 2009, (IARIGAI, Stockholm, Sweden, 2009), pages 372-382.

[11] Preucil, A.: "New Method of Rating the Efficiency of Paper for Color Reproduction", GATF Research Progress General, 1963.

[12] Sharma, N.: "Use of ultrasound to predict inkjet print quality", MSc thesis, Miami University, Oxford, Ohio, 2005.

[13] Tutak, D.: "Comparing the Color Gamuts Of Different Paperboard Surfaces Used in Package Printing", AJIT-e: Online Academic Journal of Information Technology 5(17), 57-66, 2014. doi: 10.5824/1309-1581.2014.4.004.x.

[14] Yang, Y., Hou, Q., Cao, Z., Liu, Q.: "Research on the Revision and Application of the Paper Surface Efficiency Formula", Advanced Materials Research 156-157, 868-872, 2010. doi: 10.4028/www.scientific.net/AMR.156-157.868.

[15] Yang, Y., Gao, Q., Liu, Q.: "The Influences of New Paper Surface Efficiency on Printing Quality", Applied Mechanics and Materials 477-478, 374-378, 2013. doi:

10.4028/www.scientific.net/AMM.477-478.374. 


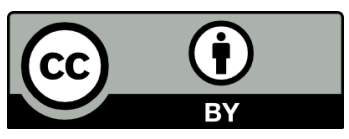

(C) 2020 Authors. Published by the University of Novi Sad, Faculty of Technical Sciences, Department of Graphic Engineering and Design. This article is an open access article distributed under the terms and conditions of the Creative Commons Attribution license 3.0 Serbia

(http://creativecommons.org/licenses/by/3.0/rs/). 



\title{
MEASUREMENTS OF SURFACE FREE ENERGY AS A TOOL TO ASSES THE EFFECT OF VARNISHING AND PRINTING OF THE PAPER SUBSTRATES
}

\author{
Zuzanna Żołek-Tryznowska (D), Marta Więcek \\ Warsaw University of Technology, Mechanics and Printing Institute, Faculty of Production \\ Engineering, Warsaw, Poland
}

\begin{abstract}
Nowadays, printing products might be finished in various ways. Varnishing process is one of the most popular finishing method which gives various effect, such as mate, glossy etc. However, the varnish layer applied on the paper is very thin, therefore it can be invisible to the naked human eye. The aim of this work was to use contact angle measurement and surface free energy determination as a tool to assess the effect of printing and varnishing process of paper materials. We have used various tools in order to analyses the changes of surface: surface roughness, gloss, water contact angle absorption and surface free energy determination. Those tools were used in order to confirm whether the print has been covered with varnish or not.

In this work six various paper substrates were used (glossy, coated and un-coated papers). The printing and varnishing was performed in laboratory conditions using flexographic water-based printing and waterbased varnish. Samples were prepared as follows: paper with ink coating, paper with varnish coating and paper with ink layer and varnish layer on the top. The surface roughness was determinated of all samples and compared. The surface roughness changes were observed for pure paper, overprinted and overvarnished. Next, the gloss of samples prior and after printing and varnishing was measured. The gloss of the samples increases when they are printed or varnished, what is related with properties of ink and varnish. Also, the thickness of ink and varnish layers was determinated. The thickness of the samples increases when the number of layers increases. Finally, the water contact angle was measured and surface free energy was calculated with Owens-Wendt method.

Our results reveal the possibility of using various tools in order to confirm the performance of varnishing of the prints. The printing with various colors is always seen by the naked human eye. On the other hand, the varnish layer might be not visible. However, such a comparison is not possible if we do not have the pure paper substrates prior printing or varnish.
\end{abstract}

Key words: contact angle, surface free energy, paper varnishing, paper finishing

\section{INTRODUCTION}

Paper is one of the most important carriers of the information (Car et al, 2018). Moreover, the history of human culture and civilization is directly connected with the history of paper. Nowadays, a large variety of paper are produced to suit to the customer requirements. Paper can be impregnated, coated, laminated, creped, molded etc. (Holik et al, 2013). One of the technique used to improve the paper and print resistance and its appearance is varnishing process (Majnarić et al, 2012). Various varnishes might be used, i.e. matt and gloss water based dispersive varnish, oil-base and UV varnish (Hudika et al, 2018). The typical varnish layers are applied with a thicknesses between about 0.5 and $6 \mu \mathrm{m}$ depending on the specific printing method and the chemistry of the printing inks and varnishes (Mirschel et al, 2013). This roughly corresponds to coating weights from 0.6 to $7 \mathrm{~g} \mathrm{~m}^{-2}$. Additionally, the composition of the varnish and the choice of a paper substrate used for printing may strongly influence the final coating properties.

The purpose of this analysis is estimation - which indirect methods might be used in order to evaluate whether the printing is enriched with transparent varnish layer or not. In the case of color layers of printing inks, the quality of the layer might be checked with reflectance densitometry or spectrophotometric techniques (Galić et al, 2015). However, this method are useless in the case of transparent layers. The goal was to assess the effect of varnished layer on the changes of the water contact values and surface free energy and its polar and dispersive components. Other methods, such as surface roughness, layer thickness and gloss measurement, were used in order to compare the influence of the printing and vanishing process on surface layer. The authors of this work, would like find answer, whether the measurements of the water contact angle are sufficient to evaluate the presence of varnish layer. 


\section{METHODS}

Six paper substrates were investigated: 1 - glossy, $73.5 \mu \mathrm{m}$ thickness; 2 - uncoated, $100 \mu \mathrm{m}$ thickness; 3 uncoated, $136 \mu \mathrm{m}$ thickness; 4 - uncoated, $70 \mu \mathrm{m}$ thickness; 5 - coated, $140 \mu \mathrm{m}$ thickness; 6 - coated, 143 $\mu \mathrm{m}$ thickness. The printing ink, color cyan and water-based dispersive varnish (SunChemicals) was used. Laboratory printing and varnishing was carried out with a K Paint Applicator coater (TMI Machines, UK) equipped with wire wound bar No. 1, which allows to obtain $6 \mu \mathrm{m}$ thickness of wet coating. Coating was performed under controlled environmental conditions $\left(23^{\circ} \mathrm{C}\right.$ and $50 \% \mathrm{RH}$ ).

The thickness was measured using digital thickness gauge FD-50 with the resolution $1 \mu \mathrm{m}$ with the error \pm 5 $\mu \mathrm{m}$. Data collection was performed at six different positions of the samples.

The surface roughness of the samples was measured by gauge SRT-220 roughness meter before and after printing or varnishing. It measures Ra and Rz parameters in a cut off path line of $0.8 \mathrm{~mm}$. In the present research, Ra parameter was only used to measure the roughness of the samples. The roughness value (Ra) was randomly measured 6 times on the surface of 2 various sample, the reported values are the average of these measurement.

The gloss (in the gloss units, GU) of the prints was measured at $20^{\circ}, 60^{\circ}$ and $85^{\circ}$ geometry conditions with the use of a Micro-Tri-Gloss glossmeter (BYK-Gardner, Germany). Data collection was performed at six different positions of the samples in both directions: cross and machine direction, and the reported values are the average of these measurements.

The contact angle of distilled water and diiodomethane (99\% Purity, CAS No. 75-11-6, Sigma-Aldrich) was measured using a DSA 100 drop shape analysis system (Krüss, Germany). The water contact angle was measured according to ISO 15989 standard. Smooth and horizontal sessile drops of the liquids (water, diiodomethane and printing ink) were deposited on a solid surface. Needles of $0.5 \mathrm{~mm}$ diameter were used for all liquids. The contact angle was measured on static drops. The drop shape analysis was done $15 \mathrm{~s}$ after the drop deposition with Tangent method 2. Environmental conditions were stable; with temperature 23 $\pm 1^{\circ} \mathrm{C}$. The reported contact angle values are the mean of five samples. The surface free energy of PE film was calculated with the Owens-Wendt method.

The results of measurements were presented as the mean \pm standard deviation. Statistical analysis was performed using one-way Analysis of Variance (ANOVA) employing the Statgraphics Centurion 18 (v.18.1.06 (StatPoint ${ }^{\circledR}$, Inc., USA) software. When ANOVA indicated a significant difference, the Tukey's honestly significant difference test (Tukey's HSD) was used to evaluate average differences (at a 95\% of confidence interval).

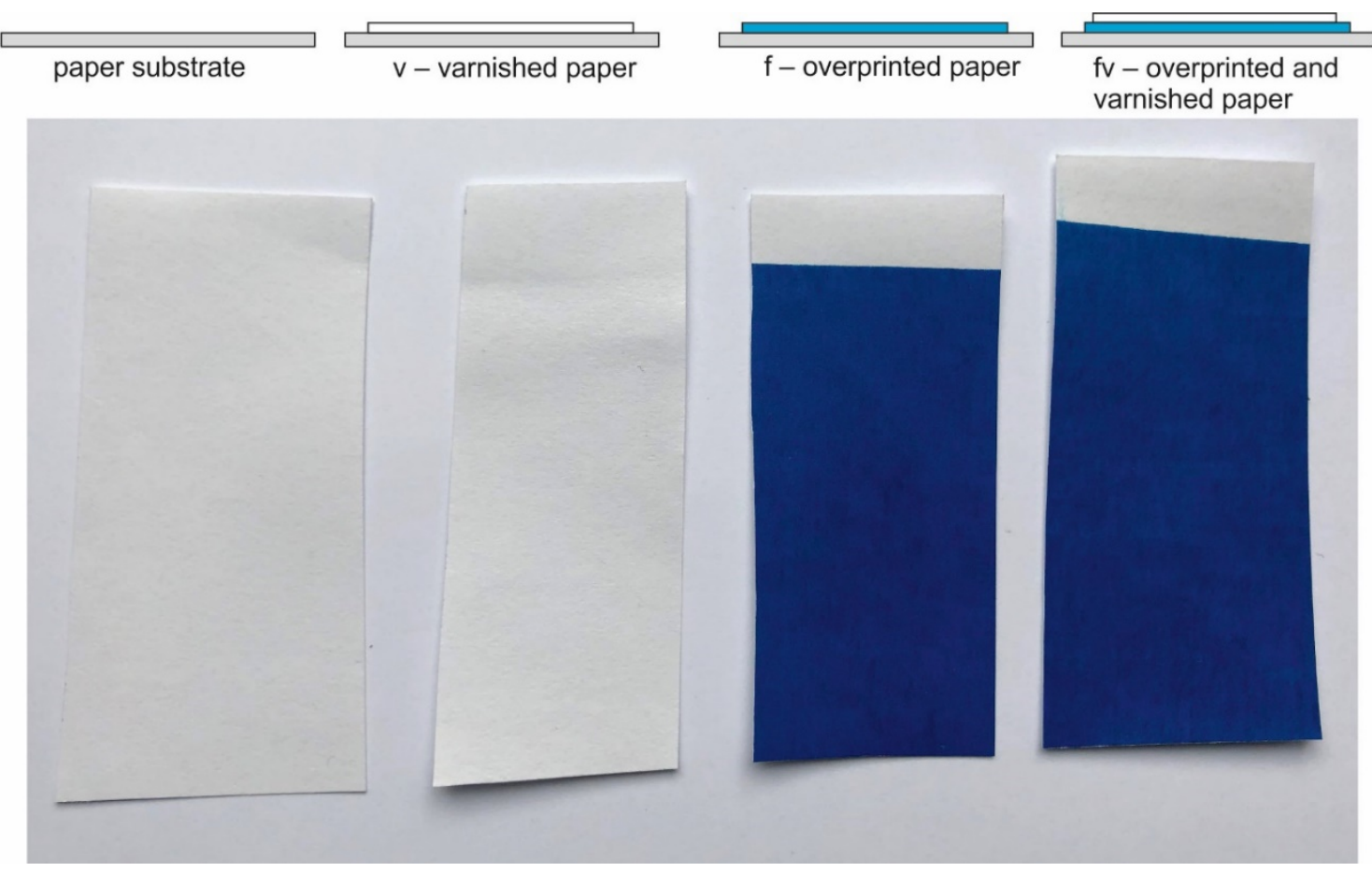

Figure 1: The samples of paper 3, overvarnished paper, over printed paper and both layer on th epaper 
Table 1: The values of thickness, values of gloss, water contact angle and surface free energy and its component of investigated samples: 1, 2, 3, 4, 5, 6-pure paper substrates; $v$-over varnished paper substrates; $f$-overprinted paper substrates; $f v$-overprinted with printing ink and afterwards finished with varnish

\begin{tabular}{|c|c|c|c|c|c|c|c|}
\hline Sample & $\begin{array}{c}\text { Thickness / } \\
\mu \mathrm{m}\end{array}$ & $\begin{array}{c}\text { Surface roughness / } \\
\mu \mathrm{m}\end{array}$ & Gloss / GU & Water CA $/^{\circ}$ & $\begin{array}{c}\text { Polar } \\
\text { component / } \\
\mathrm{mJ} \cdot \mathrm{m}^{-2}\end{array}$ & $\begin{array}{c}\text { Dispersive } \\
\text { Component / } \\
\mathrm{mJ} \cdot \mathrm{m}^{-2}\end{array}$ & $\mathrm{SFE} / \mathrm{mJ} \cdot \mathrm{m}^{-2}$ \\
\hline 1 & $73.4 \pm 5.1^{a}$ & $1.204 \pm 0.400^{\mathrm{bc}}$ & $24.5 \pm 11^{\text {cde }}$ & $90.45 \pm 3.44^{\mathrm{hi}}$ & $1.83 \pm 0.91^{\mathrm{ab}}$ & $32.79 \pm 3.36^{\text {abcde }}$ & $34.62 \pm 2.98^{\mathrm{abc}}$ \\
\hline $1 v$ & $83.3 \pm 1.7^{\mathrm{ab}}$ & $0.656 \pm 0.223^{\mathrm{ab}}$ & $35.95 \pm 2.9^{\text {def }}$ & $52.27 \pm 6.10^{b}$ & $18.89 \pm 3.54^{\mathrm{gh}}$ & $35.08 \pm 1.53^{\text {abcdef }}$ & $53.96 \pm 3.60^{\mathrm{ij}}$ \\
\hline If & $79.4 \pm 0.2^{b}$ & $0.845 \pm 0.289^{\mathrm{ab}}$ & $23.7 \pm 1.5^{\mathrm{cd}}$ & $86.11 \pm 4.97^{\mathrm{gh}}$ & $3.63 \pm 1.61^{\mathrm{abc}}$ & $30.10 \pm 3.32^{\mathrm{a}}$ & $51.25 \pm 1.12^{\mathrm{ab}}$ \\
\hline $1 \mathrm{fv}$ & $95.1 \pm 2.8^{c}$ & $0.554 \pm 0.115^{a}$ & $39.0 \pm 1.6^{\mathrm{e}}$ & $55.92 \pm 1.58^{\mathrm{bcd}}$ & $17.08 \pm 1.22^{\mathrm{fgh}}$ & $34.17 \pm 1.32^{\text {abcde }}$ & $51.25 \pm 1.12^{\text {fghij }}$ \\
\hline 2 & $99.6 \pm 0.8^{\text {cd }}$ & $3.105 \pm 0.530^{g}$ & $5.5 \pm 1.7^{a}$ & $108.27 \pm 5.60^{j}$ & $0.26 \pm 0.45^{a}$ & $31.38 \pm 2.04^{\mathrm{ab}}$ & $31.64 \pm 2.28^{a}$ \\
\hline $2 v$ & $101.7 \pm 0.6^{\text {cd }}$ & $2.047 \pm 0.289^{\text {def }}$ & $7.0 \pm 0.5^{a}$ & $76.74 \pm 9.85^{\mathrm{fgh}}$ & $6.56 \pm 4.25^{\mathrm{abcd}}$ & $34.56 \pm 4.00^{\mathrm{abcde}}$ & $41.12 \pm 3.68^{\text {bcde }}$ \\
\hline $2 f$ & $102.7 \pm 1.2^{\text {cd }}$ & $2.103 \pm 0.339$ def & $4.3 \pm 0.2^{\mathrm{a}}$ & $73.77 \pm 4.46^{\mathrm{efg}}$ & $7.69 \pm 2.01^{\text {bcde }}$ & $33.14 \pm 1.06^{\text {abcde }}$ & $40.83 \pm 2.53^{\text {bcde }}$ \\
\hline $2 f v$ & $106.3 \pm 4.9^{d}$ & $1.907 \pm 0.428^{\mathrm{de}}$ & $9.4 \pm 0.9^{a b}$ & $59.65 \pm 4.94^{\text {bcde }}$ & $13.98 \pm 2.20^{\text {efgh }}$ & $36.24 \pm 1.87^{\text {bcdef }}$ & $50.22 \pm 3.82^{\text {fghij }}$ \\
\hline 3 & $136.3 \pm 0.6^{\mathrm{e}}$ & $2.469 \pm 0.454^{e f}$ & $4.8 \pm 1.2^{\mathrm{a}}$ & $104.35 \pm 5.21^{i j}$ & $0.30 \pm 0.39^{a}$ & $35.46 \pm 3.53^{\text {abcde }}$ & $35.76 \pm 3.34^{\mathrm{abc}}$ \\
\hline $3 v$ & $142.0 \pm 4.0^{\mathrm{ef}}$ & $2.611 \pm 0.230^{\mathrm{fg}}$ & $5.8 \pm 0.3^{a}$ & $72.95 \pm 6.76^{\text {efg }}$ & $6.78 \pm 2.53^{\mathrm{abcd}}$ & $37.93 \pm 1.53^{\text {defg }}$ & $44.71 \pm 3.44$ defg \\
\hline $3 f$ & $145.0 \pm 3.6^{\text {efgh }}$ & $2.195 \pm 0.383^{\text {def }}$ & $3.1 \pm 0.1^{\mathrm{a}}$ & $78.87 \pm 3.82^{\mathrm{fgh}}$ & $5.82 \pm 2.10^{\mathrm{abcd}}$ & $32.19 \pm 2.91^{\text {bcdef }}$ & $38.01 \pm 1.12^{\mathrm{abcd}}$ \\
\hline $3 f v$ & $145.3 \pm 2.5^{\text {efgh }}$ & $1.747 \pm 0.300^{\mathrm{cd}}$ & $8.0 \pm 0.9^{a}$ & $66.65 \pm 7.41^{\text {cdef }}$ & $10.35 \pm 3.93^{\text {de }}$ & $36.22 \pm 2.55^{\text {bcdefg }}$ & $46.58 \pm 4.22^{\text {efghi }}$ \\
\hline 4 & $69.8 \pm 1.5^{\mathrm{a}}$ & $2.644 \pm 0.231^{\mathrm{fg}}$ & $4.5 \pm 1.0^{\mathrm{a}}$ & $72.82 \pm 14.72^{\mathrm{efg}}$ & $7.40 \pm 6.10^{\text {bcde }}$ & $38.80 \pm 2.78^{\text {efgh }}$ & $46.20 \pm 6.85^{\text {efgh }}$ \\
\hline $4 v$ & $77.0 \pm 0.4^{\mathrm{ab}}$ & $2.302 \pm 0.259^{\text {def }}$ & $5.7 \pm 0.3^{a}$ & $69.57 \pm 2.28^{\text {cde }}$ & $8.08 \pm 1.74^{\text {bcde }}$ & $38.32 \pm 2.57^{\text {efgh }}$ & $46.40 \pm 1.39^{\text {efghi }}$ \\
\hline $4 f$ & $78.3 \pm 1.1^{\text {bcd }}$ & $2.646 \pm 0.498^{\mathrm{fg}}$ & $3.4 \pm 0.2^{\mathrm{a}}$ & $69.55 \pm 8.15^{\text {cde }}$ & $10.54 \pm 4.61^{\text {def }}$ & $31.78 \pm 4.86^{\mathrm{fgh}}$ & $42.33 \pm 5.62^{\text {cde }}$ \\
\hline $4 \mathrm{fv}$ & $137.3 \pm 2.3^{\mathrm{e}}$ & $2.109 \pm 0.333^{\text {def }}$ & $3.9 \pm 1.1^{\mathrm{a}}$ & $61.46 \pm 0.73^{\text {bcde }}$ & $11.21 \pm 1.06^{\text {def }}$ & $41.04 \pm 2.75^{\mathrm{fgh}}$ & $52.25 \pm 1.81^{\text {ghij }}$ \\
\hline 5 & $139.7 \pm 5.0^{\mathrm{e}}$ & $0.465 \pm 0.065^{a}$ & $46.5 \pm 22^{\mathrm{e}}$ & $65.41 \pm 8.03^{\text {bcdef }}$ & $8.77 \pm 4.00^{\text {cde }}$ & $43.24 \pm 0.71^{\mathrm{gh}}$ & $52.02 \pm 3.50^{\text {fghij }}$ \\
\hline $5 \mathrm{v}$ & $141.0 \pm 4.6^{\mathrm{ef}}$ & $0.535 \pm 0.113^{a}$ & $62.7 \pm 4.0^{\mathrm{e}}$ & $68.02 \pm 5.58^{\text {cdef }}$ & $10.35 \pm 3.37^{\text {de }}$ & $34.12 \pm 2.14^{\text {abcde }}$ & $44.48 \pm 2.20^{\text {def }}$ \\
\hline $5 f$ & $149.7 \pm 1.2^{\text {fgh }}$ & $0.472 \pm 0.038^{a}$ & $42.3 \pm 2.0^{\mathrm{e}}$ & $85.90 \pm 3.44 \mathrm{gh}$ & $2.19 \pm 0.99^{a b c}$ & $37.64 \pm 2.44^{\text {cdefg }}$ & $39.82 \pm 2.39$ bcde \\
\hline $5 \mathrm{fv}$ & $152.0 \pm 3.6^{\text {gh }}$ & $0.425 \pm 0.047^{a}$ & $61.5 \pm 3.4 \mathrm{e}$ & $52.35 \pm 4.18^{\mathrm{b}}$ & $19.51 \pm 2.91^{\mathrm{h}}$ & $33.75 \pm 1.79$ abcde & $53.25 \pm 2.57^{\text {hij }}$ \\
\hline 6 & $142.7 \pm 2.9^{\text {efg }}$ & $0.788 \pm 0.193^{\mathrm{ab}}$ & $23.6 \pm 15^{\text {cd }}$ & $57.51 \pm 5.32^{\text {bcdebcd }}$ & $12.24 \pm 2.28^{\text {defg }}$ & $44.08 \pm 1.99^{h}$ & $56.33 \pm 3.87 j$ \\
\hline $6 \mathrm{v}$ & $146.0 \pm 5.6^{\text {efgh }}$ & $0.611 \pm 0.093^{\mathrm{ab}}$ & $36.1 \pm 1.9^{\text {def }}$ & $54.24 \pm 3.75^{\mathrm{bc}}$ & $19.12 \pm 2.87^{\mathrm{h}}$ & $32.21 \pm 2.49^{\mathrm{abcd}}$ & $51.33 \pm 2.41^{\text {fghij }}$ \\
\hline $6 f$ & $150.0 \pm 4.2^{\text {fgh }}$ & $0.582 \pm 0.123^{\mathrm{ab}}$ & $22.3 \pm 1.0^{\mathrm{bc}}$ & $89.95 \pm 3.55^{\mathrm{h}}$ & $1.55 \pm 0.84^{\mathrm{ab}}$ & $35.49 \pm 1.76$ abcdef & $37.04 \pm 1.69^{\mathrm{abcd}}$ \\
\hline $6 f v$ & $154.3 \pm 2.9^{h}$ & $0.677 \pm 0.135^{\mathrm{ab}}$ & $37.9 \pm 3.4^{\text {de }}$ & $33.08 \pm 2.56^{\mathrm{a}}$ & $30.56 \pm 2.43^{i}$ & $34.53 \pm 1.99$ abcde & $65.08 \pm 0.91^{k}$ \\
\hline
\end{tabular}

Values are means \pm SD

Means having the same letter for a parameter are not significantly different $(p<0.05)$ through the Tukey test

\section{RESULTS}

The schematic representation of the samples and samples photos are shown on Figure 1.

Table 1 shows the values of measured parameters: thickness of the layers, surface roughness, water contact angle and surface free energy and its total and polar component. ANOVA results indicate statistically significant differences for thickness, surface roughness, water contact angle and surface free energy and its total and polar component. The large $F$-value indicates there are more differences between groups than within groups. With a $p$-value $<0.0001$, the null hypothesis (there are no differences between different sample groups) is rejected. Post hoc analysis using Tukey's honestly significant difference (Tukey's HSD) was performed.

Printing or varnishing increases the thickness of the samples. It is related with the application of ink or varnish layer on the paper substrate. However, the thickness of the layers formed on the paper, differs for each paper, what is related with the various absorbency of the papers. The varnish layer is in the range of 1.3 to $9.9 \mu \mathrm{m}$ and the ink layer is in the range of 3.1 to $10 \mu \mathrm{m}$. In general the thickness of varnish layer is thinner than the ink layer.

The measured surface roughness of pure papers is much higher than overprinted or over varnished papers. It might be related with the proper cohesion forces in the ink or varnish layer. On the contrary, Gajadhur has observed the increase of surface roughness after printing or varnishing and at the same time, the varnish caused a much greater increase in the roughness surface than the ink coating (Gajadhur, 2018).

Gloss is a property of materials responsible for light reflection from a surface. The methods for gloss measurements depend on the kind of base. Firstly the gloss was measured with geometry $60^{\circ}$ for all samples, despite the uncoated papers prior and after finishing are matt. For this samples a measuring geometry with an angle of $85^{\circ}$ for uncoated paper samples was used, because the film coatings of the investigated inks and varnish for uncoated papers exhibit gloss below 10 units at a measuring geometry angle of $60^{\circ}$ according to ISO 2813 standard. However, the $60^{\circ}$ is most universal and might be used for all samples. The gloss of ink or varnish dried ink layer of overcoated glossy or coated papers are much higher that the gloss of uncoated papers. The gloss of the top layer is strongly influence by the substrate properties 
which may be related with a very thin layers. Furthermore, the influence of the gloss of the coatings is related with lower surface roughness of the coating.

Based on the obtained results of water contact angle and the values of components of the surface free energy (SFE), influence of printing and varnishing on SFE maybe assessed. The analyses of water contact angle and changes of water contact angle during time provides useful information about wetting of the solid by a liquid and its wettability. The values of water contact angles indicates that lowest wettability was determinate for papers prior printing or varnishing process. In general, the dried printing ink layer as a top layer exhibited higher values of water contact angles than varnished layer and simultaneously lower wettability. It might be related with the type of printing ink components. The values of water contact angles strongly affects the values of polar components of surface free energy. The values of polar components are very low and in the range of $0.26-12.24 \mathrm{~mJ} \cdot \mathrm{m}^{-2}$ for uncoated paper and coated paper, respectively. Simultaneously, the values of dispersive component are in the range of $31.38-44.08 \mathrm{~mJ} \cdot \mathrm{m}^{-2}$ for uncoated paper and coated paper, respectively. In general, the varnishing process increase the values of polar and dispersive component of surface free energy and, hence, the values of total surface free energy also increases. Furthermore, the values of total surface free energy of paper substrates are much lower than the values of dried varnish or ink layer.

\section{CONCLUSION}

The aim of this work was to analyze the surface properties of paper ink layer prior and after printing and varnishing process. The dried ink layer can be observed by human eye and the quality might be assessed by colorimetric method, whether the varnish is not observed by human eye or without reference samples. Based on our results, we can conclude, that the printing or varnishing increases the thickness of the sample. Next, the varnishing process increases the gloss of the samples (depending on the varnish used; in this work, semi-gloss water based dispersive varnished was used). Finally, the printing or varnishing finishing of the paper substrate affects the dispersive and polar part of surface free energy. Finishing of the paper substrate increases the total value of surface free energy. Simultaneously, we have observed poorer wettability of the coatings layers, so the varnish layer protects the print layer.

The surface free energy measurements as well as the measurement of the water contact angle might be a useful tool in order to observe whether the varnishing was used in order to improve the coating. However, this measurement needs a reference sample without varnished layer.

\section{REFERENCES}

[1] Car, I., Majnarić, I., Lozo, B.: "Colorimetric Changes Caused by UV Varnishing", Proceedings of 8th Conference On Information And Graphic Arts Technology, 37-40, 2018.

[2] Gajadhur, M.: "Paper and plastic roughness properties after surface refinement processes", Welding Technology Review 90 (3), 2018. doi:10.26628/wtr.v90i3.870.

[3] Galić, E., Ljevak, I., Zjakić, I.: "The Influence of UV Varnish on Colorimetric Properties of Spot Colors", Procedia Engineering 100, 1532-1538, 2015. doi:10.1016/j.proeng.2015.01.525.

[4] Holik, H., Moldenhauer, T., Rentrop, G.-H., Tschudin, P. F., von Kendenich, W. K.: "Introduction. In Handbook of Paper and Board", 1-31, 2013. doi:10.1002/9783527652495.ch1.

[5] Hudika, T., Tomašegović, T., Cigula, T., Poljičak, A.: "Analysis Of The Interactions In The "VarnishPhotopolymer" System", Proceedings of 8th International Symposium on Graphic Engineering and Design 2018, (Department of Graphic Engineering and design, Faculty of Technical Sciences, Novi Sad, 2018), pages 152-159, 2018. doi:10.24867/GRID-2018-p18.

[6] Majnarić, I., Mirković, I. B., Golubović, K.: "Influence of UV curing varnish coating on surface properties of paper", Tehnicki Vjesnik-Technical Gazette 19 (1), 51, 2012.

[7] Mirschel, G., Savchuk, O., Scherzer, T., Genest, B.: "Process control of printing processes with in-line NIR spectroscopy and elimination of the influence of the substrate on the prediction of the coating weight", Progress in Organic Coatings 76 (1), 86-93, 2013. doi:10.1016/j.porgcoat.2012.08.016. 


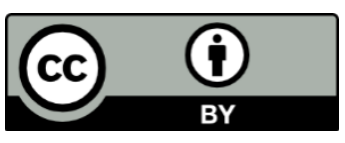

(C) 2020 Authors. Published by the University of Novi Sad, Faculty of Technical Sciences, Department of Graphic Engineering and Design. This article is an open access article distributed under the terms and conditions of the Creative Commons Attribution license 3.0 Serbia

(http://creativecommons.org/licenses/by/3.0/rs/). 



\title{
ADHESION STRENGTH OF TEMPERATURE VARIED NANOCELLULOSE ENHANCED WATER BASED PAPER AND CARDBOARD ADHESIVES
}

\author{
Barbara Šumiga $^{1}$ (D) , gor Karlovits $^{1}$ (D), Boštjan Šumiga ${ }^{2}$ \\ ${ }^{1}$ Pulp and Paper Institute, Ljubljana, Slovenia \\ ${ }^{2}$ University of Ljubljana, Faculty of Natural Sciences and Engineering, Ljubljana, Slovenia
}

\begin{abstract}
Water-based dispersion adhesives consist of a solid adhesive dispersed in an aqueous phase. These adhesives contain water-soluble additives such as surfactants, emulsifiers, and protective colloids, which act as links between the solid adhesive particles and the aqueous phase. They prevent the adhesive particles from sticking together and separating during storage. During drying, these additives evaporate or are absorbed into the adhesive. Polyvinyl acetate (PVAC) and polyvinyl alcohol (PVOH) are further examples of ethylene copolymers. PVAc is used as an emulsion adhesive for production of bags, sacks and cartons. Recently there have been some preliminary investigations concerning the addition of nanocellulose as adhesion improver. Nanocellulose is a term that refers to nanostructured cellulose. It can be either cellulose nanocrystal (CNC or NCC), cellulose nanofibres (CNF) also called nanofibrillated cellulose (NFC), or bacterial nanocellulose, which refers to nanostructured cellulose produced by bacteria. CNF is a material consisting of nanofibrillated cellulose fibrils with a high aspect ratio (length to width ratio). In this study, we tested the adhesion strength of two PVAC adhesives by adding 0,5, 1 and 2\% [wt.\%] of two types of nanocellulose to two commercial adhesives. The adhesive was applied to the cardboard with a rod coater. To test the influence of temperature, we varied the mixture at two different temperatures $\left(23\right.$ and $\left.45^{\circ} \mathrm{C}\right)$. The adhered samples were tested for $z$-direction tensile strength (according to ISO 15754:2009) and T-peel test (ASTM D1876-08) on a mechanical testing device. The results showed no significant improvement in adhesion strength compared to pure adhesive, indicating that further optimization of the adhesive mixture and testing procedure is required.
\end{abstract}

Keywords: adhesion strength, nanocellulose, paper, PVAc

\section{INTRODUCTION}

Adhesives are used in a wide range of paper bonding applications, from the construction of corrugated boxes and lamination of printed sheets to packaging materials for all types of consumer goods to the manufacture of large industrial tubes and cores used by producers of rolling stock and other materials. Adhesives are used to bond cardboard surfaces together and create a permanent bond. The bond formed by adhesion must be strong enough to be processed as soon as the paperboard leaves the glueing machine. Therefore, the adhesive must be selected by taking into account the absorption properties such as setting time which is adapted to the paperboard and the glueing line process. The main criterion for successful glueing of packaging products is almost always a $100 \%$ fibre tear when the adhesion line is separated. The type of adhesive typically used to bond coated paperboard substrates is based on polyvinyl acetate (PVAc) chemistry together with water and other additives for functionality. In order to achieve uniform fibre tearing when bonding coated/uncoated substrates, the base sheet of both substrates must always be the weakest link when separating. The mechanism for achieving a uniform fibre tear under the coated surface is such that adhesive carriers (mainly water) must penetrate the fibre matrix to cause "fibre bond breaks" (weakening) which in turn trigger a fibre tear. During this process, adhesive particles are trapped in the pores of the substrate where they "harden" and form a permanent bond (Parker, 2004). The importance of porosity for the penetration of water-based PVAc adhesive has been investigated and confirmed by microscopic measurements (Williams et al., 2011). In a study by (Petković et al., 2016) they tested various other paper properties and polyvinyl acetate adhesives. Their research indicates that the influence of the ratio between polar and disperse fractions on the decreasing or increasing influence of the free energy between the phases has an impact on the adhesive joint. The interphase energy controls the durability and strength of an adhesive joint and is primarily responsible for the transfer of stress from one adhesive to another. The analysis of fillers showed that the increased amount due to ion-dipole interactions could reduce the interphase energy between these two phases.

On the other hand, in addition to stickiness and adhesiveness of cardboard and paper, the adhesive formulations are also essential. Polyvinyl acetate (PVAc) and polyvinyl alcohol (PVOH) are further examples of ethylene copolymers. PVAc is used as an emulsion adhesive for the production of bags, sacks 
and cardboard boxes. PVOH is produced by hydrolysis of PVA, and the strong hydrogen bonding mediated by the $-\mathrm{OH}$ groups means that pure $\mathrm{PVOH}$ is water-soluble. The amount of hydrolysis controls the degree of water solubility. PVAc softens when its temperature is raised above room temperature and is less resistant to moisture and humidity than thermosetting resins.

For this reason, PVAc adhesives are used in indoor applications. Besides, PVAc tends to creep ('cold flow') under prolonged exposure (Conner and Bhuiyan, 2017). Previous research on some adhesives of plywood to paper has shown the positive effect of adding nanocellulose on adhesion strength and has enabled a remarkable increase in shear strength values to be achieved. The introduction of cellulose nanoparticles has had a positive influence on mechanical properties such as flexural bending strength and modulus of elasticity. Advantages of using nanocellulose as reinforcement in adhesives for the production of woodbased panels are the possibility to modify the properties of the adhesives, the improvement of the mechanical and physical properties of the panels and the reduction of formaldehyde emissions through the use of synthetic adhesives. A variation in viscosity was observed with an increasing percentage of cellulose nanocrystals (CNC) added to the adhesive (Damásio et al., 2017), while in (Vineth et al., 2019) an overview of nanocellulose applications in wood adhesives was given. In a study on PVAc adhesives (Jiang et al., 2018), the results showed that the optimal amount of CNF, $0.48 \%$ suspensions, added to PVAC increased the average overlap joint strength (EN 205:2003) by 74.5\% compared to control samples with pure PVAc. Accordingly, $0.96 \%$ of CNF suspensions also increased the strength of the starch adhesive by 34.5\%. Lower and higher CNF concentrations showed a significantly worse performance.

Further studies were conducted by (Veigel et al., 2011). Temperature changes of PVA adhesives on wood panels were studied by (Motohasi et al., 1984). They concluded that the adhesive strength is strongly dominated by the final strength of the adhesive films, which in turn depends on rheological fluctuations caused by temperature changes, i.e. if adhesive polymers are in a rubbery state corresponding to a high test-temperature, the adhesive strength is weak due to cohesive fracture of the adhesives. As adhesive polymers harden with decreasing test-temperature, the bond strength increases to a maximum where the wood/adhesive interface force appears to be most effective. If the test-temperature is lowered from this point, the strength begins to decrease significantly due to the decreasing interfacial forces in the case of the cross-impact lap test. In a review by Heinrich (2019) some problems with nanocellulose as an additive in adhesives has been pointed out. The water content of nanocellulose, which is generally up to $97 \%$, and its price. A solution to the first problem seems to be cold pressing the water after slurry, while a solution to the second problem could be the use of lignocellulose nanofibers obtained from recycled particleboards or other sources. If these developments are successful, the nanocellulose could have a function both as structural reinforcement and as an adhesive material in the product. Since the addition of nanocellulose as an additive in PVAc adhesives for paper and board (mainly for wood panels) is not being extensively investigated, we have tested two PVAc adhesives with two different types of nanocellulose.

\section{MATERIALS AND METHODS}

To test the adhesion strength of the nanocellulose reinforced PVAc adhesives we used a commercial 235 $\mathrm{g} / \mathrm{m}^{2}$ cardboard (produced by Količevo Karton) with $5 \%$ surface treatment and total absorption (DIN ENISO 535) of the $60 \mathrm{~s}$ under $30 \mathrm{~g} / \mathrm{m}^{2}$ from COBB. As adhesives, we used two types of PVAc adhesives MEKOL 1301/1 (M1) and MEKOL 1413/G (M2) (produced by Mitol d.d., Slovenia). The adhesive MEKOL $1301 / 1$ has $50 \%$ solids content (ISO 3251) and initial viscosity at room temperature $\left(23^{\circ} \mathrm{C}\right)$ of $1.700-$ $2.200 \mathrm{mPa}$ s (ISO 2555 - Brookefiled) while the adhesive MEKOL 1413/G has 46,5\% solids content and viscosity at room temperature of $15.000-22.000 \mathrm{mPa}$ s (ISO 2555 - Brookefield). For both adhesives, an excellent working adhesion range up to $250^{\circ} \mathrm{C}$ was specified. The main difference is that adhesive MEKOL $1413 / \mathrm{G}$ forms a more elastic film after drying. For the nanocellulose, we used two different types of it: nanocrystalline (NCC) with a solid content of 7,8 \% and a diameter of 10-20 nm and a length of 40-200 $\mathrm{nm}$ (produced by National Institute of Chemistry, Ljubljana, Slovenia) and commercial nanofibrillated cellulose (NFC) with a solid content of $4 \%$ and a diameter of 10-200 nm and a length of $<50 \mu \mathrm{m}$. The nanocellulose was added in the ratio of 0,5, 1 and $2 \%$ content (weight \%). All determined quantities of nanocellulose were weighed and added to the adhesive. The adhesive formulations were prepared using IKA digital overhead stirrer. Homogenization was achieved by intensive mixing of the prepared mixtures for at least 3 minutes at a mixing speed of $2000 \mathrm{rpm}$. For the application of the adhesive, a laboratoryscale rod coater (K Control Coater, RK PrintCoat Instruments Ltd., Litlington, UK) was used. We have applied the rod with the number 4 and the speed 6. Immediately after the adhesive coating, a new sheet 
was glued onto the adhesive layer. Then we used rod number 0 to achieve the same pressure over the entire paper surface. In the second series of adhesive applications performed, the applied elevated temperature was $45^{\circ} \mathrm{C}$. The amount of adhesive which was applied was minimal in order to minimize the possible tearing of the cardboard layers, to isolate and determine the adhesive strength of the different adhesive formulations and to exclude the adhesive strength of the cardboard. The determination of the adhesive strength between the two adhered cardboard sheets was carried out with mechanical testing device ZWICK/Roell Z010 using the analytical methods Z direction tensile strength (ISO 15754:2009) and T- peel test (ASTM D1876-08).

\section{RESULTS}

The results for the z-direction tensile strength for the different amounts of NCC and NFC (for both temperatures) are shown in Figure 1.

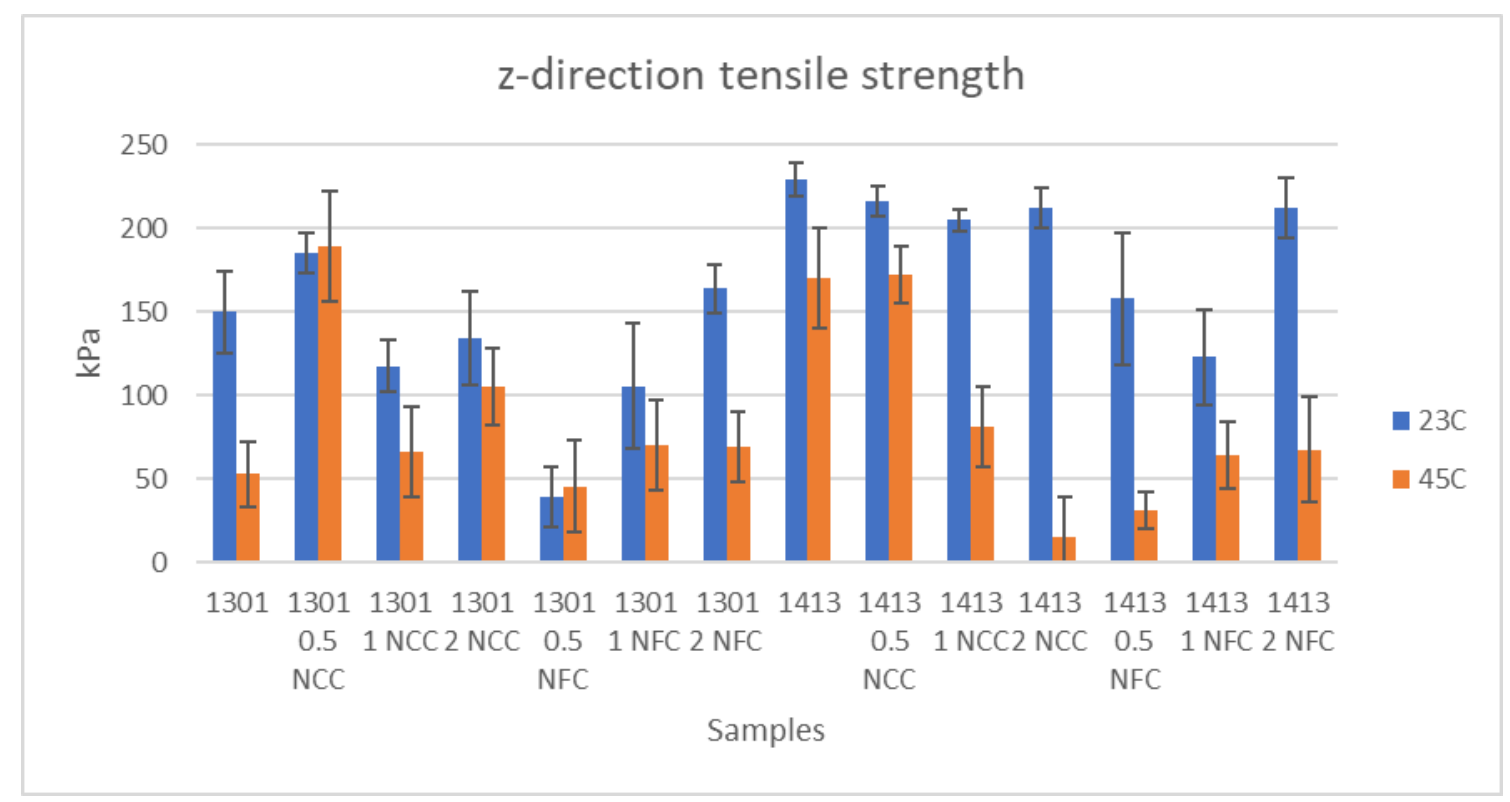

Figure 1: Z- direction tensile strength

From the tensile strength results in the z-direction, it can be seen that at room temperature (and in the optimum temperature range concerning the base adhesive) the addition of NCC and NFC has improved the tensile strength of the samples in the z-direction compared to the $\mathrm{M} 1$ adhesive alone. For the adhesive $\mathrm{M} 2$, the addition resulted in similar or slightly lower tensile strength. The temperature increase of the adhesive mixtures resulted in lower $\mathrm{kPa}$ values in almost all samples except the mixtures with the lowest concentration (0,5 \% wt). The increased temperature and lower water content resulted in lower $\mathrm{z}$ tensile strength values for both NCC and NFC compounds. From Figure 2., it is clear that the most common joint failure and adhesion separation was due to delamination of the cardboard ply's rather than the adhesive joint. This effect means that the cardboard internal cohesion values are lower than the adhesive strength. On the right side of the Figure 2. which was taken on samples with elevated temperature of the applied adhesive, it can be seen that the cohesion failure, was between two cardboard samples where the adhesive was applied. 

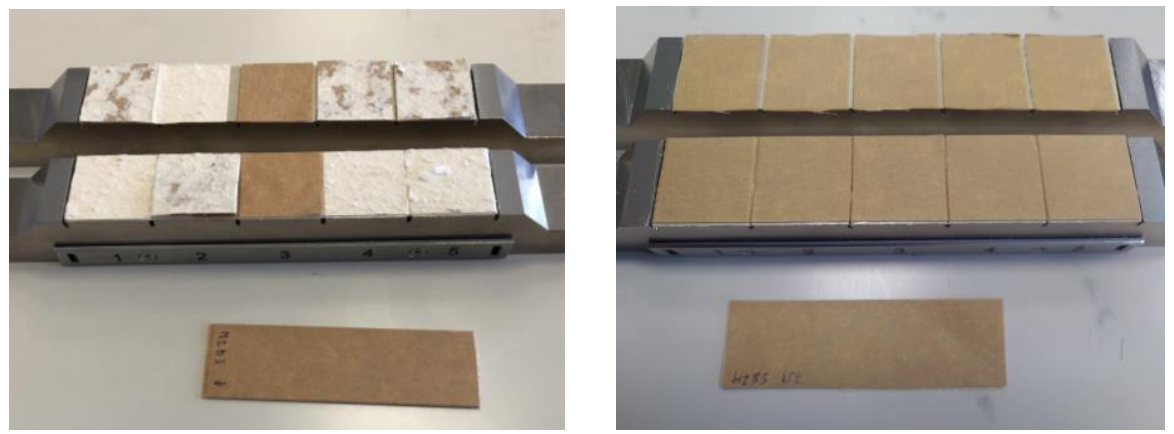

Figure 2: Z- direction tensile strength samples after the test has been performed

The results for the T-peel test for the samples joined at room temperature $\left(23^{\circ} \mathrm{C}\right)$, and elevated temperature is shown in Figure 3.

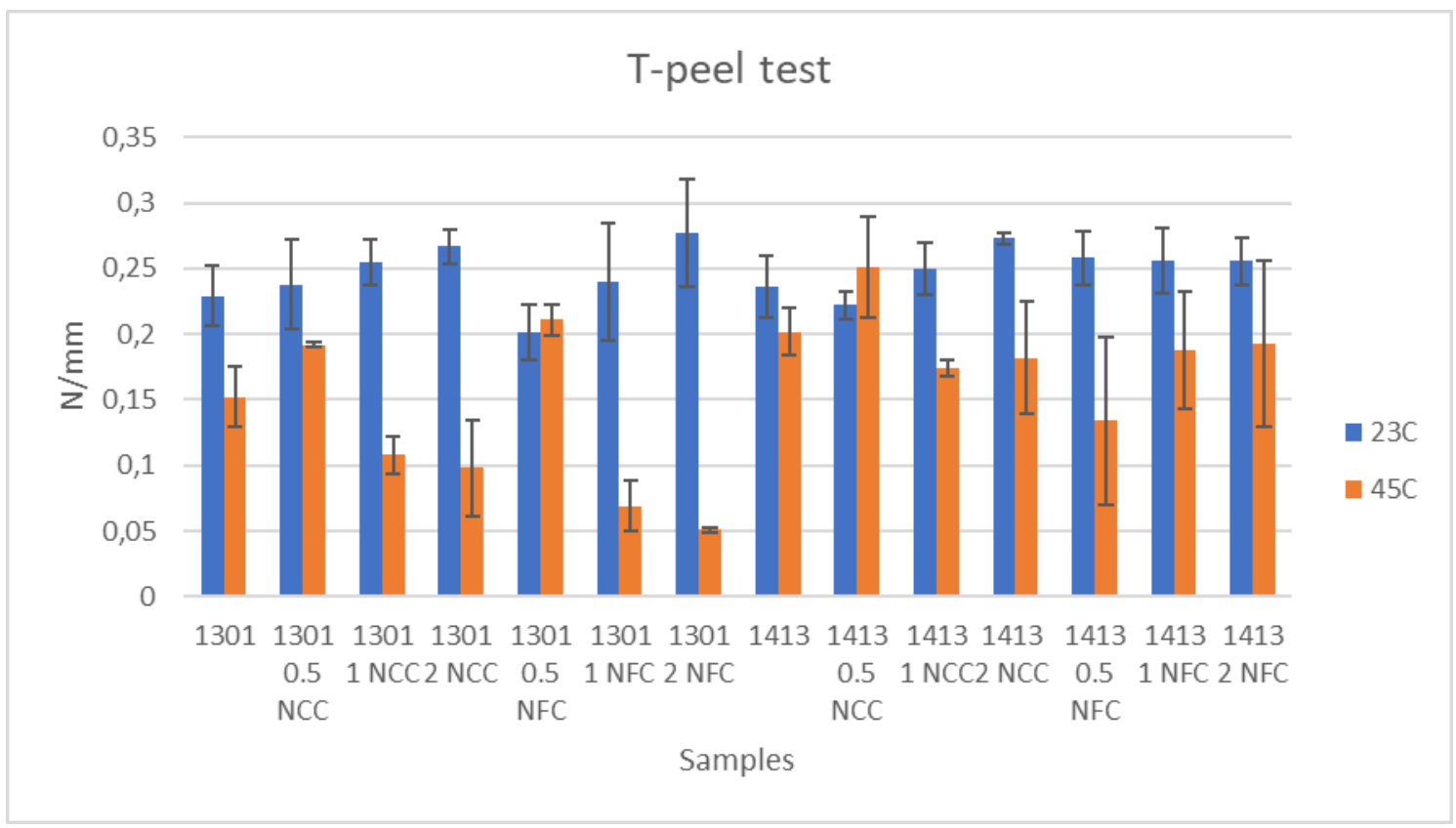

Figure 3: T peel adhesion strength

From Figure 3, we can observe that the addition of NCC and NFC positively influences the average N/mm values for all combinations $(0,5 \%, 1 \%$ and $2 \%)$ and in all cases, the peel adhesion strength was higher (except M1 NFC 0,5\%) and M2 (0,5\% NCC) which may indicate that higher concentrations of NCC and NFC at room temperature lead to higher peel strength values. Also, it can be seen that the increased temperature lowered the adhesion strength values for all adhesives and adhesive formulation combinations, but the NCC and NFC additives had even higher values for the M1 base adhesive and similar values for the $\mathrm{M} 2$ adhesive.

\section{CONCLUSION}

Replacing synthetic components in adhesives with natural ones is a challenge from various aspects regarding chemical compatibility, pricing and application technology. The addition of NCC and NFC in adhesives has proved useful in wood composites, while our results show mixed results, with the addition of NFC and NCC in some cases giving higher and slightly lower values in the z-direction tensile strength measurements. In the $\mathrm{T}$ peel adhesion test at room temperature, the addition was beneficial for both additives as the average peel force $(\mathrm{N} / \mathrm{mm})$ increased. One of the possible reasons for differences between the two test methods could also be the variation in the adhesive application, where the rod system creates a slight time delay between the sample sides, with the bottom side having more moisture 
at the moment of contact of two cardboard layers. Due to this effect, the z- strength method can lead to a higher variation of results. The increased temperature caused a deterioration of the basic components, and the results were not as consistent. The ambiguous results indicate that in our future research we need to optimize the mixtures, procedures further, and compatibilities of the NCC and NFC addition with the base adhesive formulations and investigate the influence of the water content on the adhesive strengths of the paper and board compound.

\section{ACKNOWLEDGMENTS}

We want to thank company Mitol, d.d. for providing the base adhesive samples.

\section{REFERENCES}

[1] Conner A.H., Bhuyian M.S.H.: "Wood: Adhesives", In book: Reference Module in Materials Science and Materials Engineering, Elsevier, 2017. doi: 10.1016/B978-0-12-803581-8.01932-9.

[2] Damásio, R., Carvalho, A., Gomes, F., Carneiro, A., Ferreira, J., Colodette, J.: "Interação de nanocristais de celulose com o adesivo ureia-formaldeído em juntas coladas de Eucalyptus sp. ", Scientia Forestalis 45(113), 2017. doi: 10.18671/scifor.v45n113.17.

[3] Heinrich, L.A.: "Future opportunities for bio-based adhesives - advantages beyond renewability", Green Chemistry 21(8), 1866-1888, 2019. doi: 10.1039/c8gc03746a.

[4] Jiang, W., Tomppo, L., Pakarinen, T., Sirviö, J., Liimatainen, H., Haapala, A.: "Effect of Cellulose Nanofibrils on the Bond Strength of Polyvinyl Acetate and Starch Adhesives for Wood", BioResources 13(2), 2018. doi: 10.15376/biores.13.2.2283-2292.

[5] Parker, Q.: "Aqueous Gluing of Coated Paperboard Packaging Products in North America, Solutions! Online Exclusives, April 2004", URL: https://imisrise.tappi.org/TAPPI/Products/04/APR/04APROE01.aspx (last request: 2020-09-15).

[6] Petković G., Rožić M., Vukoje M., Pasanec P.: "Interactions in polyvinyl acetate - paper adhesive joint and influence on its adhesion parameters", Proceedings of 8th International Symposium on Graphic Engineering and Design 2016, (University of Novi Sad, Serbia, 2016), pages 91-101.

[7] Veigel, S., Müller, U., Keckes, J., Obersriebnig, M., Gindl-Altmutter, W.: "Cellulose nanofibrils as filler for adhesives: effect on specific fracture energy of solid wood-adhesive bonds", Cellulose 18(5), 1227-1237, 2011. doi: 10.1007/s10570-011-9576-1.

[8] Vineeth, S., Gadhave, R., Gadekar, P.: "Nanocellulose Applications in Wood Adhesives-Review", Open Journal of Polymer Chemistry 09(04), 63-75, 2019. doi: 10.4236/ojpchem.2019.94006.

[9] Williams, D., Ninness, B., Ventresca, D., Welsch, G.W.: "Microscopy Characterization of Aqueous PVAc Glue Penetration in Double Coated Paperboard Systems", Microscopy and Microanalysis 17(S2), 1046-1047, 2011. doi: 10.1017/S1431927611006106.

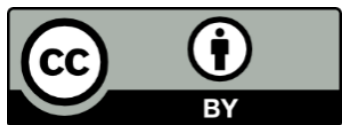

(C) 2020 Authors. Published by the University of Novi Sad, Faculty of Technical Sciences, Department of Graphic Engineering and Design. This article is an open access article distributed under the terms and conditions of the Creative Commons Attribution license 3.0 Serbia (http://creativecommons.org/licenses/by/3.0/rs/). 

GRAPHIC MATERIALS AND PROCESSES EFFICIENCY 



\title{
THE EVALUATION OF THE ORGANIC LOAD OF THE WASTE OFFSET DEVELOPER WITH EXTRACTION METHODS
}

\author{
Savka Adamović (D), Ivan Pinćjer (D), Bojan Banjanin (D), Stefan Đurđević (iD, Nada Miketić \\ University of Novi Sad, Faculty of Technical Sciences, \\ Department of Graphic Engineering and Design, Novi Sad, Serbia
}

\begin{abstract}
The validation of the extraction method is significant for the characterization of the offset effluent and the selection of an adequate effluent treatment for its safe disposal in a printing environment. For the aforementioned reasons, the qualitative characterization of the organic load profile of the waste offset developer was evaluated based on the application of two liquid/liquid $(L / L)$ extraction methods. The gas chromatographic/mass spectrometric (GC/MS) method was used for the qualitative detection of the organic compounds present in the offset effluent. The cumulative qualitative GC/MS profile of organic substances in the waste offset developer indicates that the effluent contains 69 organic compounds with a probability of presence higher than $70 \%$ according to the AMDIS software and the NIST database.
\end{abstract}

Key words: offset developer, effluent, extraction, organic compounds

\section{INTRODUCTION}

An offset developer and a printing plate are in a close interdependent relationship. On one hand, the composition of the offset developer and the parameters according to which the developer is applied, like temperature, time of exposure, $\mathrm{pH}$ value, and age, affect the characteristics of the printing plate. On the other hand, the developer has to be adjusted in its composition to the type of the copy layer of the printing plate, the developing of which it is being used for (Mahovic Poljacek et al, 2012). Unfortunately, most manufacturers in Material Safety Data Sheet (MSDS) do not define the exact chemical composition of the offset developer or other offset printing liquid materials such as fountain solutions, cleaning agents, etc. Information about the chemical composition of offset printing materials are available partially in MSDS, in patent holders, or in scientific publications (Adamović, 2016; Adamović et al, 2019).

In literature data, a small number of authors have dealt with the problem of analysis of the initial and waste offset developers as well as their possible treatments. Thus, Vengris et al. (2007) state that in the starting developers under the commercial names of Polychrome 4003, Polychrome $2000 \mathrm{~K}$ and HD-P1 are the following chemical substances: potassium silicate, sodium silicate, potassium hydroxide, and Dsorbitol. After the process of developing, these waste offset developers are enriched by matters from the surface of the printing plate, such as: novolac, organic polymeric binders, photosensitive compounds, and pigments. Via the treatment by the Fenton's advanced oxidation process, almost all organic substances are removed (Vengris et al, 2007). In the paper by Lin et al. (2002), it is stated that the average waste offset developer consists of: p-phenylenediamine, hydroquinone, phenidone, benzyl alcohol, diethylene glycol, triethylene glycol, hydroxylamine, triethanolamine, formalin (consisting of $40 \%$ formaldehyde, $8 \%$ methanol and 52\% water), dialdehyde glutamic acid, organic heterocyclic compounds, p-toluene sulfonate, 5-sulfosalicylic acid, acetic acid, surfactants, then inorganic compounds (sodium sulfite, potassium sulfite, potassium carbonate, sodium hydrogen carbonate, boric acid, potassium hydroxide, sodium hydroxide, ammonium bromide and potassium bromide).

The waste offset developer as a byproduct of the developing of the offset printing plate is most commonly toxic by its characteristics and potentially harmful to the environment. For this purpose, this paper deals with the qualitative characterization of the organic load profile of the waste offset developer and with the validation of the two L/L extraction methods for the future selection of an adequate effluent treatment for its safe disposal in a printing environment.

\section{METHODS}

GC/MS method was used for the qualitative detection of the organic compounds present in the waste offset printing developer. A gas chromatograph with a mass detector (Agilent 7890A GC with 5975C MSD, USA) and with an Agilent J\&W Scientific DB-5MS chromatographic column of appropriate dimensions (30 $\mathrm{m} \times 0.25 \mathrm{~mm}$ ID $\times 0.25 \mu \mathrm{m}$ ) was used. The mass detector temperature was $150^{\circ} \mathrm{C}$, while the samples were 
injected at an injector with the temperature of $270^{\circ} \mathrm{C}$. Helium was used as the carrier gas (Adamović, 2016; Adamović et al, 2019).

Two $L / L$ extraction methods were used for the preparation of the waste offset printing developer samples: L/L extraction with methylene chloride (I method) and sequential L/L extraction with $n$-pentane, methylene chloride and methylene chloride at $\mathrm{pH} 2$ (II method).

In the I method, the extraction was performed in the following order: $1 \mathrm{~L}$ of waste printing developer was extracted with $30 \mathrm{ml}$ of methylene chloride $\left(\mathrm{CH}_{2} \mathrm{Cl}_{2}\right.$, J.T. Baker, USA) in a separation funnel. The extract was first collected in a laboratory beaker with three tablespoons of anhydrous sodium sulfate $\left(\mathrm{Na}_{2} \mathrm{SO}_{4}\right.$, p.a., Sigma-Aldrich, Germany) due to high contamination of the offset effluent. The extract was then transferred to a separation funnel. The extraction was repeated once more with another $30 \mathrm{ml}$ of methylene chloride. The cumulative extract was evaporated to dryness and reconstituted with $2 \mathrm{ml}$ of phenanthrene $\mathrm{d} 10(0.4 \mathrm{\mu g} / \mathrm{mL})$ in a mixture of hexane and methylene chloride $(1: 1)$. After the $\mathrm{L} / \mathrm{L}$ extraction with methylene chloride at the actual $\mathrm{pH}$ of the waste printing developer $(\mathrm{pH} 12.0)$, the $\mathrm{pH}$ of effluent was adjusted to 2 additions of concentrated hydrochloric acid ( $\mathrm{HCl}, 35 \%$, p.a., Merck, Germany). As the $\mathrm{pH}$ values of the compounds change their shape, adjusting the $\mathrm{pH}$ of effluent to 2, the invisible ionized compounds at $\mathrm{pH} 12.0$ become visible at $\mathrm{pH}$ 2. The L/L extraction process with methylene chloride at $\mathrm{pH} 2$ was repeated according to the same procedure as described above (Adamović, 2016; Adamović et al, 2019).

In the II method, the extraction was performed according to the procedure: $1 \mathrm{~L}$ of offset effluent was filtered through a membrane filtration set with a cellulose nitrate membrane filter (Sartorius Stedim Biotech $\mathrm{GmbH}$, Germany) and a vacuum pump (MILIPORE, Germany) to remove suspended solids from the waste offset developer. Then, $2 \mathrm{~mL}$ of 2,4,5,6-tetrachloro-m-xylene $(1 \mu \mathrm{g} / \mathrm{mL})$ and $2 \mathrm{~mL}$ of decachlorobiphenyl $(1 \mu \mathrm{g} / \mathrm{mL}$ ) were added to the filtered effluent. By the extraction with $50 \mathrm{ml}$ of $\mathrm{n}$ pentane, the first $\mathrm{n}$-pentane fraction was obtained. The $\mathrm{n}$-pentane fraction was filtered through anhydrous sodium sulfate. Following the same procedure with methylene chloride $(50 \mathrm{~mL})$ and methylene chloride at $\mathrm{pH} 2(50 \mathrm{~mL})$, the second and third fractions were obtained, respectively. Then, $400 \mu \mathrm{L}$ surrogate standards (chrysene-d12 and acenaften-d10) were added to all three fractions. Then the $\mathrm{n}$-pentane and methylene chloride fractions were evaporated in a stream of nitrogen to $1 \mathrm{~mL}$. The third fraction with methylene chloride in an acidic medium was subjected to a methylation procedure.

Methylation was performed according to the procedure of Santos-Delgado et al. (2000) as follows: the evaporated extract was dissolved in $1 \mathrm{~mL}$ of methanol. $250 \mu \mathrm{L}$ of concentrated sulfuric acid $\left(\mathrm{H}_{2} \mathrm{SO}_{4}\right.$ p.a., Merck, Germany) was slowly added to the extract, after which the extract was left in the ultrasonic bath for 1 minute. The extract was then heated in a water bath for 12 minutes at $59^{\circ} \mathrm{C} .6 \mathrm{~mL}$ of $2 \%$ potassium chloride solution was added to the cooled extract. The esters were extracted with $1 \mathrm{~mL}$ of hexane, and then $0.5 \mathrm{~mL}$ of the extract was separated for GC/MS analysis. After the evaporation of the first and second extracts and methylation and evaporation of the third extract, $2 \mu \mathrm{L}$ of phenanthrene d-10 (100 $\mu \mathrm{g} / \mathrm{mL}$ ) was added to each extract $(0.5 \mathrm{~mL}$ ). The prepared samples were analyzed by GC/MS (Adamović, 2016; Adamović et al, 2019). 1 L of distilled water as a blank sample was prepared for each fraction according to the same procedure as for the waste offset developer. The dishes were washed with the mixture of acetone: hexane in a 1: 1 ratio before use.

The Deconvolution Reporting Software was used to create the qualitative GC/MS organic profile of the offset effluent. The Automated Mass Spectral Deconvolution and Identification System (AMDIS) software was used to identify organic substances. Also, all mass spectra obtained with the AMDIS software were compared with the NIST (National Institute of Standards and Technology) reference spectra of the database. The presence of an organic compound in a waste offset developer sample has been proved if the probability of presence (match), obtained by using AMDIS software and the NIST database, is higher than 70\% (Adamović, 2016).

\section{RESULTS AND DISCUSSION}

By using the L/L extraction with methylene chloride (I method) and the sequential extraction (II method), 45 and 24 organic substances were detected in the waste offset developer, respectively. In order to obtain a qualitative profile with the maximum number of detected organic substances, a cumulative GC/MS profile was determined for both extraction methods. The cumulative and qualitative GC/MS profiles of organic substances in the waste offset developer indicate that the effluent contains 69 organic substances with a probability of presence (match) higher than $70 \%$ by using the AMDIS software and the NIST database (Table 1). 
Table 1 (part 1): Cumulative and qualitative GC/MS profile of organic substances in the waste offset developer

\begin{tabular}{|c|c|c|c|c|c|}
\hline $\begin{array}{c}\text { Class of } \\
\text { organic } \\
\text { compounds }\end{array}$ & Organic compounds & $\begin{array}{c}\text { I } \\
\text { method }\end{array}$ & $\begin{array}{c}\text { II } \\
\text { method }\end{array}$ & $\begin{array}{l}\text { AMDIS } \\
\text { Match }\end{array}$ & $\begin{array}{l}\text { NIST } \\
\text { Match }\end{array}$ \\
\hline \multirow{3}{*}{ Hydrocarbons } & Pentadecane & & + & 79 & 84 \\
\hline & Undecane & & + & 85 & 86 \\
\hline & Tetradecane & & + & 71 & 78 \\
\hline \multirow{2}{*}{$\begin{array}{l}\text { Bicyclic } \\
\text { hydrocarbons }\end{array}$} & 5-Ethyl-bicyclo [2.2.1] hept-2-ene & + & & 76 & 81 \\
\hline & Indane & + & & 88 & 79 \\
\hline \multirow{6}{*}{$\begin{array}{l}\text { Polycyclic } \\
\text { Aromatic } \\
\text { Hydrocarbons } \\
\text { (PAH) }\end{array}$} & Biphenyl & & + & 71 & 79 \\
\hline & Naphthalene & + & & 97 & 93 \\
\hline & 1-Naphthalenol & + & & 98 & 92 \\
\hline & 2-Naphthalenol & & + & 91 & 86 \\
\hline & Fluoranthene & + & & 90 & 84 \\
\hline & Pyrene & + & & 85 & 84 \\
\hline \multirow{6}{*}{ Alcohols } & 2-ethyl-1-Hexanol & & + & 99 & 92 \\
\hline & 1-Undecanol & + & & 75 & 81 \\
\hline & 1-Dodecanol & + & & 96 & 92 \\
\hline & 1-Tetradecanol & + & & 78 & 88 \\
\hline & Phenylmethanol or Benzyl Alcohol & & + & 100 & 94 \\
\hline & $\alpha, a 4$-trimethyl-3-cyclohexene-1-Methanol & + & & 92 & 84 \\
\hline \multirow{2}{*}{ Ethers } & 2-(2-butoxyethoxy)-Ethanol & + & & 84 & 89 \\
\hline & 2-phenoxy-Ethanol & + & & 89 & 79 \\
\hline \multirow{5}{*}{$\begin{array}{l}\text { Aldehydes } \\
\text { and } \\
\text { Ketones }\end{array}$} & Benzaldehyde & + & & 97 & 94 \\
\hline & 2-chloro-1-phenyl-ethanone & & + & 87 & 90 \\
\hline & 2,3-dihydro-1H-Inden-1-one & + & & 78 & 77 \\
\hline & 1,2,3,4-tetrahydronaphthalen-1-one & + & & 72 & 76 \\
\hline & Diphenylmethanone & + & & 78 & 82 \\
\hline \multirow{11}{*}{ Phenols } & Phenol & + & & 87 & 82 \\
\hline & 3-methyl-Phenol & + & & 99 & 98 \\
\hline & 4-methyl-Phenol & + & & 100 & 94 \\
\hline & 2-ethyl-Phenol & + & & 72 & 74 \\
\hline & 3,5-dimethyl-Phenol & & + & 77 & 79 \\
\hline & 4-(1-methylethyl)-Phenol & & + & 73 & 70 \\
\hline & m-tert-butyl-Phenol & + & & 73 & 70 \\
\hline & p-tert-butyl-Phenol & & + & 87 & 85 \\
\hline & 2,4-di-tert-butyl-Phenol & + & & 96 & 89 \\
\hline & o-phenyl-Phenol & & + & 96 & 89 \\
\hline & Bis-4,4'-(1-methylethylidene)-Phenol & + & & 90 & 83 \\
\hline \multirow{13}{*}{$\begin{array}{l}\text { Substituted } \\
\text { benzenes and } \\
\text { benzene } \\
\text { derivatives }\end{array}$} & Methylbenzene & & + & 73 & 83 \\
\hline & 1-methyl-3-(1-methylethyl)-Benzene & & + & 83 & 87 \\
\hline & 1-methyl-3-propyl-Benzene & + & & 77 & 77 \\
\hline & 1-methoxy-4-(2-propenyl)-Benzene & & + & 91 & 85 \\
\hline & 4-methyl-1,2-diamino-Benzene & & + & 79 & 76 \\
\hline & Vanillin & + & & 86 & 80 \\
\hline & Benzoic acid & + & & 86 & 76 \\
\hline & 2,5-dimethyl-Benzoic acid & + & & 77 & 81 \\
\hline & 3,5-dimethyl-Benzoic acid & + & & 93 & 88 \\
\hline & p-tert-butyl-Benzoic acid & + & & 86 & 74 \\
\hline & Benzoic acid methyl ester & & + & 100 & 96 \\
\hline & Benzoic acid 4-methyl methyl ester & & + & 95 & 94 \\
\hline & Benzonitrile & + & & 73 & 73 \\
\hline \multirow{7}{*}{$\begin{array}{l}\text { Organic acids, } \\
\text { Esters and } \\
\text { Salts of } \\
\text { organic acids }\end{array}$} & 3-Phenylpropanoic acid & + & & 90 & 86 \\
\hline & Pentanoic acid & + & & 74 & 76 \\
\hline & Heptanoic acid & + & & 88 & 88 \\
\hline & Octanoic acid & + & & 88 & 86 \\
\hline & Nonanoic acid & + & & 92 & 88 \\
\hline & Decanoic acid & + & & 93 & 89 \\
\hline & Dodecanoic acid & + & & 97 & 94 \\
\hline
\end{tabular}


Table 1 (part 2): Cumulative and qualitative GC/MS profile of organic substances in the waste offset developer

\begin{tabular}{|l|l|c|c|c|c|}
\hline & Tertradecanoic acid & + & & 78 & 88 \\
\hline \multirow{5}{*}{} & Hexadecanoic acid & + & & 92 & 88 \\
\cline { 2 - 5 } & Octanoic methyl ester & & + & 95 & 92 \\
\cline { 2 - 5 } & Decanoic acid methyl ester & & + & 92 & 92 \\
\cline { 2 - 5 } & Dodecanoic acid methyl ester & & + & 96 & 93 \\
\cline { 2 - 5 } & Tetradecanoic acid methyl ester & & + & 98 & 94 \\
\cline { 2 - 5 } & Hexadecanoic acid methyl ester & + & & 98 & 91 \\
\cline { 2 - 5 } & 1-naphthyl methylcarbamate & + & & 91 & 70 \\
\cline { 2 - 6 } & $1(3 \mathrm{H})-$ Isobenzofuranone (lactone) & + & & 99 & 96 \\
\cline { 2 - 6 } & Phthalic anhydride & & + & 93 & 88 \\
\hline \multirow{5}{*}{ Terpenes } & N-butyl-1-Butanamine & + & & 100 & 98 \\
\cline { 2 - 6 } & Aniline & + & & 96 & 91 \\
\cline { 2 - 6 } & Diphenylamine & Camphor & + & 75 & 75 \\
\hline
\end{tabular}

By comparing the GC/MS profiles obtained by the I and II methods, it was found that the L/L extraction with methylene chloride (with 45 organic compounds) detected $47 \%$ more organic substances compared to the sequential L/L extraction (with 24 organic compounds). Also, bicyclic hydrocarbons, ethers, organic acids, some salts of organic acids, and terpene (camphor) were detected only by the L/L extraction with methylene chloride, while hydrocarbons and esters of organic acids were detected only in sequential $\mathrm{L} / \mathrm{L}$ extraction. It is concluded that the nature of the solvent determines the number and class of extracted organic compounds.

\section{CONCLUSIONS}

In case of a complex effluent such as the waste offset developer, in order to obtain a profile with a higher number of detected organic substances it is best to determine the cumulative GC/MS profile of both L/L extraction methods. The obtained cumulative GC/MS profiles show that almost 2 times more of the organic substances are detected by the $\mathrm{L} / \mathrm{L}$ extraction with methylene chloride compared to the sequential $\mathrm{L} / \mathrm{L}$ extraction. Thus, the extraction solvent determines the class of organic compounds that will be extracted from the offset effluent.

\section{ACKNOWLEDGMENTS}

This research (paper) has been supported by the Ministry of Education, Science and Technological Development through the project no. 451-03-68/2020-14/200156: "Innovative scientific and artistic research from the FTS (activity) domain".

\section{REFERENCES}

[1] Adamović, S.: "Electrocoagulation and Adsorption Treatments of Effluents in Offset Printing Graphic Processes", PhD thesis, University of Novi Sad, Faculty of Technical Sciences, Novi Sad, 2016.

[2] Adamović, S., Rajs, V., Mihailović, A., Lakatoš, R., Adamović, D.: "Characterization of the organic load of the waste fountain solution", Proceedings of 25th International Symposium on Analytical and Environmental Problems (ISAEP 2019: Szeged, Hungary, 2019), pages 453-457.

[3] Lin, B.-L., Hosomi, M., Murakami, A.: "Effects of high salinity and constituent organic compounds on treatment of photo-processing waste by a sulfur-oxidizing bacteria/granular activated carbon sludge system", Water Research, 36 (4), 1076-1083, 2002. doi: 10.1016/s0043-1354(01)00280-9.

[4] Mahovic Poljacek, S., Risovic, D., Cigula, T., Gojo, M.: “Application of electrochemical impedance spectroscopy in characterization of structural changes of printing plates", Journal of Solid State Electrochemistry, 16 (3), 1077-1089, 2012. doi: 10.1007/s10008-011-1490-9.

[5] Santos-Delgado, M.J., Crespo-Corral, E., Polo-Díez, L.M.: "Determination of herbicides in soil samples by gas chromatography: optimization by the simplex method", Talanta, 53 (2), 367-377, 2000. doi: 10.1016/s0039-9140(00)00498-7. 
[6] Vengris, T., Binkienè, R., Butkienè, R., Dikčius, A., Karitanas, R., Manusadžianas, L.: "Treatment of waste offset-printing developer with Fenton's reagent", Chemija, 18 (2), 1-6, 2007.

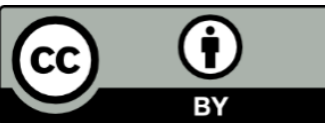

(C) 2020 Authors. Published by the University of Novi Sad, Faculty of Technical Sciences, Department of Graphic Engineering and Design. This article is an open access article distributed under the terms and conditions of the Creative Commons Attribution license 3.0 Serbia

(http://creativecommons.org/licenses/by/3.0/rs/). 



\title{
A MINI REVIEW: OPTIMAL DYE REMOVAL BY FENTON PROCESS CATALYSED WITH WASTE MATERIALS
}

\author{
Aleksandra Kulić Mandić ${ }^{1}$ (D), Milena Bečelić-Tomin ${ }^{1}$ (D), Đurđa Kerkez ${ }^{1}$ (D), \\ Gordana Pucar Milidrag ${ }^{1}$ (D), Vesna Pešić ${ }^{1}$ (D), Miljana Prica ${ }^{2}$ (i) \\ ${ }^{1}$ University of Novi Sad, Faculty of Sciences, Department of Chemistry, Biochemistry and \\ Environmental Protection, Novi Sad, Serbia \\ ${ }^{2}$ University of Novi Sad, Faculty of Technical Sciences, Department of Graphic Engineering and \\ Design, Novi Sad, Serbia
}

\begin{abstract}
Large quantities of solid waste from different industries are commonly disposed in landfills, where can generate wide range of environmental problems. Therefore, the aim of this paper is to give insight on the usage of various waste materials as oxidation catalysts in different Fenton processes for dye removal. In that manner the circular value chain of these materials will be reinforced, obtaining disposal cost reduction and further value addition. Some of industrial wastes (fly ash, electric arc furnace dust, red mud, coal bottom ash, activated carbon from biomass, etc.) that have been used to catalyse Fenton reaction in various researches are reviewed from optimization point of view. Both types of optimization, one-factor-at-a-time (OFAT) and response surface methodology (RSM) are investigated. The study revealed that factors as catalyst concentration, $\mathrm{pH}$ value, hydrogen peroxide concentration, dye concentration and reaction time are main factors that influence final Fenton capacity as oxidation process catalysed with reviewed waste materials.
\end{abstract}

Key words: Waste, Catalyst, Dye, Optimization, Fenton

\section{INTRODUCTION}

One of high demanding industries in terms of water and chemical usage is the textile industry. Only in wet process of cotton dying more than $100 \mathrm{~L}$ of water is spent per $\mathrm{kg}$ of textile. Also, unfixed dyes are a known problem in textile effluents, whose chemical structures widely differentiate (Kerkez et al, 2018; Kulić et al, 2018; Nasuha et al, 2017). Wastewater treatment is necessary to obtain an acceptable effluent quality for its discharge in the environment and thus contribute to industrial sustainability.

Worldwide legislation is forcing industries to treat wastewater to the level without any negative influence on the environment and aquatic organisms. Among biological and physicochemical treatments, Fenton process stands out between advanced oxidation processes as efficient in dye degradation (Rubeena et al, 2018; Becelic-Tomin et al, 2014). That does not exclude its use in the treatment of other toxic organic pollutants. The heterogeneous Fenton process is based on $\mathrm{H}_{2} \mathrm{O}_{2}$ reaction with $\mathrm{Fe}$ (or other transition metals) ions present on the catalyst surface, thus producing highly reactive species - hydroxyl radicals $(\bullet \mathrm{OH})$. Pollutants oxidation takes place through a chemical reaction with $\bullet \mathrm{OH}$ in an aqueous solution and on the catalyst surface, where chemisorption of $\bullet \mathbf{O H}$ and pollutants is possible (Drumm et al, 2019). Simplified heterogeneous Fenton reaction mechanism and the main environmental problem of the textile industry are illustrated in Figure 1. In order to mineralize dye molecules (inorganic degradation intermediates, $\mathrm{H}_{2} \mathrm{O}$ and $\mathrm{CO}_{2}$ ) optimization if often needed. Literature research points out to a few efficiency determining factors, such as $\mathrm{pH}$ value, initial oxidant concentration, catalyst concentration, dye concentration, reaction time and temperature (Grassi et al, 2020; Drumm et al, 2019). Their influence is commonly investigated through one-factor-at-a-time (OFAT) and response surface methodology (RSM). Differences between them will be further explained in the Methods section.

The number of materials used as a heterogeneous Fenton catalyst is high, and two main types are supported and non-supported materials. Different solids can be used as a support for active ions and generally those are: clays, zeolites, silica, activated carbon and biosorbents (Maleki Rizi et al, 2019; Zhou et al, 2015). Physicochemical treatment is often required for the dispersion of active ions on the support surface. While non-supported ones already have Fe and/or other transition metal species present on the surface. They can be used without any treatment, but also chemical and/or physical treatments may be implemented in order to improve overall catalyst activity. Typical examples are: red mud, pyrite ash/cinder, fly ash, blast furnace dust, electric arc furnace dust, coal bottom ash (Drumm et al, 2019; Nasuha et al, 2017; Becelic-Tomin et al, 2014). 
The main focus of this study is on solid wastes that can be used beneficially in a heterogeneous Fenton treatment of coloured wastewaters. Such application is an alternative to landfill disposal and promotes industrial symbiosis. Also, cost reduction of handling solid waste is reinforced and further value addition is boosted.

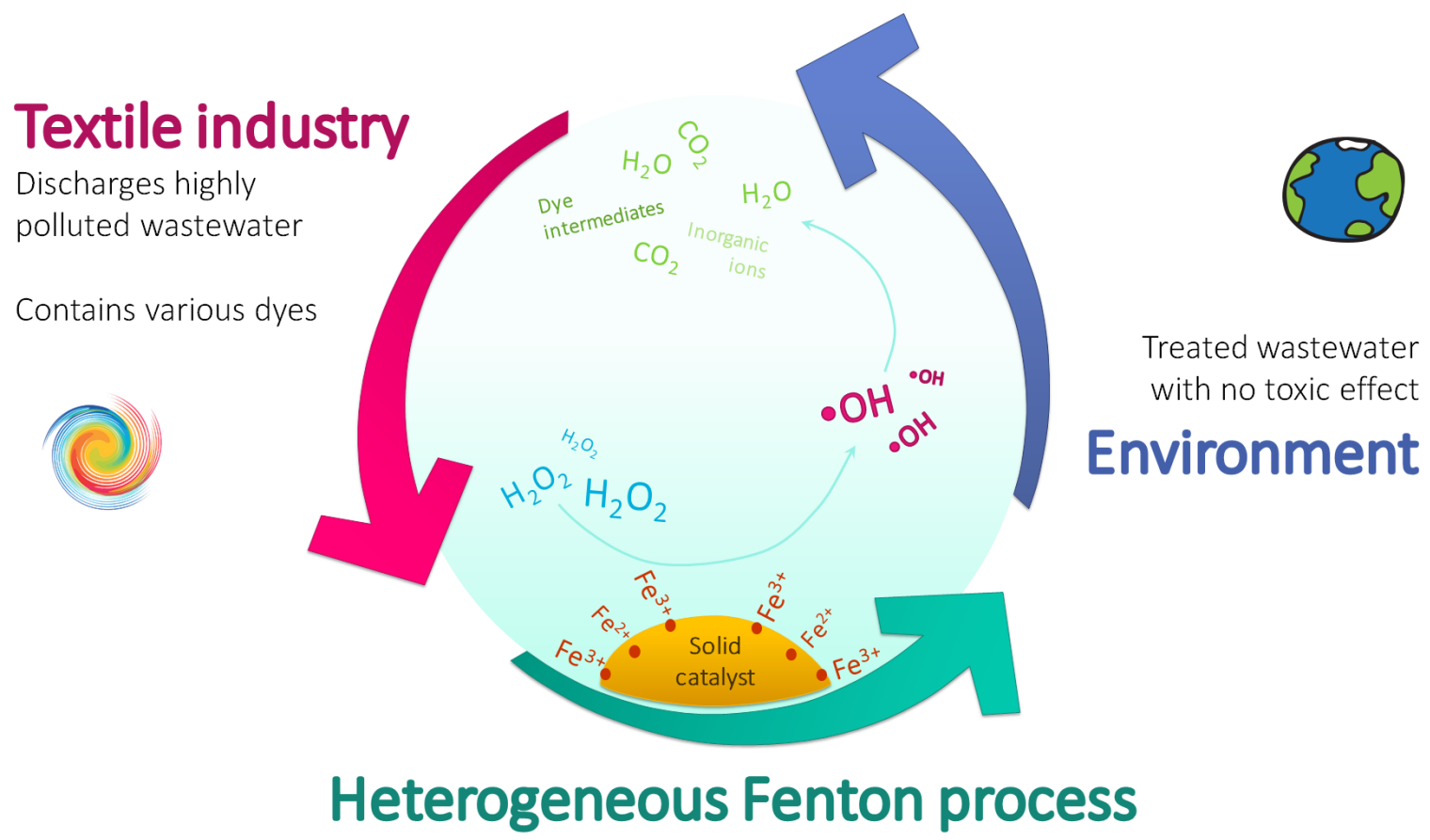

Figure 1: Illustrative depiction of textile industry main environmental problem and heterogeneous Fenton process mechanism for degradation of present dyes

\section{METHODS}

Optimization studies are based on screening experiments in order to determine which factors have the greatest (positive or negative) impact on Fenton process outcome (decolourization efficiency). The commonly used approach is OFAT, where one parameter influence is explored while all other significant process variables are kept constant (Karimifard and Moghaddam, 2018). This type of univariate analysis may suggest inadequate optimal conditions due to the narrow experimental domain.

Statistical design of experiments, on which RSM is based, has been recognized in recent years by researchers since interaction effects between parameters is easier to study and determine (Karimifard and Moghaddam, 2018). Some of the main advantages of using a multivariate approach are: (1) process is optimized with lesser number of experiment probes than in OFAT method, (2) understanding the wide experimental range of tested process parameters, (3) comparing and analysing factor interactions and nonlinear relationships with the response and (4) obtained data quality can be confirmed by statistical analysis. Thus, experiments are performed with less time, cost and physical consumption (Drumm et al, 2019; de Matos Vargas et al, 2019). Central composite design (CCD) and Box-Behnken (BBD) are widely used multi-factor optimization techniques, based on the fit of empirical models to the experimentally obtained data. A CCD has three groups of design points: (1) two-level factorial, (2) central points which present replicate terms, and they are used for estimation of experimental error and (3) axial or star points who are fixed axially and are used as quadratic terms (Grassi et al, 2020). A BBD has fewer points than CCD because star points are not included in this design. Both designs are used for fitting second order polynomial equations, by which it is possible to determine optimal Fenton reaction conditions (Karimifard and Moghaddam, 2018). Design Expert, Minitab and Statistica are commonly used softwares for data processing. Figure 2. presents visual differences in explored design space with OFAT and RSM methodology. 


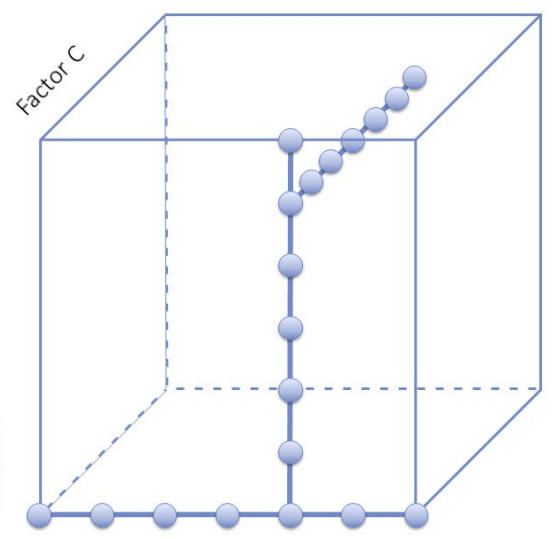

Factor A

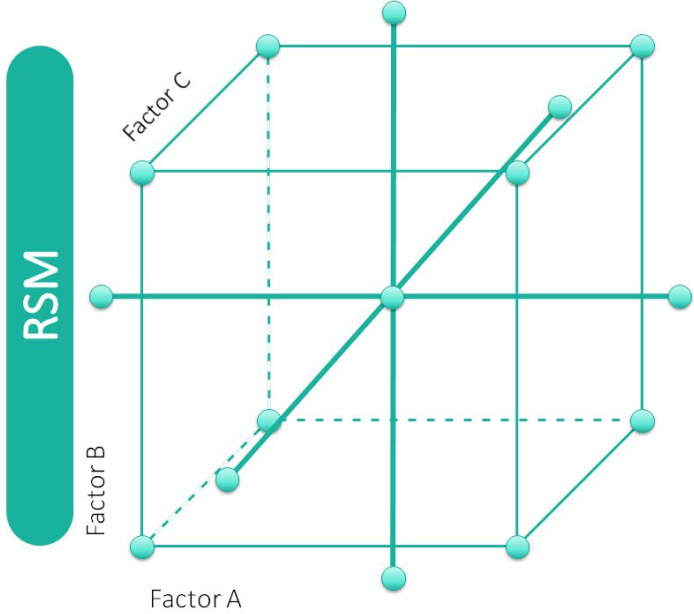

Factor A

Figure 2: Experiment design space explored by OFAT and RSM (CCD) approach

\section{RESULTS AND DISCUSSION}

The waste management focus is to control and decrease waste and non-wanted by-products generation, and also their recycling. General practices are waste collecting and sorting, if possible, materials are recovered. End-of-life practices imply waste reduction, thermal and biological processes and materials recycling techniques (Taelman et al, 2018; Natarajan and Ponnaiah, 2017; Rajput et al, 2016). In this paper, we will focus on possible waste recycling in textile wastewater treatment, thus supporting industrial symbiosis and environmental sustainability.

Firstly, researches based on OFAT methodology will be evaluated. Figure 3. presents results of selected papers of the heterogeneous Fenton process with foundry sand (Fe and steel metal casting), steel industry waste (Fe dust and furnace slag), fly ash (coal burning furnace), pyrite ash and cinder (pyrite roasting furnace), which were used without further modification. These wastes were applied for aqueous dye solutions and real textile effluent treatment. Rajput et al (2016) have investigated the removal of reactive, diazo dye $(100 \mathrm{mg} / \mathrm{L})$ in photo-Fenton process, catalysed with foundry sand and fly ash. Low initial $\mathrm{H}_{2} \mathrm{O}_{2}$ concentration and fly ash concentration were needed to significantly degrade dye molecules in short time. When comparing it with foundry sand (higher catalyst concentration and longer reaction period were required), fly ash showed great potential as photo-Fenton catalyst probably due to a higher Al content. Even though optimization of all process parameters was not conducted in Oliveira et al (2011) research, $90 \%$ of indigo carmine dye decolourization was achieved with foundry waste sand as a heterogeneous catalyst. Similarly, the reaction was slower, with higher catalyst and oxidant concentration demand. Other reaction conditions were: $\mathrm{pH}=6,50 \mathrm{mg}$ dye/L and $210 \mathrm{~min}$. In the heterogeneous Fenton reaction, steel industry waste was efficient in azo dye removal $(20 \mathrm{mg} / \mathrm{L})$ with low catalyst loading and short reaction, but with high oxidant concentration $(34 \mathrm{mM})$. The advantage of using this waste catalyst is magnetic properties and easier removal from aqueous phase (Ali et al, 2013). Becelic-Tomin et al (2014) achieved complete decolourization of reactive, anthraquinone dye with pyrite ash as catalyst. Acidic Fenton conditions lead to high solubilisation of present heavy metals as $\mathrm{Pb}, \mathrm{Cu}$ and $\mathrm{Zn}$, where additional step after heterogeneous treatment for their removal was needed. Likewise, obtained removal of six dyes mixture $(702 \mathrm{mg} / \mathrm{L}$ ) was satisfactory, but $\mathrm{Pb}, \mathrm{Cu}, \mathrm{Cr}$ and $\mathrm{Cd}$ were leached from a pyrite cinder surface after real textile effluent treatment (Kerkez et al, 2018).

Besides solids without pre-treatment some waste materials should be modified prior Fenton reaction. Activated carbons produced from agricultural waste (biochars) are commonly impregnated with active ions (Fe). Rubeena et al (2018) prepared two biochars (rice husk and coir pith) and impregnated them with $\mathrm{Fe}\left(\mathrm{NO}_{3}\right)_{3}$ for Acid Red 1 dye $(50 \mathrm{mg} / \mathrm{L})$ decolourization. With impregnated rice husk biochar $98 \%$ removal was achieved at $\mathrm{pH} 3$ with $5 \mathrm{~g}$ catalyst/L and $16 \mathrm{mM} \mathrm{H}_{2} \mathrm{O}_{2}$. On the other hand, with coir pith biochar $99 \%$ degradation was obtained at $\mathrm{pH} 3$ with $4 \mathrm{~g}$ catalyst/L and $16 \mathrm{mM}$ oxidant. Both prepared materials showed high stability and activity in 4 successive cycles. Incipient wet impregnation was implemented for paper mill sludge modification (Zhou et al, 2015) to produce stable and active catalyst for Methylene Blue (50 mg/L) degradation. $94 \%$ dye removal was obtained at $\mathrm{pH} 4$ with $1 \mathrm{~g}$ catalyst/L and $2 \mathrm{ml} / \mathrm{L}$ of $3 \% \mathrm{H}_{2} \mathrm{O}_{2}$. Also, red mud (from aluminium production) can be further improved by controlled 
reduction with $\mathrm{H}_{2}$ to produce active Fe phases (Costa et al, 2010). They only gave insight in Methylene Blue $(100 \mathrm{mg} / \mathrm{L})$ decolourization (the optimization study was not carried out), where 65\% dye was removed at $\mathrm{pH}=6$ with $3 \mathrm{~g}$ red mud/ $\mathrm{L}$ and $300 \mathrm{mM} \mathrm{H}_{2} \mathrm{O}_{2}$.

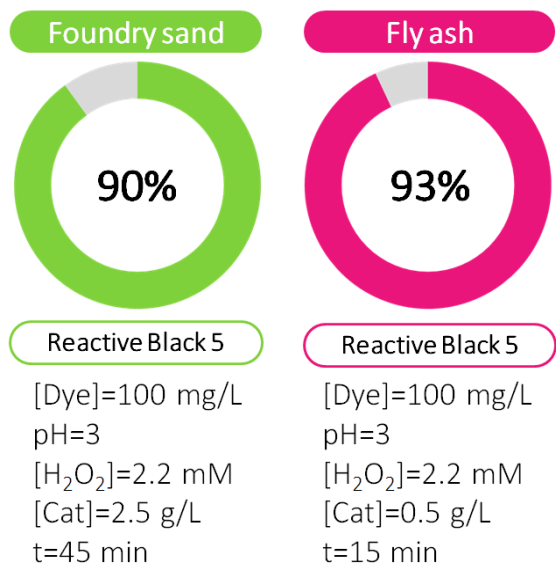

Rajput et al., 2016

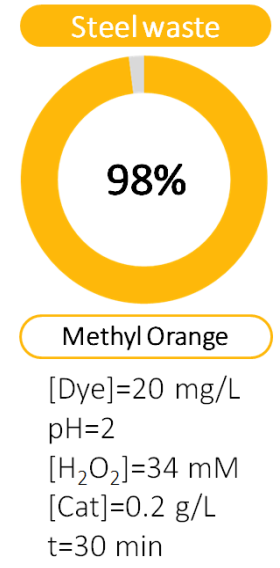

Ali et al., 2013

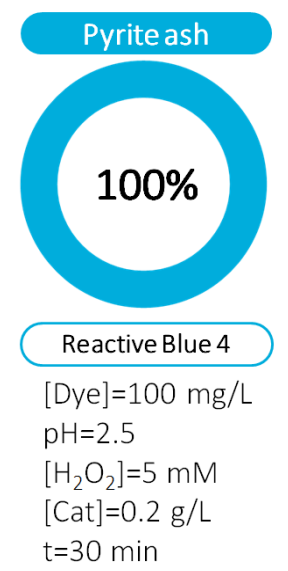

Becelic-Tomin et al., 2014

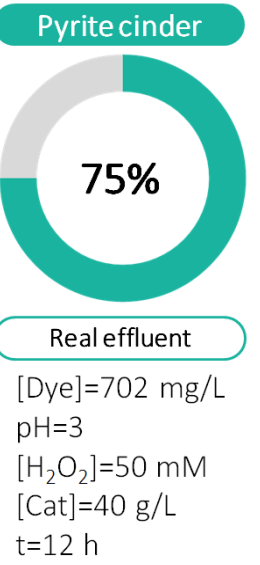

Kerkez et al., 2018

Figure 3: OFAT optimal conditions achieved with industrial waste catalysed Fenton process

Further, review of RSM based researches was conducted and selected papers are shown in Figure 4. Depicted results are obtained after CCD experiment design with various waste catalysts (coal burning bottom ash, lithium-ion batteries cathodes, sewage sludge, electric arc furnace dust and red mud). 91\% of chosen azo dye was degraded in photo-Fenton process catalysed with coal bottom ash (rich in $\mathrm{Al}_{2} \mathrm{O}_{3}$ and $\mathrm{SiO}_{2}$ ). This material is commonly disposed in abandoned mines or landfills with no commercial value (Drumm et al, 2019). Another catalyst was implemented in the de Matos Vargas et al (2019) work, which was produced from discarded mobile phone lithium-ion batteries. Namely, present cathodes are made from lithium cobalt oxide $\left(\mathrm{LiCOO}_{2}\right)$. After drying, solid residue was used in a heterogeneous Fenton process. Solution $\mathrm{pH}$ was not determined nor observed during treatment. When comparing it to other waste catalysts, high amount of oxidant $(1710 \mathrm{mM})$ was needed to decolorize low concentration of thiazine dye solution $(6 \mathrm{mg} / \mathrm{L}$ ). General residue of municipal wastewater treatment plant is sewage sludge abundant in Fe and Al after flocculation step in water purification (Grassi et al, 2020; Kong et al, 2016). Thermal treatment of Al-rich sludge was conducted in Grassi et al (2020) research, where mesoporous catalyst with $\mathrm{Al}_{2} \mathrm{O}_{3}$ and $\mathrm{Fe}_{2} \mathrm{O}_{3}$ active sites was formed. This material was used in fast (30 min) photo-Fenton treatment of azo dye (Amaranth) in acidic medium with low oxidant and catalyst demand. For comparison, Kong et al (2016) have treated Fe-rich sludge in carbothermal process in order to produce nano-flake catalyst for the heterogeneous Fenton reaction. Process optimization was conducted with OFAT methodology where $98 \%$ of Acid Orange II, azo dye, was removed after $30 \mathrm{~min}$ at $\mathrm{pH}=8$ with relatively higher Fenton reactants need $\left(2 \mathrm{~g}\right.$ catalyst/L and $17 \mathrm{mM} \mathrm{H}_{2} \mathrm{O}_{2}$ ). Also, investigation of Co impregnation of electric arc furnace dust and its use in the heterogeneous Fenton reaction was described in Maleki Rizi et al (2019). Complete decolourization of Methylene Blue was achieved with high catalyst load $(4 \mathrm{~g} / \mathrm{L})$ and low oxidant application $(0.5 \mathrm{mM})$. In contrast, 94\% of Methylene Blue was removed with $\mathrm{NaOH}$ activated electric arc furnace slag, used in photo-Fenton process (Nasuha et al, 2017). Optimal OFAT conditions were: $180 \mathrm{~min}, \mathrm{pH}=3,1 \mathrm{~g}$ catalyst/L and $20 \mathrm{mM} \mathrm{H}_{2} \mathrm{O}_{2}$. Real effluent from textile industry was decolorized with waste red mud (thermally treated) in Kulić et al (2018). Structure and concentration of present dyes were not indicated, but $80 \%$ heterogeneous Fenton process efficiency was achieved after 180 min with $1 \mathrm{~g} / \mathrm{L}$ of red mud in acidic medium. In Natarajan and Ponnaiah (2017) work red mud was used to extract $\mathrm{Fe}(\mathrm{II})$ oxalate and is further used to produce nanoparticles in reaction with black plum leaves extract. The nano-catalyst was used in BBD optimization of Reactive Blue 235 dye removal by Fenton process. $98 \%$ dye removal $\left(10 \mathrm{mg} / \mathrm{L}\right.$ ) was obtained with $1.5 \mathrm{~g}$ catalyst/L, $23 \% \mathrm{H}_{2} \mathrm{O}_{2}, 239$ min, while $\mathrm{pH}$ value was not indicated. Likewise, Kerkez et al (2017) prepared oak leaves nano zero valent Fe (nZVI) to treat three different dyes (Reactive Red 120, Reactive Blue 4 and Brilliant Blue R). Optimization of Fenton process parameters was conducted according to BBD. 99\% removal of reactive dyes (50 mg/L) was achieved with $0.4 \mathrm{~g} \mathrm{nZVI} / \mathrm{L}, \mathrm{pH}=2,9.9$ and $2.3 \mathrm{mM} \mathrm{H}_{2} \mathrm{O}_{2}$ for Reactive Red 120 and Reactive Blue 4 respectively. While $75 \%$ decolourization of Brilliant Blue $\mathrm{R}$ dye was obtained with same dye and catalyst concentration, $\mathrm{pH}$ value and with $10 \mathrm{mM} \mathrm{H}_{2} \mathrm{O}_{2}$. 


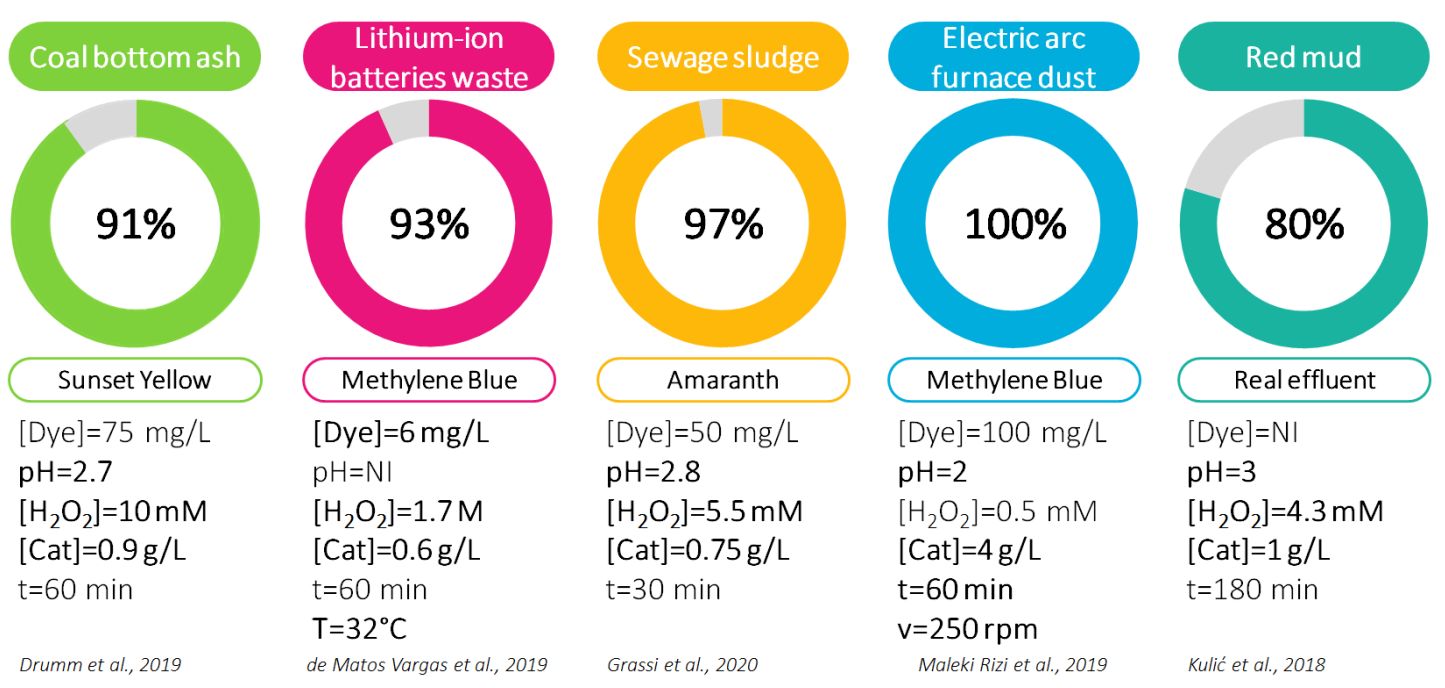

Figure 4: RSM optimal conditions achieved with industrial waste catalysed Fenton process; *NI-not indicated

\section{CONCLUSION}

The aim of this mini review is to give insight on the various waste materials use as Fenton reaction catalysts for dye removal. Published researches were selected based on applied optimization methods for evaluating main process parameters influence. It was revealed that catalyst concentration, oxidant concentration, $\mathrm{pH}$ value, dye concentration and reaction time are main factors that influence final decolourization efficiency. In this study fly ash, foundry sand, pyrite ash, steel industry waste, coal bottom ash, red mud, sewage sludge was covered as potential catalysts with thermal or without modification. While paper mill sludge, activated biochars and electric arc furnace dust were used after chemical modification in Fenton oxidation. Reported materials showed great potential from a decolourization efficiency point of view, thus reinforcing their value addition and possible future industrial symbiosis. But, in order to obtain fully sustainable waste management, further stability (leaching) studies of waste catalysts has to be done.

\section{ACKNOWLEDGEMENTS}

The authors acknowledge the financial support of the Science Fund of the Republic of Serbia for the Program for excellent projects of young researchers (PROMIS) - WasteWaterForce project (6066881) and the Ministry of Education, Science and Technological Development through the project No. 451-0368/2020-14/200156: "Innovative scientific and artistic research from the FTS (activity) domain".

\section{REFERENCES}

[1] Ali, M.-M., Gad-Allah, T.A., Badawy, M.I.: "Heterogeneous Fenton process using steel industry wastes for methyl orange degradation", Applied Water Science 3, 363-270, 2013. doi: 10.1007/s13201-013-0078-1.

[2] Becelic-Tomin, M., Dalmacija, B., Rajic, Lj., Tomasevic, D., Kerkez, Dj., Watson, M., Prica, M.: "Degradation of Anthraquinone Dye Reactive Blue 4 in Pyrite Ash Catalyzed Fenton Reaction", The Scientific World Journal 234654, 8, 2014. doi: 10.1155/2014/234654.

[3] Costa, R-C., Moura, F.-C., Oliveira, P.-F., Magalhães, F., Ardisson, J.D., Lago, R.M.: "Controlled reduction of red mud waste to produce active systems for environmental applications: Heterogeneous Fenton reaction and reduction of $\mathrm{Cr}(\mathrm{VI})^{\prime \prime}$, Chemosphere 78, 1116-1120, 2010. doi: 10.1016/j.chemosphere.2009.12.032.

[4] de Matos Vargas, A.M., da Silva Santos, C., Cagliari, J.V., Rossi, A.: "Multivariate optimization of the degradation conditions of methylene blue using a catalyst recovered from electronic waste", Journal of Environmental Chemical Engineering 7, 103191, 2019. doi: 10.1016/j.jece.2019.103191. 
[5] Drumm, F.C., Grassi, P., Sulkovski, A.A., Pfingsten Franco, D.S., Georgin, J., Dotto, G.L., Foletto, E.L., Jahn, S.L.: "Applicability of Coal Bottom Ash from Thermoelectric Power Plant as an Alternative Heterogeneous Catalyst in Photo-Fenton Reaction", Water, Air \& Soil Pollution 230, 274, 2019. doi: 10.1007/s11270-019-4327-2.

[6] Grassi, P., Drumm, F.C., Georgin, J., Pfingsten Franco, D.S., Foletto, E.L., Dotto, G.L., Jahn, S.L.: "Water treatment plant sludge as iron source to catalyze a heterogeneous photo-Fenton reaction", Environmental Technology \& Innovation 17, 100544, 2020. doi: 10.1016/j.eti.2019.100544.

[7] Karimifard, S., Moghaddam, M.-A.: "Application of response surface methodology in physicochemical removal of dyes from wastewater: A critical review", Science of the Total Environment 640-641, 772-797, 2018. doi: 10.1016/j.scitotenv.2018.05.355.

[8] Kerkez, Đ., Bečelić-Tomin, M., Kulić, A., Tomašević Pilipović, D., Leovac Maćerak, A., Dalmacija, B., Prica, M.: "Treatment of wastewater containing dye mixture using pyrite cinder in heterogeneous Fenton process", Proceedings of $9^{\text {th }}$ International Symposium on Graphic Engineering and Design 2018, (GRID: Novi Sad, SRB, 2018), pages 169-173.

[9] Kerkez, Dj., Becelic-Tomin, M., Tomasevic Pilipovic, D., Prica, M., Kulic, A., Dalmacija, B., Watson, M.: "Usage of green synthesized nZVI for degradation of three different dye molecules", Proceedings of $15^{\text {th }}$ International Conference on Environmental Science and Technology 2017, (CEST: Rhodes, GRE, 2017), pages 00983.

[10] Kong, L., Zhu, Y., Liu, M., Chang, X., Xiong, Y., Chen, D.: "Conversion of Fe-rich waste sludge into nano-flake Fe-SC hybrid Fenton-like catalyst for degradation of AOII", Environmental Pollution 216, 568-574, 2016. doi: 10.1016/j.envpol.2016.06.012.

[11] Kulić, A., Bečelić-Tomin, M., Kerkez, Đ., Pucar Milidrag, G., Kecić, V., Prica, M.: "Examination of the application possibilities of waste red mud in treatment of colored effluent", Proceedings of $9^{\text {th }}$ International Symposium on Graphic Engineering and Design 2018, (GRID: Novi Sad, Serbia, 2018), pages 175-180.

[12] Maleki Rizi, M.H., Alizadeh, M., Khanlarkhani, A., Martinez Huerta, M.V.: "The role of cobalt and copper nanoparticles on performance of magnetite-rich waste material in Fenton reaction", International Journal of Environmental Science and Technology 16, 373-382, 2019. doi: 10.1007/s13762-017-1579-5.

[13] Nasuha, N., Ismail, S., Hameed, B.H.: "Activated electric arc furnace slag as an effective and reusable Fenton-like catalyst for the photodegradation of methylene blue and acid blue 29", Journal of Environmental Management 196, 323-329, 2017. doi: 10.1016/j.jenvman.2017.02.070.

[14] Natarajan, E., Ponnaiah, G.P.: “Optimization of process parameters for the decolorization of Reactive Blue 235 dye by barium alginate immobilized iron nanoparticles synthesized from aluminum industry waste", Environmental Nanotechnology, Monitoring \& Management 7, 73-88, 2017. doi: 10.1016/j.enmm.2017.01.002.

[15] Oliveira, P.-F., Oliveira, L.D., Ardisson, J.D., Lago, R.M.: "Potential of modified iron-rich foundry waste for environmental applications: Fenton reaction and $\mathrm{Cr}(\mathrm{VI})$ reduction", Journal of Hazardous Materials 194, 393-398, 2011. doi: 10.1016/j.jhazmat.2011.08.002.

[16] Rajput, H., Verma, A., Kaur, M., Kaur, T., Toor, A.P.: “Heterogeneous solar photo-Fenton degradation of Reactive Black 5 using foundry sand and fly ash: value addition to waste", Journal of Environmental Engineering and Landscape Management 24(01), 124-132, 2016. doi: 10.3846/16486897.2015.1109517.

[17] Rubeena, K.K., Prasad Reddy, P.H., Laiju, A.R., Nidheesh, P.V.: "Iron impregnated biochars as heterogeneous Fenton catalyst for the degradation of acid red 1 dye", Journal of Environmental Management 226, 320-328, 2018. doi: 10.1016/j.jenvman.2018.08.055.

[18] Taelman, S.E., Tonini, D., Wandl, A., Dewulf, J.: “A Holistic Sustainability Framework for Waste Management in European Cities: Concept Develpoment", Sustainability 10, 2184, 2018. doi: 10.3390/su10072184.

[19] Zhou, G., Chen, Z., Fang, F., He, Y., Sun, H., Shi, H.: "Fenton-like degradation of Methylene Blue using paper mill sludge-derived magnetically separable heterogeneous catalyst: Characterization and mechanism", Journal of Environmental Sciences 35, 20-26, 2015. doi: 10.1016/j.jes.2015.01.026 


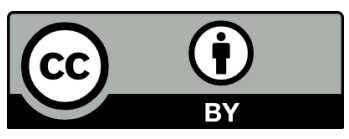

(C) 2020 Authors. Published by the University of Novi Sad, Faculty of Technical Sciences, Department of Graphic Engineering and Design. This article is an open access article distributed under the terms and conditions of the Creative Commons Attribution license 3.0 Serbia

(http://creativecommons.org/licenses/by/3.0/rs/). 



\title{
PASTA PACKAGING WITH BIO-BASED BARRIER TO PREVENT INSECT INFESTATION
}

\author{
Urška Vrabič Brodnjak ${ }^{1}$ (D), Pasquale Trematerra ${ }^{2}$ (D) \\ ${ }^{1}$ University of Ljubljana, Faculty of Natural Sciences and Engineering, Department of Textiles, \\ Graphic Arts and Design, Ljubljana, Slovenia \\ ${ }^{2}$ University of Molise, Department of Agricultural, Environmental and Food Sciences, \\ Campobasso, Italy
}

\begin{abstract}
The results of the infestation by maize weevil, Sitophilus zeamais (Coleoptera, Curculionidae) in various packages filled with pasta are presented. Three different types of packaging were used, i.e. two paper tubes (a novel one laminated with bio-based polyethylene and one without lamination) and a commercially available polypropylene pillow pouch packaging. Material properties such as moisture and water resistance and compressive strength were analysed. The results obtained showed that adult maize weevils revealed significant preferences to penetrate the pasta packaging through the already existing holes that were present in the polypropylene packaging, whereas no infestation was observed inside the paper tube packaging. The study showed that the shape and construction, e.g. tube packaging with an innovative bio-polyethylene film, is very effective against insect infestation and mechanical overload.
\end{abstract}

Key words: bio based polymer, S. zeamais, properties, paper tube, pillow pouch

\section{INTRODUCTION}

Recently, many researches have demonstrated that biodegradable plastic mixtures could be produced with certain limitations (Ramos et al, 2018; Yousefi et al, 2016; Hayes et al, 2019). Furthermore, postconsumer management and recyclability must be carefully managed. Biobased polyethylene (bio- PE) is presented as a suitable substitute due to its superior barrier properties (reduced permeability to $\mathrm{O} 2, \mathrm{CO} 2$ and water) and its higher heat resistance than polyethylene (PE) (Hayes et al, 2019; Briassoulis and Giannoulis, 2018; Luzi et al, 2019). Therefore, bio- PE has been frequently investigated in recent years (Ramos et al, 2018; Bandyopadhyay et al, 2019, Helanto et al, 2019). The production of bio- PE is mainly based on sugar cane, which is produced by chemical synthesis from renewable, biologically derived monomers (Ojha and Kapoor, 2018; Regubalan et al, 2019).

A major disadvantage of the existing packaging material is that insects infest the packaged food by penetrating it. Insect infestation depends on the pest species, exposure time, food, packaging material and prevailing environmental conditions. The solution to prevent infestation could be to use resistant laminated packaging that is both environmentally friendly and recyclable. Several insect species can infest pasta factories, which can have negative economic and commercial consequences. Infestation may occur during the storage process in production facilities, warehouses, general stores and retail outlets already colonised by insects derived from other products. Three species, i.e. S. zeamais Motschulsky, S. oryzae (L.) and S. granarius (L.) (Coleoptera Curculionidae), are most probably the most widespread and destructive primary pests of stored cereals. Pasta in particular can be infested by the corn weevil, S. zeamais, during transport in trucks, railway waggons and ships, and during storage at retail level or even in the consumer's home (Trematerra, 2009; Trematerra and Savoldelli, 2014; Stejskal et al, 2017). Adult corn beetles enter commercial pasta packaging through the openings made by other insects or through the existing openings caused by poor sealing or mechanical damage (Trematerra, 2009; Trematerra and Savoldelli, 2014; Stejskal et al, 2017). Most foods available on the market are packaged in a way that prevents infestation, although insect contamination is still common (Mullen et al, 2012; Heeps, 2016; Riudavets et al, 2018). Resistant and sealed packaging can be used to prevent infestation. Paper and cardboard packaging are the most common materials and are generally considered the most susceptible to insect infestation (Trematerra and Savoldelli, 2014). The widespread use of these susceptible food packaging materials should be carefully considered, as losses due to insect infestation in packaged food may be equivalent to the costs of cultivation, harvesting, transport, processing and packaging (Mullen et al, 2012; Heeps, 2016).

The aim of our work was to evaluate different packaging and to consider the possibility of using this packaging to better protect the food, in our case pasta, from insect attack. 


\section{MATERIALS AND METHODS}

\subsection{Materials}

\subsubsection{Packaging}

In this research, three different types of packaging were used: two unprinted paper tubes with and without a barrier film, and one commercial polypropylene packaging as presented in Table 1.

Table 1: Packaging characteristics

\begin{tabular}{|l|l|l|l|l|}
\hline Sample & Packaging & $\begin{array}{l}\text { Material } \\
\text { - outer base }\end{array}$ & $\begin{array}{l}\text { Material } \\
- \text { inner barrier }\end{array}$ & $\begin{array}{l}\text { Package dimension } \\
\text { [mm] }\end{array}$ \\
\hline $\begin{array}{l}\text { Sample A } \\
\text { not laminated }\end{array}$ & Paper tube & $\begin{array}{l}\text { Recycled kraft paper; } \\
\text { unprinted }\end{array}$ & $\begin{array}{l}\text { Recycled } \\
\text { kraft paper }\end{array}$ & $275.0 \times 65.7^{\text {a }}$ \\
\hline $\begin{array}{l}\text { Sample B } \\
\text { laminated }\end{array}$ & Paper tube & $\begin{array}{l}\text { Recycled kraft paper; } \\
\text { unprinted }\end{array}$ & $\begin{array}{l}\text { Laminated paper with bio- } \\
\text { Re film }\end{array}$ & $275.0 \times 65.7^{\text {a }}$ \\
\hline $\begin{array}{l}\text { Sample C } \\
\text { foil }\end{array}$ & $\begin{array}{l}\text { Plastic pillow pouch } \\
\text { with gussets and fin } \\
\text { seal }\end{array}$ & Polypropylene & No & $95 \times 304^{\text {b }}$ \\
\hline
\end{tabular}

a Length $\times$ diameter $(\varnothing)$ for paper tube packaging.

b Width $\times$ length for pouches, within the seals.

\subsubsection{Pasta products and olfactometer arena}

Pasta packages of durum wheat commercial spaghetti sample of 500 g, called "Spaghetti Ristorante 8" (produced by F. Divella S.p.A., Rutigliano, Bari, Italy) were used in the tests. The following nutritional information (average values) for $100 \mathrm{~g}$ was reported in the packages: energy $1508 \mathrm{KJ}$ (355 kcal), fats $1.7 \mathrm{~g}$ (of which saturated fats $0.9 \mathrm{~g}$ ), carbohydrates $72.0 \mathrm{~g}$ (of which sugars $3.9 \mathrm{~g}$ ), proteins $13.0 \mathrm{~g}$, salt $0.004 \mathrm{~g}$ (equivalent to sodium $1.6 \mathrm{mg}$ ). The tests were performed using 20 rectangular olfactometer arenas (each $30 \mathrm{~cm}$ wide, $40 \mathrm{~cm}$ long and $10 \mathrm{~cm}$ high). The tests were conducted at the temperature of $27 \pm 1^{\circ} \mathrm{C}$ with the relative humidity $(\mathrm{RH})$ of $70 \pm 5 \%$ and in dark conditions.

\subsection{Methods}

\subsubsection{Moisture content, water absorptiveness (Cobb value), capillary rise (Klemm method) and water} vapour transmission rate (WVTR)

Each paper tube packaging was tested for moisture content in accordance with ISO 287 at $105 \pm 1{ }^{\circ} \mathrm{C}$ and the results were expressed in percentage.

Water absorptiveness (Cobb60 value, $\mathrm{g} / \mathrm{m}^{2}$ ) was determined as described in the standard method ISO 535. Capillary rise was determined as described in ISO 8787 (ISO 8787: Paper and board -Determination of capillary rise - Klemm method).

Water vapour transmission rate (WVTR) was determined as described in the ISO 2528 standard method (ISO 2528: Determination of water vapour transmission rate (WVTR) - Gravimetric (dish) method).

\subsubsection{Compressive strength}

Compressive strength of paper tubes was determined with a pressurised plate, at which failure was determined. The test was performed on a tensile testing machine with the plate speed of $13 \mathrm{~mm} / \mathrm{min}$, standard atmosphere $23 \pm 1{ }^{\circ} \mathrm{C}$ and $50 \pm 2 \% \mathrm{RH}$. For each sample, five replicas were done as described in the ISO 12192:2011 standard. 


\subsubsection{Insect trials}

Unsexed, mixed-age, 1-2 week old adults obtained from the population of S. zeamais reared in a laboratory on durum wheat, with no history of exposure to insecticides, were used in all tests. This population was reared under the conditions of $27 \pm 1{ }^{\circ} \mathrm{C}$ and $70 \pm 5 \% \mathrm{RH}$. In each test, 50 S. zeamais adults were used. The experimental plan duration was 30 days.

Four different trial series were organised in arenas:

Trial 1: Sample A with $500 \mathrm{~g}$ of spaghetti inside +50 adults of S. zeamais.

Trial 2: Sample B with $500 \mathrm{~g}$ of spaghetti inside +50 adults of S. zeamais.

Trial 3: Sample A with $500 \mathrm{~g}$ of spaghetti inside + Sample $C+50$ adults of S. zeamais.

Trial 4: Sample B with $500 \mathrm{~g}$ of Spaghetti inside + Sample $C+50$ adults of S. zeamais.

Each trial was replicated 5 times (trial series), using a total of 1000 adults of S. zeamais (Figure 1). After 50 days, the adults that were outside were counted and the pasta packages were carefully examined, using a stereo microscope to check for the presence of both mechanical holes and holes due to the activity of insects. All packages were then opened and the adults inside the packages were counted.

\section{RESULTS AND DISCUSSION}

The permeation of water vapour through the packaging material influences the growth of microorganisms in food and damages the packaging material within a certain time. When selecting suitable materials for food packaging, it is important to analyze the moisture properties as shown in Table 2.

Table 2: Results of moisture properties of sample packaging

\begin{tabular}{|c|c|c|c|c|}
\hline Sample & $\begin{array}{c}\text { Moisture } \\
\text { content } \\
{[\%]}\end{array}$ & $\begin{array}{c}\text { Cobb } \\
\text { value } \\
{\left[\mathrm{g} / \mathrm{m}^{2}\right]}\end{array}$ & $\begin{array}{c}\text { Capillary } \\
\text { rise } \\
{[\mathrm{mm}]}\end{array}$ & $\begin{array}{c}\text { WVTR } \\
{\left[\mathrm{g} / \mathrm{m}^{2} \cdot \mathrm{day}\right]}\end{array}$ \\
\hline $\begin{array}{c}\text { Sample A } \\
\text { not } \\
\text { laminated }\end{array}$ & 10.1 & 2.15 & 54.2 & 3.52 \\
\hline $\begin{array}{c}\text { Sample B } \\
\text { laminated }\end{array}$ & 8.9 & 1.95 & 34.6 & 2.34 \\
\hline $\begin{array}{c}\text { Sample C } \\
\text { foil }\end{array}$ & 0.2 & 0.00 & 0.00 & 0.004 \\
\hline
\end{tabular}

It is necessary to consider the material's ability to absorb water (Cobb value), the amount of water vapour transmission rate (WVTR) transmitted through a unit area in time under a given temperature and relative humidity. Certain methods, such as capillary rise, help to determine where liquid, in our case water, rises by capillary action in a vertical strip of paper, cardboard. The results in Table 2 show that the PE film (sample C) has excellent resistance to water. On the other hand, the packaging of paper tubes with biofilm PE showed improved water resistance, especially with an average capillary rise of $19.6 \mathrm{~mm}$ compared to the non-laminated sample. The same trend could be observed for water vapour, where a decrease in transmission through the material by $1.18 \mathrm{~g} / \mathrm{m}^{2}$.day was observed. It is known that when paper comes into contact with water, hydrogen bonds between the fibers are broken and replaced by water bridge bonds. To protect fibre-fibre bonds and improve wet strength, lamination of board is one of the solutions. Laminations of bio- PE enhanced the moisture properties and mechanical properties shown below. 
Table 3: Results of tear and compressive strength of paper tube packaging

\begin{tabular}{|l|c|c|c|}
\hline Sample & $\begin{array}{c}\text { Tear strength } \\
{[\mathrm{mN}]}\end{array}$ & $\begin{array}{c}\text { Compressive } \\
\text { strength } \\
{[\mathrm{MPa}]}\end{array}$ & $\begin{array}{c}\text { Axial Young's } \\
\text { modulus } \\
{[\mathrm{GPa}]}\end{array}$ \\
\hline $\begin{array}{l}\text { Sample A } \\
\text { not laminated }\end{array}$ & 2100 & 10.13 & 2.07 \\
\hline $\begin{array}{l}\text { Sample B } \\
\text { laminated }\end{array}$ & 2300 & 11.75 & 2.47 \\
\hline
\end{tabular}

The compressive strength of the carton packaging depends on several factors, e.g. the weight of the carton and its contents, storage conditions, duration and transport conditions (stacking pattern, safety factor). The sample A achieved the tear strength of $2100 \mathrm{mN}$ and sample B $2300 \mathrm{mN}$.

The average compressive strength at the laminated paper tube was $16 \%$ higher. When exposed to the axial modulus of elasticity, it was also $2 \%$ higher on the laminated tube. This confirms that the packaging produced with spiral winding is durable and stable. If it is additionally laminated, the inner part is included and stability is increased (Figure 1).

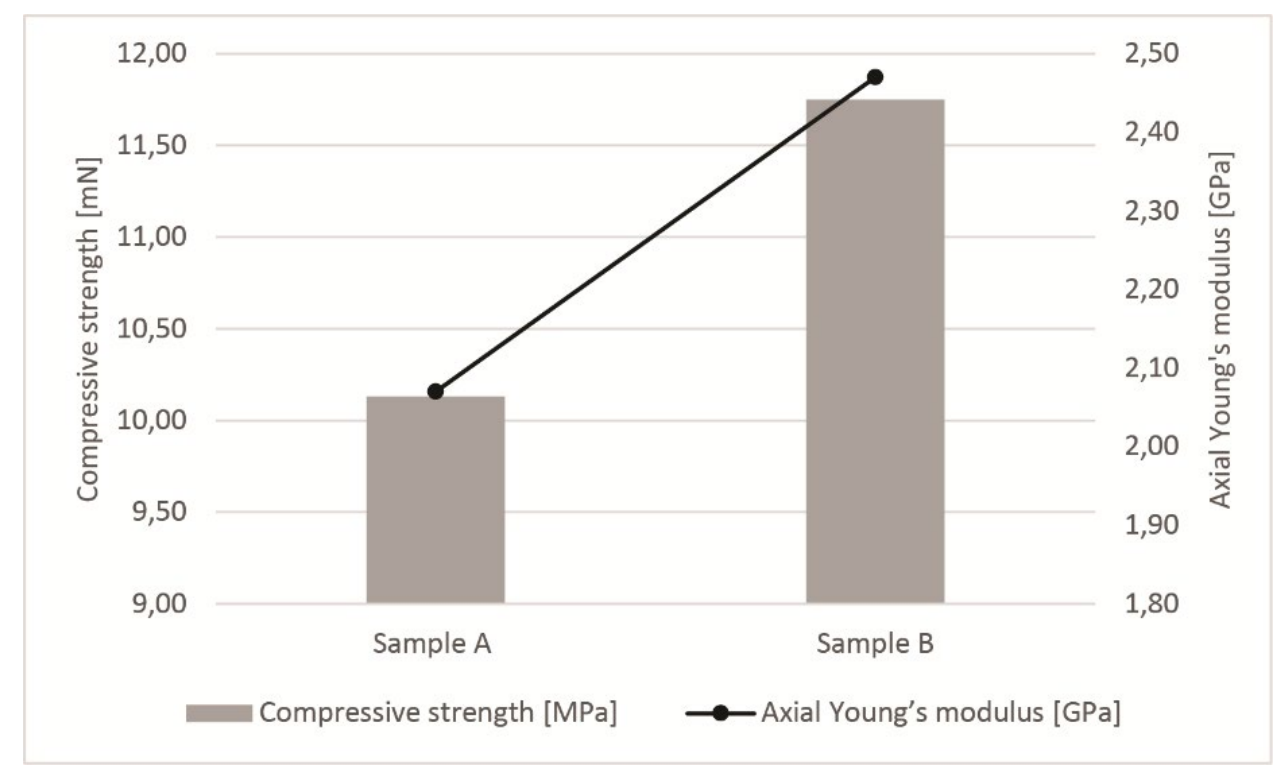

Figure 1: Compressive strength and Axial Young's modulus of sample $A$ and $B$

To check whether some insects have penetrated the commercial packaging, the samples were incubated to show the damage to the packaging. The final check was carried out after 50 days, which is the time required to complete the biological cycle of S. zeamais. The controls were carried out by opening each individual commercial package (sample C) before incubation. The observations on the package did not reveal any further damage to the polypropylene film. The observations made on the pasta did not show any damage caused by insect activity on the pasta itself. The results show that sample $A$ and sample $B$ were not attacked by insects (Table 4), while on sample C, i.e. the packaging of commercial pasta, attempts by insects to penetrate the packaging were observed, namely in the parts with transpiration micropores normally made on pasta packages.

The results show that Sample A and Sample B were not attacked by insects (Table 4), while in Sample C, i.e. the packaging of commercial pasta, attempts by insects to penetrate the packaging were observed in the parts with transpiration micropores normally found on pasta packaging (Figure 2). 
Table 4: Packaging effect regarding insect infestation.

\begin{tabular}{|c|c|c|c|c|c|c|c|}
\hline \multirow{2}{*}{ Test } & \multirow{2}{*}{$\begin{array}{l}\text { No of } \\
\text { dead } \\
\text { adults }\end{array}$} & \multicolumn{2}{|c|}{$\begin{array}{l}\text { Packaging } \\
\text { damage }\end{array}$} & \multicolumn{2}{|c|}{$\begin{array}{l}\text { Packaging } \\
\text { damage }\end{array}$} & \multirow{2}{*}{$\begin{array}{l}\text { Incubation } \\
\text { for } \\
50 \text { days }\end{array}$} & \multirow{2}{*}{$\begin{array}{l}\text { Check of } \\
\text { infestation } \\
\text { after } 50 \\
\text { days }\end{array}$} \\
\hline & & $\begin{array}{l}\text { Sample } \\
\text { A }\end{array}$ & $\begin{array}{l}\text { Sample } \\
\text { C }\end{array}$ & $\begin{array}{l}\text { Sample } \\
\text { B }\end{array}$ & $\begin{array}{l}\text { Sample } \\
\text { C }\end{array}$ & & \\
\hline \multirow{5}{*}{ Sample A + 50 insects } & 50 & No & - & - & - & - & - \\
\hline & 50 & No & - & - & - & - & - \\
\hline & 50 & No & - & - & - & - & - \\
\hline & 50 & No & - & - & - & - & - \\
\hline & 50 & No & - & - & - & - & - \\
\hline \multirow{5}{*}{ Sample B +50 insects } & 47 & - & - & No & - & - & - \\
\hline & 49 & - & - & No & - & - & - \\
\hline & 50 & - & - & No & - & - & - \\
\hline & 50 & - & - & No & - & - & - \\
\hline & 49 & - & - & No & - & - & - \\
\hline \multirow{5}{*}{$\begin{array}{l}\text { Sample A + Sample C + } \\
50 \text { insects }\end{array}$} & 48 & No & Yes & - & - & - & - \\
\hline & 50 & No & No & - & - & - & - \\
\hline & 50 & No & Yes & - & - & $x$ & No \\
\hline & 50 & No & Yes & - & - & $x$ & No \\
\hline & 50 & No & Yes & - & - & $x$ & No \\
\hline \multirow{5}{*}{$\begin{array}{l}\text { Sample B + Sample C + } \\
50 \text { insects }\end{array}$} & 50 & - & - & No & Yes & $x$ & No \\
\hline & 50 & - & - & No & No & - & - \\
\hline & 50 & - & - & No & No & - & - \\
\hline & 49 & - & - & No & Yes & $x$ & No \\
\hline & 50 & - & - & No & Yes & $x$ & No \\
\hline
\end{tabular}

Damage caused by S. zeamais adults on sample C, packaging made of polypropylene pillow bags with side gussets and fin seal. In some cases only trials were found, in other cases the microholes were enlarged to allow the insects to enter the packaging (Figure 2).

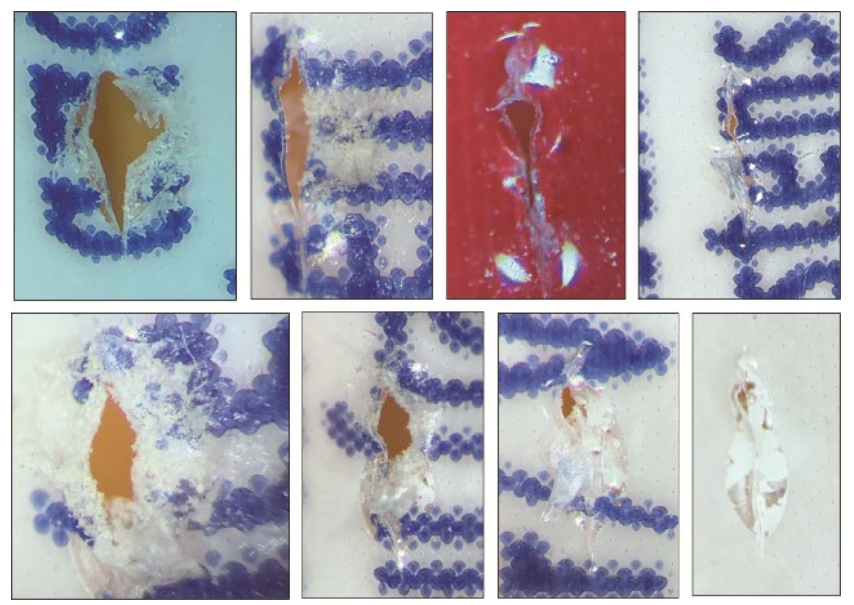

Figure 2: Damages produced by S. zeamais adults on Sample C, packages of polypropylene pillow pouch with gussets and fin seal

\section{CONCLUSIONS}

Infestation may occur during the storage process in production plants, warehouses, general stores and retail outlets already colonised by insects derived from other products, and in the home of the consumer.In polypropylene pasta packages, which had one or two rows of micro-holes with mechanical ventilation on the back, the holes facilitated the penetration of adult insects. The mechanical holes present in the packs allow the diffusion of volatile components that attract insects and facilitate the penetration of adult insects. When the holes were large enough, adult corn beetles penetrated without difficulty, while in other cases, clear signs of insect jawbone were observed, as determined in our tests. 
Packaged food products are susceptible to infestation along the entire marketing and supply chain channels, especially if the packaging is permeable to food odours.

To prevent insect infestation, the escape of food odours from the packaging can be prevented by the use of natural repellents or by the use of barrier materials. Our study found that materials and construction, e.g. paper tube packaging, are more effective against insect infestation compared to pillow bags, polypropylene packaging. In our case, no infestation was observed within the packaging of two different paper tubes without and with a biologically based PE barrier film. The paper tube with bio- PE achieved better mechanical and moisture properties; therefore, such packaging could be used for pasta products. Moreover, it can be refilled after the first use. The shelf life of the mentioned packaging is long compared to traditional polypropylene and other paper packaging on the market. Therefore, in order to obtain safer, healthier and higher quality food products, the lamination of paper tubes can be a more effective packaging for pasta products. An additional analysis should be carried out to determine the toxicological risk.

The risks of pasta contamination along the processing cycle, from the field raw material to the consumer, remain unclear due to specific aspects of carelessness in warehouses and shops and due to the long shelf life of the products. For these reasons it would be necessary to pay more attention to the packaging and the material used for packaging, which must be resistant to insect infestation.

\section{ACKNOWLEDGMENTS}

The authors are thankful to the Cost Action for Mathematical and Computer Science Methods for Food Science and Industry CA 15118 (FoodMC) for the support given in this research. The mention of trade names or commercial products in this publication is solely for providing specific information.

\section{REFERENCES}

[1] Bandyopadhyay, S., Saha, N., Brodnjak, U. V., Sáha, P.: "Bacterial cellulose and guar gum based modified PVP-CMC hydrogel films: Characterized for packaging fresh berries", Food Packaging and Shelf Life 22, 100402, 2019. doi: 10.1016/j.fpsl.2019.100402

[2] Briassoulis, D., Giannoulis, A.: "Evaluation of the functionality of bio-based food packaging films", Polymer Testing 69, 39-51, 2018. doi: 10.1016/j.polymertesting.2018.05.003

[3] Hayes, D. G., Anunciado, M. B., DeBruyn, J. M., Bandopadhyay, S., Schaeffer, S., English, M., Sintim, H. Y.: "Biodegradable plastic mulch films for sustainable specialty crop production", In: Polymers for Agri-Food Applications, (Springer, Cham, 2019.), pages 183-213.

[4] Heeps, J.: "Insect management for food storage and processing", (Elsevier, Amsterdam, 2016.)

[5] Helanto, K. E., Matikainen, L., Talja, R., Rojas, O. J.: "Bio-based Polymers for Sustainable Packaging and Biobarriers: A Critical Review", BioResources 14 (2), 4902-4951, 2019. doi: 10.15376/biores.14.2. Helanto

[6] Luzi, F., Torre, L., Kenny, J. M., Puglia, D.: "Bio-and fossil-based polymeric blends and nanocomposites for packaging: Structure-property relationship”, Materials 12 (3), 471, 2019. doi: 10.3390/ma12030471

[7] Mullen, M. A., Vardemann, J. M., Bagwell, J.: “Insect-Resistant Packaging", In: Stored Product Protection, Part II, Management: Prevention Methods, (Kansas State University, Manhattan KS, 2012.), pages 135-142.

[8] Ojha, S., Kapoor, S.: "Bio-Plastics: The Suitable and Sustainable Alternative to Polyethylene based Plastics", Microbiology 2, 145-148, 2019. doi: 10.31080/ASMI.2019.02.0254

[9] Ramos, Ó. L., Pereira, R. N., Cerqueira, M. A., Martins, J. R., Teixeira, J. A., Malcata, F. X., \& Vicente, A. A.: "Bio-based nanocomposites for food packaging and their effect in food quality and safety", In: Food Packaging and Preservation, (Academic Press, Cambridge MA, 2018.), pages 271-306.

[10] Regubalan, B., Pandit, P., Maiti, S., Nadathur, G. T., Mallick, A.: "Potential Bio-Based Edible Films, Foams, and Hydrogels for Food Packaging", In: Bio-based Materials for Food Packaging, (Springer, Singapore, 2018.), pages 105-123.

[11] Riudavets, J., Pons, M. J., Messeguer, J., Gabarra, R.: "Effect of CO2 modified atmosphere packaging on aflatoxin production in maize infested with Sitophilus zeamais", Journal of stored products research 77, 89-91, 2018. doi: 10.1016/j.jspr.2018.03.005 
[12] Stejskal, V., Bostlova, M., Nesvorna, M., Volek, V., Dolezal, V., Hubert, J.: "Comparison of the resistance of mono-and multilayer packaging films to stored-product insects in a laboratory test", Food control 73, 566-573, 2017. doi: 10.1016/j.foodcont.2016.09.001

[13] Trematerra, P.: "Preferences of Sitophilus zeamais to different types of Italian commercial rice and cereal pasta", Bulletin of Insectology 62, 103-106, 2009.

[14] Trematerra, P., Savoldelli, S.: "Pasta preference and ability to penetrate through packaging of Sitophilus zeamais Motschulsky (Coleoptera: Dryophthoridae)", Journal of Stored Products Research 59, 126-132, 2014. doi: 10.1016/j.jspr.2014.06.008

[15] Yousefi Shivyari, N., Tajvidi, M., Bousfield, D. W., \& Gardner, D. J.: "Production and characterization of laminates of paper and cellulose nanofibrils", ACS applied materials \& interfaces 8 (38), 25520-25528, 2016. doi: 10.1021/acsami.6b07655

(C) 2020 Authors. Published by the University of Novi Sad, Faculty of Technical Sciences, Department of Graphic Engineering and Design. This article is an open access article distributed under the terms and conditions of the Creative Commons Attribution license 3.0 Serbia (http://creativecommons.org/licenses/by/3.0/rs/). 



\title{
THE PRODUCTION OF ECOFRIENDLY BIOFILM WITH NATURAL OIL FOR FOOD PACKAGING
}

\author{
Emine Arman Kandirmaz ${ }^{1}$ (D), Omer Bunyamin Zelzele ${ }^{2}$ \\ ${ }^{1}$ Marmara University, School of Applied Sciences, Printing Technologies, Istanbul, Turkey \\ ${ }^{2}$ Marmara University, Vocational School of Technical Sciences, Printing and Publishing \\ Technologies, Istanbul, Turkey
}

\begin{abstract}
The use of edible biofilms in food packaging reduces the use of petrochemical polymers that are harmful to human health, such as PE, PP, PET. The second most common biopolymer in nature, chitosan is a nontoxic, nonantigenic, biocompatible and biodegradable polymer. Considering these features, it is frequently used in food packaging applications. Increasing needs for food amount and quality canalized food industry to fund in new packaging techniques that improve storage life and grade of foods. Active packaging systems, one of these methods, can be designed as a sensor, antimicrobial or antimigrant in order to extend the shelf life of the food product and to inform the shelf life in possible degradation. Essential oils, which are antimicrobial environmentally friendly packaging material additives, are used due to their effective biological activities. Essential oils that have known antimicrobial properties include lavender, rosemary, mint, eucalyptus and geranium. These oils are also edible. In this study, it is aimed to produce antimicrobial, ecofriendly, edible, printable biofilm for active packaging, using chitosan and peppermint essential oil. For this purpose, chitosan biofilms containing different rates $(0,1,2.5,5,10 \%)$ of peppermint essential oil were produced by solvent casting method. Surface morphology were examined by SEM. The transparency of biofilms was determined by UV spectroscopy. Antimicrobial properties of the obtained films were determined against S. aureus and E. coli. Biofilms were printed with screen printing. The color, gloss, contact angle, surface tension values of all printed and unprinted samples were examined. As a result, chitosan biofilms which are loaded with peppermint essential oil were successfully produced. Biofilms are colorless, highly transparent and have good printability. It is concluded that the amount of peppermint essential oil increased inhibitory feature against S. aureus and E. coli. When the obtained results are examined, it is determined that the printable, ecofriendly, edible biofilms can be used in active food packaging applications.
\end{abstract}

Keywords: Biofilm, Edible, Printability, Antimicrobial, Peppermint oil

\section{INTRODUCTION}

Food packages basically provide barrier and protective functions to protect food against the environmental conditions, fungal, and bacteria. Packaging industry is developing and advancing in order to meet these conditions. These developments are in the direction of being cheap, healthy, bio-sourced, lightweight, printable and protective, keeping food fresh for longer. Packages should be printable enough to present the final product well enough. For this purpose, packages play not only a passive promotion role, but also play active roles such as preserving food and extending shelf life in many different areas with newly developed types. Active packaging; They are auxiliary packaging materials added to the packaging to improve the use of food (Zhong et al., 2020) Different agents such as enzymes, natural materials or bacteriocins can be added into packaging which are used different materials papers, films etc. (Han, 2003). Some useful flavoring agents and important substances for food preservation such as antioxidant and antimicrobials can be incorporated into packaging systems to be released into food products during their storage instead being used in food formulations as ingredients or additives. This technique allows the release of active substances in the correct amount, gradually during storage time and in the place where more useful (Dutta et al., 2009).

Antimicrobial active packaging can be achieved in by incorporating antimicrobial agents directly into packaging polymers and by using polymers that are antimicrobial by themselves. The most commonly antimicrobials are used in packaging, natural essential oils, enzymes, silver ions and organic acids (Corrales et al., 2014). Peppermint plant is a member of the Labiatae family and has been frequently used in the pharmaceutical industry since ancient times due to its carminative and antiseptic properties (Herrmann and Kucera, 1967). Peppermint oil is effective against many known bacteria and fungi. These include fungi 
such as Candida albicans, C. tropicalis and gram-negative and positive bacteria such as Aspergilus niger, Xanthamonas campestris, Escherichia coli, Salmonella typhimurium (Chao et al., 2000). According to studies on Gram-negative bacteria, the oil obtained from the leaf parts of mint has higher efficiency than the oil obtained from the stem part. In addition, the sensitivity of mint to gram negative bacteria is higher than gram positive (McKay and Blumberg, 2006). Having a high antioxidant effect, peppermint oil can also be used against viruses such as influenza and herpes (Schuhmacher et al., 2003).

In recent years, synthetic polymers have begun to be used more than other materials in food packaging due to reasons such as ease of production, lightness, cheapness and accessibility (Tajeddin and Arabkhedri, 2020). According to the needs of the material to be packaged; The production of a wide variety of packaging materials is another factor in increasing usage. With the decrease in oil, which is the main raw material of polymers, the increase in price and the problems in getting rid of its waste, the interest in environmentally friendly natural polymers increases. In this respect, interest in natural and biodegradable packaging materials that can be used in food packaging is increasing and its production becomes essential. Natural polymers are described as macromolecules which are completely or partially obtained from renewable plants or animals. Bio-based polymers are generally classified three categories: natural polymers extracted from animal or plant sources (starch, cellulose, casein), chemical synthisized polymers which are produced by renewable bio-based monomers (polylactate), genetically modified bacteria's produced polymers (polyhydroxy alkanoates). Chitosan is a natural polymer that is usually made from shellfish. Chitosan has been proven in many studies to have antibacterial properties (Yaday et al., 2019). It can be used in active packaging applications due to its ability to be made into a film structure, and its natural antibacterial properties. Chitosan biofilms can be a good packaging material due to their low permeability and high barrier against oil, but their low resistance to water limits their usage areas.

In this study, it is aimed to produce edible, environmentally friendly biofilm that can be used in food packaging using chitosan and peppermint oil. Essential oil and biopolymer were chosen for their antimicrobial properties.

\section{METHODS}

The mint samples obtained from Yalova region were weighed $200 \mathrm{~g}$ from the sample after drying at $30{ }^{\circ} \mathrm{C}$. These samples were then subjected to hydro distillation for 6 hours with the NeoClevenger apparatus. Essential oils were dried with anhydroussodiumsulfate and stored in dark bottles and stored at $4{ }^{\circ} \mathrm{C}$.

Chitosan blank films (FO) were produced with a solvent casting method. A solution of chitosan $(0.5 \% \mathrm{w} / \mathrm{v})$ was prepared by dissolving $1.0 \mathrm{~g}$ of chitosan in $200 \mathrm{~mL}$ of deionized water/acetic acid (2\%) at $25^{\circ} \mathrm{C}$ under stirring for 3 hours $750 \mathrm{rpm}$. After complete dissolution, PEG $(0.2 \mathrm{~g})$ was added as a plasticizer to increase film flexibility, decrease fragility and to simplified film separation from petri. The obtained bio based polymeric film solution was spilled onto petri that $9 \mathrm{~cm}$ diameter and dried in vacuum at $30{ }^{\circ} \mathrm{C}$ for a day. The films were removed from the petri. Similar to the procedure described above, 1, 2.5, 5, 10\% peppermint oil was added into the same formulation and mixed in an ultrasonic mixer for 5 minutes at room temperature and F1,2,3,4 films were produced. The contents of all films are given in Table 1.

Table 1: The film formulations

\begin{tabular}{|c|c|c|c|}
\hline Formulation No & Chitosan & PEG & Peppermint Oil \\
\hline F0 & 83 & 17 & 0 \\
\hline F1 & 83 & 17 & 1 \\
\hline F2 & 83 & 17 & 2.5 \\
\hline F3 & 83 & 17 & 5 \\
\hline F4 & 83 & 17 & 10 \\
\hline
\end{tabular}

Surface morphology were examined by SEM with Phillips XL 30 ESEM-FEG microscope. Bio based films were cryo-fractured with liquid nitrogen. Fractured films surfaces coated with gold before SEM imaging. The transparency of biofilms was determined by Shimadzu UV-vis spectrophotometer 2450 (Kyoto Jap). Antimicrobial properties of the obtained films were determined against S. aureus and E. coli. Antimicrobial 
activity of films was defined using the inhibition zone (disc diffusion) method. Each bacterial culture was activated, by inoculation in Tryptic Soy Broth (TSB) at $37{ }^{\circ} \mathrm{C}$ for 24 hours. Inoculum $(0.1 \mathrm{~mL})$ was spread over the Mueller-Hinton ( $\mathrm{MH}$ ) agar petri plates, then 4-mm-wide films were placed into the petri plates. The disc film involving the petri plates and control samples were incubated at $37^{\circ} \mathrm{C}$ for 24 hours. Following the incubation process, the petri plates were examined for bacterial growth and the inhibition zones around the disc films were assessed in qualitative and quantitative terms. Quantitative assessment was performed based on the inhibition zone diameter. The zones around the disc films were assessed as the indicator of the inhibition of bacterial growth.

All films were printed with Process Magenta (TOYO ink) commercial screen printing ink using an ARUS semiautomatic printability test device (Printing parameters; weaving density of $77 \mathrm{tpc}, 75$ degree scraping angle and 75 degree shore hardness). CIE L*a*b* rates of all films were determined with X-Rite eXact spectrophotometer in accordance with ISO 12647-2:2013, (spectral range $400-700 \mathrm{~nm}$, with D50 light, 2 observer angle, with polarize filter, 0/45-degree). The color differences formula was dedicated below. All calculations were made with 5 repetitions.

$\Delta E_{00}=\sqrt{\left(\frac{\Delta L^{\prime}}{k_{L} S_{L}}\right)^{2}+\left(\frac{\Delta C^{\prime}}{k_{C} S_{C}}\right)^{2}+\left(\frac{\Delta H^{\prime}}{k_{H} S_{H}}\right)^{2}+R_{T} \frac{\Delta C^{\prime}}{k_{C} S_{C}} \frac{\Delta H^{\prime}}{k_{H} S_{H}}}$

Gloss values were measured by BYK-Gardner GmbH glossmeter according to ISO 2813:2014 with 60 geometry. Contact angle and total surface energies of the biofilms were determined with Pocket Goniometer PGX+ in line with ASTM D5946.

\section{RESULTS AND DISCUSSION}

Figure 1 demonstrate that the SEM micrographs of the fracture surface morphology of biofilms. Figure 1 shows that polymeric biofilm was a uniform and non-cracked surface.

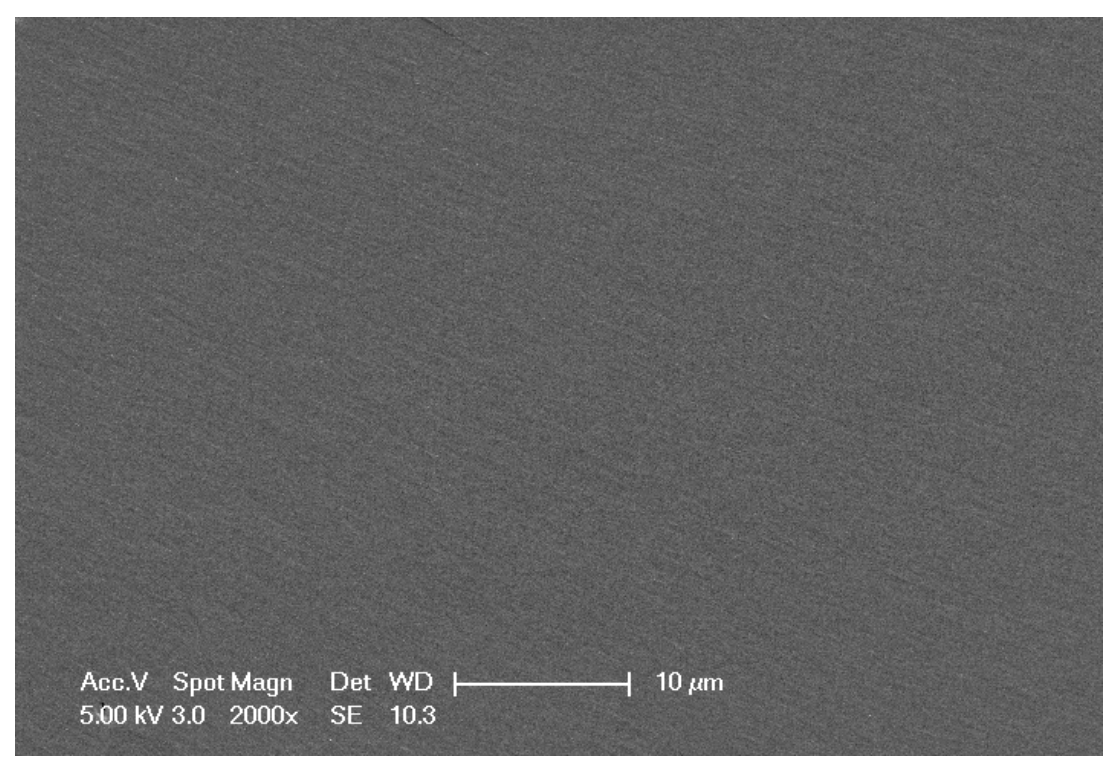

Figure 1: SEM image of F4

Chitosan containing biofilm was transparent. The mint oil containing films were also found to transparent. The optical properties of biofilms were investigated with measuring of transmittance among 300-800 nm. The transmittance spectrums of bio films transmittance value of the films at $750 \mathrm{~nm}$ are 99,5 (\%T). This results was observed that the addition of pepper mint oil causes a negligible decrease transmittance of the chitosan biofilms. 

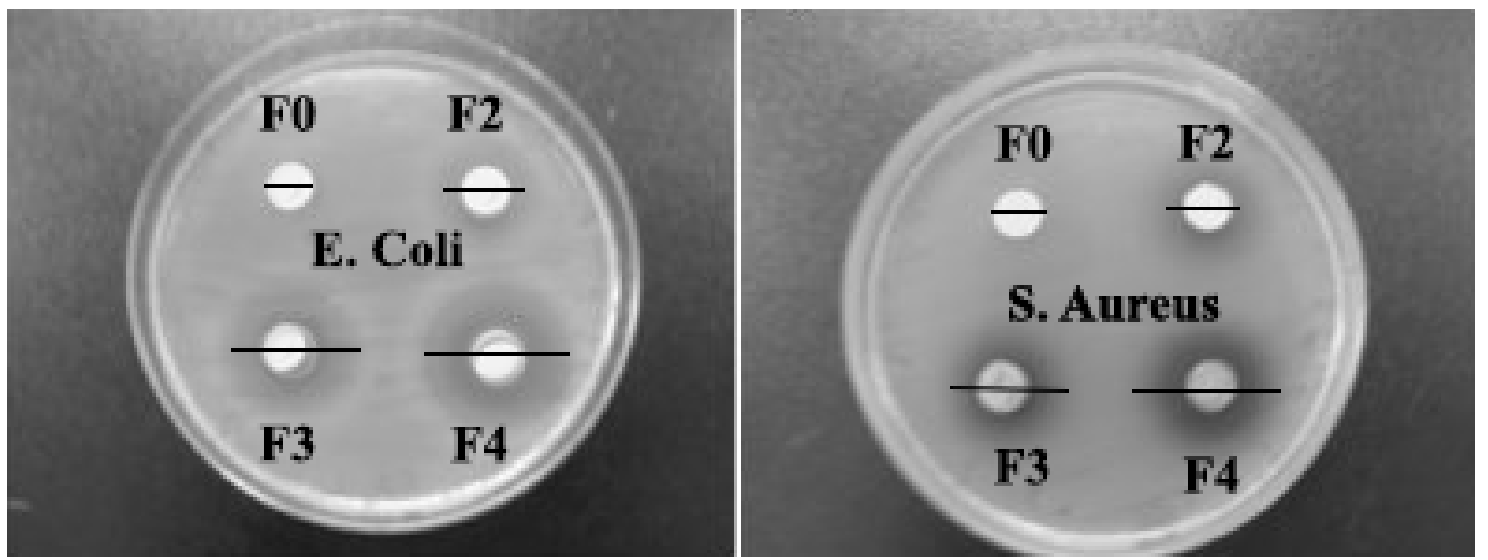

Figure 2: Antimicrobial activity of films using the inhibition zone (disc diffusion) method

Table 2: The antibacterial activity of biofilms

\begin{tabular}{|c|c|c|}
\hline $\begin{array}{c}\text { Formulation } \\
\text { No }\end{array}$ & $\begin{array}{c}\text { S. aureus diameter of } \\
\text { inhibition zone }(\mathrm{mm})\end{array}$ & $\begin{array}{c}\text { E. coli diameter of } \\
\text { inhibition zone }(\mathrm{mm})\end{array}$ \\
\hline F0 & 5 & 5 \\
\hline F2 & 14 & 12 \\
\hline F3 & 20 & 18 \\
\hline F4 & 24 & 22 \\
\hline
\end{tabular}

In bio films include solely chitosan no respectable inhibition zone was considered versus Escherichia coli and Staphylococcus aureus. This result may be concerned to the fact that chitosan does not diffuse owing to neighboring agar environment in the agar diffusion test method, thus only bacteia's in directly touch with the real medium of chitosan are inhibited. As regards chitosan added pepper mint oil, this bio film demonstrated an inhibitive impact for four concentrations, onto 2 bacteria type experienced as well inhibitory effect was concentration-dependent. From the two microorganisms compared, it is understood from the inhibition diameters that the inhibition effect of peppermint oil is more pronounced on S. aureus. The white substrate was used in the measurements and the color values of the films are given in Table 3.

Table 3: Color and gloss properties of biofilms

\begin{tabular}{|c|c|c|c|c|c|}
\hline Formulation No & $\mathrm{L}^{*}$ & $\mathrm{a}^{*}$ & $\mathrm{~b}^{*}$ & $\Delta \mathrm{E}_{00}$ & Gloss \\
\hline White Substrate & 96.4 & 2.8 & -7.3 & Ref. & 5.2 \\
\hline F0 & 96.2 & 2.7 & -5.9 & 1.09 & 28.9 \\
\hline F1 & 96.3 & 2.8 & -5.2 & 1.68 & 28.6 \\
\hline F2 & 96.5 & 2.9 & -4.9 & 1.99 & 28.6 \\
\hline F3 & 96.4 & 2.87 & -4.3 & 2.46 & 28.5 \\
\hline F4 & 96.3 & 2.81 & -4.1 & 2.62 & 28.4 \\
\hline
\end{tabular}


Color differences were calculated by delta $\mathrm{E}$ of films (F0, F1, F2, F3, F4) how it differs from white substrate. When the table is examined, it is concluded but only biofilms shifted the color slightly to yellow but also Bio films did not variety the color much. $\Delta E$ difference did not notice with eye because of color difference was below 3. It is also within the acceptable reference range according to ISO 12647-2. When the gloss values were examined, it was determined that all films were at least five times glossier than the base paper. This is due to the fact that the roughness on the paper surface is covered by the coating and the diffuse reflection is prevented. Thus, the papers became glossier.

Surface energy plays an important role in the interaction of printing process. The content of the substrate is among the parameters that affect surface, contact angle and surface energy. The contact angles and surface energies of the obtained coatings are given in Table 4.

Table 4: Total surface energy and Contact Angle values of biofilms according to ASTM D5946 method

\begin{tabular}{|c|c|c|c|}
\hline Formulation No & $\begin{array}{c}\text { Surface } \\
\text { Energy } \\
\text { (mJ/m2) }\end{array}$ & $\begin{array}{c}\text { Contact } \\
\text { Angle }\end{array}$ & Image \\
\hline F0 & 38.9 & 72.3 & \\
\hline F1 & 37.3 & 76.8 & \\
\hline F2 & 36.4 & 79.1 & \\
\hline F3 & 35.2 & 82.5 & \\
\hline F4 & & 83.9 & \\
\hline
\end{tabular}

The water contact angle of FO was found as $72.3^{\circ}$. When pepper mint oil was added to base formulation, the contact angle increased to $76.8^{\circ}$. This is due to the hydrophobic nature of the oil. It is seen that the contact angle increases when the amount of oil in the biofilm formulation is increased. In all biofilms, contact angle values were higher than F0. This improves the offset and screen printing printability of the biofilms with less ink. Because the oleophilic groups in the offset and screen printing ink structure will interact more with the peppermint oil on the biofilm surface and a good ink surface relation will be provided and the printing process will be easier.

Screen printing test prints were made with ARUS printing test machine on the all biofilms. CIEL*a*b* color, gloss, color differences are given in Table 5. When Table 5 is examined, it is determined that the color has shifted to yellow a little, as in unprinted films, it changes the color a little. However, the color difference is lower than the films and is too small to be detected by the human eye. As the amount of oil increases, the color difference increases slightly. This shows that the ink tolerates the color difference of the magenta tone. When the gloss results were examined, the results were obtained in the same direction with the unprinted films. However, it has been determined that due to the solid particles in the ink roughening the surface, it has been determined that there is a proportional decrease in gloss in all films by $1 / 3$. 
Table 5: Color and gloss properties of printed biofilms

\begin{tabular}{|c|c|c|c|c|c|c|}
\hline Formulation No & $\mathrm{L}^{*}$ & $\mathrm{a}^{*}$ & $\mathrm{~b}^{*}$ & $\Delta \mathrm{E}_{00}$ & Image & Gloss \\
\hline F0 & 47.7 & 74.2 & -3.5 & Ref. & & 16.9 \\
\hline F1 & 47.8 & 74.6 & -1.4 & 1.02 & & 16.2 \\
\hline F2 & 47.9 & 74.5 & -1.2 & 0.92 & & 16.3 \\
\hline F3 & 47.8 & 74.8 & -0.9 & 1.45 & & 16.3 \\
\hline F4 & 47.6 & 74.7 & -0.8 & 1.44 & & \\
\hline
\end{tabular}

\section{CONCLUSIONS}

As a result, peppermint oil containing chitosan-based biofilms have been successfully prepared. The obtained films have uniform surface and transparent. Biofilms containing peppermint oil have inhibitory properties against both gram positive and negative bacteria. The highest activity was observed against s.aureus. When the colors of the films were examined, it was determined that the color difference was below 3, that is, there is no color difference that can be seen by the eye. With increased contact angle of oil-containing biofilms, the surface has become more sensitive to oil-based ink. The printability of the biofilm is increased by adding peppermint oil. Screen prints were made on biofilms without any problem.

\section{REFERENCES}

[1] Chao, S. C., Young, D. G., Oberg, C. J.: "Screening for inhibitory activity of essential oils on selected bacteria, fungi and viruses", Journal of essential oil research 12 (5), 639-649, 2000. doi: 10.1080/10412905.2000.9712177.

[2] Corrales, M., Fernandez, A., \& Han, J. H.: “Antimicrobial packaging systems. In Innovations in food packaging" (, Academic Press, 2014.), pages 133-170.

[3] Dutta, P. K., Tripathi, S., Mehrotra, G. K., Dutta, J.: "Perspectives for chitosan based antimicrobial films in food applications", Food chemistry 114 (4), 1173-1182, 2009. doi: 10.1016/j.foodchem.2008.11.047.

[4] Han, J. H.: "Innovations in food packaging" (Academic Press, Cambridge MA, 2014.), pages 133-170.

[5] Herrmann Jr, E. C., Kucera, L. S.: "Antiviral Substances in Plants of the Mint Family (Labiatae). III. Peppermint (Mentha piperita) and other Mint Plants", Proceedings of the Society for Experimental Biology and Medicine 124 (3), 874-878, 1967. doi: 10.3181/00379727-124-31874.

[6] McKay, D. L., Blumberg, J. B.: "A review of the bioactivity and potential health benefits of peppermint tea (Mentha piperita L.). Phytotherapy Research", An International Journal Devoted to Pharmacological and Toxicological Evaluation of Natural Product Derivatives 20 (8), 619-633, 2006. doi: 10.1002/ptr.1936.

[7] Schuhmacher, A., Reichling, J., \& Schnitzler, P.: "Virucidal effect of peppermint oil on the enveloped viruses herpes simplex virus type 1 and type 2 in vitro", Phytomedicine 10 (6-7), 504-510, 2003. doi: 10.1078/094471103322331467.

[8] Tajeddin, B., \& Arabkhedri, M.: "Polymers and food packaging." In Polymer Science and Innovative Applications (pages 525-543). Elsevier, 2020. doi: 10.1016/B978-0-12-816808-0.00016-0

[9] Yadav, M., Goswami, P., Paritosh, K., Kumar, M., Pareek, N., Vivekanand, V.: "Seafood waste: a source for preparation of commercially employable chitin/chitosan materials", Bioresources and Bioprocessing 6 (1), 8, 2019. doi: 10.1186/s40643-019-0243-y. 
[10] Zhong, Y., Godwin, P., Jin, Y., \& Xiao, H.:"Biodegradable polymers and green-based antimicrobial packaging materials: A mini-review.", Advanced Industrial and Engineering Polymer Research 3 (1), 27-35, 2020. doi: 10.1016/j.aiepr.2019.11.002

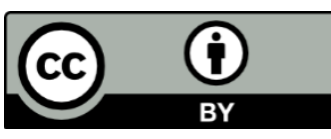

(C) 2020 Authors. Published by the University of Novi Sad, Faculty of Technical Sciences, Department of Graphic Engineering and Design. This article is an open access article distributed under the terms and conditions of the Creative Commons Attribution license 3.0 Serbia (http://creativecommons.org/licenses/by/3.0/rs/). 



\title{
INVESTIGATIONS ON BOOK CUTTING BY CIRCULAR KNIFE WITH ECCENTRIC BLADE MOVEMENT
}

\author{
Georgij Petriaszwili $^{1}$ (D), Piotr Janicki ${ }^{2}$, Serhii Komarov ${ }^{3}$ \\ ${ }^{1}$ Warsaw University of Technology, Institute of Mechanics and Printing, Warsaw, Poland \\ ${ }^{2}$ Drukarnia Wydawnicza im. W.L. Anczyca S.A., Kraków, Poland \\ ${ }^{3}$ Ukrainian Academy of Printing, Lviv, Ukraine
}

\begin{abstract}
The paper describes investigations on new method of the book cutting by using special circular knife with eccentric blade movement. Analysis of kinematic parameters of book block cutting shows, that by using eccentric circular cutting knife the cutting process may be realized in two different modes: continuous cutting - with the constant contact between cutting edge and cut material, and interrupted cutting process - with the impulse cutting knife action to treated material. The results of the conducted experimental studies confirm the kinematic analysis of the cutting process.
\end{abstract}

Key words: book cutting, circular knife, eccentric blade movement, kinematic analysis

\section{PREFACE}

Paper cutting operations are widely applied in the implementation of the printing process: before printing - to trim the stacks to the desired format by single-knife cutting machines, as well as the treatment of the final book blocks - by three-knife trimmers. Until recently, cutting the paper was to be regarded as secondary operation and auxiliary. But today, applied to the much more attention, as it is proven that the correct cutting largely influences on the smooth running of other technological operations, which has a large impact on the quality of the final product and the cost of production.

Development of modern three-knife trimmers goes towards the maximum automation of auxiliary processes, while the principle of work practically unchanged for over more than 170 years. The most part of the modern trimmers realized a knife cutting movement as a combined motion (saber movement). However, this cutting process is characterized by relatively large values of cutting force, repeatedly increasing when it working with blunt knives, makes cutting quality worse and reduces the processing speed. However, the modern bookbinding automatic lines works much faster. There is a need to look for the possibility of using other cutting methods enabling the implementation of streamline processing.

\section{BACKGROUNDS}

Most of the research on paper cutting processes is devoted to single-knife cutting process (Dittrich, 1965; Ginzburg, 1957; Mordowin, 1962; Neumann et al, 2012; Rusin and Petriaszwili, 2013). The process of cutting paper stacks and books with a circular knife is relatively poorly researched. Krabisch (1962) (Krabisch, 1962) found that the strength and quality of the trimming of brochures largely depend on the thickness of the block, the feed rate, and the rotary speed and direction of rotation of the circular knife. The main obstacle in using this method for processing thick book blocks is a significant increase in trimming forces and the phenomenon of excessive heating of the knife as a result of rubbing against the paper, which causes local "burns" and deterioration of the cutting quality. Research conducted by Grushevski (1963) (Gruszewski, 1963) confirmed the limitation of the possibility of qualitative trimming of books.

There is intensive research into the practical use of vibration of cutting tools in the machining of various materials (Kumabe, 1985; Markov, 1966; Podurajev, 1970). The results of these tests show a significant reduction in cutting forces and an improvement in the quality of the treatment with lower energy consumption. The performed studies also indicated the possibility of vibration trimming of paper stacks (Komarov and Petriaszwili, 1989). These studies showed a significant reduction in the cutting forces of paper stacks and an improvement in the quality of cutting. However, for the implementation of vibratory cutting it is necessary to use special vibrators to drive the knife. In order to reduce the cutting forces, without using vibrators, an eccentric setting of the rotary knife was proposed (Petriaszwili et al, 2019; Petriaszwili and Janicki, 2017). 
The purpose of this work is to analyze the possibility of the streamline book cutting using special circular knife with eccentric blade movement and to test the possibility of new method of book cutting.

\section{KINEMATICS OF CIRCULAR BOOK CUTTING}

During the process of cutting using circular knife, a kinematic transformation of the cutting angle occurs the mentioned transformation depends on kinematic and geometrical parameters of the cutting process as: cutter angular speed and rotation direction, feed rate, knife diameter and book thickness. The kinematics of the cutting process with a circular knife differs from the kinematics of cutting with a straight knife. The effective cutting angle value (the kinematic one) becomes smaller, than actual sharpened edge angle. It also causes a significant decreasing of cutting forces (Figure 1):

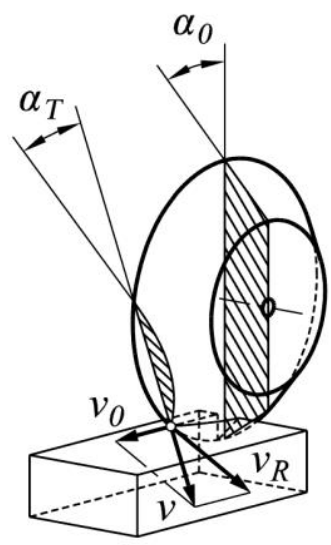

Figure 1: Transformation of real cutting angle $\alpha_{T}$ of circular knife during cutting process

When cutting with the circular knife cutter (Figure 1), the real cutting angle $\alpha_{T}$ is calculated with the following formula [11]:

$$
\alpha_{T}=\arctan \left\lfloor\tan \left(\alpha_{0}\right) \frac{v_{0} \cos (\varphi)}{\sqrt{\left[v_{R} \sin (\varphi)-v_{0}\right]^{2}+\left[v_{R} \cos (\varphi)\right]^{2}}}\right\rfloor
$$

where: $v$-actual cutting speed, $v_{0}$-feed speed, $v_{R}$ - linear speed of the circular knife, $\alpha_{0}$ - angle of sharpened edge, $\varphi$ - rotating angle of knife at the point of cutting.

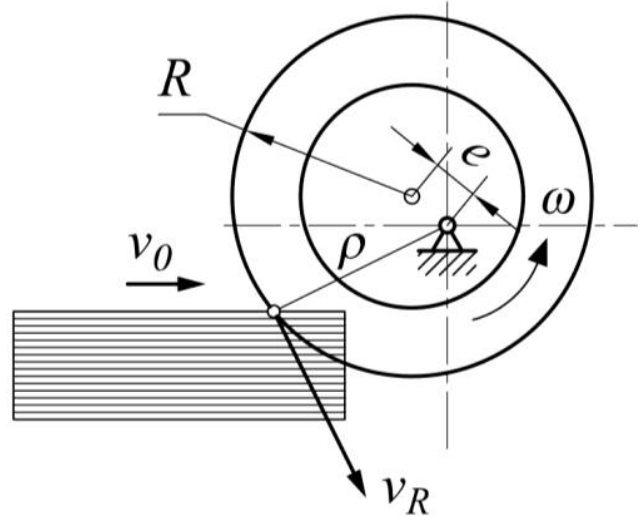

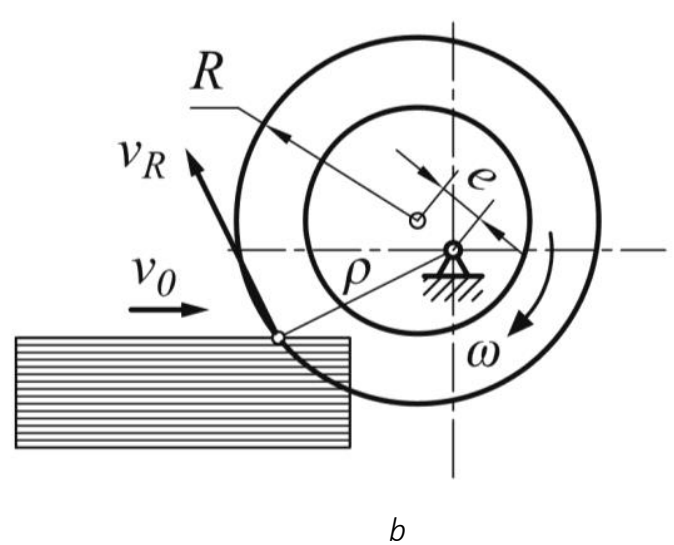

$b$

Figure 2: Scheme of book cutting with eccentric circular knife: $a$-forward cutting, $b$ - reverse cutting $v_{0}$-feed speed, $v_{R}$-linear speed of the circular knife, $\omega$-rotating speed of the knife, $e$-value of eccentric, $R$ - radius of circular knife 
The kinematic analysis has been carried out for two rotation directions of the circular knife (figure 2): forward cutting - takes place when the cutter rotation direction is synchronous to the movement direction of the book and reverse cutting - takes place when the cutter rotation direction is antisynchronous to the feed direction of book.

Figure 3 shows the calculated graphs of changes of the actual cutting angle in the cycle of one full rotation of the circular knife set with the eccentricity e for various ratios $\mathrm{V}_{\mathrm{R}} / \mathrm{v}_{\mathrm{O}}$. The value $20^{\circ}$ of the knife sharpening angle was used in the calculations. The vertical dashed lines in both graphs indicate the knife position when the cutting process interrupted.

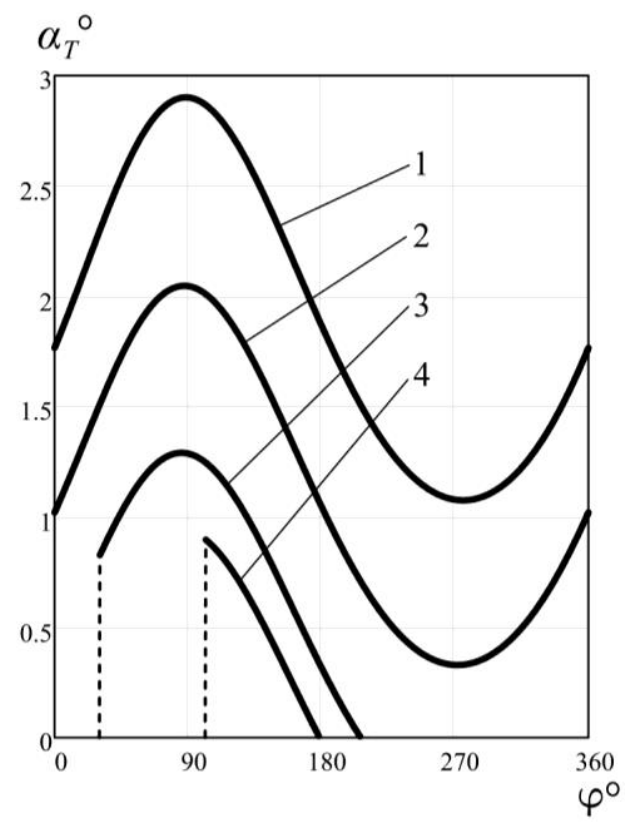

a

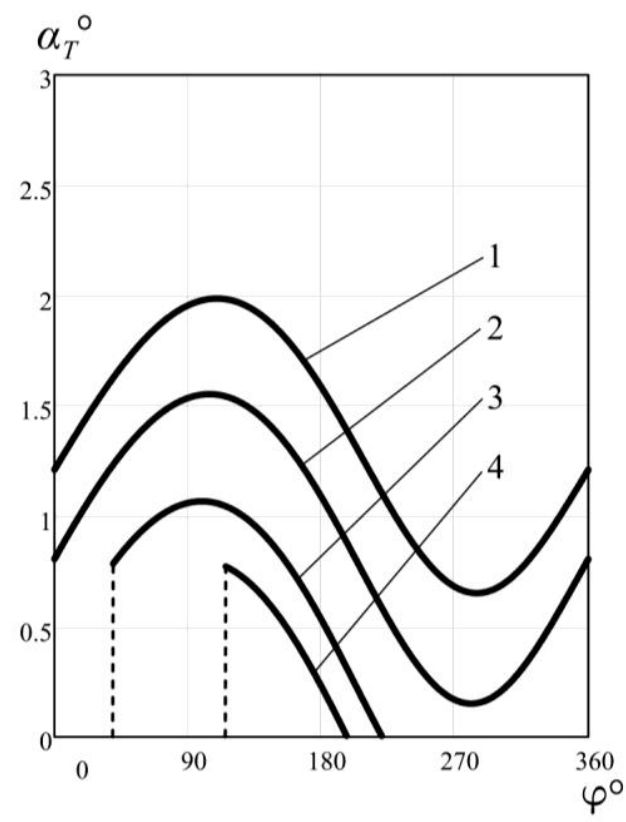

$b$

Figure 3: Changes of real cutting angle $\alpha_{T}$ in the cycle of full rotation of circular knife with eccentric blade movement e for different ratios $v_{R} / v_{O}$ $a$-forward cutting, $b$ - reverse cutting

$1-\mathrm{V}_{\mathrm{R}} / \mathrm{V}_{0}=5 ; 2-\mathrm{V}_{\mathrm{R}} / \mathrm{V}_{0}=8 ; 3-\mathrm{V}_{\mathrm{R}} / \mathrm{V}_{0}=20 ; 4-\mathrm{V}_{\mathrm{R}} / \mathrm{V}_{0}=80$

Analysis of kinematic parameters of book cutting shows, that by using eccentric circular knife the cutting process may be realized in two different modes:

- continuous cutting - when the knife's blade is in constant contact with the book during the processing, and

- $\quad$ interrupted (impulse) cutting - when the knife's blade comes out of contact with the book paper in a certain phase of the knife rotation cycle - at this point, the cutting process is interrupted, and the edge of cutting knife does not touch the part of the book during this time.

Continuous cutting is performed under the condition that the horizontal component of the linear cutting speed is $\geq 0$. The condition of cutting in the interrupted mode is that the horizontal cutting speed has the direction opposite to the feed speed and its absolute value is greater than the value of the feed speed. During the investigation, mathematical description of the interrupted and contiguous cutting was established. The equations allow calculating of the needed kinematic parameters for the interrupted cutting mode (Petriaszwili and Janicki, 2017). The equations are transcendental, so all calculations and graphs were made using Mathcad. It was found that the greatest influence on the characteristics of the process and the value of cutting angle are: feed rate of the book, distance between the block and the knife rotation axis, knife rotation speed and others. The calculations allow selecting of the kinematic parameters of the cutting process, taking into account the path of knife blade inside the paper of the book during cutting with the circular knife, in order to minimize the blade wear (Petriaszwili et al, 2019). By analyzing the charts, it can be concluded that for the reverse cutting mode, the real cutting angle is smaller than for the forward cutting. This means that in the case of using a reverse cutting with an eccentric knife, lower forces of books cutting can be expected. 


\section{EXPERIMENTAL RESEARCH}

In order to verify the formulated scientific hypothesis about two modes of cutting: continuous and interrupted cutting, a special laboratory stand was designed and built with a drive unit for transport books with different speed and a rotary cutting unit equipped with circular knives.

The special laboratory stand with mounted circular knives enables research on the processes of streamline cutting of books both with one circular knife and with several sets of circular knives at the same time. Laboratory stand makes possible to test the cutting process of clamped books with cutting length - up to $240 \mathrm{~mm}$ and thickness - up to $30 \mathrm{~mm}$ with the book feed speed - up to $3 \mathrm{~m} / \mathrm{s}$.

A National Instruments (USA) data acquisition system was used to register and analyze fast-changing signals. Enhanced data acquisition system enables simultaneous recording the process of cutting books of the following parameters: three components of cutting force, clamping force, three components of knives vibrations together with spectral analysis and measurement of knife blade wear. The measuring path of the acquisition system consists of three basic blocks: measuring, signal processing and analyzing block. Registration and analysis of signals takes place in a PC computer using specialized programs LabVIEW SignalExpress and DIAdem (National Instruments).

Figure 4 shows the distribution of force components that act on the transport carriage registered during cutting. The cutting force can be presented in the form of three components: horizontal Fx - operating in the cutting plane in the direction of transport of the book, Fz component - perpendicular to the transport direction in the cutting plane, and vertical component Fy - perpendicular to the cutting plane.

As a result of the research, it was found that in the cutting process (continuous and interrupted) of books, the components of the forces Fx and Fz are the most significant, the size of which depends on the appropriate selection of the parameters of the cutting process.

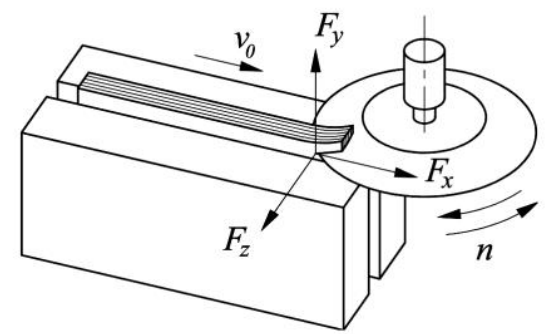

Figure 4: Three components of the force acting on the transport carriage when cutting books with a circular knife

Figure 5 presents the experimental plots of recording the component Fx of cutting force during the revers cutting of books with an eccentric circular knife:
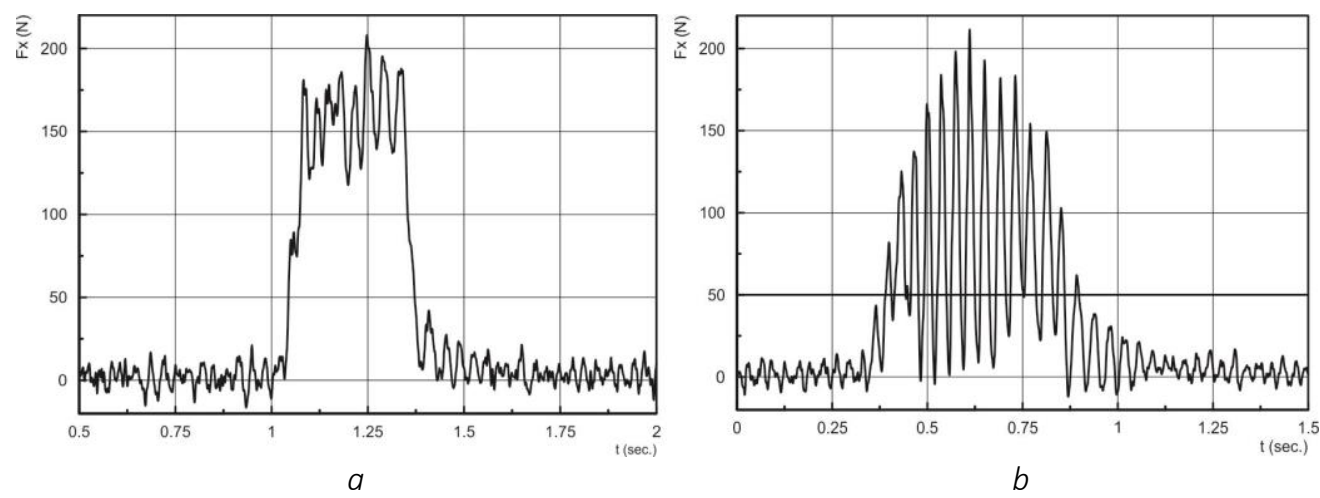

Figure 5: Changes of Fx component of cutting force during cutting the book with an eccentric circular knife $(e=1 \mathrm{~mm}) a$-continuous cutting, $b$-interrupted cutting

In the interrupted (pulse) cutting mode, the force on the knife drops practically to zero when the blade is detached from the paper and increases again from the moment the knife's cutting edge comes into 
contact with the book's paper (Figure 5a). Cyclical fluctuations and a decrease in the average values of the actual knife cutting angle as well as the dynamic nature of the interaction between the knife blade and the paper result in a reduction of the processing forces. The intermittent nature of the cutting also increases the efficiency of the processing with the circular knife by reducing the temperature in the cutting zone, due to the periodic lack of contact between the cutter blade and the paper being cut.

In the continuous cutting mode (Figure 5b), cyclic fluctuations in the value of the Fx component of the cutting force with an eccentric knife are noted. However, due to the higher feed speed of the book, the knife blade cannot keep up with the contact with the paper being cut and the nature of the cutting force changes on the experimental plot is different than in the case of interrupted cutting.

\section{CONCLUSIONS}

The conducted experimental studies confirm the analytical conclusions of the performed kinematic analysis of the cutting process on the implementation of two cutting modes: continuous cutting - with the constant contact between cutting edge and cut material, and interrupted cutting process - with the impulse action on paper block. The choice of cutting mode can be determined depending on the selected parameters of the machining process. Using the special circular knife with eccentric blade movement it becomes possible to implement book-flow-cutting in automatic lines for producing books.

\section{REFERENCES}

[1] Dittrich H.: "Cutting machines - selected articles", (Nachdruck, Institut fur polygraphische Maschinen Leipzig, Leipzig, 1965.)

[2] Ginzburg, W., (1957) "Research of cutting process on legged paper-cutting machines", Sbornik WNIIPM N3, (WNIIPM N3, Moscow, 1957.)

[3] Gruszewski V.: "Technological parameters of brochure cutting with disk knives", Trudy NIIPM, 23, (Moscow, 1963), pages 37-48.

[4] Komarov S., Petriaszwili, G.: " Dynamic study of vibratory paper cutting", Maschinenbautechnik 11 (38), 503-506, 1989.

[5] Krabisch K.: "Cutting with rotating knives", (IPM, Leipzig, 1962.)

[6] Kumabe D.: "Vibration cutting", (Maszynostrojenije, Moscow, 1985.)

[7] Markov A.: "Ultrasonic Machining of intractable materials", (Iliffe books, London, 1966.)

[8] Mordowin B.: "Bookbinding machines I", (VEB Verlag Technik, Berlin, 1962.)

[9] Neumann J., Desch M., Spiehl D., Dörsam E.: "Measuring forces appearing while cutting a stack of sheets with the aim to improve post press process", IARIGAI, Advances in Printing and Media Technology (IARIGAI, Ljubljana, 2012), pages $253-260$.

[10] Petriaszwili G., Janicki P, Komarov S.: "Investigations on the trajectory of eccentric circular knife blade movement in book cutting process", Innovations in Publishing, Printing and Multimedia Technologies, Kauno Kolegija, (Kauno Kolegija, Kaunas, 2019), pages 47-53.

[11] Petriaszwili G., Janicki P., Komarov S.: "Influence of the work parameters of the eccentrically set circular knife on the reducing during cutting the trajectory of contact of the blade with a book block", Przegląd Papierniczy 75 (4) , 253-257, 2019.

[12] Petriaszwili G., Janicki P.: "The kinematic analysis of book blocks cutting process using eccentric circular cutting knife", Przegląd Papierniczy 875, 468-472, 2017.

[13] Podurajev V.: "Vibration cutting", (Maszynostrojenije, Moscow, 1970.)

[14] Rusin A., Petriaszwili G.: "Analysis of changes in paper cutting forces during the cutting cycle in single-knife guillotine", XI ${ }^{\text {th }}$ Symposium of Graphic Art 2013, (UPCE, Pardubice, 2013), pages 161164.

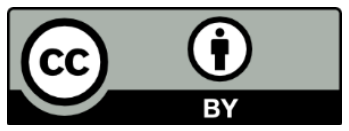

(C) 2020 Authors. Published by the University of Novi Sad, Faculty of Technical Sciences, Department of Graphic Engineering and Design. This article is an open access article distributed under the terms and conditions of the Creative Commons Attribution license 3.0 Serbia (http://creativecommons.org/licenses/by/3.0/rs/). 



\title{
FENTON-LIKE OXIDATION OF FLEXOGRAPHIC WATER-BASED KEY (BLACK) DYE: A DEFINITIVE SCREENING DESIGN OPTIMIZATION
}

\author{
Vesna Gvoić ${ }^{1}$ (D), Miljana Prica ${ }^{1}$ (D), Đurđa Kerkez 2 (D), Ognjan Lužanin ${ }^{3}$ (D), \\ Aleksandra Kulić Mandić ${ }^{2}$ (D), Milena Bečelić-Tomin ${ }^{2}$ (D), Dragana Tomašević Pilipović ${ }^{2}$ (iD) \\ ${ }^{1}$ University of Novi Sad, Faculty of Technical Sciences, \\ Department of Graphic Engineering and Design, Novi Sad, Serbia \\ ${ }^{2}$ University of Novi Sad, Faculty of Sciences, \\ Department of Chemistry, Biochemistry and Environmental Protection, Novi Sad, Serbia \\ ${ }^{3}$ University of Novi Sad, Faculty of Technical Sciences, \\ Department of Production Engineering, Novi Sad, Serbia
}

\begin{abstract}
Fenton oxidation process has obtained large applicative use for efficient water remediation, whereby overall reaction efficiency could be improved by developing advanced Fenton catalysts. In order to synthesize iron nanoparticles with higher catalytic activity, a simple and eco-friendly method using $\mathrm{FeCl}_{3}$ and aqueous plant extract (oak leaves) was applied in this paper. The nano zero valent iron particles were used as a catalyst in Fenton treatment to remove organic dye from aqueous solution. The objective of this study was to optimize Fenton-like process for the removal of black printing dye using a recently developed design of experiment method - definitive screening design. This novel design framework significantly reduces the number of experiments required to estimate the model parameters and to establish the optimum operation conditions. The experiments were carried out in a batch mode technique, investigating the influence of dye concentration (20 - $\left.180 \mathrm{mgL}^{-1}\right)$, nanoparticles dosage $\left(0.75-60 \mathrm{mgL}^{-1}\right), \mathrm{H}_{2} \mathrm{O}_{2}$ concentration (1 - $11 \mathrm{mM})$ and $\mathrm{pH}$ value of the solution (2 - 10) on the decolorization efficiency. The Fenton-like process resulted with $79 \%$ of dye removal from aqueous solution under the optimal process conditions: dye concentration of $180 \mathrm{mgL}^{-1}$, nanoparticles dosage of $0.75 \mathrm{mgL}^{-1}, \mathrm{H}_{2} \mathrm{O}_{2}$ concentration of 1 $\mathrm{mM}$ and $\mathrm{pH}$ of 2. Increasing the $\mathrm{pH}$ value to slightly acidic or near neutral (5-7) medium resulted with slight decrease in the process efficiency (69.14 -62.63\%), but a limitation in the form of sludge generation is noticeable.
\end{abstract}

Key words: definitive screening design, optimization, printing dye removal, Fenton-like process, iron nanoparticles

\section{INTRODUCTION}

Synthetic dyes and pigments are widely used in printing, pharmaceutical, textile, leather and other industries. As a result, the industrial effluents are loaded with residual dyes and easily find their way into public waterways (Noreen et al, 2020). Wastewaters generated after the printing process are enriched with dyes, solvents (dioxins, dibenzofurans, pesticides, polychlorinated biphenyls, acids, bases), heavy metals, surfactants, additives, categorized as highly hazardous and toxic substances (Natarajan et al, 2018). Therefore, printing wastewaters are characterized with high $\mathrm{pH}$ value, temperature and conductivity, high content of suspended solids and total organic carbon (TOC), high values of chemical oxygen demand (COD), but low values of biological oxygen demand (BOD), where low BOD/COD ratio implies to high content of non-biodegradable organic matter (Tung et al, 2013; Natarajan et al, 2018; Zhu et al, 2018). More than $80 \%$ of the global demand for synthetic dyes is directed to azo dyes production, which are mostly used for dyeing of paper, leather textiles and plastics. These dyes represent heterocyclic systems with chromophore azo group $(-\mathrm{N}=\mathrm{N}-)$ bond to the $\mathrm{sp}^{2}$ carbon atoms of the aromatic rings. They are soluble in water, showing high stability at different $\mathrm{pH}$ values, high temperatures and brightness (Kong et al, 2018; Srinivasan and Sadasivam, 2018).

Numerous studies have been conducted in the field of wastewater treatment and dye removal. Researchers suggest that the ideal treatment should provide efficient removal of high dyes concentration in a short period of time without creating secondary contamination, whereby treated wastewater could be reused (Galiano et al, 2018; Maučec et al, 2018; Wang et al, 2019b). However, a difference must be made when defining the terms of treated wastewater decolorization and dye molecules degradation. Decolorization implies to the reduction of initial dye concentration, whereby the treated wastewater may still be rich with organic matter. When the process of dye removal is accompanied by COD and TOC 
reduction, a dye degradation phenomenon is conducted (Collivignarelli et al, 2015; Massoudinejad et al, 2015). Studies indicate that there is no single method that can be applied to all types of dyed effluents, whereby both type of industry that generates wastewater and the pronounced variability of the dye nature must be taken into account (Collivignarelli et al, 2019). Many studies have recently been conducted using advanced oxidation processes (AOPs) to degrade organic pollutants including $\mathrm{UV} / \mathrm{H}_{2} \mathrm{O}_{2}$ (Ramos et al, 2020), UV/TiO 2 (Sriprom et al, 2019), and homogeneous or heterogeneous Fenton processes (Sreeja and Sosamony, 2016). The application of nanozerovalent (nZVI) particles in Fenton-like process for degradation of wide range of organic substances has achieved certain advantages over conventional methods and solved their practical disadvantages, such as application of iron in high concentrations, sludge generation in a form of metal hydroxide after treatment, work in a narrow $\mathrm{pH}$ range, as well as the regeneration of the catalyst and the impossibility of its reuse. Due to the properties and surface of nanomaterials, numerous studies have proven the success of nZVI particles application as Fenton catalyst (Mukherjee et al, 2016; Chen et al, 2017; Pirsaheb et al, 2019).

Process optimization is crucial to enhance the efficiency of applied treatment. This paper aims to investigate and examine the impact of Fenton-like process conditions (dye concentration, nanoparticles dosage, $\mathrm{pH}$ and $\mathrm{H}_{2} \mathrm{O}_{2}$ concentration) for black printing dye degradation, by using a novel statistical approach - definitive screening design (DSD).

\section{MATERIALS AND METHODS}

\subsection{Reagents}

In the present study, degradation of black water-soluble flexographic printing dye (Flint group, CAS number: 1064-48-8; color index: PK7; molecular weight: 616.49 gmol$^{-1}$; absorption wavelength: $613 \mathrm{~nm}$ ), is studied. Black printing dye poses two azo $(-\mathrm{N}=\mathrm{N}-)$ groups in its structure (figure 1$)$ and belongs to the group of diazo dyes. The presence of the $\pi$-bond in the azo group makes it a desirable site of attack for hydroxyl $\left(\mathrm{HO}^{*}\right)$ radicals in advanced oxidation processes. (Meetani et al, 2010).

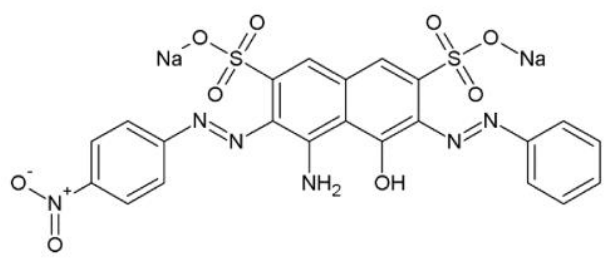

Figure 1: Chemical structure of black printing dye

Sample of wastewater was obtained from one flexographic printing facility in Novi Sad. Aqueous dye solution was prepared by dissolving appropriate amounts of black dye with deionized water to the desired concentration.

nZVI particles, as Fenton catalyst, were synthesized according to the previous report through the "green" synthesis method (Machado et al, 2013; Kecić et al, 2018).

Hydrogen peroxide, 30\% (NRK Engineering, Serbia), sodium hydroxide, >98.8\% (POCH), $\mathrm{CcH}_{2} \mathrm{SO}_{4},>96 \%$ (J.T. Baker) were of analytical grade and used without any further purification.

\subsection{Experimental procedure}

The degradation process of black dye was carried out in a $500 \mathrm{~mL}$ glass beaker containing $250 \mathrm{~mL}$ dye solution (Kecić et al, 2018). Various concentrations of $\mathrm{nZVI}\left(0.75-60 \mathrm{mgL}^{-1}\right)$ and $\mathrm{H}_{2} \mathrm{O}_{2}(1-10 \mathrm{mM})$ were mixed with the solution, whereby $\mathrm{pH}$ value was adjusted using $0.1 \mathrm{M} \mathrm{ccH}_{2} \mathrm{SO}_{4}$ and $\mathrm{NaOH}$. All reaction systems were mixed on a JAR apparatus (FC6S Velp Scientific, Italy) at $120 \mathrm{rpm}$ and constant temperature of $23{ }^{\circ} \mathrm{C}$. The residual dye concentration was established immediately by measuring the absorbance of the aqueous solutions at $613 \mathrm{~nm}$ with UV/VIS spectrophotometer (UV-1800 PG Instruments Ltd T80+ UV/VIS, Japan). Dye removal efficiency was calculated using the equation (1):

$E(\%)=A_{0}-A / A_{0} * 100$ 
where the $A_{0}$ indicates the absorption of dye before Fenton-like treatment and $A$ indicates the dye absorption after the treatment.

\subsection{Statistical analysis}

The DSD platform was utilized to evaluate the main and interaction effects of the Fenton-like process's parameters on the decolorization efficiency. The experimental design was built around four factors, each having three levels representing the low (-), central (0), and high (+), with the addition of two central points. The factors and corresponding operating conditions are: dye concentration (20 $\mathrm{mgL}^{-1}, 100 \mathrm{mgL}^{-1}$, $\left.180 \mathrm{mgL}^{-1}\right), \mathrm{nZVI}$ dosage $\left(0.75 \mathrm{mgL}^{-1}, 30 \mathrm{mgL}^{-1}\right.$ and $\left.60 \mathrm{mgL}^{-1}\right), \mathrm{H}_{2} \mathrm{O}_{2}$ concentration ( $1 \mathrm{mM}, 5 \mathrm{mM}$ and 10 $\mathrm{mM}$ ) and $\mathrm{pH}$ value (2, 6 and 10). A randomized experimental sequence was followed and the obtained values for the decolorization efficiency (\%) were obtained (Felix et al, 2019; Zhao et al, 2019). JMP 13 software was used for the statistical analysis.

\section{RESULTS AND DISCUSSIONS}

\subsection{Model fitting}

Using the fitted full quadratic model, a response surface regression analysis for decolorization efficiency was performed. It contained a total of 28 terms with four input factors, including the main effects and two-way interaction terms. Table 1 presents the results of black dye decolorization efficiency with the yields of $0.43-88.86 \%$. The models were fit using a forward stepwise JMP's regression analysis, while the results are presented through summary of fit (Table 2), ANOVA table (Table 3), parameter estimates (Table 4), surface plot (Figure 2) and optimization plots (Figure 3).

Table 1: DSD matrix and obtained decolorization efficiency

\begin{tabular}{|c|c|c|c|c|c|}
\hline No. & $\begin{array}{l}\text { Dye concentration } \\
\qquad\left(\mathrm{mgL}^{-1}\right)\end{array}$ & $\begin{array}{l}\text { nZVI dosage } \\
\left(\mathrm{mgL}^{-1}\right)\end{array}$ & $\mathrm{pH}$ & $\begin{array}{c}\mathrm{H}_{2} \mathrm{O}_{2} \text { concentration } \\
(\mathrm{mM})\end{array}$ & $\begin{array}{l}\text { Decolorization } \\
\text { efficiency (\%) }\end{array}$ \\
\hline 1 & 180 & 0.75 & 10 & 11 & 2.96 \\
\hline 2 & 20 & 30.375 & 2 & 11 & 10 \\
\hline 3 & 180 & 60 & 2 & 11 & 44.08 \\
\hline 4 & 20 & 60 & 10 & 6 & 1.11 \\
\hline 5 & 100 & 60 & 10 & 11 & 0.46 \\
\hline 6 & 20 & 0.75 & 10 & 1 & 2.22 \\
\hline 7 & 20 & 60 & 2 & 1 & 11.11 \\
\hline 8 & 180 & 0.75 & 2 & 6 & 47.99 \\
\hline 9 & 100 & 30.375 & 6 & 6 & 42.01 \\
\hline 10 & 180 & 60 & 6 & 1 & 88.86 \\
\hline 11 & 100 & 0.75 & 2 & 1 & 54.79 \\
\hline 12 & 180 & 30.375 & 10 & 1 & 49.53 \\
\hline 13 & 20 & 0.75 & 6 & 11 & 1.11 \\
\hline 14 & 180 & 0.75 & 10 & 11 & 2.42 \\
\hline 15 & 20 & 30.375 & 2 & 11 & 36.7 \\
\hline 16 & 180 & 60 & 2 & 11 & 45.28 \\
\hline 17 & 20 & 60 & 10 & 6 & 1.83 \\
\hline 18 & 100 & 60 & 10 & 11 & 0.43 \\
\hline 19 & 20 & 0.75 & 10 & 1 & 0.92 \\
\hline 20 & 20 & 60 & 2 & 1 & 12.84 \\
\hline 21 & 180 & 0.75 & 2 & 6 & 56.87 \\
\hline 22 & 100 & 30.375 & 6 & 6 & 40.18 \\
\hline 23 & 180 & 60 & 6 & 1 & 18.32 \\
\hline 24 & 100 & 0.75 & 2 & 1 & 47.03 \\
\hline 25 & 180 & 30.375 & 10 & 1 & 44.59 \\
\hline 26 & 20 & 0.75 & 6 & 11 & 2.22 \\
\hline 27 & 100 & 30.375 & 6 & 6 & 25.8 \\
\hline 28 & 100 & 30.375 & 6 & 6 & 18.55 \\
\hline
\end{tabular}


Descriptive factors for selected statistical model that best approximate the experimental data are shown in Table 2. The adopted regression model explains approximately 84 per cent of variance in the observed experiments. Although the correlation factor $\left(R^{2}=0.834\right)$ was characterized with low level, the result of ANOVA test (Table 3 ) indicates that regression model is highly significant $(F<0.0001)$, while the validity of selected model is confirmed based on the "lack of fitness" test ( $\mathrm{P}>0.05)$.

Table 2: Summary of fit

\begin{tabular}{|l|c|}
\hline Descriptive factor & Value \\
\hline RSquare & 0.834 \\
\hline RSquare Adj & 0.750 \\
\hline AIC & 244.730 \\
\hline BIC & 242.880 \\
\hline Root Mean Square Error & 11.997 \\
\hline
\end{tabular}

Table 3: ANOVA and lack of fit test

\begin{tabular}{|c|c|c|c|c|}
\hline Source & ${ }^{\mathrm{a} D F}$ & bSS & ${ }^{\mathrm{c} M S}$ & F parameter \\
\hline Model & 9 & 12968.554 & 1440.950 & 10.012 \\
\hline Error & 18 & 2590.494 & 143.920 & Prob $>\mathrm{F}$ \\
\hline C. Total & 27 & 15559.048 & - & $<0.0001$ \\
\hline Lack of Fit & 16 & 2348.093 & 146.756 & 1.211 \\
\hline Pure Error & 2 & 242.401 & 121.201 & Prob $>\mathrm{F}$ \\
\hline Total Error & 18 & 2590.494 & - & 0.544 \\
\hline
\end{tabular}

aDegrees of freedom, bSum of squares, cMean square

Based on the estimated regression coefficients (Table 4), it can be noticed that the dye concentration and $\mathrm{pH}$ value achieve the greatest impact on the Fenton process efficiency. Although both statistically significant, dye and $\mathrm{H}_{2} \mathrm{O}_{2}$ concentration are a part of a statistically significant interaction (Figure 2). Its interaction plot shows that maximum decolorization efficiency is obtained for $\mathrm{H}_{2} \mathrm{O}_{2}$ concentration at lowest level $(1 \mathrm{mM})$, and dye concentration at highest level $\left(180 \mathrm{mgL}^{-1}\right)$.

Table 4: Parameter estimates

\begin{tabular}{|l|c|c|c|c|}
\hline Parameter & Estimate & Standard Error & $t$ value & Prob $>|\mathrm{t}|$ \\
\hline Dye $\left(\mathrm{mgL}^{-1}\right)$ & 16.042 & 2.6825 & 5.98 & $<0.0001$ \\
\hline $\mathrm{pH}$ & -13.011 & 2.6825 & -4.85 & 0.0001 \\
\hline $\mathrm{H}_{2} \mathrm{O}_{2}(\mathrm{mM})$ & -9.228 & 2.6825 & -3.44 & 0.0029 \\
\hline Dye ${ }^{*} \mathrm{H}_{2} \mathrm{O}_{2}$ & -9.553 & 3.0975 & -3.09 & 0.0064 \\
\hline $\mathrm{nZVI}{ }^{*} \mathrm{H}_{2} \mathrm{O}_{2}$ & 5.850 & 3.0975 & 1.89 & 0.0752 \\
\hline $\mathrm{nZVI}\left(\mathrm{mgL}^{-1}\right)$ & 0.299 & 2.6825 & 0.11 & 0.9153 \\
\hline
\end{tabular}

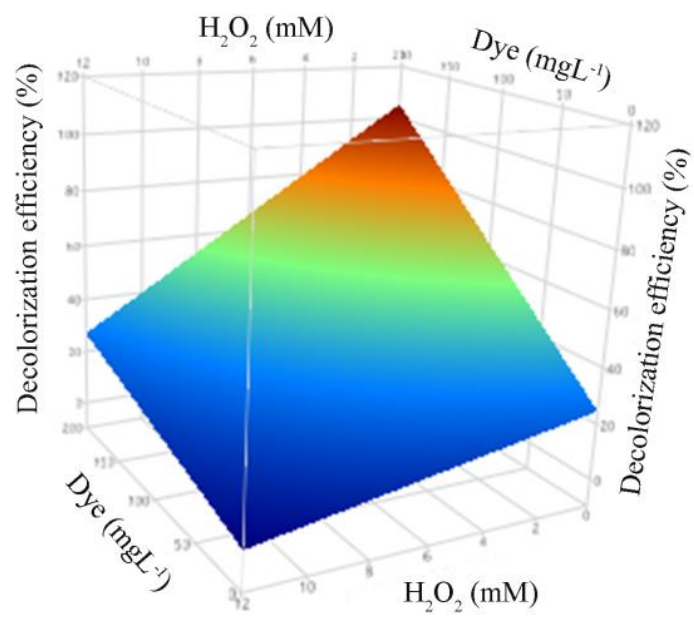

Figure 2: Surface plot showing the interaction effects between dye and $\mathrm{H}_{2} \mathrm{O}_{2}$ concentration 
Within the $\mathrm{nZVI} / \mathrm{H}_{2} \mathrm{O}_{2}$ Fenton treatment, statistical software proposes a maximum decolorization efficiency of $78.89 \%$ within the following optimum process conditions (Figure 3a): dye concentration of $180 \mathrm{mgL}^{-1}, \mathrm{nZVI}$ dosage of $0.75 \mathrm{mgL}^{-1}, \mathrm{H}_{2} \mathrm{O}_{2}$ concentration of $1 \mathrm{mM}$ and $\mathrm{pH}$ value 2 . However, the $\mathrm{pH}$ value 2 is unfavorable from the environmental aspect: experiment requires the consumption of large amounts of chemicals in order to acidify the treated medium and subsequent neutralization of the effluent before its release into the recipient is required.

Figure $3 \mathrm{~b}$ shows the modified optimal process conditions, whereby it was found that increased $\mathrm{pH}$ value slightly reduces the decolorization efficiency of the synthetic black dye solution. Namely, with the $\mathrm{pH}$ values increase to 5, 6 and 7, the efficiency of $\mathrm{nZVI} / \mathrm{H}_{2} \mathrm{O}_{2}$ Fenton process decreased from $79 \%$ to $69.14 \%$, $65.89 \%$ and $62.63 \%$, respectively. Taking into account the environmental aspects and the potential negative impact of the release of highly acidic effluents into the recipients, the researcher is offered the opportunity to choose a more favorable process. In this case it can be a process optimized to $\mathrm{pH} 7$, but a limitation in a sludge formation in neutral environment is noticeable. This observation implies that a $\mathrm{nZVI} / \mathrm{H}_{2} \mathrm{O}_{2}$ Fenton process is more favorable and cost effective in acidic medium then in neutral, which would have to be accompanied by additional sludge treatment.

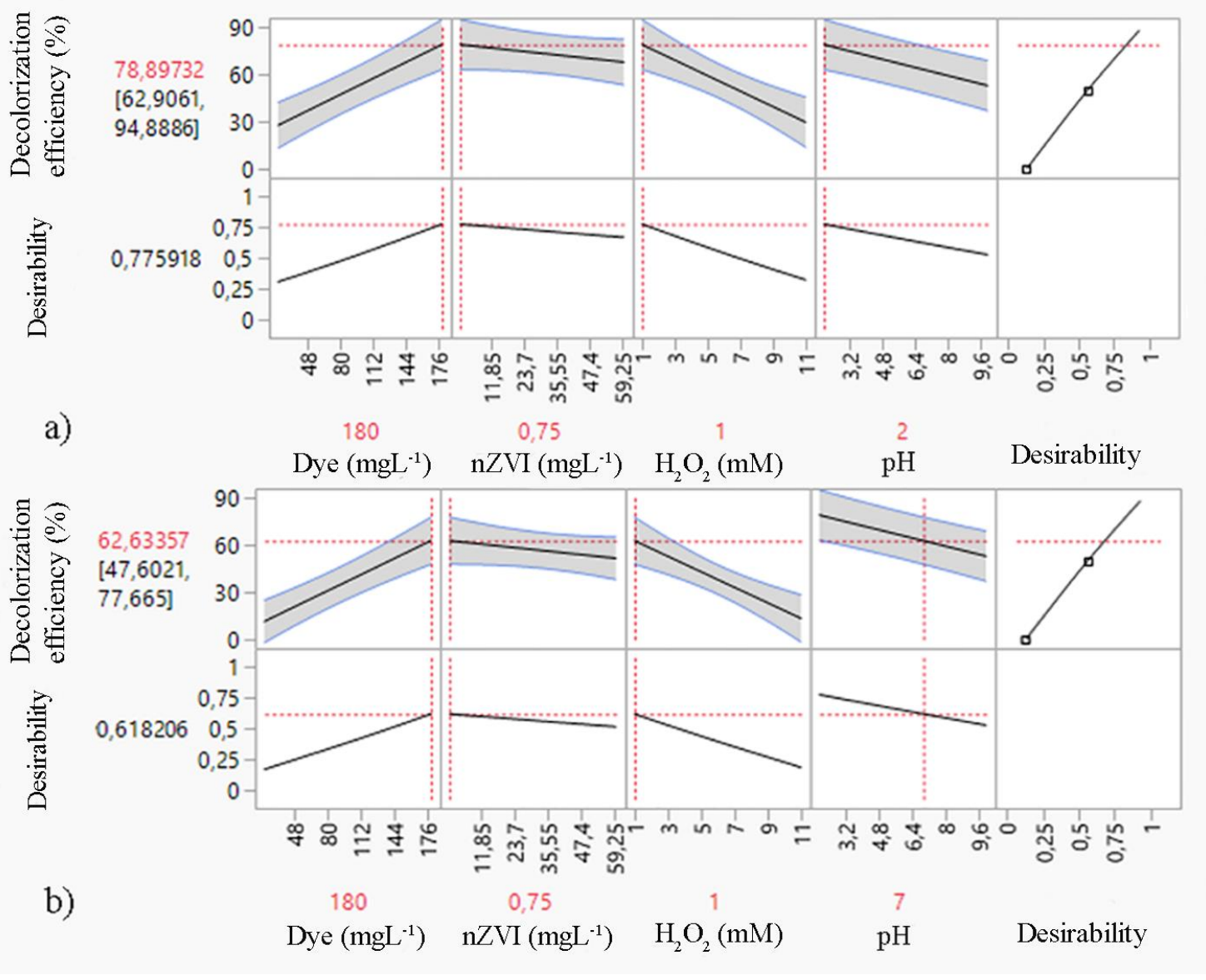

Figure 3: Optimization plot in a) acidic and b) neutral medium

The accuracy and reliability of the mathematical model can be confirmed by validation experiments. The verification of the analytically defined optimum is based on the performance of eight same experiments under the determined optimal process conditions (decolorization efficiency were: 68,25; 69.18; 69.12; $68.22 ; 69.46 ; 68.73 ; 67.96$ and $68.62 \%$ ). Based on the calculated $95 \%$ confidence interval of 68.25 $69.14 \%$ (Figure 4), it is concluded that the proposed decolorization efficiency is experimentally confirmed by verification of the selected models. 


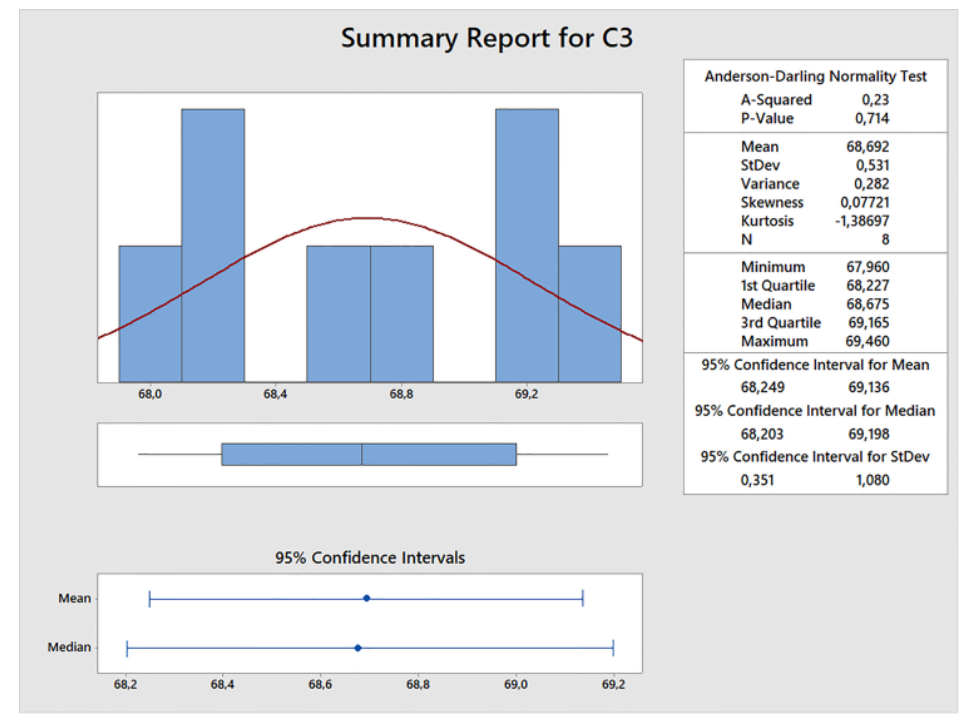

Figure 4: Verification of the optimized $n Z \mathrm{VI} / \mathrm{H}_{2} \mathrm{O}_{2}$ Fenton process

\section{CONCLUSIONS}

The aforementioned study implies that DSD is a feasible method to investigate the effect of Fenton-like process parameters on the printing dye removal efficiency with the reduction of a large number of traditional experiments. Four investigated process parameters, initial dye concentration, nanoparticles dosage, $\mathrm{H}_{2} \mathrm{O}_{2}$ concentration and $\mathrm{pH}$ value were studied using the DSD model approach. Based on the experimental results, it can be concluded that the highly effective parameters for Fenton-like process are dye concentration and $\mathrm{pH}$ value, while $\mathrm{nZVI}$ dosage had the lowest impact on printing dye removal. The optimal combination of process parameters was obtained as dye concentration of $180 \mathrm{mgL}^{-1}, \mathrm{nZVI}$ dosage of $0.75 \mathrm{mgL}^{-1}, \mathrm{H}_{2} \mathrm{O}_{2}$ concentration of $1 \mathrm{mM}$ and $\mathrm{pH}$ of 2 resulted with $79 \%$ of dye removal. The obtained results implied that Fenton-like process as environmentally friendly treatment can be used for printing dye removal from synthetic solutions. However, this study can be extended by considering real printing effluent treatment under obtained optimal process conditions, as well as its physico-chemical characterization.

\section{ACKNOWLEDGMENTS}

This research has been supported by the Ministry of Education, Science and Technological Development through the projects No. 451-03-68/2020-14/200156: "Innovative scientific and artistic research from the FTS (activity) domain" and No. 451-03-68/2020-14/ 200125.

\section{REFERENCES}

[1] Chen, X., Ji, D., Wang, X., Zang, L.: “Review on nano zerovalent iron (nZVI): from modification to environmental applications", Proceedings of IOP Conf. Series: Earth and Environmental Science (CEESD, China, 2017) 012004.

[2] Collivignarelli, M., Bertanza, G., Sordi, M., Pedrazzani, R.: "High-strength wastewater treatment in a pure oxygen thermophilic process: 11-year operation and monitoring of different plant configurations", Water Science \& Technology 71, 588-596, 2015. doi: 10.2166/wst.2015.008.

[3] Collivignarelli, M., Abba, A., Miino, M., Damiani, S.: "Treatments for color removal from wastewater: State of the art", Journal of Environmental Management 236, 727-745, 2019. doi: 10.1016/j.jenvman.2018.11.094.

[4] Felix, C., Ubando, A., Madrazo, C., Sutanto, S., Tran-Nguyen, P., Go, A., Ju, Y. Culaba, A., Chang, J., Chen, W.: "Investigation of direct biodiesel production from wet microalgae using definitive screening design", Energy Procedia 158, 1149-1154, 2019. doi: 10.1016/j.egypro.2019.01.296. 
[5] Galiano, F., Friha, I., Deowan, S., Hoinkis, J., Xiaoyun, Y., Johnson, D., Mancuso, R., Hilal, N., Gabriele, B., Sayadi, S., Figoli, A.: "Novel low-fouling membranes from lab to pilot application in textile wastewater treatment", Journal of Colloid and Interface Science 515, 208-220, 2018. doi: 10.1016/j.jcis.2018.01.009.

[6] Kecić, V. Kerkez Đ., Prica, M., Lužanin O., Bečelić-Tomin M., Tomašević Pilipović D., Dalamcija B.: "Optimization of azo printing dye removal with oak leaves-nZVI/ $\mathrm{H}_{2} \mathrm{O}_{2}$ system using statistically designed experiment", Journal of Cleaner Production 202, 65-80, 2018. doi: 10.1016/j.jclepro.2018.08.117.

[7] Kong, F., Ren, H., Pavlostathis, S., Wang, A., Nan, J., Ren, N.: "Enhanced azo dye decolorization and microbial community analysis in a stacked bioelectrochemical system", Chemical Engineering Journal 354, 351-362, 2018. doi: 10.1016/j.cej.2018.08.027.

[8] Machado, S., Pinto, S., Grosso, J., Nouws, H., Albergaria, J., Delerue-Mato C.: "Green production of zero-valent iron nanoparticles using tree leaf extracts", Science of the Total Environment 445-446, 1-8, 2013. doi: 10.1016/j.scitotenv.2012.12.033.

[9] Massoudinejad, M., Ghaderpoori, M., Azari, M.: "The removal of COD and color from textile industry by chlorine hypochlorite", International Journal of Advanced Science and Technology 76, 35-42, 2015. doi: 10.14257/ijast.2015.76.05.

[10] Maučec, D., Šuligoj, A., Ristić, A., Dražić, G., Pintar, A., Tušar, N.: "Titania versus zinc oxide nanoparticles on mesoporous silica supports as photocatalysts for removal of dyes from wastewater at neutral pH", Catalysis Today 310, 32-41, 2018. doi: 10.1016/j.cattod.2017.05.061.

[11] Meetani, M., Hisaindee, S., Abdullah, F., Ashraf, S., Rauf, M.: "Liquid chromatography tandem mass spectrometry analysis of photodegradation of a diazo compound: A mechanistic study", Chemosphere 80, 422-427, 2010. doi: 10.1016/j.chemosphere.2010.04.065.

[12] Mukherjee, R., Kumar, A., Sinha, A., Lama, Y., Saha, A.: "A review on synthesis, characterization and applications of nano-zero valent iron (nZVI) for environmental remediation", Critical Reviews in Environmental Science and Technology 46, 443-466, 2016. doi: 10.1080/10643389.2015.1103832.

[13] Natarajan, S., Bajaj, H., Tayade, R.: "Recent advances based on the synergetic effect of adsorption for removal of dyes from waste water using photocatalytic process", Journal of Environmental Sciences 65, 201-222, 2018. doi: 10.1016/j.jes.2017.03.011.

[14] Noreen, S., Bhatti, H.N., Iqbal, M., Hussain, F., Sarim, F.M.: “Chitosan, starch, polyaniline and polypyrrole biocomposite with sugarcane bagasse for the efficient removal of Acid Black dye", International Journal of Biological Macromolecules 147, 439-452, 2020. doi: 10.1016/j.ijbiomac.2019.12.257.

[15] Pirsaheb, M., Moradi, S., Shahlaei, M., Wang, X., Farhadian, N.: "A new composite of nano zerovalent iron encapsulated in carbon dots for oxidative removal of bio-refractory antibiotics from water", Journal of Cleaner Production 209, 1523-1532, 2019. doi: 10.1016/j.jclepro.2018.11.175.

[16] Ramos, R.O., Albuquerque, M.V.C., Lopes, W.S., Sousa, J.T., Leite, V.D.: "Degradation of indigo carmine by photo-Fenton, Fenton, $\mathrm{H}_{2} \mathrm{O}_{2} / \mathrm{UV}-\mathrm{C}$ and direct UV-C: Comparison of pathways, products and kinetics", Journal of Water Process Engineering 37, 101535, 2020. doi: 10.1016/j.jwpe.2020.101535.

[17] Sreeja, P.H., Sosamony, K.J.: "A Comparative Study of Homogeneous and Heterogeneous PhotoFenton Process for Textile Wastewater Treatment", Procedia Technology 24, 217-223, 2016. doi: 10.1016/j.jwpe.2020.101535. doi: 10.1016/j.protcy.2016.05.065.

[18] Sriprom, P., Krobthong, W., Assawasaengrat P.: "Investigation of important parameters for PhotoFenton degradation of methyl orange over $\mathrm{Fe} / \mathrm{TiO}_{2}$ catalyst", Proceeding of $6^{\text {th }}$ International Conference on Power and Energy Systems Engineering 2019, (CPESE, Okinawa, Japan, 2019), pages 731-736.

[19] Srinivasan, S., Sadasivam, S.: "Exploring docking and aerobic-microaerophilic biodegradation of textile azo dye by bacterial systems", Journal of Water Process Engineering 22, 180-191, 2018. doi: 10.1016/j.jwpe.2018.02.004.

[20] Tung, C., Shen, S., Chang, J., Hsu, Y., Lai, Y.: "Treatment of real printing wastewater with an electrocatalytic process", Separation and Purification Technology 117, 131-136, 2013. doi: 10.1016/j.seppur.2013.07.028.

[21] Wang, C., Zeng, W., Jiang, T., Chen, X., Zhang, X.: "Incorporating attapulgite nanorods into graphene oxide nanofiltration membranes for efficient dyes wastewater treatment", Separation and Purification Technology 214, 21-30, 2019. doi: 10.1016/j.seppur.2018.04.079. 
[22] Zhao, J., Li W., Qu, H., Tian, G., Wei, Y.: “Application of definitive screening design to quantify the effects of process parameters on key granule characteristics and optimize operating parameters in pulsed-spray fluid-bed granulation", Particuology 43, 56-65, 2019. doi: 10.1016/j.partic.2018.03.007.

[23] Zhu, Y., Xu, J., Cao, X., Cheng, Y.: "Characterization of functional microbial communities involved in different transformation stages in a full-scale printing and dyeing wastewater treatment plant", Biochemical Engineering Journal 137, 162-171, 2018. doi: 10.1016/j.bej.2018.05.026.

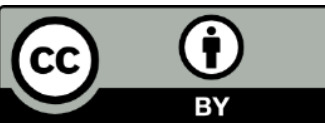

(C) 2020 Authors. Published by the University of Novi Sad, Faculty of Technical Sciences, Department of Graphic Engineering and Design. This article is an open access article distributed under the terms and conditions of the Creative Commons Attribution license 3.0 Serbia

(http://creativecommons.org/licenses/by/3.0/rs/). 


\title{
APPLICATION OF ADVANCED OXIDATION PROCESS FOR THE REMOVAL OF SYNTHETIC WATER-BASED PRINTING DYE AND MICROPLASTICS FROM AQUEOUS SOLUTION
}

\author{
Miljana Prica ${ }^{1}$ (D), Aleksandra Tubić ${ }^{2}$ (D), Maja Lončarski ${ }^{2}$, Vesna Gvoić $^{1}$ (D), \\ Sanja Vasiljević ${ }^{2}$, Živko Pavlović ${ }^{1}$ (D), Jasmina Agbaba ${ }^{2}$ \\ ${ }^{1}$ University of Novi Sad, Faculty of Technical Sciences, Department of Graphic Engineering and \\ Design, Novi Sad, Serbia \\ ${ }^{2}$ University of Novi Sad, Faculty of Sciences, Department of Chemistry, Biochemistry and \\ Environmental Protection, Novi Sad, Serbia
}

\begin{abstract}
Starting from the assumption that wastewater treatments can have a significant impact on the interactions between microplastics (MPs) and various pollutants in different matrices, a focus must be directed on examination of classic and redesigned treatments to remove synthetic dyes in the presence of MPs from wastewater. This paper investigates the potential application of Fenton-like process for the removal of water-based printing dye (Cyan) from aqueous solution containing MPs in a form of granulated polyethylene (PEg). The influence of five quantitative parameters on decolorization efficiency was investigated: initial dye concentration (20-180 mgL ${ }^{-1}$ ), nano zero valent iron (nZVI) dosage (0.75-60 mgL $\mathrm{L}^{-1}$ ), PEg concentration (1-10 $\mathrm{gL}^{-1}$ ), hydrogen-peroxide concentration (1-11 mM) and $\mathrm{pH}$ value (2-10). A novel statistical approach, definitive screening design, resulted with the optimization process which yielded highest removal efficiency of $92 \%$ under following conditions: initial dye concentration of $155 \mathrm{mgL}^{-1}, \mathrm{nZVI}$ dosage of $55 \mathrm{mgL}^{-1}, \mathrm{PEg}$ concentration of $2.35 \mathrm{gL}^{-1}, \mathrm{H}_{2} \mathrm{O}_{2}$ concentration of $2 \mathrm{mM}$ and $\mathrm{pH}$ value 2.5. Available data indicate that in the future, wastewater containing MPs will dictate ways to reuse this water in terms of closing the water material cycle and reducing environmental pollution. Therefore, the industrial wastewater reuse is an important component of sustainable wastewater management practices, namely, water resource augmentation and pollutant reduction.
\end{abstract}

Key words: microplastics, printing dye, definitive screening design, optimization, Fenton-like process

\section{INTRODUCTION}

Microplastics (MPs) pollution is raising environmental concern in recent years due to its global distribution. MPs are plastic particles smaller than $5 \mathrm{~mm}$ in size, which can be classified as primary and secondary MPs, according to the source. Primary MPs are produced in a small size on purpose (toothpastes, facial cleaners, cosmetic products, resin balls, drug carriers, etc.), whereas secondary MPs are formed by degradation of larger plastic waste via physical, chemical and biological processes. Because of their low density and small particle size, they are easily discharged into the wastewater drainage systems. Therefore, the municipal wastewater treatment plants are indicated to be the main recipients of MPs before getting discharged into the natural waterbodies (Gulliver, 2017).

Printing inks and varnishes are industrial mixtures. In the manufacture process of certain printing dyes, polymers as resins and waxes are an essential ingredient, used in order to provide superior adhesion of dyes to non-porous surfaces. These polymers may fall under the proposed definition of MPs: solid nonbiodegradable polymeric particle with physical dimensions between $1 \mu \mathrm{m}-5 \mathrm{~mm}$ originating from anthropogenic sources. Additionally, MPs and dyes can be found in wastewater after the printing process on the polymer packaging material, or screens that are usually made of polyethylene or polypropylene, mainly in flexo and screen-printing process (Somalu et al, 2017; Pekarovicova and Huskova, 2016). In that way, MPs can act as a carrier of synthetic dyes, heavy metals and other toxic contaminants. Printing wastewater due to the presence of non-biodegradable compounds, high concentrations of chemical oxygen demand (COD), trace amounts of toxic metals, persistent colors, adhesives, pigments and etc. must be treated before discharging to water streams (Collivignarelli et al, 2019). The presence of synthetic waterbased dyes and MPs in industrial wastewater poses a threat to aquatic ecosystems, as well as a source of indirect negative effects on human health. Commonly applied method for COD and dye removal from industrial wastewaters are: electrocoagulation (Hendaoui et al, 2020), flocculation (Feng et al, 2021), adsorption (Atrous et al, 2019), biological methods (Mojtabavi et al, 2020), advanced oxidation processes (Kecić et al, 2018a), either individually or combined with other physicochemical methods, as well as nano- 
technology (Papadopoulos et al, 2019). However, classical wastewater treatments are not designed for the removal of synthetic dyes in the presence of MPs. That is why the improvement of technologies for the removal of various pollutants in the presence of MPs is an extremely important field of research.

The aim of this study is directed on examination of advanced oxidation treatment based on the Fenton-like process to remove synthetic water-based Cyan dye in the presence of MPs, polyethylene. Nano zero valent iron (nZVI) particles were synthesized by using green-tea leaves and utilized as a catalyst in Fenton-like process.

\section{MATERIALS AND METHODS}

\subsection{Materials and chemicals}

Water-based printing dye, Cyan, was produced from Flint group and obtained from one printing facility in Novi Sad, Serbia. Structure and properties of Cyan dye are presented in Table 1. Hydrogen peroxide, 30\% (NRK Engineering, Serbia), sodium hydroxide, >98.8\% (POCH), $\mathrm{CCH}_{2} \mathrm{SO}_{4},>96 \%$ (J.T. Baker) were of analytical grade and used without any further purification.

Table 1: Structure and properties of Cyan dye

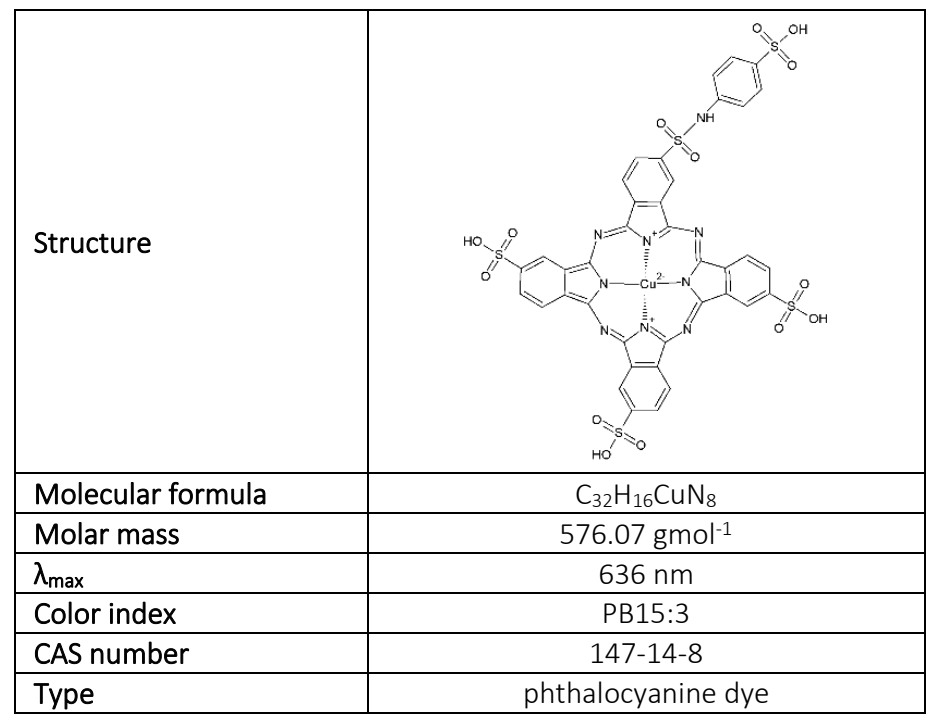

In this study, granulated polyethylene (PEg) microplastic particles were added to synthetic dye solution in order to investigate Fenton-like process efficiency for the removal of printing dye in the presence of MPs. MPs particles were purchased from Sigma Aldrich and basic physico-chemical properties of PEg are presented in Table 2.

Table 2: Physico-chemical properties of PEg (Lončarski, 2020; Tubić et al, 2019)

\begin{tabular}{|l|c|}
\hline PEg appearance & \\
& \\
\hline Particle size $(\mathrm{mm})$ & 3.0 \\
\hline Density $\left(\mathrm{gcm}^{-3}\right)$ & 0.918 \\
\hline Crystallinity $(\%)$ & 44.0 \\
\hline Melting Temperature $\left({ }^{\circ} \mathrm{C}\right)$ & 114 \\
\hline Glass Transition Temp. $\left({ }^{\circ} \mathrm{C}\right)$ & -120 \\
\hline
\end{tabular}




\subsection{Synthesis of Fenton catalyst}

"Green" synthesis method of nZVI particles was conducted by using green-tea leaves combined with iron chloride. Extraction procedure was carried out as described by Machado et al (2013). Extraction of $60 \mathrm{~g}$ green-tea leaves was performed with $1000 \mathrm{ml}$ of deionized water on a magnetic stirrer at temperature of $80^{\circ} \mathrm{C}$ for $60 \mathrm{~min}$. After extraction, the resulting mixture was filtered with Büchner Vacuum Filtration Funnel and mixed with $0.1 \mathrm{M} \mathrm{Fe}^{3+}$ solution in a volume ratio of 1:3. Mixture color turned from yellow to dark brown, indicating the formation of nanoparticles.

\subsection{Experimental procedure}

The lab scale of Fenton-like process was performed by a series of 15 experiments on a JAR test apparatus (FC6S Velp scientific, Italy) in a glass beaker containing $250 \mathrm{~mL}$ of Cyan dye solution at desired concentration (20-180 $\left.\mathrm{mgL}^{-1}\right)$. After the addition of $\mathrm{nZVI}$ in different concentrations $\left(0.75-60 \mathrm{mgL}^{-1}\right)$ and MPs particles (1$\left.10 \mathrm{gL}^{-1}\right)$, the $\mathrm{pH}$ adjustment (2-10) was conducted with $0.1 \mathrm{M} \mathrm{ccH}_{2} \mathrm{SO}_{4}$ and $0.1 \mathrm{M} \mathrm{NaOH}$ solution. The Fenton reaction was initiated by adding the hydrogen peroxide in various concentrations (1-11 $\mathrm{mM})$. The mixture was kept at a constant stirring of $120 \mathrm{rpm}$ at the temperature of $23^{\circ} \mathrm{C}$ for $60 \mathrm{~min}$ (Kecić et al, 2018a). The initial, as well as residual dye concentrations in the reaction mixture were determined by measuring the absorbance of the aqueous solutions at $636 \mathrm{~nm}$ by using UV/VIS spectrophotometer (UV 1800, Shimadzu, Japan). The decolorization efficiency was calculated according to equation (1):

$E(\%)=\frac{A_{0}-A_{t}}{A_{0}} * 100$

where: $A_{0}$ is the initial dye absorbance of Cyan dye aqueous solution; $A_{t}$ is absorbance of Cyan dye aqueous solution after Fenton-like process.

\subsection{Statistical analysis}

In this study, a novel three-level definitive screening design (DSD) approach was employed to investigate the printing dye removal in the presence of MPs particles by Fenton-like process. Five operating variables were included in one single experimental design: initial dye concentration, $\mathrm{nZVI}$ dosage, MPs concentration, $\mathrm{pH}$ and $\mathrm{H}_{2} \mathrm{O}_{2}$ concentration. Each factor had three levels representing the low (-), central (0), and high $(+)$, presented in Table 3. JMP 13 (SAS Institute, USA) software was used for the statistical analysis. What makes DSD a new class three-level screening design is a fact that it requires only one more experiment than twice the number of factors under analysis, which is of significant interest to practitioners. Still, it allows to estimate the main effects without any aliasing with each other or with two-factor interactions (Pereira et al, 2018).

Table 3: Process variables with experimental levels

\begin{tabular}{|l|c|c|c|c|}
\hline Variables & Unit & \multicolumn{3}{|c|}{ Levels } \\
\hline \multicolumn{2}{|c|}{} & -1 & 0 & +1 \\
\hline Dye concentration & $\left(\mathrm{mgL}^{-1}\right)$ & 20 & 100 & 180 \\
\hline nZVI dosage & $\left(\mathrm{mgL}^{-1}\right)$ & 0.75 & 30 & 60 \\
\hline $\mathrm{PEg}$ concentration & $\left(\mathrm{gL}^{-1}\right)$ & 1 & 5.5 & 10 \\
\hline $\mathrm{pH}$ & - & 2 & 6 & 10 \\
\hline $\mathrm{H}_{2} \mathrm{O}_{2}$ concentration & $(\mathrm{mM})$ & 1 & 6 & 11 \\
\hline
\end{tabular}

\section{RESULTS AND DISCUSSIONS}

Table 4 shows the 5 -variable DSD matrix designed with JMP 13 program and obtained Fenton process efficiencies (\%) for 15 experimental runs. It is observed that the maximum and minimum decolorization efficiencies during Fenton-like process are achieved under different sets of process conditions, which confirms the assumption that dye removal process mostly depends on the applied experimental conditions. When compared with classical fractional factorial designs, DSD's have the advantage of estimating independently the main and the quadratic effect, as well as of being unaliased with two-factors interactions (Pereira et al, 2018). 
Table 4: Experimental design layout and observed response

\begin{tabular}{|l|c|c|c|c|c|c|}
\hline No. & $\begin{array}{c}\text { Dye } \\
\text { concentration } \\
\left(\mathrm{mgL}^{-1}\right)\end{array}$ & $\begin{array}{c}\mathrm{nZVI} \text { dosage } \\
\left(\mathrm{mgL}^{-1}\right)\end{array}$ & $\begin{array}{c}\mathrm{PEg} \\
\text { concentration } \\
\left(\mathrm{gL}^{-1}\right)\end{array}$ & $\mathbf{p H}$ & $\begin{array}{c}\mathrm{H}_{2} \mathrm{O}_{2} \\
\text { concentration } \\
(\mathrm{mM})\end{array}$ & $\begin{array}{c}\text { Fenton process } \\
\text { efficiency (\%) }\end{array}$ \\
\hline 1 & 100 & 60 & 10 & 10 & 11 & 1.41 \\
\hline 2 & 100 & 0.75 & 1 & 2 & 1 & 81.54 \\
\hline 3 & 180 & 30 & 1 & 10 & 11 & 0.74 \\
\hline 4 & 20 & 30 & 10 & 2 & 1 & 18.99 \\
\hline 5 & 180 & 0.75 & 5.5 & 2 & 11 & 69.41 \\
\hline 6 & 20 & 60 & 5.5 & 10 & 1 & 1.73 \\
\hline 7 & 180 & 60 & 1 & 5,5 & 1 & 84.76 \\
\hline 8 & 20 & 0.75 & 10 & 5,5 & 11 & 0.68 \\
\hline 9 & 180 & 60 & 10 & 2 & 6 & 91.67 \\
\hline 10 & 20 & 0.75 & 1 & 10 & 6 & 1.58 \\
\hline 11 & 180 & 0.75 & 10 & 10 & 1 & 1.70 \\
\hline 12 & 20 & 60 & 1 & 2 & 11 & 0.15 \\
\hline 13 & 100 & 30 & 5.5 & 5,5 & 6 & 30.54 \\
\hline 14 & 100 & 30 & 5.5 & 5,5 & 6 & 33.43 \\
\hline 15 & 100 & 30 & 5.5 & 5,5 & 6 & 29.94 \\
\hline
\end{tabular}

The adopted regression model contained eleven terms. As shown in Table 5, the adopted regression model explains approximately $99.9 \%$ of variance in the observed Fenton efficiency values. The value of adjusted $\mathrm{R}^{2}$ is $99.8 \%$, which reveals good relationship between the expected values and the actual values. Compared to mean of response, root mean square error is small, indicating good fit and accuracy of model prediction. Results of ANOVA test shown in Table 6 confirmed the significance of the adopted regression model (the value of the parameter $F<0.0001)$.

Table 5: Summary of fit

\begin{tabular}{|l|c|}
\hline Source & Value \\
\hline$R^{2}$ & 0.999 \\
\hline$R^{2}$ Adj & 0.998 \\
\hline Root Mean Square Error & 1.361 \\
\hline Mean of Response & 29.885 \\
\hline
\end{tabular}

Table 6: ANOVA

\begin{tabular}{|l|c|c|c|c|}
\hline Source & Degrees of freedom & Sum of Squares & Mean Square & F parameter \\
\hline Model & 10 & 16969.039 & 1696.900 & 916.245 \\
\hline Error & 4 & 7.408 & 1.850 & Prob $>\mathrm{F}$ \\
\hline C. Total & 14 & 16976.447 & - & $<0.0001$ \\
\hline
\end{tabular}

Based on the estimated parameter and standard error values, the statistically significant factors that contribute the most to the efficiency of Cyan dye removal in Fenton-like process were determined (Table 7 - bolded values). Statistical analysis revealed that all main process parameters are statistically significant and contribute to the decolorization efficiency. The results demonstrated that dye concentration, nZVI dosage and interaction effect between PEg concentration and $\mathrm{H}_{2} \mathrm{O}_{2}$ concentration, dye concentration and $n Z \mathrm{VI}$ dosage as well as $\mathrm{pH}$ and $\mathrm{H}_{2} \mathrm{O}_{2}$ concentration have a positive influence on the Fenton process efficiency, while other variables have a negative effect. Furthermore, all single terms are a part of four significant two-way interactions, whereby dye concentration, $\mathrm{pH}$ and $\mathrm{H}_{2} \mathrm{O}_{2}$ concentrations are involved in two significant interactions.

Based on Table 7, a surface response plots of significant two-way interactions in the model are shown in Figure 1. From the surface plot diagram (Figure 1a) it follows that maximal Fenton process efficiency is reached when $\mathrm{nZVI}$ dosage is kept at its high level $\left(60 \mathrm{mgL}^{-1}\right)$, while dye concentration increases from 20 to $180 \mathrm{mgL}^{-1}$. However, maintained at low level $(1 \mathrm{mM}), \mathrm{H}_{2} \mathrm{O}_{2}$ concentration exhibits the most pronounced influence on the impact of PEg concentration on dye removal (Figure 1c). The phenomenon can be ascribed to the fact that dye removal can be achieved with both advanced oxidation process and adsorption process of dye on MPs surface. 
Table 7: Parameter estimates sorted by statistical significance

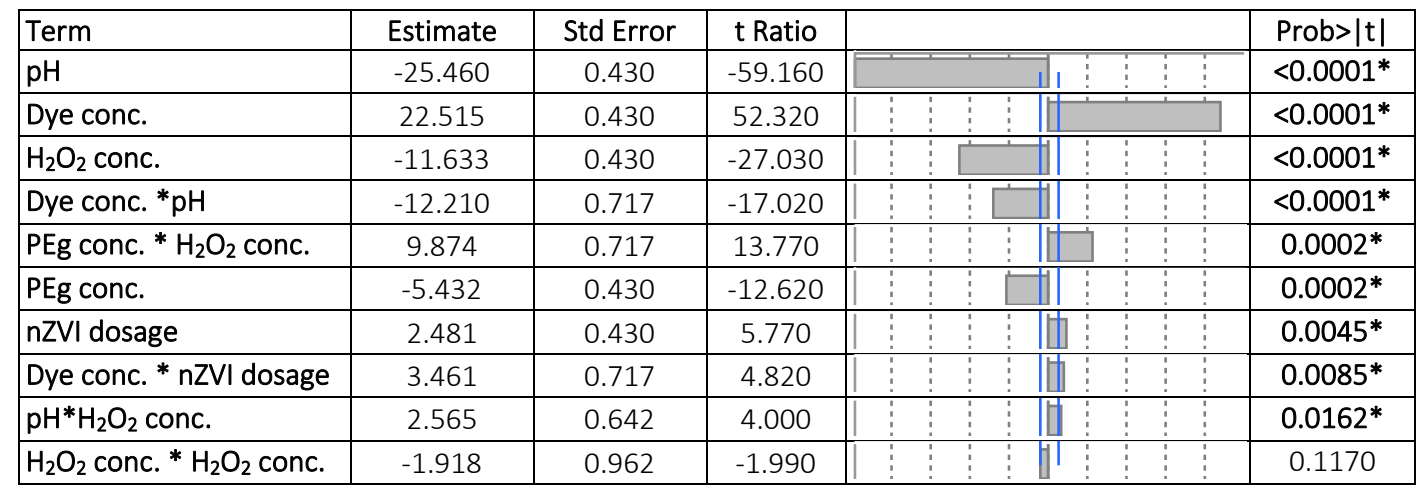

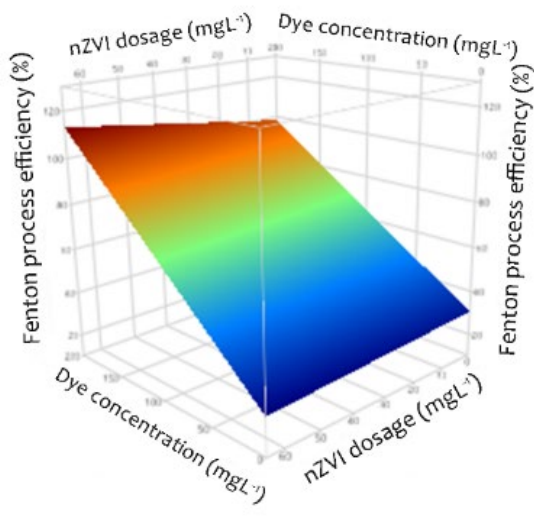

a)

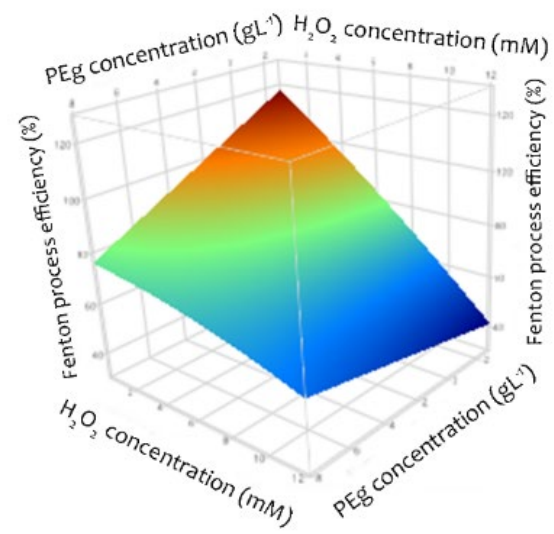

c)

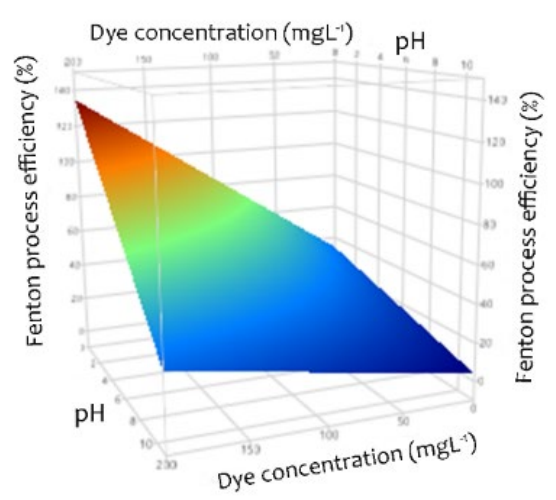

b)

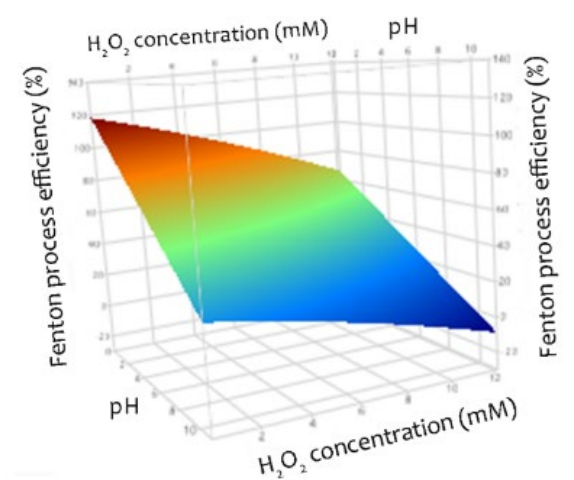

d)

Figure 1: Surface response plots illustrating two significant interactions between: a) dye concentration and nZVI dosage; b) dye concentration and $\mathrm{pH}$; c) PEg concentration and $\mathrm{H}_{2} \mathrm{O}_{2}$ concentration; d) $\mathrm{pH}$ and $\mathrm{H}_{2} \mathrm{O}_{2}$ concentration

Prediction profiler with optimal settings is shown in Figure 2. The optimization plot graphically illustrates how the Fenton process efficiency changes as a function of one of the variables, while all other variables remain constant. According to optimization results, maximum Fenton process efficiency of $92 \%$ is obtained for the following settings: $155 \mathrm{mgL}^{-1}$ of Cyan dye concentration, $55 \mathrm{mgL}^{-1}$ of nZVI dosage, $2.35 \mathrm{gL}^{-1} \mathrm{of} \mathrm{PEg}$ concentration, $2 \mathrm{mM}$ of $\mathrm{H}_{2} \mathrm{O}_{2}$ concentration and $\mathrm{pH}$ 2.5. This confirms that the process efficiency increases with $\mathrm{H}_{2} \mathrm{O}_{2}$ and $\mathrm{pH}$ decreasing. 


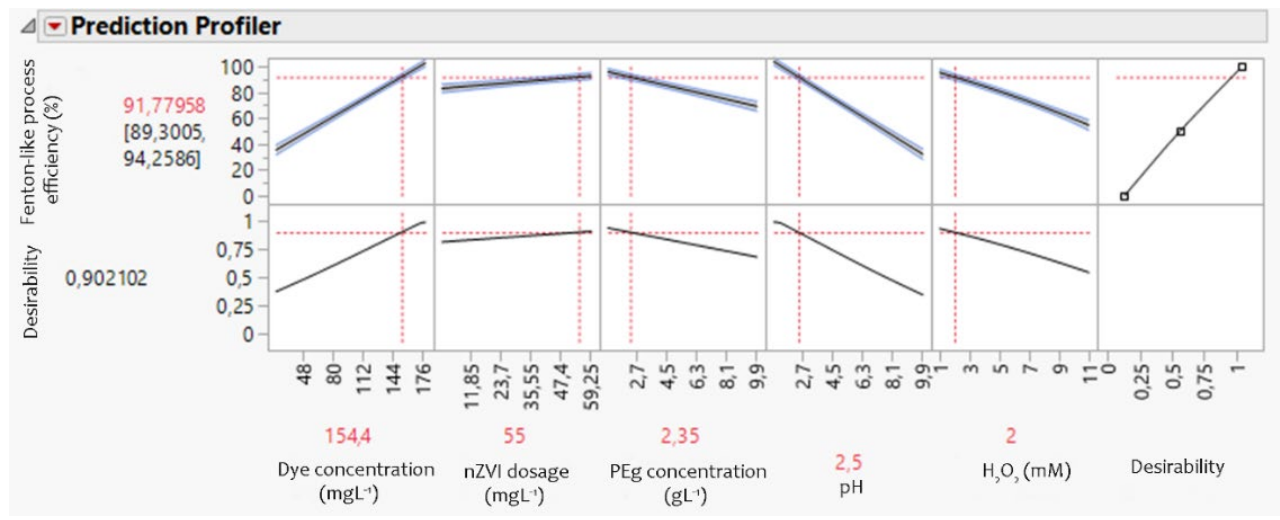

Figure 2: Optimization diagram for Fenton-like process

In the study conducted by Kecić et al (2018b), Cyan dye removal with nZVI-induced Fenton process without MPs particles resulted with $87 \%$. The obtained higher Fenton process efficiency in this experiment is probably due to the partial dye adsorption on MPs surface, indicating that the presence of MPs particles in wastewater may contribute to higher Fenton process efficiency than actually obtained. Certainly, future studies must include printing wastewater treatments containing dyes and MPs of various types and concentrations.

\section{CONCLUSIONS}

In this study, Fenton-like treatment of Cyan water-based printing dye with the addition of microplastic in a form of granulated polyethylene was investigated. A novel statistical method, definitive screening design, was used in order to allow screening and preliminary optimization in a single experiment. The method proposed enables efficient treatment of synthetic aqueous solutions in the presence of microplastics, optimized for maximum decolorization efficiency of $92 \%$ by the adopted statistical model. The results confirmed the significant influence of all main process parameters on decolorization efficiency, as well as four significant two-way interaction. Furthermore, higher decolorization efficiency was obtained in comparison to Fenton-like process without the addition of microplastic, indicating a possible adsorption dye mechanism with the simultaneous Fenton process conduction. Nevertheless, further investigation should be directed towards the evaluation efficiency of various treatments for the synthetic dye removal in the presence of microplastic in wastewater treatments, while focusing on possible influence of microplastic on desorption of synthetic dyes into the aquatic environment and assessment of effluent toxicity before and after treatment.

\section{ACKNOWLEDGMENTS}

This research has been supported by the Provincial Secretariat for Science and Technological Development, Autonomous Province of Vojvodina through the project: "Synthetic dye removal in the presence of microplastics in advanced water treatment" (Grant No. 142-451-3186/2020-03).

\section{REFERENCES}

[1] Atrous, M., Sellaoui, L., Bouzid, M., Lima, E., Thue P., Bonilla-Petriciolet, A., Lamine, A.: "Adsorption of dyes acid red 1 and acid green 25 on grafted clay: Modeling and statistical physics interpretation", Journal of Molecular Liquids 294, 111610, 2019. doi: 10.1016/j.molliq.2019.111610.

[2] Collivignarelli, M., Abba, A., Miino, M., Damiani, S.: "Treatments for color removal from wastewater: State of the art", Journal of Environmental Management 236, 727-745, 2019. doi: 10.1016/j.jenvman.2018.11.094.

[3] Feng, Q., Gao, B., Yue, Q., Guo, K.: “Flocculation performance of papermaking sludge-based flocculants in different dye wastewater treatment: Comparison with commercial lignin and coagulants", Chemosphere 262, 128416, 2021. doi: 10.1016/j.chemosphere.2020.128416.

[4] Gulliver, T.: "Degradation of PHB and PE microbeads in aerobic and anaerobic biological wastewater treatment microcosms", PhD thesis, Colorado School of Mines, Arthur Lakes Library, 2017. 
[5] Hendaoui, K., Trabelsi-Ayadi, M., Ayari, F.: "Optimization and mechanisms analysis of Indigo dye removal using continuous electrocoagulation", Chinese Journal of Chemical Engineering, 2020. doi: 10.1016/j.cjche.2020.07.065, 2020.

[6] Kecić, V., Kerkez, Đ., Prica, M., Lužanin, O., Bečelić-Tomin, M., Tomašević Pilipović, D., Dalamcija, B.: "Optimization of azo printing dye removal with oak leaves-nZVI/ $\mathrm{H}_{2} \mathrm{O}_{2}$ system using statistically designed experiment", Journal of Cleaner Production 202, 65-80, 2018a. doi: 10.1016/j.jclepro.2018.08.117.

[7] Kecić, V., Prica, M., Kerkez, Đ., Lužanin, O., Bečelić-Tomin, M., Tomašević Pilipović D., Leovac Maćerak, A.: Definitive screening design for the optimization of flexographic water-based Cyan dye removal from aqueous solution by $\mathrm{nZVI-induced} \mathrm{Fenton} \mathrm{process.} \mathrm{Proceedings} \mathrm{of} 9^{\text {th }}$ International Symposium on Graphic Engineering and Design 2018b, (GRID: Novi Sad, Serbia, 2018), pages 161-167.

[8] Lončarski, M.: "Impact of physicochemical properties of microplastics and selected persistent organic pollutants on interactions in the aqueous matrix", PhD thessis, University of Novi Sad, Faculty of Sciences, 2020.

[9] Machado, S., Pinto, S., Grosso, J., Nouws, H., Albergaria, J., Delerue-Matos, C.: "Green production of zero-valent iron nanoparticles using tree leaf extracts", Science of the Total Environment 445-446, 1-8, 2013. doi: 10.1016/j.scitotenv.2012.12.033.

[10] Mojtabavi, S., Khoshayand, M., Fazeli, M., Samadi, N., Faramarzi, M.: "Combination of thermal and biological treatments for bio-removal and detoxification of some recalcitrant synthetic dyes by betaine-induced thermostabilized laccase", Environmental Technology \& Innovation 20, 101046, 2020. doi: 10.1016/j.eti.2020.101046.

[11] Papadopoulos, K., Argyriou, R., Economou, C., Charalampous, N., Dailianis, S., Tatoulis, T., Tekerlekopoulou, A., Vayenas D.: "Treatment of printing ink wastewater using electrocoagulation", 2019. Journal of Enviornmental Management 237, 442-448, 2019. doi: 10.1016/j.jenvman.2019.02.080.

[12] Pekarovicova, A., Husovska, V.: "Printing ink formulations", Printing on Polymers 41-52, 2016. doi: 10.1016/B978-0-323-37468-2.00015-4.

[13] Pereira, A., Reis, M., Leca, J., Rodrigues, P., Marques, J.: “Definitive Screening Designs and latent variable modelling for the optimization of solid phase microextraction (SPME): Case study Quantification of volatile fatty acids in wines", Chemometrics and Intelligent Laboratory Systems 179, 73-81, 2018. doi: 10.1016/j.chemolab.2018.06.010.

[14] Somalu, M., Muchtar, A., Daud, W., Brandon, N.: "Screen-printing inks for the fabrication of solid oxide fuel cell films: a review", Renewable and Sustainable Energy Reviews 75, 426-439, 2017. doi: 10.1016/j.rser.2016.11.008.

[15] Tubić, A., Lončarski, M., Maletić, S., Molnar Jazić, J., Watson, M., Tričković, J., Agbaba, J.: "Significance of Chlorinated Phenols Adsorption on Plastics and Bioplastics during Water Treatment", Water 11, 2358, 2019. doi: 10.3390/w11112358.

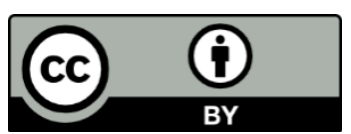

(C) 2020 Authors. Published by the University of Novi Sad, Faculty of Technical Sciences, Department of Graphic Engineering and Design. This article is an open access article distributed under the terms and conditions of the Creative Commons Attribution license 3.0 Serbia (http://creativecommons.org/licenses/by/3.0/rs/). 



\title{
THE INFLUENCE OF ARTIFICIAL AGING ON RECYCLABILITY AND MECHANICAL STABILITY OF PHARMACEUTICAL PACKAGING
}

\author{
Marina Vukoje (D), Ivana Bolanča Mirković (D), Martina Bešlić, Gorana Petković (iD \\ University of Zagreb, Faculty of Graphic Arts, Zagreb, Croatia
}

\begin{abstract}
Recycling of wastepaper and packaging is one of the most desirable options for the purpose of preservation the environment and increasing the sustainability of production. Changes in customer behaviour have increased a demand for packaging materials, such as the growth of online shopping and/or demand for optimal sized packaging foods and medicines. During storage and transport, products can be exposed to different weather conditions, which ultimately affects their quality and disposal. Therefore, in this paper, the influence of moisture and temperature on the mechanical properties of pharmaceutical packaging as well as on the possibility of their recycling was investigated. The printed and formed pharmaceutical packaging was subjected to a process of accelerated aging in a chamber under the action of temperature and humidity, according to standard methods and defined conditions. Thereafter, the samples were subjected to mechanical testing to determine the effect of moisture on the mechanical properties. In addition, the impact of moisture on pharmaceutical packaging recycling performance was examined. Recycling was carried out in laboratory conditions by chemical deinking flotation according to the INGEDE 11 method, while the obtained recycled laboratory sheets were characterized by the determination of optical properties and the image analysis. It was found that the mechanical properties of the tested pharmaceutical packaging were deteriorated. From the results obtained by determination of the optical properties, in recycled samples the brightness decreases with aging. As the sample ages, the printing ink binds to the recycled fibres, so the ERIC is lower in recycled fibres obtained from non-aged samples compared to the old ones. The CIE coefficient $b^{*}$ is higher for samples obtained from recycling of aged pharmaceutical packaging than for samples obtained from recycling of non-aged samples, and aged recycled samples will be yellower than non-aged ones. Therefore, the whiteness is lower in recycled fibres obtained from aged samples. When measuring the image analysis, the obtained results show that the number of ink particles and their surface area are significantly reduced with the duration of aging time.
\end{abstract}

Key words: pharmaceutical packaging, artificial aging, recycling, mechanical properties

\section{INTRODUCTION}

The changes in costumers' behaviour have increased the demand for packaging materials (Holik, 2013). The global increase of production and consumption of different packaging materials resulted in higher environmental loads and waste generation. In order to reduce the overall environmental impact of packaging, in the last decade, the trend of developing sustainable packaging has been growing. Sustainable packaging as defined in research by Steenis et al, (2017) is a packaging that has a comparatively low environmental impact as assessed by life-cycle assessment. Sustainable packaging should be composed of non-toxic materials, most preferably made of natural renewable materials. When it comes to its end of life, it should be recyclable, reusable, biodegradable or compostable. From a consumer-perspective, there are different definitions of sustainable packaging. Nguyen et al, (2020) reported that consumers definition of sustainable packaging is more related to packaging materials (biodegradability and recyclability), and market appeal (attractive graphic design and good price), while Steenis et al, (2017) gave a definition of "a packaging design that evokes explicitly or implicitly the ecofriendliness of the packaging". Packaging design involves a combination of structural and graphical and verbal elements. In that case, the materials are being structural elements with and the main contributor to direct (objective) environmental impacts. Graphical and verbal elements are informational and both may be used to signal sustainability. Verbal features can be used to communicate sustainability explicitly, (e.g. through labelling), while green colouring communicate sustainability implicitly (Steenis et al, 2017). When talking about market appeal, consumers expectations about eco-friendly packaging are related to attractive graphic design, functional performance, and price (Nguyen et al, 2020). According to Tamani et al, (2015) when designing a new packaging products, the packaging industry limitations (the scalability of production process, the row material availability, etc.), the end of life waste packaging management regulation and legislation (related to biodegradability, recyclability, incineration, etc.) and consumer 
preferences (transparent packaging, environment-friendly packaging, no extra-cost due to packaging, etc.) should be taken into account.

When it comes to pharmaceutical packaging, the type of packaging affects the emission generated during packaging of medicines and their release to the environment. For example, (Raju et al, 2016) investigated the LCA of two packaging systems in accordance to the CML 2001 impact assessment method and reported that the environmental performance of PVC blister packaging is better than the aluminium blister packaging.

Due to a significant share of plastic packaging in the overall volume of municipal solid waste, different concerns have led to an increased demand for use of biodegradable and renewable light-weight materials for sustainable packaging applications.

The higher use of packaging nowadays has resulted in the higher share of paper based packaging products in the waste stream collection system compared to that of graphic products (Runte et al, 2015). According to CEPI (Confederation of European Paper Industries), defined targets for the recycling of paper-based packaging are $75 \%$ by 2025 and $85 \%$ by 2030 . CEPI suggested a list of recommendations for the improvement of the recyclability of paper packaging products in the paper recycling process (CEPI, 2019). The most important parameters for the good recyclability of paper-based packaging products are repulpability, yield of fibrous material, coarse reject, flake content, stickies, and technical quality. According to the guideline, a design phase should consider the intended purpose and end-of-life stage of the packaging to optimise the recycling of paper packaging, i.e. the producers should take into account the quantity of non-paper constituents, the use of recycled alternative fibres, the use of adhesives, chemicals, coatings and varnishes. When it comes to use of printing inks in packaging, the quantity of used ink should be optimised. The used inks should also be free of mineral oils and with the minimal share of metallic components in the ink formulation. When it is possible, deinkable printing technology when producing packaging from bleached paper and board should be considered (CEPI, 2019). With the appropriate collection and sorting, all paper packaging can be recycled. The increased amount of collected paper resulted in a reduction of the quality of the paper for recycling (Runte et al, 2015). Iosip et al, (2012) showed in their research the importance of selective collection of paper and board and their advanced sorting technologies implementation and their influence on the quality of recovered paper grades supplied to paper mills. Additionally, they showed that utilization of recovered paper batches with a low quality, contributes to an increased environmental impact due to increased energy consumption and higher volumes of generated waste, resulting in higher emissions released into the air and water.

Deinking is of major importance in the production of graphic papers due to the high demand of optical properties of the finished products but it is also becoming of interest in packaging grades, due to the growing tendency of printing some packaging products (Blanco et al, 2013). Deinking is the most important step in the paper recycling process. It depends upon the quality of the collected paper for recycling, the type of printing process and the properties of the printing inks, the age of the product and climatic conditions (light, temperature, moisture and storage time) during its life cycle (Faul, 2010; Kemppainen et al, 2013; Kemppainen et al, 2015; Vukoje and Rožić, 2018). In deinking process, the printing ink and other contaminants must be removed from the recycling mixtures (Kemppainen et al, 2015). The most common deinking process is flotation, where air bubbles are used for collection of hydrophobic ink particles and their removal in the sludge rejects as subsequently formed froth.

The studies conducted up to now, have mainly studied the influence of climatic conditions on the recycling efficiency of the offset prints on newsprint and graphic papers. The research by Kemppainen et al, (2015) showed that deinkability of old or thermally aged ink from offset-printed papers is difficult due to chemical and/or physical interactions, fragmentation during the repulping process (higher amounts of free microscopic ink particles, visible dirt specks, and inky fibres) and formation of strong agglomerates with fibres, which results in flaky pulp suspension. According to Kemppainen et al, (2015) ink particles strongly bound to fibres due to oxidative polymerization reactions that occur at accelerated rates and at a magnifying effect with unsaturated offset ink components, such as vegetable oils and/or alkyd resins.

Given that the effect of moisture and temperature on the process of paper recycling was mainly the topic of the previous known research, the aim of this paper is to determine how humidity and temperature in accelerated aging test, affect the process of ink particles separation during recycling of packaging. Since moisture plays an important role in papers dimensional stability and physical strength (Kemppainen et al, 2013), the influence of temperature and humidity on pharmaceutical boxes physical strength was investigated as well. 


\section{METHODS}

\subsection{Materials}

Previously formed and printed pharmaceutical boxes were used for this study. The boxes were printed by offset printing process.

\subsection{Accelerated aging test}

The samples were subjected to the accelerated aging test, i.e. they were exposed to elevated humidity and temperature. Samples were exposed to controlled conditions for 3, 6, and 9 days, at relative humidity of $40 \%$ and temperatures of $60^{\circ} \mathrm{C}$. The "Kottermann" air chamber Type 2306 was used in the experiment.

\subsection{Flat Crush Test}

After the aging simulation, the pharmaceutical packaging samples were subjected to the Flat Crush Test method, manufactured by Lorentzen \& Wettre.

\subsection{Recycling of the pharmaceutical boxes}

Pharmaceutical packaging boxes (aged and non-aged) were recycled according to standard laboratory procedure defined in INGEDE method 11 (INGEDE e. V., 2012). Samples were disintegrated in Enrico Toniolo disintegratior while the flotation process was performed in the laboratory flotation cell. According to INGEDE method 1, a certain amount of pulp suspension was separated after disintegration process before flotation (BF) and after flotation process (F) to prepare laboratory sheets of $45 \mathrm{~g} / \mathrm{m}^{2}$, using automatic sheet-forming device Rapid-Köthen Sheet, PTI. The obtained laboratory handsheets from undeinked pulp (BF) and deinked pulp (F) were used for the evaluation of optical parameters.

\subsection{Deinkability evaluation}

The efficiency of deinking process was evaluated by determination of undeinked (BF) and deinked pulp (F) handsheets optical properties as well as the residual ink area. The residual ink (particle) area on handsheets was determined by image analysis and data processing, using Spec Scan 2000 (Apogee Systems Inc.). Undeinked (BF) and deinked pulp (F) handsheets were tested for their optical properties. All the measurements were carried out on Technydine Colour Touch 2 Spectrophotometer, according to standard methods: ISO Brightness (ISO 2470), CIE whiteness and colour components $L^{*} a^{*} b^{*}$ (ISO 11475), ISO Opacity (ISO 2471) and ERIC.

\section{RESULTS AND DISCUSSION}

Figures 1-7 show the results of the optical properties of recycled fibres before and after conducted flotation process, depending on the aging days of the exposed samples in the climate chamber.

In the Figure 1 it can be seen that by increasing the aging time and with longer exposure of the samples to increased humidity and temperature, the ISO brightness of the obtained recycled handsheets is reduced. However, the ISO Brightness of the fibres obtained after flotation process is smaller compared to fibres obtained without flotation process. This can be explained by the loss of optical brighteners and fillers during flotation process. The loss of fillers can be conformed additionally by the reduction of opacity of deinked fibres during flotation process (Figure 2). The aging time in elevated humidity and temperature does not have a significant influence on the opacity of recycled fibres since the results do not differ significantly. 


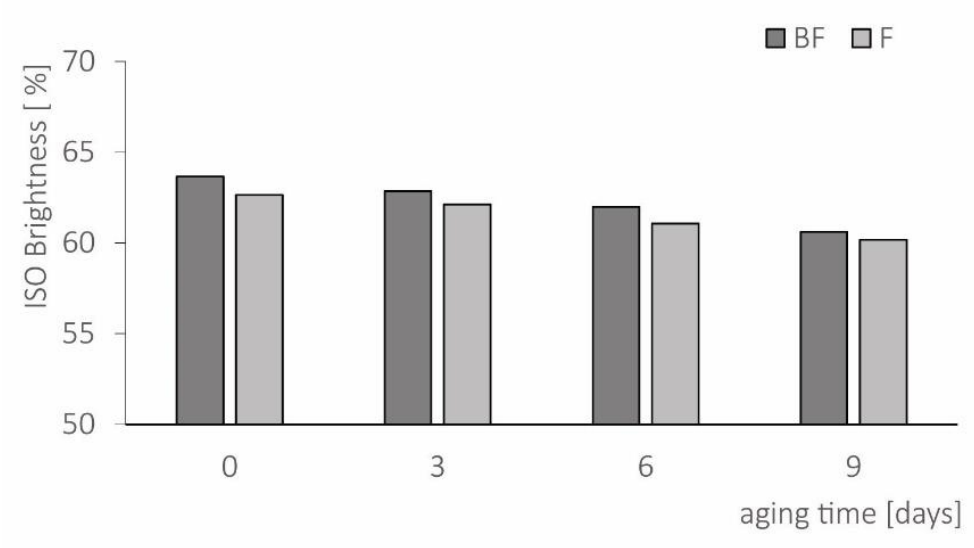

Figure 1: ISO Brightness of recycled fibres depending on aging time

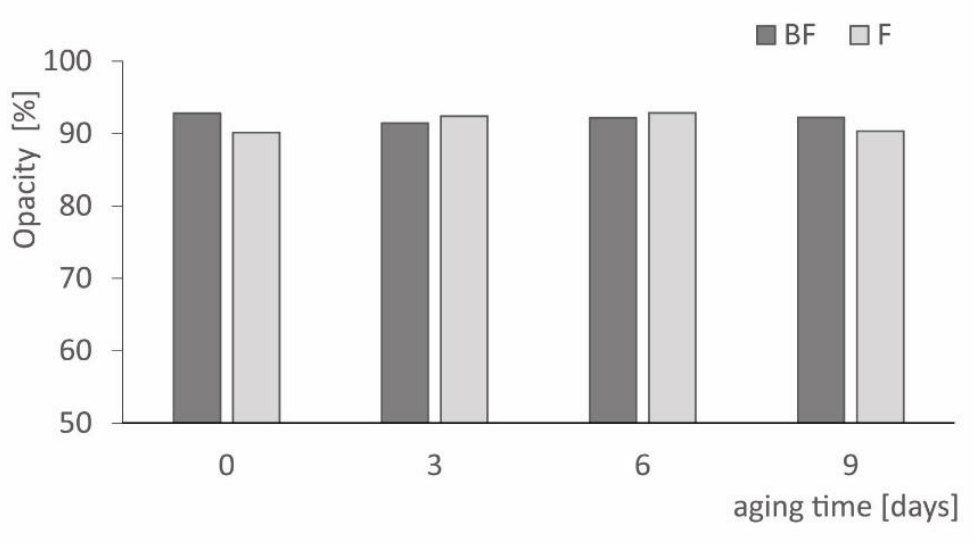

Figure 2: ISO opacity of recycled fibres depending on aging time

The ERIC method evaluates the residual ink by measuring the absorbed light in the infrared range, namely at $950 \mathrm{~nm}$. At this wavelength, the ink absorbs significantly more radiation than paper, and the measurements are quite insensitive to the presence of lignin, dyes or other colorants (Pala et al, 2007). Figure 3 shows that the value of ERIC decreases after flotation process, because in the flotation process the printing ink is removed from the suspension altogether with collected flotation froth (foam). The highest percentage of removed ink particles is visible on the non-aged sample (approx. 38\%), while in aged samples the percentage of ink particles removal is significantly lower compared to the non-aged sample (25\% in 3 days, 31\% in 6 days and 32\% for 9 days). Moreover, these results explain the lower ISO brightness of the recycled handsheets obtained from aged samples (Figure 1). As the samples age, the ink film during disintegration breaks into the larger particles (Table 1). Additionally, the printing ink during aging binds to the recycled fibres, so the ERIC values of the aged samples (after the disintegration process) is slightly smaller compared to the ERIC value of the non-aged sample. 


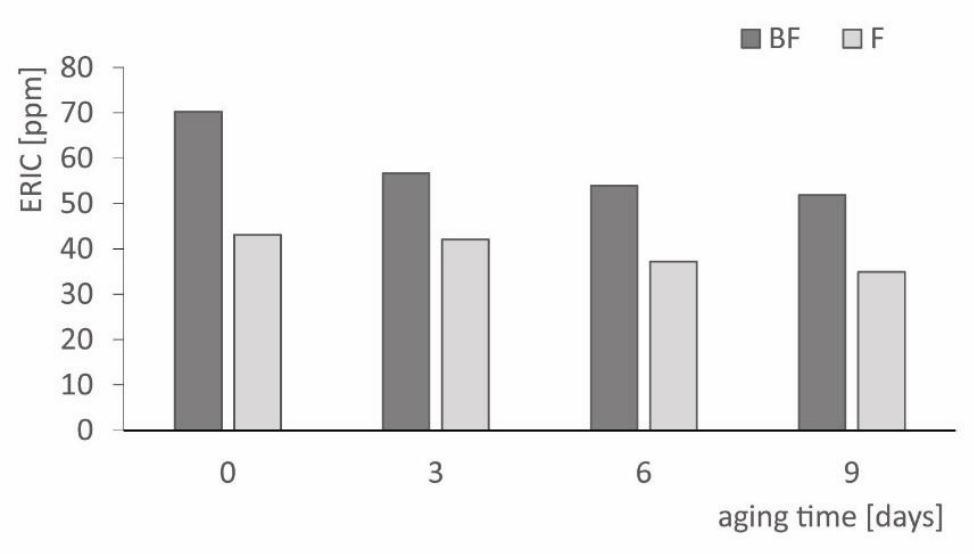

Figure 3: ERIC of recycled fibres depending on aging time

Figure $4 a$ shows that the coefficient $L^{*}$ is not affected by the influence of elevated humidity and temperature, i.e. the value of the coefficient $L^{*}$ does not change significantly during aging time. Moreover, the value of the coefficient $L^{*}$ does not change during deinking process, thus the obtained handsheets have the same values before and after flotation process. Figure $4 b$ shows the values of the difference between the CIE $L^{*}$ coefficient measured in conditions with and without UV-content of illumination. It can be seen from the results that the largest difference was obtained in all samples after flotation, very likely due to the loss of fillers (probably optical brighteners) during the flotation process.

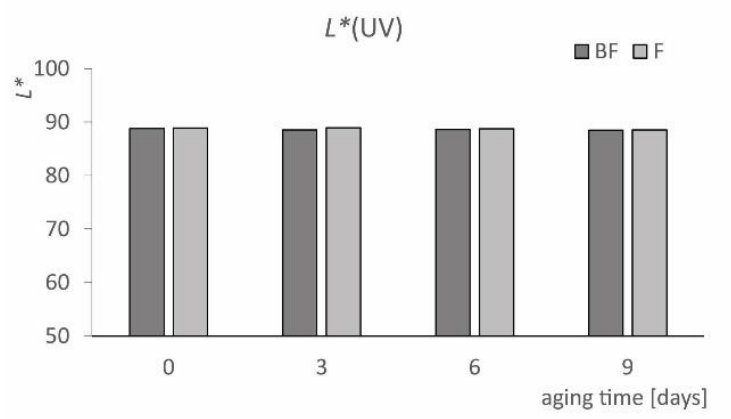

a

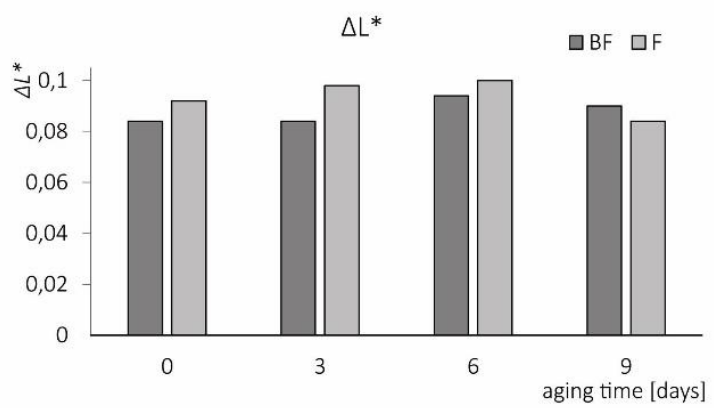

b

Figure 4: CIE Lightness ( $\left.L^{*}\right)$ of recycled fibres depending upon the aging time; a) measured with UV-content of illumination, b) difference measured with and without UV-content of illumination

The value of the CIE coefficient $a^{*}$ (Figure 5a) before and after conducted deinking flotation process for samples made from aged boxes, varies considerably and their values differ significantly. In the case of samples made from non-aged boxes, the difference between measurements is also visible, and the result after deinking flotation is twice less than the result obtained before the flotation process. The results show that recycled samples of non-aged boxes and samples of aged boxes after 3 days have a shift to the green area, while recycled samples after aging of 6 and 9 days show a shift to the red area. From the results obtained for the value of $\Delta a^{*}$ (the difference between the CIE $a^{*}$ coefficient measured in conditions with and without UV-content of illumination) (Figure 5b) the largest differences obtained for aged samples, especially after 9 days of aging. 


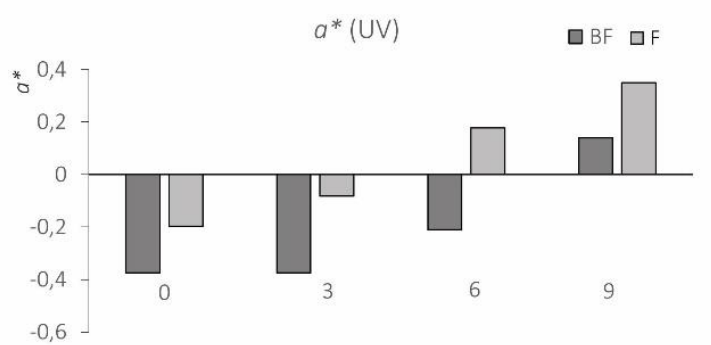

aging time [days]

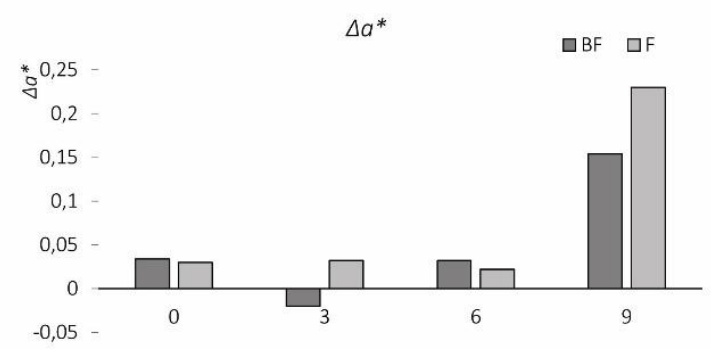

aging time [days]

b

Figure 5: CIE $a^{*}$ values of recycled fibres depending upon the aging time; a) measured with UV-content of illumination, b) difference measured with and without UV-content of illumination

The values of the CIE coefficient $b^{*}$ for samples made from aged boxes before and after the deinking flotation process have a more positive value than non-aged samples before and after deinking flotation (Figure 6a). This can be explained by the fact that the samples of laboratory sheets are darker after the aging process, i.e. they show a shift to the yellow area. It can also be seen that in all cases, the CIE coefficient $b^{*}$ has a higher value after deinking flotation process. From the results obtained for the value of $\Delta b^{*}$ (the difference between the CIE $b^{*}$ coefficient measured in conditions with and without UVcontent of illumination) (Figure $6 \mathrm{~b}$ ), it can be seen that the largest differences were obtained for aged samples, especially after 3 and 9 days of aging. The smallest difference in the $\Delta b^{*}$ value is for samples obtained from non-aged boxes.

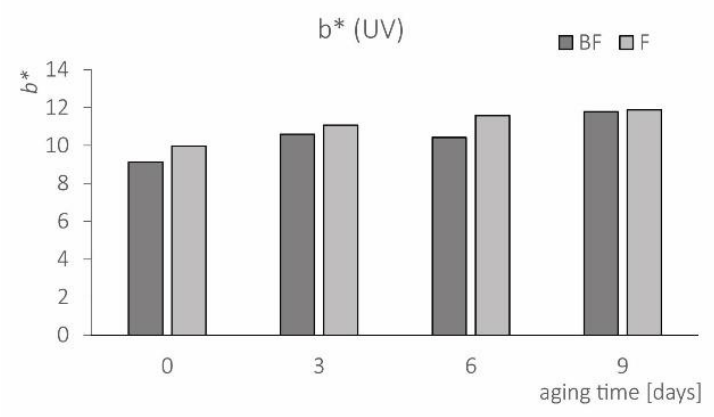

a

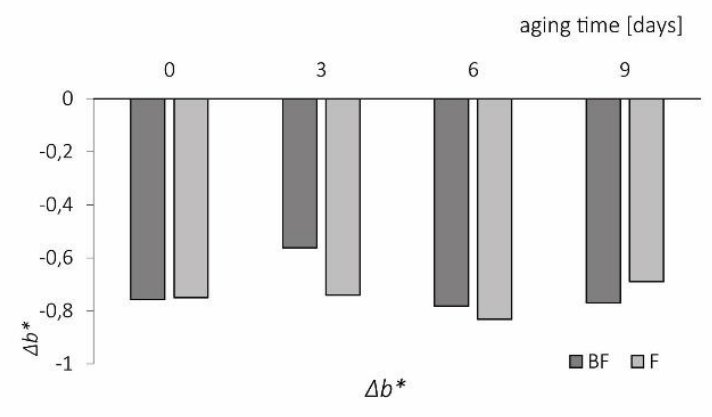

b

Figure 6: CIE $b^{*}$ values of recycled fibres depending upon the aging time; a) measured with UV-content of illumination, b) difference measured with and without UV-content of illumination

From the results shown in Figure 7a it can be seen that the whiteness value decreases after the deinking flotation process in all measured samples. Sample made from non-aged boxes has the highest whiteness value. The values of whiteness of the mentioned samples are not as high as when graphic paper grades are recycled, probably due to CIE coefficient $b^{*}$, which increases with aging time. However, the obtained results are not so small, and thus it can be said that optical brightener is present in the paper, which loses its effectiveness as the aging process progresses. Figure $7 \mathrm{~b}$ shows the difference values of whiteness measured with and without UV-content of illumination. Differences in measurement have quite high values, and it can be seen from the results that the differences in whiteness in non-aged boxes before and after the deinking flotation process are very similar. As the aging time (days of aging) increases, the difference of whiteness increases. 


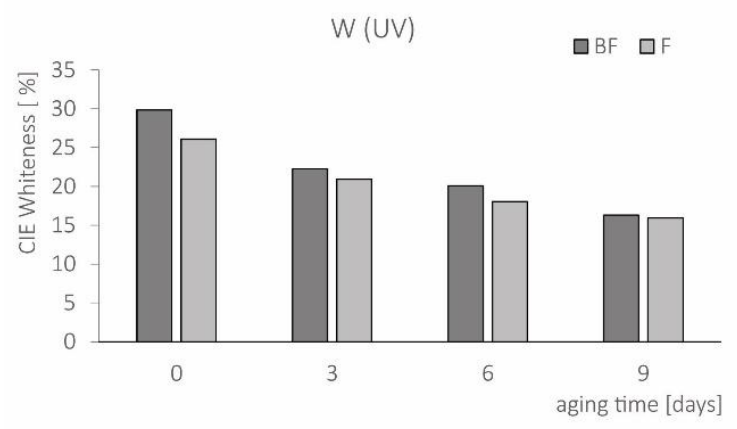

a

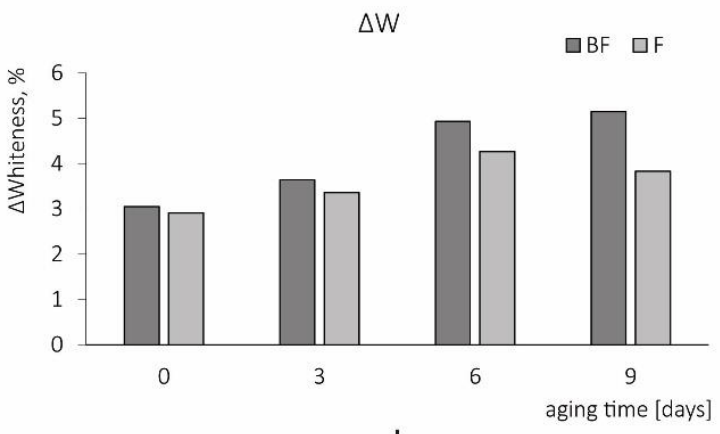

b

Figure 7: CIE Whiteness values of recycled fibres depending upon the aging time; a) measured with UV-content of illumination, b) difference measured with and without UV-content of illumination

Flat crush test is designed to measure the resistance of paperboard to flute crushing. The results are presented in the values of the force required for their crushing. From the results shown in Figure 8 , it can be seen that bending force decreases over aging time, i.e. the bending force of non-aged box was 12.3 $\mathrm{kPa}$, while the bending force of the 9-day-old box required a force of $11.87 \mathrm{kPa}$. Even though these values do not vary significant, the results may indicate that the mechanical properties of the boxes were slightly deteriorated by the influence of elevated humidity and temperature. The paperboard used for production of pharmaceutical boxes must be stable for a longer period of time, so it is assumed that the length of exposure time to elevated humidity and temperature of the samples should be increased in order to notice more significant changes in the mechanical properties of the boxes.

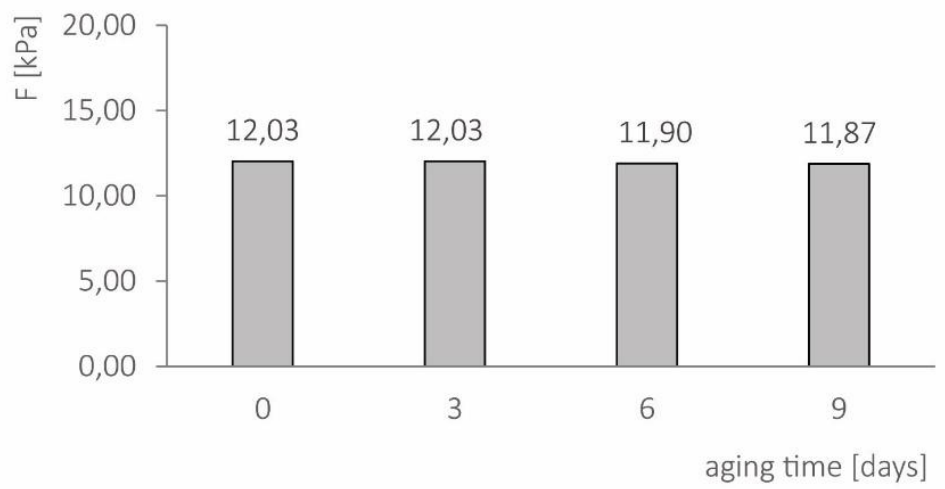

Figure 8: Flat Crush Test results

The results of the image analysis are presented in two size classes, i.e. ink particles smaller and larger than $0.04 \mathrm{~mm}^{2}$ (Table 1). The results show the number of ink particles and their surface area. According to the obtained results, it can be concluded that the print on the packaging breaks into very small particles during disintegration process, mostly in the class of sizes smaller than $0.04 \mathrm{~mm}^{2}$. In addition, it is seen that the total number of particles decreases with aging time. The number of particles decreases significantly after the flotation process in all samples, as well as their surface area. The results are in accordance with the ISO Brightness and ERIC values (Figures 1 and 3). Larger particles are clearly visible to the naked eye and manifest themselves as specks in the finished sheet. Particles smaller than $40 \mu \mathrm{m}$ in size cannot be visible by the naked eye, but they contribute to a general greyness to the appearance of the paper (Thompson, 1998). As the aging process progresses, the number of larger particles and their surface increases. 
Table 1: Image analysis results: The ink particle number and their area in size classes smaller and larger than $0.04 \mathrm{~mm}^{2}$

\begin{tabular}{|c|c|c|c|c|c|c|c|c|}
\hline \multirow{3}{*}{$\begin{array}{l}\text { aging } \\
\text { time } \\
\text { [days] }\end{array}$} & \multicolumn{4}{|c|}{ Smaller than $0,04 \mathrm{~mm}^{2}$} & \multicolumn{4}{|c|}{ Larger than $0,04 \mathrm{~mm}^{2}$} \\
\hline & \multicolumn{2}{|c|}{ Undeinked pulp (BF) } & \multicolumn{2}{|c|}{ Deinked pulp (F) } & \multicolumn{2}{|c|}{ Undeinked pulp (BF) } & \multicolumn{2}{|c|}{ Deinked pulp (F) } \\
\hline & No. & $\mathrm{P}\left[\mathrm{mm}^{2}\right]$ & No. & $\mathrm{P}\left[\mathrm{mm}^{2}\right]$ & No. & $\mathrm{P}\left[\mathrm{mm}^{2}\right]$ & No. & $\mathrm{P}\left[\mathrm{mm}^{2}\right]$ \\
\hline 0 & 577 & 4.59 & 272 & 2.10 & 7 & 0.36 & 6 & 0.52 \\
\hline 3 & 676 & 6.22 & 362 & 3.55 & 18 & 1.01 & 16 & 1.09 \\
\hline 6 & 378 & 3.05 & 242 & 3.41 & 8 & 0.47 & 5 & 0.60 \\
\hline 9 & 388 & 3.00 & 246 & 2.25 & 8 & 0.53 & 8 & 0.68 \\
\hline
\end{tabular}

\section{CONCLUSIONS}

Elevated humidity and temperature in the accelerated aging test affected the process of the printing ink separation from the surface of the printing substrate, i.e. cardboard during recycling, which resulted in production of recycled fibres with different optical properties compared to recycled fibres from the recycling process of boxes that were not exposed to aging test. The results showed that in recycled samples the ISO brightness decreases with aging.

The value of ERIC decreases after flotation process in all samples because the printing ink is separated in the process altogether with collected flotation froth. The largest percentage of removed ink particles is visible on the non-aged sample. As the sample ages, the printing ink binds to the recycled fibres, resulting in lower ERIC value of non-aged samples compared to the old ones. The CIE coefficient $b^{*}$ is higher for samples obtained from recycling of aged boxes than for samples obtained from non-aged boxes, and it is clear that samples obtained by recycling of aged boxes will be yellower than non-aged ones. Therefore, the CIE whiteness is lower in laboratory paper sheets obtained by recycling of aged boxes. When measuring the image analysis, the obtained results show that the number of ink particles and their surface area are significantly reduced over aging time. Therefore, it can be assumed that by the occurrence of the aged paper based packaging material in the recycling plant would reduce the quality of the recycled fibre in terms of its optical characteristics, i.e. such material have lover brightness and whiteness values. Furthermore, it was found that the mechanical properties of the boxes were slightly deteriorated by the influence of elevated humidity and temperature, since there are insignificant differences in the values of the forces required for their bending. The bending force decreases over aging time, i.e. the bending force of non-aged box was $12.3 \mathrm{kPa}$, while the bending force of the 9-day-old box required a force of $11.87 \mathrm{kPa}$. Further research related to influence of elevated temperature and humidity in accelerated aging test on the recycling performance of pharmaceutical packaging, should be focused on the stickies potential in recycled fibres due to presence of adhesives in packaging.

\section{ACKNOWLEDGMENTS}

The authors are grateful for the financial support of the University of Zagreb.

\section{REFERENCES}

[1] Blanco, A., Miranda, R., Monte, M. C.: "Extending the limits of paper recycling: Improvements along the paper value chain", Forest Systems 22 (3), 471-483, 2013.

[2] CEPI.: "Paper-Based Packaging Recyclability Guidelines", URL: https://www.cepi.org/paper-basedpackaging-recyclability-guidelines/ (last request: 2020-09.24), 2019.

[3] Faul, A.: "Quality requirements in graphic paper recycling", Cellulose Chemistry \& Technology 44 (10), 451-460, 2010.

[4] Holik, H. (Ed.): "Handbook of Paper and Board", 2nd. Edition, (Wiley - VCH, Weinheim, 2013.)

[5] INGEDE e. V.: "INGEDE Method 11- Assessment of Print Product Recyclability (Deinkability Test)", URL: https://www.ingede.com/ingindxe/methods/ingede-method-11-2018.pdf (last request: 2020-09-27), 2012. 
[6] Iosip, A., Dobon, A., Hortal, M., Bobu, E.: "The influence of contaminants in the environmental impact of recovered paper: a life cycle assessment perspective", The International Journal of Life Cycle Assessment 17 (8), 1050-1058, 2012. doi: 10.1007/s11367-012-0430-y

[7] Kemppainen, K., Haapala, A., Körkkö, M., Niinimäki, J.: "Ink and dirt behavior in pulping after artificial aging of cold-set offset printed newspapers in different humidity conditions", Resources, Conservation and Recycling 76, 41-49, 2013. doi: 10.1016/j.resconrec.2013.03.008

[8] Kemppainen, K., Upola, H., Körkkö, M.: "Ink and dirt behavior in repulping after artificial aging of coldset offset-printed newspapers at different temperatures", Nordic Pulp and Paper Research Journal 30 (3), 527-534, 2015. doi: 10.3183/npprj-2015-30-03-p527-534

[9] Nguyen, A. T., Parker, L., Brennan, L., Lockrey, S.: "A consumer definition of eco-friendly packaging", Journal of Cleaner Production 252, 119792, 2020. doi: 10.1016/j.jclepro.2019.119792

[10] Pala, H., Mota, M., Gama, F. M.: "Laboratory paper pulp deinking: An evaluation based on Image Analysis, ISO brightness and ERIC", Appita Journal 60 (2), 2007.

[11] Raju, G., Sarkar, P., Singla, E., Singh, H., Sharma, R. K.: "Comparison of environmental sustainability of pharmaceutical packaging", Perspectives in Science 8, 683-685, 2016. doi: 10.1016/j.pisc.2016.06.058

[12] Runte, S., Putz, H.-J., Bussini, D., Limongi, L., Elegir, G.: "Recyclability criteria for paper-based packaging products", Cellulose Chemicstry and Technology 49 (7-8), 667-676, 2015

[13] Steenis, N. D., van Herpen, E., van der Lans, I. A., Ligthart, T. N., van Trijp, H. C. M.: "Consumer response to packaging design: The role of packaging materials and graphics in sustainability perceptions and product evaluations", Journal of Cleaner Production 162, 286-298, 2017. doi: 10.1016/j.jclepro.2017.06.036

[14] Tamani, N., Mosse, P., Croitoru, M., Buche, P., Guillard, V., Guillaume, C., Gontard, N.: "An argumentation system for eco-efficient packaging material selection", Computers and Electronics in Agriculture 113, 174-192, 2015. doi: 10.1016/j.compag.2015.02.012

[15] Thompson, R. C.: "The Impact of Inks and Coatings on Fibre Reclamation", Surface Coatings International Part B: Coatings Transactions 5, 230-233, 1998.

[16] Vukoje, M., Rožić, M.: "Various valorisation routes of paper intended for recycling - A Review", Cellulose Chemicstry and Technology 52 (7-8), 515-541, 2018.

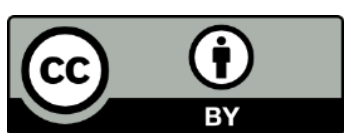

(C) 2020 Authors. Published by the University of Novi Sad, Faculty of Technical Sciences, Department of Graphic Engineering and Design. This article is an open access article distributed under the terms and conditions of the Creative Commons Attribution license 3.0 Serbia (http://creativecommons.org/licenses/by/3.0/rs/). 



\title{
EXPLORING THE VARIOUS PARAMETERS OF $\mathrm{CO}_{2}$ LASER IN THE CUTTING OF PAPER
}

\author{
Ivan Pinćjer (D), Nada Miketić (D), Ivana Tomić (D), Savka Adamović \\ University of Novi Sad, Faculty of Technical Sciences, Department of Graphic Engineering and \\ Design, Novi Sad, Serbia
}

\begin{abstract}
The revolution in the printing industry started by digital printing has resulted in the introduction of personalised production of small runs, fast job changes and short deadlines. By introducing digital printing into mainstream and production focus, even for the largest printing machine manufacturers, a new era of the graphic industry has just begun. After these significant changes in the printing process, the following process of graphic production - post-press needs to be digitalised. The initial goal is to back up the possibilities of digital printing and enable it to be applied as widely as possible to its full potential. Postpress has become a bottleneck in the digital world. One of the analogous processes, which is the focus of improvement, is the cutting of graphic materials in irregular shapes in the process of creating packaging. The use of lasers enables the digitisation of the die-cut or partial cutting post-press process. Cutting of different shapes is obtained when the laser touches the substrate and where it evaporates at that moment. A thermal process accompanies this evaporation, that to a greater or lesser extent affects the substrate to be cut. The parameters that govern laser are the subject of this paper. The development of laser cutting technology has opened various possibilities for innovations in the graphic and printing industry. Since this is still considered as new technology, extensive researches on its options are essential to reach the full potential of this technology. This paper is going to analyse the overall characteristics and use of laser technology in the graphic industry by focusing on the processing of paper materials. Indispensible to mention are the advantages and disadvantages of this technology. There are a lot of comparisons among existing technologies developed for cutting graphic materials and paper. The importance of this topic is concerning all production phases of the graphic product-from processing the raw material to cutting the final product such as packaging. Regarding that, the scope of the laser processing of the graphic materials is reviewed. The paper gives suggestions for further research and experiments regarding this topic.
\end{abstract}

Keywords: post-press, die-cutting, $\mathrm{CO}_{2}$ laser, packaging, paper

\section{INTRODUCTION}

Postpress remains one of the last stages in graphic production that still resists digitisation. The processes that take place in it are either manual or are done on specialised machines that are not so sophisticated and flexible. The handling of the post-press itself is of such a nature that it can be automated and even integrated into the in-line process of graphic production, but it isn't easy to fully digitise.

By analysing the trends in the printing industry, it can be seen that the sales of conventional solutions for finishing machines are in constant decline in the last decade. Only devices designed for digital printing resist the demand reduction, so it is not surprising that many large manufacturers of graphic finishing machines adapt their machines to the requirements of digital printing, smaller runs and ink-jet and toner prints. The growth of the production of packaging and labels must undoubtedly be in the focus of development of post-press machines because the packaging sector will take over $50 \%$ of the total printing in the coming period.

Getting the final shape of particular printed products, primarily when its merits compared with a standard, rectangular, was associated with mechanical cutting blades - mechanical dies. This process is time-consuming and expensive, noisy and can be dangerous for the operator. It enables minimal flexibility because the smallest changes in the shape of the final product require re-creation of the dies-cut form. To make the dies-cutting process more flexible, machines that perform cutting with the help of $\mathrm{CO}_{2}$ lasers have come into use. Computer-guided $\mathrm{CO}_{2}$ lasers are specially adapted to paper materials. Although these are high power lasers, so they are very safe because of the use of internal gas which prevents the paper materials ignition. Laser power is such that when the laser hits the surface of the substrate, the substrate evaporates, leaving behind a precise cut. The laser is guided to the material by optics that can be changed. When different optics is set, it influences the size and distance of the laser focus. 
By adjusting the laser parameters, the paper can be completely cut but also kissed-cut. The adjustment also allows you to cut different types of papers and cardboards as well as film materials, without the need to change even one tool on the machine. The trajectory of the laser is determined digitally, which eliminates the need for a dies cut forme when cutting irregular shapes. Also, the precision of laser guidance, with an extremely small diameter of the laser beam, enables very fine and precise cutting of material. Small shapes and diameter were impossible to cut with the mechanic dies-cut. One of the most significant benefits concerning the dies-cut form is precise that each cut can be of a completely different shape, which completely fits into the possibilities of digital printing.

Laser cutting systems, paired with digital printing, are the focus of companies that manufacture the graphic equipment, so further growth, development and production of laser cutting machines can be expected.

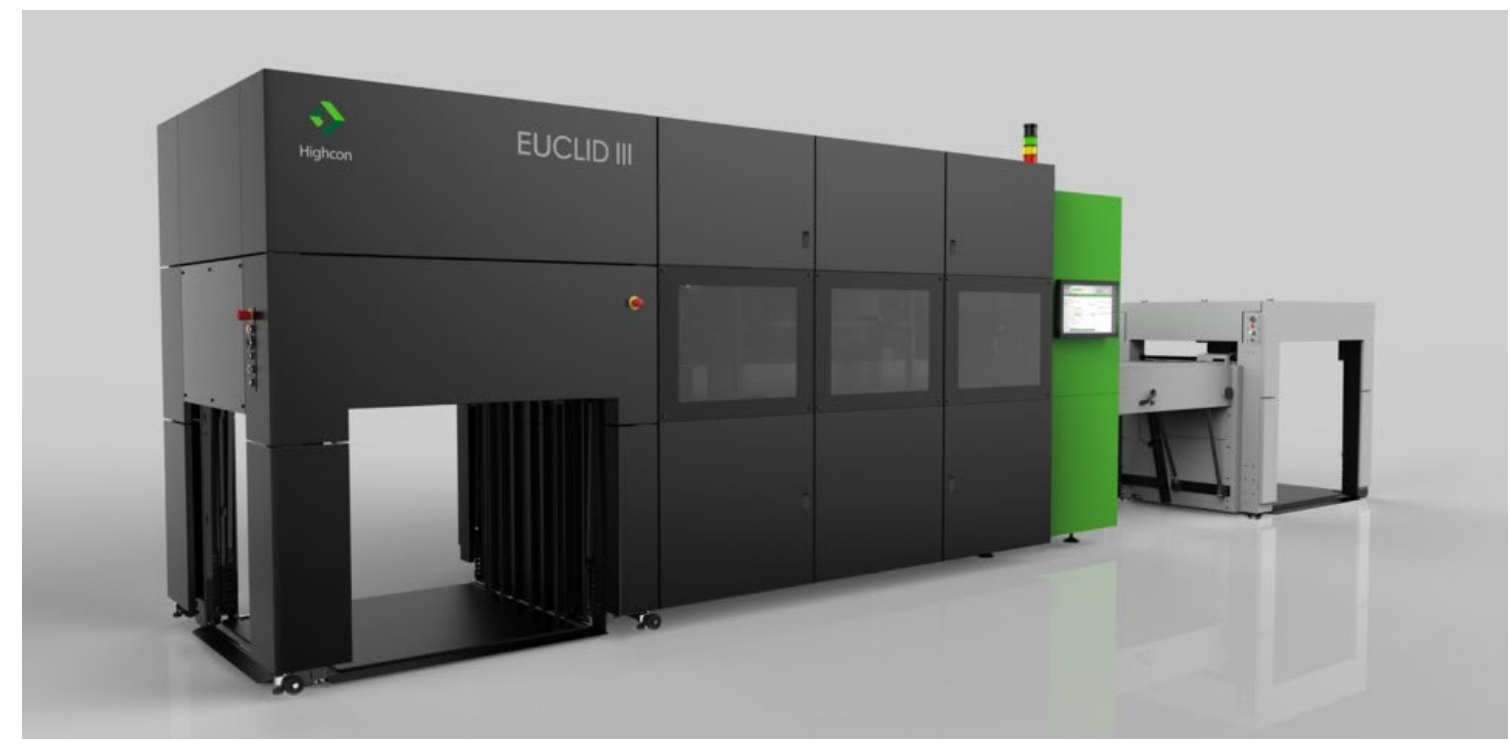

Figure 1: Modern laser cutting machine (image taken from https://www.highcon.net/press-release/highcon-launcheseuclid-iiic-corrugated/)

\section{A FUNDAMENTAL PRINCIPLE OF $\mathrm{CO}_{2}$ LASER PAPER CUTTING}

The word laser comes from the acronym "light amplification by stimulated emission of radiation" (Gould, 1959). The laser emits monochromatic coherent light whose energy affects the surface it hits. $\mathrm{CO}_{2}$ laser (carbon dioxide) is a gas laser that emits infrared light with a wavelength of 9.6 and 10.6 microns ( $\mu \mathrm{m})$. It is highly efficient and suitable for both industrial and medical use.

To use the techniques of laser cutting, optimally is necessary to know the principle of cutting material. The mechanism of paper cutting by laser is based on the evaporation of the substrate. Laser cutting mechanism involves heating the material to the temperature of evaporation, or the temperature at which chemical degradation of the material occurs. The physical change that a material undergoes is the conversion of the material directly from a solid to a gaseous state (Piili, 2013). The temperature that will be reached depends on the material that receives the laser beam and whose molecules are excited by it If the material evaporates at $150^{\circ} \mathrm{C}$ for the material to degrade, the laser should excite the molecules to move at a speed that will raise the temperature to the point of evaporation.

Consequently, the temperature of the laser depends on the substrate that receives the laser beam. The largest part of the laser power is used for breaking chemical bonds in the material. When paper materials are cut with a laser beam, chemical degradation involves breaking long chains of cellulose molecules to carbon and water vapour (Malmberg et al, 2006a). Products formed by chemical degradation of the material evaporate or are removed from the kerf by the action of a jet of auxiliary gas of the laser beam. With the development of laser technology, due to the use of various inert gases within the laser structure, the ignition of the material that evaporates is prevented. Therefore, laser cutting is safe and is used both in the paper industry for paper production and in graphic finishing processes. (Federle and Keller, 1992a; Malmberg and Kujanpää, 2006b). 


\section{THE USE OF LASERS FOR PAPER CUTTING}

Laser cutting of fibrous materials has several possibilities of application. Laser cutting of uncoated as well as coated paper materials, does not affect the printing properties of the paper (Piili, 2013). Also, printed papers and cardboards can be cut using a laser beam, so the cutting quality is excellent (Malmberg and Kujanpää, 2006a; Malmberg and Kujanpää, 2006b).

Laser cutting of paper materials can be used in combination with digital printing. The advantage of digital printing is the ability to produce small runs with a rapid change of the image being printed. The advantage of laser cutting is the fact that there is no change in tools when changing jobs. The shape that needs to be cut is set digitally, like in digital printing (Boyle, 1999).

Further, using a laser beam offers the possibility of making perforations on paper or cardboard with great precision and speed. Perforations done with mechanical tools leads to the problem of weakening the material due to broken fibres and uneven sized hole cut, which occurs due to mechanical wear of tools with which to perform perforation (Piili, 2013). On the other hand, by using a laser to make a perforation, the holes that are created are open and of equal size (Mommsen and Stürmer, 1990; Brockmann, 1999). The use of lasers is possible even for kiss cutting (partial cutting) of multilayer materials such as stickers and labels (Figure 2). Kiss cutting can also be used instead of the process of corrugated cardboard creasing on die-cutting machines.

Malmberg et al. (2006b) state the situations in which the use of lasers for cutting paper materials is recommended:

- when the cutting process is done by hand

- $\quad$ when working with small circulations below 1000 pieces

- $\quad$ always with products that are printed using a digital printing technique

- when it is necessary to achieve a high degree of cutting accuracy, as well as cutting complex geometric shapes

- when making samples or batches of samples

- if an expensive material is used for the processing of which a high degree of manufacturing accuracy is necessary

- $\quad$ in production where different types of products are made and when the high speed of delivery is required

One of the most critical questions that arise when analysing the quality of laser cutting is the appearance of the cut face. Cut face with carbonation due to the consequences of combustion changes the colour and reduces the overall quality of printed products. The cut face of the material cut mechanically contains fibres that protrude beyond the edge, which can also cause many problems in the production. (Piili, 2013). However, laser cutting is a non-contact technique, and no tool can damage the cut face. Also, when cutting with a laser, the loss of material is smaller. If the laser is optimally adjusted, there will be no change in the colour of the material around the cut face, and the cut will be clean, without free fibres, making it firmer and more compact.

In the case of Nd: YAG laser, the absorption of its wavelength by the paper is unsatisfactory. Cutting edge looks like a faint imprint on the surface of the paper material. Cutting paper materials with this laser is feasible, at very high laser power, low laser speed, resulting in a cutting edge that is mostly carbonised and the width of the cutting edge is over 300 microns.

Paper materials best absorb the wavelength of $\mathrm{CO}_{2}$ lasers, which is why this type of laser is used to cut paper, cardboard and pulp. (Ainsworth, 1978; Federle and Keller, 1992b; Joore et al, 2003; Malmberg and Kujanpää, 2006a).

\section{INFLUENTIAL LASER PARAMETERS}

\subsection{Laser power and speed}

Laser power is defined as the total amount of energy emitted in one unit of time. The unit in which the laser power is expressed is Watt (W). The maximum laser power intensity is expressed in watts per unit area (usually $\mathrm{W} \mathrm{cm}^{-2}$ or $\mathrm{W} \mathrm{mm}^{-2}$ ). When cutting non-metals, maximum intensity is required to achieve high temperatures when cutting the substrate, which results in good cutting quality combined with high cutting speeds (Steen, 1991). 
Federle and Keller (1992) have conducted an experiment in which $\mathrm{CO}_{2}$ laser was used to cut paper intended for offset printing grammage substance of $80 \mathrm{~g} / \mathrm{m}^{2}$. It is noticed that the laser power and the laser speed are in a linear relationship with each other. As the laser power increases, the cutting quality increases. However, if cutting is performed with a higher laser power than is required for a given material, the kerf increases, the cut face carbonisation increases, and the quantity of evaporation increases (Federle and Keller, 1992a; Federle and Keller, 1992b).

a)

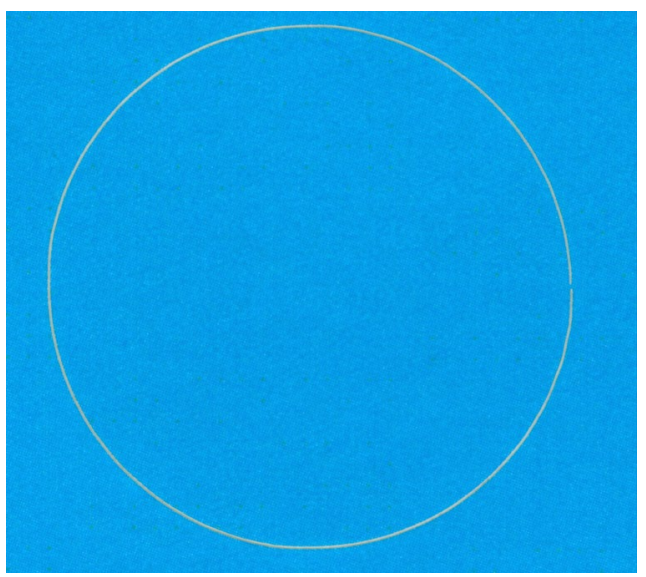

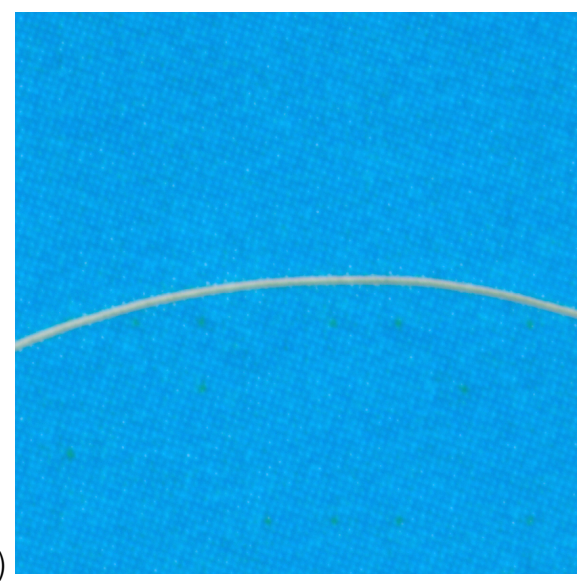

Figure 2: a) Optimal laser power for kiss-cut of printed self-adhesive paper b) detail

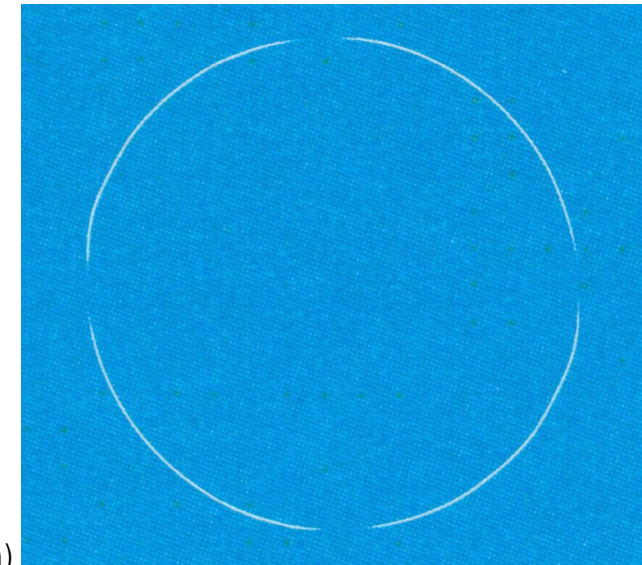

b)

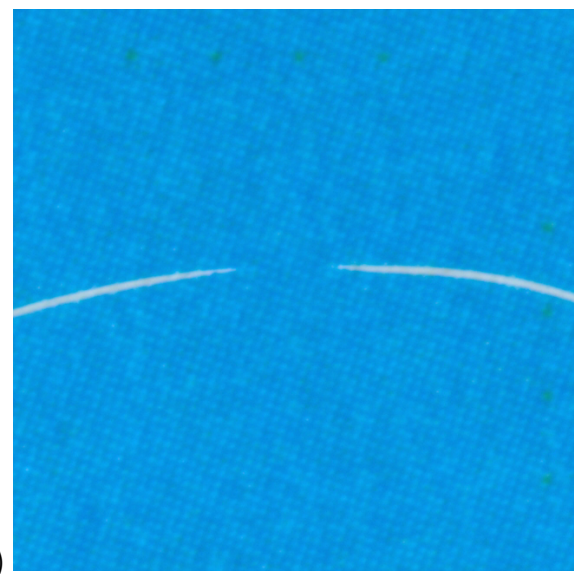

Figure 3: a) Low laser power for kiss-cut of printed self-adhesive paper b) detail
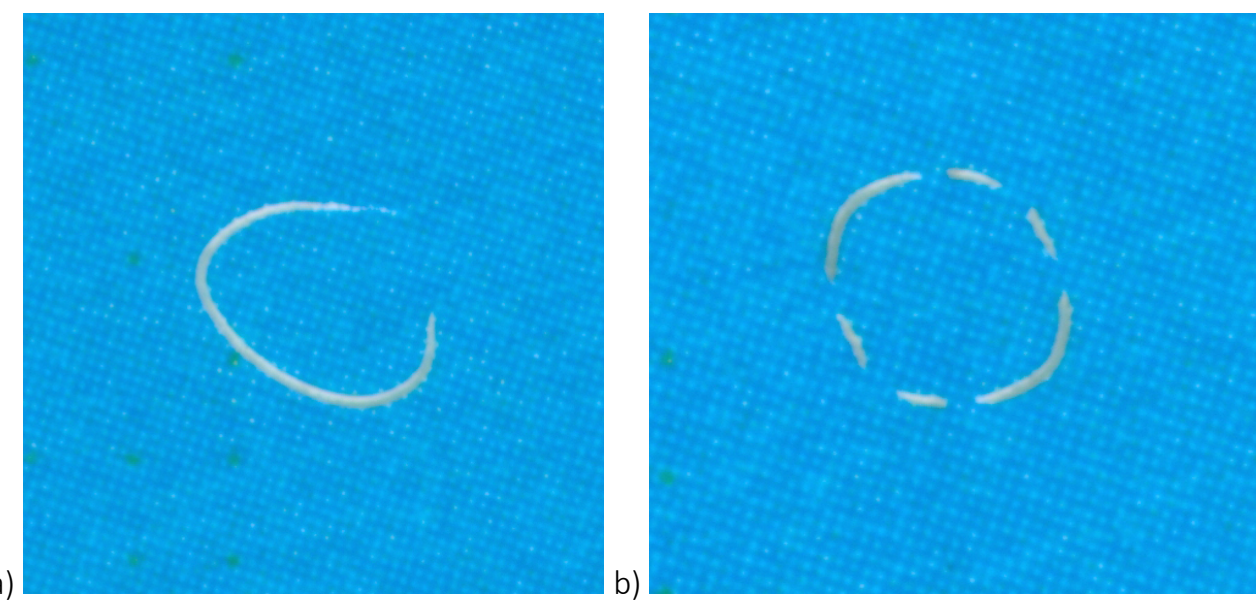

Figure 4: Influence of cutting speed and power on laser precision: a) high power and cutting speed b) lower power and cutting speed 


\subsection{Grammage substance}

Some studies investigated how grammage affects the cutting speed when cutting with a $\mathrm{CO}_{2}$ laser. Federle and Keller (1992a) experimented with paper materials for offset printing, grammage from 80 to $170 \mathrm{~g} / \mathrm{m}^{2}$, at a laser power of $600 \mathrm{~W}$. It was concluded that grammage and cutting speed are not linearly dependent. They also concluded that the grammage has no effect on the quality of laser cutting, nor on the kerf.

Research by Ramsay and Richardson (1992) showed that more laser power is needed to cut thicker paper materials as opposed to thinner paper materials. They also concluded that with constant laser power, when cutting thicker materials, a lower laser speed is needed to perform a successful cut, where this is not the case for thin materials.

The cutting of paper materials with a grammage of 500 to $1700 \mathrm{~g} / \mathrm{m}^{2}$, with a laser power of $1700 \mathrm{~W}$, was also tested. The experiment showed that there is a relationship between the grammage of paper materials, the laser cutting speed and laser power. Increasing the grammage causes the laser speed to decrease, so that cutting can occur (Joore et al, 2003).

\subsection{Paper thickness}

The influence of material thickness on successful laser cutting was investigated. The cutting of several different paper materials with a constant laser power of $550 \mathrm{~W}$ was examined. Maximum cutting speeds for different material thicknesses were found. It was concluded that cutting speed increases with decreasing material thickness. The less material needs to evaporate, the cutting is faster (Malmberg et al, 2006).

\subsection{Bulk}

Bulk is the thickness of a sheet of paper and is the opposite property of paper density. High bulk is a type of paper with a greater thickness than other papers with the same grammage. This property of the paper is essential if the paper is required to be stiff. Malmberg et al. (2006) examined the effect of bulk on laser cutting speed. CTMP and pine pulp cuts were performed at a constant laser power of $90 \mathrm{~W}$ and $550 \mathrm{~W}$. It was concluded that as the bulk increases, the cutting speed increases. High bulk papers have lower density, so there is less material required to evaporate when cutting, resulting in faster laser cutting (Malmberg et al, 2006).

\subsection{The amount of moisture in the paper}

Natural fibres have a hollow cross-section. The amount of water in the paper has a significant effect on laser cutting. If the moisture content increases, then the following happens:

- The thermal conductivity of paper materials increases

- Paper reflection increases

- $\quad$ part of the laser power is spent on evaporating water from the material

It has been proven that water absorbs the wavelength of CO2 lasers very well (Ojala, 1993). The laser power required to cut the material increases with increasing paper moisture, as more heating is needed to convert larger amounts of water into water vapour (Malmberg et al, 2006). Stepanov et al. (2015), examined the possibilities of cutting dry and wet paper (with 30\% - 40\% dry matter content) using CO2 lasers and showed a significant difference in the laser power needed for cutting dry and wet paper. Laser energy of $16.4 \mathrm{~J} / \mathrm{m}$ was calculated to cut dry paper, while laser energy of $94 \mathrm{~J} / \mathrm{m}$ was required to cut wet paper.

\subsection{Coating}

Authors Federle and Keller, based on their studies, claim that there is no difference in cutting different paper materials when cutting with a laser (Federle and Keller, 1992a; Federle and Keller, 1992b). They noticed that there is a difference between coated and non-coated materials, where the coating edges are coloured, and smoke appears, depending on the quality of the coating. Increasing the amount of coating causes greater scattering and absorption of laser light due to the higher amount of coating material (Rämö, 2004). 
In their paper, Malmberg et al. (2006) tested the following paper materials: LWC (lightweight coated), CWF (coated wood-free) and SC (supercalendered). The laser used for cutting was Triumpf TLF $2700 \mathrm{HQ}$ carbon dioxide laser, which has a power range from $115 \mathrm{~W}$ to $2700 \mathrm{~W}$. The results showed that uncoated LWC paper cuts faster than coated. The explanation given for this results is that the paper coating absorbs the laser light and thus less laser cutting power remains which are manifested by reduced cutting speed. It has also been proven that the amount of coating affects the laser power required for cutting higher laser power is needed if the amount of paper coating increases. When it comes to the kerf, it was noticed that the paper coating caused the kerf to expand, which is a consequence of the laser light scattering due to the presence of coating pigment particles. Increasing the power of the laser also led to the widening of the kerf.

\section{CONCLUSION}

The need to find a solution in post-press that will match the advantages of digital printing is a very demanding task. Through the development of modern technologies, the graphic product kept its digital form further and further from one phase to next. Keeping the product in digital form for as long as possible meant speeding up the work process, reducing errors and increasing the possibility of correcting any shortcomings. First, digitalisation appeared in the process of prepress, layout, while the other phases remained analogous. Then slowly digitalisation moved step by step until it reached the printing process. In the printing process, the print finally turns into an analogue form, and its further processing also continues analogue. This is where the problems that plagued graphic artists for centuries arise. Although the automation of the finishing process is at a high level, the machines used still process the product with the help of mechanical tools. This is in no way conducive to the philosophy of today's business in the printing industry as we have seen the gradual progress of digital technology through the process of prepress to the printing itself, so it will undoubtedly continue in the process of post-press.

The use of laser cutting systems is no longer science fiction. The development of lasers has made it possible to cut even sensitive materials such as paper without any traces of cutting like burning or combustion. The ability to influence different parameters of the laser such as its speed, power, frequency and resolution allows it to adapt to a vast range of different materials from paper, cardboard to films and foils. Different materials react differently to the laser beam, so it is necessary to increase the number of experiments that will show the influence of the laser beam and its parameters on different substrates. In addition to cutting, the laser can be used for various surface treatment such as engraving, especially for cardboard, but also cover materials.

The negative aspects of the use of lasers must also be investigated experimentally, especially the part related to environmental protection and safety at work. Also, the downside of laser processing is its low speed. It can be increased if more laser heads are installed in the machines that will cut the material at the same time, but this significantly increases the cost of the process. Whether the laser cutting system will be able to fit into the dominant offset printing technique is jet to be seen, but for now, this system is not usable for conventional graphic production.

\section{ACKNOWLEDGEMENT}

This research paper has been supported by the Ministry of Education, Science and Technological Development through the project no. 451-03-68/2020-14/200156: "Innovative scientific and artistic research from the FTS domain".

\section{REFERENCES}

[1] Ainsworth, H.: "Laser cutting, Paper Technology and Industry", (9), 220-225, 1978.

[2] Boyle, E.: "Lasers are on the cutting edge, digitally speaking", Paper, film \& foil converter, (4), 1415, 1999.

[3] Brockmann, R.: "Laserperforation ermöglicht bis zu 30000 Mikrobohrungen pro Minute", Das Papier, 53 (2), 1999.

[4] Federle, H., Keller, S.: "Papierschneiden mit Laser (Teil 1)", Papier Kunststoff Verarbeiter 27 (7), 3239, $1992 a$. 
[5] Federle, H., Keller, S.: "Papierschneiden mit Laser (Teil 2)", Papier Kunststoff Verarbeiter 27 (9), 54 58, 1992b.

[6] Gould, R. G.: "The LASER, Light Amplification by Stimulated Emission of Radiation", In: Franken, P.A., Sands R.H. (eds.). Proceedings of The Ann Arbor Conference on Optical Pumping 1959, (The University of Michigan, Michigan, 1959).

[7] Highcon, "Highcon Launches Euclid IIIC for Corrugated", URL: https://www.highcon.net/pressrelease/highcon-launches-euclid-iiic-corrugated [last request: 20-01-10].

[8] Joore, L., Hüsslage, W., Veenstra, P.: "Schneiden von karton mittels lasertechnologie", Wochenblatt für Papierfabrikation 6, 301-305, 2003.

[9] Malmberg, H., Kujanpää, V.: "Laser cutting of mineral pigment coated papers", Proceedings of ICALEO 2006, (ICALEO: Scottsdale, USA, 2006a), page 10.

[10] Malmberg, H., Kujanpää, V.: "Laser Cutting of Paper Materials", Industrial Laser Solution 6, 4, $2006 \mathrm{~b}$.

[11] Malmberg, H., Leino, K., Kujanpää, V.: "Laser Cutting of Paper and Board (ILACPaper)", Research Report 68, (Department of Mechanical Engineering, Lappeenranta University of Technology, Finland, 2006), page 344.

[12] Mommsen, J., Stürmer, M.: "Laserschneiden und perforieren von Filterpapier", Papier Kunststoff Verarbeiter (8), 10-14, 1990.

[13] Ojala, K.: "Studies on infrared drying of paper, use of integrating spheres in FTIR-measurements, and heat and mass transfer inside paper", PhD thesis, Helsinki University of Technology, Department of Mechanical Engineering, Espoo, 1-70, 1993.

[14] Piili, H.: "Characterisation of laser beam and paper material interaction", PhD thesis, Lappeenranta University of Technolgy, 2013.

[15] Rämö, S.: "Effects of coating on laser cuttability of coated papers and boards", MSc thesis, Lappeenranta University of Technology, 2004.

[16] Ramsay, I., Richardson, B.: "Workington tries laser slitting on coated paperboard", Paper Technology 33 (9), 17-22, 1992.

[17] Smitthers, "Digital to underpin evolution of print finishing market", URL: https://www.smithers.com/resources/2018/aug/evolution-of-print-finishing-market [last request: 20-01-10].

[18] Steen, W.: "Laser material processing", (London, Springer-Verlag, 1991.), page 266.

[19] Stepanov, A., Saukkonen, E., Piili, H., Salminen, A.: "Effect of moisture content of paper material on laser cutting", Physics Procedia 78, 120- 127, 2015. doi: 10.1016/j.phpro.2015.11.024.

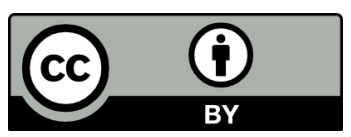

(C) 2020 Authors. Published by the University of Novi Sad, Faculty of Technical Sciences, Department of Graphic Engineering and Design. This article is an open access article distributed under the terms and conditions of the Creative Commons Attribution license 3.0 Serbia (http://creativecommons.org/licenses/by/3.0/rs/). 



\title{
PRELIMINARY ANALYSIS OF IMAGE PROCESSING-BASED EVALUATION OF EMBOSSING QUALITY
}

\author{
Magdolna Pál (D), Bojan Banjanin (D), Sandra Dedijer (D), \\ Gojko Vladić (D), Gordana Bošnjaković (D) \\ University of Novi Sad, Faculty of Technical Sciences, \\ Department of Graphic Engineering and Design, Novi Sad, Serbia
}

\begin{abstract}
The embossing process in graphic industry utilizes custom made dies to create raised or lowered permanent relief patterns according to the design. It can be combined with other print finishing embellishments, such as foil stamping or pearlescent coating, but the simplest version of this process, the blind embossing is also a very effective technique to create a distinguished and sophisticated look. The quality control of embossing features was done only visually for a long time, but in the recent years it became an important target for graphic instrument manufacturers focusing on the embossing depth, as one of the most important parameters for high quality processing. This analysis was aiming to investigate the applicability of a simple flatbed scanner and the developed image processing algorithm for embossing quality evaluation. The results of detailed visual assessment of all scanned paper samples and the obtained values of average greyscale difference (shadow-based contrast), showed that single-level embossed samples can be realistically digitalized using a simple flatbed scanner, as an image acquisition equipment. Additionally, the proposed image feature, the shadow-based contrast had increasing tendency by increasing the applied compression force, in general, suggesting that it has a potential as an objective measure for the deformation rate in the embossing quality evaluation. The obtained results gathered for different combinations of observed parameters (paper grade, basis weight, type of test elements on the embossing dies) with the optimal compression forces, implied that the shadow-based contrast could be used as a reference parameter to ensure adequate visibility of embossed elements by defining the minimum value of needed contrast.
\end{abstract}

Key words: embossing, blind embossing, quality control, image processing

\section{INTRODUCTION}

During the embossing process, paper fibres are reshaped into well-defined permanent relief patterns, usually by using heat and force. The design can be raised or lowered, depending on which type of techniques and dies are employed. If the relief is raised, it is defined as positive or embossed, but if the relief is lowered, it is negative and commonly called debossed. In both cases, usually two dies are employed: an impressed (concave) female die and a matching male die. The embossed image itself could have flat or sculpted design. In accordance, they are obtained by a single-level or multi-level die, respectively (Blechschmidt, 2013; Holik, 2013; Topac, 2016; Terril, 2019; FSEA, 2020). Although, the embossing process can be used as stand-alone operation, there are numerous combinations using different type of foils, inks, varnishes, holograms, etc. Blind embossing, as the simplest technique among them, creates a visible image without colour or foil. The visual sensation and legibility are coming from the shadows created by incident light hitting the edges of the recessed or raised elements on the embossed surface. The greater the relief, the more emphasized the shadow, clearer the visibility. In some cases, the applied pressure and heat can change the original texture and colour of the substrate, so the design could be visible through them too. Theoretically, any types of paper and paperboard can be embossed, but there are some recommendations regarding to the substrates' properties, such as material thickness, composition, fibre nature and length, surfaces and overall strength properties (tensile strength, elongation, toughness tearing resistance, delamination strength, compression strength and especially bursting strength). If the substrate is thick, dense and strong, the embossed image will hold better, with more details, complicated patterns, pronounced relief and embossed depth. At the other hand, bulky substrates will respond in a spongier way, since they are more compressible that other paper grades, but also recycled paper and paperboard will require significantly higher pressure compared to virgin fiber stock due to the high compression levels of recycled fibres. Howsoever, embossing as a reshaping process will reach its limits where surface damages appear on the substrates (Topac, 2016; Storaenso, 2019; Terril, 2019; FSEA, 2020; Iggesund, 2020). Another limitation of the embossing application is the design element's dimensions. Illustration with small details 
and fine lines cannot be embossed as deeply as larger areas, since these fine details are prone to rupture the substrate. In contrast, larger elements have to be embossed more deeply to create a proper tactile effect (Peret, 2020), but high-quality embossing is not just all about depth. There are physical limitations to how much a paper can stretch, therefore creating a pronounced texture with fine detail is often more important than getting a lot of depth (SAPPI, 2020).

Beside the substrates, dies are the other critical element for achieving the desired embossed image. Different metals are suitable to manufacture embossing dies by etching or engraving, but nowadays as new approaches, 3D printed and laser-engraved dies were utilized successfully in proof of concept setups or in trial runs. Copper, magnesium, brass and steel are the conventional materials for embossing dies, manufactured by etching and engraving. The material and producing technique are determined by the run length, complexity of the design and the desired longevity of the dies (Iggesund, 2020; FSEA, 2020; SAPPI, 2020).

Although, it is a traditional print finishing technique used for high-quality and luxury printed products, its quality control was done only visually for a long time (Iggesund, 2020; FSEA, 2020). In the recent years with the development of different machine or computer-based control systems, the quality control of embossing features was becoming an important target for graphic instrument manufacturers (Peret, 2019; Inspectron, 2020; Peret, 2020; Starrett, 2020). As one of the most important parameters for high quality processing, the embossing depth was in their focus. Low embossing depth would not result in adequate visual and tactile effects on the substrates, but also, too deep embossing would cause problems in the form of ruptures, cracks, wrinkles and other surface damages. These commercially available instruments are fine-tuned, optimized for fast and accurate quality control in real manufacturing environment, however, they could represent an expensive investment for small businesses, design studios, craft workshops, etc. A simple and more affordable computer-aided visual assessment of embossing quality could be a good alternative, but also it would be a great help for 3D printed or laser-engraved dies development. For that purpose, a detailed investigation was performed to analyse the applicability of a simple flatbed scanner and an image processing algorithm for embossing quality evaluation. This study is focusing on the embossing pressure analysis, based on the difference between the average grayscale levels of areas under and outside shadows on the previously scanned embossed substrates.

\section{MATERIALS AND METHODS}

In order to ensure a wide variety in thickness, structure and surface characteristics of the embossing substrates, commercially available coated, uncoated and bulk papers with different basis weights were chosen for this investigation. The values of basic properties of selected papers and the corresponding standards are presented in Table 1 (Fedrigoni, 2020; Mondigroup, 2020).

Table 1: Basic properties and corresponding standards of selected papers

\begin{tabular}{|c|c|c|c|c|}
\hline $\begin{array}{l}\text { Group } \\
\text { number }\end{array}$ & Paper grade & $\begin{array}{l}\text { Basis weight } \\
{\left[\mathrm{g} / \mathrm{m}^{2}\right]} \\
\text { ISO } 536\end{array}$ & $\begin{array}{l}\text { Thickness } \\
{[\mu \mathrm{m}]} \\
\text { ISO } 534\end{array}$ & $\begin{array}{l}\text { Roughness } \\
\text { (Bendsten) } \\
\text { [m/lmin] } \\
\text { ISO 8791-2 }\end{array}$ \\
\hline 1. & \multirow{4}{*}{$\begin{array}{l}\text { Coated } \\
\text { (Fedrigoni Symbol } \\
\text { Freelife Satin) }\end{array}$} & $130 \pm 3.9$ & $160 \pm$ & $20 \pm 10$ \\
\hline 2. & & $150 \pm 4.5$ & $180 \pm$ & $20 \pm 10$ \\
\hline 3. & & $170 \pm 5.1$ & $200 \pm$ & $20 \pm 10$ \\
\hline 4. & & $200 \pm 8.0$ & $230 \pm$ & $20 \pm 10$ \\
\hline 5. & \multirow{5}{*}{$\begin{array}{l}\text { Uncoated } \\
\text { (Mondi MAESTRO } \\
\text { PRINT) }\end{array}$} & $80 \pm 3.0$ & $105 \pm 4.0$ & $225 \pm 75$ \\
\hline 6. & & $100 \pm 4.0$ & $126 \pm 5.0$ & $225 \pm 75$ \\
\hline 7. & & $120 \pm 4.5$ & $144 \pm 6.0$ & $225 \pm 75$ \\
\hline 8. & & $140 \pm 5.5$ & $164 \pm 6.0$ & $225 \pm 75$ \\
\hline 9. & & $170 \pm 7.0$ & $198 \pm 7.0$ & $225 \pm 75$ \\
\hline 10. & \multirow{3}{*}{$\begin{array}{l}\text { Bulk } \\
\text { (Hellefos Snowbulk } \\
70 \text { ISO) }\end{array}$} & $60 \pm 3.9$ & $120 \pm 3.0$ & - \\
\hline 11. & & $70 \pm 3.9$ & $140 \pm 3.0$ & - \\
\hline 12. & & $80 \pm 3.9$ & $160 \pm 3.0$ & - \\
\hline
\end{tabular}

For easier handling during the embossing process, the paper samples were cut into $350 \mathrm{~mm}$ long and 70 $\mathrm{mm}$ wide stripes using a high-speed cutting machine (Perfecta 72 HTVC). Two paper stripes were prepared 
for each paper grade, basis weight and embossing tool combinations (one for the compression force testing serial and one for the optimal force repeatability test).

In order to get into the limitation of different typographic and graphic elements as a base for the situations from real production process, four customised test forms were prepared based on previous investigations (Bošnjaković et al, 2017; Žarko et al, 2017, Banjanin et al, 2018) and corresponding industrial recommendations (Topac, 2016; Peret, 2019; FSEA, 2020; SAPPI, 2020). The test forms consisted of four sans-serif, technical letters (X, T, A and O) and different basic geometric elements (squares, circles, hexagons, octagon, triangles with different inner angles, lines with different thicknesses, rounded and flat ends) mostly in positive and at least in 3 different sizes (Figure 1). The embossing tools were prepared as single-level pair of two matching parts, a die and a counter die. Depending on the test forms' elements, usually the upper die was a female part, with the design etched into it, while the counter die was a male part with the corresponding raised design. Although, two different tool manufacturing methods were employed for the complete investigation, a conventional method of metal etching and a 3D printing method, for the purpose of this study, only the conventional tools were used and analysed. The embossing test tools were made of commercially available magnesium plates for embossing dies (Red Top, Magnesium Electron). Technical details of the die production process are shown in Table 2, while Figure $1 a$ and $b$ presents the developed test forms and the prepared embossing die sets, respectively.

Table 2: Technical details of the die production process

\begin{tabular}{|c|c|c|}
\hline $\begin{array}{l}\text { Process } \\
\text { step }\end{array}$ & $\begin{array}{l}\text { Production } \\
\text { process }\end{array}$ & Details, equipment and chemicals \\
\hline 1. & Film preparing & $\begin{array}{l}\text { Heidelberg Ultre } 5400 \text { Laser Imagesetter; light source: visible red laser diode with } \\
\text { emission wavelength of } 670 \mathrm{~nm} \text {; imaging principle: rotation monogon, maximum } \\
\text { screen frequency up to } 2001 \mathrm{pi} \text { at } 3386 \mathrm{dpi}\end{array}$ \\
\hline 2. & Exposure & $\begin{array}{l}\text { Duplomat Rectoplan; imaging principle: flatbed; light sources: one mercury bulb } \\
\text { with } 400 \mathrm{~W} \text {, four LED bulb with } 300 \mathrm{~W} \text {, one point light bulb with } 100 \mathrm{~W} \text {; exposure } \\
\text { time: } 15 \mathrm{~min}\end{array}$ \\
\hline 3. & Developing & $\begin{array}{l}\text { in basic container with solution of trichlorethylene } \mathrm{C}_{2} \mathrm{HCl}_{3} \text { (p.a. >99\%), developing } \\
\text { time: } 10 \mathrm{~min} \text { with an additional } 5 \mathrm{~min} \text { for drying }\end{array}$ \\
\hline 4. & Etching & $\begin{array}{l}\text { custom made frame, corrosive agent consists of nitric acid (HNO3), water and } \\
\text { mineral corrosive oil REV-FLEX Etch Additive, etching time: } 20 \mathrm{~min}\end{array}$ \\
\hline 5. & Stripping & With clean tap water \\
\hline
\end{tabular}
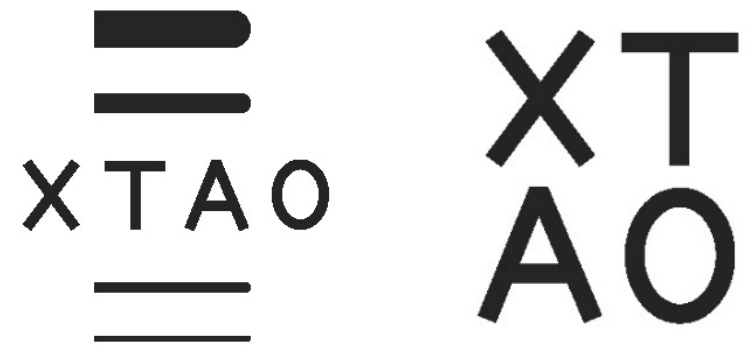

a)

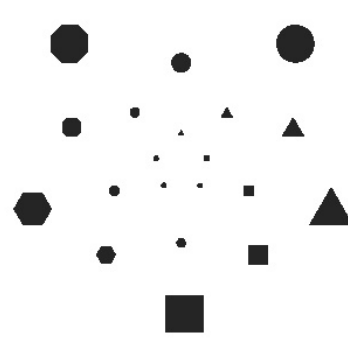

c) b)

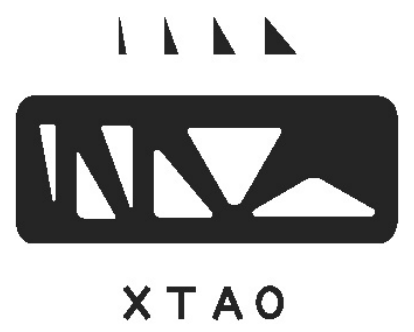

d)

Figure 1: The developed test forms: line elements and medium letters - die no. 1 (a), large letters - die no. 2 (b), smallscale geometric elements - die no. 3 (c), various triangles with small letters - die no. 4 (d) 
The embossing process was performed on a table top, single column, electromechanical universal testing machine Shimadzu EZ-LX (Shimadzu, Japan) using a high-precision load cell (capacity of 2500N, ISO 376 accuracy class 00), a fixed lower and a movable upper compression plates with radius of $118 \mathrm{~mm}$. The testing parameters were monitored and controlled by TRAPEZIUM X software (version 1.4.2, Shimadzu, Japan) in Single test mode and compression test type (Shimadzu, 2012). The speed of traction displacement, sampling frequency and compression time were constant for all paper samples $(2 \mathrm{~mm} / \mathrm{min}$, $10 \mathrm{~ms}$ and $2 \mathrm{~s}$, respectively), while the compression force has been varied for each paper sample individually and set up as a break detection threshold.

In order to determine the highest compression force (which would provide the highest possible contrast but without any damages, crispy edges, uneven or insufficient embossed depth), it was applied in gradually increasing manner with at least five different force values. Once paper sample reached its maximum deformability and the embossed surface was starting showing some damages, the embossing serial was stopped and the previous compression force was determined as the optimal force value. For the repeatability testing, five embossed samples were prepared with the optimal compression forces for each paper grade, basis weight and embossing tool combinations. All the embossing procedures were conducted in a controlled environment (at room temperature and standard relative air humidity) and the samples were conditioned for more than 48 hours prior to testing. The embossing process, its evaluation and the optimal compression force selection was performed by an expert on the spot, while the evaluation of embossing uniformity and repeatability were subsequently characterized by a digital image analysis method, described in the following section.

For the purpose of digital image analysis, all the embossed paper samples needed to be scanned first. The previously prepared samples have been digitized with a flatbed scanner (Canon CanoScan 5600F) at resolutions of 1200 spi, in grayscale mode without any advanced image settings of luminance and contrast. The dimensions of scanned area were $45 \times 45 \mathrm{~mm}$ and the images were saved as TIFF files with colour depth of 8 bit (Canon, 2020). In this manner 480 sample images were collected (12 different paper samples 4 embossing dies, 5 different compression force + the selected optimum force $x 5$ for each paperdie combination).

To obtain objective measure of compression force for adequate embossing quality, an image processing algorithm has been developed. It is based on the idea that embossed surfaces of different substrates such as paper, cardboard, polymer, metal, can be realistically digitalized by simple flatbed scanning (at higher resolution). During the scanning process, the scanner's built-in lamp evenly illuminates the complete embossed surface, but on the edges of recessed or raised elements, it creates shadows and the embossed image in digital form could be perceived similarly like in real viewing conditions. Moreover, the areas under shadows captured in that way could be analyzed by digital image processing. This represents a great potential, since in real viewing conditions, shadows as a phenomenon, cannot be really used in that way. The initial hypothesis of the developed algorithm for digital image processing lies on the difference between the average grayscale levels of areas under and outside shadows. That greyscale value difference, referred further as shadow-based contrast, hypothetically will rise with the applied pressure/force, since the higher compression forces will generate greater deformation on the paper, i.e. the recessed or raised elements of embossed images will be more emphasized. These emphasized elements will lead to greater distance between the original (non-embossed) surface and the processed (recessed or raised) surface which will result in darker shade of grayscale level of areas under shadows, therefore higher value of shadow-based contrast (higher value of average grayscale level difference). Additionally, the shadow-based contrast could be used as a reference value to ensure adequate visibility of embossed elements by defining the minimum value of needed contrast. Based on the described hypotheses and the analogy with the specific tasks for image processing presented in (Drobchenko et al, 2011; Malek, 2014; Nashat et al, 2014; Sinha, 2014; Goncalves et al, 2015), the developed algorithm includes the following image-processing steps: image segmentation (binarization), masking of the two regions of interest (ROIs): areas under shadows and the regularly illuminated areas, determination of average greyscale level for those two ROls and calculation of the difference between them. The simplified illustration of described method is shown in Figure 2. 

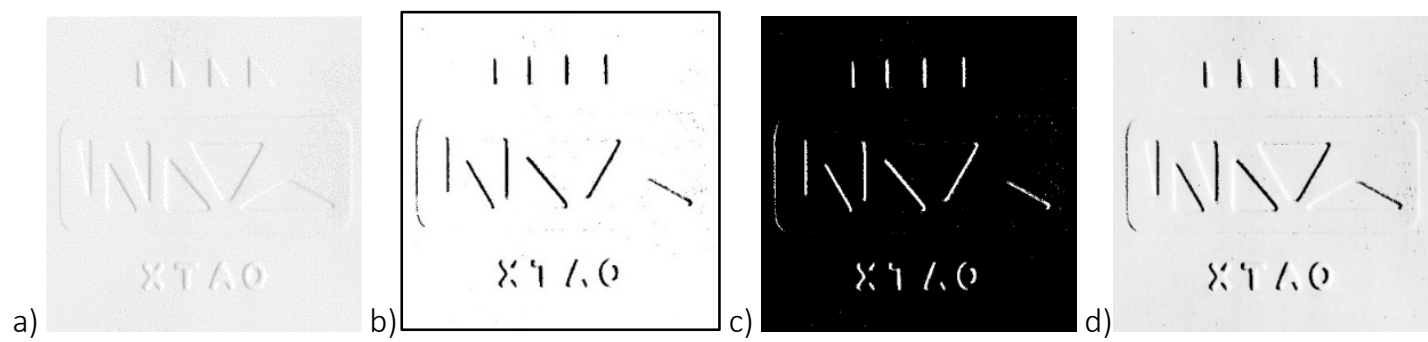

Figure 2: The shadow-masking procedure: original scanned image (a), segmented image (b), generated mask image (c) and selected areas under shadows (d)

First, the original grayscale image (Figure 2a) was converted to binary (Figure 2b) via image segmentation. For images with significant unimodal histogram, which is the current case as well, different thresholding methods were identified as suitable: three general-purpose thresholding methods (Kittler's, Otsu's and Kapur's) and two specific methods for unimodal histograms (Tsai's and Rosin's). After a detailed visual assessment of the original images and the corresponding segmented ones, Kapur's algorithm has been selected for the given task, since it can provide a well-balanced segmentation, without large-scale over or under-detection of fine details. As a result of segmentation, all the areas under shadows were replaced with black pixels, while all other areas were converted to white pixels. Therefore, the original binary image was suitable for masking the shadow areas and calculating the average grayscale level outside the shadows (Figure $2 \mathrm{~d}$ ), and vice versa, the negative binary image (Figure $2 \mathrm{c}$ ) was used for the average greyscale level calculus of surfaces under the shadows. The algorithm for image processing and average greyscale difference calculus was developed using software package MATLAB ${ }^{\circ}$ R2011a with the corresponding Image Processing Toolbox ${ }^{\mathrm{TM}}$.

\section{RESULTS AND DISCUSSION}

Results are presented and discussed in two phases. In the first, the applicability of the selected image attribute, the greyscale level of the areas under shadows and the proposed image feature, the shadowbased contrast, have been analysed in the function of realistic digital representation of embossed samples and an objective measure for the deformation rate in the embossing quality evaluation, respectively. In the second phase, the obtained results of shadow-based contrast were analysed regarding to the different paper grade, basis weight and type of test elements on the embossing dies.

Figure 3 shows the typical transition of grayscale levels from lighter to darker on scanned images due to increased compression force of the embossing process (coated paper with basis weight of $170 \mathrm{~g} / \mathrm{m}^{2}$ embossed with die no. 1). As it can be noticed, the lowest compression force of $600 \mathrm{~N}$ left a very light/mild/pale shadow (Figure 3a). The compression force of $800 \mathrm{~N}$ made a more apparent shadow (Figure $3 b)$, while the highest applied force, in this case $1000 \mathrm{~N}$, resulted in the most dominant shadow formation (Figure 3c). Similar tendencies could be noticed on the uncoated (Figure 4) and bulk (Figure 5) paper samples, regardless of the used die type. Additionally, the presented images clearly prove/demonstrate that embossed samples were realistically digitalized, therefore it is possible to use a simple flatbed scanner, as an image acquisition equipment for embossed paper samples, at least for the single-level embossed images.

a)

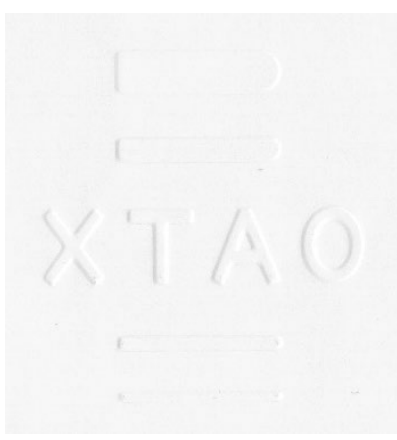

b)

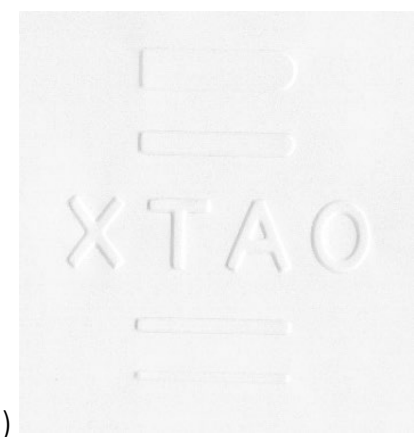

C)

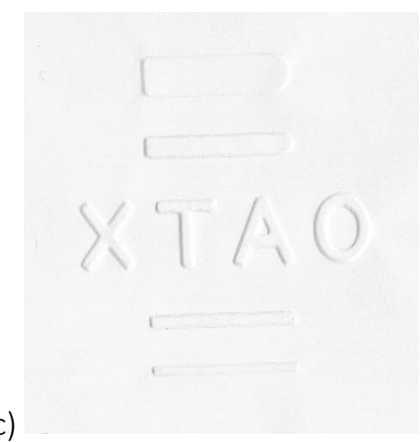

Figure 3: Samples of $170 \mathrm{~g} / \mathrm{m}^{2}$ coated paper embossed with $600 \mathrm{~N}(\mathrm{a}), 800 \mathrm{~N}(\mathrm{~b})$ and $1000 \mathrm{~N}(\mathrm{c})$ 
a)

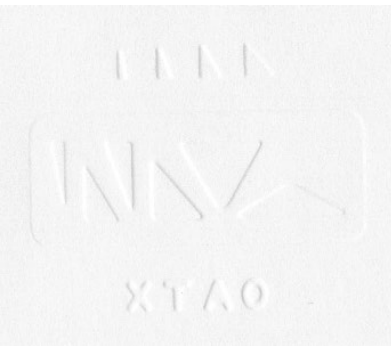

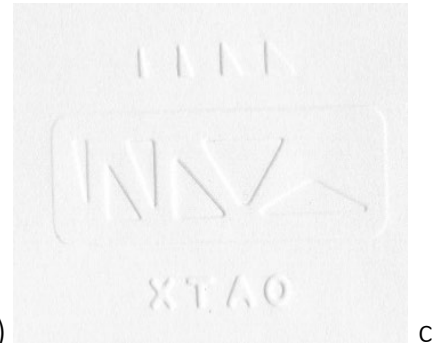

c)

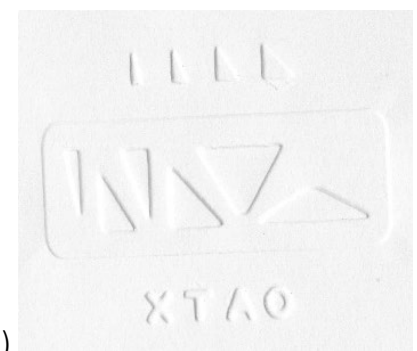

Figure 4: Samples of $120 \mathrm{~g} / \mathrm{m}^{2}$ uncoated paper embossed with $800 \mathrm{~N}(\mathrm{a}), 1000 \mathrm{~N}(\mathrm{~b})$ and $1200 \mathrm{~N}(\mathrm{c})$

a)

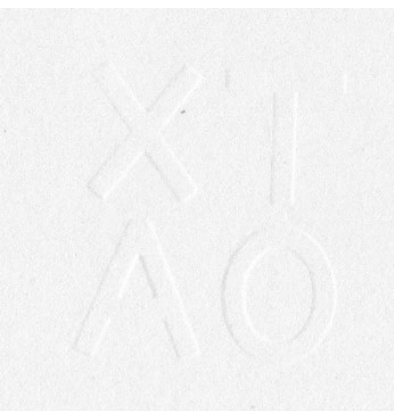

b)

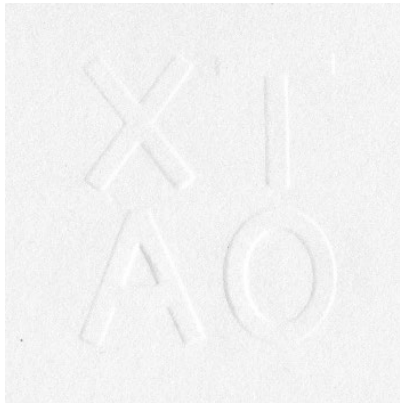

Figure 5: Samples of $80 \mathrm{~g} / \mathrm{m}^{2}$ bulk paper embossed with $325 \mathrm{~N}(\mathrm{a}), 375 \mathrm{~N}(\mathrm{~b})$ and $400 \mathrm{~N}(\mathrm{c})$

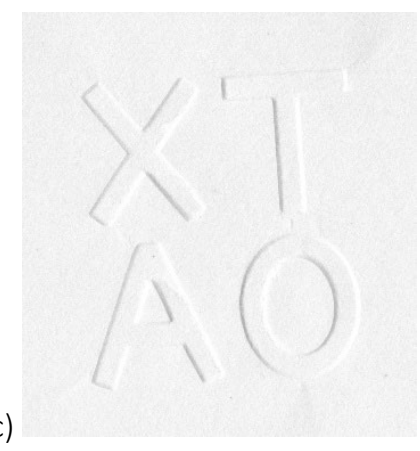

c)

The obtained results of average greyscale difference for the analysed sample papers embossed with different compression forces were grouped by the used die type and they are presented in Figure 6.

As it can be noticed, the values of average greyscale difference (i.e. shadow-based contrast) show increasing tendency by increasing the applied compression force in most of the observed paper and die combinations. Deviations could be noticed for bulk papers in the combination with all embossing dies, and for embossing die type 3 used almost on any type of paper sample. The corresponding values of coefficients of determination for uncoated and coated papers in the combinations of embossing die type 1, 2 and 4 were very high, ranging from $R^{2}=0.6079$ to $R^{2}=0.9971$, while bulk paper and embossing die no. 3 resulted in lower values, from $R^{2}=0.3420$ to $R^{2}=0.8502$ and from $R^{2}=0.2351$ to $R^{2}=0.8802$, respectively.

These low values of coefficients of determination for bulk paper can be associated with the structural and surface characteristics of these examined papers. Namely, they have a porous and spongy structure, with lower surface and overall strength due to a significant filler reduction and absence of surface sizing or coating. They usually exhibit poor deformability with significant tendency to creasing, cracking and tearing. During the embossing process they often randomly cracked or creased along the embossed elements even with a small or no compression force increase. These surface damages later on led to significantly darker patches on the scanned images and to the corresponding higher value of shadow-based contrast. Similarly, numerous surface cracks and/or creases were observed on almost every paper sample embossed with die type 3. The small-scaled geometric elements on the embossing die punched through the paper at higher compression forces instead of embossing it and generated dark spots on the scanned images. In the light of the fact that these damages were actually expected for bulk papers and also for the small, needle-like embossing elements, the low values of coefficients of determination for those samples are reasonable.

As it was mentioned before, this part of the experiment was dedicated to optimal compression force determination trough applying successively increasing compression forces until damages occurred on the embossed sample. When they occurred, the previous compression force, highest one which could provide the largest embossing deformation but without any damages, was determined as the optimal force value. Usually, all the embossed sample papers got more or less defined crease lines/wrinkles or cracks at the highest scheduled compression force, which were resulting in darker shade of greyscale value and higher shadow-based contrast.

By analysing the results regarding to the shadow-based contrast for these step-like force increments, the obtained greyscale difference values could be grouped into two major groups. The first one contains values of shadow-based contrast for lower compression forces and they are typically from 20 to 30 or slightly above. The second group includes greyscale difference values around 50, sometimes even 60, delivered by higher compression forces, which could potentially generate some damages on the samples and therefore 
a higher difference between the grayscale levels of the initial and the shadow-covered areas, too. This pattern suggests that damages on the embossed samples could be recognized not just visually, but also based on the difference in shadow-based contrast for successively increasing compression forces. In addition, since the presented results are indicating strong correlation between the shadow-based contrast value and the applied compression force, it is possible to track changes in the values of shadow-based contrast in accordance to the applied compression force, therefore the initial hypothesis was correct.

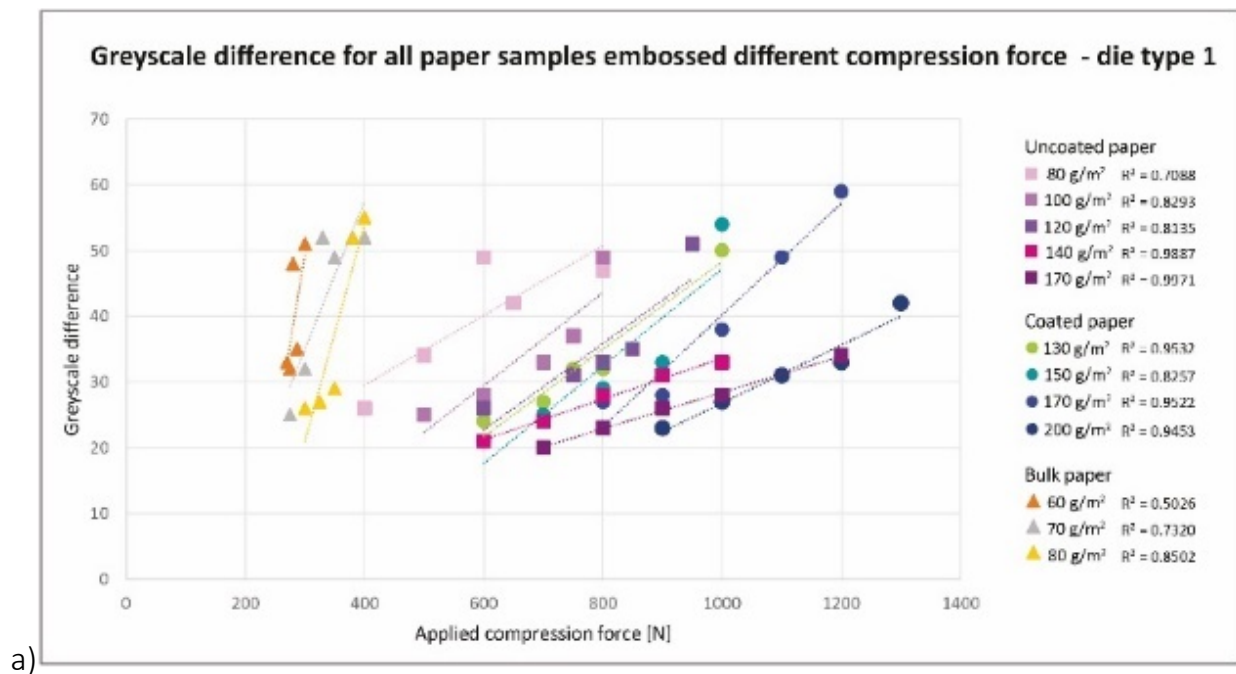

a)

Greyscale difference for all paper samples embossed different compression force - die type 2

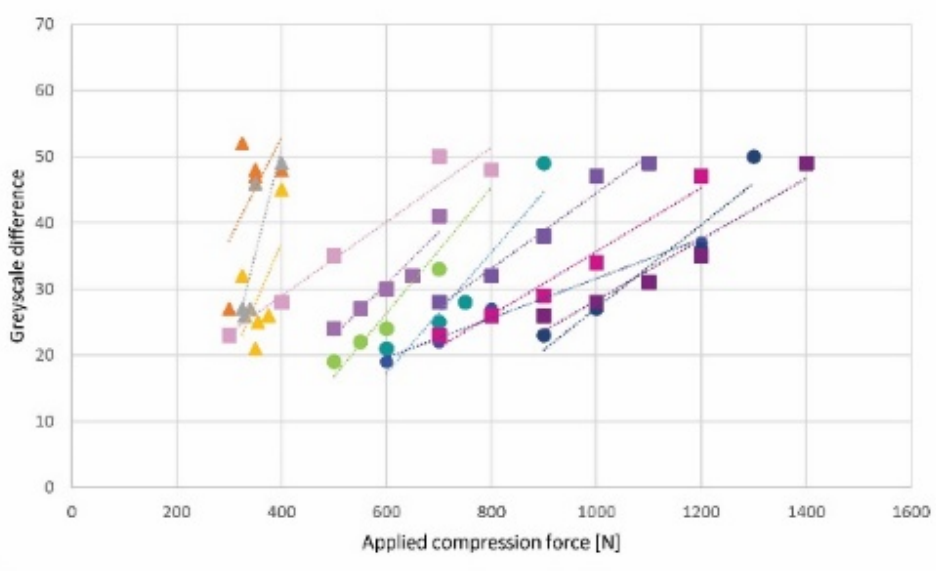

Uncoated paper

$80 \mathrm{~g} / \mathrm{m}^{2} \quad \mathrm{R}^{2}=0.9465$

$100 \mathrm{~g} / \mathrm{m}^{2} \mathrm{R}^{2}-0.9119$

$120 \mathrm{~g} / \mathrm{m}^{2} \mathrm{R}^{2}=0.9704$

$140 \mathrm{~g} / \mathrm{m}^{2} \mathrm{R}^{2}=0.9654$

- $170 \mathrm{~g} / \mathrm{m}^{2} \mathrm{R}^{2}-0.9387$

Coated paper

- $130 \mathrm{~g} / \mathrm{m}^{2} \mathrm{R}^{2}-0.9538$

- $150 \mathrm{~g} / \mathrm{m}^{2} \mathrm{R}^{2}=0.0410$

- $170 \mathrm{~g} / \mathrm{m}^{\prime} \mathrm{R}^{2}-0.9834$

$200 \mathrm{~g} / \mathrm{m}^{\prime} \mathrm{R}^{\mathrm{r}}-0.9078$

Bulk paper

$\Delta 60 \mathrm{~g} / \mathrm{m}^{2} \mathrm{R}^{2}-0.3420$

$\Delta 0 \mathrm{~g} / \mathrm{m}^{2} \quad \mathrm{R}^{t}=0.7067$

$\Delta 80 \mathrm{~g} / \mathrm{m}^{2} \quad \mathrm{R}^{2}=0.3088$

b)

Greyscale difference for all paper samples embossed different compression force - die type 3

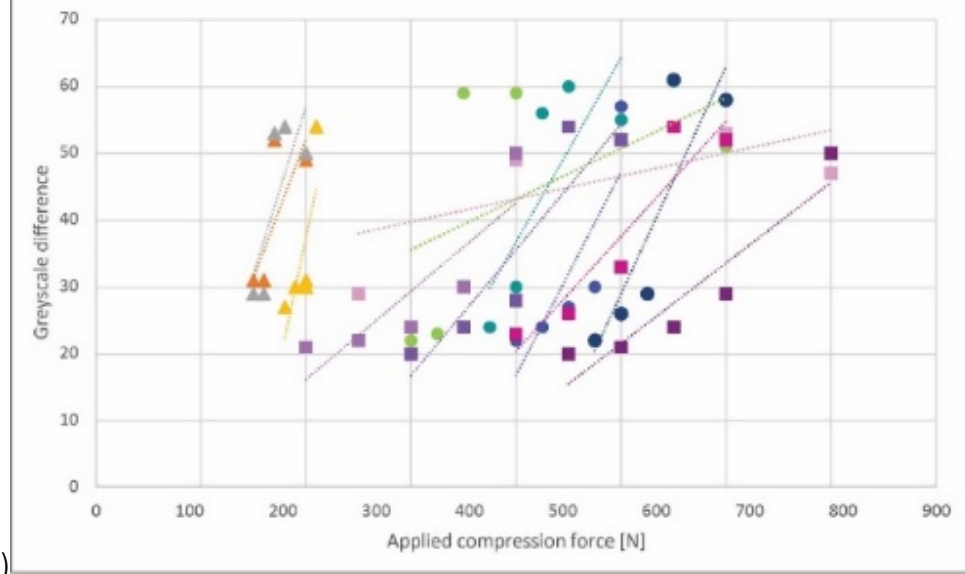

Uncoated paper

$=80 \mathrm{~g} / \mathrm{m}^{2} \quad \mathbf{R}^{2}=0.4145$

$=100 \mathrm{~g} / \mathrm{m}^{2} \mathrm{R}^{2}=0.7522$

= $120 \mathrm{~g} / \mathrm{m}^{2} \quad \mathrm{R}^{2}=0.8470$

$140 \mathrm{~g} / \mathrm{m}^{2} \mathrm{k}^{2}=0.875$

$170 \mathrm{~g} / \mathrm{m}^{2} \mathrm{R}^{2}=0.8802$

Coated paper

- $130 \mathrm{~g} / \mathrm{m}^{2} \mathrm{~F}^{2}-0.2351$

- $150 \mathrm{~g} / \mathrm{m}^{2} \mathrm{k}^{2}=0.6322$

- $170 \mathrm{~g} / \mathrm{m}^{2} \mathrm{R}^{2}=0.706$

- $200 \mathrm{~g} / \mathrm{m}^{2} \mathrm{R}^{2}-0.7623$

Bulk paper

$\triangle 60 \mathrm{~g} / \mathrm{m}^{2} \quad \mathrm{R}^{2}-0.5600$

$\triangle 70 \mathrm{~g} / \mathrm{m}^{2} \quad \mathrm{R}^{2}=0.5589$

$80 \mathrm{~g} / \mathrm{m}^{2} \quad \mathrm{R}^{2}=0.5918$

c)

Figure 6 (part 1): Greyscale difference for all paper samples embossed with different compression forces and die type 1 (a), 2 (b), 3 (c) and 4 (c) 


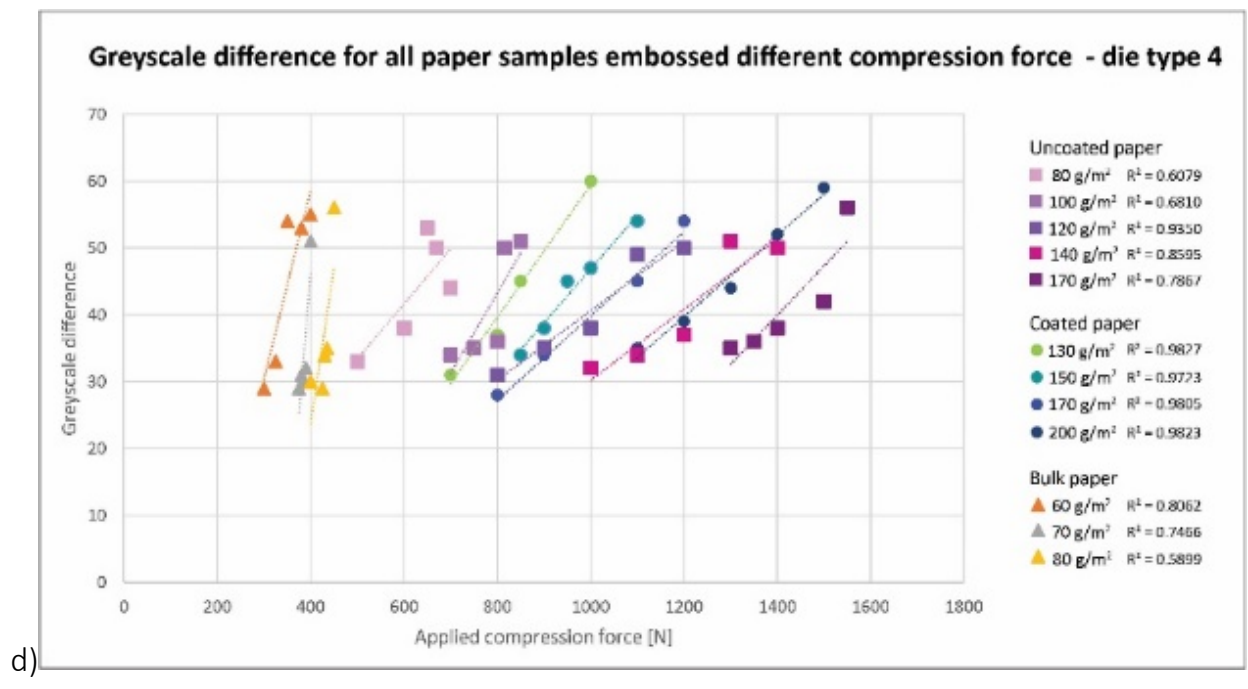

Figure 6 (part 2): Greyscale difference for all paper samples embossed with different compression forces and die type $1(a), 2(b), 3(c)$ and 4 (c)

After the optimal compression force selection, the repeatability test took place and the obtained results are presented in Figure 7.

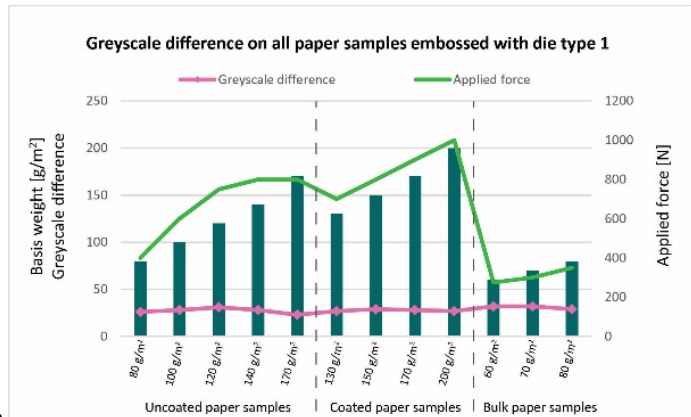

a)

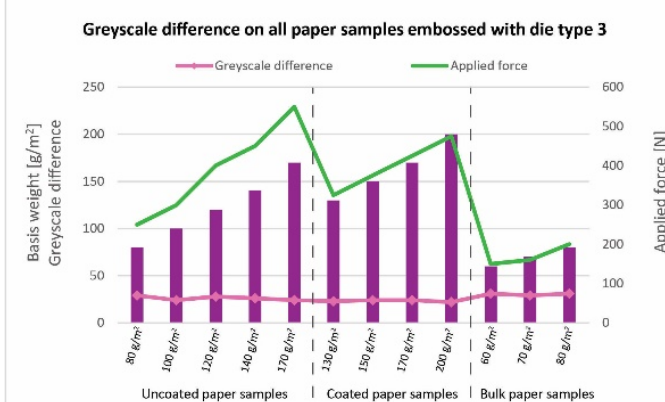

c)

Figure 7: Greyscale difference for all paper samples embossed with the previously selected optimal compression force and embossing die type 1 (a), 2 (b), 3 (c) and 4 (c)

At first sight, the presented graphs look very similar, suggesting a certain level of homogeneity among the obtained results, however there are some differences. The similarities among the obtained results are primarily related to the values for optimal compression forces and shadow-based contrast values in general. Based on the presented graphs, it can be noticed, that the optimal compression forces (selected in previous step for every paper grade and basis weight individually) had increasing tendency with the basis weight increasement. Papers with lower basis weight needed lower compression forces to form sufficiently visible embossed image without damages, while for the papers with higher basis weight the compression forces were also higher. This tendency was identical for all paper grade or embossing die. The other 
similarity between the presented graphs is the uniform structure of the obtained values of greyscale level difference for each embossing die individually, but at the same time, these results gave the first difference among the presented diagrams. Namely, three of four embossing dies derived greyscale level differences in very close range (die 1: from 23 to 32; die 2: from 24 to 31; die 3: from 22 to 31), while for embossing die type 4, slightly higher values were observed (from 29 to 39). This fourth embossing die had a larger geometric element in negative image, which could have caused more emphasized shadow areas on the scanned images, thus higher values of shadow-based contrast. The second difference between the derived results was regarding to paper grade. Namely, the uncoated papers needed the highest compression forces in 3 out of 4 cases to provide the adequate visibility without damages (800N, 1100N, 550N and 1350N for the embossing dies 1, 2, 3 and 4, respectively). The coated papers required slightly lower values (1000N, $1000 \mathrm{~N}, 475 \mathrm{~N}$ and $1200 \mathrm{~N}$ ) except the 1. die, while the bulk papers were embossed with significantly lower values regardless of the used die $(350 \mathrm{~N}, 375 \mathrm{~N}, 200 \mathrm{~N}$ and $430 \mathrm{~N})$. The possible explanation for these variations in compression forces lies in the structural and surface properties, as well as the overall strength of the selected papers.

\section{CONCLUSIONS}

In this paper, the applicability of a simple flatbed scanner and an image processing algorithm for embossing quality evaluation have been analysed and presented. The main focus was given to the embossing pressure analysis, based on the difference between the average grayscale levels of areas under and outside shadows on the previously scanned embossed substrates. After a detailed visual assessment of all scanned paper samples and analysis of the obtained results, it can be stated that a simple flatbed scanner, as an acquisition equipment, can realistically digitalized the embossed paper samples (at least the single-level embossed images). Additionally, although, there were some low values of coefficients of determination, the presented results are indicating strong correlation between the shadow-based contrast value and the applied compression force, i.e. the initial hypothesis was correct: it is possible to track changes in the values of shadow-based contrast in accordance to the applied compression force. Regarding the paper grade, basis weight and type of test elements on the embossing dies, the obtained results imply that the proposed image feature, the shadow-based contrast has a potential to be used in embossing quality evaluation as an objective measure not only for deformation rate tracking, but also as a reference parameter to ensure adequate visibility of embossed elements by defining the minimum value of needed contrast.

\section{ACKNOWLEDGMENTS}

This research(paper) has been supported by the Ministry of Education, Science and Technological Development through the project no. 451-03-68/2020-14/200156: "Innovative scientific and artistic research from the FTS (activity) domain".

\section{REFERENCES}

[1] Banjanin, B., Vladić, G., Pál, M., Dimovski, V., Adamović, S., Bošnjaković, G.: "Production factors influencing mechanical and physical properties of FDM printed embossing dies", Proceedings of the 9th International Symposium on Graphic Engineering and Design GRID 2018, (University of Novi Sad, Faculty of technical sciences, Department of graphic engineering and design, Novi Sad, 2018), pages 225-236.

[2] Blechschmidt, J.: "Papierverarbeitungstechnik", (Hanser Verlag, München, 2013.).

[3] Bošnjaković, G., Vladić, G., Pál, M., Banjanin, B., Dedijer, S.: "Performance evaluation of paper embossing tools produced by fused deposition modelling additive manufacturing technology", Journal of Graphic Engineering and Design 8 (2), 47-54, 2017. doi: 10.24867/JGED-2017-2-047.

[4] Canon: "Instruction Manual for Canon CanoScan 5600F", URL: https://www.canon.rs/scanners/flatbed-scanners/canoscan_5600f/ (last request: 2020-08-09).

[5] Drobchenko, A., Kamarainen, J-K., Lensu, L., Vartiainen, J., Kälviäinen, H., Eerola, T.: "Thresholdingbased detection of fine and sparse details", Frontiers of Electrical and Electronic Engineering in China 6 (2), 328-338, 2011. doi: 10.1007/s11460-011-0139-x. 
[6] Fedrigoni: "Technical data Symbol Freelife Satin", URL:

ttps://www.fedrigonipapers.com/sites/default/files/2019-12/Symbol\%20Freelife\%20Satin_1.pdf (last request: 2020-08-06).

[7] FSEA: "Embossing and Foil Stamping Techniques Made Easy Reference Guide", URL: https://www.fsea.com/content/design/designer-guidebook.shtml (last request: 2020-07-16).

[8] Goncalves, N., Carvalho, V., Belsley, M., Vasconcelos, R.M., Soares, F.O., Machado, J.: "Yarn features extraction using image processing and computer vision - A study with cotton and polyester yarns", Measurement 68, 1-15, 2015. doi: 10.1016/j.measurement.2015.02.010.

[9] Hellefoss: "Technical data Hellefos Snowbulk 70 ISO" URL: https://www.hellefoss.com/files/Product_assortment_Snowbulk_70_ISO.pdf (last request: 2020-08-06).

[10] Holik, H.: "Handbook of paper and board", (Wiley-VCH Verlag, Weinheim, 2013.).

[11] Iggesund: "Reference manual", URL: https://www.iggesund.com/services/our-services/downloadcentre/\#id10162_Knowledge (last request: 2020-07-05).

[12] Inspectron: "Gold Embossing", URL: https://www.inspectron.com/goldembossing\# (last request: 2020-07-10).

[13] Kluge: "The Designers Guide to Foil Stamping Embossing", URL: https://www.kluge.biz/wpcontent/uploads/2015/10/Embossing-and-Foil-Stamping-Techniques-Made-Easy-ReferenceGuide.pdf (last request: 2020-07-16).

[14] Malek, A. S.: "Online fabric inspection by image processing technology", Ph.D. thesis, University of Haute Alsace, 2012.

[15] Mondigroup: "Technical data Maestro Print", URL: https://igepa.hr/media/1271/maestro-print.pdf (last request: 2020-08-06).

[16] Nashat, S., Abdullah, A., Abdullah, M. Z.: "Machine vision for crack inspection of biscuits featuring pyramid detection scheme", Journal of Food Engineering 120 (1), 233-247, 2014. doi: 10.1016/j.jfoodeng.2013.08.006.

[17] Peret, Application Note Embossing Depth CREASY Software Version v5.x, peret, URL: http://www.peret.it/PDF/Manual/CREASY\%20EGUIDEPRO\%20Embossing\%20Application\%20Note.pdf (last request: 2020-07-18).

[18] Peret, EGUIDE-PRO Embossing Test Patch, URL: http://www.peret.it/Articles/Embossing\%20Test\%20Patch.pdf (last request: 2020-07-18).

[19] SAPPI: "Standard 5: Tip 5 - Embossing", URL: https://www.sappi.com/standard-5-tip-5-embossing (last request: 2020-07-10).

[20] Shimadzu Corporation, Shimadzu Compact Tabletop Testing Machine EZ test EZ-LX/EZ-SX Series Instruction Manual, Shimadzu, URL:

https://www.ssi.shimadzu.com/sites/ssi.shimadzu.com/files/Products/literature/testing/C224E055c.pdf (last request: 2020-08-11).

[21] Sinha, S. K. "Automated underground pipe inspection using a unified image processing and artificial intelligence methodology", Ph.D. thesis, University of Waterloo, 2000.

[22] Starrett, Embossing Depth Measurement for Profile Extrusion Processes, Starrett, URL: https://www.starrett.com/docs/other-downloadable-resources/embossing-depth-measurement--bulletin-3004.pdf?sfvrsn=5 (last request: 2020-07-15).

[23] Storaenso: "Paperboard Guide 2019", URL: https://info.storaenso.com/signup-paperboardguide?cc-option-checkbox=Essential (last request: 2020-07-10).

[24] Terrill, A.: "Embossing vs Debossing: An In-depth Guide", URL: https://www.printpeppermint.com/embossing-vs-debossing-an-in-depth-guide/ (last request: 2020-08-05).

[25] Topac, Technical information on embossing/debossing, Topac, URL: https://www.topac.de/fileadmin/content/c_Leistungen/Embossing_Debossing.pdf (last request: 2020-07-25).

[26] Žarko, J., Vladić, G., Pál, M., Dedijer, S.: "Influence of printing speed on production of embossing tools using FD M 3D printing technology", Journal of Graphic Engineering and Design 8 (1), 19-27, 2017. doi: 10.24867/JGED-2017-1-019. 


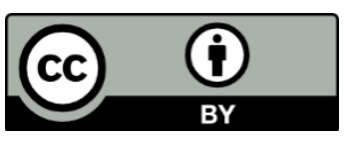

(C) 2020 Authors. Published by the University of Novi Sad, Faculty of Technical Sciences, Department of Graphic Engineering and Design. This article is an open access article distributed under the terms and conditions of the Creative Commons Attribution license 3.0 Serbia

(http://creativecommons.org/licenses/by/3.0/rs/). 



\title{
STATISTICAL ANALYSIS OF THE INFLUENCE OF PRINT RUN ON SURFACE ROUGHNESS OF DIGITAL FLEXO PRINTING PLATES' SOLID TONE AREAS
}

\author{
Sandra Dedijer ${ }^{1}$ (D), Magdolna Pal ${ }^{1}$ (D), Ivana Tomić ${ }^{1}$ (D), Stefan Poljak ${ }^{2}$, \\ Živko Pavlović ${ }^{1}$ (D), Ivana Jurič ${ }^{1}$ (D), Neda Milić Keresteš ${ }^{1}$ (iD \\ ${ }^{1}$ University of Novi Sad, Faculty of Technical Sciences, \\ Department of Graphic Engineering and Design, Novi Sad, Serbia \\ ${ }^{2}$ Tetra Pak Produktions GmbH \& Co KG, Limburg, Germany
}

\begin{abstract}
In this study we have aimed to present statistical evaluation of changes in the surface roughness of the solid tone areas on CtP flexo printing plate in dependence of print run. Changes in flexo plate surface roughness is influenced by the plate-making process, printing pressure and speed, the interaction with the ink and printing substrate and by the wear of the printing plate due to long print-runs. Thus, the aim of this research was to evaluate the changes in the amplitude surface roughness parameters $(R a, R p$, $R v$ and $R z$ ), between the printing plates used for different print runs. In the experiment, we have employed three sets of CtP flexo printing plates, for three colors-cyan, magenta and blue. The first set was not used for printing, the second was used to print 7 rolls of substrate and the third is used to print 11 rolls of printing substrate. The amplitude surface roughness parameters were compared by applying independentsamples t-test method using the software SPSS (Statistical Package for Social Science) with a 0.05 significance level. Statistical analysis revealed that the difference between the amplitude surface roughness parameters measured on CtP flexo printing plates are significant with a 95\% confidence level, whereas the statistical significance pointed out that with the longer print runs, the difference will be strongly expressed.
\end{abstract}

Key words: CtP flexo printing plate, solid tone area, surface roughness, long print run

\section{INTRODUCTION}

Flexography is a direct printing technique primarily recognisable due to its exceptional ability to print on the various substrates delivering high quality imprints. Due to its cost effectiveness, versatility and efficiency, it became growing printing process on a highly demandable graphic arts industry market.

The printing substrates which can be utilized in flexography are mainly used in the packaging industry and are different types of the absorbent and non-absorbent materials, coated and uncoated paper board, metalized foils, paper foils and plastic films (Kipphan, 2001; Rentzhog, 2006; Lanska, 2007).

Flexography is a high-speed printing process which uses relief printing plates. It means that the image areas on the printing plate are raised above the non-image areas. Image areas receive the printing ink which is, due to slight contact pressure, transferred onto the printing substrate. The ink transfer concept in flexography is simple, but still there is a wide diapason of variable parameters which directly influence ink transfer and consequently the quality of the final printed result (Dedijer et al., 2012).

For example, printing pressures which are required to print solids and halftones differ significantly, which may result in image distortion especially if printing is conducted on substrates with textured surface (Bould et al, 2004). The flexographic printing plate is also one of the key factors which highly influence the stability and quality of the printing process.

In light of ink transferring, especially from the large solid areas which are not rare in flexography, the controlled and uniform ink transferring from the printing plate onto the printing substrate is a must if the high-quality output is a goal. One of the parameters which are directly linked with the ink transferring rate is printing plate surface property. The analyses of surface topography give relevant information to make possible prediction of behaviour of the flexo plate surface during printing process (Barros et al, 2005). Moderate surface roughness of flexo printing plate is desirable since it enables optimal ink transfer, while excessive roughness of the solid areas cause low solid ink density due to failure to make contact between the printing plate surface and a given substrate (Choi and O'Brate, 2010). Too low surface roughness may lead to again insufficient ink transfer onto the printing plate.

There are a variety of methods proposed in order to quantify the surface roughness: profilometric methods, like MSP-mechanical stylus contact profilometry or non-contact laser profilometry or different imaging methods such as SEM (Scanning Electron Microscopy) or AFM method (Atomic Force 
Microscopy) (Risović et al, 2009; Chappard et al, 2003). In direct contact profilometry, surface roughness is measured directly, where measuring unit's (sharp diamond tip) displacements are recorded and used for further surface roughness parameters calculation (Risović et al, 2009). Among many roughness parameters which can be used for the surface characterization, the most commonly used are amplitude ISO roughness parameters: Ra (average surface roughness), Rz (mean value of the single roughness depths $\mathrm{Zi}$ ), $\mathrm{Rp}$, the height from the highest profile peak and $\mathrm{Rv}$, the height from the lowest profile peak (Mahović, 2007; Pavlović et al, 2010).

In this paper we have explored the influence of print run on changes in surface roughness of solid tone areas on three sets of CtP flexo printing plates consisting of cyan, magenta (process colors) and blue (spot color) plate. The first set represents the CtP flexo printing plates that were not used in printing process, the second one consists of printing plates that were used for printing of 53075 meters of printing substrate, while the third set represents flexo plates used for printing the 82025 meters of the substrate. The obtained data were compared by applying independent-samples t-test in software SPSS (Statistical Package for Social Science, version 20) with a 0.05 significance level.

\section{METHODS}

The printing plates utilized in the experiment were digital flexo plates (Table 1). For the purpose of the experiment, printing plates were processed according to manufacturer's recommendation: UVA back exposure 35 seconds, UVA main exposure 10 minutes (lamp temperature $40^{\circ} \mathrm{C}$, intensity $19,6 \mathrm{~mW} / \mathrm{cm}^{2}$ ), developing speed $150 \mathrm{~mm} / \mathrm{min}$ (developer temperature $32^{\circ} \mathrm{C}$ ), drying 120 minutes (drying temperature $60^{\circ} \mathrm{C}$ ) and UVA and UVC postexposure and finishing 9 and 10 minutes, respectively. For the laser ablation, we have used laser imager for direct exposure on flexo plates (energy $4 \mathrm{~J} / \mathrm{cm}^{2}$, resolution $2450 \mathrm{ppi}$ ). The printing process was performed on roll fed flexo printing machine on matte duplex cardboard $270 \mathrm{~g} / \mathrm{m}^{2}$ using water-based colors and printing speed of $600 \mathrm{~m} / \mathrm{min}$. During the experiment, 17 cardboard rolls, or 82025 meters, were printed with the same printing plates. The sampling was done at the beginning of the print, after 11 and after 17 printed rolls. The measurements were done on the solid tone area of each prewashed printing plates. Amplitude surface roughness parameters, Ra, Rp, Rv and Rz, were measured at 11 positions, in printing and cross printing direction, whereas 32 measurements for each parameter was used for further statistical one factorial ANOVA analysis in SPSSv20 statistical tool. For the surface roughness measurements, we have used hand held portable stylus roughness tester TR 200: cut-off 0.80 $\mathrm{mm}$, sampling length 5xcut-off, Gauss filter, resolution $0.01 \mu \mathrm{m}$, measuring speed $\mathrm{Vt}=0.5 \mathrm{~mm} / \mathrm{s}$.

In results presentation, the values measured from the printing plates before printing, after 1 and 17 rolls, will be noted as 1, 2 and 3, respectfully.

Table 1: Technical parameters of used flexo printing plates

\begin{tabular}{|c|c|}
\hline Thickness & $1.70 \mathrm{~mm}$ \\
\hline Hardness & 69 Shore A \\
\hline Ton value reproduction & $1-95 \%$ \\
\hline Minimal line width & $80 \mu \mathrm{m}$ \\
\hline Minimal single dot diameter & $150 \mu \mathrm{m}$ \\
\hline
\end{tabular}

\section{RESULTS AND DISCUSSION}

Direct profilometric measurements of flexo printing plates resulted in a range of profilometric parameters' values, providing a basis for a further statistical analysis (Table 2, Table 3 and Table 4). The measured roughness profiles, for all three colors, indicate a remarkable similarity in corresponding surface roughness parameters values. 
Table 2: Surface roughness parameters of three flexo printing plates (cyan process color)

\begin{tabular}{|c|c|c|c|c|}
\hline & Plate & Average value $(\mu \mathrm{m})$ & Std. Dev. & Koef. of variation (\%) \\
\hline \multirow{3}{*}{ Ra } & 1 & 0.083 & 0.014 & 17.05 \\
\cline { 2 - 5 } & 2 & 0.082 & 0.048 & 12.24 \\
\cline { 2 - 5 } & 3 & 0.073 & 0.010 & 13.72 \\
\hline \multirow{3}{*}{$\operatorname{Rp}$} & 1 & 0.216 & 0.042 & 19.61 \\
\cline { 2 - 5 } & 2 & 0.223 & 0.048 & 21.54 \\
\hline \multirow{3}{*}{$\operatorname{Rv}$} & 3 & 0.210 & 0.034 & 16.24 \\
\cline { 2 - 5 } & 1 & 0.222 & 0.049 & 21.88 \\
\hline \multirow{3}{*}{$\operatorname{Rz}$} & 2 & 0.213 & 0.034 & 15.90 \\
\cline { 2 - 5 } & 3 & 0.183 & 0.036 & 19.48 \\
\cline { 2 - 5 } & 2 & 0.438 & 0.041465 & 23.33 \\
\hline
\end{tabular}

Table 3: Sufrace roughness parameters of three flexo printing plates (magenta process color)

\begin{tabular}{|c|c|c|c|c|}
\hline & Plate & Average value $(\mu \mathrm{m})$ & Std. Dev. & Koef. of variation (\%) \\
\hline \multirow{3}{*}{$\operatorname{Ra}$} & 1 & 0.079 & 0.012 & $15.56 \%$ \\
\cline { 2 - 5 } & 2 & 0.077 & 0.007 & $9.61 \%$ \\
\cline { 2 - 5 } & 3 & 0.071 & 0.015 & $21.49 \%$ \\
\hline \multirow{3}{*}{$\operatorname{Rp}$} & 1 & 0.291 & 0.071 & $24.37 \%$ \\
\cline { 2 - 5 } & 2 & 0.246 & 0.052 & $21.01 \%$ \\
\cline { 2 - 5 } & 3 & 0.213 & 0.045 & $21.34 \%$ \\
\hline \multirow{3}{*}{$\operatorname{Rv}$} & 1 & 0.206 & 0.041 & $20.02 \%$ \\
\cline { 2 - 5 } & 2 & 0.204 & 0.034 & $16.78 \%$ \\
\hline \multirow{3}{*}{$\operatorname{Rz}$} & 3 & 0.177 & 0.043 & $24.04 \%$ \\
\cline { 2 - 5 } & 1 & 0.496 & 0.101 & $20.37 \%$ \\
\cline { 2 - 5 } & 2 & 0.450 & 0.073 & $16.17 \%$ \\
\hline
\end{tabular}

Table 4: Sufrace roughness parameters of three flexo printing plates (blue spot color)

\begin{tabular}{|c|c|c|c|c|}
\hline & Plate & Average value $(\mu \mathrm{m})$ & Std. Dev. & Koef. of variation (\%) \\
\hline \multirow{3}{*}{ Ra } & 1 & 0.080 & 0.008 & 9.81 \\
\cline { 2 - 5 } & 2 & 0.076 & 0.010 & 13.55 \\
\cline { 2 - 5 } & 3 & 0.072 & 0.013 & 18.11 \\
\hline \multirow{3}{*}{ Rp } & 1 & 0.185 & 0.039 & 21.03 \\
\cline { 2 - 5 } & 2 & 0.202 & 0.030 & 14.74 \\
\cline { 2 - 5 } & 3 & 0.240 & 0.046 & 19.00 \\
\hline \multirow{3}{*}{ Rv } & 1 & 0.217 & 0.034 & 15.56 \\
\cline { 2 - 5 } & 2 & 0.202 & 0.021 & 10.32 \\
\hline \multirow{3}{*}{ Rz } & 3 & 0.181 & 0.035 & 19.45 \\
\cline { 2 - 5 } & 1 & 0.402 & 0.065 & 16.10 \\
\cline { 2 - 5 } & 2 & 0.405 & 0.072 & 17.85 \\
\hline
\end{tabular}

According to values represented in Tables 2-4, we have detected decreeing tendency in average surface roughness parameter in dependence of print run. Namely, overall surface roughness expressed through the value of Ra parameter is decreased after printing 11 rolls of cardboard. It is clearly showing that the flexo plate surface is becoming smoother. This is also reflected through the values of $R p, R v$ and $R z$ parameter for two process colors indicating that the longer interaction of printing plate, ink and printing substrate, followed with the applied printing pressure and printing speed, results in wearing the profile peaks and lowering valleys depth. The exception from this are $\mathrm{Rp}$ and $\mathrm{Rz}$ values for the printing plate for blue spot color, where, on contrary, we detect the mild increasing tendency with the print run. The changes detected in highest peak value may be due to possible higher granulation of printing ink, or their abrasive nature, where there is possibility that micro damages might occur on the flexo printing plate 
surface which might be detected as profile peaks. The value of coefficient of variation is below $25 \%$ which classifies the obtained measurement as stable and repeatable, with low variability (Papić, 2020).

\subsection{Statistical analysis}

In order to determine level of significance of changes in surface roughness parameters due to print run, statistical analysis method, independent-samples t-tests were performed. In Tables 5 - 13 are presented statistical test results carried out for a 5\% significance level, i.e., for a 95\% confidence level.

Table 5: Independent-samples t-test carried out for surface roughness parameters obtained on plate 1 and 2 (cyan process color)

\begin{tabular}{|c|c|c|c|c|c|c|c|}
\hline \multicolumn{8}{|c|}{ Independent Samples Test } \\
\hline & \multirow{3}{*}{$\begin{array}{l}\text { Partial Eta } \\
\text { squared }\left(\eta^{2}\right)\end{array}$} & \multirow[b]{3}{*}{ Sig. } & \multicolumn{5}{|c|}{ t-test for Equality of Means } \\
\hline & & & \multirow[b]{2}{*}{$t$} & \multirow[b]{2}{*}{ df } & \multirow{2}{*}{$\begin{array}{c}\text { Sig. } \\
\text { (2-tailed) }\end{array}$} & \multicolumn{2}{|c|}{$\begin{array}{l}\text { 95\% Confidence } \\
\text { Interval of the } \\
\text { Difference }\end{array}$} \\
\hline & & & & & & Lower & Upper \\
\hline $\mathrm{Ra}$ & 0.002 & .062 & .327 & 62 & .745 & -.005107 & .007107 \\
\hline $\mathrm{Rp}$ & 0.002 & .003 & -.382 & 62 & .704 & -.040124 & .027249 \\
\hline $\mathrm{Rv}$ & 0.012 & .551 & .868 & 62 & .389 & -.011840 & .030027 \\
\hline $\mathrm{Rz}$ & 0.000 & .017 & .120 & 62 & .905 & -.041468 & .046781 \\
\hline
\end{tabular}

Table 6: Independent-samples t-test carried out for surface roughness parameters obtained on plate 2 and 3 (cyan process color)

\begin{tabular}{|c|c|c|c|c|c|c|c|}
\hline \multicolumn{8}{|c|}{ Independent Samples Test } \\
\hline & \multirow{3}{*}{$\begin{array}{l}\text { Partial Eta } \\
\text { squared }\left(\eta^{2}\right)\end{array}$} & \multirow[b]{3}{*}{ Sig. } & \multicolumn{5}{|c|}{ t-test for Equality of Means } \\
\hline & & & \multirow[b]{2}{*}{$\mathrm{t}$} & \multirow[b]{2}{*}{$d f$} & \multirow{2}{*}{$\begin{array}{c}\text { Sig. } \\
\text { (2-tailed) }\end{array}$} & \multicolumn{2}{|c|}{$\begin{array}{l}\text { 95\% Confidence } \\
\text { Interval of the } \\
\text { Difference }\end{array}$} \\
\hline & & & & & & Lower & Upper \\
\hline $\mathrm{Ra}$ & 0.163 & .779 & 3.473 & 62 & .001 & .003686 & .013689 \\
\hline $\mathrm{Rp}$ & 0.008 & .015 & .688 & 62 & .494 & -.024465 & .050152 \\
\hline Rv & 0.098 & .022 & 2.596 & 62 & .012 & .006876 & .052936 \\
\hline $\mathrm{Rz}$ & 0.047 & .022 & 1.758 & 62 & .084 & -.005860 & .091360 \\
\hline
\end{tabular}

Table 7: Independent-samples t-test carried out for surface roughness parameters obtained on plate 1 and 3 (cyan process color)

\begin{tabular}{|c|c|c|c|c|c|c|c|}
\hline \multicolumn{8}{|c|}{ Independent Samples Test } \\
\hline & \multirow{3}{*}{$\begin{array}{c}\text { Partial Eta } \\
\text { squared }\left(\eta^{2}\right)\end{array}$} & \multirow[b]{3}{*}{ Sig. } & \multicolumn{5}{|c|}{ t-test for Equality of Means } \\
\hline & & & \multirow[b]{2}{*}{$t$} & \multirow[b]{2}{*}{$\mathrm{df}$} & \multirow{2}{*}{$\begin{array}{c}\text { Sig. } \\
\text { (2-tailed) }\end{array}$} & \multicolumn{2}{|c|}{$\begin{array}{l}95 \% \text { Confidence } \\
\text { Interval of the } \\
\text { Difference }\end{array}$} \\
\hline & & & & & & Lower & Upper \\
\hline $\mathrm{Ra}$ & 0.139 & .045 & 3.168 & 62 & .002 & .003575 & .015800 \\
\hline $\mathrm{Rp}$ & 0.001 & .949 & .290 & 62 & .773 & -.037781 & .050593 \\
\hline $\mathrm{Rv}$ & 0.126 & .187 & 2.985 & 62 & .004 & .012881 & .065119 \\
\hline $\mathrm{Rz}$ & 0.042 & .762 & 1.650 & 62 & .104 & -.009620 & .100432 \\
\hline
\end{tabular}


In Tables 5-7 are presented results of independent-samples t-test carried out for surface roughness parameters obtained on plates for cyan process color. The result presented in column Sig. (significance) and partial eta squared indicates the presence of the statistical significance and the degree of influence on the result. Statistical significance at level of $<0.05$ for the average surface roughness was denoted between 1 and 3 printing plate indicating that the changes in surface roughness influenced by print run are significant. The values of partial eta squared points out the high effect size and confirms determined statistical significance between mean values of roughness parameter Ra measured on printing plates used for different print runs (according to Cohen, if partial eta squared is higher than 0.14 than it can be denoted high effect size (Pallant, 2007). If we look at the expressed statistical significance for the other three parameters which reflects the changes in more specific surface attributes, peaks and valleys, we can see that the statistically significant result was obtained between 1 and 2 , and 2 and 3 printing plate.

Table 8: Independent-samples t-test carried out for surface roughness parameters obtained on plate 1 and 2 (magenta process color)

\begin{tabular}{|c|c|c|c|c|c|c|c|}
\hline \multicolumn{8}{|c|}{ Independent Samples Test } \\
\hline & \multirow{3}{*}{$\begin{array}{c}\text { Partial Eta } \\
\text { squared }\left(\eta^{2}\right)\end{array}$} & \multirow[b]{3}{*}{ Sig. } & \multicolumn{5}{|c|}{ t-test for Equality of Means } \\
\hline & & & \multirow[b]{2}{*}{$\mathrm{t}$} & \multirow[b]{2}{*}{$\mathrm{df}$} & \multirow{2}{*}{$\begin{array}{c}\text { Sig. } \\
\text { (2-tailed) }\end{array}$} & \multicolumn{2}{|c|}{$\begin{array}{c}95 \% \text { Confidence } \\
\text { Interval of the } \\
\text { Difference }\end{array}$} \\
\hline & & & & & & Lower & Upper \\
\hline $\mathrm{Ra}$ & 0.003 & .000 & .411 & 62 & .683 & -.008216 & .012466 \\
\hline $\mathrm{Rp}$ & 0.032 & .000 & 1.440 & 62 & .155 & -.017427 & .107239 \\
\hline Rv & 0.000 & .000 & .107 & 62 & .915 & -.026418 & .029418 \\
\hline Rz & 0.024 & .000 & 1.227 & 62 & .224 & -.029172 & .121984 \\
\hline
\end{tabular}

Table 9: Independent-samples t-test carried out for surface roughness parameters obtained on plate 2 and 3 (magenta process color)

\begin{tabular}{|c|c|c|c|c|c|c|c|}
\hline \multicolumn{8}{|c|}{ Independent Samples Test } \\
\hline & \multirow{3}{*}{$\begin{array}{c}\text { Partial Eta } \\
\text { squared }\left(n^{2}\right)\end{array}$} & \multirow[b]{3}{*}{ Sig. } & \multicolumn{5}{|c|}{ t-test for Equality of Means } \\
\hline & & & \multirow[b]{2}{*}{$\mathrm{t}$} & \multirow[b]{2}{*}{$\mathrm{df}$} & \multirow{2}{*}{$\begin{array}{c}\text { Sig. } \\
\text { (2-tailed) }\end{array}$} & \multicolumn{2}{|c|}{$\begin{array}{l}\text { 95\% Confidence } \\
\text { Interval of the } \\
\text { Difference }\end{array}$} \\
\hline & & & & & & Lower & Upper \\
\hline $\mathrm{Ra}$ & 0.053 & .000 & 1.868 & 62 & .066 & -.000393 & .011643 \\
\hline $\mathrm{Rp}$ & 0.055 & .003 & 1.891 & 62 & .063 & -.001912 & .068599 \\
\hline Rv & 0.113 & .426 & 2.808 & 62 & .007 & .007813 & .046437 \\
\hline $\mathrm{Rz}$ & 0.120 & .195 & 2.906 & 62 & .005 & .018835 & .101852 \\
\hline
\end{tabular}

Table 10: Independent-samples t-test carried out for surface roughness parameters obtained on plate 1 and 3 (magenta process color)

\begin{tabular}{|c|c|c|c|c|c|c|c|}
\hline \multicolumn{8}{|c|}{ Independent Samples Test } \\
\hline & \multirow{3}{*}{$\begin{array}{c}\text { Partial Eta } \\
\text { squared }\left(\eta^{2}\right)\end{array}$} & \multirow[b]{3}{*}{ Sig. } & \multicolumn{5}{|c|}{ t-test for Equality of Means } \\
\hline & & & \multirow[b]{2}{*}{$t$} & \multirow[b]{2}{*}{ df } & \multirow{2}{*}{$\begin{array}{c}\text { Sig. } \\
\text { (2-tailed) }\end{array}$} & \multicolumn{2}{|c|}{$\begin{array}{l}\text { 95\% Confidence } \\
\text { Interval of the } \\
\text { Difference }\end{array}$} \\
\hline & & & & & & Lower & Upper \\
\hline $\mathrm{Ra}$ & 0.029 & .000 & 1.362 & 62 & .178 & -.003628 & .019128 \\
\hline $\mathrm{Rp}$ & 0.081 & .001 & 2.342 & 62 & .022 & .011454 & .145046 \\
\hline Rv & 0.058 & .001 & 1.952 & 62 & .055 & -.000685 & .057935 \\
\hline $\mathrm{Rz}$ & 0.107 & .001 & 2.730 & 62 & .008 & .028571 & .184929 \\
\hline
\end{tabular}


In Tables 8-10 are presented results of independent-samples t-test carried out for surface roughness parameters obtained on plates for magenta process color.

Statistical significance at level of $<0.05$ for the average surface roughness was denoted between all printing plates indicating that the changes in surface roughness influenced by print run are significant. The values of partial eta squared points out the small to mild effect size (Pallant, 2007). If we look at the statistical significance values for the other three parameters it is noticed that the statistically significant result was not only obtained between 2 and 3 printing plate and Rv and Rz surface roughness parameters.

Table 11: Independent-samples t-test carried out for surface roughness parameters obtained on plate 1 and 2 (blue spot color)

\begin{tabular}{|c|c|c|c|c|c|c|c|}
\hline \multicolumn{8}{|c|}{ Independent Samples Test } \\
\hline & \multirow{3}{*}{$\begin{array}{c}\text { Partial Eta } \\
\text { squared }\left(\eta^{2}\right)\end{array}$} & \multirow[b]{3}{*}{ Sig. } & \multicolumn{5}{|c|}{ t-test for Equality of Means } \\
\hline & & & \multirow[b]{2}{*}{$\mathrm{t}$} & \multirow[b]{2}{*}{ df } & \multirow{2}{*}{$\begin{array}{c}\text { Sig. } \\
\text { (2-tailed) }\end{array}$} & \multicolumn{2}{|c|}{$\begin{array}{l}\text { 95\% Confidence } \\
\text { Interval of the } \\
\text { Difference }\end{array}$} \\
\hline & & & & & & Lower & Upper \\
\hline $\mathrm{Ra}$ & 0.049 & .084 & 1.786 & 62 & .079 & -.000483 & .008608 \\
\hline $\mathrm{Rp}$ & 0.039 & .284 & -1.583 & 62 & .118 & -.040019 & .004644 \\
\hline $\mathrm{Rv}$ & 0.040 & .352 & 1.614 & 62 & .112 & -.003615 & .033928 \\
\hline $\mathrm{Rz}$ & 0.000 & .554 & -.148 & 62 & .883 & -.036794 & .031731 \\
\hline
\end{tabular}

Table 12: Independent-samples t-test carried out for surface roughness parameters obtained on plate 2 and 3 (blue spot color)

\begin{tabular}{|c|c|c|c|c|c|c|c|}
\hline \multicolumn{8}{|c|}{ Independent Samples Test } \\
\hline & \multirow{3}{*}{$\begin{array}{c}\text { Partial Eta } \\
\text { squared }\left(\eta^{2}\right)\end{array}$} & \multirow[b]{3}{*}{ Sig. } & \multicolumn{5}{|c|}{ t-test for Equality of Means } \\
\hline & & & \multirow[b]{2}{*}{$\mathrm{t}$} & \multirow[b]{2}{*}{$\mathrm{df}$} & \multirow{2}{*}{$\begin{array}{c}\text { Sig. } \\
\text { (2-tailed) }\end{array}$} & \multicolumn{2}{|c|}{$\begin{array}{l}95 \% \text { Confidence } \\
\text { Interval of the } \\
\text { Difference }\end{array}$} \\
\hline & & & & & & Lower & Upper \\
\hline $\mathrm{Ra}$ & 0.025 & .084 & 1.272 & 62 & .208 & -.002126 & .009563 \\
\hline $\mathrm{Rp}$ & 0.137 & .819 & -3.131 & 62 & .003 & -.061240 & -.013510 \\
\hline Rv & 0.046 & .135 & 1.730 & 62 & .089 & -.003266 & .045328 \\
\hline Rz & 0.012 & .466 & -.866 & 62 & .390 & -.054080 & .021392 \\
\hline
\end{tabular}

Table 13: Independent-samples t-test carried out for surface roughness parameters obtained on plate 1 and 3 (blue spot color)

\begin{tabular}{|c|c|c|c|c|c|c|c|}
\hline \multicolumn{8}{|c|}{ Independent Samples Test } \\
\hline & \multirow{3}{*}{$\begin{array}{c}\text { Partial Eta } \\
\text { squared }\left(\eta^{2}\right)\end{array}$} & \multirow[b]{3}{*}{ Sig. } & \multicolumn{5}{|c|}{ t-test for Equality of Means } \\
\hline & & & \multirow[b]{2}{*}{$\mathrm{t}$} & \multirow[b]{2}{*}{ df } & \multirow{2}{*}{$\begin{array}{c}\text { Sig. } \\
\text { (2-tailed) }\end{array}$} & \multicolumn{2}{|c|}{$\begin{array}{l}95 \% \text { Confidence } \\
\text { Interval of the } \\
\text { Difference }\end{array}$} \\
\hline & & & & & & Lower & Upper \\
\hline $\mathrm{Ra}$ & 0.120 & .001 & 2.903 & 62 & .005 & .002424 & .013139 \\
\hline $\mathrm{Rp}$ & 0.304 & .125 & -5.201 & 62 & .000 & -.076224 & -.033901 \\
\hline Rv & 0.139 & .021 & 3.162 & 62 & .002 & .013312 & .059063 \\
\hline $\mathrm{Rz}$ & 0.017 & .178 & -1.048 & 62 & .299 & -.054868 & .017118 \\
\hline
\end{tabular}


In Tables 11-13 are presented results of independent-samples t-test carried out for surface roughness parameters obtained on plates for blue spot color. The result presented in column Sig. (significance) and partial eta squared indicates the presence of the statistical significance and the degree of influence on the result. Statistical significance, looking at the average surface roughness, was denoted between 1 and 3 printing plate indicating that the changes in surface roughness influenced by print run are significant. The value of partial eta squared value confirms high effect size (Pallant, 2007). If we look at the expressed statistical significance for the peaks and valleys, we can see that the statistically significant result was obtained only between 1 and 3 printing plate and only for the Rv surface roughness parameter. This may lead to the conclusion that during printing, statistically there are no significant changes in the average values of the highest peaks and lowest valleys.

\section{CONCLUSIONS}

In this paper detailed statistical surface roughness analysis of CtP flexo plates in correlation with print run was conducted. The conclusions derived from the conducted research are as follows:

- $\quad$ The changes in values of four amplitude surface roughness parameters ( $R a, R p, R v$ and $R z)$ due to print run, obtained by the by direct stylus profilometric method, generally correspond to anticipated trend: longer print run will result in lowering the surface roughness of the flexo printing plate.

- The decreasing tendency is clearly expressed through changes of the average surface roughness value - Ra: the differences between average Ra values at the beginning of the printing and after 82025 meters of printed material were found to be statistically different in case of all printing plates utilized in the experiment.

- $\quad$ On the basis of values obtained for more specific surface roughness parameters - peaks and valleys $(R p, R v$ and $R z$ ), it is seen that the longer print run will, generally lead to in wearing the profile peaks and lowering valleys depth. The contradictory result was obtained only in case of Rp and Rz values for the printing plate for blue spot color. The noticed increasing tendency, may indicate that the abrasive nature of printing inks or substrate may lead to micro damages on the flexo printing plate surface which might be detected as profile peaks.

- Values of partial eta squared points out the mild to high influence of print run on the changes in surface roughness of digital flexo printing plates.

- The statistical analysis reveal that the influence of print run on changes of the peak and valleys surface roughness values may not be in case of all printing plates considered as statistically significant. This might be connected with the type of ink used (process vs. spot colors) and its characteristics in terms of granulation and influence on the printing plate surface.

- With further analysis, extended on other printing substrates and inks, as well as printing plates in terms of processing parameters, this research can be significantly upgraded and may deeply reveal the changes in surface roughness on the CtP flexo printing plates in dependace of print run.

\section{ACKNOWLEDGMENTS}

This research (paper) has been supported by the Ministry of Education, Science and Technological Development through the project no. 451-03-68/2020-14/200156: "Innovative scientific and artistic research from the FTS (activity) domain".

\section{REFERENCES}

[1] Barros, G.G., Fahlcrantz, C.M., Johansson, P.A.: "Topographic distribution of uncovered areas (UCA) in full tone flexographic prints", Taga Journal 2 (1), 43-57, 2005.

[2] Bould, D. C., Claypole, T. C.,Bohan, M. F. J., Gethin, D. T.: "Deformation of Flexographic Printing Plates", URL: http://www.printing.org/page/8623\#, (last request: 2018-05-18).

[3] Chappard, D., Degasne, I., Huré, G., Legrand, E., Audran, M., Baslé, Mf.: "On image analysis measurements of roughness by texture and fractal analysis correlate with contact profilometry", Biomaterials 24 (8), 1399-1407, 2003. doi: 10.1016/s0142-9612(02)00524-0.

[4] Choi, J., O'Brate, K.: US 2010/0173135 A1, "Method of Controlling Surface Roughness of a Flexographic Printing Plate", United States Patent, 2010. 
[5] Dedijer, S., Novaković, D. Pál, M. Pavlović, Ž.: "Statistical analysis of printing elements reproduction on thermally developed CTP flexo printing plates", Journal Of Graphic Engineering And Design 3, 12 22, 2012

[6] Kipphan H.: "Handbook of Print Media", (Springer, Berlin,2001.), pages 503-626.

[7] Lanska D. J.: "Common-Sence Flexography - A User's Guide to Improved Pressroom Productivity", (Printing Industries Press, Pittsburg, 2007.).

[8] Mahović, S.: "Karakterizacija površinskih struktura ofsetnih tiskovnih formi - doktorska disertacija", (Sveučilište U Zagrebu, Grafički Fakultet, 2007.), pages 38-50.

[9] Pallant, J: "Postupni vodič kroz analizu podataka pomoću SPSS-a za Windows (verzija 15)", (Allen\&Unvin, Mikro knjiga, Beograd, 2007.).

[10] Papić, M.: "Poslovna statistika", URL: http://www.oss.unist.hr/zg/rif/kolegiji/20100301_pred_PSTA.pdf, (last request: 2020-09-12).

[11] Pavlović, Ž., Novaković, D., Dedijer, S., Apro, M.: "Changes in the surface roughness of aluminium oxide (non-printing) areas on offset printing plate depending on number of imprints", Journal Of Graphic Engineering And Design 1 (1), 32 -38, 2010.

[12] Rentzhog, M.: "Water-Based Flexographic Printing on Polymer-Coated Board", Doctoral Thesis, Royal Institute of Technology Stockholm, Sweden, 2006.

[13] Risović, D., Mahović - Poljaček, S., Gojo, M.: "On correlation between fractal dimension and profilometric parameters in characterization of surface topographies", Applied Surface Science 255(7), 4283-4288, 2009. doi: 10.1016/j.apsusc.2008.11.028.

(C) 2020 Authors. Published by the University of Novi Sad, Faculty of Technical Sciences, Department of Graphic Engineering and Design. This article is an open access article distributed under the terms and conditions of the Creative Commons Attribution license 3.0 Serbia (http://creativecommons.org/licenses/by/3.0/rs/). 


\title{
TREATMENT OF WASTEWATER CONTAINING PRINTING DYES: SUMMARY AND PERSPECTIVES
}

\author{
Đurđa Kerkez ${ }^{1}$ (D), Milena Bečelić-Tomin ${ }^{1}$ (D), Gordana Pucar Milidrag ${ }^{1}$ (D), Vesna Gvoić ${ }^{2}$ (D), \\ Aleksandra Kulić Mandić ${ }^{1}$ (D), Anita Leovac Maćerak ${ }^{1}$ (D), Dragana Tomašević Pilipović ${ }^{1}$ (D) \\ ${ }^{1}$ University of Novi Sad, Faculty of Sciences, Department of Chemistry, Biochemistry and \\ Environmental Protection, Novi Sad, Serbia \\ ${ }^{2}$ University of Novi Sad, Faculty of Technical Sciences, Department of Graphic Engineering and \\ Design, Novi Sad, Serbia
}

\begin{abstract}
Synthetic dyes are widely used in textile, printing, leather tanning, cosmetic, drug and food processing industries. The printing and dyeing industry is considered as one of the most polluting industrial sectors. The printing process is very versatile and includes printing on paper as well as printing on textile, plastic and other materials. After the printing process is completed, various chemicals such as ethers, alcohols, phenols, aldehydes, ketones, benzene, and esters are used in the cleaning procedure. Resulting wastewater often contains a variety of solvents, surfactants, dyes, and other chemicals, thus greatly increasing the difficulty of wastewater treatment. Improper discharge of printing and dyeing wastewater into water bodies will have several effect, beginning with aesthetical issues followed by destruction of the aqueous ecosystem due to light attenuation, oxygen consumption and toxicity effects. Therefore, it is very important to find out and optimize printing and dying wastewater treatment techniques. Processes for dye removal from wastewater can be physical, chemical, biological and more recently hybrid treatments. Physical processes such as adsorption, based on mass transfer mechanism, are commonly used method mainly due to ease of operation and high efficiency. Chemical processes including coagulation and flocculation, advanced oxidation processes and electrochemical treatment are usually more expensive due t chemicals use, equipment requirements and electrical energy consumption. However, these techniques are destructive and may lead to total mineralization of dye molecules and accompanying pollutants. Biological treatment is a low-cost and environmentally friendly process that produces less sludge. This method has significant advantages but dye molecules are less prone to this kind of treatment as they are made to be stable and reluctant. So, the adjustment and optimization of biological treatment, for dye removal, is an ongoing field of research. In recent studies hybrid processes are gaining more attention, combining different techniques. Integrating treatments, as a cost-saving and time-saving process, can represent optimal solution for printing wastewater treatment.
\end{abstract}

Key words: printing dyes, wastewater management, wastewater treatment, decolourization, mineralization

\section{INTRODUCTION}

Fast industrial development and overpopulation have caused serious contamination of the freshwater resources with different kind of pollutants.. These organic and inorganic contaminants pose serious health risks to humans and wildlife. Among these pollutants, dyes and pigments, as a large group of pollutants, are of major concern. These substances are utilized in industries such as textile, plastic, leather, paint, cosmetics, printing, and paper (Shah, 2018; Wazir, 2020). Around 10000 types of synthetic and natural dyes are produced every year all over the world which is roughly weighed in between $7 \times 10^{5}-$ $1 \times 10^{6}$ tons and a significant amount of dyes is wasted during manufacturing and application processes . Large amount of chemicals and dyestuffs are remaining unused during textile dying and printing process and is discharged as excess waste effluent into the environment (Chowdhury et al, 2020; Katheresan et al, 2018). Synthetic dyes and pigments released into the environment in the form of industrial effluents causes severe ecological problems. This kind of wastewater is intensively coloured with varying degrees of chemical oxygen demand. Neither simple chemical nor biological treatment alone has proved adequate in decolourization and sufficient depletion of organic matter (Swaminathan et al, 2005). Generally, printing and dyeing wastewaters are characterized by high $\mathrm{pH}$ value, low ratio of $\mathrm{BOD}_{5} / \mathrm{COD}$, toxic and contain bio-recalcitrant compounds. Chemicals such as sulphur, naphthols, dyes, aromatic amines, acetic acid, soaps, chromium compounds and heavy metals are identified in this wastewaters making them highly toxic. As a result, treatment of this king of effluents is challenging from 
engineering aspect. Various approaches such as aerobic, anaerobic and anaerobic combined with oxic biological treatments have been reported in wastewater treatment. Due to the inhibitory nature of many compounds in these effluents for biological oxidation, pretreatment is often required and chemical oxidation as well as adsorption and membrane technology are highlighted in treating and separating complex organic compounds (Zhang et al, 2012; Zhu et al, 2018).

\section{BIOLOGICAL AND PHYSICAL-CHEMICAL PROCESESS}

Regarding biological process, activated sludge plays an essential role in decolourization and degradation of dyes to inorganic products. Treatment efficiency of activated sludge depends on the characteristics of the microorganisms involved in biological community. Specialized cultures are necessary for decolourization of dyes. In recent years, with the development of molecular biological techniques, highthroughput sequencing technology, which overcomes the limitation of conventional techniques, is developed, become the most popular method for the evaluation of microbial community. Contaminants and microorganisms involved in the printing and dying wastewater biotransformation process are complicated. Finding the important functional bacteria is difficult if activated sludge is studied directly for this kind of wastewater. Decolourization of, for example, azo dyes was firstly happened by the cleavage of $\mathrm{N}-\mathrm{N}$ bond, producing aromatic amines. Further on, to aromatic rings were remained after hydrolyzation of, resulting in the formation of phenol and naphthol. Then ring opening reactions occurred by introducing the atoms of $\mathrm{O}_{2}$ into the aromatic nucleus. Further mineralization goes towards end products into $\mathrm{CO}_{2}$ and $\mathrm{H}_{2} \mathrm{O}$. For azo dyes genera of Enterococcus, Acidaminococcus, Bacteroides, Megasphaera, Klebsiella demonstrated significantly positive relationships with cleavage of $\mathrm{N}-\mathrm{N}$, while Pseudomonas, Anaerovorax and Longilinea played important roles in breaking the aromatic rings (Zhu et al, 2018).

Reverse osmosis process, are one of physical processes, that has been widely applied in printing and dyeing wastewater treatment as it can effectively barrier various organic/inorganic contaminants and also biological constituents. After being treated, a large proportion of influent stream can be reused directly in printing and dyeing process, while the residual reverse osmosis concentrate (ROC) of printing and dyeing wastewater, which is characterized by recalcitrant organics, high hardness and high salinity, cannot be directly discharged and still remains serious environmental risks. On the other hand, the physical and chemical treatments such as coagulation, membrane distillation and adsorption will eventually cause secondary pollution and most of them come with a high waste disposal cost (Wang et al, 2018).

The adsorption process is one of the potential and efficient methods among all the possible techniques for coloured effluent treatment due to its low initial investment, design simplicity and availability of lowcost adsorbents. Low-cost and readily available natural bio-adsorbents are commonly applied for the elimination of several kinds of pollutants from printing and dying wastewater. They have developed specific surface area and functional properties. Bio-sorbents are considered possible substitute for the costly and currently existing activated carbon for the uptake of the dyes from aqueous media. Removal capacity can reach $40.89 \%$ to $69.76 \%$ with the decrease of initial concentration (Chowdhury et al, 2020).

Electrocatalytic technology has also been used for the treatment of pollutants that are more toxic and difficult to handle. There are several advantages of the electrocatalytic technology, such as simple equipment, easy operation, high removal efficiency, and little sludge generation. Among many kinds of electrocatalytic materials, titanium dioxide $\left(\mathrm{TiO}_{2}\right)$ is relatively cheap. Our research team has applied $\mathrm{TiO}_{2}$ electrode to treat two types. With nano- $\mathrm{TiO}_{2}$ electrode, dye and $\mathrm{TOC}$ removal efficiencies can reach $97 \%$ and $56 \%$ after 160 -min treatment, respectively. Under the same operation conditions but using two pairs of electrodes, the removal efficiencies of TOC and dye were enhanced to $75.0 \%$ and $82.0 \%$, respectively, and could be further improved to $90.0 \%$ and $92 \%$ if the electrolytic effluent was polished by powder activated carbon absorption (Tung et al, 2013). Development of alternate methods that can degrade toxic organic compounds brought up ozone $\left(\mathrm{O}_{3}\right)$ that becoming a versatile and environmentally sound oxidation agent. Ozonation of water is a well-known technology and the strong oxidative properties of $\mathrm{O}_{3}$ have the ability to effectively oxidize many organic compounds. Due to its high electrochemical potential $(2.08 \mathrm{~V}), \mathrm{O}_{3}$ is the strongest oxidant available and applicable as compared to $\mathrm{H}_{2} \mathrm{O}_{2}(1.78 \mathrm{~V})$ and can react with several classes of compounds through direct or indirect reaction. $\mathrm{O}_{3}$ leaves no toxic residues that have to be removed or disposed. Ozone combinations are the most applied advanced oxidation processes (AOP) enhancing the biodegradability of wastewater. Maximum dye and COD (87.8\%) removal could be achieved at an ozone dose of $4.33 \mathrm{mg} / \mathrm{I}$ at 30 min ozonation. In addition, Increase in the BOD $/$ COD ratio is observed after ozonation indicating that during ozonation biodegradability of reluctant printing and 
dying wastewater has increased. Besides ozonation, Fenton process is well known among AOPS that can reach almost $100 \%$ of dye removal (Swaminathan et al, 2005).

\section{PHOTOCHEMICAL PROCESSES}

Printing dyes wastewater contains significant amount of dye, therefore, the energy of light may be absorbed by organic molecule. As a result, the light penetration is limited to a thin layer. In order to prevent this many techniques, which use natural or artificial radiation, are widely used in treatment processes in order to provide cleaner water, some of them are described in this review.

\subsection{UV/ $\mathrm{H}_{2} \mathrm{O}_{2}$ process}

During the last decade, some researchers have reported the successful applications of the $U V / \mathrm{H}_{2} \mathrm{O}_{2}$ process of coloured wastewater treatment. Namely, when using hydrogen peroxide as oxidating agens under UV radiation, hydrogen peroxide is directly photolyzed in to two hydroxyl radicals (Rosa et al, 2020). During this process, ultraviolet radiation is used to cleave the O-O bond in molekul of hydrogen peroxide. Process of its photolysis is described by following reactions:

$$
\begin{aligned}
& \mathrm{H}_{2} \mathrm{O}_{2}+\mathrm{hv} \rightarrow 2 \mathrm{HO} \cdot \\
& \mathrm{H}_{2} \mathrm{O}_{2}+\mathrm{HO}^{\circ} \rightarrow \mathrm{HO}_{2}^{-}+\mathrm{H}_{2} \mathrm{O} \\
& \mathrm{H}_{2} \mathrm{O}_{2}+\mathrm{HO}_{2}^{-} \rightarrow \mathrm{HO} \cdot+\mathrm{H}_{2} \mathrm{O}+\mathrm{O}_{2} \\
& 2 \mathrm{HO} \rightarrow \mathrm{H}_{2} \mathrm{O}_{2} \\
& 2 \mathrm{HO}_{2}^{-} \rightarrow \mathrm{H}_{2} \mathrm{O}_{2}+\mathrm{O}_{2} \\
& \mathrm{HO}^{-}+\mathrm{HO}_{2}^{-} \rightarrow \mathrm{H}_{2} \mathrm{O}+\mathrm{O}_{2}
\end{aligned}
$$

Reaction 1 is rate limiting when compared with other reactions that have much higher rate. Also, higher initial dose of hydrogen peroxide provide more generated hydroxil radicals, but too much peroxide will lead to reaction with hydroxyl radical and formation of $\mathrm{HO}_{2} \bullet$ (reaction 2). The major factors affecting this process are the initial concentration of the target compound, the amount of $\mathrm{H}_{2} \mathrm{O}_{2}$ used (beyond its optimum limit the presence of $\mathrm{H}_{2} \mathrm{O}_{2}$ in excess will lead to scavenging action). Wastewater $\mathrm{pH}$ ( $\mathrm{pH}$ values 2.5 - 3.5 are mostly used, but it really depends on the pKa of the target compounds), presence of bicarbonate (the increase of bicarbonate anion concentration affected negatively its removal) and reaction time. Process degradation kinetic rate is inversely proportional to the initial concentration of the pollutant (Stasinakis, 2008).

\subsection{Photocatalytic degradation}

Photocatalysis is the process in which photoactivation of semiconductors is initiated by irradiation, with electron-hole pairs appearing as a result of band gap excitation. Positive holes generated by light can react with electron donors and generate hydroxile radicals (Alinsafi et al, 2007). Organic compounds which include dyes, can undergo oxidative degradation through their reactions with valence bond holes, hydroxyl and peroxide radicals as well as reductive cleavage through their reactions with electrons. The most widely used metal oxide semiconductor is $\mathrm{TiO}_{2}$ because of its photocatalytic and strong metal support interaction properties as well as, possibility of operating at ambient conditions, the lack of mass transfer limitations when nanoparticles are used as photocatalysts and the possible use of solar irradiation. Moreover, $\mathrm{TiO}_{2}$ is a cheap, readily available material and the photogenerated holes are highly oxidizing (Sajan et al, 2010), Ag (Kavitha et al, 2014), ZrO2 (Suresh et al, 2015), NiO (Suresh et al, 2015) and $\mathrm{MgO}$ (Jorfi et al, 2016). In parallel, suspended composites begun to be used: $\mathrm{TiO}_{2} \mathrm{impregnated}_{\text {with }}$ 5 wt\% $\mathrm{Nb}_{2} \mathrm{O}_{5}$, magnetic ferrites $\left[\mathrm{CoFe}_{2} \mathrm{O}_{4}\right.$ ] encapsulated by $\mathrm{TiO}_{2}$ (Aquino, 2010), $\mathrm{TiO}_{2}$ supported molybdenum oxide catalyst (Sajan et al, 2010), $\mathrm{Ag}^{+}$doped $\mathrm{TiO}_{2}$ (Sahoo et al, 2012), $\mathrm{ZnO90 \% /Ag10 \%}$ (Saravanan et al, 2013), $\mathrm{TiO}_{2} / \mathrm{ZrO}_{2}$ (Das and Basu, 2015), $\mathrm{TiO}_{2} / \mathrm{SnO}_{2}$ (Karthikeyan et al, 2015), $\mathrm{ZnO} / 15 \mathrm{Zn}_{2} \mathrm{SnO}_{4}$ (Danwittayakul et al, 2015), cerium doping $\mathrm{TiO}_{2}$ (Touati et al, 2016), CulnSe (Karthikeyan et al, 2017). Recently, composites/nanocomposites have been increasingly used such as: copper 
sulfide/reduced graphene oxide (Saranya et al, 2015), ZnO/CdO (Saravanan et al, 2015), ZnO/Ag/CdO (Saravanan et al, 2015) and iodine doped $\mathrm{TiO}_{2}$ (Barkul, 2017). Also, in the synthesis of the catalyst, it is important to take into account its easy separation from wastewater due to their particle sizes sizes (for example calcinated semiconductors) (Souza et al, 2017). Moreover, materials with good adsorption have been added to photocatalysts - powdered active carbon (Dhas et al, 2015), Lewatit anion exchange resin (Dhas et al, 2015), scoria coated with $\mathrm{ZnO}$ (Mahdizadeh et al, 2015), ZrO2, NiO and $\mathrm{ZnO}$ loaded activated carbon (Suresh et al, 2015) and zeolite coated with $\mathrm{TiO}_{2}$ (Guesh et al, 2016).

\subsection{Photo-Fenton process}

The photo-Fenton (or photo-assisted Fenton) process involves the use of solar radiation or an artificial radiation source, which increases the rate of contaminant degradation by stimulating the reduction of ferric ions $\left(\mathrm{Fe}^{3+}\right)$ to ferric ions $\left(\mathrm{Fe}^{2+}\right)$ (Parsons, 2005). This process shows high efficiency of oxidation of organic pollutants and inactivation of microorganisms in wastewater (Villegas-Guzman et al, 2017). The photo-Fenton process is a combination of iron ions, hydrogen peroxide and solar and UV-VIS radiation ( $\lambda$ $<600 \mathrm{~nm}$ ), which leads to higher production of hydroxyl radicals through the following reactions: 1$)$ reduction of $\mathrm{Fe}^{3+}$ to $\mathrm{Fe}^{2+}(7)$ and 2) photolysis of hydrogen peroxide at smaller wavelengths (8) (Pouran et al, 2015).

$$
\begin{aligned}
& \mathrm{Fe}(\mathrm{OH})^{2+}+\mathrm{hv} \rightarrow \mathrm{Fe}^{2+}+\mathrm{HO}^{-} \\
& \mathrm{H}_{2} \mathrm{O}_{2}+\mathrm{hv} \rightarrow 2 \mathrm{HO}^{-}
\end{aligned}
$$

The ferro ions formed by the photo-Fenton reaction will further react with hydrogen peroxide [Fenton reaction] generating additional hydroxyl radicals, which will increase the rate of oxidation of the photoFenton process, reduce iron consumption and sludge formation compared to the Fenton process (Pouran et al, 2015).

In addition, research has shown that the use of iron species [ions, iron mixed with other species or other complexes on a solid] support can: prevent sludge formation, overcome iron release into the effluent, and overcome the challenge of range of operational $\mathrm{pH}$ and the challenge of iron removal from sludge before discharge. However, modified clays, used as catalysts, such as (Yatmaz and Sen, 2018) zeolite (Bokare and Choi, 2014) silica fabric (Moncayo-Lasso et al, 2008) resins (De Oliveira et al, 2007) and Alumina (Clarizia et al, 2017) showed good results in treatment of dye removal. Moreover, a chelate can be considered suitable for photo-Fenton process. Common iron-chelating agents are: citric acid, oxalic acid, Ethylenediamine Tetra Acetic Acid (EDTA), Ethylenediamine- $N, N^{\prime}$-disuccinic acid (EDDS), Nitrilotriacetic acid (NTA). They can provide neutral conditions of the reaction and it is very important that they are benign, resistant to oxidation in the medium of application and is able to generate $\mathrm{HO} \bullet$ or other reactive oxidants. It should also possess high iron-chelate complexation strength. As photo-Fenton showed good results in dye removal, scientists investigated also non ferous catalyst such as are cerium, copper, manganese, wich has to have multiple oxidation states to be adequate replacement for iron in order to generate hydroxyl radicals from $\mathrm{H}_{2} \mathrm{O}_{2}$ at wide $\mathrm{pH}$ ranges, making the process appropriate for the treatment of various dyes (Alinsafi et al, 2007).

\section{CONCLUSIONS}

No technique fully capable of satisfactory treatment exists since the nature of effluents from dying and printing industries contains complex compounds. Various processes different in nature were applied in research for treating this kind of effluents. High efficiencies od effluent decolourization is achieved, but main problem that remains is mineralization degree of remaining effluents. Many scientific researches are focused on biological treatments, while some of them had attended to chemical or physical treatments. For further improvement, a combination of several treatments known as hybrid processes is becoming a practice to gain the most efficient quality in the most economical way. 


\section{ACKNOWLEDGMENTS}

Author acknowledge the Science Fund of the Republic of Serbia for the Program for excellent projects of young researchers (PROMIS) - WasteWaterForce project (6066881). Additionally, this research has been supported by the Ministry of Education, Science and Technological Development through the projects No. 451-03-68/2020-14/200156: "Innovative scientific and artistic research from the FTS (activity) domain".

\section{REFERENCES}

[1] Alinsafi, A., Evenou, F. Abdulkarim, E.M.,Pons, M.N., Zahraa, O., Benhammou, A., Yaacoubi, A., Nejmeddine A.: "Treatment of textile industry wastewater by supported photocatalysis", Dyes Pigments 74, 439-445, 2007. doi: 10.1016/j.dyepig.2006.02.024.

[2] Aquino, S.F., Lacerda, C.A., Ribeiro, D.R.: "Use of ferrites encapsulated with titanium dioxide for photodegradation of azo dyes and color removal of textile effluents", Environmental Engineering Science 27(12), 1049-1059, 2010. doi: 10.1089/ees.2010.0249.

[3] Barkul, R.P., Patil, M.K., Patil, S.M., Shevale, V.B., Delekar, S.D.: "Sunlight-assisted photocatalytic degradation of textile effluent and Rhodamine B by using iodine doped TiO2 nanoparticles", Journal of Photochemistry and Photobiology A: Chemistry 349, 138-147, 2017. doi: 10.1016/j.jphotochem.2017.09.011.

[4] Bokare, A.D., Choi, W.: "Review of iron-free Fenton-like systems for activating H2O2 in advanced oxidation processes", Journal of Hazardous Materials 275, 121-135, 2014. doi: 10.1016/j.jhazmat.2014.04.054.

[5] Yatmaz, C.H., Sen U.D.K.: "Photocatalytic efficiencies of alternate heterogeneous catalysts: Iron modified minerals and semiconductors for removal of an AZO dye from solutions", Environment Protection Engineering 44(1), 2018. doi: 10.5277/epe180101.

[6] Chowdhury, M.F., Khandaker, S., Sarker, F., Islam, A., Rahman, M.T., Awual, R.: "Current treatment technologies and mechanisms for removal of indigo carmine dyes from wastewater: A review", Journal of Molecular Liquids 318, 2020. doi: 10.1016/j.molliq.2020.114061.

[7] Clarizia, L., Russo, D., Di Somma, I., Marotta, R. Andreozzi R.: "Homogeneous photo-Fenton processes at near neutral pH: A review“, Applied Catalysis B Environmental 209, 358-371, 2017. doi: 10.1016/j.apcatb.2017.03.011.

[8] Danwittayakul, S., Jaisai, M. Dutta, J.: "Efficient solar photocatalytic degradation of textile wastewater using ZnO/ZTO composites", Applied Catalysis B Environmental 163, 1-8, 2015. doi: 10.1016/j.apcatb.2014.07.042.

[9] Das, L., Basu, J.K.: "Photocatalytic treatment of textile effluent using titania-zirconia nano composite catalyst", Journal of Industrial and Engineering Chemistry 24, 245-250, 2015. doi: 10.1016/j.jiec.2014.09.037.

[10] De Oliveira, I.S., Viana, L., Verona, C., Fallavena, V.L.V., Azevedo, C.M.N., Pires M.: “Alkydic resin wastewaters treatment by fenton and photo-Fenton processes", Journal of Hazardous Materials 146(3), 564-568, 2007. doi: 10.1016/j.jhazmat.2007.04.057.

[11] Dhas, P.G.T.N., Gulyas,H., Otterpohl, R.: "Impact of powdered activated carbon and anion exchange resin on photocatalytic treatment of textile wastewater", Journal of Environmental Protection 6(3), 191-203, 2015. doi: 10.4236/jep.2015.63020.

[12] Guesh, K., Mayoral, Á., Márquez-Álvarez, C., Chebude, Y., Díaz I.: "Enhanced photocatalytic activity of TiO2 supported on zeolites tested in real wastewaters from the textile industry of Ethiopia", Microporous and Mesoporous Materials 225, 88-97, 2016. doi: 10.1016/j.micromeso.2015.12.001.

[13] Jorfi, S., Barzegar, G., Ahmadi, M., Darvishi Cheshmeh Soltani, R., Alah Jafarzadeh Haghighifard, N., Takdastan, A., Saeedi, R., Abtahi, M.: "Enhanced coagulation-photocatalytic treatment of Acid red 73 dye and real textile wastewater using UVA/synthesized MgO nanoparticles", Journal of Environmental Management 177, 111-118, 2016. doi: 10.1016/j.jenvman.2016.04.005.

[14] Karthikeyan, N., Narayanan, V., Stephen, A.: "Degradation of textile effluent using nanocomposite TiO2/SnO2 semiconductor Photocatalysts", International Journal of ChemTech Research 8(11), 443 449, 2015. 
[15] Karthikeyan, N., Sivaranjani, T., Dhanavel, S., Gupta, V.K., Narayanan, V., Stephen A.: “Visible light degradation of textile effluent by electrodeposited multiphase CulnSe2 semiconductor photocatalysts", Journal of Molecular Liquids 227, 194-201, 2017. doi: 10.1016/j.molliq.2016.12.019.

[16] Katheresan, V., Kansedo, J., Lau, S.Y.: "Efficiency of various recent wastewater dye removal methods: a review", Journal of Environmental Chemical Engineering 6(4), 4676-4697, 2018. doi: 10.1016/j.jece.2018.06.060.

[17] Kavitha, S.R., Umadevi, M., Janani, S.R., Balakrishnan, T. Ramanibai R.: "Fluorescence quenching and photocatalytic degradation of textile dyeing waste water by silver nanoparticles", Spectrochimica Acta Part A: Molecular and Biomolecular Spectroscopy 127, 115-121, 2014. doi: 10.1016/j.saa.2014.02.076.

[18] Mahdizadeh, F., Aber, S., Karimi A.: "Synthesis of nano zinc oxide on granular porous scoria: application for photocatalytic removal of pharmaceutical and textile pollutants from synthetic and real wastewaters", Journal of the Taiwan Institute of Chemical Engineers 49, 212-219, 2015. doi: 10.1016/j.jtice.2014.11.021.

[19] Moncayo-Lasso, A., Torres-Palma, R.A., Kiwi, J., Benítez, N., Pulgarin C.: "Bacterial inactivation and organic oxidation via immobilized photo-Fenton reagent on structured silica surfaces", Applied Catalysis B: Environmental 84(3-4), 2008. doi: 10.1016/j.apcatb.2008.05.022.

[20] Parsons, S.: "Advanced Oxidation Processes for Water and Wastewater Treatment", (IWA Publishing, 2005.).

[21] Pouran, S.M., Abdul Aziz, A.R., Ashri Wan Daud, W.M.: "Review on the main advances in photoFenton oxidation system for recalcitrant wastewaters", Journal of Industrial and Engineering Chemistry 21, 53-69, 2015. doi: 10.1016/j.jiec.2014.05.005.

[22] Rosa, J.M., Tambourgi, E.B, Vanalle, R.M., Gamarra, F.M.C., Santana, J.C.C., Araújo, M.C.: "Application of continuous H2O2/UV advanced oxidative process as an option to reduce the consumption of inputs, costs and environmental impacts of textile effluents", Journal of Cleaner Production 246, 2020. doi: 10.1016/j.jclepro.2019.119012.

[23] Sahoo, C., Gupta, A.K., Pillai, I.M.S.: "Heterogeneous photocatalysis of real textile wastewater: evaluation of reaction kinetics and characterization", Journal of Environmental Science and Health, Part A 47, 2109-2119, 2012. doi: 10.1080/10934529.2012.695996.

[24] Sajan, C.P., Shahmoradi, B., Shivaraju, H.P., Rai, K.M.L., Ananda, S., Shayan, M.B., Thonthai, T., Rao, G.V.N., Byrappa, K.: "Photocatalytic degradation of textile effluent using hydrothermally synthesised titania supported molybdenum oxide photocatalyst", Material Research Innovations 14, 2010. doi: 10.1179/143307510X12599329343484.

[25] Saranya, M., Ramachandran, R., Kollu, P., Jeong, S.K., Grace. A.N.: "A template-free facile approach for the synthesis of CuS-rGO nanocomposites towards enhanced photocatalytic reduction of organic contaminants and textile effluents“, RSC Advances 5, 15831-15840, 2015. doi: 10.1039/C4RA09029B.

[26] Saravanan, R., Gracia, F., Khan, M.M., Poornima, V., Gupta, V.K., Narayanan, V., Stephen. A.: "ZnO/CdO nanocomposites for textile effluent degradation and electrochemical detection", Journal of Molecular Liquids 209, 374-380, 2015. doi: 10.1016/j.molliq.2015.05.040. (a)

[27] Saravanan, R., Karthikeyan, N., Gupta, V.K., Thirumal, E., Thangadurai, P., Narayanan, V., Stephen, A.: "ZnO/Ag nanocomposite: an efficient catalyst for degradation studies of textile effluents under visible light", Materials Science and Engineering 33, 2235-2244, 2013.

[28] Saravanan, R., Mansoob Khan M., Gupta, V.K., Mosquera, E., Gracia, F., Narayanan, V., Stephen A.: " $\mathrm{ZnO} / \mathrm{Ag} / \mathrm{CdO}$ nanocomposite for visible light-induced photocatalytic degradation of industrial textile effluents",Journal of Colloid and Interface Science 452, 126-133, 2015. doi: 10.1016/j.jcis.2015.04.035 (b)

[29] Shah, M.P.: "Bioremediation-waste water treatment", Journal of Bioremediation and Biodegradation 9, 2018. doi: 10.4172/2155-6199.1000427.

[30] Souza, R.P., Ambrosio, E., Souza, M.T.F., Freitas, T.K.F.S., Ferrari-Lima, A.M., Garcia J.C.: "Solar photocatalytic degradation of textile effluent with $\mathrm{TiO} 2, \mathrm{ZnO}$, and $\mathrm{Nb} 2 \mathrm{O} 5$ catalysts: assessment of photocatalytic activity and mineralization“, Environmental Science and Pollution Research 24, 12691-12699, 2017. doi: 10.1007/s11356-017-8408-8.

[31] Stasinakis, A.S.: "Use of selected advanced oxidation processes (AOPs) for wastewater treatment - A mini review“, Global Nest Journal 10(3), 376-385, 2008. 
[32] Suresh, P., Vijaya, J.J., Kennedy, L.J.: "Photocatalytic degradation of textile dyeing wastewater through microwave synthesized Zr-AC, Ni-AC and Zn-AC", Transactions of Nonferrous Metals Society of China, 25 (12), 4216-4225, 2015. doi: 10.1016/S1003-6326(15)64072-9.

[33] Swaminathan, K., Pachhade, K., Sandhya, S.: "Decomposition of a dye intermediate, (H-acid] 1 amino-8-naphthol-3,6 disulfonic acid in aqueous solution by ozonation", Desalination 186, 155-164, 2005. doi: 10.1016/j.desal.2005.05.018

[34] Touati, A., Hammedi, T. Najjar, W., Ksibi, Z. Sayadi, S.: "Photocatalytic degradation of textile wastewater in presence of hydrogen peroxide: effect of cerium doping titania", Journal of Industrial and Engineering Chemistry 35, 36-44, 2016. doi: 10.1016/j.jiec.2015.12.008.

[35] Tung, C.H., Shen, S.Y., Chang, J.H., Hsu, Y.M., Lai, Y.C.: "Treatment of real printing wastewater with an electrocatalytic process", Separation and Purification Technology 117, 131-136, 2013. doi: 10.1016/j.seppur.2013.07.028.

[36] Villegas-Guzman, P., Giannakis, S., Torres-Palma, R.A., Pulgarin C.: "Remarkable enhancement of bacterial inactivation in wastewater through promotion of solar photo-Fenton at near-neutral pH by (natural organic acids", Applied Catalysis B: Environmental 205, 219-227, 2017. doi: 10.1016/j.apcatb.2016.12.021.

[37] Wang, J., Zhang, T., Mei, Y., Pan, B.: „Treatment of reverse-osmosis concentrate of printing and dyeing wastewater by electro-oxidation process with controlled oxidation-reduction potential (ORP)", Chemosphere 201, 621-626, 2018. doi: 10.1016/j.chemosphere.2018.03.051.

[38] Wazir, M.B., Daud M., Ali F., Al-Harthi M.A.: "Dendrimer assisted dye-removal: A critical review of adsorption and catalytic degradation for wastewater treatment", Journal of Molecular Liquids 315, 2020. doi: 10.1016/j.molliq.2020.113775.

[39] Zhang, J.X., Zhang, Y.B., Quan, X., Li, Y., Shuo, C., Zhao, H., Wang, D.: "An anaerobic reactor packed with a pair of Fe-graphite plate electrodes for bioaugmentation of azo dye wastewater treatment", Biochemical Engineering Journal 63, 31-37, 2012. doi: 10.1016/j.bej.2012.01.008.

[40] Zhu, Y., Xua, J., Cao, X., Cheng, Y.: "Characterization of functional microbial communities involved in different transformation stages in a full-scale printing and dyeing wastewater treatment plant", Biochemical Engineering Journal 137, 162-171, 2018. doi: 10.1016/j.bej.2018.05.026.

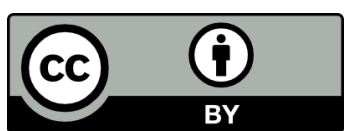

(C) 2020 Authors. Published by the University of Novi Sad, Faculty of Technical Sciences, Department of Graphic Engineering and Design. This article is an open access article distributed under the terms and conditions of the Creative Commons Attribution license 3.0 Serbia (http://creativecommons.org/licenses/by/3.0/rs/). 

PACKAGING ADDED VALUE 



\title{
EVALUATION OF ZIPPER TEAR STRIP DESIGN STRUCTURE FOR PAPERBOARD PACKAGING
}

\author{
Josip Bota (D), Gorana Petković \\ University of Zagreb, Faculty of Graphic Arts, Zagreb, Croatia
}

\begin{abstract}
Zipper tear strips (ZTS) are the most common user friendly, tamper-proof, opening system for paperboard and corrugated cardboard packaging. The base of ZTS design structure has parallel partial cuts repeated in the direction of the desired tearing line. The height (strip-width) of the tab can vary same as the shape in the cut design structure. In order to collect the most common zipper tear structure data, parameters were measured from samples of paperboard packaging found in a frequent Croatian supermarket. The obtained data was used to define 8 types of samples which were together with 4 new samples tested on two mainly used paperboards (250 g/m $/ \mathrm{m}^{2} \mathrm{GC1}$ and $270 \mathrm{~g} / \mathrm{m}^{2} \mathrm{GC2}$ ). Three type of tests were conducted: pull test for maximal tearing force, compression test to measure the structural degradation of a packaging and manual tearing to test the ZTS opening functionality success rate in real-life handling conditions.

The results show that the $45^{\circ}$ angle is most functional option and should be combined with the wider $13 \mathrm{~mm}$ ZTS instead of the usual $10 \mathrm{~mm}$. Also, there is an indication that a $0,5 \mathrm{~mm}$ increase between cuts can slightly improve structural stability and when combined with the wider tab can attain an increased tear resistance while having the adequate opening functionality success rate.
\end{abstract}

Key words: Zipper tear strip, tamper-proof opening, paperboard packaging

\section{INTRODUCTION}

The zipper tear strip (ZTS) also known as a zipper, zipper tab, zipper pull tab, tear-strip, zip-strip is a tamper proof opening system for paperboard and corrugated cardboard packaging. The design consists of cut and uncut parts (connected portions - CP, nicks) (Kirwan, 2012; Yam, 2009). The main goal of this feature is to provide the packaging a one-time opening or unlocking system. It allows the consumer feedback that the packaging was sealed from when its packed.

Construction of the tearing design varies depending on the manufacturer and preferences. Figure 1 shows the most common design structures that also vary with the lengths and curvatures of the cutting lines.

a)

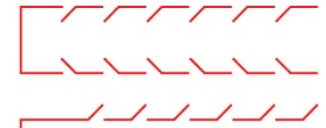

b)

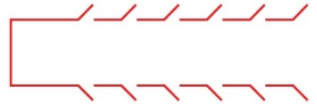

c)

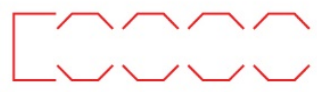

d)

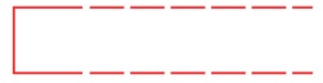

Figure 1: Types of zipper tear strips (ZTS)

Currently there are no standardized shapes or ratios in the paperboard industry, no guidelines, even research on this topic is scares. Just two available papers were found that tested five types of ZTS designs using the uncut parts and paperboard grain direction as variable (Nagasawa et al, 2017, 2018). One paper is written in Japanese which limits the comprehension using translation software's. As expected they found that the ZTS parallel to the machine direction of grain and the smaller uncut parts have a larger success rate than cross direction (CD) and longer uncut pars, respectively. In the research they used machine pulling without testing manual opening with participants. There are also two more papers from the same group of authors that were not accessible but the author stated that they are preparing an English version (Uehara et al, 2017, 2016). 
There are specialized book suggesting packaging designs with ZTS (Wybenga and Roth, 2013) and research that tests opening systems on people with limited range of motion and strength (Marks et al, 2012) but no specific guidelines. Australia even made guidelines for inclusive design for people with arthritis (Fain, 2018) but rarely there is a mention of this type of opening systems.

The issue with the ZTS is that the cutting across and around the paperboard and corrugated cardboard packaging decreases the structural stability and stackability. The strip needs to be durable enough not to collapse during transportation and handling, and have a $100 \%$ opening success rate. This is hard to achieve, especially in corrugated cardboard packaging, due to the variability in paper properties (cellulose grains, filament, humidity, etc.). Manufacturers sometimes sacrifice the rate of successful opening in favor of the mechanical properties so the package fulfills its role in product protection and as tamper proof evidence. The failure of opening is most commonly the result of delamination of paperboard and separation of layers in corrugated cardboards rarely because of breakage. This is mostly common when ZTS are narrow and not adequate to paperboard properties (tear resistance). One of the solutions used in the industry is gluing a plastic strip on the inside of the packaging that makes the ZTS multilayered and adds to the mechanical properties. This is mostly used in mailing packaging and envelopes. It requires an additional manufacturing process and makes the stripped part harder to recycle. Therefore, there is an interest to achieve maximal opening success rates with adequate mechanical properties produced with less manufacturing processes and keeping the recyclability of the packaging as a whole.

The goal of this paper is to test and evaluate the currently most commonly used ZTS designs on the market, using two standard packaging paperboards as a starting point to optimize this feature and suggest potential changes in design. The ZTS design and variables for this research was chosen for evaluating the currently most common type used in the Croatian market for paperboard packaging, shown in Figure 1 type a).

\section{METHODS}

\subsection{Materials}

The selected paperboards (DIN graded) are commonly used for packaging of food and drugs. Paperboard specifications, grades (according to DIN Standard 19303 "Paperboard - Terms and grades") sample variables and nomenclature are seen in Table 1. The paperboard was conditioned according to the ISO 187:1990 standard at temperature of $23^{\circ} \mathrm{C} \pm 1^{\circ} \mathrm{C}$ and humidity RV $50 \% \pm 2 \%$ before and during the testing.

Table 1: Paperboard samples nomenclature and specifications

\begin{tabular}{|c|c|c|c|c|c|c|c|c|}
\hline sample name & grammage & $d$ & $\alpha$ & w & ZTS shape & DIN grade & thickness & manufacturer \\
\hline Z43_d_a_w & $250 \mathrm{~g} / \mathrm{m}^{2}$ & \multirow{2}{*}{ 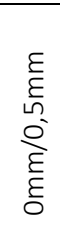 } & \multirow{2}{*}{ 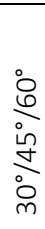 } & \multirow{2}{*}{ } & \multirow{2}{*}{ 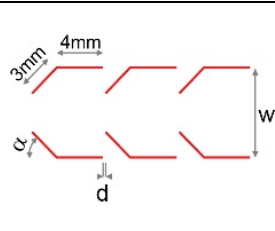 } & $\begin{array}{l}\text { GC1 (virgin } \\
\text { mechanical } \\
\text { pulp) }\end{array}$ & $0,41 \mathrm{~mm}$ & Ningbo $^{\circledR}$ \\
\hline T43_d_a_w & $270 \mathrm{~g} / \mathrm{m}^{2}$ & & & & & $\begin{array}{l}\text { GC2 (virgin } \\
\text { mechanical } \\
\text { pulp) }\end{array}$ & $0,46 \mathrm{~mm}$ & AllyKing ${ }^{\circledR}$ \\
\hline
\end{tabular}

\subsection{Samples}

The samples were made and named according to the variables presented in Table 1 . The cutting length of parallel and angled lines were defined at $4 \mathrm{~mm}$ and $3 \mathrm{~mm}$, respectively. These variables are fixed because over $90 \%$ of the ZTS found in frequent Croatian supermarket (with this type of strip design) had the specified lengths. All of the other variables $(w, d, \alpha)$ were defined according to the same findings with an exception of the $30^{\circ}$ angle. This angle was not found on any packaging with ZTS but was incorporated for this evaluation study. All samples were prepared using EngView Packaging and Display Designer Suite software and cut on a Zund M-800 flatbed cutter/plotter using a Z10 drag blade. The samples for the compression resistance and manual test were glued by using a water based dispersion of polyvinyl acetate with additives (Signokol ${ }^{\circledR}$ ) which is commonly used in the packaging line.

Two types of samples were prepared with the dimension specified in Table 2. The grain direction used in the samples was defined according to the most common position of the ZTS in relation to the design of the packaging. The panel ratio of the packaging simulation sample is defined as 4:1. This ratio has a reduced structural stability when compared with other shapes with a identical extent and are more often found on the supermarket shelfs (Bota et al, 2018). 


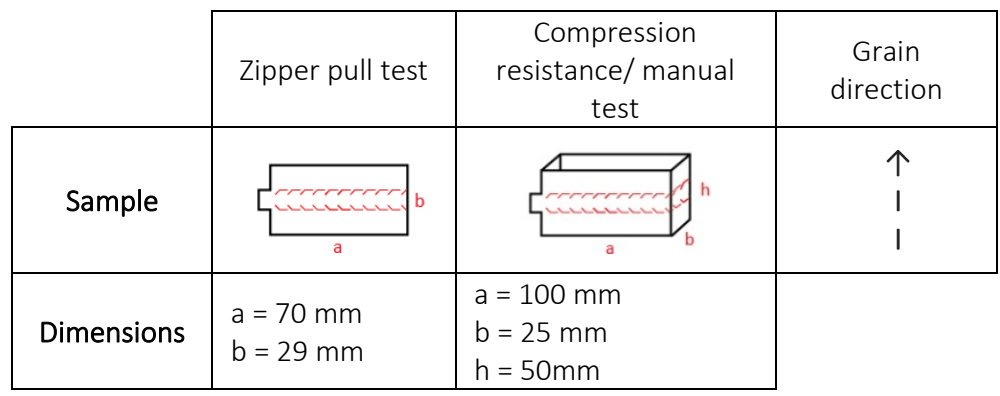

\subsection{Zipper pull test}

Measurement of the maximal force needed to tear off the ZTS was conducted on a modified digital force gauge, Mark-10 series 4, type M4-100. The sample was clamped to a 3D printed adapter to ensure a $45^{\circ}$ pulling direction that finishes under a $90^{\circ}$ angle (Figure 2). This simulates a typical angle of user handling. The pulling speed was $3,5 \mathrm{~mm} / \mathrm{sec}$ and the data was collected with the MESUR ${ }^{\mathrm{TM}}$ Lite data acquisition software. The results are show as Newton's (N).

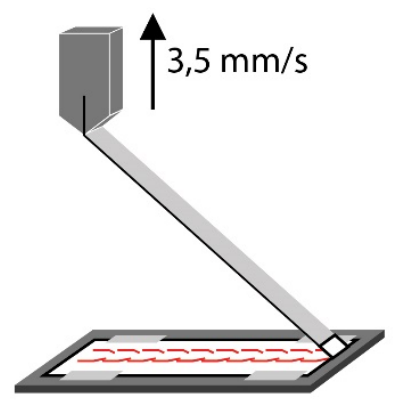

Figure 2: Zipper pull test

\subsection{Compression resistance test}

When the glue was completely dry (24h after gluing) the samples were tested for compression resistance using a modified Crush test instrument (Lorentzen \& Wettre Crush Tester) using Mode 1. The samples were pressed between two plates at a speed (movement of the upper plate) of $0,8 \mathrm{~mm} / \mathrm{sec}$ (Figure 3). The instrument records the maximum force in Newton's ( $N$ ) achieved till barreling occurs (shape deformation). Each shape and material was tested with six identical samples.

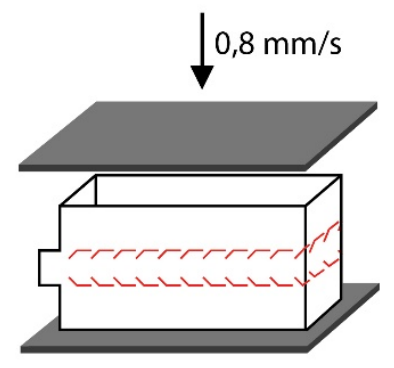

Figure 3: Compression resistance test

\subsection{Manual opening test}

After the compression resistance the test samples (six) were given to a user to tear of the ZTS. The user held the sample in the left hand and pinching the opening tab with his right hand thumb and index finger. The user was instructed to use the same grip, opening movement and speed for each sample. The handling 
and opening technique of the participant was not unusual. All twenty-four types of samples were handled by the same user.

\section{RESULTS AND DISCUSSION}

The goal of the results was to evaluate and compare the pull test, compression resistance and manual test (user handling and tearing of the ZTS) to provide conclusions about the optimal design and direction of further in-depth research on this topic.

\subsection{Zipper pull results and discussion}

Each sample had 9-12 tears depending on the angle and distance between the cuts. Every sample type was tested with 10 tests. For this study each maximum force of the pull test was collected. The ten results are presented as a mean with the maximum value in Figure 4.

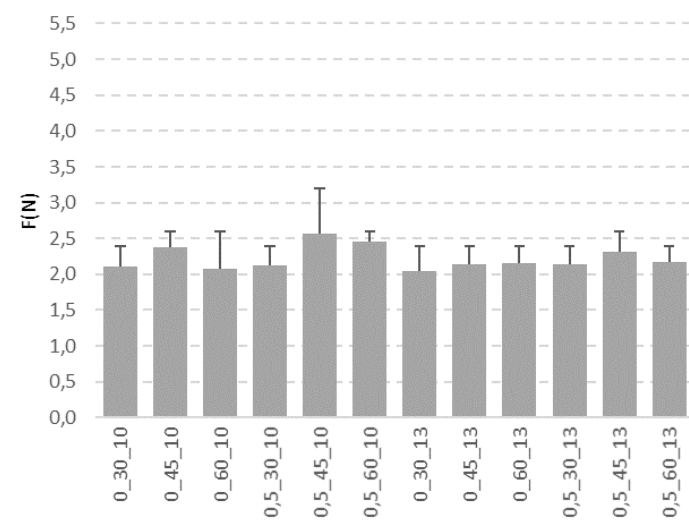

a) GC1 $250 \mathrm{~g} / \mathrm{m}^{2}$ paperboard

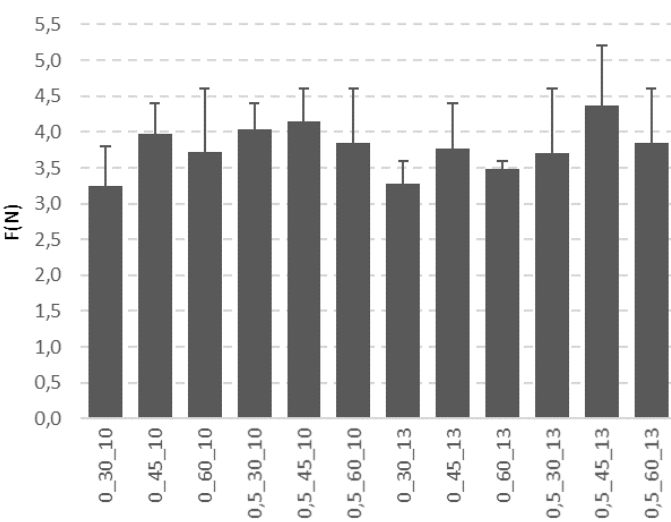

b) GC2 $270 \mathrm{~g} / \mathrm{m}^{2}$ paperboard

Figure 4: Zipper pull results for $250 \mathrm{~g} / \mathrm{m}^{2}$ and $270 \mathrm{~g} / \mathrm{m}^{2}$ paperboard samples

The results show that there are more prevalent pulling force variation in the $270 \mathrm{~g} / \mathrm{m}^{2}$ in comparison with the $250 \mathrm{~g} / \mathrm{m}^{2}$ paperboards. Most of the maximum forces in the $250 \mathrm{~g} / \mathrm{m}^{2}$ (Figure 4. a)) are in-between 2,4N and $2,6 \mathrm{~N}$ only the sample with the connected portion (CP) distance of $0,5 \mathrm{~mm}, 45^{\circ}$ angle and $10 \mathrm{~mm}$ ZTS width show an increase of pull resistance. Mostly the $45^{\circ}$ samples show increased pulling force resistance than other variables. Similar trend can be observed in the $270 \mathrm{~g} / \mathrm{m}^{2}$ (Figure 4. b)) results. It can be also seen that the samples with $60^{\circ}$ angled cuts show a larger pulling resistance than the $30^{\circ}$ samples. It can be augmented that those two samples have lower force resistance due to cuts more parallel /perpendicular to the grains but the $60^{\circ}$ has better results because the diagonal CP distance is larger due to the larger angle. An observation was made during conducting the test: Rarely both of the parallel CP tore at the same time during apparatus pulling. Mostly one side would tear off then the other partially rotating the ZTS in the process. According to Nagasawa and all (Nagasawa et al, 2017) this could be eliminated using Y shaped cuts (guiding routes).

\subsection{Compression resistance results and discussion}

Each variable variation was tested with six identical samples. The results are presented in Figure 5 as a mean of the results with standard deviation. Comparing the results with the control (without the ZTS) it can be seen an approximately $40 \%$ reduction in compression resistance. This is not a negligible decrease in structural stability. 


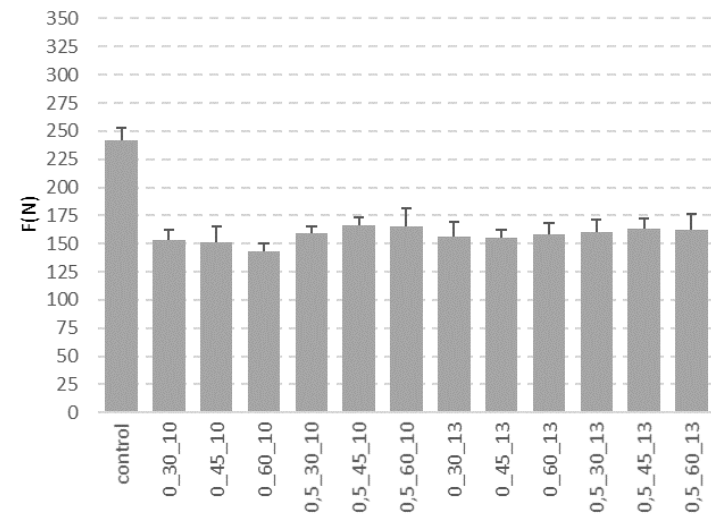

a) GC1 $250 \mathrm{~g} / \mathrm{m}^{2}$ paperboard

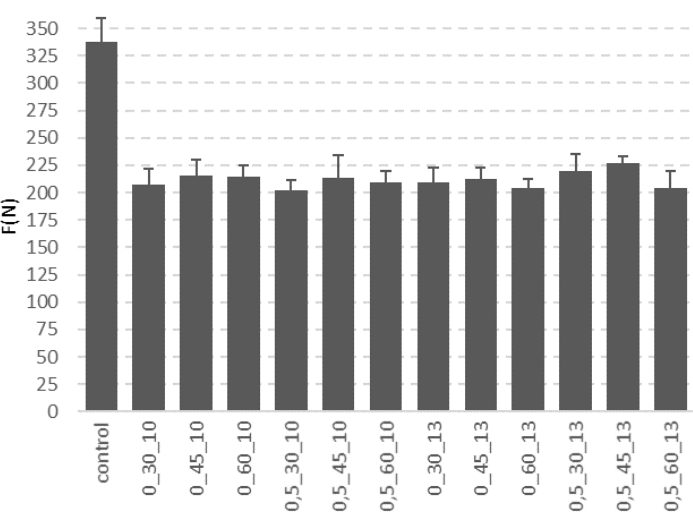

b) GC2 $270 \mathrm{~g} / \mathrm{m}^{2}$ paperboard

Figure 5: Compression resistance results for $250 \mathrm{~g} / \mathrm{m}^{2}$ and $270 \mathrm{~g} / \mathrm{m}^{2}$ paperboard samples

Similar to the pull test there is a more uniform set of results with the $250 \mathrm{~g} / \mathrm{m}^{2}$ paperboard samples (Figure 5. a)). Across the variables there can be observed a clearer trending line. The samples with the $0,5 \mathrm{~mm} \mathrm{CP}$ increase show a better compression resistance and again the $45^{\circ}$ ZTS show slightly increased resistance than $30^{\circ}$ and $60^{\circ}$ samples. This is more visible in the $270 \mathrm{~g} / \mathrm{m}^{2}$ paperboard samples (Figure 5 . b)). The horizontal and vertical distance in between cut lines are identical for samples with $45^{\circ}$ angle but in the $60^{\circ}$ the horizontal distance is less and there are more cut segments around the packaging simulation sample while in the $30^{\circ}$ angle there are less cut segments and the vertical distance is smaller. So if the structural stability is more dependent to the grain direction a $30^{\circ}$ cut cuts more grains than the $60^{\circ}$.

\subsection{Manual opening test results and discussion}

In order to truly test the ZTS design and variables a manual test was needed to find out the opening success rate of each sample. It's important to emphasize that all of the zipper pull tests were $100 \%$ successful and the samples were clamped to the base near the ZTS to reduce bending, but these are not real-life handling conditions. Figure 6 shows the success rate of manual opening of the samples that simulated packaging.

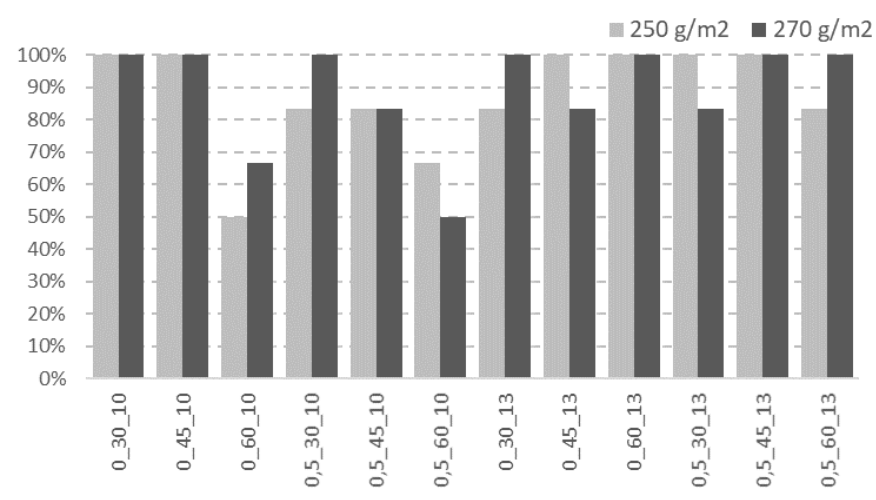

Figure 6: Opening success rate (\%) for $250 \mathrm{~g} / \mathrm{m}^{2}$ and $270 \mathrm{~g} / \mathrm{m}^{2}$ paperboard samples

This test was made on six samples and shows that not all samples have a 100\% success rate like in the controlled pull test. Only four samples achieved the targeted success rate for both types of paperboard. These samples were first tested to the compression resistance (similar to real-life conditions) and then submitted to "opening". There was no correlation found between the samples with higher compression resistance and successful opening. As expected (Nagasawa et al, 2018) most of the failed openings were a result of delamination and not because of the tearing of the strip (Figure 7). But this might be an issue with lighter paperboards for $10 \mathrm{~mm}$ wide ZTS strips. 

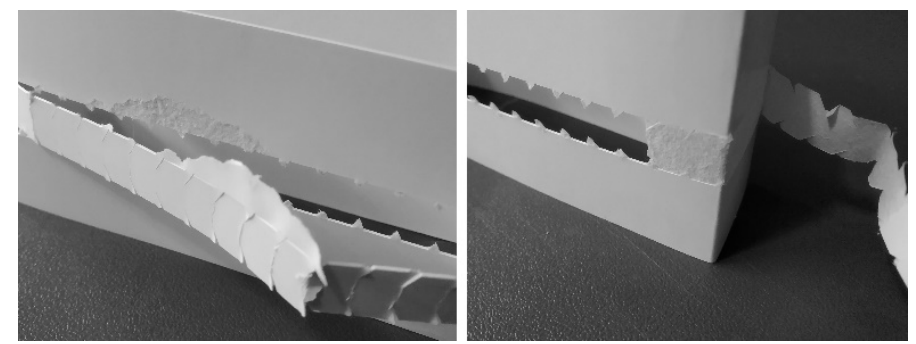

Figure 7: Delamination of the ZTS manual opening test

It is also observed that the wider $(13 \mathrm{~mm})$ ZTS have a higher success rate. This might be due to less rotation during handling of the strip which can lead the tearing force in the direction of a weak point in the lamination. Overall the sample that had a $45^{\circ}$ cut combined with the $0,5 \mathrm{~mm}$ CP distance for $10 \mathrm{~mm}$ ZTS with showed a higher pull resistance, a slighter increase in compression resistance but an $83 \%$ manual opening success rate. The same was not observed in the similar sample with wider $(13 \mathrm{~mm})$ ZTS. This should be investigated more thoroughly to better understand the anomaly.

\section{CONCLUSIONS}

This research was aimed to evaluate and investigate the difference between different ZTS variables together with the use of two common types of paperboards. For this research a new type of testing was developed using a digital force gauge. The results led to these conclusions:

- $\quad$ The ZTS decreases the compression resistance (stackability) of the packaging

- The $45^{\circ}$ angled cuts are an optimal solution and according this research the most functional design option

- Wider $(13 \mathrm{~mm})$ ZTS improves the successful opening rate for human handling

- There is an indication that $0,5 \mathrm{~mm}$ increase between cuts can slightly improve compression resistance

This research could be improved by preparing samples using a die-cut and increasing the number of samples and participants in the manual test. Also the ZTS should be further studied with other grammage of paperboard and with other types of fiber layer (recycled, non-bleached etc.) and compared with other types of designs to construct a model or find an optimal overall solution.

\section{REFERENCES}

[1] Bota, J., Jamnicki Hanzer, S., Banić, D., Brozović, M.,: "Compression resistance of small paperboard packaging shapes", Proceedings of $9^{\text {th }}$ International Symposium on Graphic Engineering and Design 2018, (GRID: Novi Sad, Serbia, 2018), pages 237-242.

[2] Fain, B.: "Food Packaging Design Accessibility Guidelines", URL: https://arthritisaustralia.com.au/wordpress/wp-content/uploads/2018/01/Food-Packaging-DesignAccessibility-Guidelines_Arthritis-Australia.pdf (last request: 2020-09-10).

[3] Kirwan, M.J.: "Handbook of Paper and Paperboard Packaging Technology" (Wiley-Blackwell, Hoboken NJ, USA, 2012), pages 268-277.

[4] Marks, M., Muoth, C., Goldhahn, J., Liebmann, A., Schreib, I., Schindele, S.F., Simmen, B.R., Vliet V.: "Packaging-A problem for patients with hand disorders? A cross-sectional study on the forces applied to packaging tear tabs.", Journal of Hand Therapy 25, 387-396, 2012. doi: 10.1016/j.jht.2012.04.003.

[5] Nagasawa, S., Uehara, M., Matsumoto, C.: "Effects of Guiding Routes and Grain Direction of Whiteclay-coated Paperboard on Tearing Characteristics of Zipper Pull Tab", Journal of the Japan Society for Technology of Plasticity, 2018. doi:10.9773/sosei.59.15.

[6] Nagasawa, S., Uehara, M., Matsumoto, C., Kambe, H., Jina, W.:" Estimation of stress and displacement around nick zone of zipper pull tab formed on paperboard", Proceedings of the JSME 2017 International Conference on Materials and Processing 2017, (JSME 2017: Los Angeles, California, 2017), pages 1-6. 
[7] Uehara, M., Nagasawa, S., Jina, W., Matumoto, C.: "Tearing characteristic of zipper pull tab of paperboard", The Proceedings of Conference of Hokuriku-Shinetsu Branch 2017, (Hokuriku-Shinets, Japan, 2017).

[8] Uehara, M., Nagasawa, S., Matumoto, C.: "Peeling behaviour of zipper tag and crack propagation on nicked zone", The Proceedings of Conference of Hokuriku-Shinetsu Branch 2016, (Hokuriku-Shinets, Japan, 2016).

[9] Wybenga, G.L., Roth, L: "The Packaging Designer's Book of Patterns, Packaging", (Wiley, Hoboken NJ, USA, 2012).

[10] Yam, K.L.: "Encyclopedia of Packaging Technology", (Wiley, Hoboken N.J., USA, 2009), pages 235236.

\section{(c) (1)}

(C) 2020 Authors. Published by the University of Novi Sad, Faculty of Technical Sciences, Department of Graphic Engineering and Design. This article is an open access article distributed under the terms and conditions of the Creative Commons Attribution license 3.0 Serbia (http://creativecommons.org/licenses/by/3.0/rs/). 



\title{
PACKAGING PAPER COATED WITH PLA
}

\author{
Diana Gregor-Svetec (D), Tadeja Šumrada \\ University of Ljubljana, Faculty of Natural Sciences and Engineering, Department of Textiles, \\ Graphic Arts and Design, Chair of Information and Graphic Arts Technology, Ljubljana, Slovenia
}

Abstract: Nowadays, eco-design of products is becoming one of the most important directions at packaging development. Efficient use of materials, use of materials from renewable sources, design for recycling and reuse are especially important. In our research, we were interested in the development of sustainable, biodegradable protective paper packaging. In order to make packaging resistant against water, paper was coated with a biodegradable biopolymer, instead of using synthetic polymer. The base packaging paper was coated with a PLA solution, which was obtained by dissolving PLA pellets in dichloromethane. Two different concentrations were used. Technological and surface properties of coated paper were determined. The results of analyses have shown that sustainable packaging paper with good surface properties and barrier against water can be obtained by coating it with a PLA solution. Comparison with a commercial packaging paper has shown, that for PLA coated paper even higher water resistance was obtained.

Key words: packaging paper, PLA, coating, surface properties

\section{INTRODUCTION}

Today, sustainable development and eco-design of products are important directions in all areas. Ecodesign is an approach to designing products with special consideration for the environmental impacts of the product during its whole lifecycle and is becoming a core design concept in packaging. (Birkeland, 2002) The main purpose of packaging is to contain and protect the packed items from their point of production through to the point of use. The challenge is to do so by optimizing the use of materials, water and energy, minimizing waste and maximizing the recovery of used packaging (Incpen, 2008). The sustainable packaging design principles of effective, efficient, cyclic, and safe should be consider (Park et al, 2014). For packaging with short-life span is even more important to focus on material choice, to use materials from renewable sources, that are recyclable or compostable, and design for maximum sustainability and recoverability (Birkeland, 2002; McDonough and Braungart, 2009).

Protective paper packaging has lot of uses, from packing products for transport to protecting them in storage, from wrapping product or filling the space inside the box. Paper is widely used in packaging applications and is biodegradable and therefore environmentally friendly material. The barrier resistance and wettability of papers are commonly controlled by the application of petroleum-based derivatives such as polyethylene, waxes and/or fluor-derivatives as coating (Rastogi and Samyn, 2015). Because of such coated layer, protective paper packaging loses its biodegradation and recyclability characteristics (Khwaldia et al, 2010). Petroleum-based polymers represent the largest segment of global waste, because of their limited recyclability and non-biodegradability. As alternative, naturally renewable biopolymers can be used as barrier coatings on paper packaging materials. Polylactide (PLA) is one of the most promising polymers because of its biocompatibility, biodegradability and the fact that it can be produced from the bio based feedstocks (Vukić et al, 2018). PLA is extremely versatile and can be injection molded, extruded, foamed, thermoformed or applied onto the paper with different coating techniques (Khwaldia et al, 2010; Vartiainen et al, 2004). In our research, we used PLA solution for coating. We prepared PLA solutions in different concentrations and used them for coating the base paper sheets, analyzed them and compared with a commercial packaging paper.

\section{METHODS}

\subsection{Materials}

One side coated, woodfree flexible packaging paper with high surface quality was used as a reference paper. For our research, a base uncoated paper of the mentioned commercial packaging paper was supplied by the producer. 
PLA pellets (6201D, Natureworks, USA) were dissolved in the solvent dichloromethane (DCM) at raised temperature. In this way, two coating solutions were prepared, in concentrations of 15 wt $\%$ and 20 wt $\%$ (dry solids weight). PLA pellets were dried in a vacuum oven at $60^{\circ} \mathrm{C}$ for $24 \mathrm{~h}$ before use. Analytical grade dichloromethane (DCM) was obtained from Carl Roth, Germany.

Coating was carried out at ambient temperature on a lab coater (RK Print-Coat Instruments, Hertz, UK) using a wire-wound bar. The coat weight was varied by varying the diameter of the wire on the bar. Two bars were used, No. 3 with the wire diameter of 0,31 mm and No. 6 with the wire diameter of 0,76 mm. After coating, the samples were allowed to dry overnight at the room temperature.

Sample identification and description is summarised in Table 1.

Table 1: Sample identification and description

\begin{tabular}{|l|l|}
\hline Sample identification & Sample description \\
\hline BP & Base paper, uncoated packaging paper \\
\hline BP-15-3 & Base paper; coated with PLA solution with concentration of 15 wt\%; bar No. 3 \\
\hline BP-15-6 & Base paper; coated with PLA solution with concentration of $15 \mathrm{wt} \%$; bar No. 6 \\
\hline BP-20-3 & Base paper; coated with PLA solution with concentration of $20 \mathrm{wt} \%$; bar No. 3 \\
\hline BP-20-6 & Base paper; coated with PLA solution with concentration of $20 \mathrm{wt} \% ;$ bar No. 6 \\
\hline CP & Commercial product; one-side coated packaging paper \\
\hline
\end{tabular}

\subsection{Methods}

Before testing, all samples were conditioned at $23^{\circ} \mathrm{C}$ and $50 \% \mathrm{RH}$. Basis weight (grammage) was determined with an analytical balance Mettler Type AE200 (Ohio, USA) with readability of 0.1 mg. Coating weight was obtained by subtracting from the weight of a defined area of coated paper, the weight of the same size area of the uncoated paper. Thickness of samples was measured in accordance with ISO 534, using micrometer Mitutoyo (Kawasaki, Japan) with $0.001 \mathrm{~mm}$ accuracy.

Surface properties were tested according to their respective standards. Roughness was measured using Bendtsen N3500 roughness tester (PTA Group, France) in accordance with ISO 8791-2. With the same measuring device the air permeance was determined following ISO 5636-3. Spectrophotometer X-Rite i1Pro2 (Michingan, USA) was used to measure ISO brightness (ISO 2470-1), opacity (ISO 2471) and colour (ISO 5631-1). Water absorbency was tested with Cobb method according to ISO 535, Klemm method according to ISO 8787 and the water absorbency rate according to Tappi T432. The morphology of the samples was examined with the Scanning electron microscopy (SEM). Prior to analysis, the samples were coated with a thin layer of gold. The images were captured with a SEM system (JSM-6060 LV, Jeol, Japan) equipped with a detector of secondary electrons.

\section{RESULTS AND DISCUSSION}

A single-layer method was used to apply PLA solution onto the base woodfree packaging paper. Two concentrations of PLA solution, 15 and $20 \mathrm{wt} \%$, were used. To deposit the coating solution on the paper, a wire-wound bar was used. Using standard wire-wound bar an uniform and repeatable coating was obtained. Two bars with different wire diameter were used, No. 3 and No. 6, for depositing 24 and $60 \mu \mathrm{m}$ wet film onto the substrate, which resulted in four different coat weights: 6 and $9 \mathrm{~g} / \mathrm{m}^{2}$ at lower PLA solution concentration, 8 and $11 \mathrm{~g} / \mathrm{m}^{2}$ at higher concentration.
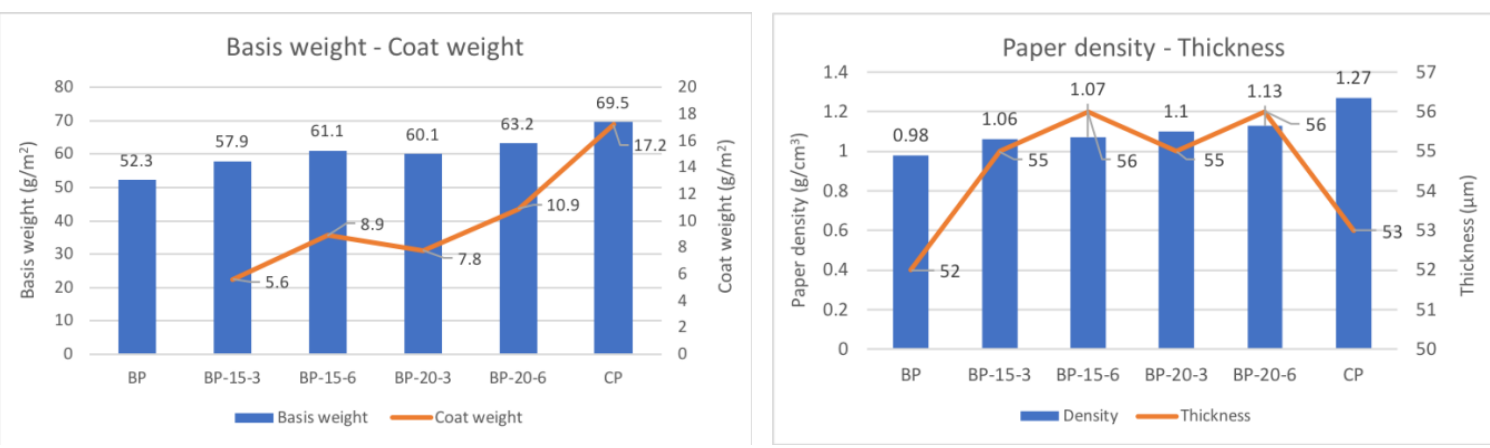

Figure 1: Technological properties of paper samples 

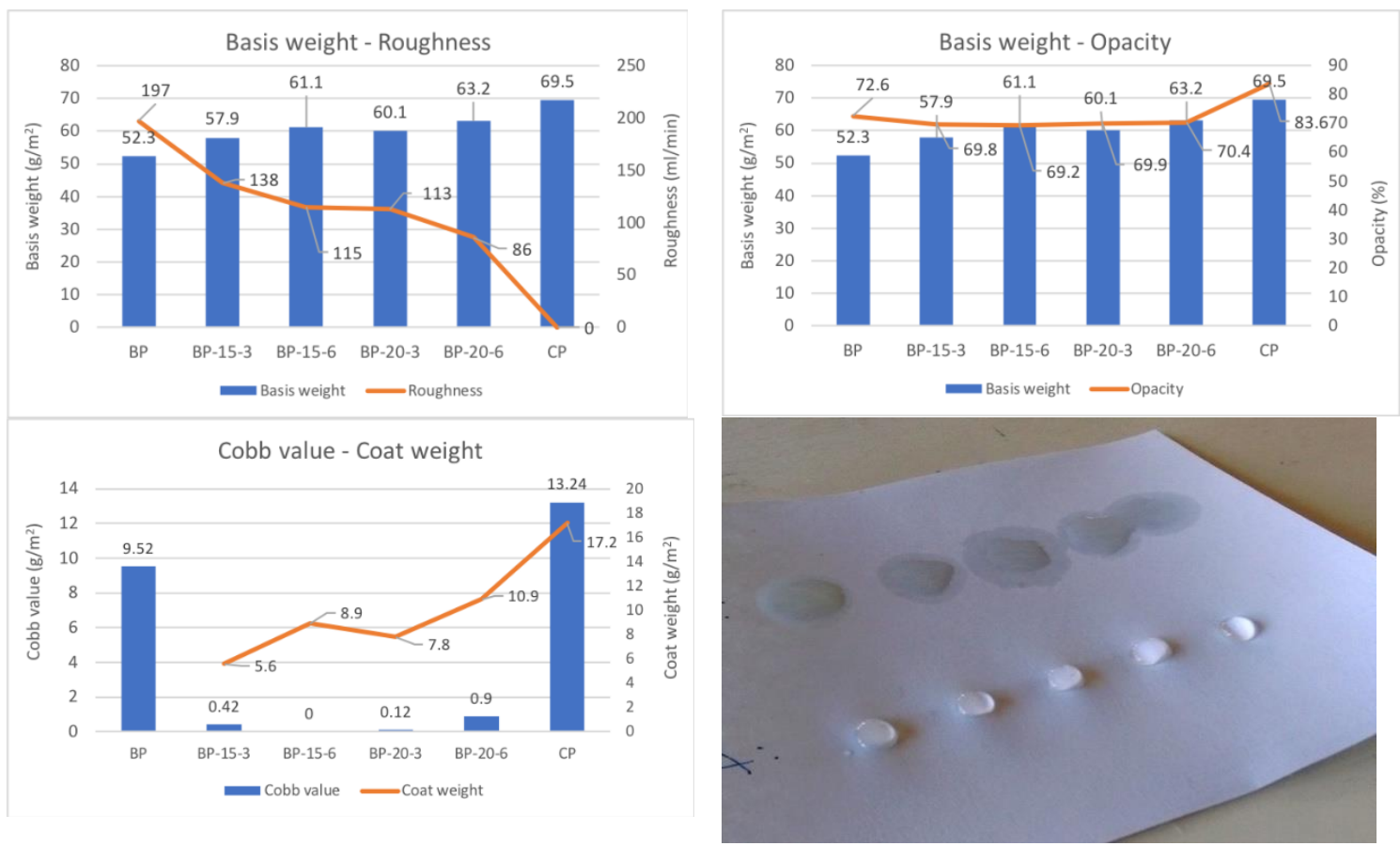

Figure 2: Surface properties of paper samples

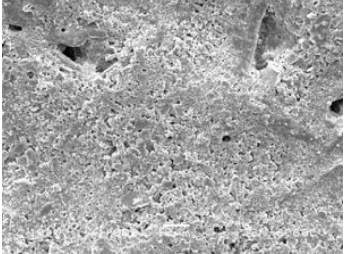

BP - top side

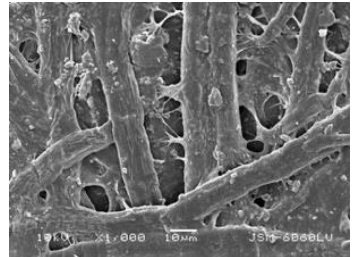

$\mathrm{BP}$ - reverse side

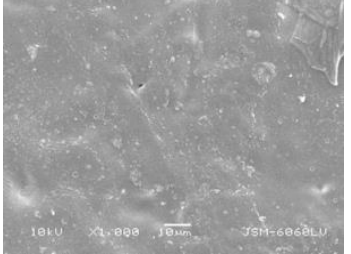

BP-15-3 - top side

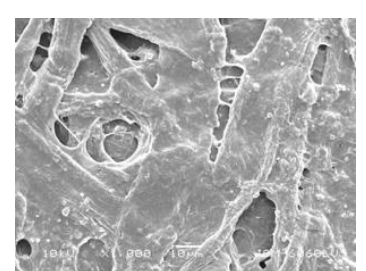

BP-15-3 - reverse side

Figure 3: SEM images of paper surface

Table 2: Colorimetric properties of paper samples

\begin{tabular}{|l|c|c|c|c|}
\hline Sample & $\mathrm{L}^{*}(/)$ & $\mathrm{a}^{*}(/)$ & $\mathrm{b}^{*}(/)$ & ISO brightness (\%) \\
\hline BP & 96,07 & 0,635 & 0,938 & 83,9 \\
\hline BP-15-3 & 95,65 & 0,656 & 1,102 & 82,4 \\
\hline BP-15-6 & 95,41 & 0,655 & 1,045 & 82,1 \\
\hline BP-20-3 & 95,75 & 0,654 & 1,021 & 83,2 \\
\hline BP-20-6 & 95,35 & 0,637 & 0,718 & 82,6 \\
\hline CP & 93,5 & 1,179 & $-1,226$ & 81,1 \\
\hline
\end{tabular}

Coat weight is in very high correlation with the basis weight, thickness and paper density, as expected (Figure 1). It is obvious, that thickness depends more on the volume of the deposited PLA solution onto the paper and less on the solution concentration (Figure 4). Base paper was precoated on one side, as seen from the Figure 3. Surface sizing has improved barrier and surface properties of base paper and gave good foundation for coating. The smoothness of paper surface was raised with coating, but mainly barrier properties improved, especially barrier properties to water (Figure 2). With increasing coat weight, the surface roughness decreased (Figure 4).

Coating with the PLA solution closed the surface, which resulted in very low water absorptiveness into the surface (Cobb value around $0 \mathrm{~g} / \mathrm{m}^{2}$, water droplet didn't change its shape in 10 minutes) and no water absorbency due to capillary action (Klemm value bellow $1 \mathrm{~mm}$ ). Already, lower concentration of PLA solution (15 wt\%) and lower volume of wet film deposited (bar No. 3) resulted in excellent paper barrier properties to water. As seen from the Figure 3, the top side of the paper is completely covered with the PLA polymer, and even reverse side of the paper is partly coated. PLA solution obviously penetrated into the paper and closed also the pores in the paper, not only voids on the surface of the paper. This was 
confirmed by the measurement of air permenance, which showed that no air has penetrated through the paper. That is way increasing the concentration of PLA solution or volume of deposited solution on the paper had little effect on improvement of surface properties (Figure 4).

To check if coating suspension has any influence on color of the paper surface, the CIELab values and ISO brightness were determined. With coating ISO brightness decreases, though the difference is small, below 2\% (Table 2). Lower values were obtained at lower concentration of PLA solution and higher volume of deposited solution on the paper (Figure 4). Also, a small decrease in opacity is seen. The color differences between base paper and coated samples are negligible, $\Delta \mathrm{E}$ is bellow 1 (Table 2).

Compared to reference sample, commercially produced one-side coated packaging paper, PLA coated papers have lower basis weight and density, and higher thickness. Commercially produced coated paper is calendred, which increases density and lowers the thickness of paper. The coat weight at commercial product is higher compared to PLA coated papers, which has some influence on surface properties, though lower than expected. A bit higher opacity and smoothness, lower ISO brightness, and higher Cobb value are more connected to the composition of coated layer and finishing process and less with the coat weight.
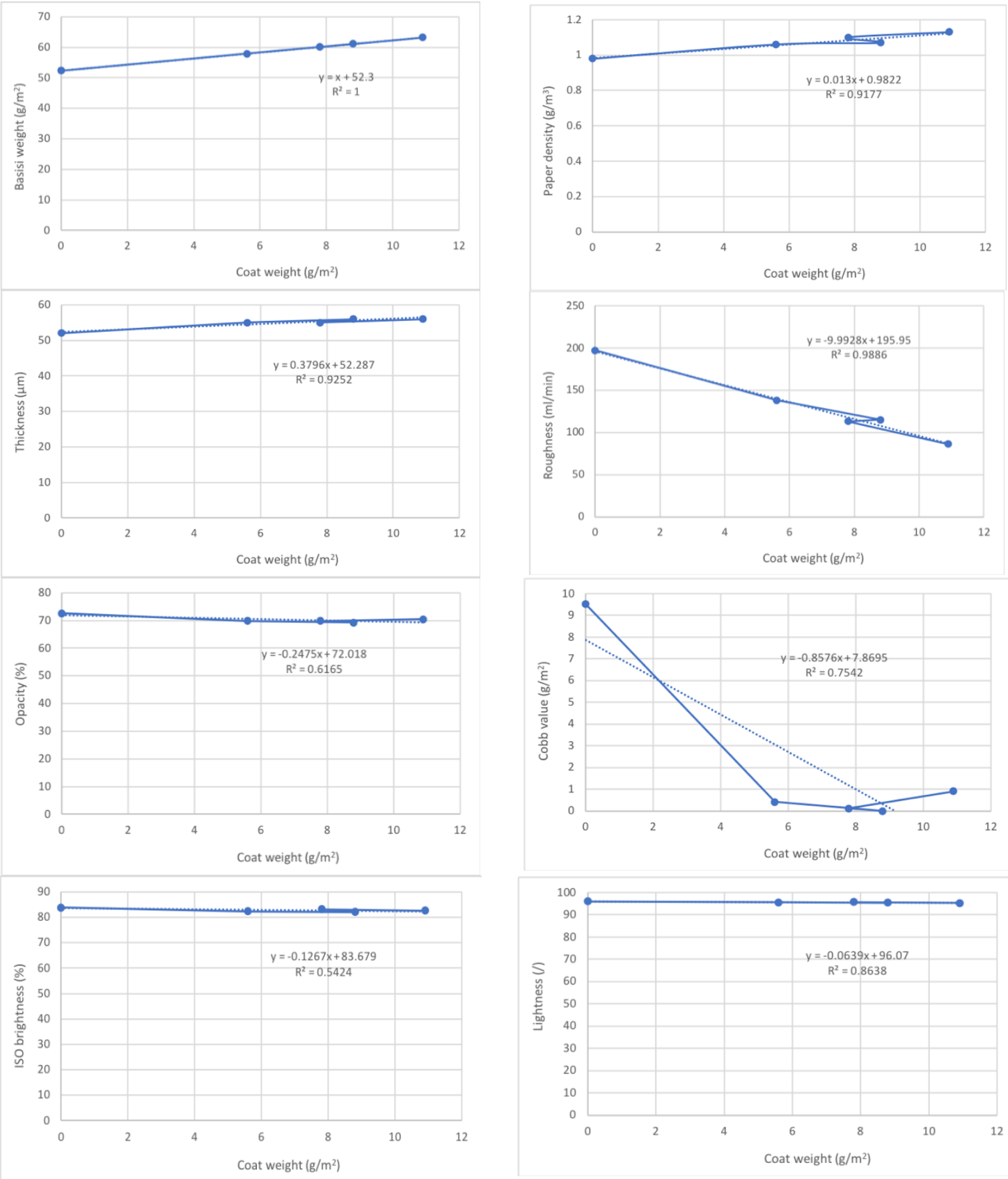

Figure 4: Dependence between coat weight and paper properties 


\section{CONCLUSIONS}

In the present research, packaging paper was made by coating the base paper with the PLA solution, with two different concentrations. The comparison with the commercial packaging paper has shown that similar surface properties were obtained. The influence of coating on optical properties of paper is small, roughness and brightness decrease a little, opacity is higher, colour change is negligible. The analysis has shown, that already lower concentrations of PLA solution enable uniform coating, which lowers permeability and gives good barrier properties to water. Higher concentrations of PLA solution further improve barrier properties, but also has a drawback. Because in this case, the non-uniformity of coated surface also increases, the variation in paper properties is higher. The results of analysis have shown that eco-friendly packaging paper with good resistance to water can be obtained by coating with a suitable concentration of PLA solution.

\section{ACKNOWLEDGMENTS}

This work was supported by the Slovenian Research Agency (Programme P2-0213).

\section{REFERENCES}

[1] Birkeland, J.: "Design for sustainability", (Earthscan, London, 2002.)

[2] Envirowise, Packguide: a guide to packaging eco-design, Incpen. URL: http://www.packagingfedn.co.uk/images/reports/Incpen\&Envirowise\%20Guide\%20to\%20Packaging \%20Eco\%20Design.pdf (last request: 2020-06-21.).

[3] Khwaldia K., Arab-Tehrany E., Desobry, S.: "Biopolymer Coatings on Paper Packaging Materials", Comprehensive reviews in food science and food safety 9 (3), 82-91, 2010. doi: 10.1111/j.15414337.2009.00095.x.

[4] McDonough, W., Braungart, M.: "Cradle to cradle: remaking the way we make things", (Vintage, London, 2009.).

[5] Park, S-I., Lee, D.S., Han, J.H.: "Innovations in Food Packaging", (Academic Press, 2014.), pages 537-547.

[6] Rastogi, V.K., Samyn, P.: "Bio-Based Coatings for Paper Applications", Coatings 5 (4), 887-930, 2015. doi: 10.3390/coatings5040887.

[7] Vartiainen, J., Motion, R., Kulonen, H., Ratto, M., Skytta, E., Ahvenainen, R.: "Chitosan-coated paper: effects of nisin and different acids on the antimicrobial activity", Journal of Applied Polymer Science 94, 986-93, 2004. doi: 10.1002/app.20701.

[8] Vukić, N., Erceg, T., Teofilović, V., Nikolić, L., Cakić, S., Simendić, B., Ristić, I.: "The use of the green chemistry concept in the synthesis of packaging material based on polylactide", Proceedings of GRID 2018, (Faculty of Technical Sciences: Novi Sad, Serbia, 2018), pages 281-287.

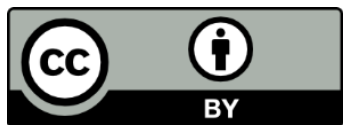

(C) 2020 Authors. Published by the University of Novi Sad, Faculty of Technical Sciences, Department of Graphic Engineering and Design. This article is an open access article distributed under the terms and conditions of the Creative Commons Attribution license 3.0 Serbia (http://creativecommons.org/licenses/by/3.0/rs/). 



\title{
ECO-FRIENDLY MATERIAL FOR PACKAGING
}

\author{
Laura Gegeckienè, Ingrida Venyte \\ Kaunas University of Technology, Faculty of Mechanical Engineering and Design, Department \\ of production engineering, Kaunas, Lithuania
}

\begin{abstract}
At the moment there exists a predominant prevalence of the combined packaging (i. e. cardboard is covered with polyethylene) in the food packaging market, which provides the necessary barrier properties for a packaged product. However, there also exist a great number of problems regarding the issue such as packaging sorting, recycling, waste management, and economic losses. According to the latest data, 65 enterprises in Lithuania are currently working in the recycling industry. They can recycle different types of packaging.

The issue of ecology is highly relevant in the printing industry. It is not a secret that the global population is growing rapidly. As the demand for food and non-food product packaging increases, the production volume increases accordingly. In the future, it is expected that the volume of packaging production will increase accordingly. MMK cardboard can be called a revolution in the industry of packaging. Until now, packaging which has direct contact with food must be laminated with films such as PE. Plastic waste is one of the most common types of waste that takes a very long time to decompose. Normally, plastic packaging can take up to several hundred years to decompose in landfills, while cardboard is easily recyclable and takes up to half a year to biodegrade.

The aim of this research is to investigate the physical and mechanical properties and characteristics (in order to offer analog materials in the perspective) of the new materials with the necessary properties and compared to the properties of the most using materials.
\end{abstract}

Key words: environmentally friendly, MMK cardboard, force

\section{INTRODUCTION}

Water and air pollution have reached critical levels in much of the world's cities. Consequently, the chemicals in question are intensively depleting the ozone layer of our planet. Thanks to the scientists and the efforts of environmentally friendly institutions, the public is educated and encouraged to nurture nature, to understand its importance and potential threats. In the face of increasing education and human soprano about the importance of ecology, it can be assumed that people will pay even more attention in the future organic materials, for example, will choose a product that will be labeled as biodegradable packaging. In this case, the label that decomposes in an extremely fast time, instead of standard labels/packaging with a decomposes time of even a few hundred years.

\section{METHODS}

MMK cardboard was developed in late April 2016 in Frohnleiten, Austria (MMK, 2020). The main essence of this packaging material is to maintain different types of barrier properties.

The experimental investigation of bending was chosen for that to understand which cardboard as a raw material has the highest resistance on bending fatigue and also that to compare MMK cardboard mechanical properties to other most frequently used cardboard in the packaging industry. The following cardboard samples were compared to each other:

- $\quad$ MMK cardboard $305 \mathrm{gr} / \mathrm{m}^{2}$;

- ARKTIKA cardboard $305 \mathrm{gr} / \mathrm{m}^{2}$ - it is GC1 grade cardboard with multiple structures and a double coating on the topside and one layer of coating on the backside, and is printable on both sides (Arktika cardboard characteristics, 2020).

- Ensocoat cardboard $305 \mathrm{gr} / \mathrm{m}^{2}$ - one side fully coated board with a light coating on the reverse. Ensocoat has a strong bleached chemical pulp in a multiply structure (Ensocoat cardboard characteristics, 2020).

- Korsnäs White cardboard $305 \mathrm{gr} / \mathrm{m}^{2}$ - it is coated cardboard and made out of $100 \%$ virgin fiber (double-coated on the top side and single-coated on the reverse side) (Korsnäs White cardboard characteristics, 2020). 
The crushing test was performed using a Tinius Olsen H10KT electromechanical device for testing samples of rubber, metal, plastic, textile, cardboard, and other materials. In the experimental study, 5 samples were used in one sample group. All samples from these packages were acclimatized to $20 \pm 1^{\circ} \mathrm{C}$ for at least 24 hours prior to the test temperature and $50 \pm 3 \%$ humidity. Compression speed $12.5 \mathrm{~mm} / \mathrm{s}$. For packaging with static load, two identical dimensions and liners were chosen:

- MMK cardboard packaging (without barrier properties), $305 \mathrm{gr} / \mathrm{m}^{2}$, dimensions: 7x7x9 cm;

- $\quad$ ARKTIKA cardboard packaging, $305 \mathrm{gr} / \mathrm{m}^{2}$, dimensions: 7x7x9 cm.

\section{RESULTS}

Table 1: Results of the experimental investigation on bending fatigue

\begin{tabular}{|c|c|c|c|c|}
\hline No. & $\begin{array}{c}\text { Name of the } \\
\text { cardboard }\end{array}$ & $\begin{array}{c}\text { Grammage, } \\
\mathrm{g} / \mathrm{m}^{2}\end{array}$ & $\begin{array}{c}\text { Average number of cycles } \\
\text { (longitudinal direction of } \\
\text { the fibers) }\end{array}$ & $\begin{array}{c}\text { Average number of cycles } \\
\text { (transverse direction of fibers) }\end{array}$ \\
\hline 1. & MMK & 305 & 77 & 56 \\
\hline 2. & Arktika & 305 & 1261 & 990 \\
\hline 3. & Ensocoat & 305 & 4211 & 3837 \\
\hline 4. & Korsnäs White & 305 & 3071 & 2785 \\
\hline
\end{tabular}

From the study, we can conclude that the samples cut in the machine direction (MD) of the fibers are on average $12 \%$ stronger than the cross direction (CD) and withstand a higher number of bending cycles. This is because specimens that are cut in the CD direction of the fiber are bent parallel to the fibers, so they break faster.

The dependences of the compressive strength of MMK packaging are shown in Figure 1.

\section{MMK carton static load compressive strength dependencies}

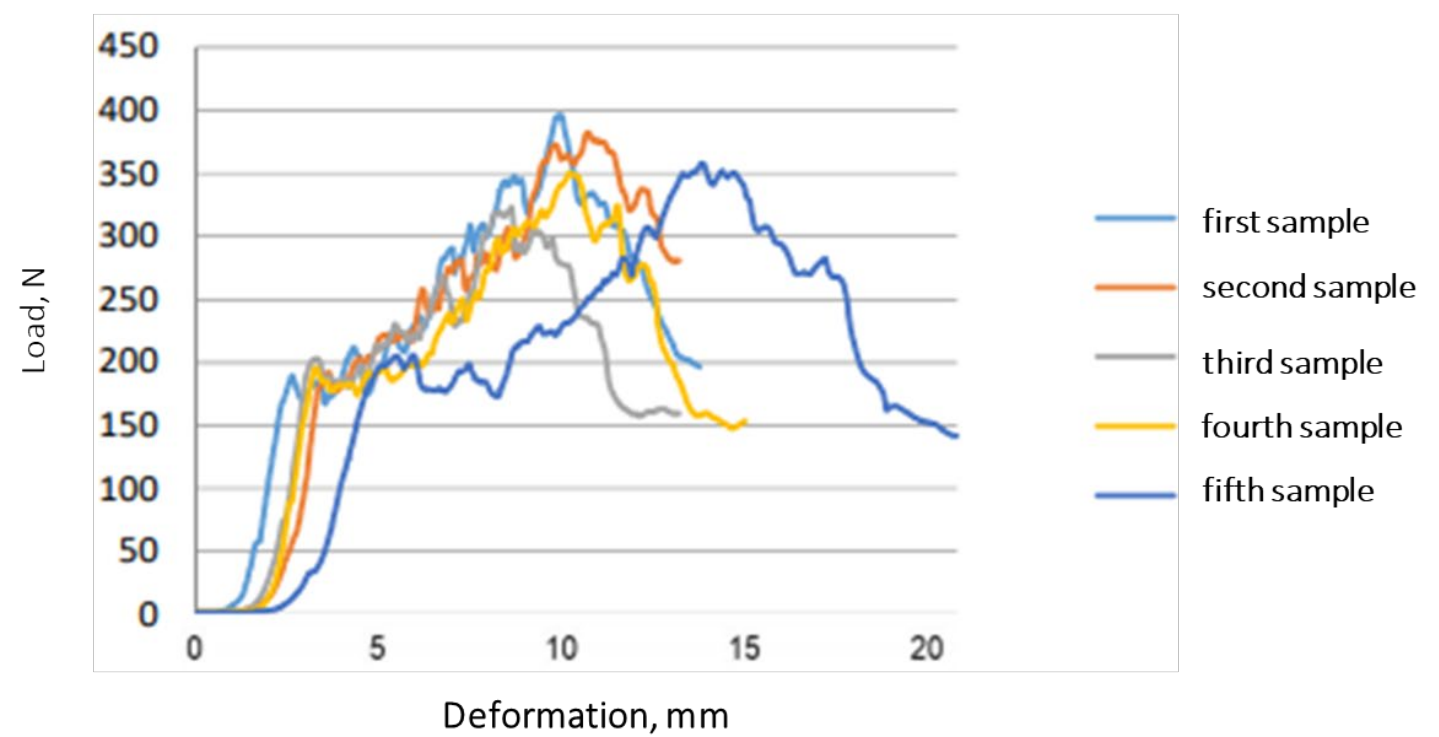

Figure 1: MMK carton static load compressive strength dependencies

As we can see from the graph for all five analyzed packaging results are similar. Initial deformation for MMK carton was observed when $F_{\text {critical }}=195.6 \mathrm{~N}$ (19.56 KG). 
The dependences of the compressive strength of ARKTIKA packaging are shown in Figure 2.

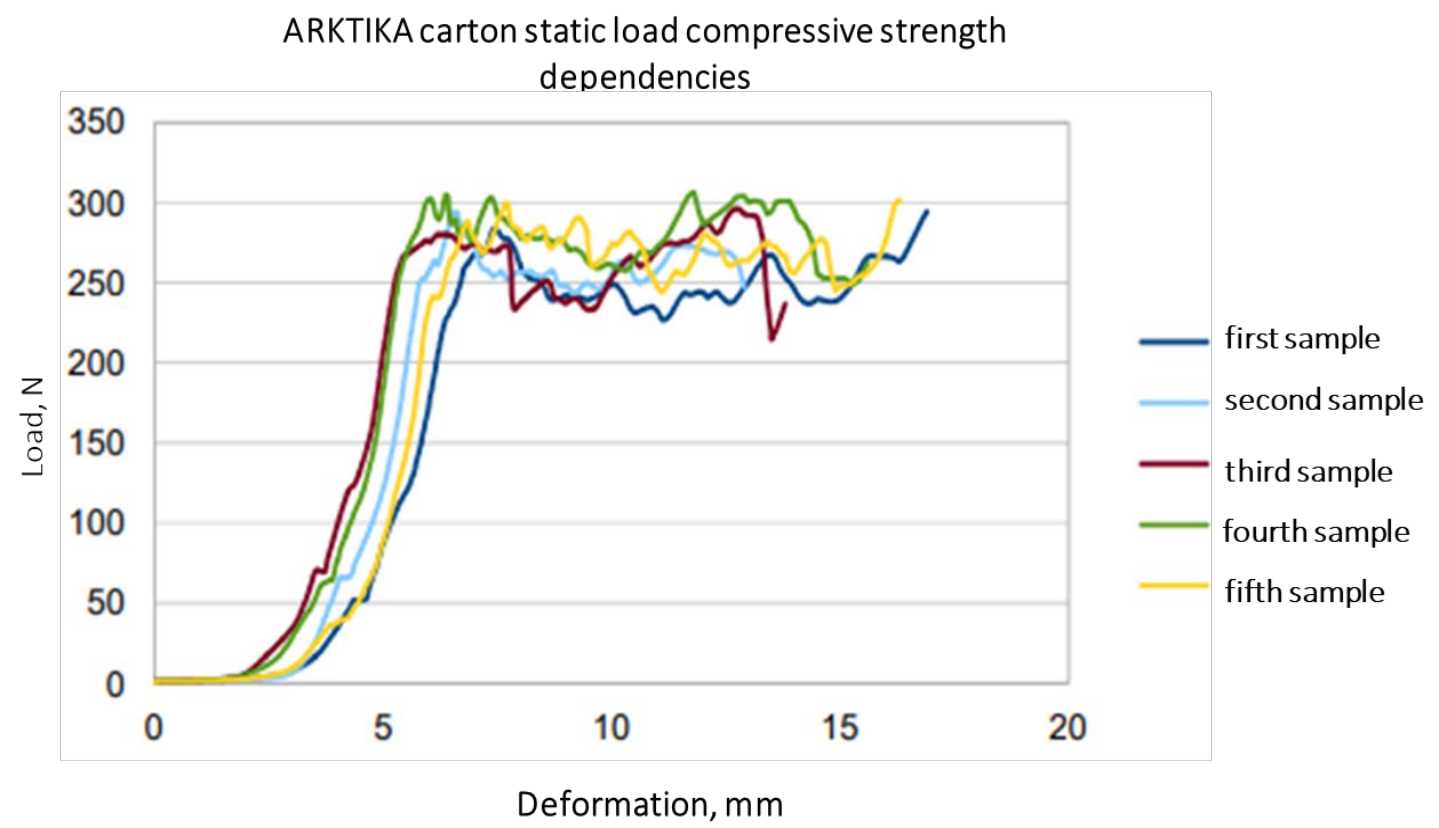

Figure 2: ARKTIKA carton static load compressive strength dependencies

As we can see from the graph, all five ARKTIKA analyzed packaging showed similar experiment results. The initial deformation was observed when $F_{\text {critical }}=300 \mathrm{~N}(30.00 \mathrm{KG})$.

Comparative static load compression strength dependencies are shown in Figure 3.

\section{Comparative static load compression strength dependencies}

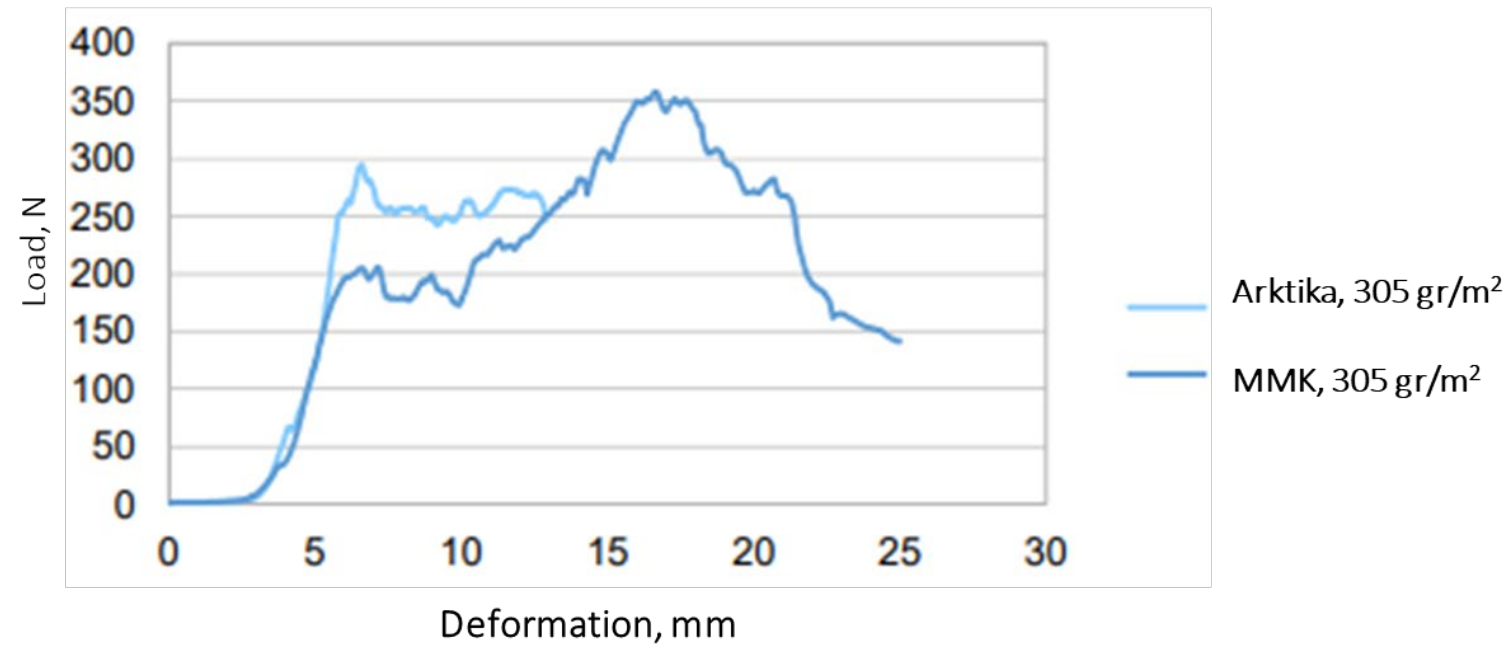

Figure 3: MMK and ARKTIKA carton static load compressive strength dependencies

After performing a crushing test the same size packages, we can conclude that MMK cardboard is less resistant than one of the main packaging raw materials - ARKTIKA cardboard. The graphs show that MMK cardboard can withstand 104.4 N (10.44 kg) less load than ARKTIKA cardboard. 


\section{CONCLUSIONS AND DISCUSIONS}

From the mechanical compression and bending experimental results, we can clearly see that the mechanical effect of the biodegradable MMK cardboard is weaker than the other ordinary materials using in the packaging industry. Decreased strength was shown in the bending test ( 30 times less resistant than other specimens) and the crushing test ( $10 \mathrm{~kg}$ less resistant to load).

However, it is worth considering the growing ecological problem. Primary food packaging that does not require additional PP coating and is biodegradable is better than now ordinary using packaging with PP. And analyzed packaging's are suitable for light products and results show that the critical force it's enough the strength of these types of packaging.

An ecological solution to start using MMK cardboard as a raw material for food packaging would raise the company's reputation vis-à-vis customers and direct competitors, and the company could call itself an environmental organization and thus attract new customers.

\section{REFERENCES}

[1] Arktika cardboard characteristics, URL: https://www.budak.com.tr/upload/specs-international-paper-sun-arktika.pdf (last request: 2020-08-12.).

[2] Ensocoat cardboard characteristics, URL: https://www.paper.co.uk/PremierPaper/media/Graphical-Board/Ensocoat.pdf (last request: 2020-07-15.).

[3] Korsnäs White cardboard characteristics, URL: https://www.antalis.no/mediashare/g4media/pdf/PE_EN_Korsnas_White_EXP_31122013_00.pdf (last request: 2020-07-15.).

[4] MMK cardboard, URL: https://www.mm-karton.com/en/produkte/foodboardtm/ (last request: 2020-08-17.).

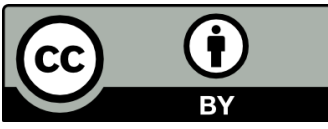

(C) 2020 Authors. Published by the University of Novi Sad, Faculty of Technical Sciences, Department of Graphic Engineering and Design. This article is an open access article distributed under the terms and conditions of the Creative Commons Attribution license 3.0 Serbia (http://creativecommons.org/licenses/by/3.0/rs/). 


\title{
CONSUMER'S EXPERIENCE OF TEA PACKAGING AS ENVIRONMENT-FRIENDLY
}

\author{
Jesenka Pibernik (D), Tamara Tomašegović (D), Sanja Mahović Poljaček (D), Anđela Madžar \\ University of Zagreb, Faculty of Graphic Arts, Zagreb, Croatia
}

\begin{abstract}
The packaging design is perceived as environmentally friendly when deploying established "green" conventions for design, materials, form, colours, and symbolism. The paper aims to determine which tea packaging design choices mainly influence consumer's impression of eco-friendliness. After the sustainable solutions for packaging form were examined, additional attributes of sustainability in terms of the materials were established. These were the shape of the packaging for the ease of use, closing solution, content visibility, printing paper perception, and other use-friendly attributes. Upon experimenting with six versions of prototype designs, following the guidelines of user-centered design, the final prototype has been selected for further development and testing. The alternatives for appropriate printing ink, printing pressure, and substrate were tested on various paper samples. Due to the various recycled substrate's surface colours and morphology, the flexographic printing process resulted in various shades of image colours and line sharpnesses. To determine correlations between different attributes and make a final design decision, the subjective quality assessments were implemented.
\end{abstract}

Keywords: Tea Packaging, User-centered Design, Eco-friendly, Recycling, Evaluation

\section{INTRODUCTION}

Packaging waste is a dominant contributor in today's world and responsible for half of the waste in the globe (Hannah and Roser, 2020). Due to the problems the waste creates for the environments, consumers are increasingly associating sustainability with higher quality and awareness. One group of consumers that are significantly concerned about environmental pollution and packaging attributes are organic tea consumers. Due to its graining substance, the tea can be packaged in a variety of ways having in mind that the design and materials of the package contribute significantly to the perception of sustainability. Filter bags are often applied to differentiate the portions. The tea filter bags are packaged in paper, a combination of paper and plastic, or a combination of paper, plastic, and aluminum, so-called multilayer packaging. Besides, each filter bag generally has a thread sewn onto the bag or joined with a small metal. At the end of the thread, there is a paper with a print that is often coated. The coating, as well as the paint, make it difficult to decompose, which makes the product less eco- friendly. Therefore, bulk tea packaging is considered a eco-friendlier solution.

Aluminum and tinplate, combined or laminated, is often used for the bulk tea packaging. The metal is soft enough to be easily cut and bent into air-tight containers, which extend the shelf life of the product. The problem with metal packaging is that it does not convey eco-efficienct (Better Meets Reality, 2020). For its price, lightweight and flexibility, cardboard is often used for the smaller amounts of bulk tea packaging. Using recycled paper as raw material for packaging has multiple environmental benefits and economic savings. The cardboard needs to have an additional inner layer for different purposes: aesthetics, prevention of damage and heat, or preservation of freshness. Cardboard packaging can protect the tea against the light in two ways. One way is using a larger amount of paper-based material which will make the layer thicker and denser. The advantage of this is the ease of recycling, and the disadvantage is the use of a larger amount of material. Another way is to use a minimum amount of paper. Such a material can be transparent, which is why it needs a coating or a layer of dark paint on the outer surface which prevents the penetration of light. The downside of this alternative is that the paint and coating need to be removed before recycling.

From an environmental point of view, the most acceptable packaging is a combined packaging made of recycled cardboard and transparent foil. The tea is protected from moisture and heat by a foil that acts as an insulator. Currently, transparent foil and PLA coating are the most common. PLA stands for polylactic acid and is a resin made from corn starch which is not bio-degradible (BioSphere Plastic, 2020). It is degradable only in industrially produced conditions. Temperature must be $70^{\circ} \mathrm{C}$ or higher and humidity must be $70 \% \mathrm{RH}$ at least. So PLA is not an option for eco-friendly solution. The transparent foil is usually separated from the material that protects the tea from light and joined only at the ends of the packaging while the middle is free. Such packaging can be completely recycled if the foil is sorted into containers 
intended for that purpose. The economy of space is important, as well as safety concerns. The package must preserve and protect the tea from moisture and exposure to oxygen, it must be practical, but it also needs an artistic presentation to attract gourmet shoppers. Packaging must balance substance and style with the sense that buying the product makes consumers feel they belong to a special group (Better Meets Reality, 2020). Minimalism is an effective aesthetic for designing sustainable packaging.

To determine which tea packaging design choices mainly influence consumer's impression of ecofriendliness we have conducted the three steps experiment. The tea packaging final design decision was based on the results of several iterations of prototype testing, the consumer's interview, and the questionnaire.

\section{METHODS}

\subsection{User-centered design process}

The user-centered design process for packaging resulted in six successive prototypes. Each prototype was tested and subsequently improved. The process began with the interview of a group of six eco-friendly tea consumers. Their experiences with tea packaging provided the designer with valuable insights. Some of the opinions the consumers shared were:

- The common tea packaging container is high and narrow, which makes it impractical.

- The additional elements for closing often crack.

- $\quad$ The consumers prefer the content to be visible from the outside.

Based on the input, the packaging designer created the first solution for the final container in the shape of a five-sided prism with a closing solution without the use of additional materials (Figure 1). The shape of the prism made the packaging more resistant to material defects and overturning, and strong enough so that thinner paper is required. The closed packaging additionally retained the tea freshness because it was shrunk at the top. The corresponding dieline template layout was appropriately created to use the maximum space of the printing format (Figure 2).

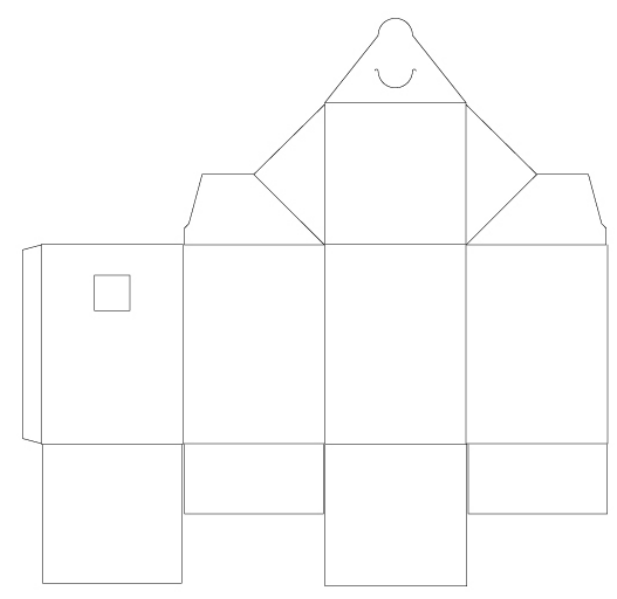

Figure 1: The first testing prototype

For the second solution, the distance of the "closing" valve was prolonged. The lateral sides were beveled for greater convenience (Figure 3). For the third solution, the opening was reduced and a different approach for closing was made (Figure 4). Connected flaps that overlap during closing were impractical because they created resistance to closing by accumulating materials that are interconnected. The bottom of the fourth design was reconfigured since it turned out to be a weak point during the testing (Figure 5). The fifth solution was designed with lateral sides to compresses the opening, which significantly reduced the possibility of the accidental fall out of content. When opened, the packaging expanded, making it more convenient to use. The width of the opening depended on the thickness of the paper because in case of bends and stretches the cracking could occur. The closing flap was problematic 
as corners were found to break very quickly (after only a few openings and closures) (Figure 6). Therefore, in the final design (sixth prototype), the first solution of the closing valve was re-applied. The bottom sides overlapped, which secured the contents, especially because only the inner side will be glued with cellophane, while the other sides will be glued paper to paper (Figure 7). The end on the closing cutout was reduced from half a circle to $3 / 4$ of its size (Figure 8 ).

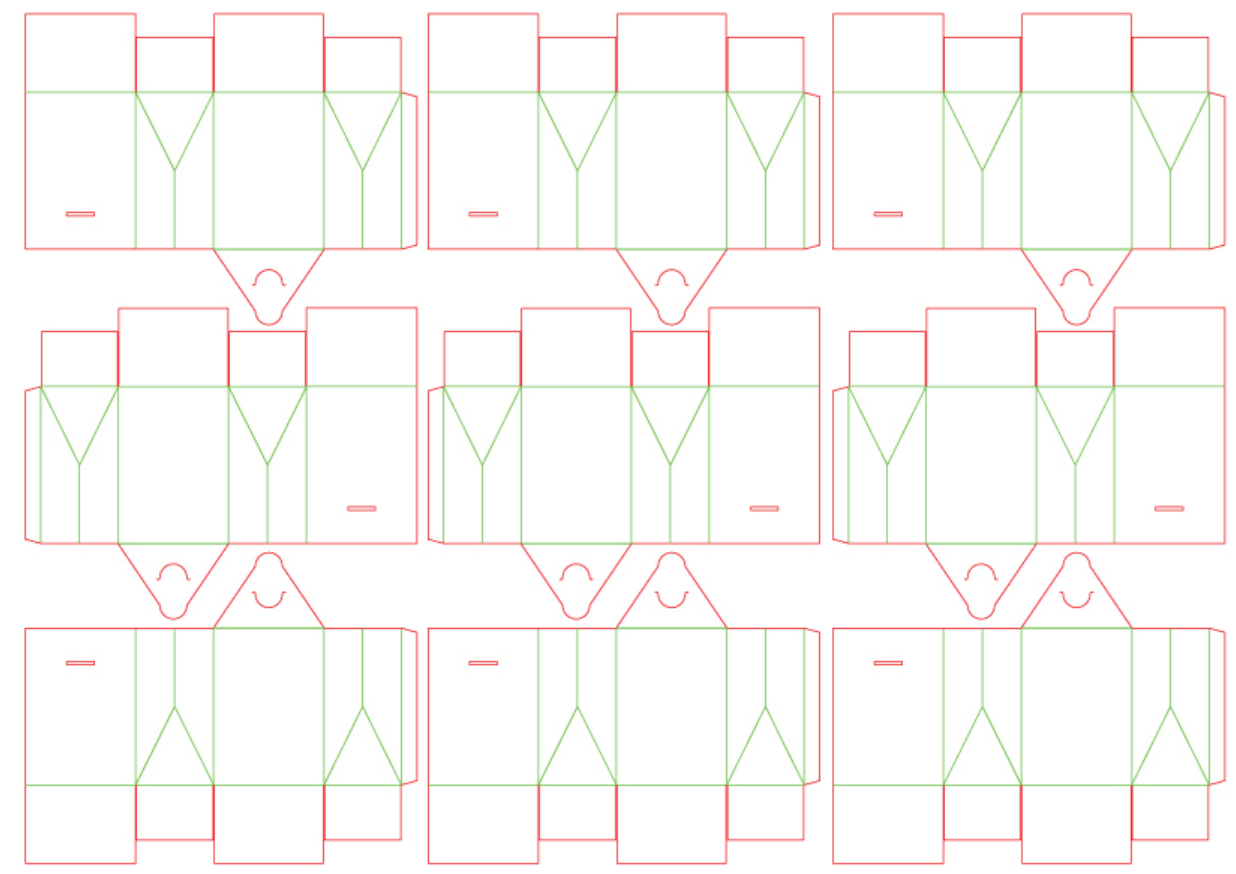

Figure 2: The third testing prototype

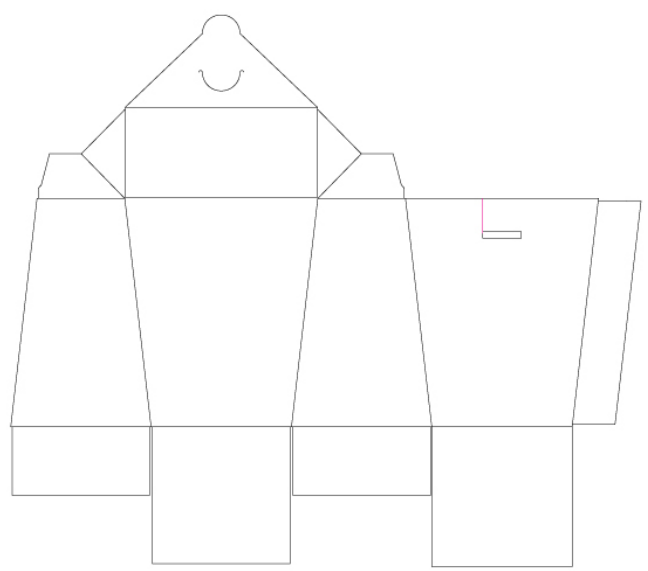

Figure 3: The second testing prototype 


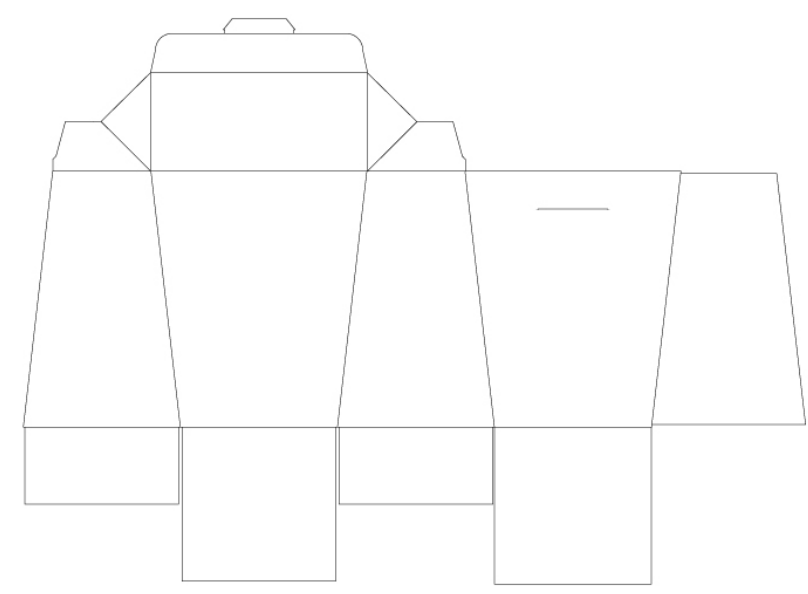

Figure 4: The third testing prototype

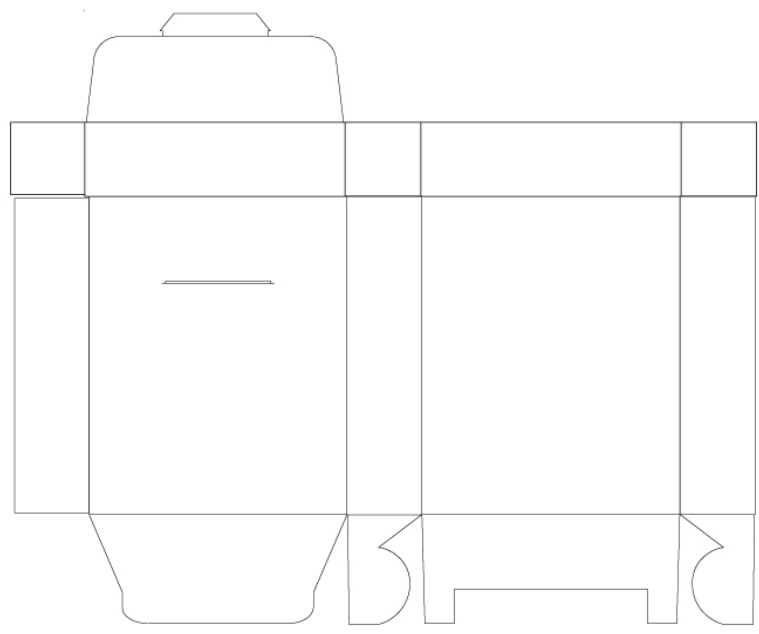

Figure 5: The fourth testing prototype

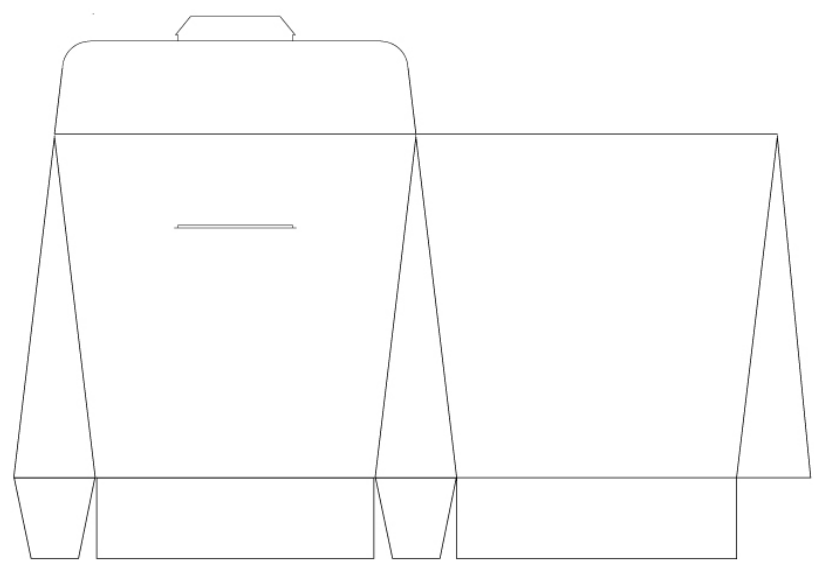

Figure 6: The fifth testing prototype 


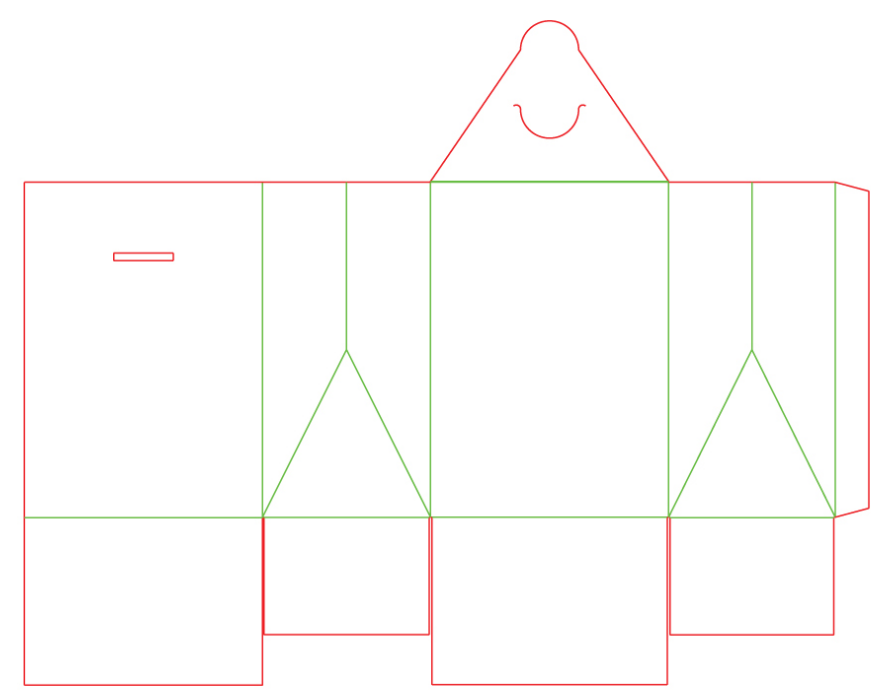

Figure 7: The sixth, final testing prototype

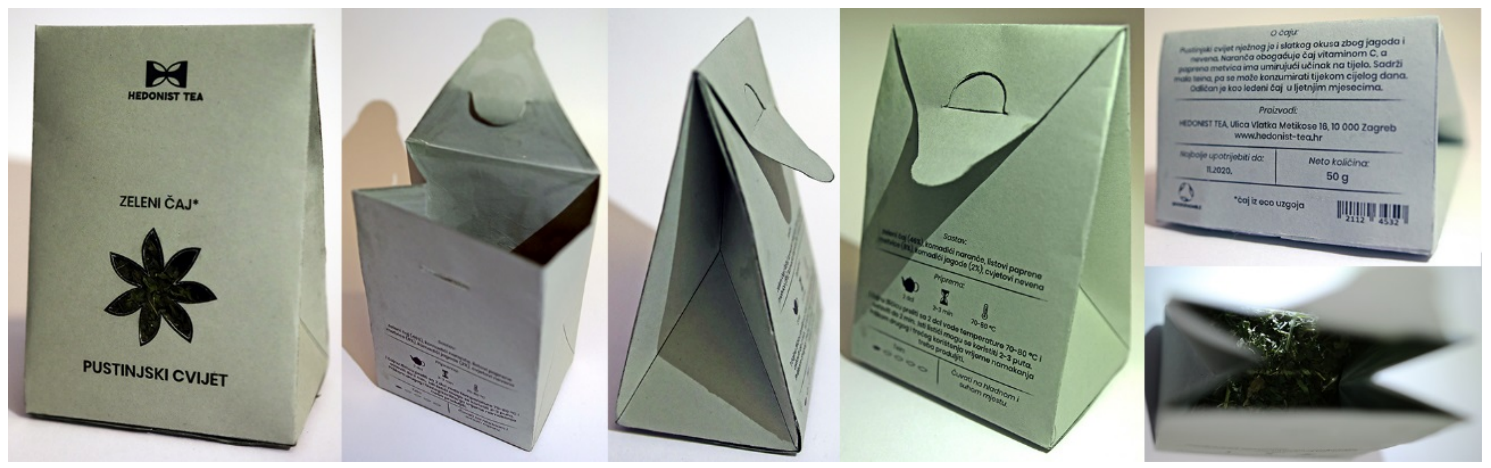

Figure 8: The final packaging design

\subsection{The binder, substrate, ink, and printing process selection}

Modern ecological binders show equal or better mechanical properties than non-ecological ones (Gasket,2020). Some of the options considered were solvent-free water-based adhesives with a low content of volatile organic compounds, solvent-free adhesives with a low content of volatile organic compounds or dextrin, and other natural starch-based adhesives. Each group had several types of adhesives to choose from. Water-based binders may be based on homopolymers, copolymers, polyvinyl alcohol, cohesive latex, etc. (Bond Tech Industries,2020).

The best choice is binders that can be composted. The product that can be composted must have the "OK compost" logo. This logo complies with the requirements of the EU Packaging Directive (94/62 / EEC). The certificate is obtained according to the European standard: EN 13432: 2000 for the packaging of composted material. In addition to the binders, this also applies to dyes and all other additives in the packaging industry.

After selecting the composting binder, an adequate dye should be selected. This choice is connected to the printing process and substrate selection. For this research, five recycled papers were selected (CordenonS, 2020; Cosper, 2020; Forest Stewardship Council, 2020; Mohawk, 2020; Felix Schoeller Group, 2020). Testing prototypes were made of paper $80 \mathrm{~g} / \mathrm{m} 2,100 \mathrm{~g} / \mathrm{m} 2,130 \mathrm{~g} / \mathrm{m} 2,140 \mathrm{~g} / \mathrm{m} 2,220$ $\mathrm{g} / \mathrm{m} 2$ and $300 \mathrm{~g} / \mathrm{m} 2$. After functional testing, we concluded that $80 \mathrm{~g} / \mathrm{m}^{2}$ was too thin and cracked after several uses, $300 \mathrm{~g} / \mathrm{m}^{2}$ was too stiff and thick to use, and the paper of the remaining weights was taken for further testing.

Data on papers can be seen in Table 1. Each paper has a Forest Stewardship Council certificate that "promotes the environmentally friendly, socially beneficial and economically sustainable management of the world's forests" (Forest Stewardship Council, 2020). All papers were recycled and uncoated. 
Flora papers are made of $30 \%$ of pulp that has been subjected to deinking flotation twice, $60 \%$ of primary woodless pulp, and $10 \%$ of cotton fibers (Cordenons, 2020). Since all papers were uncoated, the surface was rough, which is why etching and flexographic printing were considered. For the printing process to be truly environmentally friendly, attention should be paid to the way the printing plate is made, as well as to the compatibility of the printing plate with the used printing substrate (Sherin, 2008). Due to the elasticity of the printing plate, flexographic printing which offers the possibility of laser engraving of the printing plate was chosen. The plate is directly engraved with a laser, without the development process or use of aggressive solvents and harmful wastewater. The printing plate was made by the manufacturer Birkan $\mathrm{GmbH}$. It is made of EPDM material. EPDM is an elastomer - polymer synthetically obtained from ethylene, propylene, and a small proportion of one diene, and it is characterized by exceptional resistance. It is resistant to aging, the influence of the atmosphere, high and low temperatures, and electrical penetration, which means that the plate can be used for a long time.

Table 1: The papers characteristics and sample tagging

\begin{tabular}{|l|l|l|l|l|l|}
\hline PAPER/PRESSURE & A & B & C & D & E \\
\hline BRAND & MOHAWK & FLORA & FLORA & SCHOELLERS & SCHOELLERS \\
\hline COLOR & white & avorio & gigilio & light brown & dark brown \\
\hline WEIGHT & $220 \mathrm{~g} / \mathrm{m}^{2}$ & $130 \mathrm{~g} / \mathrm{m}^{2}$ & $100 \mathrm{~g} / \mathrm{m}^{2}$ & $140 \mathrm{~g} / \mathrm{m}^{2}$ & $140 \mathrm{~g} / \mathrm{m}^{2}$ \\
\hline $50 \mathrm{~N}$ & A1 & B1 & C1 & D1 & E1 \\
\hline $150 \mathrm{~N}$ & A2 & B2 & C2 & D2 & E2 \\
\hline $400 \mathrm{~N}$ & A3 & B3 & C3 & D3 & E3 \\
\hline
\end{tabular}

Printing took place at the Faculty of Graphic Arts in the laboratory for printing forms on the device: IGT Printability Tester F1. The samples measuring $5 \times 70 \mathrm{~cm}$ were cut from each paper. The pressure of the anilox roller on the printing plate was a constant of $300 \mathrm{~N}$. Each of the five papers was imprinted with three different pressures $(50 \mathrm{~N}, 150 \mathrm{~N}$, and $400 \mathrm{~N}$ ) to obtain 15 different imprint samples (Table 1). The most eco-friendly ink would be water-based, but due to the limitations of laboratory conditions, UV ink was used. The advantage of UV inks is fast drying without creating VOC (volatile organic) compounds. UV inks are in liquid form and need to be UV-cured before further use. They were dried in a UV dryer by Aktiprint $L$ with a radiation spectrum of UV lamps with a radiation intensity of $60 \%$. The drying speed was $4 \mathrm{~m} / \mathrm{s}$, with two passes during drying. The UV ink used for printing is PANTONE $363 \mathrm{U}$. The LAB value for this ink is: $L=50.19 ; a=-24.88$ and $b=24.05$. $L A B$ values of each sample are displayed in the HEX colour (Figure 9). The shades indicate that Group A imprints have the most similar values to PANTONE $363 \mathrm{U}$ colour. A1, B1, and C1 sample $L$ value is increased, which means that the colours are brighter. D1 and E1 have the lowest value of a, which means that these imprints colours contain the least green pigment.

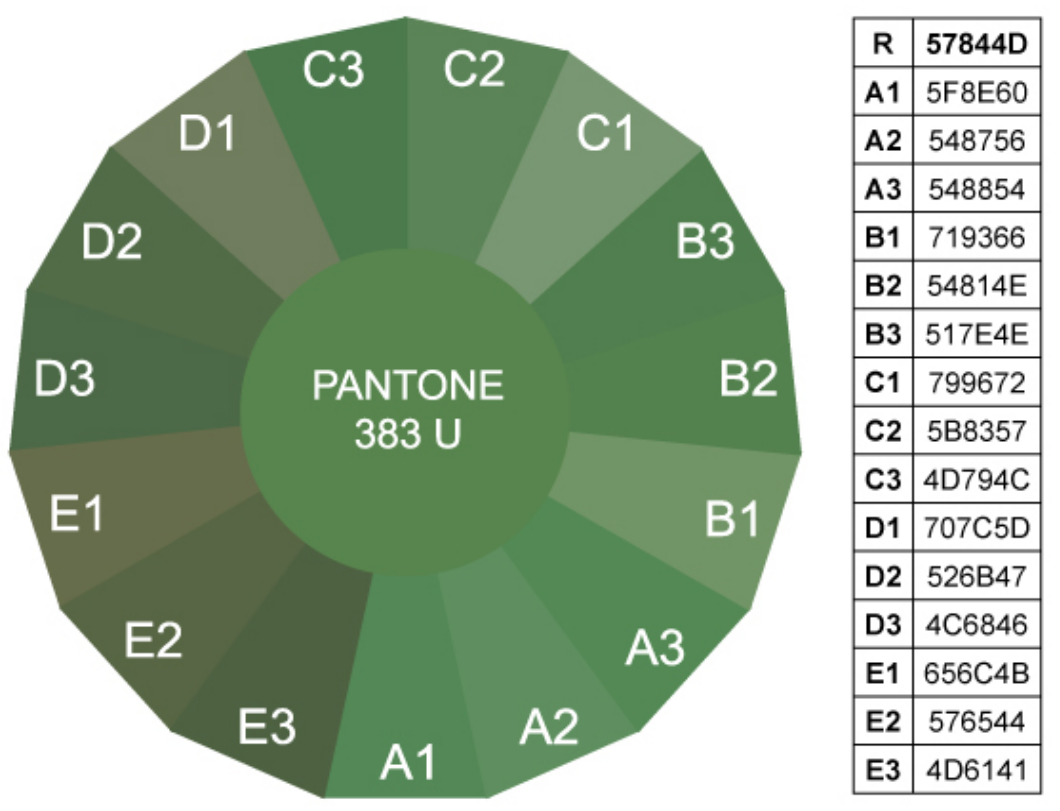

Figure 9: $L A B$ values of each paper displayed in the HEX colour system 


\subsection{Consumer experience testing process}

The survey aimed to find out target consumers' attitudes towards the eco-friendliness of several tea packaging attributes. The survey was conducted on 31 participants, 21 females, 9 males. Most of the respondents were between 21 and 26 years old, and the oldest respondent was 49. As far as education is concerned, they are evenly distributed: 11 respondents have secondary education, 10 higher education, and 10 university education. The participants were chosen from the group of people who care about the environment, who recycle or separate waste, at the same time they were people who consume and buy tea in bulk. Each of the participants was given the packaging without a print. The packaging was made on $140 \mathrm{~g} / \mathrm{m}^{2}$ Flora Tabacco paper so that the design would not influence the further decision of the respondents (CordenonS, 2020). Based on the packaging, participants were questioned about their experience. They were given 15 substrate samples (Figure 8) based on which they filled out a questionnaire to determine, in their own opinion, whether each of them was recycled paper. Only after that were the subjects shown the packaging with the imprint (Figure 8).

The packaging with the print was made on gray $135 \mathrm{~g} / \mathrm{m}^{2}$ paper with a black print not to influence the decisions of the respondents. Based on these samples, the participants had to fill in five points Likert scale questionnaire to decide which one was most aesthetically appealing to them, which was the most suitable for packaging and purchasing, and finally which one seemed to them to be the most ecofriendly. At the end of the evaluation, respondents were interviewed again to explain their decisions.

\section{RESULTS}

Paper $\mathrm{C}$ was rated as the most eco-friendly of the five offered, followed by paper $\mathrm{E}$, then $\mathrm{B}$. The paper $\mathrm{A}$ was not chosen as the environmentally friendly because of its pure white colour. Pressure samples of 50 $\mathrm{N}$ were perceived as the most readable on lighter papers (A1, B1, and C1). Pressure samples of $150 \mathrm{~N}$ were perceived as the most readable on darker papers (D2 and E2). The ratings of $50 \mathrm{~N}$ pressure samples were perceived as eco-friendly for the imprint. The imprints of $400 \mathrm{~N}$ were the lowest rated in terms of ecology, aesthetics, and purchase. Sample C2 was rated as the most environmentally friendly, suitable for purchase and packaging, and aesthetically most acceptable, followed by samples D. Paper A received the worst overall rating, was not suitable for purchase nor is it environmentally friendly (Figure 10).

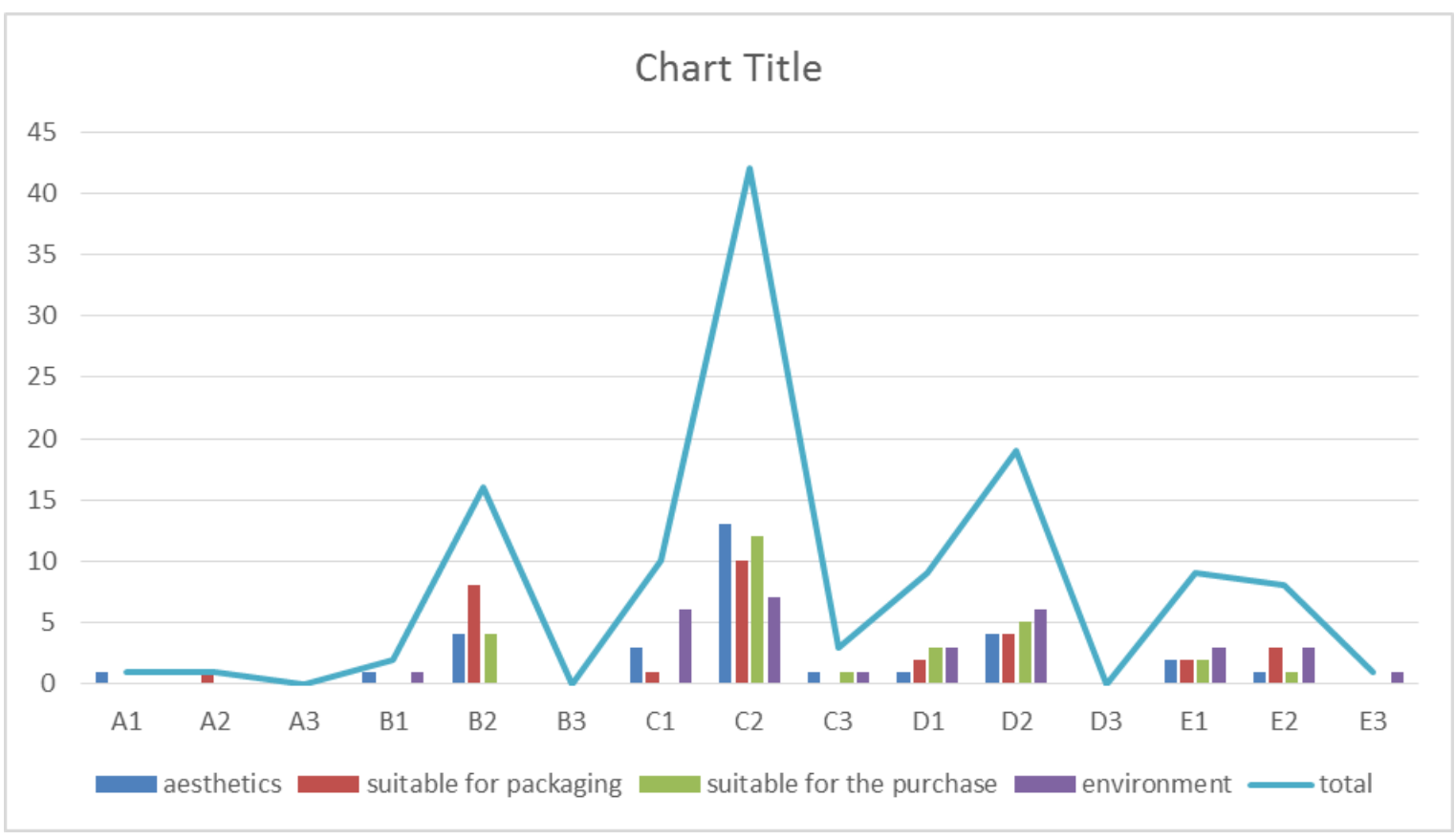

Figure 10: Subjective evaluation results 
All respondents said they would buy packaging. Some explanations were:

"The packaging is a compact, attractive, and a good size to use."

"It's great that the packaging expands after opening. That's how I get tea without any problems. "

"It is practical and opens well. It's nicely lined on the inside. It seems easy to use and provides longlasting storage."

"I would buy it to avoid creating waste because it is biodegradable and recyclable and because it is simple and closes functionally."

"The packaging is more compact and more beautiful than the others that exist on the market. It's great that there are no extra parts to close. "

"I like what can be opened and closed again indefinitely, which makes it practical and I like the look."

Some explanations for the preference of $\mathrm{C} 2$ sample were:

"Somehow this middle one seems to be the most appropriate, the most attractive and the most recycled ..."

"It looks the most natural and the least harmful to the environment."

"I like the colour and the pattern of the paper. The text is visible, and it is in good combination with the paper. It also looks appealing to me as a tea container. "

"It's not an offensive shade, it's a gentle tone. It looks natural and recycled. The green tone of the print can be seen beautifully and in contrast."

"This pattern is the most readable, has a good contrast of text and background, looks the most environmentally friendly, and is very attractive to buy."

"I like the colour and quality of the paper. The print is nicely printed and easy to read."

\section{DISCUSSION}

The user-centered design process enabled the consumers to test and choose the most usable and appropriate packaging form, paper, and printing pressure for eco-friendly tea packaging. Of the five papers with eco-certificates offered, the respondents chose medium paper by brightness and lightest by weight (paper C) as the most environmentally friendly. White paper of higher weight (paper A) was not perceived as environmentally friendly nor suitable for packaging or purchase. Dark recycled papers, made from paper paste, were not acceptable for consumers unless they are coated, but then they lose on environmental friendliness. On smoother papers, the print is perceived as better even at lower printing pressure, while on rougher papers the print is worse regardless of the pressure. The results of LAB colour measurements have been compared with the original UV ink values to analyze the choices of printing pressure and substrate objectively.

\section{CONCLUSIONS}

The consumers' perception of cardboard tea packaging as eco-friendly is influenced by several attributes. The packaging form, closing and binding solution, paper structure, weight, colour, and the width of the lines in the print all play a significant role in the assessment of environmental acceptability. User-centered design and development were proven as a successful framework of processes in which usability goals and the environmental concerns were given extensive attention at each stage of the process. The consumers' choices have shown that the best papers are those in neutral colours with visible fibers as the indication that they are made with a share of recycled paper.

\section{REFERENCES}

[1] Better Meets Reality: "How Many Times Can You Recycle Different Materials? (Plastic, Paper, Metal, Glass, etc.)“, URL: https://www.bettermeetsreality.com/how-many-times-can-you-recycle-differentmaterials-plastic-paper-metal-glass-etc/ (last request: 2020-28-05).

[2] Biosphere Plastic: "Is PLA Compostable?", URL: http://www.biosphereplastic.com/biodegradableplastic/uncategorized/is-pla-compostable/ (last request: 2020-28-05). 
[3] Bond Tech Industries, Eco-Friendly Adhesives: "What makes and eco-friendly adhesive?", URL: https://www.bond-tech-industries.com/about-us/blog/eco-friendly-adhesives/ (last request: 202028-05).

[4] Gasket: "EPDM - tablica karakteristika materijala", URL: http://gasket.hr/documents/EPDM_tablica.pdf (last request: 2020-28-05).

[5] Cordenons: "Flora ecofriendly", URL: http://www.gruppocordenons.com/en/products/schedaprodotto.html?id=2496\&brand_id=38 (last request: $2020-28-05$ ).

[6] Cosper, A.: "Food Packaging - Suitable Materials for presenting tea, coffee, and spices", URL: https://www.desjardin.fr/en/blog/food-packaging-suitable-materials-for-presenting-tea-coffee-andspices\#: :text=Cardboard\%2C\%20like\%20glass\%2C\%20tinplate\%20and,moisture\%20and\%20exposu re\%20to\%20oxygen (last request: 2020-28-05).

[7] Forest Stewardship Council: "About us", URL: https://www.fsc.org/en/page/about-us (last request: 2020-28-05).

[8] [8] Mohawk: "Mohawk's Environmental Program Attributes", URL: https://www.mohawkconnects.com/education/resources/environment (last request: 2020-28-05).

[9] Felix Schoeller Group: "Protection of resources", URL: https://www.felixschoeller.com/en_en/company/sustainability/environment/protection-of-resources.html (last request: 2020-28-05).

[10] Hannah, R., Roser, M.: "Plastic Pollution", Our World in Data, URL: https://ourworldindata.org/plastic-pollution (last request: 2020-28-05).

[11] Sherin, A.: „SustainAble: a handbook of materials and applications for graphic designers and their clients", (Rockport Publishers, Inc., Beverly, Massachusetts, 2008).

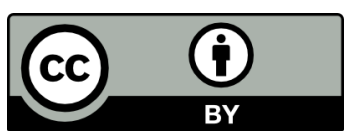

(C) 2020 Authors. Published by the University of Novi Sad, Faculty of Technical Sciences, Department of Graphic Engineering and Design. This article is an open access article distributed under the terms and conditions of the Creative Commons Attribution license 3.0 Serbia (http://creativecommons.org/licenses/by/3.0/rs/). 



\title{
PROMOTIONAL PACKAGING FROM CARTON OF INVASIVE ALIENT PLANT
}

\author{
Kaja Klančar, Urška Vrabič Brodnjak \\ University of Ljubljana, Faculty of Natural Sciences and Engineering, Department of Textiles, \\ Graphic Arts and Design, Ljubljana, Slovenia
}

\begin{abstract}
In this research, the design of innovative promotional packaging made of carton, which was made from the invasive, non-native acacia is presented. The entire planning process was based on the principle of ecological design. One of the main objectives was to create an innovative and versatile ecological product, a calendar that does not require any adhesive in its composition. The basic, mechanical, surface and structural properties of the ecological carton with a high grammage made of acacia compared them with the most commonly used one-side coated white cardboard made of wood fibres has been analysed. The result of this work is the environmentally friendly multi-purpose promotional packaging, the calendar, which could also be used as a storage place for pens and other office supplies.
\end{abstract}

Key words: bio based polymer, eco design, analysis, material.

\section{INTRODUCTION}

The main function of packaging is to store and protect the product during transport, storage, use and external influences. Together with the product, it must form a whole, and its construction must be simple, original and functional. It can be made of various materials and also economic efficiency should be taken into consideration (Shah et al, 2013; Tencati et al, 2016, Schoonbrood et al, 2016). The importance of packaging has increased rapidly in recent years, as thousands of new products are launched each year. Advanced technological development and the use of new materials and design processes have brought the importance of packaging to a higher level. The original purpose, to protect and inform the product, was to take the form of advertising and appeal to the purchase decision. Packaging has thus become an integral part of the product, the basis of advertising and an important marketing tool offering a wide range of business opportunities (Kumar et al, 2017; Hahladakis and lacovidou, 2018; Hawkins, 2020; Shekhar and Raveendran, 2016).

Promotional packaging is characterized by its innovative, unique shape, design or even interactivity, which makes it stand out from the crowd. This includes products that leave a lasting impression, gift packaging that is a gift in itself and sales packaging that educates, motivates or pampers.

Nowadays, the market offers us a wide range of materials that can be used to produce promotional and gift packaging. It can be chosen between paper, cardboard, paperboard, carton, glass, metal, wood, plastic, etc. The choice of material is usually based on the properties and usability of the product, although several materials can also be combined (Tomar and Gaur, 2017; Hawkins, 2020).

The aim of the research was the production of an environmentally friendly promotional product, which does not require an adhesive in its composition, but includes guidelines for sustainable development after use. A calendar for the promotional product, which we wanted to transform into an unusual image, in order to achieve more functionality and user-friendliness has been made.

The primary material for the production of the final product-the promotional packaging was carton made from fibres of invasive alien plant acacia (Nentwig et al, 2017). One-sided coated carton made of wood fibres was used for comparison, as it is better known and most commonly used in the production of packaging.

On the basis of measurements of ecological acacia carton and one-side coated wood fibre board, the analysis of basic (basis weight, thickness, density), mechanical (resistance to cracking, bending stiffness), surface (roughness, porosity, surface absorption), water and structural properties (capillary absorption) have been carried out.

It has been found that organic acacia carton is suitable for lighter packaging forms that do not require greater strength. Despite its softer structure, lower tensile strength, its great advantage is its hydrophobicity, since without coating it has very similar (non-)absorbency results to wood fibre boards coated on one side. In addition to functionality, the appearance of packaging is also important. Its ecological elements make it stand out from the mass of promotional gifts or packaging. It is designed for easy handling, contains a minimalist and transparent design, and moreover the product is designed for 
multi-purpose use. By designing such products, we would certainly contribute to reducing the amount of packaging waste, thus reducing the negative impact on the environment.

\section{MATERIALS AND METHODS}

\subsection{Materials}

To manufacture the final product two different cartons were used, as described below.

Sample 1 (S1)

The first sample used for the final product was a high-grade carton from an invasive plant species, the acacia. It was produced within the European APPLAUSE project, namely at the Institute of Pulp and Paper in Ljubljana.

Sample 2 (S2)

The second sample used was a $300 \mathrm{~g} / \mathrm{m}^{2}$ white wood folding carton, coated on one side: with a glossy coated side $A$ and a matt finish on $B$ side.

\subsection{Methods}

At the research analysis of the materials (sample 1 and 2) such as grammage, thickness, density, bursting resistance, roughness, porosity and absorptiveness were performed.

\subsubsection{Basic properties (grammage, thickness and density)}

Grammage of samples was determined in accordance with the ISO 536 standard. The thickness of samples was with a precision digital micrometre, to the nearest $0.0001 \mu \mathrm{m}$ at 10 random locations on each paper measured. Both analysis done at whole package and separately for each layer, where necessary.

\subsubsection{Bursting strength}

The method was performed according to the SIST EN ISO 2758: 2014 standard. It determines how much pressure is needed to break through paper or cardboard. For each sample, 10 specimens were analyzed.

\subsubsection{Roughness and porosity}

The roughness was determined by Bendtsen method which determines the amount of air ( $\mathrm{ml} / \mathrm{min}$ ) that passes between the measuring ring of the measuring head of the apparatus and the surface of the test piece. Higher airflow along the surface of the test specimen means greater surface roughness. The method was performed according to the ISO 8791-2: 2013 standard.

The porosity analyzed by Bendtsen method determines the amount of air $(\mathrm{ml} / \mathrm{min})$ that passes through the test piece. In general, it is about permeability or. absorbency of the printing material, which affects the speed and quality of absorption of the printing ink. The method was performed according to the ISO 5636-3: 2013 standard.

\subsubsection{Absorptiveness (Cobb value)}

Absorptiveness (the Cobb60 value, $\mathrm{g} / \mathrm{m}^{2}$ ) was determined as described in the standard method ISO 535. For each sample packaging, 10 sample tests were made.

After that the development and design of promotional packaging has been proceeded, using program Engview Package and Display Designer and cutter Esko Kongsberg.

\section{RESULTS AND DISCUSSION}

\subsection{Material analysis}

From Table 1, which presents the results of the basic properties of the samples, it can be seen that the sample of S2 is slightly thicker than the sample S1, while it also has a higher basis weight and density. The weight of the sample S2 is $298.2 \mathrm{~g} / \mathrm{m}^{2}$, density of $743 \mathrm{~kg} / \mathrm{m}^{3}$, a thickness measured $0.402 \mathrm{~mm}$, while the 
basis weight of the sample S1 is $210.9 \mathrm{~g} / \mathrm{m}^{2}$, density of $526 \mathrm{~kg} / \mathrm{m}^{3}$, a thickness of $0.401 \mathrm{~mm}$. In addition to the thickness, which strongly influences the density of the material, the amount of trapped air in the structure of the material, finishing, the binding capacity of the fibers and the substances that fill the gaps in the material also play an important role.

Table 1: Average value, standard deviation and coefficient of variation of the basic properties of samples S1 and S2.

\begin{tabular}{|c|c|c|c|c|}
\hline \multicolumn{2}{|c|}{} & $\begin{array}{c}\text { Grammage } \\
{\left[\mathrm{g} / \mathrm{m}^{2}\right]}\end{array}$ & $\begin{array}{c}\text { Thickness } \\
{[\mathrm{mm}]}\end{array}$ & $\begin{array}{c}\text { Density } \\
{\left[\mathrm{kg} / \mathrm{m}^{3}\right]}\end{array}$ \\
\hline \multirow{3}{*}{ S1 } & $\bar{x}$ & 210.9 & 0.401 & 526 \\
\cline { 2 - 5 } & $\mathrm{S}_{\mathrm{x}}$ & 3.393 & 0.009 & 9.730 \\
\cline { 2 - 6 } & $\mathrm{CV}[\%]$ & 1.61 & 2.26 & 1.85 \\
\hline \multirow{3}{*}{ S2 } & $\overline{\mathrm{x}}$ & 298.2 & 0.402 & 743 \\
\cline { 2 - 6 } & $\mathrm{S}_{\mathrm{x}}$ & 3.208 & 0.004 & 9.943 \\
\cline { 2 - 6 } & $\mathrm{CV}[\%]$ & 1.08 & 1.01 & 1.34 \\
\hline
\end{tabular}

Higher values in the S2 sample were expected, as higher grammage and density required more puncture pressure. In addition, the shorter fibres present in the composition of sample S1 reduce the crack resistance, so the values here in this sample are lower.

Table 2: Average value, standard deviation and coefficient of variation of bursting resistance of samples S1 and S2 on $A$ and $B$ side.

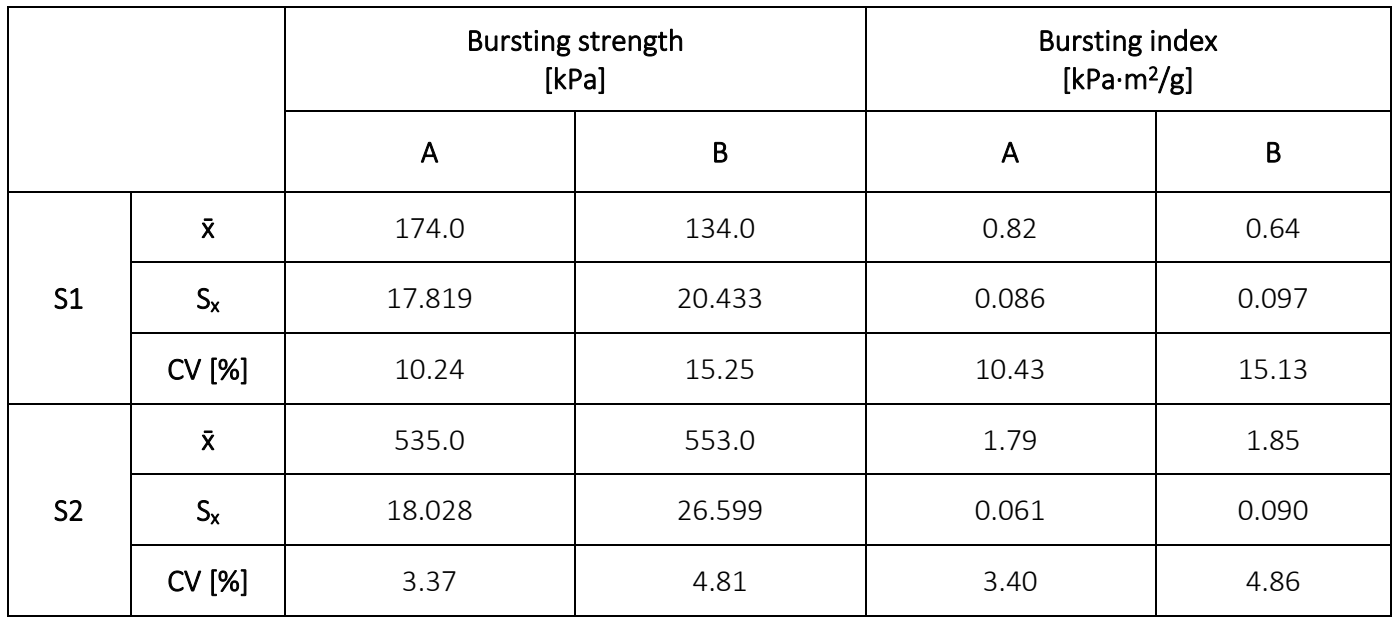

The roughness indicated in Table 3 for sample $\mathrm{S} 2$ is $56.5 \mathrm{ml} / \mathrm{min}$ on side $\mathrm{A}$ and $123.0 \mathrm{ml} / \mathrm{min}$ on side $\mathrm{B}$. The A-side has a glossy coating so that the roughness is lower than on the B-side, which is more matte. The sample $\mathrm{S} 1$ is much rougher and measures $2124.0 \mathrm{ml} / \mathrm{min}$ on side A and $2090.0 \mathrm{ml} / \mathrm{min}$ on side B. A greater roughness was expected in sample S1, since the difference between the samples already scans the tactile properties. Furthermore, sample S1 is made of organic material (acacia plant parts) and does not contain any subsequent processing such as smoothing, coating, etc. 
Table 3: Mean value, standard deviation and Bendtsen roughness and porosity of samples S1 and S2.

\begin{tabular}{|c|c|c|c|c|c|}
\hline & & \multicolumn{2}{|c|}{$\begin{array}{l}\text { Roughness } \\
{[\mathrm{ml} / \mathrm{min}]}\end{array}$} & \multicolumn{2}{|c|}{$\begin{array}{l}\text { Porosity } \\
\text { [ml/min] }\end{array}$} \\
\hline & & $A$ & B & A & B \\
\hline \multirow{3}{*}{ S1 } & $\bar{x}$ & 2124.0 & 2090.0 & 1220.0 & 1195.0 \\
\hline & $S_{x}$ & 122.9 & 126.5 & 42.2 & 43.8 \\
\hline & CV [\%] & 5.8 & 6.1 & 3.5 & 3.7 \\
\hline \multirow{3}{*}{ S2 } & $\bar{x}$ & 56.5 & 123.0 & 0 & 0 \\
\hline & $S_{x}$ & 13.8 & 24.1 & 0 & 0 \\
\hline & $\mathrm{CV}$ [\%] & 24.3 & 19.6 & 0 & 0 \\
\hline
\end{tabular}

Table 4, which shows the water absorptiveness, shows that in the sample S1 measures $88.0 \mathrm{~g} / \mathrm{m}^{2}$ on side $A$ and $82.0 \mathrm{~g} / \mathrm{m}^{2}$ on side $B$, while in the sample $S 2$ measures $78.0 \mathrm{~g} / \mathrm{m}^{2}$ on side $A$ and $84.0 \mathrm{~g} / \mathrm{m}^{2}$ on side $B$. The difference between the sides is small for both samples, namely $6 \mathrm{~g} / \mathrm{m}^{2}$. The absorptiveness is higher on side A in sample $\mathrm{S} 1$ and on side B in sample S2, which is not glossy coated.

Based on the measurement results we can say that both samples have a poor absorption capacity. Both samples are well glued, as the amount of water absorbed in the cardboard paper is very low. Acacia fibres are less absorbent, which is also confirmed by the surface absorption results of sample S1.

Table 4: Mean value, standard deviation and coefficient of variation of water absorption by the Cobb methodabsorptiveness on samples $\mathrm{S} 1$ and $\mathrm{S} 2$.

\begin{tabular}{|c|c|c|c|c|c|c|c|}
\hline & & \multicolumn{2}{|c|}{ A } & \multicolumn{2}{|c|}{ B } & \multicolumn{2}{|c|}{$\begin{array}{l}\text { Absorptiveness } \\
C_{60}\left[\mathrm{~g} / \mathrm{m}^{2}\right]\end{array}$} \\
\hline & & $\mathrm{m}_{1}[\mathrm{~g}]$ & $\mathrm{m}_{2}[\mathrm{~g}]$ & $\mathrm{m}_{1}[\mathrm{~g}]$ & $\mathrm{m}_{2}[\mathrm{~g}]$ & A & B \\
\hline \multirow{3}{*}{ S1 } & $\bar{x}$ & 4.6 & 5.5 & 4.6 & 5.5 & 88.0 & 82.0 \\
\hline & $S_{x}$ & 0.114 & 0.084 & 0.055 & 0.089 & 8.367 & 4.472 \\
\hline & CV [\%] & 2.46 & 1.52 & 1.18 & 1.64 & 9.51 & 5.45 \\
\hline \multirow{3}{*}{ S2 } & $\bar{x}$ & 6.5 & 7.3 & 6.5 & 7.4 & 78.0 & 84.0 \\
\hline & $S_{x}$ & 0.045 & 0.055 & 0.084 & 0.055 & 8.367 & 5.477 \\
\hline & CV [\%] & 0.69 & 0.75 & 1.28 & 0.74 & 10.73 & 6.52 \\
\hline
\end{tabular}

\subsection{Design and the production of final packaging}

In spite of many solutions with the lid and flaps, the final design of the packaging, which is shown in Figure 1, was finally successful. The originally designed construction had 12 flat plots and a perforated lid. The inner flaps were redesigned and arranged alternately on the lid. In order to facilitate handling and to give an innovative image, we have added a perforated cut-out to the lid, which is intended for inserting pens. 


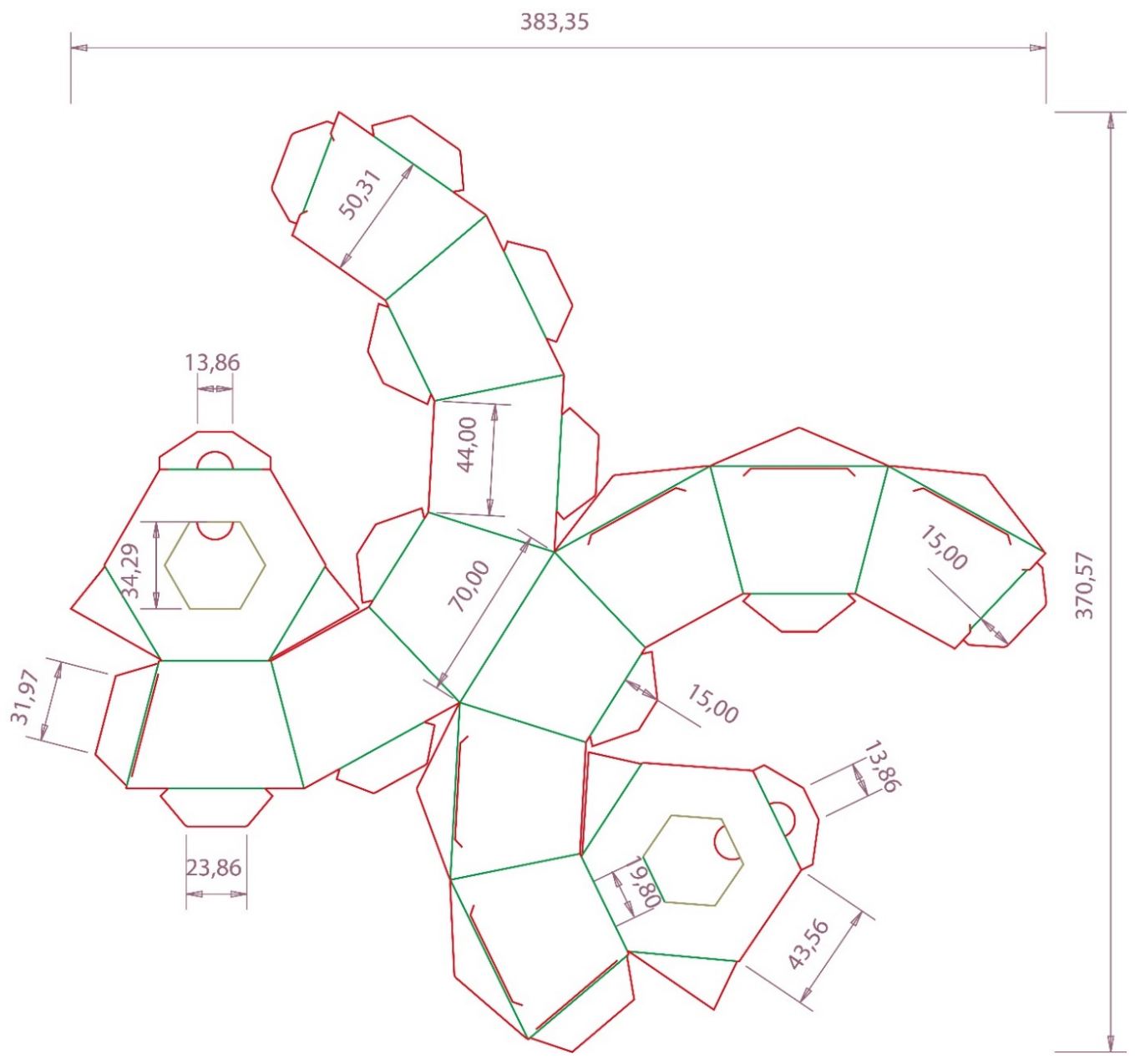

Figure 1: Construction of the final packaging (dimensions are in millimeters)

The drawn construction from the EngView Package \& Display Designer program to the Adobe Illustrator CC 2018 program has been exported. Firstly a calendar, for each month separately has been designed (Figure 2). For the numerical display the linear font Quicksand and displayed names of the months in a Cookie-Regular font that resembles handwriting has been used. The months were arranged over 12 flat plots. Each month was designed on a side surface that had the shape of an isosceles trapezium. The design details also included the illustration of detailed acacia leafs.
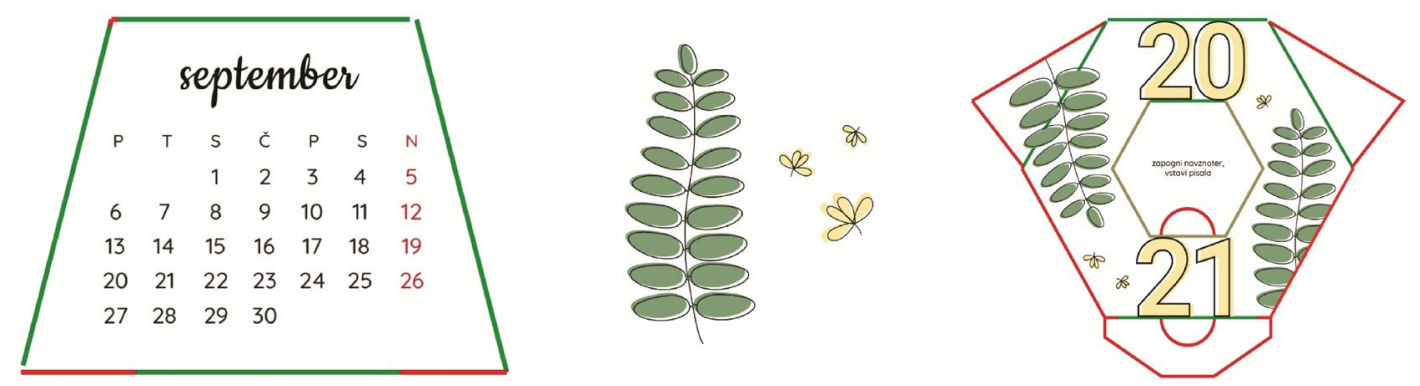

Figure 2: Design details of the packaging

The printed and cut sheet was used to produce the final product as shown in Figure 3. It was folded according to the creasing lines and assembled into the final packaging without adhesive. 

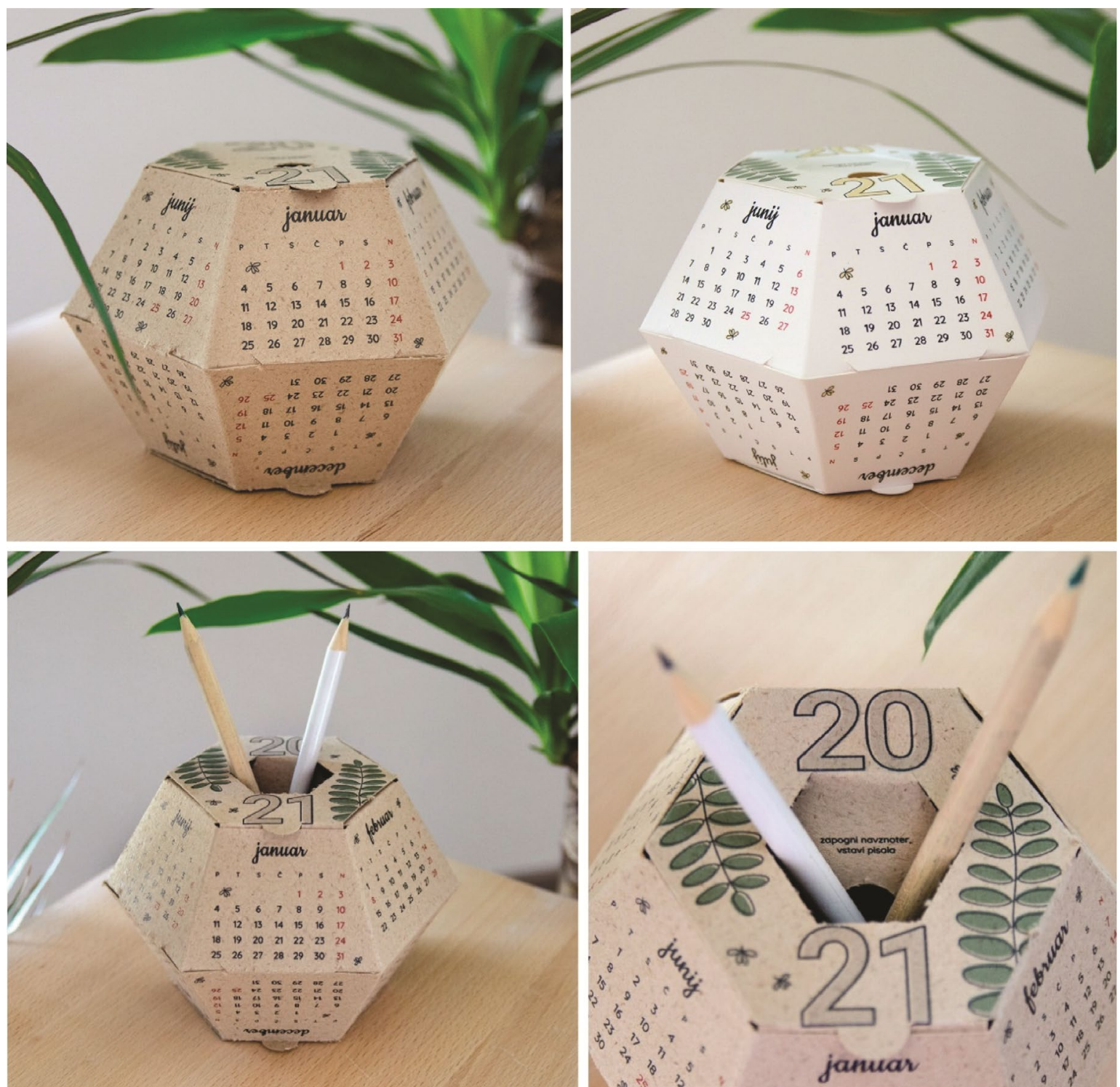

Figure 3: Final printed packaging on both carton samples

\section{CONCLUSIONS}

The main objective was to use the carton of an invasive alien plant - acacia - and more functional form of the calendar. The used high grade ecological carton from acacia was also tested and its basic, mechanical, surface and structural properties were compared with the most commonly used one-side coated carton from wood fibers. It was found that ecological acacia carton is suitable for lighter packaging forms that do not require higher strength. Despite its softer structure or lower strength, its great advantage is its hydrophobicity, since without coating it has very similar (non-)absorption results to single-sided coated wood fiber boards.

In addition to functionality, the appearance of packaging is also important. Its unusual shape and ecological elements make it stand out from the mass of promotional gifts or packaging. It is designed for easy handling, contains a minimalist and transparent design, and moreover the product has a sustainable knowledge as it is designed for multi-purpose use. By designing such products, we would certainly contribute to reducing the amount of packaging waste, thus reducing the negative impact on the environment. 


\section{ACKNOWLEDGMENTS}

The research was supported by the European project Applause (Alien Plant Species from harmful to useful with citizens' led activities) and University of Ljubljana, Faculty of Natural Sciences and Engineering, Department of Textiles, Graphic Arts and Design.

\section{REFERENCES}

[1] Hahladakis, J. N., lacovidou, E.: "Closing the loop on plastic packaging materials: What is quality and how does it affect their circularity?", Science of the Total Environment 630, 1394-1400, 2018. doi: 10.1016/j.scitotenv.2018.02.330

[2] Hawkins, G.: "Detaching from plastic packaging: reconfiguring material responsibilities", Consumption Markets \& Culture, 1-14, 2020. doi: 10.1080/10253866.2020.1803069

[3] Kumar, M., Agarwal, A., Singh, P.: "Green packaging and marketing in promoting agribusiness", Management 3 (1), 2017.

[4] Nentwig, W., Bacher, S., Kumschick, S., Pyšek, P., Vilà, M.: "More than "100 worst" alien species in Europe", Biological Invasions 20 (6), 1611-1621, 2018. doi: 10.1007/s10530-018-1671-x

[5] Schoonbrood, J. M. J.: "Shaping designs: Effects of the graphic design of packaging sales promotion shapes and products' packaging shapes on customers' expectations, pre-purchase attitude and purchase intention", MSc thesis, University of Twente, 2016.

[6] Shah, S., Ahmed, A., Ahmad, N.: "Role of packaging in consumer buying behavior", International Review of Basic and Applied Sciences 1 (2), 35-41, 2013.

[7] Shekhar, S. K., Raveendran, P. T.: "Product Packaging and Competitive Advantage", Asian Journal of Management 7 (1), 1-4, 2016

[8] Tencati, A., Pogutz, S., Moda, B., Brambilla, M., Cacia, C.: "Prevention policies addressing packaging and packaging waste: Some emerging trends", Waste management 56, 35-45, 2016. doi: 10.1016/j.wasman.2016.06.025

[9] Tomar, R. S., Gaur, M. S.: "Packaging-a turnaround way to advertise", Asia Pacific Journal of Research in Business Management 8 (4), 2017.

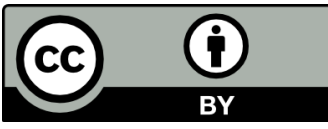

(C) 2020 Authors. Published by the University of Novi Sad, Faculty of Technical Sciences, Department of Graphic Engineering and Design. This article is an open access article distributed under the terms and conditions of the Creative Commons Attribution license 3.0 Serbia (http://creativecommons.org/licenses/by/3.0/rs/). 



\title{
RESEARCH METHODOLOGIES FOR ASSESSING THE ERGONOMICS OF PACKAGING PRODUCTS - A REVIEW
}

\author{
Gordana Bošnjaković (D), Gojko Vladić (D) \\ University of Novi Sad, Faculty of Technical Sciences, \\ Department of graphic engineering and design, Novi Sad, Serbia
}

\begin{abstract}
In today's increasingly competitive market environment, new packaging must meet more requirements than before to meet customer expectations. The packaging must meet not only functional and aesthetic requirements but also ergonomic requirements to ensure satisfying user experience. An important issue in ergonomic design is the identification of factors that lead to user comfort and discomfort. The packaging is a product that undergoes manual manipulation and given the various forms of packaging and it's opening and closing systems, they require using different grip types and movements. Using packaging that is not well designed can cause intense physical exertion and frustration for users. The subject of this paper is a review of methodologies for assessing the ergonomics of packaging products. Methodologies for evaluating the ergonomic characteristics of packaging provide a proposal for structuring the investigation. Also, it gives a proposal for the proper prioritization of a packaging problem that should be identified as the most dangerous risks for physical injuries or for causing stressful situations to users. First, it is necessary to gain a clear insight into how the users handle the packaging in order to create knowledge and a clear idea of what is useful or harmful in the existing packaging design and to find the potential for its improvement. There are various methods for studying, analyzing and evaluating user experience while using a packaging. Combining such methods with knowledge of the anatomical structure of the body and how it reacts to the load enables the creation of efficient and ergonomically designed packaging. This paper will present methodologies and guidelines for assessing and improving the ergonomic qualities of packaging. The aim of this paper is to define the key factors and most relevant methodologies for conducting successful ergonomic research.
\end{abstract}

Keywords: ergonomics, packaging, methods

\section{INTRODUCTION}

\subsection{Ergonomics}

Ergonomics is a scientific discipline that deals with understanding the interactions between people and other elements of the system applying theory, principles, data and design methods, in order to optimize human well-being and overall system performance (Dul, 2008; Chebykin, Bedny and Karwowski, 2008; Bridger, 2003; Salvendy, 2012; Stanton et al, 2014). Knowledge of ergonomic design is focused on the relationship between objects and environments and human factors (Kaljun and Dolšak, 2012). In the human-workplace interaction, the workplace must be adapted to the worker so that he/she can safely perform his/her task. Therefore, the ergonomic design of the workroom, tools, furniture and products (Figure 1) must be based on the anthropometry and biomechanics of the human body (Oyewole et al, 2010; Hashim and Dawal, 2012).

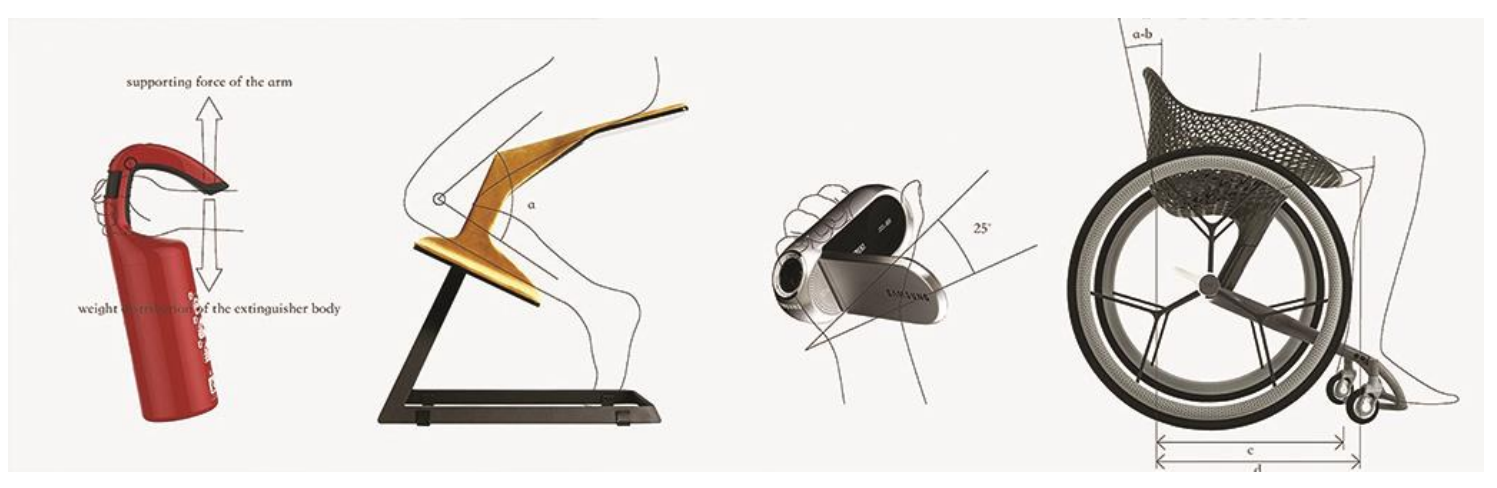

Figure 1: Examples of ergonomically designed products (Points, 2019) 
Anthropometry (Greekanthropos $=$ man, methros $=$ measure) is a bioanthropological method that deals with measuring the physical dimensions of the human body, processing and analysis of the obtained measures. It quantitatively determines the morphological characteristics of the body and provides objective information about the growth state of the examined person (Rogulj et al, 2012; Sudarov and Fratić, 2010). Biomechanics is a science focused on forces and their effects applied to biological systems (Freivalds, 2011). The general goal in the biomechanics of handles and tools is to optimize the relationship between the handle and the user in the sense of ensuring the use of the handle while avoiding the possibility of physiological and musculoskeletal problems (Kumar, 1999). The design, selection and installation of tools, such as those used in production and construction, are often done without considering the specific intensity of the forces required to be applied when using the tool, or any product that is a subject to manual manipulation. It is often done without considering the user's abilities, whether he/she can support the tool and produce necessary forces. Although sometimes these forces can be measured directly while product is in use, this is often not practical and it is preferable to predict the strengths, capabilities, limits, and tolerances of users before using the product (Armstrong et al, 2010).

\subsection{Packaging in interaction with the consumer}

The packaging is an unformed or formed material in which a product is packed, in order to protect it and transport it safely or to make an easier purchase or use of the product (Novaković, 2013). The packaging has reached high quality in terms of the functions it needs to fulfil: protection from external influences, barrier properties, aesthetic functions, providing information and presenting the product that is packed in, etc. However, there is another requirement that packaging should fulfil and that is the ease of opening and use of the product packed in it (Figure 2). Sometimes this is a challenge not only for consumers of the older generation and those who suffer from rheumatoid arthritis and osteoarthritis arthritis, but the entire population sometimes faces a similar problem. To design and produce a packaging that will solve these problems, it is necessary to define the most important factors affecting consumers when opening and using packaging. When the factors are defined, it is necessary to create a packaging design that will be in accordance with these factors. This paper will cover all the important factors that need to be considered during the development of an ergonomic packaging:

- Physical qualifications and consumer capabilities for easy product handling,

- Critical aspects when using the product,

- Methods for researching consumer opportunities and critical aspects when using products and for evaluating the ergonomic characteristics.
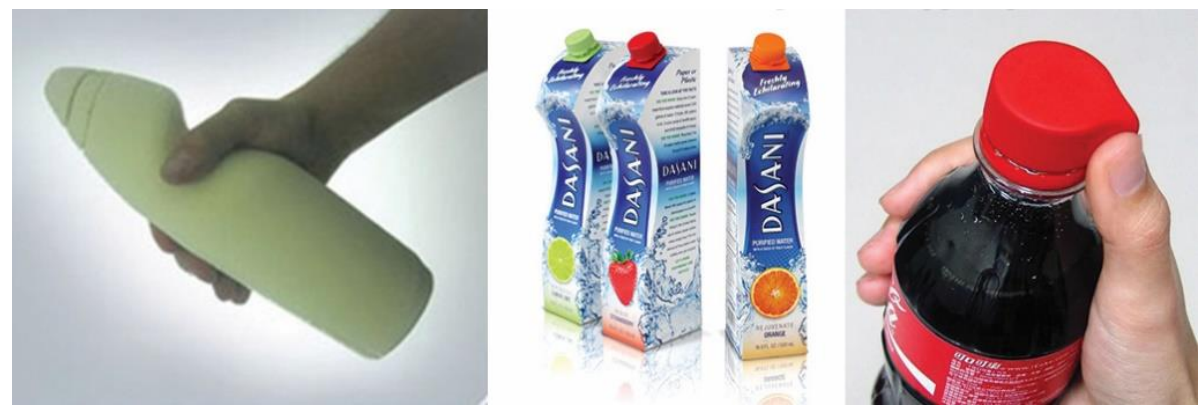

Figure 2: Examples of ergonomically designed packaging

The subject of this paper is a review of methodologies for assessing the ergonomics of packaging products, ie. the methodologies that can be implemented when developing, analyzing and evaluating work tasks and specific products. The methodologies explain how to assess ergonomic characteristics concerning one or more physical load factors. The described methodologies for evaluating the ergonomic characteristics of products provide a proposal for structuring the analysis the investigation and a proposal for approaching prioritization by identifying the greatest risks for physical injuries to users/causing stressful situations. It is first necessary to gain a clear insight into how the consumer uses the product to create knowledge and a clear idea of what is useful or harmful in the existing product design solution and to find the potential for its improvement. There are various methods for studying, analyzing and evaluating users while using a product. Combining such methods with knowledge of the anthropometrics and biomechanics enables the design of efficient and ergonomically designed packaging. 


\section{PHYSICAL QUALIFICATIONS AND CAPABILITIES OF CONSUMERS FOR EASY PRODUCT HANDLING}

Different techniques and methods have been developed and used to measure different aspects of a user's physical qualifications and abilities. Most of them are based on the measurement of human strength using various mechanical devices, which has limitations in their applicability to actual daily activities. Extensive research has been done that includes a series of publications containing ergonomic data for use in the design of consumer products. There are publications on children, adults, and older adults (Norris and Wilson, 1995; Peebles and Norris, 1998; Smith et al, 2000) with human factor data on these three groups and have been used for packaging design, but "gaps" in the data available for direct use in packaging design were discovered. These difficulties have triggered new research and collected new data on user strengths such as finger pressure strength, pull strength, hand grip strength, wrist-twisting strength, and pressure and pull strength (Peebles and Norris, 2003). Research has also been conducted on the difficulties that people with disabilities or people with severe physical difficulties have in everyday life and with this, a number of problematic products have been identified, one of which is packaging (Nordenskiöld, 1996; Rosengren and Brodin, 2013). In addition to identifying the products that people with disabilities had the most problems with, research also identified strategies that people with disabilities had to use while dealing with products. These strategies mainly involved special ways of reaching, grasping and lifting. Often products that require coordinated movement with two hands, e.g. unscrewing the jar of jam was complicated and difficult. Researchers have also tried to gain insight into the types of grips that users typically use (Rowson and Yoxall, 2011). Data on the physical abilities of persons with disabilities for several hand functions can be found in the report "Specific Anthropometric and Strength Data for People with Dexterity Disability" (Consumer and Competition Policy Directorate, 2002). There are significant differences between the abilities of people with disabilities and people without disabilities. In all tests, the strength of healthy people was between two and three times higher that of people with disabilities, which is a significant challenge for packaging designers and manufacturers if they want to produce products that people with disabilities will be able to use with the same degree of ease and convenience that is expected from healthy people. For example, the unscrewing forces of the jar lid should be limited to a torque of only $0.25 \mathrm{Nm}$ so that people with hand limitations can open the product. Also opening a package that involves pulling on small tabs will have to be limited to pulling that requires a force level of approximately $5 \mathrm{~N}$, to match the capabilities of people with hand problems. However, many of the tests used to measure strength do not represent the exact operations used to open the packaging, and human strength is highly dependent on the action being performed. Also, as age increases, strength begins to decline rapidly and even seemingly small changes in material or geometry can have a major impact on the force a person can apply. When the ease of use of a product is viewed from the user's point of view, several factors can be defined that can affect the ease of use of the product: strength in hands, skin sensitivity, dexterity, lefthandedness/right-handedness, coordination, pain, cognition, sight, attention, memory and problem solving, personality. When using the product, consumers are required to use different movements and apply force. Some of the movements that are necessary to avoid are "key grip", "power grip", twisting or rotation of the wrist (Heinö et al, 2008). The position of the whole arm and spine must be considered, especially when it comes to frequent lifting of loads so that muscle and spine injuries can be avoided (Moore et al, 2011). An illustration of the neutral and awkward position of the wrist is given in Figure 3.

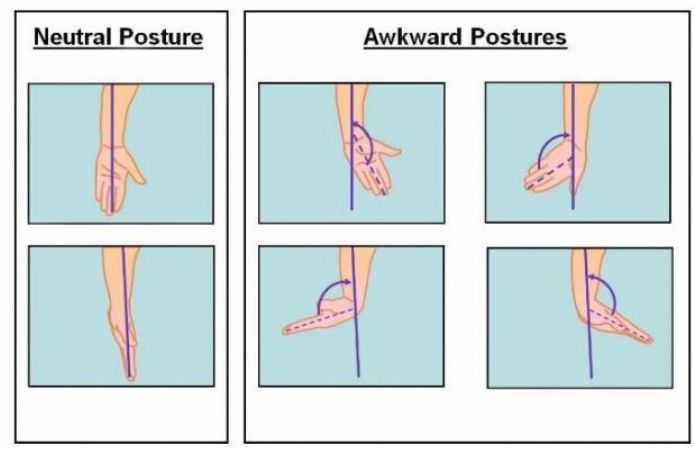

Figure 3: Neutral and awkward wrist position (Moore et al, 2011) 
To get information about human forces, force measuring device, the so-called. dynamometers are often used in research. They come with different extensions suitable for different tasks and equipment and they are relatively inexpensive and easy to use (Figure 4).

a)

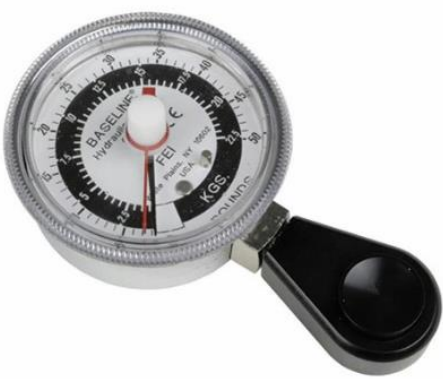

b)

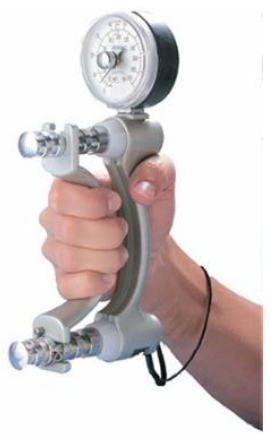

Figure 4: Example of dynamometers for measuring force

a) for thumb and fingers b) for whole hand (Avramović, 2018; Baseline, 2018)

Advanced testing techniques that are used are electromyography (EMG), measuring contact pressure using flexible force sensors, postural technique, etc. (Figures 5 and 6).

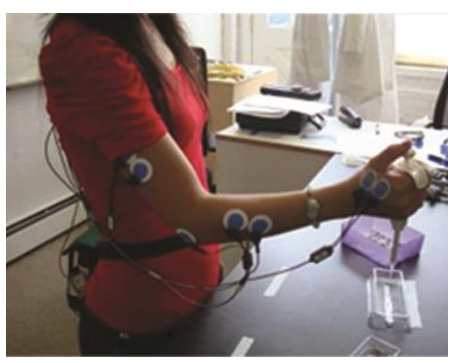

Figure 5: Electromyography equipment (US-Ergo, 2019)

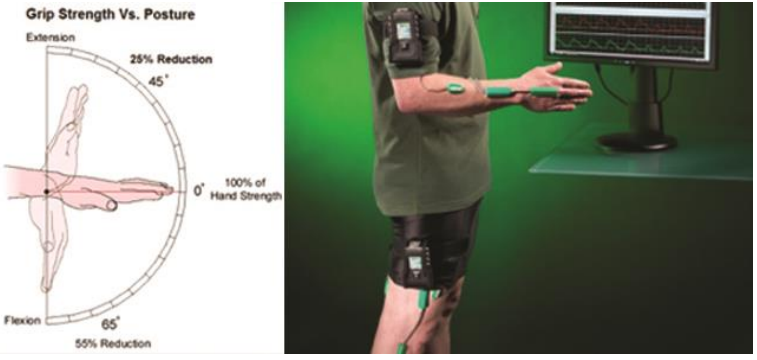

Figure 6: Postural technique (US-Ergo, 2019)

\section{CRITICAL ASPECTS WHILE USING THE PACKAGING}

There are different types of packaging opening mechanisms. The most critical factors influencing the ease of opening a packaging are visibility and clarity of the opening mechanism, the position of the opening mechanism relative to the holding position, tightness/brittleness and fragility of the opening mechanism, the strength required to open packaging, the need to use both hands when opening, the strength and slipperiness of the packaging material, required grip of the packaging, breakage of the packaging during the opening and the degree of retention of the product in the packaging after opening (Kroemer Elbert, Kroemer and Kroemer Hoffman, 2018).

\section{METHODS FOR EVALUATION OF THE ERGONOMIC CHARACTERISTICS OF PACKAGING PRODUCTS}

Methods for assessing critical aspects of using products can be divided into subjective methods, objective methods, combined methods and usability methods.

\subsection{Subjective methods}

When a product should be evaluated based on the comfort it provides to the user, subjective methods and measurements are most often used. Most of them are focused on the discomfort that the user feels when using the product. Although the validity and usefulness of subjective measurements are often questioned, Johnson (1999) emphasizes the use of subjective assessments of comfort, productivity, and ease of use of a product. Subjective comfort and discomfort in the case of products subject to manual manipulation are usually assessed using questionnaires using rating scales to assess the characteristics 
examined (Boyles et al, 2003; Chandra and Chandna, 2011; Lee and Chen, 2008; Carse et al, 2007). Also are used pain maps, measurement of pain and discomfort assessment (Kihlberg et al, 1995; Trejo et al, 2006; Lin and McGorry, 2009). Subjective evaluations have some disadvantage: they require a large number of participants and therefore require a lot of time (Lee et al, 1993), and they are influenced by personal preferences (Chen et al, 1994). Some commonly known causes of unreliability in the use of subjective measures are time error and context effects (Annet, 2002). Therefore, it is advisable to use objective measurements in addition to subjective measurements (Bisht and Khan, 2013). Various techniques are available to obtain information on consumer preferences and most involve the use of questionnaires or interviews. The form of the questions asked is extremely important. Questions must be asked in such a way that the answers can be quantitatively analyzed. One way to achieve this is to ask questions in the form of a rating scale and ask the subject to define a rating from a scale that corresponds to his assessment. The answers can be followed by questions, which can be of an open type that reveal the reasons for a certain answer/grade. For example, if the answer to the previous question was very difficult or difficult, the following question could be: what were the reasons for the difficulty? Answers to such open-ended questions often provide information about possible improvements to the products being tested. Another way to obtain additional information of this type is to use checklists where all possible difficulties are listed from which the respondent chooses the ones he experienced during the test. It is useful to include at the end of the questionnaire general assessment questions that allow the respondent to define the acceptability of the product he/she observes as a whole. An example of study based on the subjective method is the study by Winder et al. (2002) that was designed to examine the relationship between consumers, their complaints about food and beverage packaging, and the occurrence of injuries and accidents when opening food and beverage packaging. Two hundred customers from four Sainsbury stores filled out a four-page questionnaire. Participants answered questions about eight different categories of packaging (canned goods, canned goods with a ring, cans, plastic bottles and jars, glass bottles and jars, cardboard boxes/packaging, flexible packaging and "tray goods"). Examples of these categories of packaging were presented to participants through photographs.

\subsection{Mechanical methods}

The mechanical method implements a mechanical test and it is quite fast and easily reproducible. Mechanical testing measures only one dimension (force) that is used for a particular job/action and requires certain equipment. The measurements aim to provide the lower limit of force required when consumers perform the required action using the product. However, as the measurements do not mimic the human use of the product, they can only be used as an indicator of the required level of force, and the measurement failure caused by this varies from package to package. The method does not involve human perception. The level of force depends on factors such as adhesion, the slipperiness of the material and the type of mechanism and these factors are not included in the mechanical test. To create a replication of the packaging opening procedure, various instruments such as meters are used. The Danish Technological Institute (Heinö et al, 2008) has been measuring the torque required to open the packaging. The equipment used was the Instron 5569 torque meter. Samples were prepared by emptying the entire contents and cutting out the mechanism for opening each sample of the packaging. Wires and clamps were used to mimic the force-displacement during the opening procedure for most measurements. It was necessary to open the packaging in two operations. The bottle tester, Tornado (JKM systems, DK), was used to measure torque during the opening of the lid of medical products. The packaging was attached to the measuring cell. The cover is released manually and the maximum required torque is measured (Figure 7a) in the first step. Then the second step of the experiment involves the pullring method of the lid with the ring for pulling the opening which can be seen in Figure $7 \mathrm{~b}$.
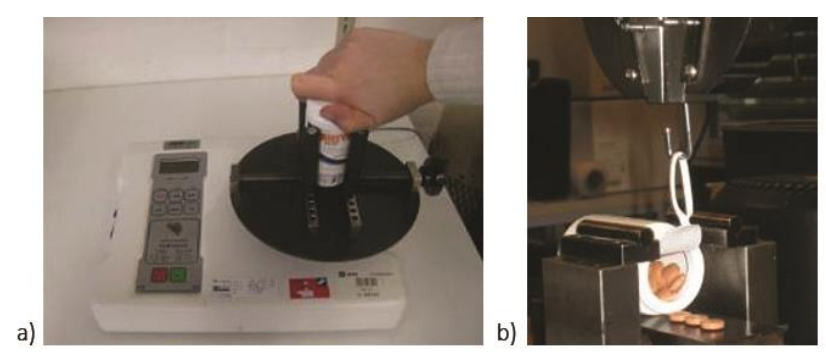

Figure 7: Experimental apparatus used in Danish research a) the first step b) the second step (Heinö et al., 2008) 
Tetra pak (Heinö et al, 2008) used the Instron torque meter to investigate the opening of the packaging and to measure the torque during the opening of the lid. The packaging for medical products is attached to a plate that registers torque, and the rotating fixture opens the lid. The Zwick machine is used to measure the force when opening the lid with the pull ring (Figure 8). The fixture holds the packaging at 20 degrees and the pull ring is fastened with a clamp attached to the movable clamp. The pulling head moves upwards at a speed of 100 $\mathrm{mm} / \mathrm{min}$, and the force is measured by a measuring cell. The measurement is completed when the diaphragm of the pull ring is completely loosened.

a)

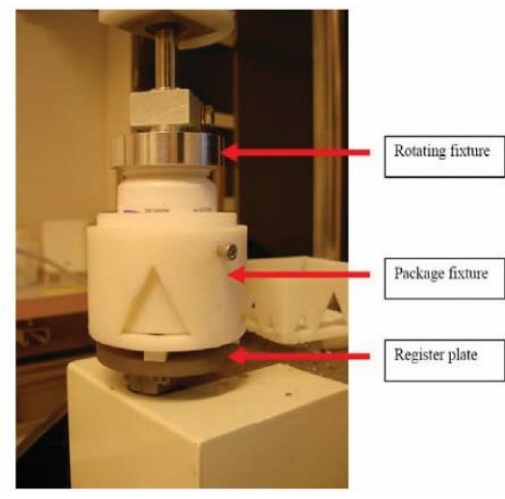

b)

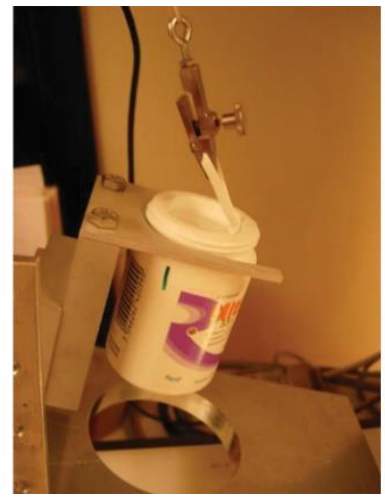

Figure 8: Experimental apparatus used in Tetra pak research a) the first step b) the second step (Heinö et al., 2008)

\subsection{Objective methods}

Objective methods are a combination of subjective and mechanical methods. Objective methods help to provide scientific logic and the reason behind subjective answers. In most cases, in addition to subjective estimates by users, some objective parameters are also recorded. Different user responses can be attributed to the levels of different physiological and biomechanical responses of the human body. The choice of parameters to be collected is based on the type of research being conducted and on the parts of the body involved in performing the task. Measuring the anthropometry of the hands is a key activity that is usually performed in various research papers dealing with any research in which the user uses the hands. Researchers have conducted various studies such as examining the optimal grip span concerning an individual's anthropometry for isometric power grip exertion (Eksioglu, 2004). Objective measurements such as pressure pain threshold measurements (Madeleine et al, 2003), joint and body posture and deviation, grip force/force/ torque, (Motamedzade et al, 2007; Jung, 2008; Wu et al, 2009) and the size and distribution of hand pressure (Aldien et al, 2005) are some of the frequently performed measurements in objective methods (Bisht and Khan, 2013). Various researches have been performed in the field of ease of opening packaging. Packaging that has torque-requiring closures (Heinö et al, 2008; Yoxall et al, 2006; Yoxall et al, 2008) that require a coordinated two-handed procedure are assessed as particularly challenging. A lot of the research work that can be found is based on the measurement of torque forces (Yoxall et al, 2006; Carus et al, 2006; Duizer et al, 2009; Langley et al, 2005; Yoxall et al, 2010; Yoxall and Rowson, 2015).

\subsection{Usability methods}

In addition to subjective and objective methods of product evaluation and tasks, usability methods are widely used to study user performance while using a product. Various metrics such as safety, reliability, ease of use (Woods and Buckle, 2005; Wu et al, 2008; Vanderwal et al, 2011), task efficiency, precision, stability, duration (Lee and Chen, 2008; Wu et al, 2009; Jung and Hallbeck, 2005; Chang et al, 2007), etc. researchers have used it in the past to assess the usability of different types of products. To measure the parameters of different metrics that are responsible for assessing the usability of a test, the parameters would have to be both subjective and objective in nature. Data can be collected using various rating scales and ranking procedures, direct observation or using equipment such as algometer, dynamometer, goniometer, heart rate monitor, accelerometer, etc. (Bisht and Khan, 2013). Opening vacuum-sealed jars can be a problem for a large percentage of the elderly population (Berns, 1981) because they are unable to exert sufficient turning force, and it is a topic that is continuously being researched. In research screw force required to open the jar is usually examined. With such packaging, a minimum torque is required to maintain the vacuum. No regulations are prescribing the torque required to open 
the jar. The degree of torque applied in the production process is often high because other factors are involved, such as preventing people from accidentally opening jars or stopping consumers from rummaging through the product before purchase (Voorbij and Steenbekkers, 2002). Several studies have been conducted to characterize the opening moments of typical glass jar packaging (Peebles and Norris, 2003; Voorbij and Steenbekkers, 2002; Carse et al, 2011) as well as to examine the torques typically required to remove the lid (Janson, 2007) and what impact the change in shape and dimensions of the lid has on opening moments (Crawford et al, 2002). By researching of Wei-Ting et al. (2016) examined several lid design features (diameter, height, tip shape, side view shape, and surface texture) using controlled laboratory testing with older women with hand function limitations. The subjective evaluation procedure was applied to examine the main effects and interactions of cover design characteristics on usability, determined by the perceptions of the effort and discomfort of the participants. In addition to the subjective assessment, an objective assessment of the lids was designed by creating a special experiment where objective results were collected. Each participant's diameter-specific maximum voluntary torque was tested at the beginning of the test session by turning a prototype model of the jar lid. Similarly, in the research of Carse, Thomson and Stansfield (2011), a new measuring device was used to characterize torque and pressure during a dynamic jar opening action by a younger and older adult. Older adults tend to twist the jar lid more slowly ( $0.038 \mathrm{Nm}$ / s vs $0.044 \mathrm{Nm} / \mathrm{s}$ ) and open the jar at a slower speed (0.84 Rad / s vs $1.59 \mathrm{Rad} / \mathrm{s})$ than younger people while using a higher proportion of their maximum grip strength (40\% vs. $27 \%$ ) indicating that older adults used a more cautious opening strategy. These differences suggest that a simple test of maximum torque is not enough to characterize the abilities of older adults concerning opening the packaging. Usability tests are more complexed since sometimes special equipment needs to be built, but the results that can be obtained can better represent a real human interaction with the packaging.

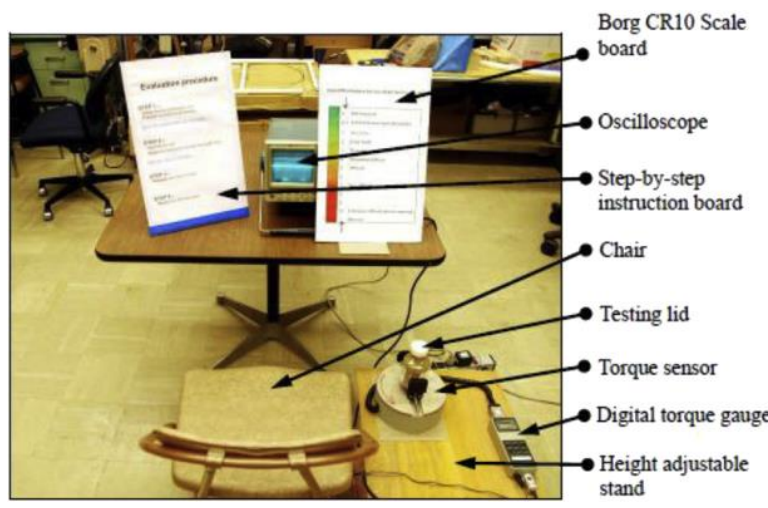

Figure 9: Experimental setup (Wei-Ting et al., 2016)

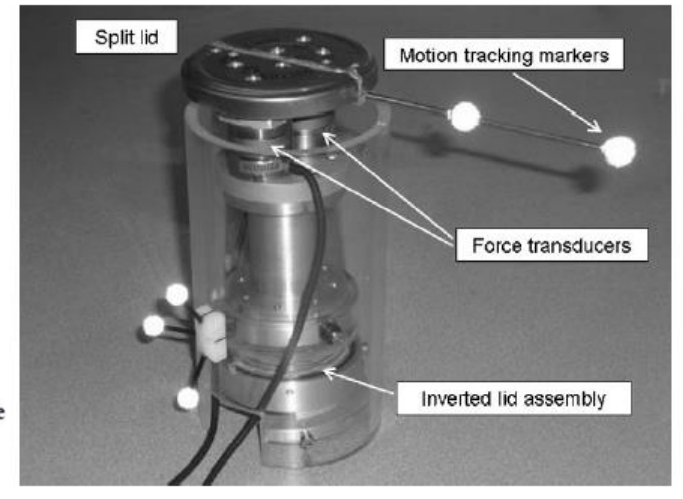

Figure 10: Experimental apparatus (Carse et al,, 2011)

\section{CONCLUSIONS}

Ergonomically designed packaging is becoming an increasingly popular demand among consumers. Ergonomically designed packaging implies that it is easy to open, allows easy access to a product that is packed in it, has a good closing system if the goods are not intended to be consumed at the first opening. Ergonomically design packaging should be adjusted to the size of the user's hand, it should not require excessive physical force from the user, etc. Easy opening of the packaging becomes the main problem that users face in their interaction with packaging. All consumers face this problem but people with disabilities, the elderly, people with some kind of hand problem mostly deal with this. The type of required grip and the possibility of applying the force required to open the packaging differ depending on the type of packaging. To proper develop an ergonomically shaped packaging, physical qualifications and consumer capabilities and possible critical aspects of packaging that can affect using the product should be considered. In this paper, a review of methodologies that can be implemented in the design development, analysis and evaluation of work tasks and packaging shape was given. Methods for assessing critical aspects of product use can be divided into subjective methods, mechanical methods, objective methods and usability methods.

When the product should be evaluated based on of the comfort it provides to the user, subjective methods and measurements are most often used. Most of them are focused on the discomfort that the user feels when using the product. Subjective methods are useful for assessing comfort, productivity, and ease of use of a product. Subjective comfort and discomfort in the case of products that undergoes 
manual manipulation are usually assessed using questionnaires or through conducting interviews. Subjective evaluations have some clear shortcomings: they require a large number of respondents and therefore research takes a long time, and they are influenced by personal preferences. There are some commonly known sources of the unreliability of the use of subjective measures, such as time error and context effects.

Mechanical tests measure the force required to use a product. The measurements aim to provide the lower limit of power required when consumers perform the required action using the product. However, as the measurements do not mimic the human use of the product, they can only be used as an indicator of the required level of strength, and this varies from packaging to packaging. The level of force depends on factors such as adhesion, the slipperiness of the material and the type of mechanism and these factors are not included in the mechanical test. The mechanical test is quite fast, easy and cheap to implement. Mechanical testing measures only one dimension (strength) used for a particular job and requires certain equipment.

Objective methods help to verify the authenticity of subjective tests based on our knowledge of the physical and biomechanical limitations and capacities of the human body. The objective method is a combination of subjective methods and mechanical methods. Objective methods also help to provide scientific logic and reason behind subjective answers.

In addition to subjective, mechanical, and objective methods of evaluating products and tasks, usability methods are widely used for studying consumer while using a product. To measure the various parameters responsible for assessing the usability of a test, the parameters would have to be both subjective and objective in nature. Data can be collected using various rating scales and ranking procedures, direct observation or using equipment such as algometer, dynamometer, goniometer, heart rate monitor, accelerometer, etc. Often a special equipment is built for a particular experiment which makes the method more complex but also can gives more interesting and more correct results.

Each of these methods can be useful for ergonomic research of packaging products. If the research goal and research hypotheses are clearly defined and if the research setting is defined in accordance with the rules proposed by the type of selected method, then the research results will be of high quality.

\section{ACKNOWLEDGMENTS}

This research (paper) has been supported by the Ministry of Education, Science and Technological Development through the project no. 451-03-68/2020-14/200156: "Innovative scientific and artistic research from the FTS (activity) domain".

\section{REFERENCES}

[1] Aldien, Y., Welcome, D., Rakheja, S., Dong, R., Boileau, P. E.: “Contact pressure distribution at hand-handle interface: role of hand forces and handle size", International Journal of Industrial Ergonomics 35, 267-286, 2005.

[2] Annet, J.: "Subjective rating scales: science of art?", Ergonomics 45(14), 966-987, 2002. doi: 10.1080/00140130210166951.

[3] Armstrong, T., Cochran, D. J., Bleed, P. A., Lin, J-H., Freivalds, A., Radwin, R. G., Rempel, D. M.: “Hand Tool Ergonomics - Past and Present", Proceedings of the Human Factors and Ergonomics Society Annual Meeting 2010, pp. 1145-1148. doi:10.1177/154193121005401512.

[4] Berns, T.: "The handling of consumer packaging", Applied Ergonomics 12, 153-161, 1981.

[5] Bisht, D. S., Khan M. R.: "Ergonomic Assessment Methods for the Evaluation of Hand-Held Industrial Products: A Review", Proceedings of the World Congress on Engineering 2013, (WCE: London, U.K., 2013.).

[6] Boyles, J. L., Y earout, R. D., RYS, M. J.: "Ergonomic scissors for hairdressing", International Journal of Industrial Ergonomics 32, 199-207, 2003.

[7] Bridger, R. S.: "Introduction to Ergonomics", (Taylor \& Francis, New York, 2003.).

[8] Carse, B., Thomson, A., Stansfield, B.: "A novel device for evaluating forces during the dynamic jar opening action: Do older and younger adults do things differently?", Medical Engineering and Physics 33, 521-525, 2011. doi: 10.1016/j.medengphy.2010.11.017.

[9] Carse, B.,Thomson, A., Stansfield, B.: "Packaging and the Older Adult", An International Conference on Inclusive Design 2007, (Helen Hamlyn Centre at the Royal College of Art, London, UK, 2007.). 
[10] Carus, D.A., Grant, C., Wattie, R., Pridham, M.S.: "Development and validation of a technique to measure and compare the opening characteristics of tamper-evident bottle closures", Packaging Technology and Science 19(2), 105-118, 2006. doi:10.1002/ pts.721.

[11] Chandra, A., Chandna, O.: "Ergonomic design of hand tool (screwdriver) for Indian worker using comfort predictors: a case study", International Journal of Advanced Engineering Technology 2(4), 231-238, 2011

[12] Chang, B. C., Huang, B. S., Chen, C. K., Wang, S. J.: "The pincer chopsticks: The investigation of a new utensil in pinching function",Applied Ergonomics 38, 385-390, 2007. doi: 10.1016/j.apergo.2006.03.009.

[13] Chebykin, O. Y., Bedny, G. Z., Karwowski, W.: "Ergonomics and Psychology Developments in Theory and Practice", (Taylor \& Francis Group, Boca Raton, 2008.).

[14] Chen, H., Nigg, B. M., Koning, J. D.: "Relationship between plantar pressure distribution under the foot and insole comfort", Clinical Biomechanics 9, 335-342, 1994. doi: 10.1016/02680033(94)90062-0.

[15] Consumer and Competition Policy Directorate: "Specific Anthropometric and Strength Data for People with Dexterity Disability", (DTI, Great Britain, 2002.).

[16] Crawford, J.O., Wanibe, E., Nayak, L.: "The interaction between lid diameter, height and shape on wrist torque exertion in younger and older adults", Ergonomics 45(13), 922-933, 2002. doi: 10.1080/00140130210162243.

[17] Duizer, L. M., Robertson, T., Han, J.: “Requirements for packaging from an ageing consumer's perspective", Packaging Technology and Science 22(4), 187-197, 2009. doi:10.1002/pts.834.

[18] Dul, J.: "Ergonomics for Beginners: A Quick Reference Guide [Kindle version]", 3rd Edition, (TNO Institute, 2008.).

[19] Eksioglu, M.: "Relative optimum grip span as a function of hand anthropometry", International Journal of Industrial Ergonomics 34, 1-12, 2004. doi: 10.1016/j.ergon.2004.01.007.

[20] Freivalds, A. : "Biomehanics of the upper limbs: Mechanics, modeling and musculoskeletal injuries", 2nd Edition, (CRC Press Taylor \& Francis Group, Boca Raton, 2011.).

[21] Hashim A., Dawal, S. Z.: "K ano Model and QFD integration approach for Ergonomic Design Improvement", Procedia - Social and Behavioral Sciences 2012, The 2012 International (Summer) Conference on Business Innovation and Technology Management, (Elsevier, Genting, Malaysia, 2012), pages 22-32. doi: 10.1016/j.sbspro.2012.09.1153.

[22] Heinö, R-L., Åström, A., Antvorskov, H., Mattsson, M., Østergaard S.: “Easy Open Pack Scientific background for the basis of an international standard for easy-to-open packages", ( Nordic cooperation project (NICe), Norway, 2008.).

[23] Janson, R. G.: "Openability of vacuum lug closures", PhD thesis, Department of Mechanical Engineering, University of Sheffield, 2007.

[24] Johnson, J.: Applying Ergonomics to Tool Design, In: Alexander, D. (eds.), “Applied Ergonomics: Case Studies, 1", (GA: Engineering and Management Press, Norcross, 1999.).

[25] Jung, H. S.: "Design of liquid container handles in accordance with user preferences", Ergonomics 51(3), 247-260, 2008. doi: 10.1080/00140130701636157.

[26] Jung, M. C., Hallbeck, M. S.: "Ergonomic redesign and evaluation of a clamping tool handle", Applied Ergonomics 36, 619-624, 2005. doi: 10.1016/j.apergo.2005.01.016.

[27] Kaljun, J., Dolšak, B.: "Ergonomic design knowledge built in the intelligent decision support system", International Journal of Industrial Ergonomics 42, 162-71, 2012. doi: 10.1016/j.ergon.2011.11.009.

[28] Kihlberg, S., Kjellberg, A., Lindbeck, L.: "Discomfort from pneumatic tool torque reaction: Acceptability limits", International Journal of Industrial Ergonomics 15, 417-426, 1995. doi: 10.1016/0169-8141(94)00059-C.

[29] Kroemer Elbert, K.E., Kroemer, H. B., Kroemer Hoffman, A. D.: “Ergonomics - How to Design for Ease and Efficiency", 3 rd Edition, (Academic Press, 2018.). doi: https://doi.org/10.1016/C2016-002516-0.

[30] Kumar, S.: "Biomechanics in Ergonomics", (Tylor and Francis, UK, London, 1999.).

[31] Langley, J., Janson, R., Wearn, J., Yoxall, A.: "Inclusive' design for containers: improving openability", Packaging Technology and Science 18(6), 285-293, 2005. doi:10.1002/pts.699.

[32] Lee, K. S., Ferraiuolo, D., Temming, J.: "Measuring seat comfort", Automotive Engineering 101(7), 25-30, 1993.

[33] Lee, Y. C, Chen, Y. L.: "An auxiliary device for chopsticks operation to improve the food-serving performance”, Applied Ergonomics 39, 737-742, 2008. doi:10.1016/j.apergo.2007.11.006. 
[34] Lin, J. H., McGorry, R. W.: "Predicting subjective perceptions of powered tool torque reactions", Applied Ergonomics 40, 47-55, 2009. doi: 10.1016/j.apergo.2008.01.020.

[35] Madeleine, P., Lundager, B., Voigt, M., Arendt-Nielsen, L.: "Standardized low-load repetitive work: evidence of different motor control strategies between experienced workers and a reference group", Applied Ergonomics 34, 533-542, 2003.

[36] Moore, S. M., Torma-Krajewski, J., Steiner, L. J.: "Practical Demonstrations of Ergonomic Principles. Report of investigations/2011, RI 9684", (Department of Health and Human Services, Centers for Disease Control and Prevention, National Institute for Occupational Safety and Health, Pittsburgh, 2011.).

[37] Motamedzade, M., Choobineh, A., Mououdi, M. A., Arghami, S.: "Ergonomic design of carpet weaving hand tools", International Journal of Industrial Ergonomics 37, 581-587, 2007. doi: 10.1016/j.ergon.2007.03.005.

[38] Nordenskiöld, U.: "Daily Activities in Women with Rheomatoid and Arthritis", PhD thesis, University of Gothenburg, 1996 .

[39] Norris, B. J., Wilson, J. R.: “CHILDATA: The Handbook of Child Measurements and CapabilitiesData for Design Safety", (Department of Trade and Industry, London, 1995.).

[40] Novaković, D.: "Grafička ambalaža", Materijal sa predavanja, GRID, Fakultet tehničkih nauka, Novi SAD, 2013.

[41] Oyewole, S. A., Haight, J. M., Freivalds, A.: "The ergonomic design of classroom furniture/computer work station for first graders in the elementary school", International Journal of Industrial Ergonomics 40, 437-47, 2010. doi: 10.1016/j.ergon.2010.02.002.

[42] Peebles, L., Norris, B. J.: “ADULTDATA: The Handbook of Adult Anthropometric and Strenght Measurements-Data for Design Safety", (Department of Trade and Industry, London, 1998.).

[43] Peebles L., Norris B. J.: "Filling 'gaps' in strength data for design", Applied Ergonomics 34, 73-88, 2003. doi:10.1016/S0003-6870(02)00073-X.

[44] Rogulj, N., Srhoj, Lj., Čavala, M.: "Differences in Anthropologic Characteristics between Kinesiologically Active and Inactive Female Students", Collegium antropologicum 36(3), 945-950, 2012.

[45] Rosengren, J., Brodin, N.: "Validity and reliability of the Swedish version of the Patient Specific Functional Scale in patients treated surgically for carpometacarpal joint osteoarthritis", Journal of Hand Therapy 26, 53-61, 2013. doi: 10.1016/j.jht.2012.10.007.

[46] Rowson, J., Yoxall, A.: "Hold, grasp, clutch or grab: consumer grip choices during food container opening", Applied Ergonomics 42(5), 627-633, 2011. doi:10.1016/j.apergo.2010.12.001.

[47] Salvendy, G.: "Handbook of human factors and ergonomics", 4th Edition, (Wiley, New Jersey, 2012.).

[48] Smith, S. A., Norris, B. J., Peebles, L.: "OLDER ADULTDATA: The Handbook of Measurements and Capabilities of Older Adult- Data for design Safety", (Department of Trade and Industry, London, 2000.).

[49] Stanton, N. A., Young, M. S., Harvey, C.: "A Guide to Methodology in Ergonomics: Designing for Human Use", 2nd Edition, (CRC Press, Boca Raton, 2014.).

[50] Sudarov, N., Fratić, F.: "Dijagnostika treniranosti sportista”, (Pokrajinski zavod za sport, 2010.).

[51] Trejo, A. E., Done, K. N., DiMartino, A. A., Oleynikov, D., Hallbeck, M. S.: "Articulating vs. conventional laparoscopic grasping tools- surgeons' opinions", International Journal of Industrial Ergonomics 36, 25-35, 2006. doi: 10.1016/j.ergon.2005.06.008.

[52] Vanderwal, L., Rautiainen, R., Kuye, R., Peek-Asa, C., Cook, T., Ramirez, N., Culp, K., Donham, K.: "Evaluation of long- and shorthandled hand hoes for land preparation, developed in a participatory manner among women vegetable farmers in The Gambia", Applied Ergonomics 42, 749-756, 2011. doi: 10.1016/j.apergo.2010.12.002.

[53] Voorbij, A. I. M., Steenbekkers, L. P. A.: "The twisting force of aged consumers when opening a jar", Applied Ergonomics 33, 105-109, 2002. Avalable from: doi: 10.1016/S0003-6870(01)00028-X.

[54] Wei-Ting, Y., Sommerich, C.M., Lavender S.A., Flinn S.R., Sanders E.B.N.: "Evaluation of jar lid design characteristics by older women with hand use limitations", Applied Ergonomics 52, 177-184, 2016. doi: 10.1016/j.apergo.2015.07.011.

[55] Winder, B. Ridgway, K., Nelson, A., Baldwin, J.: "Food and drink packaging: who is complaining and who should be complaining", Applied Ergonomics 33, 433-438, 2002. doi: 10.1016/s00036870(02)00026-1. 
[56] Woods, V., Buckle, P.: "An investigation into the design and use of workplace cleaning equipment", International Journal of Industrial Ergonomics 35, 247-266, 2005. doi: 10.1016/j.ergon.2004.09.004.

[57] Wu, S. P., Ho, C. P., Chi, H. C.: "Ergonomic study of a vertical rope-pulling task from a scaffolding", Ergonomics 51(3) 345-354, 2008. doi:10.1080/00140130701627875.

[58] Wu, X., Thomson, G., Tang, B.: "An investigation into the impact of safety features on the ergonomics of surgical scalpels", Applied Ergonomics 40, 424-432, 2009. doi: 10.1016/j.apergo.2008.11.003.

[59] Yoxall, A., Janson, R., Bradbury, S. R., Langley, J., Wearn, J., Hayes, S.: "Openability: producing design limits for consumer packaging", Packaging Technology and Science 19(4), 219225, 2006. DOI:10.1002/pts.725.

[60] Yoxall, A., Janson, R.: "Fact or friction: a model for understanding the openability of wide mouth closures", Packaging Technologyand Science 21(3), 137-147, 2008. doi:10.1002/pts.785.

[61] Yoxall, A., Langley, J., Janson, R., Lewis, R., Wearn, J., Hayes, S. A., Bix, L.: "How wide do you want the jar?: The effect on diameter for ease of opening for widemouth closures", Packaging Technology and Science 23(1), 11-18, 2010. doi:10.1002/pts.874.

[62] Yoxall, A., Rowson, J.: "Talking about torque: measuring pack accessibility - a review", Packaging Technology and Science 28(1), 1-14, 2015. doi:10.1002/pts.2079.

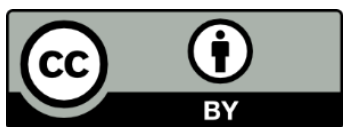

(C) 2020 Authors. Published by the University of Novi Sad, Faculty of Technical Sciences, Department of Graphic Engineering and Design. This article is an open access article distributed under the terms and conditions of the Creative Commons Attribution license 3.0 Serbia (http://creativecommons.org/licenses/by/3.0/rs/). 



\title{
PACKAGING DESIGN AND TESTING BY EYE TRACKING
}

\author{
Gregor Franken \\ University of Ljubljana, Faculty of Natural Sciences and Engineering, Department of Textiles, \\ Graphic Arts and Design Ljubljana, Chair of Information and Graphic Arts Technology, \\ Ljubljana, Slovenia
}

\begin{abstract}
The importance of packaging design has been increasing in today's competitive world. Approximately $70 \%$ of purchasing decisions are made in a store. Over $60 \%$ of purchasing decisions are based on packaging; the actual shopping is thus the final chance for the packaging to attract the buyer. Packaging has between 2 and 3 seconds to convince the buyer. In addition to the appearance of the individual packages, the appearance of brand packaging is important. We compared different designs of packages. Finally, we placed individual packages on the shelves in a store and carried out measurement of in-store noting. The measurements were carried out using eye tracking equipment (Tobii X120). For each participant, the observing time and the number of fixations in individual areas of interest were measured; both were then compared with heat maps. In this way, we compared the suitability of the form of individual packages and the salience of the packages on the shelves for potential buyers.
\end{abstract}

Keywords: packaging, design, online observing, fixations, observing time, heat maps

\section{INTRODUCTION}

With steep competition of products on the market, packaging is one of the most important factors in product sale. Design and the search for the optimal design preferred by the buyers, which enhances the recognition on the market, present the greatest challenge for both the designers and the company itself. We might say that packaging is the medium between the buyer and the product, representing the first contact with the consumer. Many purchases are spontaneous, and because of the growing competition on the market, packaging plays a special role in convincing the buyer. From the consumer perspective, packaging also plays a major role when products are purchased: packaging is crucial, given that it is the first thing that the public sees before making the final decision to buy. (Giovannetti, 1995)

In our study, we attempt to determine how the consumer views individual packages, and how he or she reacts to all the packaging on the shelves. Consumer behaviour was tracked using eye-tracking equipment. What is particularly interesting about eye-tracking measurements and testing is the fact that the answers regarding the attention may be completely different from the actual visual attention. Without suitable eye-tracking analyses, any comparison of the design elements of packaging is irrelevant in this day and age. The technology takes into account the physiological movements of the human eye, analysing the psychological consequences of these movements; moreover, accurate judgements or recommendations on how to improve packaging design are based on the data obtained through testing and analyses.

\subsection{Packaging}

The process of packaging can be defined as the activity of designing, as well as the packaging or wrapping of a product. Packaging is much more than just protection of the content; it is an active means of communication on the shelf, generally in the company of other, similar products, representing a contact between potential consumers in the process of purchasing decision making. It is at the same time an advertising medium and a mute salesperson that has less than two seconds to convince the buyer. (Stephenson, 2020)

Packaging decisions have an important impact on the product, as packaging can contribute to maintaining a successful market position of a product, enhancing its positioning, improving the quality of the content when newer materials are used (above all in food sales), reaching new target groups, etc. The importance of packaging is growing for several reasons. One of them is the increasingly stronger competition, which means that the product needs to stand out among all the other similar products. In addition to the design of the individual package, two issues addressed by visual merchandising, i.e., brand packaging design and the salience of packaging on the shelves in a store, are also important. (Morgan, 2016) 
Reiner in Rose (2002) list three points which distinguish advertising from packaging. 1) Packaging without any subconscious influence of advertising represents 70\% of impulsive shopping. 2) Packaging advertises a product before and after purchase. 3) Packaging outlasts an advertisement. (Reiner and Rose, 2020) The next, equally important reason is that the differences in quality and price are decreasing. Products are becoming very similar, and, as a consequence, it is the packaging that attracts the consumer. Moreover, consumers are becoming less loyal, and any detail of packaging, however minor, may attract them. Around $70 \%$ of purchasing decisions are made in the store. (Clark, 2020)

\section{2 Eye-tracking}

Eye-tracking is the process of recording the point of gaze and eye movements in an individual, using equipment relying on optical methods of tracking eye movements. In eye-tracking, infrared diodes are used to create reflection patterns on the cornea. These reflection patterns are collected by video-based sensors along with other visual information on the subject of testing.

\subsubsection{Gaze plots}

Gaze plots show the location, order, and time spent looking at locations on the stimulus, whether packaging, web page, print advertisement, or moving pictures. So the primary function of the gaze plot is to reveal the time sequence of looking or where we look and when we look there. Time spent looking, most commonly expressed as fixation duration, is shown by the diameter of the fixation circles. The longer the look, the larger the circle. (Tobi Pro, 2020)

\subsubsection{Saccades}

When we read or observe, the eyes move in a discontinuous manner. The motion of the eye from one fixation to the next occurs in a rapid jump called the saccade. Saccades are exceptionally rapid eye movements in which we momentarily change the viewing direction and align the image of the observed object with the area of the yellow spot. Saccades are the most frequent eye motion. Their angular velocity can exceed $500^{\circ}$ s. (Hochberg, 1978)

\subsubsection{Fixations}

Fixations are short pauses at picture or at individual text elements during the reading or observing process, and are needed for the brain to process the text being read (Figure 1). Reading fixations typically last from 200 to 250 milliseconds (ms) and are significantly longer when reading unknown or less familiar words (Rayner et al, 2010). In observing elements and pictures, fixations typically last from a few milliseconds to several seconds.

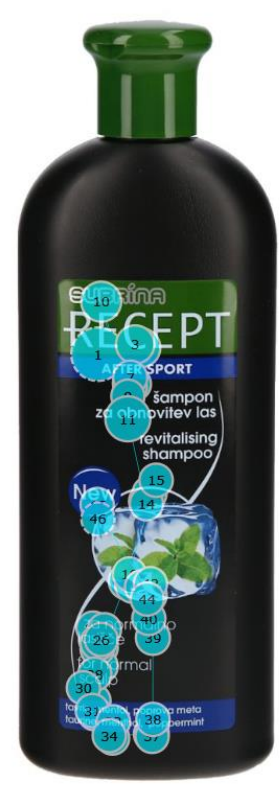

Figure 1: Fixations of one participant detected and recorded with eye-tracker on packaging 


\subsubsection{Heat maps}

A heat map is a graphical representation of how looking is distributed over the stimulus. Heat maps are generally used by online marketers to show what percentage of people interacted with different parts of a web page. This is usually done using software such as eye tracking, click tracking, mouse tracking, etc. Unlike gaze plot, there is no information about the order of looking in a static heat map (Figure 2).

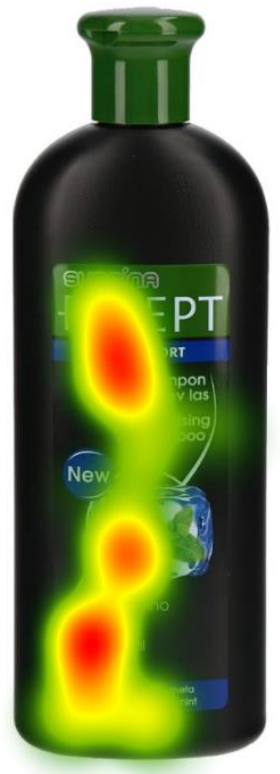

Figure 2: Heat maps detected and recorded with eye-tracker on packaging

\subsection{Form, colour, typography and image}

In designing a new package, the form is certainly of utmost importance. The form is limited by the volume, as it must adjust to the content. The design of the form and it being pleasant to the touch are vital: Will the edges be sharp or soft? Ergonomics is foregrounded here: How will the package feel in our hands? Since we used shampoo as the focus of our packaging design, it is essential to take into account the stability of the package. Will it be prone to toppling over, can it stand upside down on the part which opens... The surface structure of the packaging is crucial. Will it be glossy or soft touch matte? When designing shampoo packaging, the fact that it will mostly be touched with wet hands should be taken into consideration.

The colour is certainly one of the most important factors in packaging. White, blue and yellow dominate in shampoo design. In the context of colour, Fructis Garnier shampoos are worthy of attention: The packaging of these shampoos has stood out with its non-traditional choice of attractive and vibrating apple green. With a suitable advertising campaign and a decisive colour, these shampoo bottles certainly stand out in the colour palette of the other shampoos on the shelf. (Sleever International, 2020)

The typography, the colour palette, the noticeable visual images and the identity of the brand work together to create a synergetic effect, and may eventually end up becoming iconic if rigorously maintained. That is why the choice of typography is so important. In packaging design it is not necessary to use imagery as a design element. A suitably attractive packaging can also be designed without using imagery.

\section{METHODS}

\subsection{Preliminary measurements}

In the preliminary measurements, we chose between two forms of packaging shown on the screen. All participants had normal or corrected-to-normal vision. The study was performed in accordance with the latest declaration of Helsinki. The measurements were performed in a quiet room with walls painted in neutral matte gray, according to the ISO 3664 standard (ISO, 2009). The picture of packaging were displayed on a 24 -inch LCD screen with a resolution of $1900 \times 1200$ pixels (pixel size $0.27 \mathrm{~mm}$ ) at a $60 \mathrm{~Hz}$ 
refresh rate in dark characters on light backgrounds. The tested individuals were positioned $60( \pm 1) \mathrm{cm}$ from the screen according to the recommendations of the ISO 9241 standard (ISO, 2011).

\subsection{Main measurements}

In the main study, we used one form packaging with suitable typographic and graphic elements in the preliminary measurements. We limited the observing time for the packaging on the screen to 5 seconds. We marked different target areas of interest (AOI), dividing them into brand, product name, body text and image. For each participant, the number of fixations, fixation duration, the time to first fixation and the total fixation duration in AOI (Figure 3) were measured. Using the method of the longest fixation duration or the so called heat maps, recommendations for changing the graphic elements of the packaging were made. In placing the package on the shelves in the store, the noticeability of the package among other products was measured; the showing time was limited to 3 seconds. On the shelves, AOI was only marked in the spot where our package was placed. In the AOI marked, the number of fixations, the time to first fixation and the whole fixation duration were measured.

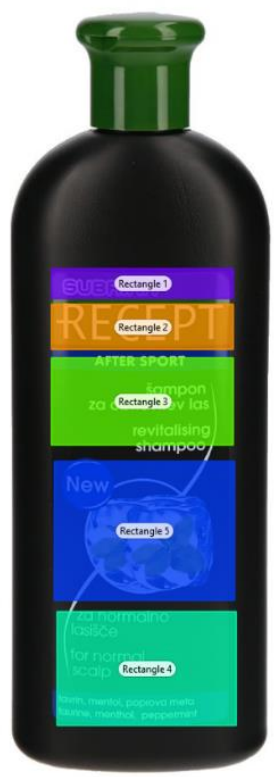

Figure 3: Target area of interest (AOI) on packaging

There were 24 participants, 12 were male and 12 female, ages ranged from 18 to 40, with an average of 23.50 years; all participants had normal or corrected-to-normal vision.

\subsection{Apparatus}

To track the eye movement we used the Tobii X120 eye tracking device and the Tobii Studio 3.1.3 software. The eye tracker tracks the movement of the eye by following the reflection of the image from the cornea. This reflection is generated when the infrared illuminators at the front side of the eye tracker create patterns of light reflecting from the cornea. Eye tracker contains an infrared-sensitive camera that tracks the individual's eye movements and fixations. Prior to the measurement, each individual adapted to the lighting conditions of the room for 5 minutes and then underwent a 9-point screen-based calibration. We also used in shop Tobii Pro Glasses 3 with full HD resolution scene camera with $106^{\circ}$ field of view and Tobii Pro Lab software.

\section{RESULTS}

It was necessary to establish the impact of the different elements of packaging on information reception. Which factors influence changes in eye movement. The time to first fixation, the number of fixations and the fixation duration were compared.

For packaging, the results were very much in accordance with the expectations. The paths of the participants were more or less homogeneous, and their eye movement basically followed the standard 
reading pattern. The time of the first fixation is supposed to be as short as possible, as the participant must focus on the elements of packaging. The participants first focused on textual elements, such as the product name and later on the brand name. This can be attributed to larger font size and the use boldface for the product name. More time was spent on the picture than on the body text. All the data on eye movements and the number of eye movements in packaging observation are given in Table 1.

Table 1: Eye tracking results for packaging design (average of all individual results) within the area of interest (AOI). (1) Time of first fixation. The time of first fixation (in seconds) indicates, when a certain was first focused. (2) Fixation duration. Fixation duration is the average time for fixations. (3) Number of fixations. The fixation count is the amount of fixation. (4) Total fixation duration.

\begin{tabular}{|l|c|c|c|c|}
\hline Gaze plots & (1) & (2) & (3) & (4) \\
\hline Brand & 0.20 & 0.09 & 2.4 & 0.32 \\
\hline Product name & 0.61 & 0.15 & 6.4 & 0.94 \\
\hline Body text & 1.66 & 0.10 & 8.4 & 1.14 \\
\hline Image & 3.84 & 0.05 & 9.1 & 0.42 \\
\hline
\end{tabular}

\subsection{Brand}

The participants noticed the brand of the package the fastest (Figure 4). On average, they needed 0.2 seconds to notice it. The average time of an individual fixation was 0.09 seconds. The number of all fixations in the area of the brand logo was 2.4. The total fixation duration was 0.32 seconds.

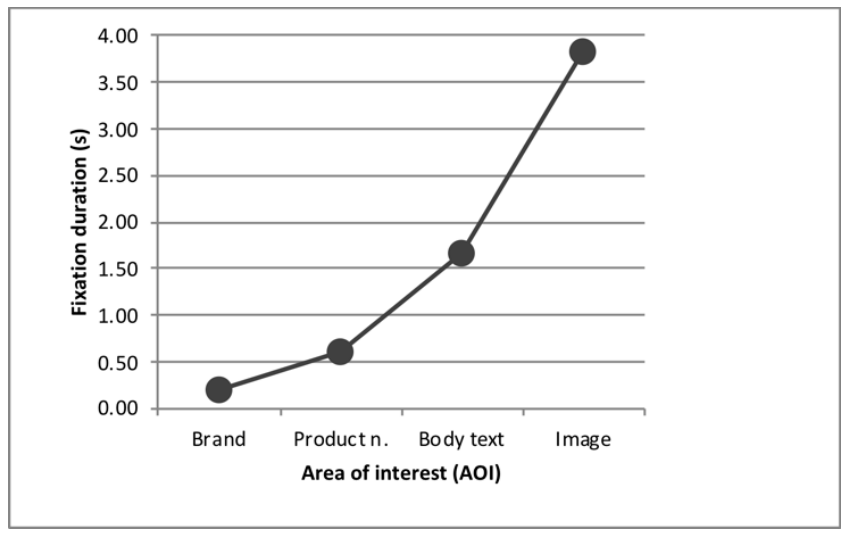

Figure 4: Time to first fixation

\subsection{Product name}

The time of the first fixation was 0.61 seconds on average; the average fixation duration was 0.15 seconds (Figure 5). The total number of fixations on the product name was 6.4. On average, the total fixation duration on the product name was 0.94 seconds.

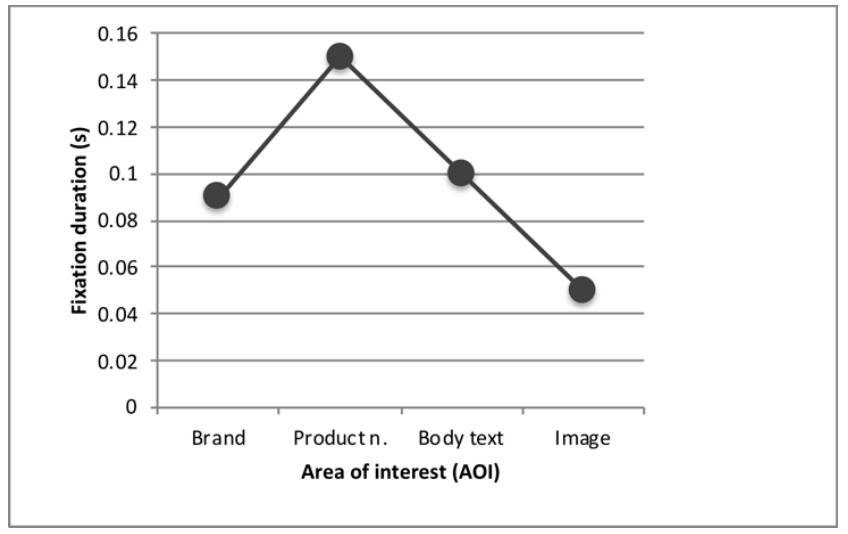

Figure 5: Fixation duration 


\subsection{Body text}

For the body text, the average time of the first fixation was 1.66 seconds and the participants spent an average of 0.1 seconds on it. As body text involves reading, the participants made 8.4 fixations. The total fixation duration was 1.14 seconds (Figure 6).

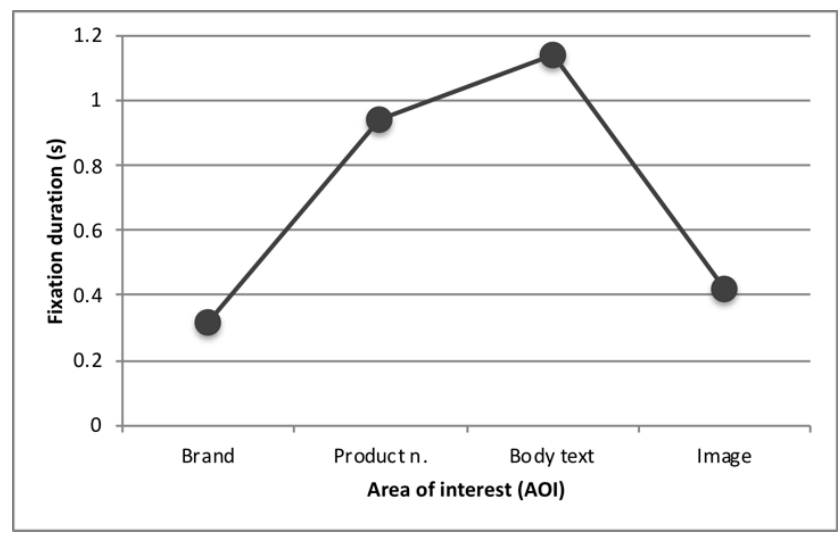

Figure 6: Total fixation duration

\subsection{Image}

The time of the first fixation was 3.84 seconds on average (Figure 7), and an average of 0.15 seconds were spent on the image. The number of fixations was greatest for the image, 9.1; however, the total fixation duration was only 0.42 seconds.

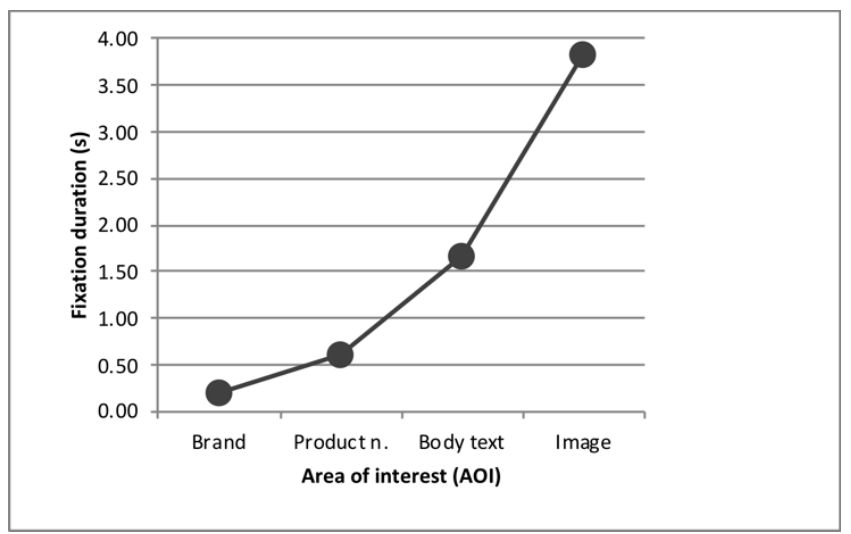

Figure 7: Time of the first fixation

\subsection{Attention to packaging on the sales shelf}

As mentioned above, the participants only had 3 seconds to find the shampoo in question on the shelf in the store. In measuring the fixations, the following results were obtained: the average time to first fixation was 0.67 seconds, the average fixation duration was 0.20 seconds and an average of 6.2 fixations were made on the packaging.

\section{DISCUSSION}

Our results yield four conclusions. First, the form of the packaging: softer forms seem to be preferred. Second, the noticeability of the packaging is influenced by the label itself or the brand logo. The label certainly has the power to attract the consumer, which corresponds to the findings in advertising research (Wedel and Pieters, 2008). Our results suggest that sans serif fonts are more attractive than serif fonts. Similar conclusions have been reported by Ampuero and Vila (Ampuero and Vila, 2006). The right choice of sans serif fonts is also crucial. The strokes of the fonts must be soft and rounded. Third, in packaging design, we used a small image that did not exceed the message value of the colour of 
packaging, the colour of the label and the text on the packaging. Fourth, the results of our study show that the time needed to notice individual packages very much depends on the colour and thus impacts the noticeability among other products on the shelf. It is very important that the colour of the product stands out among other products. In our case, there were several black shampoos on the shelves. Black itself does not stand out, but it creates the feeling of higher price range.

\section{CONCLUSIONS}

The eye tracking method has a number of advantages in the context of marketing research. Its greatest advantage is that it collects data on consumer behaviour directly, thus solving the traditional problem of the discrepancies between what an individual says and what an individual does. Data gathered in this way are more reliable. At the same time, eye movements are direct indicators of an individual's attention, which is difficult to control consciously; as a results, eye tracking resolves the problem of subjective data gathered using interviews or individual focus groups. In marketing research, the eye tracking method means progress in the field of objective data gathering. In terms of marketing, it is worth mentioning that suitable packaging is certainly a key element of marketing itself. The concept of the packaging, its visual elements, its colour and its fonts are crucial in positioning the packaging in strong competition; packaging thus represents an element of marketing. By using advance testing, choosing wrong design elements, which may lead to additional costs associated with redesign, can be avoided; and, above all, potential consumer response can be researched in advance, prior to placing the packaging on the market. It is important to bear in mind that in today's competitive market only some of the new products will make it. In future research on product salience on the shelf, it may be worth comparing the product positioned in different parts of the shelf, as we know that different locations of the product on the shelf play a role in how quickly the product is found; another factor is also the number of other product on the shelf.

\section{REFERENCES}

[1] Ampuero, O., Vila, N.: "Consumer perceptions of product packaging", Journal of Consumer Marketing 23 (2), 100-112, 2006. doi: 10.1108/07363760610655032.

[2] Clark N.: "70\% of purchasing decisions are made in-store", URL: https://economictimes.indiatimes.com/70-of-purchasing-decisions-are-made-instore/articleshow/3816087.cms?from=mdr (last request: 2020-08-10).

[3] Giovannetti, V. M. D.: "El mundo del envase: Manual para el diseño y producción de envases y embalajes", (Editorial Gustavo Gili, México, 1995.).

[4] Hochberg, J.: "Perception (Prentice-Hall foundations of modern psychology series)", (Prentice-Hall, New Jersey, 1978.).

[5] International Organization for Standardization, ISO 3664:2009 Graphic technology and photography - Viewing conditions, International Organization for Standardization, 2009.

[6] International Organization for Standardization, ISO 9241-303:2011, Ergonomics of human-system interaction - Part 303: Requirements for electronic visual displays, International Organization for Standardization, 2011.

[7] Morgan, T.: "Visual Merchandising", (Laurence King Publishing, London, 2016.).

[8] Rayner, K., Timothy, J., Slattery, T. J., Bélanger, N. N.: "Eye movements, the perceptual span, and reading speed", Psychonomic Bulletin and Review 17, 834-839, 2010. doi: 10.3758/PBR.17.6.834.

[9] Reiner T., Rose D.: "Packaging design VS. conventional advertising, Austropack", URL: http://www.berndtundpartner.de/images/pdf/veroeffentlichungen/2002/article_designvsadvertising.pdf (last request: 2020-08-08).

[10] Sleever International: "Fructis - a green shelf revolution", URL: http://www.sleever.com/article/fructis-a-green-shelf-revolution (last request: 2020-08-05).

[11] Stephenson A.: "One, two seconds ... the time your package has to engage your shopper", URL: https://explorerresearch.com/optimize-your-package/ (last request: 2020-07-10).

[12] Tobi Pro: "Working with Heat Maps and Gaze Plots", URL: https://www.tobiipro.com/learn-andsupport/learn/steps-in-an-eye-tracking-study/interpret/working-with-heat-maps-and-gaze-plots/ (last request: 2020-08-08).

[13] Wedel, M., Pieters, R.: "Eye Tracking for Visual Marketing", Foundations and Trends in Marketing 1 (4), 231-320, 2008. doi: 10.1561/1700000011. 


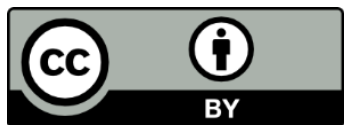

(C) 2020 Authors. Published by the University of Novi Sad, Faculty of Technical Sciences, Department of Graphic Engineering and Design. This article is an open access article distributed under the terms and conditions of the Creative Commons Attribution license 3.0 Serbia (http://creativecommons.org/licenses/by/3.0/rs/). 


\title{
CHILD-RESISTANT FEATURES OF PHARMACEUTICAL PACKAGING IN THE EGYPTIAN AND GLOBAL MARKET; A COMPARATIVE STUDY
}

\author{
Mai Ahmed S. Hussein ${ }^{1}$ (D), Mohamed Attia ${ }^{2}$ (D), Noha Mohamed ${ }^{2}$ (i) \\ ${ }^{1}$ Higher Institute of Applied Arts, Printing, Publishing \& Packaging, New Cairo, Egypt \\ ${ }^{2}$ Helwan University, Faculty of Applied Arts, Printing, Publishing \& Packaging, Helwan, Egypt
}

\begin{abstract}
Child-Resistant packaging is substantial requirement especially when it is related to pharmaceuticals. Children under five years old are the most groups in risk of drug poisoning, as a result of their constant passion and attracting their attention to medicines, especially the distinctive color and small size. Due to the presence of medicines for adults, especially chronic diseases that require the presence of the drug always at home with exciting properties for the passion of a young child who is affected by colors and the small size which they can insert easily into their mouths.

The child-resistant features attached to packages may present a problem (e.g., how to open the package) to its potential user (child or adult). Many of these features are used with the primary packaging and less for the secondary ones. Are these features efficient with available cost or not. Evaluation of each one might be varied according to package structure, level and child behavior.

Therefore, the importance of adding some features in the pharmaceutical packaging Child-Resistant, in order to achieve the safety of children with a targeted age (children under 5 years old).

By adding these special properties to the pharmaceutical packaging it will affect the design of the pharmaceutical packaging.

Finally, this paper aimed to review and evaluate the child resistant features \& securing methods that are used with pharmaceutical products in the Egyptian market, with which are available globally, then make a comparison between them by description and analysis.
\end{abstract}

Keywords: Blister Packaging, Strip packaging, Child-Resistant C.R, bills, Seal. OTC

\section{INTRODUCTION}

Packaging can be defined as an economical means of providing presentation, protection, identification information, containment, convenience and compliance for a product during storage, carriage, display and until the product is consumed. Packaging must provide protection against climatic conditions biological, physical and chemical hazards and must be economical. The package must ensure adequate stability of the product throughout the shelf life (Shete et al, 2020).

Pharmaceutical packaging firms are some of the industry's leading innovators evident by the recent advancement in technology. The current trends are result of continuous series of challenges faced by industry. Packaging is a science which is continuously evolving and is a major success contributor for pharmaceutical industries (Nasa, 2014). According to Poison Prevention Packaging Act (PPPA), the child resistant packaging should be designed or constructed so as to be significantly difficult for children under five years of age to open within a reasonable time, so as to get a toxic effect of substance contained and also not difficult for normal adults to use properly (Sangeeta and Gupta 2015).

As regards socio-demographic data, the highest percentage of children admitted to the poison center $(44.8 \%)$ was in the age group of 3-5 years. At this age, children usually gain motor independence and they go around actively exploring their environment. Therefore, children become highly mobile and able to get into dangerous situations quickly. Additionally, children at that age have well developed skills to locate and ingest liquids and solids, but are unable to discriminate rapidly between edible liquids and solids from toxic ones. It's reported that the peak of accidental poisoning was seen in children between 2-5 years, (Maklad et al, 2012).

Through this research Child-resistant features at different types of pharmaceutical packages used in the Egyptian and Global market will be evaluated and compared.

\subsection{Types of package}

There are three level/ types of packaging; they can be described as the following (Kulkarni and Agrawal, 2015; Nasa, 2014): 
- Primary packaging : is the material that first envelops the product and holds it i.e., those package components and subcomponents that actually come in contact with the product, or those that may have a direct effect on the product shelf life e.g., ampoules and vials, prefilled syringes, IV containers, etc. (Kulkarni and Agrawal, 2015).

The main aim of primary package is to protect the formulation from environmental, chemical, mechanical and/or other hazards (Nasa, 2014).

- Secondary packaging : The package external to Primary package is known as secondary package. This package provides additional protection during warehousing and also provides information about drug product for e.g. Leaflets (Nasa, 2014).

- Tertiary packaging: is used for bulk handling and shipping e.g., barrel, container, edge protectors, etc. (Kulkarni and Agrawal, 2015). The most common form is a palletized unit load that packs tightly into the container (Nasa, 2014).

This paper will focus on studying the primary packaging of solid forms of packaging, as it is considered the first risk to the child as a result of the granular shape of tablets and colored pills that are similar to their colored candies in both size and color

\section{CHILD-RESISTANT PACKAGING}

\subsection{Child-resistant packaging definition :}

Child-resistant packaging (CRP) or C-R packaging is special packaging used to reduce the risk of children ingesting dangerous items. The CRP containers defy penetration by children but can be opened by adults. This is often accomplished by the use of a special safety cap with locking mechanism. In developed countries like UK, it has been made compulsory to pack drugs like Aspirin, Paracetamol, Elemental iron, Contraceptives and many other drugs to be packed in CRP (Zadbuke and Shahi, 2013).

\subsection{Importance of using Child-resistant features at pharmaceutical packaging:}

Medications are high on the list of pediatric toxins and are to blame for hundreds of thousands of incidents each year. Part of the problem is that parents may not be aware that child-resistant packaging isn't childproof, and that even young children have the dexterity to eventually open these containers. There are certain common medications and substances that may place a child at greater risk for fatality, such as antidepressants, prenatal iron supplements, and salicylates, all of which have been reported to cause severe toxicity in toddlers (Maklad et al, 2012).

Further compounding the aforementioned problems are two other phenomena that cannot be ignored (Chen, 2015):

- Children are becoming increasingly skillful at younger and younger ages. Tablets, smartphones and gaming systems, many of which contain software applications and games intended for toddlers and preschoolers, have improved children's fine motor skills and made it easier for them to interpret symbols.

- Children are around more medicine than ever before. The "typical" household is changing; increasing numbers of grandparents reside in homes with small children.

\subsection{General Classification of packaging requirements for polymers:}

Child-resistant is one of the five basic requirements for pharmaceutical packaging which can be classified as shown in Figure 1 (Lyashenko et al, 2018):

- Senior friendliness.

- Hermetically sealed.

- Modularized machinery.

- Easy dispensing.

- Child-resistant. 


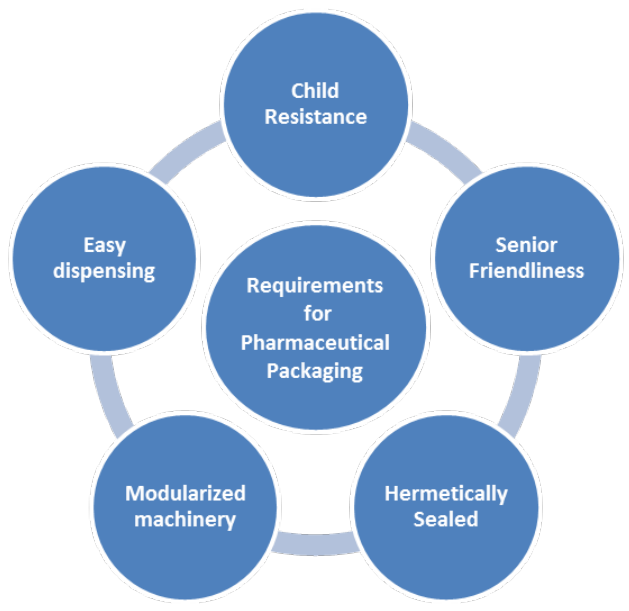

Figure 1: General classification of Packaging requirements for polymers

\subsection{Factors affecting Child-resistant:}

Child resistance is a factor of the packaging system and containers and closures must be tested together. Should aspects of the packaging system change it may be necessary to vary the marketing authorization and include additional evidence that the new packaging system has been shown to comply with the relevant international standard. Factors which may affect the child resistant properties of a containerclosure system include (but are not restricted to) (Malhotra et al, 2013):

- Change in foil material.

- Change in blister material.

- Change in adhesive.

- $\quad$ Different orientation of blister pockets.

- Different wadding materials in closures.

- Inclusion of a liquid medicine in a container-closure system previously used for solid dosage forms.

\subsection{Pharmaceutical packaging closing systems for solid forms:}

We should pay attention to the securing against tampering of pharmaceutical packages, as it is considered the first obstacle for the child before opening the package for the first time, so it must be taken into consideration.

\section{- Tamper-Evident Containers:}

Are closed containers fitted with a device that irreversibly indicates if the container has been opened. As shown in figure 2 \& figure 3. (Shete et al, 2020)

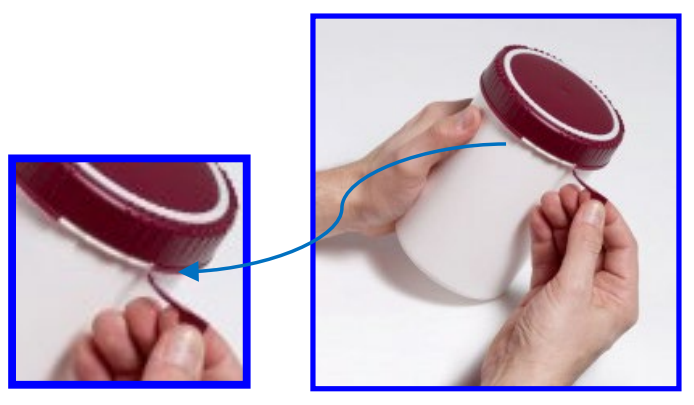

Figure 2: Tamper-Evident Containers

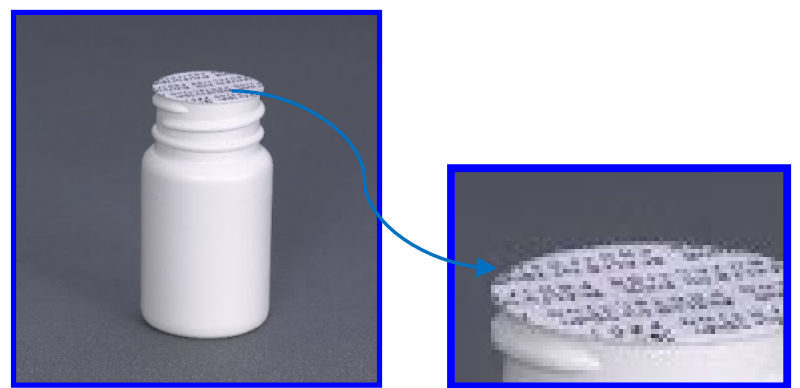

Figure 3: Tamper-Evident Containers 
We should also pay attention to the effect of the cap design in the repeated opening operations, as a large proportion of medicines require taking them for a certain period, not once, and throwing the package after that. Therefore, attention must be paid to the repeated use of different caps

There are many shapes and designs for caps, and some but not all of them will be covered in the evaluation process later.

- Strip packages:

Figure 4, have at least one sealed pocket of material with each pocket containing a single dose of the product. The package is made of two layers of film or laminate material. The nature and level of protection which is required by the contained product will affect the composition of these layers. (Shete et al, 2020)

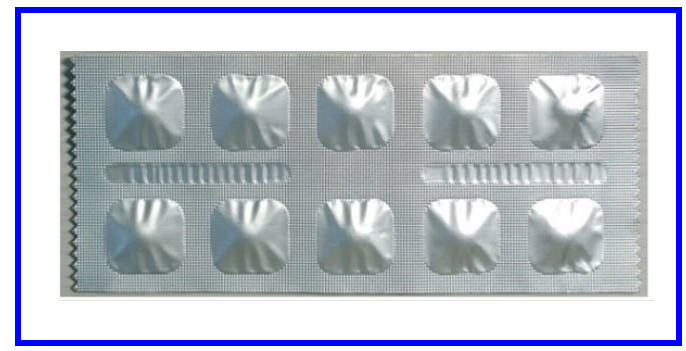

Figure 4: Strip packages

\section{- Blister packages:}

Figure 5, Are composed of a base layer, with cavities called blisters which contain the pharmaceutical product, and a lid. This lid is sealed to the base layer by heat, pressure or both. They are more rigid than strip packages and are not used for powders or semi-solids. In tropical areas blister packages with an additional aluminum membrane is used which provide greater protection against high humidity. (Shete et al, 2020)

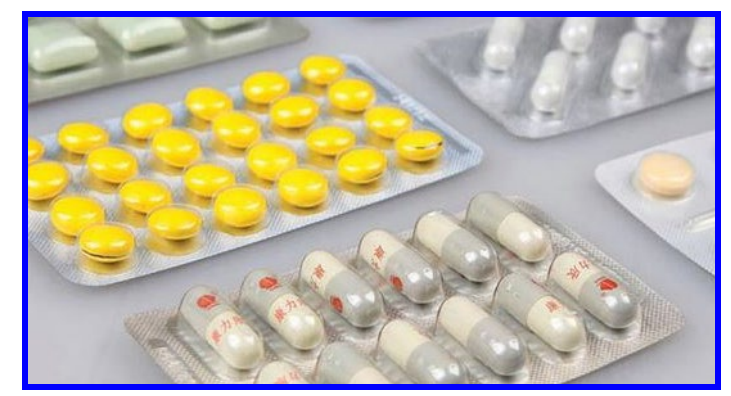

Figure 5: Blister packages

- Child Resistant Containers:

Figure 6 \& Figure 7, commonly referred to as CRC's, are designed to prevent the child accessing the potentially hazardous product. (Shete et al, 2020)

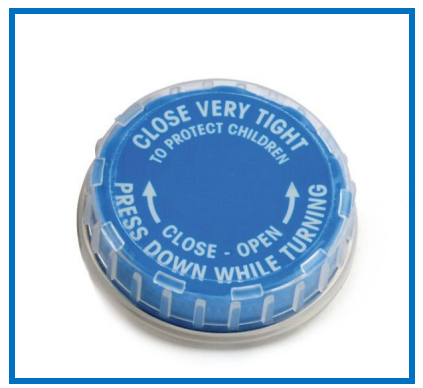

Figure 6: child-resistant Containers

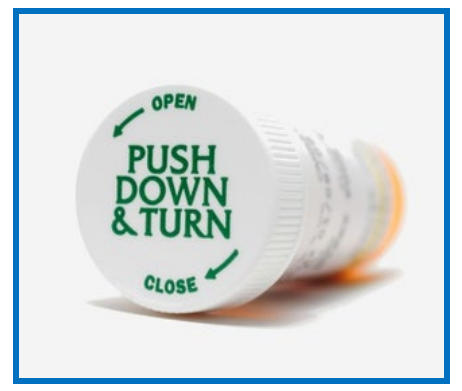

Figure 7: child-resistant Containers 
It should be noted that there are many designs of caps to secure against opening by children and the most common is what has been mentioned.

\section{REQUIRMENTS TO DEVELOP CHILD RESISTANT PACKAGING}

In essence, there are five principle activities that have been used to develop child resistant packaging over the past several decades. These include, requiring the user to (Chen, 2015):

1. Perform two deliberate and different simultaneous motions.

2. Perform a hidden alignment.

3. Have adult strength.

4. Have an adult-sized finger or hand.

5. Have a tool.

Through this table1, the main points will be reviewed in detail for developing the child-resistant packaging feature, with illustrations showing the required movement.

Table 1 (part1): Main Principles to develop Child-resistant Packaging

\begin{tabular}{|c|c|c|c|c|c|}
\hline \multicolumn{9}{|c|}{ Main Principles to develop Child-resistant Packaging. } \\
\hline \multicolumn{2}{|c|}{} & $\begin{array}{c}\text { Two } \\
\text { deliberate } \\
\text { and different } \\
\text { simultaneous } \\
\text { motions }\end{array}$ & $\begin{array}{c}\text { Perform a } \\
\text { hidden } \\
\text { alignment }\end{array}$ & $\begin{array}{c}\text { Requiring } \\
\text { the user to } \\
\text { have adult } \\
\text { strength }\end{array}$ & $\begin{array}{c}\text { have an } \\
\text { adult- } \\
\text { sized } \\
\text { finger or } \\
\text { hand }\end{array}$ \\
\hline
\end{tabular}


Table 1 (part2): Main Principles to develop Child-resistant Packaging

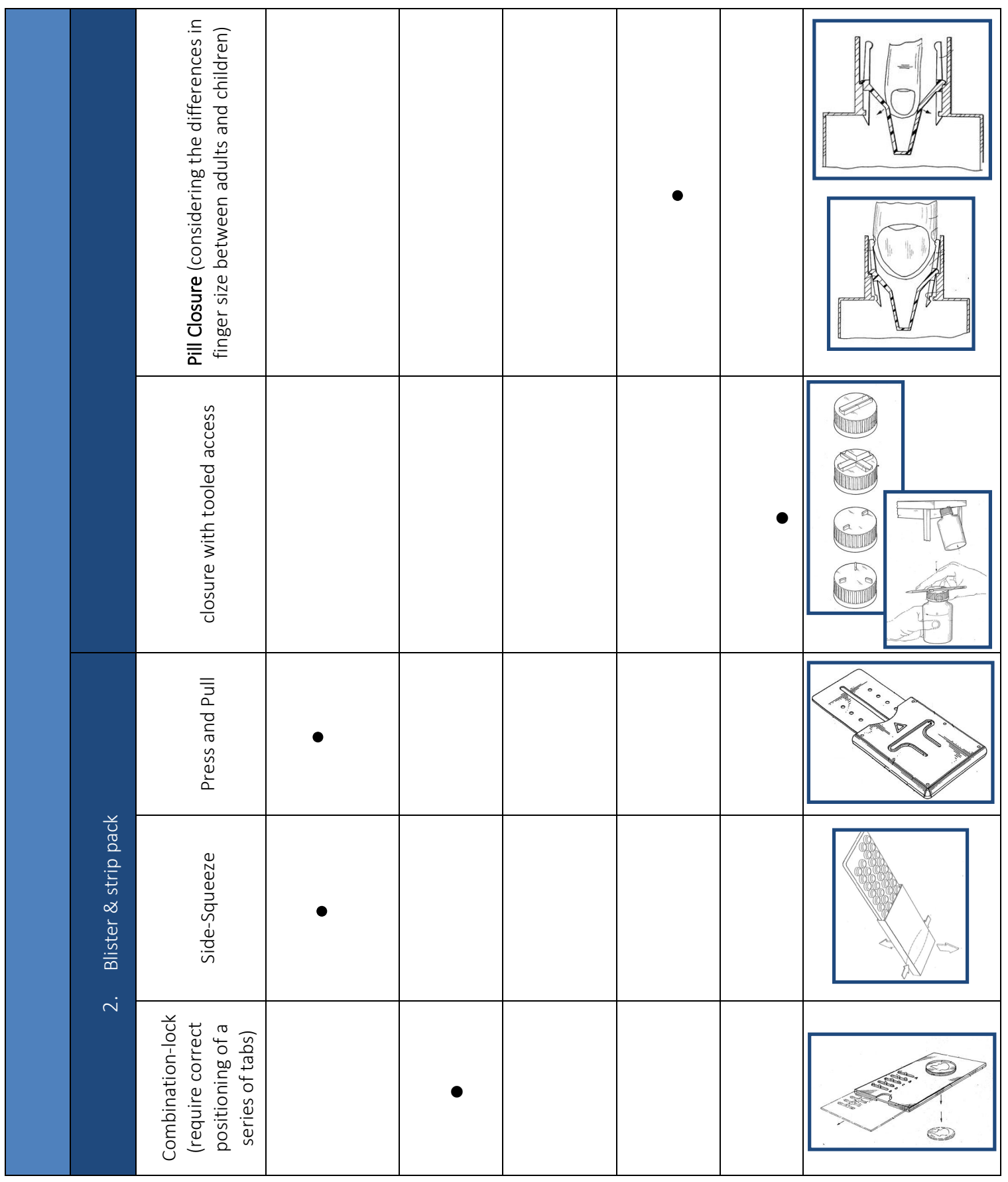




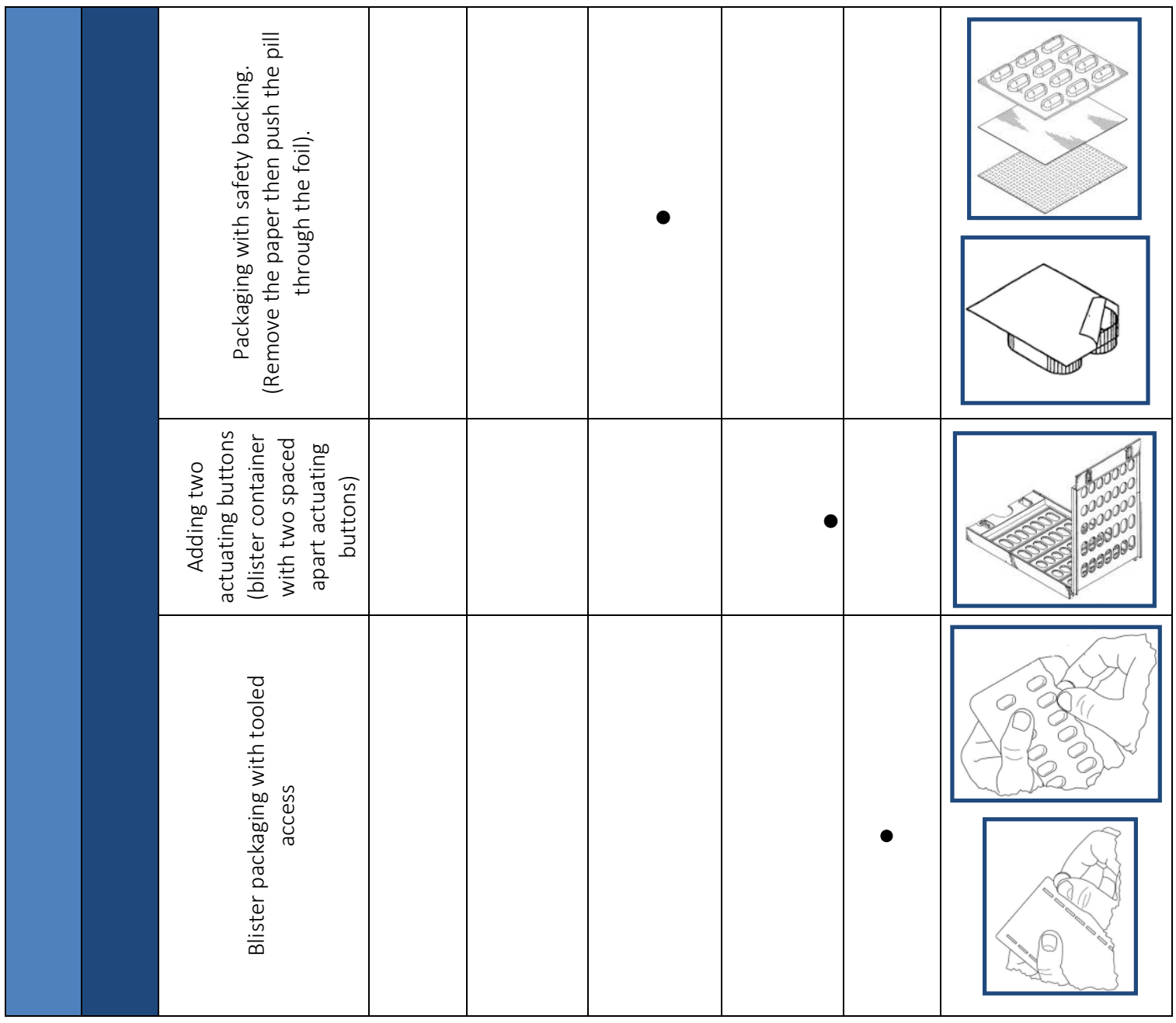

\section{RESULTS \& DISCUSSION}

After reviewing the Egyptian pharmaceutical market, it was found that one of the characteristics of protecting children from the danger of poisoning has been applied, which is the child resistant features by applying it at the cap of medicine bottles, but when looking at the strip and blister packaging, there was no application for the child-resistant features except for the feature "Packaging with safety backing" on some medicines only. While the child-resistant features have not yet been implemented at the rest of the medicine, as shown in Table 2.

Table 2: Availability of child-resistant features at pharmaceutical packaging in Egypt.

\begin{tabular}{|l|c|c|}
\hline Child-Resistant Features & Closures & Strip \&blister Packs \\
\hline \begin{tabular}{l|l|}
\hline 1. Press and Turn \\
\hline 2. Squeeze and Turn
\end{tabular} & - & - \\
\hline 3. Combination-lock (Line-up, snap-off closures) & - & - \\
\hline 4. Pill Closure & - & - \\
\hline 5. Closure with tooled access & - & - \\
\hline 6. Press and Pull & - & - \\
\hline 7. Side-Squeeze & - & - \\
\hline 10. Packaging with safety backing & - & - \\
\hline 11. Adding two actuating buttons & - & - \\
\hline 12. Blister packaging with tooled access & - & - \\
\hline 13. Closure with tooled access & - & - \\
\hline
\end{tabular}


From Table 2, it can be summarize that in Egypt we can find the child-resistant features has been applied in the caps of pharmaceutical bottles, but in the blister \& strip pack was found that it applied only with the features "packaging with safety backing" and wasn 't applied with the other types of medicines.

\section{CONCLUSION}

As a final result, the researchers can conclude the importance of the presence of the property of Childresistant features in all types of medicines, especially in primary packaging, and we can notice that the developed countries of the world besides some of the developing are continuously creating and developing guidelines for each type of pharmaceutical packaging, it's noticed that in Egypt, for example, there are some bottled medicines with Child-resistant features, but the cartoon types (blister and strip packaging) with child-resistant features have not yet been fully produced. But they have been started to produce one type until now from the child resistant blister \& strip packaging. So this research highlights the importance of reaching the implementation of Child-resistant features in the blister and strip pharmaceutical packaging, as a complement to the protection of children under the age of five years.

\section{REFERENCES}

[1] Chen, R.: "Visual distraction as a means of enhancing child resistance", MSc thesis, Michigan State University, 2015.

[2] Fuente, C.J.: "The use of a universal design methodology for developing child-resistant drug packaging", MSc thesis, Michigan State University, 2006.

[3] Kulkarni, S., Agrawal, A.: "Creative Innovations in Pharmaceutical Packaging", Indian Journal of Pharmacy and Pharmacology 2 (4), 230-235, 2015. doi: 10.5958/2393-9087.2015.00009.6.

[4] Lorenzini, G.C.: "Toward inclusive pharmaceutical packaging an innovation and design process perspective", MSc thesis, University of Lund, 2018.

[5] Lyashenko, V., Sotnik, L., Babker, A.M.: "Features of Packaging from Polymers in Pharmaceutics", Saudi Journal of Medical and Pharmaceutical Sciences 4 (2), 166-174, 2018, doi: 10.21276/sjmps.2018.4.2.2.

[6] Maklad, A.I., Emara, A., Elmadah, E.: "Pediatric poisoning in egypt", Journal of Applied Pharmaceutical Science 2 (2), 01-06, 2012.

[7] Malhotra, S., Arora, R.K., Singh, B., Gakhar, U., Tonk, R.: "Child Resistant Packaging: A Prime Concern for Packaging of Medicinal Products", International Journal of Pharmaceutical Sciences Review and Research 22 (2), 2013.

[8] Nasa, P.: "A review on pharmaceutical packaging material", World Journal of Pharmaceutical Research 3 (5), 344-368, 2014.

[9] Sangeeta, S., Gupta, M.: "Critical survey on the guidelines under recommendation of child resistant packaging for pharmaceutical products", International Journal of Drug Regulatory Affairs 3 (3), 3641, 2018. doi: 10.22270/ijdra.v3i3.170.

[10] Shete, N.A., Mohan R.S., Kotame R.N., Gore S.J. and Tagad R.R.: "Changing scenario of packaging in pharmaceutical industry", World Journal of Pharmaceutical Research 9 (1), 1728-1808, 2020. doi: 10.20959/wjpr20201-16569.

[11] Zadbuke, N., Shahi, S.: "Recent trends and future of pharmaceutical packaging technology", Journal of Pharmacy and Bioallied Sciences 5 (2), 2013. doi: 10.4103/0975-7406.111820.

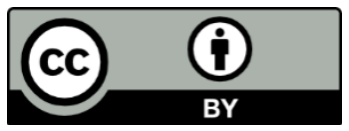

(C) 2020 Authors. Published by the University of Novi Sad, Faculty of Technical Sciences, Department of Graphic Engineering and Design. This article is an open access article distributed under the terms and conditions of the Creative Commons Attribution license 3.0 Serbia (http://creativecommons.org/licenses/by/3.0/rs/). 


\title{
BIOBASED INTELLIGENT PACKAGING APPLICATION
}

\author{
Aslı Beyler Çiğil (D) \\ Amasya University Technical Sciences Vocational, Department of Chemistry and Chemical \\ Process Technology School, Amasya, Turkey
}

\begin{abstract}
Changes in consumer preferences in order to reach safe food have led to innovations in packaging technologies. Intelligent and active packaging is a constantly developed packaging technology that plans to offer safer and higher quality products. Active packaging refers to the inclusion of additives in the package in order to maintain and / or extend shelf life and product quality. Intelligent systems, on the other hand, are systems that monitor the status of packaged food during this entire period to provide information about the quality of the packaged during storage and transportation. The aim of this study is to produce a completely natural intelligent packaging material using rosehip extract and biopolymer, which is a substance that naturally changes color with $\mathrm{pH}$. In this study, cellulose acetate butyrate biobased films containing different rates $(1,2.5,5,10 \mathrm{wt} \%)$ of rosehip extract were produced by solvent casting method. The chemical structure the rosehip containing biobased film and blank biobased film were characterized by ATR-FTIR. The transparency of prepared five different films were determined by UV spectroscopy. The color characteristic of blank and rosehip containing films measured with spectrophotometer. Surface energy of all films and contact angles were determined with goniometer. Biobased films were printed and printability parameters such as color, gloss, contact angle, surface tension were examined. It is concluded that blank biobased film is colorless, transparent and all biobased films have good printability. It was determined that the amount of rosehip extract increased the color change visibly. The biobased films obtained are pink in acidic medium and yellow-green in alkaline medium. The results prove that biobased film produced with rosehip extract and cellulose acetate butyrate can be used in intelligent packaging applications.
\end{abstract}

Keywords: intelligent packaging, biobased films, rosehip, indicator

\section{INTRODUCTION}

Packaged foods such as takeaway and fast food have become an important component of daily life with the intensification of business life. The safety of all food used is the most important element of public health in the society (Ghasemi-Varnamkhasti et al, 2018). Perishable foods seriously adversely affect people's health, but determining the freshness of some foods is very difficult (Idumah et al, 2020). Oldstyle food packaging methods are not intended to provide information about freshness, but only to protect food from external factors. Compared to the old-style packaging, smart packaging can provide information about the freshness of the packaged food, so the need for the development of new packaging has increased in order to preserve and determine the freshness of food. pH-sensitive packaging is defined as packaging on which a small and inexpensive pH-sensitive label is affixed to examine the freshness of the packaged food. When food spoilage begins, large amounts of inorganic or organic compounds are released and these compounds change the chemical component content, moisture and $\mathrm{pH}$ of the food. Developing a $\mathrm{pH}$ sensitive color-changing label or pattern on a food packaging can be a quick indicator of food freshness. They can be more time-saving, cheap, convenient and simple compared to the old-fashioned food packaging procedure (Liu et al, 2019; Zhang et al, 2019). Cellulose acetate butyrate (CAB) is a thermoplastic ester of cellulose, the most abundant natural polymer in nature. It contains $30 \%$ to $55 \%$ by weight of butyryl groups. It is a commercially important cellulose ester and has many attractive properties such as high transparency, improved resistance to moisture and ultraviolet light (UV), low viscosity, good interlayer adhesion and surface gloss. Cellulose acetate butyrate is compatbile with many different resin systems, including most acrylic, polyester, phenolic, ureas and isocyanates. $C A B$ has been an important component for coating formulations because it controls viscosity, improves leveling and flow, and reduces drying time (Saha et al, 2018; Laíse et al, 2020; Furtado et al, 2020). Cellulose acetate butyrate biocompatibility allows it to be used in applications such as antibacterial coatings, drug release system (Edgar, 2007; Sobral et al, 2008; Shokri and Adibkia, 2013) tissue engineering and effective support for enzymes. 
This study evaluated the influence of different concentrations rosehip extracts in CAB (cellulose acetate butyrate) polymeric films made by solvent casting, evaluating the printability, chemical, surface properties and color changes with $\mathrm{pH}$ for their potential application in intelligent packaging.

\section{METHODS}

Rosehip extraction: Rosehips (rosehip purchased at a local market) used in extraction experiments were dry fruits from Turkey. Whole fruits were ground to particles that were smaller than $2 \mathrm{~mm}$ and $5 \mathrm{~g}$ of dry and ground plant material were mixed with $50 \mathrm{~mL}$ of water. The colored mixture was separated from the solid particles by filtration. Two thirds of the solvent of the mixture was removed in the vacuum evaporator. The produced concentrated rosehip-water mixture in red-pink color was used directly in biobased films.

Preparation of biobased films: Biobased films were prepared by dissolving 10 grams of CAB (cellulose acetate butyrate) (CAB was obtained from Sigma Aldrich) in $100 \mathrm{~mL}$ of acetone and stirred until complete dissolution into the shaker. Then, rosehip extract were added to the CAB solution according to Table 1. The solutions were poured onto glass plate and dried under room temperature. Subsequently, biobased films was removed from the glass plate and stored in a vacuum desiccator before use. The average thickness of the biobased films were $10 \mu \mathrm{m}$.

Table 1: The biobased film formulations.

\begin{tabular}{|c|c|c|c|}
\hline Formulation & $\begin{array}{c}\text { CAB(cellulose } \\
\text { acetate butyrate } \\
\%\end{array}$ & Water \% & $\begin{array}{c}\text { Rosehip } \\
\text { extract \% }\end{array}$ \\
\hline C & 10 & 100 & 0 \\
\hline CR1 & 10 & 100 & 1 \\
\hline CR2.5 & 10 & 100 & 2.5 \\
\hline CR5 & 10 & 100 & 5 \\
\hline CR10 & 10 & 100 & 10 \\
\hline
\end{tabular}

Determination of printability: Base formulation film (C formulation) and rosehip added biobased films (CR1, CR2.5, CR5, CR10) were printed with IGT C1 test printing machine using equal amount of process magenta ink (DIN ISO 2846-1). Printing parameters; $0.2 \mathrm{~m} / \mathrm{s}$ printing speed and $300 \mathrm{~N}$ printing pressure. The polymeric ink film thickness of all biobased printed samples was measured as $5 \mu \mathrm{m}$.

Characterization: The color absorption character of rosehip dye with different $\mathrm{pH}$ was characterized with Shimadzu UV-Vis spectrophotometer 2450 (Kyoto Jap).

The transmission spectra of the biobased films were recorded in the wavelength range of 500-900 nm using a Shimadzu UV-vis spectrophotometer 2450 (Kyoto Jap).

Structural properties of all biobased films were measured with ATR-FTIR spectrum with Perkin Elmer Spectrum100 ATR-FTIR spectrophotometer.

The wettability properties of all biobased films were measured using the contact angle with the sessile water droplet method. The characteristics of surfaces were measured with contact angle (TAPPI T 458). Distilled water was used as standard wetting fluid in a Pocket Goniometer Model PG-X, (FIBRO Systems $A B$, Sweden), which was determined as a function of time.

Surface energies of all biobased films were measured on contact angle using ASTM D5946 standard test method.

The color measurements of the biobased films and prints on different films were made by CIE L*a*b* procedure using X-Rite eXact spectrophotometer according to ISO 12647-2:2013 standard. The measurement conditions of the spectrophotometer are measured as polarization filter with $0^{\circ} / 45^{\circ}$ geometry with 2 observer angle with D50 light source in the range of $400-700 \mathrm{~nm}$. The difference between the colors of the different prints were calculated according to formula 1 according to the CIE $\triangle E$ 2000 ISO 13655 standard.

$\Delta E_{00}=\sqrt{\left(\frac{\Delta L^{\prime}}{k_{L} S_{L}}\right)^{2}+\left(\frac{\Delta C^{\prime}}{k_{C} S_{C}}\right)^{2}+\left(\frac{\Delta H^{\prime}}{k_{H} S_{H}}\right)^{2}+R_{T} \frac{\Delta C^{\prime}}{k_{C} S_{C}} \frac{\Delta H^{\prime}}{k_{H} S_{H}}}$ 
The gloss measurements of biobased films were carried out with BYK Gardner GmbH micro gloss 750 geometry in accordance with ISO 8254-1:2009, and the gloss measurements of prints with BYK Gardner GmbH micro Tri-gloss 60 geometry in accordance with ISO 2813:2014.

\section{RESULTS AND DISCUSSION}

The functional groups in different biobased films, C, CR1, CR2.5, CR5 and CR10 formulations were determined by ATR-FTIR spectrum, and the spectra was given in Figure 1.

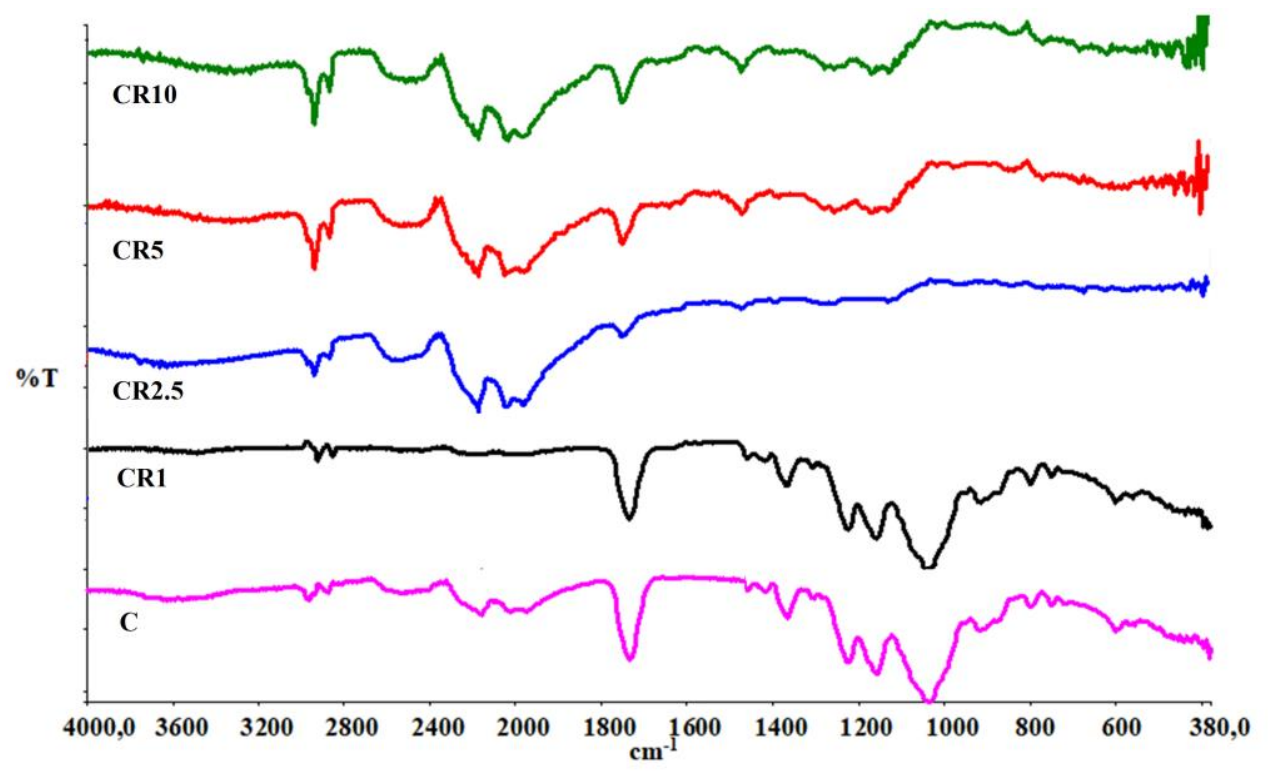

Figure 1: ATR-FTIR spectrums of all biobased films

The characteristic absorption bands that appeared at $2880 \mathrm{~cm}^{-1}$ in all the spectra, is due to the characteristic absorption peak of methylene associated with butyryl substituents in the cellulose acetate butyrate. The peak at approximately $1750 \mathrm{~cm}^{-1}$ represented ester carbonyl groups $(C=0)$ stretching vibrations in the cellulose acetate butyrate. The absorption peaks at 1050, 1238, 1376 and $3455 \mathrm{~cm}^{-1}$ were assigned $\mathrm{C}-\mathrm{O}$ stretching, $\mathrm{C}-\mathrm{O}-\mathrm{C}$ ether stretching vibration, $\mathrm{C}-\mathrm{H}$ bending and $\mathrm{O}-\mathrm{H}$ stretching vibration, respectively. The presence of metabolites such as phenolic acids, tannins, fatty acids, proanthocyanidins, flavonoids, pectin, fruit acids, sugars and carotenoids, such as malic acid, ascorbic acid and citric metabolites with antioxidant activity are known in fruits (rosehip) (Aimin Huang et al, 2020) Therefore, strong $\mathrm{O}-\mathrm{H}$ peaks are expected in CR1, CR2.5, CR5 and CR10 film spectra, but these peaks are not seen due to esterification between rosehip and CABs.

When Figure 2 is examined, it is determined that maximum absorbance of rosehip dyestuff in water shows a peak at $465 \mathrm{~nm}$. Absorption of the rosehip is compatible with magenta-red color. In addition, the obtained UV spectrum is in line with literature (Go and Song, 2019). In the UV spectrum, at acidic pHs, the wavelength value (also color) did not change, while the absorption value increased. So the color has become darker. In the UV spectrum, at alkaline pHs, the wavelength value (also color) changed and was determined to be $685 \mathrm{~nm}$. This value is compatible with the yellow-green color. The absorption value has decreased, is the color has become lighter. 


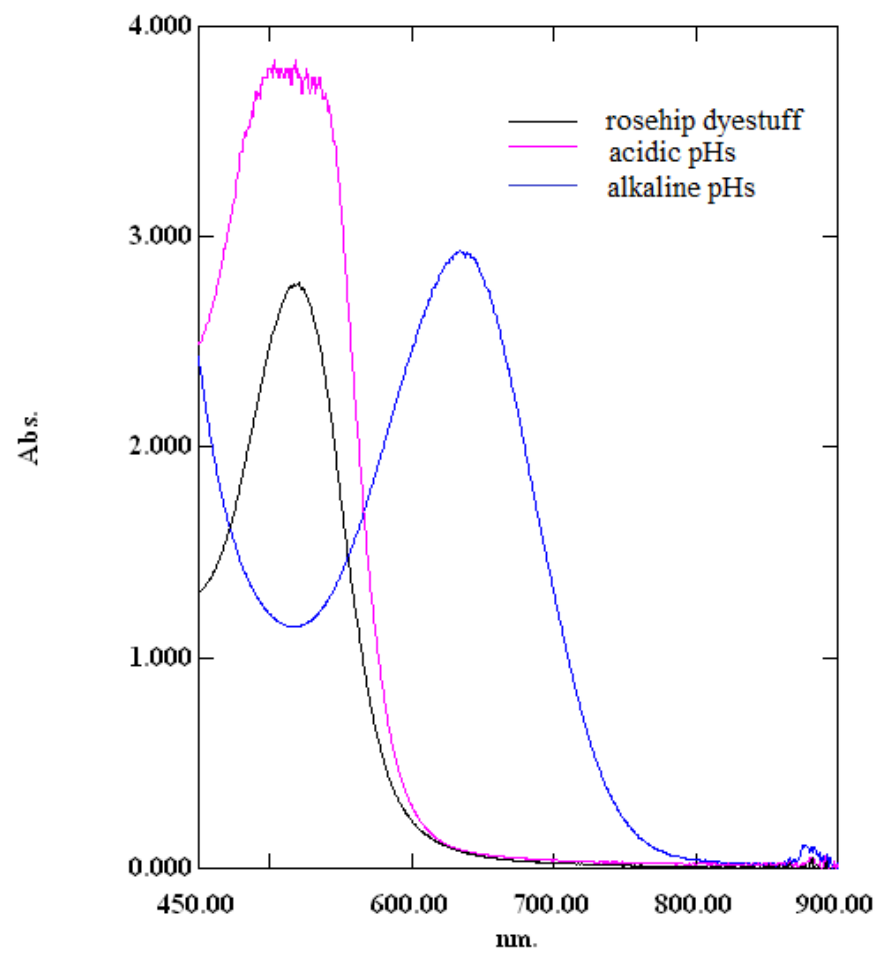

Figure 2: UV-vis absorption spectra of rosehip dyestuff

The optical transparencies of rosehip containing biobased films were characterized by UV-vis spectroscopy. Figure 3 shows the transmission spectra of rosehip containing films in the range between 500 and $900 \mathrm{~nm}$. Rosehip containing biobased films transmittance value is at $620 \mathrm{~nm}$. When the Figure 3 examined It was seen that transmittance of rosehip containing biobased macromolecular films decreased with increasing amount of rosehip amount. Since even the least amount of rosehip (CR1) causes an effective reduction in transparency, attention should be paid to its use in packaging applications that should be transparent. The obtained results are compatible with the literature (Çakmakçı and Güngör, 2013).

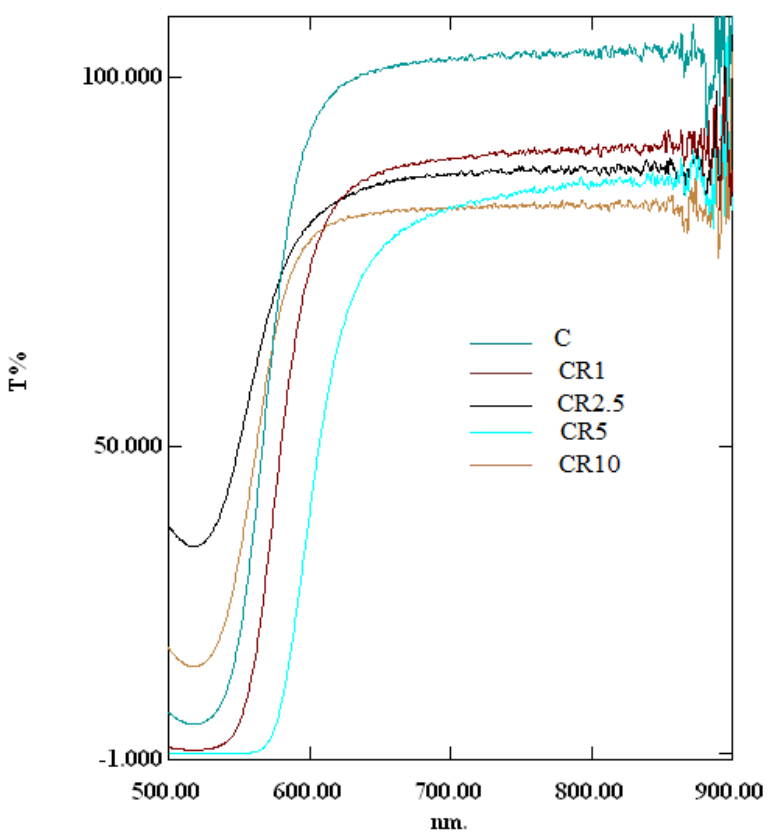

Figure 3: UV transmittance of all biobased films 
The color values of the biobased films in acidic condition and alkaline condition are given in Table 2. Color differences were calculated by delta $\mathrm{E}$ of films (C, CR1, CR2.5, CR5 and CR10) how it differs from acidic and alkaline conditions. When the table is examined, it is seen that the colors of the biobased films are brown-red in acidic conditions. However, when the films are brought into contact with the base, the colors suddenly turn green. The change in colors can be perceived by the eye, as well as evidenced by spectral measurements. When the color differences in acidic and alkaline conditions were examined, it was determined that the difference was 7.93 even in the formulation containing the least rosehip extract. As the amount of rosehip extract increases, the color difference increases rapidly. However, as the amount of rosehip extract increases, areas of different color intensity (heterogeneous colored regions) may occur on the film. It can be planned to be used in smart packaging applications because of the color change feature of rosehip at different $\mathrm{pH}$ and color change will occur due to bases such as ammonia released from spoiled foods. When the gloss value was examined, it was measured that the gloss of all biobased films was close to each other. However, as the amount of rosehip increases, there is a small decrease in gloss. This is due to the roughness of the surface.

Table 2: Color and gloss properties of biobased films

\begin{tabular}{|c|c|c|c|c|c|c|c|}
\hline Formulation & $L^{*}$ & $a^{*}$ & $\mathbf{b}^{*}$ & Image (acid) & $\begin{array}{l}\text { Image } \\
\text { (base) }\end{array}$ & $\Delta \mathrm{E}_{00}$ & Gloss \\
\hline C & 83 & -1 & 2 & & & 1.62 & 28 \\
\hline CR1 & 58 & 12 & 43 & & & 7.93 & 26 \\
\hline CR2.5 & 44 & 14 & 41 & 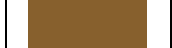 & & 15.02 & 26 \\
\hline CR5 & 26 & 20 & 32 & & & 23.72 & 25 \\
\hline CR10 & 23 & 21 & 28 & & & 25.09 & 24 \\
\hline
\end{tabular}

The surface energies and water contact angles (WCA) of the biobased films are presented in Table 3. The WCA of base formulation film (C) was found as $72.7^{\circ}$. When rosehip extract was added to $C$ film, the contact angle increased to $76.7^{\circ}$. As the amount of rosehip in the formulation increases, the contact angle increases slightly. The reason for this is that the rosehip creates some indentation on the surface and therefore the lotus effect occurs.

Table 3. Total surface energy and contact angle values of the all biobased films

\begin{tabular}{|c|c|c|}
\hline Formulation & $\begin{array}{c}\text { Surface Energy } \\
\left(\mathbf{m J} / \mathbf{m}^{\mathbf{2}}\right)\end{array}$ & $\begin{array}{c}\text { Contact Angle } \\
\left.\mathbf{(}^{\circ}\right)\end{array}$ \\
\hline C & 38.7 & 72.7 \\
\hline CR1 & 37.3 & 76.7 \\
\hline CR2.5 & 37.1 & 76.9 \\
\hline CR5 & 36.9 & 77.1 \\
\hline CR10 & 36.7 & 77.4 \\
\hline
\end{tabular}




\section{CONCLUSIONS}

When the data obtained were examined, it was concluded that the film containing rosehip could be used in active packaging. When the color results are examined, it is seen that the color is brown in acidic conditions and green in basic conditions, and the color difference varies between 7-25. This shows that the color change can be easily detected both with the eye and with the spectrophotometer. Thus, an inexpensive, easily detectable, effective active packaging material was produced. As the amount of rosehip added to the medium increases, the amount of active substance added should be kept under control, since heterogeneous color distribution is obtained. The gloss values of the film obtained are quite high. However, as the amount of rosehip increased, there was a slight decrease in gloss. Likewise, the contact angle increased slightly with the lotus effect caused by surface roughness. However, this increase can be ignored.

\section{REFERENCES}

[1] Aimin Huang, A., Wei, L., Zhao, Z., Wei, G., Zhang, Y., Huang, Z., Li, X., Hu, H., Qin, X., Yang, M.: “A comparative analysis of the preparation of cellulose acetate butyrate and the characteristics of applying in pearlescent coating film", Polymer Bulletin, 77, 2873-2887, 2020. doi: 10.1007/s00289019-02886-w.

[2] Çakmakçı, E., Güngör, A.: "Preparation and characterization of flame retardant and proton conducting boron phosphate/polyimide composites", Polymer Degradation and Stability 98 (5), 927-933, 2013. doi: 10.1016/j.polymdegradstab.2013.03.003.

[3] Edgar K. J.: "Cellulose esters in drug delivery", Cellulose, 14, 49 -64, 2007. doi: 10.1007/s10570006-9087-7.

[4] Furtado, L. M., Hilamatu, K. C. P., Balaji, K., Ando, R. A., Petri, D. F. S.: "Miscibility and sustained release of drug from cellulose acetate butyrate/caffeine films", Journal of Drug Delivery Science and Technology 55, 101472-101479, 2020. doi: 10.1016/j.jddst.2019.101472.

[5] Ghasemi-Varnamkhasti, M., Mohammad-Razdari, Ayat., Yoosefian S. H., Izadi, Z.: "Effects of the combination of gamma irradiation and $\mathrm{Ag}$ nanoparticles polyethylene films on the quality of fresh bottom mushroom (Agaricus bisporus L.)", Journal of Food Processing and Preservation 42 (7), 13652-13659, 2018. doi: 10.1111/jfpp.13652.

[6] Go, E. J., Song, K. B.: "Antioxidant properties of rye starch films containing rosehip extract and their application in packaging of chicken breast" Starch-Stärke 71 (11-12), 1900116, 2019. doi: 10.1002/star.201900116.

[7] Idumah, C. I., Zurina, M., Ogbu, J., Ndem, J. U., Igba, E. C.: "A review on innovations in polymeric nanocomposite packaging materials and electrical sensors for food and agriculture", Composite Interfaces 27 (1), 1-72, 2020. doi: 10.1080/09276440.2019.1600972.

[8] Liu, Y., Qin, Y., Bai, R., Zhang, X., Yuan, L., Liu, J.: "Preparation of pH-sensitive and antioxidant packaging films based on k-carrageenan and mulberry polyphenolic extract", International Journal of Biological Macromolecules 134, 993-1001, 2019. doi: 10.1016/j.ijbiomac.2019.05.175.

[9] Saha, N. R., Roy, I., Sarkar, G., Bhattacharyya, A., Das, R., Rana, D., Banerjee, R., Pau, A. K., Mishra, R., Chattopadhyay, D.: "Development of active packaging material based on cellulose acetate butyrate/polyethylene glycol/aryl ammonium cation modified clay", Carbohydrate Polymers 187, 818, 2018. doi: 10.1016/j.carbpol.2018.01.065.

[10] Shokri, J., Adibkia, K.: "Application of Cellulose and Cellulose Derivatives in Pharmaceutical Industries", In: Cellulose - Medical, Pharmaceutical and Electronic Applications, (IntechOpen Limited, London, 2013). doi: 10.5772/55178.

[11] Sobral, M. C. C. M., Sobral, A. J. F. N., Guthrie, J. T., Gil, M. H.: "Ketotifen controlled release from cellulose acetate propionate and cellulose acetate butyrate membranes", Journal of Materials Science: Materials in Medicine 19,677-682, 2008. doi: 10.1007/s10856-007-0168-4.

[12] Zhang, H., Hou, A., Xie, K., Gao, A.: "Smart color-changing paper packaging sensors with pH sensitive chromophores based on azo-anthraquinone reactive dyes", Sensors and Actuators B: Chemical 286, 362-369, 2019. doi: 10.1016/j.snb.2019.01.165. 


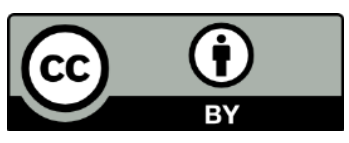

(C) 2020 Authors. Published by the University of Novi Sad, Faculty of Technical Sciences, Department of Graphic Engineering and Design. This article is an open access article distributed under the terms and conditions of the Creative Commons Attribution license 3.0 Serbia (http://creativecommons.org/licenses/by/3.0/rs/). 

PRINTING QUALITY

$-----$ 



\title{
COMPENSATION OF DEFECTS IN PRINTING PROCESS WITH HISTOGRAM METHODS
}

\author{
Ekaterina Pukhova (D), Vladislav Vereshchagin \\ Moscow Polytechnic University, Faculty of Information Technology, Moscow, Russia
}

\begin{abstract}
A method of image preparation for printing reproduction is suggested. This method allows to automatically compensate transformations that occur during reproduction, by analyzing a histogram of test chart image and based on it, creating a compensation pre-correction function. It also takes into consideration the visual perception of images. Pre-correction function is applied to images at the prepress stage after all other corrections. It is aimed to compensate defects, occurring at the printing stage, caused by the process of tone value increase and restriction of tonal range reproduction. It is suggested to use a test chart, which is a gradient with an even increase of lightness in the range from 0 to 255. After printing the test chart its digital image is created by scanning. Then Gaussian filter is applied to the image with parameters according to the visual perception, and lightness distribution histogram is calculated. This histogram will have changes in lightness distribution in comparison with the original digital image. These changes will correspond to the influence of tone value increasing process during printing. The cumulative sum is calculated from the received histogram, and the pre-correction is being formed. And this precorrection applies to an image, prepared for printing in similar conditions as test chart. The algorithm was written on Python and allows to create a pre-correction using a press sheet with the test chart. It is shown that the use of the suggested method gives a positive result and doesn't require expensive measurement equipment. Having a scanner calibrated for linear transmission of lightness and developed programming module is enough. This method was tested on electrographic printing equipment on three different types of paper. Statistic parameters of a histogram, such as mean, standard deviation and the Skewness, were used for evaluation. It is shown that the suggested method can be used as part of an automatized system based on histogram methods for image preparation before printing.
\end{abstract}

Keywords: tone value increase, histogram methods, pre-correction functions

\section{INTRODUCTION}

There are two main stages during the process of image reproduction: digital and printing. On the digital stage color and tone value correction, sharpness increase and compensation of defects, typical for the printing stage, using color management system is made (Hunt, 2004; Gonzalez \& Woods, 2018). Color management is the most automatized stage of whole process, but requires a huge amount of measurements, using a spectrophotometer and specialized software (Маргулис, Д, 2003).

On each stage of reproduction process image histogram changes (Пухова et al, 2018). This changes correlate with the degree and nature of the influence on the image. This correlation allows to use the image histogram as the main tool for controlling processes of correction and reproduction.

There is a suggested effective method of automatic correction of monochrome and colored images, using the law of normal distribution for histogram specification (Пухова and Андреев, 2017; Пухова and Андреев, 2014; Пухова and Андреев, 2018). This correction method removes gradation distortions, raises contrast and allows to reach psychological accuracy of tone perception in the image, intended for representation (Пухова and Андреев, 2017).

Digital imprint image histogram represents changes, depending on halftoning method, printing process and visual perception (Нюберг, Н.Д., 1947; Пухова et al, 2018). It means that a histogram contains information about main distortions, occurring during the printing process. There is an aim to develop algorithm that allows to consider printing distortions, during preparation for the printing stage, based on the analysis of the digital imprint image histogram. It creates a possibility to develop the unified automatized system of image preparation, minimizing costs for measuring equipment and simplifying of process.

\section{METHODS}

We will base on the fact that used materials and tone increasing process affect on the range of tone reproduction and distribution of tones inside the range (Пухова et al, 2016). Therefore, it is necessary to evaluate changes in the histogram during the printing process and calculate pre-correction function, using 
this information. This function is had to be applied to the image before printing. It is suggested to use histogram methods to solve the problem.

If there is the image histogram his $(I)=n_{i} / N$, where $I$ is the tone level, $n_{i}-$ number of pixels, corresponding to the level I, $\mathrm{N}$ is the number of pixels in the image, it is possible to count cumulative sum - cs (1).

$c s=\sum_{l=0}^{k} h i s(l) \quad k=0,1, \ldots, L-1$

There is the known method that allows to give base image histogram a shape of distribution close to the sample. In this case firstly cumulative sum is counted, then transformation function $T(I)=\operatorname{cs} \times 255$ is calculated and inverse function is applied to the equalized histogram of corrected image (Gonzalez and Woods, 2018).

$\operatorname{Tk}(I)=T^{-1}(I)$

This method showed itself well in correction of images from different sources and in bringing them to the unified view, when reproducing in one issue (Пухова and Андреев, 2018). It is suggested to develop the algorithm of pre-correction compensation of defects in printing process, based on this method.

It is necessary to evaluate the influence of printing process on tonal distribution in all range, for solving the problem of calculating pre-correction function, considering distortions of the printing process. Any changes in tone transmission during the printing process will change the shape of the histogram, therefore changes in the shape of the histogram will represent distortions of the printing process. The test image with equal distribution of tones in the range from 0 to 255 is used (Figure 1).

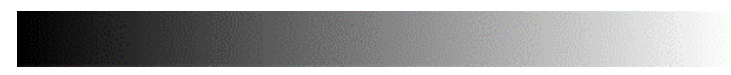

a)

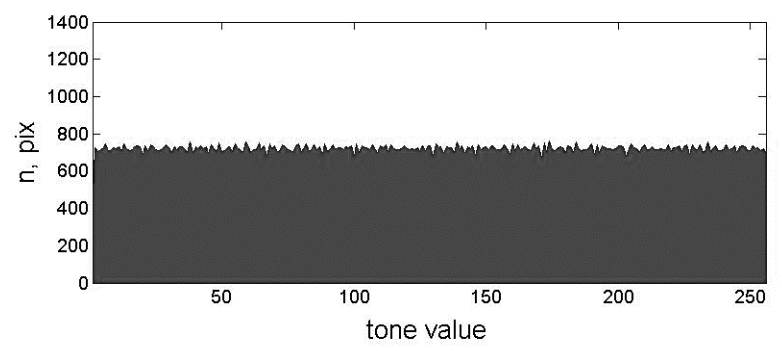

b)

Figure 1: The test image $-a$; The test image histogram $-b$

The test image is printed in the defined conditions. The press sheet is scanned with the test image to receive its histogram from the digital imprint image. There is only one requirement for scanner: linear tone transmission. Then it is required to reduce noises, formed because of screening structure of the image, to form the histogram. Gaussian blur filter is used with parameters calculated, based on resolution of digital imprint image and MTF of an eye. It allows to consider the visual perception of images. Methods of choosing filter parameters are described in the article (Гнибеда \& Андреев, 2016). After blur, the image histogram is received, then cumulative sum is counted (1), after that transformation function $T(I)$ and pre-correction functions (2) are counted. This pre-correction function will be applied to the test image, prepared for printing (Figure 2). 

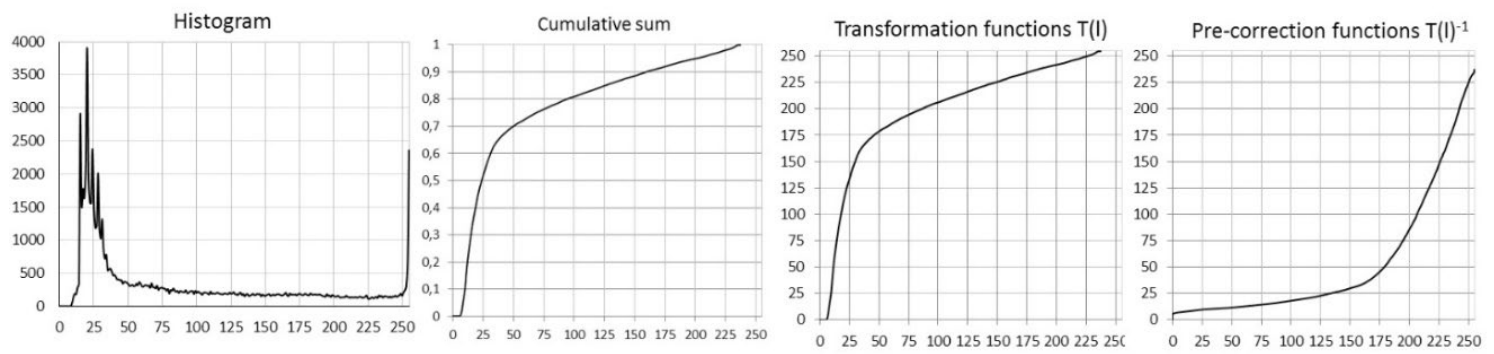

Figure 2: Receiving of pre-correction function

After that, the image is reprinted to receive digital imprint image histogram, which would be compared with the histogram of the original image.

Histograms can be compared both quantitatively and qualitatively. It is suggested to use histogram statistics for quantitative evaluation (Gonzalez and Woods, 2018).

The mean - $m$ shows an average value of lightness level in the image and allows to evaluate shifting of levels in light or dark zones of tonal range (3).

$m=\sum_{l=0}^{k} l P(l)$

The standard deviation $-\sigma$ allows to evaluate shifting of lightness levels in comparison with the mean (4).

$\sigma=\sqrt{\sum_{l=0}^{k}(l-m) P(l)}$

The Skewness - Skew shows asymmetry of histogram relative to the average value. If the value of Skew is negative, it means that histogram is shifted into the dark area, if Skew is positive, histogram is shifted into the light area (5).

Skew $=\frac{m-m e d}{\sigma}$,

where med - means median.

Comparing of these parameters, received from the original image and the digital imprint image, allows to evaluate distortions in tone transmission. Then closer would be these parameters, than more similar would be images in the tone transmitting.

\section{RESULTS}

The test image is screened with lineature $150 \mathrm{lpi}$ and printed on the electrographic printing machine Canon ImagePress C60 with standard profiles for different types of paper: glossy (gl), matte (mat) and without covering (off).

Digital imprint images are received by scanning with subsequent blur using the Gaussian filter.

It is possible to evaluate redistribution of lightness levels after screening and printing on received histograms (Пухова et al, 2018).

Pre-correction functions are counted for every type of paper (3), based on cumulative sums from histograms. They are applied to the base test image and as a result there are 3 images, prepared for printing on different types of paper. After all images are printed on the corresponding types of paper in the same condition as the test image.

After printing digital imprinting image histograms on different papers with applied Gaussian blur filter are received. These histograms are compared with the histogram of the original digital image and histograms of images without pre-correction (Figure 3), (Table 1).

It is visible, from shown histograms and statistic parameters, that press sheets with pre-correction are closer to the original image in the distribution of tones inside the tonal range. The algorithm of appliance of histogram methods for compensation of distributions of the printing process on the preprinting stage is developed, based on these results (Figure 4). 
gl

a

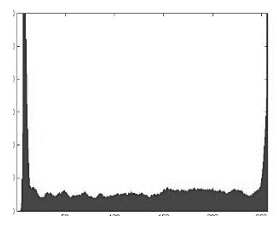

b

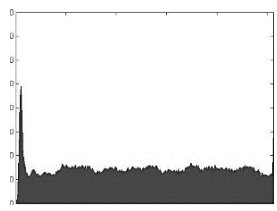

mat
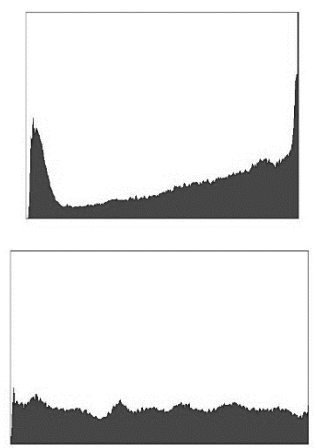

off

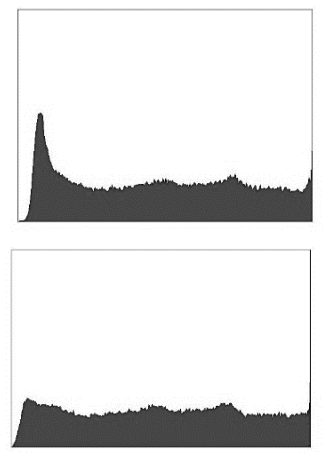

Figure 3: Histograms of digital imprint images on different types of paper $a$-without pre-correction; $b$ - with pre-correction

Table 1: Histogram statistics

\begin{tabular}{|l|c|c|c|}
\hline \multirow{2}{*}{ original } & m & $\sigma$ & Skew \\
\cline { 2 - 4 } & 128,00 & 73,76 & 0,00 \\
\hline gl & \multicolumn{5}{|l|}{} \\
\hline without pre-correction & 126,46 & 88,45 & $-0,06$ \\
\hline with pre-correction & 127,71 & 74,34 & $-0,01$ \\
\hline mat & 156,18 & 83,03 & $-0,26$ \\
\hline without pre-correction & 125,60 & 74,07 & $-0,02$ \\
\hline with pre-correction & \multicolumn{5}{|c|}{} \\
\hline off & 159,75 & 81,37 & $-0,26$ \\
\hline without pre-correction & 122,31 & 74,26 & 0,00 \\
\hline with pre-correction &
\end{tabular}

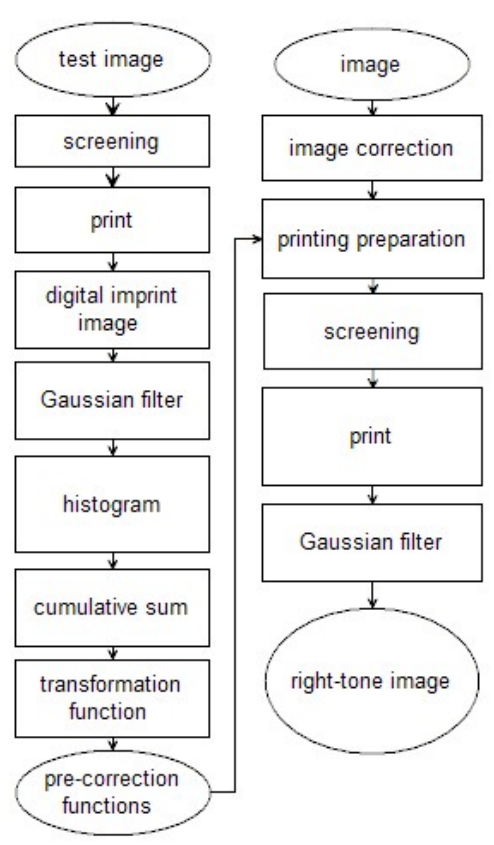

Figure 4: The algorithm of appliance of histogram methods for compensation of distributions of the printing process on the preprinting stage 
Let's see the realization of this algorithm on complex images. Pre-correction functions are applied to images before printing.

On Figure 5 there are images and their histograms, in Table 2 there are statistic parameters of histograms.

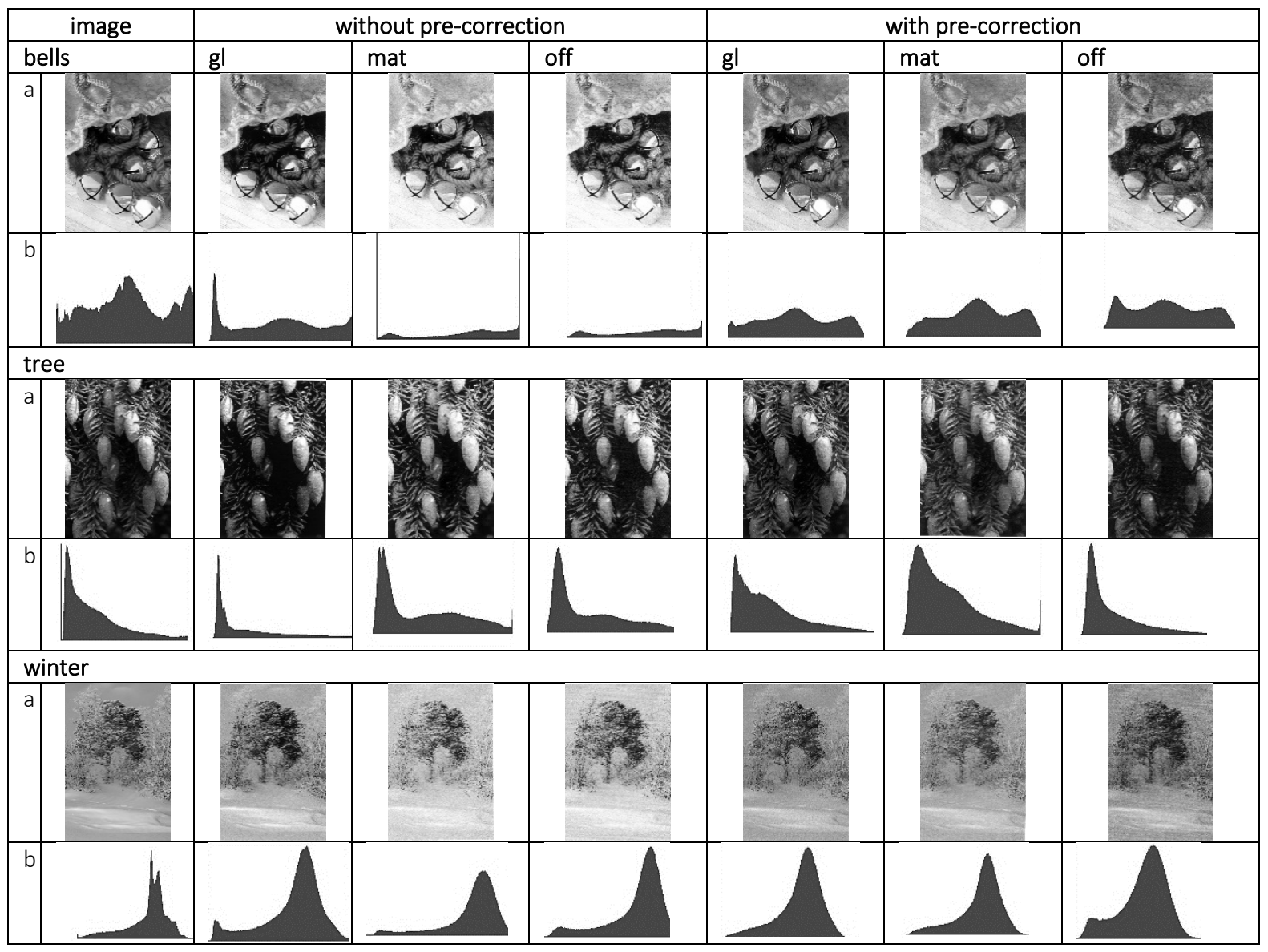

Figure 5: Images and histograms of digital images and digital imprinted images on different types of paper. $a$-image; $b$-histogram

Table 2 - Statistic parameters of histograms of digital images and digital imprinted images on different types of paper.

\begin{tabular}{|l|c|c|c|c|c|c|c|c|c|c|}
\hline \multicolumn{1}{|c|}{ bells } & \multicolumn{3}{c|}{ tree } & \multicolumn{3}{c|}{ winter } \\
\hline \multirow{2}{*}{ original } & $\mathbf{m}$ & $\boldsymbol{\sigma}$ & Skew & $\mathrm{m}$ & $\boldsymbol{\sigma}$ & Skew & $\mathrm{m}$ & $\boldsymbol{\sigma}$ & Skew \\
\cline { 2 - 10 } & 128,73 & 66,74 & 0,04 & 68,52 & 56,59 & 0,29 & 143,84 & 40,86 & $-0,22$ \\
\hline \multicolumn{8}{|c|}{ gl } \\
\hline without pre-correction & 134,78 & 81,02 & $-0,02$ & 60,53 & 64,57 & 0,49 & 152,12 & 50,81 & $-0,27$ \\
\hline with pre-correction & 128,69 & 66,45 & 0,04 & 67,94 & 56,05 & 0,25 & 142,87 & 39,99 & $-0,20$ \\
\hline \multicolumn{7}{|c|}{ mat } \\
\hline without pre-correction & 166,73 & 73,07 & $-0,24$ & 90,76 & 71,52 & 0,22 & 188,55 & 44,87 & $-0,28$ \\
\hline with pre-correction & 139,04 & 62,41 & 0,00 & 83,73 & 57,70 & 0,26 & 153,65 & 38,19 & $-0,22$ \\
\hline \multicolumn{8}{|c|}{ off } \\
\hline without pre-correction & 162,39 & 75,46 & $-0,19$ & 83,01 & 68,12 & 0,40 & 183,73 & 51,81 & $-0,35$ \\
\hline with pre-correction & 123,14 & 67,72 & 0,05 & 61,25 & 52,51 & 0,39 & 134,07 & 44,31 & $-0,20$ \\
\hline
\end{tabular}


Received data, calculated with histogram method, gives good results, for images with different tone distribution in tonal range and correction. Press sheets with pre-correction on different types of paper have tonal distribution, that is close to the original image.

\section{CONCLUSIONS}

A method of image preparation for printing reproduction is suggested. This method allows to automatically compensate transformations that occur during reproduction, by analyzing a histogram of test chart image and based on it, creating a compensation pre-correction function. It also takes into consideration the visual perception of images. Appliance of the described method does not require expensive hardware and software. Only scanner and programming module, with the described algorithm are needed. At this moment, algorithm is realized on Python. The suggested method allows to automatize the process of the image preparation for reproduction. It is an addition for another histogram correction methods.

This method can be spread on the colored images. To do so, it is required to analyze histograms of colored image channels and apply compensation to the corresponding channel.

\section{REFERENCES}

[1] Gonzalez, R. C.; Woods, R. E.: "Digital Image Processing", 4th edition, (Piarson: New York, 2018), page 1168.

[2] Гнибеда, А.Ю.; Андреев, Ю.С.: “Разработка метода оценки визуального восприятия однородности печатного изображения", Известия высших учебных заведений. Проблемы полиграфии и издательского дела, 1 (4), 63-70, 2016.

[3] Hunt, R.W.G.: "The Reproduction of Color", 2nd edition, (John Wiley \& Sons: Chichester, 2004), page 724.

[4] Маргулис, Д.: "Photoshop для профессионалов: классическое руководство по цветокоррекции", (пер. с англ. М.: ООО «Интерсофтмаррк», 2003), page 464.

[5] Нюберг, Н.Д.: “Теоретические основы цветной репродукции”, (Советская наука, 1947), page 177.

[6] Пухова, Е.А.; Андреев, Ю.С.; Винокур, А.И.: “Анализ и сопоставление методов градационной коррекции изображений, предназначенных для полиграфического воспроизведения", Известия высших учебных заведений. Проблемы полиграфии и издательского дела 2016, 1 (3), 28-34.

[7] Пухова, Е.А.; Андреев, Ю.С.; Панкин, О.В.: “Оценка гистограммных преобразований в печатном процессе", Известия Тульского государственного университета. Технические науки 1 (6), 298-308, 2018.

[8] Пухова, Е.А.; Андреев, Ю.С.: “Коррекция цвета изображений методом приведения гистограммы по закону нормального распределения", Известия ТулГУ серия технические науки 6, 335-347, 2017.

[9] Пухова, Е.А.; Андреев, Ю.С.: “Применение гистограммной коррекции для устранения градационных искажений при цифровой обработке изображений”, Известия высших учебных заведений. Проблемы полиграфии и издательского дела 1 (6), 41-47, 2014.

[10] Пухова Е.А., Андреев Ю.С.: “Применение гистограммных методов для коррекции черно-белых и цветных изображений”, (Материалы научно-практической конференции Innovations of publishing, printing and multimedia technologies' Kaunas, 2018), pages 113-121.

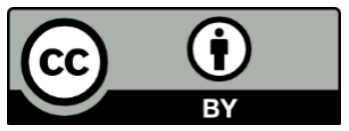

(C) 2020 Authors. Published by the University of Novi Sad, Faculty of Technical Sciences, Department of Graphic Engineering and Design. This article is an open access article distributed under the terms and conditions of the Creative Commons Attribution license 3.0 Serbia (http://creativecommons.org/licenses/by/3.0/rs/). 


\title{
ANALYSIS OF RASTER IMPRINTS PARAMETERS ON THE BASIS OF MODELS AND EXPERIMENTAL RESEARCH
}

\author{
Bohdan Durnyak ${ }^{1}$, Mikola Lutskiv ${ }^{1}$, Georgij Petriaszwili ${ }^{2}$ (D), Petro Shepita ${ }^{1}$ \\ ${ }^{1}$ Ukrainian Academy of Printing, Lviv, Ukraine \\ ${ }^{2}$ Warsaw University of Technology, Institute of Mechanics and Printing, Warsaw, Poland
}

\begin{abstract}
Structural scheme of models for determining the integral density of raster scale of an imprint, raster tone in percentage, optical density of scales on the basis of the measured optical density of the solid area and other characteristics have been worked out. The results of imitation design in the form of characteristics for different parameters have been provided. Optical density of raster scales obtained on the models has been found out to be quite similar to the results of experimental studies.
\end{abstract}

Key words: raster scale, imprints, models, optical density parameters, imitation design.

\section{PREFACE}

To represent graphical and text information by printing means, it is necessary to provide the high quality of an image that can lost during the preprint processes. It occurs during screening, production of printing plates and during printing itself due to different kinds of influences and distortions. Therefore, to provide quality of the printed products, it is necessary to control quality of implementation of separate technological operations and printing, to assess the optical density of raster image, in particular. An assessment is carried out mainly on experimental basis by means of densitometers on the basis of which graphic specifications of tone transfer are built, and analysis, synthesis, and correction of an image are maintained. Modern densitometers are devices that on the basis of measuring of intensity of the reflected or skipped light by certain algorithms determine optical density, relative area of the printed elements, their geometrical sizes, fineness, etc. (Pashulja, 2011; Predko, 2009). The producers of densitometers, for well-known reasons, do not present algorithms of calculation of separate parameters crucial for measurement accuracy that can be considerable. Therefore, it is a relevant task to compare simulation results on the basis of well-known expressions with experimental researches.

\section{BACKGRAUNDS}

In most cases, digital images used in printing are processed in the packages of computer graphics and visually perceived as qualitative ones (Blanter, 1999; Gonsales and Vuds, 2012; Vorobel, 2012). Converting of digital images into a raster form as well as printing plate making is carried out by CtP technology (Gonsales and Vuds, 2012; Vorobel, 2012). Quality of printing plate making can be experimentally assessed by means of a densitometer defining this or that parameter (Blanter, 1999; Pashulja, 2011; Predko, 2009). The existing methods of digital images processing use levels (gradations) of grey within limits [0, 255] and operate the arrays of numbers (Baranovskyj et al, 2013; Kuznetzov, 2002). Printing image, on the contrary, is much more complex: it has raster structure, is defined by an area of a raster (printed) element that has the set form of elements and fineness (Baranovskyj et al, 2013; Blanter, 1999; Lutskiv, 2012). Thus, it is impossible to apply various existing methods of digital images processing directly to raster images and raster printing (demodulation). To prepare qualitative image for printing, it is necessary to assess optical density of raster images, the area of raster elements and geometrical sizes. These days this estimation is carried out mainly experimentally by means of densitometers, gradation specifications of tone transfer are built on their basis as well as analysis, synthesis and correction of images are maintained, that makes it impossible to give objective estimation, optimization and anticipating of tone transfer on certain stages of preparation to printing (Baranovskyj et al, 2013; Lutskiv, 2012; Lutskiv and Buben, 2018). There is a formula of demodulation of raster transformation obtained by Murray and Davies and amendments of Yul - Nikols to this formula, however, the calculation of optical density is inaccurate and depends on ink, and paper properties as well as halftone frequency (Pashulja, 2011; Predko, 2009; Vorobel, 2012). In the work (Nazar et al, 2011) the authors represented a structural scheme of simulation model in Matlab package: Simulink, that makes it possible to calculate and build specifications of demodulation of linear raster scale for different fineness, define deviations of 
characteristics depending on halftone frequency and demodulation index, which is useful for practical applications. Gradation transforming of images tone in printing is mainly assessed by densitometry methods. For operative control and reproduction of raster tones multifunctional densitometers are widely used, that on the basis of measuring of intensity of the reflected or transmitted light by certain algorithms determine optical density of a solid tint, relative area of printing elements, tone, contrast, etc. (Pashulja, 2011; Predko, 2009). Optical density of a solid tint of printed (blackened) areas of an imprint is mostly assessed in number by a reflection optical density on the basis of reflectivity coefficient in a simplified way (Vorobel, 2012):

$$
D_{i}=\lg \frac{1}{R}
$$

Where $\mathrm{R}=\mathrm{F} / \mathrm{F}_{0}, \mathrm{~F}_{0}$ - intensity of the incident flow of light, $\mathrm{F}$ - intensity of the reflected light.

According to Weber-Fechner law the reaction of perception of the human visual system is proportional to logarithm of light stimulus (impulse). That is why the choice of optical density as measures of photographic darkening seems quite reasonable (Vorobel, 2012), as a change of optical density is proportional to lightness. A number of researches prove that non-linearity of human sight is characterized by a psychophysical function often described by logarithmic functions in semi-logarithmic coordinates. As optical density of a solid tone is determined in the reflected light, then measurement accuracy depends on uniformity of coverage of the scales fields, ink properties, whiteness of the solid tone (paper) (Pashulja, 2011). To increase the accuracy, it is necessary to take into account diffusion of a light stream, take $\mathrm{F} / \mathrm{n}$, where $\mathrm{n}$-is a coefficient, which characterizes the light diffusion.

The purpose of the article is to develop structural scheme of a model for determining the integral and optical densities of raster tone, to design special full format testing printing form, and to compare the results of simulation and experiment on the basis of simulation modelling, printing and experimental densitometry measurements.

\section{SUMULATION RESEARCHERS}

In printing reproduction, a solid tone is dispensed into raster elements in such a way that visually it corresponds to the value of the original tone. At densitometry control of raster imprints, a densitometer measures integral (raster, average) density that indicates the ability of light absorption by inked printing elements. On the basis of the raster scales of an imprint located on the fields, a densitometer determines an integral density. For this purpose it is necessary to the optical density (1) in a simplified version to add an expression of integral density in semi-logarithmic scale:

$$
D_{i}=\lg \frac{\phi_{0}}{\phi}, \text { if } 99 \leq \phi \leq 1
$$

where $\Phi_{0}=100 \%$ - incident flux of light, $\Phi \%$ - a light stream in percentage, reflected off the raster field. The majority of modern densitometers determine optical density and value of the raster tone. For instance, the value of the raster tone on a positive full tone (solid area) is $100 \%$, but the value of a raster tone without raster dots (paper) is $0 \%$. At alternate image the value of raster tone is $50 \%$ and it consists of half darkened area and half-light area.

The value of a positive of raster tone is determined by the formula (Predko, 2009):

$$
F_{r t}=\left[\Phi_{0}-\Phi\right] \%
$$

Integral density is subordinate to each value of raster tone:

$$
F_{r t}=\left(1-10^{D_{i i}}\right) 100 \%
$$

The integral density measured by the densitometer is the main output variable for which other indices of raster, printing production and printing are calculated. Simple densitometers determine the optical density of raster fields based on the measured optical density of the die by a simple expression (Pashulja, 2011):

$$
D_{M}=S \cdot D_{n}, \text { if } 0 \leq S \leq 1
$$


where Dn is the optical density of the solid area, $\mathrm{S}$ is the degree of coverage of the raster element with ink, which is physically close to the relative area of the raster element.

Densitometer does not directly measure the optical density of the solid area and the degree of coating of raster elements with ink, but determines them by one or other algorithms, so the accuracy depends on the chosen algorithm. Therefore, the convergence of the results of densitometry measurements can only be obtained for the same type of ink and its thickness, the same printed material under the same measurement conditions and using the same densitometer.

The calculation of the integral density of the imprint by expression (2) in the semi-logarithmic scale and the values of the raster tone according to the positive function (4), their comparison with the results of experimental studies is inconvenient, so on the basis of these expressions a structural diagram of the model was developed to determine the integral density of the raster imprint and the bitmap in Matlab package Simulink (Figure 1).

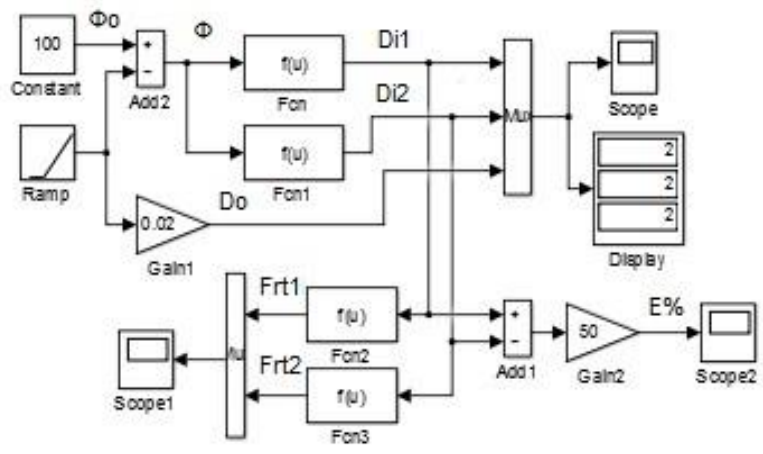

Figure 1: Structural diagram of integral density and raster tone model

The Constant and Ramp blocks form signal $F$ at the output of the summation block Add, which corresponds to the light flow reflected from the raster field and is fed to the output of the block of mathematical functions Fcn in a dialogue windows of which the program for calculating the integral bitmap density on the basis of expression (2) has been written. The second block of mathematical functions Fcn1 is similar to the previous one and additionally takes into account the individual effects on the integral density. The simulation results are visualized by Scope and Display blocks. To calculate the raster tone of the scales of expression (4), the block of mathematical functions Fcn2 and Fcn3 of multiplication and the block Constant were applied, to the inputs of which the calculated optical densities Di1 and Di2, located at the bottom of the scheme, are being fed.

Adjusted the Constant block to the stream falling $\Phi_{0}=100 \%$ and the Ramp block to the reflected stream $F$ according to expression (2). In block Fcn1 set the flux $F / n$, where $n=1,15$ - coefficient characterizing light scattering, which depends on the properties of paper and ink. The results of the simulation modelling of the integral density are presented in Figure 2.

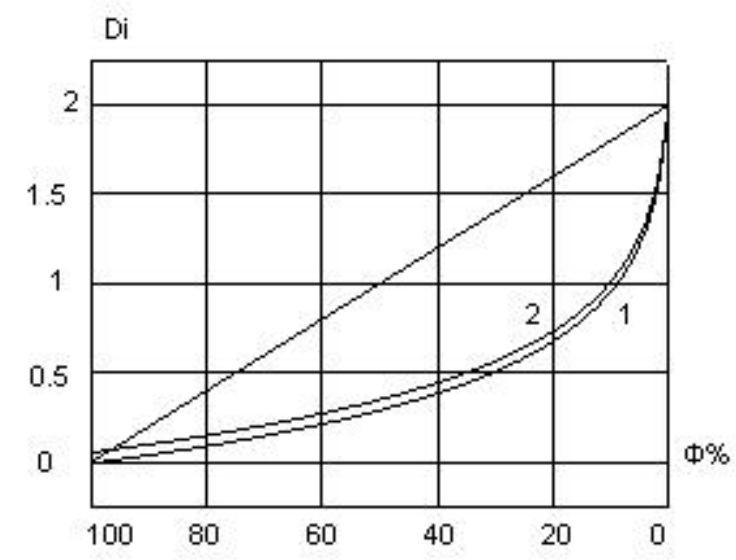

Figure 2: Characteristics of integral density

1 - calculated by expression (2), 2 - takes into account different influences 
For comparison, the linear characteristic $D_{0}$ is given in the figure 2. The peculiarities of features are their presentation on a semi-logarithmic scale. In addition, the beginning of the countdown of the reflected flux is reversed and begins with $\Phi=100 \%$, which is due to the method of measuring the integral density by the reflected light fluxes from the raster field of the raster scale of the print in which the image is formed in black. The designed characteristic is a rather non-linear curve, which is caused by logarithmic transformation (2). More precise results of the simulation are presented in Table 1 . The second characteristic takes into account different influences, for example, the paper's optical density or ink properties, which are higher than of the previous one. In order to evaluate the properties of the integral density objectively, it is suggested to determine its deviation from the previous one:

$E=\frac{D_{i} 1-D_{i}^{2}}{2} 100 \%$

which is determined by the Add1 block and is rendered by the Scope2 block. The results of the deviation of the integral density under the influence of the effects are presented in Figure 3.

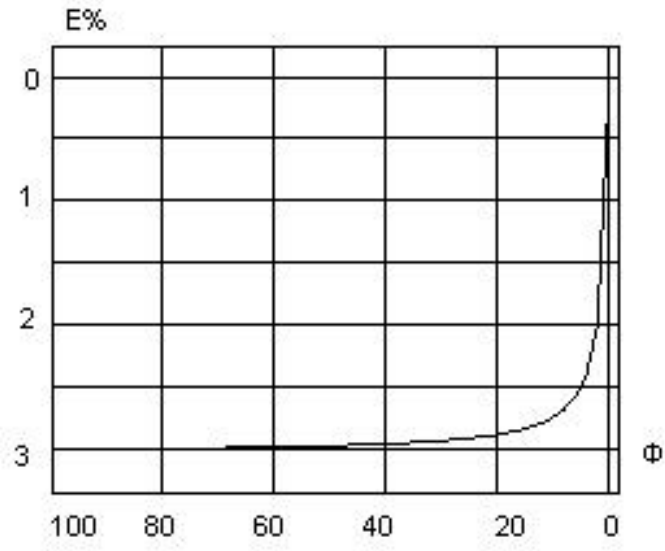

Figure 3: Deviation of integral density under the action of different influences

In light areas, the deviation of the integral density is $-3 \%$, and in the shadows $(\Phi<5 \%)$ it rapidly shifts to zero. As already noted, integral density is the main output variable by which other parameters are calculated, including the raster tone of the positive percentage (4), which is calculated in blocks of mathematical functions Fcn2 and Fcn3 based on the above calculated integral density, the results of which are visualized by Scope1. The simulation values of raster tone in percentage are calculated by the expression (4) and presented in Figure 4:

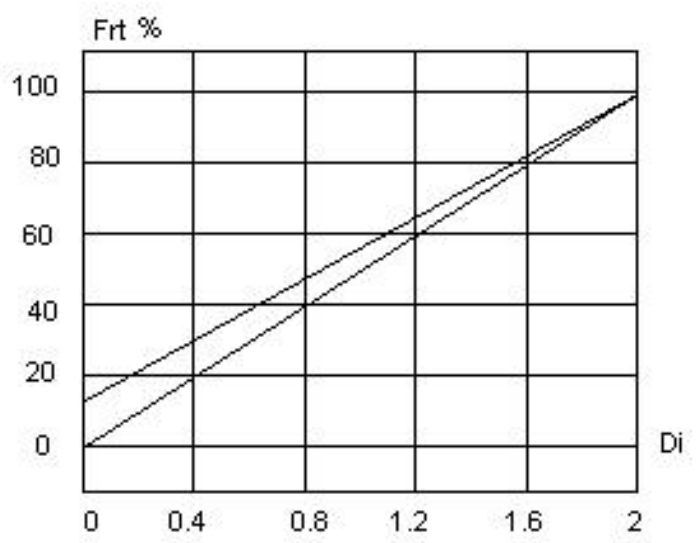

Figure 4: The characteristic of the raster tone of the positive is determined by the integral density 1-calculated by the expression (4), 2-with regards to different influences 
Characteristics of a raster tone under the action of various influences of the location are above the initial one. The maximum deviation is at a small integral density of $12.9 \%$, and at the end of the range gradually goes to zero. The percentage character of the raster tone is a straight line that is convenient for comparing the raster tone as a percentage on the films, printing plates and raster prints. Characteristics of a raster tone under the influence of various impacts of the location are above the initial one. The maximum deviation is at a small integral density of $12.9 \%$, and at the end of the range goes to zero. Results of simulation of optical linear density of raster scales based on the optical density of the plate by the simple expression (5) are given in Figure 5:

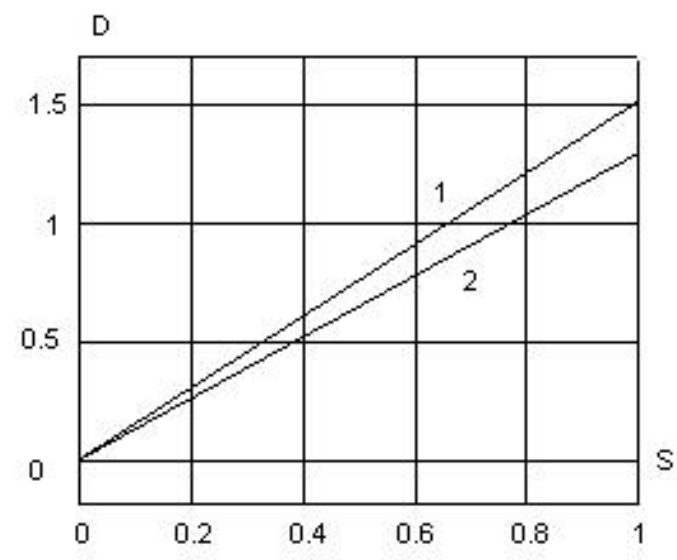

Figure 5: Optical density characteristics for different values the optical density of the solid area $1-$ for $D_{1}=1.52 ; 2-$ for $D_{2}=1.30$

At the beginning of the pitch range, the absolute tone difference is equal to zero, gradually increasing, and at the end of the range it is 0.22 . Therefore, increasing the thickness of the ink supply significantly affects the optical density of the print.

\section{EXPERIMENTAL RESEARCHERS}

As the manufacturers of densitometers for known reasons do not provide algorithms and expressions for calculations, certain indicators may be different Therefore, the task is to equate and compare the results of simulation modelling obtained from the expressions (2) - (5) of experimental studies. To achieve this goal, a special testing multipurpose raster printing plate has been developed. Typically, traditional tests are intended for the operational control and adjustment of tone transmission at a given circulation, so they are small in size and are located in places of further bending of the sheet when it is folded or at its edge. Therefore, the thickness of the ink on the text boxes may be much larger than on the surface of the print, which is the disadvantage of such small-format texts, which can lead to distorted results of experimental studies. Therefore, a special full-format test form has been developed for research, which ensures adequate experimental studies. The test typeface contains a sequence of stripes whose height is equal to the height of the shape. The width of the strips corresponds to the step of placing the ink supply onto the strip. The strips contain continuous raster fields of 5, 10, 20, 40, 60, 80, 90 and 100\% tonal graduation and small-format $100 \%$ solid areas for measurement. The test form is made using CtP technology, from the computer to the plate, providing greater accuracy in the production of the plate. The results of the experimental studies were performed on offset printing machine ADAST Dominant 525 format B3 521x415mm. Printing was done with Michel Huber Rapida Black ink on $120 \mathrm{~g} / \mathrm{m}^{2}$ coated paper. The zonal supply of the inking unit to the test plate at the $40^{\circ}$ rotation angle of the ink fountain roller has been adjusted. Press proofing has been completed, then a print check of test prints has been performed. The measurement of the optical density of the raster fields and solids has been performed using a X-Rite 504 digital spectral densitometer. The averaged results of the optical density measurements on the bands are presented in the table. After that, the second stage of the experimental studies has been carried out at a maximum angle of rotation of ink fountain roller by $170^{\circ}$. From the table we can conclude that the optical density on the test strips depends significantly on the angle of rotation of the ink fountain roll and stretches the dynamic range of the transmission from 0.06 to $1.30 \mathrm{D}$ and from 0.08 to $1.51 \mathrm{D}$. 
The optical density of raster fields has been calculated on the basis of experimental studies of the optical densities of the solid area by expression (5), provided that the degree of ink coating of the raster element is equal to the degree of coverage of the raster strips, and the calculation results are presented in the Table 1:

Table 1: Measurement and simulation results

\begin{tabular}{|c|c|c|c|c|c|c|c|}
\hline $\begin{array}{l}\text { Tonal } \\
\text { graduation }\end{array}$ & \multicolumn{2}{|l|}{$\begin{array}{l}\text { Measured optical } \\
\text { density of scales }\end{array}$} & \multicolumn{2}{l|}{$\begin{array}{l}\text { Absolute } \\
\text { difference }\end{array}$} & \multicolumn{2}{l|}{$\begin{array}{l}\text { Calculated optical } \\
\text { density of scales }\end{array}$} & \multicolumn{2}{l|}{$\begin{array}{l}\text { Absolute difference of } \\
\text { densities }\end{array}$} \\
\hline S\% & D1 & D2 & $\Delta$ D & $D_{\text {H1 }}$ & $D_{\text {H2 }}$ & $\Delta D 1$ & $\Delta D 2$ \\
\hline 5 & 0,06 & 0,08 & 0,02 & 0,065 & 0,075 & $-0,005$ & 0,015 \\
10 & 0,15 & 0,18 & 0,03 & 0,13 & 0,151 & 0,02 & 0,03 \\
20 & 0,30 & 0,36 & 0,06 & 0,26 & 0,302 & 0,04 & 0,06 \\
40 & 0,51 & 0,64 & 0,13 & 0,52 & 0,604 & $-0,01$ & 0,04 \\
60 & 0,83 & 0,95 & 0,12 & 0,78 & 0,906 & 0,05 & 0,044 \\
80 & 1,14 & 1,35 & 0,21 & 1,04 & 1,208 & 0,10 & 0,14 \\
90 & 1,21 & 1,46 & 0,25 & 1,17 & 1,359 & 0,04 & 0,01 \\
100 & 1,30 & 1,51 & 0,21 & 1,30 & 1,520 & 0 & 0 \\
\hline
\end{tabular}

According to the tabular data of the results of measuring the optical densities of the raster scales, we conclude that increasing the thickness of the ink transfer by increasing the angle of rotation of the ink fountain roller significantly affects the optical density of the raster scales. In the middle tones the absolute difference in optical densities $D 2-D 1=\Delta D$ is in the range 0.1-0.2, and in the dark tones $\Delta D=0.2-$ 0.25. Therefore, the thickness of the ink is a major factor influencing the optical density of images. Therefore, the inking unit of the offset printing machine could be adjusted using a multi-channel automatic zonal feed system for each circulation in particular. The optical density of the raster scales, calculated by the simple expression (5), is quite similar to the results of experimental studies and practically independent of the studies and of the thickness of the ink layer. The absolute difference of the optical densities of the scales is in the range $\Delta D=D I-D M$, and in the range -0.01 to 0.14 . The National Standards of Ukraine - DSTU:ISO 12647-2:2005 recommend a list of indicators for offset printing at an optical density of D from 1.4 to 1.6 in which the optical density of raster scales for chalked paper is \pm 0.15 . Therefore, the calculation of the optical density of the scales on the basis of the simple model (5) provides the required accuracy.

\section{CONCLUSIONS}

Densitometers do not directly measure optical density, the degree of coverage of raster scales, and other parameters, but determine them by one or another, in most unknown algorithms, on which the accuracy of measurement depends. The models of integral (average) density are presented on a semi-logarithmic scale, and the values of the raster tone of the positive, used in densitometers operating in reflected light, and the relationships between them, have been justified. The structural scheme of the model is developed to determine the integral density of raster scales of the imprint, raster tone in percentage, optical density of scales on the basis of the measured optical density of the solid area, which calculate and construct their characteristics. The simulation results are presented in the form of characteristics for different parameters.

For the experimental research of the simulation results, a special proof plate with wide strips - with raster scales - has been developed to ensure adequate experimental research. The results of the measurements of the optical density of the scales and the results of the measurements have been summarized in the table, on the basis of which it has been concluded that an increase in the thickness of the ink supply significantly affects the optical density of the scales. On the middle tones, the absolute difference in optical densities is in the range 0.1-0.2, and on the dark tones it is 0.2-0.25. The optical density of the raster scales obtained on the models is quite similar to the results of experimental studies and practically does not depend on the thickness of the ink layer. The absolute difference of optical densities is in the range from 0.01 to 0.14 , which corresponds to the tolerance of the optical densities of raster scales for chalked paper \pm 0.15 , which ensures the accuracy of modelling. 


\section{REFERENCES}

[1] Baranovskyj V., Lutskiv M., Fil L., Chernozubova G.: "Construction and analysis of screening characteristics", Journal Naukovi zapysky UAP 4, 131-138, 2013.

[2] Blanter D.: "Scanning and screening images", (ECOM, Moscow, 1999.)

[3] Gonsales R., Vuds R.: "Digital image processing", (Tekhnosfera, Moscow, 2012.)

[4] Kuznetzov J.: "Technology for image information processing", (Petersburg Institute of Printing, St. Petersburg, 2002.)

[5] Lutskiv M.: "Digital printing technology", (Ukrainian Academy of Printing, Lviv, 2012.)

[6] Lutskiv M., Buben V.: "Construction of the characteristics of demodulation linear tint chart", Journal Computer printing technology 2 (40), 2018, 109-115.

[7] Nazar I., Lazarenko E., Jakutsevych S.: "Offset printing options: management and influence factors", (UAP, Lviv, 2011.)

[8] Pashulja P.: "Standardization, metrology, compliance, printing quality", (UAP, Lviv, 2011.)

[9] Predko L.: "Prepress Process Design: tutorial", (UAP, Lviv, 2009.)

[10] Vorobel R.: "Logarithmic image processing", (Naukova dumka, Kyiv, 2012.)

(C) 2020 Authors. Published by the University of Novi Sad, Faculty of Technical Sciences, Department of Graphic Engineering and Design. This article is an open access article distributed under the terms and conditions of the Creative Commons Attribution license 3.0 Serbia (http://creativecommons.org/licenses/by/3.0/rs/). 



\title{
THE EFFECT OF DEINKING AND BINDER TYPE ON INKJET PRINT QUALITY
}

\author{
Arif Ozcan ${ }^{1}$ (D), Emine Arman Kandirmaz ${ }^{1}$ (D), Omer Bunyamin Zelzele ${ }^{2}$ \\ ${ }^{1}$ Marmara University, School of Applied Sciences, Printing Technologies, Istanbul, Turkey \\ ${ }^{2}$ Marmara University, Vocational School of Technical Sciences, Printing and Publishing \\ Technologies, Istanbul, Turkey
}

\begin{abstract}
In the printing industry, as in all other industries, efficient use of resources, sustainable production and economics are among the most important issues. The increasing use and purpose of printed products, the increasing consumer demands and the development of technology also increase the demand for paper products. Paper and cardboard materials in line with the increasing consumer demand to give better printing characteristics are implemented in a number of operations. These processes are sizing, coating, and calendering. The recycling and re-use of paper and cartons that have been treated on the surface may also differ from those that have not been treated on the surface. For this purpose, test prints were made on paper coated with cationic starch and PVOH binders and precipitated calcium carbonate (PCC) pigment before and after recycling with Inkjet printing system, which is widely used today. The effect of both recycling and binder type on the quality of the resulting prints has been studied. The colour value, dot gain, whiteness and yellowness of the prints were made using X-Rite exact spectrophotometer. The gloss measurements were carried out with BYK-Gardner glossmeter. In addition, images of coated papers were analyzed with scanning electron microscope SEM. As a result, it was determined that there was a negative change in the colour and whiteness of the papers after recycling, but the resulting papers had a good printability value when examined in terms of printability. It has also been concluded that the PVOH binder has a more positive impact on printability.
\end{abstract}

Keywords: Inkjet, Printability, PVOH, Recycle, Starch.

\section{INTRODUCTION}

With the industrial and technological developments and the increase in consumption in recent years, all industrial enterprises have begun a search of different alternatives in supplying the required raw materials. One of the foremost alternatives among these efforts is the efficient use of raw material resources without waste, and another alternative is the importance of recycling. The most important basic raw materials used in the printing industry are paper and cardboard. Despite the increase in digital publishing, the need for paper does not decrease, and they still remain the most important raw materials due to their use in different areas. In parallel with the technological developments in the printing industry, productivity has increased and waste rates have decreased. In addition, the importance of recycled paper and cardboard in raw material supply has increased day by day. This is because in the recycling process, it is easier to collect paper and cardboard and re-use them as raw materials compared to many other waste materials and paper and cardboard can be recycled 5-6 times. Paper recycling involves the collection of used or waste paper for reprocessing for reuse. According to CEPI statistics, the rate of recycled fiber in paper production was 53.1\% in 2018 and 54.6\% in 2019, and the rate of paper recycling was $72 \%$ in 2019 with an increase of $1 \%$ compared to the previous year (Confederation of European Paper Industries, 2019). In addition, it is known that more than $60 \%$ of the paper consumed in the USA is recycled (Du et al, 2016) and the demand for recycled fiber has increased over the years (Dorris et al, 2011). In terms of the environment and the economy, paper recycling reduces the need for raw materials (cutting less trees), the use of energy resources (water, electricity, etc.), raw material costs, and creates new business opportunities in the recycling sector.

One of the most important factors affecting print quality is the treatments applied to paper and cardboard, during or after production, which are widely used as printing substrates. During or after paper and cardboard production, a number of surface treatments such as sizing, coating and calendering are performed in order to have better workability and printability (Ozcan and Kandirmaz, 2020). Sizing is the process of filling the pores by bonding the surface of the paper with a binding agent, and coating is the process of coating paper and cardboard surfaces with mixed formulas obtained with pigment, binder and some additional substances. Calendering is a type of compression process done to increase the brightness and smoothness of the paper surface (Ozcan and Tutak, 2020). Today, calcium carbonate derivatives, pigments such as kaolin, titanium dioxide and silica are widely used in paper coatings, and 
starch types, some cellulose types, PVA, PVOH and latex types are used as binders. Binders allow for better adhesion of pigments in the coating formulation to the paper surface and fills the pores caused by the fibers. The functions of binders can be briefly listed as good adhesion properties, water retention, and improving optical and mechanical properties. After coating, the paper exhibits better printability properties.

Deinking is the process of separating printing inks and other foreign matter from paper fibers in order to reuse waste paper. The ratio of ink and other foreign matter to be removed varies between 0.5 and $2 \%$. These substances other than ink are usually adhesives and fillers. Deinking agents are usually fatty acids, nonionic surfactants, or mixtures of both; but these materials can be modified with different chemicals to achieve better results (Tutak, 2017). Recycled fibers are essential for paper production and environmental protection (Toppinen et al, 2017). There are two basic stages: pulping of waste papers and removal of ink and other foreign matter. Flotation and washing are the two most commonly used methods. In recent years, the flotation method has been preferred over washing because of higher efficiency while consuming less water (İmamoğlu and Peşman, 2012). The performance of the deinking process may vary depending on the printing technique used, printing conditions, type of ink, and type of printing substrate (Bolanča and Bolanča, 2004; Tsatsis et al, 2017).

Flotation is the process of attaching hydrophobic ink and foreign particles to air bubbles and the removal of these air bubbles by sending them to the foamy surface formed on the suspension surface. Flotation is a much more complex separation process than it seems. Factors affecting the performance of flotation are ink particle quantity, size, shape, density, surface chemistry, air bubble type, number, size, surface chemistry and structure, mixing type, intensity, duration, and process conditions. These process conditions are determined by the waste paper type, ink amount and type, amount of inorganic matter, fiber characteristics, $\mathrm{pH}$, and chemical environment (Mavros and Matis, 2009).

Inkjet printing is a widely used digital printing technology where printing takes place by ejecting ink from a nozzle via piezoelectric motion in a closed chamber (Figure 1). Inkjet ink consists of a solute dissolved or otherwise dispersed in solvent (Tekin et al, 2008). The ink inside the continuously moving print head ejects a fixed amount of ink out of the nozzle due to the shock effect by electrical voltage changes (Lim et al, 2008). Printing is performed as these droplet-shaped inks are transferred to various printing substrates such as paper, cardboard, fabric, metal, ceramic, glass, etc. As with other digital technologies, there is no need for a printing plate and the ink is transferred directly to the printing substrate. The popularity of inkjet printing has grown significantly over the past decade, and this trend will continue in the future due to faster printing, better print quality, on-demand printing capabilities and exceptional features of inkjet printing (Du et al, 2016). In addition, the use of inkjet printing has also increased over the years due to environmental and health concerns (Aksoy et al, 2006).

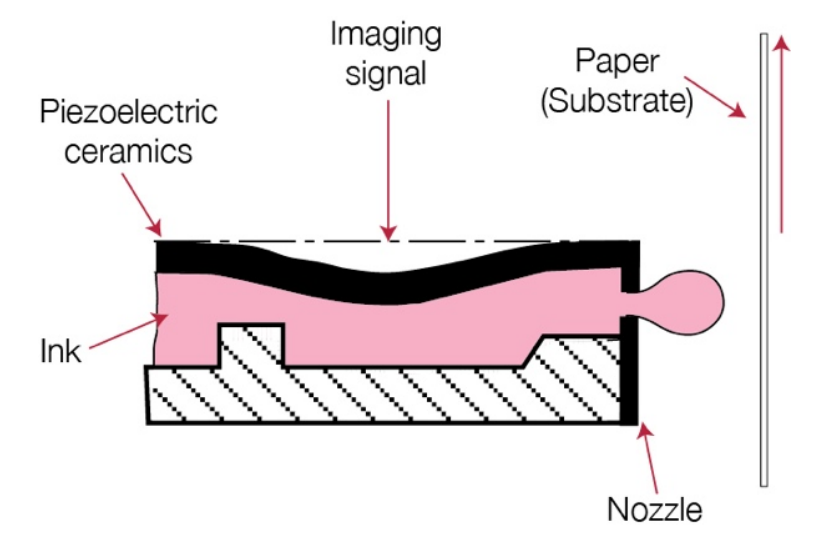

Figure 1: Drop on demand piezo inkjet printing (Kipphan, 2001)

For this purpose, two different coating formulations will be prepared in this study using PCC pigment with $\mathrm{PVOH}$ and cationic starch binders and these formulations will be coated on base paper. The coated papers will be printed with the inkjet printing system, whose usage has increased in recent years. After printing, deinking will be performed according to the Ingede method 11. Inkjet printing will be performed again on the hand-sheets obtained after the deinking process. By doing so, firstly, the effect of binder type on the printability of paper coatings and secondly, the surface properties of these coatings after deinking will be examined. 


\section{METHODS}

To examine the effects of different binders, coating formulations were prepared by using calcium carbonate pigment precipitated with polyvinyl alcohol (PVOH) and cationic starch binders (Table 1). PCC and water were mixed for $25 \mathrm{~min}$ and polyvinyl alcohol and cationic starch were cooked for $25 \mathrm{~min}$ at $30^{\circ} \mathrm{C}$ with $45 \%$ solid content in a cold water with three blade mixer at $1200 \mathrm{rpm}$ speed and were dispersed with lab dissolver. The $\mathrm{pH}$ of coating was adjusted to 8.5. The viscosities of the coatings were being measured at room temperature using a Brookfield viscometer, \#4 spindle, at $100 \mathrm{rpm}$. The papers were conditioned for 48 hours before coating. Coating was performed with a bar coater (model K303 Multicoater, RK Print) to $21.0 \times 29.7-\mathrm{cm}$ base sheets with the speed of $2 \mathrm{~m} / \mathrm{min}$ automatically. Coatings were allowed to dry for $24 \mathrm{~h}$ at $20^{\circ} \mathrm{C}$ and $65 \%$ relative humidity (RH). A laboratory-type paper coating device was used in the presence of Mayer rod number 2. Optical and physical properties of base paper and coated papers are given in Table 2. The inkjet printer used for this study was Epson L365. Its printing technology is drop-on-demand and uses piezo print heads and the ink is pigment based. Ingede Method 11:2018 was used for recycling process with the standard chemicals (Figure 2).

Technidyne Brightimeter Micro S-5 was used to measure brightness according to ISO 2470-2:2008. The colour properties of the coated papers and deinked hand-sheets were determined using CIEL*a*b* colour values. The X-Rite eXact hand-held spectrophotometer was used to measure $\mathrm{CIEL}^{*} \mathrm{a}^{*} \mathrm{~b}^{*}$ according to ISO 5631-2:2008. The spectrophotometer was used in a spectral range of 400-700nm, using a D50 light source, a 2-degree observer, polarization filters open and 0/45 degrees of geometry. Gloss measurements were made with BYK-Gardner GmbH glossmeter according to ISO 8254-1:2009 $75^{\circ}$ geometry.

Table 1: Paper coating formulations used in the study

\begin{tabular}{|l|l|l|l|}
\hline & $\begin{array}{l}\text { Solid } \\
\text { content }\end{array}$ & $\begin{array}{l}\text { F1 } \\
\text { (Coated with } \\
\text { PVOH) }\end{array}$ & $\begin{array}{l}\text { F2 } \\
\text { (Coated with } \\
\text { Cationic Starch) }\end{array}$ \\
\hline Ingredients & & \multicolumn{2}{|l|}{ Dry Parts Added (gram) } \\
\hline $\begin{array}{l}\text { Precipitated Calcium } \\
\text { Carbonate } \mathrm{CaCO}_{3}(\mathrm{PCC})\end{array}$ & $65 \%$ & 100 & 100 \\
\hline Polyvinyl Alcohol (PVOH) & $45 \%$ & 10 & - \\
\hline Cationic Starch & $45 \%$ & - & 10 \\
\hline Dispersant & $40 \%$ & 0.2 & 0.2 \\
\hline Thickener & $30 \%$ & 0.8 & 0.8 \\
\hline
\end{tabular}

Table 2: Physical and optical properties of base paper and coated papers

\begin{tabular}{|c|c|c|c|c|c|}
\hline & & Standard & Base Paper & F1 & F2 \\
\hline ISO & ness (\%) & ISO 2470-2:2008 & 84.30 & 90.75 & 90.05 \\
\hline Opa & & ISO $2471: 2008$ & 88.66 & 89.12 & 90.08 \\
\hline Wei & & ISO 536:2012 & 51.31 & 57.45 & 57.76 \\
\hline Rou & Bendtsen (ml/min) & ISO 8791-3:2017 & 206.34 & 230.87 & 235.55 \\
\hline Thic & & ISO 534:2005 & 78 & 94 & 98 \\
\hline Glos & & ISO 8254-1:2009 & 5.7 & 15 & 16.9 \\
\hline \multirow{3}{*}{\multicolumn{2}{|c|}{$\mathrm{CIE}$}} & \multirow{3}{*}{ ISO 5631-2:2008 } & 94.08 & 96.88 & 96.90 \\
\hline & & & 0.08 & 0.14 & 0.15 \\
\hline & & & 1.68 & 1.17 & 0.98 \\
\hline $\mathrm{CIE}$ & hess & ISO 11475:2017 & 76.06 & 79.66 & 76.75 \\
\hline
\end{tabular}




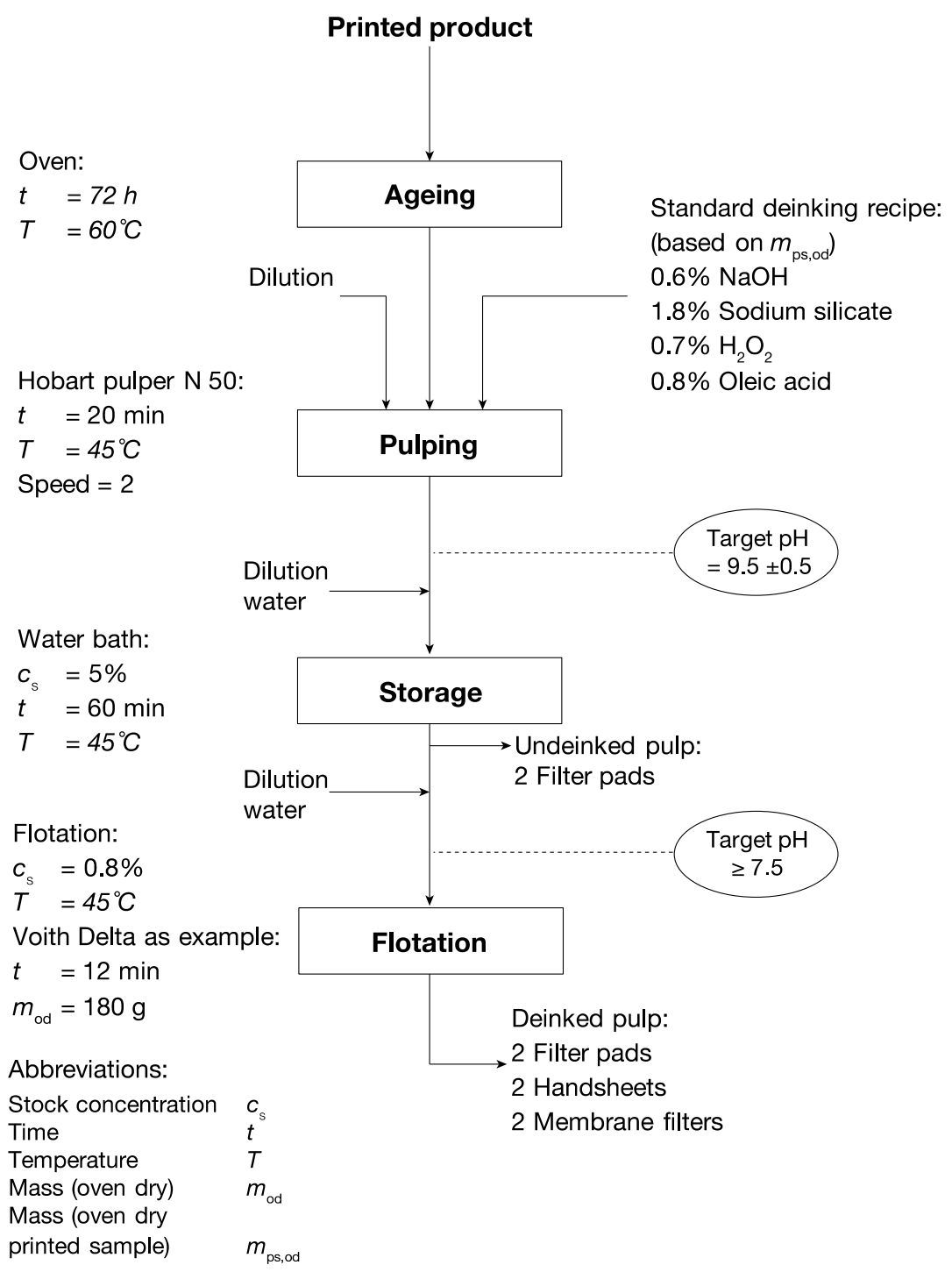

Figure 2: Procedure for testing deinkability with standard deinking recipe (INGEDE Method 11, 2018)

\section{RESULTS}

The paper deinking was completed, deinked hand-sheets and filter-pads were measured to compare their whiteness values according to ISO 11475:2017 and ISO 5631-2:2008 standard was used for their CIEL*a*b* values (Table 3). The highest whiteness value was obtained in coatings made with PVOH (79.66). The whiteness value of the coating made with cationic starch was higher compared to the base paper. In the hand-sheets obtained after the deinking process, the highest whiteness value was obtained in the coating made with PVOH (62.97), followed by the coating made with cationic starch. The lowest whiteness value in hand-sheets was also obtained in base paper.

Table 3: CIE L*a*b* colour and whiteness values of coated papers and deinked hand-sheets

\begin{tabular}{|c|l|l|l|l|l|l|}
\hline & $\begin{array}{l}\text { Base } \\
\text { Paper }\end{array}$ & $\begin{array}{l}\text { Base paper } \\
\text { deinked } \\
\text { hand-sheet }\end{array}$ & F1 & $\begin{array}{l}\text { F1 deinked } \\
\text { hand-sheet }\end{array}$ & F2 & $\begin{array}{l}\text { F2 deinked } \\
\text { hand-sheet }\end{array}$ \\
\hline CIE $\quad \begin{array}{l}\text { L* } \\
\text { a* } \\
\text { b* }\end{array}$ & 94.08 & 87.15 & 96.88 & 89.13 & 96.90 & 86.18 \\
\cline { 2 - 8 } & 0.08 & -0.34 & 0.14 & -2.10 & 0.15 & -2.93 \\
\cline { 2 - 8 } & 1.68 & 4.36 & 1.17 & 1.87 & 0.98 & 1.79 \\
\hline CIE Whiteness & 76.06 & 46.07 & 79.66 & 62.97 & 76.75 & 57.58 \\
\hline
\end{tabular}


Colour differences of inkjet printing made on base paper, coated papers and hand-sheets obtained after deinking are given in Table 4. When the table is examined, there are visible colour differences in the coated papers in the $\Delta \mathrm{E}$ colour difference measurements made with reference to the base paper inkjet printing results. This difference indicates the improvement in printability for coated papers. Colour differences in inkjet printing on hand-sheets after deinking are at acceptable levels. These results show that all hand-sheets are very similar to each other after deinking, and ink particles and coating materials are removed from the environment during the flotation process.

Table 4: $\Delta E$ colour differences between printed base paper, coated papers and deinked hand-sheets

\begin{tabular}{|c|c|c|c|c|}
\hline & $\Delta \mathrm{E}_{00} \mathrm{C}$ & $\Delta \mathrm{E}_{00} \mathrm{M}$ & \multicolumn{4}{|c|}{$\Delta \mathrm{E}_{00} \mathrm{Y}$} & $\Delta \mathrm{E}_{00 \mathrm{~K}}$ \\
\hline Base Paper & \multicolumn{4}{|c|}{ Reference } \\
\hline F1 & 0.72 & 5.67 & 4.10 & 4.49 \\
\hline F2 & 2.66 & 9.34 & 7.06 & 7.04 \\
\hline Base Paper Deinked & \multicolumn{5}{|c|}{ Reference } \\
\hline F1 Deinked & 1.67 & 0.86 & 1.67 & 0.65 \\
\hline F2 Deinked & 1.86 & 0.69 & 1.78 & 1.33 \\
\hline
\end{tabular}

Comparison of ISO brightness values of base paper, coated papers and hand-sheets obtained after deinking according to ISO 2470-2:2008 are shown in Figure 3. When the brightness values are examined, it can be seen that the brightness values in both coatings are higher compared to the base paper. The brightness value of coating made with $\mathrm{PVOH}$ (F1) was obtained as 90.05, which was higher than that of the coating made with cationic starch (F2), obtained as 90.75 .

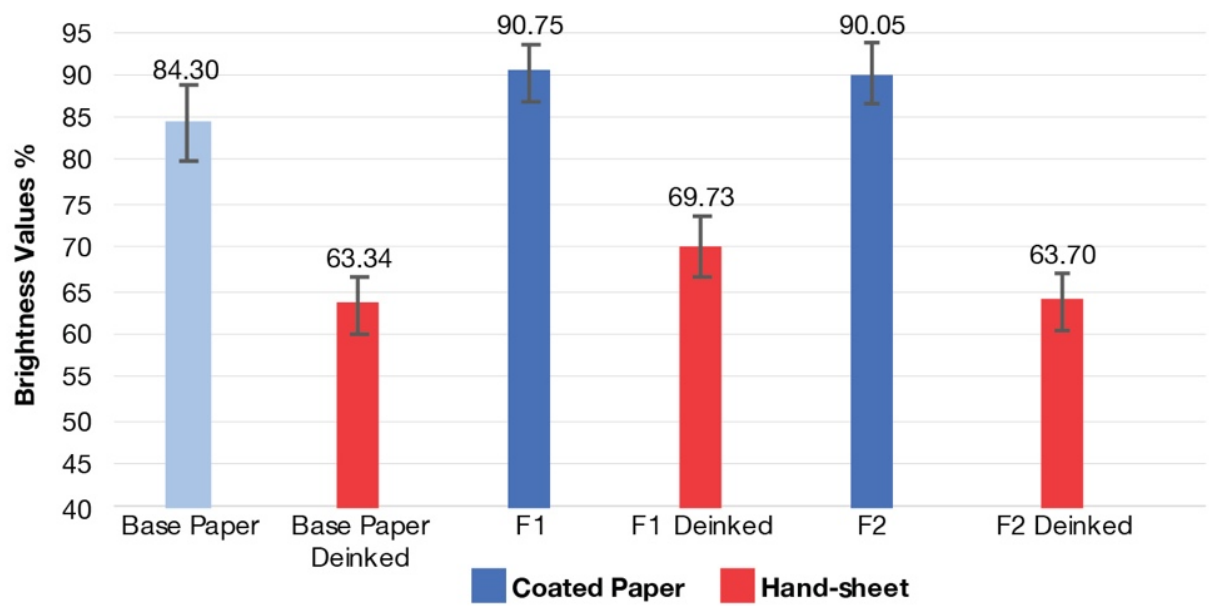

Figure 3: Brightness values of coated papers and hand-sheet papers

The paper deinking was completed, base paper, coated papers and deinked hand-sheets were measured to compare their gloss values according to ISO 8254-1:2009 (Figure 4). When the gloss values are examined, it can be seen that the gloss values of both coatings increased compared to base paper. The gloss value of the coating made with cationic starch (16.9) was higher than the gloss value of the coating made with PVOH (15.0). 


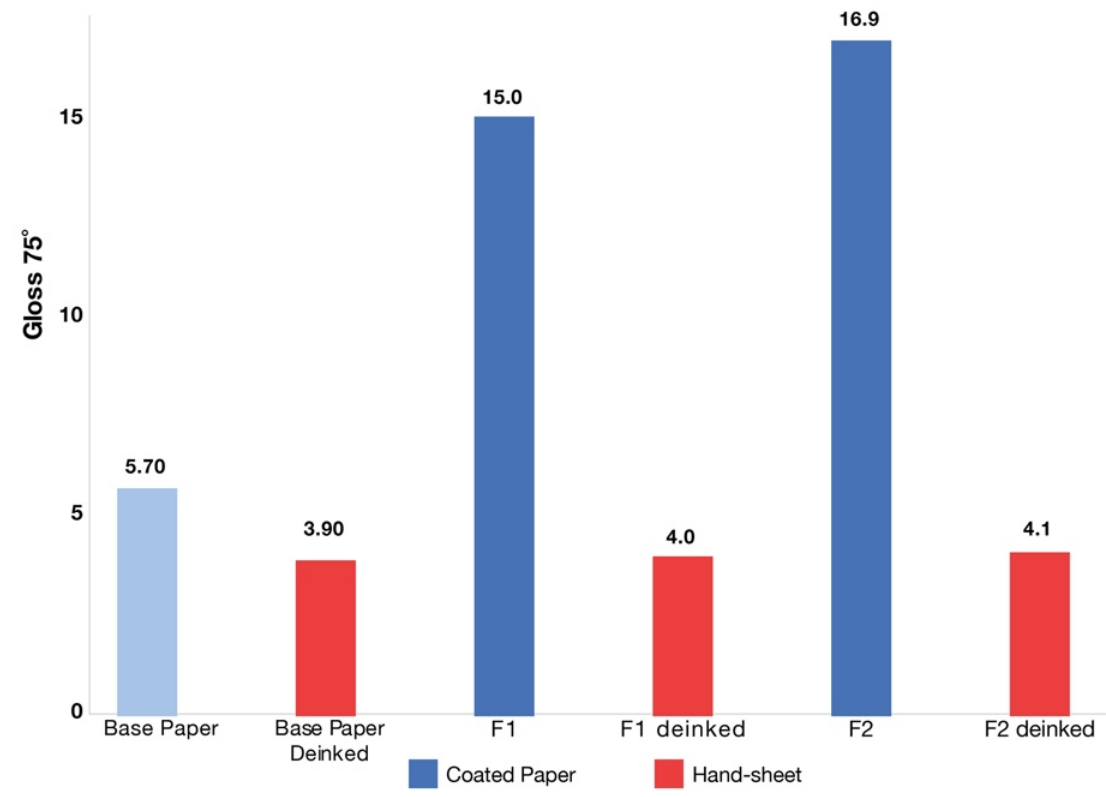

Figure 4: Gloss values of coated papers and hand-sheet papers

The X-Ray Diffraction patterns of PCC doped PVOH hybrid film and PCC doped cationic starch hybrid film are shown in Figure 5. When the PCC doped PVOH film is examined, three peaks between $2 \theta=24.11^{\circ}$, $36.14^{\circ}$ and $39.58^{\circ}$ are proves the crystalline structure of calcium carbonate and $2 \theta=15^{\circ}$ clearly show the semicrystalline structure of PVOH. The results are supported by literature (Kisku et al, 2014; Zidan, 2003). PCC doped cationic starch film were examined, the above-mentioned peaks of $2 \theta=24.11^{\circ}, 36.14^{\circ}$ and $39.58^{\circ}$ of calcium carbonate are clearly visible. Besides, the strong reflections of cationic starch were revealed at $2 \theta=15^{\circ}$ and $23^{\circ}$. These results are in line with the literature (Pi-Xin et al, 2009). According to the obtained results, the structure of the coatings is proven by XRD.

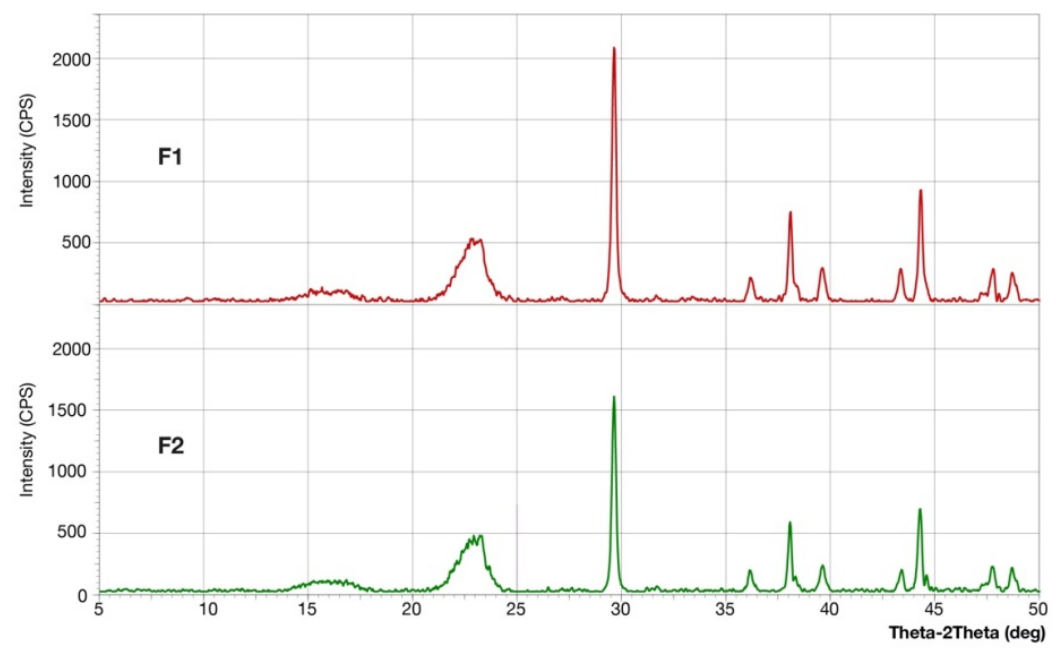

Figure 5: X-ray diffractograms of PCC doped PVOH hybrid film (F1) and PCC doped cationic starch hybrid film (F2)

The dimensions of the coatings obtained were studied using the scanning electron microscope (Figure 6). When the obtained coated papers surfaces were examined with SEM, it was determined that the surface was smooth and without cracks in both coatings. These surfaces increase the visibility of even small dots in printing and improve print quality. When the coatings are compared among themselves, the surface of the PCC-PVOH coating is smoother. Because the cationic starch polymer is a fibrous macromolecule and it is usual to create some roughness compared to $\mathrm{PVOH}$. However, this difference is not enough to affect the print quality. Both polymeric materials have provided the desired smooth surface by closing the gaps on the paper surface. 


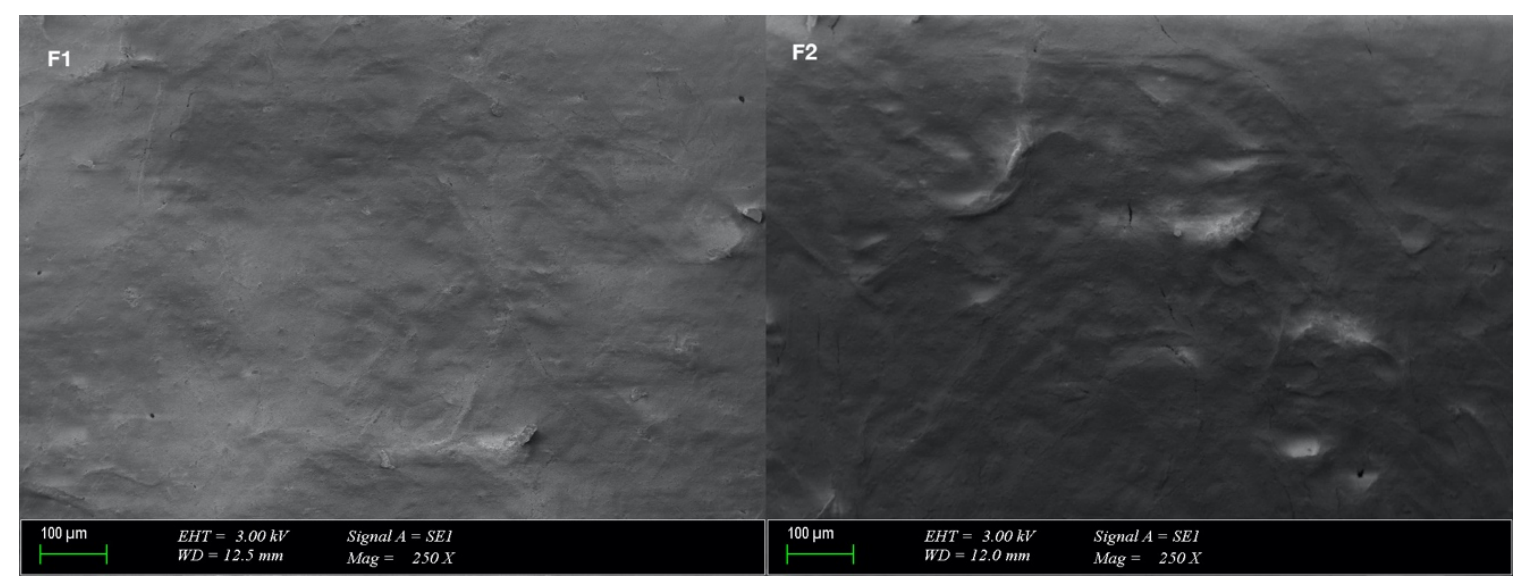

Figure 6: SEM image of the PCC-PVOH coated (F1) and PCC-cationic starch coated (F2) papers

\section{CONCLUSIONS}

Higher brightness values were obtained in coated papers. When the binders were compared, a slightly higher brightness value was obtained in the coatings made with PVOH compared to cationic starch. In hand-sheets obtained after deinking, the brightness value was also higher in coatings made with $\mathrm{PVOH}$ (Figure 3). The reason for this is that the coated papers do not prevent the ink from penetrating into the paper, thus increasing colour saturation. The higher values obtained with $\mathrm{PVOH}$ can be attributed to better movement in capillaries, thus the effect described above is exhibited more clearly. The higher brightness after deinking in coatings made with $\mathrm{PVOH}$ indicates that $\mathrm{PVOH}$ can be removed less from cellulose fibers. Higher opacity values were obtained in coatings made with cationic starch compared to coatings made with PVOH (Table 2). This is because starch is more opaque than PVOH due to its structure. This is reflected in the opacity of the coatings. Basis weight values were found to be the same. This shows that the coating amounts are set correctly. Thickness values were slightly higher in coatings made with cationic starch. This difference is due to the fact that cationic starch is denser than PVOH. Gloss values were slightly higher in coatings made with cationic starch (Figure 4). This is because PVOH moves better through capillary spaces, therefore it remains less on the surface. Starch remained on the surface more and spread the polymeric chain brightness on the surface. Whiteness values were higher in coatings made with PVOH. This is because the crystalline form of $\mathrm{PVOH}$ is white, which increased the whiteness of the paper. When the CIEL*a*b* values are examined, the results show that colour differences decrease after the deinking process, that is, the dirt remaining in the paper is removed to a large extent, bringing the colour closer to that of the reference paper. When XRD results are examined, the crystalline structure of the coating formulations can be seen clearly. SEM results show that both coatings produce a smooth, crack-free paper with better printability. In conclusion, it was determined that the type of binder affects both colour, gloss, and opacity. Cationic starch use is recommended when the emphasis is on opacity and gloss, whereas $\mathrm{PVOH}$ use is recommended when the emphasis is on brightness, whiteness, and surface roughness.

\section{REFERENCES}

[1] Aksoy, H., Yõlmaz, S., Çelik, M., Yüzbaşığlu, D., Ünal, F.: “Genotoxicity study in lymphocytes of offset printing workers", Journal of applied toxicology 26 (1), 10-15, 2006. doi: 10.1002/jat.1098.

[2] Bolanča, I., Bolanča, Z.: "Chemical and enzymatic deinking flotation of digital prints", 4th International DAAAM Conference 2004, (Industrial Engineering-Innovation As Competitive Edge for SME, Tallinn, Estonia, 2004), pages 173-176.

[3] Dorris, G., Ben, Y., Richard, M.: "Overview of flotation deinking", Progress in paper recycling 20 (1), 3-42, 2011.

[4] Du, X. T., Lee, D. T., Hsieh, J. S.: "Inkjet ink behaviors and its implication in adsorption deinking", Separation Science and Technology 51 (18), 2857-2867, 2016. doi: 10.1080/01496395.2016.1226902. 
[5] İmamoğlu, S., Peşman, E.: "Flotasyon süresinin mürekkep giderme işlemi ve hamur kalitesine etkisi", Artvin Çoruh Üniversitesi Orman Fakültesi Dergisi 13 (2), 250-269, 2012.

[6] INGEDE, International Association of the Deinking Industry: "INGEDE Method 11 - Assessment of print product recyclability - Deinkability test - ", URL:

https://www.ingede.com/ingindxe/methods/ingede-method-11-2018.pdf (last request: 2020-09-30).

[7] Kipphan, H.: "Handbook of print media: technologies and production methods", (Springer Science \& Business Media, Heidelberg, 2001).

[8] Confederation of European Paper Industries (CEPI), "Key statistics, European Pulp \& Paper Industry", URL: https://www.cepi.org/wp-content/uploads/2020/07/Final-Key-Statistics-2019.pdf (last request: 2020-09-30).

[9] Kisku, S.K., Sarkar, N., Dash, S., Swain, S.K.: "Preparation of starch/PVA/CaCO3 nanobiocomposite films: study of fire retardant, thermal resistant, gas barrier and biodegradable properties", PolymerPlastics Technology and Engineering 53 (16):1664-1670, 2014. doi:10.1080/03602559.2014.919650.

[10] Lim, J. A., Lee, W. H., Lee, H. S., Lee, J. H., Park, Y. D., Cho, K.: "Self-Organization of Ink-jet-Printed Triisopropylsilylethynyl Pentacene via Evaporation-Induced Flows in a Drying Droplet", Advanced functional materials 18 (2), 229-234, 2008. doi: 10.1002/adfm. 200700859.

[11] Mavros, P., Matis, K. A.: "Innovations in Flotation Technology", (NATO ASI Series, 2009).

[12] Ozcan, A., Arman Kandirmaz, E.: "Natural ink production and printability studies for smart food packaging", Color Research \& Application 45 (3), 495-502, 2020. doi: 10.1002/col.22488.

[13] Ozcan, A., Tutak, D.: "The effect of zeolite on inkjet coated paper surface properties and deinking", Nordic Pulp \& Paper Research Journal 35 (3), 432-439, 2020. doi: 10.1515/npprj-2020-0025.

[14] Pi-Xin, W., Xiu-Li, W., Xue, D. H., Xu, K., Tan, Y., Du, X. B., Li, W. B.: "Preparation and characterization of cationic corn starch with a high degree of substitution in dioxane-THF-water media", Carbohydrate Research 344 (7), 851-855, 2009. doi: 10.1016/j.carres.2009.02.023.

[15] Tekin, E., Smith, P. J., Schubert, U. S.: "Inkjet printing as a deposition and patterning tool for polymers and inorganic particles". Soft Matter 4 (4), 703-713, 2008. doi: 10.1039/B711984D.

[16] Toppinen, A., Pätäri, S., Tuppura, A., Jantunen, A.: "The European pulp and paper industry in transition to a bio-economy: A Delphi study", Futures 88, 1-14, 2017. doi: 10.1016/j.futures.2017.02.002.

[17] Tsatsis, D. E., Papachristos, D. K., Valta, K. A., Vlyssides, A. G., Economides, D. G.: "Enzymatic deinking for recycling of office waste paper", Journal of environmental chemical engineering 5 (2), 1744-1753, 2017. doi: 10.1016/j.jece.2017.03.007.

[18] Tutak, D.: "Modified deinking of digitally printed paper with water based inkjet ink", Cellulose Chemistry and Technology 51 (5-6), 483-488, 2017.

[19] Zidan, H.M.: "Structural properties of CrF3-and $\mathrm{MnCl}$-filled poly (vinyl alcohol) films", Journal of Applied Polymer Science 88 (5), 1115-1120, 2003. doi: 10.1002/app.12123.

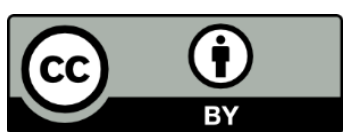

(C) 2020 Authors. Published by the University of Novi Sad, Faculty of Technical Sciences, Department of Graphic Engineering and Design. This article is an open access article distributed under the terms and conditions of the Creative Commons Attribution license 3.0 Serbia (http://creativecommons.org/licenses/by/3.0/rs/). 


\title{
DEVELOPMENTS IN DIGITAL PRINT STANDARDIZATION
}

\author{
Christos Trochoutsos 2, 3 (1D), Anastasios Politis 1,2,3 (10) \\ ${ }^{1}$ University of West Attica, Graphic Arts Technology, Egaleo, Greece \\ ${ }^{2}$ Hellenic Open University, School of Applied Arts, Patras, Greece \\ ${ }^{3}$ HELGRAMED - The Hellenic Union of Graphic Arts \& Media Technology Engineers, \\ Athens, Greece
}

\begin{abstract}
Digital Printing has been established as one of the most rapidly evolving printing processes since its first introduction in 1982. In the years that followed, digital printing became the one significant new technology for print media production. Digital printing is continuously changing the print media landscape. Although, DP creates structural changes in production workflow and processes, it lacks in terms of print standardization, compared to offset printing for example, where consistent aim values and guidelines apply by means of ISO 12647-2. This drawback basically depends on two factors, which are interrelated. Firstly, there are many different technologies that are used in digital printing, and, each of them shows substantial difference in printing technology, substrates, data preparation, process control and image quality requirements. Secondly, compared to conventional printing, some digital printing technologies are still developing. After all, digital printing is versatile and variable in every way and cannot be standardized under a single standard.

A research on the digital printing technologies, processes and workflows is needed, to determine if a print specifications and quality controls (among them color management), can be applied in Digital Printing, and if possible, to which segment. Since color is very important to printing, especially in packaging and marketing applications, the print evolution demands for matching colors across technologies, substrates, materials and colorants. This paper intends to reveal the present status regarding Digital Printing Standardization. The question posed is whether standards can be applied and in which segments of digital printing either as technology or print sector (commercial decoration, packaging).

Within the paper, an analysis of the current industrial typical guidelines ranging from data creation all the way to printing will be made. Guidelines that are determined either by the manufactures of the digital printing machines, or by Institutes, such as FOGRA are reviewed for output process control and colour fidelity. As such, this paper can be regarded as a first attempt to preview the basis where standardization for digital printing processes can be developed.
\end{abstract}

Key words: Digital printing, Standardization, developments, technologies

\section{INTRODUCTION}

\subsection{Introduction}

Digital Printing (DP) has been established as a principal printing process since its first commercial introduction in the 90s. In the years that followed, digital printing became a significant new technology for print media production. Since then, Digital Printing has been developed rapidly and has brought about significant changes not only in printing itself but also in production workflow and in the total landscape of media market.

The establishment and the introduction of DP as well as its commercial application have led to predictions that this technology will eliminate traditional printing processes. Some older remember the title of an exhibition at a DRUPA (probably DRUPA 1982): "Good Bye Gutenberg". This "apostrophe" has been related with the digitalization of the production processes in the prepress field, the Internet and digital publishing, as well as with the introduction of digital printing.

\subsection{History of Digital Printing}

The history of digital printing is relatively short compared to printing as a whole, which dates back to 1439, when German businessman Johannes Gutenberg created a press that started the mass production of books. The first digital printing presses came onto the market in the early 1990s.

In 1993 the world's first digital colour printing press was launched called Indigo. The name of the printing press series came from a company formed by Benny Landa in 1977 to develop the world's fastest 
photocopier. Landa later discovered that the ink developed for the photocopier, called Electrolnk, could also be used in printers.

The first introduction of the Indigo printing machine, triggered a transformation in the printing world - all of a sudden, customers and print buyers were able to choose short-run, personalized, "high quality" print straight from prepress and the "desktop publishing" systems.

Print media industry expert Chris Baker, who worked as vice-president at HP and Indigo for five years, predicts that this growth will continue into the future: "Digital print will be everywhere in the future. Digital printing will not just be used for commercial printing; it will be used for publishing and packaging. I believe that digital presses will be developed to go after the packaging market - the personalization of packaging will be huge in the future. Digital presses will also become faster and be designed to handle more types of printing," (printed.com, 2020)

\subsection{Facts \& benefits of Digital Printing}

The growth of digital printing can be attributed by the many benefits claimed that offers to customers:

- Green: This method of printing can boost the green credentials of any company. Unlike conventional printing, there are no pre-press stages between the digital document file and the final print, so there is no need for film plates or photo chemicals. The process can be very environmentally friendly when water based inks are used and no powders or coatings are applied. It is sometimes cost prohibitive to go completely green but there are ways to keep costs down without harming the environment more than absolutely necessary.

- $\quad$ Speed: Digital printing offers a quicker response time due to its minimal press setup. It simplifies the printing process, traditional plates and film are redundant, there is no press make-ready needed, no plate mounting, no registration adjustments and no ink keys. There are less steps and people involved in the printing process, and as result the final product can be delivered quicker.

- Cost effective: Enabling companies to make financial savings is another benefit offered by digital printing. Traditional printing services have always had quotas or minimum orders required when you used their services. However, because of the flexibility of the printing press, digital printing companies do not have these sorts of boundaries, proving the freedom for the businesses and individuals to save and get the exact amount that they need.

- Short runs: Digital printing is the ideal method of producing short- to medium-runs in more effective ways than traditional print. Digital data is easily stored and updated; therefore changes are easily made either prior to printing or in the following batch. Digital printing allows more effective print management: there's no need for bulk stock and no need to dump out of date stock. Some machines that use digital technology can not only print out the materials but also finish the final product at the same time. (inline post-press)

- Print Enables Smarter Marketing: Variable data printing gives direct marketing a highly effective way to talk to customers, allowing companies to tailor their message to their audience. Delivering the right message to the right people at the right time. QR codes have also linked printed materials to the digital realm. Digital printing facts include information about variable data and variable imaging. Because computers control the printing process it is much easier to change the content of the item while it is being printed. This adds a new level of customization and personalization that can greatly improve your finished product appeal. (PEARL, 2013)

\section{GUIDELINES AND SPECIFICATIONS FOR COLOR PRINTING}

\subsection{Color image quality in printing}

The publishing industry is constantly changing. New disruptive digital printing techniques enter the market, standards continue to evolve or to be revised; electronic media allows print service providers to become communication providers. That implies more complex processes and related interactions.

Color image quality is a very important deciding factor for buyers of color imaging devices. It is therefore of utmost importance for manufacturers of imaging equipment such as digital presses, to pay special attention to this factor. After several years of market hesitation, digital presses have now become common (most of them). In today's printing market, where flexibility, variable content, shorter lead times, and on demand publishing, are being demanded, digital presses represent an attractive 
supplement to conventional offset presses. It is important for customers of digital press equipment to be able to take into account the quality of the equipment, typically to be able to make a trade-off between price and quality. The total quality of a device is, however, a very complex entity, involving technical aspects such as expected lifespan, printing speed, accepted media, as well as customer relation aspects such as service agreements. (FOGRA, 2018)

There are indeed many factors that contribute to the quality of an image, such as spatial resolution, color depth, sharpness, naturalness, colorfulness, and visual artifacts (banding, streaking, grain, blocking, moire, etc.). There exists an ongoing effort to standardize the definitions of these and other image quality factors, as well as their assessment methodology.

Potential uses of quantifiable data on color image quality for manufacturers include the following:

- Tradeoff analysis of speed and implementation cost versus color image quality in image processing algorithm development

- Benchmarking of imaging systems and algorithms to other vendor's products

- Documentation of color image quality improvements resulting from efforts spent on optimization of technology parameters

For customers, it would obviously be advantageous to have access to reliable and objective information about the image quality that devices can provide when considering several alternatives for purchasing. Every print shop is committed to a high level of quality. A basic prerequisite for this is to use meaningful rules, hence a standard. In standardization a distinction is often made between the specification of the final aim and the needed (process) steps to achieve that aim. A good example for the latter one is the PSO - Process Standard Offset, which has been successfully in place for years. (Hardeberg and Skarsbo, 2002)

\subsection{Color management}

Two main components are needed to successful color management, no matter in offset printing or in digital printing. These are the technology part (meaning to have the appropriate hardware and software) and the proper education (understanding color management theory and the workflow knowledge).

Hardware is complicated, as it insists of different digital printing presses (and there are literally hundreds of models), different ink sets, different ink types, different substrates and so on.

Color measuring devices are used to measure the resulting colors of ink mixtures on the substrate. Standard devices are designed to measure on flat and even surfaces. Substrate properties can interfere with the measurement. Measuring colors correctly on those surfaces requires measurement equipment designed for that purpose. More information about measuring in different conditions can be found in section 2.4. (Gerrit, 2017)

Some of the major construction companies for digital presses have developed integrated tools to simplify and automate the colour management process. These tools ensure that the colour accuracy remains consistent and uniform across presses and sites and over time, without laborious manual calibration.

These tools usually consist of an Inline Spectrophotometer scans a colour chart to describe the individual colour space of a specific substrate (the "Media Fingerprint"). The DFE (Digital Front End) then automatically generates a dedicated ICC profile, ensuring accurate colour matching of that specific substrate against a given FOGRA, GRACOL etc. tool based on standard such as ISO 12647-2.

Accurate matching to these industry standards also enables seamless emulation of output from other print technologies (such as offset). A three-dimensional LUT is then used to regularly calibrate the press, automatically compensating for any variations in press conditions to return it to the baseline established by the Media Fingerprint, ensuring that colour output always remains consistent. On web-fed presses this process happens at a pre-determined interval, whereas on sheet-fed presses the operator is free to determine the frequency of calibrations. Media Fingerprints can be saved and shared between presses and sites, and over time, to ensure a consistent output regardless of where or when the file is printed.

\subsection{Why digital printing is hard to standardize}

Since there are many different printing technologies, processes and workflows it is under research to determine if a color management process can be applied in digital printing, and if possible, to which applications of digital print. The physics of the lithographic process doesn't vary from one model or machine to another. But, all digital press manufacturers have unique, patented processes. 
The very term "digital" is misleading, because it refers to many disparate processes. Digital is commonly taken to mean toner/laser technology, but in the printing world, it may just as readily mean inkjet. Laser and inkjet are about as different as anything can be.

In the digital process, a crucial consideration for color quality is gamut-the range of color that a press can reproduce. The wider the gamut, the more colors can be printed. But gamuts of equal size are not always equal. One device may be weak in reds, another in blues. Sometimes, same size gamut can produce very different results.

Usually, digital presses have a wider color gamut than the offset process. Because the offset gamut is still the standard in many people's minds, this is often not understandable and is a more confusing fact. Unlike offset, each digital press model has a difference color gamut. All are different from offset. And it's even more complicated when considering also the spot colors reproduction and not just the conventional CMYK colors. There is also a belief that because of the massive range of applications, which is one of the key benefits of digital printing, this also makes it hard to standardize.

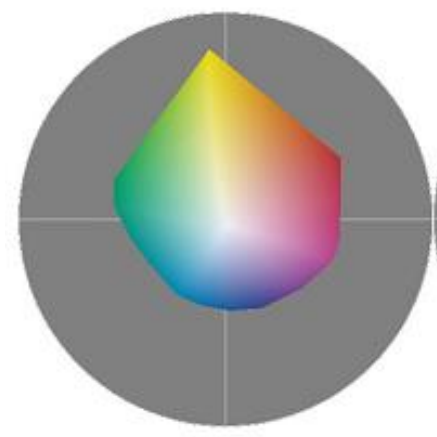

(a) Océ CPS700

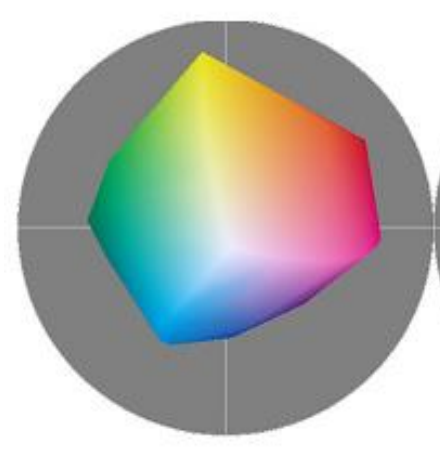

(c) Canon CLC5000

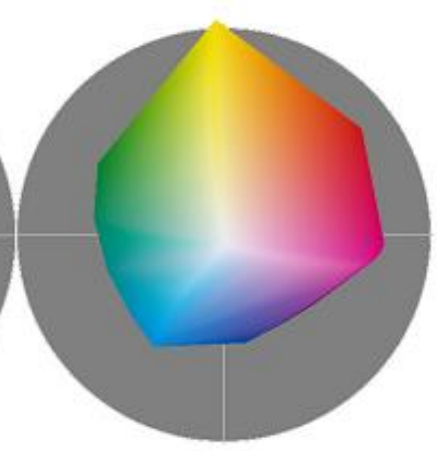

(b) Xerox DC2060

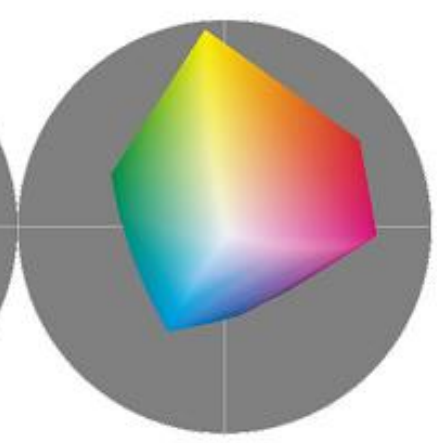

(d) NexPress 2100

Figure 1: Different digital presses, different color gamuts

\subsection{ISO 12647-2: Process Standard Offset}

The Process Standard Offset (PSO) was developed by Fogra in co-operation with the German Printing And Media Industries Federation. It is the description of an industrially orientated and standardized procedure for the creation of print products. The PSO is in conformance with the international standardization series ISO 12647 and therefore internationally recognized.

By using PSO the quality of the production of a complete print product can be guaranteed, from data creation to the finished printing product. The PSO describes adequate testing devices and control methods by which the production process can be supervised, guided and proved. This includes measuring devices with spectral and densitometric settings, as well as suitable testing elements (for example test stripes). Furthermore, the PSO sets nominal values and tolerances for the print production that, relating to modern production materials, represents what is sensible and feasible. (printed.com, 2020)

The goal is to ensure that the production process is as efficient as possible and at the same time to ensure that interim and final results show a predictable quality of colour. In the printing 
industry very rarely data is printed where it was created. Customers often hand jobs to different print and media specialists. Printing plants collaborate in order to concentrate themselves on their core competences. This trend will continue and will extend across borders as well. The PSO and ISO 12647 are in constant development in order to benefit the user. This way, quality becomes measurable, verifiable and reproducible. ISO 12647-2 is part of the ISO 12647, which contains the following:

- $\quad$ ISO 12647-1 - Part 1 Parameters and measurement methods

- ISO 12647-2 - Part 2 Standardized offset printing

- $\quad$ ISO 12647-3 - Part 3 Standardized press printing

- $\quad$ ISO 12647-4 - Part 4 Standardized gravure printing

- $\quad$ ISO 12647-5 - Part 5 Standardized screen printing

- $\quad$ ISO 12647-6 - Part 6 Standardized flexo-printing

- $\quad$ ISO 12647-7 - Part 7 Standardized digital printing

Unfortunately, part7 is not about digital printing products, but for proof prints, that are printed with digital printers. (gmg, n.d.)

Process standard offset is a living process, so as the paper technology and other factors that affect printing changes, the standards may also change. For example, latest ISO 12647/2-2013 printing conditions and Fogra 51 and 52 it's the revised ISO standard printing conditions for sheet and web fed heatset-offset litho. This revision was published at the end of 2013 and it replaces the 2004 version. The main changes to the revised standard and the new data sets and profiles being developed by Fogra for coated and uncoated papers. Changes are also made due to the implications of the new spectrophotometer specifications, M1, in relation to the new 2013 version and the Fogra data sets.

- $\quad$ First, papers have been revised to better reflect the papers in current use with their high OBA (Optical Brightening Agents), so there are now 4 coated and 4 uncoated paper types in this new version, three more than the old 2004 version. These are now called 'Print Substrates' (PS), replacing the 'Paper Types' (PT) is the 2004 version.

- Colour differences are still measured and evaluated using De76, however De2000 tolerance values are also given.

- $\quad$ The new specifications for CIE Lab figures and TVI curves will result in new colour data sets and ICC profiles being needed. At present Fogra are working on a coated profile for PS1, based on a new dataset, Fogra 51 and an uncoated profile for PS5, also based on a new dataset, Fogra 52.

- This new version of $12647 / 2$ is much more than just changing to new ICC profiles and new measurement figures. This change also may need new lighting, new spectrophotometers and changing digital proofing papers to have OBA/UV content.

One of main factors as referred to above for this new version of $12647 / 2$ is to reflect the use of OBAs in papers. The viewing and lighting conditions standard, ISO 3664 was revised in 2009 in order to support the extra UV emissions caused by the OBA content. So, this is now within the standard and the latest D50 tubes will meet this requirement.

However, to measure accurately printed sheets a new spectrophotometer measurement standard is needed, M1. The 2004 standard uses M0 measurements, which do not correctly record the UV content of the paper, so can affect the accuracy of the ink colour readings.

The M1 spectrophotometer measures and allows for the UV content caused by the OBAs. For example, an $\mathrm{M} 0$ reading giving $\mathrm{b}$ at -4 , on reading using $\mathrm{M} 1$ would result in a more accurate $\mathrm{b}-6$.

Older spectrophotometers will not be able to read in the M1 mode; so, some updating of instruments is inevitable, both to off-line handhelds and on-press online devises.

Current 'approved' inkjet proofing papers are often OBA free. Proofing papers for the new profiles and M1 spectrophotometer readings will need to match the OBAs in the chosen paper type as closely as possible. (Sherfield, 2014)

\subsection{PSO and Digital Printing}

After the success of the Standardization for Offset, the production also needs Digital Print Standardization for matching colors across technologies, substrates, materials. Process control needs to cover all print specific settings and the corresponding visual and instrumental measures, in order to establish a repeatable and stable printing condition. The process control measure therefore strongly depends on the 
printing technology and media used. Although process control is considered to be the responsibility of the print service provider some basic principles are important.

In the majority of such applications the requirement could be termed as "matching offset". In light of this it stands to reason that where possible it would be good to make use of the established means to control offset printing processes. This would include the usage of the same control wedges, measurement devices [in particular densitometers to measure the tone response] and, last but not least, the evaluation and the comparison of digital prints by means of press acceptance tests established for offset printing.

Press acceptance tests usually cover the solid coloration, the tone value increase [formerly known as dot gain] as well as grey reproduction. Those figures are compared against aim values derived from state of the art characterization data sets such as FOGRA39. Whilst ISO 12647-2 and hence PSO make provisions for a binary [conforming or not-conforming print] evaluation, manufactures of such solutions also offer a single value index also known as scoring value. Such scores typically range from 0\% to 100\% or from 1 star to 5 stars. The problem with these scores is that there is no agreed basis for their calculation so any score is somewhat proprietary and can't be compared among different vendors.

But Process Standard Offset can't be applied in Digital Printing it the same way. Contrary to digital printing the binary [Yes/No] evaluation of offset prints represents the results of many years' research and practical implementations. Still, some problematic aspects describe why the "offset concept" can't be transferred without some modification to the digital domain. That's the reason, why Fogra's working group created a new digital printing standard ISO 15311. Three of these main aspects are described below:

1. Inadequate definition of the pertinent scope. The usage of PSO for digital printing needs to be critically reviewed as there is no description as to what technologies and substrates it should be applied to. The term "digital printing" as a description for a given printing technology or imaging process is quite unsuitable. While the use of PSO for digital printing might be considered intuitive for toner based systems it is more than questionable for large format banner printing using UV-curing inkjet or textile printing using thermal processes.

2. Lack of scientific knowledge and practical experience. The various digital printing technologies are compared to conventional printing processes at a relatively early stage of their development and so that standardization activities and the necessary research is still scarce. This means that the implementation of procedures and methods which are successfully used in offset printing are not necessarily transferable to every kind of digital printing. Rather, such a "transfer" must be tailored and optimized for each use case, considering strengths and weaknesses of the pertinent imaging processes. Examples include the typical inkjet banding or a characteristic graininess as is found in some inkjet printing systems induced by coalescence. These digitalprinting-specific problems might severely affect the final image quality but are not included in the "offset evaluation method toolbox". An audit or a compliance check in accordance with PSO ignores this property completely.

3. Missing Link to underlying process parameters. The primary aim of densitometry is to monitor the amount of colorant per area on a print. In order to measure the tone reproduction [the tonal response $[\mathrm{CIEY}]$ of the primary colours from $0 \%$ to $100 \%$ ] the graphic arts industry uses the tone value, better known to some as apparent dot area. The solid densities and the tone value increase helped conventional process control reliably by indicating [with high sensitivity] press problems and monitoring the relative changes in tone reproduction of an image as it moved through the various stages of data preparation to a printing plate and eventually to the printed image. The underlying concept in ISO 12647-2 is that once the correct process colour solids and two-colour solid overprints are achieved, a satisfactory overall result can be reached by simply adjusting the tone value curve to match the specified tone value curve defined for the pertinent printing condition. In general, this assumption can't be made for digital printing although it is possible to measure solid density and tone value increase. This doesn't allow for any direct link to the underlying process parameters since they can't be easily identified. They are dependent on the imaging process and the interaction of the colorants with substrates used. For example, there is no doubling in inkjet printing. A possible evaluation of established doubling-slur patches thus leads to results that are hard to interpret by the user or are simply meaningless. Further it should be noted that densitometers mostly use a cross polarizer to reduce the effect of first surface reflections which reduce the measured differences between wet and dry prints. This may not be suitable for many digital printing technologies since it differs from colorimetrical readings 
which are made without polarization filters. Note that the machine's internal use of density measurements for dedicated control processes, for example the control of the toner transfer to the photoconductor, is not considered as being inappropriate [it actually might be a very good solution]

\subsection{Digital Print Standardization - ISO 15311}

The basic prerequisite for printing predictable print quality is to use meaningful rules, hence a standard. In standardization a distinction is often made between the specification of the final aim and the needed (process) steps to achieve that aim. For digital printing the PSD - Process Standard Digital provides industrial typical guidelines ranging from data creation all the way to printing and is provided by Fogra. The ISO title is: Graphic Technology - Requirements for printed matter for commercial and industrial production. However, there is some discussion within ISO TC130 WG3 if the standard should be restricted to digital printing or not (since it can be applied also to conventionally printed products).

Contrary to ISO 12647-x, ISO 15311 is a multipart standard based on representative use cases (rather than printing technologies). Substantial contribution has been made in the Fogra digital printing working group (DPWG). The current structure looks as follows:

- $\quad$ ISO 15311-1 - Part 1 Parameters and measurement methods

- $\quad$ ISO 15311-2 - Part 2 Commercial production printing (almost published)

- $\quad$ ISO 15311-3 - Part 3 Large format printing (draft will be published as Fogra specification)

- $\quad$ ISO 15311-4 - Part 4 Additional parts based on use case (in discussion)

As far as the problematic aspects appear in digital printing in comparison to offset printing, Fogra proposes the following solutions:

1. The recently started multi-part standard ISO 15311 [Graphic Technology - Requirements for printed matter utilizing digital printing technologies for the commercial and industrial production] will provide a process-independent classification of the relevant use cases and applications and these will be accurately defined. Thus, for example, part 2 of ISO 15311 addresses commercial production printing while part 3 stipulates aim values and tolerances for large-format signage printing.

2. Fogra has applied for a research project that has started recently. It focuses on the development [and improvement] of objective methods for evaluating inhomogeneity and sharpness. First ideas were discussed during the last meeting of the DPWG [Fogra Digital Printing Working Group] and in the October 2010 ISO/TC130 WG3 meeting. In the short- and mid-term results from this research project can be expected that contribute to the vendorneutral, objective evaluation of the pertinent print image quality attributes.

3. Many manufacturers of digital printing systems are moving towards a colorimetric evaluation or inspection of their prints. This begins with the adjustment and calibration, via ICC profiling and ends with the colorimetric print quality evaluation. This development is already covered in the process independent definitions of contract proofs [ISO 12647-7] and the so-called "Validation Prints" [ISO/DIS 12647-8]. Both are fully defined without using any densitometric methods. The DPWG [Digital Printing Working Group] is working on a fullyfledged all colorimetry-based metrology including the respective statistical analysis [and uncertainty analysis] for process control and quality assurance (Kraushaar, 2010)

The Process Standard Digital has three main objectives:

- Output process control - Achieving a repeatable print output. Different output processes need to be checked against their known and constant behaviour.

- Colour fidelity. The second goal addresses a consistent colour communication by means of faithful image reproduction. Guide by the motto: "Printing the Expected" quality-oriented print service providers do first understand the needs and expectations of their clients and are second able to accurately reproduce that expectation. In that light the Process Standard extends the established way of colour reproduction namely the absolute reproduction ("Side-by-Side") by means of an all new media relative colour reproduction.

- PDF/-X compliant workflow. As in this paper, an analysis of the current industrial typical guidelines from data creation all the way to printing will be made, it's important that the entire workflow is subject to critical scrutiny as to its capacity for sustained achievement of consistent 
print quality and colour fidelity. So, Process Standard needs to provide guidelines for creating, preflighting and processing PDF based documents.

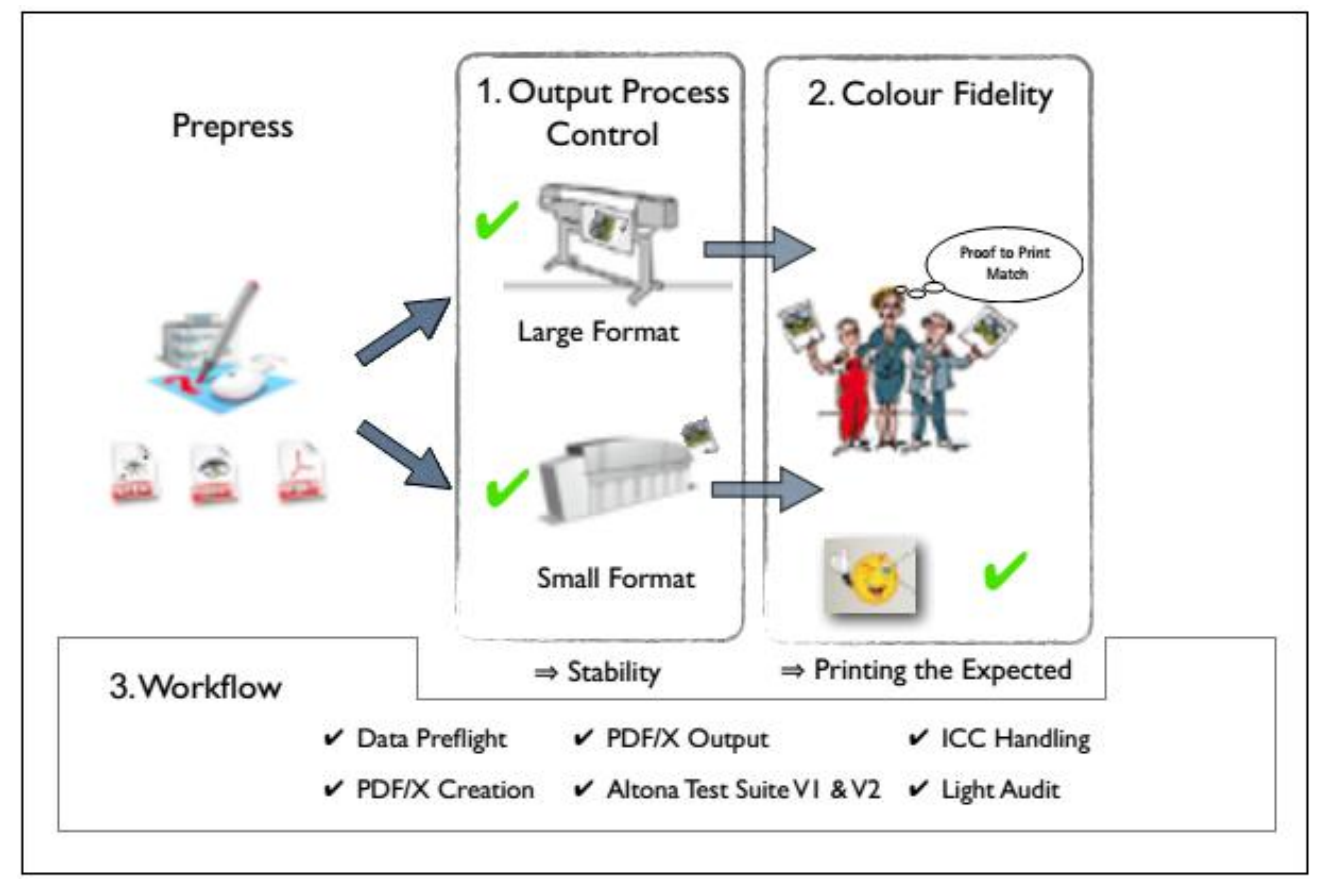

Figure 2: Fogra PSD-concept. Aiming for a consistent and predictable print quality.

Standardization does not mean that materials such as substrates, inks, toner or machinery must be limited. On the contrary, standardization aims toward a manageable facilitation of a material and process diversity in terms of rigors and consistent print quality. Only then is it possible to identify suitable "combinations", i. e. collection of a driving (RIP \& colour management), a substrate, ink or toner and a printing press. Although many factors are the same in almost every digital printing press (for example the E.F.I. Fiery is used in most cases for RIP), as mentioned before, the publishing industry is constantly changing. New disruptive digital printing techniques enter the market. From xerography, to electrophotography and the latest one: nanotechnology, which is still being developed. That implies more complex processes and related interactions. To meet these changes the standardization process is designed as a "living document".

\subsection{Factors that affect quality of Digital Printing}

The color gamut of a digital press (or any other imaging device) is the sum of all colors it can reproduce. Colors that are outside of this gamut cannot be reproduced. The color gamut, and in particular its size, is thus a quality factor. A press with a larger gamut than another is typically able to reproduce more saturated colors, which can be appreciated for many applications. The color gamut of a digital press depends on many factors such as substrate, toner/colorant, and halftoning algorithm. And unfortunately, every digital press has its own color gamut, as mentioned in section 2.3.

\subsubsection{Substrate}

Two main types are available: swellable and porous. In general, acid-free, buffered, and lignin-free paper bases are recommended for long-term storage.

Using swellable paper, its surface of this type of inkjet paper swells in the presence of the moisture in the water-based ink, allowing the colorants to penetrate the top layers. Swellable papers typically have three active layers: a protective top layer, a layer that fixes the ink droplets in place, and, below that, a layer that absorbs additional ink components. The paper base is sandwiched between two polyethylene layers and backed by an anti-curl coating and an antistatic layer. Premium swellable papers contain all of these layers, but less expensive ones may not. The polymer coating on swellable papers acts to maximize image 
brightness by keeping the colorants from spreading, and, to some extent, it protects the image from atmospheric pollutants. Images printed on coated paper may require a significant amount of drying time. On the other hand, the surface of porous paper is coated with very small, inert particles, which create numerous minute cavities in which the ink is deposited. These particles prevent the ink from spreading. Porous paper has a higher resistance to moisture and humidity. This paper requires minimal drying time, so the print can be handled immediately without fear of smudging. This type of print has no protective polymer layer; therefore, the colorants are susceptible to attack by atmospheric pollutants, such as ozone and oxides of sulfur and nitrogen, which can be present in the environment in fairly high concentrations. Porous paper is preferred when pigment inks are used.

That's why in ISO 12647-2 there are different standards regarding the different type of paper, and the same difference have to be considered on digital printing.

\subsubsection{Toner/Colorant}

Dye Diffusion thermal transfer Prints In this process, which is also referred to as dye sublimation, heat transfers colorant from a donor ribbon to the final print. Dye diffusion thermal transfer printers frequently apply a clear protective layer to the print during the transfer process to prevent the image from smearing when rubbed. This process is frequently used for snapshot-size photo printers or in photo kiosks, where customers can print images in a few minutes. The permanence of these images has not been widely studied, and there is very little information available.

The majority of photo-quality printers use inkjet technology, in which very small droplets of ink are deposited onto paper. Inkjet prints vary widely not only in the composition of the colorants and paper, but also in stability. Inkjet images may be composed of dyes like those used in traditional photographic prints, or of pigments, which are the colorants used in paints. In general, pigments tend to be more stable than dyes.

Inkjet prints can be made on either uncoated or coated paper, but only coated paper will provide photoquality prints. Plain, uncoated paper tends to absorb the ink, resulting in a blurred image and loss of color intensity. In high-quality paper, a coating prevents the ink from bleeding into the paper; this results in brighter, more saturated color and greater image detail. Coated papers may closely resemble traditional color print supports. (IPI, 2004)

In electrophotographic prints, the same process used to produce office photocopies is used to make the prints. In electrophotography, toner is transferred to the paper base and then fused in place. The paper is usually uncoated, and the images are reasonably stable, because they are composed of pigment particles that are fused to the paper with a durable polymer binder material. This technology is used less widely than inkjet for photo-quality printing (Fogra, 2018) Electrophotography is the most widespread nonimpact-printing technology that exists. Many companies, like Xerox and Canon use variants of the electrophotographic principle with electrostatic powder toner, based on an invention of Chester Carlson from 1939 (HP, 2012).

\section{TYPICAL GUIDELINES RANGING FROM DATA CREATION ALL THE WAY TO PRINTING}

Printing the expected is not easy. To standardize printing we need to have the same printing results and not just print the expected, but have the same output across different printing technologies, different substrates, production batches.

Problems might occur not only on the output procedure, but in many occasions in input file formats as well. PFD files are container files and elements can include bitmap graphics in different color modes (RGB, CMYK, LAB, ...), vector elements, spot colors, overprints, transparencies, etc.

Depending on the creation application the result can be overly complex which leads to longer processing time and mistakes during PDF processing. Missing color management information (embedded profiles and output intent) leaves room to interpretation and errors.

$\mathrm{PDF} / \mathrm{X}$ is the ideal data exchange format for the printing industry. The purpose of it is to facilitate graphic content exchange with specific requirements linked to production workflow needs. In the following table some typical tasks of the prepress side are provided to avoid faults. 
Table 1: Typical tasks together with the corresponding party being responsible for that specific job.

\begin{tabular}{|c|c|c|c|}
\hline Nr. & Task & Responsible & Note \\
\hline 1 & $\begin{array}{l}\text { Data creation - open } \\
\text { (application) files }\end{array}$ & $\begin{array}{l}\text { Print service provider } \\
\text { should inform the } \\
\text { data deliverer about } \\
\text { the status of the data } \\
\text { integrity. }\end{array}$ & $\begin{array}{l}\text { Providing a reliable visualization e.g. by } \\
\text { means of a hard- or softproof based on the } \\
\text { corrected (optimised) data is needed for } \\
\text { colour critical jobs. }\end{array}$ \\
\hline 2 & $\begin{array}{l}\text { Providing Print-ready } \\
\text { data - marked as } \\
\text { PDF/X. }\end{array}$ & Data deliverer & \\
\hline 3 & Preflight of data & Print service provider & \\
\hline 4 & $\begin{array}{l}\text { Agreement and } \\
\text { negotiation about } \\
\text { the output condition } \\
\text { (printing condition) }\end{array}$ & $\begin{array}{l}\text { Print service provider } \\
\text { together with the cli- } \\
\text { ent (print buyer) }\end{array}$ & $\begin{array}{l}\text { These include the definition of the quality } \\
\text { type for CMYK (and spot if present), the } \\
\text { intended viewing distance, the reference } \\
\text { characterization data set as well as the } \\
\text { colour reproduction (.Side-by-Side" or } \\
\text { media relative) }\end{array}$ \\
\hline 5 & $\begin{array}{l}\text { Printability of the } \\
\text { substrate }\end{array}$ & Print service provider & $\begin{array}{l}\text { Unless the manufacturer of the print- } \\
\text { ing system has "certified" the pertinent } \\
\text { substrate. }\end{array}$ \\
\hline 6 & $\begin{array}{l}\text { Process Conversion } \\
\text { when data is not pre- } \\
\text { pared for the intended } \\
\text { printing condition }\end{array}$ & Print service provider & $\begin{array}{l}\text { The print service provider is required to } \\
\text { inform the print buyer about potential } \\
\text { limitations preferably with a contract proof } \\
\text { based on the re-separated data. }\end{array}$ \\
\hline
\end{tabular}

During the printing process, even more tasks are needed to ensure the right output. A printing system is only as good as its maintenance status. A printer has to:

- Follow manufacturer periodically recommended operations

- Ensure that both printing system and substrates used are in appropriate environment conditions

- Identify and check material combination

- Choose the desired print mode(s)

- Understand specific parameters for printer (hardware) and workflow (software)

- $\quad$ For drying/curing printing systems, the temperatures applied during printing and post-printing stages are very important for both printability and runnability

- Select colour reference(s). The achievable colour gamut results from the substrate and ink interaction and performance

Most important one the measurement procedure. To control colour adjustments and calibrations are needed and in many occasions the printer must create a specific characterization and profiling (e.g. ICC) for the specific job. This is not needed in offset printing, since the ICC profiles that are being used are provided by ISO 12647. In digital printing the characterization data set for the selected printing combination must be created and then the printing condition becomes a fully characterized printing condition. In this stage a typical ICC Output Profile will be generated, but in some occasions a device link profile may be also used.

Lastly, to validate the printing output the stability of the printing system for a given printing condition needs to be checked, as well as the deviation from aim values of the printing condition to be simulated. This is done by using the control strip or chart, using the properly measuring device in proper conditions and check the pass/fail tolerances adapted from already established validation print tolerances.

Periodically calibration or re-calibration is recommended in case of a faulty evaluation. Monitoring and recording the pass/fail evaluation for tracking purposes is also recommended as it will show up trends useful to fix issues before they become problems. 


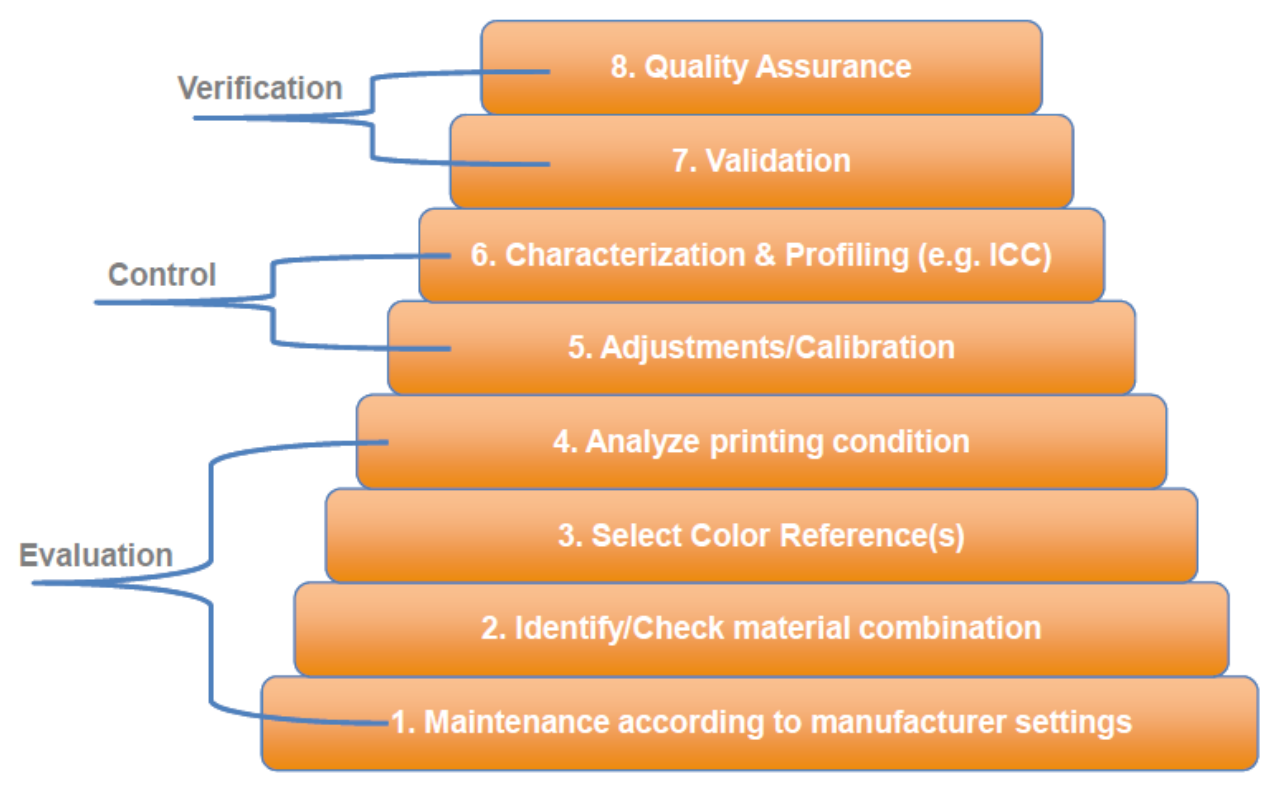

Figure 3: Process Control pyramid - 8 steps to success

\section{FURTHER RESEARCH}

Color image quality is of very high importance in a digital imaging device such as a digital press. For manufacturers and customers of such devices it is important to be able to quantify color image quality. Unfortunately, as of today there are no analytical techniques that can quantify color image quality in this context. Contrary to ISO 12647-x, ISO 15311 is a multipart standard based on representative use cases (rather than printing technologies). Despite this fact, some researches rely on experiments using ISO 126147-x. Some others rely on experiments involving real observers. We claim that the notion of color image quality is ultimately tied to the preferences of customers and end users. Because of this, a very useful tool to quantify color image quality is psychophysical experiments involving a panel of human observers. However, such experiments are relatively time consuming. Definitively, Yendrikhovskij (1999) hits the nail on the head when he states that "most studies on image quality employ subjective assessment with only one goal - to avoid it in the future." Therefore, results from ongoing research toward analytical models for color image quality is eagerly anticipated. An example of such research is the development of metrics for color differences between complex images. However, much more use cases must be analyzed in different digital presses, different substrates, different settings etc. to assure a standardize process in digital printing. And this is even more complicated, since digital printing consists of commercial printing, large format printing, printing in special materials and so on. And nobody knows the evolution of digital printing by using nano technology. Landa's presses are believed to print the same output no matter what (any size, any substrate and matching ISO 12647-2). Will this set a new standard for digital printing?

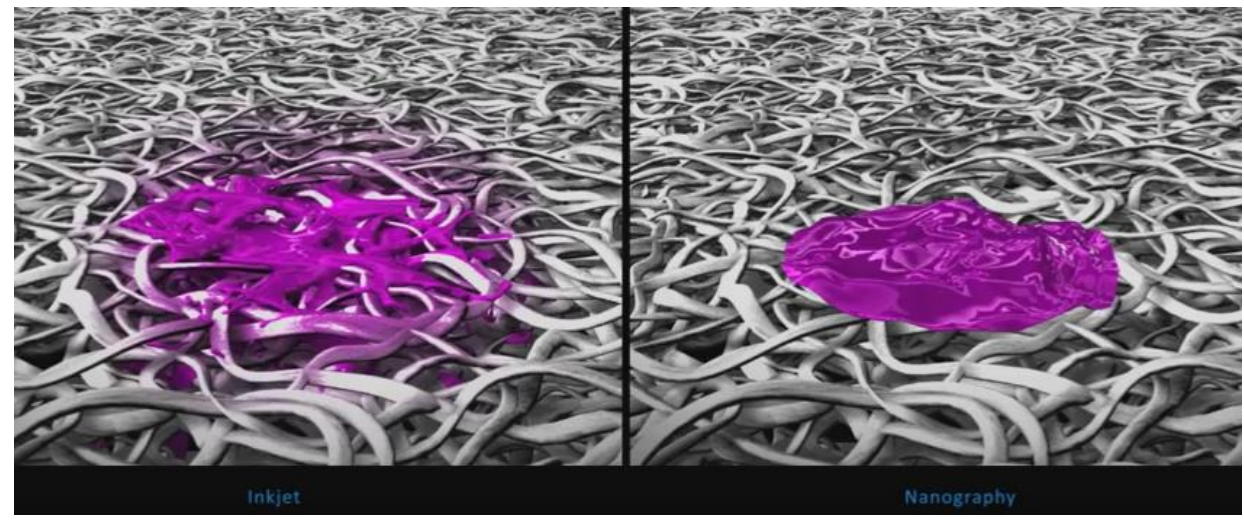

Figure 4: Landa's nano-pigment toner penetration to substrate in comparison with inkjet 


\section{CONCLUSIONS}

In summary, it can be stated that the underlying concept of ISO 12647-1/2/3 [including the recently started revision] is completely adequate for offset printing. In contrast, digital printing tailored to specific technologies is hard to imagine. Instead, a process-independent concept that addresses the individual applications with dedicated print quality measures seems more appropriate. The demand for a digital printing standard alongside methods for process control and quality assurance is evident. The use of established methods in offset printing, in particular by offset printers that also use digital printing systems might be quite useful - but it comes quickly to many limits that are outlined in this paper. Although it might be tempting to simply use the existing PSO system for digital printers, too, this has a poor technical basis and is, thus, likely to reduce the industry's confidence in certification altogether. Fogra is making research on Process Standardize Digital and there's still a lot of space for further research, as mentioned above. The various digital printing technologies are compared to conventional printing processes at a relatively early stage of their development and so that standardization activities and the necessary research is still scarce. This means that the implementation of procedures and methods which are successfully used in offset printing are not necessarily transferable to every kind of digital printing.

\section{REFERENCES}

[1] Fogra: "Process Standard Digital Handbook, Step by step toward printing the expected", (Fogra Research Institute for Media Technologies, Bayern, 2018.)

[2] Gerrit, A.: "Innovative Solution Committed to Color, Color Management for Industrial Printing Applications", URL: http://www.inprintshow.com/usa/conference/pdf/Gerrit-Andre.pdf (last request: 2020-09-28), 2017.

[3] gmg: "New ISO standards for proof prints", URL: https://www.gmgcolor.com/specials/new-isostandard/ (last request: 2020-09-28)

[4] Hardeberg, J. Y., Skarsbo, S.: “Comparing color image quality of four digital presses", URL: http://www.ansatt.hig.no/jonh/archive/ipgac02_iq.pdf (last request: 2020-09-28), 2002.

[5] HP: "HP Indigo Digital Offset Colour Technology", URL: http://directedonline.com/wpcontent/uploads/2014/08/HP-Indigo-Tech-F.pdf (last request: 2020-09-28), 2012.

[6] IPI: "A consumer Guide to traditional and digital print stability", URL: https://scrlc.org/data/consumerguide_traditional.pdf (last request: 2020-09-28), 2004.

[7] Kraushaar, A.: "Process Standard Offset print for Digital Printing?", Fogra extra 23, 2010.

[8] PEARL: "The digital future of print", URL: http://www.pearlprintdesign.com/the-digital-future-ofprint/ (last request: 2020-09-28), 2013.

[9] printed.com: "History of Digital Print", URL: https://www.printed.com/history-of-digital-print (last request: 2020-09-28), 2020.

[10] Sherfield, P.: "The new ISO 12647/2 -2013 standard printing conditions Fogra 51 and 52", URL: http://www.missinghorsecons.co.uk/wordpress/2014/06/the-new-iso-126472-2013-standardprinting-conditions-and-fogra-51-and-52/ (last request: 2020-09-28), 2014.

[11] Yendrikhovskij, S. N.: "Color reproduction and the naturalness constraint", PhD thesis, Eindhoven University of Technology, 1999.

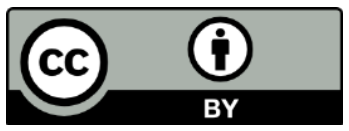

(C) 2020 Authors. Published by the University of Novi Sad, Faculty of Technical Sciences, Department of Graphic Engineering and Design. This article is an open access article distributed under the terms and conditions of the Creative Commons Attribution license 3.0 Serbia (http://creativecommons.org/licenses/by/3.0/rs/). 


\title{
COMBINATION OF AM AND FM SCREENING AS SECURITY PRINTED FEATURE
}

\author{
Vladislav Vereshchagin ${ }^{1}$ (D), Ekaterina Pukhova ${ }^{1}$ (D), Margarita Khokhlova ${ }^{2}$ (iD) \\ ${ }^{1}$ Moscow Polytechnic University, Faculty of Information Technology, \\ Infocognitive Technologies, Moscow, Russia \\ ${ }^{2}$ LIRIS, Lyon Area, France
}

\begin{abstract}
Protection of goods and packaging from counterfeiting and copying, tracking their movement requires improvement of existing labeling and security methods and the development of new ones. Making changes to the image at the prepress stage is the cheapest and easiest way of protection compared to using special printing techniques, special substrates, and inks or additional tags such as RFID.

In the article, we suggest a new method to create security printed features, identify them in prints, and confirm the authenticity of the image. The method uses a combination of regular (AM) and stochastic (FM) screening in one image. There are two ways of separating images for AM and FM screening. First is to choose several random intervals in shadows of image tonal distribution and in accordance with values in these intervals original image is separated into two. The second is to separate by structure, for example, use FM screening on edges or textures. We tried Canny edge detector and local binary patterns. By using random values as the parameters, it is possible to generate unique print runs or even individual prints using digital printing. And large variability in the areas of separation gives reason to consider that the suggested method is reliable.

Fourier analysis in the suggested method allows not only to detect the presence of security printed features but also to confirm the authenticity of the image on a print. Authentication is implemented by obtaining a digital image of the print by scanning or photographing and comparing the spectral composition of the original image and the digital image of the print.

An expert survey showed that after our method presence of a combination of AM and FM screening in images on prints is barely visible. As a result, this method can be used to protect packaging labels with images from copying.
\end{abstract}

Key words: Fourier analysis, image processing, screening, halftone, security printing

\section{SECURITY PRINTING}

Today, the problem of protecting consumer goods from falsification is urgent. The simplest method of protection is to introduce protective elements into the product packaging, since packaging is the main element that identifies the product.

Most often, there is an image on the package that performs several functions at once: informing about the product and its purpose, attracts buyer, and indicates that it belongs to a particular brand. The image on the package is applied by printing, which implies the use of a complex multi-stage process. The complexity of the process allows us to use different methods to create security printed features in image. This can be the use of special methods of printing, materials, inks, or image processing methods that allow us to enter hidden information in addition to the original design. (Maresin, 2012)

It is possible to introduce protective elements into the package using one method or combine different ones (Mihalenko and Andreev, 2017). But it is necessary to consider that the cost of production of the package must have minimal impact on the cost of the final product, so if one of the methods is used that require additional costs or operations on the material stage of the process, then it is better to combine it with the protections implemented at the prepress stage (digital) when the image and the layout of the package is not yet put on media. Such methods require almost no additional costs.

To create secure packaging, security methods are needed at the digital stage that do not change the product design, for example, the introduction of hidden information - a marker (Mihalenko and Andreev, 2017). It is most advisable to insert such a marker into the image itself, which is part of the design, since most likely the packaging contains widespread open security methods, such as bar codes. The presence of a hidden marker is not obvious to the consumer, which makes this protection focused on regulatory authorities that use special means to identify such a marker. 
There are methods specially developed for the printing industry that allow introducing a hidden marker into an image at the digital stage: removing a tonal range, introducing a hardware-readable label in a color image, but these methods have restrictions on the area of introduction and are not suitable for all images and designs. (Andreev et al, 2014; Andreev et al, 2015)

Methods of introducing a hidden marker into a digital image are also widely used in steganography, but most of them are not resistant to transformations during printing, since they change the pixel structure of the image, which is converted during printing to raster.

The rasterization process affects the structure, gradation, and color of the image. There are two main rasterization methods - amplitude-modulated (AM) regular and frequency-modulated (FM) irregular. Each of these methods has its advantages and disadvantages, for example, regular and irregular structures reproduce the image tones and structure differently and have different resistance to moire formation (Gurjanova and Andreev, 2015). Currently there are algorithms and software that allows you to combine different parameters of the structure in a single image, such algorithms are aimed at improving tone reproduction or increasing sharpness of the graphical element edges (Samworth, 1997a; Samworth, 1997b; Shigeta, 2004).

Based on a combination of structures with different parameters, there are also methods for protecting images. The parameters that can be changed are frequency, dot shape, angle, and regularity (AM/FM). The area for introducing hidden information is selected by segmenting the image by spatial coordinates depending on the location of the composition elements in the image or design, which makes it easy to calculate the principle of introducing security tags. Identification of authenticity and detection of hidden information in such methods is carried out using templates with a regular structure that interacts with the structure of the print (Chugunov and Konstantinov, 2016; Zaicevskij, 2002).

\section{METHOD OF CREATING SECURITY PRINTED FEATURES}

A new method of introducing a hidden marker into the protected image was developed based on a combination of raster structures with different parameters that is not tied to the elements of the composition and does not require additional elements to be introduced into the design while being resistant to the process of tone value increase during printing reproduction.

The General algorithm of the method of introducing protection is that the image is divided into two according to a certain principle, then each of them is rasterized by the corresponding structure and then they are combined again (Figure 1). During the rasterization process, it is necessary to consider the difference in tone value increase for AM and FM structures and it can be done based on method described in following article (Pukhova, 2019).

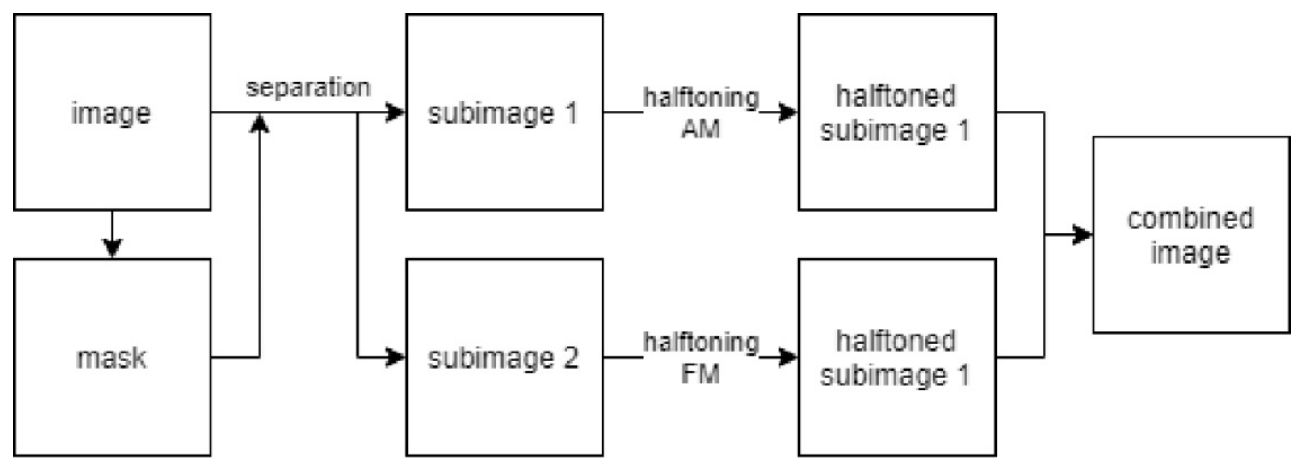

Figure 1: Flowchart for the suggested method of introducing security features

Two principles of image segmentation were chosen, which are difficult for a potential falsifier to calculate or copy: by tone value and by structure.

The degree of protection is achieved by the fact that for classical printing methods, the image can be changed from one print run to another, and then you can detect a discrepancy between the image and the period of its use, if the structure is completely copied. In the case of digital printing, it is possible to create each print unique, and if one image is repeatedly encountered, it can be concluded that there is a counterfeit. 


\subsection{Image separation by tone value}

The possibility of combining AM and FM structures when printing one image with the selection of the area for introducing FM structures in the selected tone range is considered. It is based on the method of removing the tone range (Andreev et al, 2015). The disadvantage of this method of protection is that the removed tone range is more than 40 levels of gradation, which in turn can lead to the effect of posterization in some parts of the images. Therefore, a method was proposed in which the removed tone range is replaced with a structure with changed parameters. Let us consider replacing it with an FM structure, while most of the image will be formed by AM structure.

To introduce the FM structure, a section of the tone range corresponding to the shadow area is selected, since an irregular structure has advantages over a regular one in shadows and at the borders of details (Daniel and Gonzalo, 2011). The introduction interval corresponds to 30\% of the total tone range of the image. Setting this range is determined by the zone theory, and in accordance with it, deep shadows and areas with a pronounced texture fall into the selected section of the tone range (Reinhard et al, 2002). If the range of image lightness [0:255], then the range of introduction of FM structure is [0:80], which corresponds to the size of the raster dots from $100 \%$ to $70 \%$.

When combining the FM structure with the AM, the difference in tone amplification of the two structures must be considered. The tone amplification effect is most pronounced for FM structures since with such structures a smaller point is formed. (Pukhova, 2019)

It is proposed to extract a subimage based on the image intensity histogram. We select image regions using the following scheme: The user defines the approximate desired percent of the image to be extracted (i.e, a percent of all the image pixels). Our recommendation is $30 \%$. Then a subimage with width of $\mathrm{N}$ bins is randomly selected and extracted from the histogram (Figure 2). The process in repeated until the number of pixels from the original grayscale image selected is equal (or bigger) than the percent specified by the user.

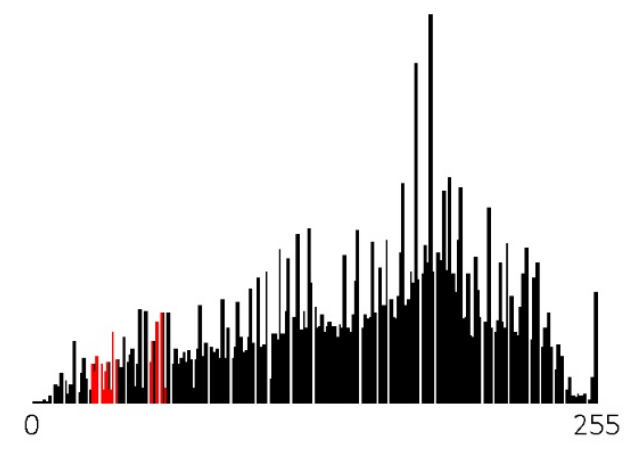

Figure 2: Example of resulting histogram (black) with selected regions (red) for extraction

Result of this stage is two subimages that will be halftoned differently (Figure 3). First subimage is used to introduce parameters that are variable relative to the second subimage, for example, it can be used for halftoning using a frequency-modulated raster structure. Also, several parameters can be replaced at once if it is necessary.
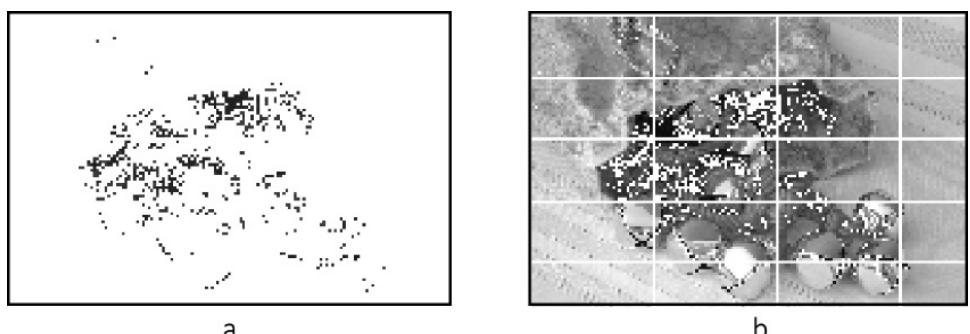

Figure 3: Subimages extracted from original image based on histogram: $a$-from red region (for FM structure), $b$-black region (for AM structure) 
Thus, before printing, two subimages are combined and this way image with security feature is generated. Exampled of combined image is shown in Figure 4.

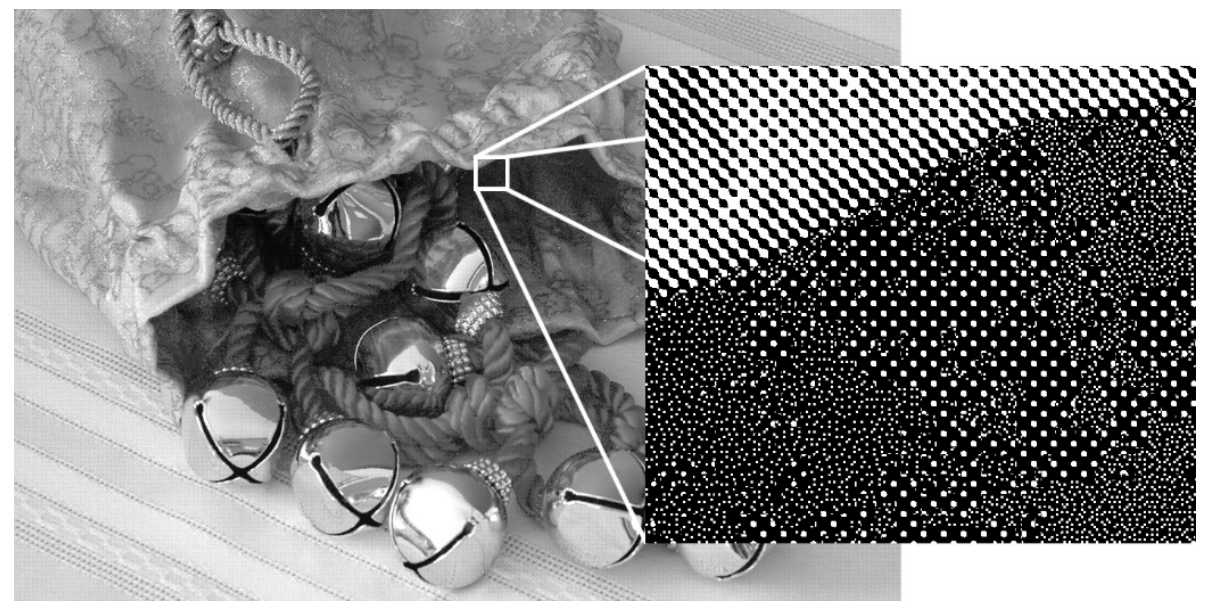

Figure 4: An example of combined image with magnified part that shows two structures

The proposed algorithm works for natural images, where the histogram has values in all the spectra, which are evenly distributed.

\subsection{Image separation by structure}

Another principle of introducing the FM structure into the image is by structure. In this work we used the Canny edge detector to extract edges from original image and Local Binary Patterns to extract corner-like regions.

For this specific image parameters for Canny edge detector were following:

- Standard deviation of the Gaussian filter - 2,

- Lower bound for hysteresis thresholding - 10,

- Upper bound for hysteresis thresholding -90,

and for Local Binary Patterns:

- Number of circularly symmetric neighbor - 24,

- Radius of circle -3,

- Method - uniform.

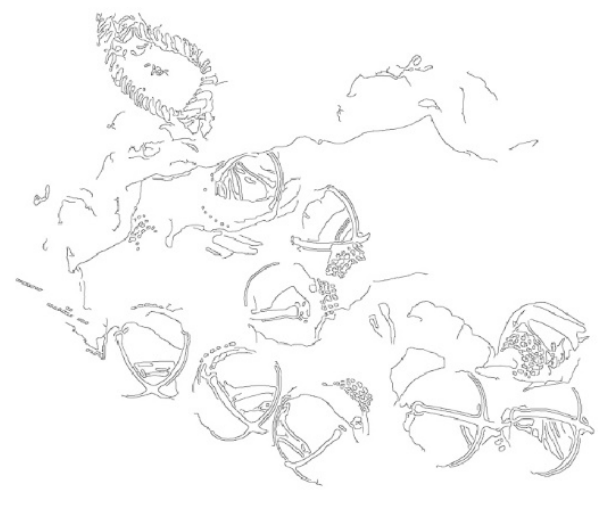

a

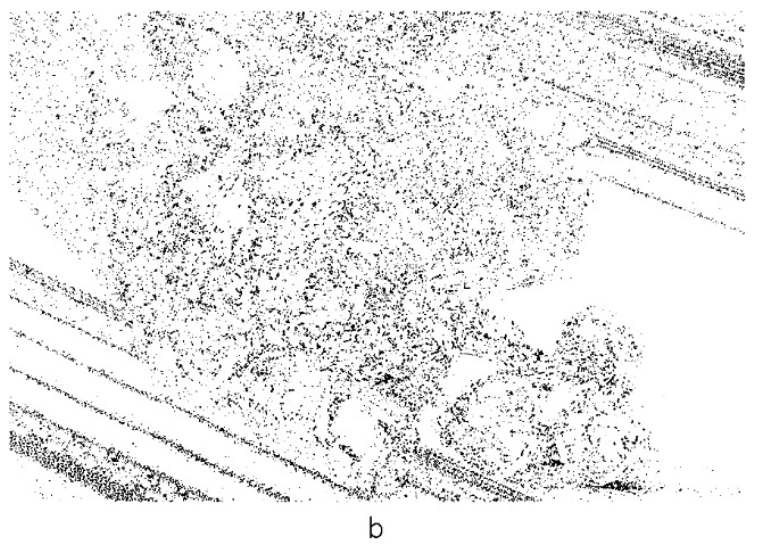

b

Figure 5: Examples of identifying areas by structure with: $a$ - Canny edge detector, $b$ - Local Binary Patterns with corner-like regions of the image 
By using this algorithm, we create masks to separate original image into two subimages, which will be halftoned with FM and AM structures accordingly and before printing combined creating an image with security features.

By making small changes in parameters of algorithms we can generate unique set of secured images.

\section{VISIBILITY OF SECURITY PRINTED FEATURES}

To check the visibility of security features in prints that were made with suggested method, an expert survey was conducted. Twelve experts were shown three images, which were printed without security features (Group 1), and with security features introduced by three ways (Group 2). The experts were asked the question "Do you notice any difference between images in group 1 and 2?" And the following answers were offered: "There is no difference", "The difference is hardly noticeable", "The images are clearly different". The results of the expert survey are shown in Table 1 - numbers are sum of given answers for each separation.

Table 1: Results of an expert survey on the visibility of security features in prints that were made with suggested method.

\begin{tabular}{|l|r|r|r|}
\hline & «no difference» & "hardly noticeable» & "clearly different» \\
\hline Separation by tone value & 27 & 8 & 1 \\
\hline $\begin{array}{l}\text { Separation by structure: } \\
\text { Canny edge detector }\end{array}$ & 22 & 12 & 2 \\
\hline $\begin{array}{l}\text { Separation by structure: } \\
\text { Local binary templates }\end{array}$ & 11 & 16 & 9 \\
\hline
\end{tabular}

According to the survey results, it can be concluded that the developed protection method has no visibility or sometimes hardly noticeable changes in image except separation with Local binary templates. Separation with Local binary templates require further research in finding optimal parameters. But at the same time, the presence of the introduced protective method can be detected using the Fourier analysis of the images and the authentication of the print can be performed when comparing the spectrum of the original image and the scanned one.

\section{SECURITY PRINTED FEATURES DETECTION AND IMAGE AUTHENTICATION}

To detect if printed image has suggested security features and authenticate the print, Fourier analysis is required. First step is to scan or photograph printed image. Then divide image back into two subimages using original masks and carry out spectral analysis. By the form of the spectrum we can detect the presence of AM or FM structures in the subimages.

If AM structure is present in the area with FM structure, then this will be noticeable in the image spectrum and vice versa, which allows us to conclude that the image is not genuine (Figure 6). For example, in the Figure $6(\mathrm{~d})$ presence of AM structure is identified by periodic peaks in spectrum, which are not expected in subimage that were halftoned with FM structure.

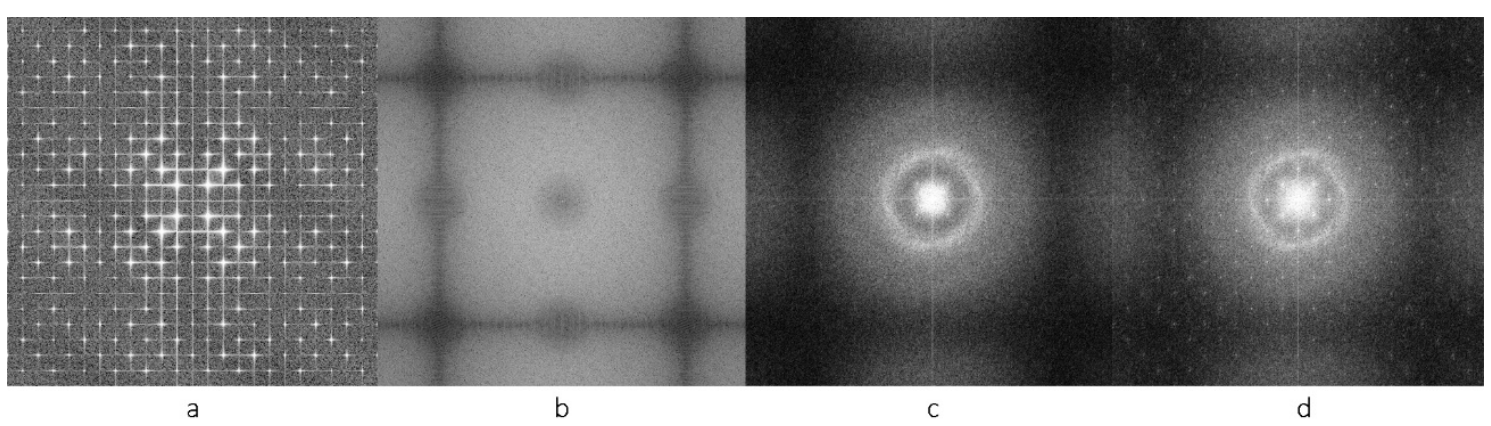

Figure 6: Image spectrum after Fourie transformation: a -AM structure, $b$-FM structure, c - FM structure of scanned image, $d$-FM structure of scanned image, where AM structure is present 
Also, it is possible to create database of original images, masks, and timestamps of generated images with suggested method and then use it to check if printed image authentic in case if someone copied the algorithm. It can be achieved by comparing the spectral composition of the original image and the digital image of the print.

\section{CONCLUSIONS}

As a result, a new method of protecting goods from counterfeiting and copying by introducing security features into images on labels and packaging was suggested. Method based on by combining AM and FM structures in one image. According to the results of an expert survey, changes in the images are visually hardly noticeable, except separation by Local binary templates with tested parameters. Fourier analysis of images allows to establish the authenticity of the examined prints.

Also, this method can be considered for the introduction of an additional dye corresponding in color to one of the colors of the triad, but different in that it has the property of fluorescence.

\section{REFERENCES}

[1] Andreev, Y. S., Pukhova, E. A., Tkacheva, M. V.: "Algorithm for introducing hidden hardware readable tags into a color image", Proceedings of higher educational institutions. Problems of printing and publishing 4, 3-8, 2014

[2] Andreev, Y. S., Pukhova, E. A., Yakhina, A. V.: "Application of the tonal range extraction method to protect information from unauthorized use", Proceedings of higher educational institutions. Problems of printing and publishing 4, 98-104, 2015.

[3] Chugunov, A. A., Konstantinov, V. A.: RU 2587 433, “Latent image acquisition method”, Полиграфзащита, 2016.

[4] Daniel, L., Gonzalo R.: 'Modern digital halftoning", (CRC Press, Boca Raton FL, 2011.), page 664.

[5] Gurjanova, O. A., Andreev, Y. S.: "A method for evaluating the fluctuation characteristics of halftone structures using the statistical parameters of the histogram", Proceedings of higher educational institutions. Problems of printing and publishing 3, 78-87, 2015.

[6] Maresin, V. M.: "Secured printing: reference book", (ФЛИНТА, Moscow, 2012.), page 640.

[7] Mihalenko, A. V., Andreev, Y. S.: "Rational classification of security technologies as the basis for designing a method for protecting printed products", Proceedings of higher educational institutions. Problems of printing and publishing 1, 24-29, 2017.

[8] Pukhova, E.: "Application of histogram method for valuation and compensation tone value changes, combining am-fm screens at press sheet", Proceedings of 3rd International Printing Technologies Symposium, (Printing Industry Education Foundation: Istanbul, Turkey, 2019), pages 119-124.

[9] Reinhard, E., Stark, M., Shirley, P., Ferwerda, J.: "Photographic tone reproduction for digital images", Proceedings of the 29th annual conference on Computer graphics and interactive techniques SIGGRAPH '02, (Association for Computing Machinery: San Antonio TX, USA, 2002), pages 267-276.

[10] Samworth, M.: US5892588A, "Digital halftoning combining dot size modulation screen with dot frequency modulation screen within a single image", PROFESSIONAL SOFTWARE TECHNOLOGIES Inc, 1997a.

[11] Samworth, M.: US6118935A, "Digital halftoning combining multiple screens within a single image", $1997 b$.

[12] Shigeta, K.: US20050155502A1, "Gravure printing method and gravure printed item", Think Laboratory Co Ltd, 2004.

[13] Zaicevskij, A.: LT-4922, "Method of technical protection of printed matter from falsification", 2002.

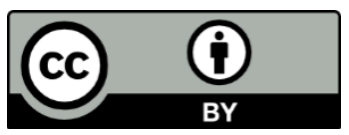

(C) 2020 Authors. Published by the University of Novi Sad, Faculty of Technical Sciences, Department of Graphic Engineering and Design. This article is an open access article distributed under the terms and conditions of the Creative Commons Attribution license 3.0 Serbia (http://creativecommons.org/licenses/by/3.0/rs/). 


\title{
PROSPECTS FOR THE FUTURE OF COMMERCIAL PRINTING
}

\author{
Csaba Horváth ${ }^{1}$ (D), László Koltai ${ }^{1}$ (iD), Klaudia Maňúrová ${ }^{2}$ (iD \\ ${ }^{1}$ Óbuda University, Institute of Media Technology \\ and Light Industry Engineering, Budapest, Hungary \\ ${ }^{2}$ University of Sopron, József Cziráki Doctoral School \\ of Wood Sciences and Technologies, Sopron, Hungary
}

\begin{abstract}
The rate of change for the commercial printing industry with regard to technology, business models and customer demand is growing, and the landscape of the industry already looks vastly different from a few short decades ago. Across the commercial print sector today, there are many different types of companies - some very successful, with a young, skilled, enthusiastic workforce who have no trouble innovating and recruiting. However, as in any rapidly developing sector, other companies are trailing behind.

Demographic changes are entering the market (Generation Z), as well as the upper levels of management in printing companies (Millennials), and "their preferences are now their demands". This requires business models to be re-invented and a more intensive focus on issues relating to sustainability.

The authors of the article summarize the future of the world of commercial printing and the current state of European commercial printing. They have based their work on a report published by the Smithers Research Institute in January 2020 on this topic and on the professional findings and arguments presented at major scientific conferences over the past two years, with the aim of getting these latest ideas to the earliest helping the researchers and practitioners to adapt to the rapidly changing situation and the challenge.
\end{abstract}

Key words: commercial printing, the future of commercial printing, new business model, sustainability, printing technologies

\section{INTRODUCTION AND METHODOLOGY}

The rate of change for the commercial printing industry with regard to technology, business models and customer demand is growing, and the landscape of the industry already looks vastly different from a few short decades ago. The authors of the article summarize the future of the world of commercial printing and the current state of European commercial printing. They have based their work on a report published by the Smithers Research Institute in January 2020 on this topic and on the professional findings and arguments presented at major scientific conferences over the past three years, with the aim of getting these latest ideas to the earliest helping practitioners to adapt to the rapidly changing situation and the challenges.

The conferences are as follows:

- $\quad$ Print Matters for the Future: PRINT 4.0 - The annual conference of INTERGRAF (European Federation of for Print and Digital Communication), Milano, Italy, June 1, 2018

- TAGA 2019 - The Annual Conference of the Technical Association of the Graphic Arts, Minneapolis, USA, March 16-19, 2019;

- $\quad$ Print Matters for the Future - The annual conference of INTEGRAF, London, UK, May 24, 2019

- $\quad$ IARIGAI 2019 - 46 $6^{\text {th }}$ International Research Conference of IARIGAI (International Association of Research Organization for the Information, Media and Graphic Arts Industries), Stuttgart, Germany, September 15-18, 2019;

- Shaping the Future of Print: Commercial Print 2020 - International conference of INTERGRAF, Brussels, Belgium, February 21, 2020

\section{COMMERCIAL PRINT}

What is the commercial print? it encompasses a broad range of printed items, generally undertaken on a print-for-pay basis, and excludes home/office/workgroup printing. The commercial print covers the a wide-range of informational, promotional and advertising printed items, such as photobooks, indoor/outdoor signage, brochures/leaflets, envelopes, business cards/stationary, direct mail, vinyl record 
sleeves, display products and much more. It mostly excludes books, directories, newspapers, magazines, labels, packaging, various functional \& industrial and textile printing.

Broadly speaking, commercial print encompasses informational, promotional and advertising print, mostly undertaken on paper, and includes the following.

- Direct mail - addressed advertising mail: printed envelopes, sales letters, packets (nonpersonalised coupon books), self-mailers (include reply address in single piece), reply cards, postcards, advertising mail flyers \& notices, others; unaddressed advertising mail items (similar items to direct mail including door drops);

- Inserts - newspaper inserts, magazine inserts excluding coupon books;

- Brochures \& pamphlets (excluding financial publications, etc.), other promotional print brochures (sales), leaflets, flyers \& notices, price lists, datasheets (technical, etc.), booklets, folders, other promotional print;

- Indoor point-of-sale materials/signage

posters, other temporary point-of-sale materials, counter \& floor displays, large-format point-ofpurchase materials, corporate graphics, exhibition \& trade show materials, fine art reproduction, photo-printing;

- $\quad$ Outdoor point-of-sale materials/signage -billboards, banners, flags \& backdrops, vehicle/ fleet graphics, building wraps/other graphics, decals (transfers), sails, hot air balloons, marquees, etc.;

- Catalogues - sales catalogues, mail order catalogues, magalogues;

- Business forms - manifold business forms;

- Business ID - letterheads, compliment slips, business cards, printed envelopes and quotes/ invoices;

- Financial \& legal printing - annual reports \& other earnings releases, company brochures, prospectuses, etc.;

- Coupons, tickets \& tapes;

- Manuals - user guides (technical communication document) giving assistance to people using a particular system. This only includes manuals given away with products and excludes manuals sold separately;

- Newsletters - printed report containing news concerning the activities of a business or an organisation that is sent to its members, customers, employees or other subscribers;

- Transactional print - bills, statements, etc.;

- Security printing - cheques (unless shown separately), personal ID (passports, driving licenses, etc.), credit/debit cards, banknotes, secure documents, etc.;

- $\quad$ Others - includes non-categorised products, as well as other one-off jobbing work that will be a significant part of the market and also a certain amount of photo printing carried out by quick printers and others. Non-categorised products include scientific/technical recording chart/chart paper printing, maps and similar, calendar/calendar pads, playing cards, decalcomanias (transfers), art reproduction, postcards, certificates, games, customised gifts, greeting cards, etc. It also includes some 'informational print', leaflets and similar printed items often used in public sector/ similar institutions. There is wrapping paper and the scope extends to printed beer mats and even printed napkins and branded table mats.

\section{MARKET OVERVIEW: THE COMMERCIAL PRINTING IN EUROPE}

The commercial printing industry in Europe has in recent years been encountering significant challenges as a result of declines in graphic printing demand across a range of areas. Advertising print has been hit by the growth in online advertising

and also, the growth in electronic screens used in outdoor advertising locations. Similar declines have been seen elsewhere, as products like business forms, annual reports and other traditional printed items have switched largely away from print to digital. The impact of this has been seen in the declines in the numbers of companies operating in Europe's printing and allied industries, projected to fall by around 13\% between 2014 and the end of the current year, 2020. It should be noted, however, that commercial printing establishments - as defined by Eurostat and other statistical offices - do not represent the whole picture. Many companies engaged in printing activities often do not self-define officially as printers.

These include some or all of the following. 
- Direct mail publishing houses

- Signage companies

- In-plants (reprographics)

- Print management companies

- Designers and agencies

- Marketing service providers

- High-street print shops

- Mailing houses

- Speciality print finishers

There may be other players producing commercial print products, and catalogues.

The largest individual elements in value terms tend to be major advertising segments such as PoS/signage, brochures/other promotional print, direct mail and catalogues, with significant revenues also accounted for by transactional print, financial \& legal printing and other areas. 'Others' shown in figure 1 includes a variety of one-off jobbing print that is often difficult to categorize, and could sometimes be reallocated to defined segments.

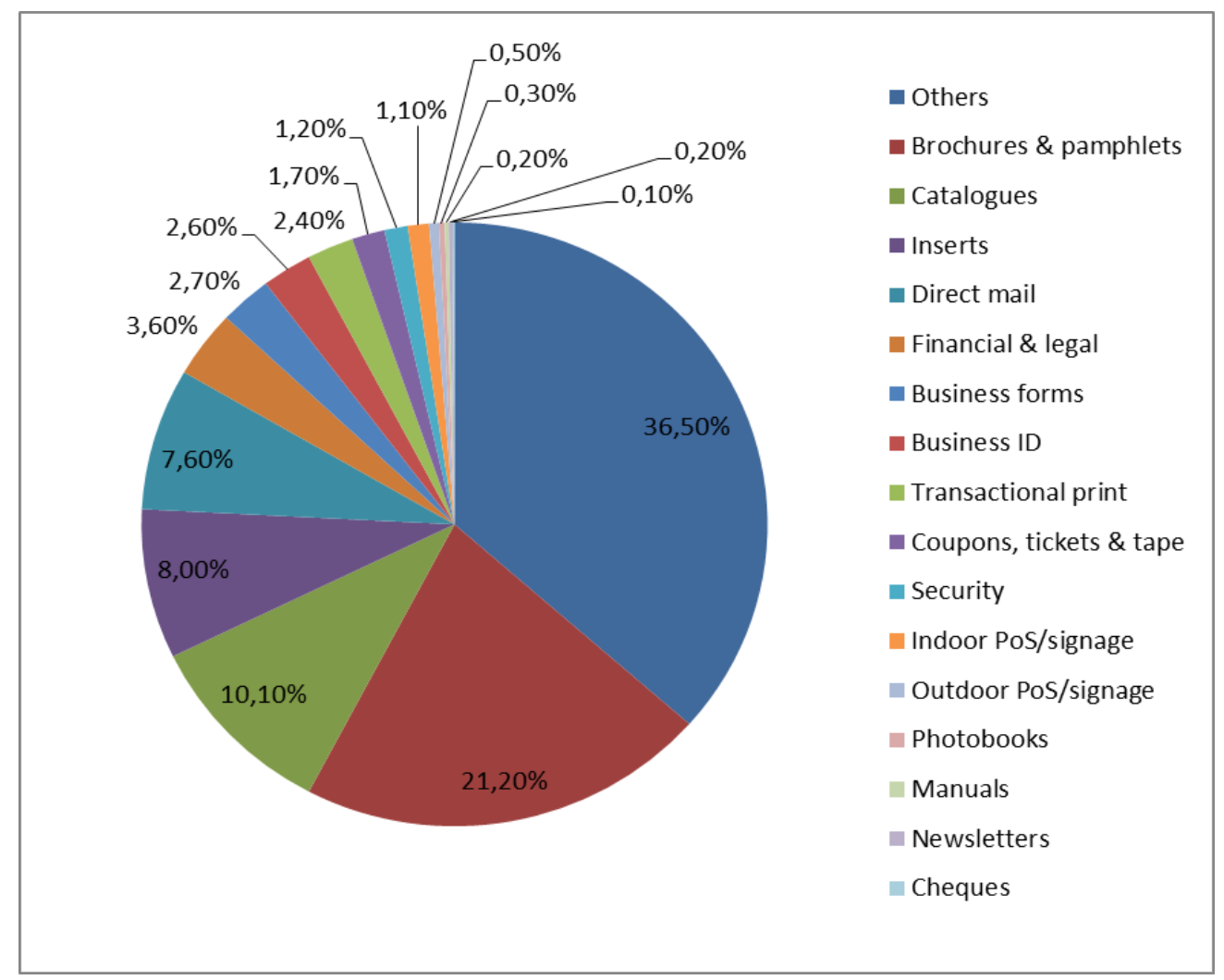

Figure 1: European commercial printing output by print product, 2020 (share by volume, A4 prints or equivalent) (Smyth, 2020)

In volume terms, the splits are similar although higher-priced areas such as PoS/signage take a smaller share, mainly down to the short runs employed and high level of digital penetration that tend to push prices up.

Almost all commercial printing segments have been in decline in both volume and value terms in recent years, and are forecast to develop along the same lines broadly going forward (Hawkins, 2018). Where there is growth in value, this tends to be focused on those areas where digital print has made some inroads, and this also often translates into A4 volume growth in those areas where digital overprinting is undertaken - however, because overprinting counts as two, this also means that the final printed is not necessarily increasing. 


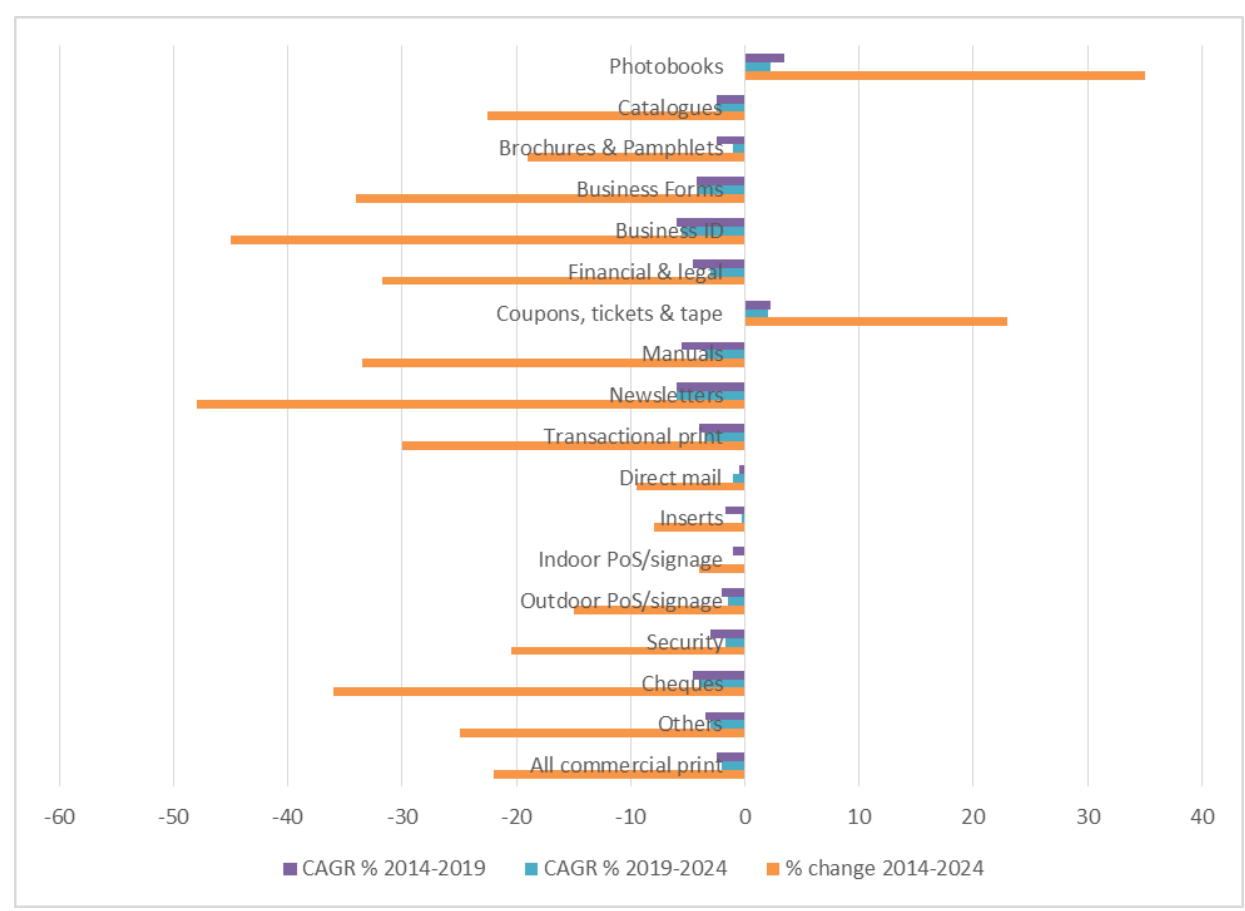

Figure 2: Trends in European commercial printing ouzput by print product, 2014-2024 (billion A4 prints or equivalent) (Smyth, 2020)

One key area that has been hit by the switch to digital alternatives has been catalogues. Catalogue printing has declined rapidly as retailers have switched to a large extent to online sales channels that offer a quicker, more dynamic means to advertise, promote and sell a company's products. There has been growth in more targeted 'magalogues' (magazine+catalogues), although this has not prevented an overall decline in printing output, from 353 billion A4 prints or equivalent in 2014 valued at €4.05 billion at constant 2018 prices \& exchange rates to 310 billion A4 prints (€3.32 billion) by 2019.

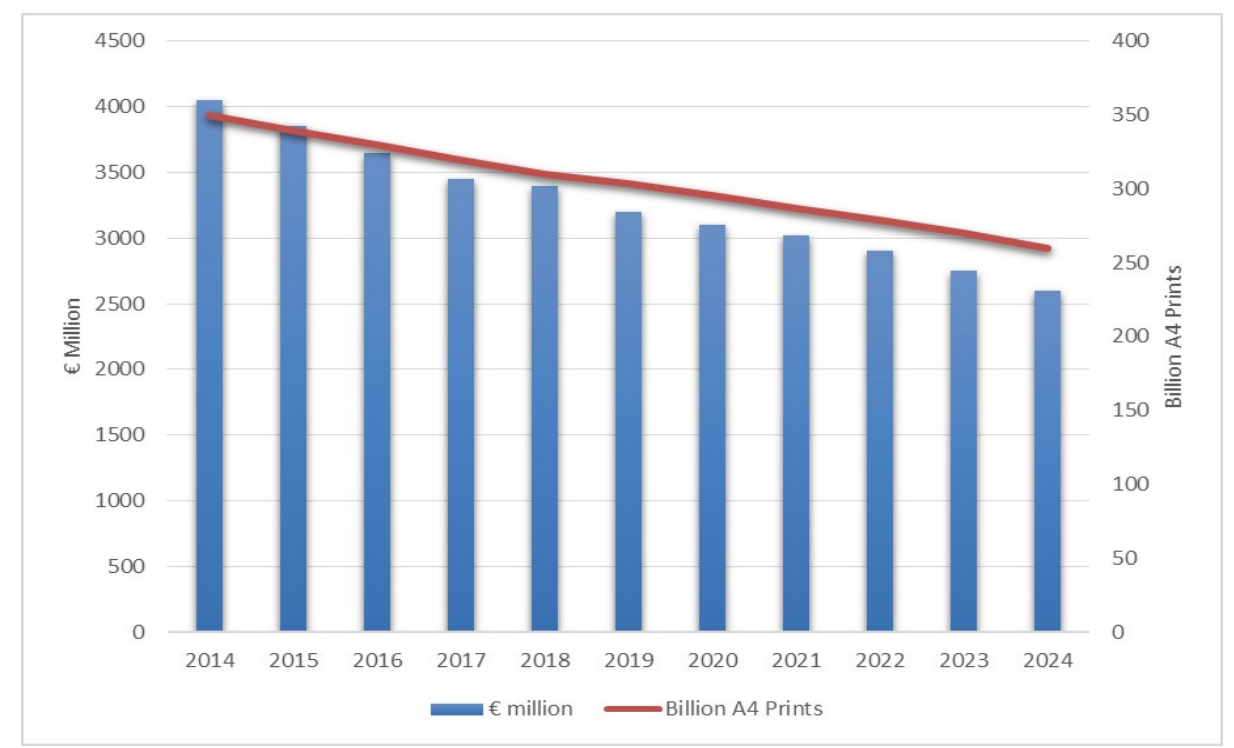

Figure 3: European catalogue printing output, 2014-2024

(€ million, constant 2018 prices c exchange rates; billion A4 prints or equivalent) (Smithers, 2020)

\section{COMMERCIAL PRINTING TECHNOLOGY TRENDS}

Commercial printing is dominated by sheetfed offset litho and digital, with inkjet growing beyond the key mailing \& display areas into broader areas of commercial print. The share of digital in 2019 stood at $10 \%$ 
in volume terms vs $41 \%$ in value terms, up from $8 \%$ and $31 \%$ respectively in 2014 and forecast to rise to $14 \%$ and $49 \%$ respectively by 2024 .

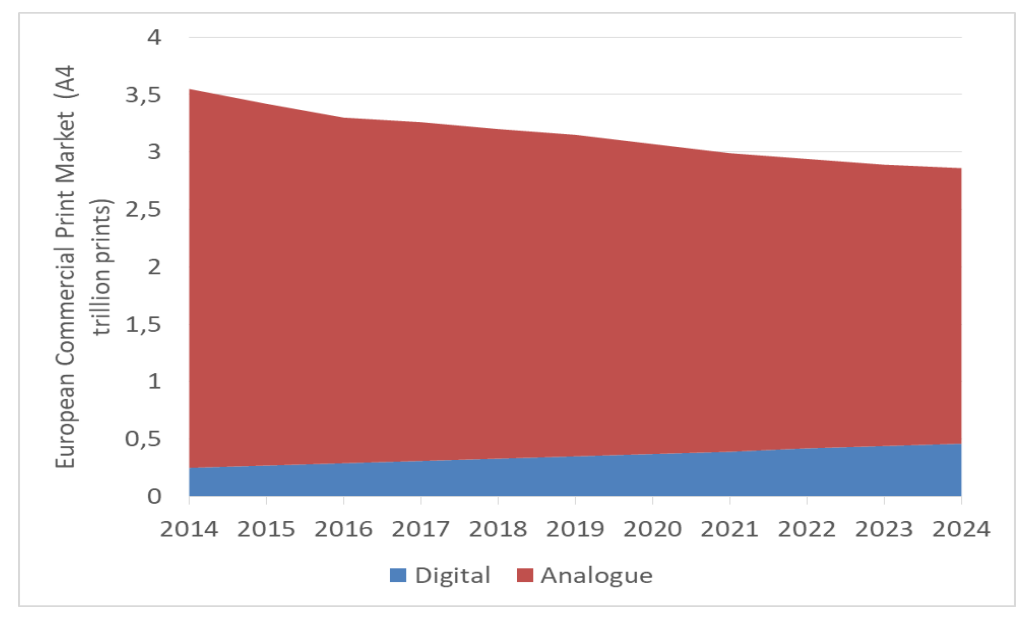

Figure 4: Commercial Print Technology Dominated by sheetfed litho (offset) and digital (inkjet growing beyond mailing \& display into commercial) (Smyth, 2020)

Although digital is expected to make further inroads during the coming years, there are a number of trends that have contributed towards improvements in business efficiencies and profitability in the sheetfed offset litho arena incorporating increasing automation (push-to-stop) and standardisation, as well as growing use of UV to speed turnround. Productivity has been boosted through the implementation of lean processes, with rising adoption of web-to-print leading to the ganging-together of standard jobs to share make-readies and lower cost. In electrophotography, much of the focus today has been in improvements in print quality and also moves towards larger format print, with step changes in productivity and cost being seen in the current year. In inkjet, meanwhile, print quality improvement is also a few focus, including on standard papers, wide format, webfed (new finishing solutions) and sheetfed presses (Mellor, 2019; Politis et al, 2019). Digital finishing and embellishment is also growing across the board.

A number of new inkjet machines are set for launch at DRUPA in 2020 (now 2021). Improvements in productivity, speed and quality are set to open up new areas for inkjet, not only in commercial printing areas including promotional and informational print, but also in areas like packaging, décor, and textiles and promotional objects (Mechling, 2019).

There is much interest in key Landa installations, with its sheetfed and web nanographic printing presses said to offer the versatility of digital printing with the qualities and speed associated with offset, employing water-based inks and a novel image transfer system. The ink image is converted into a very thin polymeric film on a hot blanket, which is then transferred onto the cool paper surface. This is claimed to avoid any issues of paper saturation that can be associated with conventional inkjet processes, and to provide high-quality images at high print speeds. In Europe, Landa machines are being used or about to be installed in four plants in Germany, the UK, France and the Netherlands, as well as at several packaging providers. Early adopters report the Landa technology is highly competitive in the range of 250-500 sheets against litho and other digital processes (Martowidjojo, 2018).

\section{CHANGING BUSINESS MODELS - THE RISE OF WEB-TO-PRINT}

Business models are changing in a variety of business sectors, and these changes are finding their way to a greater or lesser degree into the commercial printing industry. User expectations are changing, and moves towards just-in-time delivery and fast turnround across the board are being shadowed in commercial printing through the use of appropriate workflow solutions. Next day are even same day delivery are becoming more common, with printers seeking to serve the increasingly demanding customer - more quickly, more sustainably, more cheaply, more relevantly and with less or no stock to burden them. Workflow, from customer enquiry to delivery, is critical for commercial print businesses to be successful as run lengths fall while customers expect ever faster delivery. 
A key change has been in the role of commercial printing companies at the cutting edge, many of which now has reduced direct relations with their customers but instead deal mainly or in some exclusively with resellers, and focus entirely on building the most efficient printing business, in part through the adoption of on-line ordering, web-to-print. This has opened the market for individual consumers and micro businesses, to create small quantities of promotional and marketing collateral at affordable costs (Martowidjojo, 2018; Zipper, 2019).

This is mirroring trends elsewhere, as companies have been finding ways of creating value for themselves, their suppliers, converters and users, by developing a new layer that integrates them all with maximum utility. 'Uberisation' is developing in many industries, where the focus is on the customer and not the manufacturing.

The key is to own the relation with the buyer, not the manufacturing capability or service provision. It is happened in printing as commercial printers develop workflow solutions that automate artwork production and administration (Karlovits, 2019). Some printers have succeeded in trapping the series of processes - design, materials, suppliers, production and distribution - into an on-demand appaccessible service. This has led to a new way to fill presses, and it has revolutionised the sheetfed litho sector in Europe.

Definitions can vary, but fundamentally web-to-print (Web2Print, WTP) is a broad term that covers the eprocurement mechanism of print buying. Orders are placed on a web site or portal, choosing from a catalogue of stock items or specifying and creating the printed material using the online app. Typically, these systems will generate artwork (or allow upload of artwork into a workflow with pre-flight); provide estimates and accept payment (as an order number for established client or through funds transfer for a new customer) as part of the process (Karlovits, 2019). Customers may be businesses or individual consumers. Trade print services are growing strongly - often offering a service branded as the buying organisation. There is no direct sales person involvement; the system handles the transaction completely (Zipper, 2019).

The web-to-print market worldwide was valued at around $€ 22$ billion in 2018 , equating to around some $3.0 \%$ of all print and printed packaging set to rise to $3.6 \%$ by 2023 . There are regional variations, with the highest proportion in Western Europe where $7.2 \%$ of all print was purchased and specified through webto-print in 2018, rising to $8.6 \%$ in 2023 . This is a consequence of the activities of a range of sheetfed litho companies using online printing - in Germany, Austria and Switzerland especially. Web-to-print output grew by around 12\% per annum in Western Europe in value terms between 2013 and 2018, and is set to grow by around 4\% per annum over the period from 2018-2023.

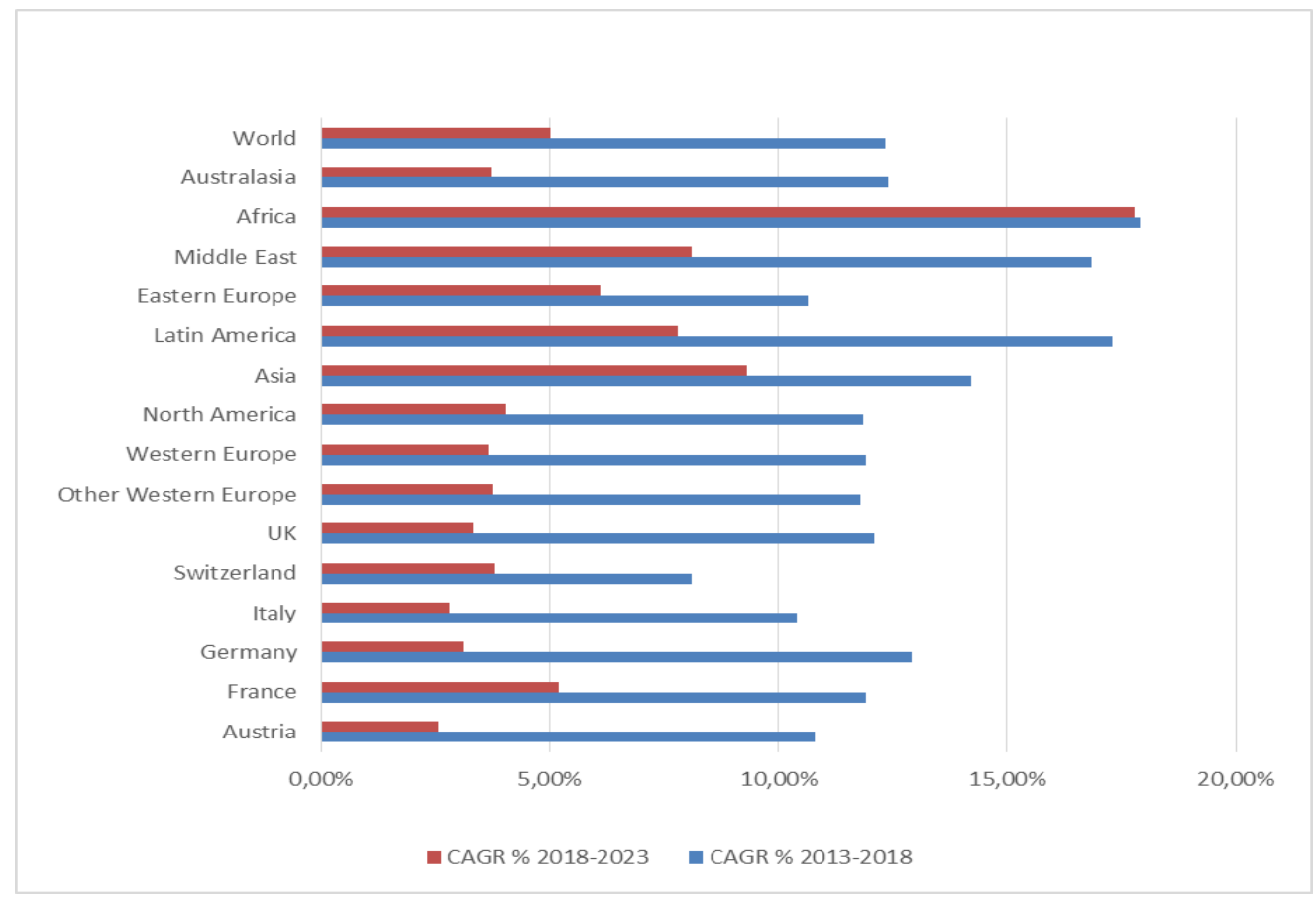

Figure 5: Trends in global web-to-print output by geographic market, 2013-2023 (change in value, constant prices \& exchanges rates) (Smithers, 2020) 
Demographic changes are entering the market (Generation Z), as well as the upper levels of management in printing companies (Millennials), and "their preferences are now their demands". This requires business models to be re-invented and a more intensive focus on issues relating to sustainability. In order to not only survive, but thrive in today's new context printers to think about their customers in a different way and re-invent their business models to better meet customers' - and employees' - changing demands (Gerosa, 2018)

\section{CONCLUSIONS}

The commercial printing sector in Europe as a whole will continue to face major challenges, particularly in line with declining demand for graphic printing volumes with many catalogues and commercial print products no longer existing physically. Further consolidation within the sector seems inevitable, with the number of commercial printers in operation set to fall still further. There will be winners and losers, with new no-touch workflows allowing culture shifts from focusing on being the best ink-on-paper printer into optimizing customer relationships and experiences.

Other companies who succeed in this new decade may adopt a combination of diversification into new products and services on the one hand (e.g. packaging and labels, industrial/object printing, etc.) and into new customer markets on the other.

\section{MANAGE THE RISK!}

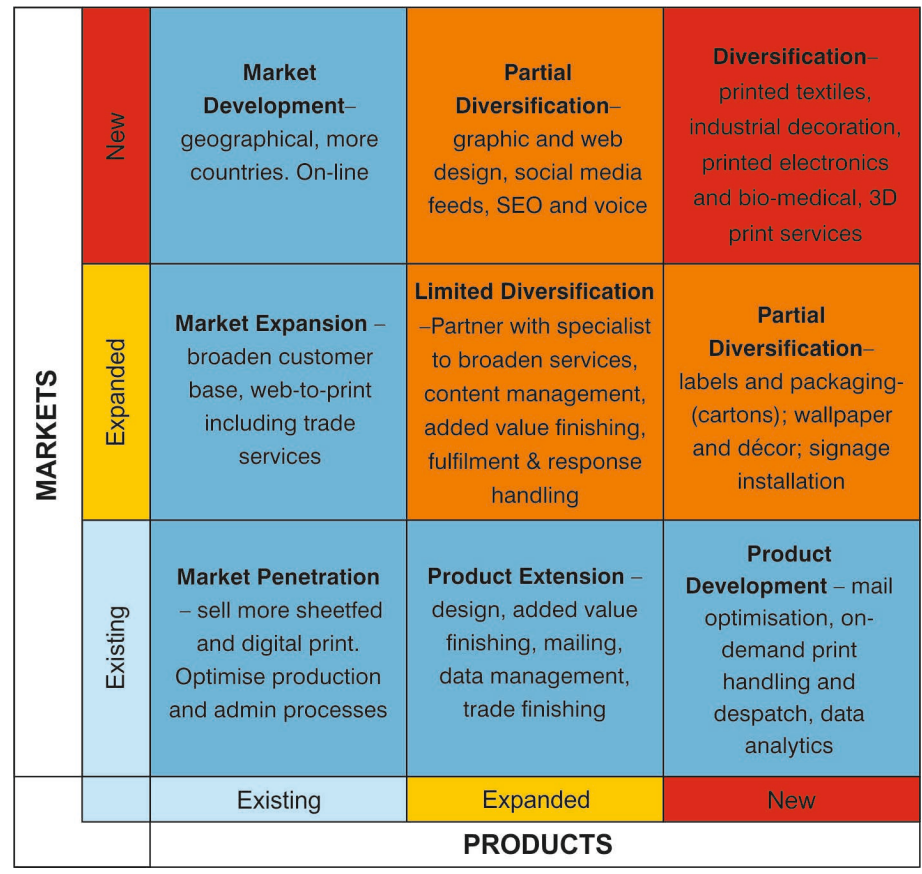

Figure 6: Opportunities for diversification in commercial print (Smithers, 2020)

\section{ACKNOWLEDGMENTS}

The authors thank the INTERGRAF staff (conference organizers) for giving the presentations at the conferences and the Smithers-INTEGRAF Report made available to them.

\section{REFERENCES}

[1] Gerosa, A.: "Think Young (Europe)", Print Matters for the Future 2018, (PRINT 4.0 - The annual conference of INTERGRAF, Milano, Italy, 2018).

[2] Hawkins, F.: "The print paradox", Print Matters for the Future 2018, (PRINT 4.0 - The annual conference of INTERGRAF, Milano, Italy, 2018). 
[3] Karlovits, I.: "Print and Packaging in the world of Big Data, Al and Blockchains", Proceedings of International Joint Conference on Environmental and Light Industry Technologies 2019, (IJCELIT, Budapest, Óbuda University, 2019), pages 8-14.

[4] Martowidjojo, A.: "The Future of print", Print Matters for the Future 2018, (PRINT 4.0 - The annual conference of INTERGRAF, Milano, Italy, 2018).

[5] Mechling, S.: "Digital transformation in the print media industry - how to drive the change?", 46th International Research Conference 2019, (Stuttgart, Germany 2019).

[6] Mellor, G.: "Print trends: a guide to improving operational performance", Print Matters for the Future 2019, (INTEGRAF, London, UK, 2019).

[7] Politis, A., Macro, K., Gamprellis, G., Trochoutsos, C., Tsigonias, M.: "Matching lean manufacturing and industry 4.0 for the graphic communication - printing industry", Proceedings of the $46^{\text {th }}$ International Research Conference of IARIGAI 2019, (IARIGAI, Stuttgart, Germany, 2019), pages 9197.

[8] Smithers, Intergraf: Commercial Print and Catalogues - Market Report, 2020.

[9] Smyth, S.: "Commercial printing futures", International conference of INTERGRAF 2020, (Brussels, Belgium, 2020).

[10] Zipper, B.: “Online print: Intermediate stage to PRINT 2.0 or a revolution?", Print Matters for the Future - The annual conference of INTEGRAF 2019, (London, UK, 2019).

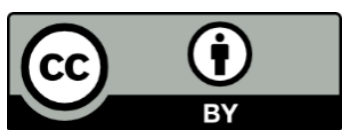

(C) 2020 Authors. Published by the University of Novi Sad, Faculty of Technical Sciences, Department of Graphic Engineering and Design. This article is an open access article distributed under the terms and conditions of the Creative Commons Attribution license 3.0 Serbia (http://creativecommons.org/licenses/by/3.0/rs/). 


\title{
COLOUR QUALITY TESTING OF CYAN OFFSET PRINTS DEPENDING ON PIGMENT CONCENTRATION AND DIFFERENT CTP SCREENING MODE
}

\author{
Sandra Mustač, Igor Majnarić (iD), Stanko Bauk, Slaven Miloš \\ University of Zagreb, Faculty of Graphic Arts, Zagreb, Croatia
}

\begin{abstract}
One of the problems in the offset printing technique is the picking of uncoated paper, which occurs due to the activity of pressure cylinder and sticky offset inks. To reduce offset ink stickiness, it is possible to add cheaper ink filler that will indirectly reduce the concentration of pigment. However, there is also a reduction in the colour tones and quality of reproduction. In this experiment we used: standard cyan offset ink (Sun Lit Express ink which consists of phthalocyanine based pigment) and high-quality gloss coated cardboard ( $250 \mathrm{~g} / \mathrm{m} 2$ Euroart plus gloss). This paper aims to show how the CTP screening type (AM/FM mode) and the CTP line screening (80, 100, 120 line/ $\mathrm{cm}$ and $10 \mu \mathrm{m}, 20 \mu \mathrm{m} 25 \mu \mathrm{m}$ diameter of print elements) manifest on the reproduction quality of a standard gradation wedge. This research will create the possibility of correlating the factors of user reduction of pigment concentration and reproduction quality of cyan colour separation. By using the AM screenings and adding different concentrations of ink filler, more stable cyan prints are achieved.
\end{abstract}

Key words: Offset printing, Cyan offset ink, filler additive, AM and FM CTP screening

\section{INTRODUCTION}

\subsection{Offset printing technology}

Offset or lithographic printing is the most common printing technique because offset printing can print a wide range of products. The technique is popular for large print-run products such as magazines, posters, flyers, packaging, brochures, business cards, etc. The great advantage of offset printing is the quality of prints with low product cost, quick and easy preparation (Majnarić, 2004). Unlike gravure and letterpress techniques, the offset technique is specific because of the printing form relief (printing and nonprinting elements be in almost the same plane). The difference between the two surfaces is in their different physical-chemical properties.

\subsection{Offset printing inks}

The offset printing technique uses very specific and complex ink composition. The reason for this complexity is the fact that during printing the ink must meet many different conditions (ink must be transferred to the printing elements on the form, then to the offset cylinder, and finally to the printing substrate). Offset ink must be extremely viscous, have specific tack, good dispersion, and must not be prone to emulsification and toning. Their dynamic viscosity does not exceed the limits of 40 to $100 \mathrm{~Pa}$ s. Imprints obtained by offset technique are considered high quality, and it is possible to reproduce even the finest details. In its composition, the offset ink contains a binder, pigment, and various additives. The filler is one of the possible additives. The amount of filler in the ink will have a direct impact on the transfer and price of the ink, as well as on the print quality. Therefore, it is very important to prepare the ink well before use. Due to the good coverage of the printing elements, the offset ink must have a higher amount of pigment (for better moisture resistance). Offset ink must be made from pigments of high tone hue and higher concentration.

Also, offset ink must not destroy the offset rubber and cause it to swell. The ink should not be diluted too much, as poor paper acceptance may occur. On the other hand, it is known that the pigments in the lithographic offset ink must emulsify to achieve a good water-ink balance. Pigments are the most expensive ink component (Christie, 2001). To reduce the price and stickiness, a cheaper filler is added to the ink, which reduces the concentration of pigment. With such a change, it is still possible to get a quality print. 


\subsection{Pigment for cyan ink}

The pigment is one of the main components of the ink. The most important property of pigments is that it determines the exact tone of the ink. The pigments must be insoluble in the binder, but they must be well dispersed and well wetted. Process ink (cyan, magenta, yellow and black) with synthetic pigments have satisfactory properties and ensure good transfer from the printing form to the offset blanket and printing substrate (Thompson, 2004).

The cyan pigment reflects $2 / 3$ of the visible spectrum (absorbs the red part of the spectrum well, and reflects the blue and green part of the spectrum). The cyan ink most commonly used today is based on a pigment built from phthalocyanine. It is also the only substance capable of achieving a satisfactory colour tone value. Cyan ink contains phthalocyanine pigment of molecular formula $\mathrm{C}_{32} \mathrm{H}_{18} \mathrm{~N}_{8}$, which is mostly used today as a pigment for inks, coatings, and colouring plastics. Phthalocyanine was discovered as a pigment in 1907 when Swiss scientists accidentally synthesized it and characterized it as extremely stable. Patrick Linstead, in 1928, defined and characterized phthalocyanine as a good pigment for ink (Turinski, 1970). Today's phthalocyanine-based cyan ink include two variations: copper-phthalocyanine blue (Copper Phthalocyanine Blue) and copper polychlorophthalocyanine green (Copper Polychlorophthalocyanine Green) (Leach and Pierce, 1993).
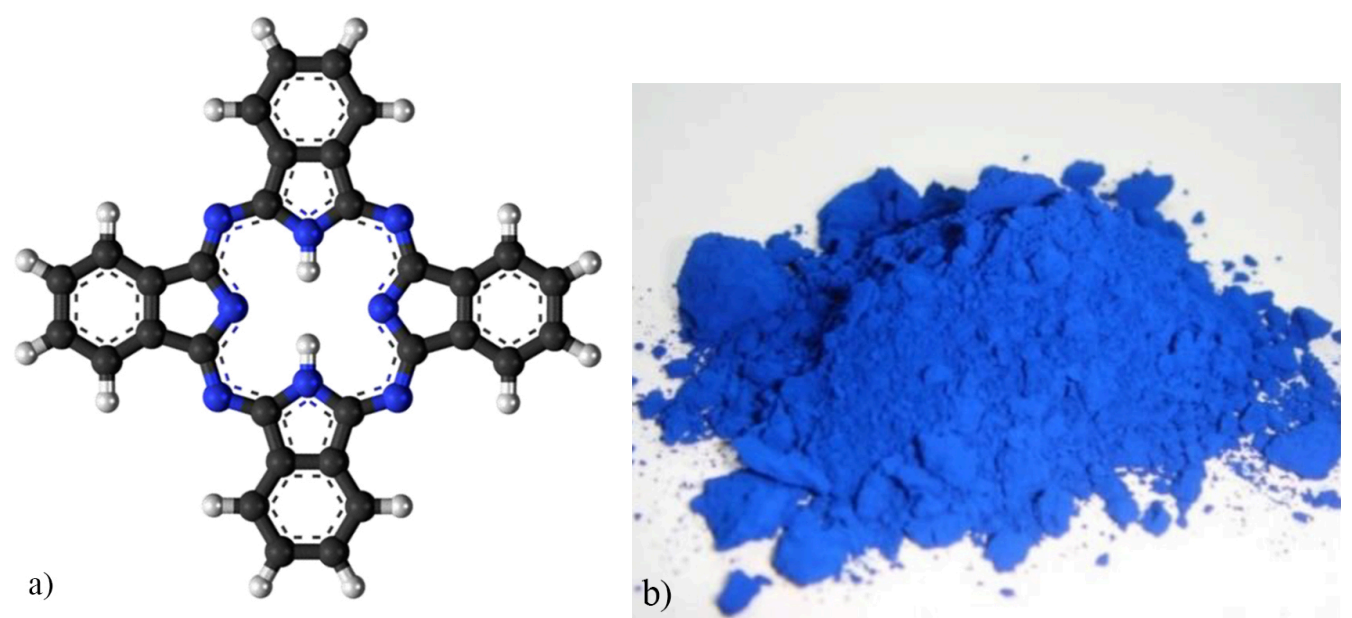

Figure 1: Blue 15 pigment: a) chemical structure b) visual appearance

Cyan pigment is insoluble in water and resistant to acids and alkalis. Due to their exceptional resistance to air, light, and water, they have found a very wide application. As shown in figure 7 Phthalocyanine pigments are most commonly blue and green hue and consist of multiple rings including 4 benzene rings and 8 nitrogen atoms attached to copper. They are thermally very stable and insoluble but can sublimate over time. Sublimation occurs at a temperature higher than $500^{\circ} \mathrm{C}$. Pigments absorb light well between 600 and $700 \mathrm{~nm}$, and such material has a blue or green colour tone. Copper phthalocyanine will be formed if phthalonitrile is heated with divalent copper salts (Figure 8). The compounds thus formed are very stable and can form substituted benzene derivatives by heating in the presence of nitrogen and metal salts. Ecologically, the copper phthalocyanine compound is not toxic to fish and plants, but it is not biodegradable. The pigment is not carcinogenic on short-term exposure.

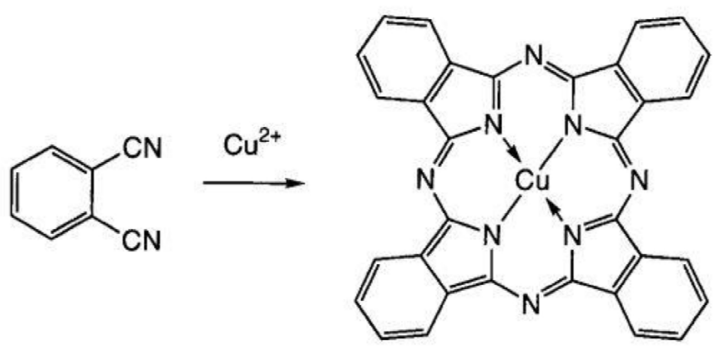

Figure 2: Synthesis of phthalocyanine. 


\subsection{Binders}

Binder is the second most important component in printing ink. It serves to bind and disperse the pigment particles into one unit. Binders give the ink good chemical and physical properties and ensure good quality of transfer to the substrate. The binder can be a viscous liquid (various oils) or a resinous solution (obtained by dissolving a solid resin in an organic solvent or oil). They do not contain many VOC = Volatile Organic Compound (unpleasant odor and harmful to the environment and people). Solvents by chemical structure can be ketones (acetone), esters (various acetates), alcohols (isopropyl alcohol), and hydrocarbons (toluene, xylene, oil) (Majnarić, 2004). The binder of offset ink is based on linseed oil and artificial resins, and mineral oil is used as a solvent (Vančina and Mikota, 1993). Drying is relatively fast, and time is essential for the final drying of the ink after printing.

Linseed oil is vegetable oil and is obtained by pressing or extracting flax seeds. It belongs to the category of semi-dry binders. Drying takes three to six days and can be accelerated by adding dry agents. When drying on the surface of the print, such ink creates a thin layer of film. Resins occupy a very important place in the production of offset graphic inks and varnishes. They give the ink specific properties: strength, gloss, adhesion, flexibility, resistance to higher temperatures, resistance to acids, resistance to alkalis, faster drying. Resins are VOC and can be viscous liquids or amorphous solids of relatively large molecular weight. They are insoluble in water and soluble in some organic solvents.

\subsection{Fillers}

Fillers or auxiliary pigments are solids and can be of natural or artificial origin. They are an important component of ink because they replace the more expensive pigment. Excessive concentration of pigments in the ink, also, has a higher price, and a negative effect on printing properties. Their role is to replace pigments as well as possible, but without affecting the original tone of the ink. By reducing the concentration of pigments, there is a reduced intensity of printed colours. In composition may be white or transparent inorganic powders. Today's mineral fillers or more expensive artificial fillers are used.

Artificial fillers are white fine-grained powders formed by the sedimentation of sparingly soluble salts. Artificial fillers have lower hardness but also higher dispersion. Therefore, their use is greater. Fillers must not chemically react with the binder and dissolve in it. Fillers are insoluble in water and are well dispersed and wettable. Aqueous dispersion fillers are visually opaque, and oil dispersion fillers are only partially transparent. Fillers have a difference in chemical composition and fineness of particles. The particle size can be chemically affected, which adapts to the binder (it will affect its wetting). The refractive index of the filler ranges is between 1,45 and 1,65 . When choosing a filler, its refractive index must be as close as possible to the refractive index of printing binders (near 1,48). The specific gravity of the filler is between 1,5 and $4,5 \mathrm{~g} / \mathrm{cm}^{3}$ (Jamnicki, 2013a). Fillers used to replace pigments in the printing ink are shown in Figure 3.

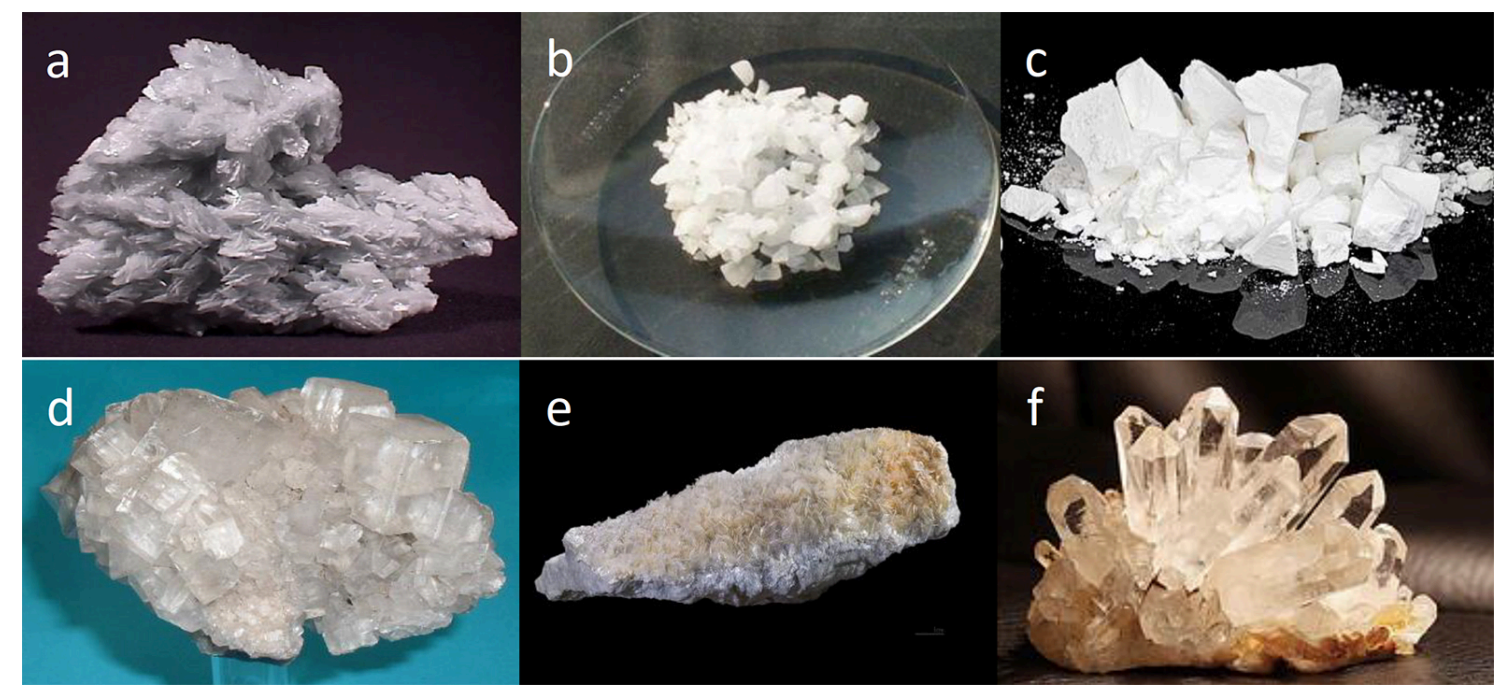

Figure 3: Typical fillers in offset inks: a) barium sulfate - $\mathrm{BaSO}_{4}$, b) aluminum hydroxide - $\left.\mathrm{Al}(\mathrm{OH})_{3}, \mathrm{c}\right)$ magnesium carbonate $-\mathrm{MgCO}_{3}$, d) calcium carbonate $-\mathrm{CaCO}_{3}$, e) talc $-\mathrm{Mg}_{3} \mathrm{Si}_{4} \mathrm{O}_{10}(\mathrm{OH})_{2}$, f) silicon dioxide $\mathrm{SiO}_{2}$ 


\subsection{Additives}

For good printability offset inks contain various additives such as microorganism control agents, wetting agents, antioxidants, scents. They improve certain colour properties or eliminate unwanted appearances on the printing process. Depending on the problems in printing, the printing additives can be solved: poor ink drying, high ink stickiness, printing error concerning the appearance on the printing form, incorrectly printed surface, rubbering of paper, colour remaining on the offset blanket, etc.

Dryers or siccatives are substances that are added to printing ink to improve the time of dryings. The dryers are added to the ink afterward by adding them directly to the printing press. They must be added carefully because due to the high concentration of the same ink in the printing process may begin to dry prematurely. Metals salts that contain lead, manganese, and cobalt are used as driers. The offset printing technique usually uses concentrated or oily driers made from concentrated solutions of linoleate, resin, or borate of lead and manganese, dissolved in linseed or some other suitable oil with or without the addition of synthetic resins or rosin (Jamnicki, 2013b). This paper aims to determine the quality of cyan offset prints and if is possible to reduce the concentration of pigments without losing the basic function of the offset inks (appearance of the appropriate colour tone on the print). It can be assumed how to affect the changes in the colour properties of the print with different screenings settings.

\section{EXPERIMENTAL}

The paper will examine the quality of cyan prints depending on the filler content. Euroart plus gloss coated paper $(250 \mathrm{~g} / \mathrm{m} 2)$ was used as the printing substrate. Before printing, test patches were created using the Kodak Prinenergy EVO workflow (enables control of the preparation process). Each part of the patch was treated separately by determining the type and shape of the raster elements, the line screening, or the fineness of the raster. As a result, all samples were on only one printing sample (AM raster with three different 80, 100, and $150 \mathrm{lin} / \mathrm{cm}$ lines and FM raster with 10, 20, and 25 microns).

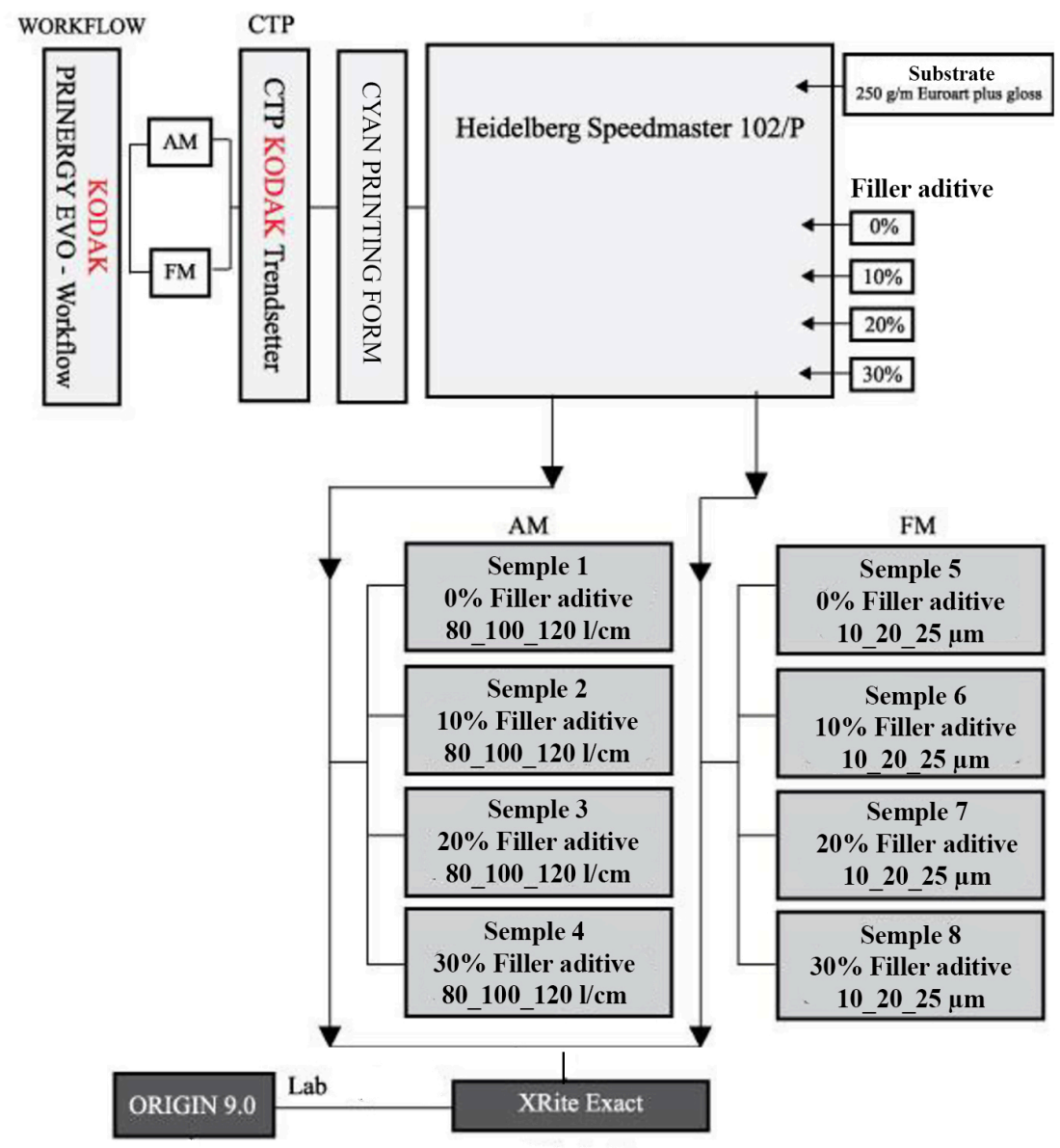

Figure 4: Schematic representation of the performed experiment 
After screening, the printing form was generated on a CTP Kodak Trendsetter. Before each printing, the inks were changed in the machine, which difference in the percentage of additional filler. This meant that the machine had to be cleaned and re-prepared for printing after each print (four times in total). Four mixtures of cyan inks were used: cyan ink with $0 \%$ added filler, cyan ink with $10 \%$ added filler, cyan ink with $20 \%$ added filler, and cyan ink with $30 \%$ added filler. All samples were printed on a two-colour offset machine Heidelberg Speedmaster 102/P with a hard offset rubber blanket. The impression cylinders were dimension B2 and samples were cut into 8 pieces for the work. All samples were measured with an X-rite Exact colorimeter and spectrophotometer. After all tests, the obtained $L^{*}, a^{*}$, and $b^{*}$ coordinate values were processed in the ORIGIN 9.0 program (Figure 4).

\section{RESULTS AND DISCUSSION}

After the experiment, all samples were subjected to colorimetric testing. Using X-rite Exact, 5 measurements of each sample were performed (with activation of the DE calculation mode and automatic display of the measured mean value). From the obtained $L^{*}, a^{*}, b^{*}$ coordinate values, the colour difference was calculated between prints without filler additives and prints with $10 \% 20 \%$, and 30\% added filler. Based on DE 2000 formula in Origin 9.0, was made 3D graphs of the colour difference depending on the filler addition. A separate graph of colour difference was made for each type of screening. The colour deviation of the cyan fields of $20 \%, 40 \%, 60 \%, 80 \%$, and $100 \%$ TV generated during the experiment is shown in Figure 5 and Figure 6.
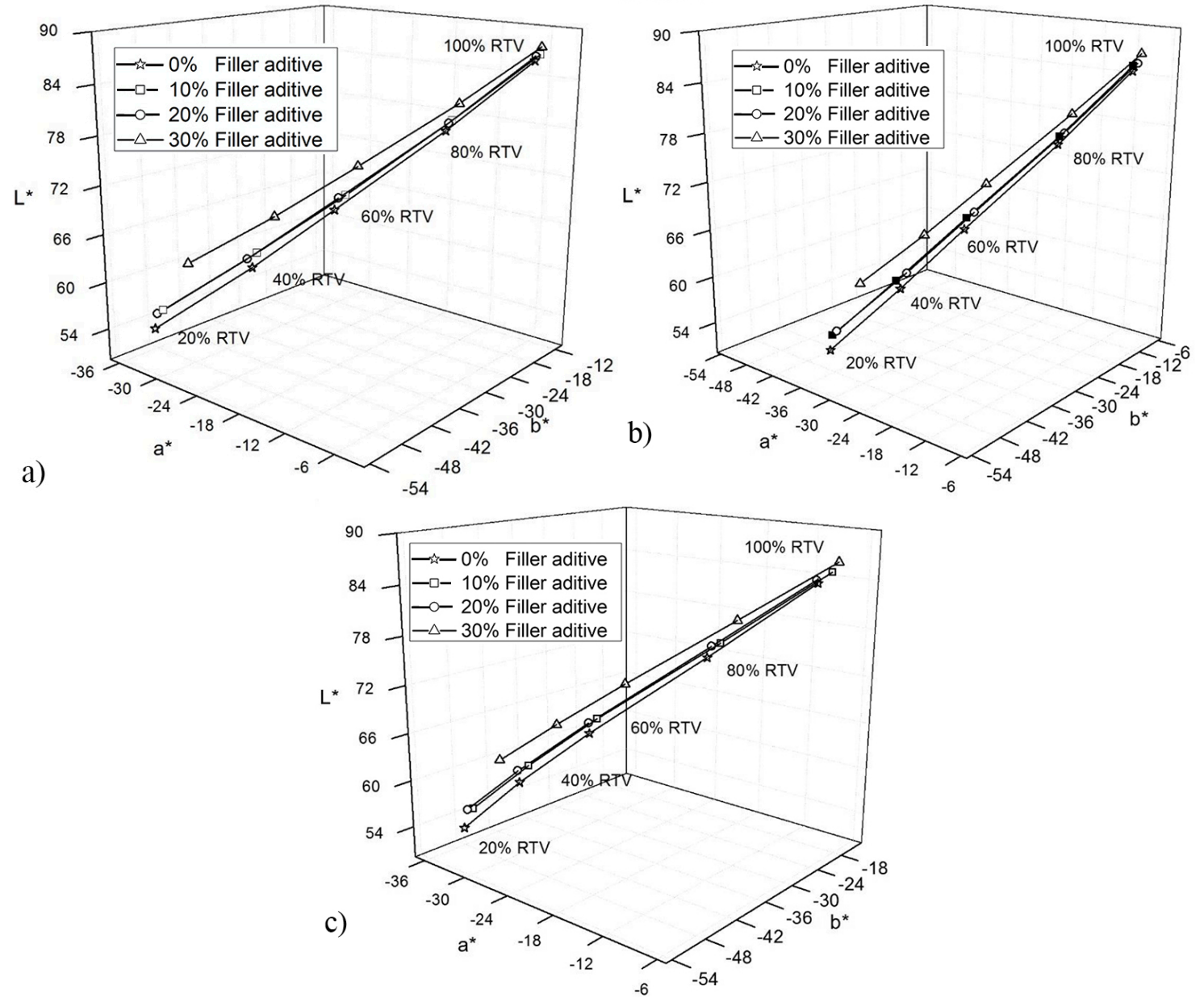

Figure 5: Colour change of cyan tones from for FM raster: a) $25 \mu \mathrm{m}$; b) $20 \mu \mathrm{m}$ and c) $10 \mu \mathrm{m}$.

In the printing industry, FM screening is enabled by the use of powerful computers whose algorithm achieves different tonal value with the application of the same dimensions of the least printing elements (raster dots). In all three FM cyan prints, the full tone is stable, which is achieved by printing all screenings at once. 
The deviation of the full tone was thus achieved only by the addition of ink filler, which led to a reduction in the concentration of pigments in the printed layer. This is particularly pronounced in the brightness and colour change of $\mathrm{DE}=5$.

The addition of $10 \%$ ink filler in a screening with larger raster elements achieves slightly larger colour changes in cyan tones. They are visually visible in dark areas $\left(D E_{00}>1\right)$. Reducing the raster dot sizes of cyan prints was stabilizes and reduces the cyan colour deviation value.

With a larger addition of filler ( $20 \%$ and $30 \%$ mass weight), colour changes are more pronounced (visible to the human eye). Such a trend was observed in all analyzed tonal areas and especially in darker tones where colour differences are greater than DE60\% TV_80\% TV>5. The reason for this a movement of the results is manifested in the increase of the dot gain in the finer FM screening, which leads to an increase in the surface coverage of the same tones (Table 1).

Table 1: Colour changes caused by cyan prints realized with FM screenings

\begin{tabular}{|c|c|c|c|c|c|}
\hline \multirow{2}{*}{$\mathrm{FM} 25 \mu \mathrm{m}$} & \multicolumn{5}{|c|}{ Cyan Colour difference CIE LAB DE2000 } \\
\hline & $20 \% \mathrm{TV}$ & $40 \% \mathrm{TV}$ & $60 \% \mathrm{TV}$ & $80 \% \mathrm{TV}$ & $100 \% \mathrm{TV}$ \\
\hline $\begin{array}{c}0 \% \_10 \% \\
\text { Filler_aditive }\end{array}$ & 0,75 & 0,89 & 1,24 & 1,25 & 1,53 \\
\hline $\begin{array}{c}0 \% \_20 \% \\
\text { Filler_aditive }\end{array}$ & 0,94 & 1,45 & 1,62 & 1,78 & 2,15 \\
\hline $\begin{array}{c}0 \% \_30 \% \\
\text { Filler_aditive }\end{array}$ & 2,00 & 3,07 & 4,66 & 5,42 & 6,43 \\
\hline \multirow{2}{*}{$\mathrm{FM} 20 \mu \mathrm{m}$} & \multicolumn{5}{|c|}{ Cyan Colour difference CIE LAB DE2000 } \\
\hline & $20 \% \mathrm{TV}$ & $40 \% \mathrm{TV}$ & $60 \% \mathrm{TV}$ & $80 \%$ TV & $100 \%$ TV \\
\hline $\begin{array}{c}0 \% \_10 \% \\
\text { Filler_aditive }\end{array}$ & 0,77 & 0,64 & 0,73 & 1,23 & 1,49 \\
\hline $\begin{array}{c}0 \% \_20 \% \\
\text { Filler_aditive }\end{array}$ & 1,38 & 1,59 & 1,79 & 2,14 & 2,19 \\
\hline $\begin{array}{c}0 \% \_30 \% \\
\text { Filler_aditive } \\
\end{array}$ & 2,45 & 3,96 & 4,98 & 5,72 & 6,33 \\
\hline \multirow{2}{*}{$\mathrm{FM} 10 \mu \mathrm{m}$} & \multicolumn{5}{|c|}{ Cyan Colour difference CIE LAB DE2000 } \\
\hline & $20 \%$ TV & $40 \% \mathrm{TV}$ & $60 \% \mathrm{TV}$ & $80 \%$ TV & $100 \% \mathrm{TV}$ \\
\hline $\begin{array}{c}0 \% \_10 \% \\
\text { Filler_aditive }\end{array}$ & 0,54 & 0,52 & 1,01 & 1,09 & 1,86 \\
\hline $\begin{array}{c}0 \% \_20 \% \\
\text { Filler_aditive } \\
\end{array}$ & 0,94 & 1,55 & 2,14 & 2,07 & 1,95 \\
\hline $\begin{array}{c}0 \% \_30 \% \\
\text { Filler_aditive }\end{array}$ & 2,60 & 3,88 & 5,28 & 5,59 & 6,23 \\
\hline
\end{tabular}

Opposite to FM, old amplitude-modulate screenings are often used in print. They have different surface coverage achieved by increasing the raster elements. For this test, a line screening sample is used, which is characterized by a high frequency of raster elements (80, 100, and 120 lpc). In the performed experiment, the colour deviations of the full tones are identical to the FM screening. This is a direct result of different filler concentrations. In all three cyan AM prints, the full tone is stable and achieves an overall colour change around DE 5 .

The addition of $10 \%$ ink filler in screenings with a smaller lineage achieves the least colour changes in cyan tones. They are visually invisible. Increasing the line screening in AM rasters does not lead to major changes in cyan tone values.

With a larger addition of fillers (20\% and 30\%), colour changes become more pronounced and visible to the human eye. Such a trend was observed in all analyzed tonal areas, especially in darker tones (colour differences greater than DE80\% TV>5). By reducing the size of the raster elements and cyan pigment concentration, a colour change is achieved (deviation tone value is about DE 1). Dot gain of a finer AM screening thereby reducing the surface coverage of such tones (Table 2). 

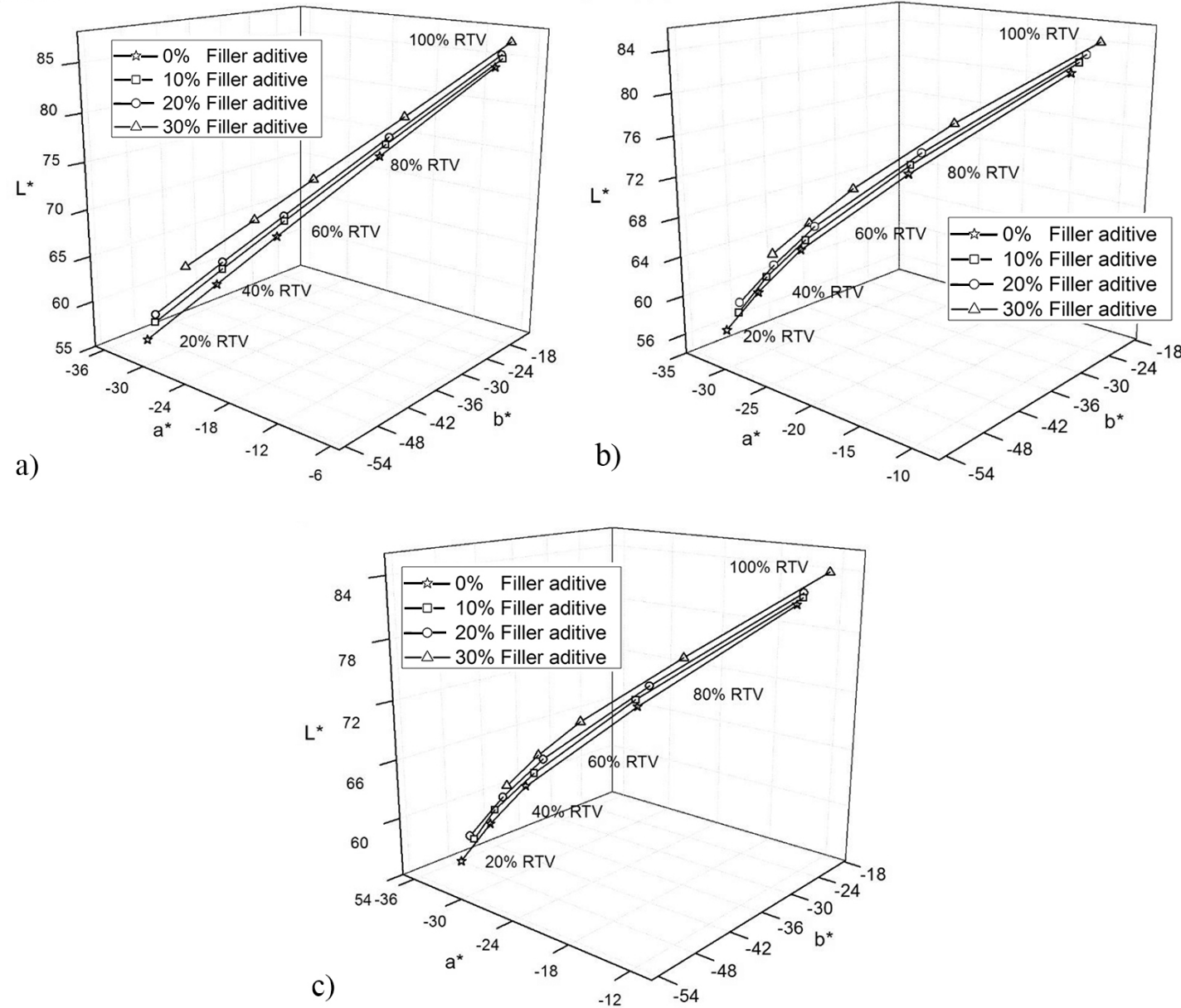

Figure 6: Colour change of cyan tones from for AM raster: a) 80 Ipc; b) 100 lpc and c) 120 lpc.

Table 2 Colour changes caused by cyan prints realized with AM screenings

\begin{tabular}{|c|c|c|c|c|c|}
\hline \multirow{2}{*}{ AM 80 Ipc } & \multicolumn{5}{|c|}{ Cyan Colour difference CIE LAB DE2000 } \\
\hline & $20 \%$ TV & $40 \%$ TV & $60 \%$ TV & $80 \%$ TV & $100 \%$ TV \\
\hline $\begin{array}{c}0 \% \text { } 10 \% \\
\text { Filler_aditive }\end{array}$ & 0,41 & 0,65 & 1,03 & 0,82 & 1,36 \\
\hline $\begin{array}{c}0 \% \_20 \% \\
\text { Filler_aditive }\end{array}$ & 0,61 & 0,90 & 1,37 & 1,32 & 1,85 \\
\hline $\begin{array}{c}0 \% \_30 \% \\
\text { Filler_aditive }\end{array}$ & 1,24 & 2,33 & 3,87 & 4,62 & 6,45 \\
\hline \multirow{2}{*}{ AM $100 \mathrm{lpc}$} & \multicolumn{5}{|c|}{ Cyan Colour difference CIE LAB DE2000 } \\
\hline & $20 \%$ TV & $40 \% \mathrm{TV}$ & $60 \% \mathrm{TV}$ & $80 \% \mathrm{TV}$ & $100 \% \mathrm{TV}$ \\
\hline $\begin{array}{c}0 \% \_10 \% \\
\text { Filler_aditive }\end{array}$ & 0,46 & 0,69 & 1,01 & 0,84 & 1,39 \\
\hline $\begin{array}{c}0 \% \_20 \% \\
\text { Filler_aditive }\end{array}$ & 0,76 & 1,01 & 1,54 & 1,41 & 1,82 \\
\hline $\begin{array}{c}0 \% \_30 \% \\
\text { Filler_aditive } \\
\end{array}$ & 1,55 & 2,60 & 3,98 & 4,84 & 6,39 \\
\hline \multirow{2}{*}{ AM $120 \mathrm{lpc}$} & \multicolumn{5}{|c|}{ Cyan Colour difference CIE LAB DE2000 } \\
\hline & $20 \%$ TV & $40 \% \mathrm{TV}$ & $60 \% \mathrm{TV}$ & $80 \% \mathrm{TV}$ & $100 \%$ TV \\
\hline $\begin{array}{c}0 \% \_10 \% \\
\text { Filler_aditive }\end{array}$ & 0,39 & 0,98 & 0,93 & 1,01 & 1,65 \\
\hline $\begin{array}{c}0 \% \_20 \% \\
\text { Filler_aditive }\end{array}$ & 1,25 & 1,36 & 1,36 & 1,60 & 1,85 \\
\hline $\begin{array}{c}0 \% \_30 \% \\
\text { Filler_aditive }\end{array}$ & 2,17 & 3,39 & 4,64 & 5,54 & 6,65 \\
\hline
\end{tabular}




\section{CONCLUSIONS}

With the FM screening, the addition of a filler in cyan ink will result in colour changes in which the brightness coordinate increases and the prints become brighter. By reducing the size of the screening dots, the brightness decreases, and the colour differences become lower.

By using the AM screenings and adding different concentrations of ink filler, more stable cyan prints are achieved. The colour difference is less pronounced than prints with the FM screenings. This will result in that cyan prints that are closer to the PSO reference values. By applying a larger line screening (120 AM screenings) colour deviation of cyan tones are larger and is not recommended for the realization of cyan tones.

Although the addition of fillers changes the rheological properties of ink (reduces the stickiness and possible tearing of the printing substrate), the optimal amount of filler additives should not exceed $10 \%$. A higher percentage of ink fillers lose the target solid tone reference value and thus the contrast of the prints.

These tests and results make more sense in security printing where more expensive printing inks (pigments) are used. Therefore, the following tests will be performed on printing inks that have a response outside the visible colour spectrum (UV and IR range).

\section{REFERENCES}

[1] Christie, R.M.: "Colour chemistry", (Royal Society of Chemistry United Kingdom, 2001.).

[2] Jamnicki, S.: Tiskarske boje, 2013a, URL: http://materijali.grf.unizg.hr/media/punila_cadje_bronce\%20[Compatibility \%20 Mode].pdf (last request: 2020-09-03.).

[3] Jamnicki, S.: Tiskarske boje 2013b, URL: http://materijali.grf.unizg.hr/media/susenje\%20TB\%20[Compatibility \%20Mode].pdf (last request: 2020-09-03.).

[4] Leach, R.H., Pierce, R.J.: "The Printing Ink Manual", (Springer, London, 1993.).

[5] Majnarić, I.: "The quality of digital prints caused by aging of printing substate", Msc thesis, University of Zagreb, 2004.

[6] Thompson, B.: "Printing materials: science and technology", (Pira International, Surrey, United Kingdom, 2004.).

[7] Turinski, Ž.: "Boje, veziva, tehnike slikanja”, (Biblioteka Zodijak, Beograd, 1970.).

[8] Vančina, V., Mikota, M.: "Materijali u grafičkoj proizvodnji”, (Grafički fakultetu Sveučilišta u Zagrebu, Zagreb, 1993.).

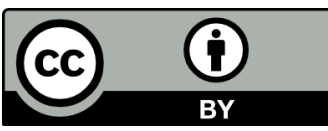

(C) 2020 Authors. Published by the University of Novi Sad, Faculty of Technical Sciences, Department of Graphic Engineering and Design. This article is an open access article distributed under the terms and conditions of the Creative Commons Attribution license 3.0 Serbia (http://creativecommons.org/licenses/by/3.0/rs/). 


\title{
INVESTIGATION OF PROCESS COLOURS VARIATIONS OF ELECTROPHOTOGRAPHY COLOUR PRODUCTION PRESSES
}

\author{
Iskren Spiridonov (D), Simeon Yordanov (D), Rumyana Boeva (D), Aleksandar Milkov \\ University of Chemical Technology and Metallurgy, \\ Department of Pulp, Paper and Printing Arts, Sofia, Bulgaria
}

\begin{abstract}
In this investigation is approached method for assessing and evaluation of colour repeatability and variation for digital electrophotography printing presses. Two of most popular midlevel electrophotography colour production presses were chosen. These presses are widely used in printing houses for the printing of book covers, posters, etc. in small circulations. The similar perception of quality of digital production to the offset printing quality (ISO 12647-2:2013) is required from most of the clients of printing houses, publishers, etc. One of the problems of midlevel electrophotography colour production presses are variations of colours in the printing run and variations of colours during the time - weeks, months, years. The variation degree depends on many factors like - the precision of internal calibration method and types of sensors during the printing run, quality of used materials, calibration precision made by press operator, temperature and humidity variation, etc. (Kachin, Spiridonov, 2000) Specially designed for experiment test forms have been printed on two of most widely used materials for book covers, business cards, etc. $-300 \mathrm{~g} / \mathrm{m} 2$ matt-coated board and $300 \mathrm{~g} / \mathrm{m} 2$ offset uncoated board. The evaluation method is based on colorimetrical and densitometrical measurements (Kachin, Spiridonov, 2004) of 100 continuous printed sheets. The experiment was repeated in different time periods -between 6 hours and 4 months, to collect data for colour variation between reprinting the same test images in the time.
\end{abstract}

Key words: Digital printing, printing quality, colour variation, electrophotography, colour reproduction accuracy

\section{INTRODUCTION}

Digital printing systems are designed to cover the production of small circulations and are aimed at reproducing the printing quality of offset printing Printing Presses, combined with shorter runtime and save the expenses on creating print forms for every colour. Digital electrographic printing systems are used to create marketing materials, brochures, books, photobooks, calendars, tickets, magazines, foldable boxes, flexible packages, labels, posters, etc. (Kipphan, 2001).

Digital printing technology allows for the creation of full colour prints which can be customizable or customized even during production. Digital Presses are no longer required to stop in order to load new printing forms for each and every new incoming order.

The digital electrophotographic printing method is one of the most widely spread and fast developing techniques in the past few years. It is perfectly suited to print individual items, covers, business cards, labels and magazines in small circulations, as well as to put additional circulations to the result of offset printing, etc. Whenever there is need to supplement the core circulation, the customer, naturally, wishes to attain the same colours he had during offset printing. To meet this goal, it is necessary to use quality print media as recommended by the manufacturer of the corresponding electrophotographic printing press. The manufacturers of digital print media, on the other hand, use their own brands with different properties and features (whiteness, texture, type of coatings, smoothness, wear resistance, mechanical properties, etc.). The majority of print houses, however, use lower end alternatives to manufacturer's recommendation. The quality of these substitute printing media is considerably lower and this often leads to un uniformity of contents and un uniformity of thickness, which in turn inevitably lead to bad colour reproduction, colour variations within the circulation, inconsistencies, etc.

One of the problems when using this type of printing technology is the presence of colour variation within the circulation. Another important factor is the presence of colour difference between two separate circulations. This variation is largely due to climate changes within the printing hall, which may include humidity, temperature, change of seasons, paper acclimatisation, paper transport and storage conditions, paper quality, etc.

It is also paramount to consider the type of print media (paper or board) itself as designated for digital print purposes. 


\section{EXPERIMENTAL}

For the purposes of the current test, the team has modelled designated samples in the A3 format, which include specific ranges and control elements, all considered according to the specifics of electrophotographic print (International Organization for Standardization, ISO 12647-7:2016, 2016). Some of the pictures for visual analysis materials are taken from FOGRA, ECI, etc. due to the fact they are widely used while testing conventional and digital printing presses, and because every professional would catch the slightest deviation in tone and colour reproduction (Kraushaar, 2018). Test forms contain varied elements to analyse the colour characteristics of the four fundamentals (CMYK), backgrounds made of varied number of colours, gradation ranges $0-100 \%$ with varied steps $1-10 \%$ for CMYK, etc.

Besides optical density, there is investigation on colour variations within the circulation. It is noted, that in some cases, due to printing environment conditions change (such as air humidity, temperature in the printing hall, paper tempering) there is variations in colours and optical density.

Some of the ranges of test forms used are shown in Figure 1.
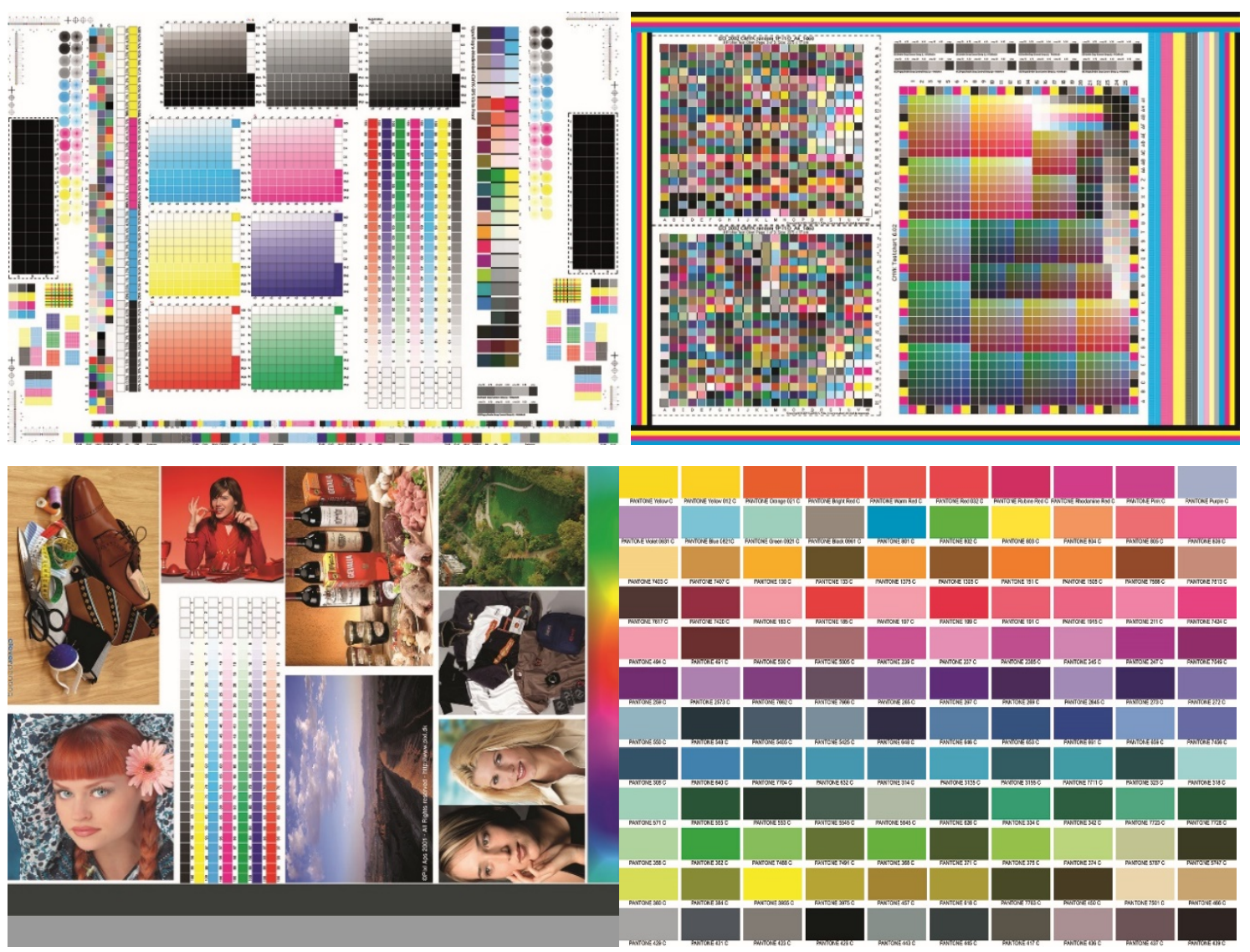

Figure 1: Some test forms, used during the investigation phase

Testing forms are printed with presents for different ICC colour profile outputs, depending of used paper board type (ICC - International Color Consortium, 2020). Before printing the test runs, all 2 digital presses underwent calibration according manufacturer's instruction with the aid of spectrophotometer.

\subsection{Test materials used}

The test incorporates two types of cardboards. They were chosen due to their mass use in print houses thanks to their optimal price, and also because they present an affordable solution with good optical features, but with lower printability in terms of digital printing.

1. Surface matt coated board (colour characteristics $L=96.33 a=1.19 \mathrm{~b}=-5.84), 300 \mathrm{~g} / \mathrm{m}^{2}$

2. Plain offset uncoated board ( $L=95.56 \mathrm{a}=2.71 \mathrm{~b}=-10.69), 300 \mathrm{~g} / \mathrm{m}^{2}$ 
Before every test, regardless if it is on a conventional or digital printing press, one can vary within the parameter tolerances, considering the required precision and the test goals. In this case study, the fundamental goal is to investigation the factors, forming image quality, their consistency and the possibilities to achieve quality printing over mass-used affordable materials.

\subsection{The test completion comprehends the following parameters:}

1. Optical density variation of $100 \%$ CMYK fields (CMYK solid tones) for circulation of 100 pcs.

2. Colour variation of $100 \%$ CMYK fields (CMYK solid tones), expressed in colour difference $-\Delta \mathrm{E}_{76}$ and $\Delta \mathrm{E}_{2000}$ for circulation of 100 pcs.

3. Optical density variation of $100 \%$ CMYK fields (CMYK solid tones) as function of time - between 6 hours and 4 months.

4. Colour variation of $100 \%$ CMYK fields (CMYK solid tones), expressed in colour differences $-\Delta \mathrm{E}_{76}$ and $\Delta \mathrm{E}_{2000}$ as function of time - between 6 hours and 4 months.

The authors would like to abstract the precise brands and models of the digital electrographic print presses in order to prevent influencing customer's choice, and also to propose an investigation methodology combined with what has to be considered when purchasing that type of Printing Press. This is why one may observe that the Printing Presses have been denoted as Electrophotography printing press 1 (EPP 1) and Electrophotography printing press 2 (EPP2). EPP 1 and EPP 2 are among the most common electrophotographic digital printing systems.

The experiment at hand focuses on exploring a multitude of adjacent factors, all relative to colour reproduction quality, which have not been included in the scope of this paper due to their volume. The latter will be presented in sequel publications.

\section{RESULTS AND DISCUSSION}

Colour variation within the circulation and between orders as a function of time is one of the fundamental problems facing all printing houses. It is due to a number of factors that colour tone variation impacts digital electrophotographic presses from the mid-price tier and less in the high-price tier.

In order to investigation colour tone variation within the circulation, a run of 100 consecutive sheets were made for both the matt and offset boards. Optical density and colour characteristics have been measured in identical spots for $100 \%$ CMYK fields throughout the print run.

\subsection{Investigation on the optical density variation of $100 \%$ CMYK fields (CMYK solid tones) for circulation of 100 pcs.}

The measurements of colour coordinates are made using a spectrophotometer under the following conditions (MediaStandard Print, 2018):

- $\quad$ Standard illuminant D50;

- $\quad 2^{\circ}$ standard observer;

- No polarisation filter;

- $\quad$ Measurement geometry $-45^{\circ} / 0^{\circ}$ or $0^{\circ} / 45^{\circ}$;

- Measuring aperture $-4 \mathrm{~mm}$;

Figure 2 shows optical density variations of 100\% CMYK fields, matt coated board, EPP1 and EPP2 printing press.

For matt board, results show optical density variation in the circulation (compared to the first sheet) as follows Cyan \pm 0.04 , Magenta \pm 0.05 , Yellow \pm 0.03 and Black \pm 0.02 for EPP 1 and Cyan \pm 0.11 , Magenta \pm 0.14 , Yellow \pm 0.05 and Black \pm 0.05 for EPP2

Figure 3 shows optical density variations of 100\% CMYK fields, offset uncoated board,EPP1 and EPP2 printing press.

For matt board, results show optical density variation in the circulation (compared to the first sheet) as follows Cyan \pm 0.03 , Magenta \pm 0.02 , Yellow \pm 0.03 and for Black \pm 0.04 for EPP 1 and Cyan \pm 0.06 , Magenta \pm 0.07 , Yellow \pm 0.13 and for Black \pm 0.06 for EPP2. 


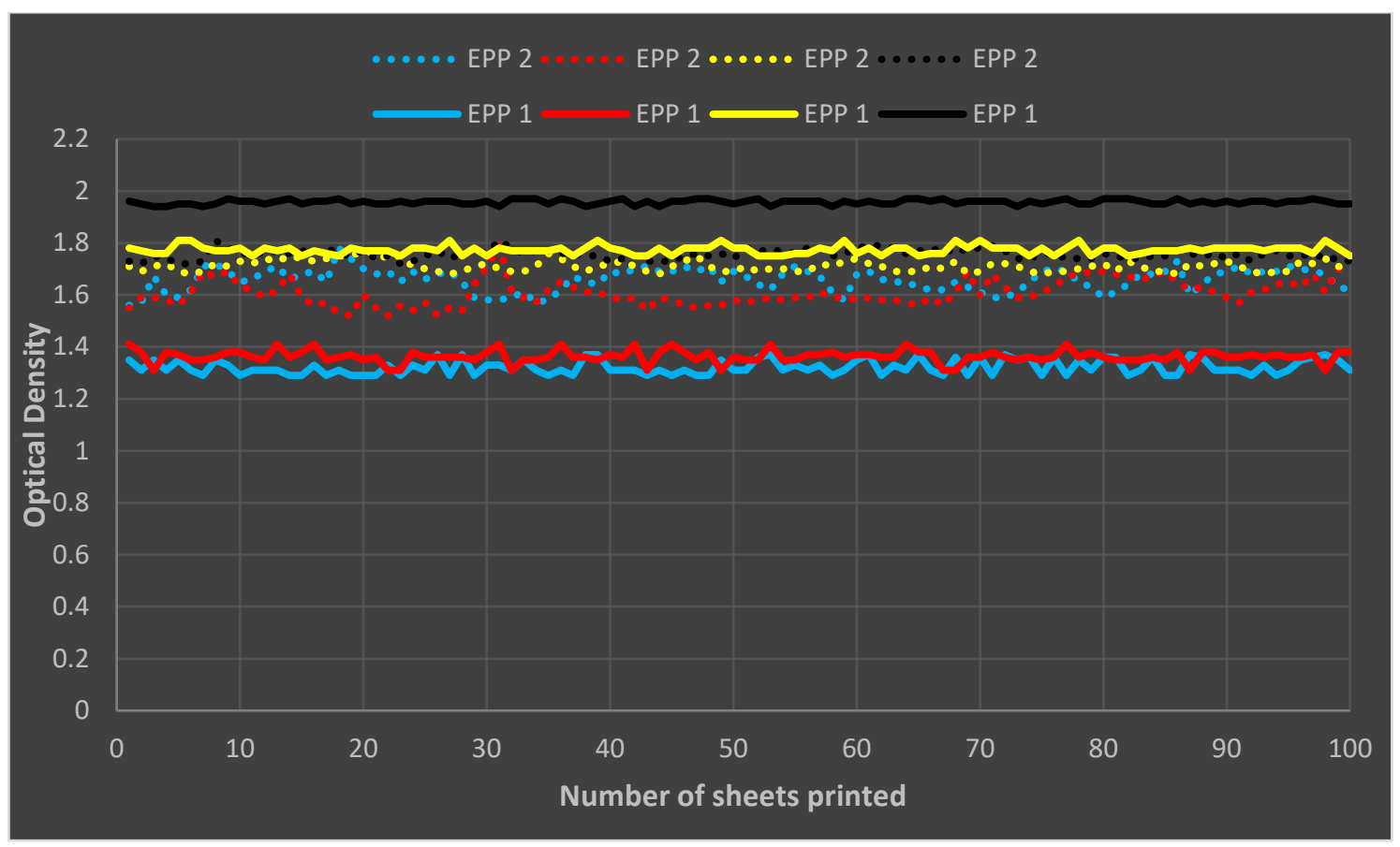

Figure 2: Graphic representation of optical density variation within a print run of 100 consecutive sheets of matt coated board

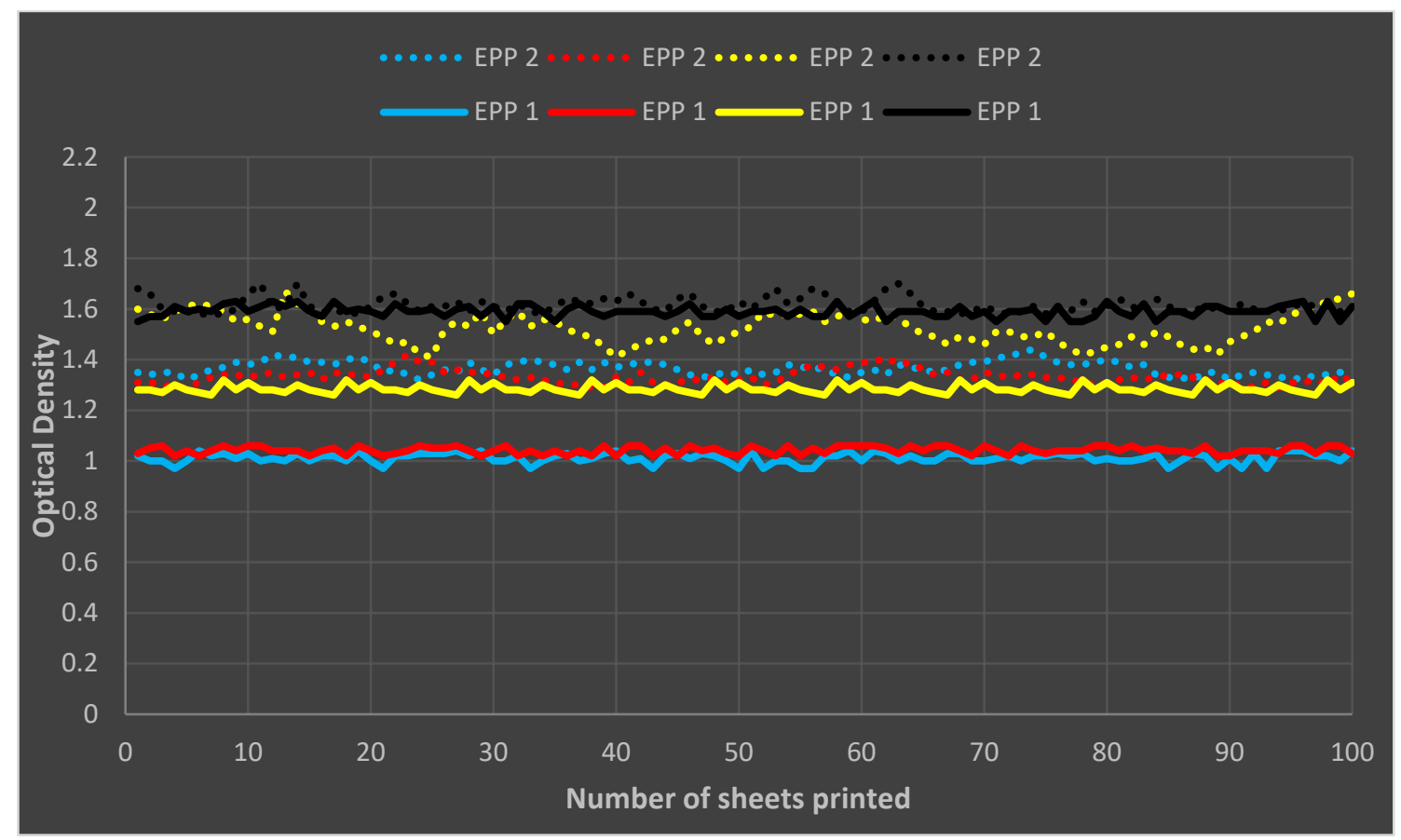

Figure 3: Graphic representation of optical density variation within a print run of 100 consecutive sheets of offset uncoated board 


\subsection{Investigation of the colour characteristics variation of $100 \%$ CMYK fields, expressed with colour difference $-\Delta \mathrm{E}_{76} \mathrm{n} \Delta \mathrm{E}_{2000}$ over a print run of 100 pcs.}

Due to electrographic digital print, and in order to get an even more precise characterisation of colour variation within the circulation, an additional investigation concerning colour variations over CMYK fields was made for the print run of 100 pcs. This variation is presented in the calculation of colour difference $\Delta E_{76}$ and $\Delta E_{2000}$ over the entire print run compared to the first sheet. The notation and representation of colour tone variation via deltas is made in order to allow maximal consideration of the particularities relative to human eye perception. Apart from the latter, this is the way to determine and limit colour variation in ISO printing standards as applied worldwide by the graphic technology.

Figure $4(a, b, c, d)$ shows the CMYK colour difference variation (compared to the first sheet) within the circulation of matt board from both EPP 1 и EPP 2 (Electrophotography Printing Press-EPP), where these are some of the most common electrophotographic printing systems available on the market.

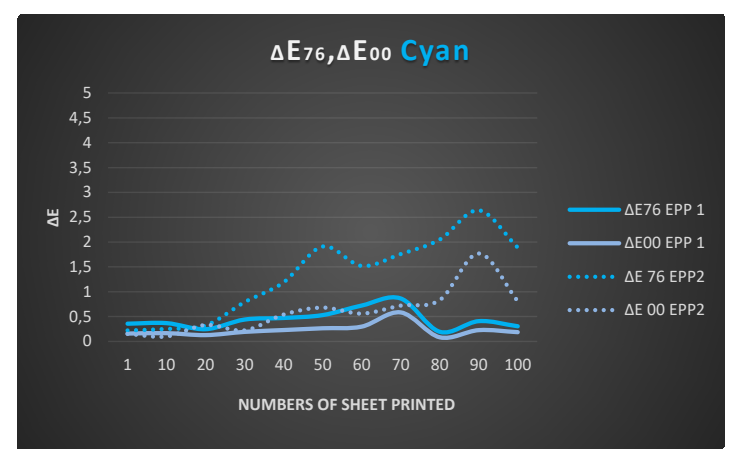

a.

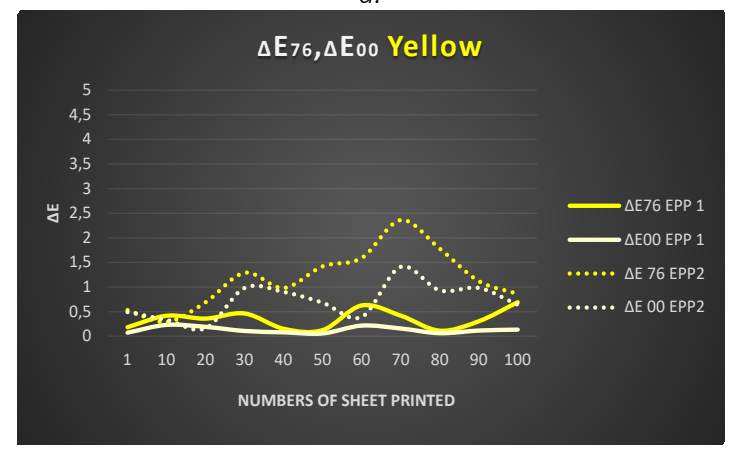

C.

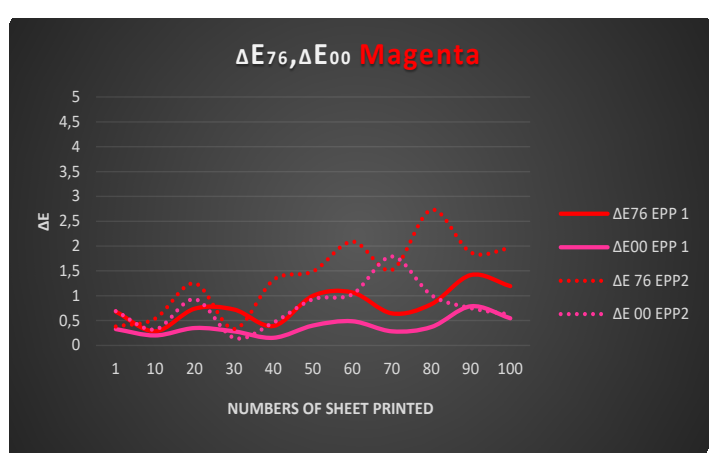

b.

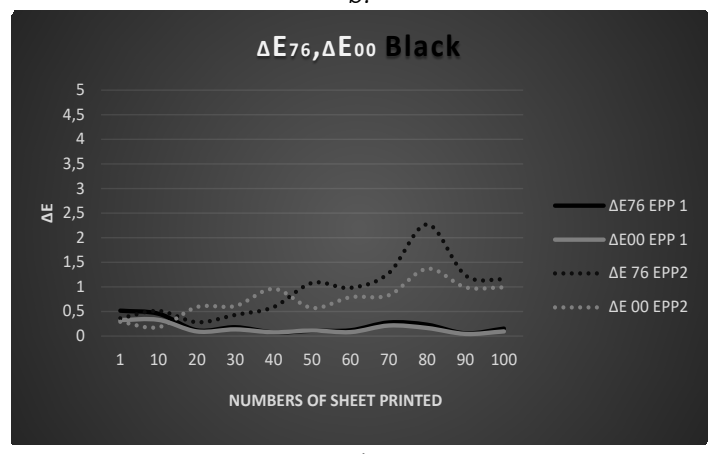

d.

Figure 4: Colour variation of $C M Y K$ expressed by $\triangle E_{76}$ and $\triangle E_{2000}$ during a print run of matt coated board in both EPP 1 and EPP 2 (Electrophotography Printing Press-EPP).

Matt board in EPP1 yielded out average colour variation for the print run (compared to the first sheet) as follows: Cyan $\Delta \mathrm{E}_{2000}=0.27$, Magenta $\Delta \mathrm{E}_{2000}=0.38$, Yellow $\Delta \mathrm{E}_{2000}=0.14$ and Black $\Delta \mathrm{E}_{2000}=0.37$. Maximal values of $\Delta E_{2000}$ vary between 0.27 and 0.78 . Matt board in EPP 2 yielded out average colour variation for the print run (compared to the first sheet) as follows: Cyan $\Delta \mathrm{E}_{2000}=0.65$, Magenta $\Delta \mathrm{E}_{2000}=0.83$, Yellow $\Delta \mathrm{E}_{2000}=0.76$ and Black $\Delta E_{2000}=0.82$. Maximal values of $\Delta E_{2000}$ vary between 1.37 and 1.79 .

Figure 5 ( $a, b, c, d)$ shows the CMYK colour variations (compared to the first sheet) within the circulation of offset board from both EPP 1 and EPP 2.

Offset board yielded out average colour variation for the print run (compared to the first sheet) as follows: Cyan $\Delta \mathrm{E}_{2000}=0.31$, Magenta $\Delta \mathrm{E}_{2000}=0.41$, Yellow $\Delta \mathrm{E}_{2000}=0.15$ and Black $\Delta \mathrm{E}_{2000}=0.75$. Maximal values of $\Delta \mathrm{E}_{2000}$ vary between 0.32 and 1.35. Offset board in EPP2 yielded out average colour variation for the print run (compared to the first sheet) as follows: Cyan $\Delta \mathrm{E}_{2000}=0.70$, Magenta $\Delta \mathrm{E}_{2000}=0.88$, Yellow $\Delta \mathrm{E}_{2000}=1.78$ and Black $\Delta \mathrm{E}_{2000}=1.01$. Maximal values of $\Delta \mathrm{E}_{2000}$ vary between 1.56 and 2.93.

Both paper types, when printed via EPP 1 show very little colour variation $\Delta E_{2000}$ values, the maximum of which is $\Delta \mathrm{E}_{2000}=0.78$ for $C M Y K$ - a negligible value. EPP 2 and the exact same two board types, yielded colour variation $\Delta E_{2000}$ values, the maximum of which reaches 2.93 , which is within standard tolerances and is completely satisfactory as a result. 


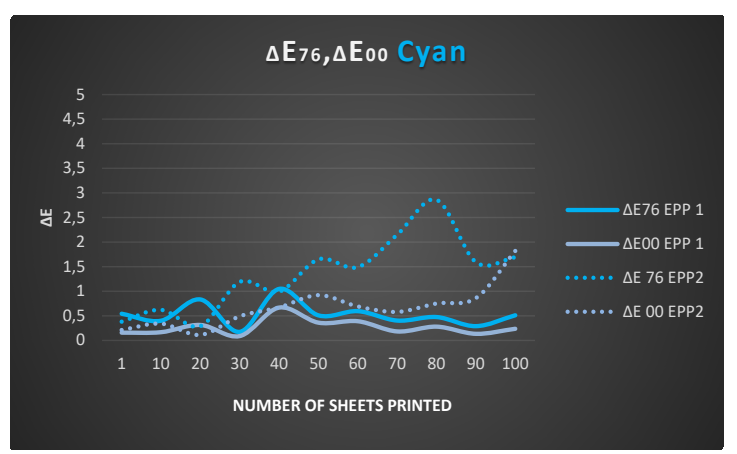

a.

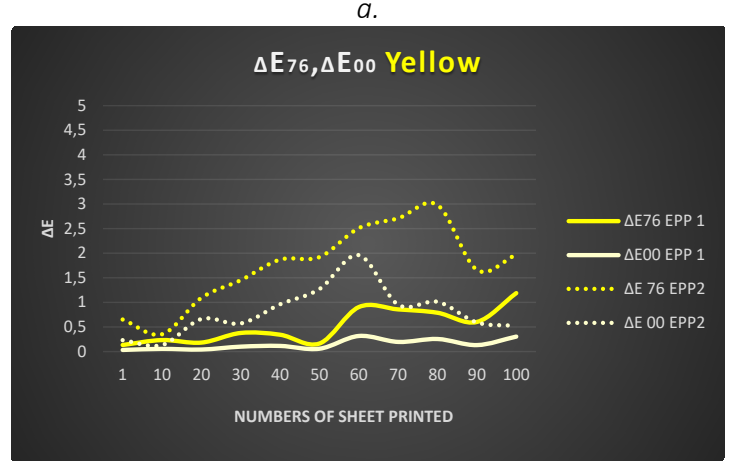

C.

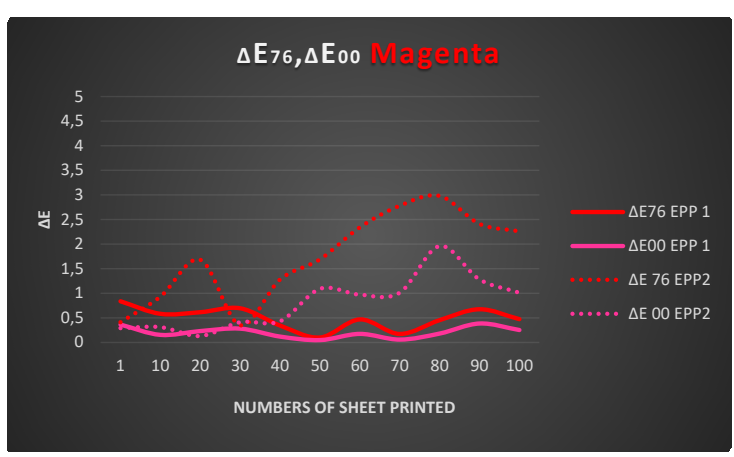

b.

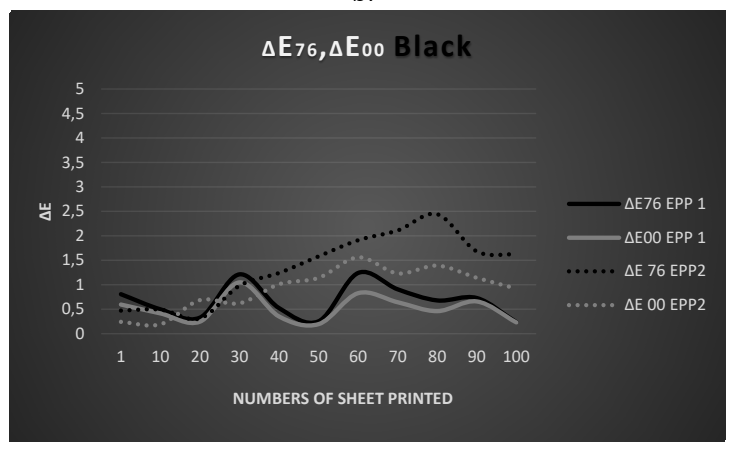

d.

Figure 5: Colour variation of CMYK expressed by $\triangle E_{76}$ and $\triangle E_{2000}$ during a print run of offset uncoated board in both EPP 1 and EPP 2 (Electrophotography Printing Press-EPP).

\subsection{Investigation of $\Delta E_{76}$ and $\Delta E_{2000}$ colour variation of $100 \%$ CMYK fields (CMYK solid tones) as a function of time - between 6 hours and 4 months.}

One of the problems with digital electrographic print presses is colour variation, which is visible when printing the same order after a certain amount of time. Practically anyone has come across evident colour variations while re-printing covers, business cards, etc. Often times these differences are due to irregular calibration or the lack of an algorithm to do that in lower-priced printing presses.

In order to investigation this factor, two parameters have been observed as defining colour difference in re-print - difference within one business day and difference within a long period of time -4 months. This investigation excludes the black colour due to the fact it has high optical density values and very low brightness $L=8-9$, which makes it impossible for the human eye to catch any of its nuances, therefore rendering it irrelevant in this case. The average colour difference are calculated for 100 sheet print run on each colour C, M, Y, K and based on the results the colour difference over short and long period of time are calculated.

Table 1: Colour variations $\triangle E_{2000}$ for $C M Y$ between two orders over short period of time for matt coated and offset uncoated board, printed on EPP1 and EPP2

\begin{tabular}{|l|c|c|c|c|}
\hline & $\begin{array}{c}\text { Colour difference } \\
\Delta \mathrm{E}_{2000} \text { for 2 orders }- \\
\text { short interval- }(6 \mathrm{hrs})\end{array}$ & $\begin{array}{c}\text { Colour difference } \\
\Delta \mathrm{E}_{2000} \text { for 2 orders }- \\
\text { short interval }-(6 \mathrm{hrs})\end{array}$ & $\begin{array}{c}\text { Colour difference } \\
\mathrm{E}_{2000} \text { for 2 orders }- \\
\text { short interval }-(6 \mathrm{hrs})\end{array}$ & $\begin{array}{c}\text { Colour difference } \\
\Delta \mathrm{E}_{2000} \text { for } 2 \text { orders }- \\
\text { short interval }-(6 \mathrm{hrs})\end{array}$ \\
\hline & EPP1 & EPP2 & EPP1 & EPP2 \\
\hline Cyan & Matt coated board & Matt coated board & Offset uncoated board & Offset uncoated board \\
\hline Magenta & 0.60 & 0,91 & 0.53 & 0,93 \\
\hline Yellow & 0.65 & 1,14 & 0.30 & 1,19 \\
\hline
\end{tabular}

The results of table 1 show that both types of board in Printing Press 1 (EPP 1) exhibit a negligible $\Delta \mathrm{E}_{2000}$ over short periods of time 0.27-0.65. With a re-print after a long period of time in table 2, Printing Press 1 (EPP 1) yields a $\Delta E_{2000}$ value between 1.89 and 2.90, which is within tolerance values as set for sheet offset printing, for example. The values correspond completely to the digital prints validation standard ISO 12647 2/7/8 (International Organization for Standardization, ISO 12647-2:2013, 2013; International Organization 
for Standardization, ISO 12647-7:2016, 2016; International Organization for Standardization, ISO/DIS 12647-8, 2012). Electrophotographic print presses allow for the required accuracy of re-printing of circulations. In table 2 one can observe the comparison drawn between Printing Presses 1 and 2 (EPP 1 and EPP 2) over a longer period of time (four months) between two orders. In the case of re-print after a long period of time Printing Press 2 (EPP 2) yields difference values $\Delta \mathrm{E}_{2000}$ between 3.12 and 4.88 , which again is within the tolerable values for matt board and over the limit for offset board. It is due noting, that while testing colour change over long period of time, team members used different batches of paper, different Printing Press calibrations, etc., which in turn inevitably affects colours.

Table 2: Colour variationss $\triangle E_{2000}$ for $C M Y$ between two orders over long period of time for matt coated and offset uncoated boards, printed on EPP1 and EPP2

\begin{tabular}{|c|c|c|c|c|}
\hline & $\begin{array}{l}\text { Colour difference } \\
\Delta \mathrm{E}_{2000} \text { for } 2 \text { orders - } \\
\text { long interval- (4 } \\
\text { months) }\end{array}$ & $\begin{array}{l}\text { Colour difference } \\
\Delta \mathrm{E}_{2000} \text { for } 2 \text { orders - } \\
\text { long interval- }(4 \\
\text { months) }\end{array}$ & $\begin{array}{l}\text { Colour difference } \Delta \mathrm{E}_{76} \\
\text { for } 2 \text { orders - long } \\
\text { interval- (4 months) }\end{array}$ & $\begin{array}{l}\text { Colour difference } \Delta \mathrm{E}_{76} \\
\text { for } 2 \text { orders - long } \\
\text { interval- (4 months) }\end{array}$ \\
\hline & EPP1 & EPP2 & EPP1 & EPP2 \\
\hline & Matt coated board & Matt coated board & Offset uncoated board & Offset uncoated board \\
\hline Cyan & 1.89 & 3.12 & 2.58 & 4.36 \\
\hline Magenta & 1.94 & 3.25 & 2.66 & 4.51 \\
\hline Yellow & 2.03 & 3.46 & 2.90 & 4.88 \\
\hline
\end{tabular}

\section{CONCLUSIONS}

Based on the results obtained within the scope of this paper, the following conclusions could be presented:

1. This paper offered a method to investigate colour tone variations with the aid of parallel measurement of optical density variation $\Delta \mathrm{D}$ and colour differences $\Delta \mathrm{E}_{76}$ and $\Delta \mathrm{E}_{2000}$ within the circulation. Each of these factors brings valuable information regarding colour tone variations.

2. Results show a very good overall distribution and small delineations from the average of $\Delta \mathrm{D}$ for the print run on EPP1. As a function of colours vary between $\Delta \mathrm{D}$ from 0.01 to 0.05 . Results also show good distribution and larger deviances from the average of $\triangle \mathrm{D}$ on the print run of EPP2. As a function of colours vary between $\Delta \mathrm{D}$ from 0.04 to 0.15

3. The experimental results regarding colour characteristics variation in the circulation, in terms of $\Delta \mathrm{E}_{76}$ and $\Delta \mathrm{E}_{2000}$ show minimal variation on $\mathrm{EPP} 1$ ( $\Delta \mathrm{E}_{2000}$ from 0.02 to 1.99), and somewhat worse variations with large delta values for EPP2 ( $\Delta \mathrm{E}_{2000}$ from 0.10 to 2.93). Both Printing Presses can maintain stability and consistency of colours within a circulation, which in turn is of paramount importance for their practical use.

4. After analysing the results over a brief period, we have established that EPP1 and EPP2 both show good readings in terms of repeatability. EPP1 has $\Delta \mathrm{E}_{2000}$ variations of $\Delta \mathrm{E}_{2000}$ from 0.3 to 0.6 , and EPP2 $\Delta \mathrm{E}_{2000}$ from 0.9 to 1.2 .

5. Investigation also demonstrated that over long periods (4 months) both EPP1 and EPP2 exhibit different repeatability rates. EPP1 has far superior readings compared to its counterpart. The repeatability variations with that Printing Press over 4 months (for both media used) is within the $\Delta \mathrm{E}_{2000}$ from 1.89 to 2.9. As a point of reference, EPP2 yielded out variance values in the range $\Delta \mathrm{E}_{2000}$ from 3,1 to 4,88 . The presence of such high values with EPP2 would, inevitably, lead to problems in case of reprint.

6. From all results obtained during this experiment in real industrial conditions, one can conclude that the two Electrophotographic Printing Presses from the mid-price tier give excellent colour variations results over brief periods. Over longer periods of time, the two systems begin to diverge significantly. EPP1 holds good repeatability rate, whereas EPP2 shows large colour variations. This is most likely due to the different calibration methods from the manufacturers, as well as to the varied sensitivity of the two Printing Presses regarding the materials used, and las but not least the impact of environment conditions changes. Results show that the print hall observes clear, well-defined rules throughout the production process - from the provision and storage of the printing media to the very printing. These rules may include the implementation of an ISO standard, combined with internal rules of the print house. Here is why it is important and necessary, for the users of digital and conventional presses, to use and adhere, as much as possible, to a defined set of rules, regardless if it is an ISO standard or an alternative instrument. 


\section{REFERENCES}

[1] ICC, International Color Consortium, URL: www.color.org (last request: 2020-09-20.)

[2] International Organization for Standardization, ISO/DIS 12647-8, Graphic technology - Process control for the production of half-tone colour separations, proof and production prints - Part 8: Validation print processes working directly from digital data, 2012.

[3] International Organization for Standardization, ISO 12647-2:2013 Graphic technology - Process control for the production of half-tone colour separations, proof and production prints - Part 2: Offset lithographic processes, International Organization for Standardization, 2013.

[4] International Organization for Standardization, ISO 12647-7:2016 Graphic technology - Process control for the production of halftone colour separations, proof and production prints - Part 7: Proofing processes working directly from digital data, 2016.

[5] Kachin, N., Spiridonov, I.: "Printing Processes - Part 1, Theoretical bases", (Pleyada, Sofia,2000).

[6] Kachin, N., Spiridonov, I.: "Optical Density and Colour Difference in Printing on Different Types of Paper", Cellulose Chemistry And Technology 39(3-4), 255-264, 2004.

[7] Kipphan, H.: "Handbook of Print Media", (Springer-Verlag Berlin Heidelberg, Heidelberg, 2001), doi: 10.1007/978-3-540-29900-4.

[8] Kraushaar, A.: "Process Standard Digital", Handbook 2018, URL: www.fogra.org (last request: 2020-09-15.).

[9] MediaStandard Print 2018, Technical Guidelines for Data, Proof and Production Run Printing, URL: www.bvdm-online.de/handreichungen (last request: 2020-09-03.).

(c) $\underset{\mathrm{ar}}{\mathrm{ar}}$

(C) 2020 Authors. Published by the University of Novi Sad, Faculty of Technical Sciences, Department of Graphic Engineering and Design. This article is an open access article distributed under the terms and conditions of the Creative Commons Attribution license 3.0 Serbia (http://creativecommons.org/licenses/by/3.0/rs/). 


\title{
INFLUENCE OF INKJET PRINT PARAMETERS ON THERMAL RESISTANCE OF PRINTED KNITWEARS
}

\author{
Mladen Stančić (D), Branka Ružičić (D), Đorđe Vujčić (D), Dragana Grujić (D), \\ Miroslav Dragić (D), Bojan Janković \\ University of Banja Luka, Faculty of Technology, Banja Luka, Bosnia and Herzegovina
}

\begin{abstract}
Textile materials are increasingly being subjected to the process of printing. The printing process with its parameters significantly affects the properties of textile materials and clothes made from these materials. This paper examines the effect of the parameters of inkjet printing on thermal resistance characteristics of printed textile materials. As the essential print parameters were selected tone value and a different number of passes. In this research were used knitted fabric materials of 100\% cotton fibers and $100 \%$ polyester fibers. Results of the research demonstrated that, in addition to material composition, the inkjet printing process with its parameters have a significant influence on the thermal resistance of printed textile materials. The values of the thermal resistance of the printed samples show that the increase in the number of applications of ink in the printing results in a rise in the value on cotton knitwear, and decrease in thermal resistance value on polyester knitwear.
\end{abstract}

Keywords: Inkjet textile printing, Thermal resistance

\section{INTRODUCTION}

For the past decade, many innovations and the launching of new, improved machines brought Inkjet printing technologies a worldwide annual growth rate of $11 \%$ (Tyler, 2011). This has been achieved by the parallel development of inks, printing technologies and new application areas. Inkjet printing technology provides possibilities for new design styles and workflows, short production runs, sustainable printing environments, quick response time, and customization. One of the most significant contributions of this technology is the concept of the neo-cottage industry (Ujiie, 2005). Mostly used materials for clothing are cotton and polyester, or those two combined. From the whole amount of printed textile materials $35 \%$ is print on cotton, $25 \%$ on polyester and 16\% on the mixture substrate (Stančić, 2016; Momin, 2008; Siemensmeyer et al, 1999). Digital printing efficiency, as flexible way of ink transfer on substrate in the form of a desirable design, is primarily reflected in respect of costs and time needed for production of smaller circulations (Novaković et al, 2010). Besides that, digital printing technique enables faster response to market demands and mass individualization. More important, for clothes, is to meet the ergonomic and physiological requirements (Mecheels, 1992). Comfort is a basic and universal need of a human being and represents one of the most important aspects of clothing. When wearing clothes, the heat and humidity produced by the body stop as layers of air before passing into the environment, resulting in a characteristic microclimate between skin and clothing and is defined as a feeling of comfort (Yoo et al, 2000; Grujić et al, 2010). One of the most important thermal characteristics of clothing is, of course, thermal resistance; which represents the ability of a material to resist heat transfer. The thermal resistance of garments, made of a number of textile materials, mostly depends on the thickness and porosity of individual layers (Matusiak, 2010). Thus, increasing the thickness of the material leads to an increase in the value of thermal resistance (Oğlakcioğlu and Marmarali, 2007). To a lesser extent, the thermal resistance of textile materials is also determined by the thermal conductivity of the fibers of the material (Haghi, 2004). It is expected that there is an inverse relationship between thermal resistance and thermal conductivity. However, the results of various tests have shown that there are certain cases in which the increase in thermal conductivity leads to an increase in the thermal resistance of garments. This can be explained by the structural characteristics and thickness of the material. Namely, in the case that the volume increase of the material thickness is greater than the volume increase of the thermal conductivity of the material, there will be an increase in the value of thermal resistance (Chidambaram et al, 2012; Oğlakcioğlu and Marmarali, 2007). In the printing process, a layer of ink is transferred to the clothes, and part of the printing ink covers the surface clothing, while the other part fills the pores between the fibers. In this way the paint represents a new layer material, i.e. an additional barrier in heat transfer from the body surface to the environment. This paper will show the influence of this new layer of material obtained by the printing process on the thermal resistance of clothing. The influence of the number of ink applications and the tone value, as well as the influence of material type, are making a 
difference on the thermal resistance of printed textile materials. The thermal resistance of textile materials is very important characteristic to the degree of comfort that the user perceives from clothing. The thermal resistance of textile materials depends on the type of fiber. Then a layer of printing ink is applied to and in the textile material by the printing process. Printing ink covers the surface of the fibers, making a significant influence on the thermal resistance of textile material (Kašiković et al, 2019).

\section{METHODS AND MATERIALS}

Research of the effect of tone value and a different number of ink applications on thermal resistance was performed on two types of textile knitwear, of approximately the same surface mass and surface structures but different material composition. Material characterization was done according to following parameters: material composition (International Organisation for Standardization 1833, 2006), fabric weight (International Organisation for Standardization 3801, 1977) and thread count (International Organisation for Standardization 7211-2, 1984). Characteristics of the materials are presented in Table 1.

Table 1: Basic characteristics of materials used in research

\begin{tabular}{|c|c|c|c|c|c|c|}
\hline \multirow{2}{*}{$\begin{array}{l}\text { Code of } \\
\text { fabrics }\end{array}$} & \multirow{2}{*}{$\begin{array}{c}\text { Type of } \\
\text { materials }\end{array}$} & \multirow{2}{*}{$\begin{array}{l}\text { Type of } \\
\text { weaves }\end{array}$} & \multirow{2}{*}{$\begin{array}{c}\text { Raw material } \\
\text { composition (\%) }\end{array}$} & \multirow{2}{*}{$\begin{array}{l}\text { Mass per unit } \\
\text { weight }\left(\mathrm{g} / \mathrm{m}^{2}\right)\end{array}$} & \multicolumn{2}{|c|}{ Density $\left(\mathrm{cm}^{-1}\right)$} \\
\hline & & & & & Warp & Weft \\
\hline $\mathrm{CO}$ & Knitwear & Single & Cotton $100 \%$ & 111.89 & 17 & 17 \\
\hline PES & Knitwear & Single & Polyester 100 \% & 114.12 & 12 & 20 \\
\hline Method & & & ISO 1833 & ISO 3801 & ISO & $1-2$ \\
\hline
\end{tabular}

For this study it was created a special test image using Adobe Illustrator CS5 software. Test image contained $200 \times 200 \mathrm{~mm}$ patches, with $10 \%, 50 \%$ and $100 \%$ tone values of cyan process colour. Samples were printed by ink-jet printing system Polyprint TexJet. Samples were printed in one, three and five passes, resolution $720 \times 720$ dpi. It was printed with water-based inks (DuPont Artisti Pigment Ink - P5100 Cyan). Because of a need for a low viscosity, inks contain demineralised water (51\%), the appropriate pigment (1-5\%), poly(oxyethylene) (14\%), ethane-1.2-diol (12\%), 1- methyl-2-pyrrolidone (15\%), poly(1hydroxyethylene) (3\%), tris(2-hydroxyethyl)amine (1\%), biocide $(0.1 \%)$ and buffer $(0.3 \%)$. Ink fixation was performed at a temperature of $130{ }^{\circ} \mathrm{C}$ for 120 seconds. Thermal resistance, i.e. thermal insulation, is greatest when a person is at rest, because then the air under clothes is also at rest. Examination of thermal resistance of knitwear is performed with KES-F7 (Thermo Labo II) measuring device with a larger measuring body BT, which is located in the wind tunnel and which is heated to a temperature of $35^{\circ} \mathrm{C}$. At the same time, the air in the wind tunnel was constantly moving at a speed of $1 \mathrm{~ms}^{-1}$, at a temperature of $20{ }^{\circ} \mathrm{C} \pm 2{ }^{\circ} \mathrm{C}$. Constant air movement is achieved by turning on the fan. Heat loss or heat flow can be determined by the following methods: dry contact method, dry non-contact method, wet contact method, wet non-contact method. The dry non-contact method was used to analyse the thermal resistance of textile materials according to the expression (Kato Tech Co. Ltd., 1998):

$R_{c}=\frac{\left(T_{s}-T_{a}\right) \cdot A}{H_{c t}}$

where:

- $\mathrm{Rc}$ - heat resistance of textiles [ $\left.\mathrm{m}^{2} \mathrm{~K} / \mathrm{W}\right]$,

- Hct - dry heat flow, which goes through the material [W],

- A - Area of the BT measuring body $\left[\mathrm{m}^{2}\right]$,

- Ts - temperature of the BT measuring body (skin temperature) $\left[{ }^{\circ} \mathrm{C}\right]$,

- $\mathrm{Ta}$ - air temperature $\left[{ }^{\circ} \mathrm{C}\right]$. 


\section{RESULTS AND DISCUSSION}

The results of the research on the influence of printing parameters, i.e. tone values and number of ink applications, and properties of materials (raw material composition and surface structure) on a change of thermal resistance of printed textile materials, are presented below.

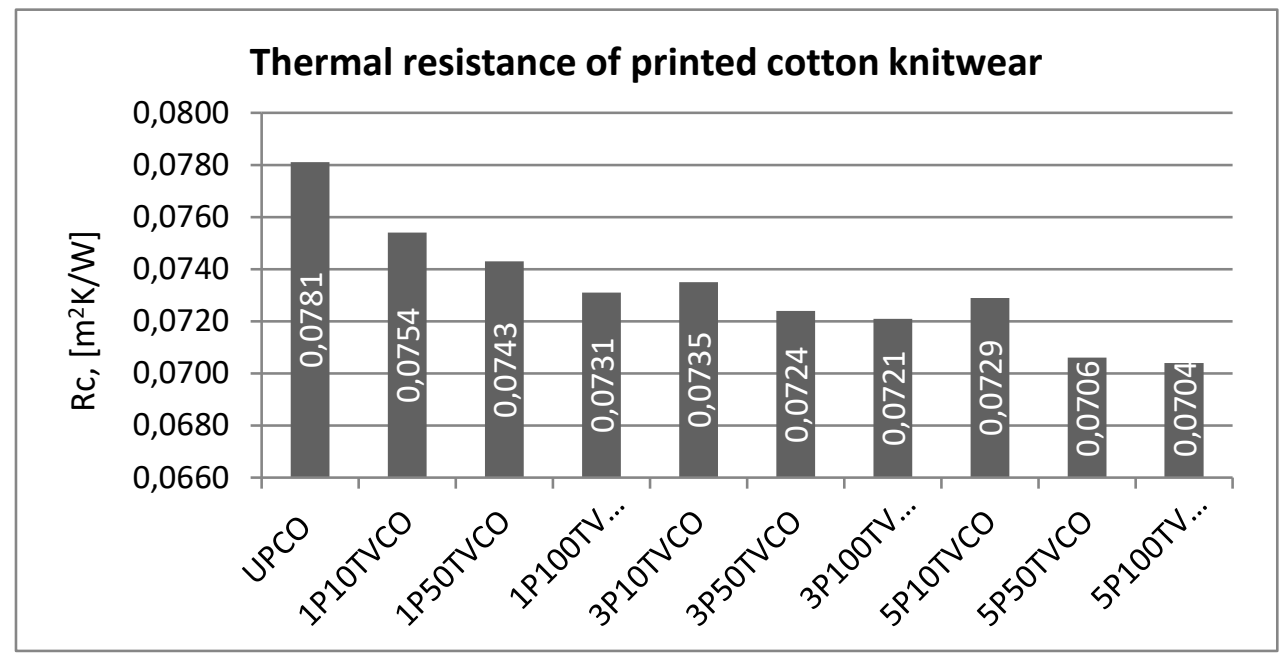

Figure 1: Thermal resistance of cotton knitwear subjected to the printing process (Note: UP - Unprinted, 1P, 3P and 5P mark indicates the print with 1, 3 and 5 passes, 10TV, 50TV and 100TV denote a print with 10\%, 50\% and 100\% of tonal values, CO stands for cotton)

The measured values of thermal resistance of printed cotton knitwear materials (CO) are shown in Figure 1. They are noticeably lower than the given values of the unprinted sample. It can be also noticed that the thermal resistance of printed cotton knitwear decreases with increasing of ink coverage. At the same time, with the increase in the number of ink applications, there is also a decrease in the value of thermal resistance. By analyzing the values of thermal resistance of printed cotton knitwear, it can be noticed that by combining the tone value and the number of ink applications, it is possible to achieve similar values of thermal resistance. The obtained results showed that approximately equal values of thermal resistance were obtained by printing samples with 10\% TV with five coats of ink and 100\% TV with one coat of ink.

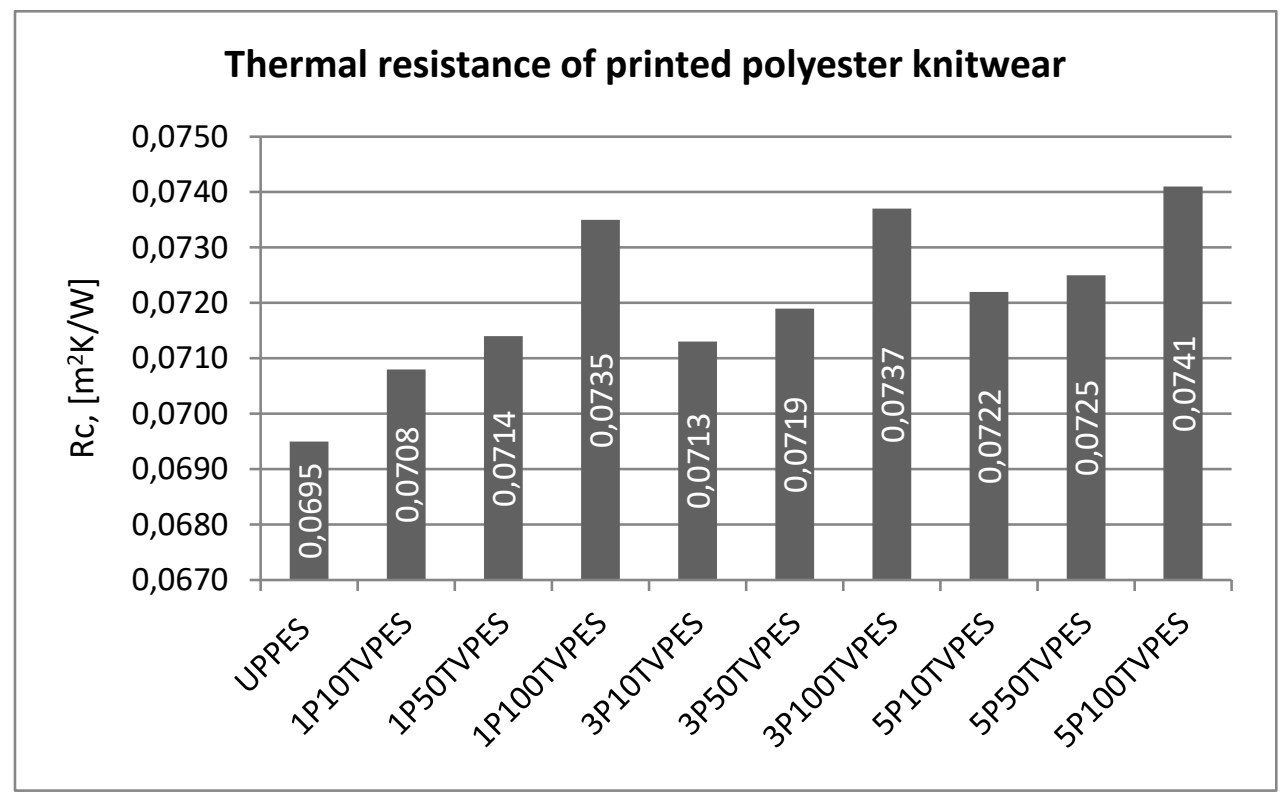

Figure 2: Thermal resistance of polyester knitwear subjected to the printing process (Note: UP - Unprinted, 1P, 3P and 5P mark indicates the print with 1, 3 and 5 passes, 10TV, 50TV and 100TV denote a print with 10\%, 50\% and 100\% of tonal values, PES stands for polyester) 
The results of thermal resistance analysis of printed polyester knitwear (PES) are shown in Figure 2. It can be noticed that increasing of the tone value leads to an increase in the value of thermal resistance. At the same time, the obtained measurement results indicate that as the number of ink applications increases, the values of thermal resistance increase, regardless of whether the samples were printed in one, with three or five ink applications. It is also noticed that the polyester knitwear obtained higher values of thermal resistance in the printing process in relation to the values that occur with unprinted material. Further analysis of the obtained results shows that approximately equal values were obtained in the case of printing samples with $10 \%$ TV with three print passes and $50 \%$ TV with one print pass, and in the case of printing 10\% TV with five print passes and 50\% TV with three print passes.

In order to determine dependence of thermal resistance of printed cotton and polyester knitwear, when printing with different tone value (TV) and different number of ink applications (NP), mathematical dependence models were created using multiple regression analysis. In creating model, as independent variable value were used printing process parameter values, i.e. values of ink layers applications and tone values. At the same time, as the dependent variable values were used experimentally obtained values of measuring thermal resistance of tested knitwear. Results are presented in Table 2 and Table 3.

Table 2: Values of multiple linear regression coefficients for the obtained mathematical models of the dependence of thermal resistance on tone values and the number of print passes for the tested cotton materials (Note: TV - tonal value, NP-number of passes)

\begin{tabular}{|c|c|c|c|c|c|c|c|c|c|c|}
\hline \multicolumn{11}{|c|}{$R_{c}=0,076-0,000022 \cdot T V-0,001 \cdot N P$} \\
\hline $\begin{array}{l}\text { Multiple } \\
\text { regression }\end{array}$ & Std. error of & \multicolumn{3}{|c|}{$b_{\circ}=0,076$} & \multicolumn{3}{|c|}{$b_{1}=-0,000022$} & \multicolumn{3}{|c|}{$b_{2}=-0,001$} \\
\hline$R^{2}$ & $\mathrm{~s}$ & std. error & $\mathrm{t}$ & $P$ & std. error & $\mathrm{t}$ & $P$ & std. error & $\mathrm{t}$ & $P$ \\
\hline 0,930 & 0,0004919 & 0,000417 & 182,581 & $1,8213 \cdot 10-12$ & 0,000004 & $-5,049$ & 0,002 & 0,0001 & $-7,386$ & 0,000316 \\
\hline
\end{tabular}

Table 3: Values of multiple linear regression coefficients for the obtained mathematical models of the dependence of thermal resistance on tone values and the number of print passes for the tested polyester materials (Note: TV - tonal value, NP-number of passes)

\begin{tabular}{|c|c|c|c|c|c|c|c|c|c|c|}
\hline \multicolumn{11}{|c|}{$R_{c}=0,070+0,000026 \cdot T V+0,000258 \cdot N P$} \\
\hline $\begin{array}{l}\text { Multiple } \\
\text { regression }\end{array}$ & Std. error of & \multicolumn{3}{|c|}{$b_{0}=0,070$} & \multicolumn{3}{|c|}{$b_{1}=0,000026$} & \multicolumn{3}{|c|}{$b_{2}=0,000258$} \\
\hline $\mathrm{R}^{2}$ & $\mathrm{~s}$ & std. error & $t$ & $P$ & std. error & $t$ & $P$ & std. error & $t$ & $P$ \\
\hline 0,929 & 0,0003589 & 0,000304 & 230,631 & $4,4840 \cdot 10-13$ & 0,000003 & 8,115 & 0,000188 & 0,000073 & 3,526 & 0,012 \\
\hline
\end{tabular}

The results show statistically reliable dependences of thermal resistance on tone values and the number of passes when printing for the test of cotton and polyester knitwear.

\section{CONCLUSION}

Textile materials are increasingly being subjected to the process of printing. This paper examines the effect of the parameters of digital printing on thermo-physiological characteristics of printed textile materials. For this purpose, the influence of the tone value and different number of ink applications on the thermal resistance. In the analysis of cotton knitwear it was noted that increase of the tone values as well as increase of number of ink applications leads to increase of the thermal resistance. In printing the polyester knitwear initial increase of tone value results in reduction of thermal resistance. This confirms that the change in the tone value or the number of ink applications, as the parameters of digital printing, can affect change in thermal resistance.

The values of thermal resistance highly depend on the surface structure of the material. For all tested materials, it is possible to create mathematical models of the dependence of thermal resistance on the number of ink applications and tone value.

Summarizing the results, it can be concluded that the print parameters have an important effect on thermal resistance, as one of the parameters of textile materials thermal comfort. In order to further 
knowledge it is planned to test how other process colours affect the studied parameters. Also, research is needed to expand to other physiological parameters of thermal comfort, such as thermal conductivity, warm and cold feeling, resistance to the flow of water vapour and others. In addition to the knitwear tests, listed research is needed to carry out on fabrics too.

\section{REFERENCES}

[1] Chidambaram, P., Govindan, R., Venkatraman, K. C.: „Study of Thermal Comfort Properties of Cotton/Regenerated Bamboo Knitted Fabrics", African Journal of Basic and Applied Sciences 4 (2), 60-66, 2012. doi:10.5829/idosi.ajbas.2012.4.2.1032.

[2] Grujić, D., Geršak, J., Ristić, M.: „Uticaj fizikalnih i sorpcijskih svojstava tkanina na količinu upijenog znoja u odjeći“ Tekstil, 59 (3), 68-79, 2010.

[3] Haghi, A.K.: „Moisture Permeation of Clothing, A Factor Governing Thermal Equilibrium and Comfort", Journal of Thermal Analysis and Calorimetry 76 (3), 1035-1055, 2004. doi: 10.1023/B:JTAN.0000032288.16502.d2.

[4] International Organisation for Standardization, ISO 3801:1977 Textiles - Woven fabrics -Determination of mass per unit length and mass per unit area, Geneva, International Organisation for Standardization, 1977.

[5] International Organisation for Standardization, ISO 7211-2:1984 Textiles - Woven fabrics -Construction -- Methods of analysis -- Part 2: Determination of number of threads per unit length, Geneva, International Organisation for Standardization, 1984.

[6] International Organisation for Standardization, ISO 1833-1:2006 Textiles - Quantitative chemical analysis -- Part 1: General principles of testing, Geneva, International Organisation for Standardization, 2006.

[7] Kašiković, N., Novaković, D., Stančić, M.: „Procesni parametri štampe tekstilnih materijala“, monografija, (Fakultet tehničkih nauka u Novom Sadu, Novi Sad, 2019), pages 282-292.

[8] Kato Tech Co. Ltd.: "Operating Instruction KES-F7: Manual for KES-F7 Thermo Labo II (Precise and Prompt Thermal Prosperity Measurement Instrument)“, Kyoto Tech Co. Ltd, 1998.

[9] Matusiak, M.: „Thermal Comfort Index as a Method of Assessing the Thermal Comfort of Textile Materials", Fibres and Textiles in Eastern Europe 18 (2), 45-50, 2010. URL: http://www.fibtex.lodz.pl/2010/2/45.pdf (last request: 2020-21-10).

[10] Mecheels, J.: „Anforderungsprofile für Funktionsgerechte Bekleidung“, DWI -Schriftenreihe des Deutschen Wollforschungsinstitutes an der TH Aachen, Aachener Teksiltagung, 109, 263-268, 1992.

[11] Momin, N. H.: "Chitosan and Improved Pigment Ink Jet Printing on Textiles", PhD thesis, School of Fashion and Textiles, RMIT University, Melbourne, 2008.

[12] Novaković, D., Kašiković, N., Zeljković, Ž., Agić, D. i Gojo, M.: „Thermographic Analysis of Thermal Effects on the Change of Colour Differences on the Digitally Printed Textile Materials", Tekstil 59 (7), 297-306, 2010. URL:

https://www.researchgate.net/publication/215601315_Thermographic_analysis_of_thermal_effect s_on_the_change_of_colour_differences_on_the_digitally_printed_textile_materials/link/09e41506 9c4d00960a000000/download (last request: 2020-21-10).

[13] Oğlakcioğlu, N., Marmarali, A.: "Thermal Comfort Properties of Some Knitted Structures", Fibres and Textiles in Eastern Europe 15 (5-6), 94-96, 2007. URL: http://www.fibtex.lodz.pl/64_26_94.pdf (last request: 2020-21-10).

[14] Siemensmeyer, K., Seigel, B., Ervine, S., Bullock, J.: "Solutions for Digital Textile Printing", Proceedings of IS\&Ts NIP 15: International Conference on Digital Printing technology 1999, (IS\&Ts NIP 15: Orlando, Florida, 1999), pages 280-283.

[15] [15] Stančić, M.: "Model of thermal properties of printed garment", PhD thesis, Faculty of Technical Sciences, Novi Sad, 2016.

[16] Tyler, D. J., „Digital printing technology for textiles and apparel“, (Editor(s): Jinlian Hu, In “Woodhead Publishing Series in Textiles, Computer Technology for Textiles and Apparel“, Woodhead Publishing, 2011), pages 259-282.

[17] Ujiie, H., „Innovative Product Development in Digital Fabric Printing", 2005, URL: http://www.hitoshiujiie.com/Documents/libraryResearch/WebCons05.pdf (last request: 2020-2110). 
[18] Yoo, H. S., Hu, Y. S., Kim, E. A.: „Effect of Heat and Moisture Transport in Fabrics and Garments Determined with a Vertical Plate Sweating Skin Model“, Textile Research Journal 70 (6), 542-549, 2000. doi: 10.1177/004051750007000612.

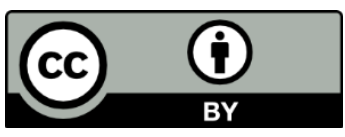

(C) 2020 Authors. Published by the University of Novi Sad, Faculty of Technical Sciences, Department of Graphic Engineering and Design. This article is an open access article distributed under the terms and conditions of the Creative Commons Attribution license 3.0 Serbia

(http://creativecommons.org/licenses/by/3.0/rs/). 


\title{
FACTORS INFLUENCING MECHANICAL PROPERTIES OF POLYURETHANE FOAMS USED IN COMPRESSIBLE FLEXOGRAPHIC SLEEVES
}

\author{
Saša Petrović (D), Nemanja Kašiković (D), Željko Zeljković (iD, Rastko Milošević \\ University of Novi Sad, Faculty of Technical Sciences, Department of Graphic Engineering and \\ Design, Novi Sad, Serbia
}

\begin{abstract}
Polyurethanes are a group of polymers which are in many ways different from other types of plastic. They are used in many different areas due to the fact that many different chemicals can be used during their synthesis, resulting in a variety of structures. Sleeves are comprised of hard base often covered with compressible polyurethane (PU) foam layer. PU foam layer can have different composition and level of porosity which are the main factors influencing compressibility of the sleeve and therefore its area of use. Sleeves are also one of the least researched components in the flexographic printing process. However, mechanical properties of the polyurethane, its fatigue, lifespan and parameters influencing all of them have been extensively investigated in different areas and for different types and formulations of polyurethane. The aim of this paper is to investigate factors influencing mechanical properties of polyurethane foams used in compressible flexographic sleeves. Investigated parameters are foam density, level of strain and strain rate, influence of microstructure under different conditions and parameters influencing creep and stress relaxation. The review of the existing literature regarding mechanical properties of the $P U$ foams makes it possible to select the parameters with the greatest possible influence on the flexographic printing process, as well as to find the most suitable methods to investigate the effect of exploitation on sleeve properties. As a large number of parameters influencing $P \cup$ foam mechanical properties are fixed during printing, it can be concluded, through the review of the existing literature, that the main parameters to be investigated are the resilience of the sleeve compressible layer during cyclic compression testing (residual strain), maximum stress, Young's modulus, hysteresis loss, and creep and stress relaxation during cyclic compression testing with strain retention.
\end{abstract}

Keywords: flexography, compressible sleeves, polyurethane foams, mechanical properties

\section{INTRODUCTION}

Packaging is nowadays, a multi-disciplinary field, a rapidly evolving science and a dynamic industry with continuous positive indicators (Politis, 2018), with the print quality being determined by many factors connected with printing process (Izdebska, 2015). Manufacturers of flexographic printing components are focused towards development of new printing plates, inks, anilox engraving techniques, stickyback tapes and sleeves, all of which have a significant impact on the product quality.

Sleeves are comprised of hard base often covered with compressible polyurethane (PU) foam layer. PU foam layer can have different composition and level of porosity which are the main factors influencing compressibility of the sleeve and therefore its area of use. Sleeves are also one of the least researched components in the flexographic printing process. However, mechanical properties of the polyurethane, its fatigue, lifespan and parameters influencing all of them have been extensively investigated in different areas and for different types and formulations of polyurethane.

Polyurethanes are a group of polymers which are in many ways different from other types of plastic. They are used in many different areas due to the fact that many different chemicals can be used during their synthesis, resulting in a variety of structures. Polyurethanes are currently one of the most universal, widespread and investigated materials in the world (Zia et al, 2014). These materials combine durability and toughness of metal with the elasticity of the rubber, making them suitable alternatives for metal, plastic or rubber in different products (Rafiee, 2015; Priscariu, 2011). Namely, PU elastomers have found use in a large number of various products, i.e. inks, liquid coatings, elastomers, foams, footwear, furniture, tires, construction materials, machines, sportswear, electronics, etc. (Akindoyo et al, 2016; Engels et al, 2013). They have outstanding capability of recovery from the compression or tension stress, and can withstand exposure to a large number of environment factors (Chattopadhyay and Webster, 2009; Zia et al, 2007).

Among the wide spectrum of possible shapes and types of PU, the most common are PU foams. Namely, in 2018., the PU foam market was estimated at 50.21 billion USD, and is expected to rise up to 79.77 billion USD until 2023. (Markets and Markets, 2018). Apart from that, PU foams make up half of the 
polymer foams market (Szycher, 2006). Based on the mechanical properties and crosslinking density, PU foams are classified in two groups, rigid and flexible (Randall and Lee, 2003; Wirpsza and Kemp, 1993).

\section{PARAMETERS INFLUENCING MECHANICAL PROPERTIES OF POLYURETHANE FOAMS}

\subsection{Foam density}

Density is mass of substance per its unit of volume. It is most often expressed in $\mathrm{g} / \mathrm{cm}^{3}$, while its values can be obtained from the sample of any size. Density is not correlated to the size of pores. Namely, foams with coarse and fine pores may have the same density. Density is also not a measure of strength, stiffness or load-bearing capacity. Those are defined by the measure of deflection of the compressive force defined by the stress required to keep the sample compressed by $25 \%$ after one minute. The higher the stress value, the greater the ability of the foam to carry the load (QFP, 2019).

The authors (Chen et al, 2015) concluded that expanded polystyrene of higher density has a higher energy absorption capacity than when its density is lower.

(De Vries, 2009) through research defined the influence of relative foam density on the stress-strain curve (Graph 1). As the density increases, so does the Young's modulus, the plateau modulus, and the elastic collapse stress, and the strain at which densification begins decreases. More about the mechanisms that lead to that will be stated in the influence of the microstructure, i.e. the cells in the material.

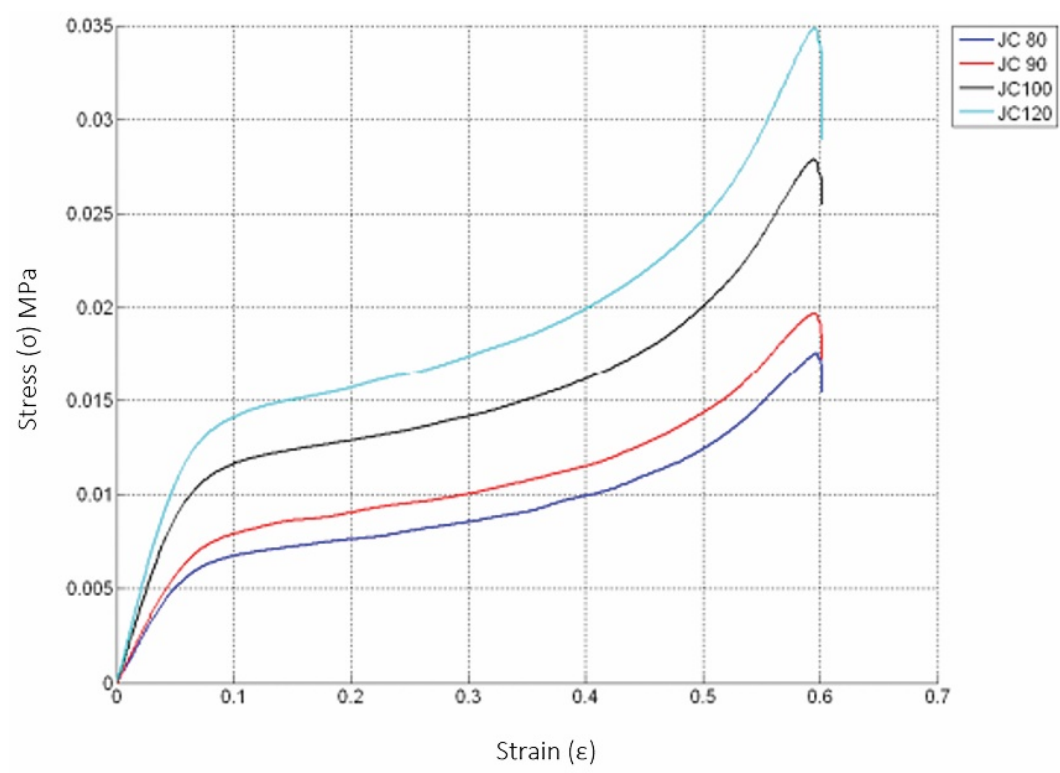

Graph 1: Stress-strain curves of JC foams with different densities (80,90, 100 and 120) at a constant strain rate (de Vries, 2009)

The yield strength increases by almost $100 \%$ with an increase in foam density of only $20 \%$ (Lu et al, 2016). The density of the foam is controlled by the amount of gas released during the reaction of water with the isocyanate (Saint Michel et al, 2006).

According to the authors (Alzoubi et al, 2014), the elastic properties depend on the relative density of the foam, the shape and size of the cross section of the struts, the Young's modulus and the Poisson's ratio. Foams such as flexible polyurethane foam are cellular solids whose microstructure consists of a network of struts (open cells) or panels (closed cells) as shown in Figure 1. The cavities that are surround by them create cells that are filled with gas, liquid, or just open. 


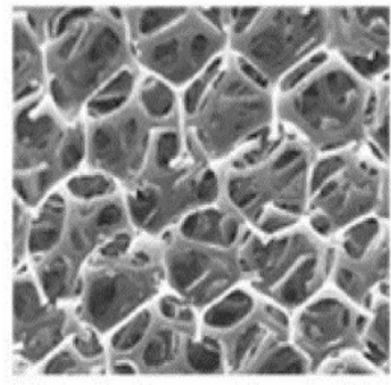

a)

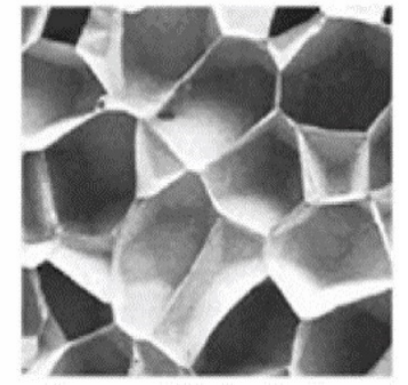

b)

Figure 1: Microscopic image of a foam with a) open; b) closed cells (Alzoubi et al, 2014)

The authors (Gibson and Ashby, 1988) and (Alzoubi et al, 2011) described the effects of foam density on the mechanical properties of cellular solids with closed and open cells. (Gibson and Ashby, 1982) described the ratios of densities as a function of the modulus of elasticity to the ratios of the yield strengths of open cell foams for a linear elastic region in the manner shown by equation 1.

$\frac{E^{*}}{E_{S}}=C_{1}\left(\rho^{*} / \rho_{S}\right)^{2}$

where $E^{*}$ is Young's modulus of the foam, Es Young's modulus of cell wall material, $\rho^{*}$ and $\rho_{S}$ are respectively foam and foam cell wall material densities and $C_{1}$ is the constant obtained through testing of a number of foam samples with different densities.

Uniaxial quasi-static compression tests were performed on all foam samples. It was concluded that Young's modulus of elasticity increases with increasing foam density. The modulus of elasticity increases rapidly in foam samples with higher densities, and the stresses measured at $5 \%$ and $70 \%$ of the strain increase in parallel with the density (Alzoubi et al, 2014).

It has been experimentally proven that hysteresis (Kreter, 1985; Lee, 1985; Cavender, 1990) and reduction of stress due to fatigue (Dwyer, 1976; Courtney et al, 1989) decrease with increasing foam density. These conclusions are supported by the observations of the author (Dwyer, 1976) who showed that with flexible polyurethane foams, density reduction is not the main reason for increased fatigue (i.e. stress reduction) but water levels and physical inflating agents that affect foam durability. He concluded that higher density foams show less fatigue loss, and therefore less hysteresis through a reduction in the urea content in the solid polymer.

\subsection{Level of strain and strain rate}

According to (Molded Dimension, LLC., 2019), the increase in the initial strain is followed with an increase in the level of creep.

(De Vries, 2009) has shown on the example of commercially available open-cell PU foam that the zone of elasticity is initially linear. However, at the strain level of about $4 \%$, the slope of the stress-strain curve begins to decrease and at strain level of around $10 \%$ forms a plateau of elastic collapse. At a strain level of about $60 \%$, densification occurs. After compression, the foam sample returns almost completely to its initial dimensions, which means that the deformation is completely elastic. At a strain level of about $60 \%$, stress relaxation was also observed. Those three characteristic zones of the stress-strain curve during compression are typical of elastomeric foams (Gibson and Ashby, 1988).

In addition to the strain levels, the strain rate can have a large influence on the mechanical properties of the polymer. As the application of polymers expanded, so did the influence of the strain rate factor on researchers' interest. In recent years, several experimental approaches have been developed to study the influence of strain rate on the mechanical properties of polymers (Sarva et al, 2007; Río and Rodríguez, 2010; Mulliken and Boyce, 2006). One of the most important characteristics used to evaluate the mechanical properties of a material is the stress-strain curve. Polymers can be classified into different classes according to the parameters in the region of the yield strength.

(Lu et al, 2016) experimentally concluded that the Young's modulus and the elastic buckling stress of the foam are obviously dependent on the strain rate. The values of the Young's modulus and the elastic buckling stress at a strain rate of $200 \mathrm{~s}^{-1}$ are about five times or twice as high as those at $0.1 \mathrm{~s}^{-1}$. During the unloading, hysteresis behaviour is noticeable, where the unloading strain is late compared to the stress, but after a sufficient time it returns to zero with a small permanent deformation. 
In the research of the authors (Omar et al, 2011a), all tested samples showed a growing trend in the yield strength with increasing strain rate. In contrast, the strain at the elastic limit decreases significantly with increasing strain rate. This decrease is attributed to an increase in adiabatic temperature within the sample with increasing strain rate (Omar et al, 2011b; Guo and Li, 2007) where the accumulated heat weakens the material. Another explanation for this phenomenon was given by the authors (Nakai and Yokoyama, 2008) where it is directly related to the accumulation of micro damage during deformation. The authors stated that the higher the strain rate, the more serious the damage done to the sample as more cracks must occur due to the adaptation to larger strains at higher rates. The result is that the combination of both phenomena causes a decrease in the strain of all polymeric materials at the elastic limit with an increase in the strain rate.

Theoretically, under impact loads compression can be classified into high or low energy compression (Omar et al, 2011a). It is believed that high energy compression usually leads to instantaneous failure of the material. However, damage from low-energy compression is difficult to detect and can lead to sudden and catastrophic failures. The absorbed energy capacity was one of the main parameters in the work of (Omar et al, 2011a). Energy absorption is most often determined by measuring the area under the stress-strain curve to a certain strain. In the aforementioned work, this strain limit was $2.5 \%$. The relationship between the absorbed energy and the strain rate is such that the strain energy increases with increasing velocity. The authors noted that tested polymers have different stress-strain curves and are therefore classified into classes of elastic and brittle polymers. The conclusions drawn from their research are that the mechanical properties of polymers largely depend on the strain rate. The yield strength, the compression modulus and the compressive strength increase in proportion to the increase in the strain rate, and the strain at the elastic limit opposite to them shows a gradual decrease.

(Wang et al, 2016) conducted quasi-static and cyclic deformation tests of polycarbonate ABS at different strain rates $\left(10^{-4}, 10^{-3}\right.$ and $\left.10^{-2} \mathrm{~s}^{-1}\right)$ and different temperatures $\left(20,50\right.$, and $\left.80^{\circ} \mathrm{C}\right)$. Cyclic compression tests were performed at different strain rates $\left(10^{-4}, 10^{-3}\right.$ and $\left.10^{-2} \mathrm{~s}^{-1}\right)$ at room temperature $\left(20^{\circ} \mathrm{C}\right)$. The level of strain was at least $80 \%$. It was concluded that the mechanical behaviour of polycarbonate ABS is greatly influenced by the strain rate, and also by the temperature when subjected to a monotonic load. Yield strength increases significantly with an increase in strain rate or a decrease in temperature, and the stress at higher strain rates grows faster than at lower strain rates. Also, at higher strain rates, the Young's modulus is significantly higher. The behaviour in the cyclic test is also dependent on the strain rate and is not linearly elastic during unloading and reloading. As the strain rate increases, so does the stress during loading and reloading after unloading.

When expanded polystyrene is subjected to compression, the air trapped inside the cells is compressed and a viscous force is created. Viscous forces increase with the strain rate (Ouellet et al, 2006). (Croop and Lobo, 2009) found that the behaviour of expanded polystyrene is such that it is stiffer as the air trapped inside the cells creates "cushions" due to the inability to leave the material at high strain rates. (Chakravarty et al, 2003) found that changes in the properties of foam materials during higher strain rate deformations are due to the variable nature of the gas during compression. The influence of strain rate has also been addressed in the work of (Di Landro et al, 2002). They found that with a large increase in the strain rate, the modulus of elasticity of the material also increased slightly. Also, the yield strength and the plateau stress increase with increasing strain rate (Tedesco et al, 1993). A similar thing was observed by (Song et al, 2005) when they concluded that the modulus of elasticity increases with an increase in the strain rate. (Chen et al, 2015) concluded that when the strain rate is greater than $113 \mathrm{~s}^{-1}$, the compressive strength of expanded polystyrene increases rapidly, but the level of strain during densification decreases. The Young's modulus does not show a significant dependence on the strain rate in the tested range $\left(1-280 \mathrm{~s}^{-1}\right)$.

By conducting experiments on porous polypropylene ( $94 \%$ porosity) with a closed cell structure (Yonezu et al, 2016) found that the macroscopic stress-strain curve shows the plateau zone when the material undergoes plastic deformation, and that the influence of strain rate is expressed in material behaviour in the plateau zone.

\subsection{Influence of microstructure on foam properties under different conditions}

It is known that at the macroscopic level, polymer foams are very sensitive to the strain rate. For a large number of polymer foams, an exponential dependence of stress at material failure and strain rate has been observed (Ouellet et al, 2006). It is also known that the transition in sensitivity to the strain rate of these materials mainly occurs at strain rates greater than $103 \mathrm{~s}^{-1}$, where the stress at failure and modulus 
of elasticity of the material rapidly follow the increase in strain rate (Song et al, 2005; Zhao, 1997; Nagy et al, 1974; Yi et al, 2006; Mulliken and Boyce, 2006; Koohbor et al, 2016).

A large number of studies involving the microstructure of open-cell foams have shown that most of the cells within the foam are to some extent elongated in a certain direction originating from the production process. Using X-ray tomography, (Perrot et al, 2007) measured a ratio of 1.26 to 1.56 in open-cell aluminum foams. (Jang et al, 2008) and (Gong et al, 2005) investigated the geometric characteristics of a whole series of open-cell polyester urethane foams. The research included the geometry of cells and struts, as well as the arrangement of material in struts and nodes. The conclusion they derived is that the anisotropic ratio is generally between 1.2 and 1.5 .

(Lu et al, 2016) used new and 30 year old foam samples in their study. Although the average cell size is almost equal to the cell size of the new foam $(200 \mu \mathrm{m})$, the shape of the cells is slightly different. Namely, the cells of the new foam have an oval shape (Figure 2).

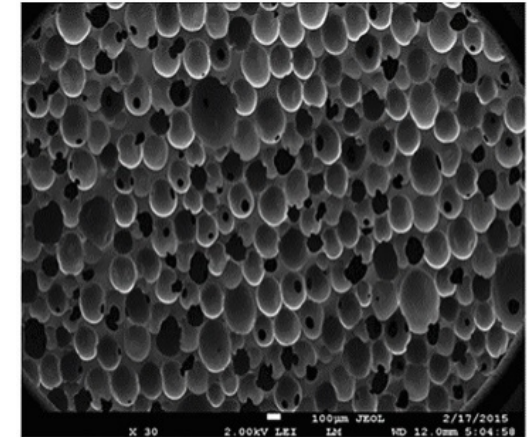

a)

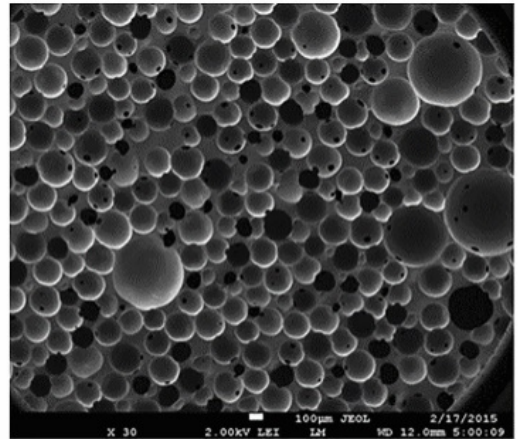

b)

Figure 2: Microscopic image of cells in a) new; b) 30 year old foam (Lu et al, 2016)

According to the model of authors (Gibson and Ashby, 1988), closed cell foams are described as complex cuboidal structures constructed of struts and walls. The strength of closed cells depends on three components. The flexibility of the struts (as with open cell foams), the stretching of the cell walls and the pressure of the gas trapped in the cells. (Saint Michel et al, 2006) and (Lu et al, 2015) found that open-cell foams with sections of equilateral triangles show significantly greater asymmetry in strength than those with square or circular sections, while circular sections showed the smallest asymmetry.

The pronounced sensitivity of polymer foams to the strain rate has two sources. One is the release of gas trapped inside the cells (in the structure of closed cells), and the other is the mechanical response of the solid parent material (Sun and Li, 2015). The first source is the main cause that contributes to the pronounced sensitivity of closed cell foams to the strain rate, as well as to their hardening (Di Landro et al, 2002; Bouix et al, 2009; Mondal et al, 2009).

(Bouix et al, 2009) investigated the contribution of gas release to strain rate sensitivity and hardening of expanded closed cell polypropylene foam by performing a quasi-static and dynamic test on submerged samples. The analysis was performed in relation to the formation of air bubbles on the surface of the samples as a consequence of the release of gas that accompanies the deformation and tearing of closed cells inside the material.

The contribution of the mechanical behaviour of the parent polymer material to the macroscopic response to foam deformation has been investigated mostly through deformation behaviour at the cellular level. However, most research in this field, conducted on such small dimensions is based on micromechanical simulations without experimental evidence (Pal et al, 2010; Alkhader et al, 2008; Brydon et al, 2005; Mills et al, 2009; Li et al, 2003).

Relatively recent theoretical studies have shown that deformation at low forces (lesser than the elastic buckling stress) is associated with bending of cellular elements (Figure 3) (Gibson and Ashby, 1988; Warren and Kraynik, 1988) rather than with normal deformation of struts parallel to the force vector, as was previously assumed, e.g. in the work of authors (Gent and Thomas, 1963). 

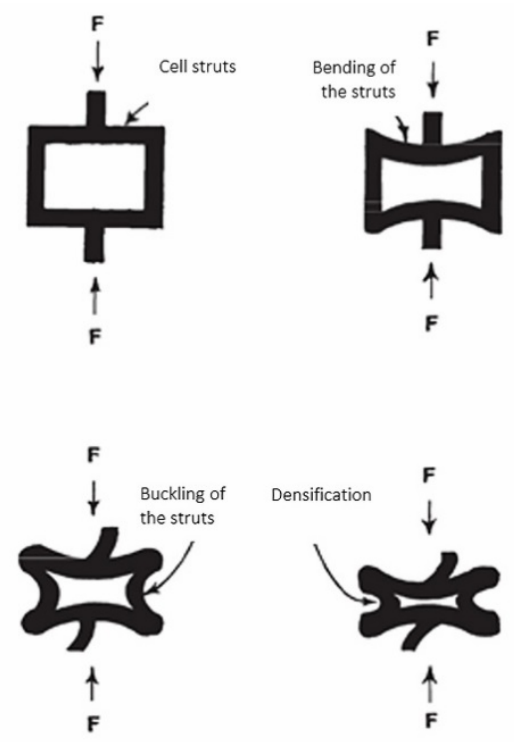

Figure 3: Bending of the cell walls parallel to the force vector

(Koohbor et al, 2018) showed that under conditions where there is no significant influence of the strain rate on the strength and modulus of elasticity of the parent polymer, elastic buckling and failure due to brittleness inside the thinner cell walls become competing failure modes. Elastic buckling is a more likely failure mode in areas where the cell walls are very thin. On the other hand, brittle failure is evidently the dominant mode of failure within thicker cell walls. In addition, they proved that as the strain rate increases, so does the difference between the critical stresses for all material failure modes. Thus, although the failure mode due to brittleness (Figure 4. c) is the main failure mode for all strain rates, the chances of failure occurring due to elastic buckling (Figure 4. a) and/or plastic collapse (Figure 4. b) grow. The overlap of these modes at higher strain rates occurs due to a significant increase in the yield strength of the parent polymer. Although the modulus of elasticity of a material increases, its growth is not at the same rate as the increase in the yield strength. As elastic buckling is based on the elastic response of cell walls to deformation, its growth with increasing strain rate is less significant. This leads to overlapping of the curves of the three failure modes at higher rates. The global deformation and the strain rate on the sample at the macro level differ significantly (are at least one magnitude less) than those at the local level of the cell walls.

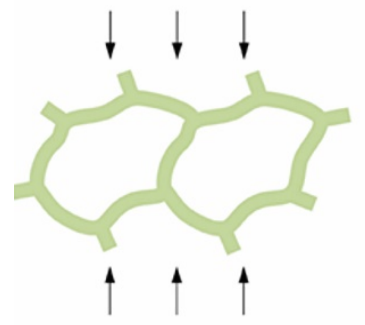

a)

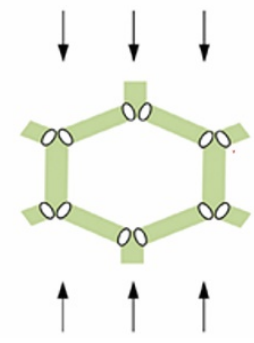

b)

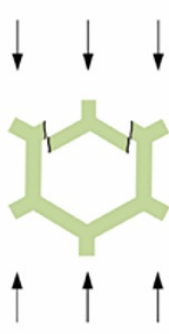

c)

Figure 4: Schematic representation of cell deformation due to a) elastic buckling; b) plastic collapse; c) brittleness (Koohbor et al, 2018)

The elastic response of a linear character in foam is controlled by bending the cell walls, and in the case of closed cells by stretching of the cell walls. Young's modulus (E) is the initial slope of the stress-strain curve of the polymer foam. For small strains, the foam will have an elastic response. In this zone, the compression stress can be expressed by equation 2 .

$\sigma=E x \varepsilon$

where $\sigma$ is stress, and $\varepsilon$ strain. 
During compression, the plateau of plastic behaviour is associated with cell collapse. The plateau is different for elastomeric and elastoplastic foams. In elastomeric foams, the plateau is determined by elastic buckling (Gibson and Ashby, 1999). With pure elastomeric foams, there is no plastic deformation, but elastoplastic materials also have a plasticity zone.

When the cells undergo almost complete collapse, the opposite cell walls touch and further deformation compresses only the solid, resulting in a final zone of rapidly increasing stress relative to the strain known as the densification zone with a slope approaching the Young's modulus of solid-full polymers at the limit of deformation.

If the density is low, foams with open cells are deformed primarily by bending the cell walls. With increasing relative density $(R>0.1)$, the contribution of simple stretching or compression of cell walls becomes more significant. There are models in the literature that predict the Young's modulus of foam based on the shape of the cells in the structural sequence, such as the structure of a honeycomb (Mills, 2007; Gibson and Ashby, 1988). In practice, cell shapes and structural sequences are not like that.

In closed cell foams, the cell walls twist and elongate on contact, and the membranes that form the face and back of the cell stretch, increasing the contribution of the axial strength of the cell walls to the modulus of elasticity. If the membranes do not tear, the compression of the air inside the cells also increases the strength. Therefore, for Young's modulus there are three main contributors to the initial foam hardness (de Vries, 2009).

During compression, the stress-strain curve for polymer foams has an extending plateau at a stress that does not change significantly. This stress level is called the elastic collapse stress, and the slope of the plateau is the modulus of the plateau. The elastic collapse of the foam is caused by the elastic bending of the cell walls. When the elastomeric foam with open cells compresses, the cell walls will slowly bend to the critical stress at which buckling will occur.

Another factor that contributes to the dependence on the strain rate comes from the fluid in the foam cells. When the foam compresses, the fluid deforms or is forced to flow from cell to cell. In open cell foams, air is expelled from the foam during compression. This causes viscous forces that depend on the strain rate (de Vries, 2009).

Unlike the influence on the mechanical properties of foam, the size of the cells greatly affects the properties of air flow. In closed cell foams, this is irrelevant as long as the membranes do not tear, thus releasing air inside the foam. When the open cell foam is compressed, air is expelled from it, which requires a certain amount of work that opposes the viscous forces. The higher the strain rate, the faster the air flow, and thus the work invested to overcome the viscous forces.

Skochdopole and Ruben gave a qualitative model that suggests that the air inside the cells and the microstructures of closed-cell polymers act in parallel during deformation. The model is simple and is based on the addition of the stress of the polymer structure to the stress originating from the air inside the cells (Mills, 2007).

In the research of the author (de Vries, 2009), it was observed that the strain rate affects the Young's modulus of the examined open-cell polymer foam. This influence comes from the inside of the material, that is, from the polymer walls of the cells. Therefore, it was concluded that the Young's modulus was determined by the parameters of the cell wall material and the complex microstructure of the foam, as well as the strain rate. Therefore, it would be more correct to call the zone of elastic response with a linear character a viscoelastic zone. For the tested foam, it was observed that the Young's modulus increases with increasing strain rate and that in most zones of the curve the sample size has no effect, as well as that the air flow does not contribute significantly to the stress level. Thicker foams (with smaller pores) will contribute to the influence of air flow due to higher viscosity forces and the work required to expel air.

\subsection{Parameters influencing the creep and stress relaxation}

(Tobushi et al, 2002) investigated the phenomena of creep and stress relaxation of polymer memory foam. They concluded that the creep is higher if the initial strain is smaller. Also, the creep and recovery from deformation are very pronounced at temperatures lower than the glass transition temperature $\left(T_{g}\right)$. In addition, they concluded that after some time, the stress after relaxation is proportional to the initial stress. The level of stress relaxation is large below the temperature $T_{g}$, but above that temperature it is small. The stress relaxation level is also high if the strain rate is also high. With large strain and maintaining of a constant stress above the temperature $T_{g}$, irreversible deformation occurs. When a large 
strain is constantly maintained above the temperature $T_{g}$, almost complete stress relaxation occurs and the deformation becomes fixed.

The level of stress relaxation also depends on the history of material deformations and temperature fluctuations during measurements (Derham, 1973).

According to (Molded Dimension, LLC., 2019), a loading that allows occasional periods of material recovery will lead to a smaller creep than continuous loading. However, continuous vibration loading will lead to increased creep due to internal heat generation. Also, after a certain period of time, the creep reaches the plateau and becomes almost constant, and the creep level itself is represented by a function of the stress level.

(Qi and Boyce, 2005) during loading and unloading of materials periodically paused testing for 60s at strain levels of $20 \%, 40 \%, 60 \%$ and $80 \%$ and measured the stress response, i.e. stress relaxation at constant strain. During loading, the stress decreased in the strain retention phases, while during unloading the stress increased in the retention phases. This behaviour is typical time-dependent behaviour of some more conventional elastomeric materials (e.g., in studies by the authors (Lion, 1996) and (Bergstrom and Boyce, 1998)).

(Petrů and Novák, 2017) subjected different types of polyurethane foams to strain levels of $10 \%, 25 \%$, $50 \%$, and $65 \%$ over duration of 3600s while measuring stress relaxation. Their research concludes that regardless of the type of polyurethane foam, stress relaxation increases with increasing initial strain.

\section{CONCLUSIONS}

Knowledge of the factors influencing $\mathrm{PU}$ foam properties enables further research regarding characterization of the flexographic sleeves. The review of the existing literature regarding mechanical properties of the $\mathrm{PU}$ foams makes it possible to select the parameters with the greatest possible influence on the flexographic printing process, as well as to find the most suitable methods to investigate the effect of exploitation on sleeve properties. Another benefit lies in the knowledge of mechanisms of PU foam structure deformation which makes it possible to find the main causes of change in mechanical properties of the sleeves originating from the plate mounting/demounting and the printing process. As a large number of parameters influencing PU foam mechanical properties are fixed during printing, it can be concluded, through the review of the existing literature, that the main parameters to be investigated are the resilience of the sleeve compressible layer during cyclic compression testing (residual strain), maximum stress, Young's modulus, hysteresis loss, and creep and stress relaxation during cyclic compression testing with strain retention. These parameters should be selected as they are the ones mostly influenced by the changes in the PU foam structure and mechanical properties after exploitation. With that in mind, they can be used to pinpoint the main sources leading to the aforementioned changes, as well as the influence of those changes on other materials and parameters of importance to the flexographic printing process and cardboard packaging print quality.

\section{ACKNOWLEDGEMENTS}

This research has been supported by the Ministry of Education, Science and Technological Development through the project no. 451-03-68/2020-14/200156: "Innovative scientific and artistic research from the FTS domain".

\section{REFERENCES}

[1] Akindoyo, J. O., Beg, M. D. H., Ghazali, S., Islam, M. R., Jeyaratnam, N., Yuvaraj, A. R.: "Polyurethane types, synthesis and applications - A review", RCS Advances 115, 2016. doi: 10.1039/C6RA14525F

[2] Alkhader, M., Vural, M.: Mechanical response of cellular solids: "Role of cellular topology and microstructural irregularity", International Journal of Engineering Science 46 (10), 1035-1051, 2008. doi: 10.1016/j.ijengsci.2008.03.012

[3] Alzoubi, M. F., Al-Hallaj, S., Abu-Ayyad, M.: "Modeling of Compression Curves of Flexible Polyurethane Foam with Variable Density, Chemical Formulations and Strain Rates", Journal of Solid Mechanics 6 (1), 82-97, 2014. 
[4] Alzoubi, M. F., Tanbour, E. Y., Al-Waked, R.: "Compression and hysteresis curves of nonlinear polyurethane foams under different densities, strain rates and different environmental conditions", Proceeding of ASME - International Mechanical Engineering Congress \& Exposition, (ASME: Denver CO, USA, 2011), pages 101-109. doi: 10.1115/IMECE2011-62290

[5] Bergstrom, J. S., Boyce, M. C.: "Constitutive modelling of the large strain time-dependent behavior of elastomers", Journal of the Mechanics and Physics of Solids 46 (5), 931-954, 1998. doi: 10.1016/S0022-5096(97)00075-6

[6] Bouix, R., Viot, P., Lataillade, J.: "Polypropylene foam behavior under dynamic loadings: strain rate, density and microstructure effects", International Journal of Impact Engineering 36 (2), 329-342, 2009. doi: 10.1016/j.ijimpeng.2007.11.007

[7] Brydon, A. D., Bardenhagen, S. G., Miller, E. A., Seidler, G. T.: "Simulation of the densification of real open-celled foam microstructures", Journal of the Mechanics and Physics of Solids 53 (12), 26382660, 2005. doi: 10.1016/j.jmps.2005.07.007

[8] Cavender, K. D.: "New dynamic flexibility test. 1. Polyurethanes 90", Proceedings of the 33rd Annual Polyurethane Technical/Marketing Conference, (1990).

[9] Chakravarty, U., Mahfuz, H., Saha, M., Jeelani, S.: "Strain rate effects on sandwich core materials: an experimental and analytical investigation", Acta Materialia 51 (5), 1469-1479, 2003. doi: 10.1016/S1359-6454(02)00541-4

[10] Chattopadhyay, D., Webster, D. C.: "Thermal stability and flame retardancy of polyurethanes", Progress in Polymer Science 34 (10), 1068-1133, 2009. doi: 10.1016/j.progpolymsci.2009.06.002

[11] Chen, W., Hao, H., Hughes, D., Shi, Y., Cui, J., Li, Z. X.: "Static and dynamic mechanical properties of expanded polystyrene", Materials \& Design 69, 170-180, 2015. doi: 10.1016/j.matdes.2014.12.024

[12] Courtney, M. H., Charlton, L. J., Seal, K.: "Influence of foam density on automobile seat performance", Journal of Cellular Plastics 25 (5), 472-485, 1989. doi: 10.1177/0021955X8902500505

[13] Croop, B., Lobo, H.: "Selecting material models for the simulation of foams in LS-DYNA", Proceedings of 7th European LS-DYNA conference, (LS-DYNA: Salzburg, Austria, 2009), URL: https://www.dynalook.com/conferences/european-conf-2009/D-II-04.pdf (last request: 2019-09-27).

[14] de Vries, D.V.W.M.: "Characterization of polymeric foams", MSc Thesis, Eindhoven University of Technology, 2009.

[15] Derham, C. J.: "Creep and stress relaxation of rubbers - the effects of stress history and temperature changes", Journal of Materials Science 8 (7), 1023.-1029, 1973. doi:10.1007/BF00756634

[16] Di Landro, L., Sala, G., Olivieri, D.: "Deformation mechanisms and energy absorption of polystyrene foams for protective helmets", Polymer Testing 21 (2), 217-228, 2002. doi: 10.1016/S01429418(01)00073-3

[17] Dwyer, F. J.: "A review offactors affecting durability characteristics of flexible urethane foams", Journal of Cellular Plastics 12 (2), 104-113, 1976. doi: 10.1177/0021955X7601200205

[18] Engels, H.W., Pirkl, H. G., Albers, R., Albach, R. W., Krause, J., Hoffmann, A., Casselmann, H., Dormish, J.: "Polyurethanes: Versatile Materials and Sustainable Problem Solvers for Today's Challenges", Angewandte Chemie International Edition 52 (36), 9422-9441, 2013. doi: 10.1002/anie.201302766

[19] Gent, A. N., Thomas, A. G.: "Mechanics of foamed elastic materials", Rubber Chemistry and Technology 36 (3), 597-602, 1963. doi: 10.5254/1.3539591

[20] Gibson, I. J., Ashby, M. F.: "The mechanics of three-dimensional cellular materials", Proceedings of Royal Society of London 382 (1782), 1982. doi: 10.1098/rspa.1982.0088

[21] Gibson, L. J., Ashby, M. F.: “Cellular solids - Structure and properties", (Pergamon Press, Oxford, 1988.)

[22] Gibson, L. J., Ashby, M. F.: "Cellular solids - Structure and properties. 2nd edition”, (Cambridge University Press, Cambridge, 1999.)

[23] Gong, L., Kyriakides, S., Jang, W.- Y.: “Compressive response of open-cell foams. Part I: Morphology and elastic properties", International Journal of Solids and Structures 42 (5-6), 1355-1379, 2005. doi:10.1016/j.ijsolstr.2004.07.023

[24] Guo, Y., Li, Y.: "Quasi-static/dynamic response of SiO2-epoxy nanocomposites", Materials Science and Engineering: A 458 (1-2), 330-335, 2007. doi: 10.1016/j.msea.2007.02.011

[25] Jang, W. Y., Kraynik, A. M., Kyriakides, S.: "On the microstructure of open-cell foams and its effect on elastic properties", International Journal of Solids and Structures 45 (7-8), 1845-1875, 2008. doi: 10.1016/j.ijsolstr.2007.10.008 
[26] Izdebska, J., ŻołekTryznowska, Z., Świętoński, A.: "Correlation between plastic films properties and flexographic prints quality", Journal of Graphic Engineering and Design 6 (2), 19-25, 2015. ISSN: 2217-9860.

[27] Koohbor, B., Kidane, A., Lu, W. Y.: "Effect of specimen size, compressibility and inertia on the response of rigid polymer foams subjected to high velocity direct impact loading", International Journal of Impact Engineering 98, 62-74, 2016. doi: 10.1016/j.jimpeng.2016.08.006

[28] Koohbor, B., Ravindran, S., Kidane, A.: "Effects of cell-wall instability and local failure on the response of closed-cell polymeric foams subjected to dynamic loading", Mechanics of Materials 116, 67-76, 2018. doi:10.1016/j.mechmat.2017.03.017

[29] Kreter, P. E.: "Polyurethane foam properties as a function of foam density", Journal of Cellular Plastics 21 (5), 306-310, 1985. doi: 10.1177/0021955X8502100502

[30] Lee, W. M.: "A new approach to humid age compression set study in high resilient molded foams", Journal of Cellular Plastics 21 (6), 417-422, 1985. doi: 10.1177/0021955X8502100607

[31] Li, K., Gao, X. L., Roy, A. K.: "Micromechanics model for three-dimensional open-cell foams using a tetrakaidecahedral unit cell and Castigliano's second theorem", Composites Science and Technology 63 (12), 1769-1781, 2003. doi: 10.1016/S0266-3538(03)00117-9

[32] Lion, A.: "A constitutive model for carbon black filled rubber, experimental investigation and mathematical representation", Continuum Mechanics and Thermodynamics 8 (3), 153-169, 1996. doi: 10.1007/BF01181853

[33] Lu, W.- Y., Neidigk, M., Wyatt, N.: "Cyclic Loading Experiment for Characterizing Foam Viscoelastic Behavior", Experimental and Applied Mechanics 4, 135-144, 2016. doi:10.1007/978-3-319-42028$8 \_16$

[34] Lu, Z.X., Huang, J.X., Yuan, Z.S.: "Effects of microstructure on uniaxial strength asymmetry of opencell foams", Applied Mathematics and Mechanics 36 (1), 37-46, 2015. doi: 10.1007/s10483-0151893-9

[35] Markets and Markets: "Market Research Report", URL: https://www.marketsandmarkets.com/Market-Reports/polyurethane-foams-market1251.html?gclid=CjOKCQjwpfHzBRCiARIsAHHzyZqvSdW_pIDxDiu5vMypdyOOkMHDxp6gcecOJWOaAl Ly_I5h1Fz34x0aAgClEALw_wcB (last request: 2019-09-27).

[36] Mills, N.: "Polymer Foams Handbook - Engineering and Biomechanics Applications and Design Guide", (Butterworth-Heinemann, Oxford, 2007), doi: 10.1016/B978-0-7506-8069-1.X5000-4

[37] Mills, N. J., Stampfli, R., Marone, F., Bruhwiler, P. A.: "Finite element micromechanics model of impact compression of closed-cell polymer foams", International Journal of Solids and Structures 46 (3-4), 677-697, 2009. doi: 10.1016/j.ijsolstr.2008.09.012

[38] Molded Dimension, LLC.: "Creep and Stress Relaxation", URL: https://moldeddimensions.com/creepand-stress-relaxation.php (last request: 2019-09-27)

[39] Mondal, D. P., Goel, M. D., Das, S.: "Compressive deformation and energy absorption characteristics of closed-cell aluminum-fly ash particle composite foam", Materials Science and Engineering: A 507 (1-2), 102-109, 2009. doi: 10.1016/j.msea.2009.01.019

[40] Mulliken, A. D., Boyce, M. C.: "Mechanics of the rate-dependent elastic-plastic deformation of glassy polymers from low to high strain rates", International Journal of Solids and Structures 43 (5), 13311356, 2006. doi: 10.1016/j.ijsolstr.2005.04.016

[41] Nagy, A., Ko, W. L., Linholm, U. S.: "Mechanical behavior of foamed material under dynamic compression", Journal of Cellular Plastics 10 (3), 127-134, 1974. doi: 10.1177/0021955X7401000306

[42] Nakai, K., Yokoyama, T.: "Strain rate dependence of compressive stress-strain loops of several polymers", Journal of Solid Mechanics and Materials Engineering 2 (4), 557-566, 2008. doi: 10.1299/jmmp.2.557

[43] Omar, M. F., Akil, H. M., Ahmad, Z. A.: "Measurement and prediction of compressive properties of polymers at high strain rate loading", Materials \& Design 32 (8-9), 4207-4215, 2011a. doi:10.1016/j.matdes.2011.04.037

[44] Omar, M. F, Akil, H. M., Ahmad, Z. A.: "Static and dynamic compressive properties of mica/polypropylene composites", Materials Science and Engineering: A 528 (3), 1567-1576, 2011 b. doi: 10.1016/j.msea.2010.10.071

[45] Ouellet, S., Cronin, D., Worswick, M.: "Compressive response of polymeric foams under quasi-static, medium and high strain rate conditions", Polymer Testing 25 (6), 731-743, 2006. doi: 10.1016/j.polymertesting.2006.05.005 
[46] Pal, S., Maiti, S., Subhash, G.: "Effect of microscopic deformation mechanisms on the dynamic response of soft cellular materials", Mechanics of Materials 42 (2), 118-133, 2010. doi: 10.1016/j.mechmat.2009.11.014

[47] Perrot, C., Panneton, R., Olny, X.: "Periodic unit cell reconstruction of porous media: application to open-cell aluminum foams", Journal of Applied Physics 101 (11), 113538 - 113538-11, 2007. doi: 10.1063/1.2745095

[48] Petrů, M., Novák, O.: "Measurement and Numerical Modeling of Mechanical Properties of Polyurethane Foams", In: Faris Yilmaz. Aspects of Polyurethanes, (IntechOpen, 2017). doi: 10.5772/intechopen.69700

[49] Politis, A.: "Innovations in the graphic arts, media and packaging fields", Proceedings - The Ninth International Symposium GRID 2018, (GRID 2018: Novi Sad, Serbia, 2018). doi: 10.24867/GRID2018-p2

[50] Prisacariu, C.: "Polyurethane elastomers: from morphology to mechanical aspects", (Springer, Vienna, 2011). doi: 10.1007/978-3-7091-0514-6

[51] QFP: "Polyurethane Glosarry", URL: http://www.qualityfoam.com/polyurethane-glossary.asp (last request: 2019-09-27).

[52] Qi, H. J., Boyce, M. C.: "Stress-strain behavior of thermoplastic polyurethanes", Mechanics of Materials 37 (8), 817-839, 2005. doi: 10.1016/j.mechmat.2004.08.001

[53] Rafiee, Z.: "Synthesis and characterization of polyurethane/microcrystalline cellulose bionanocomposites", Progress in Organic Coatings 86, 190-193, 2015. doi: 10.1016/j.porgcoat.2015.05.013

[54] Randall, D., Lee, S.: "The Polyurethanes Book", (Wiley Ltd., New York, 2003).

[55] Río, G. D., Rodríguez, J.: "Compression yielding of polypropylenes above glass transition temperature", European Polymer Journal 46 (6), 1244-1250, 2010. doi: 10.1016/j.eurpolymj.2010.02.016

[56] Saint-Michel, F., Chazeau, L., Cavaillé, J.-Y., Chabert, E.: "Mechanical properties of high-density polyurethane foams: I. Effect of the density", Composites Science and Technology 66 (15), 27002708, 2006. doi:10.1016/j.compscitech.2006.03.009

[57] Sarva, S., Deschanel, S., Boyce, M., Chen, W.: "Stress-strain behavior of a polyurea and a polyurethane from low to high strain rates", Polymer 48 (8), 2208-2213, 2007. doi: 10.1016/j.polymer.2007.02.058

[58] Song, B., Chen, W. W., Dou, S., Winfree, N. A., Kang, J. H.: "Strain-rate effects on elastic and early cell-collapse responses of a polystyrene foam", International Journal of Impact Engineering 31 (5), 509-521, 2005. doi: 10.1016/j.ijimpeng.2004.02.003

[59] Sun, Y., Li, Q. M.: "Effect of entrapped gas on the dynamic compressive behavior of cellular solids", International Journal of Solids and Structures 63, 50-67, 2015. doi: 10.1016/j.ijsolstr.2015.02.034

[60] Szycher M.: "Szycher's Handbook of Polyurethanes. 2nd edition", (CRC Press, New York, 2006).

[61] Tedesco, J., Ross, C., Kuennen, S.: "Strain rate effects on the compressive strength of shockmitigating foams", Journal of Sound Vibration 165 (2), 376-384, 1993. doi: 10.1006/jsvi.1993.1265

[62] Tobushi, H., Hayashi, S., Endo, M., Shimada, D.: "Creep and Stress Relaxation of Polyurethane-Shape Memory Polymer Foam", Transactions of the Japan Society of Mechanical Engineers Series A 68 (676), 1788-1793, 2002. doi: 10.1299/kikaia.68.1788

[63] Wang, H., Zhou, H., Huang, Z., Zhang, Y., Qiao, H., Yu, Z.: "Experimental investigation and modeling of the mechanical behavior of PC/ABS during monotonic and cyclic loading", Polymer Testing 50, 216-223, 2016. doi: 10.1016/j.polymertesting. 2015.12.010

[64] Warren, W. E., Kraynik, A. M.: "The linear elastic properties of open-cell foams", Journal of Applied Mechanics 55 (2), 341-346, 1988. doi: 10.1115/1.3173680

[65] Wirpsza, Z., Kemp, T. J.: "Polyurethanes: chemistry, technology, and applications", (E. Horwood, New York, 1993).

[66] Yi, J., Boyce, M. C., Lee, G. F., Balizer, E.: "Large deformation rate-dependent stress-strain behavior of polyurea and polyurethanes", Polymer 47 (1), 319-329, 2006. doi: 10.1016/j.polymer.2005.10.107

[67] Yonezu, A., Hirayama, K., Kishida, H., Chen, X.: "Characterization of the compressive deformation behavior with strain rate effect of low-density polymeric foams", Polymer Testing 50, 1-8, 2016. doi: 10.1016/j.polymertesting.2015.11.021

[68] Zhao, H.: "Testing of polymeric foams at high and medium strain rates", Polymer Testing 16 (5), $507-$ 516, 1997. doi: 10.1016/S0142-9418(97)00012-3 
[69] Zia, K. M., Bhatti, H. N., Bhatti, I. A.: "Methods for polyurethane and polyurethane composites, recycling and recovery: A review", Reactive and Functional Polymers 67 (8), 675-692, 2007. doi: 10.1016/j.reactfunctpolym.2007.05.004

[70] Zia, K. M., Anjum, S., Zuber, M., Mujahid, M., Jamil, T.: "Synthesis and molecular characterization of chitosan based polyurethane elastomers using aromatic diisocyanate", International Journal of Biological Macromolecules 66, 26-32, 2014.

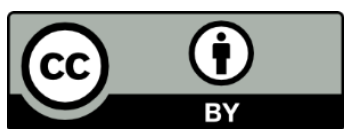

(C) 2020 Authors. Published by the University of Novi Sad, Faculty of Technical Sciences, Department of Graphic Engineering and Design. This article is an open access article distributed under the terms and conditions of the Creative Commons Attribution license 3.0 Serbia (http://creativecommons.org/licenses/by/3.0/rs/). 
EDUCATION 



\title{
3D PRINTING IN THE EDUCATION OF GRAPHIC ENGINEERING AND DESIGN STUDENTS
}

\author{
Bojan Banjanin (D), Magdolna Pál (D), Vladimir Dimovski (D), Savka Adamović (D), Ana Lilić (D) \\ University of Novi Sad, Faculty of Technical Sciences, \\ Department of Graphic Engineering and Design, Novi Sad, Serbia
}

\begin{abstract}
Today, 3D printing is taking its constantly growing part in a lot of different manufacturing industries, educational institutions and a lot of entrepreneurship and home businesses. Besides prototyping and proof of concept, utilization of $3 D$ printing is undoubtedly spreading its roots in manufacturing of production and spare parts but also in aiding research and teaching processes. 3D printing has reinforced the self-employed segment of market called makers but also has influenced forming a significant number of educational online video channels. A lot of crowdfunded web sites promote affordable desktop 3D printers and 3D modellers and designers who design models exclusively for $3 D$ printing, taking its specificity into account. Also, a community of designers, through 3D printing hubs where their work can be purchased, are thriving. There is also a massive trend in developing new materials for 3D printing such as electrically conductive composites, fire-resistant materials and materials with high strength or resilience. In the graphic industry, there is some progress regarding the utilization of $3 D$ printing in the form of tactile maps and picture books, manufacturing customizable packaging, embossing tools, making parts for colour measuring equipment and printing of textiles. However, there is undoubtedly undiscovered usage intended for improvements in this branch of industry. The first part of this research aims to present existing researches and projects regarding the usage of $3 D$ printing in creative and interdisciplinary industries such as graphic industry. The second part of this paper focuses on different initiatives in aiding educational process worldwide, and some of the methodology of implementing 3D printing in education. In the final part of this research, the potential of 3D printing for educational purposes of graphic engineering and design students is discussed. Methodology for getting theoretical and practical knowledge is proposed through a designed catalogue of 3D printing parameters. The purpose of this catalogue is to introduce undergraduate students with one of the most used and affordable 3D printing technique known as Fused Deposition Modelling (FDM) and to provide them with basic knowledge of 3D printing parameters which further on can be expanded and supplemented.
\end{abstract}

Key words: 3D printing, education, graphic industry, printing parameters, FDM

\section{INTRODUCTION}

Additive manufacturing, commonly known as 3D printing, is taking its constantly growing part in a lot of different manufacturing industries, educational institutions and a lot of entrepreneurship and home businesses. Utilization of 3D printing can be seen in different industries, such as engineering, product design, technology, medicine, architecture and entertainment. In all these industries, in order to implement 3D printing in the production process, some form of education and training about basics of 3D printing should be provided to employees or much earlier to students in educational institutions. Therefore, educators need appropriate training, practice, and lastly good teaching plan.

One of the most commonly used and certainly most available and affordable 3D printing technique is Fused Deposition Modelling (FDM). This technique uses printing material in the form of filament (plastic or composite) which is heated through the extruder and melted and deposited through a printing nozzle in successive layers onto the printing platform (also known as build plate). Each layer is cooled down and solidified, which enables the next layer to be deposited. This repetitive process, in the end, forms the desired object. In order to begin printing, first, a 3D model must be acquired. Usually, it is an STL (an acronym for stereolithography), but there can also be used formats such as $3 \mathrm{MF}$ file (.3mf), Wavefront OBJ File (.obj), X3D file (.X3d) etc. Files of 3D models are then prepared in "slicer" software to generate code understandable by 3D printers, called G-code, which contains information about the movement of the print head and all the essential printing parameters needed for the print job.

These different parameters are essential for successful printing, and their combination varies depending on the requirements of the job. Parameters such as printing temperature, layer height, percentage of infill, printing speed etc. are to be taken into consideration when starting a print job. So, it is essential to 
get familiar with them. Every slicer program comes with different capabilities of setting up a print job, and many parameters which can be modified, but some basic knowledge is necessary to begin with printing.

There is an increasing number of educational materials, tutorials, tips and tricks, reviews and projects that are available online. For beginners and, in the case of this research paper, undergraduate students, catalogue of models with the variation of basic printing parameters are printed using FDM 3D printing technique, as an introduction to the understanding of 3D printing process. These printing parameters are essential for designing and modifying different 3D models and prepare them for printing.

\subsection{D printing in creative and interdisciplinary industries}

Production of tactile maps and Braille alphabet has been a popular topic among researchers. In 2009 Voženílek et al. evaluated and developed different aspects of interpretation and perception of geospace by modern tactile maps based on 3D printing. They produced 3D printed tactile maps which can serve for the development of geospace perception and orientation of the blind - both children and adults. The maps will assist in removing the fear of space and recognising unknown places. The new method of 3D printing of tactile maps can be an efficient tool for schools for blind children and many organisations which need to integrate the blind into various activities (employers, shopping centres, transport companies, subjects of emergency management etc.).

Jo et al. (2014) fabricated printed tactile patterns in a size controllable manner with a fused deposition modelling 3D printer. They tested and improved smoothness and interfacial adhesion strength of 3D printed letters and patterns on cellulose paper by using the thermal reflow process as a post-processing step. Thermal reflow was performed to thermally anneal printed patterns on the paper above the PLA

filament temperature $\left(1 \mathrm{~min}\right.$ at $160{ }^{\circ} \mathrm{C}$ on a hot plate in the air). Compared to traditionally punched patterns on paper, the printed dots maintained their original shape without any damage caused to the pattern surfaces before or after the tribology test.

Gual et al. (2014) tested whether the process of memorising a tactile map key or legend can be improved by including three-dimensional (3D) symbols produced utilising 3D printing. They developed the method of using the combination of flat relief symbols (2D elements) with 3D tactile symbols. 3D tactile symbols appear to yield a $48.72 \%$ reduction in the number of errors while identified by the group of 20 participants. This occurs because 3D symbols can be distinguished and memorised better from the 2D features by touch (haptic memory). In 2015 study (Gual et al, 2015), researchers used two maps of the city of Barcelona, one produced on monochrome microencapsulated (swell paper), and the second, that same map, produced using 3D printing. They concluded that the use of tactile 3D symbols improves the mean of time of certain tasks such as the localisation of specific symbols on a map.

In the research paper of Stangl, Kim and Yeh (2014), a 3D printed picture book was designed to aid the educational methodology of children with visual impairments. They focused on 3D printed book because it makes content readily, supports a community that needs specialised, child-specific learning aids, and to use emerging technology as an incentive for parents to become engaged in learning how to design tactile picture books for their children and support emergent literacy skills.

Divine, Thompson and Colson (2016) released a patent on 3D printed packaging, where they describe packaging production line which consists of modules (Scanner module, Modeling module, Print module etc.) and different areas (Scanning area, Printing area, Output area) where products can be scanned, and customised packaging can be printed.

In the fashion industry, 3D printing has an essential role with distinguished fashion designers (Tatiana, 2012; Boorman, 2014; Condon, 2013; Marmey, 2014). Vanderploeg, Lee and Mamp (2016) investigates the potential of five 3D printing techniques, including stereolithography, selective laser sintering, fused deposition modelling, Polyjet, and binder jetting in an application in the fashion industry. They discuss the advantages and disadvantages of each $3 \mathrm{D}$ printing technique and specific printers. They provide a conclusion that design done using 3D CAD software, printers, and materials is a complex process that may require a collaboration of interdisciplinary knowledge and skills.

There are researches done in the field of colour quality evaluation of colour 3D printing. Walters et al. (2009) investigated the capabilities of the powder-binder colour 3D printing system and application of this technology in art and design practice. 3D printed colour test blocks are produced for evaluation of reproduction of primary colours, accuracy and consistency of colour output. GretagMacbeth EyeOne spectrophotometer is used for this research. Results have shown that the reproduction of colours is dependable on the position and orientation of the surface, finishing method and type of printer used. 
They concluded that by developing a practical understanding of materials and process parameters, artists and designers could obtain pleasing creative outcomes.

Yuan et al. (2018) in their paper, discussed standardization efforts of colour quality evaluation of 3D printing techniques. They concluded that it is possible to develop a completed colour quality evaluation standard for colour 3D printing based on approaches in colour 2D printing when colour measurement method and devices are standardized together. Usage of the GretagMacbeth (X-rite) XTH sphere spectrophotometer, the X Rite's TAC7 scanner and MA98 series portable multi-angle spectrophotometer can be used as a 3D object appearance visualization solution.

Two research papers from 2015 (Grasse et al, 2015; Grasse, 2015) describe the creation of portable, FDM 3D printed spectrophotometer and teaching UV - Vis spectroscopy with this device. This allowed to produce an expensive piece of equipment inexpensively and with an open design so that the students can see each relevant part and experiment with the parameters. Another paper from 2016 (Porter et al, 2016) describes user-friendly 3D printed colourimeter models for students to explore instrument design and performance. Authors showed that flexible designs that can be printed quickly and cheaply using consumer-level 3D printers have great potential for students and educators.

Pei, Shen and Watling (2015) investigated adhesion of polymers (acrylonitrile butadiene styrene (ABS), polylactic acid (PLA) and nylon) directly printed onto textiles using entry-level FDM 3D printing technique. They printed decorative and functional parts onto textiles to determine limitations and potential applications of 3D printed textiles.

In the work of Korger et al. (2016), the influence of textile surface properties on the adhesion strength of printed flexible polymers was examined considering mechanical, physical and chemical adhesion mechanisms. They concluded that adhesion strength is influenced by the form-locking connections of the molten polymer with the textile substrate and by the wettability of the textile surface.

Rivera et al. (2017) demonstrated how the malleability, flexibility and aesthetic qualities of textiles can enhance rigid printed objects, and how textiles can be augmented with functional properties enabled by 3D printing. They propose different designs for embedding 3D printed polymers into the textile fabric.

In the work of Spahiu et al. (2017) adhesion of 3D printed polymers onto textile material was investigated. They concluded that parameters such as nozzle temperature and bed temperature have a significant impact on the adhesion force.

One of the 3D printing research fields that are tightly connected to the graphic industry is investigations of presenting 2D images using 3D printers by producing 3D printed lithography pictures. Lithophanes have been used since the 19th century to produce beautiful, but expensive, handcrafted decorations, revealing pictures when lit from behind (Carney, 2012). In the works of Nielsen et al. (2017), Jang and Hong (2017), Weiler et al. (2019), Wang et al. (2020) investigations on converting a 2D image to 3D printed lithophanes and parameters influencing the quality of 3D printed images were described.

\subsection{D printing in education}

In their review paper, Ford and Minshall, 2017 gathered information from other related articles where they found that 3D printing can facilitate learning, develop skills, and increase student engagement. 3D printing can inspire creativity, improve attitudes towards STEM (an acronym for Science, Technology, Engineering, and Mathematics) subjects and careers, while also increasing teachers' interest and engagement. They discuss six main ways how 3D printing is being used in education: "(1) to teach students about 3DP; (2) to teach educators about 3DP; (3) as a support technology during teaching; (4) to produce artefacts that aid learning; (5) to create assistive technologies; and (6) to support outreach activities."

In Table 1, a summary of how 3DP is used in the educational system is presented, according to exhaustive literature review of Ford and Minshall (2017). 
Table 1: Summary of how 3DP is used in educational system is presented (Ford and Minshall, 2017)

\begin{tabular}{|c|c|c|c|c|c|}
\hline & \multicolumn{4}{|c|}{ Where is 3DP being used in the education system? } \\
\hline & & $\underline{\text { Schools }}$ & $\underline{\text { Universities }}$ & $\underline{\text { Libraries }}$ & $\begin{array}{l}\text { Special Education } \\
\text { settings }\end{array}$ \\
\hline \multirow{6}{*}{$\begin{array}{l}\text { How is } \\
\text { 3DP being } \\
\text { used in the } \\
\text { education } \\
\text { system? }\end{array}$} & $\begin{array}{l}\frac{\text { Teaching }}{\text { student about }} \\
\underline{\text { 3DP }}\end{array}$ & $\begin{array}{l}\text { 3DP and 3D } \\
\text { modelling are } \\
\text { introduced to } \\
\text { students during } \\
\text { design and } \\
\text { prototyping } \\
\text { projects in class }\end{array}$ & $\begin{array}{l}\text { The fundamentals } \\
\text { of 3DP and 3D } \\
\text { modelling are } \\
\text { introduced to } \\
\text { engineering and } \\
\text { design students, } \\
\text { who apply their } \\
\text { skills during } \\
\text { in-class projects }\end{array}$ & $\begin{array}{l}\text { Improving } \\
\text { access to 3DP } \\
\text { equipment and } \\
\text { services } \\
\text { enables } \\
\text { self-directed } \\
\text { learning by } \\
\text { students } \\
\text { outside class } \\
\end{array}$ & 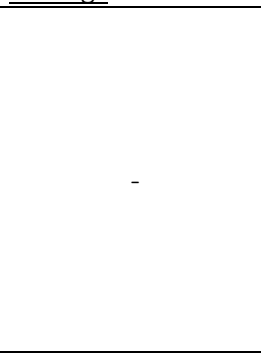 \\
\hline & $\begin{array}{l}\frac{\text { Teaching }}{\text { educators }} \\
\underline{\text { about 3DP }}\end{array}$ & $\begin{array}{l}\text { 3DP and 3D } \\
\text { modelling are } \\
\text { being introduced } \\
\text { to in-service } \\
\text { teachers }\end{array}$ & $\begin{array}{l}\text { 3DP and 3D } \\
\text { modelling are } \\
\text { being introduced } \\
\text { to preservice and } \\
\text { in-service } \\
\text { teachers }\end{array}$ & $\begin{array}{l}\text { Training } \\
\text { Librarians } \\
\text { enables them } \\
\text { to operate and } \\
\text { maintain 3DP } \\
\text { equipment, and } \\
\text { troubleshoot } \\
\text { 3D modelling } \\
\text { problems }\end{array}$ & - \\
\hline & $\frac{\frac{\text { Using 3DP }}{\text { during }}}{\text { teaching }}$ & $\begin{array}{l}\text { Using 3DP during } \\
\text { class projects to } \\
\text { improve student } \\
\text { engagement and } \\
\text { understanding of } \\
\text { STEM subjects }\end{array}$ & $\begin{array}{l}\text { Using 3DP during } \\
\text { class projects to } \\
\text { improve student } \\
\text { engagement and } \\
\text { understanding of } \\
\text { STEM subjects }\end{array}$ & - & $\begin{array}{l}\text { Using 3DP to create } \\
\text { custom adaptive } \\
\text { devices and } \\
\text { educational aids }\end{array}$ \\
\hline & $\begin{array}{l}\text { Using 3DP to } \\
\text { produce } \\
\text { artefacts that } \\
\text { aid learning }\end{array}$ & - & $\begin{array}{l}\text { 3DP models } \\
\text { enable hands-on } \\
\text { learning in } \\
\text { lectures and lab } \\
\text { sessions, } \\
\text { particularly in } \\
\text { anatomy and } \\
\text { chemistry } \\
\text { teaching }\end{array}$ & - & - \\
\hline & $\begin{array}{l}\text { Using 3DP to } \\
\text { create } \\
\text { assistive } \\
\underline{\text { technologies }}\end{array}$ & - & - & - & $\begin{array}{l}\text { Expands the range } \\
\text { of student learning } \\
\text { opportunities, } \\
\text { particularly among } \\
\text { those with visual } \\
\text { impairments }\end{array}$ \\
\hline & $\begin{array}{l}\text { Using 3DP to } \\
\frac{\text { support }}{\text { outreach }} \\
\underline{\text { activities }}\end{array}$ & $\begin{array}{l}\text { Using 3DP during } \\
\text { university outreach } \\
\text { programs improves } \\
\text { student } \\
\text { engagement with } \\
\text { STEM subjects }\end{array}$ & - & - & - \\
\hline
\end{tabular}

Ford and Minshall (2017) concluded that there is a need for additional teaching support materials for simplifying the process of integration of 3D printing into teaching, both for understanding and practice of 3D printing process and as an aiding tool in student engagement and subject knowledge acquisition.

Kostakis et al. (2014) researched to what extent the technological capabilities of open-source 3D printing could serve as a means of learning and communication. Thirty-three students from two high schools in Greece collaboratively worked on design and production of creative artefacts using an open-source 3D printer and 3D design platform. They sent those products to blind children initiating a novel way of communication and collaboration amongst blind and non-blind students. They had positive feedback and agreed that 3D printing and design could "electrify" various literacies and creative capacities of children. Their students, who were, to some extent, indifferent about their project class, when given proper 
stimulation and tools can choose what to learn themselves through exploration. They had an opportunity to truly engage in the whole process by materializing a product from an idea, and they acquired knowledge instead of dry information out of textbooks.

In the work of Menano et al. (2019) authors investigated the integration of 3D printing in art education. After reviewing papers written about the researched topic, authors stated that using 3D printing promotes student creativity and motivation, and helps them in understanding the relationship between 2D and 3D space. It aids students in the implementation of a design process. However, there is a lack of support and training for teachers as well as limited access to equipment. They concluded that it is essential for the educational system to adapt, transform and modernize to prepare future generations better and that educators must collaborate using art and technology to develop common interests and projects. 3D printing can also be beneficial to teachers and educators and not solely to students. In the research paper written by Novak and Wisdom (2020), the authors investigated the influence of using 3D printing in science for elementary teachers. The goal of this study was to positively impact teachers' attitudes toward teaching science while enhancing their understanding of how engineers approach the design process. They recorded that design thinking, teaching efficiency and science interest improved, and anxiety about teaching science dropped.

Verner and Merksamer (2015) investigates changes in the Techion technology/mechanics teacher education courses and impact these changes brought in enhancing students' knowledge and skills in teaching digital design and manufacturing. They equipped their department laboratory of technology with CAD software tools and a 3D printer, and they upgraded the course to meet the conceive-designimplement-operate (CDIO) approach. They concluded that learning activities with CAD software and 3D printer significantly enhance students' practice of visual-spatial skills.

There is a particular interest in incorporating 3D printing in the field of graphic design. Sampaio et al. (2013) investigate the implementation of 3D printing technology in a graphic design course. They identified that there is an increasing interest of students for the issues of dealing with representation and the conversion of the three-dimensional structures in tangible interfaces, such as the design of packaging, signage, game design, animation, children books and toys, among many others that are related to graphic design. Each of the five graduating students has a task to research one possibility of use for FDM 3D printing technique. Guidelines for the projects such as an emphasis on practical learning and its systematization, encouraging creative experimentation, innovation and entrepreneurship and multi and interdisciplinary approach were established. For sub-themes, they researched the creation of anthropometric dummies, systems of characters and scenarios for stop motion animation, perception of tactile textures for the blind, new concepts for packaging and redesign of the 3D printer. They also participated in the contest with the design solution of product which aid children from 3 to 5 years with partial or total amputation of the upper limb in conducting everyday tasks. They found an increasing trend in students' learning process of three-dimensional representation in the virtual world but also as 3D printed objects. Also, the learning of the printing parameters that influence properties of 3D printed products such as wall thickness, or minimum resolutions of the models or corrects preparation of STL files were improved.

\section{METHODS}

According to the research of Ford and Minshall (2017), the starting point in teaching 3D printing to university students is teaching the fundamentals of 3D printing and 3D modelling. At the Department of Graphic Engineering and Design students are introduced to fundamentals of 3D modelling in the second year of undergraduate academic studies when they learn to work in 3D CAD software, by getting familiar with virtual 3D space and basics of designing graphic products. Further on, they continue to foster their 3D modelling skills in the third year in the two subjects: Fundamentals of spatial design and Industrial design. In the third year of undergraduate academic studies, they begin to learn about the fundamentals of 3D printing within the Industrial design course. A detailed explanation of 3D printing techniques and their specificity is covered at master academic studies in the 3D printing course.

In the work of Erickson (2017) 3D modelling poster called "Essentials of 3D Printing" was designed. Author of this poster covers some of the essential 3D printing parameters by designing 3D models which can be downloaded, printed and then fixed on the cardboard poster. Inspired by this initiative to educate students about fundamentals of 3D printing in a haptic manner, we decided to broaden this set of parameters by introducing new ones which are the most common but also some of the advanced ones which are related to the type of slicing software. These broaden set of 3D printed artefacts can be applied 
to the poster, similar to one that Erickson proposed or be kept in storage boxes or registrar to be viewed by students alongside teaching sessions during their classes. In Table 2, printing parameters for artefacts used in this study are presented. These parameters are essential in any slicer software, but names from Table 2 are from Ultimaker Cura slicer software (version 4.6.2) used in this research.

Table 2: Chosen 3D printing parameters used in this study

\begin{tabular}{|c|c|}
\hline Parameter/mods/artifacts & Parameter value \\
\hline Non-printed filament & $1.75 \mathrm{~mm}$ thickness \\
\hline Extruded filament & $0.4 \mathrm{~mm}$ nozzle diameter \\
\hline Line width (deposited on the printing bed) & $0.4 \mathrm{~mm}$ \\
\hline Build plate adhesion (Skirt - line count) & 3 \\
\hline Build plate adhesion (Brim - width) & $8 \mathrm{~mm}$ \\
\hline Build plate adhesion (Raft - extra margin) & $15 \mathrm{~mm}$ \\
\hline Wall line count (wall thickness) & $1 ; 3 ; 6(0.4 \mathrm{~mm} ; 1.2 \mathrm{~mm} ; 2.4 \mathrm{~mm})$ \\
\hline Top/bottom thickness & $\begin{array}{l}\text { without top layers; w/o bottom; w/o top\&bottom; } \\
2 \text { layers }\end{array}$ \\
\hline Top/bottom pattern & Lines; Concentric; Zig Zag \\
\hline Layer height & $0.1 \mathrm{~mm} ; 0.2 \mathrm{~mm} ; 0.3 \mathrm{~mm} ; 0.4 \mathrm{~mm}$ \\
\hline Infill density & $0 \% ; 20 \% ; 40 \% ; 60 \% ; 80 \% ; 100 \%$ \\
\hline Infill pattern & $\begin{array}{l}\text { Lines; Triangles; Grid; Tri-Hexagon; Octet; Cross; Cross } \\
\text { 3D, Gyroid, Concentric }\end{array}$ \\
\hline Overhang angles & $\begin{array}{l}15^{\circ} ; 20^{\circ} ; 25^{\circ} ; 30^{\circ} ; 35^{\circ} ; 40^{\circ} ; 45^{\circ} ; \\
50^{\circ} ; 55^{\circ} ; 60^{\circ} ; 65^{\circ} ; 70^{\circ} ; 75^{\circ} ; 80^{\circ} \\
\end{array}$ \\
\hline Support structures & with/without support structures \\
\hline Support pattern & Zig Zag; Triangles; Gyroid \\
\hline Printing temperature test & $\begin{array}{c}180{ }^{\circ} \mathrm{C} ; 185^{\circ} \mathrm{C} ; 190{ }^{\circ} \mathrm{C} ; 195^{\circ} \mathrm{C} ; \\
200{ }^{\circ} \mathrm{C} ; 205^{\circ} \mathrm{C} ; 210^{\circ} \mathrm{C} ; 215^{\circ} \mathrm{C} ; 220^{\circ} \mathrm{C}\end{array}$ \\
\hline Tree support structures (Experimental mode) & - \\
\hline Spiralize outer contour (Vase mode) & - \\
\hline Mold mode & - \\
\hline Failed prints (showcase) & - \\
\hline
\end{tabular}

\subsection{Materials and printer settings}

3D printing filament made from Polylactic Acid (PLA) was used in this research. The diameter of the filament used was $1.75 \mathrm{~mm}$. Artefacts were printed at room temperature of $23 \pm 2^{\circ} \mathrm{C}$ using Creality CR10S Pro FDM 3D printer. The temperature of the printing bed was set to $50{ }^{\circ} \mathrm{C}$, and the temperature of the printing nozzle was $200{ }^{\circ} \mathrm{C}$ (except for the temperature test). Printing speed was set to $50 \mathrm{~mm} / \mathrm{s}$ with enabled retraction (Retraction distance: $6 \mathrm{~mm}$; Retraction speed: $45 \mathrm{~mm} / \mathrm{s}$ ).

After setting the list of desired 3D printing parameters, 3D models are created using Autodesk Fusion 360 CAD software, which is simplified version of Autodesk Inventor, and which is broadly used in makers' circles due to its' simplicity and fast learning curve. Each model has created bearing in mind which 3D printing parameter it needs to emphasize. Some of the models are downloaded from Thingiverse web site to show particular slicing mode (e.g. Vase (JJ76, 2018), Mold (Erickson (2017)), stringing effect using different temperatures or overhang angles (Stainhausler, 2017).

\section{RESULTS AND DISCUSSION}

Figures 1-8 showcase 3D printed artefacts using different printing parameters, mods, or some specific attribute. These are only images with some of the parameters visible. However, more detailed experience using a combination of visual and haptic senses can convey texture, structure, size and all the other attributes necessary for the more in-depth understanding of fundamentals of 3D printing.

Figure 1 represents 3D printing material and different ways parts can be adhered to build plate. 
a)

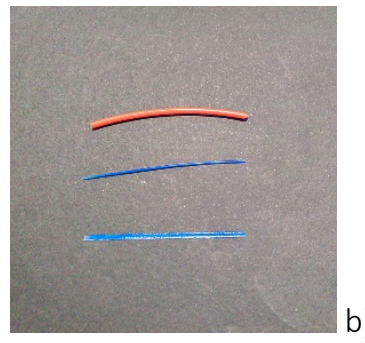

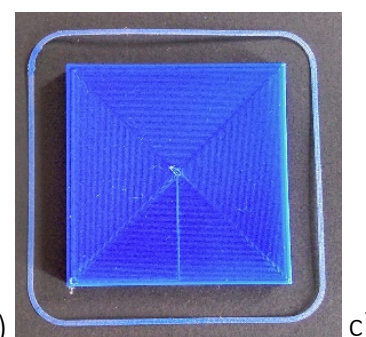

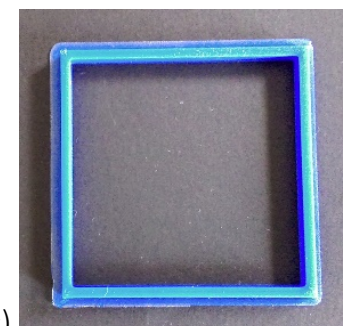

c)

d)

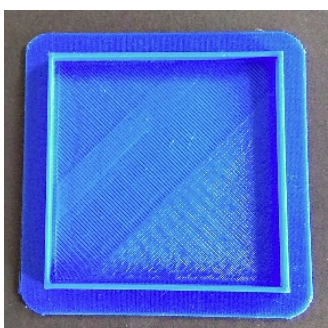

Figure 1: a) unextruded (1.75 mm), extruded $(0.4 \mathrm{~mm})$ and printing filament adhered on build plate (Line width); $b$ ) part with a skirt; c) with brim; and d) with raft

The skirt is usually used and recommended to be able to extrude some of the material on the build plate before printing a model and to ensure good adhesion of the first deposited layer. Brims are usually used when printing a large or long and thin part to increase the contact area with build plate and in that way to prevent printed parts from detaching due to deformation caused by cooling of deposited layers. Rafts are not recommended to be used often because of prolonging the printing time and using extra material but can be useful to compensate inconsistent build plate levelling. Different settings for the number of part contours (wall line count) are presented in Figure 2.
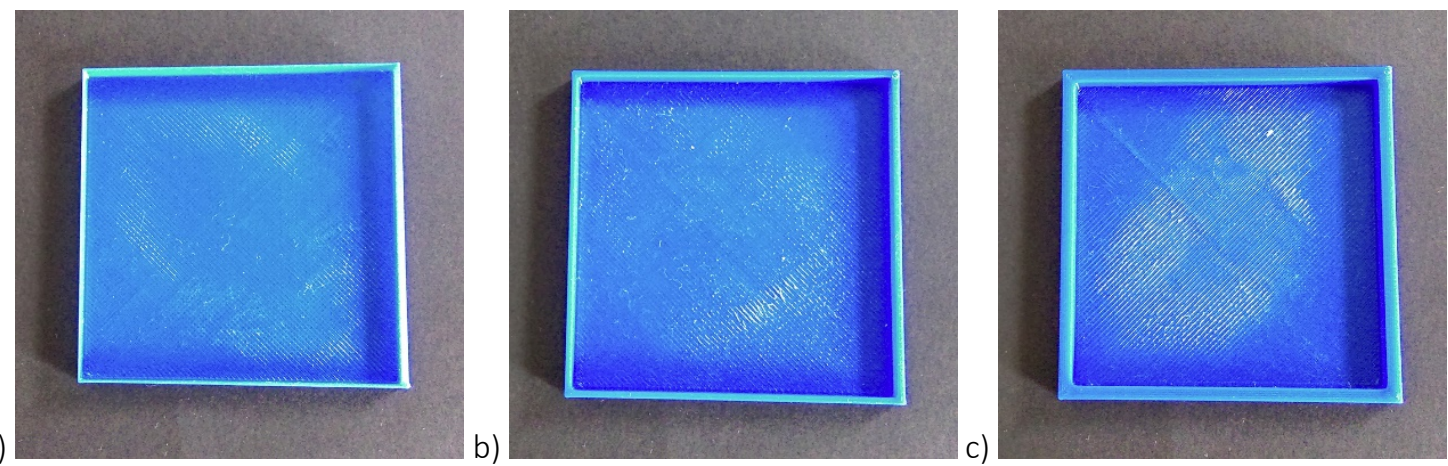

Figure 2: Wall line count. a) one, b) three and c) six walls. Printed with bottom layers and without top layers

Parts with higher wall count are sturdier then parts with less wall count, but printing time can be significantly prolonged. So it is a matter of optimization depending on the part structure and requirements for its proper use. These parts are printed without top layers and infill to emphasize the thickness of walls better.

On Figure 3, different patterns of top printed layers are presented. Each slicing software has its patterns for the top and bottom layers, and in this paper, only some of them available in Ultimaker Cura slicing software are presented. On some parts where these parameters can influence the aesthetic look of the finished product, usage of these patterns can be useful.

a)

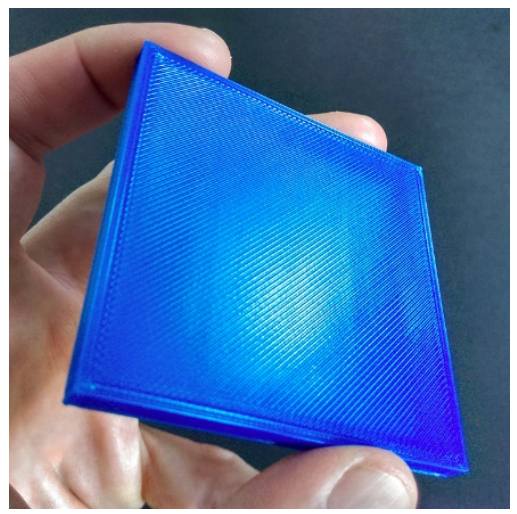

b)

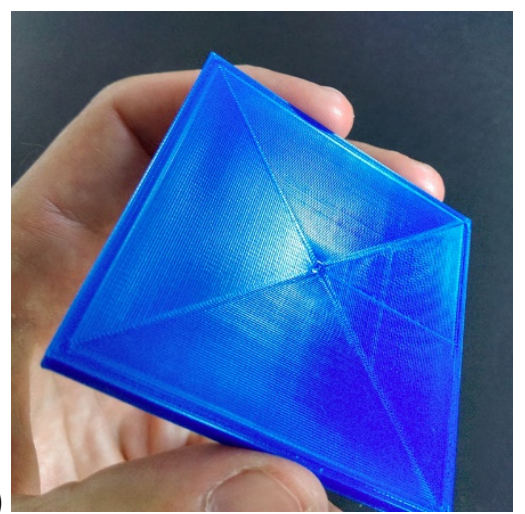

Figure 3: Top layers printed with different patterns. a) Lines and b) Concentric pattern 
Figure 4 presents a different setting for the layer height parameter. A suitable 3D model with smooth curves was created to emphasize changes made by modifying this parameter.
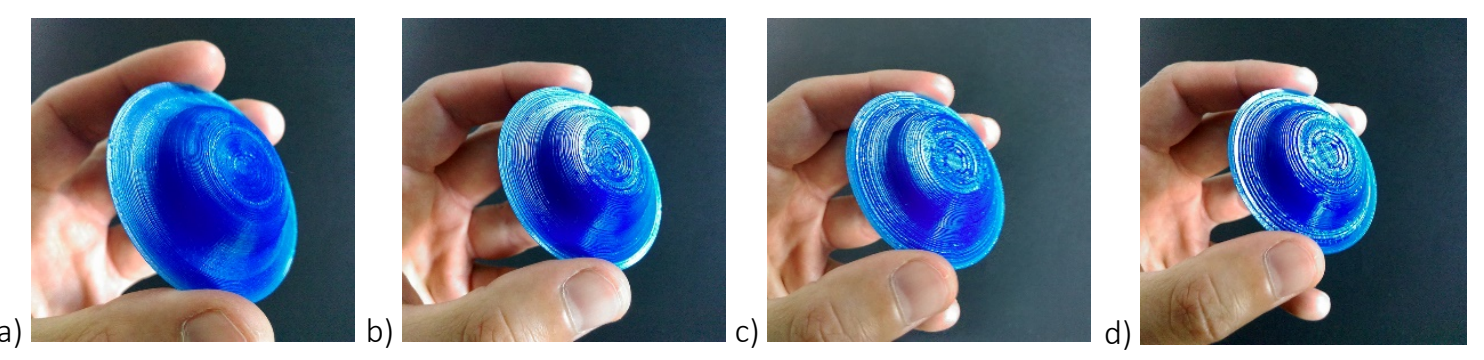

Figure 4: Models with varied layer height. a) $0.1 \mathrm{~mm}$, b) $0.2 \mathrm{~mm}$, c) $0.3 \mathrm{~mm}$, and d) $0.4 \mathrm{~mm}$

Layer height in great extent influence visual look and feel of side surfaces (surfaces along the z-axis) which can be seen from Figure 4. Increasing the layer height, the so-called "staircase effect" is more noticeable. One of the most used and changed parameters, after layer height, is the percentage of infill. In Figure 5, different percentages of infill are presented.

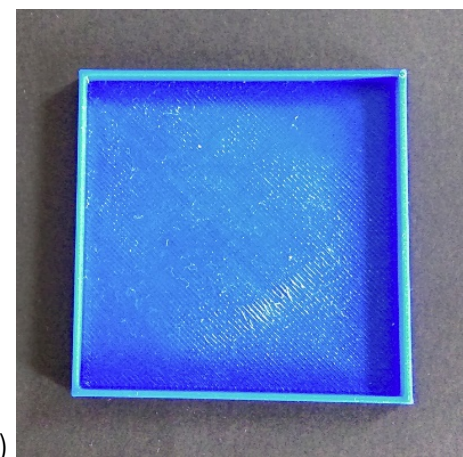

а)

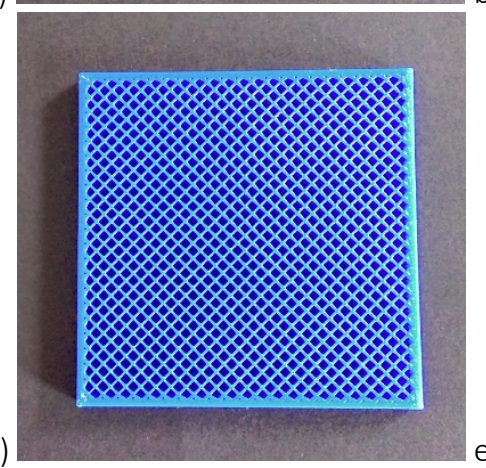

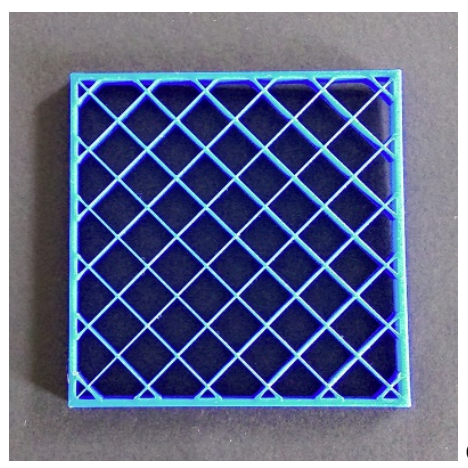

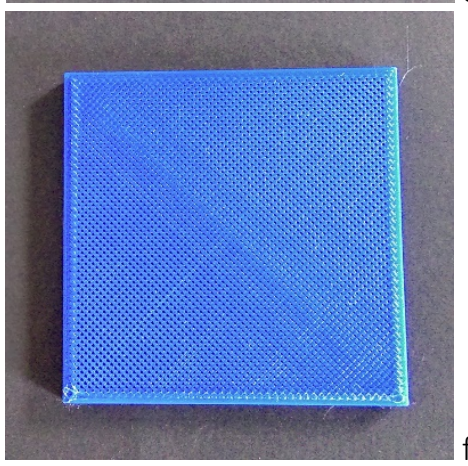

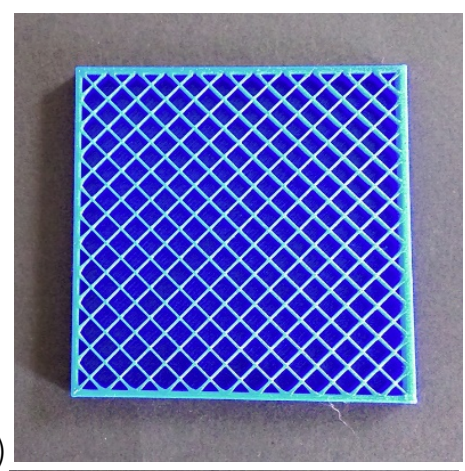

c)

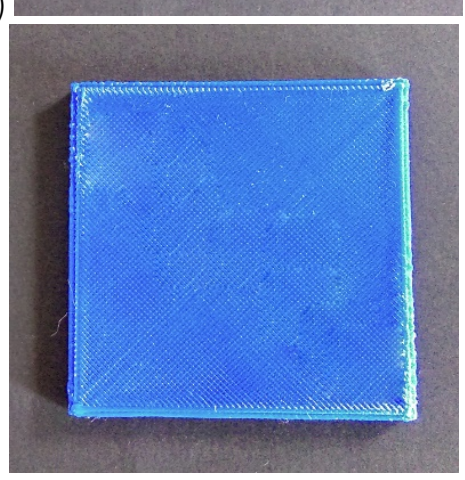

Figure 5: Models with varied percentage of infill. a) $0 \%$, b) $20 \%$, c) $40 \%$, d) $60 \%$, e) $80 \%$, and f) $100 \%$ infill

Denser the infill structure is, more printing time is required. Optimized usage of infill percentage can lead to the increased strength of the printed part, which does not mean that $100 \%$ infill is the most optimal choice. $80 \%$ infill can, in some cases, lead to similar mechanical properties of the part but with faster print time.

One of the fundamental parameters concerning infill is infill pattern (Figure 6). This parameter varies between different slicing software, and its careful consideration can improve the mechanical properties of the printed parts or lead to reduced print time. 
а)

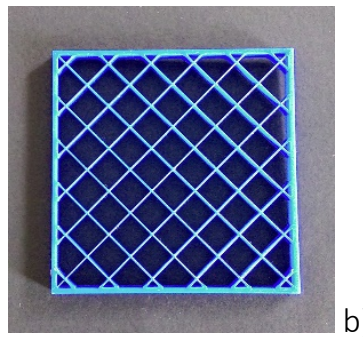

。

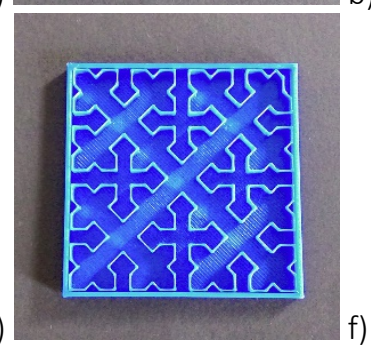

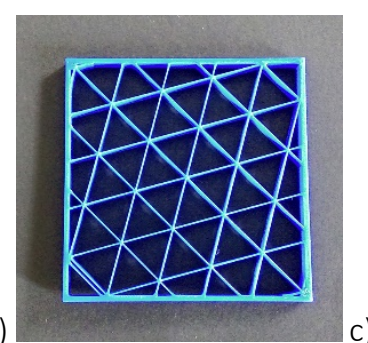

)

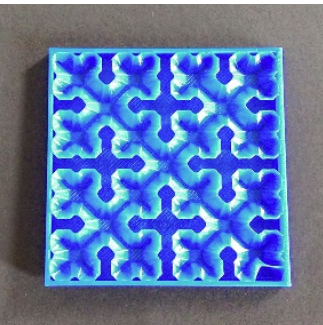

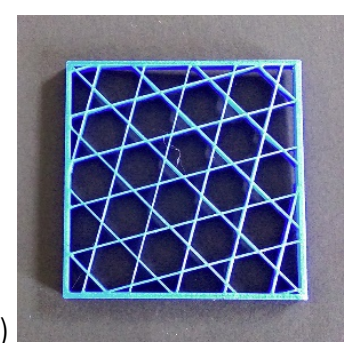

,

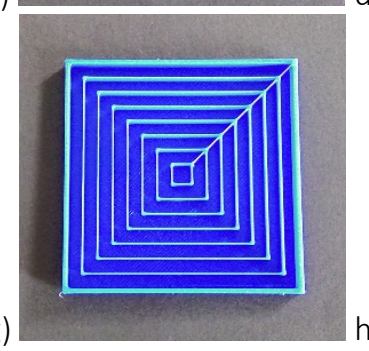

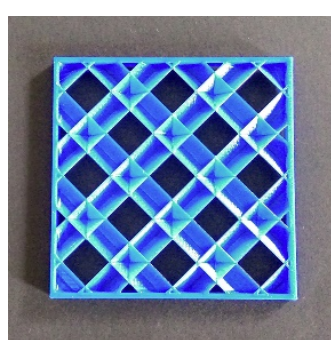

d)

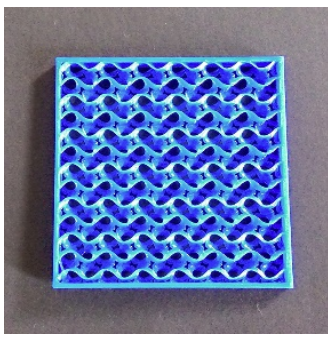

Figure 6: Models with varied infill pattern. a) grid, b) triangles, c) Octet, d) Tri-Hexagon, e) Cross, f) Cross 3D, g) Concentric, and h) Gyroid infill pattern

When printing parts with overhangs it is crucial to know capabilities of the printer, material properties, but also it is essential to generate support structures for the overhang angles which would collapse without them during the printing. These structures support these parts of models during the printing and can be removed after the printing process is finished. On Figure 7 a), b) and c) support structures with different patterns are presented. Figure 7d presents Ultimaker Cura experimental mode called Tree supports.

a)
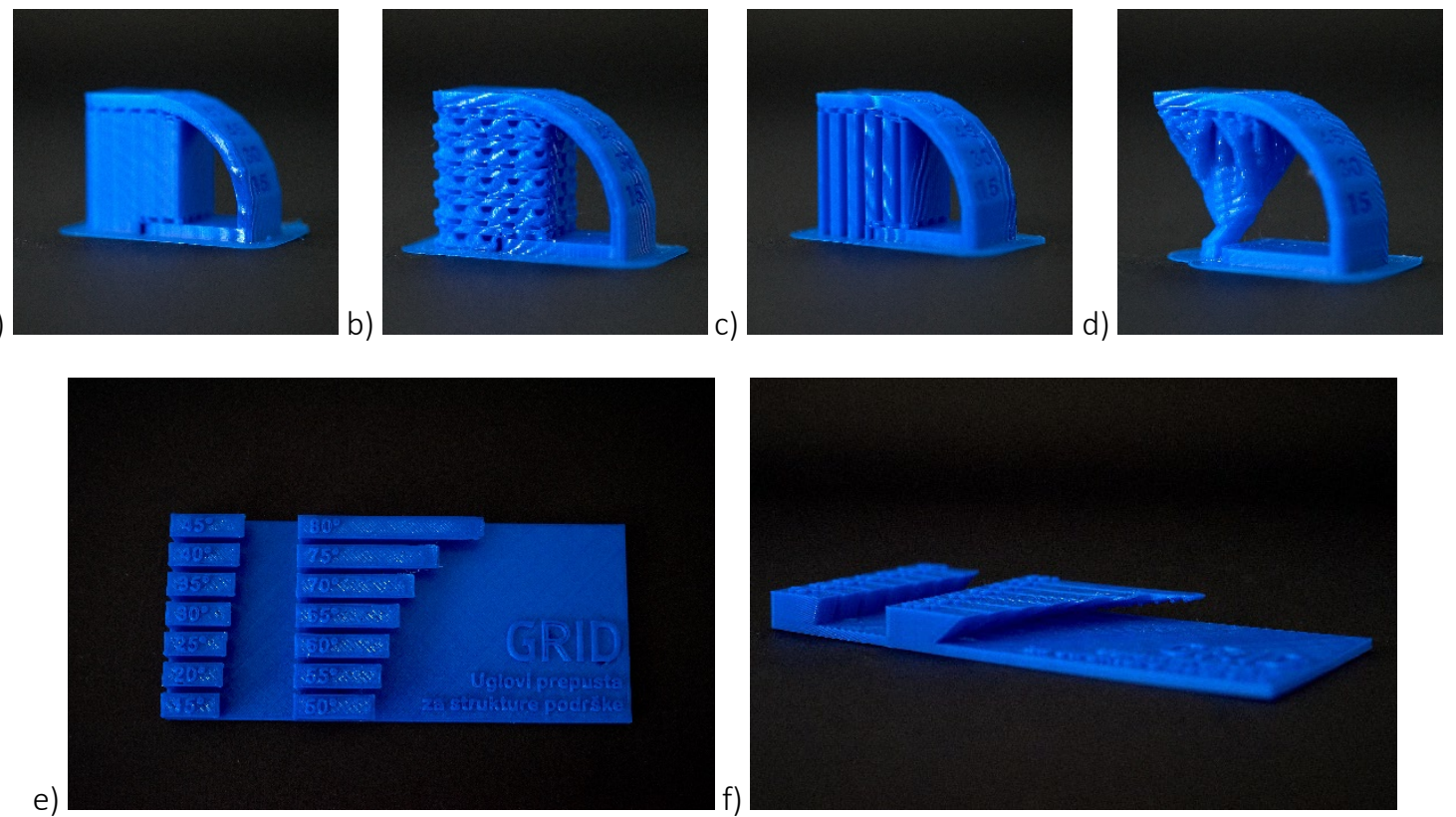

Figure 7: Models with different support pattern. a) Zig Zag, b) Gyroid, c) Triangles, and d) tree support structure.

e) if) represent model with different overhang values and no support structures

It is usually good practice to print test models to get familiar with the capabilities of the printer and material properties to see which overhang angles can be printed without supports and which requires them (Figure 7e). Then, it can be set in the slicing software when to generate support structures or in which way to model parts, so they do not require support structures. Figure 8 represents different artefacts used for education and learning different capabilities of the printer or the slicing software such as the influence of different printing temperatures (Figure 8a), vase mode (Figure 8b), mold mode (Figure 
$8 \mathrm{c})$, or to showcase some of the failed prints and open discussion about what caused that type of error (Figure 8d).

a)

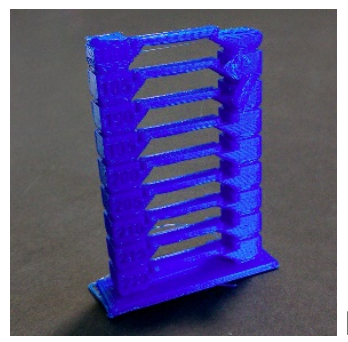

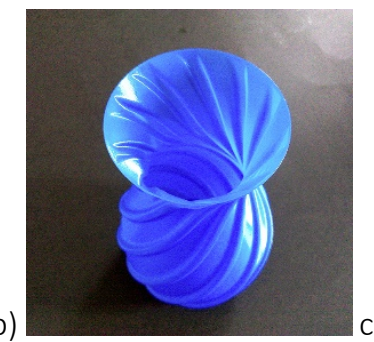

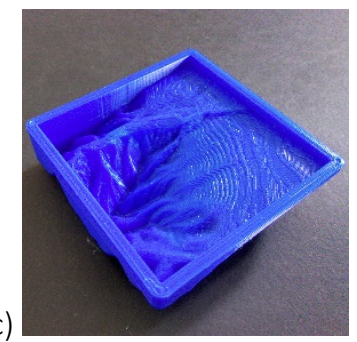

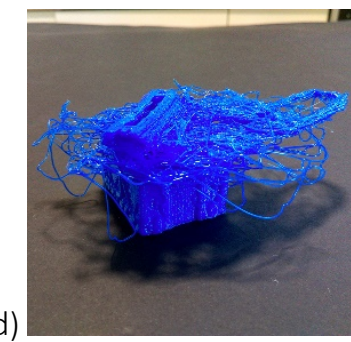

Figure 8: Different artifacts. a) "temperature tower" for testing influence of different nozzle temperatures on stringing and bridges, b) part printed with only one wall - Vase mode, c) 3D printed mold, d) example of failed print

Print temperature towers (Figure 8a) are usually used to test different printing temperatures with selected material to be able to see the optimum temperature for the printing of bridges (short unsupported beams) or to see which temperature leads to a minimum amount of stringing (oozing of extruded filament during travelling of the print nozzle). Spiralize outer contour (better known as Vase mode) is generally used for printing large volume parts which are hollow such as vases to minimize print time. These objects are printed with only one wall and are not so sturdy (Figure 8b). Mold mode is presented here to show some built-in capabilities of the slicing software (Figure $8 \mathrm{c}$ ). This mode allows injecting silicone or other casting material into the mold in order to get the final part. This can be useful for serialized production of the same part, but this option is still in developing, and there are different ways of creating molds for these kinds of jobs.

Printed artefacts are created in such manner that they can be fixed to some flat and hard surface (cardboard, plywood, plastic sheet) or can be gathered in the form of the registrar or placed in separated boxes for showcase purposes.

\section{CONCLUSIONS}

In this research paper, different ways of using 3D printing in interdisciplinary industries such as graphic engineering and design are discussed, and some practices of integrating 3D printing in education process are reviewed. There are a variety of research articles about 3D printed tactile elements such as Braille alphabet or different kind of maps for visually impaired persons, which introduce this prosperous technology with the aim of aiding and/or improving conventional methods of production. Some projects involve the production of an entire picture book using 3D printing to aid visually impaired children in the learning process.

Investigations are done in the field of joining different substrates, such as paper and textile with 3D printed polymers to test adhesive properties and rubbing or washing resistance of such elements. Experiments are done in the construction of relatively cheap colour measurement devices using 3D printing and using these devices in student education, which opens an opportunity for every student to participate in modelling, assembling and using these devices and having a better understanding how these devices work.

Interesting topics in the field of generating and printing 3D lithophane images from 2D images using a 3D printing technique are also investigated in the research community. Specific tools for automating this conversion process are available online for the broader public to experiment and make their lithophanes. In the education process, throughout the myriad of research papers, 3D printing is reported to have a positive impact on the learning and teaching process, involving both students and teachers more deeply in curriculum topic. More creativity, understanding and enthusiasm are triggered by involving 3D printing in the classes. It is reported that design thinking skills, teaching and learning efficiency is increased and anxiety on teaching certain subjects decreased.

Implementing of 3D printing in the curriculum for undergraduate students of Department of graphic engineering and design, after reviewing scientific literature, can definitively have a tremendous positive impact on students' and teachers' engagement improving both the learning and the teaching experience. The first step in this implementation process is getting familiar with the fundamentals of 3D printing process parameters and then finding a novel and creative ways of using this technology as an aiding tool 
in the graphic industry. The haptic experience involved with 3D printing, based on the reviewed literature, generally helps in better understanding of observed parts and in case of 3D printed artefacts done in this research paper it definitively can improve students' learning process.

Further research can be done by interviewing students about 3D printing fundamentals using physically 3D printed parts and comparing those results with a group of students who only used visual apparatus throughout the learning process. Also, the collection of printing parameters presented in this paper can be further on expanded in order to cover some of the advanced printing parameters and problems which can be solved by thoroughly understanding of these parameters.

\section{ACKNOWLEDGMENTS}

This research (paper) has been supported by the Ministry of Education, Science and Technological Development through the project no. 451-03-68/2020-14/200156: "Innovative scientific and artistic research from the FTS (activity) domain".

\section{REFERENCES}

[1] Boorman E.:"3D Printing Spotted at NY Fashion Week in Katie Gallagher's Spring/Summer 2015 Collection", URL http://www.materialise.com/blog/3d-printingspotted-ny-fashion-weekkatiegallaghers-springsummer-2015-collection/ (last request: 2020-08-15).

[2] Carney, M.: "Lithophanes... not a dead art form", Ceramics Art and Perception 87, 24-27, 2012.

[3] Condon C.: "How Fashion Designers Incorporate 3D Printing in their Work", URL: http://www.beyonddesignchicago.com/how-fashiondesigners-incorporate-3d-printing-in-theirwork/ (last request: 2020-08-15)

[4] De Sampaio, C. P., Spinosa, R. D. O., Tsukahara, D. Y., da Silva, J. C., Borghi, S. L. S., Rostirolla, F., Vicentin, J.: "3D printing in graphic design education: Educational experiences using Fused Deposition Modeling (FDM) in a Brazilian university", Proceedings of 6th International Conference Advanced Research Virtual Rapid Prototyping 2013, (VRAP 2013: Leiria, Portugal, 2013), pages 25-30.

[5] Divine, D. A., Thompson, D. S., Colson, S. C.: US 9,248,611, “3-D printed packaging", United States Patent, 2016.

[6] Erickson, R.: "3D modeling poster", URL: https://www.thingiverse.com/thing:2142384 (last request: 2020-08-21).

[7] Ford, S., Minshall, T.: "3D printing in teaching and education: A review of where and how it is used", Additive Manufacturing 25, 131-150, 2017. doi:10.1016/j.addma.2018.10.028.

[8] Grasse, E. K., Torcasio, M. H., Smith, A. W.: "Teaching UV-Vis spectroscopy with a 3D-printable smartphone spectrophotometer", Journal of Chemical Education 93 (1), 146-151, 2016. doi: 10.1021/acs.jchemed.5b00654.

[9] Grasse, E. K.: "Creation of a portable, 3D-printable, iPhone-compatible spectrophotometer", HonorsResearch Projects, URL: https://core.ac.uk/download/pdf/232670827.pdf (last request: 2020-08-21).

[10] Gual, J., Puyuelo, M., \& Lloveras, J.: "Three-dimensional tactile symbols produced by 3D Printing: Improving the process of memorizing a tactile map key", British Journal of Visual Impairment 32 (3), 263-278, 2014. doi:10.1177/0264619614540291.

[11] Gual-Ortí, J., Puyuelo-Cazorla, M., Lloveras-Macia, J.: "Improving tactile map usability through 3D printing techniques: an experiment with new tactile symbols", The Cartographic Journal 52 (1), 5157, 2015. doi: 10.1179/1743277413Y.0000000046.

[12] Jang, S. H., Hong, J. M.: "An Adaptive Extrusion Control Technique for Faster FDM 3D Printing of Lithophanes", Korean Journal of Computational Design and Engineering 22 (2), 190-201, 2017. doi:10.7315/CDE.2017.190.

[13] JJ76, "Spiral vase", URL: https://www.thingiverse.com/thing:2795194 (last request: 2020-08-15).

[14] Jo, W., Lee, J. S., Lee, H. J., Moon, M. W.: "3D printed tactile pattern formation on paper with thermal reflow method", RSC Advances, 4 (60), 31764-31770, 2014. doi: 10.1039/C4RA02822H.

[15] Korger, M., Bergschneider, J., Lutz, M., Mahltig, B., Finsterbusch, K., Rabe, M.: “Possible applications of 3D printing technology on textile substrates", IOP Conference Series: Materials Science and Engineering (IOP Publishing, Moenchengladbach, 2016.), pages 1-5. 
[16] Kostakis, V., Niaros, V., Giotitsas, C.: "Open source 3D printing as a means of learning: An educational experiment in two high schools in Greece", Telematics and informatics 32 (1), 118-128, 2015. doi:10.1016/j.tele.2014.05.001.

[17] Marmey E.: "Buy Lingerie Design Online And 3D-Print it at Home", URL: http://fashionlab.3ds.com/buy-lingerie-design-online-and-3-print-it-at-home/ (last request: 2020-08-15).

[18] Menano, L., Fidalgo, P., Santos, I. M., Thormann, J.: "Integration of 3D Printing in Art Education: A Multidisciplinary Approach", Computers in the Schools 36 (3), 222-236, 2019. doi: 10.1080/07380569.2019.1643442.

[19] Nielsen, J. B., Eiríksson, E. R., Lyngby, R., Wilm, J., Jensen, J. N., Aanæs, H., Pedersen, D. B.: “PicPrint: Embedding pictures in additive manufacturing", Euspen and ASPE Special Interest Group Meeting: Additive Manufacturing 2017, (Leuven, Belgium, 2017)

[20] Novak, E., Wisdom, S.: "Using 3D printing in science for elementary teachers", Active Learning in College Science (Springer, Cham, 2020.), pages 729-739.

[21] Pei, E., Shen, J., Watling, J.: "Direct 3D printing of polymers onto textiles: experimental studies and applications", Rapid Prototyping Journal 21 (5), 556-571, 2015. doi: 10.1108/RPJ-09-2014-0126.

[22] Rivera, M. L., Moukperian, M., Ashbrook, D., Mankoff, J., Hudson, S. E.: "Stretching the bounds of 3D printing with embedded textiles", Proceedings of the $\mathrm{CHI}$ Conference on Human Factors in Computing Systems 2017, (CHI '17: Denver, Colorado, 2017), pages 497-508.

[23] Spahiu, T., Grimmelsmann, N., Ehrmann, A., Piperi, E., Shehi, E.: (2017) “Effect of 3D printing on textile fabric", Proceedings of the $1^{\text {st }}$ International Conference Engineering and Entrepreneurship (ICEE-2017: Welhai, China, 2017), pages 1-7.

[24] Stangl, A., Kim, J., Yeh, T.: "3D printed tactile picture books for children with visual impairments: a design probe", Proceedings of the 2014 conference on Interaction design and children (IDC '14: Aarhus, Denmark, 2014), pages 321-324.

[25] Stainhausler: "Better temperature tower 240-180", URL: https://www.thingiverse.com/thing:2625999 (last request: 2020-08-15).

[26] Tatiana: "Iris Van Herpen: taking her dresses a level higher", URL: https://i.materialise.com/blog/irisvan-herpen-taking-her-dresses-alevel-higher (last request: 2020-08-15).

[27] Vanderploeg, A., Lee, S. E., Mamp, M.: "The application of 3D printing technology in the fashion industry", International Journal of Fashion Design, Technology and Education 10 (2), 170-179, 2017. doi:10.1080/17543266.2016.1223355.

[28] Verner, I., Merksamer, A.: "Digital design and 3D printing in technology teacher education", Procedia Cirp 36, 182-186, 2015. doi: 10.1016/j.procir.2015.08.041.

[29] Voženílek, V., Kozáková, M., Štávová, Z., Ludíková, L., Růžičková, V., Finková, D.: “3D Printing technology in tactile maps compiling", Proceedings of 24th International Cartographic Conference, International Cartographic Association, (ICC2009: Santiago, Chile, 2009), pages 15-21.

[30] Walters, P., Huson, D., Parraman, C., Stanić, M.: “3D printing in colour: Technical evaluation and creative applications", Impact 6 international printmaking conference 2009, (IMPACT 6: Bristol, United Kingdom, 2009).

[31] Weiler, J.: "Beyond Plastic Filament: An Exploration of 3D Printing as a Part of Creative Practices", PhD thesis, Arizona State University, 2020.

[32] Yuan, J., Zhu, M., Xu, B., Chen, G.: "Review on processes and color quality evaluation of color 3D printing”, Rapid Prototyping Journal 24 (2), 409-415, 2018. doi: 10.1108/RPJ-11-2016-0182.

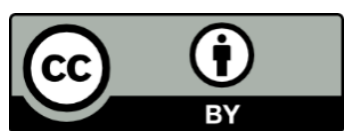

(C) 2020 Authors. Published by the University of Novi Sad, Faculty of Technical Sciences, Department of Graphic Engineering and Design. This article is an open access article distributed under the terms and conditions of the Creative Commons Attribution license 3.0 Serbia (http://creativecommons.org/licenses/by/3.0/rs/). 


\title{
CLASSIFICATION IN SCIENTIFIC AND TECHNICAL WRITING
}

\author{
Jelisaveta Šafranj (D), Marina Katić (D), Jelena Zivlak \\ University of Novi Sad, Faculty of Technical Sciences, Novi Sad, Serbia
}

\begin{abstract}
Classification is the rhetorical device closely related to formal definition. The first step in definition is to classify the term being defined. The term is placed in a group whose members have at least one outstanding characteristic in common. This member is differentiated from all other members of the class. In classification, however, the groups rather than individual members are differentiated. The reader is given the important information about the name of the class, the members of the class important for the discussion and basis for classification, often called criterion of difference. The basis of classification always reflects the particular purpose of the writer making the classification, and the basis relevant to one person may well be irrelevant to another.
\end{abstract}

Key words: classification, technical writing, English for Specific Purposes

\section{INTRODUCTION}

Classification is one of the most fundamental ways of organizing and explaining technical materials. The writer's subject is always different and comprises technical objects or incidents, ideas or sensory experiences, material properties or products of his imagination (Kieft, 2016). Thus, the only common thing is that all are capable of being classified. In classifying not only differences, but similarities are stated as well. In addition, in a class containing a large number of members, the writer chooses those members that are important to the subject under discussion and uses one or more characteristics he considers important as basis for classification (Herbert, 2018).

The purpose of classification is to increase the reader's understanding of a subject, but such an understanding is often only a preparation for writing a piece of exposition. It may serve as an outline, and often can provide the structure of discussion (Day and Gastel, 2016).

Classification can be divided into two groups: explicit and implicit depending on whether the information is stated in the form of classification, i.e., depending on whether the information is stated directly (explicit classification) or indirectly (implicit classification). In addition, classification can be complete or full and partial or incomplete depending on whether the criterion of difference is given or not. Also, classification can be simple or complex depending on the number of levels of generality given (Jordan, 2015).

\section{EXPLICIT CLASSIFICATION}

Explicit classification is easy for the reader to detect; the author tells the reader that he is going to classify. Such words as classify, group, categorize, divide, leave no doubt in the readers mind as to what is going on. The following examples illustrate explicit classification in EST.

Example 1. Explicit classification (simple)

Printing inks

Printing inks are principally made up of colorants (pigments, dyes), vehicles (binders), additives, carrier substances (solvents). Depending on the type of printing process, inks have largely variable flow properties which range from extremely thin (watery), through highly viscous, up to dry (powder-like). The ink transfer mechanism and the type of drying/fixing of the ink on the substrate principally determine the structure and the components of a printing ink (Kipphan, 2001).

In the above quoted example the writer provides the following important information: (1) the name of the class: printing inks, (2) the members, of the class: thin, highly viscous and dry inks; (3) the basis for classification: according to their flow properties. This classification is given on one level of generality and that is why it is considered simple; it is complete or full because it gives all necessary information (Murray and Moore, 2016). 
Explicit classification (complex)

Liquids

Liquids can be broadly classified as viscous liquids and thin liquids, depending on whether they offer a large or small resistance to motion relative to solid surface. Typical viscous liquids are thick oils and glycerine, while typical thin liquids are water and gasoline. The shear coefficient of viscosity of the typical viscous liquids are high, about 100 times higher than the shear coefficient of viscosity of the typical thin liquids (which, in turn, are about 10 times as high as those of gases). The thin liquids and gases are considered as fluids having very small (shear coefficient) viscosity (Owczarek, 2008).

The classification in the above example is given on two levels of generality, as can be seen from the following diagram:

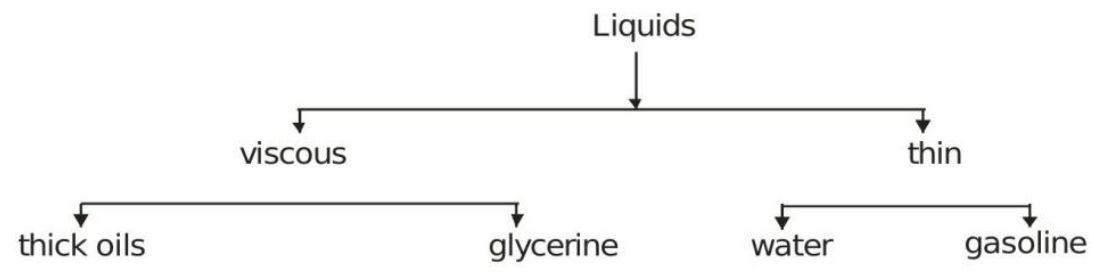

Figure 1: Complex explicit classification

For the first level of this complex explicit classification the writer differentiates the members of the main class (liquids) according to the resistance they offer to motion relative to a solid surface. The basis for classification of the members is not given.

As can be seen from the previous examples that the reader receives all three kinds of information which every complete classification should give:

a) the class,

b) the important members of the class,

c) the criterion of difference.

If the reader is given this information, the classification is considered complete. When the reader is given the class and the members, but not the criterion of difference, the classification is partial (Jordan, 2015). Sometimes the criterion of difference is left out on the assumption that it is obvious to the reader. Then the classification is partial.

Example 2. Partial classification in EST

Forms of Matter

All forms of matter can be grouped into two classes: solids and fluids. Webster's dictionary defines a fluid as a substance which yields to any force, however small, tending to alter its shape. In somewhat more technical terms a fluid may be described as a substance which, when at rest, cannot sustain a shear force, that is, a force exerted tangentially to the surface on which it acts. Solids, on the other hand, can withstand such forces, and although they may remain at rest, displacements or strains of the material result. A shear force can be sustained in a fluid, however, when relative motions between the particles of the fluid take place. Under ordinary conditions this distinction, between fluids and solids is readily apparent for such materials as water, air, or steel. However, it is difficult to determine whether some substances should be classified as solids or fluids (Owczarek, 2008).

But not always does the writer give classifying information in a well organized way as can be seen from the stated examples. The following example show a conceptual paragraph in which an explicit (partial) classifying information is given in a reversed order: 
Example 3. Explicit out of order classifying information (complex)

Drying Methods

There are two chemical drying methods:

a) oxidation is a polymerization of the binder - vehicle of printing ink,

b) polymerization by cross-linking through UV radiation or cross-linking through electron beams

The above mentioned two types of drying methods are chemical methods. Physical method or absorption is Penetration achieved by the interaction of printing ink and substrate.

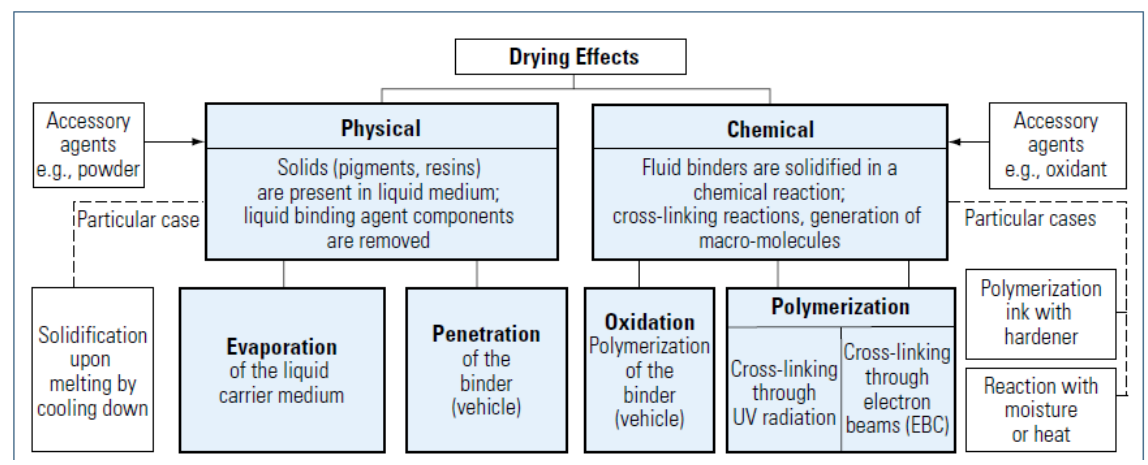

Figure: 1.7-1 Drying processes (Kipphan, 2001)

From the above drawn diagram the two levels of generality of this complex explicit classification can be noticed very easily. But for the reader to be able to abstract and reorder the information given, in the form of the above drawn diagram is not easy, unless he possesses at least elementary technical knowledge of the particular subject (Kipphan, 2001).

\section{IMPLICIT CLASSIFICATION}

If the reader can take information not stated as classification and arrange it into the form of classification, then there is obviously classificatory information in the writing. This type of classification is called implicit classification. In a paragraph containing implicit classification, a statement containing classification information is itself seldom the generalization or even a part of the generalization. Rather the implicit classifying information is buried in the information which supports and develops the core generalization. Thus, implicit classifying information should be extracted and reordered from the supporting information. The primary purpose of a paragraph containing implicit classifying information is not usually Classification but rather Definition, Description or Presenting information on experimental procedure. Like explicit classification, implicit classification is found in both simple and complex form.

Example 4. Implicit classification (simple)

A distinction is made between technologies requiring a master, conventional printing, and so called nonimpact printing (NIP) technologies which do not require a printing plate. Printing technologies requiring a printing plate are technologies like lithography (offset), gravure, letterpress, and screen printing. The most common NIP technologies are electrophotography and ink jet (Kipphan, 2001).

In the above quoted paragraph the writer implicitly classifies printing technologies. After a careful reading the reader can draw the following diagram: 


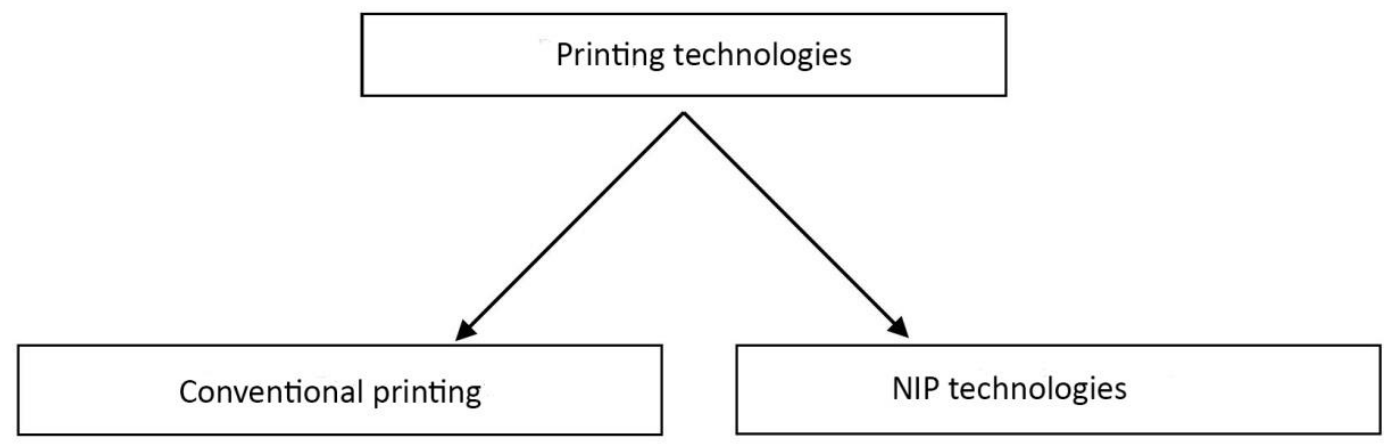

Figure 2: Simple implicit classification

The above implicit classification is a one-level classification and it is considered simple.

Example 5. Implicit classification (complex)

Printing inks

Printing inks are principally made up of colorants (pigments, dyes), vehicles (binders), additives, carrier substances (solvents). Depending on the type of printing process, inks have largely variable flow properties which range from extremely thin (watery), through highly viscous, up to dry (powder-like). The ink transfer mechanism and the type of drying/fixing of the ink on the substrate principally determine the structure and the components of a printing ink. Colorants are divided into: pigments (organically or inorganically coloured, white, or black substances that are insoluble in the ink vehicle.) These are solid particles and/or molecular agglomerates that must be held in suspension in the base liquid), dyes (organic compounds that are dissolved in the system during application) which are present in molecular form.

Pigments consist of molecules that are cross-linked with one another as crystals. Normally pigments have a particle size of 0.1-2 $\mu \mathrm{m}$. A pigment particle can consist of several million molecules. Only around $10 \%$ of the molecules lie on the surface, and it is only these molecules and a few underneath that can absorb light. Pigments disperse light and, as such, are opaque. They have a wide absorption band and are therefore not as "pure" as dyes, which possess an extremely narrow absorption band.

Dye molecules are surrounded by solvents (base liquid), so that almost every molecule can absorb photons, which leads to higher colour intensity and more luminous colours. Dyes have a larger range of colours. They are naturally transparent since the molecules are significantly smaller than the visible wave length of 380 $\mathrm{nm}$.

Pigments always require a vehicle for binding them to the substrate while dyes in most applications connect themselves directly to the substrate surface. The disadvantage with most dyes is their limited light-fastness (oxidation leads to bleaching). With respect to light fastness and stable ink impression, pigment-based inks are advantageous. Pigments as base materials are basically cheaper than dyes yet require greater expenditure when being processed into ink: dispersing agents must be added to pigments so that they do not agglomerate. Dyes are, in contrast, dissolved and do not deposit themselves in the liquid. Printing inks normally contain pigments. The most important exception is currently still those inks used in ink jet technology, but even here the trend is towards pigments (better light-fastness, less bleeding on the paper). The pigment content, depending on the colour tone, is between $5 \%$ and approximately $30 \%$. Those organic pigments which give the printing inks (process inks) the desired colours (hue) are most important for the printing industry. They can be grouped into the two main categories of chromatic pigments and black pigments.

The main inorganic pigments are: white pigment (e.g., titanium dioxide), metal effect pigment (gold and silver bronzes), pearlescent pigment, fluorescent pigment (for daylight luminous colours).

Binders. In conventional printing processes, binders are normally resins dissolved in mineral oil. The pigments are finely dispersed in the binder. The pigment particles are then enclosed by a binder shell. The shell protects the finely dispersed particles from associating into agglomerates and being deposited. The binders dry (harden) on the substrate and thereby bind the pigments.

Additives. The type of additive is dependent on the respective printing process. Additives are added to the ink in particular to influence drying, flow behaviour, and abrasion resistance. 
Carrier substances. Carrier substances for the colorants in conventional printing processes are on the one hand thinning agents such as mineral oils and on the other, insofar as available, solvents (e.g., toluene in gravure printing) (Kipphan, 2001).

The core generalization of the above paragraph is stated in the first sentence. Buried in the supporting details is information that can be put in the form of an explicit classification. From the two sentences of this paragraph, two-level classification can be extracted and reordered in the form of the following diagram (Kipphan, 2001):

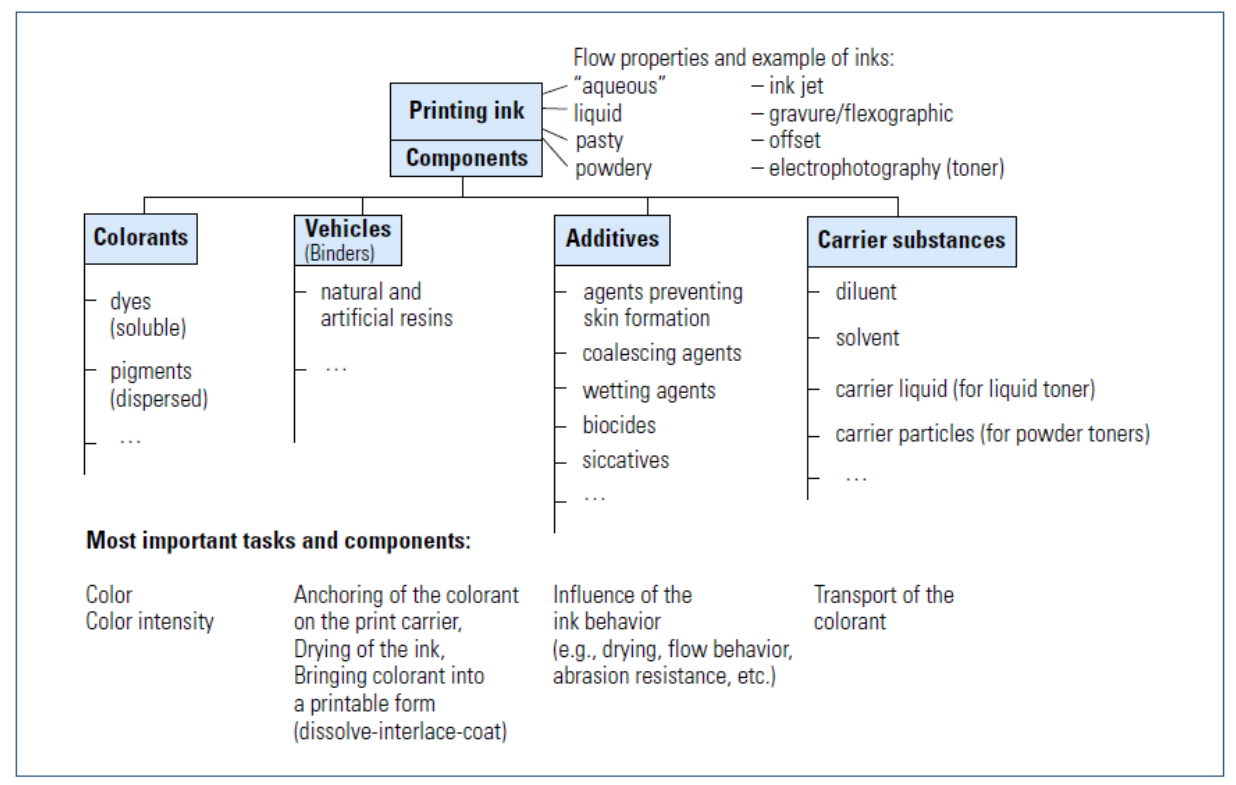

Figure 3: Complex implicit classification on two levels (Kipphan, 2001)

\section{CONCLUSION}

The purpose of the basis for classification is to tell the reader in what essential way each member of the class differs from each other member of the class. Therefore, it is a major meaning component in a statement of classification. It should be noted that statements of classification also contain by implication, as a rule, basis for similarity. Obviously, the given members of a class have one or more areas of similarity or they would not be members of the same class. A named class is not a mere sum of the members that fall within the class. It is, rather, the idea, the concept, of the qualities that any particular member should have in order to fall within the class. In other words, a class is determined by a complex of significant characteristics shared by all members of the class.

Since the rhetorical device of classification is man-made a thing may be, and usually is, classified in a number of ways depending on the basis on which the classification is made. The basis of classification will always reflect the particular purpose of the writer making classification, and basis relevant to one person may well be irrelevant to another.

\section{REFERENCES}

[1] Day, R. A., Gastel, B.: "How to write and publish a scientific paper", 6th ed., (Cambridge University Press Cambridge, 2016.).

[2] Herbert, A. J.: "The Structure of Technical English", (Longmans Green \& Co. Ltd, London, 2018).

[3] Jordan, R. R.: "English for Academic Purposes: A Guide and Resource Book for Teachers", (Cambridge University Press Cambridge, 2015.).

[4] Kieft, M.: "The Effects of Adapting Writing Instruction to Students' Writing Strategies", (University of Amsterdam, Amsterdam, 2016.).

[5] Kipphan, H.: "Handbook of Print Media", (Springer, Berlin, Heidelberg, New York, 2001.), page 130, $131,211,166,681$. 
[6] Murray, R., Moore, S.: "The Handbook of Academic Writing: A fresh approach", (Open University Press, Maidenhead, 2016.).

[7] Owczarek, J.A.: "Introduction to Fluid Mechanics", (International Textbook Com., Scranton, Pennsylvania, 2008.), page 17, 43.

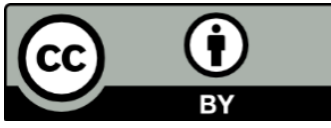

(C) 2020 Authors. Published by the University of Novi Sad, Faculty of Technical Sciences, Department of Graphic Engineering and Design. This article is an open access article distributed under the terms and conditions of the Creative Commons Attribution license 3.0 Serbia (http://creativecommons.org/licenses/by/3.0/rs/). 


\title{
ECONOMIC DISCOURSE AND VISUAL CONFIGURATION
}

\author{
Alpar Lošonc ${ }^{1}$ (D), Andrea Ivanišević ${ }^{2}$ (D), Ivana Katić ${ }^{2}$ \\ ${ }^{1}$ University of Novi Sad, Faculty of Technical Sciences, \\ Department of Fundamentals Sciences, Novi Sad, Serbia \\ ${ }^{2}$ University of Novi Sad, Faculty of Technical Sciences, \\ Department of Industrial Engineering and Engineering Management, Novi Sad, Serbia
}

\begin{abstract}
Economic discourse has always used different visual modes of shaping perception. For example, characteristic classical image in economic discourse is the "invisible hand". In doing so, economic discourse reaches for, concerning of its metaphors, for resources in physics, but also in literature. If big part of the visual figures of economic discourse (equilibrium, e.g.) was borrowed from physics in the twentieth century, mathematics is a significant, even dominant source of the formation of visual perception, based on different schemes, graphs and geometric figures. In this paper, we show the configuration dynamics of visual perceptions in economic discourse, starting from the fact that visualization of economic discourse has the following functions: a) demonstration of certain knowledge, b) the realization of a performative visual effect, that is the creation of certain forms of visibility, c) persuasion of the public regarding the fact that economic discourse has cognitive authority.
\end{abstract}

Key words: economic discourse, visuality, perfomativity, visual semantics, metaphors

\section{INTRODUCTION}

What is the purpose of "visual semantics" in economic discourse? Does it have to do with operationalization of economic propositions or something else? Why are visual dimensions of economics still present despite the evident changes? This paper focuses on two intersecting levels. The first level is conceptual and the second one is historical. Modalities of visual semantics of economic discourse are presented at the conceptual level. Wide economization, which is present in modern society, warns us about the ubiquity of economic visualisation in different segments of the society. Due to its late stabilization as a special discipline, economics reaches for metaphors, that is, visual aspects used for affirming its identity at historical level. The ambition regarding the rigorous economic categories shifts this discourse towards broader understanding of mathematically determined visualisation. Does this mean that visual formation of economic discourse is intact?

\section{SOME HISTORICAL ASPECTS: COMPLEXITY OF VISUALITY}

There are economic papers, even economic orientations that do not use visual symbols, charts, figures or graphics at all in their argumentation. This way, the most significant achievements of the Austrian movement systematically ignore the same visual expressions and continuously develop argumentation, but only at the level of textual effects. For example, in the books of Nobel memorial prize winner, Friedrich Hayek, there are no mathematical or geometric figures that present the derived material, the most important statements are expressed through verbal propositions without any quantification (Hayek, 1944). Actually, not a single number is written in the texts, no reliance on mathematical symbols is recorded and not a single table is identified. The spontaneity and uncontrollable dynamics of economic life cannot be represented by mathematical symbols that necessarily fix and stop processuality - this way, Hayek just expressed the 'general problem' of how to represent the 'processuality' of the market economy visually. The same problem is evident in the relevant texts of Joseph Schumpeter (who is not a Nobel Prize winner) who even rooted statistics at Harvard, but many of his reputable books (e.g. Theory of Economic Development on 400 pages) do not contain any visual expressions. For example, if we look at the book that represented a milestone in economic discourse in the 20th century written by John Maynard Keynes (The General Theory of Employment, Interest and Money) we can hardly find two or three mathematical formulas, and the rest of the text is only a text without any visual comments. Not a single one of them had the idea of confirming their claims with visual argumentation, or, for example, photo comments. At the same time, there is no unambiguous progress here, that is, the constellation does not change according to the rhythm of chronological order; e.g. Karl Marx, who is criticized for not using other mathematical 
procedures besides differential equations, lived earlier than Schumpeter, but he still used more mathematical processes, that is, mathematical visuality in deriving his thoughts.

However, the visual dimensions of economic discourse must be analysed broadly, that is, beyond what is indicated. For example, although we have just mentioned Keynes who presented his 'revolutionary material' in an a-visual way, there are some facts about him that should not be forgotten. When he wants to show the performance modalities of 'money managers', he takes the image of a 'beauty contest', that is, he invokes a form of competition that apparently has no connection with economic discourse. The image of the 'beauty contest' has significant impact today: starting from textbooks to popular video presentations, the same image takes on its digital form and easily reaches the addressees. In addition, although Keynes did not use a lot of mathematical figures or performances, later interpretations of his work were largely based on explicit visual/diagram representations (such as the IS-LM model of John Hicks, a Nobel Prize winner).

In other words, Keynes's texts are presented today mostly through digitized images or prepared models, or mathematical formulas, that is, visually, most often on appropriate screens where numbers and figures are converted into digital impulses. This applies not only to students but to the scientists as well who often do not even read the original text, but only receive a model presentation and formulas in which causal determinations are expressed, such as the one between investments and income

The assessment of the relationship between the text and the visual figures according to which the latter has a more significant role has slowly been stabilized: accordingly, the text is more accompanied by transparent visual presentations that enable rigor. Not a lot of people have read the original version of the famous article written by Phillips-curve (although some say that it is the "most significant curve" in the history of economics), but they have recognized the connections that were launched with the article in question. Undoubtedly, the expansion of visuality in the 20th century also contributed to this: today technology enables great visual presentations of typical economic figures (e.g. Robinson's figure was once considered to be a prototype of a basic economic figure; today it can easily be evoked through "screening"). The same technology allows both figures and graphs to be disassembled and reassembled all over again. There is no difference with the Schumpeter who has already been mentioned here. His most mentioned metaphor is 'creative destruction' which has been quoted countless times. The same metaphor suggests that investments create something new in capitalism, but they destroy something old. Actually, the price of the new is the inevitable demolition of the old, the decomposition of tradition. This is a metaphor that has its roots in various cultures (among others, in Indian mythology), but, in case of Schumpeter, it represents such a dynamic of entrepreneurs that has been attracting a lot of attention for several decades, and is marked by cultic fame. Originally, Schumpeter did not find it necessary to present this figure visually; today, however, this figure is expressed visually to a significant extent. There are different cycles in the history of technology that lead to a fluctuating intensification of innovations, and this way, the history that represents the impact of technology on the dynamics of the economy is presented. Schumpeter even has one very important visual figure that places visuality at the absolute beginning of any economic reasoning that tries to understand the dynamics of economics: it is a 'pre-analytical vision' that directs the analytical work of an economist. The ocularcentrism by Schumpeter suggests that one must first get a comprehensive $^{1}$ perspective in order to approach the analysis at all. This means that there must first be one preceding comprehensive visual perspective, that is, one visual prospect so that the analysis can be carried out. Today, the 'vision' (which can be found in business disciplines or management theories) is projected in different ways. According to this, we suggest that the visual specificity of economic discourse also depends on this 'pre-analytical vision'.

Therefore, it can be concluded that visual projections in economics are presented in both direct and indirect figures. This means that visual configuration does not only imply mathematical analytics, demonstrative geometric figures, symbols in algebra, statistical presentations of various correlations, screening of tendencies, etc. but also metaphors which visual definitions are well known to science (Lakoff and Johnson, 1980). The metaphorical nature of language, and the possibility of defining the objects using metaphors, has been repeatedly confirmed in various interpretations. Moreover, in recent times, economic discourse has noticeably focused on treating the metaphorical nature of economic speech and written expression. Deconstruction of duality between conceptual and metaphorical expression has had effect on economic discourse as well (McCloskey, 1980), which inspires appropriate efforts to respect the metaphorical nature of economics. Consequently, today the traditional view that metaphors cannot stand the test of scientific

${ }^{1}$ This does not mean that it was only Schumpeter who insisted on the significance of visuality as a primary category, see Ötsch (2020). 
rigor is criticized; metaphors are also part of the vocabulary that has the ambition to capture economic relations. The visual configuration of economic discourse is, therefore, very complex, and in the following considerations we take into account both the metaphorical nature and the mentioned figures. It is only with two-way movement that we can report about the visual configuration of economics. The dependence of economic discourse on visuality, that is, on visual demonstration, has become more and more significant over time. Mere discussion of the subject matter is insufficient for a comprehensive presentation of visual aspects, it is not just a visual application of certain propositions but much more, as we shall see. Namely, the visualization of economic argumentation has both pedagogical and demonstrative components, but also the component of persuasion. It convinces its addressees, so it is its persuasive role that is as important. The path of economic discourse to an authoritative position in modern reflexivity cannot be imagined without visuality. In order for us to understand this constellation, we must return to the very genesis of economics and, based on that, we can, in brief details, gain the understanding of today's full authority of economic discourse. Namely, economics is a relatively young discipline, despite its appearance. It took a long time for economic rationality to become hegemonic rationality. More precisely, despite the fact that there were significant economic reflections in premodernity (for example, in theology), an autonomous economic discourse with autonomous economic laws emerged gradually in the 18th and 19th century. In other words, economics is a modern scientific discipline, which suggests that its visual configuration is characterized by aspects of modernity, or dimensions of modern rationality. In the indicated sense, the economic discourse arises when other disciplines have already existed, or at least have had certain forms. In our perspective, this actually means the following: numerous economic metaphors, as well as mathematical and geometric figures in economics are the result of various transfers, and the visual specificity of the emerging economic discourse is borrowed, that is, it represents mimetic visuality. This has never meant that economic discourse only passively takes over the visual figures of other disciplines; it does not imply that the same discourse is just a 'container' that only absorbs 'foreign' discourses. The point here is that economic discourse always articulates or converts knowledge and visuality of other disciplines. Let us take a look at one of the most famous metaphors in the history of economics! It is an 'invisible hand' that is traditionally associated with the Scottish theorist Adam Smith and, of course, is related to the functioning of the market. The importance of the metaphor is still evident today in scientific discourse and in widely accepted idea about economics despite the fact that the Scottish economist used the same metaphor incidentally only a few times (Rotschild, 1994); in fact, it visually informs us that the market does not reflect only the intentions and motives of economic entities, but it also converts them into a general system of coordination. An interesting pedagogical and general issue of economic presentation is how to visually present a market that is 'invisible'; the aforementioned Austrian economists have also confronted the visualization of 'invisibility', for example, how to visualize 'business cycles' (Slobodian, 2018). When the 'invisible hand' wants to show itself, then it is confrontational, namely, against the 'visible hand' of the corporation or state. According to that, the 'invisible hand' is still a polemical visual figure that evokes criticism of all those entities that have a 'visible hand' and want to navigate the economy in this way. It evokes freedom, as well as the complexity, which tells us that despite the multitude of individual motivations, the market is a meta-individual system that enables benefits for individuals. In any case, we can notice that the metaphor of the 'invisible hand' has its origins in theology (Smith himself developed a deistic system; economics was part of it), it is its place of origin; this is the way in which the metaphor appeared in economic consideration. Actually, this extremely important metaphor was created by a transfer from theology proving the receptivity of economic discourse and necessity to borrow from others. Furthermore, when physiocrats (18th century, even before Smith) developed argumentation within the framework of the emerging economic discourse, then they already used certain visual schemes to present the general connection of economic flows. Thus, "tableau économique" of François Quesnay is considered by many to be the first successful attempt to model economic relations, that is, to promote models as paradigmatic visual sequences. Here, the economics is already presented in the form of a strong visual figure that enables considering connectivity as a modality of the existence of economic entities. In other words, they create an image of the economics as a whole, as a structure which elements are connected by certain relations. It is not a coincidence that the holistic visual scheme in question still plays a role today and experiences different variations, which is why it can be seen in different forms, now in configured forms for digital screening. This way, the model as a certain kind of a 'grid' of economic reality becomes a significant moment in the visual representation of economics and many influential achievements in economics are associated with setting the model with appropriate parameters.

Physiocrats were actually related to agricultural reflexivity, to 'naturalness' of economizing, and to one more famous figure of economic discourse, that is, to 'circulation' that was associated with the 'basis', 
namely, with constant productivity of a country. Later trends have criticized physiocrats in a different way and this is why it can be understood why categorizing the 'industry' as 'non-natural' could not be proved later when the industry progressed. However, naturalness remains deeply rooted as a source of visuality for economic discourse. Economists have many times been fascinated by 'natural images', namely, nature was once presented as 'perfect economy', and once it was mentioned that 'nature does nothing in vain' (Schabas, 2008), which could be a perfect economic principle, that is, optimum for economic reflection. It can be said that nature is an extraordinary source of different forms of 'images' in economic discourse (Mirowski, 1994). In the end, economization really represents a method of expressing 'metabolism' between a man and nature.

We could say in general that the horizon of nature plays a crucial role in economic discourse: economics is often presented as an expression of natural order, as a manifestation of natural laws. Consequently, there are many significant metaphors in economic discourse that are directly or indirectly related to 'images' of nature. The choice of metaphors is endless, so we here quote just a few, selected examples: 'organism' (Hodgson, 1993) as a visual expression of economic vitality, that is, 'organism' as a supremely-adequate visual expression of economic vitality, as well as visual presentation of totality in economization, that is, connection between the whole and its parts; 'circulation' of capital and goods has been presented many times based on the 'blood flow' (this introduces physiological metaphors); a well-known 'circular flow diagram' of Nobel prize winner Paul Samuelson is presented based on "water pumping" and alludes to the pump logic; "hydraulic-logic" of one influential orientation of Keynesianism also indicates to the nature. Alfred Marshall, an author of famous Principles of economics, emphasized the importance of biological metaphors for economic discourse; institutionalists of different colours in their heterodox rush (this particularly relates to classic institutionalists such as Thorsten Veblen) insisted on figures of evolution based on a different a type of causality, that is, a type of causality promoted in neoclassical economics. The same institutionalists made it possible to 'paint' changes on the basis of the logic of evolution, which led to 'cumulative causation'. It is nature and understanding of nature that are everywhere presented as the source of visual power of economics; the perception of nature is an inexhaustible source of visuality of economizing.

In its history, economics has positioned itself in "moral sciences" and "natural sciences" (we could trace this problem if we considered how economists treated the relationship between society and nature ${ }^{3}$ ). This also determines the dynamics of its visual metaphors. The presence of motives, intentions, generally speaking, subjectivity in economics directed economics towards 'moral sciences', i.e. towards social sciences that emerged in the 19th century. However, the ambition of some economists to create a science that develops strict determinations as natural sciences brings them closer to the models of the same sciences. During the 19th century, important (neoclassical) economists used physics that was in full swing. Physics was considered to be a model. In particular, the 'energetics metaphor' played a major role and represented a pattern for economic thinking in the same century, which means that the assessment that 'economics' became 'social physics' and that physics became 'nature of economics' (Mirowski, 1990) was valid. This way, we can recognize various appropriate visual figures that still play a significant role in economic thinking. The equilibrium figure represents such a situation; admittedly, it cannot be identified only in physics, but it is also important in the discipline in question. Balance is considered to be an expression of completeness. For example, the market-optimal relationship between the demand and supply, which is statically manifested as the equality between supply and demand, can be found in numerous textbooks. However, a visual figure of equilibrium that can always be effectively presented in a diagram and has a pedagogical effect is even more general for self-understanding of economic reflection: while some economists try to add certain meaning to equilibrium (e.g. 'punctuated equilibrium' or 'partial equilibrium') or save the figure in question, other economists explicitly reject equilibrium as a static metaphor that is visually deficient in terms of presenting a complex and ever-moving economic reality.

\section{THE DISCURSIVE POSITION OF VISUALITY IN TRANSFORMING ECONOMIC DISCOURSE}

Now we can ask the question: what is the role of visual projections in the economy? What is the purpose of visual figures in economics? Why has economics evolved towards a situation that implies an increasingly intense presence of visual representations? Has economic discourse been aestheticized by this? What does

\footnotetext{
2 This is why Margaret Schabas (2005) develops argumentation based on which economics should be 'denaturalized'

${ }^{3}$ Something about that, Mirowski (1994b), p. 11.
} 
it mean when we say that economic categories are actually 'visual artefacts'? ${ }^{4}$ Namely, today neither a textbook nor a book written within the framework of economic discourse can be imagined without the indicated visual elements. When doing the courses in microeconomics, it is inevitable to see curves of indifferences, achieved identity of supply and demand, or difference equations and on the courses in macroeconomics, inflation is represented in relation with income dynamics, in GDP dynamics graph, etc. In fact, if we look at some achievements of neoclassical economists in the 19th century (Stanley Jevons), we can see that there were already graphs, diagrams that became an immanent part of argumentation. Mapping the economy through diagrams or diagram presentation and visualization has been deeply accepted in economic discourse that it cannot be detached from such a form of "visual representation", or "mapping". It is not a coincidence that popular representations of economic flows, including the daily press, find it appropriate to use at least one diagram to represent economic trends. Many pop economics presentations on the Internet (for example on YouTube) act in the same way, for example the organic part of their performance uses some form of diagram presentation.

These issues became especially important when mathematical language started being used in economic discourse. If we say that physics used to be a 'pattern' (its presence has not disappeared, for example in ecological economics), then we can say today that the logic of mathematical procedures is followed. In addition, the mathematics, that is, mathematical means, was used for visualization of economic discourse during the 20th century. Nevertheless, in the context of the 2008 crisis, there is a debate today about the scope of mathematics for economic discourse. Some critical economists believe that excessive mathematization now represents an obstacle for gaining critical knowledge of modern trends, and that the neutrality proposed by mathematics is false. It is also claimed that there are less possibilities for the formation of the mentioned 'pre-analytic vision' by the unbalanced mathematical representation.

However, regardless of the outcome of this discussion, it seems that, for now, the strong presence of mathematics in economics is irreversible. Yet, it is interesting to note that there has always been a discussion about which modality of mathematical visualization is appropriate for economic discourse. This way, the other Nobel Prize winner (for whom "stabilization of mathematics" can be associated) Paul Samuelson ${ }^{5}$ actually had doubts in his well-known and many time published books. The books were written in a short period of time. In his book Foundations of Economic Analysis, his unwillingness to use diagram was obvious in comparison to the other book Economics: An Introductory Analysis (it can be interpreted as shifting to 'visual culture of engineering', Giraud). His critic, a well-known economist Kenneth Boulding, clarified the gap that may exist in mathematically inspired production of 'visual artefacts': 'geometric' or 'algebraic' visualisation, adhering to the first option because it is the only one that can present 'discontinuities' in economizing (Giraud, 2010).

Boulding's preference of 'geometric' over 'algebraic' was not accepted in economic discourse. There are different forms of mathematical visualization in today's economics despite, as we have already said, the anxiety caused by the crisis, including the crisis of self-understanding as well. When the economists used computers for the first time (fifth and sixth decade of the 20th century), that is, when they saw adequate algorithms for the first time, then they were driven by additional impulse towards the ideal of rigour. It can even be said that machines have become a 'pattern' for economists (Mirowski, 2002) who have intended to identify undeniable determinations of economic life. This way, visual projections adapted to deterministic 'pre analytical visions' and the triumphal victory of mathematics with its 'visual facts' is part of it.

If we can discuss about the influence of visual rhetorics in economic discourse, then it has to be related to persuausive potential of mathematics procedure. Mathematical economic discourse evokes the ideal of precision, that is, the rigour of respective procedures corresponds to the ideal of rigorous science. Economics that rely on mathematics is a certain type of 'parasitism' based on visual-rhetorical power of rigour. In the end, it is economics that many expect to measure proportions, to realize precise measurements by weighing the relationship between things as well, and above all, relationships between people, to contribute to transparent relations, that is, to create a type of 'social physics'. However, it means that visual expressions do not represent just demonstrations for economics, but they also represent what is in theory of speech acts called performative acts; the same act does not reflect but establishes certain relationships as well as relations important for economizing.

\footnotetext{
${ }^{4}$ It can be discussed about whether the mathematics additionally enhances 'visualization' of economic discourse. We start from the point that mathematics per se is a 'visual artefact'. At the same time, we change the statement of Willard Gibbs: mathematics is visual language.

${ }^{5}$ We have a detailed description by Giraud (2010). See, Samuelson $(1947,1948)$.
} 
Performative visuality has contributed to the fact that today, economics, which appears on TV, Internet, press, even in cartoons, is respected and considered to be one of paradigmatic discourse of a modern man.

However, there are a few moments that shift the frameworks today. Reductive determinism is resisted by numerous movements in economic discourse (experimental economics, behaviourism, etc.) which notice uncertainties, affective appearances of economic subjects, 'bounded rationality'. Such phenomena emerge from old deterministic frameworks. The mentioned crisis practically concentrated the mentioned objections against the alliance of determinism and mathematical visualization. Digitization and aesthetic articulation of screening are certainly helpful in understanding the mentioned problems. This is actually the second moment. The explosion of 'financialization' in recent decades has been paired with digital screening; financial entities are interested in watching the volatile movement, fluidness and vibration of various 'options' on digital screens, and to make decisions based on that (Schinckus and Christiansen, 2012). The financial sphere with a diffusion of securities represents an expansive area of visuality in which the 'engineering approach' is amalgamed with aesthetic creations of different fictions. The issue of 'representing the identity of finance' (Stäheli, 2008) is of great importance today, so this problem also shows the general problem of representing the 'identity' of economic categories in general.

Frameworks are changing in terms of transformation of economic discourse, which had its deterministic forms according to which it adjusted its visuality. The same discourse today respects "indeterminate processes" much more than before. However, the intense presence of economic visuality is never called into question. On the contrary, we can say that there are traces of visualized economic discourse everywhere, which is a condition for its authority.

\section{CONCLUSION}

The visuality of economic discourse can be analysed at two levels: the first one is the level of (explicit) visual signs, visual semantics and the second level is metaphorically determined (implicit) articulation. The history and genesis of economic discourse show either the existence of just one level or interaction between them. The economic discourse was developed in modernity and this is why its metaphors are expressions of transferred content. This is particularly evident in theology and perception of nature which were considered to be the source of visuality for economics. The visuality of economic discourse expressed this situation. It was the same way in which it expressed the process of searching for a model for the same discourse (physics, machines). In terms of economic visualization in the 20th century, a crucial role was played by mathematics, which was used to demonstrate the "discursive power" of economics in forming modern rationality. At the same time, it can be called the „performative power" of this discourse. The same situation is changing today, because economic discourse is more sensitive to indeterminate processes that are faced with real explosion of visual presentation today.

\section{REFERENCES}

[1] Boulding, K. E. "Samuelson's Foundations: The role of mathematics in economics", Journal of Political Economy 56 (3), 187-99, 1948.

[2] Giraud, Y. B.: "The changing place of visual representation in economics: Paul Samuelson between principle and strategy 1941-1955", Journal of the History of Economic Thought 32, 175-197, 2010. doi: $10.1017 /$ S1053837210000143.

[3] Hayek, F.A.: "The Road to Serfdom", (Routledge, London, 1944).

[4] Hodgson, G.: "The economy as an organism-Not a machine", (Elsevier, London, 1993.), pages 392-403.

[5] Lakoff, G., Johnson, M.: "Metaphors We Live By", (University of Chicago Press, Chicago IL, 1980.)

[6] McCloskey, D. N.: "The rhetoric of law and economics", Michigan Law Review 86 (4), 752-767, 1988. doi: 10.2307/1289214.

[7] Mirowski, P.: "Natural Images in Economic Thought: Markets read in Tooth and Claw", (Cambridge University Press, Cambridge, 1994.)

[8] Mirowski, P.: "Doing what comes naturally: four metanarratives on what metaphors are for", In: Natural Images in Economic Thought: Markets read in Tooth and Claw, (Cambridge University Press, Cambridge UK, 1994.) 
[9] Mirowski, P.: "Machine Dreams, Economic Becomes a Cyborg Science”, (Cambridge University Press, Cambridge UK, 2002.)

[10] Mirowski, P.: "More Heat than Light. Economics as Social Physics, Physics as Nature's Economics", (Cambridge University Press, Cambridge UK, 1990).

[11] Ötsch, W.: "Imagination und Bildlichkeit in der Geschichte der Wirtschaftstheorie: Von Adam Smith bis zur frühen Neoklassik", URL:

https://www.econstor.eu/bitstream/10419/222521/1/1724952994.pdf (last request: 2020-09-12).

[12] Rothschild, E.: "Adam Smith and the Invisible Hand", American Economic Review 84 (2), 319-22, 1994.

[13] Samuelson, P. A.: "Foundations of Economic Analysis", (Harvard University Press, Cambridge MA, 1947.)

[14] Samuelson, P. A.: "Economics: An Introductory Analysis", 1st edition, (McGraw-Hill, New York, NY, 1948.)

[15] Schabas, M.: "The Natural Origins of Economics", (University of Chicago Press, Chicago IL, 2005.), page 5.

[16] Schabas, M.: "Nature does nothing in vain", Dædalus 137 (2), 71-79, 2008.

[17] Schinckus, C., Christiansen, I.: "Visual Finance", Journal of Interdisciplinary Economics 24 (2), $173-$ 192, 2012. doi: 10.1177/0260107913504842.

Slobodian, Q.: "Globalists", (Harvard University Press, Cambridge MA, 2018.), page 61.

[18] Stäheli, U.: "Watching the market: Visual representations of financial economy in advertisements". In: Economic Representations, Academic and Everyday, (Routledge, London, 2008.), page 275.

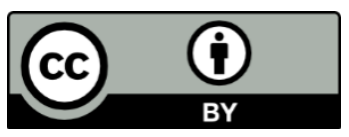

(C) 2020 Authors. Published by the University of Novi Sad, Faculty of Technical Sciences, Department of Graphic Engineering and Design. This article is an open access article distributed under the terms and conditions of the Creative Commons Attribution license 3.0 Serbia (http://creativecommons.org/licenses/by/3.0/rs/). 

NOVEL TECHNOLOGIES

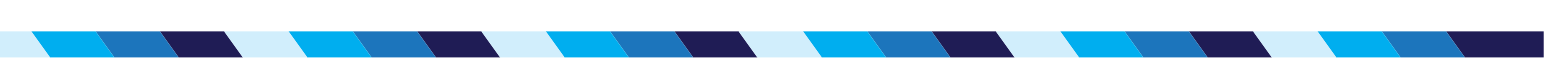





\title{
ANALYSIS OF OBSERVING AND RECOGNITION PROFILE FACIAL IMAGES USING EYE TRACKING SYSTEM
}

\author{
Andrej Iskra, Helena Gabrijelčič Tomc \\ University of Ljubljana, Faculty of Natural Sciences and Engineering, Department of Textiles, \\ Graphic Arts and Design, Chair of Information and Graphic Arts Technology, Ljubljana, Slovenia
}

\begin{abstract}
Facial images have been the subject of research for many years, using the eye-tracking system. However, most researchers concentrate on the frontal view of facial images. Much less research has been done on faces shown at different angles or profile views of faces in facial images. However, as we know, in reality we often view faces from different angles and not just from a frontal view. In our research we used a profile presentation of facial images and analyzed memory and recognition depending on the display time and dimensions of the facial images. Two tests were performed, i.e. the observation and the recognition test, and we used the well-known yes/no detection theory. We used four different display times in the observation test (1, 2, 4 and 8 seconds) and two different dimensions of facial images $640 \times 480$ and 1280 $\times$ 960). All facial images were taken from the standardized face database Minear\&Park. We measured the recognition success which is mostly presented as a discrimination index $A^{\prime}$, incorrect recognition (FA - false alarm) and time-spatial method based on fixation duration and saccade length. In this case, eye tracking provides us with objective results when viewing facial images. In the results it was found that extending the display time of facial images improves recognition performance and that the dependence is logarithmic. At the same time, wrong recognition decreased. Both parameters are independent of the dimensions of the facial images. This fact has been proven by some other researchers also for frontal facial images. It was also discovered that with an increase of the display time of facial images an increase of the fixation duration and saccade lengths occurred. In all results we detected major changes at the display time of four seconds, which we consider as a time, where the subjects looked at the whole face and their gaze returned to the center of the face (in our case eye and mouth).
\end{abstract}

Key words: eye tracking, profile face images, recognition success, fixation duration, saccade length

\section{INTRODUCTION}

Images are one of the five basic elements of online information (Kyrnin, 2020). These include facial images, which are now an integral part of the way people present themselves on their websites, be it professional, personal or social networking sites. When publishing facial images, the dimensions and resolution of these facial images (Du and Martinez, 2011), the position of the face (frontal, mid-profile or in profile) (Liu and Chaudhiri, 2002) and the expressed emotion (Tarnowki et al, 2017; Green and Guo, 2018) are of great importance. From the memory aspect, the presentation facial image is main importance. This has a decisive influence on memory and later recognition. Much research has been done on frontal facial images, but very little research has been done on profile facial images. Above all, there is a lack of research on the influence of presentation time of facial images on the memory of faces. In our research we have demonstrated this influence of time in the results of recognition success $A^{\prime}$, incorrect recognition and two parameters of the eye tracking system, i.e. fixations duration and saccade lengths.

With the rapid technological development, very accurate, affordable and, above all, user-friendly eye tracking systems have recently emerged. We too have used such a system in our research, especially for the fact that it is an objective method for obtaining results and thus also allows for in-depth research in the behavioural and cognitive area.

\section{METHODS}

\subsection{Participants}

As mentioned above, we had eight different tests (two dimensions of facial images and four different times of facial image display in the observation test. Each test was performed by six participants, so that we had a total of 48 participants (15 male and 33 female) with an average age of 20.3 (SD =0.96). These were students from our faculty who volunteered for the test and had normal vision. 


\subsection{Stimuli}

The facial images were taken from the Minear \& Park database (Minear and Park, 2000). In the observation test, we had 20 images of faces of the Caucasian race between 18 and 29 years of age with neutral expressions. The set of images was equally selected by gender (10 male and 10 female). For the recognition test we added 20 new faces to these faces (also 10 male and 10 female).

\subsection{Apparatus}

All tests were carried out in the Laboratory of Visual Perception and Colorimetry at the Department of Textile, Graphic and Design of the Faculty of Natural Sciences and Engineering at the University of Ljubljana. When setting up the environmental and testing system we followed the standards and recommendations (Pernice and Nielsen, 2009).

We performed the test with the Tobii X-120 eye tracking system. The distance between the test subjects and the screen with the facial images was $60 \mathrm{~cm}$. The setting of the test environment and the test subject is shown in Figure 1.

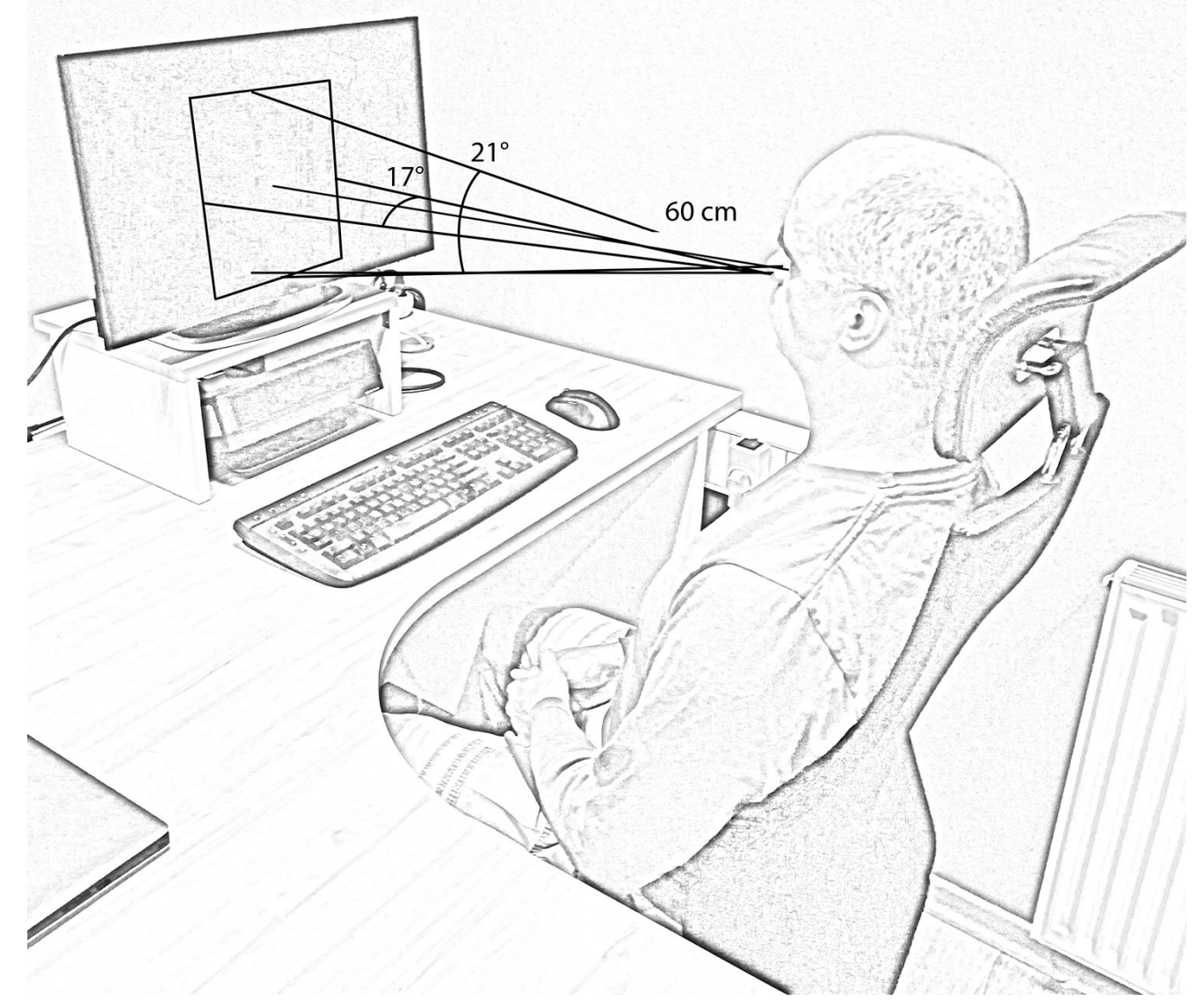

Figure 1: Testing setup

Analysis were done in Tobii Studio 3.4.8 software. The defaults setting for definition of fixation was $100 \mathrm{~ms}$ for $30 \mathrm{px}$ area. That means if eyes stayed in the area 30 pixel for at least $100 \mathrm{~ms}$ it was concerned as one fixation (Tobii, 2016).

\subsection{Procedure}

As already mentioned, we have conducted a memory test according to the well-known old/new principle. We performed two tests, an observation test and a recognition test. The procedure observation test is shown in Figure 2. 


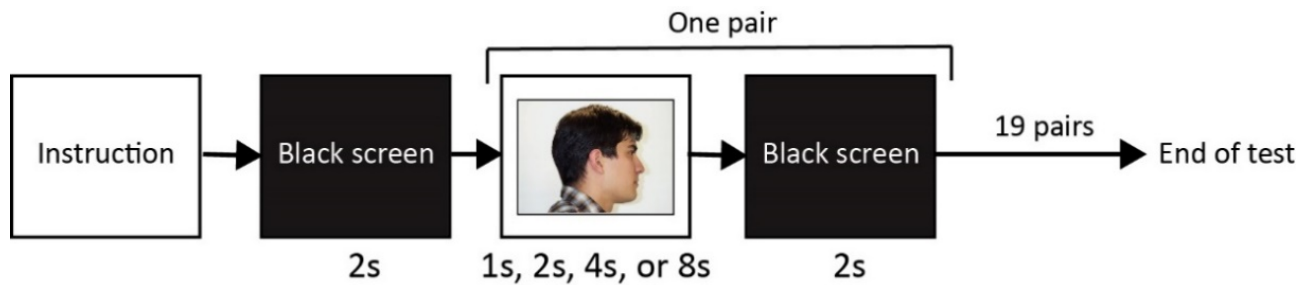

Figure 2: Procedure of the observation test

The instructions were followed by a short pause of black screen, which lasted for two seconds, then the first facial image appeared. The display time of the facial image was determined according to the test (one, two, four or eight seconds). This was followed by a two-second pause with black screen and a new facial image. Like other researchers, we randomly determined the order of the images with respect to the representation of male and female faces. The black screen between the facial image representations was designed to neutralize participant's gaze before next facial image appear. The test contained 20 facial images and was performed automatically (the participants had no influence on the facial image display). Recognition test contained 40 facial images (240 YES / NO responses for each participants), which, as in the observation test, were equally distributed according to gender and existing and non-existing facial images in the observation test. The test was controlled by the participants themselves. The instructions were followed for two seconds on a black screen, then the facial images followed. The participants responded YES / NO by saying whether or not they saw the face in the observation test. After the answer, the participants clicked the mouse button to display a new face. The results were recorded manually. Procedure of recognition test in shown in Figure 3.

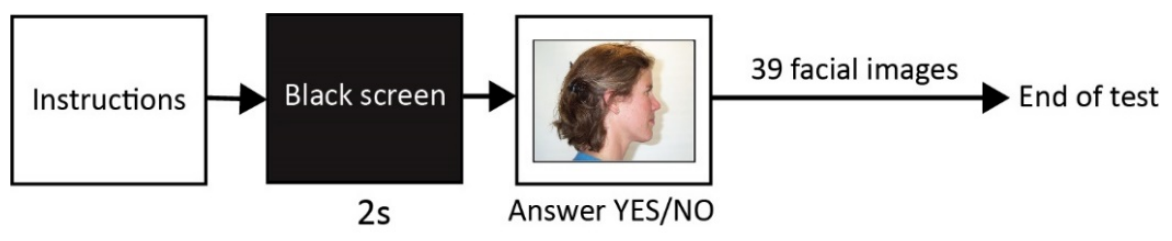

Figure 3: Procedure of the recognition test

\subsection{Analysis of results}

From the answers of the test persons we received two results. These are the percentage of correct recognition $\mathrm{CR}$ (the face was in the observation test and the participants confirmed this) and the percentage of incorrect recognition (FA - False alarm) (the face was not in the observation test and the participants answered that it was in the observation test). Those two data are then used to calculate recognition success (discrimination index $A^{\prime}$ ) with equation 1.

$A^{\prime}=0,5+\frac{(C R-F A)(1+C R-F A)}{4 C R(1-F A)}$

In addition, we presented the results as a time-spatial analysis based on the fixations duration and the saccade length. The fixations duration was obtained directly from Tobii Studio. The saccade length was calculated from the position of two consecutive fixations ( $F_{1}$ and $\left.F_{2}\right)$ according to the following equation 2.

$F_{1} F_{2}=\sqrt{\left(x_{1}-x_{2}\right)^{2}+\left(y_{1}-y_{2}\right)^{2}}$

\section{RESULTS}

\subsection{Recognition success}

As mentioned above, we conducted tests for two different dimensions of facial images and for four different times of facial image display. Figure 4 shows the recognition performance as a function of the facial image display time. The figure also shows the logarithmic trendline and $R^{2}$ (fitting coefficient). 


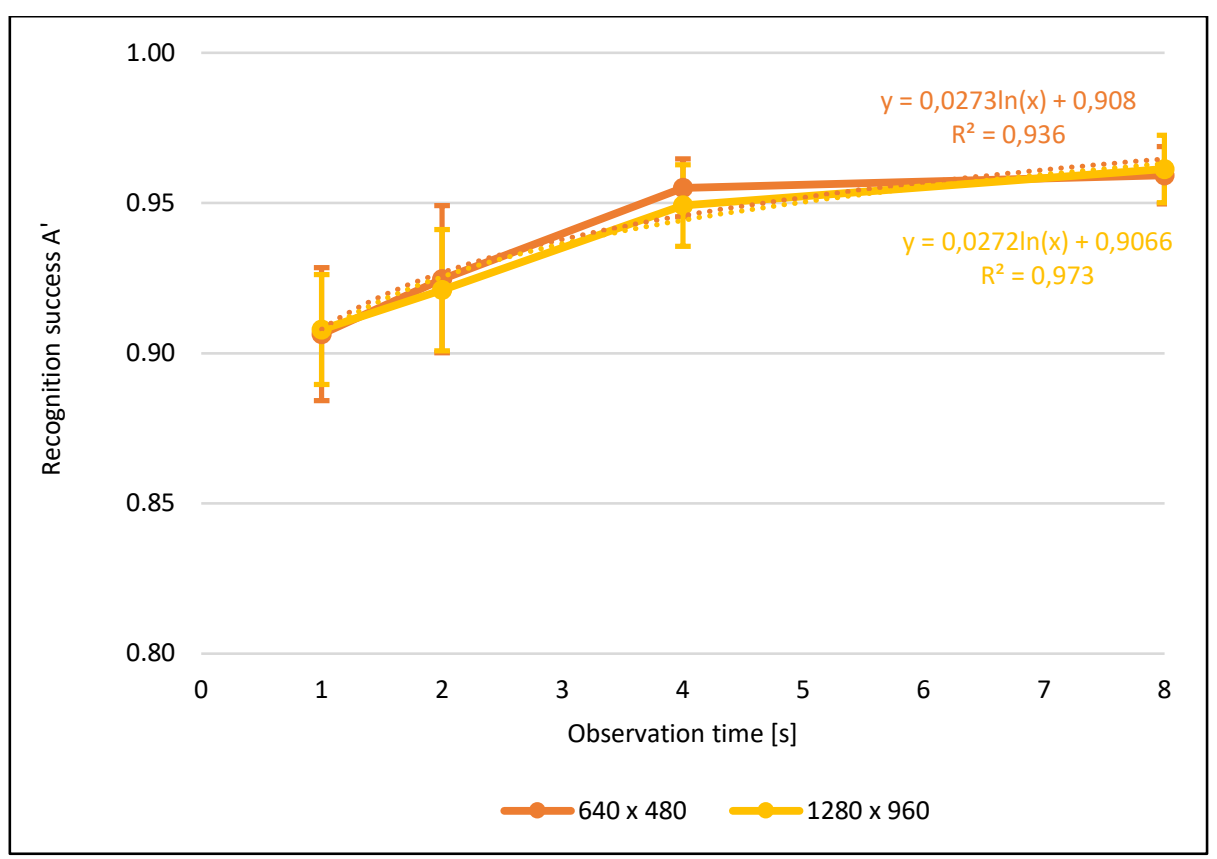

Figure 4: Results of recognition success

For all eight tests we also obtained the results of incorrect recognition (FA), which are shown in Figure 5, for both dimensions of facial images depending on the time of display of facial images in the observation test.

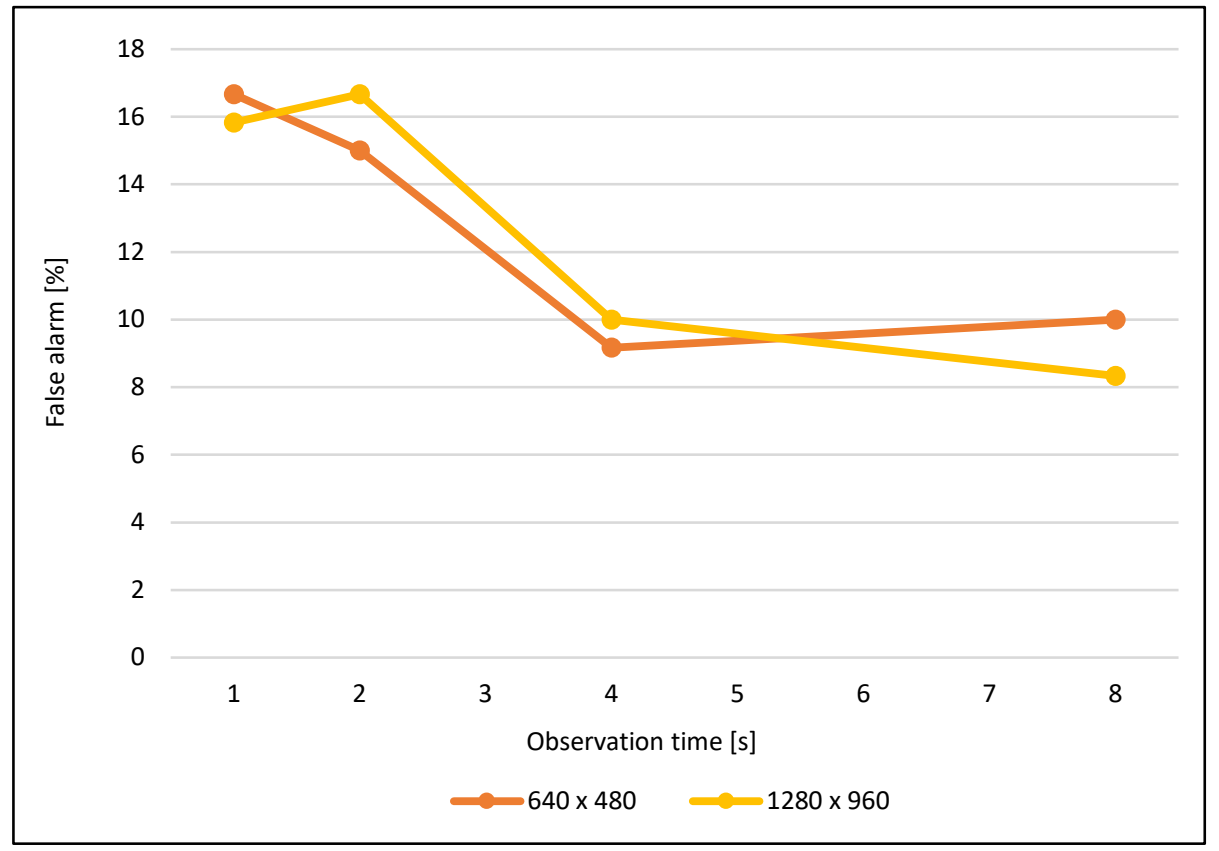

Figure 5: Results of incorrect recognition (FA)

The main results of the eye tracking system were fixations duration and saccade length, which were obtained as described in the Method section. Both results are shown in Figure 7 and Figure 8. 


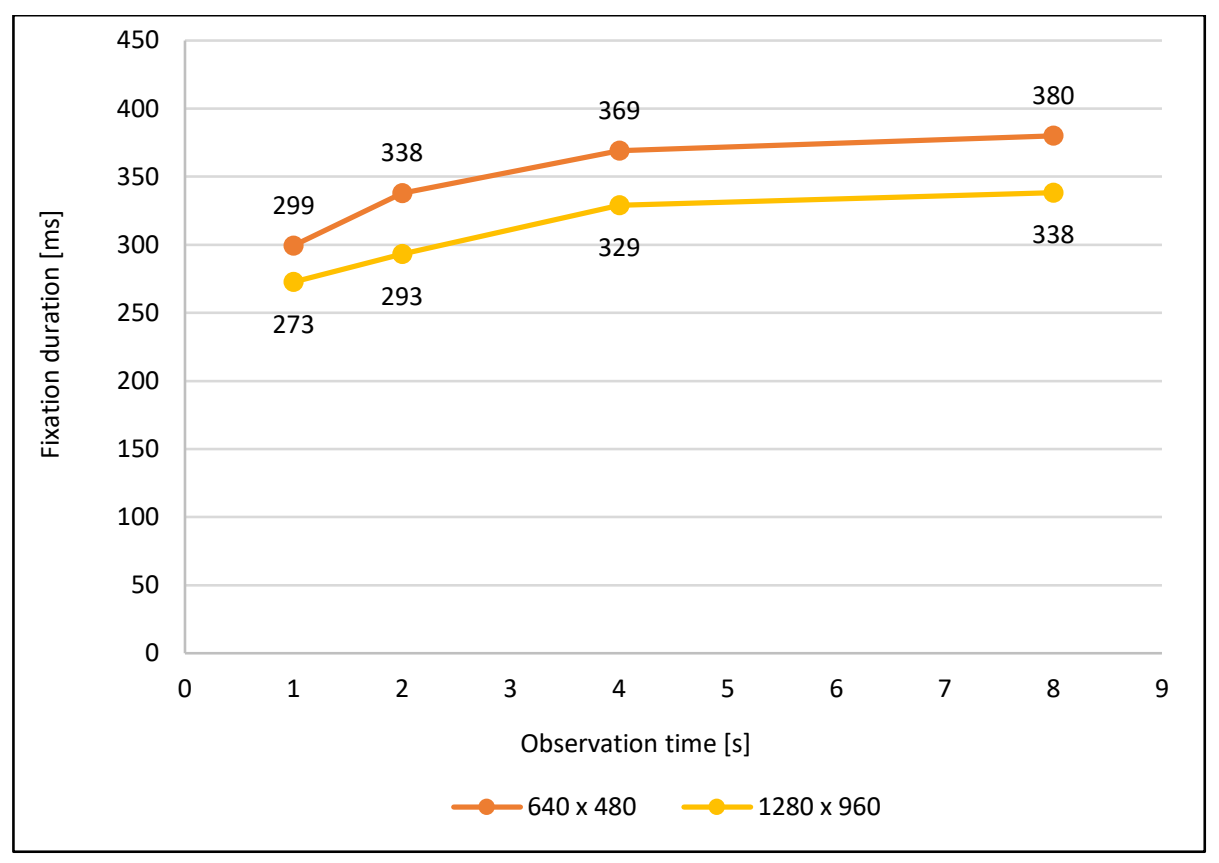

Figure 6: Results of fixation duration

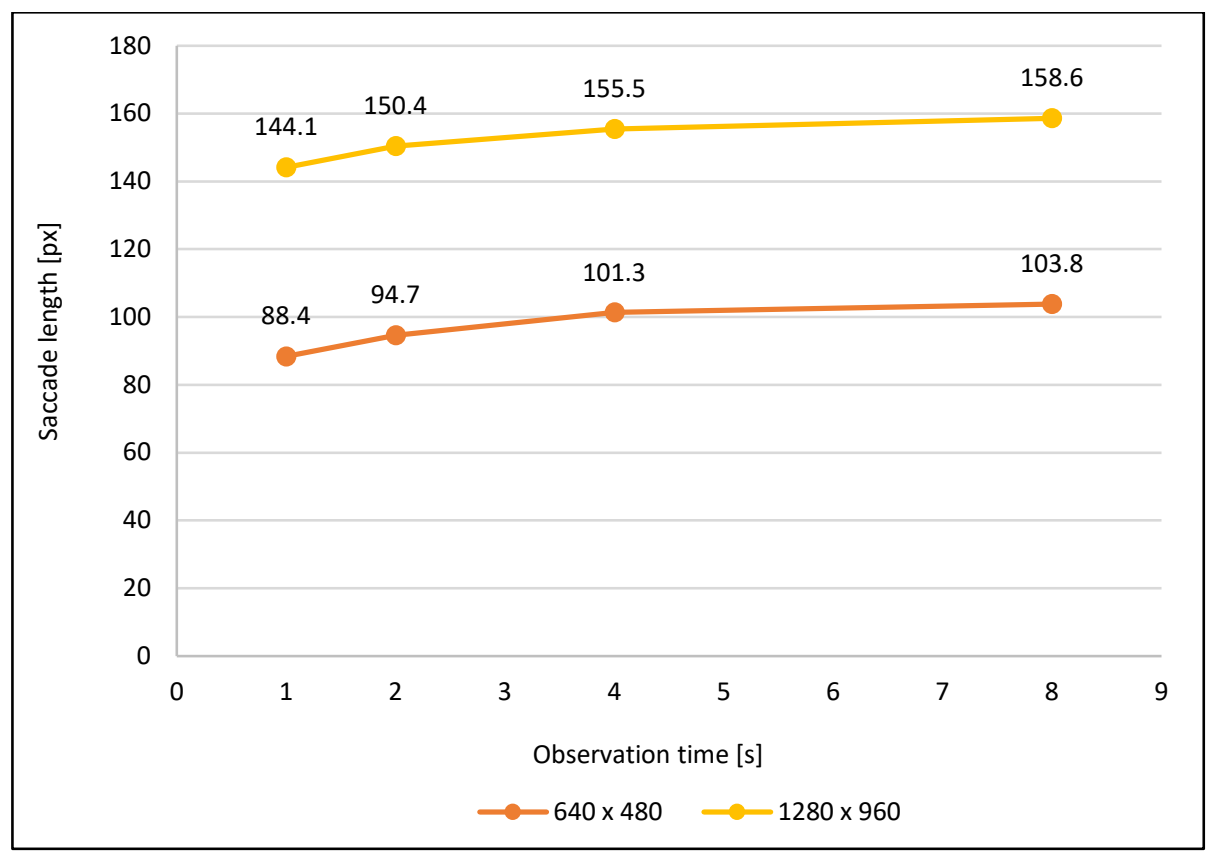

Figure 7: Results of fixation duration

\section{DISCUSSION}

The results of the recognition success show that it increases with the longer time of displaying facial images in the observation test. This is to be expected because the test subjects memorized their faces better over a longer period of display of the images and recognized them better in the recognition test. The increase in recognition success occurred up to the observation time of four seconds. In the 8-second observation test, the recognition success is almost the same (dimensions $640 \times 480$ ) or only slightly increased (dimensions $1280 \times 960$ ). However, the results are very similar for the two different dimensions of facial images, so we see that the dimensions of facial images have no influence on memory and recognition. Even before the tests, we assumed that the recognition curve would have a logarithmic shape as a function of time. This means that in the short time of displaying facial images the recognition success improves rapidly, 
and in the longer time it slows down or remains almost the same (we reach saturation). The very good matching of the result curves with the logarithmic curve is also shown by the determination coefficient R2 (for the dimensions $640 \times 480$ it is 0.936 , for the dimensions $1280 \times 9600.973$ ). These logarithmic curves can be used to predict the recognition success for other facial image display times (e.g. three seconds or six seconds).

In the case of incorrect recognition, we see that it decreases with increasing display time of the facial images. This can be explained by the fact that the test persons remembered facial images better with longer display time and therefore made fewer errors in recognition process. The results show us an interesting turning point. With short display times of facial images (one and two seconds) the error detection is high (approx. 15\%), with 4s and 8s tests it is significantly lower (approx. 10\%). Here, too, we see a big change in the results in the 4 s test.

As for the fixation duration, we obtained the results of an increasing fixations duration with longer display time of the facial images. This is due to the fact that the eyes calmed down more with longer display times of the facial images and the facial images were observed in a more relaxed manner. This leads to a longer fixation duration. With fast change of the facial images (display time of one second) the eye was more disturbed and moved faster. As a result, gaze remained at a certain location for a shorter time and the fixations duration was shorter. Here, too, we see a tendency towards a smaller increase in the results of the fixation duration in the 4-second test. If we compare the dimensions of the facial images, we see that fixations were shorter at larger dimensions. We see the reason for this in the fact that the facial parts are larger in larger facial images. Depending on the setting of the fixation threshold, the eye tracking system detected more fixations on a larger area of the facial parts and these are consequently shorter in time. In smaller facial images, however, the facial parts were closer together and some small eye movements were not even perceived by the eye tracking system as individual fixations, but as a single fixation. As a result, we had fewer fixations that last longer.

In the results of the saccade lengths we can see that they lengthened with increasing display time of the facial images. During the short display time of the facial images, the test subjects had very little time, so their gaze was mainly directed to the central part of the face (eyes, nose and mouth). When they had more time available, they also looked at other parts of the face and thus saccades were longer. Again, we see a smaller increase in saccade lengths between the $4 \mathrm{~s}$ and 8 s tests than in the tests with shorter display time. When we compare the lengths of saccades in facial images with different dimensions, it is obvious that they were longer in images with larger dimensions. There is a factor of 2 between the two dimensions of the facial images we tested, and the ratio of saccade lengths between the two dimensions of the facial images is smaller (1.53 to 1.63). The reason for the smaller factor of the ratio of the average saccade lengths compared to the ratio of the dimensions of the facial images is that in larger images, the gaze was directed more towards the face itself and left the facial area less frequently than in smaller images. So in smaller facial images we got several individual long saccades, which increased the average saccade length.

\section{CONCLUSIONS}

In our research, which focused on profile facial images, we found that extending the display time of facial images in the observation test improves memory and thus the recognition of facial images in the recognition process. This is reflected in recognition success and incorrect recognition. Similar results have been demonstrated several times for frontal facial images, but there are far fewer studies for profile facial images. The main focus of these results was mainly on the acquisition of logarithmic curves of the dependence of recognition performance from the time of display of facial images in the observation process. These logarithmic curves can be used to predict recognition performance for other facial image display times (e.g. three seconds or six seconds). Both the results of recognition success and incorrect recognition show us a turning point in the test of four seconds display time of facial images. Longer display time of facial images does not improve memory and thus recognition. This was also shown with frontal facial images (Iskra and Gabrijelič, 2019).

The turning point in the observation of facial images at a display time of four seconds was also evident in the results of the fixation duration and the saccade length, where this change (the increase in both values) was not so obvious. Similar results were also obtained for frontal facial images (Iskra and Gabrijelič, 2019). In the future, we will use the area method and the internal facial features method to further confirm the results in detail. 


\section{RERENCES}

[1] Du, S., Martinez, A. M.: "The resolution of facial expressions of emotion", Journal of Vision 11 (13), 1-13, 2011. doi: 10.1167/11.13.24.

[2] Green, C., Guo, K.: "Factors contributing to individual differences in facija expression categorisation", Cognition and Emotion 32 (3), 37-48, 2018. doi: 10.1080/02699931.2016.1273200.

[3] Iskra, A., Gabrijelič, H. T.: "Time and Spatial Eye-Tracking Analysis of Face Observing and Recognition", Technical Gazette 26 (4), 977-984, 2019. doi: 10.17559/TV-20180309142158.

[4] Kyrnin, J.: "What is Web Content? ", URL: http://webdesign.about.com/od/content/qt/what-is-webcontent.htm (last request: 2020-04-02).

[5] Liu, C.H., Chaudhiri, A.: "Reassesing the 3/4 view effect in face recognition", Cognition 83, 31-48, 2002. doi: 10.1016/S0010-0277(01)00164-0.

[6] Minear, M., Park, D.: "A lifespan database of adult facial stimuli", Behavior Research Methods, Instruments \& Computers 36 (4), 360-363, 2000. doi: 10.3758/bf03206543.

[7] Pernice, K., Nielsen, J.: "Eyetracking methodology: how to conduct and evaluate usability studies using eyetracking", (Fremont, USA, Nielsen Norman Group 2009.), page 164.

[8] Tarnowki, P., Kolidziej, M., Majkovski, A., Rak, R. J.: "Emotion recognition using facial expressions", Precedia Computer Science 108, 1175-1184, 2017. doi: 10.1016/S0010-0277(01)00164-0.

[9] Tobii Studio, User's Manual version 3.4.5, Tobii Pro, URL: https://www.tobiipro.com/siteassets/tobiipro/user-manuals/tobii-pro-studio-user-manual.pdf (last request: 2020-06-12).

(C) 2020 Authors. Published by the University of Novi Sad, Faculty of Technical Sciences, Department of Graphic Engineering and Design. This article is an open access article distributed under the terms and conditions of the Creative Commons Attribution license 3.0 Serbia (http://creativecommons.org/licenses/by/3.0/rs/). 



\title{
EYE TRACKING STUDY OF FRONTAL AND PROFILE FACE IMAGE OBSERVATION AND RECOGNITION
}

\author{
Andrej Iskra \\ University of Ljubljana, Faculty of Natural Sciences and Engineering, Department of Textiles, \\ Graphic Arts and Design, Chair of Information and Graphic Arts Technology, Ljubljana, Slovenia
}

\begin{abstract}
Facial images are an important element of nonverbal communication. Eye-tracking systems enable us to objectively measure and analyse the way we look at facial images and thus to study the behaviour of observers. Different ways of looking at facial images influence the process of remembering faces and recognition performance. In the real world we are dealing with different representations of faces, especially when we look at them from different angles. Memory and recognition performance are different when test subjects look at the face from the frontal or from a profile view. We studied crossobservation and recognition, so we performed two tests. In the first test, subjects observed facial images shown in the frontal view and recognized them in the profile view. In the second test, the faces were observed from the profile and recognized in the frontal view. The presentation time in the observation test was four seconds, which was found to be an adequate time for sufficient recognition in some previous tests. The results were analysed with the well-known time and spatial method based on fixations and saccades and with the new area method using heatmaps of the eye tracking results. We found that the recognition success (correct and incorrect recognition) was better when the combination of frontal view and profile recognition was used. The results were then confirmed by measuring the fixation duration and saccade length. More visible facial features resulted in a shorter fixation duration and shorter saccade length, which led to a better memory. We also confirmed the results of observation and recognition by area analysis, where we measured the area, perimeter and circularity of heatmaps. Here we found that larger areas and perimeter and smaller circularity of heatmaps resulted in better memory of facial images and therefore better recognition.
\end{abstract}

Key words: Face image, eye tracking, facial features, face recognition, fixation time

\section{INTRODUCTION}

We see faces in nature when we communicate with other people in different representations. We talk about different angles in the representation of facial images and also about the representation of faces in different emotional states. In our study, we limited ourselves to a neutral facial expression and defined two different angles of representation of the facial image (frontal and profile representation). Some previous studies (Brielmann et al, 2014) have shown a better memory for facial images in frontal view. There the researchers used the same representations in the recognition test. However, in our research we combined different representations of facial images in the observation and recognition process. We were interested in which combination of observation and recognition of facial images was better: observation of the frontal view and recognition of the profile representation or the inverse combination of observation of the profile representation and recognition of the frontal view. Researchers typically measure the fixations duration and the saccades length from which they can determine the appearance and thus the memory performance of facial images (Hsiao and Cottrel, 2008). In our study, we also used a relatively new method of heatmap analysis, in which we measure the area, perimeter and circularity of the viewing areas (Iskra, 2020). To obtain these results, we used eye tracking technology, which is considered the most objective method in this field and has recently been widely used in cognitive studies, ergonomics, psychology, marketing, security, etc. (Senior and Bolle, 2002).

\section{METHODS}

\subsection{Participants}

Our tests were attended by 22 test participants, 6 male and 17 female (average age of 20.6, SD = 1.02). They were our students, all of whom had normal vision. The participants received a bonus in the evaluation of their study. 


\subsection{Stimuli}

For testing purposes, we took 40 male and 40 female facial images from the Minear and Park database (Minear and Park, 2000). We selected 20 faces for both genders, as well as a frontal and a profile image for each face. An example of two face images (male frontal view and female profile view) is shown in Figure 1. The dimensions of the facial images were $800 \times 800$ and were displayed at a distance of $60 \mathrm{~cm}$ from the screen in a size corresponding to the conditions of natural observation (face viewed at a distance of 1 meter) (Henderson et al, 2005).

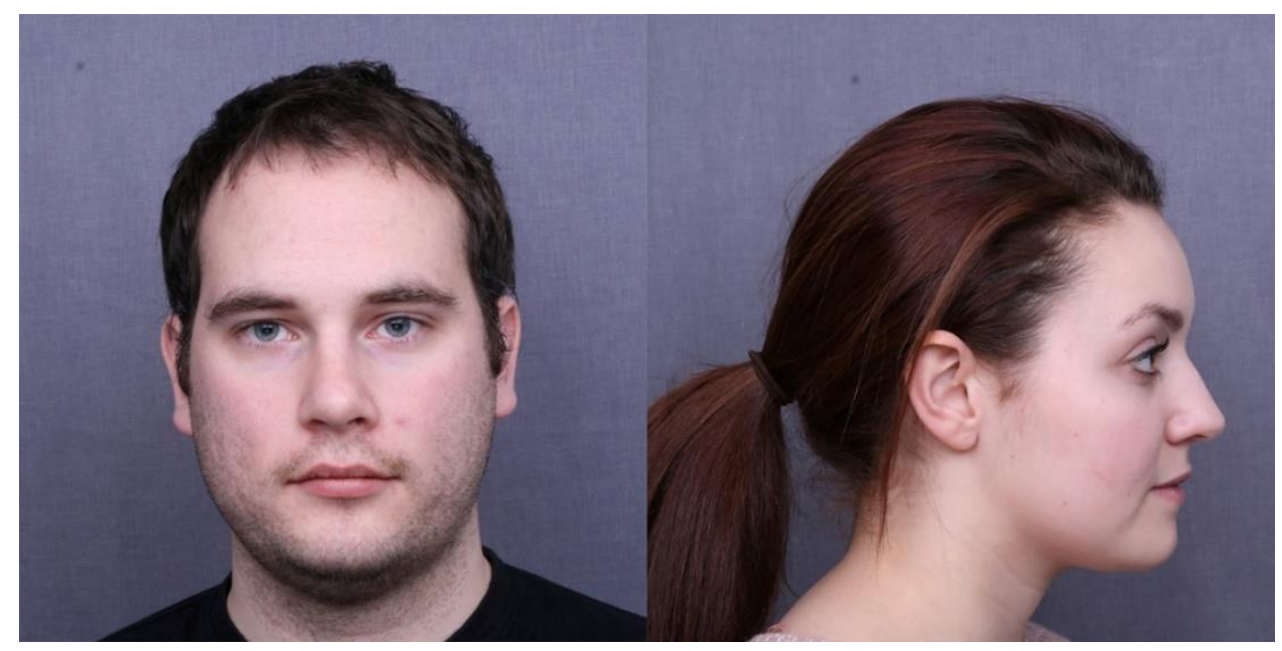

Figure 1: Stimuli facial images

\subsection{Apparatus}

The tests were carried out in the Laboratory of Visual Perception and Colorimetry at the Department of Textile, Graphic and Design of the Faculty of Natural Sciences and Engineering at the University of Ljubljana. When setting up the environmental and testing system we followed the standards and recommendations (Pernice and Nielsen, 2009).

We performed the test with the Tobii X-120 eye tracking system. The distance between the test subjects and the screen with the facial images was $60 \mathrm{~cm}$. The setting of the test environment and the test subject is shown in Figure 2.

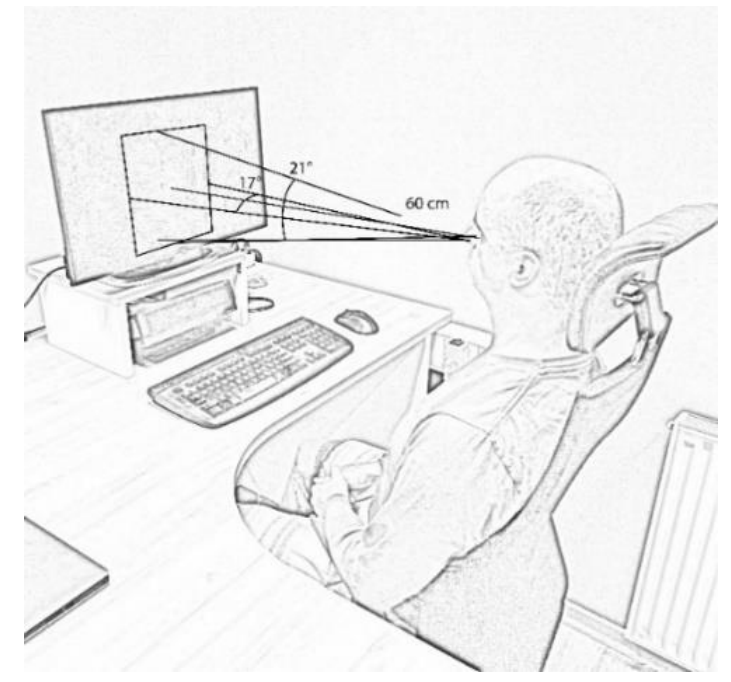

Figure 2: Testing setup

Analysis were done in Tobii Studio 3.4.8 software. The defaults setting for definition of fixation was 100 $\mathrm{ms}$ for 30 pixel area. That means if eyes stayed in the area 30 pixel for at least $100 \mathrm{~ms}$ it was concerned as one fixation (Tobii Studio, 2016). 


\subsection{Procedure}

We had two main tests, and both were divided into observation and recognition test. This is commonly referred as a memory test. However, cross-recognition meant that the images from the observation test and the recognition test were displayed at different angles. First test included 20 images of the frontal view (observation test) and 40 images of the profile view (recognition test), while second test had 20 images of the profile view in the observation test and 40 images of the frontal view in the recognition test. In this way, we wanted to find out which combination was more successful in remembering and later recognizing facial images. The observation test (Figure 3) was automatic, so that the test participants had no influence on the display of facial images which were presented for 4 seconds, a time that allows a satisfactory memory of facial images (Iskra, 2020). After the instructions and a black screen appeared to neutralize the participants gaze, then a facial image display followed for 4 seconds, then again a black screen for 2 seconds and a new facial image. The display was evenly distributed between male and female facial images.

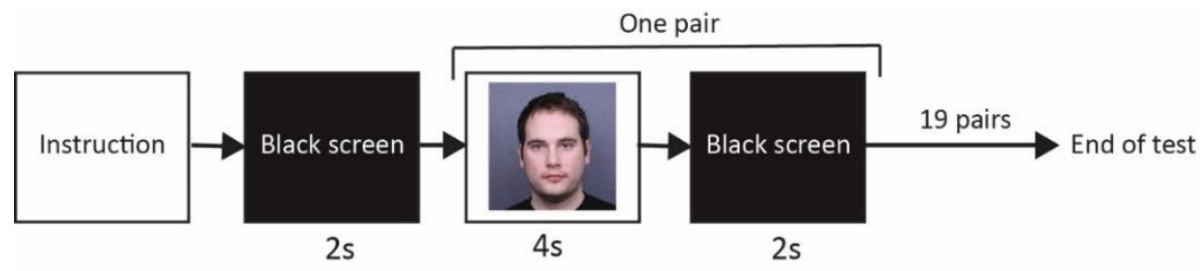

Figure 3: Procedure of observation test

However, the recognition test was controlled by the participants. After the instructions and a 2 second black screen, the facial image was displayed in a different view than in the observation test. When the participants answered whether or not they had seen the face in the observation test, they clicked the mouse button and a new facial image appeared. Recognition test contained 40 facial images. The procedure is shown in Figure 4.

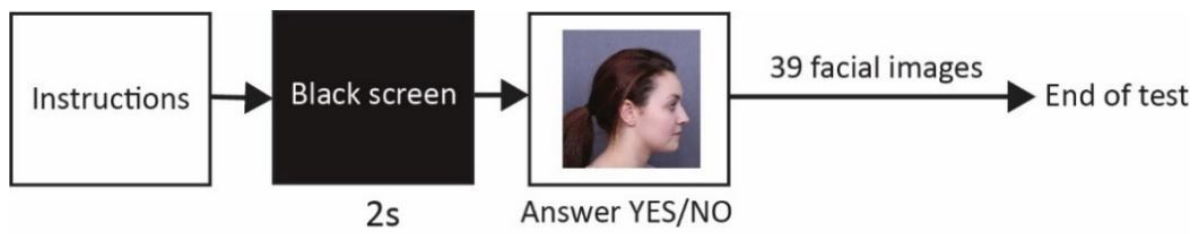

Figure 4: Procedure of recognition test

\subsection{Analysis of results}

We presented the results in several ways. The recognition results were presented as correct and incorrect recognition. The correct recognition means that the facial image was the observation test, and the test participant confirmed that in the recognition test. However, incorrect recognition, means that for a particular facial image in the recognition test, the participants answered that they had seen it in the observation test, but it was not really there.

Another group of results was measuring the fixation duration and saccade length. The fixation duration was obtained directly from Tobii Studio, and saccade length was calculated by as a distance between two consecutive fixations, as shown in Equation 1.

$\mathrm{F}_{1} \mathrm{~F}_{2}=\sqrt{\left(\mathrm{x}_{1}-\mathrm{x}_{2}\right)^{2}+\left(\mathrm{y}_{1}-\mathrm{y}_{2}\right)^{2}}$

The saccade length then had to be converted from px to angular degrees ${ }^{\circ}$ using Equation 2.

$\alpha=\arctan \frac{F_{1} F_{2}}{60 R}$

where $\mathrm{R}$ is the screen resolution. In our case we set $27.5 \mathrm{px} / \mathrm{cm}$.

However, the third group of results was the heatmap analysis, where we analysed their area, perimeter and circularity. The procedure was as follows: colour heatmaps were converted to grayscale (in Tobii 
Studio) and grayscale were then converted to black and white in ImageJ. In this program, we also calculated the parameters of these heatmaps described above. The procedure is shown in Figure 5.
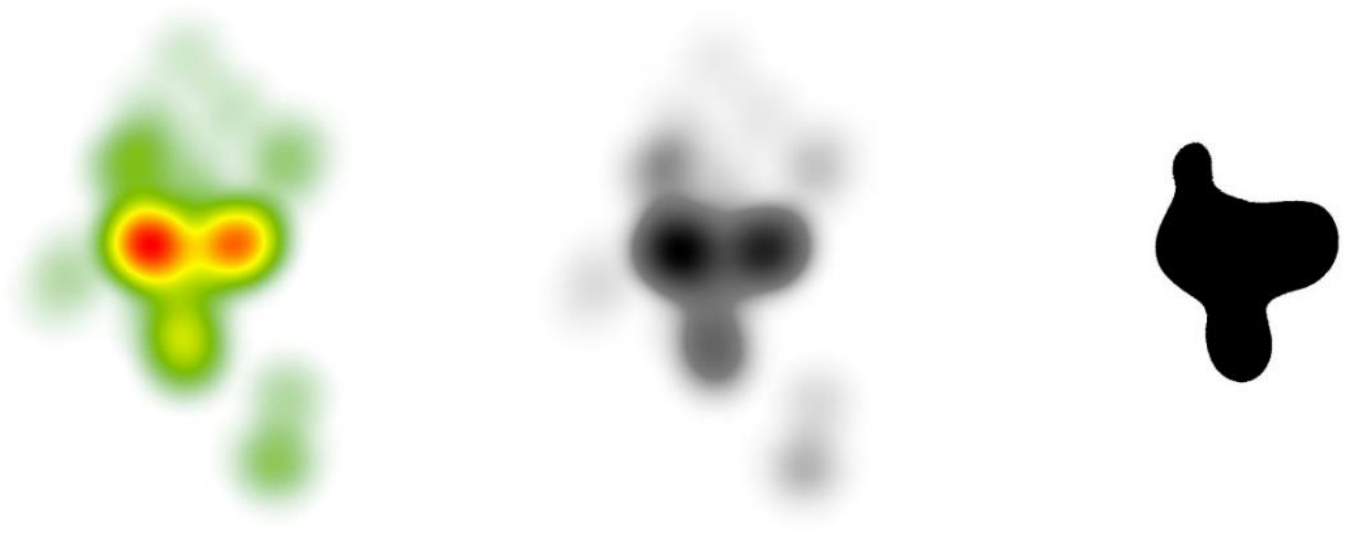

Figure 5: Colour, grey and BW heatmap

\section{RESULTS}

We compared the test results of two different conditions (frontal observation, profile recognition and opposite). Table 1 shows the correct and the incorrect recognition.

Table 1: Results of correct and incorrect recognition for both test combinations

\begin{tabular}{|l|c|c|}
\hline Test combination & Correct recognition & $\begin{array}{c}\text { Incorrect } \\
\text { recognition }\end{array}$ \\
\hline Frontal observation, profile recognition & $72,9 \%$ & $10,7 \%$ \\
\hline Profile observation, frontal recognition & $69,2 \%$ & $25,4 \%$ \\
\hline
\end{tabular}

Further results were fixation duration and saccade length (Table 2). In the controlled observation tests (4second image display) they were more comparable than in the recognition test, in which the image display times were controlled by the participants themselves when they made decision of the displayed facial image. These times were different for each facial image for each participant.

Table 2: Results of fixation duration in saccade length for both test combinations

\begin{tabular}{|l|c|c|c|c|}
\hline \multirow{2}{*}{ Test combination } & \multicolumn{2}{|c|}{ Fixation duration (ms) } & \multicolumn{2}{c|}{ Saccade length $\left(^{\circ}\right)$} \\
\cline { 2 - 5 } & Observation & Recognition & Observation & Recognition \\
\hline Frontal observation, profile recognition & 320 & 308 & 3,79 & 4,97 \\
\hline Profile observation, frontal recognition & 349 & 266 & 4,72 & 4,14 \\
\hline
\end{tabular}

We analysed heatmaps for both cross-tests, but only for the observation process, since we had controlled conditions (observation time 4 seconds). The results of the area, perimeter and circularity of heatmaps and are shown in Table 3.

Table 3: Results area, perimeter and circularity of heatmaps in the observation test

\begin{tabular}{|l|c|c|c|}
\hline Test combination & Area $(\mathrm{px})$ & Perimeter $(\mathrm{px})$ & circularity \\
\hline Frontal facial images & 46029 & 888 & 0,739 \\
\hline Profile facial images & 39269 & 784 & 0,805 \\
\hline
\end{tabular}




\section{DISCUSSION}

As can be seen from Table 1, the correct recognition was better for the combination of frontal view observation and profile recognition than the reverse combination. An even greater difference occurs with incorrect recognition. The reason is the poorer memory of profile facial images, because in profile view there are fewer facial features according to which we remember and distinguish faces. With correct identification, this difference is insignificant (72.9\% vs. 69.2\%), but with incorrect recognition a greater difference occurs (25.4\% vs. $10.7 \%$ ). Similar results of significantly worse identification when observing profile face images compared to frontal facial images were also found by other researchers (Iskra, 2020). Regarding fixation duration, we see that the fixation duration was shorter in the observation for frontal facial images. This can be seen in both the observation test (frontal $320 \mathrm{~ms}$, profile $349 \mathrm{~ms}$ ) and the recognition test (frontal $266 \mathrm{~ms}$, profile $308 \mathrm{~ms}$ ). We see the reason for this in the greater number of facial features in frontal view that attracted participants gaze, so that there are more eye movements and the fixations are consequently shorter. Here the results are more relevant for the observation process, because we had controlled conditions with the same observation time for all participants and for all facial images (4 seconds) and in this test the eyes calmed down more and looked at the facial images more relaxed (longer fixations). During recognition, the participants controlled facial image display and the test was faster, so the eyes were more "active" and the fixation duration was shorter. However, the results of the fixation duration in the observation process are a confirmation of the previous research (Iskra, 2020). The only difference is that a slightly longer fixation duration was found there (frontal facial images 331 $\mathrm{ms}$, profile facial images $362 \mathrm{~ms}$ ), but the difference is almost the same. The longer fixation duration in their research is due to the smaller facial image dimension, because with the smaller dimensions of facial images the fixation duration increases (Iskra, 2020).

Results of saccade lengths in the observation process shows that these were shorter in frontal facial images $\left(3.79^{\circ}\right)$ than in profile facial images $\left(4.72^{\circ}\right)$. Frontal facial images have more facial features that are relatively close together (eyes, nose, mouth), so saccades are shorter than in profile facial images, where fewer facial features are shown and are further apart (especially the ear is far away from an eye and the nose). Similarly, the saccades in the recognition test are shorter $\left(4.14^{\circ}\right)$ in frontal facial images than in profile facial images $\left(4.97^{\circ}\right)$. However, the saccades in the recognition process are usually longer than in the observation. We also performed a heatmap analysis. We did this for both cross-tests, but only for the observation process, because we had controlled conditions (observation time 4 seconds). The heatmaps were analysed by ImageJ, where we obtained area, perimeter and circularity. The results for the both facial images (frontal and profile) are shown in Table 3, and we can see that the area and perimeter of the heatmap are larger in the frontal facial images (46029 px and 888 px) than in the profile facial images (39269 px and 784 px). In the case of circularity, the result is the opposite, profile images have a higher circularity (0.805) than frontal images (0.739). These results can again be explained by the structure of the frontal and profile facial images themselves. Frontal facial images show several main facial features (eyes, nose, mouth), which are arranged further apart. In profile facial images, one eye and the nose are the main facial features that attract attention and are close together. Therefor the area of the heatmaps is smaller and consequently the perimeter is smaller. However, these areas are geometrically rounder and the circularity is greater. These results are confirmed by Figure 6, which shows the colour and black and white heatmap for frontal and profile facial images. In previous studies (Iskra, 2020), researchers have already shown that a larger area and perimeter, as well as a smaller circularity, leads to better memory for facial images, which was also confirmed in our results.

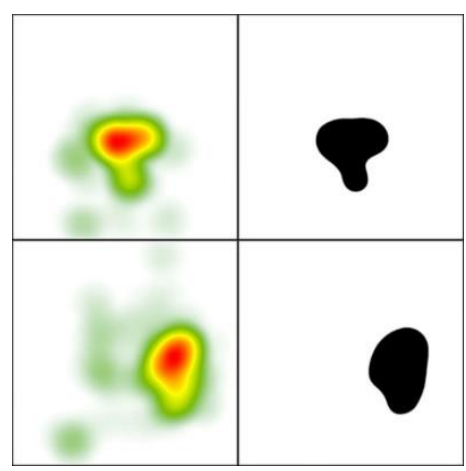

Figure 6: Colour and BW heatmap for frontal (top) and profile (bottom) facial images 


\section{CONCLUSIONS}

In our research we were interested in which combination of observation and recognition of facial images is better: observation of the frontal view and recognition of the profile view or the reverse combination of observation of the profile view and recognition of the front view. Even before the research, we predicted better results in frontal facial image observation and profile recognition. The reason is that frontal facial image contains more facial features, so the face provides more information that helps us to remember it. This was also confirmed by the results, especially in case of incorrect recognition. The way we see and remember faces is also determined by the way facial image are displayed. In the frontal facial images, we see a larger part of the face, which was confirmed by the shorter fixation duration. There were more of these fixations, which in turn leads to a better memory of the facial image. A better memory for the frontal facial images due to the placement of the facial features was also confirmed by shorter saccade lengths. The results were also presented using a newly introduced method of heatmap analysis, where we confirmed that the memory of facial images is better in frontal views, where the area and perimeter of heatmaps are larger and circularity smaller.

\section{REFERENCES}

[1] Brielmann, A.A., Büthoff, I., Armann, R.: "Looking at faces from different angles: Europeans fixate different features in Asian and Caucasian faces", Vision Research 100, 105-112, 2014. doi: 10.1016/j.visres.2014.04.011.

[2] Henderson, J.M., Williams, C.C., Falk. R.J.: "Eye movements are functional during face learning", Memory \& Cognition 33, 98-106, 2005. doi: 10.3758/bf03195300.

[3] Hsiao, J.H., Cottrel, G.W. "Two fixations suffice in face recognition", Psychological Science 9, 9981006, 2008. doi: 10.1111/j.1467-9280.2008.02191.x.

[4] Iskra, A.: "Development of combined method for analysis of facial images using eye tracking system", PhD thesis, University of Ljubljana, 2020.

[5] Minear, M., Park, D.: "A lifespan database of adult facial stimuli", Behavior Research Methods, Instruments \& Computers 36, 360-363, 2000. doi: 10.3758/BF03206543.

[6] Pernice, K., Nielsen, J.: "Eyetracking methodology: how to conduct and evaluate usability studies using eyetracking", (Fremont, USA, Nielsen Norman Group, 2009.), page 164.

[7] Senior A.W., Bolle, R.: "Face recognition and its applications. Biometric Solutions for Authentication in an E-World", (Boston, USA, Kluwer Academic Publishers, 2002.), pages 101-115.

[8] User's Manual Tobii Studio version 3.4.5 (Tobii Technology, Danderyd, Sweden, 2016.), page 40.

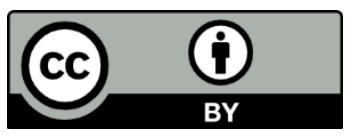

(C) 2020 Authors. Published by the University of Novi Sad, Faculty of Technical Sciences, Department of Graphic Engineering and Design. This article is an open access article distributed under the terms and conditions of the Creative Commons Attribution license 3.0 Serbia (http://creativecommons.org/licenses/by/3.0/rs/). 


\title{
3D PRINTING AND FUNCTIONALIZATION OF TEXTILES
}

\author{
Marjeta Čuk (D), Matejka Bizjak (D), Deja Muck (D), Tanja Nuša Kočevar (i) \\ University of Ljubljana, Faculty of Natural Sciences and Engineering, \\ Department of Textiles, Graphic Arts and Design, Ljubljana, Slovenia
}

\begin{abstract}
D$ printing is used to produce individual objects or to print on different substrates to produce multi-component products. In the textile industry, we encounter various $3 D$ printing technologies in fashion design, functional apparel manufacturing (protective, military, sports, etc.), including wearable electronics, where textile material is functionalized. 3D printing enables the personalization of the product, which in the apparel industry can be transformed into the production of clothing or parts of clothing or custom accessories.

Additive technology allows a more rational use of the material than traditional technologies. In the textile industry we meet different uses of it, one is the printing of flexible structures based on rigid materials, another is the printing with flexible materials and the third is the printing directly on textile substrate. All rigid, hard and soft or flexible materials can be integrated into the final design using 3D printing directly on the textile substrate. We speak of so-called multi-material objects and systems, which have many advantages, mainly in the increasing customization and functionalization of textiles or clothing.

The article gives a broader overview of 3D printing on textiles and focuses mainly on the influence of different parameters of printing and woven fabric properties on the adhesion of 3D printed objects on the textile substrate.

In our research we investigated the influence of twill weave and its derivate as well as different weft densities of the woven fabric on the adhesion of printed objects on textile substrate. Therefore, five samples of twill polyester/cotton fabrics were woven and their physical properties measured for this research. 3D objects were printed on textile substrates using the extrusion based additive manufacturing technique with polylactic acid (PLA) filament. Preliminary tests were carried out to define printing parameters and different methods of attaching the fabric to a printing bed were tested. $T$ - Peel adhesion tests were performed on the Instron dynamometer to measure the adhesion between $3 D$ printed objects and textile substrates.
\end{abstract}

Key words: 3D printing, FDM, textiles, woven structure, multi-material object

\section{INTRODUCTION}

3D printing technology has developed very rapidly over the last years and is used in various fields of industry. It is an additive manufacturing (AM) technology based on the principle of building objects by adding layers of material and connecting them in different ways depending on the type of 3D technology and the material used (Gibson et al, 2015).

Only recently 3D printing became established in the fashion and textile industry where various technologies are used for production of decorative elements, fashion accessories, various textile structures or for functionalization of textile. For example, the fashion industry uses 3D technology for innovative products such as 3D printed shoes, garments, accessories, designed by many prominent designers.

As Sitotaw and colleagues (Sitotaw et al, 2020) consider the present state of textiles and additive manufacturing, the new technology in general influences the textile production in three directions: One is printing of flexible structures based on rigid materials, where structures are made to recreate some textile properties. Designers and technologists are exploiting many possibilities of the shape complexity of 3D models and the use of material properties to create 3D printed textile-based structures. For example, Melnikova and associates used Selective laser sintering (SLS) and Fused Deposition Modeling (FDM) technology to create weft knitted fabric structures (Melnikova et al, 2014).

Another direction that is emphasized is printing with flexible materials. The third direction is 3D printing on textiles, which is the most used process at the moment. It is utilized for adding different features and functions to the textile that can make a product that is personalized and optionally customized. Different polymers can be printed directly onto textile surfaces in previously modeled forms to produce multimaterial objects that combine the advantages of both technologies and materials (Unger et al, 2018), (Kozior et al, 2018). Creating multi material objects with 3D printing on textile substrate, aesthetics and 
functionality can be added to textile fabrics by improving the mechanical properties of the fabrics and maintaining their drape and other characteristics.

Fused Deposition Modeling (FDM) technology is the most appropriate for printing on existing objects (Kozior et al, 2018), therefore it is usually used for production of multi-material objects with textiles. FDM is the AM technology based on material extrusion in which a preheating station raises the temperature of the material, which is a polymer, to the melting point so that it can flow through a feed system. The polymer is fed into the system in the form of a thread. (Gibson et al, 2015)

Polymers frequently used for 3D printing with FDM technology are polylactic acid (PLA), that is the most commonly used material, acrylonitrile butadiene styrene (ABS), and some other materials, such as polycarbonate (PC), blend of PC and ABS and others (Muck et al, 2015). Regarding polymers commonly used for 3D printing, some researches have shown that printing with ABS produces lower adhesion than with PLA (Rivera et al, 2017; Pei et al, 2015), which may be the result of a higher viscosity of the latter during the 3D printing process (Kozior et al, 2020). The most important properties of multi-material objects made of 3D printed layers on textile substrates are good adhesion while maintaining the flexibility of the fabric. Particularly good adhesion is a very important factor because it influences the quality and durability of the final product. Nevertheless, flexibility is also of great importance.

The adhesion of the polymer to the substrate is performed by three main adhesion mechanisms that are mechanical coupling, molecular bonding and thermodynamic adhesion (Awaya et al, 2009).

A lot of research was performed on adhesion of 3D printed material on textile substrates (Pei et al, 2015), (Sanatgar et al, 2017) where different parameters were investigated, such as: fabric chemical pretreatment, weave pattern and infill orientation (Kozior et al, 2018), changes in shape geometry of printed materials (Spahiu et al, 2019), changes in structural properties of the fabric, changes of textile material (Mpofu et al, 2019; Sabantina et al, 2015; Malengier et al, 2017), and so on.

One of the very important printing parameters that influences the adhesion on textile substrates is the distance between the nozzle and the printing bed. If we reduce the distance, the adhesion force increases until the minimum distance is reached and the filament does not clog the nozzle. At a smaller distance the nozzle presses the polymer into the pore of the fabric with higher force (Spahiu et al, 2018). The temperature of the printing bed and nozzle has also great influence on the adhesion force, which was determined in various investigations. By increasing both temperatures, the viscosity of the molten PLA decreases during the printing process, which causes the material to penetrate deeper into the woven fabric (Spahiu et al, 2017; Spahiu et al 2018). In addition, the adhesion force depends on different infill orientations and also on the orientation of the first printing layer (Kozior et al, 2018).

The aim of our research was to investigate the influence of the fabric structure, namely weave and thread density, which have the greatest influence on the fabric surface. In addition to the fabric surface, which is crucial for adhesion in 3D printing on textiles, the mechanical properties of woven fabric are also important for many applications, including a composite that can be used for protective clothing. Therefore, twill weave was investigated, whereas it has very good mechanical properties and higher tensile strength compared to the plain weave (Jahan, 2017).

Twill weave and its derivative as well as different weft densities of the woven fabric were used to investigate the adhesion of printed products on fabric substrate.

\section{METHODS}

Five samples of polyester/cotton twill fabric were designed in ArahWeave program and woven for the purposes of this research. Two different weaves of four - end twill are shown as technical diagrams with their labels in Figure 1.
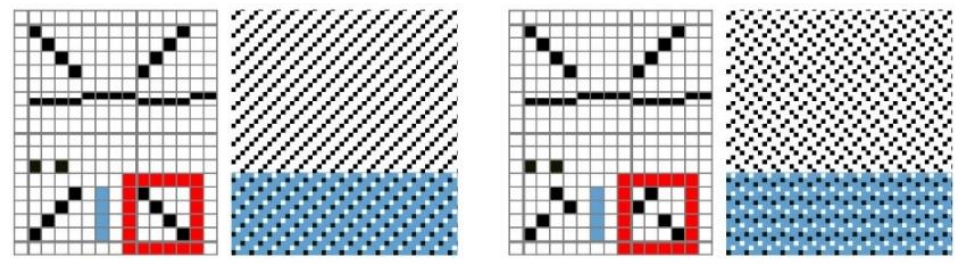

Figure 1: Technical schemes of woven fabrics and their labels (left: twill 1/3 - K13Z, right: broken twill 1/3 - K13L) 
All samples were woven on a Minifaber laboratory loom with a TIS jacquard mechanism with the preset warp density 40 ends/cm and three different weft densities: 15, 20 and 22 picks/cm. Black and white cotton yarns with a fineness of $8 \times 2$ tex were used for the warp and polyester blue yarn with a fineness of 33 tex for the weft.

Table 1 shows measured values of fabrics parameters. Physical properties such as yarn fineness, thickness, mass per square meter, real warp and weft density were measured in accordance with the standards. The thickness of the fabric was measured with a fabric thickness tester in two ways. Thickness 1 was measured according to the standard EN ISO 9863-1 with the standard circular pressure foot. Thickness 2 was measured when the fabric was placed in the mounting frame prepared for 3D printing and allowed a more accurate determination of the distance between the fabric and the nozzle. The mounting frame was designed so that the fabric could be placed on the 3D printer more accurately and quickly. The fabrics were raw and were not pretreated before 3D printing.

Table 1: Measured values of constructional properties of woven fabrics used as substrates for 3D printing (the sample label includes the name of the weave structure and the preset number of wefts per centimeter)

\begin{tabular}{|c|c|c|c|c|c|}
\hline Sample & $\begin{array}{c}\text { Thickness 1 } \\
(\mathrm{mm})\end{array}$ & $\begin{array}{c}\text { Thickness 2 } \\
(\mathrm{mm})\end{array}$ & $\begin{array}{c}\text { Mass } \\
\left(\mathrm{g} / \mathrm{m}^{2}\right)\end{array}$ & $\begin{array}{c}\text { Warp density } \\
(\mathrm{ends} / 10 \mathrm{~cm})\end{array}$ & $\begin{array}{c}\text { Weft density } \\
\text { (picks/10 cm) }\end{array}$ \\
\hline K13L 15 & 0.508 & 0.430 & 114.0 & 407 & 150 \\
\hline K13L 20 & 0.473 & 0.408 & 139.8 & 406 & 217 \\
\hline K13Z 15 & 0.489 & 0.423 & 112.8 & 404 & 146 \\
\hline K13Z 20 & 0.487 & 0.430 & 140.4 & 406 & 223 \\
\hline K13Z 22 & 0.474 & 0.424 & 152.6 & 415 & 252 \\
\hline
\end{tabular}

The 3D model of $25 \mathrm{~mm} \times 160 \mathrm{~mm} \times 0.4 \mathrm{~mm}$ was modeled, according to standard requirements, in the open source 3D creation suite Blender and exported as stl file. The stl file was imported into the slicing software Voxelizer, where all parameters for 3D printing were set (Table 2). The G-code was adjusted manually to avoid crashes of printing nozzle into the installation frame in which the fabrics were inserted. All the samples were printed with the ZMorph $2.0 \mathrm{SX} 3 \mathrm{D}$ printer with $1.75 \mathrm{~mm}$ PLA gray AzureFilm filament.

T - Peel adhesion tests were performed according to standard DIN 53530 using an Instron 5567 dynamometer, the separation rate was $100 \mathrm{~mm} / \mathrm{min}$.

Table 2: Printing parameters

\begin{tabular}{|l|c|}
\hline Parameter & Value \\
\hline Nozzle size & $0.4 \mathrm{~mm}$ \\
\hline Layer height & $0.2 \mathrm{~mm}$ \\
\hline Number of layers & 2 \\
\hline Infill print speed & $40 \mathrm{~mm} / \mathrm{s}$ \\
\hline Infill angle & $45^{\circ}$ \\
\hline Outline print speed & $30 \mathrm{~mm} / \mathrm{s}$ \\
\hline Outline count & 2 \\
\hline Extruder temperature & $210^{\circ} \mathrm{C}$ \\
\hline Bed temperature & $60^{\circ} \mathrm{C}$ \\
\hline Z-value (at first layer) & 0,35 \\
\hline
\end{tabular}

\section{RESULTS}

Figure 2 shows that in all cases, the measured warp density increased compared to the preset on-loom value, most pronounced for the fabric K13Z 22 by $3.75 \%$. The measured weft densities for the fabrics with the preset on-loom weft density 15 picks/cm stayed the same or decreased slightly, while the measured weft densities increased for the fabrics with 20 or 22 picks/cm preset weft density. The increase was highest for the sample K13Z 22 with 14.55\%.

With increasing weft density, the areal weight increased (Table 1), while the Thickness 1 and the Thickness 2 decreased. 


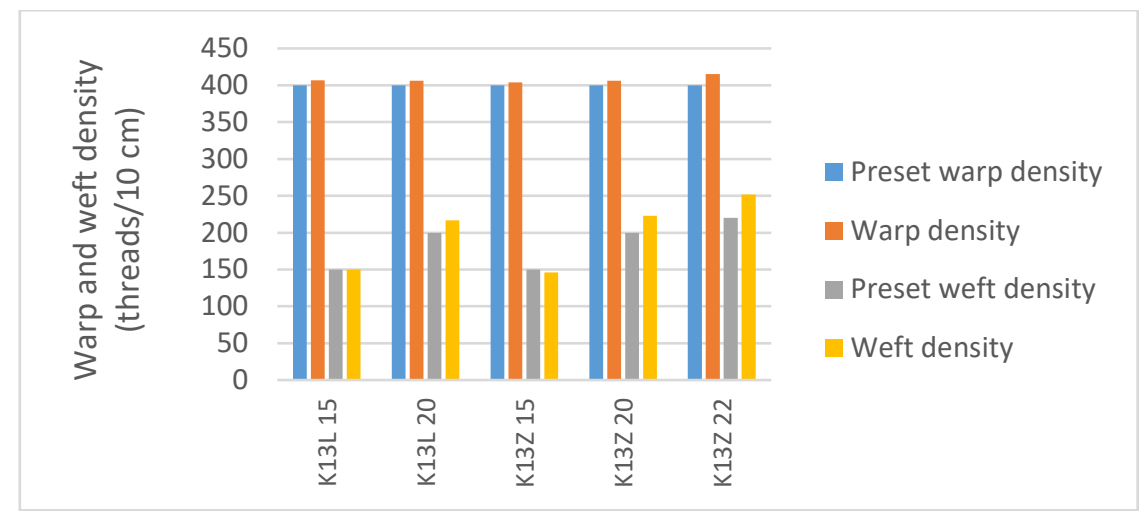

Figure 2: Preset and real densities of woven substrates

Figure 3 shows maximum adhesion forces and standard deviation on 3D printed textile substrates with the same weave and different weft densities. Stripped bars in the figures from 3 to 6 indicate that the fabric ruptured during adhesion test, before 3D printed object was detached from fabric.

The highest adhesion force was achieved at the lowest weft density at both weaves (K13Z and K13L) and the lowest adhesion force was achieved at preset weft density 20 picks $/ \mathrm{cm}$ and the broken twill $1 / 3$ (K13L). The highest standard deviation was calculated at broken twill $1 / 3$ and preset weft density 15 picks/cm (K13L 15) and the lowest at twill 1/3 and preset weft density 22 picks/cm (K13Z 22).

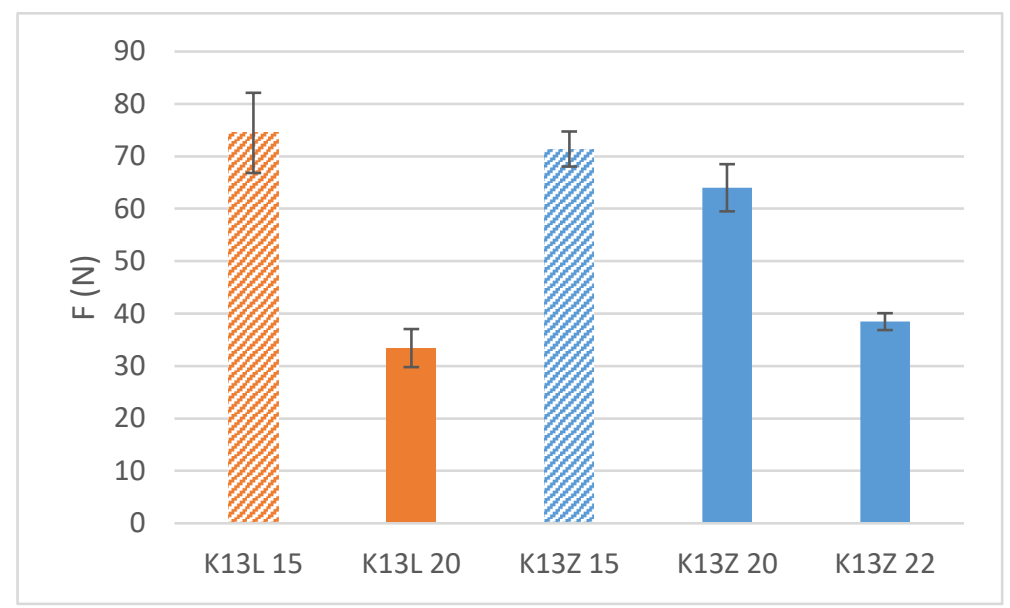

Figure 3: Dependence of the adhesion force on the woven samples

Comparing both weaves at the preset weft density 15 picks $/ \mathrm{cm}$, it can be seen that the highest adhesion forces are very similar for both samples (74,47 N for sample K13Z 15 and 71,39 N for sample K13L 15). The adhesion force on the twill $1 / 3$ is slightly lower than on the broken twill $1 / 3$. At the preset weft density of 20 picks $/ \mathrm{cm}$ the difference between the two adhesive forces is higher, the adhesion force on the twill $1 / 3$ is $64,01 \mathrm{~N}$ and on the broken twill $33,43 \mathrm{~N}$.

Figure 4 shows the influence of the mass on the adhesion force for different samples. For the same weave, the adhesion force decreases with increasing mass. Comparing all the samples, a change in the mass of the samples has no direct influence on the change in the adhesive force, but there is a general tendency that the adhesion force decreases with increasing mass. 


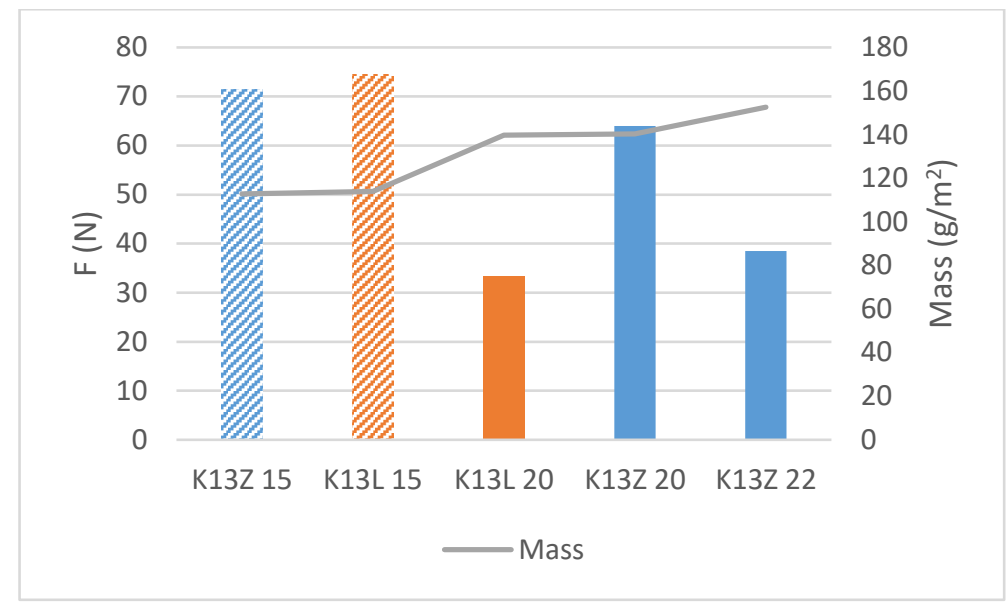

Figure 4: Dependence of the adhesion force on the mass for different samples

In Figure 5, where the dependence of the adhesion force on the thickness of the fabric, measured according to the textile standard on the samples, is shown that the adhesion force increases with increasing thickness.

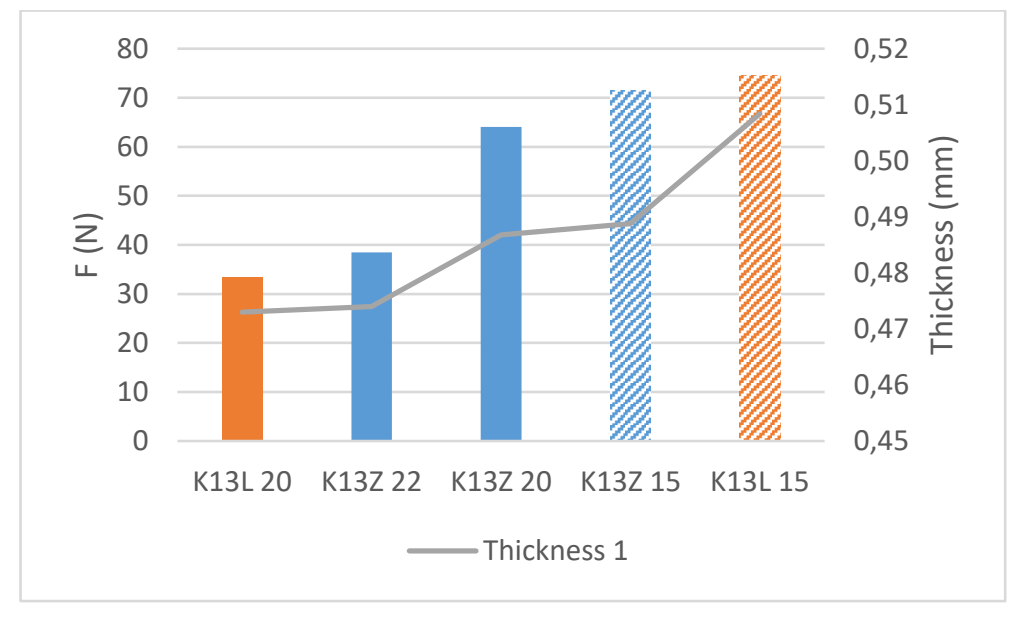

Figure 5: Dependence of the adhesion force on Thickness 1

Figure 6 shows the influence of the measured weft and warp densities on the adhesion force for different samples.

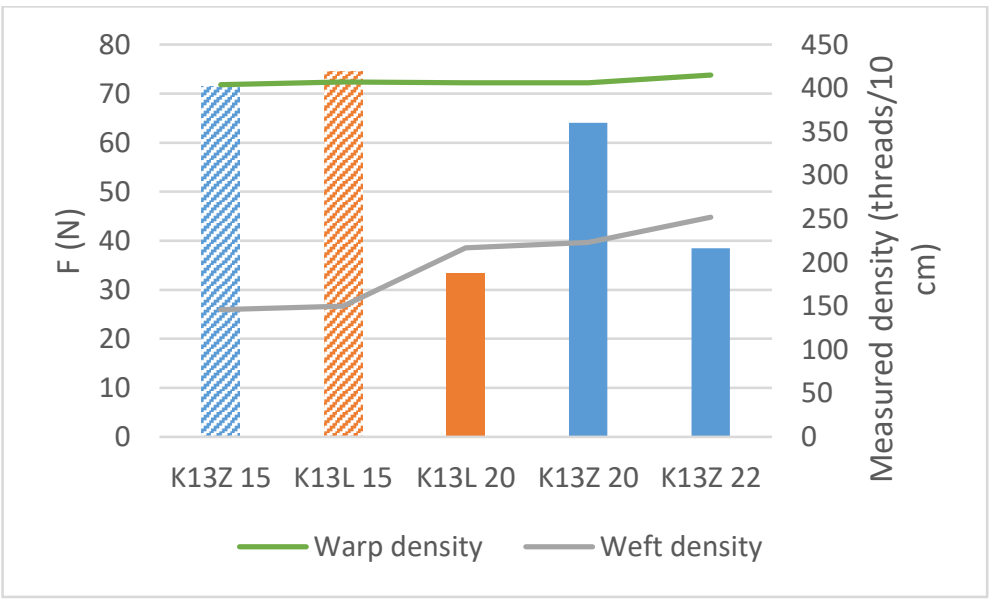

Figure 6: Dependence of the adhesion force on measured warp and weft densities 
The adhesion force decreases with increasing weft density for the same weave. Comparing all samples, the tendency is that the adhesion force decreases when the measured weft density increases, but the correlation is not direct. An increase in the measured warp density also shows a general, but not direct, tendency for the adhesion force to decrease.

\section{DISCUSSION}

In our research, we focused on the influence of the construction properties of fabrics on the adhesion of 3D printed objects on textile substrate. All textile samples were woven on the same cotton warp with the fineness $(8 \times 2$ tex) and density 40 ends/cm. The weft yarn remains the same for all samples (100\% PES, 33 tex). Three different weft densities $(15,20$ and 22 picks $/ \mathrm{cm})$ and two different weaves, namely twill $1 / 3$ and broken twill $1 / 3$, were used as textile components. 3D objects were printed with PLA on textile substrates. Preliminary tests were done to define the nozzle temperature, the $Z$ height of the nozzle and the printing angle of the first layer. The define the exact positioning of the fabric on the printing bed, different methods of attaching the fabric to a printing bed were tested.

The adhesion force was tested on all samples. The highest adhesion was found at the lowest weft density in both weaves, where the adhesion was slightly higher at broken twill $1 / 3$ than at twill $1 / 3$. The lowest adhesion was found at the highest weft density, which means that at larger pores, which is the case at low weft density, the polymer adheres more strongly to the substrate than vice versa. This can be explained by the fact that with the increasing density of the weft yarns, the polymer can hardly enclose the individual yarns. As a result, the polymer has less surface area available to adhere to the fabric, which reduces the adhesion force. The measured warp density differed only very little between the samples, but the increase in warp density also shows a general, but not direct tendency to decrease the adhesion force.

A change in the mass of the samples has no direct influence on the change in adhesive force, but there is a general tendency for the adhesion force to decrease with increasing mass. In our case, the increase in the mass of the fabric is directly related to the increase in the density of the warp and weft, so we assume that the cause of the change in adhesion force is the same as the change in the density of the warp and weft described above.

Results show that the adhesion force increases with increasing thickness. The fabric thickness measured according to the textile standard generally increases with decreasing weft density, which leads to longer floats of the warp threads and to larger available yarn surfaces for polymer adhesion.

In addition, during our research were obtained further important findings, which confirm earlier research in this field:

- The exact positioning of the fabric on the printing bed is very important, while the angles between the warp threads, the weft threads and the direction of the first printing layer must be as accurate as possible. This is why we have designed the frame for the precise attachment of the fabric to the printing bed. As described in the literature (T. Kozior et. al. 2018), the direction of the first printing layer is important. The results of our tests showed, as already indicated, that when the first layer is printed at an angle of 90 degrees to the longer size of the sample (warp direction), the adhesive force is the highest, while at 0 degrees the force is the lowest. Since the samples with first layer printed at 90 degrees, tear too quickly during the peel test, we printed the first layer at 45 degrees according to the longer size.

- The thickness of the fabric is important for setting the exact z-value of the nozzle. The distance between the nozzle and the printing bed or fabric should be small and the same for all tested samples. Therefore, the fabrics were measured in two ways, first with respect to the textile standard and second with respect to the adjusted standard: the fabrics were measured when mounted in the frame specially designed for 3D printing. If, by mistake, the z-value of the nozzle was slightly different as planned, the value of the adhesive force was changed significantly, which shows how important it is to adjust the nozzle height accurately. 


\section{CONCLUSIONS}

The adhesion of the 3D printed objects to textiles is influenced by many factors: preparing of a 3D model for printing, setting up the printer, placing the fabric on the printing table and of course the construction parameters of the fabric. The results obtained show that any change affects the adhesion.

In general, we have found that the density of the fabric has the greatest influence on the adhesion force. If we observe the differences between the weaves, we find that the highest adhesion was achieved with a broken twill $1 / 3$ at the preset weft density of 15 threads/cm. In further research it is therefore important to determine the maximum adhesion force of 3D printed objects on textiles suitable for protective clothing.

\section{ACKNOWLEDGMENTS}

This work was founded by the Slovenian Research Agency, Slovenia (Infrastructural Centre RIC UL-NTF).

\section{REFERENCES}

[1] Awaya, F., Gilbert, M., Kelly, G., Fox, B., Pigram, P. J.: "Adhesion of Polymers", Progress in Polymer Science 34 (9), 948-968, 2009. doi: 10.1016/j.progpolymsci.2009.04.007.

[2] Gibson, I., Rosen, D., Stucker, B.: “Additive Manufacturing Technologies, 3D Printing, Rapid Prototyping, and Direct Digital Manufacturing" (Springer, New York NY, 2015.), pages 1-18.

[3] Jahan, I.: "Effect of Fabric Structure on the Mechanical Properties of Woven Fabrics", Advance Research in Textile Engineering 2 (2), 1018, 2017. doi: 10.26420/advrestexteng.2017.1018.

[4] Kozior, T., Blachowicz, T., Ehrman, A.; "Adhesion of three-dimensional printing on textile fabrics: Inspiration from and for other research areas", Journal of Engineered Fibers and Fabrics 15 (1-6), 2020. doi: 10.1177/1558925020910875.

[5] Kozior, T., Döpke, C., Grimmelsmann, N., Juhász Junger, I., Ehrmann, A.: "Influence of fabric pretreatment on adhesion of three-dimensional printed material on textile substrates", Advances in Mechanical Engineering 10 (8), 1-8, 2018. doi: 10.1177/1687814018792316.

[6] Malengier, B., Hertleer, C., Cardon, L., Van Langenhove, L.: "3D printing on Textiles: Testing of Adhesion", Proccedings of the International Conference on Intelligent Textiles and Mass Customisation, 2017, (ITMC2017: Ghent, Belgium, 2017).

[7] Melnikova, R. Ehrmann, A. Finsterbusch, K.: "3D printing of textile-based structures by Fused Deposition Modelling (FDM) with different polymer materials", Procedings of the Global Conference on Polymer and Composite Materials (PCM: Xi'an, China, 2014).

[8] Mpofu, N. S., Mwasiagi, J. I., Nkiwane, L. C., Njuguna, D.: "Use of regression to study the effect of fabric parameters on the adhesion of 3D printed PLA polymer onto woven fabrics", Fashion and Textiles 6, 2019. doi:10.1186/s40691-019-0180-6.

[9] Muck, D., Križanivskij, I.: “3D tisk", (Pasadena, Ljubljana, Slovenia, 2015.), pages 80-82.

[10] Pei, E., Shen, J., Watling, J.: "Direct 3D printing of polymers onto textiles: experimental studies and applications", Rapid Prototyping Journal 21 (5), 556-571, 2015. doi: 10.1108/RPJ-09-2014-0126.

[11] Rivera, M. L., Moukperian, M., Ashbrook, D., Mankoff, J., Hudson, S. E.: "Stretching the bounds of 3D printing with embedded textiles", Proceedings of the $2017 \mathrm{CHI}$ conference on human factors in computing systems 2017, (CHI'17: Denver, Colorado, 2017), pages 497-508.

[12] Sabantina, L., Kinzel, F., Ehrmann, A., Finsterbusch, K.: "Combining 3D printed forms with textile structures - mechanical and geometrical properties of multi-material systems", Procedings of the Global Conference on Polymer and Composite Materials, Materials Science and Engineering 2015, (PCM: Xi'an, China, 2015), page 87.

[13] Sanatgar, R. H., Campagne, C., Nierstrasz, V.: "Investigation of the adhesion properties of direct 3D printing of polymers and nanocomposites on textiles: Effect of FDM printing process parameters", Applied Surface Science, pages 403, 551-563, 2017. doi:10.1016/j.apsusc.2017.01.112.

[14] Sitotaw, D. B., Ahrendt, D., Kyosev, Y., Kabish, A. K.: "Additive Manufacturing and Textiles-State-ofthe-Art", Applied Sciences 10 (15), 2020. doi:10.3390/app10155033. 
[15] Spahiu, T., Al-Arabiyat, M., Martens, Y., Ehrmann, A., Piperi, E., Shehi, E.: “Adhesion of 3D printing polymers on textile fabrics for garment production", IOP Conference Series: Materials Science and Engineering, Aegean International Textile and Advanced Engineering Conference 2018, (Levos, Greece, 2018), page 459.

[16] Spahiu, T., Grimmelsmann, N., Ehrmann, A., Piperi, E., Shehi, E.: "Effect of 3D printing on textile fabric", Proceedings of the 1st International Conference Engineering and Entrepreneurship, (ICEE: Tirana, Albania, 2017)

[17] Spahiu, T., Piperi, E., Ehrman, A., Shehi, E., Rama, D.: "3D Printed Geometries on Textile Fabric for Garment Production", Proceedings of International Conference of Progress in Digital and Physical Manufacturing, (ProDPM 2019: Leiria, Portugal, 2019), pages 271-276. doi: 10.1007/978-3-03029041-2_34.

[18] Unger, L., Scheideler, M., Meyer, P., Harland, J., Görzen, A., Wortman, M., Dreyer, A., Ehrmann, A.: "Increasing Adhesion of 3D printing on textile fabrics by polymer coating", Tekstilec 61 (4), 265-271, 2018. doi:10.14502/Tekstilec2018.61.265-271.

(c) (1)

(C) 2020 Authors. Published by the University of Novi Sad, Faculty of Technical Sciences, Department of Graphic Engineering and Design. This article is an open access article distributed under the terms and conditions of the Creative Commons Attribution license 3.0 Serbia (http://creativecommons.org/licenses/by/3.0/rs/). 


\title{
3D PRINTED JEWELLERY DESIGN PROCESS BASED ON SCULPTURE INSPIRATION
}

\author{
Karin Košak, Deja Muck (D), Marjeta Čuk (D), Tanja Nuša Kočevar \\ University of Ljubljana, Faculty of Natural Sciences and Engineering, Department of Textiles, \\ Graphic Arts and Design, Chair of Information and Graphic Arts Technology, Ljubljana, Slovenia
}

\begin{abstract}
In the article we present the educational process in which design students were guided through their design process, creating 3D printed jewellery inspired by the Forma Viva sculptures of the outdoor gallery Kostanjevica na Krki. The assignment was part of the international project Cumulus Re/Forma Viva, whose main goal was to implement digitization using 3D technology in the field of education for the preservation of cultural heritage.

The task given to the 1st year masters students of Fashion and Textile Design at the Department of Textiles, Graphic arts and Design at the University of Ljubljana was to select a wooden sculpture and transform the visual and conceptual idea into a 3D printed jewellery collection.

The curriculum of the course includes teaching the theoretical basics of 3D printing, 3D print design -fashion accessories and new production, business and marketing models as "disruptive" changes that result from this. In the practical part, students will learn the advanced design process of fashion accessory objects, including 3D technologies such as 3D modelling and 3D printing. Students are guided through a process in which selected visual and conceptual content is translated into fine jewellery that can be created using various 3D printing technologies.

In this way, students tested themselves in two new areas that allowed them to expand their design knowledge and experience in 3D modelling and jewellery design with the goal of better "arming" themselves with the latest technologies for today's competitive world.
\end{abstract}

Key words: 3D printing, jewellery design, sculpture, Forma Viva, education

\section{INTRODUCTION}

Additive manufacturing is increasingly used in the development of fashion products such as clothing, accessories and jewellery. From a design perspective, the new technology offers designers the freedom to create and manufacture things that were otherwise very difficult to produce using traditional techniques. With the new technology of 3D modelling and printing, creativity can now be explored even further (Yap et al, 2014). Master Course at the Fashion and Textile Design includes the subject Digital design 4b, which course curriculum involves teaching the advanced design process of fashion accessories objects, including 3D technologies such as 3D modelling and 3D printing. The assignment given to the students was to select the wooden sculpture from the Forma Viva outdoor gallery Kostanjevica na Krki and translate it into a 3D printed jewellery collection.

The Forma Viva presents Open Air Wood Sculpture Collection in Kostanjevica na Krki. It is the product of a biennially held International Symposia of Sculptors during which chosen artists are invited to contribute to the ever growing collection of works since 1961.

The collection comprises around 130 pieces almost exclusively fashioned out of oak wood. Most of them are gathered in a freely accessible park in front of the Kostanjevica Monastery though some can also be found in the surrounding meadows or town squares and on the banks of the river Krka (Milovanović et al, 2010). On the initial excursion to Kostanjevica, the students viewed all the sculptures and then decided on the one that appealed to them the most. Thus, each student chose one of the sculptures, analyzed it and tried to transfer the basic idea of the author as authentically as possible into usable pieces of jewellery. The jewellery industry basically still works with traditional production methods that are far too time-consuming and sometimes not efficient enough compared to the quality of the final product (Ferreira et al, 2013). 3D-printed jewellery has gained high acceptance among customers, designers and manufacturers in the fashion industry, especially because of the materials currently available that are suitable for the application. 3D printed jewellery could be made with a variety of materials, including stainless steel, bronze and even gold (Yap et al, 2014). There are many advantages of 3D printed jewellery, for example: once a designer makes a sketch of a piece of jewellery and generates a 3D model, it can be printed as a plastic prototype to verify the quality of the design, and then it can be printed in the desired metal. It is also important to note 
that 3D printing technology enables the production of very detailed objects. Software can also be used to make changes quickly and easily and to fully personalise products.

In the theoretical part, students were introduced to advanced techniques for producing tangible products and with the latest achievements of online information technologies, from social networks to support the development of the most sophisticated products possible, to websites that enable the funding of new projects. 3D printing enables a young designer to design from the student's room and also to manufacture and sell his products - jewellery - across platforms (Anderson, 2013). In such an association, it is a great new opportunity to be successful as a designer - as a small business owner.

Designers like Francis Bitonti, Iris van Herpen and Zaha Hadid show the way of avant-garde product, fashion and accessory design with new technologies. A very good example is also the company Nervous Systems, which deals with innovative business models for the design, promotion and sale of unique design and technologically advanced jewellery.

In the practical part, students applied the design part of the process to the development and implementation of jewellery prototypes on the theme of Forma Viva. This was followed by the transformation of the sculpture into a collection of functional jewellery - especially earrings, brooches, bracelets, necklaces and chokers. The jewellery was then printed on various printers at the faculty, 3D printer based on stereolithography, Form 2, 3D printers based on thermoplastic extrusion, fused deposition modeling, 3D Jozko and ZMorph 2.0 SX and 3D printer based on selective laser melting, LPM100 in the company Dentas, Maribor.

\section{DESIGN PROCESS}

\subsection{Research and analysis}

The design process began with the excursion to Forma Viva in Kostanjevica na Krki, where the students created a photographic documentation of the sculptures. Looking at the whole statue from different angles was as important as observing details and special features of statue making, so they had to take a whole series of photos to capture all views of the sculptures. Figure 1 shows two photographs of a sculpture "En rez" (A cut) by the author Primož Pugelj.
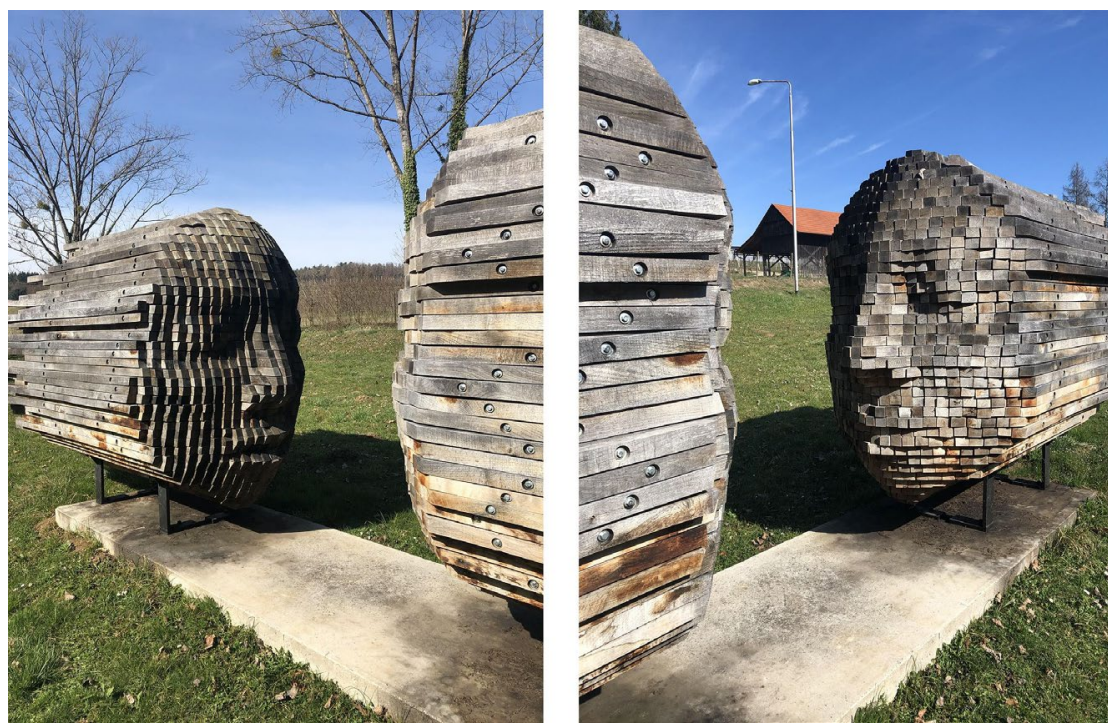

Figure 1: Photos of a sculpture "En rez" (A cut), author Primož Pugelj, photo Ajda Rep

Students thoroughly analysed chosen sculptures from a visual, conceptual and production perspective, and the investigation of possible interpretations in a jewellery collection has begun. It was important that the student really understood the intention of the author of the sculpture. It was also necessary to bring a study of contemporary jewellery up to date. Through this research, students broaden their understanding of trends in jewellery design, focusing on aesthetics, materiality and the content of the message conveyed by the design.

The process continued with the sketching of various pieces of jewellery and their rough visualisation on a body. Visualisation on the body is extremely important to correctly assess and analyse the shape and the 
proportion of a piece of jewellery according to the body silhouette. Sometimes it was also necessary to implement the ideas in paper or any other material to test the idea in 3D objects. Figure 2 and Figure 3 show the sketches in which the students thought about the type and form of the jewellery and also how it should be used or equipped to be worn.

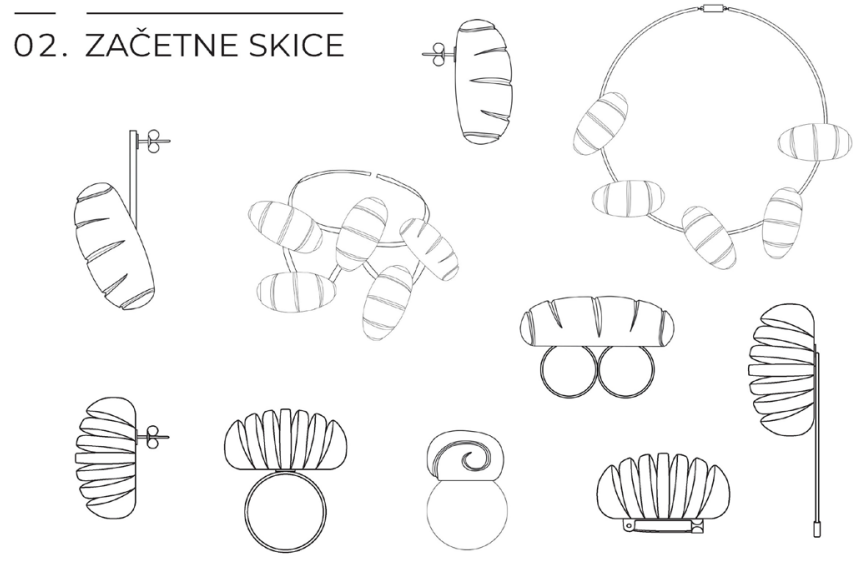

Figure 2: Initial sketches of the jewellery, author: Tina Dovjak

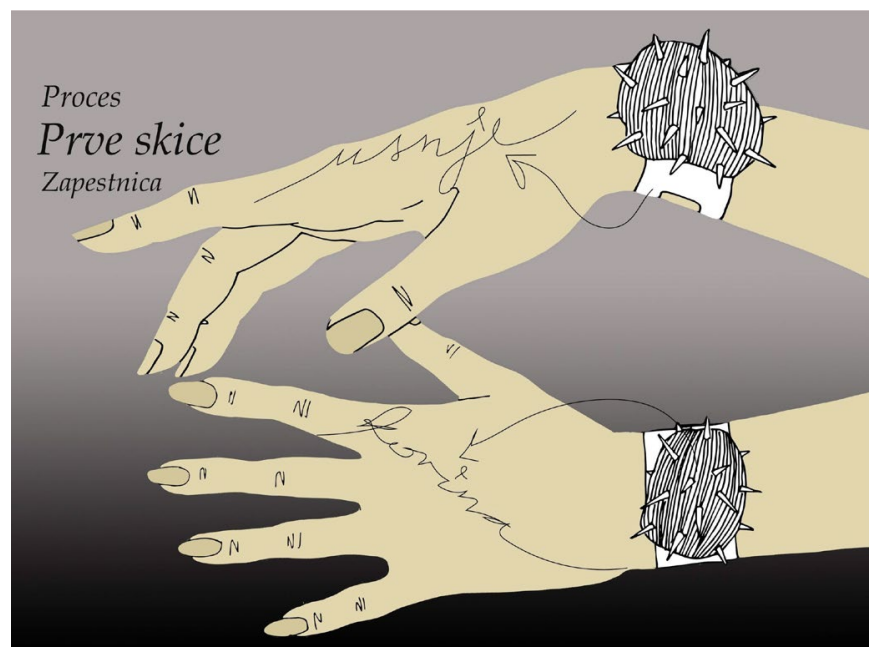

Figure 3: Visualisation of the jewellery on the body, author: Eva Jelenc

\subsection{Creation and 3D modelling}

Students were guided through a process in which selected visual and conceptual content, presented with initial sketches, was transformed into fine jewellery that can be created using various 3D printing technologies. They used a 3D programme Blender, which allows the precise modelling of very detailed objects. One student also used a 3D model originally created with photogrammetry and remodelled it and redesigned it into a piece of jewellery. The students generated various solutions that were analysed regarding concept, trends, market, technical requirements and aesthetics and the best solution was selected for 3D printing. In Figure 4 designs modelled in Blender are presented, and in Figure 5 an initial 3D model created with photogrammetry. The process of 3D modelling was sometimes very demanding, especially when designing models with additional features, as we can see in Figure 6 where some parts of the model can be moved or rotated, as is possible with the original sculpture. 


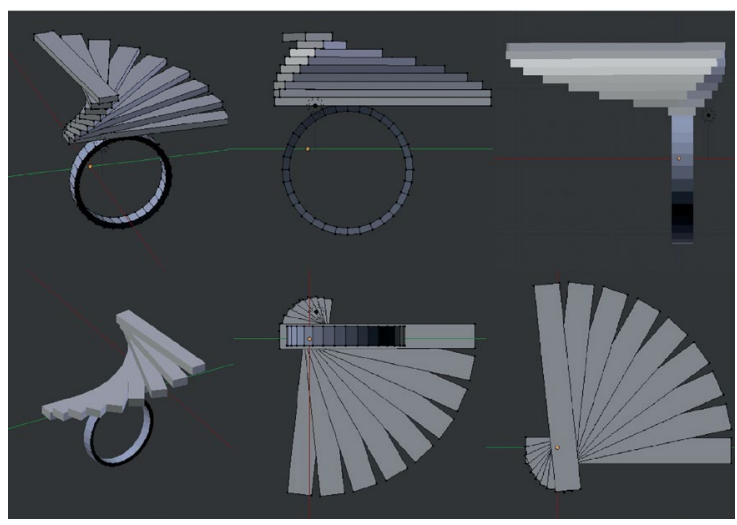

Figure 4: 3D model of the ring, author: Katrin Večerina

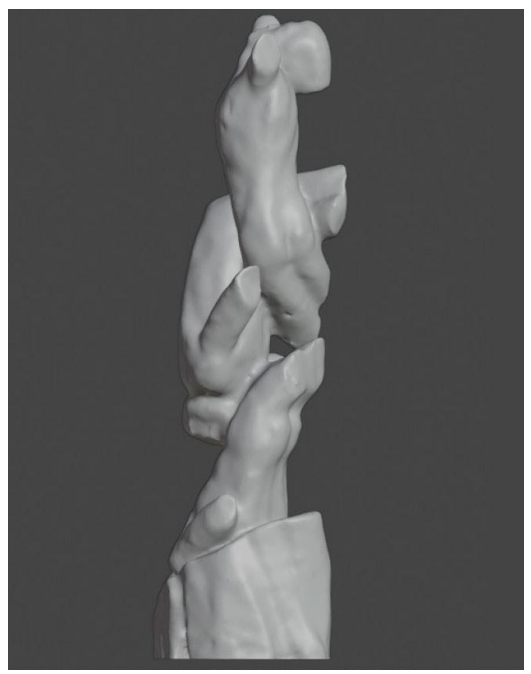

Figure 5: 3D model of the sculpture made using photogrammetry, authors: Jure Sulič, Sanja Celeste Smaragli, Ana Krklec

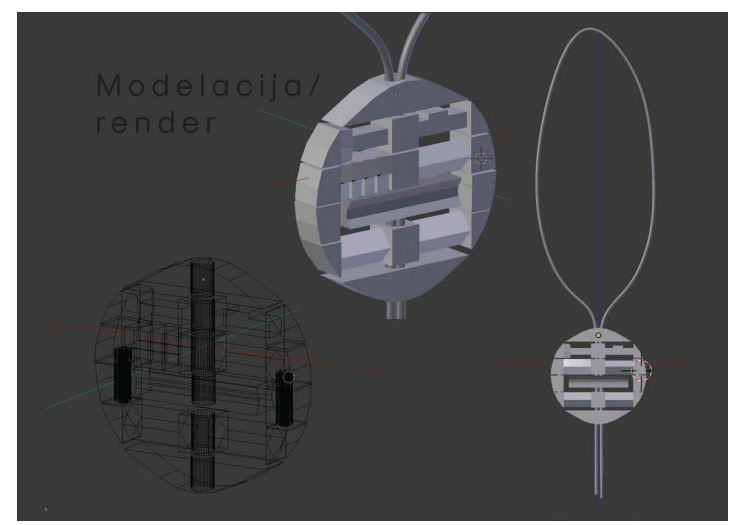

Figure 6: 3D model of the pendant with movable parts, author: Ela Vehovec

\subsection{D printing of jewellery}

When 3D models of designed jewellery were created, it was necessary to prepare them for 3D printing. The students defined the exact dimensions of the objects and checked the topology of the models. It was also important to prepare the models according to the requirements of the chosen 3D printing technology and to take into account the weight of an individual final piece of jewellery, as it should not be too heavy to wear, especially pieces printed with metal. The jewellery was printed with different 3D printing technologies. Most of the jewellery was printed with fused deposition modeling technology (FDM), using 
printer 3DJozko and multitool ZMorph $2.0 \mathrm{SX}$ printer. For pieces with very smooth surfaces the stereolithography (SLA) was used and printed with Form 2 printer. At the end some special jewellery pieces were chosen for printing with selective laser melting technology, SLM. For this reason we cooperated with company Dentas.

\section{RESULTS AND DISCUSSION}

\subsection{Fused deposition modeling, FDM}

Two different filaments based on PLA thermoplastic were used for printing with FDM technology. The first was made of coloured bronze and the second of biocomposite with wood fibers. The perimeter of both filaments was the same $1.75 \mathrm{~mm}$. The printing parameters were set by default for printing with PLA filament. Infill pattern was linear in horizontal direction at infill density $40 \%$. The layer thickness was 100 microns. In Figure 7 we see pieces of jewellery printed with bronze filament. The mentioned filament was chosen to achieve lustre, warm colour and smooth texture that enhance the appearance of printed pieces.

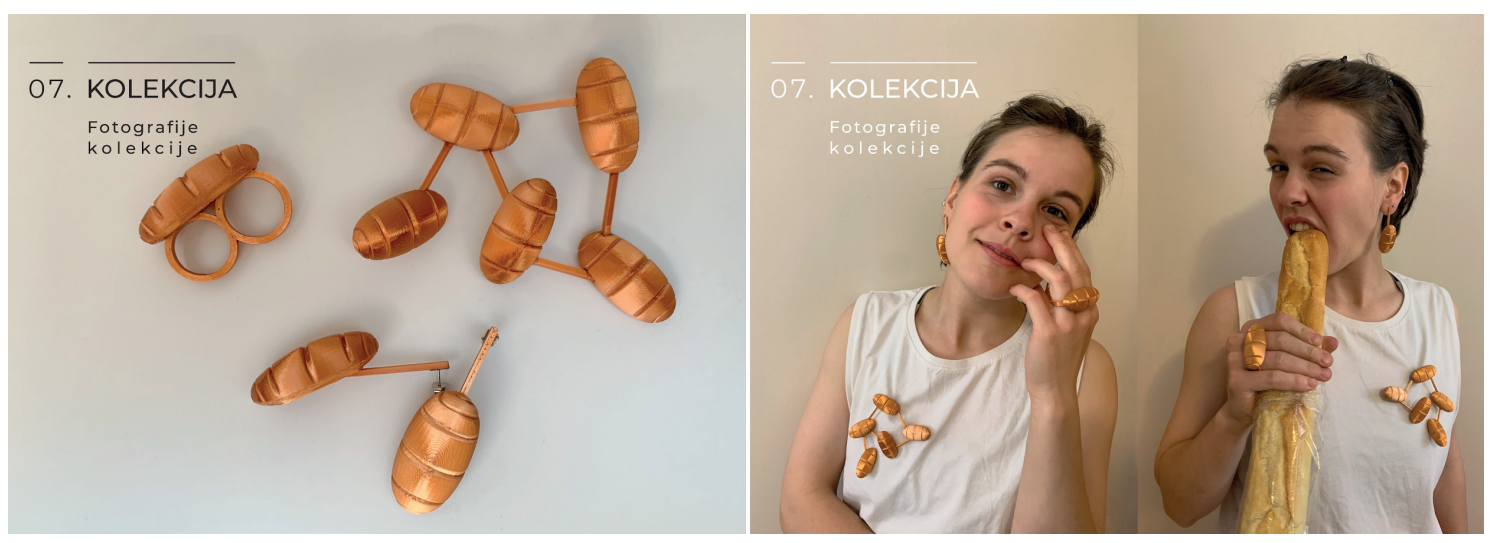

Figure 7: jewellery collection "Hlebci" (Loafs), printed with FDM technology, author Tina Dovjak, pages from presentation brochure

On Figure 8 the pendant that is printed in 6 pieces is presented. Some movable parts were printed in one piece and another were printed separately and assembled together on a string. On Figure 9, the jewellery collection is presented that is printed with the polymer that contains $40 \%$ recycled wood (PLA 2000 WOOD Bamboo). The texture is rougher and the colour is reminiscent of light wood. When printing with this polymer, the choice of the angle of the layer deposition is important to create differences in the gloss of the surface.

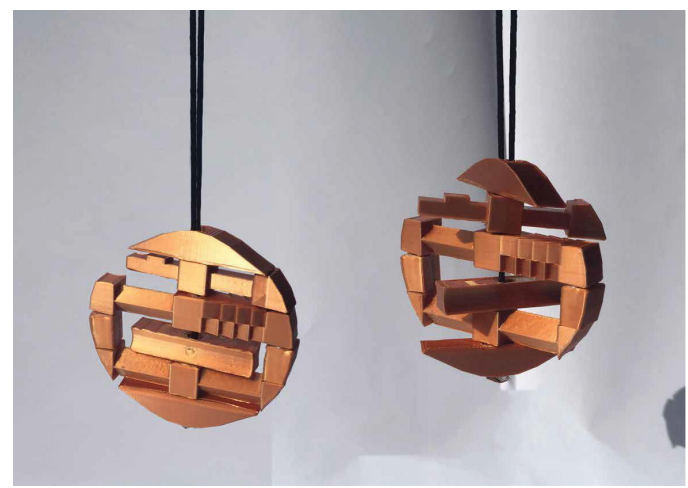

Figure 8: The pendant from the collection "Revolucija" (Revolution) printed with FDM technology, author Ela Vehovec 


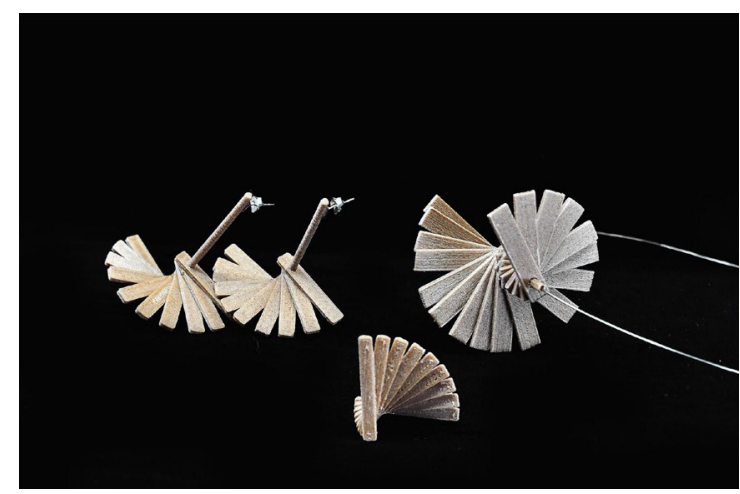

Figure 9: Jewellery collection "Spirala" (Spiral) printed with FDM technology, author Katrin Večerina, photo Maja Večerina

\subsection{Stereolithography, SLA}

Grey Pro Resin was used for printing with stereolithography printer Form 2. It is an Engineering Resin designed for high precision, moderate elongation, and low creep. These mechanical properties make Grey Pro Resin a versatile material for a wide range of applications, including concept modeling and functional prototyping. Highly resistant to deformation over time, Grey Pro Resin is especially suitable for printing parts intended for repeated use, such as jewellery (Formlabs). Printing with Form 2 printer using grey resin gives nice results. The pieces of jewellery with very smooth surfaces and visible small details. The print resolution was set to 50 microns. For better final effect post-processing was used. On Figure 10 a piece of jewellery printed with SLA technology is presented. It was printed in three pieces. After the printing process individual pieces were finished with spray painting that applied colour and shine to the product and assembled with glue what is shown on the left side of Figure 10.
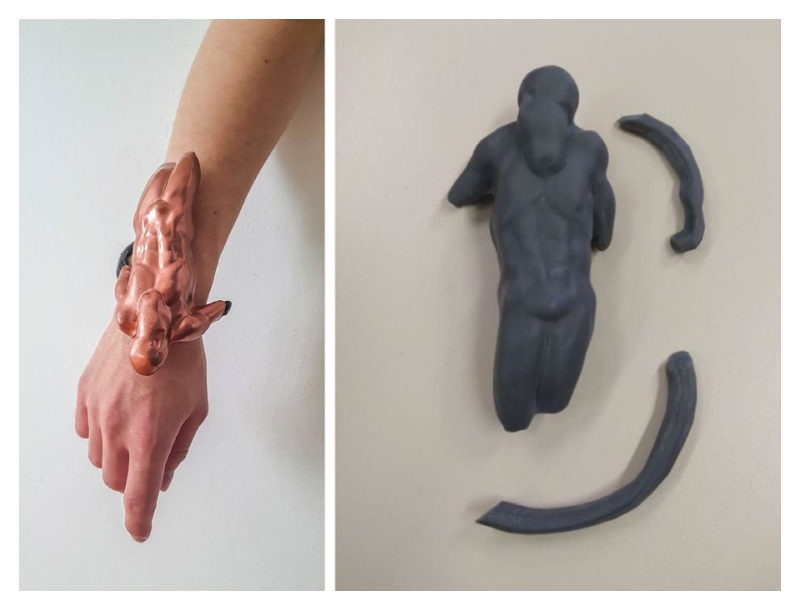

Figure 10: Bracelet from the collection "Tri dobe življenja" (Three Phases of Life), printed with SLA technology on the right and assembled and spray painted on the left, author: Uroš Topić

\subsection{Selective laser melting technology, SLM}

Only a few special pieces of jewellery were selected for printing with metal powder. This technology enables the production of jewellery with final functionality. For this purpose, a $100 \mathrm{~W}$ laser metal printer, LPM100 and a metal powder alloy Co-Cr-Mo -W were used. The layer thickness was adjusted to 100 microns.

After printing with metal powder, the surface of the object is rough to the touch. Therefore, postprocessing is necessary. We used sandblasting and in some cases also polishing. Figures 11, 12 and 13 show the ring, earring and bracelet printed with SLM technology. 

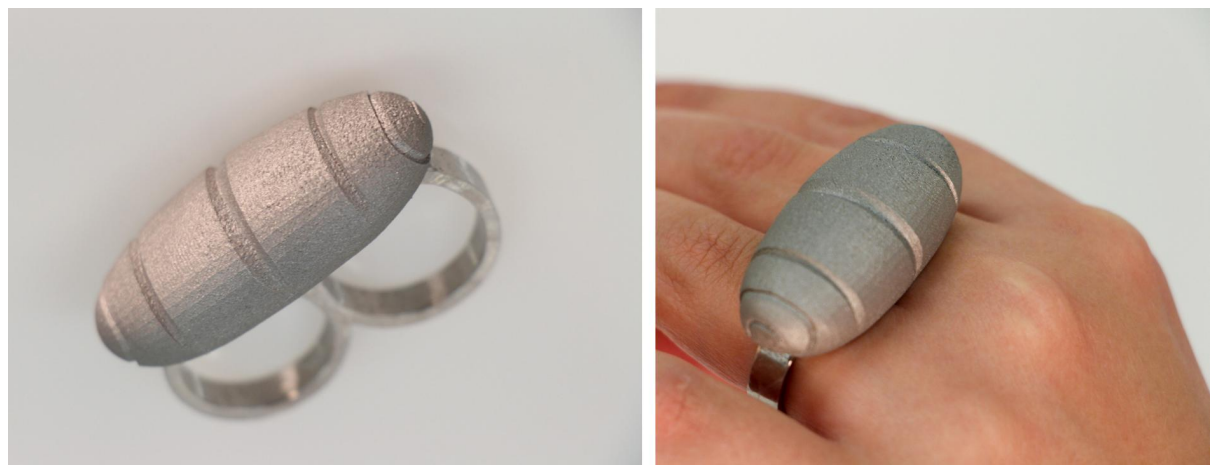

Figure 11: Ring printed with SLM technology, author: Tina Dovjak

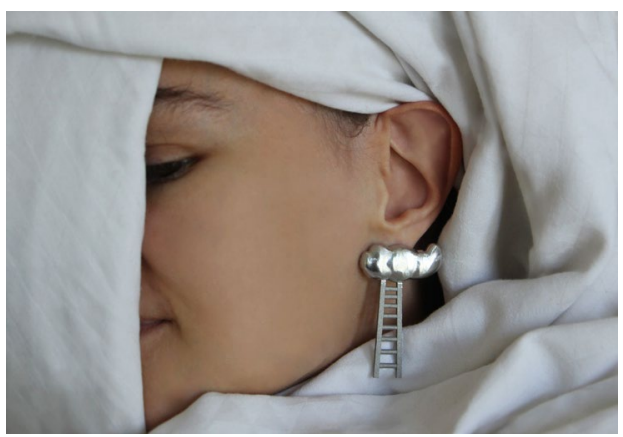

Figure 12: Earring printed with SLM technology, author: Hana Tavčar
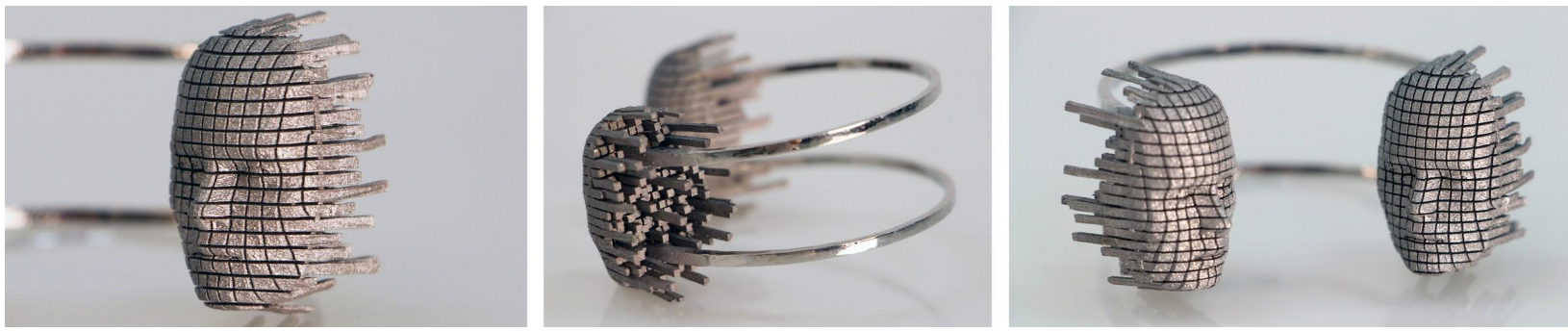

Figure 13: Bracelet from the collection "Dvogovor" (Dialogue) printed with SLM technology, author: Ajda Rep

\section{CONCLUSIONS}

During the course students tested themselves in two new areas that allowed them to expand their design experience, in the field of 3D modeling and in the field of jewellery design. They learned how to interpret a concept and the aesthetics of a piece of a wooden sculpture into a wearable piece of jewellery. They also learned how to transform hand-drawn sketches or images into 3D models. They broaden their knowledge on wooden cultural heritage, jewellery design and various 3D printing technologies.

We have proven that 3D printing technologies are extremely useful for jewellery manufacturing. The production of conceptual and functional prototypes is now possible for almost anyone. The prices of printers that allow printing with thermoplastic materials have already fallen below 300 Euros. However, if we want to print jewellery with full functionality, we have to use technologies that allow printing with metal powder. The prices of metal powder materials for 3D printing have dropped dramatically recently. As a result, printing individual pieces of jewellery is slowly becoming available to every user.

\section{ACKNOWLEDGEMENT}

The presented research is part of the International project Erasmus + Re / Forma Viva Reformation of education on wood preservation. The implementation of the project is funded by the European Commission and takes place under the auspices of the national agency CMEPIUS. 


\section{REFERENCES}

[1] Anderson, C.: "Makers: The New Industrial Revolution”, (Crown Business, USA, 2013.), pages 17-32.

[2] Ferreira, T., Almeida, H.-A., Bártolo, P.-J., Campbell, I.: "Additive Manufacturing in Jewellery Design", Proceedings of Engineering System Design and Analysis 2012, (ASME: Nantes, France, 2012), pages 187-194.

[3] FormLabs, Using Grey Pro Resin, URL: https://support.formlabs.com/s/article/Using-Grey-Pro-Resin?language=en_US (last request: 2020-09-25.).

[4] Milovanović, G., Rožman, H.: "Forma Viva", URL: https://www.galerija-bj.si/forma-viva (last request: 2020-09-27.).

[5] Yap, Y. L., Yeong, W. Y.: "Additive manufacture of fashion and jewellery products: a mini review", Virtual and Physical Prototyping 9, 195-201, 2014. doi: 10.1080/17452759.2014.938993.

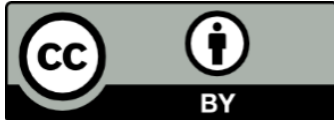

(C) 2020 Authors. Published by the University of Novi Sad, Faculty of Technical Sciences, Department of Graphic Engineering and Design. This article is an open access article distributed under the terms and conditions of the Creative Commons Attribution license 3.0 Serbia (http://creativecommons.org/licenses/by/3.0/rs/). 


\title{
STUDY OF 4D PRIMITIVES' SELF-TRANSFORMATION
}

\author{
Matej Pivar (D), Deja Muck (D) \\ University of Ljubljana, Faculty of Natural Sciences and Engineering, Ljubljana, Slovenia
}

\begin{abstract}
D$ printing is the process through which a $3 D$ printed object or primitive is transformed into another structure under the influence of external energy input such as temperature, light or other extertal stimuli. The 4th dimension is the time in which the primitive changes its appearance. In most cases, the shape changes. We call this a self-assembly or self-transformation process.

In the process of printing a primitive, capable of transforming themselves from one shape to another, we often encounter combinations of one or two thermoplastic materials that have different thermal and physico-mechanical properties. The printed primitive is transformed where the active element is contained. The active element is the basic building block of the self-transforming primitive. For this purpose, it is necessary to choose the appropriate combination of thermoplastic materials, to determine the length of the active element and the number of layers of which it is composed. For the printing of the active element two thermoplastic materials can be selected which differ from each other in their thermal transitions and physico-mechanical properties. The process of transformation under the influence of elevated temperature should be carried out in such a way that the printed primitive is heated above the temperature of the glass transition that the material used on the active elements has. This releases the residual stresses created during the printing process and causes the active material to shrink. In this way, a primitive can be transformed from a flat shape to a final 3D shape. This shape is then maintained by controlled cooling below the glass transition temperature of the active element.

In this paper the first research results of the primitive transformation were presented. The appropriate combination of materials and the optimal temperature of the water as external stimuli were determined, and finally the primitives' shape recovery. In the research we used the active element which consists of a single layer of flexible, elastic thermoplastic material (passive material) and three layers of thermoplastic materials with the properties of shape memory polymers (active material). For printing we used the multitool 3D printer ZMorph which is based on Fused Deposition Modeling (FDM) technology.
\end{abstract}

Key words: 3D printing, shape memory polymers, 4D printing, primitive, self-transformation

\section{INTRODUCTION}

3D printing is already a well-known and widespread field of application. It is an additive technology, producing a three-dimensional object from a digital model using various technologies. Recently, research in the field of 3D printing has increasingly focused on the use of functional materials. These materials allow 3D printed objects to change over time as a fourth dimension. This creates a new area of use for 3D printing, called 4D printing. Printed objects are capable of independently transforming or changing chemical or physical properties under the influence of various external stimuli. The changes can be reversible or irreversible and thus open new areas of application in biomedicine, robotics, architecture, construction, textiles, etc. (Shie et al, 2019).

One of the simplest options for $4 \mathrm{D}$ printing applications is the use of thermoplastic materials that are capable of thermoforming or thermal transformations. This group of thermoplastic materials also includes stimuli-responsive polymers, also known as shape memory polymers. They can change their shape and have the ability to regain their original shape (Shie et al, 2019).

A big advantage of thermoplastic materials is that they can be printed with fused deposition modeling. This technology is simple and affordable. In the process of printing a primitive that will be able to transform, we mostly encounter one or a combination of two thermoplastic materials. In the first case, using one material, the transformation is controlled by a different orientation of the deposited filament layers of the active material (Teunis et al, 2017). In the second case, the transformation is achieved by the right combination of thermoplastic materials, which differ in thermal transitions and have different physical and mechanical properties. For active parts of the primitive, a combination of active and passive material is used. Active material shrinks when heated above its glass transition temperature $(\mathrm{Tg})$ and below its melting temperature (Tm). Passive material does not change its shape at the same temperature but serves as support for the active material to transform into a specific direction. For the passive part of the primitive, we only use the passive material (Kačergis et al, 2019). 
In order to control the transformation, it is important to properly prepare the material for printing. Polymers are hygroscopic (Kačergis et al, 2019; Tham et al, 2016; Zaldivar et al, 2018; Valeraga et al, 2018), so the filaments must be dried before printing. In this way we achieve good printing quality. Moisture can affect the extrusion process, filament deposition and the mechanical properties of printed primitives (Almenara, 2017). Due to the presence of moisture during the printing process, air pockets can form within the printed primitive (Penjumras et al, 2015; Byoungkwon et al, 2018; Guanyun et al, 2018). This has a negative impact on transformation.

The transformation depends on the residual stress created during the 3D printing process. During the extrusion process the thermoplastic materials transition to a highly elastic state. The polymer chains are forcibly oriented in the longitudinal direction of the material flow through the extrusion nozzle. As soon as material leaves the nozzle, it begins to cool and solidify, forcing the chains to maintain their rearranged state.

When the 3D object is reheated above the glass transition temperature of the active thermoplastic material, the polymer chains begin to reorient themselves back into their chaotic, or low energy mode, causing shrinkage along the printed direction and changing the shape of the 3D printed object (Teunis et al, 2017; Kačergis et al, 2019; João et al, 2018; Uzir et al, 2015).

The printing speed and the speed of cooling play a very important role in the transformation of primitives. In literature (Kačergis et al, 2019; João et al, 2018; Song and Cassandra, 2016), it has been shown that higher transformation is achieved higher with printing speed. On the other hand, the higher the printing speed, the lower the printing accuracy and the worse the mechanical properties along with visual quality (Kadir and Türkmen, 2018; Singh, 2019; Ravichandra and Shanmugam, 2018). In case of excessive cooling, the layers of filaments will not merge with each other and stratification will occur (Kadir and Türkmen, 2018). However, if the cooling is insufficient, the quality of 3D printing is poorer, as the pre-deposited layer is not strong enough for the deposition of new layers.

To control the described transformation, it is first necessary to optimize the printing conditions. Our research presents the most important parameters that we must optimize before printing. Besides the printing conditions, we have also determined the appropriate combination of thermoplastic materials and the optimal temperature of the activation medium. In this way we create good conditions for the study of the self-transformation of primitives, based on which we intend to establish a mathematical model to predict the level of the transformation and the primitives' shape recovery.

\section{METHODS}

\subsection{Materials}

Thermoplastic materials in the form of filaments (diameter $1.75 \mathrm{~mm}$, manufactured by Plastika Trček d.o.o. (Slovenia)) were used, differing in their thermal and physico-mechanical properties. For the printing of the passive part of the primitive we used TPU thermoplastic materials with two different hardnesses, named 85 and 89 according to the Shore A scale (hereinafter referred to as TPU80 and TPU90). For printing the active part of the primitive, we used a combination of thermoplastic materials, TPU80 and PLA in the first case and TPU90 and PLA in the second. To achieve a precise and reproducible transformation the materials were dried before printing.

\subsection{Modeling of the primitives}

The modeling of primitives for the study of self-transformation was carried out in the Blender software (Blender Institute, Netherlands). To prepare the models for 3D printing we used the software Slic3r (RepRap Community).

\subsection{Optimization of the printing conditions}

In the research we used a multitool 3D printer ZMorph VX (ZMorph S.A., Poland), which allows printing with two thermoplastic materials. To achieve a reproducible and accurate primitive transformation we first have to calibrate the printer and then optimize the printing conditions. The most important thing is to optimize the printing speed, flow rate and cooling rate of the extruded material. 


\subsubsection{Printer calibration}

The calibration of the 3D printer includes the leveling of the work platform and the adjustment of the offset of the extrusion nozzles from the work platform. The build platform was manual leveled using a ZMorph probe.

The nozzle offset was adjusted by printing a $200 \mu \mathrm{m}$ thick layer. The corresponding nozzle offset was confirmed when the thickness of the printed layer reached $200 \mu \mathrm{m}$.

\subsubsection{Printing speed}

The printing speed affects the size of the final transformation. In order to eliminate as many factors that influence the transformation as possible, we have unified the speeds of both (active and passive) materials to the maximum printing speeds of TPU materials. Therefore, when producing test samples or primitives, we have used two different printing speeds, $15 \mathrm{~mm} / \mathrm{s}$, which corresponds to the maximum printing speed of the softer thermoplastic TPU80, and the speed of $22 \mathrm{~mm} / \mathrm{s}$, which corresponds to the maximum printing speed of the thermoplastic TPU90.

\subsubsection{Flow rate}

By varying the ratio of printing speed to extrusion speed, a smaller or larger amount of material can be extruded. To achieve precise and reproducible transformation, the deposition of filaments in the layers must be as uniform as possible and without overlapping or deformation.

This is achieved by determining the extrusion width and the flow rate. The extrusion width, used in the study, was left as a default value. The flow rate was controlled by an extrusion multiplier which adjusts the extrusion and the printing speed.

The flow rate was determined separately for both materials at a given extrusion temperature and printing speed. It was determined based on the printing of a 3D test object $(5(X) \times 50(Y) \times 2(Z) \mathrm{mm})$. We used a linear infill pattern of $100 \%$ density, oriented with the longer side in a longitudinal direction. Finally, we also created a 3D test object of the layered sandwich structure of both materials and analyzed the stacks when one material was deposited onto the other. Two extrusion nozzles of the print head were active simultaneously. After printing, the test 3D object was cross-cut and images were taken with a Dino-lite AM4113ZT optical microscope. We captured the photos at 50x magnification.

\subsubsection{Cooling the extruded material}

As soon as the polymer leaves the extrusion nozzle it begins to cool and solidify. Cooling is very important to achieve good visual quality of 3D printed objects and their good mechanical properties. Too much cooling leads to delamination, while insufficient cooling leads to poor visual quality and loss of detail, since the previously deposited layer is not strong enough to carry a new one.

The cooling speed with the fans has always been set by the manufacturer to a constant average recommended speed. In order to control the cooling as much as possible and to eliminate the influence of the room air temperature, we have placed the printer in a closed housing.

\subsection{The study of self-transformation}

After optimization of printing conditions, the research was focused on the effect of material combinations and the temperature of the water as external stimuli on the self-transformation on primitives. Finally, the primitives' shape recovery was studied. Primitives were printed in dimensions $10(\mathrm{X}) \times 60(\mathrm{Y}) \times 0,8(\mathrm{Z}) \mathrm{mm}$, with two lengths of active elements, 10 and $15 \mathrm{~mm}$ (Figure 1).

The active part of the primitive consisted of three layers of active PLA material and one layer of passive TPU material. The passive part of the test 3D model consisted of four layers of TPU material (Figure 1). The infill pattern was linear in longitudinal direction. As stated before, two different TPU materials, with different hardnesses were used. In the first case, the TPU80, and in the second, the TPU90. Testing of the transformation in hot water was performed in a bath with controlled heating, which was maintaining the water temperature at $\pm 1^{\circ} \mathrm{C}$. The transformation was tested at temperatures: $60,70,80$ and $90^{\circ} \mathrm{C}$. Three test specimens were tested at each temperature. The magnitude of the transformation was determined indirectly by measuring the angle of transformation (Figure 2) as a function of time. The opposite angle was calculated from the measured angle. 


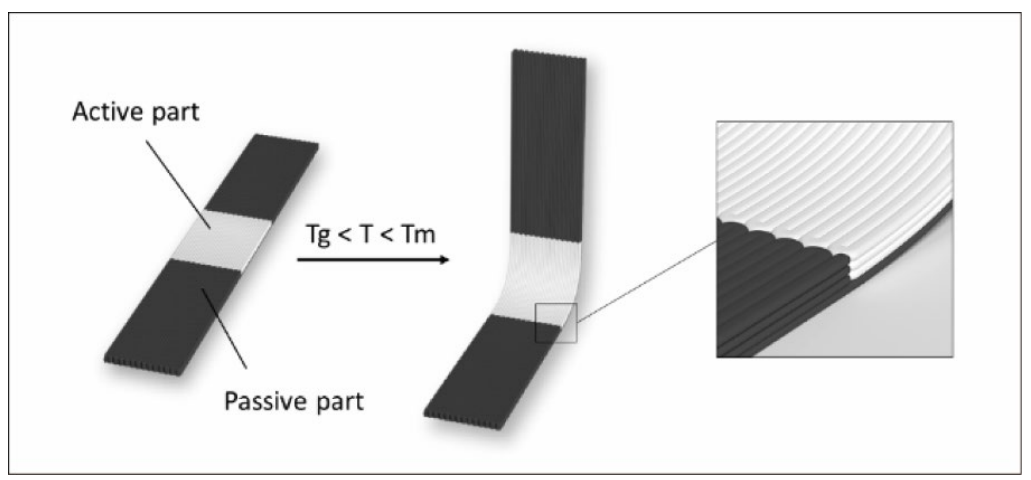

Figure 1: Schematic presentation of printed primitive and its self-transformation

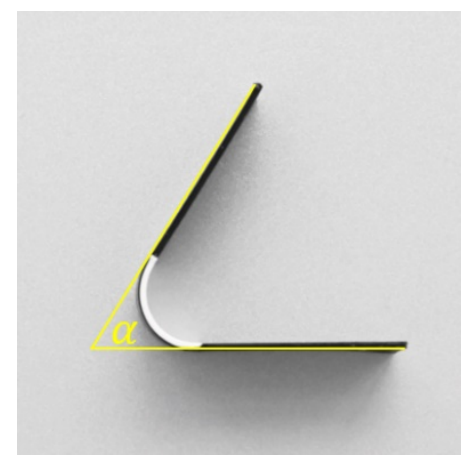

Figure 2: Determining the angle of primitives' transformation

\subsubsection{Determining the appropriate combination of materials}

In this part of the research, the combination of thermoplastic materials for the production of the active part of the primitive, was determined. In the first case, a combination of PLA and a softer TPU80 thermoplastic was used for the active part and in the second case PLA with a harder TPU90.

The active parts of the primitive had two different lengths $10 \mathrm{~mm}$ and $15 \mathrm{~mm}$. The transformation was analyzed in hot water at temperatures of 70 and $80^{\circ} \mathrm{C}$.

\subsubsection{Determination of the optimal water temperature}

The temperature of the water affects the rate and size of the primitive transformation. The higher the temperature, the faster the transformation and vice versa, the lower the temperature, the slower the transformation. The aim of our research was to determine the optimal temperature to which we need to heat water in order to perform an optimal and controlled transformation of the primitives. Primitives with an active part of $15 \mathrm{~mm}$ in length were used in the research. The transformation was tested at a temperature of $60,70,80$ and $90^{\circ} \mathrm{C}$.

\subsubsection{Determination of primitives' shape recovery}

At the end of the research, the primitives' shape recovery was determined. The primitives were produced with a combination of TPU90/PLA materials. The experiments were performed in hot water at $70^{\circ} \mathrm{C}$ (Figure 3). Primitives with an active part of $15 \mathrm{~mm}$ in length were used. The test were performed in five cycles of heating, transformation into the original form by means of force and temperature and reheating. 


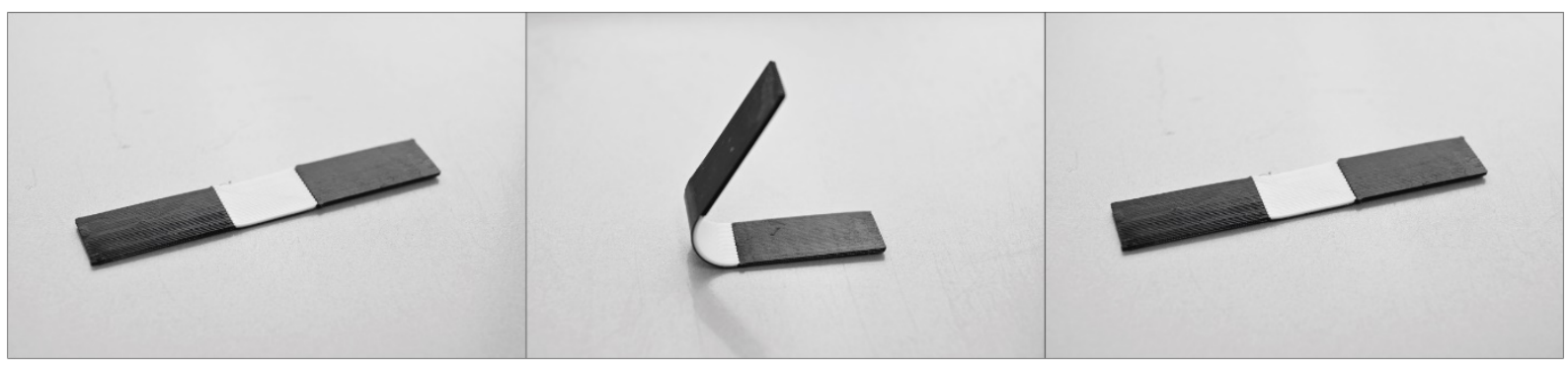

Figure 3: Shape recovery cycle of printed primitive; Phase 1 (left) - printed flat structure, Phase 2 (center) - selftransformation in hot water, Phase 3 (right) - transformation with force and hot water back into flat structure

\section{RESULTS}

\subsection{Optimization of printing conditions}

When optimizing the printing conditions, the appropriate printing speed, flow and cooling rate of the extruded material were determined. Optimal settings were set through the printing of primitives and their cross-sectional analysis (Table 1).

Table 1: Examples of unsuitable and suitable depositions of individual materials and simultaneous deposition of two thermoplastic materials

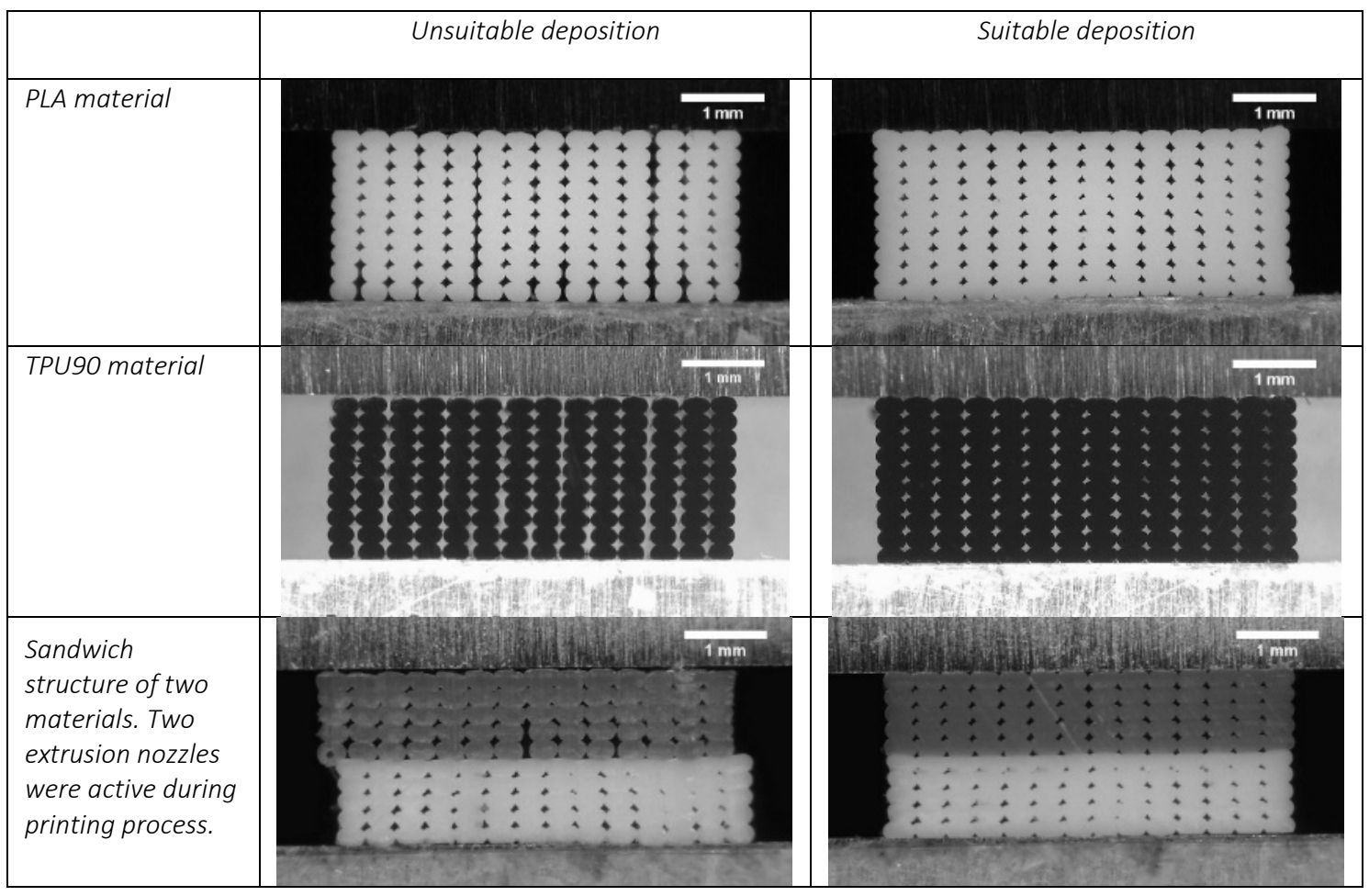

\section{2. Determining the appropriate combination of materials}

Primitives with an active part of 10 and $15 \mathrm{~mm}$ in length were printed at a printing speed of $15 \mathrm{~mm} / \mathrm{s}$. This is the maximum printing speed of the softer TPU80 thermoplastic material. A combination of TPU80/PLA and TPU90/PLA materials was used in printing of the active part. The self-transformation was tested in hot water first at a temperature of $70^{\circ} \mathrm{C}$ and $80^{\circ} \mathrm{C}$. At each temperature three primitives were tested. The results are given in Figures 4 and 5. 


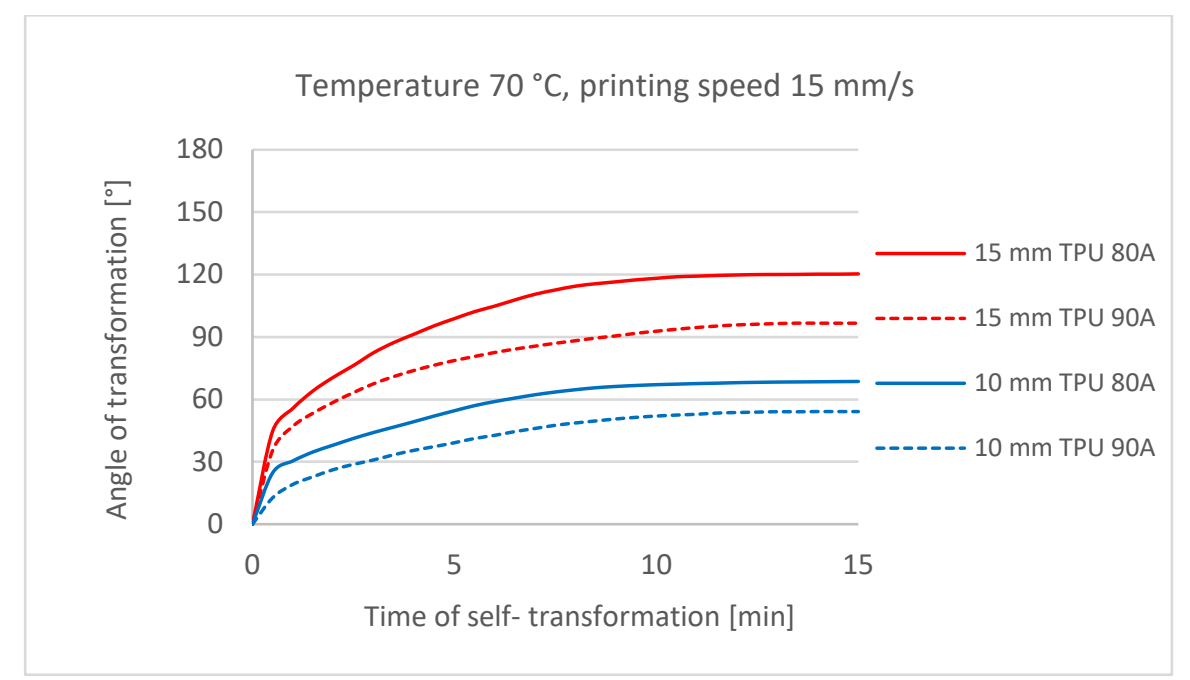

Figure 4: Angle of transformation of the primitives' (PLA/TPU80 and PLA/TPU90) depending on time in hot water at $70{ }^{\circ} \mathrm{C}$. The lengths of active part were 10 and $15 \mathrm{~mm}$. Primitives were printed at $15 \mathrm{~mm} / \mathrm{s}$

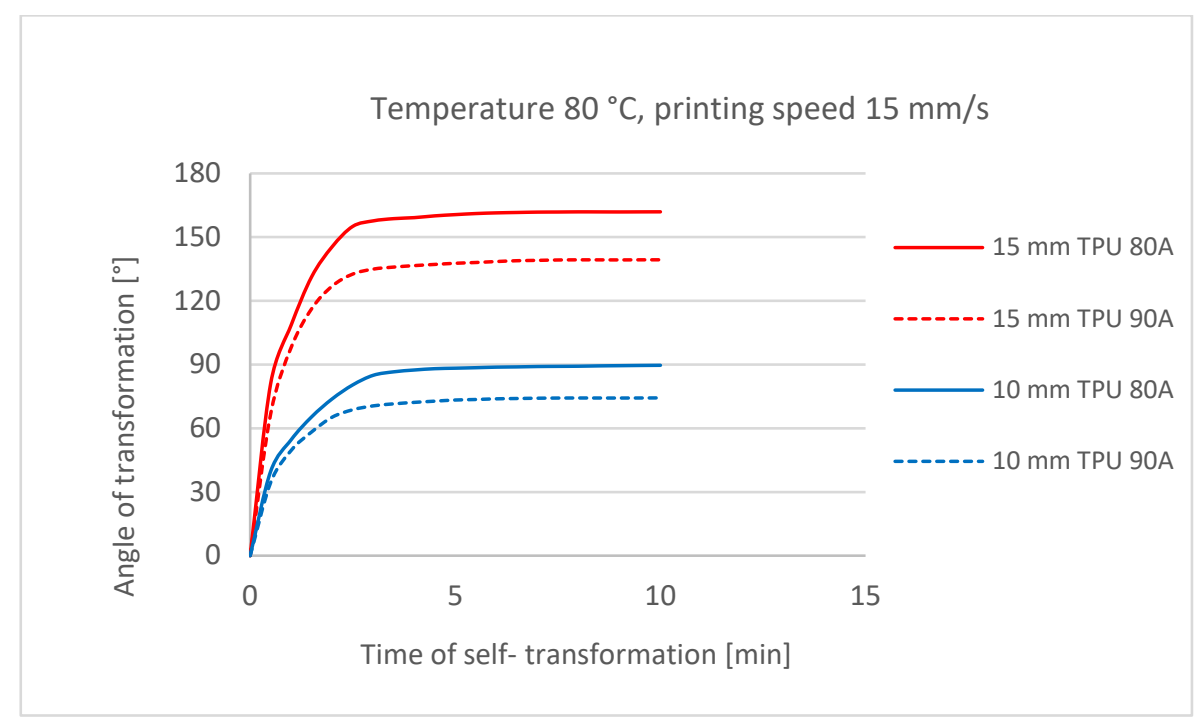

Figure 5: Angle of transformation of the primitives' (PLA/TPU80 and PLA/TPU90) depending on time in hot water at $80{ }^{\circ} \mathrm{C}$. The lengths of active part were 10 and $15 \mathrm{~mm}$. Primitives were printed at $15 \mathrm{~mm} / \mathrm{s}$

\subsection{Determining the optimal water temperature}

In this part of the research the primitives with combination of PLA and TPU90 thermoplastic materials were printed at printing speed of $22 \mathrm{~mm} / \mathrm{s}$. The printing speed was increased from 15 to $22 \mathrm{~mm} / \mathrm{s}$ to achieve higher transformations. The length of active part was $15 \mathrm{~mm}$. To determine the optimal temperature water heated to $60,70,80$ and $90{ }^{\circ} \mathrm{C}$ was used. Results are presented in Figure 6. 


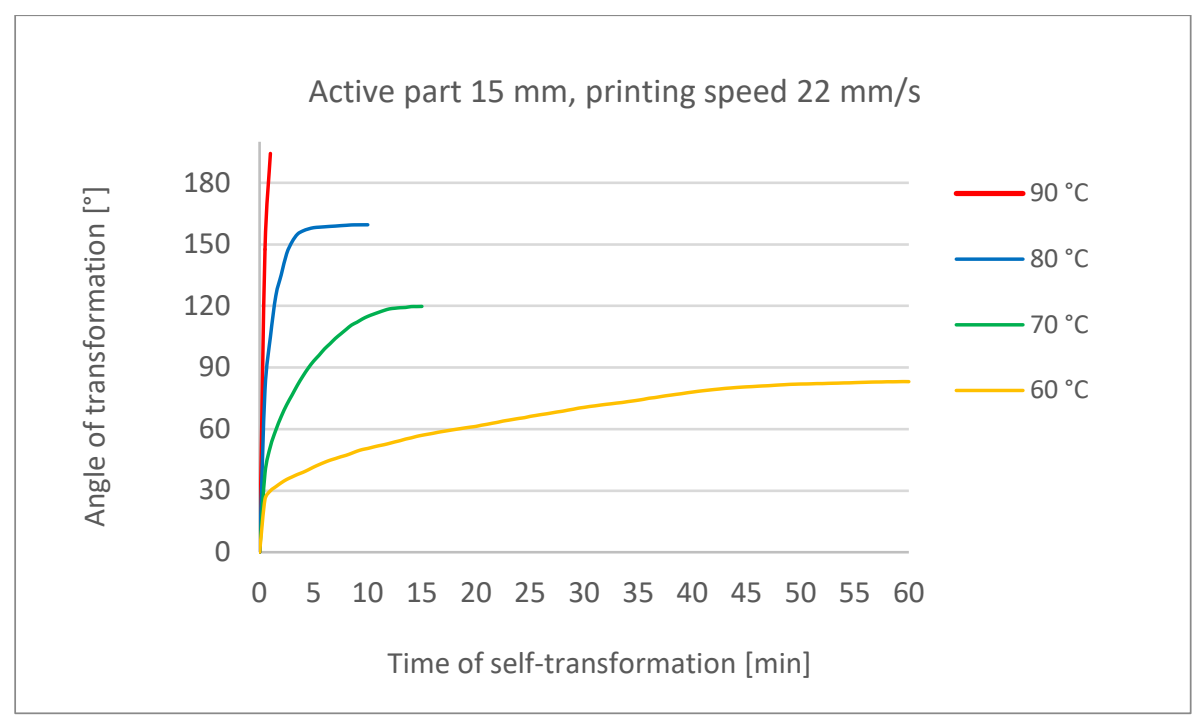

Figure 6: Angle of transformation of the primitives' (PLA/TPU90) depending on time in heated water at 60, 70, 80 and $90{ }^{\circ} \mathrm{C}$. The length of active part was $15 \mathrm{~mm}$. Primitives were printed at $22 \mathrm{~mm} / \mathrm{s}$

\subsection{Determination of primitives' shape recovery}

Testing of primitives' shape recovery response was performed on primitives immersed in hot water at $70^{\circ} \mathrm{C}$. The length of primitives' active part was $15 \mathrm{~mm}$. Firstly, the structures were subjected to four additional self-transformation cycles, i.e. they were heated and placed in a flat position, cooled and then immersed in hot water again to allow self- transformation. This process was repeated four times to increase the total number of transformation cycles to five. The results are visible in Figure 7.

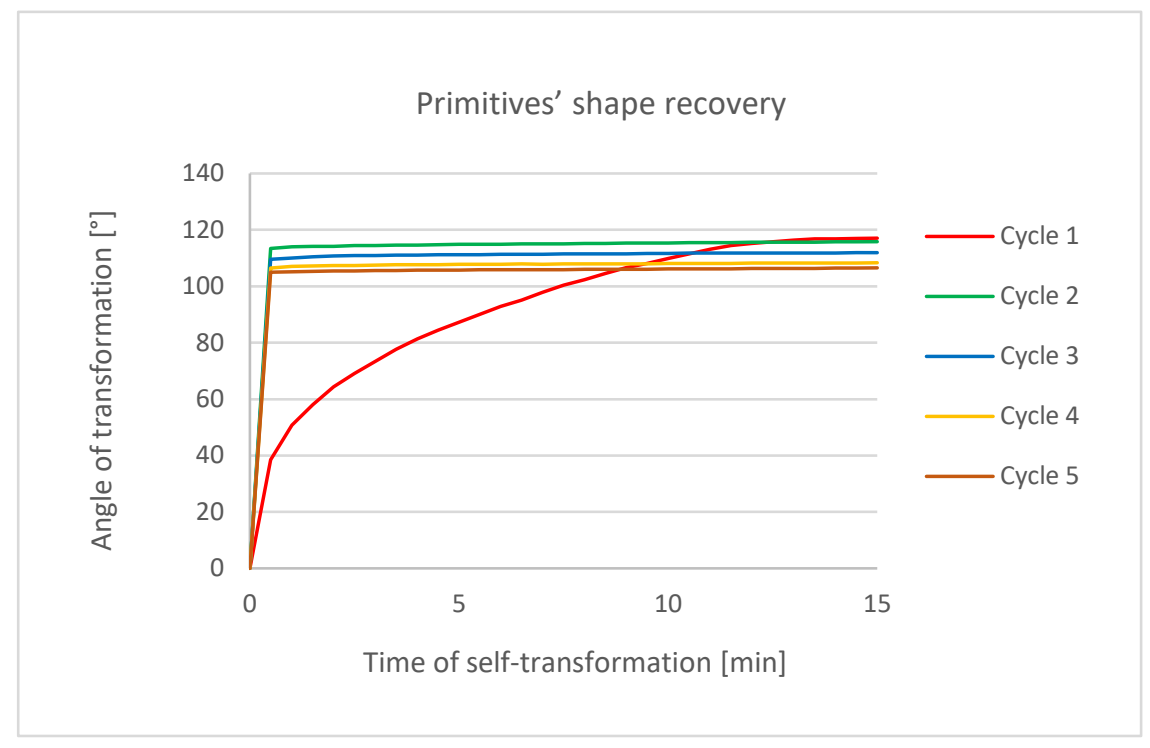

Figure 7: Results of primitives' (TPU90/PLA) shape recovery. Primitives were subjected to five self-transformation cycles in hot water at $70^{\circ} \mathrm{C}$

\section{DISCUSSION}

For a successful study of primitives' self-transformation processes, a calibrated printer and optimized printing conditions are needed. If we want to achieve a precise and controllable transformation, the deposition of filaments in layers must be even, without overlap and deformation. Layers of passive and active material printed on top of each other must achieve adequate deposition and good adhesion. This is presented in the images in Table 1. 
When determining the appropriate combination of materials, we came to the following conclusions (Figures 4 and 5). The rate of transformation decreases over time. The maximum transformation angle increases with the length of the active part of the primitive and with increasing temperature of water. By raising the activation temperature, the maximum angle of transformation is reached in a shorter time. At the temperature of $70^{\circ} \mathrm{C}$, the transformation stops within 15 minutes, and at the temperature of $80^{\circ} \mathrm{C}$ in less than 10 minutes.

If we compare primitives made of different combinations of materials, we can state the following. The maximum angle of transformation for a combination of PLA materials and softer TPU80 is higher than the transformation angle for a combination of PLA materials and harder TPU90 thermoplastic at every temperature. We had problems with extrusion of the TPU80 material. As the temperature rises, it's viscosity becomes very low, completely liquid, which causes contamination of the PLA layers of the active part. Thus, it negatively affects the transformation of the primitive. Due to these problems, we had to exclude TPU80 from the study and proceed only with the harder TPU90 thermoplastic.

In determining the optimal temperature of the activation medium, we found out that a higher activation temperature increases the rate and angle of the transformation of primitives (Figure 6). At an activation temperature of $60^{\circ} \mathrm{C}$, the transformation does not stop after 60 minutes, and at $90^{\circ} \mathrm{C}$ it is completed within 2 minutes. Due to the slow and low response of the primitives at an activation temperature of $60^{\circ} \mathrm{C}$, this temperature was excluded from further studies. We also excluded the $90^{\circ} \mathrm{C}$ temperature do to it being very difficult to control. Temperatures of 70 and $80{ }^{\circ} \mathrm{C}$ proved to be the most suitable for primitive transformation. In the end, we decided to conduct further research at a lower temperature, i.e. $70^{\circ} \mathrm{C}$. The decision is argued by the fact that the energy consumption for heating the water is lower, and the time response of primitives can be well analyzed.

From the results of the shape recovery given in Figure 7, the following conclusions can be deduced. In the first cycle, at a water temperature of $70{ }^{\circ} \mathrm{C}$, the transformation takes 15 minutes. The polymer chains orient themselves in their favorable position and when they are fully released (shrunk) the transformation stops. With each subsequent cycle, the transformation is almost completely performed in the first 2 seconds. The transformation is faster, since the chains are already oriented to their favorable position. They shrink back only in the direction in which we stretched them. With each subsequent cycle, the final transformation angle decreases by an average of $2-3^{\circ}$.

\section{CONCLUSIONS}

The following conclusions can be drawn from the conducted research. For a successful study of 4D primitives' self-transformation we must ensure optimal printing conditions, select the appropriate combination of materials and the optimal temperature of the water as external stimuli. We found that in addition to printer calibration it is necessary to determine the appropriate printing speed, flow and cooling rate of the material. Since the active part of the primitive consists of two different materials it is important that the sandwich structure of materials is properly deposited and has achieved a good adhesion between the layers. The size of the transformation is also influenced by the passive material used on the active part of the primitive since it provides support during the transformation. If its hardness is insufficient and is too flexible, the transformation may become less precise. We also found out that the size of the transformation is influenced by the length of the active part of the primitive, the printing speed and the temperature of the hot water. A higher angle of transformation is achieved when the active part is longer and when the printing speed and the temperature of the water are higher.

In our case, we can conclude that for quality and controlled transformation it is recommended to make primitives with a length of the active part of $15 \mathrm{~mm}$, to use max. print speed $22 \mathrm{~mm} / \mathrm{s}$ and hot water as external stimuli at $70{ }^{\circ} \mathrm{C}$. This is the basis on which we can make a mathematical model for predicting the primitives' self-transformation and a model for predicting the primitives' shape recovery.

\section{REFERENCES}

[1] Almenara, C. C. I.: "Anisotropy and Humidity Effect on Tensile Properties and Electrical Volume Resistivity of Fused Deposition Modeled Acrylonitrile Butadiene Styrene Composites", PhD thesis, Pontificia Universidad Catolica del Peru-CENTRUM Catolica (Peru), 2017. 
[2] Byoungkwon, A., Tao, Y., Gu, J., Cheng, T., Chen, X., Zhang, X., Zhao, W.: „Thermorph: Democratizing 4D printing of self-folding materials and interfaces", Proceedings of the $2018 \mathrm{CHI}$ conference on human factors in computing systems 2018, (Association for Computing Machinery: New York, 2018), pages 1-12. doi: 10.1145/3173574.3173834.

[3] Guanyun, W., Yang, H., Yan, Z., Ulu, N. G., Tao, Y., Gu, J., Kara, L. B., Yao, L.: "4DMesh: 4D printing morphing non-developable mesh surfaces", Proceedings of the 31st Annual ACM Symposium on User Interface Software and Technology 2018, (Association for Computing Machinery: New York, 2018), pages 623-635. doi: 10.1145/3242587.3242625.

[4] João, F., Deus, A. M., Reis, L., Vaz, M. F., Leite, M.: "Study of the influence of 3D printing parameters on the mechanical properties of PLA", Proceedings of the 3rd International Conference on Progress in Additive Manufacturing 2018, (Pro-AM: Singapore, 2018).

[5] Kadir, G., Türkmen, H. S.: "Common FDM 3D Printing Defects", Proceedings of the 3rd International Congress On 3d Printing Technologies And Digital Industry 2018, (3D-PTC2018: Antalya, 2018), pages 368-370.

[6] Kačergis, L., Rytis, M., Michael, S.: "Influence of fused deposition modeling process parameters on the transformation of 4D printed morphing structures", Smart Materials and Structures 28 (10), 105042, 2019. doi: 10.1039/C7MH00269F. doi:10.1088/1361-665X/ab3d18.

[7] Penjumras, P., Rahman, A.R., Talib, R. A., Abdan, K.: "Mechanical properties and water absorption behaviour of durian rind cellulose reinforced poly (lactic acid) biocomposites", International Journal on Advanced Science Engineering and Information Technology 5, 343-349, 2015. doi: 10.18517/ijaseit.5.5.574.

[8] Ravichandra, R. A., Shanmugam, K.: "Additive manufacturing-enabled shape transformations via FFF 4D printing", Journal of Materials Research 33 (24), 4362-4376, 2018. doi: 10.1557/jmr.2018.397.

[9] Shie, M.Y., Shen, Y.F., Astuti, S.D., Lee, A.K.-X., Lin, S.-H., Dwijaksara, N.L.B., Chen, Y.-W.: "Review of Polymeric Materials in 4D Printing Biomedical Applications", Polymers (Basel) 11 (11), 17, 2019. doi: 10.3390/polym11111864.

[10] Singh, K. M.: "Design and development of a system to detect defects in 3D printing through analysis of layer images", PhD thesis, Politecnico di Torino, 2019.

[11] Song, R., Cassandra, T.: "Material waste of commercial FDM printers under realstic conditions", Proceedings of the 26th Annual International Solid Freeform Fabrication 2016, Proceedings of the 27th Annual International Solid Freeform Fabrication Symposium- An Additive Manufacturing Conference, pp. 1217-1229.

[12] Teunis, V. M., Janbaz, S., Zadpoor, A. A.: "Programming 2D/3D shape-shifting with hobbyist 3D printers", Materials horizons 4 (6), 1064-1069, 2017. doi: 10.1039/c7mh00269f.

[13] Tham, W. L., Poh, B. T., Ishak, Z. A. M., Chow, W. S.: "Characterisation of water absorption of biodegradable poly (lactic acid)/halloysite nanotube nanocomposites at different temperatures", Journal of Engineering Science 12, 13, 2016.

[14] Uzir, W. M., Hassan, A., Ibrahim, A. N., Zawawi, N. A., Kunasegeran, K.: "Mechanical, thermal and chemical resistance of epoxidized natural rubber toughened polylactic acid blends", Sains Malaysiana 44 (11), 1615-1623, 2015.

[15] Valeraga, P. A., Batista, M., Salguero, J., Girot, F.: "Influence of PLA filament conditions on characteristics of FDM parts", Materials 11 (8), 1322, 2018. doi: 10.3390/ma11081322.

[16] Zaldivar, R. J., Mclouth, T. D., Ferrelli, G. L., Patel, D. N., Hopkins, A. R., Witkin, D.: “Effect of initial filament moisture content on the microstructure and mechanical performance of ULTEM ${ }^{\circledR} 9085$ 3D printed parts", Additive Manufacturing 24, 457-466. 2018. doi: 10.1016/j.addma.2018.10.022.

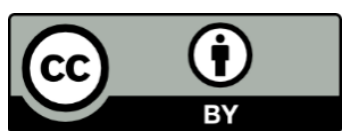

(C) 2020 Authors. Published by the University of Novi Sad, Faculty of Technical Sciences, Department of Graphic Engineering and Design. This article is an open access article distributed under the terms and conditions of the Creative Commons Attribution license 3.0 Serbia (http://creativecommons.org/licenses/by/3.0/rs/). 



\title{
IMMERSIVE INTERCULTURAL EXPERIENCE FOR GRAPHIC COMMUNICATION STUDIES THROUGH VIRTUAL REALITY
}

\author{
Mohd Asrizal Razali ${ }^{1}$, Noranis Ismail ${ }^{1}$, Nurzihan Hassim ${ }^{2}$ \\ ${ }^{1}$ Taylors University, Faculty of Innovation \& Technology, The Design School, \\ Subang Jaya, Malaysia \\ ${ }^{2}$ Taylors University, Faculty of Social Sciences and Leisure Management, School of Media and \\ Communication, Subang Jaya Malaysia
}

\begin{abstract}
At Taylor's University, Intercultural Design is a project-based module where students are exposed to different cultures of foreign countries and are required to understand the role of design in a wide cultural, political and social context. Through this experience in addition to reflective practice, conceptualizing of ideas and active experimentations, the participating graphic communication students interpret their immersion of culture subjectively and present a piece that communicates the said cultural elements to intended audiences. The present COVID-19 international travel restrictions had disrupted this knowledge acquisition process and posed limits of onsite exploration, engagement with foreign agencies and face-to-face interactions with communities and cultures. However, previous studies had posited the potential of utilizing similar approaches via virtual space, place metaphors and avatar-environment interaction. Henceforth, this paper explored Virtual Reality (VR) technology that replicated environments of foreign destinations and allowed students to map information from this perspective in order to produce a graphic design-based output. This paper intended to further examine the effectiveness of VR by comparing information and feedback of; 1)participating students who had firsthand experience of foreign environment, and 2) students who only have second hand experience via VR. This paper also proposed the suitable selection of VR tools based on cost, accessibility, technological requirements and immersion satisfaction via online learning. The results achieved during the analysis is pertinent to endorse the intention towards the use of $V R$ tools for online collaborative and student-centered learning experience for this module.
\end{abstract}

Key words: Intercultural design, virtual reality, experiential learning, immersive experience, graphic design

\section{INTRODUCTION}

The COVID-19 pandemic has challenged the norms of teaching and learning in the education sector. With its key focus on four factors; globalization, teaching and learning, governance and knowledge-based society (Grapragasem et al, 2014), the Malaysian higher education landscape was severely affected with the implementation of a strict Movement Control Order (MCO) in March 2020 with the attempt to break the chain of the virus and to flatten the pandemic curve. Academic institutions had little option but to deploy a crisis strategy to safeguard their biggest stakeholders - the students; and also to ensure smooth delivery of classes with the implementation of online learning.

Intercultural Design is a module offered by The Design School (TDS) at Taylors University, Malaysia and the class delivery is affected by the pandemic situation as nations are forced to close their borders and limit travelers. As this module focuses on experiential learning, collaborative and student-centered learning, students were encouraged to take the opportunity to understand the role of design and designers outside of their locality which demands them to look beyond the familiar setting and into a wider cultural, political and social context. The aim is to introduce students to local and global design issues and impact through active engagements with foreign agencies, face-to-face interactions with communities and cultures, which in return, may present opportunities for further collaboration. But with imposed international travel restrictions, it has disrupted the familiar knowledge acquisition process for this module through on-site exploration and aforementioned engagements. Furthermore, there is evidence that experiential learning is equally crucial to the learner's progress and takes place when; i) a person is involved in an activity, ii) he or she looks back and evaluates it, iii) determines what was useful or important to remember, iv) and uses this information to perform another activity (Kolb, 2014; Razali et al, 2018). Chavan (2011) summed experiential learning as direct encounters with the phenomena being studied rather than thinking or considering the possibility of doing something about it. Schwartz (2012) added that students hold much of the responsibility in the learning process whereby they manage their 
own learning, rather than being told what to do and when to do it. New skills, new attitudes, or new ways of thinking are also developed through experiential education where it immerses learners in an experience and then encourages reflection about the experience (Lewis and Williams, 1994).

Throughout the higher education landscape, virtual collaborative learning is implemented in a wide ranging proposition (Kopp et al, 2011). Lou (2017) mentioned three-dimensional space presentation has made design feel real and lifelike. The teaching and learning process in institutes of higher learning are constantly aided by latest technologies with systems that provide support for the practices (Chan et al, 2019). With the pandemic not showing any sign of ease, alternative methods for collaborative and student centered learning via online tools and VR devices have to be explored and implemented in an attempt to replicate environments of foreign destinations and allow students to interpret information from this secondary perspective in order to produce a graphic design based output. Jerald (2016) described VR as a user-centered technology that lends understanding towards the basis of communication. With advancement of the latest technologies, Gandhi and Patel (2018) summarized that presence in any place in the world could be mimicked vividly with VR combination of peripherals and softwares that enable users to immerse themselves into the action at the predetermined scene from the comfort of their own homes.

\subsection{Problem Statement}

As the possible COVID-19 vaccine is still in development, scientists and governments are already looking at the drastic need for a lifestyle change of the "New Normal" on a global scale in order to control the pandemic situation which includes limitation of international travels possibly for the next few years. Unfortunately, this will heavily affect the module delivery for Intercultural Design by Taylor's Design School (TDS) and requires exploring alternative methods for collaborative and student-centered learning via online tools and VR devices. The aim is to replicate environments of foreign destinations by allowing students to interpret information from the secondary VR perspective in order to produce a graphic design-based outcome from the experience.

With that said, this paper serves as a foundation study for the delivery of Intercultural Design class in January 2021 with the adoption of VR technology to replace the typical week-long excursion to a different country. We inspected the already available VR tools to access environment simulations with the use of virtual space, place metaphors and avatar-environment interaction and provide the framework to measure the immersion quality of each tool in order to determine the quality of information from a secondary VR perspective in comparison to the first-hand on-site experiences of students from the previous semesters.

\section{METHODS}

The data collected upon the completion of the semester will be analyzed with Atlas.ti CAQDAS software. As this study is to determine the immersive experience of VR tools to gather information from a secondary perspective, the basis of the data collection will be based on the reflective practices of feeling, watching, thinking and doing for each of Kolb (2014) Learning Style Index cycles of concrete experience, reflective observation, abstract conceptualization and active experimentation. The data will be utilized during the compilation of students' reflective reports for Intercultural Design January 2021 session.

We limited the selection of VR technology based on the student's capacity to access and operate the tools to gain immersive experience. The data will then be simultaneously coded to ascertain patterns based on Kolb (2005) Learning Style Index of 1) doing , 2) feeling, 3) thinking; and 4) watching.

As recommended by McClelland et al. (2008) and Schreier (2012), any emergent themes that were present during the analysis of the reflective reports will be included as subcategories to the root coding to the main categories. The data analysis and reporting will be done based on the logical flow of issues, particularly whether the VR experience participated by the learners to gather secondary perspective on information that provided immersive experience compared to the original learning excursion experience. The study constructed an inductive and thematic structure to narrate the findings from a macro level and later broke down the findings into larger meanings to identify the constructs built by learners in shaping their attitudes and behaviours towards exploring a location via VR. Select quotations were featured for each category and its subcategories to illustrate the significance themes presented. 


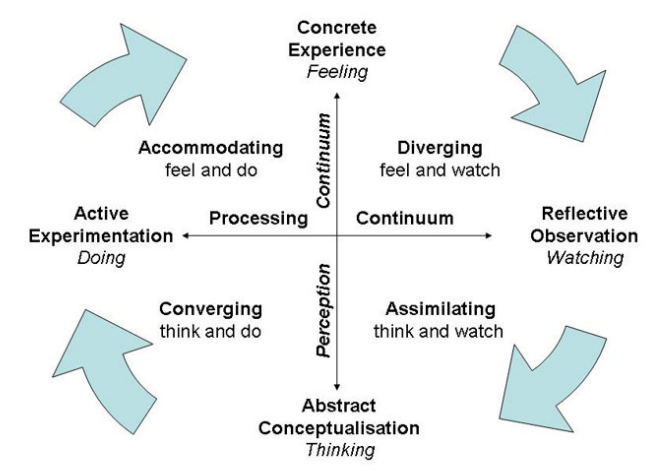

Figure 1: McLeod (2017) Summary of Kolb's Learning Style Index (LSI) through a process continuum

\section{DISCUSSION}

In the previous Intercultural Design excursion to Berlin in 2016, Razali et al (2018) analyzed the students' reflective observations as a consistent behavioural set to Kolb and Kolb (2005) Learning Style Index of 1) doing, 2) feeling, 3) thinking; and 4) thinking. While their emotions are influential, the experience of being there allowed them to identify the differences in design and local culture based on their existing knowledge of other cultures. In applying these elements, they observe and proceed to form new knowledge during the week-long trip. Although this proves to be the greater advantage to experiencing a foreign environment, but with the current pandemic situation, it is impossible to conduct the class excursion without the risk of contracting COVID-19. Therefore, an alternative experience of "being there" on-site would need to be adapted with the use of VR with hope that it would suffice in giving the students a similar experience of the tour and learning in a foreign environment as reflected in their written reports and artworks produced after.

However, due to the nature of the online class delivery where the students are required to operate the VR tools by themselves, we limited the selection of VR technology based on the account of the student's capacity to operate the equipment by themselves which means the tools and applications must be easily and readily accessible, cost free with minimum technology requirements, and provided ease of use, and immersive experience with their already available devices at home as per the following:

\subsection{Google Street View}

Ever since Google Street View was launched in 2007, it has since expanded to include cities and rural areas worldwide. This technology can be accessed for free on all devices via Google Maps by dropping the avatar Pegman; or commonly known as the Yellow Man; onto the roads on the map that are marked with blue lines and navigating the streets with the mouse. The application displays panoramas of stitched spherical images of street-level views. These images provide a complete 360-degree view of the scenery in the ground plane and 180-degree view vertically (Fernández et al, 2016) and may be able to provide a robust immersive experience for the user as they are free to navigate the scenes and revisit the old panorama images from the Street View's archives by adjusting the desired Time.

\subsection{Google Earth VR}

Released in 2017 as an extension of Google Maps, Google Earth VR (GEVR) allows users to visit the world's cities, landmarks and natural wonders with the use of VR equipment such as Oculus Rift and HTC Vive from the comfort of their home. The technology aimed to get the whole world within reach using VR by relying on sensors that track a user's position and gestures in actual space. The aim here is to immerse the user with experience of virtual earth in the same way that they experience a real one: as a world they actively embody rather than a representation they examine from the outside (Belisle, 2020). On top of that, users are able to explore the panoramas from fantastic impossible perspectives like flying, standing at the top of the highest peaks and even soar into space. It also comes with cinematic tours and handpicked destinations which allow a more relaxed exploration. 


\subsection{YouTube VR Videos}

YouTube VR is a new type of online tool that offers viewers experience in exploring a video in 360degrees with their mouse or mobile devices. This medium is called spherical video under two popular categories which are "360-degree video" (360) and VR. Like GEVR, as explained by YouTube Creators (2016) website, the YouTube VR can even be viewed in a head-mounted display and gives an immersive experience of exploring the surroundings in all directions, interacting with and experiencing the content instead of passively watching a video. With the recent COVID-19 pandemic, many YouTube content creators are producing more and more VR walkabout videos. This caters to the viewers desire of exploring the outside world from this medium and giving them the feeling of "being there". With the increase of such activities, viewers are also able to view the latest panorama or scenes of specific locations via YouTube VR such as the Japan Travel Sensei (2020) YouTube channel which produces 360degree VR videos of hot spots in Tokyo.

\section{CONCLUSIONS}

In order to transition into the workforce, one of the necessary skills required to help universities stay relevant to the students is through experiential learning (Cantor, 1995). Even with the challenges of adapting online learning, technology advancement may provide respite in easing the transition of class delivery for Intercultural Design with the use of VR tools. By allowing students some levels of sensory experience, VR may have the capacity to allow immersive experience in cultural studies. Heeter (1992), Shim and Kim (2003) in Teng (2010), mentioned that immersion, presence or telepresence refers to the strength of a user's sense of "being there". However, the quality of the immersive experience may refer to the extent to which a user is satisfied with such a feeling (Teng, 2010). This means immersive quality can be a weak feeling of "being there" while others may require a more concrete experience rather than just second hand observation in VR.

\section{REFERENCES}

[1] Belisle, B.: "Whole world within reach: Google Earth VR", Journal of Visual Culture 19 (1), 112-134, 2020. doi: 10.1177/1470412920909990.

[2] Cantor, J.-A.: "Experiential learning in higher education", (ERIC Publications, Washington D.C., 1995.)

[3] Chan, S.-C.-H., Johnny Wan C.-L., Ko S.: "Interactivity, active collaboration learning, and learning performance: The moderating role of perceived fun by using personal response systems", The International Journal of Management Education 17, 94-102, 2019. doi: 10.1016/j.ijme.2018.12.004.

[4] Chavan, M.: "Higher education students' attitudes towards experiential learning in international business", Journal of Teaching in International Business 22 (2), 126-143, 2011. doi: 10.1080/08975930.2011.615677.

[5] Fernández, L.-P., Reinoso, O., Jiménez, L. M., Ballesta, M.: "A study of visual descriptors for outdoor navigation using Google street view images", Journal of Sensors 2016, 2016. doi: 10.1155/2016/1537891.

[6] Gandhi, R.-D., Patel D.-S.: "Virtual reality - Opportunities and challenges", International Research Journal of Engineering and Technology 5 (1), 482-490, 2018.

[7] Grapragasem, S., Krishnan A., Mansor A.-N.: "Current trends in Malaysian higher education and the effect on education policy and practice: An overview", International Journal of Higher Education 3 (1), 85-93, 2014. doi: 10.5430/ijhe.v3n1p85.

[8] Japan Travel Sensei: "Yanaka Ginza Shopping Street", URL: https://www.youtube.com/channel/UCrFI4j1uXJIMrmNDCNgXUcw (last request: 2020-09-27), 2020

[9] Jerald, J.: "The VR Book", (Association for Computing Machinery and Morgan \& Claypool, New York NY, 2016.)

[10] Kolb, D.-A.: "Experiential Learning: Experience as the Source of Learning and Development (Second Edition)", (Pearson Education, Upper Saddle River NJ, 2014.)

[11] Kolb, A.-Y.: "The Kolb Learning Style Inventory-version 3.12005 technical specifications", (Hay Resource Direct, Boston MA, 2005.), page 72.

[12] Kolb, A.-Y., Kolb D.-A.: "Learning styles and learning spaces: Enhancing experiential learning in higher education", Academy of Management Learning and Education 4 (2), 193-212, 2005. 
[13] Kopp, B., Matteucci M.-C., Tomasetto C.: "E-tutorial support for collaborative online learning: An explorative study on experienced and inexperienced e-tutors", Computers \& Education 58, 12-20, 2011. doi: 10.1016/j.compedu.2011.08.019.

[14] Lewis, L.-H., Williams, C.-J.: "Experiential Learning: A New Approach", (Jossey Bass, San Francisco CA, 1994.)

[15] Lou, M.: "A virtual reality teaching system for graphic design course", International Journal of Emerging Technologies in Learning 12 (9), 117-129, 2017.

[16] McLeod, S.-A.: "Kolb - Learning Styles", URL: www.simplypsychology.org/learning-kolb.html (last request: 2020-09-26), 2017.

[17] Razali, M.-A., Ismail N., Hassim N.: "The role of experiential learning in creative design appreciation among TDS students at Taylor's University", Advances in Social Science, Education and Humanities Research 207, 203-208, 2018.

[18] Schreier, M.: "Qualitative Content Analysis in Practice", (Sage Publications, Thousand Oaks CA, 2012.)

[19] Schwartz, M.: "Best practices in experiential learning: An expanded definition", Ryerson University, 1-18, 2012.

[20] Teng, C.-I.: "Customization, immersion satisfaction, and online gamer loyalty", Computers in Human Behavior 26 (6), 1547-1554, 2010. doi: 10.1016/j.chb.2010.05.029.

[21] YouTube Creators: "Introduction to 360-degree video and virtual reality", URL: https://creatoracademy.youtube.com/page/course/360video (last request: 2020-09-24), 2016.

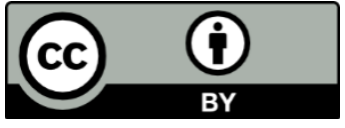

(C) 2020 Authors. Published by the University of Novi Sad, Faculty of Technical Sciences, Department of Graphic Engineering and Design. This article is an open access article distributed under the terms and conditions of the Creative Commons Attribution license 3.0 Serbia (http://creativecommons.org/licenses/by/3.0/rs/). 



\title{
COMPUTATIONAL DESIGN USED FOR JEWELRY
}

\author{
Nikolaos Efkolidis (D), Prodromos Minaoglou (D), Kyriaki Aidinli (D), Panagiotis Kyratsis $(\mathbb{1}$ \\ University of Western Macedonia, Department of Product and Systems Design Engineering, \\ Kozani, Greece
}

\begin{abstract}
Nowadays more and more computer-aided technologies and computational techniques are applied to product design. Jewelry belongs to those products. Jewelry is considered as part of human civilization and adopted to human's needs. In recent years, computational design is applied in order to overcome the limitations of traditional CAD systems, when reaching an increased level of complexity and geometrical controls. Computational design supports the evolution of creative design and develops models as a form of the computational exploration. Furthermore, additive manufacturing (AM) pieces of equipment are widely used to create models and prototype parts in various applications. AM plays an important role, when developing jewelry models, as it is utilized with an aim to produce high-quality models in rather reduced numbers and complex shapes. In the current paper, a computer-based design tool was applied in order to develop algorithms for the generation of new artistic forms for the design of a set of jewelry. Then, Stereolithography (SLA) technique is chosen for the prototype models construction.
\end{abstract}

Key words: Computational design, Jewelry design, Computer-aided-design, Additive Manufacturing

\section{INTRODUCTION}

Jewelry is one of the oldest types of products, according to the findings which are dating from almost 100,000 years ago. It is considered to be a human need and part of human civilization. Its creation depends on cultural and social impacts of a particular period. There are many types of jewelry, which is used for the decoration on human's body, such as, rings, necklaces, bracelets, earrings, brooches, etc. (Silina et al, 2015; larussi et al, 2015; Manavis et al, 2020a). So, a large variety of forms were designed and developed driven by the available materials and technology at the time. Jewelry is an industrial design product which combine aesthetics, ergonomics and usability. So, the design process involves investigation and creativity, and its development in the case of mass production is a combination of art, science, and engineering. Nowadays, the most commercially available jewelry production uses Computer-Aided Design (CAD) and manufacturing technology. Several Computer-Aided Design pieces of software have been developed to help the designers with an aim to produce quality products in shorter time-to-market.

Somlak et al (2011) proposed an aesthetic-driven evolutionary algorithm based on a genetic algorithm (GA) for fractal-based user-centered jewelry design. A two-step fitness function was created in order to determine morphology and aesthetics of the generated art forms. Human preferences Surveys, and popular long-lasting symbols were used for the creation of the aesthetic evolutionary algorithm. They reached a conclusion that the proposed GA can increase design productivity by about $80 \%$. Goel et al (2015) used Computer Aided Geometric Modeling for the recreation of traditional ornamental designs to innovate the designs due to new interpretations of the traditional styles. The basic concept was the development of mathematical models and algorithms for the design of traditional Indian jewelry by simplifying the design methodology of complex traditional ornamental designs. Miguel et al (2016) presented a computational method for designing wire sculptures consisting of interlocking wires. The computation of aesthetically pleasing wire sculptures that are structurally stable, present an extremely efficient and fast alternative for low-fidelity rapid prototyping. A similar research was done by Wang et al (2019) as they introduced a computer assisted framework for manually creating 3D wire bending art from given 3D models. They developed a method, which extracts a set of 3D contour-curves from several viewpoints as a target design of wire sculpture. Tian et al (2019) explored an efficient customization method to adapt the user's need for flexible and custom design of shoes. All the characteristic parameter and related algorithm combined with the formation characteristics of the shoe last bottom map and analysed. The parametric design was used to construct the automatic moulding program of the shoe last bottom to form a professional and feasible design method. The result was the improvement of the design and production efficiency of the customized shoe last bottom. Shen et al (2018) used computational design in order to adjust the three-dimensional structure of clothing and garment. They established garment pieces as the basic modeling form, which conforms to the perfect curvature of the human body. The result was to manage change of the logical structure for the new form of garment construction. 
In the current paper, it is presented a computer-aided fabrication approach, that was designed to make jewelry production easier and faster and to increase the popularity of hand-crafting objects by making them readily available. Our main contribution is the integration of jewelry techniques with a digital design system to produce extremely unusual forms compared with preceding methods. Computational design at the same time with jewelry design and 3D printing, suggests a different approach. The workflow used in this work is simply schematized in Figure. 1. The design steps include the conceptual stage with CAD based sketches developed and then forward the outcome to advanced computational tools for producing a series of alternative designs (family of products by altering the geometrical parameters introduced) and finally the proposed one. This is used at the next stage as the base for using additive manufacturing technology in order to deliver the final prototype of the jewelry.

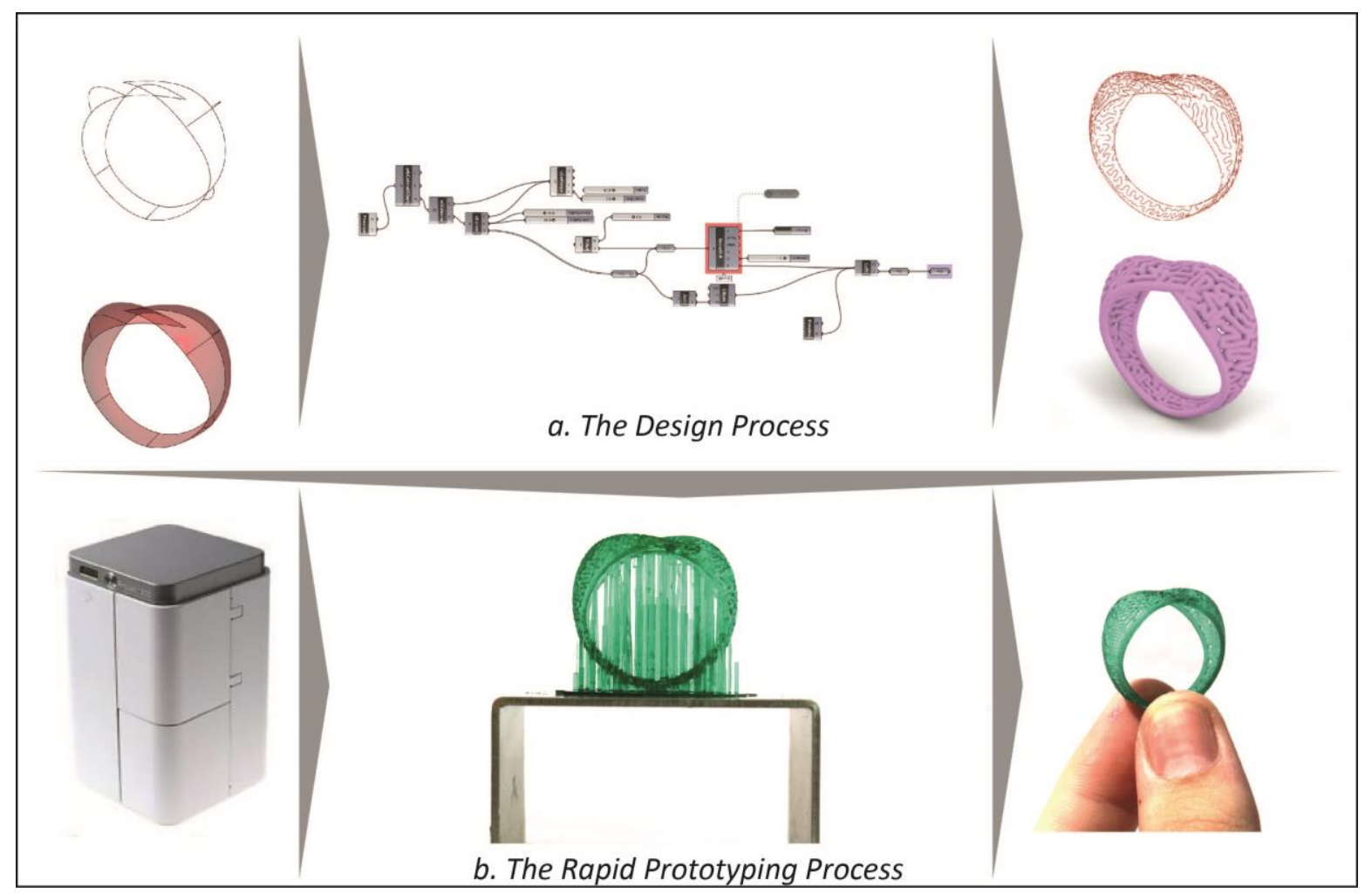

Figure 1: The research workflow applied

\section{METHODS}

Computational design is a modern methodology of using textual or visual programming interface to create and modify forms, geometries even decorations (Kyratsis, 2020; Manavis et al, 2020b). This type of design methodology permits the automation of the design procedures and extends the standard features of CAD applications going beyond their limitations. Computational design is offering several opportunities for novelty and superior solutions as allows to applications to generate structures and deals with digital fabrication tools.

In this research, we used the visual programming of Rhino ${ }^{\mathrm{TM}}$ with a graphical algorithm editor named Grasshopper $^{\mathrm{TM}}$ as the main tool. Grasshopper ${ }^{\mathrm{TM}}$ does not require programming or scripting knowledge, nevertheless, permits designers a high degree of flexibility in creating both simple and complex forms. It is a new way to expand and control the 3D design and modeling processes, involving computerizing repetitive processes, developing forms through mathematical functions, and creating complex forms through repetitions of simple geometry.

In our case, we used the Mobius strip modelling (Figure 2) to design the ring. Grasshopper ${ }^{\mathrm{TM}}$ has extended the mathematical definition of Mobius strip concept to any base geometry that flows along a circle to meet its own end. As we created a new logic structure, we followed three basic steps. The first one was to create a base geometry and a trap to flow along the track. The second step was of course the flow of the trap onto the track. And the third step was the rotation. In our case this is a ring, so we went 
further from the rotation and changed the thickness of the geometry, having different forms of our jewelry. Grasshopper ${ }^{\mathrm{TM}}$ allows us to have many iterations of the product with different geometries easily and fast. These iterations are part of the family of alternative designs that can be produced in a manageable way via the algorithm built and the suggested parameters introduced. The final selection is part of the aesthetics that every designer has and can be associated with the customer demands when a specific trend is followed. In this case, the use of computational design is the basis for creating a new trend with unusual geometries, difficult to manufacture forms and the use of advanced additive manufacturing technology with increased dimensional accuracy.

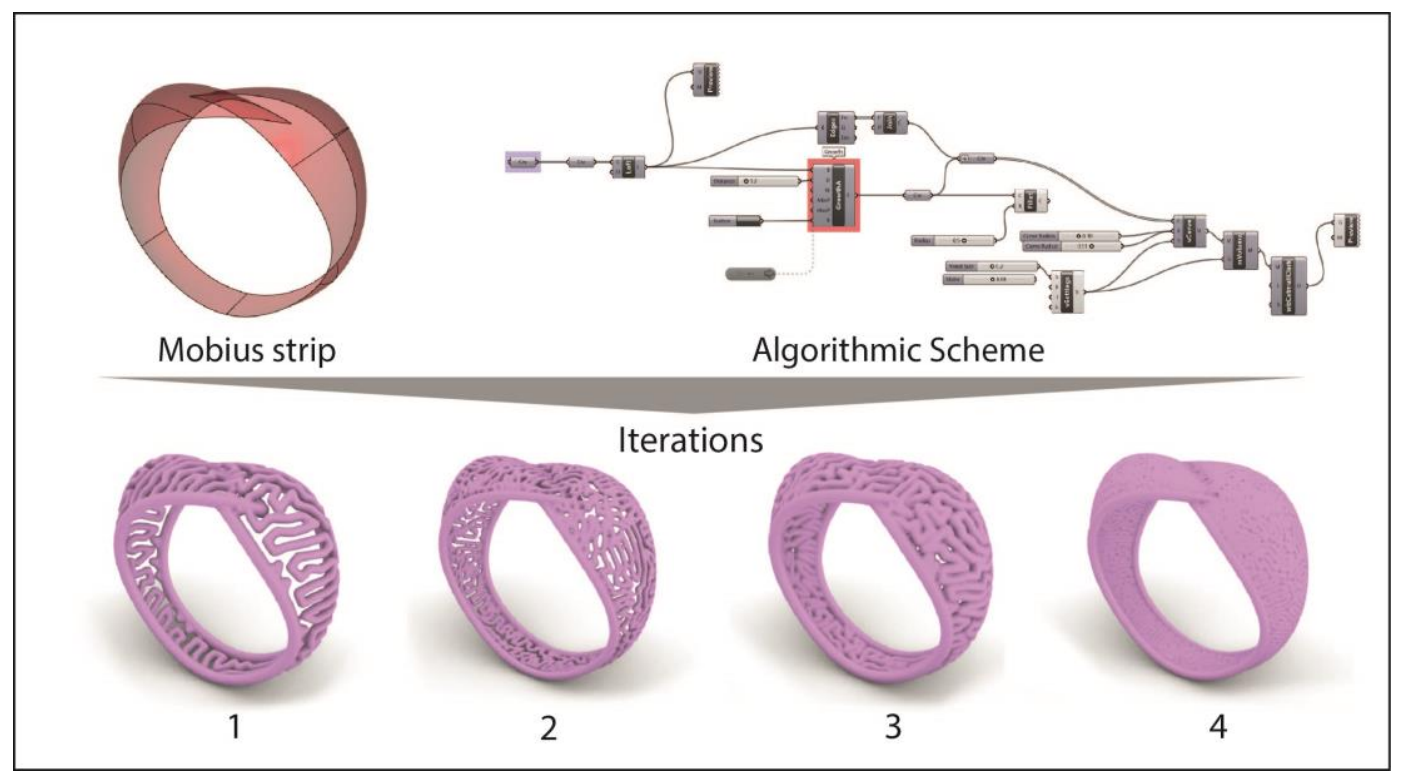

Figure 2: The steps of the design process and iterations

\section{RESULTS}

For the prototype model construction, the ProJet ${ }^{\circledR} 1200$ Micro-SLA, 3D printer from 3D Systems was used. It accepts a variety of file formats (STL, OBJ, PLY, ZPR, ZBD, WRL, 3DS, FBX, IGES, STEP etc), its native resolution is 56 microns and its layer thickness is $0.03 \mathrm{~mm}$. The Micro-SLA technology used is an additive manufacturing process that belongs to the Vat Photopolymerization family and incorporates a number of advantages when the output model has limited dimensions.

The model was created by selectively curing a polymer resin layer-by-layer using an ultraviolet (UV) laser beam. The material used was 3D Systems' VisiJet ${ }^{\circledR}$ FTX Green material. It is a material with high durability and rigidity that is made for plastic models prototyping and small item casting patterns. As a result, it is considered an excellent solution for the jewelry industry. Its tensile strength (ASTM D638) is $30 \mathrm{MPa}$ and its Ash Content is $0.01 \%$. In addition, other industries involved with small sized components can use the same technology.

This printer makes small precise parts with amazing fine features details, even more stunning jewelry casting patterns (Ferreira et al, 2012). The curing area is built into the unit and prints 30-micron layers at 585 dpi resolution with $43 \times 27 \times 180 \mathrm{~mm}^{3}$ print volume area. The smallest area lithography machines developed to produce small but highly detailed objects suitable for a range of applications including casting and jewelry. The use of this specific $3 d$ printer offers us a high precision and exceptionally fine feature detail reflecting real CAD accuracy, it delivers a smooth surface finish, minimizing polishing of precious materials. It is suitable for producing strong, precise micro parts such as figurines scale models of aircraft, fashion accessories etc.

In Figure 3, the rapid prototyping process is illustrated. Once the printing was completed, we removed all the supports from the model. Supports are necessary for successful SLA printing. Removing the marks left by supports becomes an integral step of the finishing process. It can be seen that the model is highly accurate and can be used not only for prototyping purposes but for manufacturing as well. The material used is castable with clean, ash-free burnout and can offer a great deal of accuracy when the final product is built. 


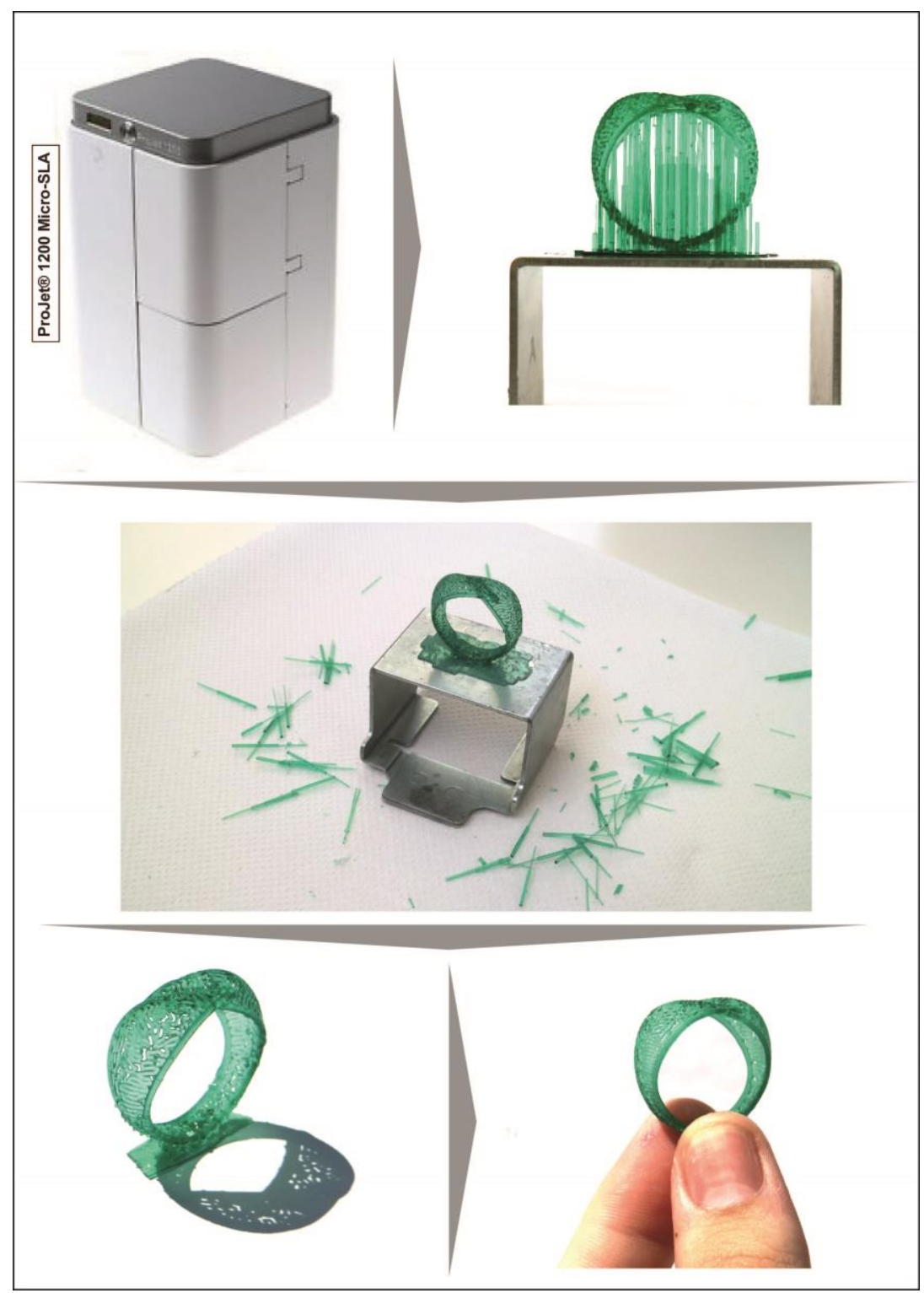

Figure 3: The steps followed during the prototyping process

\section{DISCUSSION}

Computational design allows designers to interact with geometries turned into solid three-dimensional models to develop different forms and versions of the product. The proposed approach can create many patterns on jewelry products, which is difficult and time consuming to be done with the conventional ways. Furthermore, gives the opportunity to present different aesthetic results and even more to improve the fabrication by checking a number of different versions of the product (family of products creation).

Also, there are some additional techniques that can be used in the design process, like the creation of Voronoi diagrams. This kind of techniques gives the designers unlimited geometry variations by offering them the opportunity to play more with shapes and forms. The next step of the research is the development of jewelry based on the traditional styles using Computer Aided Geometric Modeling. The target is the connection of mathematical models and algorithms with traditional patterns in order to design families of jewelry with creative sense, traditional flair and imagination. In such a way, every built algorithm can be used to produce a variety of CAD forms that can lead to alternative proposals of the product designed. These forms are used later on as the base for finalizing the product itself. Even then, more designs can be produced be altering the parameters introduced into the algorithm and thus extra inspiration, design and manufacturing capabilities can be triggered. 


\section{CONCLUSIONS}

In this paper, a computer-aided production approach for jewelry design technique is presented. It is an effort to exploring new approaches of designing and manufacturing ornamental products, using mathematical and modern CAD tools. We highlighted the potential for the design of complex geometric forms and their control during the whole process. Through computational design we generated different forms effectively with a structured manner. The examined automatic digital fabrication doesn't try to cancel the hand manipulation of physical materials, on the contrary it recommends a chance for exploration new craft-making tools and practices from a more modern point of view, showing new opportunities for digital and handmade practices.

The use of Grasshopper ${ }^{\mathrm{TM}}$ makes the digital system more user-friendly and facilitate the manipulation of complex conditions. This CAD tool allows designers to make efficient the iterative design process and enable different products in many geometries, sizes and types, while shortening simultaneously the necessary time for creating models. Finally, the usage of the ProJet ${ }^{\circledR} 1200$, 3D printer makes the final prototype aesthetically perfect as it is suitable for producing strong fashion accessories and jewelry.

\section{ACKNOWLEDGMENTS}

The authors would like to thank the Direction Team of the CODE + Laboratory in the University of Western Macedonia, for its valuable help, making available human and technical resources.

\section{REFERENCES}

[1] Ferreira, T., Almeida, H-A., Bártolo, P-J., Campbell, I.: "Additive Manufacturing in Jewellery Design”, $11^{\text {th }}$ Biennial Conference on Engineering Systems Design and Analysis 2012, (ASME 12, Nantes, France, 2012).

[2] Goel, V., Khanduja, D., Garg, T.K., Tandon, P.: "Computational Support to Design and Fabrication of Traditional Indian Jewelry", Computer-Aided Design and Applications 12(4), 457-464, 2015. doi: 10.1080/16864360.2014.997642.

[3] Iarussi, E., Li, W., Bousseau, A.: "Wraplt: computer-assisted crafting of wire wrapped jewelry", Journal ACM Transactions on Graphics 34(6), 2015. doi: 10.1145/2816795.2818118.

[4] Kyratsis, P.: "Computational design and digital manufacturing applications", International Journal of Modern Manufacturing Technologies 12(1), 82-91, 2020.

[5] Manavis, A., Minaoglou, P., Aidinli, K., Efkolidis, N., Kyratsis, P.: "CAD based design for the jewellery industry: A case study", Proceedings of Computing and Solutions in Manufacturing Engineering 2020a, (COSME, Brasov, Romania, 2020).

[6] Manavis, A., Minaoglou, P., Tzetzis, D., Efkolidis, N., Kyratsis, P.: “Computational design technologies for interior designers: a case study", Proceedings of Computing and Solutions in Manufacturing Engineering 2020b, (COSME, Brasov, Romania, 2020).

[7] Miguel, E., Lepoutre, M., Bickel, B.: "Computational Design of Stable Planar-Rod Structures", Journal ACM Transactions on Graphics 35(4), 2016. doi: 10.1145/2897824.2925978.

[8] Shen, Y., Zhang, T., Ke, Y., Wang, H.: "Design and application of three-dimensional parametric technology in construction of new forms of modern clothing", Journal of Textile Research 39(12), 118-123, 2018.

[9] Silina, Y., Haddadi, H.: "New directions in jewelry: a close look at emerging trends \& developments in jewelry-like wearable devices", Proceedings of the ACM International Symposium on Wearable Computers 2015, (ISWC, New York, USA, 2015).

[10] Somlak, S.: "Reviews of Computer-Aided Technologies for Jewelry Design and Casting", Naresuan University Engineering Journal 1(6), 41-56, 2011. doi: 10.14456/nuej.2011.8.

[11] Tian, Y., Miao, Y., Yu, Y., Zhang, Z.: "Parametric Design Method Based on Grasshopper and Shoe Last Bottom Pattern Moulding Characteristics", IOP Conference Series: Materials Science and Engineering, 520(1): 012017, 2019. doi: 10.1088/1757-899X/520/1/012017.

[12] Wang, Y., Yang, X., Fukusato, T., Igarashi, T.: "Computational Design and Fabrication of 3D Wire Bending", Proceedings of the SIGGRAPH 2019, (Asia SA, 2019), doi: 10.1145/3355056.3364575. 


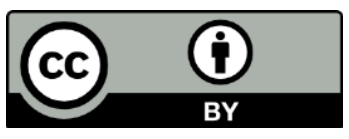

(C) 2020 Authors. Published by the University of Novi Sad, Faculty of Technical Sciences, Department of Graphic Engineering and Design. This article is an open access article distributed under the terms and conditions of the Creative Commons Attribution license 3.0 Serbia

(http://creativecommons.org/licenses/by/3.0/rs/). 


\title{
DEVELOPMENT OF PRODUCTS STATE IDENTIFICATION APPLICATION
}

\author{
Stefan Đurđević (iD, Dragoljub Novaković (iD), Željko Zeljković (iD) \\ University of Novi Sad, Faculty of Technical Sciences, \\ Department of graphic engineering and design, Novi Sad, Serbia
}

\begin{abstract}
The subject of this paper is the development and design solution of an application for product identification with smart packaging. The main goal of the study is to examine the functionality of a relatively new application design program "Adobe XD" company - "Adobe" as well as creating an application that will allow each user to very easily navigate through it. The main goal of the application is to give the user more information about the product than the packaging itself and help him choose the right product. The development of the application was preceded by research in the field of smart packaging and product state identification. This paper aims to set up an intuitive system in the form of a mobile application that would identify the product state and the information would be unambiguously obtained on the mobile device screen.
\end{abstract}

Key words: smart packaging, application design, user experience design, products state

\section{INTRODUCTION}

The term smart packaging is used for packaging that, in addition to its essential functions, also has other specific characteristics. Smart packaging systems are used in several branches of the economy, primarily in the food and pharmaceutical industries, in order to facilitate the use of the product, preserve its quality, as well as provide information about the current state of the product (Figure 1) (Obradović, 2000).
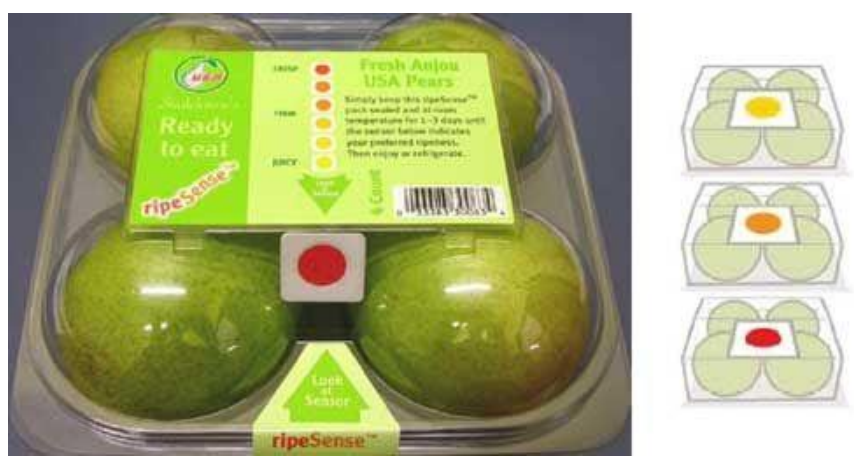

Figure 1: Product state estimation using smart packaging

Intelligent packaging is characterized by the fact that it allows the consumer to monitor information about the production of the product directly. The packaging and consumer interaction is enabled through indicators and sensors that are built into the packaging itself (Miočić, 2015).

\section{METHODS}

For creating design and interaction through an application, the program "Adobe XD 2019" was used in combination with programs such as "Adobe Photoshop 2017" and "Adobe Illustrator 2017" (Adobe, 2020).

The idea is to create an application that will enable the end-user (buyer) easier and simpler shopping during the buying process. Scanning the smart packaging will provide more information about the product compared to the basic information that can be found on the conventional packaging. After scanning the product, the application will load a specific site with a complete product description, such as - name, price, product rating, product stock information, information on intolerance to certain additives such as gluten, lactose, soy, carrageenan, etc.). Also there are comments and previous experiences of users who have already tried the product. Basic information about the product and its specifics, product 
ingredients, instructions for use, date of manufacture or expiration date of the product, net quantity and freshness of the product are also included.

Application creation is based on the basic algorithm that contains four main sections: 1 . Printed codes (Barcode, QR code) 2. Printed electronics and sensors - (RFID, NFC, Beacon, Sensor) 3. Smart indicators (TTI, Freshness, Gas indicators, Chromatic indicators); 4. Augmented Reality (Figure 2) (Đurđević, 2020).

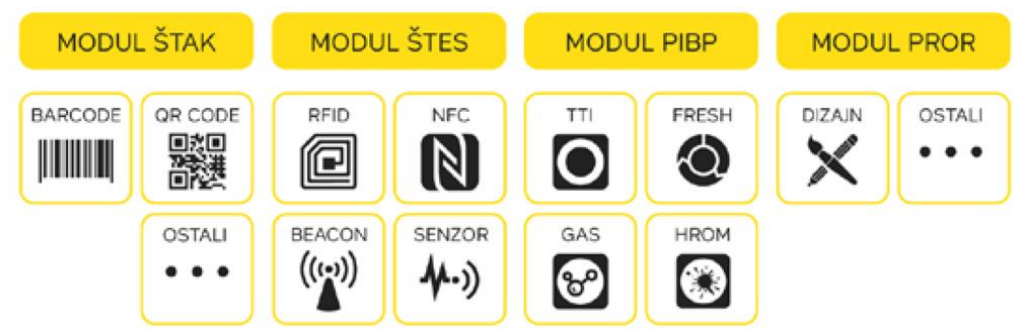

Figure 2: Algorithm as a guide for application development

\section{RESULTS}

After starting, the application is designed to load the home page and start the reading. As this application is used exclusively for scanning products, it is necessary to press the "scan" button, which takes us to page with four types of scanning. Based on the four main types of smart packaging given in algorithm, there are four different types of scans. Figure 3 shows the steps to reach the scanning page.

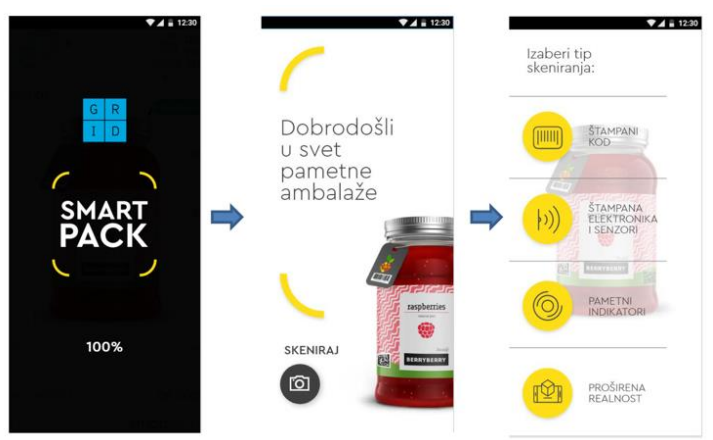

Figure 3: Initial application screens

The first button or the first type of scan is the printed code. The printed code consists of two types of codes, Bar code and QR code. When this button is pressed, the page is loaded, and we get a division where we can choose which type of scan we want. After selecting, the camera on the phone automatically starts where a predefined, transparent "frame" is placed over it, which narrows the range of the camera to one smaller square. It is necessary to find a barcode or QR code on the product and centre it in that box in order for the application to detect and scan it. When the camera finds the specific code, the application offers to "take a picture" option located at the bottom of the screen (Figure 4).
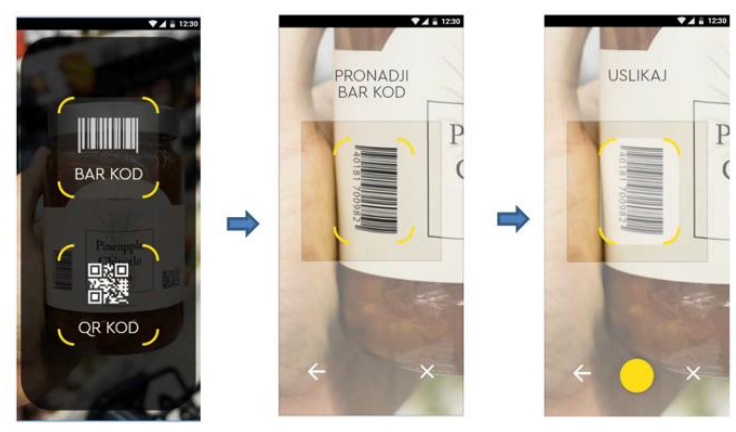

Figure 4: Code selection and scanning 
The second type of scanning is related to printed electronics and sensors. By selecting this type, four buttons appear - 2 buttons for printed electronics and two buttons for sensors. By pressing the button, a short explanation appears to the user on how to place the phone in front of the product (packaging). The distance between the phone and the indicator on the packaging must not exceed 10 centimetres in order for the application to detect it and link to the given site related to the product (Figure 5).
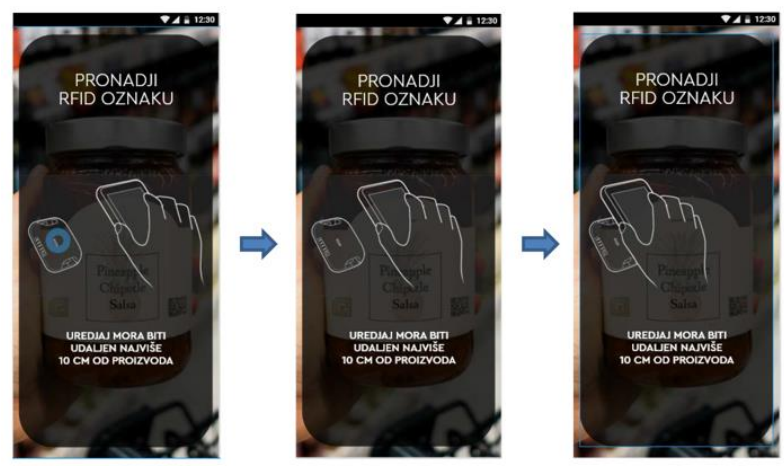

Figure 5: Finding correct distance between the phone and the indicator

A few seconds after this explanation (Figure 5), when the required indicator is found (in this case RFID or NFC indicators), the application automatically opens the product page with a "pop up" window with basic product information (unlike codes where it is necessary to take pictures of the code). By clicking on the "link" button or "pop up" window - the application sends us to the address of the main page about the product.

The next example in the application are beacons, and if we select this module, the application automatically launches the "Google Map" application, with blurred map because the emphasis is placed on the notification related to the product. In order for the application to recognize immediate vicinity, the smartphone location services must be turned on. Two buttons appear on the screen - the first "see product" button sends the user to the main page so that the user can decide if he wants to view it. The second "show path" button actually plots the path from the user to the store where the product is located inside store.

Smart indicators are the third type of devices placed on the packaging and ready to scan. The scanning principle is similar to indicator scanning. The application detects the indicator and offers the option to go to the main site with product details. Unlike the first three types, which are detected by indicators, the condition is detected on the packaging using smart (colour-changing chromatic) ink.

The fourth type is perhaps the most exciting in the visual sense because it uses augmented reality technology. Video and audio effects give the customer a superior feeling to which a particular product is experienced in real-time (Figure 6). These effects can be entertaining but also informative. When it comes to effects of an entertaining nature, these are usually effects that create a more complete and more precise image of the product, while informative effects are most often some novelties added to the product or some actions that are related to the product at that time. When the augmented reality button is pressed, after reading, the camera on the phone automatically turns on.

On the screen, the user can see the request to scan the product. When the product is brought to a required position, the application scans the packaging (product) by starting to draw an "outline" line and detecting it. A few seconds after scanning, two new buttons appear on the screen: "Run $A R^{\prime \prime}$ and the "About Product" button.

If the "Run AR" button is selected, video and audio effects will be displayed along with the scanned product in real-time. If the "About product" button is selected, the application takes the user to the main page with detailed product information. 


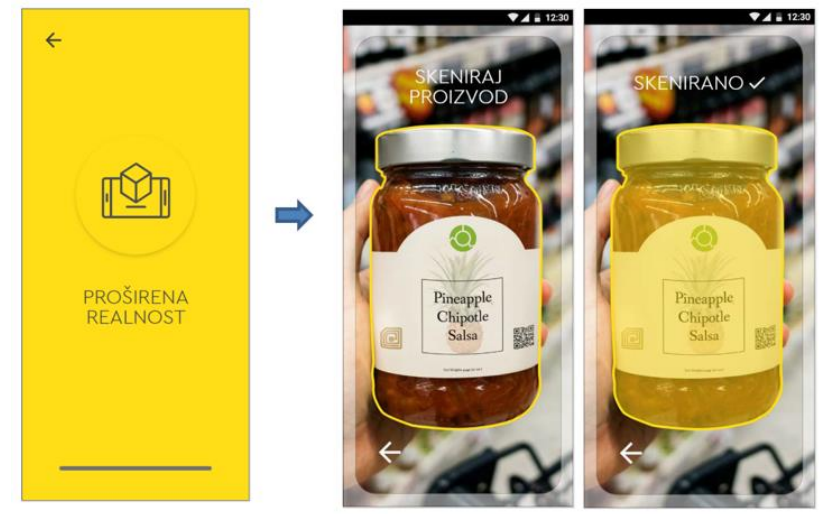

Figure 6: Product scanning via Augmented Reality module

We can conclude that each of these scanning types leads us to the main page, which is the target destination and which contains all the information related to a given product. This page is longer than the size of a single screen, so a "slider" has been added to make it easier to navigate through the app, making it easier to interact.

The first and most important information for most users is at the very beginning of the page and is related to the product price, product evaluation (users comments about the product), the option for the user to evaluate the product, product stock information and information on whether the product contains any additions the potential buyer is intolerant (Figure 7).
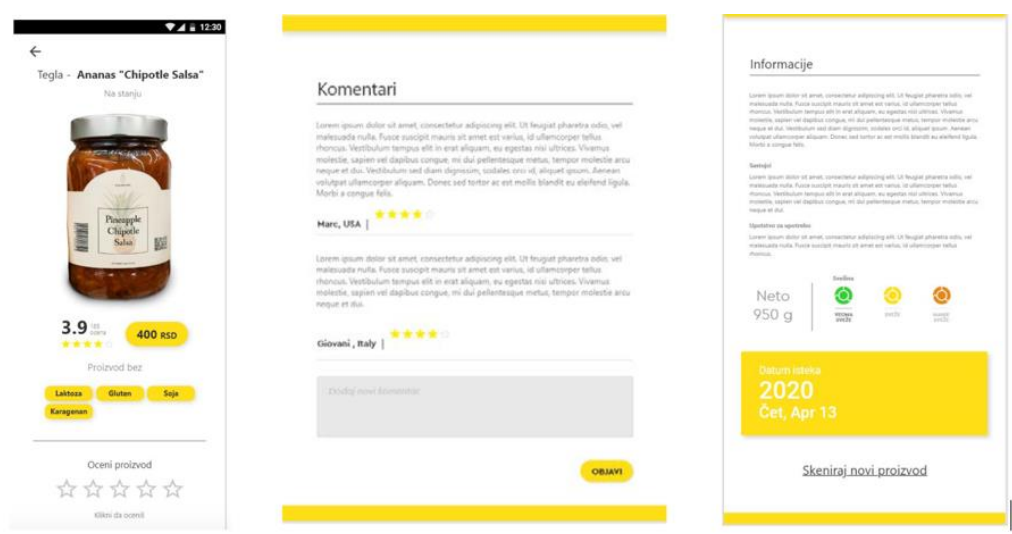

Figure 7. More detailed product information, comments and other information

There is also a section with comments from previous users and their experiences with that product. It is also possible to leave a comment here, just username and country name will be printed with the posted comment. When the comment is sent, by clicking on the "publish" button, it will be automatically added to the site.

The section below the comments is related to the information from the product declaration. Here user can find information such as the manufacturer name, country of origin, distributor, ingredients, allergens, instructions for use, product freshness, net weight as well as the product expiration date. All this information is static (does not change), except for the freshness information, which is directly related to the smart packaging and changes over time depending on the product freshness.

At the end of the page, there is an option or button "scan new product" that returns the interface to the first page in case user want to scan a new product to compare with the current one.

\section{CONCLUSIONS}

Based on the market demand, there is a growing need of the user, in this case, the customer, for technologies that more easily and quickly lead the customer to the desired product or service. In addition to these benefits, the customer becomes dissatisfied with the necessary information we can find on the 
product, and thus smart packaging becomes a precedent in choosing the desired product. In combination with the newly created application, more detailed and extensive information is offered. As a new program by Adobe, Adobe XD is becoming a revolutionary "User Experience" program with advanced interaction with the UI designer, which facilitates the development of applications necessary for the "revival" of smart indicators on the packaging.

\section{ACKNOWLEDGMENTS}

This research(paper) has been supported by the Ministry of Education, Science and Technological Development through the project no. 451-03-68/2020-14/200156: "Innovative scientific and artistic research from the FTS (activity) domain".

\section{REFERENCES}

[1] Adobe: "Creative Cloud", URL: https://www.adobe.com/creativecloud.html (last request: 2020-07-20).

[2] Đurđević, S.: "Model identifikacije stanja zaštitnih elemenata grafičke ambalaže", PhD thesis, University of Novi Sad, Faculty of Technical Sciences, 2020.

[3] Miočić, L.: "Osiguravanje kvalitete u procesu razvoja inovativne ambalaže", BSc thesis, University of Zagreb, 2015.

[4] Obradović, T.: "Savremena izrada ambalaže", (Data status, Beograd, 2000.)

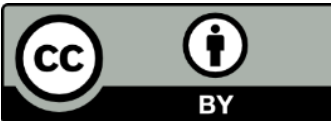

(C) 2020 Authors. Published by the University of Novi Sad, Faculty of Technical Sciences, Department of Graphic Engineering and Design. This article is an open access article distributed under the terms and conditions of the Creative Commons Attribution license 3.0 Serbia (http://creativecommons.org/licenses/by/3.0/rs/). 

DESIGN

L 



\title{
ADVERTISING ON CITY BUSES
}

\author{
Ana Dujmović, Nace Pušnik \\ University of Ljubljana, Faculty of Natural Sciences and Engineering, \\ Department of Textiles, Graphic Arts and Design, Ljubljana, Slovenia
}

\begin{abstract}
Public transportation became a prime carrier of "moving images" in many consumer cultures. The main interest was to investigate how many advertisements participants can retrieve from memory and what was their general opinion on outdoor advertising. A field and online survey (both in form of questionnaire) were carried out in a group of 1200 participants. They were divided in six groups and analyzed according to their age, gender and frequency of using the public transportation. The results indicate that memory of outdoor advertising decreases with age. The participants most frequently agreed with the assertion/claim that outdoor advertisement on city buses of Ljubljana impedes the outside view through the window of the bus making it difficult to orient themselves according to surrounding. Advertisers could take this into account and avoid posting ads on the bus windows, or limit this to the parts where ads are least distracting the users.
\end{abstract}

Key words: cityscape, city bus transport, memory, outdoor advertising, user experience

\section{INTRODUCTION}

Advertising is a part of our lives and we find it hard to avoid it. Advertisements (in further text ad-singular and ads-plural) are thus present almost everywhere; in various media, such as radio, television, newspapers and magazines, on the internet. They also appear in public places. Posters of different sizes are placed in a variety of places, e.g. along roads, bus stops, in bars and on vehicles. In Ljubljana, outdoor ads that can also cover glass surface were placed on city buses in 2009 (before that, just non-glass parts could be covered). Advertising is a broad concept, often associated with ads and businesses. Businesses often advertise themselves and their brands, but the concept of advertising is not just tied to them (Ackley and Hackley, 2015; Bernays, 2005). Politicians, political parties and non-governmental organizations are also advertised. Advertising is a paid, impersonal form of communication with which we want to encourage the process of exchanging products, services or ideas (Ackley and Hackley, 2015; Bernays, 2005). When we talk about advertising political campaigns and politics, we often use the word propaganda, which means spreading beliefs in our favour (De Pelsmacker et al, 2008). The difference between propaganda and advertising is in the establishment of a communication relationship between the sender and the recipient. Advertising and other forms of marketing communication must fulfill the promises made, as they may otherwise be subject to legal or market sanctions. Propaganda are often vague promises that are supposed to happen in a long and indefinite period of time and are not subject to criminal sanctions if they are not fulfilled or are false (De Pelsmacker et al, 2008).

With advertising we want to achieve pre-set goals, e.g. increase or maintain sales, and it is difficult to measure the actual effectiveness and performance of a campaign. The reach of a set of published messages or the reach of an entire campaign is often measured. Companies are interested in the effect of their advertising, as they can devote a large part of their resources to this. The affinity index is often used, which is calculated as the ratio between the reach of the media carrier in the target audience and the reach of the carrier in the entire population (Allaby, 2020; Loken, 2006).

In evaluation, two concepts emerge that are often equated, although there is a difference between them. The concept of performance is related to achieving the goals we have set, or changes caused by the ad in the recipient's response. Efficiency is related to the profitability of advertising with optimal use of resources. The results of sales before and after the advertising campaign are often compared; we can also focus on other parameters, e.g. brand recognition. It has been proven that efficiency increases the most when the target group are users who are not yet familiar with the brand (De Pelsmacker et al, 2008). 
When measuring efficiency and effectiveness, we distinguish several types of goals:

- $\quad$ sales targets relating to increasing or maintaining sales or market share;

- media goals that show the target group's exposure to the campaign message;

- communication goals, which are measured by various techniques, e.g. call up the ad (De Pelsmacker et al, 2008; Loken, 2006)

Professors Jennifer Gregan-Paxton and Barbara Loken (Gregan-Paxton and Loken, 1996) researched how people store information. They found that elapsed time and saturation of the space with information affect the effectiveness of advertising. The longer it takes from the moment a person is exposed to an ad, the less likely they are to retrieve information. Even if a person sees the same ad more than once, she/he will probably not remember it.

It has been investigated that emotions play an important role in consumer decision making. For effective advertising, only superficial automatic detection is enough, as the evaluation of messages is largely subconscious. Ads should also contain an emotional component, because this is what allows the ad to leave traces in the long-term memory (Gregan-Paxton and Loken, 1996; Kovačić, 2011).

Advertising messages can be measured before or after the campaign. The effects of the campaign are measured; whether we have achieved the set goals or not. We know quite a few methods of measuring ads, which are mostly used before the start of advertising, e.g. concept testing, preliminary testing, diagnostics, key concept, readability assessment, psychological test, recall test, direct opinion on the ad, indirect opinion on the ad (Ackley and Hackley, 2015; De Pelsmacker et al, 2008).

Outdoor advertising is a sub-meaning of out of home advertising, which is divided into ambient or indoor and outdoor advertising or outdoor advertising (Ackley and Hackley, 2015; Tsuji, n.d.). Internal media can be billboards in waiting rooms, cinemas, shops, shopping centers, etc. Outdoor media include ads that can be placed along roads, on the street, at bus, train stations and in a variety of places, including benches, trash cans and means of transport. These are large posters, smaller poster areas of various dimensions, ads in light showcases. They are made to distract human attention, so they often contain a simple message and a screaming visual image.

Vehicle advertising is one of the options for outdoor advertising. The ad can be placed on the outside of any vehicle, usually special foils are used, which are glued over the vehicle frame. Outdoor advertising is used on buses, trucks, trains, cars, motorcycles, bicycles... This type of advertising achieves high exposure. According to the Target Group Index, 29 million people in the UK are exposed to outdoor ads on buses every week (Tsuji, n.d.; Mrgole, 2017).

Bus advertising is part of vehicle advertising. The bus usually changes its daily lines, so in a few days the same ad can appear in different parts of the city. The large area of the bus allows various forms of ads that attract attention. Increasingly, entire buses are covered except for windows next to the driver. It can be advertised inside the bus or on the outside. Businesses prefer to advertise on the exterior surfaces of city buses rather than intercity buses. Intercity buses travel more kilometers than city buses, but are less exposed to people. There is a higher frequency of people in cities compared to driving on local roads.

A different percentage of the bus's exterior can be covered (Figure 1), and the ads can also cover the glass surfaces, the back or only certain parts. The left side and rear side are more visible to drivers of other vehicles and pedestrians, so in principle it is designed slightly differently than the right side, which is intended for those waiting at the bus station (Mrgole, 2017; Phillips and Stanton, 2004).
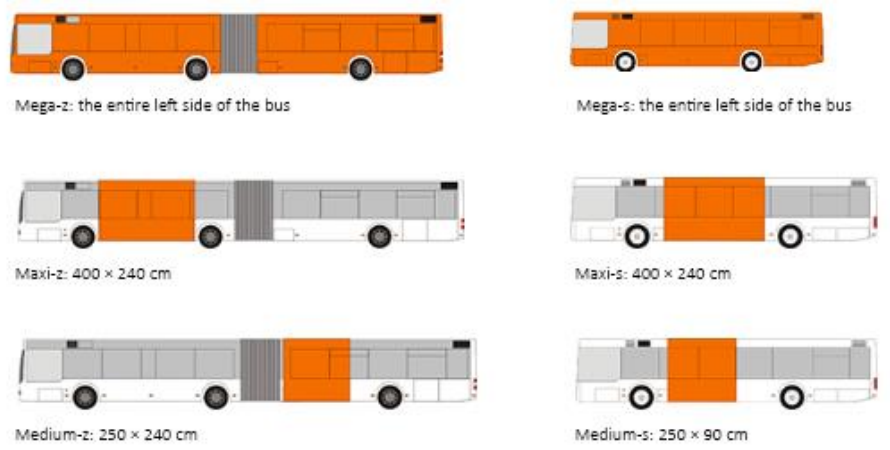

Figure 1: Advertising options on the left side of the bus (Media Bus, n.d.) 


\section{METHODS}

We conducted two surveys - field and online. The main topics of the surveys were the use of the city bus in Ljubljana and the opinion on outdoor ads on buses in Ljubljana. We included 1200 people; 600 were obtained through a field survey and 600 through an online survey. Respondents were divided into six age groups. Each age group consisted of 200 respondents of which exactly 100 were female and 100 were male. In the whole survey this represents 600 women and 600 men evenly distributed by age groups. The surveys covered the same questions, but in a different sequence. The six age groups of both surveys were: up to 24 years old; from 25 to 34 years old; from 35 to 44 years old; from 45 to 54 years old; from 55 to 64 years old; over 65 years old.

The surveys consisted of seven questions. All questions allowed the choice of only one answer. The first question referred to the frequency of use of the city bus in Ljubljana, the respondents chose between six options. The second question was used to determine whether people had noticed at least one outdoor ad on a city bus in Ljubljana in the last week, and the third question allowed people to write the answer themselves. We were interested in whether people could mention at least one ad that was on the outside of the city bus in Ljubljana in the last week. The fourth question consisted of eight statements referring to outdoor ads on city buses in Ljubljana; the respondents decided on a five-point scale (from strongly disagree to completely agree) how much they agree with the statements. The fifth question asked about gender (male or female), the sixth question ranked respondents into the above age groups. The seventh question referred to employment status.

We set up five hypotheses.

- Hypothesis 1: 70\% or more of the respondents noticed at least one outdoor ad on a city buses in Ljubljana in the last week.

- Hypothesis 2: 50\% or more of the respondents can state at least one advertising message that was on the outer part of the city buses in Ljubljana in the last week.

- Hypothesis 3: 60\% or more of the respondents think that outdoor ads on city buses in Ljubljana are interesting.

- Hypothesis 4: 50\% or more of the respondents believe that outdoor ads on city buses in Ljubljana are an unobtrusive way of advertising.

- Hypothesis 5: 75\% or more of the respondents believe that outdoor ads on city buses in Ljubljana obstruct the view through the bus window.

\section{RESULTS}

\subsection{Combined Results of Field and Online Survey}

We first analyzed the demographic data of the respondents, such as employment status. Figure 2 shows the employment status of the respondents; the answers are sorted by age groups. Most, 663 (55.3\%) of all participants are employed. Among those under the age of 24, the largest is number of students (174, 87.0\%), 14 (7.0\%) high school students and 12 (6.0\%) employees. There were 106 (53.0\%) employees, 86 (43.0\%) students and 8 (4.0\%) unemployed in the age group of 25 to 34 years. The groups aged 35 to 44 $(183,91.5 \%), 45$ to $54(183,91.5 \%)$ and 55 to $64(171,85.5 \%)$ had the largest share of employees. In the age group over 65 , most retirees $(192,96.0 \%)$ were expected.

Most respondents answered from time to time the question "How often do you use the city bus in Ljubljana?". There were 474 (39.5\%) of them. The analysis by age groups among the respondents shows that people under 24 most often use the city bus four to six times a week, 66 (33.0\%) of them in their age group, slightly less, 52 (26.0\%) chose to use the city bus every day (Figure 3 ). In the remaining age groups respondents most often use the city bus in Ljubljana occasionally. 132 (11.0\%) of all respondents do not use the city bus in Ljubljana. According to LPP's annual report for 2017, 82.5\% used the city bus in 2018, and our analysis showed an even higher share; 1068 (89.0\%) of respondents use the bus in Ljubljana at least occasionally. 


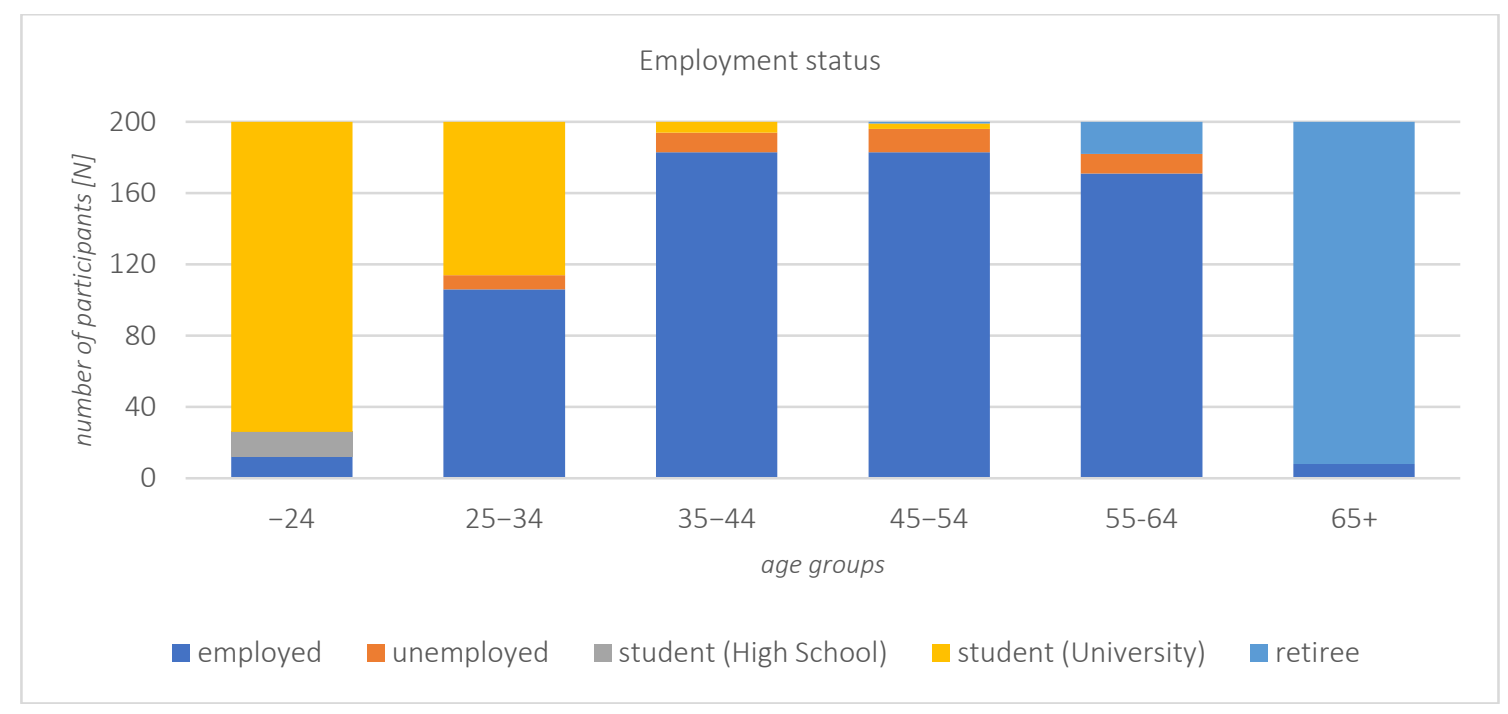

Figure 2: Display of the answer by age groups to the question "What is your employment status?"

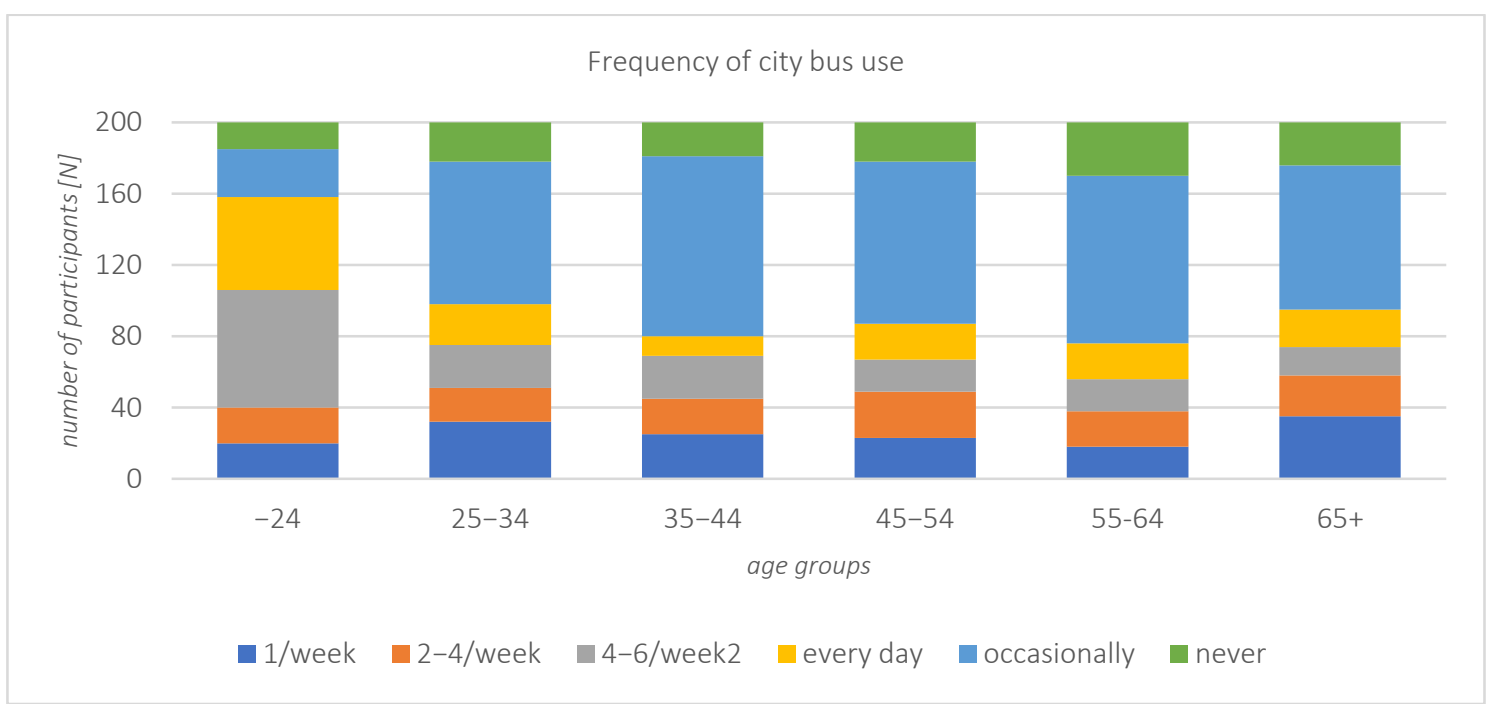

Figure 3: Display of the answer by age groups to the question "How often do you use the city bus in Ljubljana?"

The difference could be explained by the fact that young people under the age of 24 mostly do not earn enough, as most of them are not regularly employed to be able to afford a car, so they use public transport more often.

Figure 4 shows that most respondents noticed at least one outdoor ad on a city buses in Ljubljana in the last week. Most, 176 (88.0\%) were in the first age group, up to 24 years old. The lowest number of ads was noticed by people over 65 (152, 76.0\%). 218 (18.2\%) of all respondents did not notice ads on the city buses in Ljubljana in last week. 


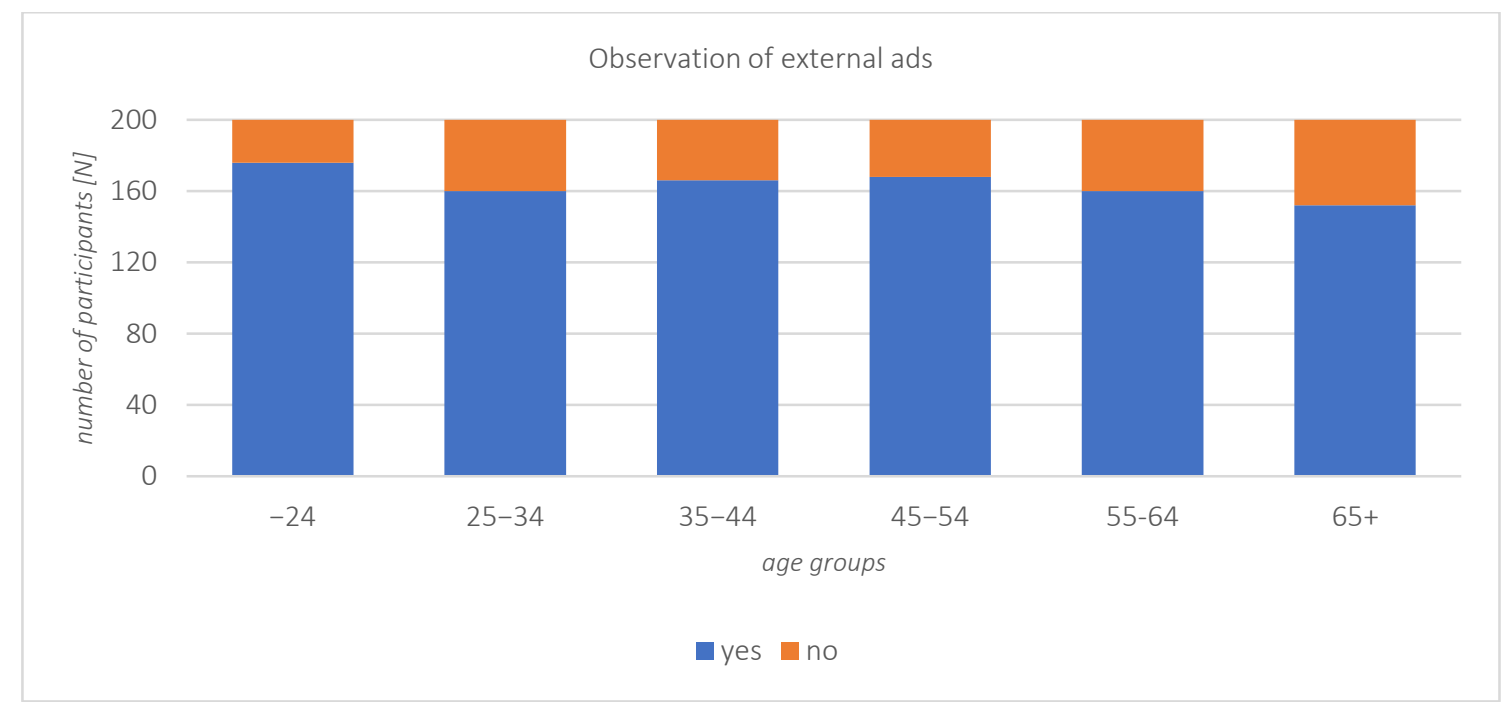

Figure 4: Display of the answer by age groups to the question

"Have you noticed at least one outdoor ad on the city bus in Ljubljana in the last week?"

$225(18.8 \%)$ respondents mentioned at least one ad that was on the outside of the city buses in Ljubljana. People under the age of 24 most often mentioned an ad, 69 (34.5\%). The least frequently reported ads were in the age groups 55-64 (176, 88.0\%) and over 65 (176, 88.0\%) (Figure 5). The indication of ads with higher age group is declining.

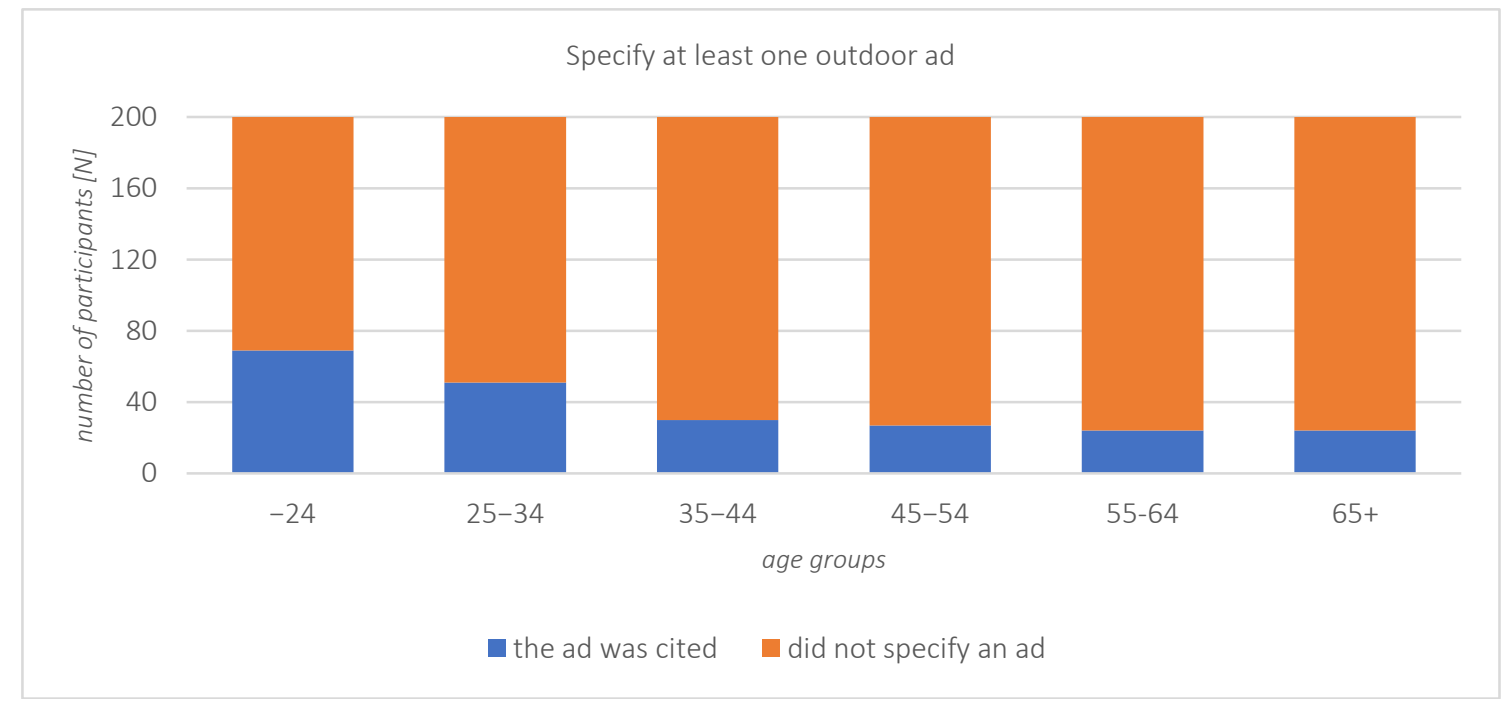

Figure 5: Display of the answer by age groups to the question

"Can you list at least one ad that was on the outside of the city bus in Ljubljana in the last week?"

People between the ages of 18 and 35 are more likely to remember information from ads, but it is harder to persuade them to make a purchase compared to a group that is older than 35 . Older people are less likely to remember information, but tend to make a purchase quicker. On the other hand, it has been shown that if the ads contain words or phrases such as new, new product, improved performance, this convinces the group of 18 to 35 old years more; people over the age of 35 are less susceptible to such messages. (Phillips and Stanton, 2004)

Those who use the bus once a week $(153,12.8 \%)$, four to six times a week $(166,13.8 \%)$ and every day $(147,12.3 \%)$ cited an ad as shown by the values in parentheses. People, who use buses two to three times a week cited an ad in $128(10.7 \%)$ cases. 474 occasional users (39.5\%) have listed the most ads. Those who never use bus $(132,11.0 \%)$ had the lowest percentage of recollecting an ad from their memory. This actually means they do not pay attention to buses even if they are just walking in city center where fluctuation of buses is the highest (Figure 6). 


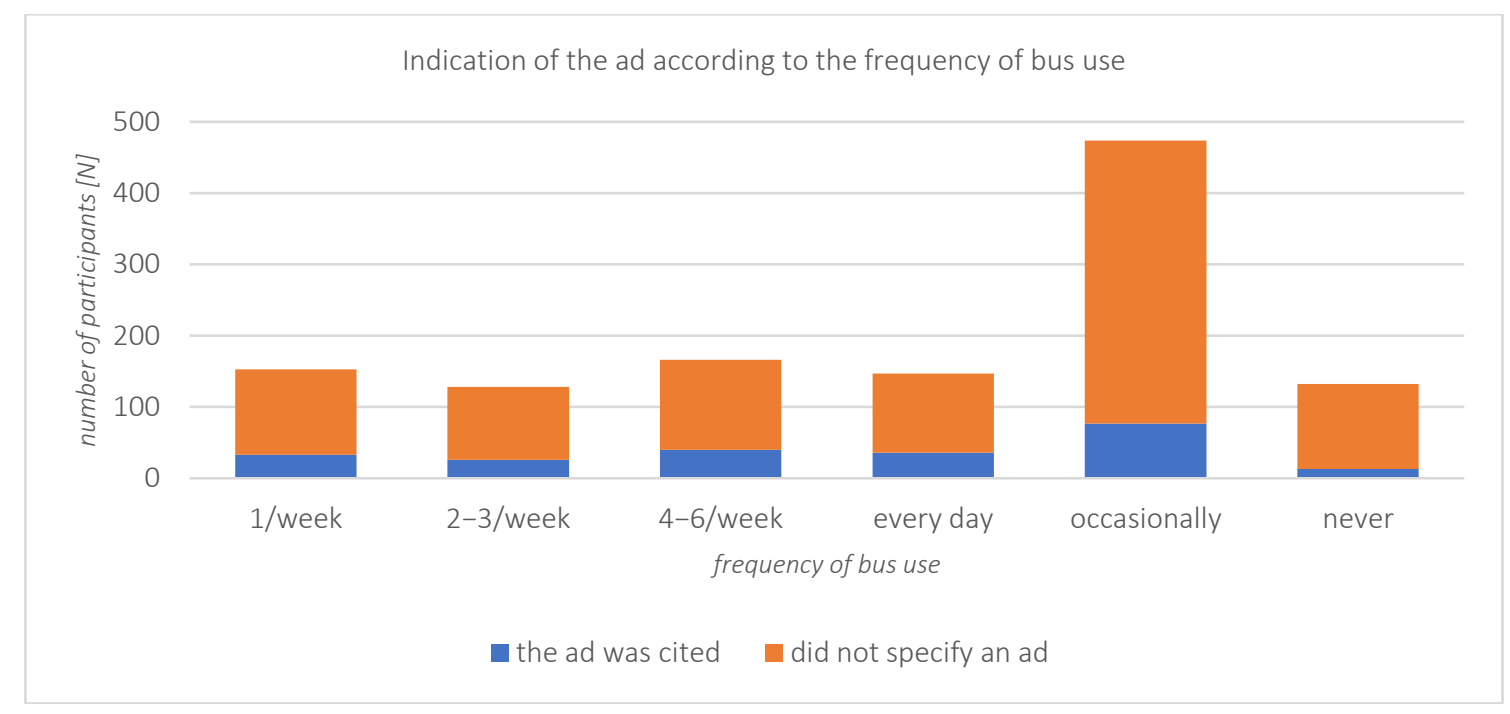

Figure 6: Display of the answer according to the frequency of bus use to the question "Can you list at least one ad that was on the outer part of the city bus in Ljubljana in the last week?"

Figure 7 shows the ads that respondents noticed on the outside of the city bus. Ads that have been listed at least three times are displayed. $18(2.0 \%)$ respondents mentioned School B2, which was also the most common answer. 93 of the 225 listed ads were different. 32 responses (some repeated) stated an ad, but it was not written which company or slogan it was. Some examples of such messages: a man, crocodile, something blue - theater, for tires, news, sausage, time ad.

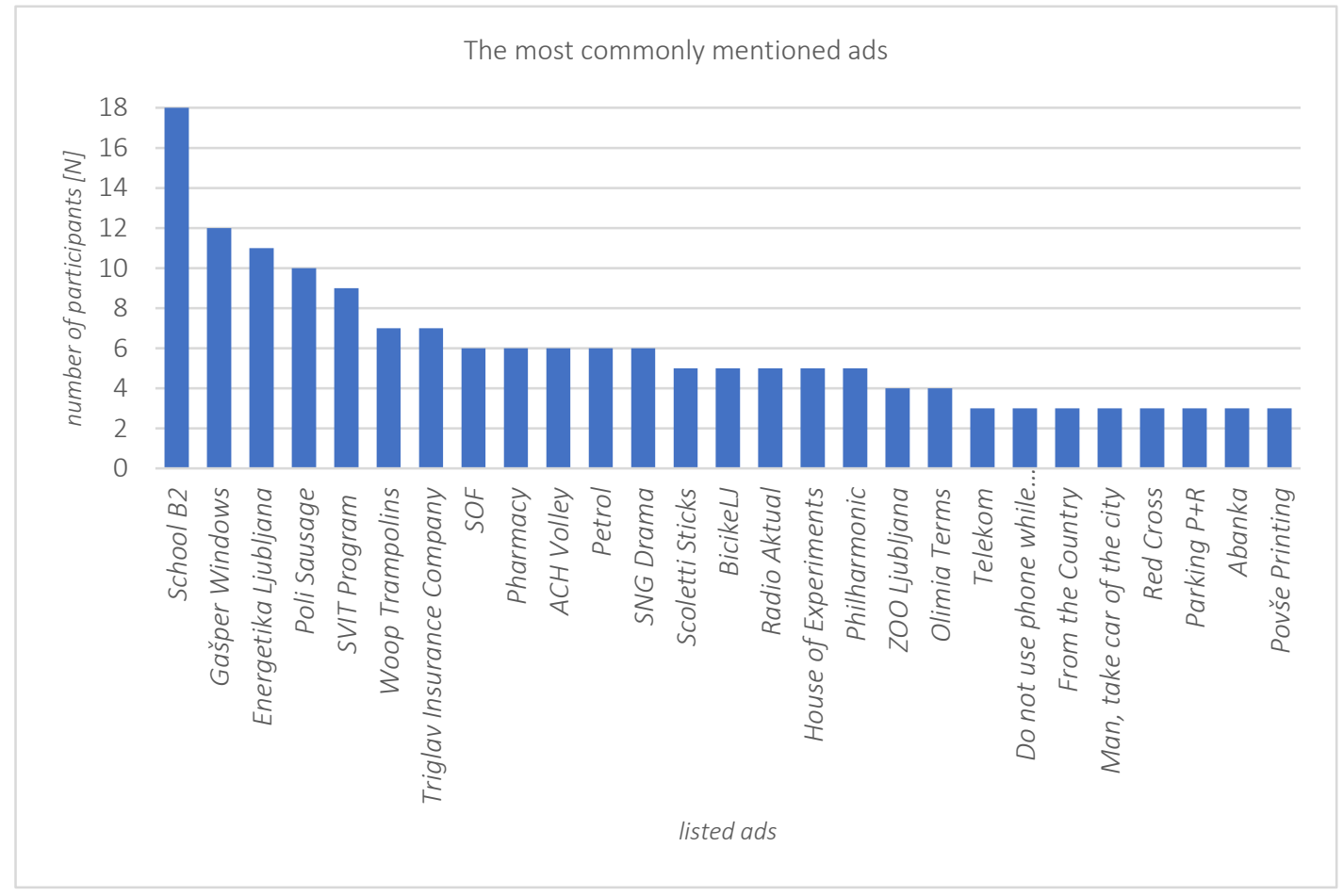

Figure 7: Display of the most frequently mentioned ads that the respondents noticed on the outer part of the city bus

Figure 8 shows the ad for School B2 that respondents most often cited. 13 (7.0\%) respondents in the age group up to 24 years old mentioned this ad; 2 (1.0\%) from the age group of 25 to 34 and 55 to 64 years and $1(0.5 \%)$ from the age group over 65 years old. The ad is bright pink with a large company logo and a photo of a smiling woman. The ad occupies the entire section below and above the windows. Part of the windows are covered with inscriptions and photography of a woman. The letters are large enough to be visible even when standing on the sidewalk or the other side of the road. 


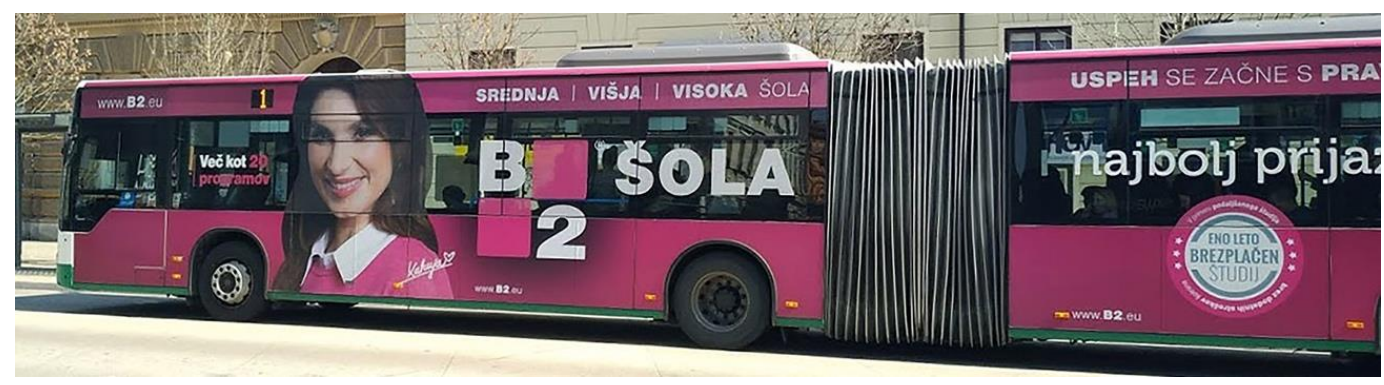

Figure 8: Ad for school B2 (Photo: A. Dujmović)

Figure 9 shows an ad for Windows and Doors Gašper. 5 (2.5\%) respondents from the age group up to 24 years wrote this answer, 2 (1.0\%) from the age groups from 25 to 35 years, from 35 to 44 years and over 65 years and $1(0.5 \%)$ respondent from the age group from 55 to 64 years. The ad on the right side of the bus, as seen in the photo (Figure 9) covers the entire right area with the exception of the door and the first window. All exit doors also have the company logo. The logo has been used at least nine times in one side of the bus. Shades of green and brown predominate. In addition to green, various wood textures and a photography of a worker holding a window frame, a company phone number, a website and some other text are used.

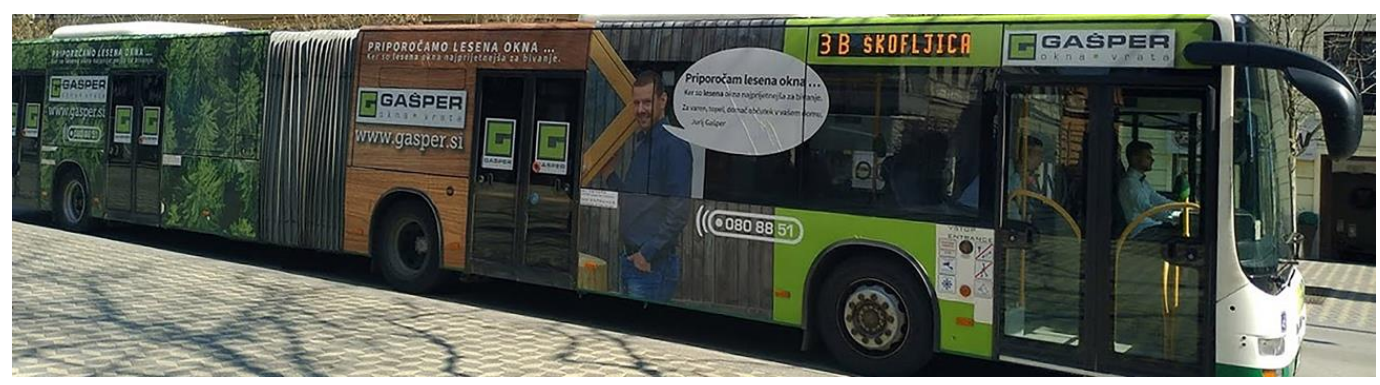

Figure 9: Ad for Windows and doors Gašper (Photo: A. Dujmović)

The ad for Energetika Ljubljana was mentioned by 3 (1.5\%) respondents in group 35 to 44 years old; 2 (1.0\%) from the age groups up to 24 , from 55 to 64 , over 65 and $1(0.5 \%)$ respondent from the age groups 25 to 34 and 45 to 54 years old. Figure 10 shows a smaller city bus that has no creases. The ad covers part of the bus under and above the windows, smaller red stickers are on all windows of the right side of bus, and the exit doors are covered with inscriptions and small illustrations.

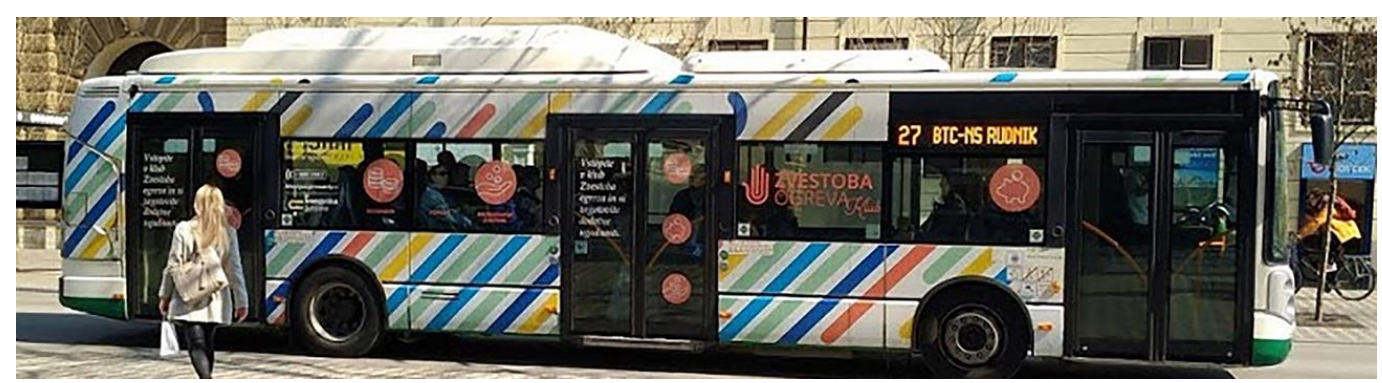

Figure 10: Ad for Energetika Ljubljana (Photo: A. Dujmović)

The ad for the SVIT Program was remembered by 4 (2.0\%) respondents from the age group 25 to $34 ; 2$ (1.0\%) from each of the groups 35 to 44 and over 65 , and 1 (0.5\%) respondent from group up to 24 years old. The SVIT program is intended for women and men between the ages of 50 and 74, but the ad is mostly remembered by young people. Only 9 respondents mentioned this ad so we cannot assess whether it reaches the desired target audience on the basis of this data; we assume they are women and men between the ages of 50 and 74 . The ad covers the entire section below and above the windows. It is mostly orange with the exception of an illustration of a roll of white paper on which the slogan is written (Figure 11). 


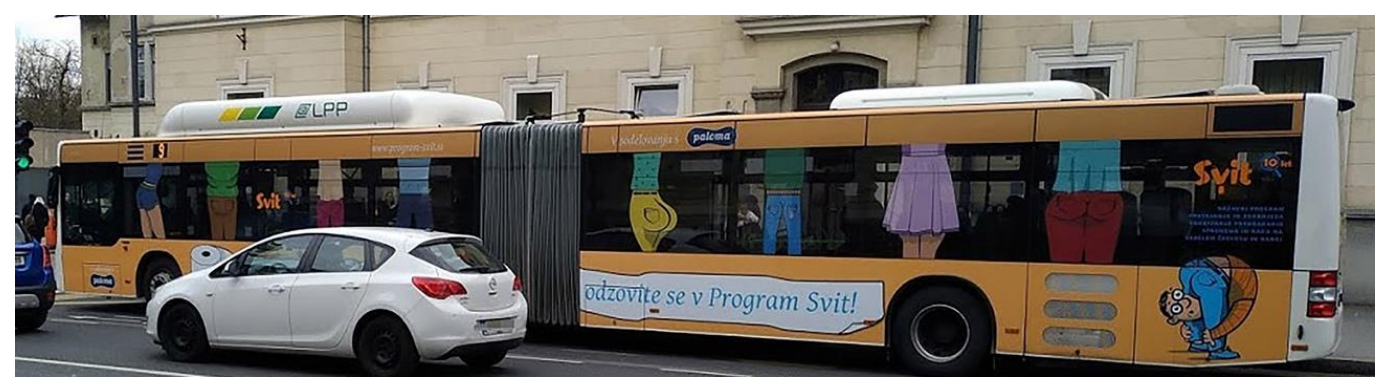

Figure 11: Ad for SVIT Program (Photo: A. Dujmović)

$5(2.5 \%)$ respondents under the age of 24 and $2(1.0 \%)$ respondents between the ages of 25 and 34 cited an ad for Woop! This ad covers the entire area under the bus windows and above them; the exit doors are covered throughout. With the exception of the first door and window, areas are mostly covered (Figure 12). The ad follows the corporate visual identity of the company being advertised; the background of the ad is dark, and the remaining elements are pink, blue, yellow and white. For reasons stated, ad is well visible from a distance. There are almost no inscriptions on the ad, in addition to the graphic elements, there is the company logo, the logo of the acrobatic group Dunking Devils and a key.

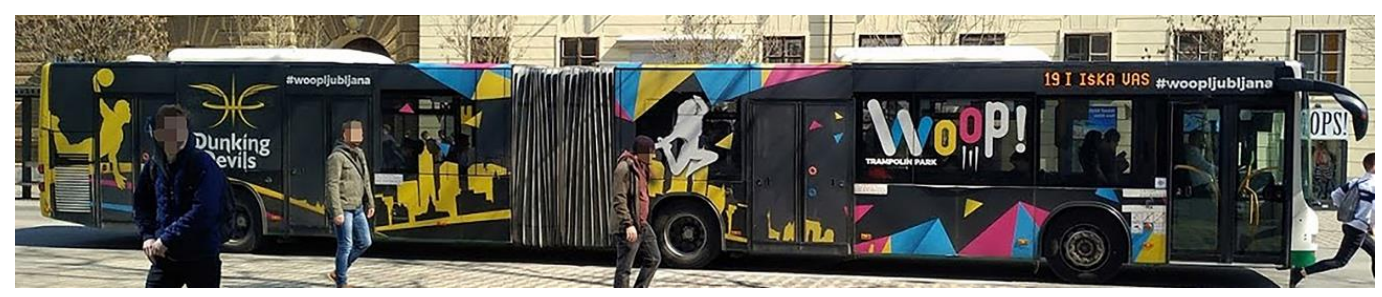

Figure 12: Trampoline ad Woop! (Photo: A. Dujmović)

Figure 13 shows an ad cited by 3 (1.5\%) respondents. It is one of the few smaller ads mentioned in the survey. The ad is in the shape of a pastel green circle between the wheels of the bus, which is used for the background; the letter $P$ is well visible, partly also $R$, but the contrast between the background and the letters is poor. From a distance you can also see what is written under the letters; the larger inscription (park and transfer) below can be noticed with some effort while the smallest text is poorly visible, almost unreadable, and the contrast between gray and pastel green is poor.

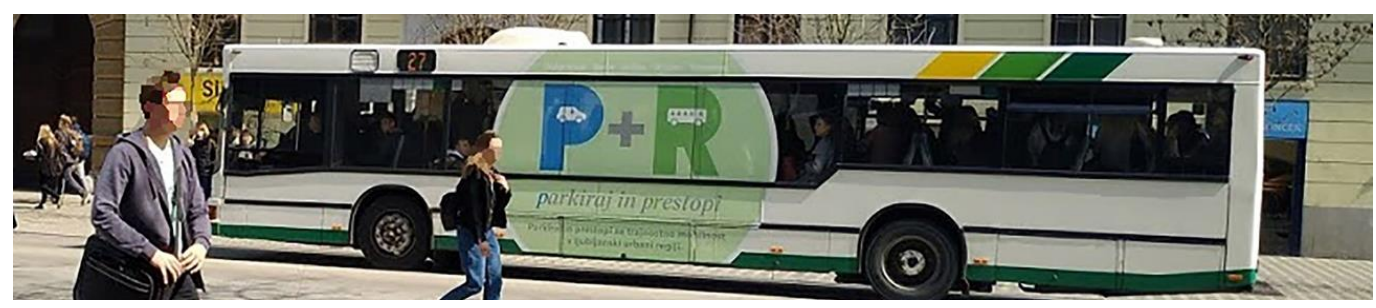

Figure 13: Ad for $P+R$ (Photo: A. Dujmović)

Figure 14 shows an ad that was not written by any of the respondents. The ad is small, covering the area between the first wheels and the second door. The inscription Kalček is not the most noticeable from a distance. The ad is probably aimed primarily at those who board the bus.

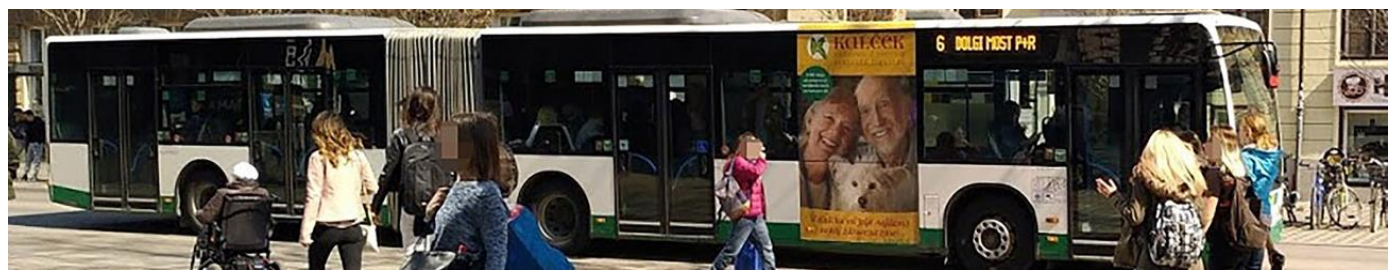

Figure 14: Ad for Kalček (Photo: A. Dujmović) 
Figure 15 shows an ad for Tuhelj Terms in Croatia. The entire left side, with the exception of the driver's window, is covered with an ad, a photo of the spa, a logo and a slogan in white. Nobody mentioned this ad, unfortunately we do not have data on when Tuhelj Terms started advertising on city buses in Ljubljana.

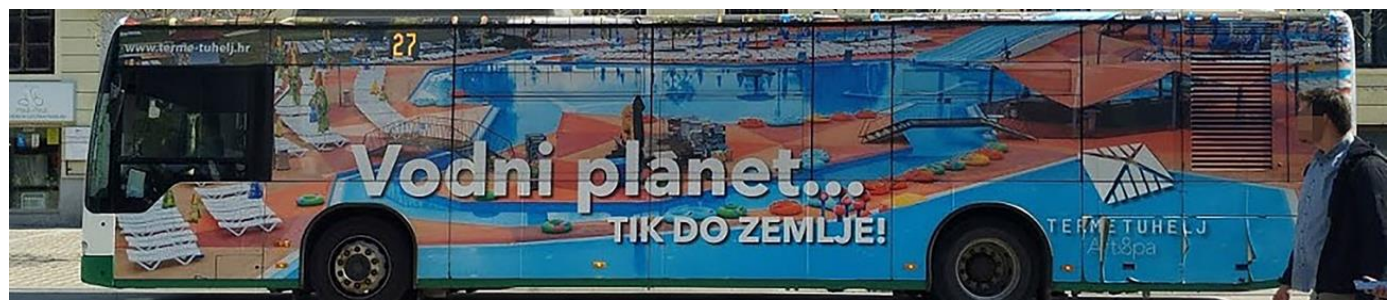

Figure 15: Ad for Tuhelj Terms, Croatia (Photo: A. Dujmović)

Interestingly, the ads cited by respondents were similar, despite companies offering different services. An analysis of the most frequently mentioned ads in the survey showed that:

- $\quad$ ads cover most of the bus, including glass surfaces;

- $\quad$ are presented in vivid colours that are well visible from a distance;

- used colours are consistent with the corporate visual identity of the company being advertised,

- have mostly small amount of text, e.g. a slogan that is well visible even from a greater distance.

$45(22.5 \%)$ people aged 25 to 34 do not agree at all with the fact that outdoor ads on the city buses in Ljubljana are interesting; other age groups opinion is between 28 (14.0\%) and 33 (16.5\%) (Figure 16). The majority $(55,27.5 \%)$ of respondents who do not agree with the statement are from the age group of 35 to 44 , and the remaining age groups range between 31 (15.5\%) and 42 (21.0\%). People under the age of 24 most often chose the answer neither agree nor disagree, $84(42.0 \%)$ were such, $44(22.0 \%)$ chose this answer in the age group 65 and higher; the remaining age groups range between 55 (27.5\%) and 72 (36.0\%). 71 (35.5\%) of people over the age of 65 agree that outdoor ads on the city buses are interesting, the remaining age groups are between 40 (20.0\%) and 72 (36.0\%). 19 (9,5\%) of those over 65 fully agreed with this statement and only $2(1.0 \%)$ of those between 35 and 44 , the remaining four groups ranging between 4 (2.0\%) and 9 (4.5\%).

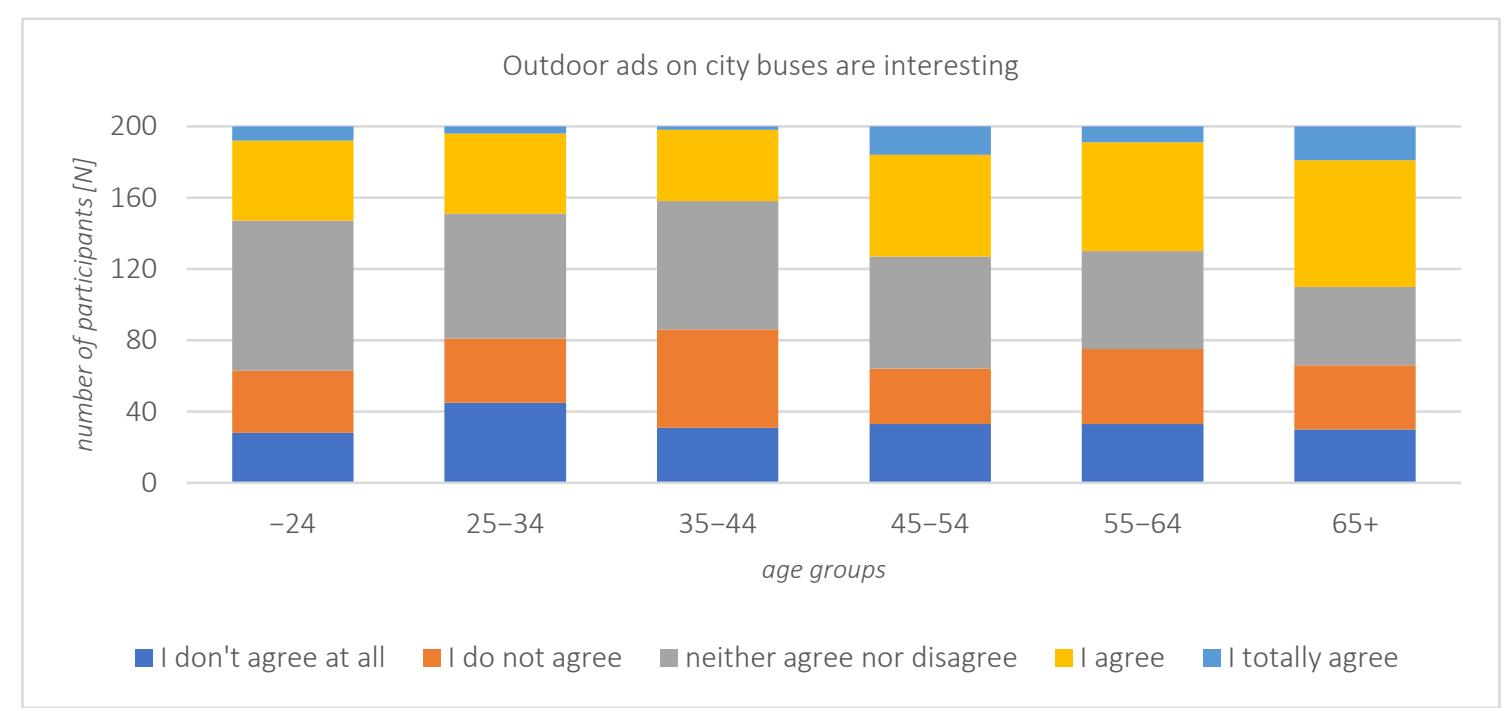

Figure 16: Display of agreement by age groups with the statement

"Outdoor ads on city buses in Ljubljana are interesting"

With the claim that outdoor ads on city buses offer useful information, 91 (45.5\%) people from group up to 24 years choose neither agree nor disagree. Dispersion of responses among other age groups was between 60 (30.0\%) and 77 (38.5\%) (Figure 17). 49 (24.5\%) people from group over 65 agreed with the statemen, the remaining age groups decided for this answer less often. No one in the 25 to 34 age group 
fully agreed that outdoor ads on buses offer useful information. Of the 1200 respondents, only 31 (2.6\%) fully agreed with this statement.

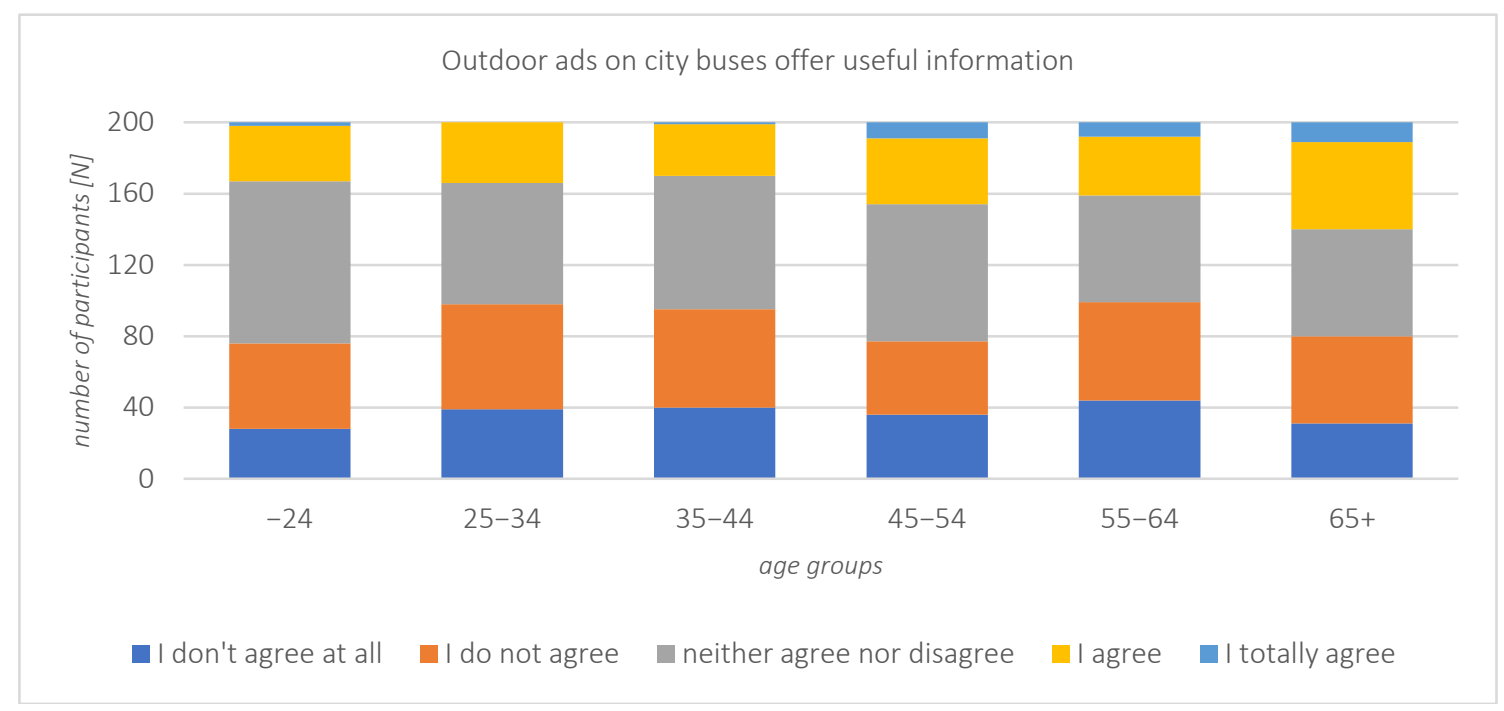

Figure 17: Display of agreement by age groups with the statement

"Outdoor ads on city buses in Ljubljana offer useful information"

$59(29.5 \%)$ of people aged 55 to 64 and same in group over 65 do not agree that they are disturbed by outdoor ads on city buses in Ljubljana. 46 (23.0\%) people under 24, over 65 and between 44 and 54 did not agree at all that they were bothered by outdoor ads; meaning 46 people in each age group (Figure 18). People between the ages of 35 and 44 agreed most with this statement, one quarter of them were from their age group, and the remaining age groups ranged between 24 (12.0\%) and 36 (18.0\%). 38 $(19.0 \%)$ of those aged 25 to 34 completely agreed with the statement, the remaining age groups are between 19 (9.5\%) and $32(16.0 \%)$.

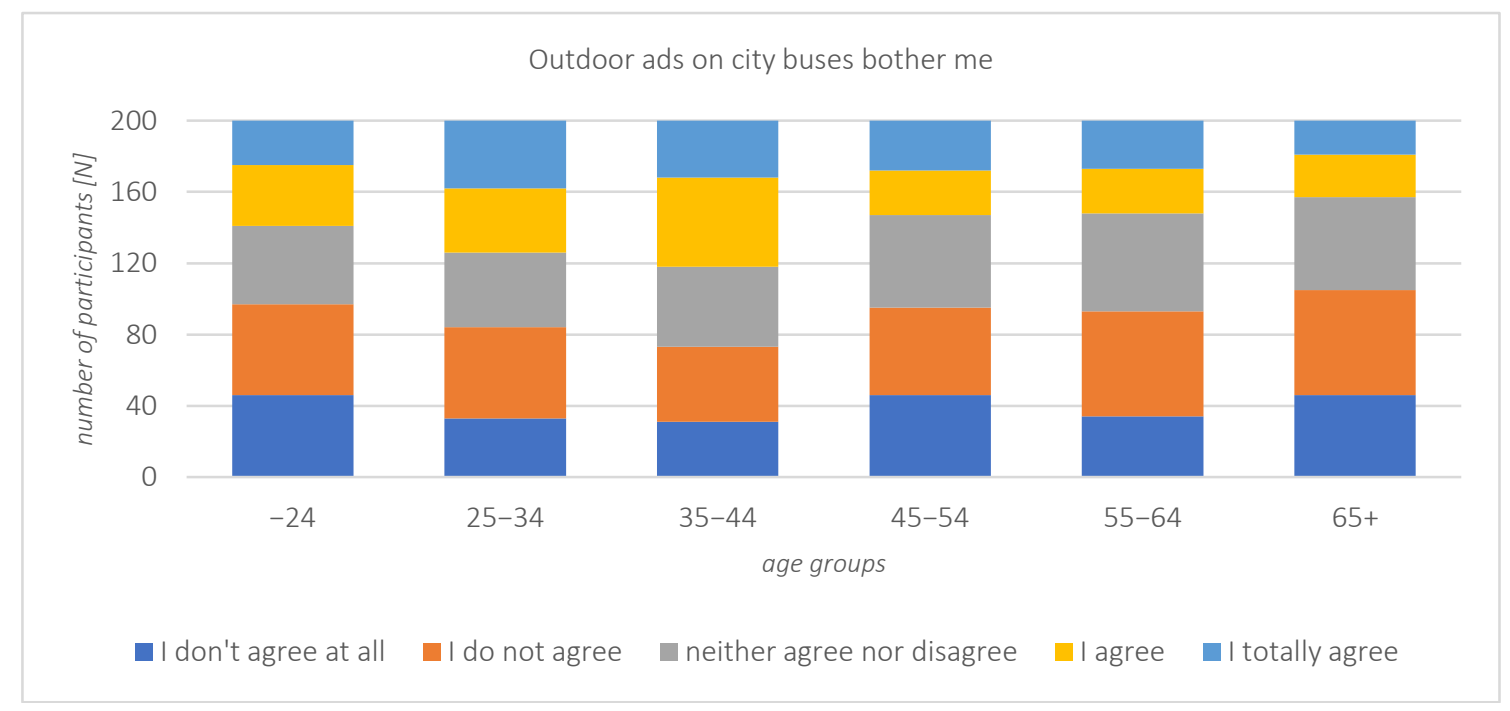

Figure 18: Display of agreement by age groups with the statement "Outdoor ads on city buses in Ljubljana bother me"

Figure 19 shows that there are no major discrepancies between the answers by age groups to the statement "Outdoor ads on city buses attract my attention". The largest deviation is $9.0 \%$ in the answer I do not agree at all between the age group 25-34 (11, 5.5\%) and 55 to 64 years $(29,14.5 \%)$. 


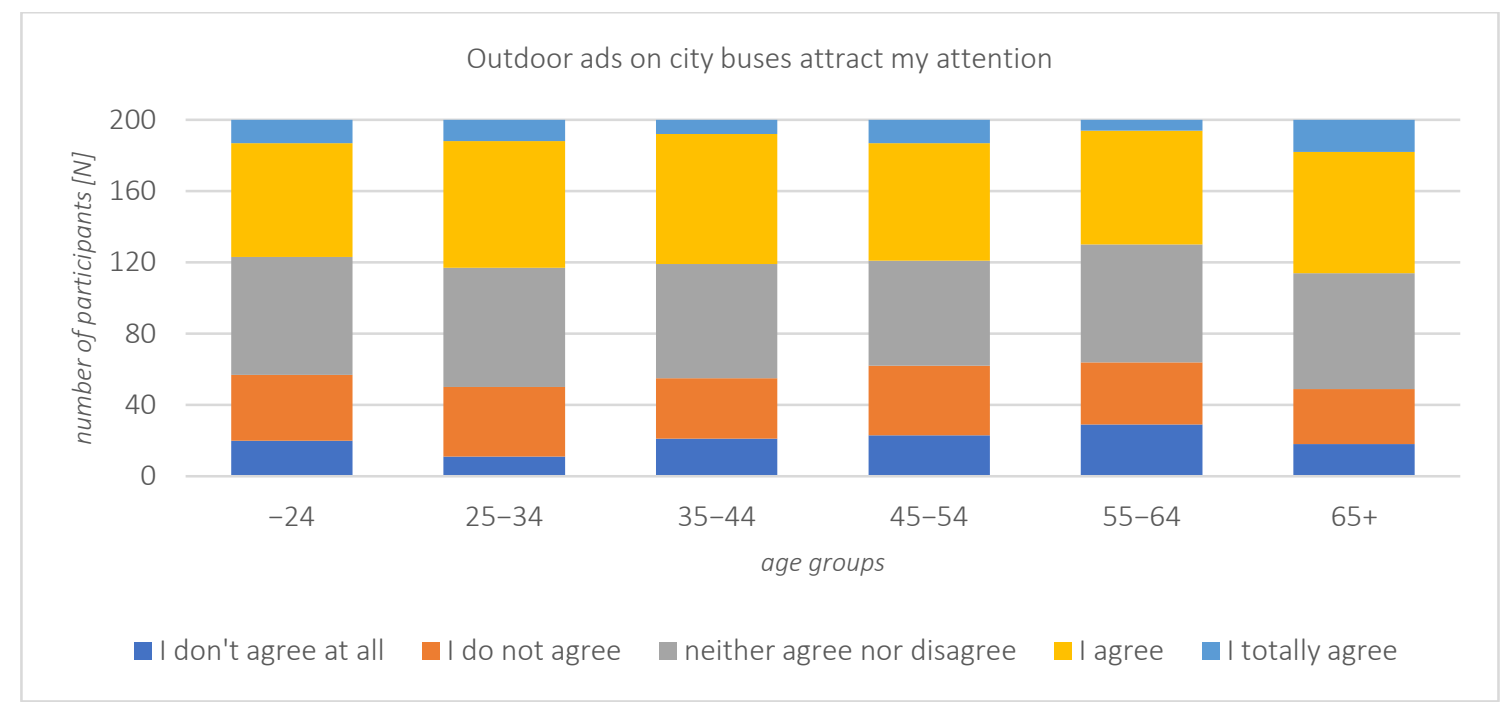

Figure 19: Display of agreement by age groups with the statement

"Outdoor ads on city buses in Ljubljana attract my attention"

61 (30.5\%) people under 24 and over 65 chose the option I agree with the statement that outdoor advertising on city buses in Ljubljana is an unobtrusive way of advertising; 61 participants in each group (Figure 20). Similar were response of the age group 55 to 64 (62, 31.0\%). 13 (6.5\%) of people aged 35 to 44, 55 to 64 and over 65 chose the option I totally agree with; 13 participants in each group. 30 (15.0\%) of people aged between 45 and 54 neither agree nor disagree with this statement, the remaining age groups are between $46(23.0 \%)$ and $57(28.5 \%)$ in this option. 56 (28.0\%) of people aged 45 to 54 do not agree that outdoor advertising is a smooth way of advertising, the remaining age groups are between 34 $(17.0 \%)$ and $49(24.5 \%)$.

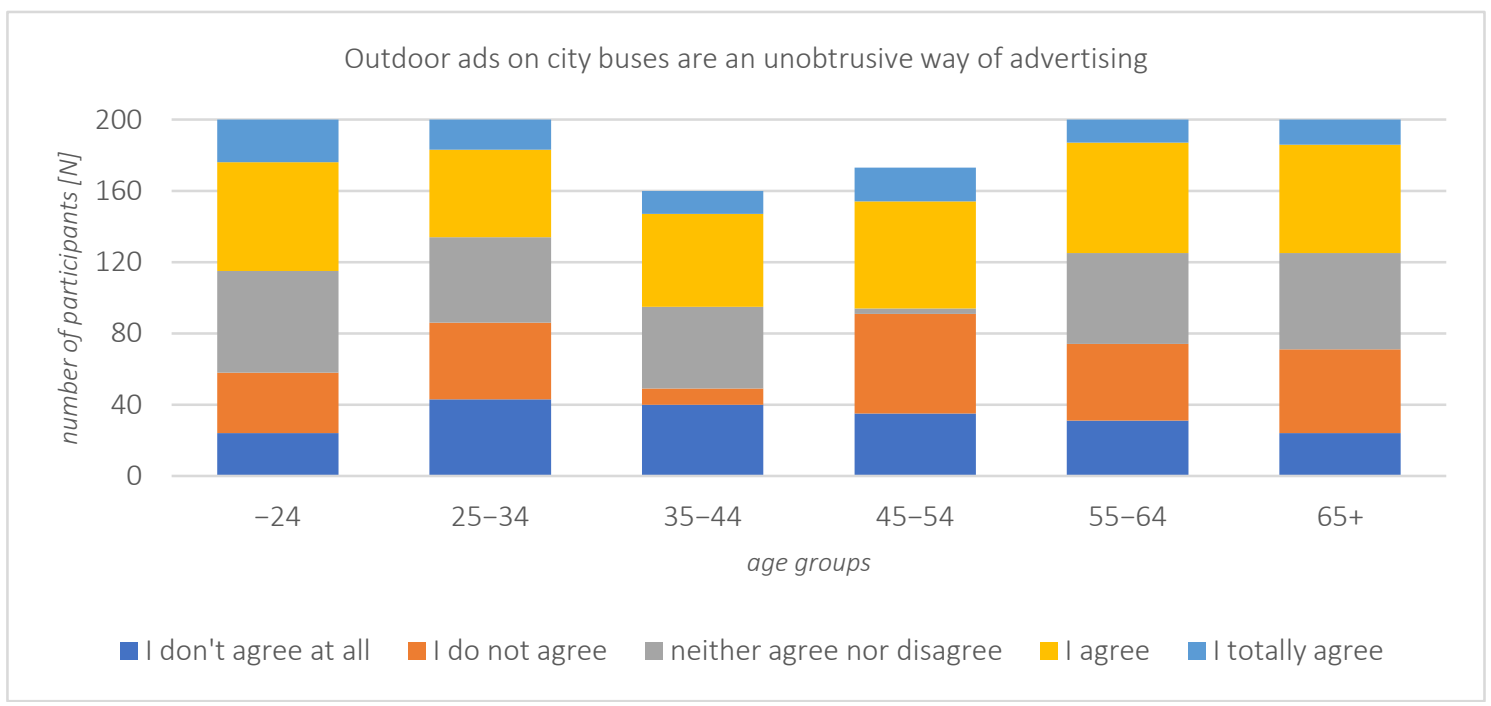

Figure 20: Display of agreement by age groups with the statement "Outdoor ads on city buses in Ljubljana are an unobtrusive way of advertising"

69 (34.5\%) of those aged 45 to 54 and 55 to 64 chose neither agree nor disagree with the statement that outdoor ads appear too often on buses in Ljubljana; 69 participants in each group (Figure 21). The option I do not agree was most often chosen by people under 24, 66 (33.0\%) of them, and least often by people aged 35 to 44, 38 (19.0\%) of them. At least often, respondents, regardless of age group, chose to disagree at all. 


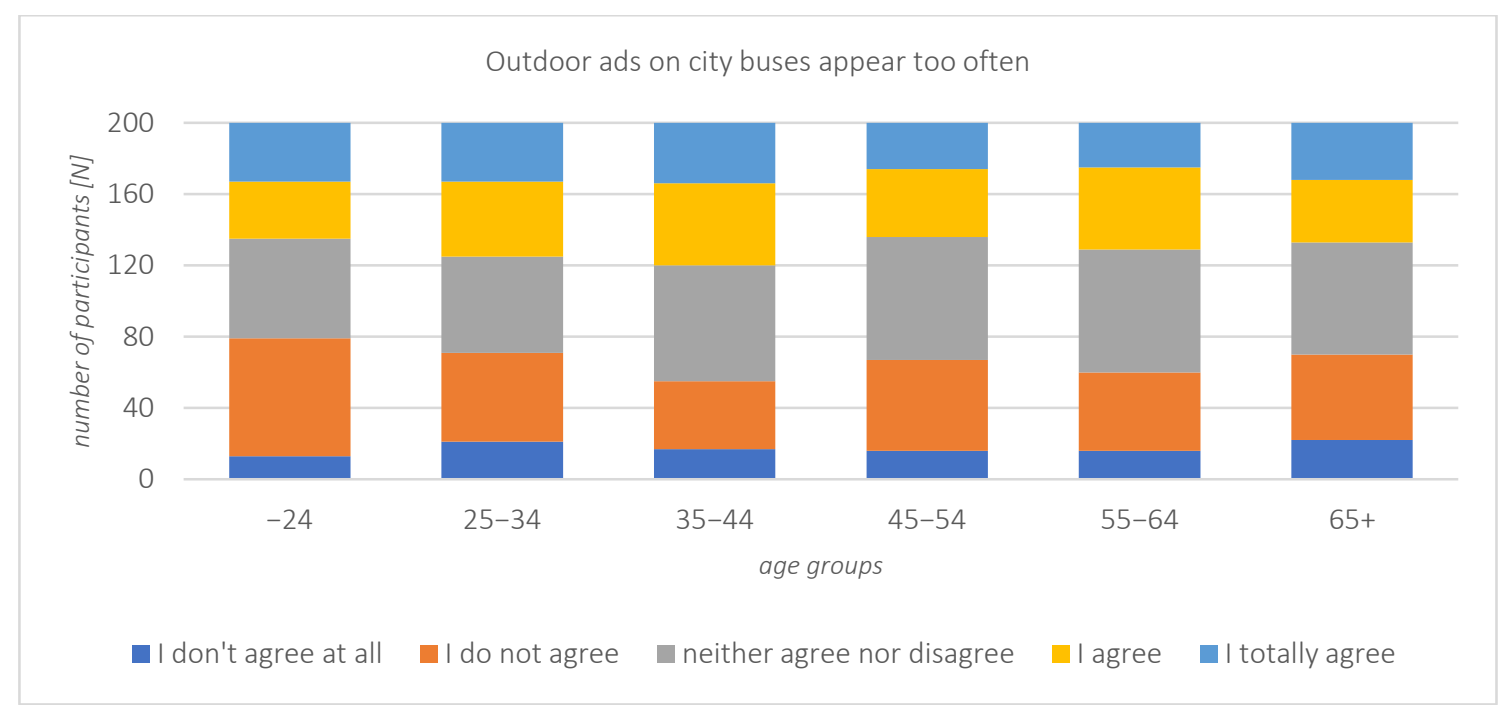

Figure 21: Display of agreement by age groups with the statement

"Outdoor ads on city buses in Ljubljana appear too often"

$68(34.0 \%)$ of the oldest and 66 (33.0\%) of the youngest chose not to agree with the fact that outdoor ads on buses in Ljubljana are too large. The remaining age groups participants were distributed between 35 $(17.5 \%)$ and $53(26.5 \%) .45(22.5 \%)$ of those aged 25 to 34 fully agree with the statement and $27(13.5 \%)$ of those over 65; this is also the lowest share for this answer (Figure 22).

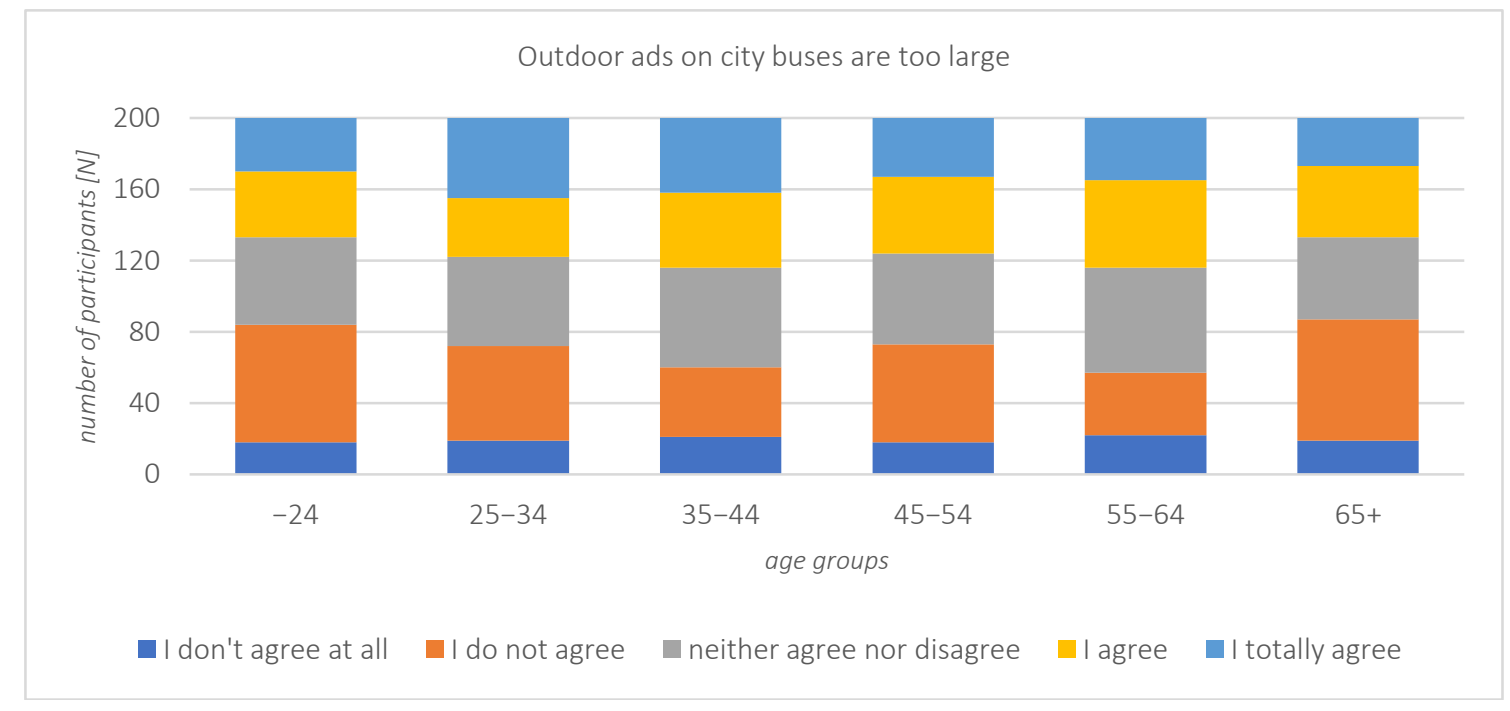

Figure 22: Display of agreement by age groups with the statement "Outdoor ads on city buses in Ljubljana are too big"

$83(41.5 \%)$ of those aged 25 to 34,81 (40.5\%) of those aged up to 24 and $80(40.0 \%)$ of those aged 35 to 44 fully agree that outdoor ads on city buses obstruct the view through the bus window (Figure 23). The least common choice was between 45 and 54 years old, 60 (30.0\%). 68 (34.0\%) of people under 24 agreed with the statement, the remaining groups ranged from 43 (21.5\%) (aged 25 to 34) to 55 (27.5\%) (35 to 44). The least common option is to either agree or disagree selected by the age group up to 24 . Disagree most commonly chose age group between 45 and 54 years, the remaining age groups are between $22(11.0 \%)$ and $31(15.5 \%)$. The least, $8(4.0 \%)$, aged up to 24 chose the option I do not agree at all; the most, $21(10.5 \%)$, chose this option between the ages of 45 and 54 . 


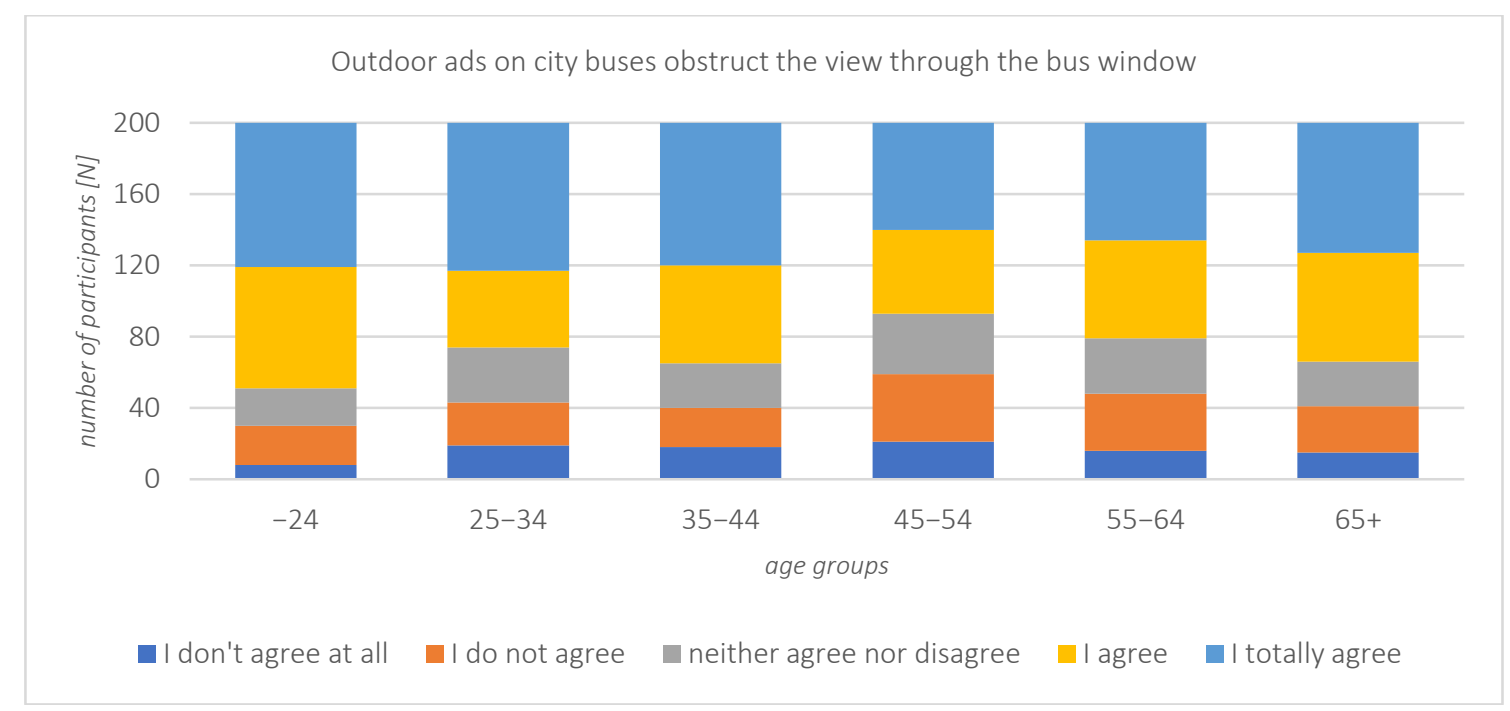

Figure 23: Display of agreement by age groups with the statement

"Outdoor ads on city buses in Ljubljana obstruct the view through the bus window"

\section{DISCUSSION}

In our research, we wanted to find out how people perceive outdoor ads on city buses in Ljubljana. We asked 1200 people about the opinion (field and online survey), which were divided into six age groups; each age group consisting of 100 women and 100 men. In this way, we obtained evenly distributed demographic data, which enabled more accurate and reliable comparison of the data. Most of the respondents were employed. 480 (40.0\%) of all respondents use the bus in Ljubljana occasionally. The frequency of bus use varies according to the age group. In the group up to 24 years old, bus is most often used four to six times a week; the remaining groups use the bus occasionally, and $132(11.0 \%)$ of all respondents do not use the city bus in Ljubljana.

It was found that $984(82.0 \%)$ of all respondents noticed at least one outdoor ad on a city buses in Ljubljana in the last week. The last week refers to the date of the survey. Interestingly, there were no major differences between women and men within the observation of ads on city buses. The youngest participants (group up to 24 years old) most often mentioned at least one ad that was on the outside of the city buses in Ljubljana (70, 35.0\%; the calculation is made based on 200 people in this age group). The difference between those aged up to 24 and those aged 55 to 64 and those over 65 , both of whom rarely mentioned an advertising message, is $23.0 \%$. Out of the 1200 respondents, $228(19.0 \%)$ cited at least one ad on the outside of the city buses.

We analyzed the ads mentioned by the respondents (Figures 8-13). The most frequently mentioned was ad for School B2; 18 (2.0\%) participants. We photographed the ads most frequently mentioned by the respondents and found out that they are covering most of one side of the bus. They are presented in vivid colours that also represent the corporate visual identity of a certain company. In most cases small amount of text is present.

Regarding the 5 hypotheses we posed.

- Hypothesis 1: 70\% or more of the respondents noticed at least one outdoor ad on a city buses in Ljubljana in the last week.

Hypothesis 1 is true because $82.0 \%$ (984) of all respondents noticed at least one outdoor ad on a city buses in Ljubljana.

- Hypothesis 2: 50\% or more of the respondents can state at least one advertising message that was on the outer part of the city buses in Ljubljana in the last week.

Hypothesis 2 is not true because only $19.0 \%$ (228) of respondents mentioned at least one ad that was on the city buses in Ljubljana.

- Hypothesis 3: $60 \%$ or more of the respondents think that outdoor ads on city buses in Ljubljana are interesting.

Hypothesis 3 is not true because $31.0 \%$ (372) of respondents agree or completely agree that outdoor ads on city buses in Ljubljana are interesting. 
- Hypothesis 4:50\% or more of the respondents believe that outdoor ads on city buses in Ljubljana are an unobtrusive way of advertising.

Hypothesis 4 is not true because $37.0 \%$ (444) of respondents agree or completely agree that outdoor ads on city buses in Ljubljana are an unobtrusive way of advertising.

- Hypothesis 5: 75\% or more of the respondents believe that outdoor ads on city buses in Ljubljana obstruct the view through the bus window.

Hypothesis 5 is not true because $64.0 \%$ (768) of respondents agree or completely agree that outdoor ads on city buses in Ljubljana obstruct the view through the bus window.

\section{CONCLUSIONS}

The analysis of the survey (field and online) showed that out of all statements about outdoor ads on city buses in Ljubljana, people most agree that outdoor ads on city buses in Ljubljana obstruct the view through the bus window. During the field survey, we heard some comments from respondents that because of the ads, they don't even see where they are, especially in bad (rainy) weather. Advertisers could take this into account and avoid sticking ads on the glass surfaces of buses, or limit this to the parts where ads are least annoying for bus users. They could cover those parts of the windows that users notice less, e.g. the back of the bus, the ad only at the bottom or top of the window. With this approach, the view through the windows would not be disturbed. On the other hand, it turned out that people most often cited ads that covered most of the bus side (including windows). Compromise about this is should be achieved.

In the future, the survey could be supplemented and checked how many of those who cited the ad later decided to buy certain product; what is the cost of a company that decides to advertise on city buses in Ljubljana, and how many new customers or users was gained because of this type of advertising. If we could ensure not to violate the provisions of the General Data Protection Regulation, we could carry out the recording with the help of an eye tracking device (glasses) and analyze how many users (passengers) look towards the city buses. Nevertheless, with the obtained data we can better know the opinion of people about ads on city buses in Ljubljana.

\section{REFERENCES}

[1] Ackley, C., Hackley, R. A.: "Advertising \& promotion", (SAGE Publications, London, 2015.)

[2] Allaby, M.: "Affinity Index - Encyclopedia.com", URL: https://www.encyclopedia.com/science/ dictionaries-thesauruses-pictures-and-press-releases/affinity-index (last request: 2020-08-09).

[3] Bernays, E. L.: "Propaganda", (Ig Publishing, Brooklyn NY, 2005.)

[4] De Pelsmacker, P., Geuens, M., Van den Bergh, J.: "Marketing Communications: A European Perspective", (Pearson, London, 2018.)

[5] Gregan-Paxton, J., Loken, B.: "Understanding Consumer Memory for Ads: Process View", In: Measuring Advertising Effectiveness, (Taylor and Francis, Philadephia PA, 1996.)

[6] Kovačič, A.: "How much attention does outdoor advertising attract and who profits", Innovative Issues and Approaches in Social Sciences 5 (3), 134-151, 2011. doi: 10.12959/issn.1855-0541.IIASS2012-no3-art08.

[7] Loken, B.: "Consumer Psychology: Categorization, inferences, affect, and persuasion", Annual Review of Psychology 57, 453-485, 2006. doi: 10.1146/annurev.psych.57.102904.190136.

[8] Media Bus: "Avtobusno oglaševanje", URL: http://mediabus.si/?page_id=35 (last request: 2020-0909).

[9] Mrgole, A.: "The influence on road safety due to driver distraction from outdoor advertising: case study", American Scientific Research Journal for Engineering Technology and Science 35 (11), 42-49, 2017.

[10] Phillips, M. D., Stanton, J. L.: "Age-related differences in advertising: recall and persuasion", Journal of Targeting, Measurement and Analysis for Marketing 13 (7-20), 2004. doi:

10.1057/palgrave.jt.5740128 
[11] Tsuji, R.: "What Factors Make Outdoor Advertising More Effective?: Effect of Corporate Color and Brand Image on the Recognition of Outdoor Advertising", URL: https://www.researchgate.net/ profile/Ryutaro_Tsuji/publication/296525779_What_Factors_Make_Outdoor_Advertising_More_Eff ective_Effect_of_Corporate_Color_and_Brand_Image_on_the_Recognition_of_Outdoor_Advertisin $\mathrm{g} /$ links/56d6654e08aee1aa5f7317ee/What-Factors-Make-Outdoor-Advertising-More-EffectiveEffect- (last-request 2017-01-10).

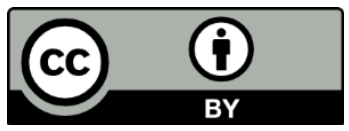

(C) 2020 Authors. Published by the University of Novi Sad, Faculty of Technical Sciences, Department of Graphic Engineering and Design. This article is an open access article distributed under the terms and conditions of the Creative Commons Attribution license 3.0 Serbia (http://creativecommons.org/licenses/by/3.0/rs/). 



\title{
OBSERVATION ON CREATIVITY AND SPATIAL VISUALISATION SKILLS OF GRAPHIC ARTS' STUDENTS
}

\author{
Helena Gabrijelčič Tomc (D), Tanja Nuša Kočevar (D) \\ University of Ljubljana, Faculty of Natural Sciences and Engineering, Department of Textiles, \\ Graphic Arts and Design, Chair of Information and Graphic Arts Technology, Ljubljana, Slovenia
}

\begin{abstract}
The aim of our research was to discover whether education in 3D computer graphics and visualisation can improve students' spatial visualisation skills and how the complex project as a design and synthesis of a 3D animation influences students' creativity. Spatial visualisation skills are extremely valuable in various professions, including graphic design and engineering, where 3D modelling and visualisation is becoming increasingly important for the qualitative execution of professional projects. Scientists define two types of three-dimensional skills, spatial visualisation and spatial orientation, where visualisation is understood as the ability to mentally rotate, flip and flip over presented images, while spatial orientation describes the ability to recognise the position or direction of objects in space. Creative process is defined as a sequence of thoughts and actions that lead to original and appropriate productions. The creative process can be discussed on two levels, i.e. macro and micro level with the related phases of the creative process: orientation, preparation, complementary stages after preparation, incubation, idea generation, production.

The facultative course Advanced computer 3D graphic and visualisations is taught in the 2nd level studies of Graphic and interactive communication. Through project work, students are encouraged to use their creativity and imagination to create a visually attractive 3D animation that is also interesting in terms of content and in which they can convey the story they want to tell. For this reason, we often held individual sessions in which the teachers made profound corrections to the students' work and made suggestions for the further development of their projects. Experimental methods were: Questionnaires for self-assessment of the creativity process, whereby the students also interpreted their creative process with an illustration and the spatial visualisation test before and after the course. Regular evaluation of their project work with regard to the entire design process, i.e. 3D content creation, planning, technical approach and production, were also carried out. Results of the analysis present an interesting insight in students' creative process, spatial ability and comprehension of 3D computer graphic that could be considered as teaching/learning guidelines in the coming academic years.
\end{abstract}

Key words: creativity, spatial visualisation skills, 3D content creation, education, graphic arts

\section{INTRODUCTION}

Spatial intelligence is the ability to perceive the visual world accurately and the capacities to transform these perceptions. The elementary operation upon which other aspects of spatial intelligence are based is the ability to perceive a form or an object. Spatial intelligence is characterized as a very important skill that has an immense impact on our everyday life as it involves our ability to navigate from one place to another, to understand drawings, charts, it is the ability to visualise objects from different angles, ability to recognise faces, scenes and fine details and so on (Gardner, 2011). Spatial ability is an important component of spatial intelligence and is defined as "the ability to mentally manipulate, rotate, twist or invert pictorially presented stimuli" by an author McGee (McGee, 1979). Spatial ability is by authors Linn and Petersen (Linn et al, 1985) divided in three categories: spatial perception, mental rotation and spatial visualization. Spatial visualisation is "the ability to mentally manipulate, rotate, twist, or invert pictorially presented stimulus objects." (McGee, 1979). This ability helps us to imagine links between reality and the model of that reality that is abstracted (Alias et al, 2002). Spatial Visualisation refers to the ability to manipulate complex spatial information and to mentaly manipulate 2D and 3D objects. This skill can be assessed using tasks such as mentally folding paper and rotating objects, and to imagine the change of objects and shapes (Roslan and Ahmad, 2017). Spatial visualisation skills are extremely valuable in a variety of professions, including graphic design and engineering. These jobs require excellent 2D and 3D visualisation skills, which are important for the qualitative implementation of highly professional projects (Patkin and Dayan, 2013). Research has shown that a person's spatial visualisation skills are very important predictors of their ability to successfully use computers to perform database manipulations 
(Norman, 1994), and are related to his or her ability to effectively learn and successfully work in a computer-based 3-D design environment (Sorby, 2000).

However, it was discovered that spatial visualisation skills can improve and the results can be tested. There are several tests to evaluate different types of spatial visualisation skills. In our research we have used some of them, such as Picture rotation test (PRT), Differential Aptitude Test: Space Rotation, (DAT:SR), The Punched Holes Test (Paper Folding Test) and others.

Designing and creating 3D animations requires a wide range of skills from students, with creativity and spatial awareness being more important. Therefore, we have investigated the connection between both in our research.

The process of creativity has often been discussed by various researchers in the past. The definitions of researchers differ slightly, but the most important research certainly has common insights into the creative process, as it is defined as a sequence of thought processes (including mental processes) and activities leading to unique and purposeful production. Researchers generally describe two levels of the creative process, namely the micro and macro levels (Botella et al, 2018). The macro level comprises the phases or steps of the creative process, while the micro level deals with the mechanisms that take place in the background of the creative process, as well as the so-called divergent and convergent or alternating thinking and engagement (Botella et al, 2018).

Here we can only mention a few typical models of the creative process that have been published in the past decades, ranging from the definition of a minimum of three phases of the creative process to a maximum of 8 phases. At the end of the 20th century, according to their analyzes, the author Carson (Carson, 1999) listed 9 phases, i.e. preparation, concentration, incubation, ideation, insight, verification, elaboration, production, while the authors of Runco and Dow (Runco and Dow, 1999) identified only 3 important phases of a typical creative process in the same year, i.e. problem finding, incubation, evaluation. In 2011, Botella (Botella et al, 2011) and co-authors published a scheme for the creative process of art students, which summarizes up to 9 steps in a comprehensive way, i.e. preparation, concentration, incubation, ideation, insight, verification, planification, production and validation, and soon after presented a scheme for artists with fewer steps, which were also named quite differently (Botella et al, 2013), i.e. idea or vision, documentation, reflection, first sketches, testing, provisional objects and series.

Research proves that differently defined creativity models can be applied to different areas (art, business), but at the same time are defined differently depending on the professional area. Botella et al. performed testing of professional artists (Botella et al, 2013) and students (Botella et al, 2018), and found out that professionals with many years of experience carry out the creative process within some established phases that suggest routine. That was not the case with the students. When the students were interviewed and invited to describe their creative process and name the stages of their creative process there were no signs of established practices, instead a trend of very individual, personal experience was detected. The named stages and their description were then compared with the already existing models giving to the researchers new insight about the creative process of students of visual graphic arts. The results of the analysis identified 17 stages (immersion, reflection, research, inspiration, illumination, trials, assembly, ideation, selection, techniques, specification, realisation, finalization, judgment, presentation, break and withdrawal), which can be used as guides for teachers, but at the same time invite them to further observe students and the phases of creative work that students carry out between specific tasks and project work of the study process.

\subsection{Aim of the research}

The aim of the research was to analyse and define the creative process and its correlation with the spatial ability of graphic arts students attending facultative course "Advanced 3D computer graphic and visualisation" at 2nd level degree studies of university study programme of Graphic and interactive communication. From the analysis it can be discovered whether the education in 3D computer graphics and visualisation can improve students' spatial visualisation skills, whether the studying of 3D graphic can improve the conception and definition of the creative process, reveal how students are personally involved in the process, what level of abstraction they use in the process, and how successfully the students carry out a practical project and acquire skills for relevant 3D modeling, animation and visualization results. 


\section{METHODS}

Seven (7) master degree study students participated in our research. Before and after the semester they were asked to fill in the questionnaire about their understanding of the creative process and to complete the spatial visualisation test.

Methodology included:

- questionnaire before and after the semester (project work) about the creative process, its phases, self-evaluation of knowledge in the 3D field (before the semester, students physically wrote the answers, and after the semester, in an online form)

- $\quad$ students were asked to define their creative process in words and with a drawing (before semester: on a white A4 sheet of paper, using any drawing tool; after semester: in on-line form); students were asked to draw their creative process twice, firstly together with the test on paper and secondly when they had to fill in the on-line form

- $\quad$ spatial ability testing (before and after the semester/project work)

- numerical evaluation of the project work including 3D computer graphic (grading technical, content and visualization level)

- semantic evaluation, analysis and correlation of written and drawn information that define the creative process

- definition of the categories based on written and drawn information (Table 2): Stages defining creative process - how many stages were defined by the student; Personal involvement - how the student expressed him/herself in terms of identification and personal involvement in the definition of the creative process and the indication of its phases (whether he/she expressed him/herself in the 1st person singular, in the passive form, etc.); Number of adjectives - how descriptively (with adjectives) the student expressed himself in the definition of the creative process and its phases; Level of abstraction - what degree of abstraction was identified in the student's descriptions and drawings; Difference of expression in physical and on-line form - what difference was recognized in the written and descriptive expression of the student when the latter used writing on paper compared to solving an on-line questionnaire; Correlation between written description and $3 D$ product - what difference was recognized between the search and outline definitions and explanations of the creative process and the final product of 3D computer graphics (3D modeling, visualization and animation); Grade of the 3D knowledge, 3D work - assessment of knowledge of the field given by the student with self-evaluation at the beginning of the semester and assessment of the final (given by the mentors) product in technical visualization and content sense after the submission of the final product; Spatial visualisation test - number of correctly solved tasks, where 4 tasks in the beginning and 9 tasks in the end of semester were performed including Paper Folding Test, The Surface Development Test, Paper Form Board Test, Differential Aptitude Test: Space Relations, Picture Rotation Test.

- Quantification of semantic evaluation - the categories defined from the written, descriptive and intimidated material of the students were numerically or descriptively defined (by the number of words used, the number of adjectives, the descriptive assessment of the correlation, i.e. low, medium, high)

- evaluation of students' visualisations of creative process was also performed that allow the explanation of semantic dimensions. 


\section{RESULTS}

In the results we present the students' answers to the questionnaire and in the discussion the analysis is presented.

The students answered all questions and visualised their perception of the creative process before and after the semester. Before the semester they were asked to write answers on paper and after the semester the test was done online, with visualisation on paper. Table 1 shows the answers to the questionnaire of a representative student (Student 5) together with a visualisation of the creative process before and after the semester.

Table 1: Student's answers to the questions before and after the semester

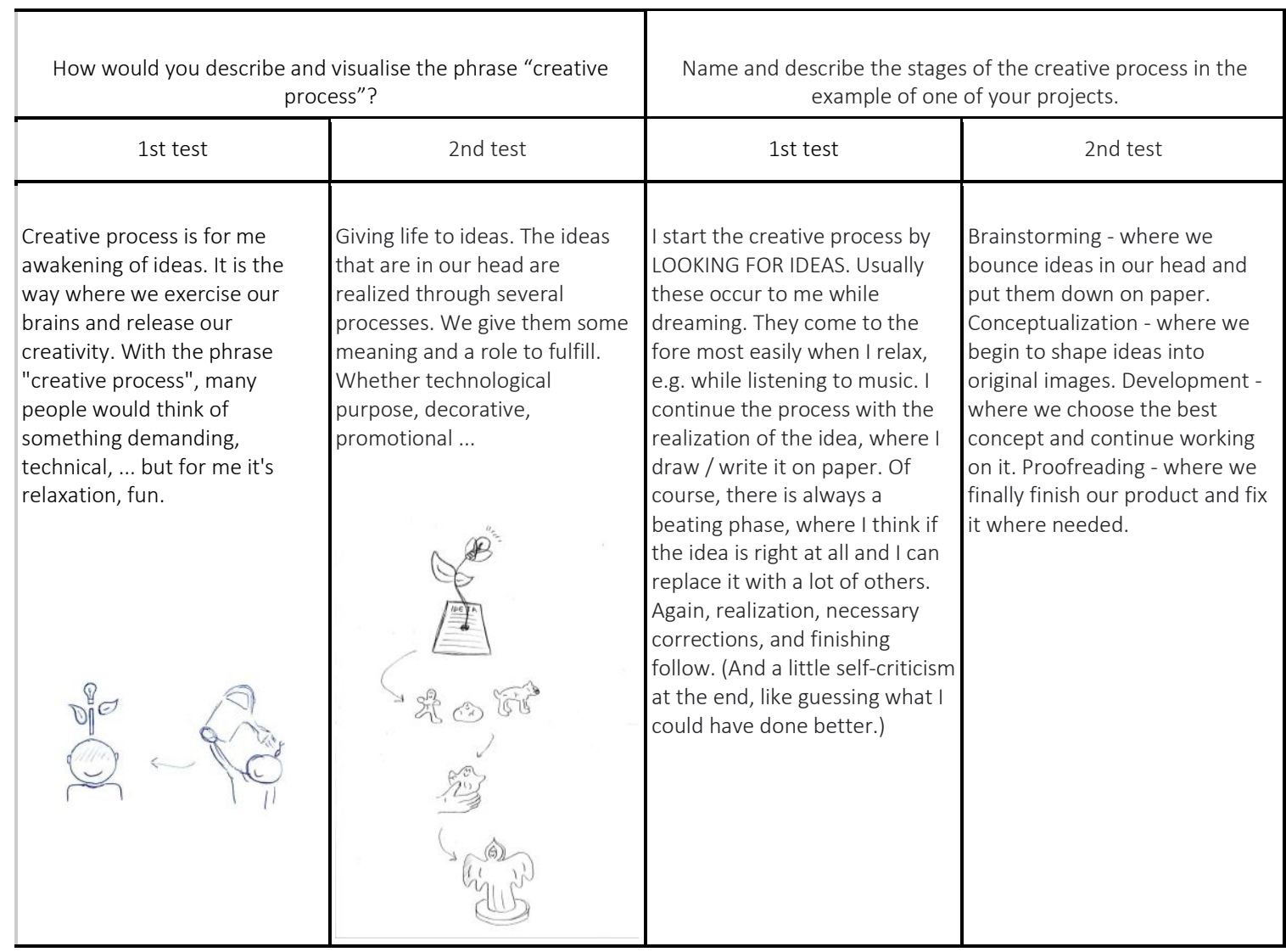

In Table 2 the results of quantification of semantic evaluation of the defined categories are presented. 


\begin{tabular}{|c|c|c|c|c|c|c|c|c|c|c|c|c|c|}
\hline \multirow{2}{*}{$\begin{array}{l}\text { Categories } \\
\\
\begin{array}{l}\text { Student, } \\
\text { before/ } \\
\text { after } \\
\text { semester }\end{array}\end{array}$} & \multicolumn{2}{|c|}{$\begin{array}{l}\text { Stages defining } \\
\text { creative process }\end{array}$} & \multicolumn{2}{|c|}{$\begin{array}{l}\text { Personal involvement; } \\
\text { writes in ... }\end{array}$} & \multicolumn{2}{|c|}{$\begin{array}{l}\text { Adjectives (No. of } \\
\text { adjectives) }\end{array}$} & \multicolumn{2}{|c|}{$\begin{array}{l}\text { Level of } \\
\text { abstraction }\end{array}$} & \multirow[b]{2}{*}{$\begin{array}{l}\begin{array}{l}\text { Difference } \\
\text { of } \\
\text { expression }\end{array} \\
\text { in physical } \\
\text { and on- } \\
\text { line form }\end{array}$} & \multirow[b]{2}{*}{$\begin{array}{l}\begin{array}{l}\text { Correlation } \\
\text { between }\end{array} \\
\text { written } \\
\text { description } \\
\text { and 3D } \\
\text { product }\end{array}$} & \multicolumn{2}{|c|}{$\begin{array}{l}\text { Grade of the 3D knowledge, 3D } \\
\text { work }\end{array}$} & \multirow{2}{*}{$\begin{array}{l}\text { Spatial } \\
\text { ability } \\
\text { before, } \\
\text { after }\end{array}$} \\
\hline & before & after & before & after & $\begin{array}{l}\text { befor } \\
\text { e }\end{array}$ & after & before & after & & & $\begin{array}{l}\begin{array}{l}\text { before } \\
\text { semester - } \\
\text { selfevalu. }\end{array} \\
\text { (1-none } 5 \\
\text { excellent) }\end{array}$ & $\begin{array}{l}\text { grade of the } \\
\text { results }\end{array}$ & \\
\hline 1 & 13 & 5 & $\begin{array}{l}\text { 1st } \\
\text { person, } \\
\text { singular }\end{array}$ & passive & 1 & 2 & no & low & high & very high & 2 & $\begin{array}{l}\text { content }=9 \\
\text { technical=9 } \\
\text { visual }=9\end{array}$ & $\begin{array}{l}4 / 4 \\
4 / 9\end{array}$ \\
\hline 2 & 11 & 11 & $\begin{array}{l}\text { 2nd } \\
\text { person, } \\
\text { singular }\end{array}$ & $\begin{array}{l}\text { 2nd } \\
\text { person, } \\
\text { singular }\end{array}$ & 0 & 0 & no & no & no & very high & 3,5 & $\begin{array}{l}\text { content }=8 \\
\text { technical }=9 \\
\text { visual }=8\end{array}$ & $4 / 9$ \\
\hline 3 & 6 & 4 & $\begin{array}{l}\text { 1st } \\
\text { person, } \\
\text { singular }\end{array}$ & $\begin{array}{l}\text { 1st } \\
\text { person, } \\
\text { plural }\end{array}$ & 4 & 2 & high & low & high & very high & & $\begin{array}{l}\text { content }=10 \\
\text { technical=10 } \\
\text { visual=10 }\end{array}$ & $6 / 9$ \\
\hline 4 & 8 & 8 & $\begin{array}{l}\text { 1st and } \\
\text { 2nd } \\
\text { person, } \\
\text { singular }\end{array}$ & passive & 8 & 1 & no & no & high & very high & 3 & $\begin{array}{l}\text { content }=10 \\
\text { technical }=8 \\
\text { visual }=8\end{array}$ & $7 / 9$ \\
\hline 5 & 11 & 5 & $\begin{array}{l}\text { 1st } \\
\text { person, } \\
\text { singular }\end{array}$ & $\begin{array}{l}\text { 1st } \\
\text { person, } \\
\text { plural }\end{array}$ & 5 & 6 & high & middle & no & very high & 4 & $\begin{array}{l}\text { content }=10 \\
\text { technical=10 } \\
\text { visual=10 }\end{array}$ & $7 / 9$ \\
\hline 6 & 12 & 6 & $\begin{array}{l}\text { 2nd } \\
\text { person, } \\
\text { singular } \\
\text { and } \\
\text { passive }\end{array}$ & $\begin{array}{l}\text { 2nd } \\
\text { person, } \\
\text { singular } \\
\text { and } \\
\text { passive }\end{array}$ & 7 & 1 & $\begin{array}{l}\text { middl } \\
\mathrm{e}\end{array}$ & middle & high & low & 3 & $\begin{array}{l}\text { content }=10 \\
\text { technical=10 } \\
\text { visual=10 }\end{array}$ & $7 / 9$ \\
\hline 7 & 10 & 6 & $\begin{array}{l}\text { 1st } \\
\text { person, } \\
\text { plural } \\
\text { and } \\
\text { passive }\end{array}$ & $\begin{array}{l}\text { 3rd } \\
\text { person, } \\
\text { plural } \\
\text { and } \\
\text { passive }\end{array}$ & 5 & 2 & low & no & high & low & 3,5 & $\begin{array}{l}\text { content }=8 \\
\text { technical=7 } \\
\text { visual }=8\end{array}$ & $7 / 9$ \\
\hline
\end{tabular}

\subsection{Analysis of written and visual results}

Student 1: At the beginning of the semester, the student visualises the creative process with a strict continuation of the process that she has determined through the numbering. The process is illustrated with variations of the light bulb, a well-known symbol of the representation of ideas. The visualisation does not contain any surprising or unconventional representation. Personal participation is represented by the symbolic drawing of a person at the beginning of the drawn scheme. The visualisation after the semester contains more pictures and details and shows the process with concretization. The drawing is more precise and defined, but without the person.

Analysis: At the beginning the student ties in the written and drawn description of the creative process without inventiveness to what is known and learned. During the study process, the creative 
expressiveness was slightly developed and also supported by improved technical knowledge. The cognitive and technical part is expressed more than emotional, although the personal style is developed and updated through the process. The spatial visualisation skills are not high.

Student 2: In the first visualisation representation of creativity contains many images created and connected by smooth, curved continued lines that loop from one complex image to another. Most of the images are associated with a digital process; variations of a screen, mouse, printer and various outputs. In the beginning and in the end of the line there are people who are closely connected to this process. The second pencil drawing is very subtle, almost invisible, the student used the whole format, as in the first visualisation. The lines are straight, completely different from the first case. Drawing is not as attractive and innovative as the first one and without any creative approach to the medium.

Analysis: The student before and after the study process describes her creative process in detail, especially about technical aspects. She writes about many phases of the process and writes in the 2 nd person singular, impersonal. There are almost no adjectives in the description and no emotional involvement. We also notice no abstractness in the description, just like in the final result - the animation. During the design process, the student tried to find her own expression in the visual style by constantly changing it, looking for a safe way to complete the task. The spatial visualisation skills are not high.

Student 3: The first drawing is very abstract, as a scheme with many arrows showing the dynamics of the process. The visualisation spreads out over the whole format, it is very bold and very assertive, but very casual. The second visualisation contains bulbs / symbols to show ideas that are incorporated into and stimulate the creative process. The drawing is still dynamic and bold, with many differently curved lines, mostly pointing upwards, showing the liveliness of the process and pointing to some developmental results, which are represented by pictures of squares similar to screens or sheets of paper. The drawing is more precise than the first and more determined.

Analysis: At the beginning of the study process the student does not use words that would show personal commitment. After the process, she writes in the singular first-person, which shows a more personal and emotional connection with the process. She describes the creative process after the process with more phases and uses many more adjectives that show a higher abstractness. All this can be related to the result, which shows a great expansion of abstract thinking in the use of visual and auditory expressions to realise ideas and to convey an emotional relationship to those ideas. The visual skills are slightly better.

Student 4: The subtle pencil drawing shows phases of the process, connected with straight lines, which end with arrows in the first drawing. The fully detailed initial image, which shows an imaginative person in a cloud, turns into less detailed images during the process and ends in a simplified illustration showing a simple silhouette. The second drawing shows a very technical approach with mathematical equations and digital tools involved in the process. In the first drawing the student includes tools like brushes and a palette, while in the second drawing she mainly shows computers.

Analysis: After the study process, the student describes fewer phases of the creative process. In the beginning she writes descriptions in the first person plural or in the second person singular, after the course she writes completely impersonal. In the first test she uses adjectives like creative, innovative, free, in the second test she uses only the adjective creative. There is no abstractness, and in the second, digital test, she describes rather stingy. The correlation between description and result is high, great ambitions and ideas were not realized.

Student 5: Attentively drawn first image, consisting of two images to be read from right to left, indicated by the curved arrow, shows a person with his thoughts or attitudes towards the process. This is shown using familiar shapes in atypical situations to explain the new concept. The visualisation expresses humour and inventiveness. The second drawing shows more phases and also conveys humour and a special attitude towards the process.

Analysis: The student describes his creative process in a very poetic and intimate way with a lot of imagination in the first person singular. After the course he uses more precise phrases that conceptualise the process, he uses the first person in the plural. The student goes from dreaming, thinking, contemplating... through conceptualization to a more structured way of thinking and observing. Great correlation between the process he describes and the end result. The visualisation is also very emotionally coloured.

Student 6: The representation of the creative process is drawn continuously, with many curved arrows and symbolic images that resemble real life and show positive emotions during the process. The visualisation tries to be very narrative, with images that tell a personal story related to the process. The visualisation is drawn with ease, but decisively, the composition takes up a whole picture format. The second drawing shows the process and the attitude towards it with various well-known symbols, almost 
emoticons, there is less originality without personal ideas, without concretization. The drawing also takes up a whole format and is decisive, bright and dynamic.

Analysis: In the first test, the student describes the creative process with many phases, very abstractly with stimulating, demanding words. The description of the process after the course is limited and without emotions, rather cognitive, third person singular or in general in the third person. There is less correlation between description and results, whose quality goes beyond the description and visualisation of the mere creative process.

Student 7: The visualisation of the creative process is shown with numbered steps, horizontally in one line with known images. At the beginning of the line a person is drawn twice, first as an interaction with the outside world and secondly as a person with inner activity. It is drawn with many short, broken lines, with one person having almost the same part in the process as a tool. The student uses only a small part of the paper format and does not show much creativity in visualisation. She did not give us the second visualisation.

Analysis: The description of the creative process is very technical, in the first person plural in the second test even in the third person plural. The description is limited, with general adjectives without emotional imprint. In the second test, after the course, the student added adjectives with more content. Abstractness is noticeable in the first description of the process, in the second test there is no abstractness and the creative process is described with fewer phases. The correlation between the description and the result is low. The student did not put much effort into the work and there were no good results. She started with a good idea to combine sound and image and the process ended in an animation without appealing content or with personal emotions. There was no creative intervention in the process, only automatic tools were used to perform the task.

\section{DISCUSSION}

From the results obtained, we can summarize, similar to the reference research (Botella et al, 2018), that the creative process of the students of the elective subject 3D computer graphics is very individual and personal. The methodology of the present research is not based on established evaluation tools and procedures, instead, it introduces a specific evaluation approach that is unique for the content of the subject under consideration. The graphic design students described the creative process numerically in 613 phases, which summarized all the main phases from planning and development to the final realization (Botella et al, 2018). They use very different levels of personal commitment when describing the phases. Only 4 students write personally in the 1st person singular, sometimes personally in the 1st person plural, while the rest respond in the 2 nd person singular or even in the passive form (recognized in 5 students). When students describe their creative process on paper, they are generally more personal, use more descriptive words (adjectives), list more phases involved in the process compared to the self-assessment of the process carried out with on-line tools. The latter points to an interesting phenomenon that we would like to investigate more closely in the future. Only two students recognized a high degree of abstraction in written and descriptive expression at the beginning of the semester, which, in our opinion, indicates the inclusion of higher-level cognitive processes (according to the taxonomy of Bloom - analysis, synthesis, creation). In other students we found a lower level of abstraction, which on average decreased when using on-line tools for self-assessment of their creative process. Here again, it would be worthwhile to explore (in further research) more closely at how the self-assessment tool used by the student affects written and sketchy expression. In five of the seven students we found a very high level of agreement between the quality (rating) of the final 3D product created during the semester and the level of the written and sketchy definition of the creative process and self-evaluation of the results of 3D work. In the case of two students, however, a greater discrepancy was found, which in our opinion indicates a disharmony between their processes of understanding and conception (both of oneself as the creator and of the 3D product), technical skills and visualization skills. The latter would of course need to be further explored with more in-depth psychometric methods.

With regard to the spatial visualisation tests conducted before and after the semester, we can state that the choice of elective course means that students have certain spatial abilities. Many of them have also completed the 3D modelling course in their basic studies. Therefore, the results of the first test, which was also easier, were better than the results of the second test. Nevertheless, we found that the students' spatial skills did not improve dramatically. 


\section{CONCLUSIONS}

It is expected that students that have chosen the subject "Advanced computer 3D graphic and visualisations" would have higher spatial abilities. "Internal imaging" is crucial for planning, modelling and to implement complex 3D visualisatons. Students have to communicate ideas verbally and visually as well, therefore visualisation skills are crucial. In our research we analysed, evaluated and synthesized information from written and visualised information gained from students.

The results show that the creative process is understood by the students as an intimate and very subjective choice of an individual, which is slightly altered by the educational process and in our case especially by the design process of 3D animation. The analysis of the students' definitions and the illustrations of the semantics of creative processes show the similarities of the answers before the educational process, where formulations such as "inner fulfilment", "idea formation", "creative aspiration" were used and simpler sketches were drawn. At the end of the semester, the definitions included phrases such as "achieving results", "transferring what has been created to a user" and "product display". Through the results of the spatial visualisation test, we also found that the course did not significantly improve students' spatial visualisation skills, which encouraged the educators to alter the curriculum towards more specific 3D content creation that would allow for improved spatial visualisation skills.

\section{REFERENCES}

[1] Alias, M., Black, T. R., Gray, D. E.: "Effect of Instructions on Spatial Visualisation Ability in Civil Engineering Students", International Education Journal 3 (1), 1-12, 2002.

[2] Botella, M., Glaveanu, V., Zenasni, F., Storme, M., Myszkowski, N., Wolff, M., Lubart, T.: "How artists create: Creative process and multivariate factors", Learning and Individual Differences 26, 161-170, 2013. doi: 10.1016/j.lindif.2013.02.008.

[3] Botella, M., Zenasni, F., Lubart, T. I.: "A dynamic and ecological approach to the artistic creative process in arts students: an empirical contribution", Empirical Studies of the Arts 29 (1), 17-38, 2011. doi: 10.2190/EM.29.1.b.

[4] Botella, M., Zenasni, F., Lubart, T.: "What Are the Stages of the Creative Process? What Visual Art Students Are Saying", Frontiers in Psychology 9, article 2266, 1-12, 2018. doi: 10.3389/fpsyg.2018.02266.

[5] Carson D. K.: "Encyclopedia of Creativity", (Academic Press, New York, 1999.), pages 395-402.

[6] Gardner, H.: "Frames of Mind: The Theory of Multiple Intelligences", (Basic Books, New York, 2011.), pages 179-216.

[7] Linn, M. C., Petersen, A. C.: "Emergence and characterization of sex differences in spatial ability: A meta-analysis", Child Development 56(6), 1479-1498, 1985. doi: 10.2307/1130467.

[8] McGee, M. G.: "Human spatial abilities: Psychometric studies and environmental, genetic, hormonal and neurological influences", Psychological Bulletin 86, 899-918, 1979. doi: https://doi.org/10.1037/0033-2909.86.5.889.

[9] Norman, K. L.: "Spatial visualization - A gateway to computer to computer-based technology", Journal of Special Education Technology 12 (3), 195-206, 1994. doi: 10.1177/016264349401200303

[10] Patkin, D., Dayan, E.: "The intelligence of observation: improving high school students' spatial ability by means of intervention unit", International Journal of Mathematical Education in Science and Technology 44(2), 179-195, 2013. doi: 10.1080/0020739X.2012.703335.

[11] Roslan, R. K., Ahmad, A.: "3D Spatial Visualisation Skills Training Application for School Students Using Hologram Pyramid", International Journal on Informatics Visualization 1 (4), 170-174, 2017. doi: 10.30630/joiv.1.4.61.

[12] Runco M. A., Dow G.: "Encyclopedia of Creativity", (New York, NY: Academic Press, 1999.), pages 433-435.

[13] Sorby, S. A.: "Spatial abilities and their relationship to effective learning of 3-D solid modeling software", The Engineering Design Graphics Journal 64 (3), 30-35, 2000. 


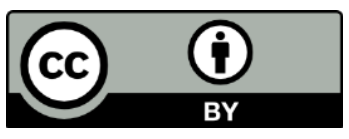

(C) 2020 Authors. Published by the University of Novi Sad, Faculty of Technical Sciences, Department of Graphic Engineering and Design. This article is an open access article distributed under the terms and conditions of the Creative Commons Attribution license 3.0 Serbia

(http://creativecommons.org/licenses/by/3.0/rs/). 



\title{
APPLYING GRAPHIC DESIGN PRINCIPLES ON TEA PACKAGING
}

\author{
Dorotea Kovačević (iD, Maja Brozović (iD), Dubravko Banić \\ University of Zagreb, Faculty of Graphic Arts, Zagreb, Croatia
}

\begin{abstract}
The aesthetic aspect of product packaging is a well-known factor in attracting consumers' attention. One of the most common ways in achieving the aesthetic appearance of the packaging is applying graphic design principles. The purpose of the study was to explore how people perceive the attractiveness of tea packaging with different levels of graphic design principles applied. The graphic design principles applied on the packaging were: contrast, dominance, alignment, symmetry, consistency and colour harmony. The manipulation of these principles resulted in three different packaging samples that were tested: aesthetic packaging, partially-aesthetic packaging and non-aesthetic packaging. The participants' tasks were to rate the attractiveness of each of the packaging samples and to select the one which they would like to buy. The statistical analysis showed that the results of both tests (rating and choice task) were consistent, indicating that the aesthetic packaging was appreciated the most, followed by the partially-aesthetic packaging and the non-aesthetic packaging. These results were the same even when taking into account whether the beauty of the packaging was important to the participants or not. The findings support the idea of using graphic design principles in packaging design whenever applicable.
\end{abstract}

Keywords: graphic design, packaging, attractiveness, tea

\section{INTRODUCTION}

The role of product packaging is multifaceted. Not only it protects the product, but also transmits the information about the product through its visual elements. The graphic design of these visual elements is one of the most powerful tools for creating the aesthetic aspect of product packaging and attracting consumers' attention during the buying process. The aesthetic packaging makes products visually appealing, which creates a potential for eliciting positive impressions on consumers. This was confirmed by many studies during the last decade (Honea and Horsky, 2012; Van der Laan et al, 2012; Westerman et al, 2013). Furthermore, it was found that people tend to choose aesthetic packaging rather than standardized packaging (Reimann et al, 2010).

One of the most common ways in achieving the aesthetic appearance of packaging is applying graphic design principles while creating the packaging. The most popular design principles are Gestalt laws for organizing visual form and space (Puhalla, 2011), which professional designers apply not only on packaging, but also on other print media as well as on screen design (Chang et al, 2002). Beside the Gestalt laws, graphic designers are trained to apply other design principles (of which some overlap with Gestalt laws or originate in them), such as unity, proportion, dominance (Pham, 1999), contrast (Williams and Stimatz, 2005; Chevalier and Kicka, 2006), alignment (Williams, 2014), symmetry (Ngo et al, 2000) and colour harmony (Puhalla, 2011).

Few of the design principles were included in previous studies that investigated the role of visual design in different experimental conditions. For example, Tomko and Zaitseva (2009) analyzed the requirements for good visual design of e-learning systems and pointed out unity as one of the criteria for their evaluation. High level of unity was also perceived as attractive to younger participants in the case of digital learning games (Javora et al, 2019). The principle of colour contrast was especially interesting to researchers. Silvennoinen et al (2014) reported about the importance of colour contrast for effective visual usability. Ling and Van Schaik (2002) investigated the use of colour on web pages and found that higher colour contrasts were rated more favorably by the participants. Web pages were also tested by Lazard and Mackert (2014), who found that principles of design complexity influenced the participants' first impressions and their evaluation of the pages' beauty and utility. However, none of the mentioned studies assessed the effect of design principles in packaging design.

Thus, our aim was to explore how people perceive the attractiveness of product packaging with different levels of applied graphic design principles. Additionally, we wanted to investigate the effect of design principles on people's choices and find out whether their evaluation of product packaging is affected by their attitude toward the importance of aesthetics in their buying decisions. 


\section{METHODOLOGY}

36 participants ( 22 women and 14 men) volunteered for the experiment. All of them were tea users. The age of the participants ranged from 24 to $83(\mathrm{M}=39.781$, SD = 13.01). All had normal or corrected-tonormal vision. The experiment was conducted in a laboratory setting of the University of Zagreb. The stimuli were presented on-screen, using a Lenovo computer display L1900pA. The resolution was set to $1280 \times 1024$ pixels. The size of each packaging stimulus (i.e. the front side of a packaging box) was $83 \times$ $125 \mathrm{~mm}$. Due to the nature of our research question and the importance of stimuli's visual appearance, a special effort was put on the stimuli's design.

As was the case in many previous studies (Germelmann and Held, 2014; Vladić et al, 2016; Kovačević et al, 2019), tea packaging was selected as stimuli. The stimuli were created according to aesthetic and ergonomic principles commonly used in graphic design projects. For the purpose of this study, we used only the principles which can be easily manipulated on the type of packaging which was selected as the object of the investigation. The graphic design principles used as variables were: colour harmony, symmetry, alignment, dominance, contrast and consistency. Manipulation of these principles resulted in three different packaging samples used as stimuli that were tested: an aesthetic packaging, a partiallyaesthetic packaging and a non-aesthetic packaging (Figure 1).

On the aesthetic packaging, we use all the above mentioned principles. We applied a harmonic colour palette as suggested by Puhalla (2011). The arrangement of visual elements was based on symmetrical composition since symmetry was pointed out as one of the useful graphic design principles in previous works (Ngo et al, 2000; Lidwell et al, 2010). According to Williams's suggestion (Williams, 2014), the elements were aligned where possible. Furthermore, we created dominance, one of the basic principles suggested by Pham (1999) by enlarging the illustration. We also used good contrast (Williams and Stimatz, 2005; Chevalier and Kicka, 2006) between the text and its background. The consistency was achieved through the use of the same font family. The exception was the tea name, which was formed to fit the illustration style.

On the partially-aesthetic packaging we kept the symmetrical composition, but the application of other principles was changed. We used a less harmonic colour palette, poorer contrast and the elements were aligned to a lesser extent. The design did not include any extremely dominant visual element. The consistency was degraded by using four different fonts.

On the non-aesthetic packaging, none of the graphic design principles was applied. The colours were nonharmonic and the composition was unbalanced. There was no alignment and no clear dominance. The contrast between the text and its background was extremely poor. The consistency was even more degraded than in the previous packaging by using five different fonts and styles.

The participants took part in the experiment one at a time. They were asked to view the packaging on the screen in the similar way as they would during their usual shopping activities. Their task was to rate the attractiveness of the packaging, one by one, using a 5-point Likert scale. After that, they had a choice task in which they were asked to select among the three examples of packaging, the one which they would most likely buy in a store. Both tasks (the evaluation of attractiveness and the choice task) had no time limit. After completing the tasks participants answered to the question "Is the beauty of the packaging important to you when you buy tea?".

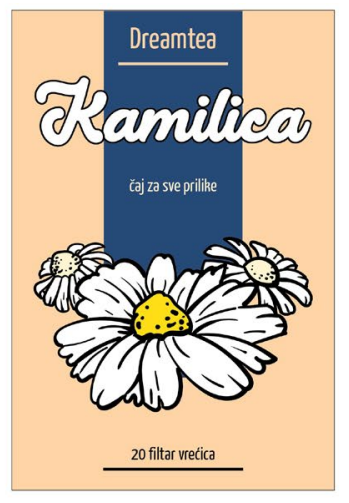

Aesthetic packaging

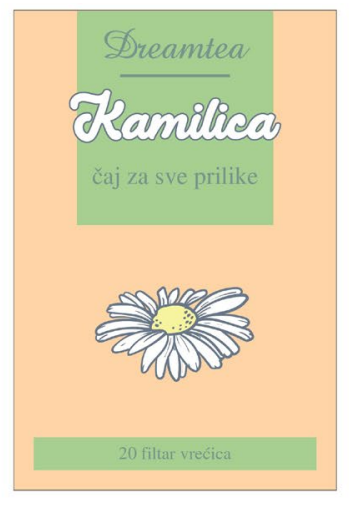

Partially-aesthetic packaging

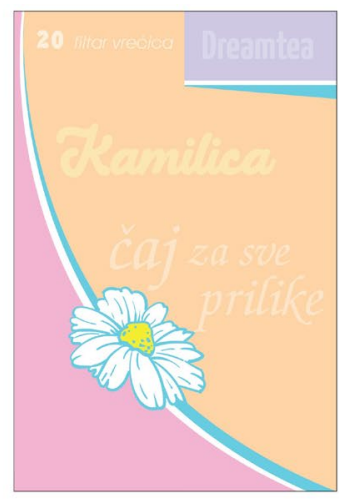

Non-aesthetic packaging

Figure 1: Packaging samples used in our experiment 


\section{RESULTS}

To examine whether aesthetics influences the perception of the attractiveness of the packaging, a repeated measures analysis of variance was used. There was a significant effect of the aesthetic aspect of the packaging, $F(2,70)=50.60, p<0.001$, suggesting that the packaging with different levels of applied graphic design principles was differently evaluated by the participants. Additional post hoc analyses with Bonferroni correction showed significant differences between all the packaging pairs. The aesthetic packaging was more attractive than the partially-aesthetic packaging, $t(35)=3.98, p<0.001$ and the nonaesthetic packaging $t(35)=9.43, p<0.001$. Furthermore, the partially-aesthetic packaging was more attractive than the non-aesthetic packaging $\mathrm{t}(35)=6.35, \mathrm{p}<0.001$. The aesthetic packaging was the best rated $(M=4.11, S D=0.85)$, followed by the partially-aesthetic packaging $(M=3.31, S D=0.98)$, and the non-aesthetic packaging $(M=2.06, S D=1.12)$. Additionally, there were no significant differences between the groups when taking into account whether the beauty of packaging was important for the participants or not; $\mathrm{t}(34)=0.38, \mathrm{p}=0.71$ in the aesthetic packaging condition, $\mathrm{t}(34)=0.15, \mathrm{p}=0.18$ in the partially-aesthetic packaging condition and $\mathrm{t}(34)=0.74, \mathrm{p}=0.61$ in the non-aesthetic packaging condition. Figure 2 illustrates these results.

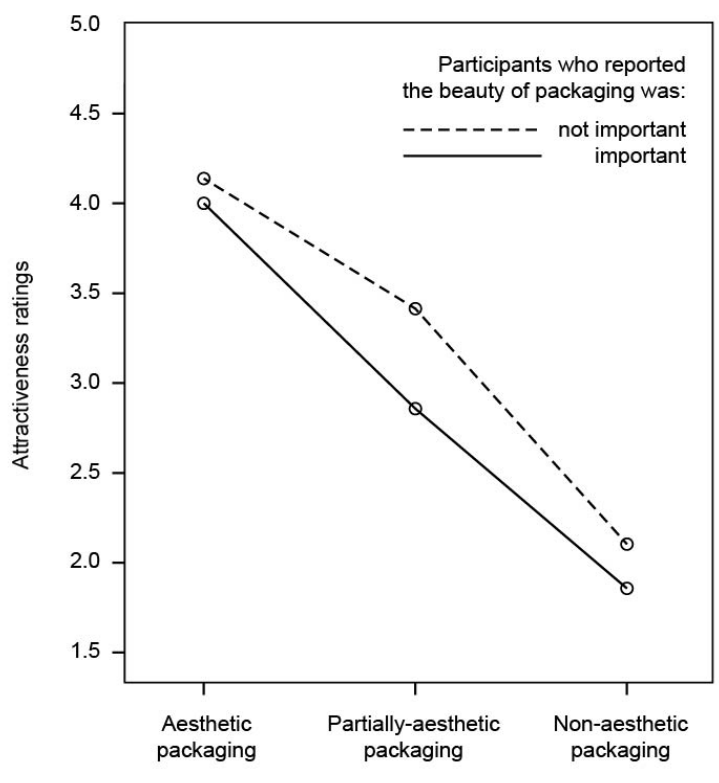

Figure 2: Attractiveness ratings across the conditions

Cochran's $\mathrm{Q}$ test was used to examine the influence of aesthetics on the frequency of participants' choices in the choice task. The results showed a significant difference in participants' selection of packaging, $\chi^{2}(2)=30.17, p<0.001$. Post hoc analyses were done by McNemar's tests with Bonferroni correction. The aesthetic packaging was chosen by the biggest number of the participants (75\%). Significantly fewer participants chose the partially-aesthetic packaging $(22.2 \%), p<0.01$ and the nonaesthetic packaging (2.8\%), $p<0.001$. However, there was no significant difference in the participants' choices between the partially-aesthetic packaging and the non-aesthetic packaging, $p=0.039$.

\section{DISCUSSION}

Our study showed that aesthetics influences consumers' perception of the packaging and their choices. When choosing between three options, the majority of the participants selected the packaging with the highest level of aesthetics (i.e. with inclusion of all the graphic design principles). The aesthetic value is an attribute which has been shown to influence people's choices (Van der Laan et al, 2012). This is in line with a research of Reimann et al (2010) who used a choice task in the investigation of aesthetic packaging for food products. The examples of packaging that were richer in their visual appeal were chosen over well-known brands, despite higher prices. The results of another task in our study (the evaluation of packaging) also confirm the participants' inclination to aesthetically appealing packaging. The aesthetic packaging was the best rated one, followed by the partially-aesthetic packaging and the non-aesthetic 
packaging. This was expected since previous research showed that package visual design can alter consumers' perception and evaluation of a product (Underwood and Klein, 2002). The effectiveness of the design of the aesthetic packaging in our experiment was based on the graphic design principles whose power was also demonstrated in several other studies. For example, Bigoin-Gagnan and LacosteBadie (2018) used the front of product packaging as stimuli in their research which revealed that aesthetic evaluation was higher when elements on the packaging were symmetrically rather than asymmetrically composed. Harmony was also found to have an influence on people's perception of attractiveness in the case of marketing visuals (Nickel et al, 2016; Nickel et al, 2020). Finally, of all the principles used in our study, the most prominent was the contrast. This attribute was found to be an effective tool for evoking the participants' positive reactions to visual content (Ling and Van Schaik, 2002), so probably this was also the case in our study. It is likely that the poor contrast in our non-aesthetic packaging sample led to a low level of visual appeal and to reduced font legibility. As demonstrated in a study focused on tea beverage packages (Mukai and Miyazaki, 2016), font legibility may play a role in rating the overall aesthetic impression of the packaging.

Another interesting finding was that positive effect of design principles on attractiveness remained the same even when taking into account whether the beauty of packaging was important for the participants or not. This suggests that people prefer aesthetic product packaging even if they do not see packaging visual appeal as an important factor in making their buying decisions. Our overall results confirm previous research on packaging design which demonstrated that visual aesthetics of food product packaging influences the consumers' evaluation of a product (Honea and Horsky, 2012). In most cases, the aesthetic packaging creates an impression of good quality in a product (Orth et al, 2010; Westerman et al, 2013). It seems that the packaging samples used in our study were not an exception.

\section{CONCLUSIONS}

The results of our study demonstrated how useful the application of design principles can be in the area of tea packaging design. If a designer applies graphic design principles intentionally, there is a greater possibility for creating an aesthetic visual design. Consumers perceive a highly aesthetic packaging as attractive and preferable when making buying choices. In line with these results, it can be concluded that the aesthetic component of the packaging is an important part of successful marketing, even with a low involvement product such as tea. Future studies should examine the perception of other low involvement products in relation to packaging aesthetics. They should also include more graphic design principles and use more objective measures of participants' responses, such as eye-tracking data.

\section{REFERENCES}

[1] Bigoin-Gagnan, A., Lacoste-Badie, S.: "Symmetry influences packaging aesthetic evaluation and purchase intention", International Journal of Retail and Distribution Management 46, 1026-1040, 2018. doi: 10.1108/IJRDM-06-2017-0123.

[2] Chang, D., Dooley, L., Tuovinen, J.E.: "Gestalt theory in visual screen design - A new look at an old subject", $7^{\text {th }}$ World Conference on Computers in Education 2002, (WCCE, 2002), pages 5-12.

[3] Chevalier, A., Kicka, M: "Web designers and web users: Influence of the ergonomic quality of the web site on the information search", International Journal of Human Computer Studies 64, 1031 1048, 2006. doi: 10.1016/j.ijhcs.2006.06.002.

[4] Germelmann, C.C., Held, J.: "Deceived or not deceived: How food consumers perceive deception", (MN: Association for Consumer Research, 2014.), pages 313-317.

[5] Honea, H., Horsky, S.: "The power of plain: Intensifying product experience with neutral aesthetic context", Marketing Letters 23, 223-235, 2012. doi: 10.1007/s11002-011-9149-y.

[6] Javora, O., Hannemann, T., Starkova, T., Volna, K., Brom, C.: "Children like it more but don't learn more: Effects of esthetic visual design in educational games", British Journal of Educational Technology 50, 1942-1960, 2019. doi: 10.1111/bjet.12701.

[7] Kovačević, D., Brozović, M., Itrić Ivanda, K.: "Eco-mark on product packaging and its effect on the perception of quality", Journal of Graphic Engineering and Design 10, 17-24, 2019. doi: 10.24867/JGED-2019-2-017.

[8] Lazard, A., Mackert, M.: "User evaluations of design complexity: The impact of visual perceptions for effective online health communication", International Journal of Medical Informatics 83, 726-735, 2014. doi: 10.1016/j.ijmedinf.2014.06.010. 
[9] Lidwell, W., Holden, K., Butler, J.: "Universal principles of design, revised and updated: 125 Ways to enhance usability, influence perception, increase appeal, make better design decisions, and teach through design", (Massachusetts: Rockport Publishers, 2010).

[10] Ling, J., Van Schaik, P.: "The effect of text and background colour on visual search of web pages", Displays 23, 223-230, 2002. doi: 10.1016/S0141-9382(02)00041-0.

[11] Mukai, S., Miyazaki, G.: "Effects of both similarity of the evaluation of impressions, between elements, and font legibility, on aesthetic impression of packaging", International Journal of Affective Engineering 15, 289-293, 2016. doi: 10.5057/ijae.IJAE-D-16-00012.

[12] Ngo, D.C.L., Samsudin, A., Abdullah, R.: "Aesthetic measures for assessing graphic screens", Journal of Information Science and Engineering 16, 97-116, 2001.

[13] Nickel, K., Orth, U.R., Bouzdine-Chameeva, T., Cohen, J., Corsi, A.M., Crouch, R.C., de Marchi, R.: "Designing culturally specific wine packages: The case of visual harmony", $9^{\text {th }}$ Academy of Wine Business Research Conference, Wine Business Research that Matters 2016, (Adelaide, Australia, 2016) pages 342-352.

[14] Nickel, K., Orth, U.R., Kumar, M.: "Designing for the genders: The role of visual harmony", International Journal of Research in Marketing, 2020. doi: 10.1016/j.ijresmar.2020.02.006.

[15] Orth, U.R., Campana, D., Malkewitz, K.: "Formation of Consumer Price Expectation Based on Package Design: Attractive and Quality Routes", The Journal of Marketing Theory and Practice, 18, 23-40, 2010. doi: 10.2753/MTP1069-6679180102.

[16] Pham, B.: "Design for aesthetics: Interactions of design variables and aesthetic properties", Proceeding of $11^{\text {th }}$ Annual Symposium - Electronic Imaging 1999, (SPIE IS\&T/SPIE San Jose, USA, 1999) pages 364-371.

[17] Puhalla, D.: “Design Elements: Form \& Space: A Graphic Style Manual for Understanding Structure and Design", (Rockport Publishers, 2011).

[18] Reimann, M., Zaichkowsky J., Neuhaus C., Bender, T., Weber, B.: "Aesthetic package design: A behavioral, neural, and psychological investigation", Journal of Consumer Psychology 20, 431-441, 2010. doi: 10.1016/j.jcps.2010.06.009.

[19] Silvennoinen, J., Vogel, M., Kujala, S.: "Experiencing visual usability and aesthetics in two mobile application contexts", Journal of Usability Studies 10, 46-62, 2014

[20] Tomko, V., Zaitseva, L.: "Visual design of e-learning systems", Proceedings of $9^{\text {th }}$ International Conference on Advanced Learning Technologies 2009, (ICALT, Latvia, 2009), pages 686-687.

[21] Underwood, R.L., Klein, N.M.: "Packaging as brand communication: Effects of product pictures on consumer responses to the package and brand", Journal of Marketing Theory and Practice 10, 5868, 2002. doi: 10.1080/10696679.2002.11501926.

[22] Van der Laan, L.N., de Ridder, T.D., Viergever, M.A., Smeets, P.A.M.: "Appearance matters: Neural correlates of food choice and packaging aesthetics", Plos One 7, 41738, 2012. doi: 10.1371/journal.pone.0041738.

[23] Vladić, G., Kecman, M., Kasikovic, N., Pal, M., Stancic, M.: "Influence of the shape on the consumers perception of the packaging attributes", Journal of Graphic Engineering and Design, 7, 27-32, 2016.

[24] Westerman, S.J., Sutherland, E.J., Gardner, P.H., Baig, N., Critchley, C., Hickey, C., Mehigan, S., Solway, A., Zervos, Z.: "The design of consumer packaging: Effects of manipulations of shape, orientation, and alignment of graphical forms on consumers' assessments", Food Quality and Preference 27, 8-17, 2013. doi: 10.1016/j.foodqual.2012.05.007.

[25] Williams, B.O., Stimatz, L.R.: "The origins of graphic screen design principles: Theory or rhetoric", International Journal of Instructional Media 32, 181-193, 2005.

[26] Williams, R.: "The non-designer's design book: Design and typographic principles for the visual novice", (Peachpit Press, 2014).

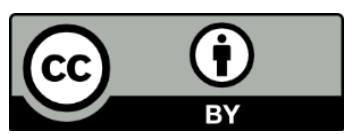

(C) 2020 Authors. Published by the University of Novi Sad, Faculty of Technical Sciences, Department of Graphic Engineering and Design. This article is an open access article distributed under the terms and conditions of the Creative Commons Attribution license 3.0 Serbia (http://creativecommons.org/licenses/by/3.0/rs/). 



\title{
THE POWER OF COMMEMORATIVE BANKNOTE DESIGN TO SUPPORT GLOBAL AND LOCAL EVENTS
}

\author{
Khloud Khaled Ahmed \\ Higher Institute of Applied Arts, Department of Printing, Publishing and Packaging, \\ New Cairo, Egypt
}

\begin{abstract}
Commemorative banknotes are issued to commemorate some particular event or issue with a distinct design with reference to the occasion on which they were issued. In this paper the author explores another aspect to utilization commemorative banknote to promote and support Global and Local events, In addition to marketing historical, artistic, and sporting events, etc., sheds light on the most important international events the covid-19 Pandemic and the utilization of commemorative banknote to support the role of doctors in the world in to Commemorate their unique experience. Further, banknote artwork that captures a personal moment, emotion, memory or other poignant event that tells their story of the Covid19 pandemic. In addition, the author elaborates on how Commemorative banknotes have a media role to promote important events and communicate the idea in a simple artistic manner.

The author concludes that the power of commemorative banknote stems from their ability to enhance the global participation in crises and disasters, through design a global limited edition unified model of banknote In accordance with each country.
\end{abstract}

Key words: Commemorative banknote, Artwork story, Covid-19 pandemic, Design features.

\section{INTRODUCTION}

Commemorative banknotes have artistic value and a rich source of information about important centuries-old events, traditions, culture, sports, and nature, these are limited edition that depict important issues and milestone events in the history of the people (National Bank of Ukraine, 2020). That is why the price of such banknotes is higher than their face value. Commemorate means to respect, hence all those banknotes that respect to certain occasions or persons are called commemorative banknotes (Sapre, 2018). Commemorative banknotes are issued in accordance with the provisions of the Bank of each country. The marketing of those banknotes is carried out by a company appointed by the Minister of Finance, with the consent of the Governor of the Bank also can be purchased on-line. There are many reasons why Commemorative banknotes are interesting. Some of the common reasons (Currency News, 2020) are listed here:

Record of cultural: The banknotes of many countries carry images relating to the culture of the country of issue. For example, the notes might display portraits of famous people and important monuments or buildings may be depicted.

A Record of History: While aspects of a nation's history might be depicted on banknote, such as famous battles, famous treaties and famous events, it is more often the change in banknotes over a course of time that portrays aspects of country's history.

The beauty of a Banknote: A banknote is a powerful symbol of the history, culture and sovereignty of a nation, so there's a great deal of responsibility in getting its design right (Payne, 2019).

Know more details by using the QR (Quick Response) Code: Digitized barcode that tells the brief history of art work which used on banknote design when scanned with an internet enabled mobile device or an iPad. It is mostly located at the back of the note. Also, you can use the QR-Code to check if the commemorative banknote is genuine (Jonathan, 2014).

Nice to have: People are interested in their own banknotes, people very quickly make a judgment on the aesthetics. They either find the banknote beautiful or ugly. For this reason, judging aesthetics is listed as User Experience Functions (UXFs), In addition to Recognizing identity, Retaining confidence, Connecting with main image, Expecting sustainability and Linking to information to meet Psychological user functions (De Heij, 2018). Banknote designer may verify the prototypical design elements of one of their banknotes by eye-tracking registration. Such a registration will indicate the elements registered by the human eye. The human eye rests at the center of the first arch (De Heij, 2010). 


\section{METHODS}

In this part of the study, the tools and materials that were used to implement the idea of research are summarized. In the first, the idea of research was presented to students of the fourth year in the Department of Printing, Publishing and Packaging in a course of design for valuable prints in order to identify the different aspects of commemorative banknote then sketch of ideas for commemorative banknote according pyramid layout, shown in Figure 1. Then print trials were made on Matte paper $80 \mathrm{gr}$ by dimensions $16 \mathrm{~cm} \times 7.5 \mathrm{~cm}$ and finally evaluated through focus group Discussion Who are interested in collecting commemorative banknotes. In Table 1 an overview of responses of citizens within the Cairo Area.

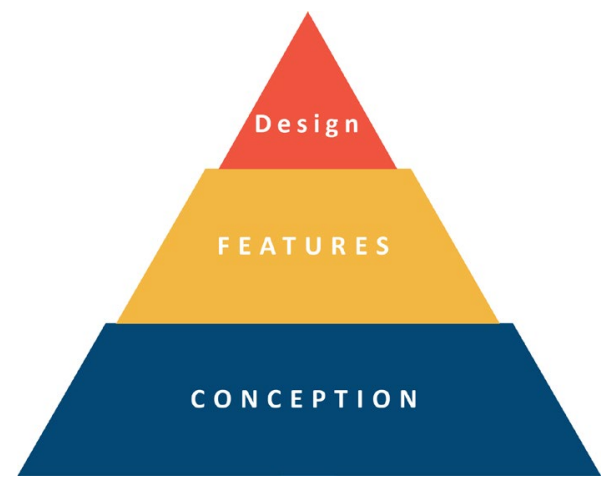

Figure 1: Pyramid layout

Basic conception in banknote requirements are presented at the bottom of the Pyramid-layout. In the center there is the security features requirement for easy identification of a genuine banknote. Security features are meant to secure the banknote and deter counterfeiters. Other aesthetic features refer to the psychological user requirements, there is the requirement that the Aesthetic features should be nice to have, surrounded by user requirements referring to the main image and colour. Design At the top of the pyramid layout, for enhance design of banknote (perception, communication). Good banknote design will reduce the need of training on real-fake banknotes and will also reduce the need of communication campaigns. For good design it is essential to know what the public wants.

Table 1: Overview of responses of citizens within the Cairo Area on the question was: "For you personally, are you interested in owning or buying commemorative banknotes? And if the answer is yes, are you prefer local or international commemorative banknotes?

\begin{tabular}{|c|c|c|c|}
\hline \multicolumn{3}{|c|}{ Cairo Area (2020) } \\
\hline \multirow{2}{*}{$\begin{array}{c}\text { Needs of commemorative banknotes } \\
\text { collector }\end{array}$} & \multicolumn{2}{c|}{ Reasons to prefer (in \%) } \\
\cline { 2 - 4 } Overview & $\begin{array}{c}\text { local } \\
\text { commemorative banknotes }\end{array}$ & $\begin{array}{c}\text { International } \\
\text { commemorative banknotes }\end{array}$ \\
\hline \multirow{3}{*}{$\begin{array}{c}\text { Landscape/ Portrait } \\
\text { Design }\end{array}$} & Portrait Design & 70 & 30 \\
\cline { 2 - 4 } & Landscape & 30 & 10 \\
\hline \multirow{4}{*}{$\begin{array}{c}\text { Security features } \\
\text { (for easy identification) }\end{array}$} & Design & 40 & 15 \\
\cline { 2 - 4 } & Embossed print & & 30 \\
\cline { 2 - 4 } & Motion thread & 60 & 20 \\
\cline { 2 - 4 } & OVatermark & 70 & 30 \\
\cline { 2 - 4 } & Serial Number & 68 & 25 \\
\cline { 2 - 4 } & See through & 70 & 20 \\
\cline { 2 - 4 } & Tactile marks & 20 & 28 \\
\hline Aesthetic features & Main image & 65 & 14 \\
\cline { 2 - 4 } (nice to have ) & Dimensions & 40 & 15 \\
\cline { 2 - 4 } & Colour & 40 & 23 \\
\hline
\end{tabular}




\section{RESULTS}

From our initial studies, we knew as a commemoration of the local and global events, the notes were going to focused on the most famous symbol for this event. Our joint challenge was how to translate this into a design that reflected event's imaging excellence and legacy, especially in its most popular events.

\subsection{Commemorative banknotes as a marketing instrumental for tourism promotion}

Using the design of commemorative banknote as a marketing instrumental for the festivals that are held annually in Egypt with the aim of consolidating the event and preserving the identity of commemorative banknotes against the spread of digital currencies This is due to the perception that digitization is the future For payments and identity and that the transition is well underway, inevitable, unstoppable and irrevocable, driven by convenience (Currency News, 2020).

\subsubsection{Alexandria International Film Festival}

Alexandria International Film Festival for Mediterranean Countries is a film festival in Egypt. Organized by the Egyptian Association of Film Writers and Critics (EAFWC). The Alexandria International Film Festival takes place every November and is a key event in Egypt's cinematic calendar, (Kamil, 2011). Independent filmmakers from across the world showcase their work here. The main venue is the Bibliotheca Alexandrina, but screenings and questions and answers with directors also take place at several other cinemas and historic buildings around town.

The Alexandria International Film Festival banknotes depict the Alexandria landmarks to promote cinema as an important cultural and educational asset and market Alexandria as a dynamic venue for making, exhibiting, and experiencing cinematic art. On the front of banknote shown figure 2 The Festival logo and cinematic symbol Symbolize the spirit of Development and progresses in Egypt. On the reverse of banknote The Citadel of Qaitbay which located on the Mediterranean Sea coast, in Alexandria, Egypt symbolize the power and fortress.
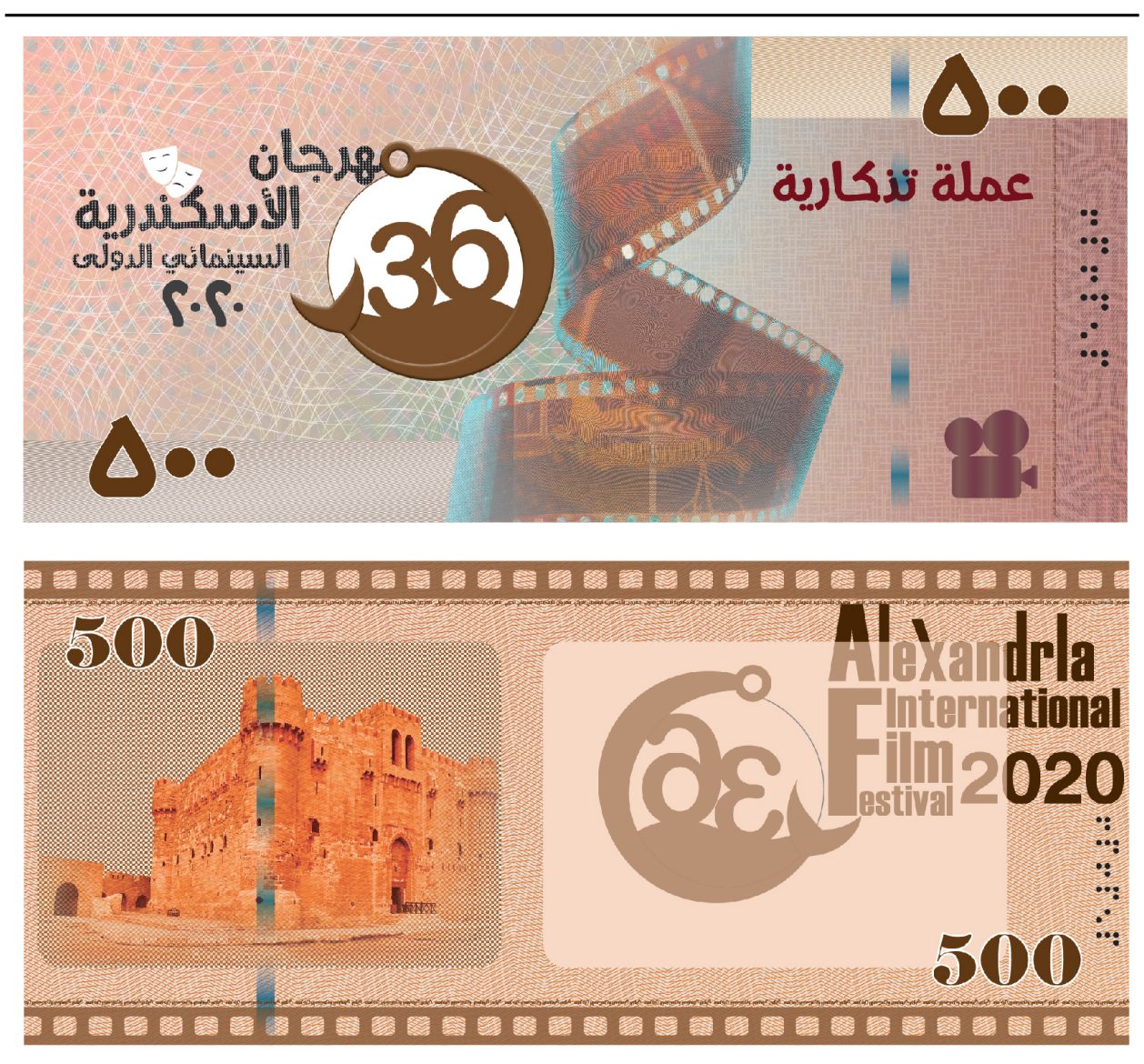

Figure 2: Example of front and reverse banknote for tourism promotion of the Trial commemorative banknote 
In figure 3 example of portrait banknote design for tourism promotion, on the front of banknote which in left side depict the actor Haitham Ahmed Zaki, who passed away In addition to cinematic elements. On the reverse of banknote which in right side represents Lighthouse of Alexandria with QR code to know more details about festival and security features of this note.

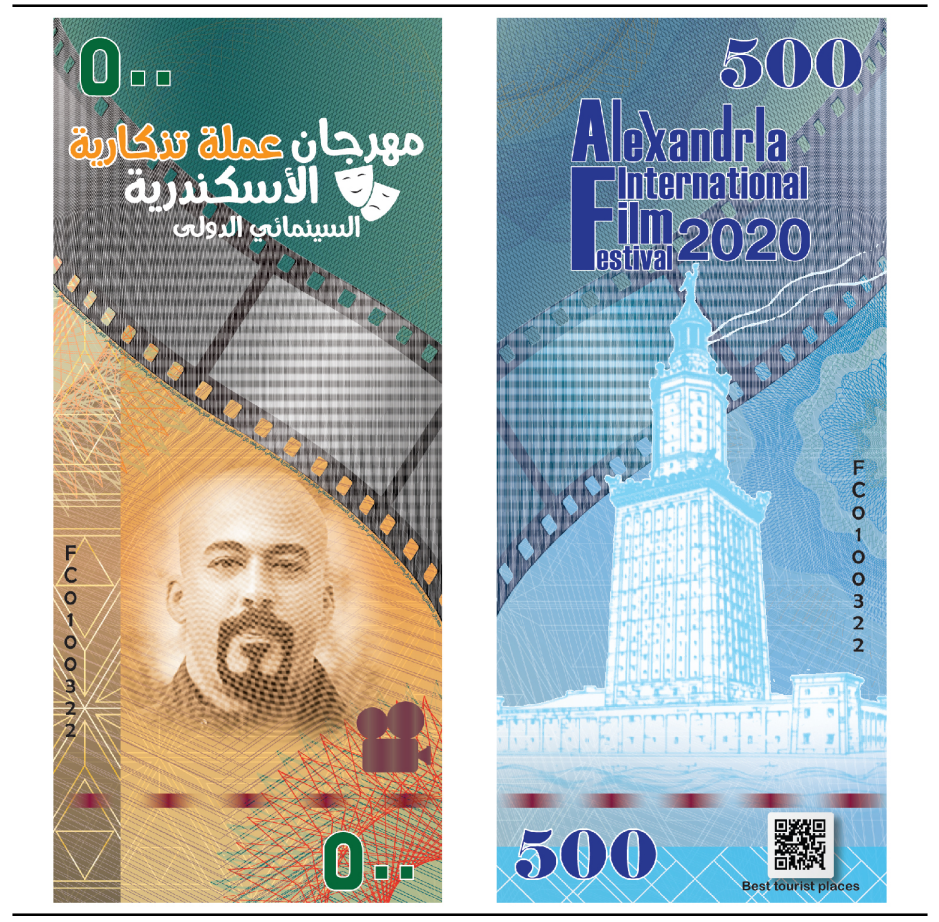

Figure 3: Example of portrait banknote for tourism promotion

\subsubsection{El Gouna Film Festival}

The mission of El Gouna Film Festival (GFF) is to showcase a lot of a wide variety of films for a passionate and knowledgeable audience; while fostering better communication between cultures through the art of filmmaking. Its goal is to connect filmmakers from the region with their international counterparts in the spirit of cooperation and cultural exchange (Kamil, 2011).

El Gouna Film Festival banknotes depict The most famous actors as well as the festival logo The festival is committed to the discovery of new voices and strives to be a catalyst for the development of cinema in the Arab world, particularly through its industry segment (EIGouna film festival, 2020).

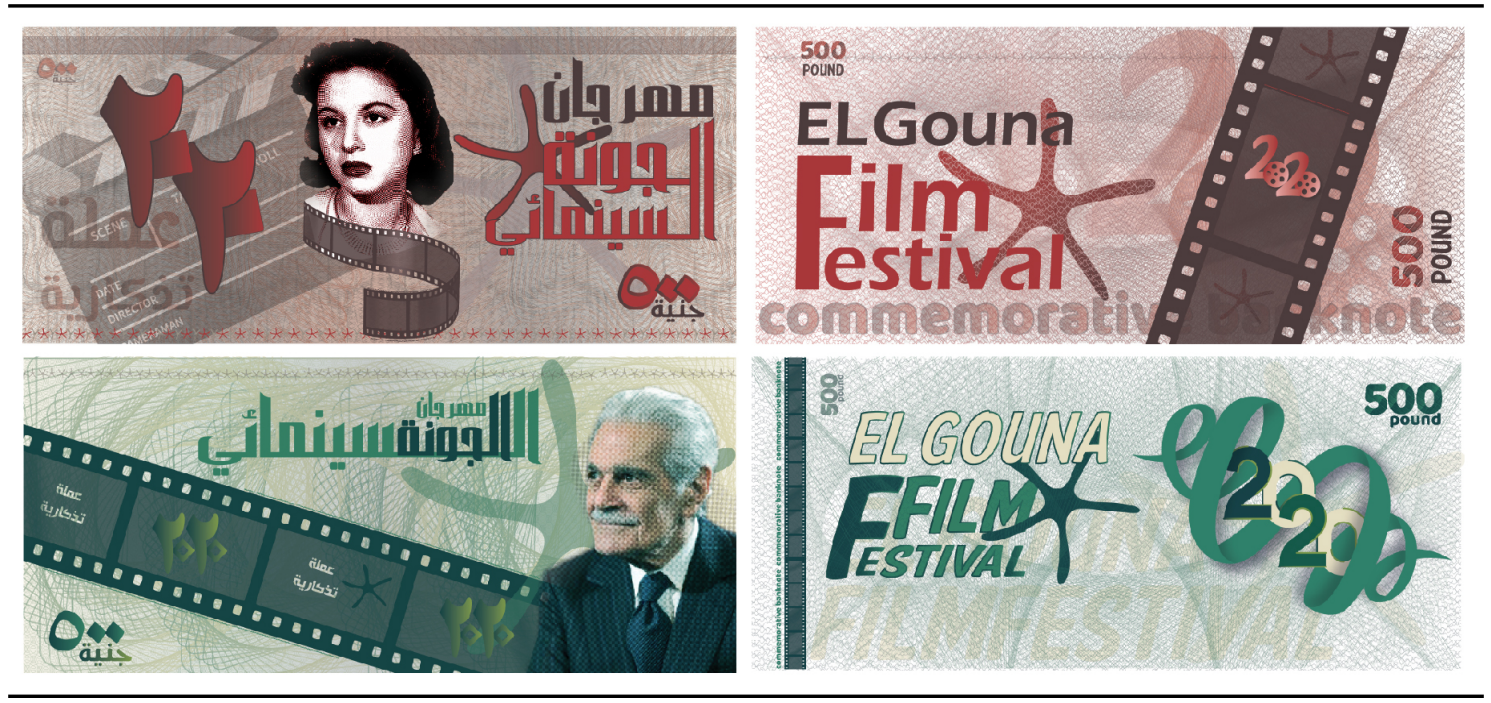

Figure 4: Two examples of El Gouna Film Festival banknotes of the Trial commemorative banknotes 


\section{2 commemorative banknote to support HealthCare workers around the world}

Our healthcare workers are on the frontlines of battling the novel coronavirus disease (COVID-19) that's spreading rapidly throughout our city, state and nation. They are putting themselves in the path of this virus. For this reason, a global commemorative banknote was designed by author to express our appreciation and gratitude for these heroes, shown in Figure 5.

The global commemorative banknote depict symbol of the medical team to support HealthCare workers around the world. Commemorative banknote which expressed of thanks from everyone around the world for our healthcare workers for the sacrifices you make, every day and especially during coronavirus (COVID-19) that's spreading rapidly throughout our world. Your dedication, commitment and courage deserve our deepest gratitude and admiration.
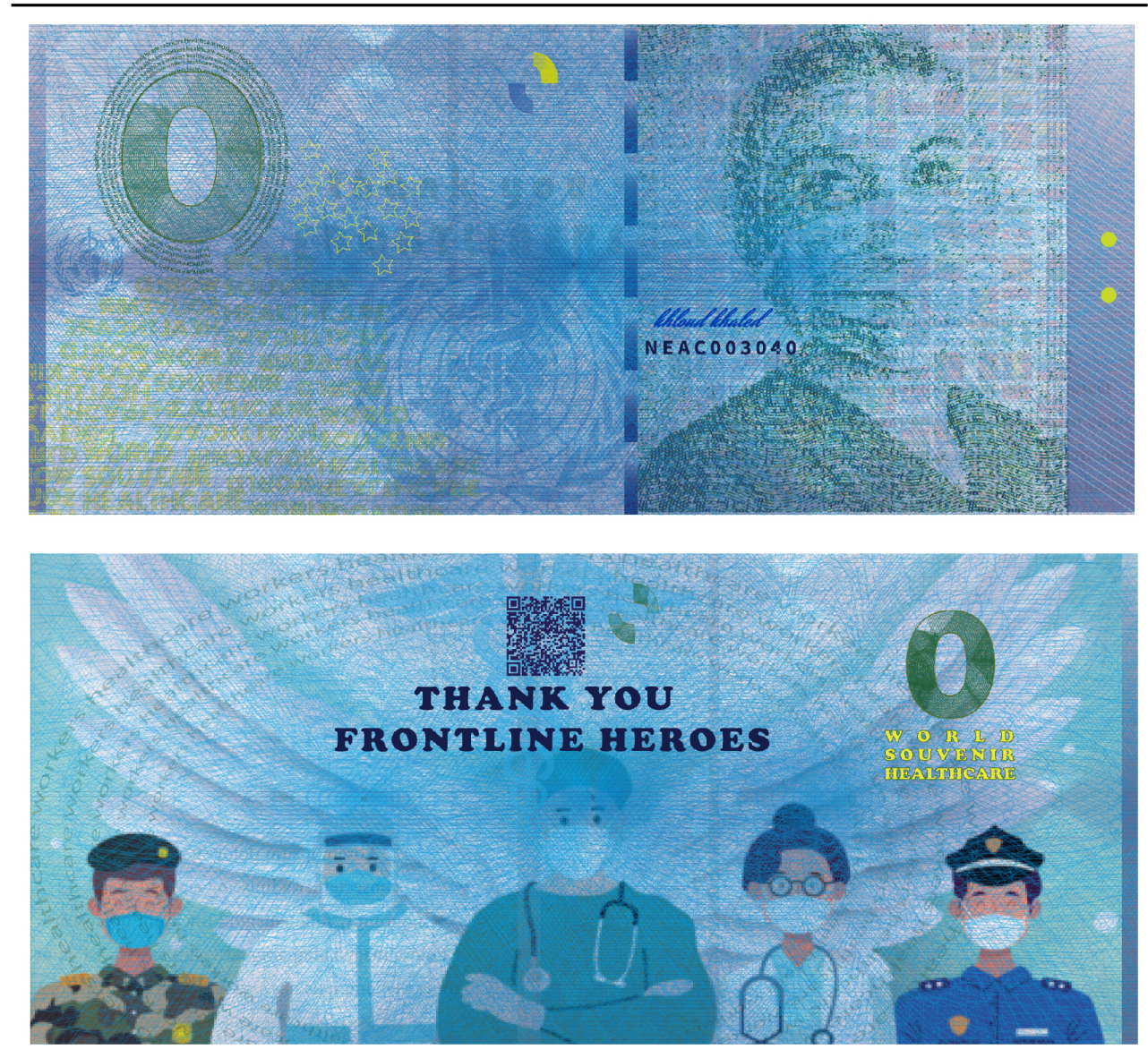

Figure 5: Example of front and reverse banknote to support HealthCare workers around the world

Features to look for on the international trial Commemorative Banknote Find below the basic look, Feel and tilt security features for easy identification follow these simple steps to make sure your banknotes are genuine. Remember, do not rely on just one feature, and check a few.

1. Check the paper and the raised embossed print: By running your fingers across the front of the new note, you will feel the raised prints in areas such as "Thank you", the image of the medical team 0 world numeral on the top left corner.

2. Check the Motion thread: This security thread is embedded on the banknote.

3. Check the water mark: Hold the note up to the light with the front of the note facing you.

4. Check the Optical Variable Magnetic Ink (OVMI Spark): A rolling bar that changes colour when tilted. This feature placed at the front of the banknote.

5. Check the QR (Quick Response) Code: that tells the Expressions of thanks to the medical team when scanned with an internet enabled mobile device or an IPad. It is located at the back of the note.

6. Check the Serial Number: consisting of letters and numbers printed on the front side of the new note.

7. Check the See through feature: located on the front of the note.

8. Tactile marks for the visually impaired: raised dots on the right corner on the front of the banknotes. 


\section{DISCUSSION}

Creating and producing a new commemorative banknote is a highly skilled and specialist challenge, and one that works best with engagement that comes from a close partnership throughout the design journey. This approach certainly paid off helping to create a positive feedback from focused group discussion, as well as experts who interested with banknote design.

\section{CONCLUSION}

Nowadays people avoid cash because other payment methods fulfil their user requirements better. Therefore, approach of a commemorative banknote design should be based on find new ways to used it and preserved on its identity. Using Commemorative banknote design to reflect the image of societal events, for example, (Alexandria International Film Festival and El Gouna Film Festival) banknote design play a crucial role in marketing and its usage as a unified expression language in common global events to its role in moral support.

Such commemorative banknotes have the perfect legal tender status, and can be used to make purchases. However, there are other uses too. Such commemorative banknotes are printed in limited quantities, so they also attain collectible value and may be sold at higher values.

It is recommended to produce commemorative banknotes by using sophisticated printing, using technology and a number of high-tech security and unique features which incorporate into them.

\section{ACKNOWLEDGMENTS}

I would thank the people who interested in collecting commemorative banknotes for their precious help and their opinions.

\section{REFERENCES}

[1] Currency News: "Physical to Digital: a Revolution in Document Security", URL: https://www.oberthur-fiduciaire.com/wp-content/uploads/2020/04/CN-v18-n3-March-2020Eng-web.pdf (last request: 2020-09-04).

[2] De Heij, H.: "Banknote design for retailers and public", De Nederlandsche Bank NV 8 (4), 110, 2010, URL: https://www.researchgate.net/publication/237137935 (last request: 202-08-05).

[3] De Heij, H.: "The Pyramid-Model. A framework for user requirements for any payment instrument", De Nederlandsche Bank NV, 2018.

URL: https://www.researchgate.net/publication/329210083_The_Pyramid-

Model_A_framework_for_user_requirements_for_any_payment_instrument (last request: 202-08-05).

[4] ElGouna film festival: "About El Gouna Film Festival”, URL: http://elgounafilmfestival.com/about-elgouna (last request: 2020-08-22).

[5] Jonathan, G.: "Features To Look For On The New N100 Commemorative Centenary Banknote", URL: https://www.cbn.gov.ng/out/2015/ccd/ccd-cod\%20_commemorative\%20banknote_.pdf (last request: 2020-08-23).

[6] Kamil, N.: "Alexandria International Film Festival”, URL: http://en.wataninet.com/culture/festivals/alexandria-international-film-festival/5108/ (last request: 2020-08-10).

[7] Members of the International Bank Note Society: "The IBNS Introduction to Banknotes\& Banknote collecting", URL: https://www.theibns.org/intro-to-banknotes/Introduction-To-Banknotes-AndBanknote-Collecting.pdf (last request: 2020-09-04).

[8] National Bank of Ukraine: "Commemorative and Bullion Coins", URL: https://bank.gov.ua/en/uah/investment-coins (last request: 2020-08-22).

[9] Payne, J.: "The Art of Designing a Banknote", URL: https://www.delarue.com/media-center/the-artof-designing-a-banknote (last request: 2002-08-08).

[10] Sapre, M.: "What is meant by a commemorative coin? Is it useful in the market?", URL: https://www.quora.com/What-is-meant-by-a-commemorative-coin-Is-it-useful-in-the-market (last request: 2020-08-02). 


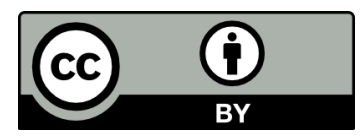

(C) 2020 Authors. Published by the University of Novi Sad, Faculty of Technical Sciences, Department of Graphic Engineering and Design. This article is an open access article distributed under the terms and conditions of the Creative Commons Attribution license 3.0 Serbia (http://creativecommons.org/licenses/by/3.0/rs/). 



\title{
DESIGNING PARTERRES ON THE MAIN CITY SQUARES
}

\author{
Milena Lakićević (D), Ivona Simić (iD), Radenka Kolarov \\ University of Novi Sad, Faculty of Agriculture, Horticulture and Landscape Architecture, \\ Novi Sad, Serbia
}

\begin{abstract}
A "parterre" is a word originating from the French, with the meaning interpreted as "on the ground". Nowadays, this term is widely used in landscape architecture terminology and depicts a groundlevel space covered by ornamental plant material. The designing parterres are generally limited to the central city zones and entrances to the valuable architectonic objects, such as government buildings, courts, museums, castles, villas, etc. There are several main types of parterres set up in France, during the period of baroque, and the most famous one is the parterre type "broderie" with the most advanced styling pattern. Nowadays, French baroque parterres are adapted and communicate with contemporary landscape design styles, but some traits and characteristics of originals are still easily recognizable. In this paper, apart from presenting a short overview of designing parterres in general, the main focus is based on designing a new parterre on the main city square in the city of Bijeljina in the Republic of Srpska. The design concept relies on principles known in the history of landscape art but is, at the same time, adjusted to local conditions and space purposes. The paper presents the current design of the selected zone parterre on the main city square in Bijeljina and proposes a new design strongly influenced by the "broderie" type of parterre. For creating a new design proposal we have used the following software AutoCad (for 2D drawings) and Realtime Landscaping Architect (for more advanced presentations and 3D previews). The paper provides detailed graphical representations for a new design proposal and explains the main design ideas and guidelines which can be applied even when designing parterres in the other urban space. Besides that, the paper lists the plant material that is suitable for establishing and maintaining parterres in the urban environment.
\end{abstract}

Key words: urban design, exterior design, Bijeljina, Republic of Srpska

\section{INTRODUCTION}

The modern design of urban areas includes green infrastructure and as an important and integral part of urban landscapes, and choosing appropriate design for different public and open spaces is crucial for the visual qualities of modern cities. When defining main ideas and guidelines for an urban open space design one can rely on the heritage of previous epochs (Lakićević and Kordić, 2018). When choosing a certain epoch as a starting point for the design process, it is essential to update the old patterns and to communicate with the present styles and design concepts. There are two main styles in landscape architecture: geometric and landscape style (Kolarov et al, 2020). Geometric style uses strict geometric forms, while landscape style is characterized by irregular lines and shapes. The geometric style is used on the small city squares and at the entrances to the important architectural objects, and landscape style is applied over large areas and suburban zones.

Geometric style reached its peak in the period of baroque in France, and the most famous examples are Versailles Park and Park of Vaux-le-Vicomte, both designed by André le Nôtre in the $17^{\text {th }}$ century. After the baroque epoch, the geometric style reduced many elements, retaining in most cases only symmetry and perspective principles (Motloch, 2001). However, French gardens are a valuable cultural heritage and carry within important constructive lessons. French baroque gardens are famous for their parterres, and there were several types of parterres in this period. The French word "parterre" literary means "on the ground", as this is a ground-level space covered with plant material. Depending on the type of plant material, we recognize English parterre (consisted of lawns predominately), water parterre (with fountains, water cascades, etc.), shaped parterre (with topiary forms, inspired by the Italian renaissance period), etc. The most complex type of French parterre is the one called "broderie", well-known for highly ornamental and colourful appearance (Lohmann, 1963). This type of parterre in some modified form can be seen in many cities worldwide. Usually, they are situated in front of the monumental architectural objects. In this paper, we present the use of French parterre in the contemporary landscape design on the example of the main square in the city of Bijeljina in the Republic of Srpska. 


\section{METHODS}

The chosen location is the Square King Peter I Karadjordjevic, in Bijeljina, in the Republic of Srpska (Figure 1). The goal of the paper is to propose a new design for this square, inspired by the French baroque style. The selected area is located in front of the building of the City Administration of the Municipality of Bijeljina in the city downtown area. The square has an elongated-semicircular shape and covers the area of $3,088 \mathrm{~m}^{2}$. Next to the square, there are many important objects: the Museum of Semberija, the National Library "Filip Visnjic", the building of the Court in Bijeljina, the Culture Centre, and the City Park. The main accent on this square is the monument of the King Peter I Karadjordjevic. The analyzed space is one of the main landmarks of the city, and therefore it is important to provide an adequate design for it.

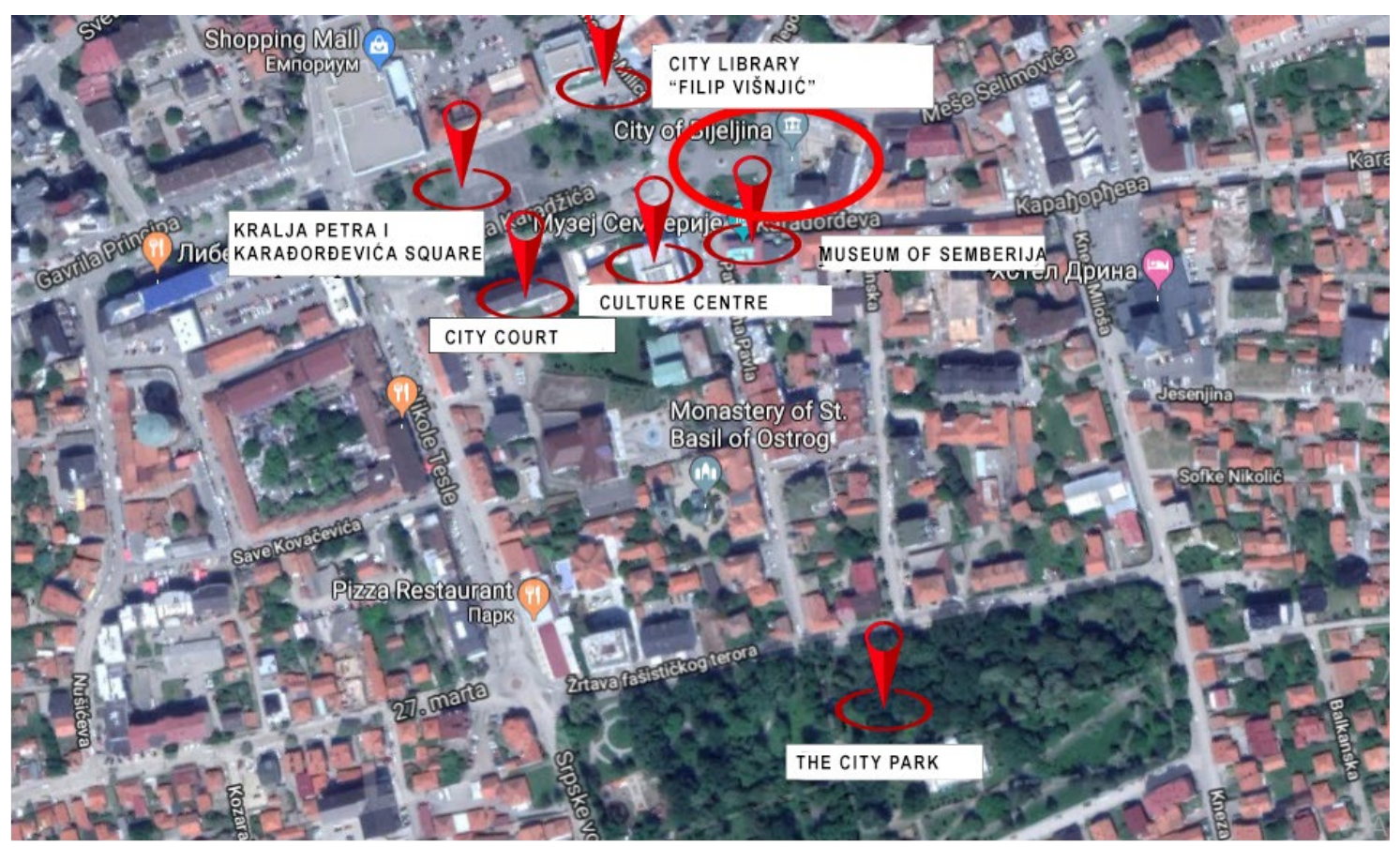

Figure 1: Location of the selected area

The square is symmetrically arranged with two grass- flower parterres that are located on both sides of the statue. There are also three circular fountains on the semicircular front of the plateau that emerge from variously designed sculptures (Figure 2). Along the edge of the parterre, there are benches on both sides and a row of medium-high trees with a decorative umbrella canopy. The plant material on this plateau consists, in addition to seasonal flower species, of lawn and trees of Acer platanoides 'Globosum'. In summer trees provide nice and cozy shade for people to sit there and rest, while in wintertime when branches are bare, they are decorated with New Year's lightning which affects and amplifies the holiday spirit in town. This public place provides multiple functions; it is used for different kinds of manifestations during the year, public gatherings, public speeches; people use it for short rest during the day, while in summer nights it becomes a popular spot to gather and hang out.

The newly proposed design follows the principles of "broderie" parterre, it combines plant material with so-called inorganic component (stones, bricks, sand, etc.) with the purpose of creating a visually appealing styling pattern. The idea is to create a high contrast between the background consisted of inorganic material and the plant components of the parterre. This way, the plant material is additionally emphasized and more effective in visual quality terms. The styling pattern of the "broderie" parterre may vary in a wide range, but in this example, we provided a design that is not so complex, and that can be easily and regularly maintained. The appearance of the new design proposal is illustrated in the Results section, Figures 3-5, and these figures should provide a clear overview of the designer's idea. The project idea is designed by the second author of this paper. 


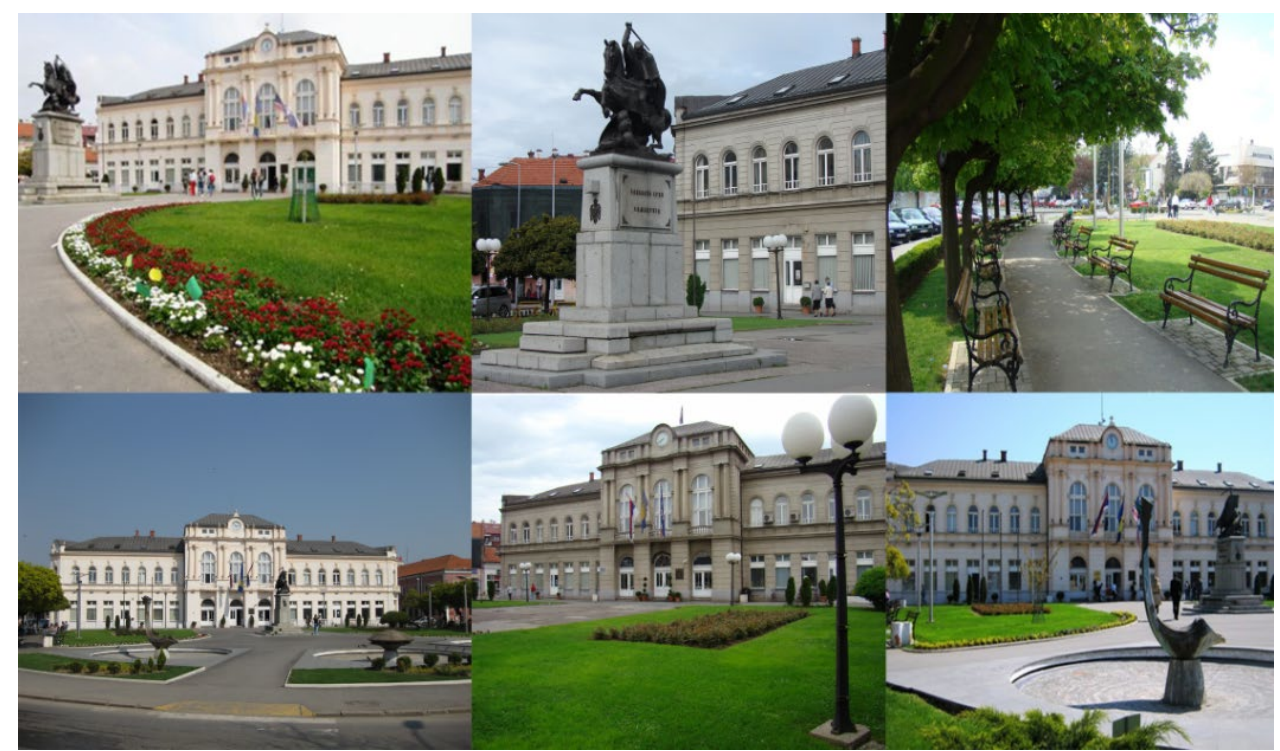

Figure 2: Photographies of the selected area

To visualize the new design solution, two software were used: AutoCAD 2017 for 2D presentations and drawings, and Realtime Landscaping Architect 2018 for creating 3D renderings.

\section{RESULTS AND DISCUSSION}

French Baroque style was a symbol of fame, power, and wealth in the $17^{\text {th }}$ century, therefore in order to fit in modern landscape design, it had to go along and follow the important object in town, such as the building of City Administration is. The structure of the building is representative, therefore it requires matching landscape design in front of it. In the newly designed project, the main focus has been kept on the statue of Peter I Karađorđević.

The Square is divided into twelve parterres that are different in shapes and sizes. There are four main parterres symmetrically arranged around the center motive of the square. Each of them is bordered with boxwood (Buxus sempervirens) and inside of them are striped alleys of flowers that are also framed with a boxwood border and together form a certain motive. In the area around the monument and the central parterres, it is planned to be a sitting area with few benches placed that people can use for longer or shorter rest. (Figure 3a; 3b).

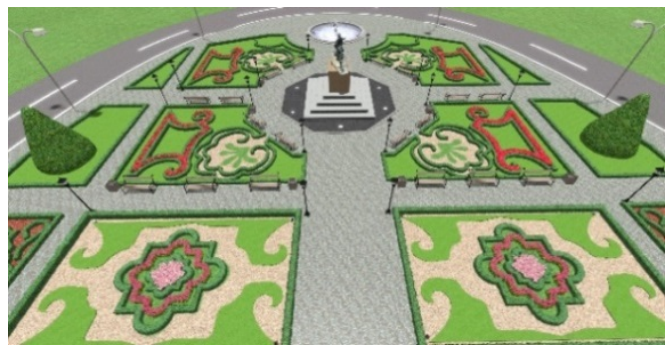

a)

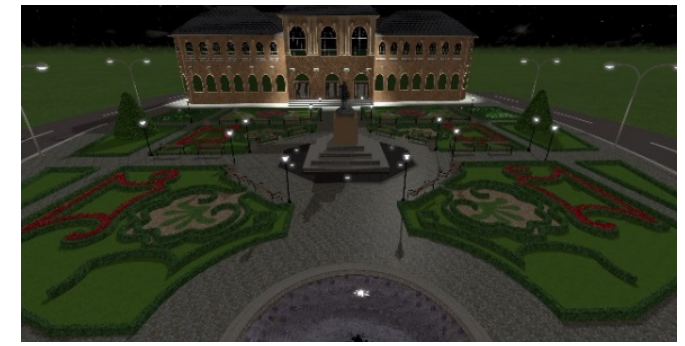

b)

Figure 3: a) View on the parterre in front of the building of the City Administration b) View on the parterre in front of the building of the City Administration at night

To the west, instead of three existing circular fountains, in new design is projected only one circular form of fountain with a bell-shaped overfall. The fountain gives a special effect, both visual and sound. Whole space can be seen from every point of the square; there are no visual obstacles in the form of tall bushes or trees. The forms of the ground floor are based on geometric principles, as the French Baroque style dictates. In front of the City Administration building, there are four "broderie" parterres. The side floors are bordered with boxwood and in the middle, there are also boxwood decorative 
shapes. There are no flowers in them, but we have a base sprinkled with reddish and bright mulch, which together with the boxwood motives give a special decorative effect and a contrast (Figure 4a).

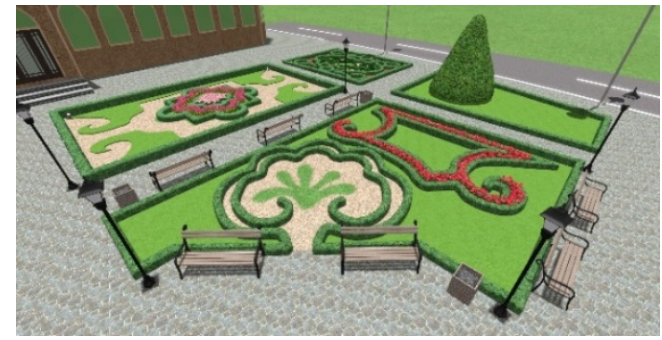

a)

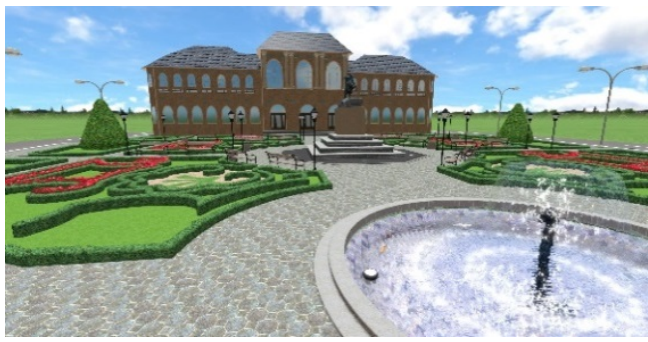

b)

Figure 4: a) Detail of embroidery parterre b) Detail of fountain

All parterres with their different shapes and sizes follow the semicircular form of the plateau and together with the fountain they round off the entire newly designed shape and create a synthesis between a strict geometric form, straight lines, and a rounded surface of the square.

In most parterres, the main element consists of the species of meadow, and therefore the lawns are based on the following ratio of grasses: - 50\% English lily (Lolium perenne) - 25\% meadow wig (Festuca pratensis) - 25\% red wig (Festuca rubra). Topiary forms of Thuja gigantea were used as accents on the side floors. Seasonal flowers are changed in the flower parterres and thus the possibility of planting different flower species during the year is given. An overview of all "broderie" parters is illustrated in Figure 5.

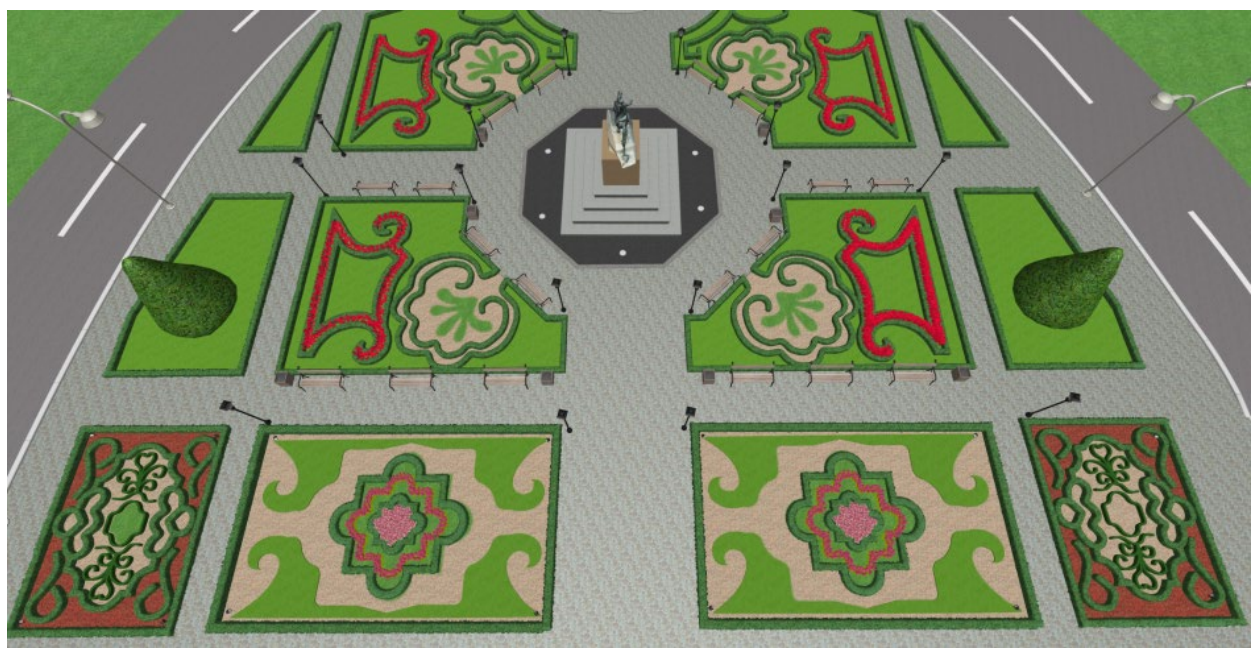

Figure 5: "Broderie" parterres

\section{CONCLUSION}

Nowadays, parterres inspired by French baroque are widely used within private gardens, but also in public areas. Generally, they are made of borders of boxwood, lavender, or rosemary the most. The low clipped hedges are laid out in a symmetrical pattern, these can be quite intricate or as simple as four squares next to each other with a gravel path separating them. Water is often a key feature of French garden design and lots of round pools and long rectangles of water will be incorporated, the reflection of the water adding to the symmetry and tranquility of the scene. Fountains and cascades are also very common features and widely used in modern design. Projects like the one we have presented through this research paper is an example of the application of the French Baroque landscape style in the modern age. Elements such as harmony, symmetry, "broderie" parterres, and water features are some of the key elements that we can recognize in many nowadays projects, that are inspired by French gardens from the $17^{\text {th }}$ and $18^{\text {th }}$ centuries. 


\section{REFERENCES}

[1] Kolarov, R., Lakićević, M., Gawryszewska, B.: "Design styles in landscape architecture", Proceedings of moNGeometrija 2020, (moNGeometrija, Serbia, 2020), pages: 1-9.

[2] Lakićević, M., Kordić, D.: "Geometric style in design of urban landscapes", Proceedings of $9^{\text {th }}$ International Symposium on Graphic Engineering and Design 2018, (GRID: Novi Sad, Serbia, 2018), pages 519-523.

[3] Lohmann, K.B.: "Fundamentals of Landscape Architecture", (International Correspondence Schools, Scranton, Pennsylvania, USA, 1963.).

[4] Motloch, J.L.: "Introductiontolandscapedesign", (Willey, Austin TX, 2001.), pages 134-146.

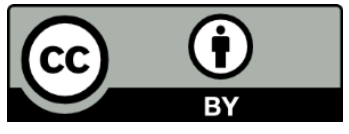

(C) 2020 Authors. Published by the University of Novi Sad, Faculty of Technical Sciences, Department of Graphic Engineering and Design. This article is an open access article distributed under the terms and conditions of the Creative Commons Attribution license 3.0 Serbia (http://creativecommons.org/licenses/by/3.0/rs/). 



\title{
JEWELLERY DESIGN AND WEARABLE APPLICATIONS: A DESIGN THINKING APPROACH
}

\author{
Athanasios Manavis $^{1}$ (D), loanna Nazlidou ${ }^{1}$ (D), Tatjana Spahiu $^{2}$ (D), Panagiotis Kyratsis ${ }^{1}$ (D) \\ ${ }^{1}$ University of Western Macedonia, Department of Product and Systems Design Engineering, \\ Kila Kozani, Greece \\ ${ }^{2}$ Polytechnic University of Tirana, Department of Textile and Fashion, Tirana, Albania
}

\begin{abstract}
The present paper examines the application of a holistic product design approach from the Design Thinking point of view. The Design Thinking process follows a number of steps with an aim to develop product design visual concepts around users' experiences and their needs. The presented case study is focused to the modern jewellery design era. The proposed design was developed by using a series of design thinking methodologies (empathy maps, persona, product design) and creative tools (mind-maps, moodboards, sketches, storyboards, and prototyping). Furthermore, through this holistic design approach an alternative version of future jewelries is achieved, while at the same time it embodies novel technologies and web-based applications. The paper discusses the potentials for reimagining the jewellery products in relation to the Design Thinking Process and CAD-based tools at the same time. Finally, the proposed products provide a novel framework of art and new technology methods for extensive production of innovative art-based products.
\end{abstract}

Key words: wearable design, Jewellery design, Computer Aided Design, design thinking tools

\section{INTRODUCTION}

Jewelleries are widely recognised as aesthetic and appealing objects that are used for personal adornment responding to customers desires. Usually wearable applications are meaningful, sophisticated iconic pieces that share a special connection with the ending users (Wilde and Marti, 2018). Based on designers' point of view, jewellery design has always been a great and interesting field for geometry form experimentation. Additionally, as technology grows rapidly there is a need for different theoretical aspects to inform new conceptual approaches in the modern jewellery design era. In that direction there is a growing challenge for all designers to consider the role and expanding capabilities of technology for innovative design in the future (Corti, 2003). An opportunity lies in the prospect to re-examine terms like wearable design, digital jewellery, interactive materiality, and embodied technologies. The term of wearability itself, implies an interaction between the human body and the object. Furthermore, the valuable aspect of any wearable products is the sensory interaction (Gemperle et al, 1998). The proposed methodology that includes design thinking, creativity and CAD based tools offers a great number of opportunities for product design development through new perspectives that could stimulate and provoke emotional responses from ending users. Certainly, the proposed research tries to conceptualize the way human experience is integrated into the design process.

\section{LITERATURE SURVEY}

Design Thinking is a non-linear iterative activity that is implicit in the process of design, involving five distinguish phases: empathize, define, ideate, prototype and test (Brondy and Kazmierczak, 2017). Design Thinking is a creative methodology used to understand users, redefine problems and create innovative solutions. Furthermore, design thinking process involves the ability to synthesize knowledge from variety of sources - an ideal tool in a holistic product design approach.

Conceptual Product Design is perceived mainly as an art than an actual science. According to Kyratsis et al., the core of Conceptual Product Design methodology is based on the design thinking principles (Kyratsis et al, 2019). The creativity process followed by a number of product designers incorporates several sessions of creative processes similar to design thinking tools (i.e. mind map, mood board, sketching, storyboard, and prototyping) with an aim to find alternative ideas for each product (Malea et al, 2020). Mind map is a graphical representation of words and phrases that are placed hierarchically based on associative logic (Buisine et al, 2007). Mood boards mostly recognised as an artistic and abstract way for expressing intangible emotions and situations through stimulating image collages (McDonagh et al, 2002). 
Furthermore, mood boards can be used by designers to communicate their vision beyond linguistic restrictions (Lucero, 2012). As well, a storyboard is used as a visual scrip of sequencing images and graphics to depict the functional aspects of the final product and the interaction with the user (Van der Lelie et al, 2006). Moreover, storyboards support product designers in getting a grip on context and time by forcing them to attend to diverse aspects, integrate these aspects and confront the implications that could be postponed with abstract considerations (Van der Lelie et al, 2006). Sketching and prototyping are flexible tools used in the early stages of the design process that allows to explore in depth a large quantity of different concepts (Qifang et al, 2018). Certainly, the act of prototyping helps designers to better understand physical characteristics of the product like form, function, and construction (Isa et al, 2015).

In holistic product design development field CAD software is a powerful tool to generate information to create three-dimensional products within a digital framework process sequence. Although the main purpose is suitability to manufacture, it is also appropriable to visualization purposes: it allows the designer to anticipate products' final look (Barros et al, 2010).

Traditional jewellery design is an art with a history of thousands of years. Only recently, the tools have changed. One way to realize a meta design today is as an executable computer program (Schinko et al, 2012). Nowadays, the boundaries of jewellery design have been continually redefined. New technologies, innovative design concepts and modern materials have overturned the notions of status traditionally implicit in jewellery (Tzintzi et al, 2017).

\section{PROPOSED METHODOLOGY}

The research presents a design case study from the holistic product development point of view. The proposed case study presents a design of a future wearable application with jewellery characteristics. The creation of the suggested application was developed by following the steps of the Design Thinking methodology based on Creativity and CAD-based tools. Furthermore, the designers examined the procedure by using information from ending users' experiences and their needs.

\begin{tabular}{|c|c|c|}
\hline \multicolumn{3}{|c|}{ The proposed design methodology } \\
\hline \multicolumn{3}{|c|}{ Stage 01 - Design Thinking tools } \\
\hline \multirow{3}{*}{$V$} & Empathy Map & Target audience \\
\hline & Persona & Fictional character \\
\hline & Product Canvas & Product details \\
\hline \multicolumn{3}{|c|}{ Stage 02 - Creativity tools } \\
\hline \multirow{4}{*}{$V$} & Mind Map & Idea exploration \\
\hline & Mood Board & Idea visualization \\
\hline & Sketching & Concept representation \\
\hline & Story Board & Concept evaluation \\
\hline 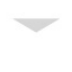 & Prototyping & User experience \\
\hline \multicolumn{3}{|c|}{ Stage 03 - CAD based tools } \\
\hline \multirow{3}{*}{$V$} & Computer-aided design modelling & Technical design approach \\
\hline & Rendering synthesis & Aesthetic design approach \\
\hline & Product visualization & Holistic design approach \\
\hline
\end{tabular}

Figure 1: The proposed design methodology

The proposed design methodology involves three crucial stages (Figure 1). First stage is a Design Thinking toolkit that it focuses to user's examination. The exploration of user's profile needs, and aspirations have become a significant part in the design thinking process. The basic tools that were used by designers are empathy maps, persona creation and product canvas. Specifically, empathy map refers to actual persons and works as a guide tool for a more descriptive analysis of the persona's mindset and needs (Ferreira et 
al, 2015). Unlike, empathy map, person creation tool do not refer to an actual user or customer, but it describes a mentality and behaviour that help designers to develop an intimate and internalized understanding of the product's audience (Guo et al, 2011). Product canvas is an organised visual chart of the most significant aspects of the product in relation to the target group needs (Pichler, 2013).

At the second stage, designers use a great number of creativity tools (i.e. mind map, mood board, sketching, storyboard, and prototype) to explore and visualize the final concept of product. All inspiration tools were used as creative techniques in order to explore the range of different ideas and concepts.

Certainly, third stage involves Computer-aided Design tools and methodologies upon to creation of final design for proposed product. The proposed product designed from technical and aesthetic design approach (CAD-based modelling, rendering synthesis and product visualization). Computer aided design is proved to be a key factor in exploring and representing much more complex forms and a helpful way for designers to better communicate their ideas.

The methodology that it is described, offers a great number of advantages to product development due to the holistic approach that involves the ending user and his needs. Finally, the suggested products provide a novel framework of art and new technology methods for extensive production of innovative art-based products.

\section{CASE STUDY - WEARABLE APPLICATION}

The first step of this research was an attempt on an in-depth knowledge of potential user's profiles. Through the empathy map tool, a research has been conducted by interviewing three different types of women. Figure 2 shows an organized template that it was created for this purpose. Empathy map questionnaires were included general guiding questions about women's feelings, thoughts, fears, concerns, behaviours, goals and hopes, in order to discover possible fields in design space for new products. The persona that came up from the combination of empathy maps refers to a woman (Zoe). Zoe is about forty years old, married with two children. Furthermore, the fictional persona of Zoe is described as an active and creative person, with an intense daily life with many obligations. Zoe enjoys travelling and contact with nature, but she feels anxious because the lack of time she does not manage to do the things she wants. In the followed product canvas board, were firstly recorded some basic characteristics of a potential product that emerged from this stage. The product canvas included requirements about the product's main goal, and its special features (i.e. time sensor, wearable gadget ad jewellery).

\begin{tabular}{|c|c|c|}
\hline \multicolumn{3}{|c|}{ Design Thinking Tools } \\
\hline \multicolumn{3}{|c|}{ Empathy Map } \\
\hline \multicolumn{2}{|c|}{ Potential user's profiles } & Questions about \\
\hline \multicolumn{2}{|c|}{ Potential user 1} & \multirow{3}{*}{$\begin{array}{c}\text { Feelings - Thoughts } \\
\text { Fears - Concerns } \\
\text { Behaviours - Goals } \\
\text { Hopes }\end{array}$} \\
\hline \multicolumn{2}{|c|}{ Potential user 2} & \\
\hline \multicolumn{2}{|c|}{ Potential user 3} & \\
\hline \multicolumn{3}{|c|}{ Persona } \\
\hline \multicolumn{2}{|c|}{ Persona ID } & Personality characteristics \\
\hline & $\begin{array}{l}\text { Zoe } \\
40 \text { years old } \\
\text { Married } \\
\text { Two children }\end{array}$ & $\begin{array}{l}\text { Active and creative } \\
\text { Intense daily life } \\
\text { Enjoy travelling } \\
\text { Contact with nature }\end{array}$ \\
\hline \multicolumn{3}{|c|}{ Product Canvas } \\
\hline \multicolumn{2}{|c|}{ Product ID } & Product characteristics \\
\hline & $\begin{array}{l}\text { Time Sensor } \\
\text { Wearable gadget } \\
\text { Jewellery }\end{array}$ & $\begin{array}{l}\text { Nature based morphology } \\
\text { Hi-tech and smart material } \\
\text { Smooth surface texture } \\
\text { User's sense of time interaction }\end{array}$ \\
\hline
\end{tabular}

Figure 2: Design Thinking tools for jewellery design and wearable application 


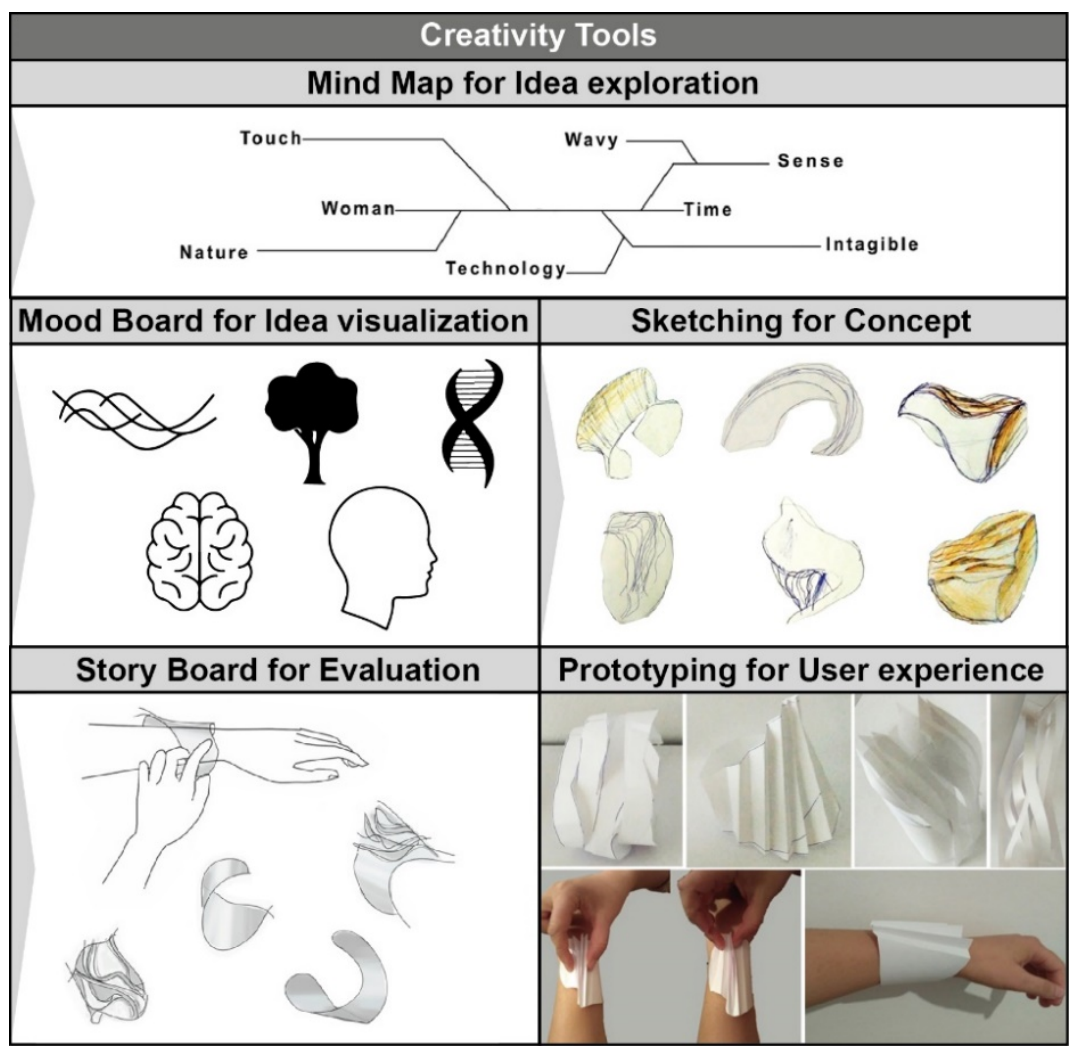

Figure 3: Creativity tools for jewellery design and wearable applications

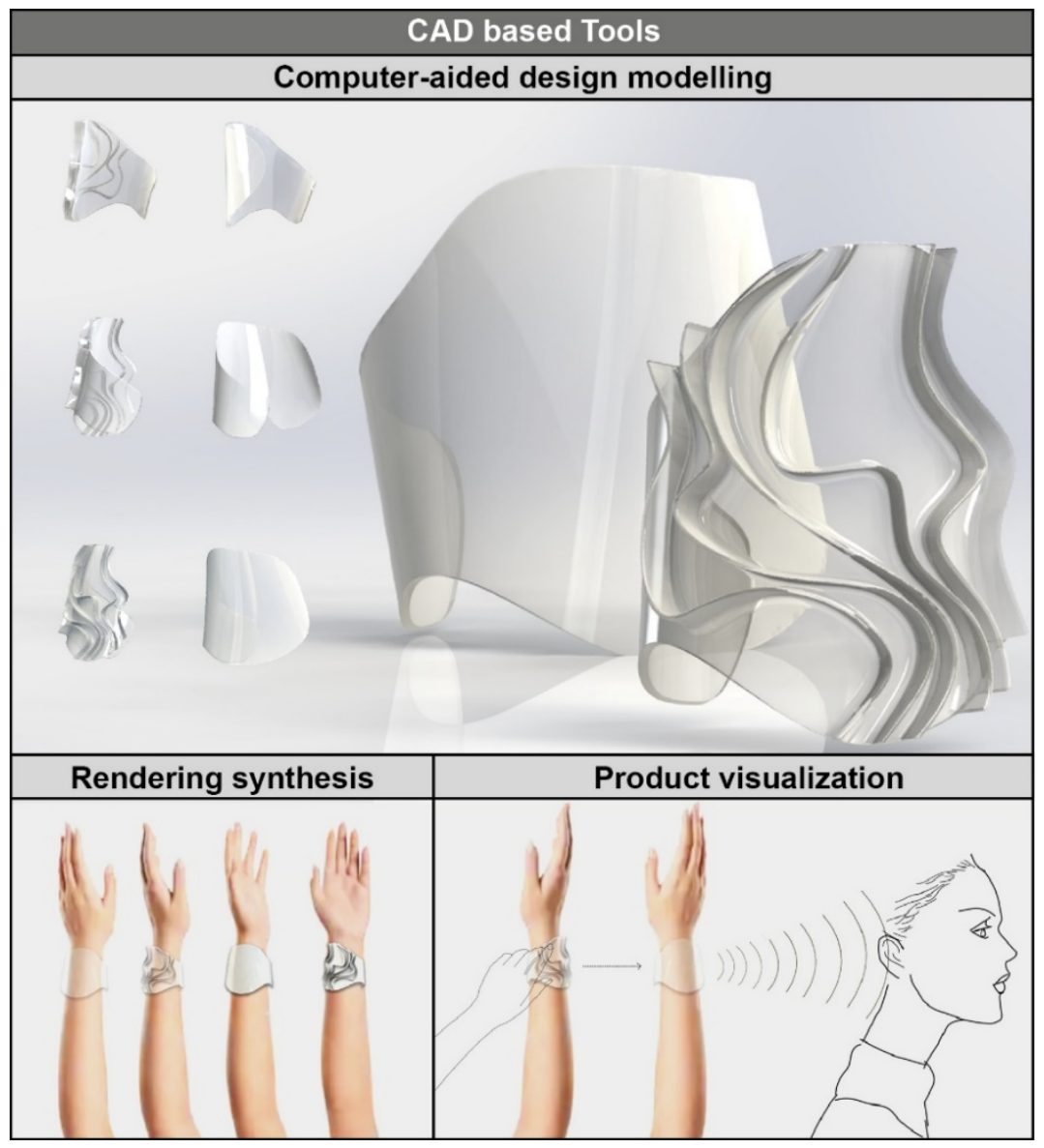

Figure 4: CAD based tools for jewellery design and wearable applications 
Second stage involves a further development of the graphical design procedure through creativity tools. Figure 3 shows the illustrative results from idea exploration tool (mind map), idea visualization tool (mood board), concept representation tool (mood board), concept evaluation tool (story board) and user experience tool (prototyping). Mind map keywords describe the main targets of the design direction, i.e. woman, time, nature, sense, and technology. Mood board visualise the keywords from mind map tool, i.e. shapes from nature and human geometries. The next step of this study is the investigation of the morphological features of the object under design. Based on the design requirements that are included in product canvas. Conceptual sketching stage illustrates the exploration of different structural concepts and the inspiration drawn by nature. Storyboard and prototyping stages include primitive prototypes of wearable application. Prototypes are made by cardboard. Figure 4 shows the final rendered versions of CAD-based models of time sensor. The final product that emerged from the Design thinking process was developed around the idea of the user interacting with time. It is an alternative version of wearable jewellery with embodied special web-based technologies, that works as a time sensor device. When the human wears the product will have the feeling through the touch that he can affect the way time passes and this could act as an anxiolytic factor in an intense daily life. The morphology of the object imitates free organic forms, enhancing a relation with nature and not giving the feeling of a latest technological device. The created product finally responds to a futuristic design logic that affects user's sense of time (Figure 5).

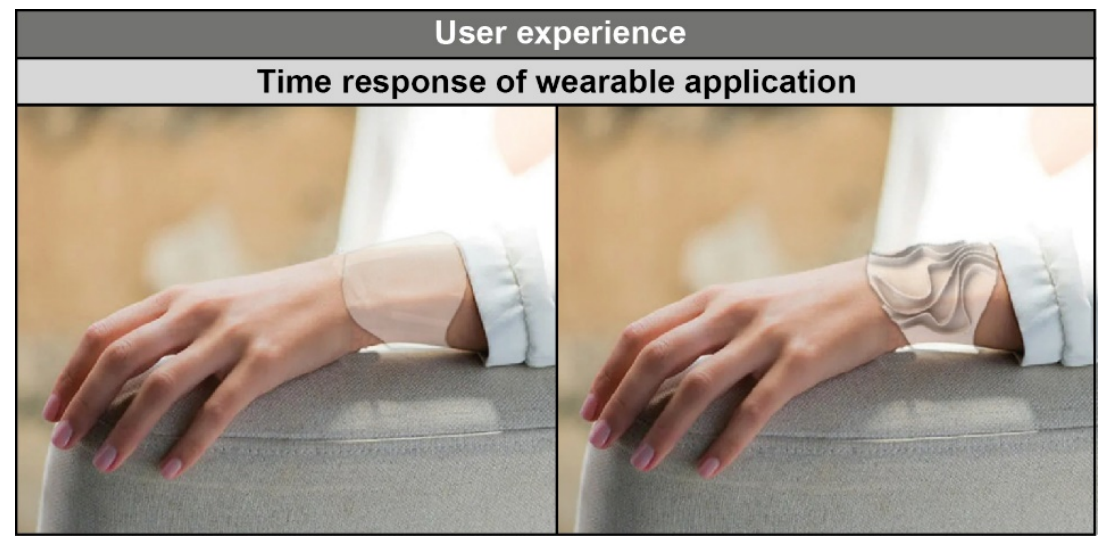

Figure 5: Time sensor based on futuristic design concept

\section{CONCLUSIONS}

The present paper examines the Design Thinking process in an attempt to reconsider a piece of jewellery not only as a luxurious accessory but as an innovative product that was created based on user's deepest needs and expectations. The research examines the aspect of wearability as an interactive relationship between the human body and the designed product. The main core of the concept was to redefine the user's relationship with time. The proposed methodology that includes design thinking, creativity and CAD based tools could offer a series of great design and marketing advantages to designers that would be willing this design procedure. Furthermore, the presented design approach based on design thinking principles, incorporate not only innovative creative design, but the creation of novel futuristic wearable applications. Certainly, the proposed design development approach tries to conceptualize the way human experience is integrated into the design process.

\section{REFERENCES}

[1] Barros, M.: "The Role of Different CAD Applications in Product Design Teaching", Proceedings of $5^{\text {th }}$ International Conference on Digital Arts - Artech 2010, (Minho University, Braga, Portugal, 2010), pages 197-200.

[2] Brondy, J., Kazmierczak, J.: "The design thinking method and its stages", Wspomagaania W Inzynierii Produkcji, 6, 247-255, 2017. 
[3] Buisine, S., Besacier, G., Najm, M., Aoussat, A., Vernier, F.: “Computer-Supported Creativity: Evaluation of a Tabletop Mind-Map Application", Proceedings of Engineering Psychology and Cognitive Ergonomics, $7^{\text {th }}$ International Conference EPCE 2007, (Springer, Berlin, Heidelberg, 2007), pages 22-31.

[4] Corti, C.W.: "Technology is irrelevant to Jewellery Design-or is it?", Proceedings of The Santa Fe Symposium on Jewelry Manufacturing Technology 2003, pages 15-28.

[5] Ferreira, B., Silva, W., Oliveira, E., Conte, T.: "Designing Personas with Empathy Map", Proceedings of The $27^{\text {th }}$ International Conference on Software Engineering and Knowledge Engineering, SEKE 2015, (KSI Research Inc., Pittsburgh, USA, 2015), pages 501-505.

[6] Gemperle, F., Kasabach, C., Stivoric, J., Bauer, M., Martin, R.: "Design for Wearability", Proceedings of Digest of Papers. Second International Symposium on Wearable Computers 1998, (IEEE, Pittsburgh - USA, 1998), pages 116-122.

[7] Guo, F.Y., Shamdasani, S., Randall, B.: "Creating Effective Personas for Product Design: Insights from a Case Study", Proceedings of $4^{\text {th }}$ International Conference IDGD: International Conference on Internationalization, Design and Global Development (Orlando, FL USA, 2011), pages 37-46.

[8] Isa, S.S., Liem, A., Steinert, M.: "The value of prototypes in the early design and development process", Proceedings of the ICED15 (Milan, Italy, 2015), pages 235-242.

[9] Kyratsis, P., Manavis, A., Gianniotis, P., Ghiculescu, L.D.: "A non-conventional methodology for interior product design using conceptual design principles and parametric tools", Nonconventional Technologies Review 23, 16-21, 2019.

[10] Lucero, A.: "Framing, Aligning, Paradoxing, Abstracting, and Directing: How Design Mood Boards Work", DIS 2012 (In the Wild, Newcastle, UK, 2012), pages 438-447.

[11] Malea, A., Tzotzis, A., Manavis, A., Kyratsis, P.: "Innovative and sustainable toothpaste packaging design", Journal of Graphic Engineering and Design 11, 19, 2020. doi: 10.24867/JGED-2020-2-019.

[12] McDonagh, D., Bruseberg, A., Haslam, C.: "Visual product evaluation: exploring users' emotional relationships with products", Applied Ergonomics 33, 231-240, 2002. doi: 10.1016/S00036870(02)00008-X.

[13] Pichler, R.: "The Product Canvas - A Lean Tool for Creating New products", Cambridge Product Management Network, 2013.

[14] Qifang, B., Faas, D., Yang, M.: "Interplay of sketching \& prototyping in early stage product design", International Journal of Design Creativity and Innovation 6, 146-168, 2018. doi: 10.1080/21650349.2018.1429318.

[15] Schinko, C., Berndt, R., Krispel, U., Settgast, V., Havemann, S., Eggeling, E., Fellner, W.D.: "Ring's Anatomy - Parametric Design of Wedding", Proceedings of CONTENT 2012, (Xpert Publishing Services, Wilmington, USA 2012), pages 72-78.

[16] Tzintzi, V., Manavis, A., Efkolidis, N., Dimopoulos, C., Kakoulis, K., Kyratsis, P.: "Conceptual design of jewellery: a space-based aesthetic approach", Proceedings of the $21^{\text {th }}$ Innovative Manufacturing Engineering and Energy Conference 2017, (IManEE, Romania 2017).

[17] Van der Lelie, C.: "The value of storyboards in the product design process", Personal and Ubiquitous Computing 10, 159-162, 2006. doi: 10.1007/s00779-005-0026-7.

[18] Wilde, D, Marti, P.: "Exploring Aesthetic Enhancement of Wearable Technologies for Deaf Women", Designing Interactive Systems (DIS) (Hong Kong, 2018), pages 201-213.

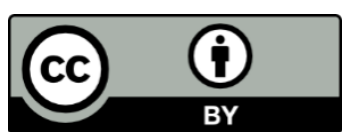

(C) 2020 Authors. Published by the University of Novi Sad, Faculty of Technical Sciences, Department of Graphic Engineering and Design. This article is an open access article distributed under the terms and conditions of the Creative Commons Attribution license 3.0 Serbia (http://creativecommons.org/licenses/by/3.0/rs/). 


\title{
DESIGN SOLUTIONS OVERVIEW OF UNIVERSAL MOTOR GEAR DRIVES WITH HELICAL GEARS
}

\author{
Milan Rackov (D), Ivan Knežević, Maja Čavić (D), Marko Penčić (D), \\ Dijana Čavić, Siniša Kuzmanović \\ University of Novi Sad, Faculty of Technical Sciences, Mechanization and Design Engineering, \\ Novi Sad, Serbia
}

\begin{abstract}
Today there are no products whose appearance is not important. Of course, the greatest attention is paid to products that are intended for mass consumption and personal use, since the customers want to emphasize their uniqueness. That doesn't mean the other products are not given any attention but on the contrary. Within this paper, only universal gear reducer with helical gears will be considered. These units are often installed within the other products, so that they are usually invisible to the customers, and this paper will give attention to their design solutions overview. Universal gear reducers are relatively simple products and around the world there is a large number of manufacturers of these gear drives of different concepts and shapes. It is interesting to note that most manufacturers try to adopt the shape of gearbox housing that is significantly different from competing solutions. The reason for that is they want to accentuate their solution in order to and to avoid the possibility of an accusation of copying some other's solution. Although, there are manufacturers which retain almost identical shape as a competing solution, which is probably a reason of bought licence or a consequence of inexperienced copying.
\end{abstract}

Key words: design solution, universal gear drives, helical gears

\section{INTRODUCTION}

Universal gear reducers, in contrast with the special gear drives, are intended for the transmission of torque and circular movement from the driving to the operating machine for different levels of power and speed as well as for different shapes and positions of installation. Because of that, they are a bit more complex to produce and have more parts than special ones (Zadnik et al, 2009). However, for smaller series, they are significantly cheaper than special reducers and can satisfy almost all customer requirements. Universal gear reducers can be divided in different ways. Today, the basic division is made according to the size of the arc of tooth clearance. There are so-called industrial gearboxes, which are most common in practice (power transmissions), and so-called gearless drives, with an arc clearance of less than 10 angular minutes, which are used only in precision engineering (motion transmitters). Further division can be made according to the position of the gears into regular gear reducers and planetary gear reducers. Within this paper, only regular (industrial) gear reducers will be considered, although today planetary gearboxes are much more used around the world, in the place where it is necessary to achieve large transmission ratios and small overall dimensions, but at a slightly higher price. Ordinary gear reducers can be divided into gearboxes with parallel and gearboxes with coaxial or almost coaxial shafts. In this paper, both types of gearboxes will be considered. Further division can be performed according to the mounting method: into gearboxes with radial, axial and both radial and axial mounting. According to the number of stages, there are single-stage, two-stage, three-stage and multistage gear reducers. According to the method of connection between the reducer and electric motor, there are gearboxes without installed motor, i.e. gearboxes supplied with a classic input shaft, gearboxes with an adapter for IEC motors, when the customer should install electric motor or when the gearbox is supplied with the electric motor. Motor gearboxes can be different: with mounted special (gearbox) electric motor or standard IEC motor. Additionally, the gearboxes can be divided according to the form of installation: footmounted, flange-mounted, foot and flange-mounted and gearboxes for mixers. Depending on the size of the gearbox, there are small (usually with an axis height less than $100 \mathrm{~mm}$ ), medium (from 100 to 500 $\mathrm{mm}$ ) and large gearboxes (over $500 \mathrm{~mm}$ ). The size of the gearbox can also have some influence on the final shape of the gearbox, i.e. its housing shape, although the efforts are made that all housings, within one row of gearboxes, are similar to each other. Only medium-sized reducers are considered in this paper (Anišić, 2004; Anišić and Krsmanović, 2008). 


\section{PROBLEM DESCRIPTION}

The shape of the gearbox largely depends on the concept of the gearbox and the adopted number of gear stages. Single-stage gearboxes are always assembled in housing for single-stage units, although there are manufacturers who do not produce single-stage gearboxes at all. Two-stage gearboxes can be assembled in special housing for two-stage or in a universal housing for two- and three-stage units. Manufacturers, who produce two-stage gearboxes in special housing for two-stage units, build their three-stage gearboxes by connecting two-stage and single-stage gearbox, or by double two-stage gearboxes, so that their three-stage (or four-stage) gearboxes are slightly more expensive than the three-stage gearboxes assembled in universal housing for two- and three-stage units. That means, if a special housing for the two-stage gearbox is used, the same housing will be used for the production of three-stage gearboxes, and if a universal housing for two-stage and three-stage gearboxes is used, it is used the same in both two-stage or three-stage version. Two-stage gearboxes are slightly more expensive than gearboxes made in a special housing for two-stage units. Depending on the market segment where the basic attention is paid, manufacturers select one of these two concepts (Kuzmanović, 2009).

\section{DESIGN SOLUTION OVERVIEW OF MOTOR GEAR UNITS}

Classic motor gearboxes (Figure 1) are, in principle, delivered with the electric motor, although this is not the rule. So, the electric motor is usually connected to the gearbox housing and forms one drive unit (Rackov, 2013).

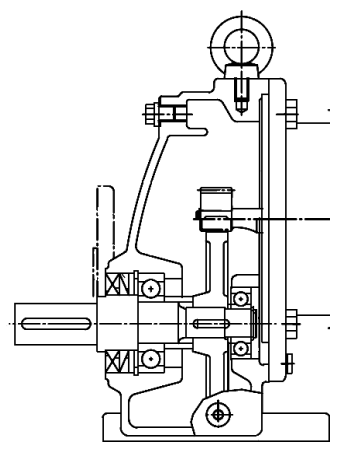

Figure 1: Characteristic solution of the single-stage gearbox, Nord (NORD Drivesystems, 2018)

These reducers are usually produced in three different installation forms: with feet, with feet and flange and with flange (Figure 2) (Rackov, 2013).

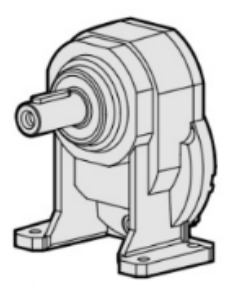

1

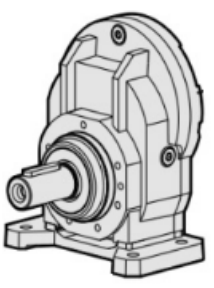

2

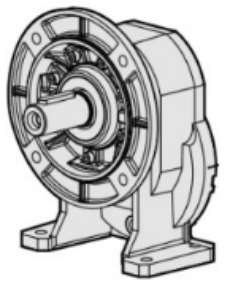

3

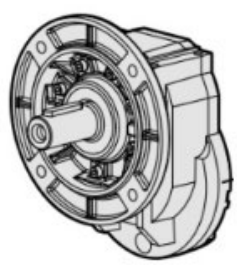

4

Figure 2: Characteristic solutions of single-stage universal gearbox: (1) foot-mounted and upper position of output shaft, (2) foot-mounted and lower position of output shaft, (3) foot and flange-mounted and (4) flange-mounted gearboxes, Motovario (Helical Geared Motors, 2018)

Some manufacturers use complex shape housings (Figure 3-1) to increase the rigidity of the gearbox unit, reduce material consumption and to improve its appearance. There are manufacturers who produce the housings in a simpler shape, with slightly higher material consumption and increase the housing surface (Figure 3-2), in order to enable to take a larger heat amount away from the unit (which occurs due to losses in the unit) to the environment. However, there are manufacturers who use a simple shape of housing, but 
achieve the high material consumption (Figure 3-3 and 3-4). Of course, simpler housing forms seem a bit outdated, but due to the possibility of taking away a larger amount of heat, they are often used in practice.

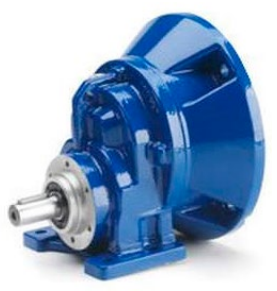

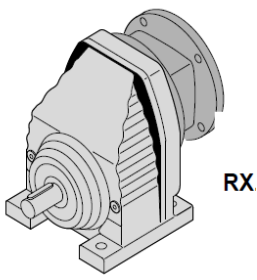

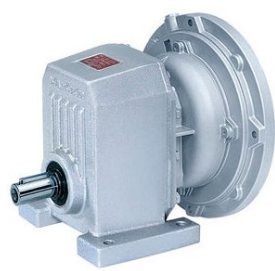

3

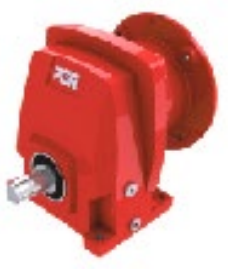

Figure 3: Characteristic solutions of single-stage universal foot-mounted gearbox: (1) solution of company STM Team (STM TEAM, 2016), (2) solution of company SEW (SEW Eurodrive, 2016), (3) solution of company Bonfiglioli (Bonfiglioli Riduttori, Anon) and (4) solution of company PGR (PGR Drive Technologies, 2011)

The manufacturers who produce motor gear reducers in special housings for two-stage gearbox (Figure 41), assemble three-stage gear units by connecting two-stage and single-stage gear reducers (Figure 4-2), and their four-stage gear reducers are assembled by connecting two units of two-stage gearbox (Figure 43). Although, there are manufacturers who produce only two-stage gear reducers. Within the gear reducers with special housing there are different kinds of interested solutions of two-stage gear reducers.

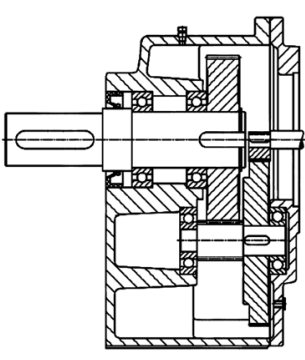

1

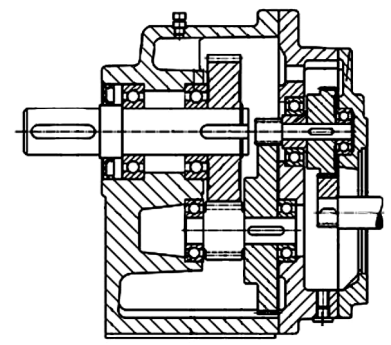

2

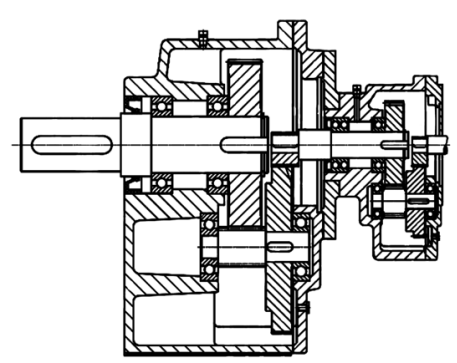

3

Figure 4: Characteristic solutions of (1) two-stage gearbox assembled in special housing for two-stage gear reducer, (2) three-stage gearbox assembled by connecting two-stage and single-stage gear reducer and (3) four-stage gearbox assembled by connecting two units of two-stage gear reducers, solution of company Bege (BEGE, 2017)

Two-stage gearboxes produced in a special housing for two-stage unit can have round housings (Figure 51 ), which fit into the circle shape of the electric motor and form an elegant shape unit. It could be also oval (Figure 5-2), square (Figure 5-3) and completely square unit (Figure 5-4). Square housings seem a bit awkward and require the highest material consumption, so they are less common in practice. They have the largest surface area and are suitable for fast dissipation of heat (which occurs due to losses in the gearbox) to the surrounding air.

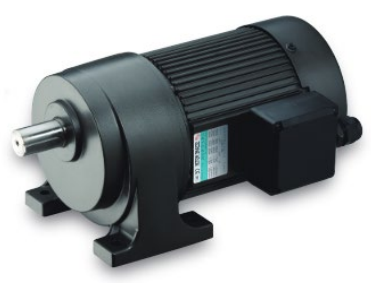

1

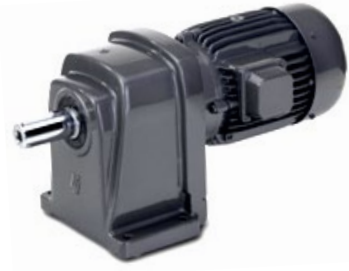

2

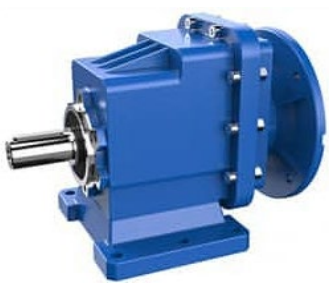

3

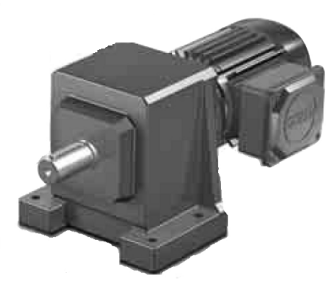

4

Figure 5: Characteristic solutions of two-stage universal foot-mounted gearbox: (1) solution of company Sesame (Sesame, 2020), (2) solution of company Bege (BEGE, 2017), (3) solution of company Aokman (AOKMAN drive, 2020) and (4) solution of company Stöber (SMS/MGS Gearunits, Anon) 
Three-stage and four-stage gear reducers that are built by connecting two-stage and single-stage (Figure 6-1) or two units of two-stages (Figure 6-2) gear units seem quite large, but these solutions are offered only in the cases when large gear ratios are required, which is still a rare situation.

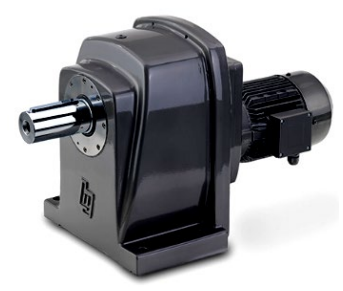

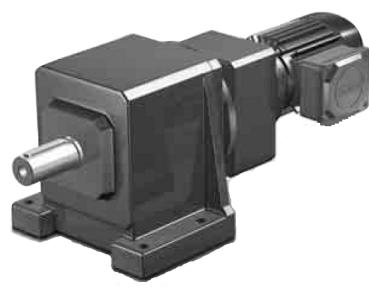

2

Figure 6: Characteristic solutions of three-stage and four-stage universal motor gear reducers built by connecting two-stage and single-stage (1) Bege (BEGE, 2017) or by two units of two-stages gearboxes (2) Stöber (SMS/MGS Gearunits, Anon)

Two-stage and three-stage motor gear reducers assembled in universal housing for two-stage and threestage unit do not have major difference in design of these two types of gearboxes (Figure 7).

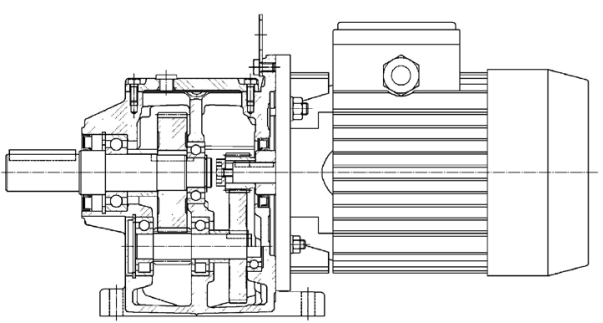

1

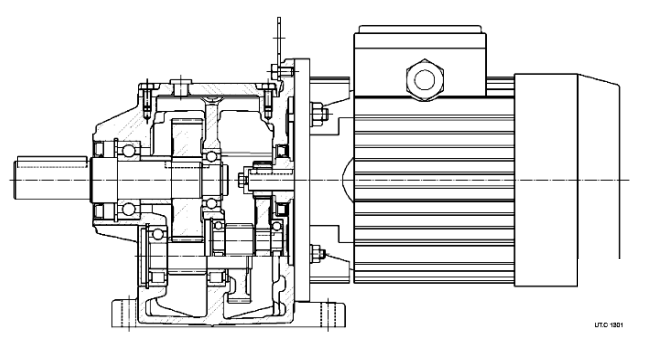

2

Figure 7: Characteristic solutions of two-stage motor gear reducer universal housing for two-stage and three-stage units (1) and three-stage motor gear reducer built in the same housing (2), solution of company Rossi (Rossi, Anon)

Gear reducers built in the universal housings for two-stage and three-stage units are distinguished in the mounting method. An axial mounting can be used, but it is now an old solution (Figure 8) and there is both radial and axial mounting. In this combined way of mounting, there is a difference between the shapes of the gearbox housings. The housing can have open slow-motion chamber (Figure 9) or it can have open both chambers (Figure 10), through which the large gears are installed.

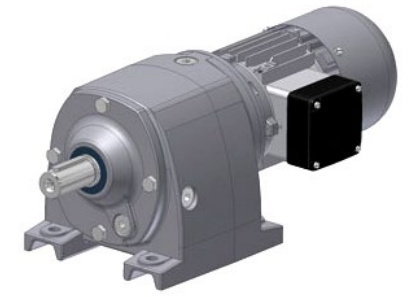

1

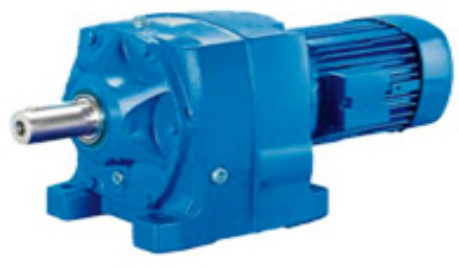

2

Figure 8: Characteristic solutions of two-stage and three-stage motor gear reducers with axial mounting, (1) solution of company Himel (Himmel, 2020) and (2) solution of company Premium Stephan (Premium Stephan, 2020) 


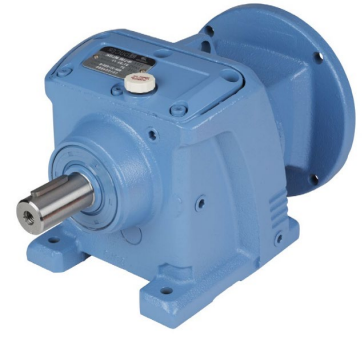

1

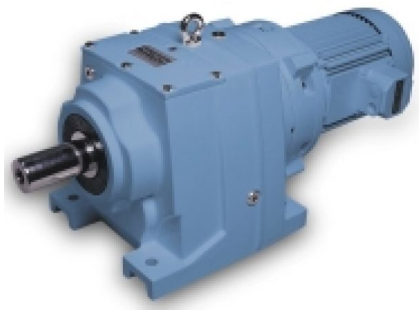

2

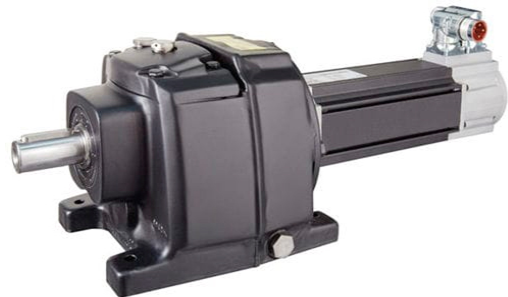

3

Figure 9: Characteristic solutions of two-stage and three-stage motor gear reducers with both radial and axial mounting and open slow-motion chamber, (1) solution of company Iron Horse (Automation Direct, 2020), (2) ASC (ASC, 2020) and (3) Leroy Somer (Leroy Somer, 2020)

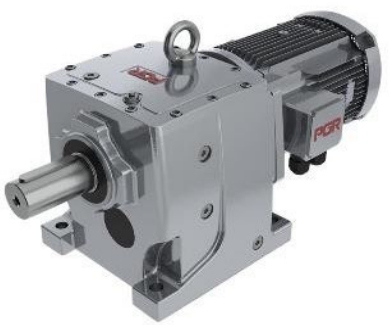

1

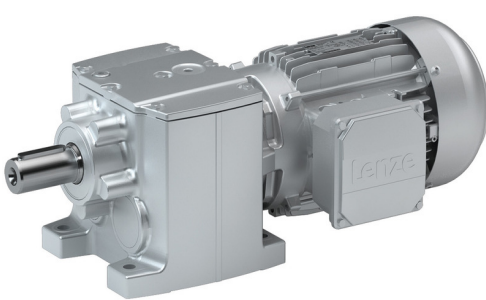

2

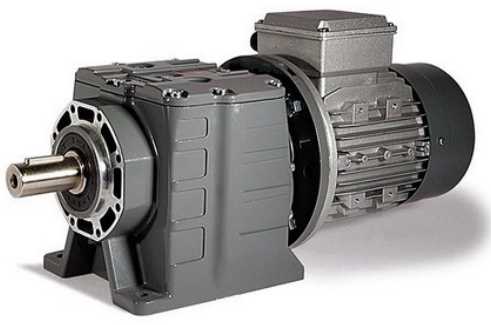

3

Figure 10: Characteristic solutions of two-stage and three-stage motor gear reducers with both radial and axial mounting and open both chamber, (1) solution of company PGR (PGR Drive Technologies, 2011), (2) Lenze (Lenze, 2020) and (3) Varvel (Varvel, 2020)

There are also gearboxes that are built in universal gearbox housing with feet and a flange. These housings are designed for flanged gearboxes, but the feet can be connected if necessary (Figure 11).

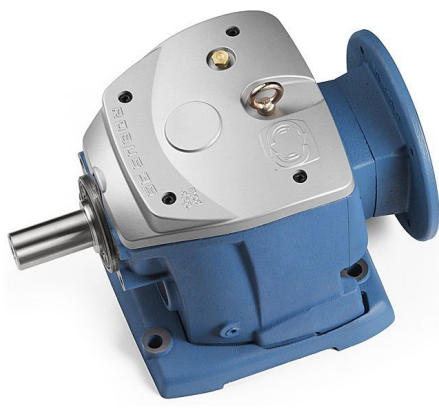

1

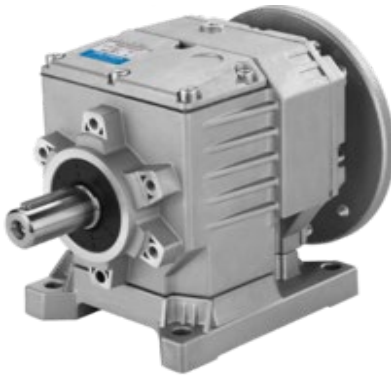

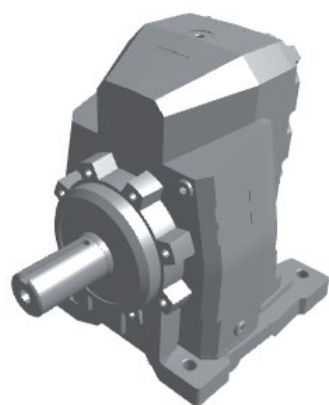

3

Figure 11: Characteristic solutions of two-stage and three-stage motor gear reducers with universal housing,

(1) solution of company Robus (Motive, 2020), (2) MSF (MSF, 2020) and (3) Regal (REGAL, 2020)

There are universal gearbox housings that can be used for foot connection, flange connection and foot and flange connection at the same time (Figure 12). 


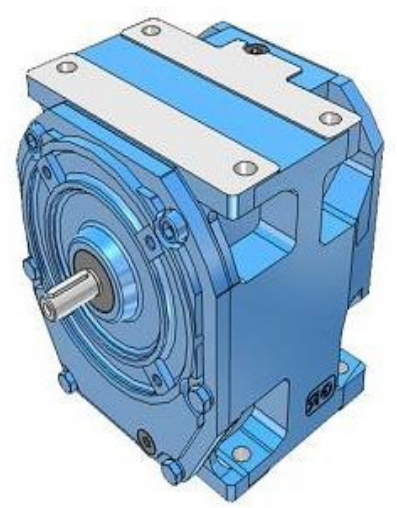

Figure 12: Characteristic solutions of two-stage and three-stage gear reducers with universal housing, solution of company Rossi (Rossi, Anon)

\subsection{Classic Gear Drives}

Classic gear drives are gear reducers with parallel shafts, which are not intended for direct installation to the electric motor, although some solutions can be delivered in this way. The number of gear stages does not significantly affect their shape (Figure 13). The main fault of these gear units is that the electric motor must be grounded separately and the shaft of the electric motor must be centred with the input shaft of the gearbox. Therefore, the concept of these gear units is often found only in large gearboxes.

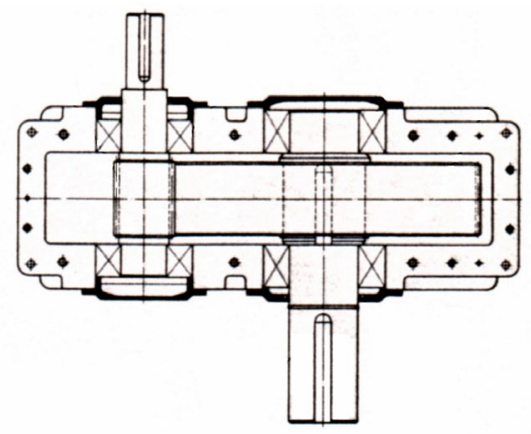

Figure 13: Characteristic solutions of single-stage gear reducer with parallel shafts, solution of company Santasalo (DB Santasalo, 2020)

The shape of the housing of single-stage gearboxes mostly depends on the position of the shaft and the way of the installation. Regarding the position of the shaft, there are gearboxes with horizontal (Figure 14) and vertical position of the shaft. Gearboxes with horizontal shaft position are usually made with radial installation. They are used for a long time and have an extremely intensive development of shapes, so that from the once common, now old-fashion shape, they have experienced a very interesting modern shape. For older solutions, the functionality and material consumption were important, while today the main attention is paid to aesthetics (Figure 14-4,5). Modern solutions are noticeable with a simple and likeable shape, with slight line transitions and slightly higher material consumption.

The housings of older solutions of these gear units consist of two parts. (Figs. 14-1 and 2), which required more extensive machining. It was necessary to machine large support surfaces, then connecting and centering both parts and further machining of cylindrical supports for bearings. Modern solutions use one-piece housings, much simpler to a machine, but somewhat more complex to assemble. In larger series, the housings are usually made by casting, while in smaller series and larger dimensions, the housings are usually made by welding.

In the case the reducer operates in an environment with higher ambient temperature, as well as connected with higher engine powers, where higher losses in the reducer can be expected, the housings must be made with ribs (Figs. 14-2 and 3) in order to increase the external housing surface and thus improved heat dissipation. In the case of gearboxes of larger dimensions, ribs are also made, but in order to increase the rigidity of the housing. 


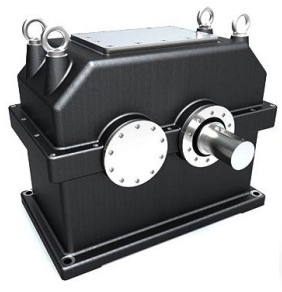

1

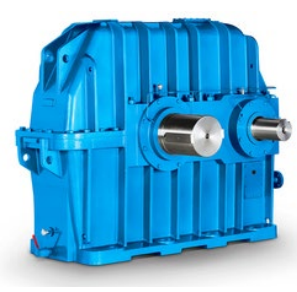

2

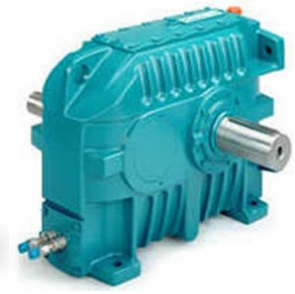

3

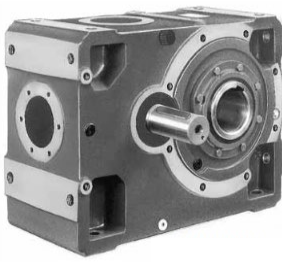

4

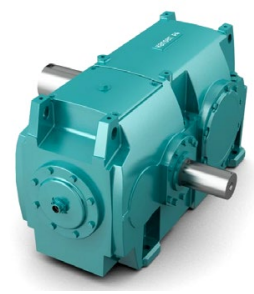

5

Figure 14: Characteristic solutions of single-stage gear reducers with parallel shafts and foot-mounted, (1) solution of company Kissling (Kissling, Anon), (2) Flender (Flender, Anon), (3) Hansen, (4) Rossi (Rossi, Anon) and (5) Hansen (Hansen, Anon)

In order to simplify the production of the gear units, many manufacturers of smaller gearboxes make one-piece housings, in order to avoid machining of large contact surfaces of two parts. They also install a large access hole, through which, during installation, the large gears are installed (Figure 14-3). Otherwise, the housing can have a large opening at the front surfaces, which is closed with a lid (Figs. 144 and 5), so the large gears are installed through them. This approach significantly simplifies the machining of the housings, although the assembling of such reducers is somewhat more complex.

Today, the basic attention of designers is paid to the aesthetics of the gearbox, i.e. its product design. Modern solutions of single-stage universal gear reducers have a simple and likeable shape, with slight surface transitions and slightly higher material consumption. It is interesting to note that some manufacturers produce single-stage gearboxes in housing for two-stage gearboxes (intended for bevel and helical gear reducers), which makes great savings.

In order to further increase the universal using of their gearboxes, some manufacturers place the feet on all four side surfaces. In this case, the gearboxes can have both horizontal and vertical shaft arrangement (Figure 14-4). Additionally, these gearboxes, as already mentioned, have an opening on one of the side or front sides of the housing, through which the gear is inserted. It is practiced to make a flange on the front surfaces of these reducers and thus further increase the universality of these gear drives (Figure 14-4).

\subsection{Shaft-Mounted Gear Drives}

Besides universal helical gear reducers, there are so-called shaft-mounted gear reducers or flat gear reducers. Shaft-mounted gear units are only the gearboxes made with a hollow shaft. The main advantage of these gearboxes is to avoid the using of a coupling, which connects the gearbox with the operating machine, and to avoid the need to center the axis of the output shaft of the gearbox with the input shaft of the operating machine. These advantages have conditioned the large application of these reducers, despite the fact that it is necessary to solve the fixing of these units, so to support the reaction torque, i.e. to prevent the unit from rotating around the output shaft. Shaft-mounted gear reducers can be divided according to the mounting method, so there are gearboxes with axial and with radial and axial mounting, i.e. with a two-part and one-part housing. The characteristic solution of a single-stage reducer with axial mounting is shown in Figure 15.

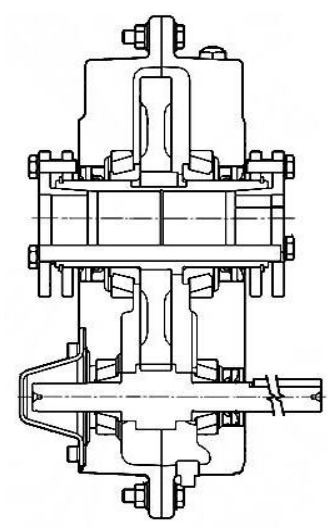

Figure 15: Characteristic solutions of single-stage shaft-mounted gear reducers with two-part housing, solution of company Dodge (Rehfuss, 2020) 
The basic feature of the two-part housings is the need for machining large contact surfaces, placing pins for centering the axis and further processing of the housing, while the transmission assembly is very simple for axial mounting, which can be done almost entirely outside the gearbox housing. Single-stage shaft-mounted gearboxes are generally simple and likeable round shape of the housing (Figure 16).

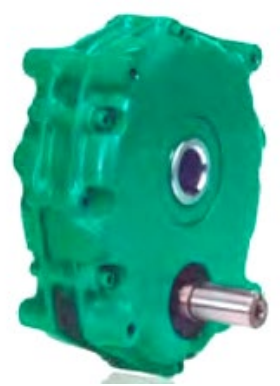

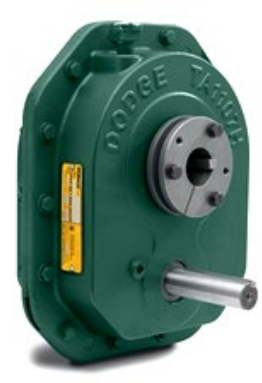

2

Figure 16: Characteristic solutions of single-stage shaft-mounted gear reducers,

(1) solution of company Leroy Somer (Poulibloc, 2000) and (2) solution of company Dodge (Rehfuss, 2020)

Two-stage and three-stage shaft-mounted gearboxes are not different significantly in the shape from single-stage gear units (Figure 17).

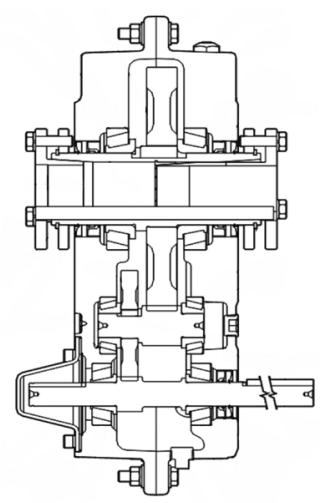

Figure 17: Characteristic solutions of two-stage shaft-mounted gearbox, solution of company Dodge (Rehfuss, 2020)

Due to the savings of material, round housings (Figure 18-1) are also present in two-stage gearboxes. Although, oval (Figure 18-2) and square (Figure 18-3) housings can be also found, mainly due to easier handling during their machining. They seem more likeable and are more common in practice.

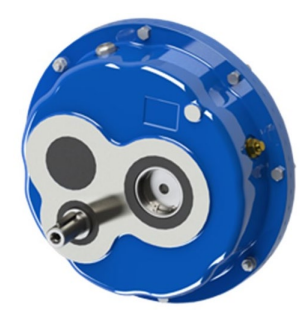

1

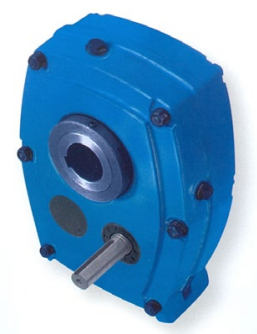

2

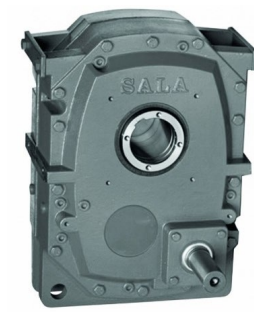

3

Figure 18: Characteristic solutions of two-stage shaft-mounted gearbox,

(1) solution of company Bonfiglioli (Bonfiglioli Riduttori, Anon), (2) Renold (Renold, 2020) and (3) Sala (ASC, 2020)

In order to avoid the processing of large adjacent surfaces, i.e. two-part housings, today most of the manufacturers of shaft-mounted (flat) gearboxes make these units as a one-part housing (Figure 19). This solution makes easier their manufacture, but complicates their assembling. Flat shaft-mounting 
gearboxes are often made as foot-mounted with the classic output shaft, in order to enable the greater application of these gearboxes, so to make some space savings in the axial direction.

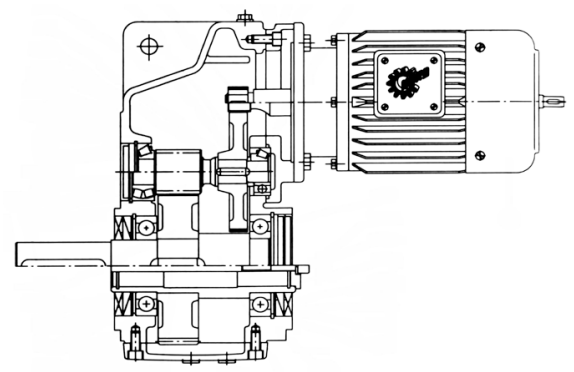

Figure 19: Characteristic solutions of two-stage shaft-mounted gearbox, solution of company Nord (NORD Drivesystems, 2018)

Flat shaft-mounted gearboxes with one-part housing are made in different versions. Some manufacturers make them as highly universal units (Figure 20-1), suitable for different shapes and mounting positions. There are also manufacturers who make them only as a shaft-mounted version (Figure 20-2 and 3).

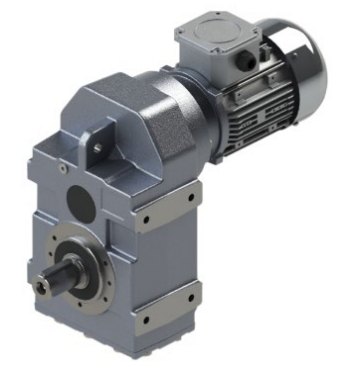

1

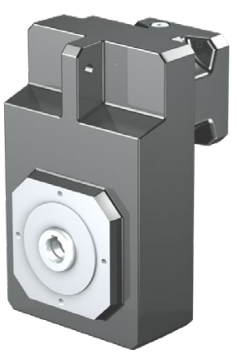

2

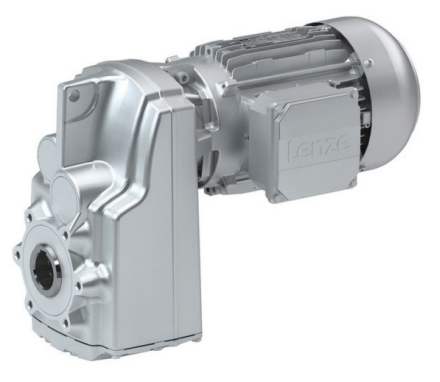

3

Figure 20: Characteristic solutions of shaft-mounted gearbox with axial assembling, (1) solution of company PGR (PGR Drive Technologies, 2011), (2) Stöber (SMS/MGS Gearunits, Anon) and (3) Lenze (Lenze, 2020)

Of course, there are also three-stage versions with a highly universal housing (Figure 21), intended for different shapes and positions of installation (Figure 22), which significantly expands the scope of their application.

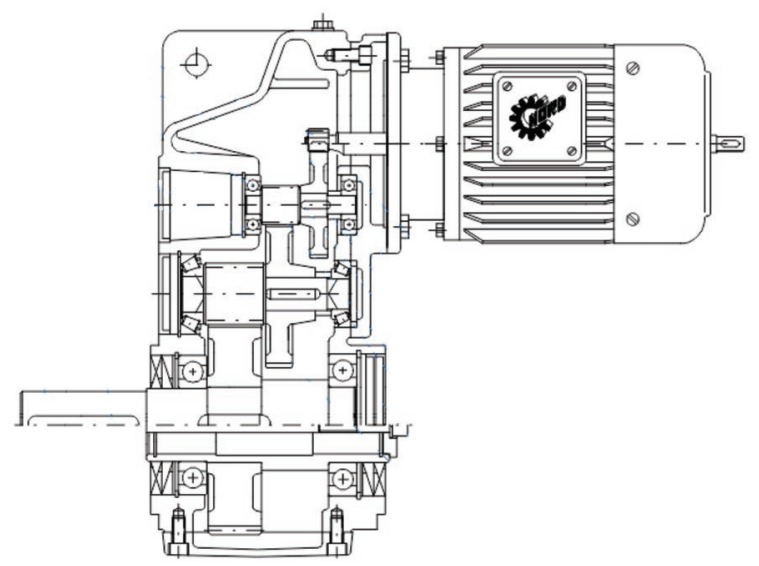

Figure 21: Characteristic solutions of three-stage flat shaft-mounted gearbox, solution of company Nord (NORD Drivesystems, 2018) 


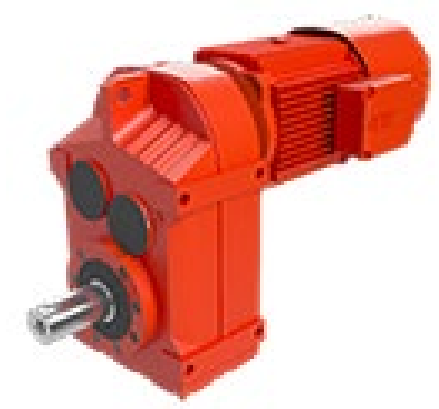

Figure 22: Characteristic solutions of three-stage flat shaft-mounted gearbox, solution of company SEW (SEW Eurodrive, 2016)

\section{ANALYSIS OF GIVEN SOLUTIONS}

Regarding the extent of the assortment, i.e. the number of types, size, the shape and mounting position, it is different for each manufacturer. It certainly depends on the capabilities of the manufacturer and the current market demands. However, it is evident that the shape of the housing, and thus the whole gearbox, is given extremely great designers attention. Each manufacturer wants to define a specific shape of the gearbox, which will distinguish it from the competition, and to use a specific (own) factory color that will immediately identify the manufacturer of the gearbox. Of course, at the customer's request, the gearboxes can be painted in a different color, but the manufacturers charge this extra. It is the reason why the gearboxes are usually delivered in the factory color, and the customers, if they want, later paint according to their taste.

\section{EXPECTED DIRECTIONS OF FURTHER DEVELOPMENT}

Based on the realized and presented solutions of the world's leading manufacturers of gear reducers, it follows that intensive development of all types of gearboxes can still be expected.

Motor gearboxes (with vertical shaft assembling) foot-mounted, flange-mounted and feet and flangemounted are the basic forms of the housings that will be the most required in the future due to relatively low production costs, harmonious shape and low material consumption. Universal shapes are less demanded and can be only produced by smaller gear reducer manufacturers that are based on the segment of the market requirements that is not covered by large manufacturers.

Classic gearboxes (with horizontal shaft assembling) foot-mounted on all side surfaces and with flanges on the front surfaces are the most universal gear units. They are adapted for all shapes and mounting positions, but they are also the most expensive gearboxes, due to extensive machining and highest material consumption. Therefore, their development and application can be less intensive than the first ones. The great weakness of these reducers is, most often, the separate connection between the electric motor and the housing, i.e. the need for a special foundation and centering of the electric motor, which is not the case with motor gear reducers. They will be produced by only a small number of manufacturers in order to meet the special requirements of the industrial machines.

In the case of shaft-mounted gearboxes, intensive development of these reducers can still be expected, since they make installation easier, i.e. there is no need to use (expensive) coupling on the output shaft of the gearbox and there is no need for centering. Additionally, they provide a more compact and simpler construction because it does not require a classic foundation of gearboxes, which is a great advantage. Therefore, their development and application can be expected to be further intensified and more applied in industry.

\section{CONCLUSIONS}

Besides functional requirements, it is evident that modern housing solutions put first aesthetic requirements, regardless of material consumption and complexity of the product. The gearbox design increasingly plays a major role in the selection of gearboxes and despite the fact that gearboxes are installed only in the industrial machines and usually are not in the direct view area of the observer. Since 
today the gearboxes are fairly uniform in terms of quality, technical characteristics and price, special attention is paid to the design of the gearbox because an attractive gearbox always draws the attention of the observer (customer) and based on it makes the final decision about the purchase. This conclusion can be reached by observing and analyzing the implemented solutions of all the world's leading gear manufacturers.

\section{ACKNOWLEDGMENTS}

This paper has been supported by the Ministry of Education, Science and Technological Development through the project no. 451-03-68/2020-14/200156: "Innovative scientific and artistic research from the FTS (activity) domain".

\section{REFERENCES}

[1] Anišić, Z., Krsmanović, C.: “Assembly Initiated Production as a Prerequisite for Mass Customization and Effective Manufacturing", Strojniški vestnik - Journal of Mechanical Engineering 54 (9), 607-618, 2008.

[2] Anišić, Z., Ćosić, I., Kuzmanović, S.: "The Influence of Customization and Requests for Prompt Delivery on Gearmotor Design Concept", Proceedings of Tools'2004 Conference 2004, (Kočovce, Slovakia, 2004), pages 68-74.

[3] AOKMAN drive, Standard Gearbox, AOKMAN, URL: https://www.aokman-gearbox.com/standardgearbox/ (last request: 2020-09-18).

[4] ASC, Antriebe Distribution and Service GMBH, ASC, URL: https://www.ascantriebe.at/en/products/shaft_mount_gearboxes/sala_shaftmount_ gearbox_series_j/ (last request: 2020-09-18).

[5] ASC, Antribe distribution and service GMBH, ASC, URL: https://www.asc-antriebe.at/en/products/ geared_motors/helical_geared_motor_series_m/ (last request: 2020-09-18).

[6] BEGE, Motorreductoren Stirnrad-Getriebemotoren, Helical Gear Motors Motoréducteurs.

[7] Bonfiglioli Riduttori, S series, Single Stage Gearboxes, COD. 1044 R8, 120127, Bologna, Italy.

[8] General Purpose Cast Iron Helical Inline Gearboxes, Automation Direct, URL: https://www.automationdirect.com/adc/overview/catalog/power_transmission_(mechanical)/ general_purpose_cast_iron_helical_inline_gearboxes (last request: 2020-09-18).

[9] DB Santasalo, David Brown Santasalo, Products, AMF Series - Agitator, Mixer and Flotation Drives, URL: https://dbsantasalo.com/products/amf-series/ (last request: 2020-09-18).

[10] Flender, gear units, Catalog MD 20.1-2009, Siemens AG.

[11] Hansen, P4 standardized heavy duty single stage gear units catalogue, DOC-CAM626E/0613.

[12] Helical Geared Motors, Motovario S.p.A., H/2018/Rev.0.

[13] Himmel geardrive, Parallel shaft helical geared motors and parallel shaft helical gear units, URL: http://www.himmel-gear.com/htm/industry/is_06_17.php?block=sub4 (last request: 2020-09-18).

[14] Kissling, The Gear Company, Catalog Helical and bevel-helical gear reducers.

[15] Kuzmanović, S.: "Universal Helical Gear Reducers", (Faculty of Technical Sciences: Novi Sad, 2009).

[16] Lenze, Stirnradgetriebe GST, Robuster Aufbau mit hohem Wirkungsgrad, Lenze, URL: https://www.lenze.com/de-de/produkte/vorgaengerprodukte/getriebe/stirnradgetriebe-gst/ (last request: 2020-09-18).

[17] Leroy Somer catalogue, Shaft mount speed reducer, 3780 en - 2017.06/e.

[18] Motive, The gearbox model ROBUS-A completes ROBUS range, ROBUS-A gearboxes, Motive, URL: https://motive.it/en/p-13-robus-a-gearboxes.html (last request: 2020-09-18).

[19] MSF Vathauver ANTRIEBSTECHNICK, Gears, MSF-Technik, URL: http://www.msftechnik.de/en/products/motors-gears/gears/helical-gear-ms-hy/ (last request: 2020-09-18).

[20] NORD Drivesystems, Standard Helical Gearboxes, Getriebebau Nord, Hamburg, 2018.

[21] PGR Drive Technologies, Catalogue Helical Gear Units, PA/PF series 02/2017. Hélicoïdaux, BEGE, URL: https://www.bege.nl/downloads/catalogues/BEGE\%20G-DSG\%20201710\%20NL\%20DE\%20GB\%20FR.pdf (last request: 2020-09-18).

[22] Poulibloc 2000, Reducer with exclusive taper bushing feature, Catalogue Leroy Somer.

[23] Premium Stephan, Geared motors, Premium Stephan, URL: https://www.premiumstephan.com/en/products/geared-motors/ (last request: 2020-09-18). 
[24] Rackov, M.: "Conceptions of Development of Universal Gear Reducers", PhD thesis, The University of Novi Sad, Faculty of Technical Sciences, 2013.

[25] REGAL, Parallel Shaft Gearing, Regal, URL: https://www.regalbeloit.com/products/gearing/parallelshaft-gearing (last request: 2020-09-18) (last request: 2020-09-18).

[26] Rehfuss, URL: https://www.rehfuss.com/de/ (last request: 2020-09-18).

[27] Renold, Gears \& Gearboxes, Renold, URL: https://www.renold.com/products/gears-gearboxes/ (last request: 2020-09-18).

[28] Rossi, Parallel shaft gear reducers catalogue, 004BRO.GPR-de1105HQR.

[29] Sesame, Foot-mount type, Sesame, URL: https://www.sesamemotor.com/en/products/detail/18 (last request: 2020-09-18).

[30] SEW Eurodrive, Catalogue - Gear Units, Edition 06/2016-16997611.

[31] SMS/MGS Gearunits, Catalogue 11, STÖBER Antriebstechnik GmbH \& Co. KG.

[32] STM TEAM catalogue, CT17 IGBD 3.1 | ITA - ENG - DEU, 3/2016.

[33] Varvel, RD Series, Varvel, URL: https://varvel.com/en/products/rd-series/ (last request: 2020-09-18).

[34] Zadnik, Ž., Karakašić, M., Kljajin, M., Duhovnik, J.: "Function and functionality in the conceptual design process", Strojniški vestnik - Journal of Mechanical Engineering 55 (7-8), 0039-2480, 2009.

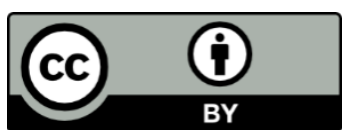

(C) 2020 Authors. Published by the University of Novi Sad, Faculty of Technical Sciences, Department of Graphic Engineering and Design. This article is an open access article distributed under the terms and conditions of the Creative Commons Attribution license 3.0 Serbia (http://creativecommons.org/licenses/by/3.0/rs/). 


\title{
INFLUENCES OF JAPANESE PRINTS ON EUROPEAN PRINTMAKING (IN THE CASE OF DEGAS-MANZI PARTNERSHIP)
}

\author{
Yeter Beris ${ }^{1}$ (D), ismail Erim Gulacti ${ }^{2}$ (iD \\ ${ }^{1}$ Altinbas University Vocational School, Graphic Design Department, Istanbul, Turkey \\ Yildiz Technical University, Faculty of Art and Design, Art and Design Departmant \\ ${ }^{2}$ Yildiz Technical University, Faculty of Art and Design, Departmant of Art, Istanbul, Turkey
}

\begin{abstract}
Contemporary artists have included classical methods together with innovative digital printing technologies to their artistic manufactures and thus their technological production interactions have been reflected on current art as well. Today's artists have also been in collaboration with each other by involving the digital printing technologies which kept advancing during the recent 20 years in their works of art just like Degas and Manzi did in their relationships of production partnerships in 19th Century. Besides, those opinions which originated from modernism ideas and movements consist of the core of this cooperation post Industrial Revolution era. Therefore, the concept of nationalism, the devastating consequences of the world wars and the latest industrial and technological advancements have all transformed human life irreversibly. Consequently, during this transformation era, various significant movements of art such as Impressionism and Expressionism emerged in the 20th century and representatives of those art movements substituted such a lot of printmaking practices in their works of art. None of those mentioned above took place in other previous movements of art. They reflected their points of view that they display social movements and none of the other artists who represent other senses of art have ever exhibited such a lot of printmaking practices. Thus, various printing technologies which present a new laboratory environment to the artists. As a result of this, printing technologies have been preferred as a sort of new artistic media value and it started to take its prominent place in collections of art as well as in museums during artistic presentations.

Within this context, this article aims at studying the phenomenon of art by considering how it has changed during the historical process by examining those works of art which reveal these variations. Common production and working techniques in traditional printmaking, contributions of the technological advantages to the artistic manufacture. Besides, periodical innovations will be examined and presented by introducing an updated point of view to the topic within the content of this article that contain some citations from the second part of the thesis titled "Effects of fine art printmaking on the phenomenon of contemporary art".
\end{abstract}

Key words: European Printmaking, Japanese printmaking, Degas-Manzi partnership

\section{INTRODUCTION}

The innovative production process of art started with the traditional Japanese printmaking and it arrived in Asia and Europe by means of commercial routes and affected the Western senses of art and also art movements in the 15th century. Although it is not clearly known when the art of engraving started in Europe, two different points of view are present. According to the first view, this art was adapted from the art and craftsmanship of weapons and it was first printed on an iron plate but according to the opposing view, first printing was made on sheets of paper by using wooden mould at the beginning of the 15th century. However, the view which overweigh is that woodcut practices started between 1400 and 1700 together with techniques of engraving, etching operations as well as on armours, a wooden and metal surfaces such as rifles and it was developed from the craftsmanship of fine art carving and engraving. It may be concluded that trends towards adopting wooden engraving rather than metal engraving stem from the constantly increasing demands and needs for fast manufacturing accelerated the practices of wooden engraving products much more because this can be repeated more rapidly. The printmaking which started in Asia with woodcut, carving and engraving evolution continued in Europe with the dominance of metal engraving in Europe. The fact that they manufactured more graphical printmaking gradually caused the increasing interest of the society such products just like in Edo (Tokyo) region. Therefore, reproduction techniques have been tried to meet boosting demands, and new techniques have been adopted and developed to achieve greater variety in the work of printmakers. Even though Albrecht Durer and Urs Graf were talented in the art of jewellery and they made both wooden 
and metal engraving practices, engraving was not practised as a serious form of art widely until the 17th century. (Savage and Kemble, 1982)

The printmaking continued with carved wooden block printing practices by drawing sketches on flat and even wood pieces by a wood carving craftsman throughout the 15th century. During this application, craftsman worked together with some other masters, artists in the printing studios. Thus, craftsmen or printmakers cut those areas of wooden blocks to prepare them as printing tools. Due to the fact that wooden blocks were much easier to cut, carve and engrave, it is thought that this practice was preferred in the 15th century. However, engraving was considered to be as more preliminary than wooden printmaking. It is supposed that the basic reason for this is that the craftsmen or the artists own much more direct control on the processes of printmaking operations. The view which suppose that the artist has more control on drawing and designing patterns on metal engraving and creating more plastic art effects as well as they are able to make more sophisticated light- shade patterns also considered to be a dominant factor. (Savage and Kemble, 1982)

Although it is not clearly known when printmaking started in Europe, there are several estimations within this regard. It takes its place among several estimations that the idea of making hollow lines on metal printing plates emerged during the innovations in making some ornamented army armours in the 15th century (Savage and Kemble, 1982). In spite of the chemical composition and various technical hardships in applications, the art of engraving, engraving artists of that era practised this art, changed its function and converted it into a new artistic manufacturing media. Drawing patterns by means of acid proof varnish or with wax background allows artists to make some hand movements which cold scratching engraving cannot enable them to perform (Spira, 2020). Another prediction is that the occupation of jewellery making is mentioned. The art of making jewellery is a delicate fine carving art which is widely practiced by skilful craftsmen who began working in this job when they were children who obtained training of apprenticeship as talented drawing artists were the pioneers of the development of printmaking. The interests of printmaking artists towards the carving art reflected on their presentations in the future. The first samples of such kinds can be observed in the Albrecht Dürer's woodcuts practices and engraving applications. The journalist and art critic Charlotte Higgins broadcasted an interview on BBC3 and she mentioned that Dürer obtained his fame from a totally new technologies with the repeatable art that spread around and he became an international unprecedented unique artist from Europe (BBC3, 2019).

Dürer gained his fame by traveling all around Europe and sealed his woodcuts and engraving with his initials $A D$ and by creating his own monogram and managing his trademark and sold them by himself. It is also mentioned Dürer's travels to Venice which is the heart of Holly Roman Empire and the centre of trade as well as the place where the printing houses take place made a great deal of contribution to make him a widely known artist after he visited Nürnberg (BBC3, 2019). It is also thought that Dürer's going back to Venice over and over again after travelling to many cities all around Europe also enabled him to use and benefit from the facilities and collaborations with workers of those printing houses located in Venice and thus he improved his skills, experience, his works of art as well as his competence in printing art. As it was seen in Rambrand's engravings, Dürer's deep interest in engraving enabled him to notice the real value of engraving and thus he both got inspiration and he also inspired other artists.

\section{METHODS}

Compiled from the second part of his doctoral thesis titled "Effects of fine art printmaking on the phenomenon of the contemporary art", which is still being written, this article has been prepared in line with qualitative research based on books, internet resources, expert view and artist interviews. Citations were made by scanning resources such as internet resources, professional books, periodicals. These study data were collected, interpreted, and formed within the scope of research based on previous years of work experience.

\section{INFLUENCES OF TRADITIONAL JAPANESE PRINTMAKING ON EUROPEAN PRINT ART}

Industrial manufacturing technologies enabled the field of printing house businesses to invent assembly lines and this triggered various radical transformations. Those books on religion which were printed by using innovative assembly line techniques for the first time in the 15th century provided an ample commercial support to the printmaking which took place in religious books. Thanks to this trend, the first samples of the art of printmaking accepted as valuable works of art and they were protected and 
exhibited in museums, in art galleries in private collections and thus they have been kept until today. Before museums and art galleries were established, such valuable works of art were collected, exhibited by religious institutions and kings by appointing temples, churches and palaces to keep and exhibit them with other valuable documents.

Such radical transformations which appeared in Europe integrated the idea of modernity to the understanding of life and the order of society. As a result of this, the movement of industrialization began in Europe and those products of craftsmanship which were produced one at a time started to be manufactured on assembly lines by means of using serial production technologies and manufacturing of products mechanised. The movement Arts and Crafts -which defend returning back to the manufacturing methods of the Medieval Age- began as a reaction movement to mechanization and thus it became the ground of modern art era. Those artists who were able cope with the innovations of this new era got interested in new production technologies and they applied different approaches to the artistic manufacturing fields. In the Impressionism which broke through as a movement of art, the painters transformed art into a new form of art by describing the nature as a real objective reality but adopting their impressions in regard to a new from which is created their perceptions of the instant impressions created by the sun light and colours. Edgar Degas, Edouart Manet, Claude Monet, Camille Pissarro and Pierre-August Renoir were pioneer impressionist artists. They reflected the lights, colours and movements which human beings perceived and they reflected them on their canvas as they felt and impressed. This new innovative style of unique art form became a pioneer movement which led the following artists and painters accordingly.

\subsection{Degas-Manzi Partnership}

Those traditional Japanese printmaking attracted a lot of European artists and painters after Japan started trade relationships with Europe in 1854. A lot of French artists and painters were inspired by Japanese printmaking including Degas. Degas, just opposite other artists and painters who spared place to the descriptions of the East, dealt with Japanese printmaking and made them unique by benefitting especially from those Japanese clipping and asymmetry usage in creative compositions as well as by taking their points of view (Figure 1, 2) (Schenkel, 2004).

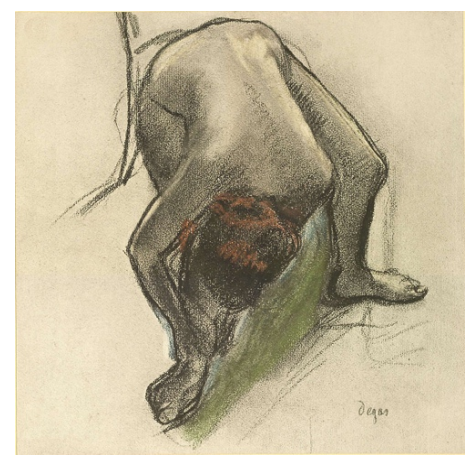

Figure 1: Edgar Degas, Vingt Dessins: "Plate 17: Étude de nu pour le movement ci-dessus" 1861-1896, Paris, Goupil, Ryerson and Burnham Libraries, Art Institute of Chicago, 1897. (Scalar, 2017)

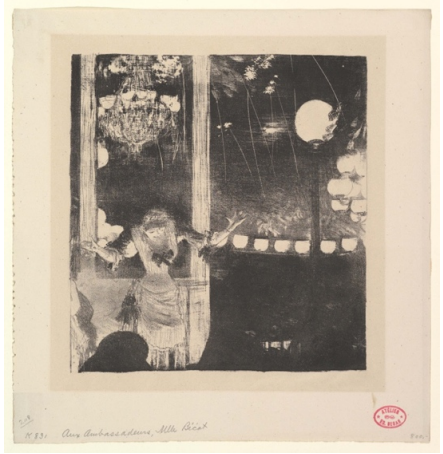

Figure 2: Edgar Degas, "Mlle Bécat at the Café des Ambassadeurs, Paris", Lithograph on wove paper (only state), 1877-78. (Metropolitan Museum, 2020) 
One of the best examples of this specialization is seventeen chromogravure prints called "Vingt Dessins". It consists of highly durable reproduction drawings created in 1897 by Degas in collaboration with the Naples printmaker Michel Manzi (Figure 3).

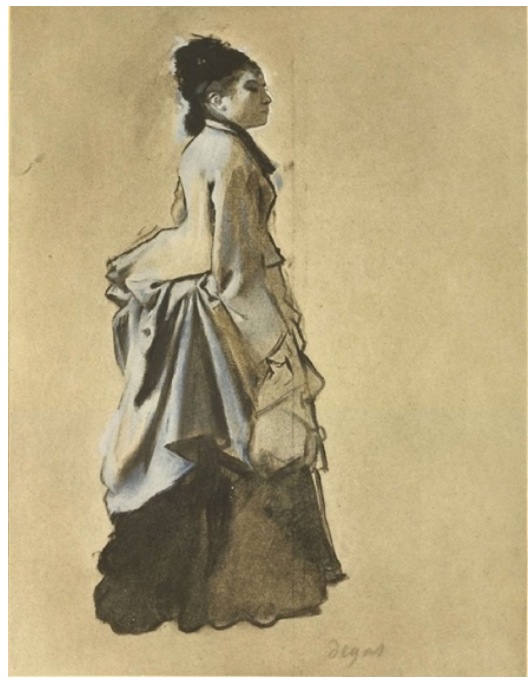

Figure 3: Edgar Degas, "Plate 11: Jeune femme en costume de ville" Vingt Dessins: 1861-1896. Paris: Goupil, Ryerson and Burnham Libraries, Art Institute of Chicago., 1897. (Scalar, 2011)

The fact that Degas and Manzi worked together in cooperation while they were printing his drawing plates and actualizing efforts was quite important. This is also an attention pointer in regard to reflecting the role of good cooperation with another artist or printmaker by presenting an opportunity. It is argued that it is an action that was deemed to lead viewers to think about the skill of a painter on his ability of drawing. "Vingt Dessins" consists of 20 drawings by Degas throughout his career life as a selection. Besides this selection is a published retrospective as an artist throughout his career. It is noted that the artist was interested in draftsmanship of his own legacy and he also emphasized that Manzi undertook a role to shape him (Kovacs, 2016). The eighth plate which takes place in this select and is different from the others (Figure 4) is commentated as one of drawings of him during his practices. It stands out because it is more completed than the others. It is observed that the artist focuses on higher quality presentations through different coloured printing trial practices. He changed the blue colour of the skirt of the laundress, and in his other printing, using only two colours, printed it on a sheet of pink paper. Here, perhaps it stems from Degas' interest in emphasizing the craft of drawing through the reproductions of Vingt Dessins. In other words, the slip of his hand movements while drawing and painting his pictures can be ascribed to his interest in his care and attention to emphasize the quality of his drawings and paintings on the reproductions of Vingt Dessins (Kovacs, 2016).
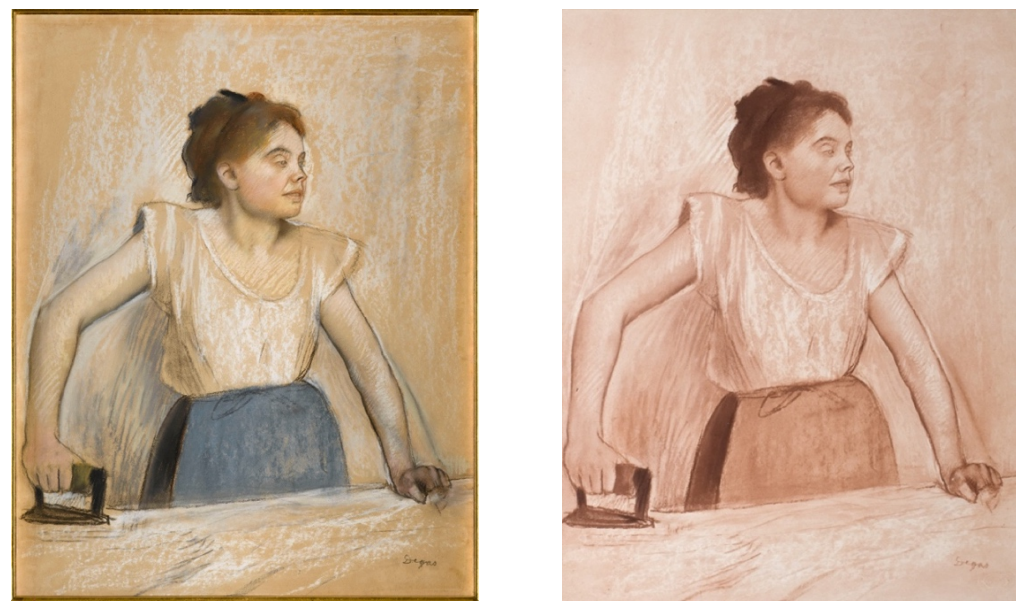

Figure 4: Edgar Degas, "Plate 8: Blanchisseuse" Vingt Dessins: 1861-1896. Paris: : Goupil, Ryerson and Burnham Libraries, Art Institute of Chicago, 1897. (Scalar, 2011) 
Degas's unique attitude can be observed especially in the 18th plate (Figure 5) and it is understood that Degas owns full control in respect to usage of colour and pattern designs, drawings and paintings combining his skills while using the pastel colours and that he improved his colour practices even more. Degas revealed his artistic qualifications and quality of his works of art in chromogravure reproduction more than his other reproductions. It is seen that the colour texture of pastel colours and toning was reprinted perfectly during the printing process. It is commented that the core of the original medium environment glitters much more allowing the essence of the original medium to shine (Kovacs, 2016).

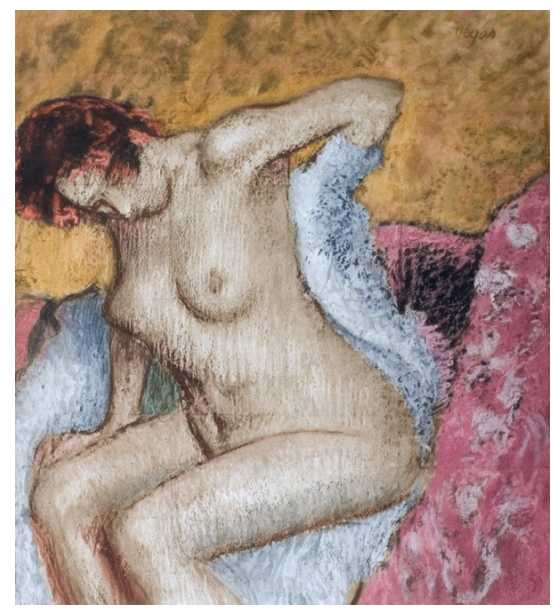

Figure 5: Edgar Degas, "Plate 18: Femme se fottant les reins avec une serviette" Vingt dessin: 1861-1896. Paris: Goupil, Ryerson and Burnham Libraries, Art Institute of Chicago, 1897. (Scalar, 2018)

Degas developed a new approach to his own pictures by means of his deep interest in women's daily life and descriptions of incidents related to traditional Japanese printings. His visit to an exhibition arranged in Paris at Ecole des Beaux-Arts ukiyo-e with various printings increased this interest even more. Consequently, he manufactured ten coloured engravings upon his admiration he felt for the topics, compositions and their innovative techniques (Ives, 2004). The artist approached to the processes of printmaking -as in the other media- with experimental soul and interest. It is known that he approached to various artistic subject matters enthusiastically together with his interest in engraving discharge printing and lithography, monotypes and other printing processes. As a result of this interest, various experimental drawings take place in his paintings which he formed through various pictorial modes and printmaking techniques. Moreover, it is stated that his experimental drawings and paintings coincide with the same period when the popularity of Japanese woodcuts increased dramatically in 1890 (Kovacs, 2016).

Degas's efforts to reproduce patterns again are not seen as a new concept from the view point of their era. In the book titled "Art in Reproduction "written by Robert Verhoogt, the rich exhibition culture of the 19th century was described and emphasized as a whole complementary factor and as the magic element of the visual culture of this period for the engraving artists. John Brunette wrote in 1836 and mentioned about the importance of the exhibitions where arranged reproductions take place for printmaking artists. Starting from the big art exhibition arranged in London in 1851, various printmaking and photographs were exhibited regularly in international exhibitions and in various world fairs arranged during the second half of the 19th century. It is stated that "Exposition Universelle" Fair was arranged in the area of the Eiffel Tower an exhibition intended to reflect a general view to printmaking art (Verhoogt, 2007). Furthermore, in various exhibition halls in Paris, engravings of the members of the Henriquel-Dupont school, printmakings of Celestin Nanteuil and Adolphe Mouileron's, engravings of Charles Albert Walter and Paul Rajon's and a lot of printmaking of other artists were also exhibited. Louis Henriquel-Dupont's reproduction displayed in the exhibition (Figure 6) was mentioned proudly in "The Art Journal" as a magnificent monument of art" (Verhoogt, 2007).

During the artistic interaction activities during that era, printmaking was exhibited together with contemporary paintings. Especially in the 1870's at the Dudley Art Gallery in London consisting of original printmaking and reproductions resembling black- white exhibitions, some of graphic print arts exhibitions drew people's attention and public interest in such art events even more. In the coming years, besides those printmaking and reproductions, more than one exhibition was held, and those important artists like 
Degas took their places in those exhibitions. Also, in Vienna, an exhibition, where printmakings were displayed, was arranged by the Association of Reproduction Works of Art. It is also stated that in 1895, great numbers of exhibitions, as examples of on both some original and reproduction retrospective works of art created by lithographic techniques, were opened during the last decade of 19th century (Verhoogt, 2007).
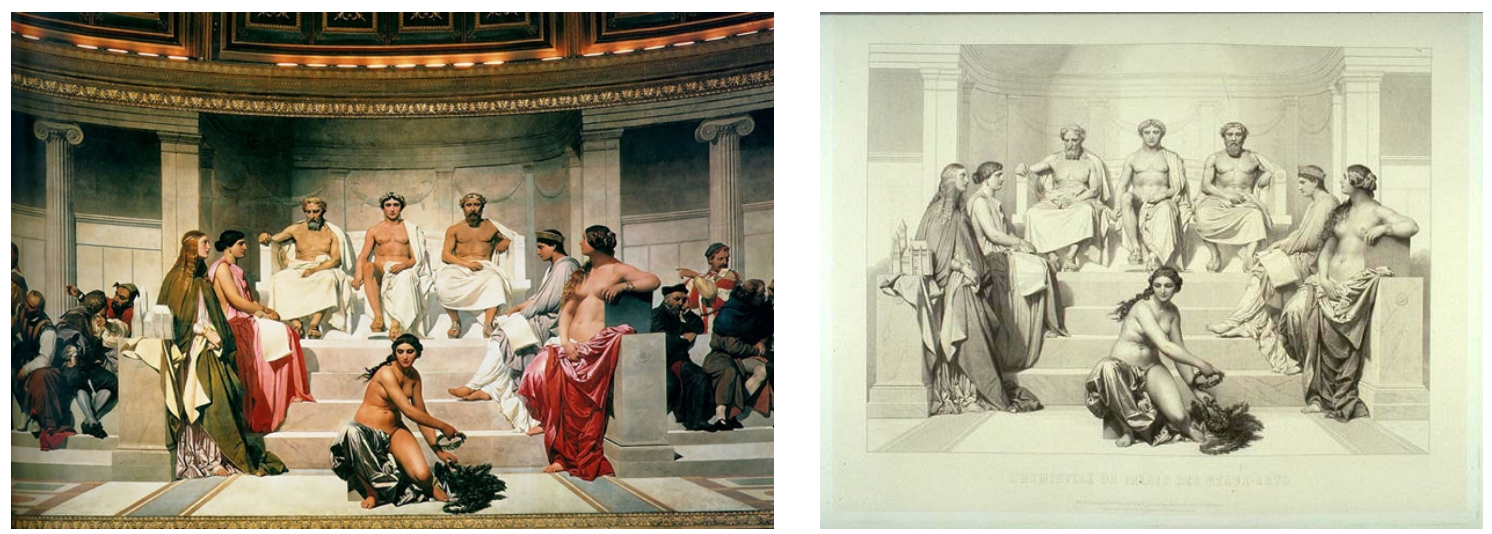

Figure 6: Left Side; Paul Delaroche, "Central portion of "L'Hémicycle des Beaux-arts" École nationale supérieure des beaux-arts", Paris. Oil and wax on wall. 1841-1842.

Right Side; Louis-Pierre Henriquel-Dupont, Central panel of "L'Hémicycle des Beaux-arts" after Paul Delaroche, Copperplate. 1797-1856

Another artist Toulouse Lautrec, who was influenced by Japanese woodcuts, reflected descriptions of women's daily routine with those exaggerated colours as in the Kabuki theatre printings, contours and face expressions in the lithography just like Degas did. To express and describe more explicitly, interests and preferences of some prominent romantic artists of that period reflecting the style in printmaking on the Ukiyo-e pictures around the markets in Europe presented the possibility of being experienced as a different and an aesthetically new form of art (Figure 7) (Wagner, 2016).
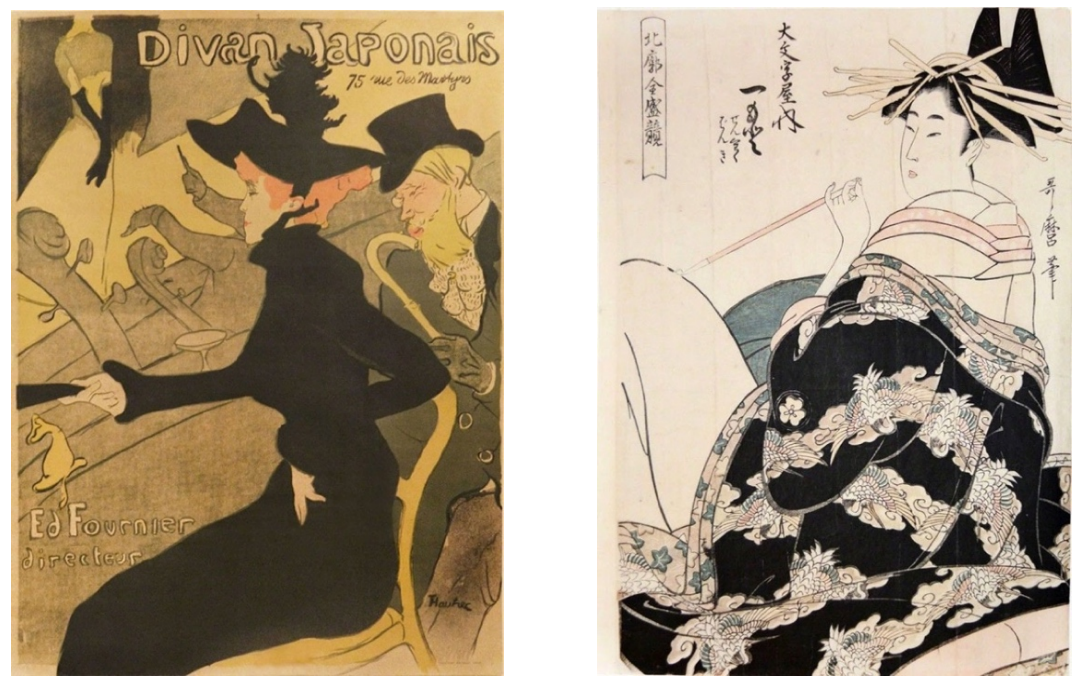

Figure 7: Left Side; Henri de Toulouse Lautrec, Divan Japonais, Ronin Gallery, 1892-1893

Right Side; Kitagawa Utamaro, Courtesan Hitomoto from the House of Daimonjiya,, Ronin Gallery, 1805. (Artsy, 2016)

"Les Nabis", which was established by a group of French artists engaged in performing their careers in Paris from 1888 to 1900 during that early transition period, played an important role while moving from Impressionism, Symbolism, and other movements. Among their members, Pierre Bonnard, Maurice Denis, Paul Ranson, Eduard Vuillard, Ker-Xavier, Felix Vallotton and Paul Serusier took their prominent places in the history of Fine Arts. It is stated that most of those artists who set up that group were students at the Academia of Jullian in Paris during the late 1880s. They moved forward by adopting the principle and the determination to innovate the drawing and painting art, the drawing and painting art is 
not a description of the nature, but it is a synthesis of the symbols and metaphor created by the painters. It was stated that the group which opened their last exhibition in 1900 dispersed later (Ives, 1990).

The members of the young artists group "Les Nabis" and among those frontiers of the movement of representatives namely painters Edouard Vulliard and Pierre Bonnard, were influenced by Hokusai and some other Japanese printmaker's prints (Duncan, 1949). And they produced some printmaking being affected by their striking sharp compositions of Ukiyo-e and their unusual points of view (Figure 8). Only Paul Gaugin, who was interested in local arts of many cultures but avoided the lithography application of that era, was also mentioned that he applied some abstract techniques of woodcuts as well as its abstract expressions of prospective practices that art (Ives, 1990).

Samuel Siefried Bing, who was engaged in the trade of art businesses, took an important role in dealing with the effects of Japanese arts and their influences on the 20th century European art trends and movements. Being a pioneer in the efforts and activities to introduce Japanese art and their printmakings Bing paved the way to improve the style of Art Nouveau at the end of the 19th century (R.C., 1905). He also published a monthly magazine namely "Le Japon Artistique" which were compiled in three volumes from 1888 to 1891 (Figure 8). It is commented that the art magazine "Le Japon Artistique" influenced various artists such as Gustav Klimt. Besides, Bing arranged a huge exhibition composed of those 700 printmaking which he brought from Japan in 1890, and afterwards he gave away them to the Louvre Museum and thus he provided a significant support (R.C., 1905).

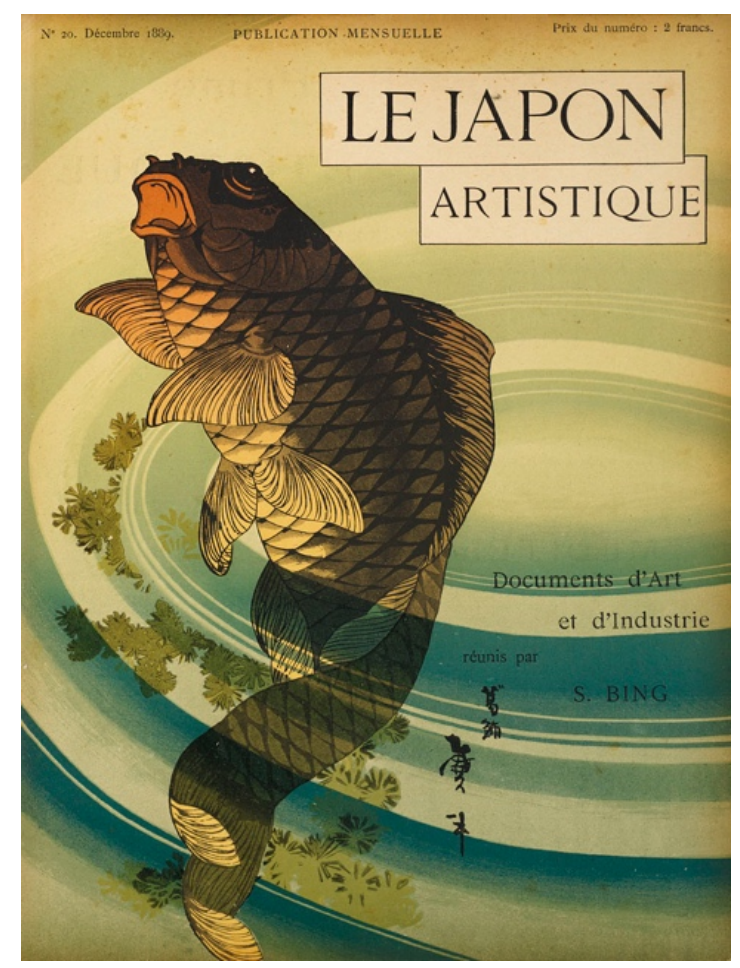

Figure 8: Le Japon artistique publication mensuelle no.20 décembre 1889

Academie Julian, which was established at Passage des Panoramas in Paris by Rudolphe Julian, is a private school of art which intends to transform the basis of art (Russell, 1989). Pierre Bonnard, who was a member of the group of young artists "Les Nabis", was affected considerably by the works of art displayed in the exhibition opened in the gallery of "Ecole des Beaux-Arts" in 1900. Those effects were also reflected on his art and played a significant role in his style of art (Figure 9). Hokusai's and some other Japanese woodcuts were displayed in the exhibition, which was organized by art dealer Bing, with Ukiyo-e prints which he brought from Japan. It is stated that the exhibition, which consisted of approximately 700 woodcuts displayed during that exhibition composed of important selections, was admired greatly by the painters of that period.

As it was mentioned above, the interaction on the artists of the Japanese traditional woodcuts among the European Artists and their interests improved and continued even more after their travels to the East. The Scottish watercolor painter Elizabeth Keith, interested in Japanese Ukiyo-e, manufactured a considerable number of printmaking after she paid a visit to Japan, China, Korea and the Philippines. 

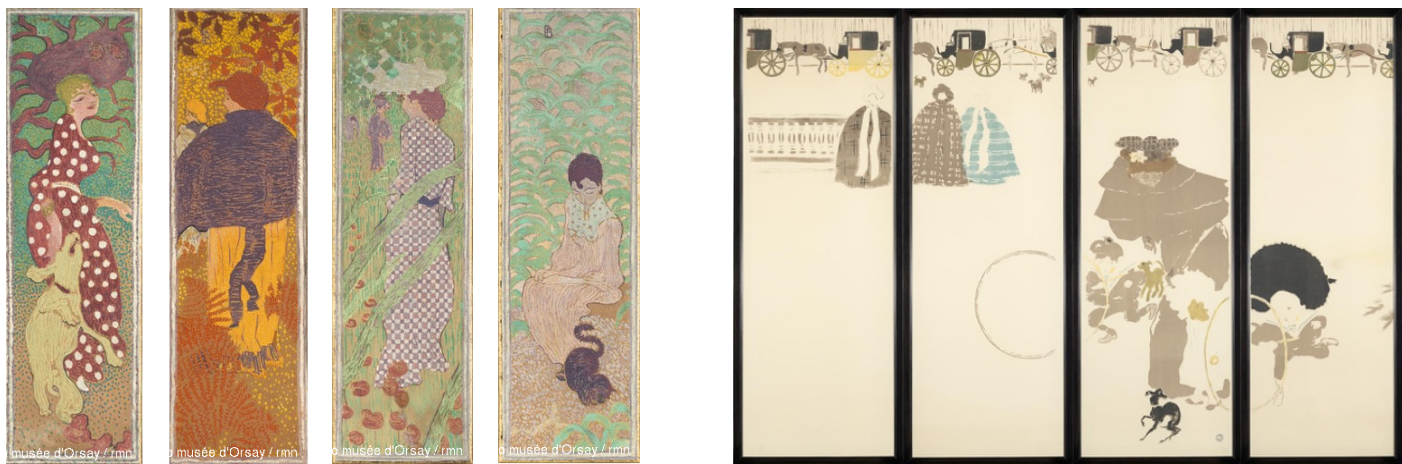

Figure 9: Left Side; Pierre Bonnard, "Femmes au jardin", Women in the Garden (1890-91), in the Japanese kakemono style, Musée d'Orsay, 1890-91

Right Side; Nannies' Promenade, decorative screen showing a procession of carriages with nurses and children (1897), National Gallery of Victoria. As in Japanese screens, the action is read from right to left.

With the attraction of the Asian culture and art, unlike the other European artists, it is possible to see the effects woodcuts in her works of art as she described Asian way of life and culture (Figure 10). It is stated that the artist Elizabeth Keith was influenced by the artists Katsushika Hokusai, Ando Hiroshige and Kitagawa Utamaro's woodcuts and she learned their art by imitating their prints (Merritt and Yamada, 1995). Keith's woodcuts became popular not only in Japan but also in London and New York became popular at the same time. Landscapes, people wearing traditional and usual clothes and their cultural rituals and images are in the centre of her woodcuts. Besides, it is also stated that Elizabeth Keith made woodcut printings of portraits called "portraits of taste" or "Xingle tu" in the Chinese portrait tradition (Claypool, 2014).

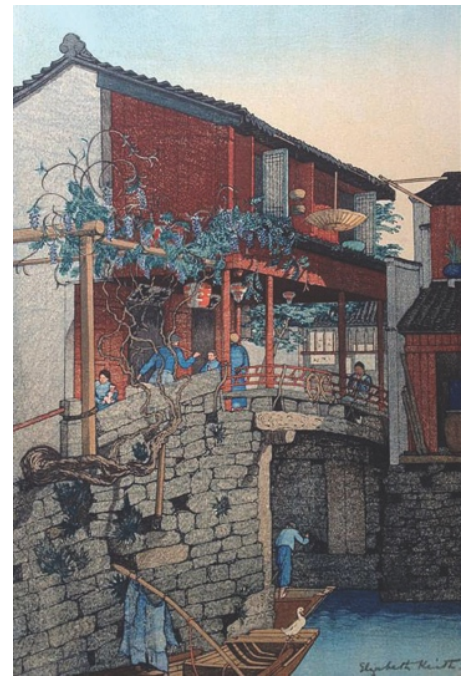

Figure 10: Elizabeth Keith, "Wisteria Bidge", Woodblock Print, 1925. (Modern Prints, 2020)

Those Shin-hanga woodcuts, which were popular in the early 1700, were transformed into the rebirth of art in Japan in the early 20th century. This movement of art, which continued with slight and short effects in 1946s and 1950s, was said that it was developed between 1915 and 1942. Between the 17th and the 19th century, during the Edo and Meiji periods, Taishö and Shöwa, revitalizing the arts of Shin-hanga, traditional Ukiyo-e again this style of art was, reborn. The art of woodcut production consisted of actions of a team which was directed by an artist. Such activities of art included team work starting from the draft of the artist and water colour pictures and a few wooden blocks being cut through for each definite colour and those wooden blocks being printed on sheets of paper by another team member (Newland, 2006).

Some creative woodcut printings and those pioneers of Shin-hanga art, which means new woodcut printings, were influenced by the European Impressionism movement at the beginning of the 20th century. They have spared place to the elements of the west in their compositions as a way of expression 
of their individual states of soul and effects of light on them (Newland, 2006). They added natural lights, shades, textures and perspective views to their works of art so as to reveal the silence and peace of the human and nature being together with each other as it was in the movement of impressionism. They also manufactured the sort of printmaking which depict famous places (meishö), landscapes (fukeiga), beautiful women (bijin ga), Kabuki Actors (yakusha-e), birds and flowers (kachö-e) and so on, concentrated on traditional topics within this content (Newland, 2006).

Lillian May Miller was an American painter who was born in Tokyo in 1895. She manufactured various woodcuts by adopting traditional Japanese art in which she was fond of, going through education and training in Japanese print art (Figure 11). Moreover, Miller included human beings and landscapes in some of her Shin-hanga being inspired by printmaking depicting the periods when she lived in Korea and Japan. Her works of art and presentations consist of lyric drawings, watercolours and woodcuts. Unlike other artists, Miller performed all stages of her production processes of her works of art alone by herself, and she sealed and signed her pictures with her own monogram made by herself (Frost, 2017). Women artists from the West, Helen Hyde, Elizabetk Keith and Bertha Lum, who began to make Shin-hanga in 1901 for the first time, all lived in Japan, but Lillian May Miller was the only woman artist who was recorded in history as a woman artist born in the Far East (Frost, 2017).

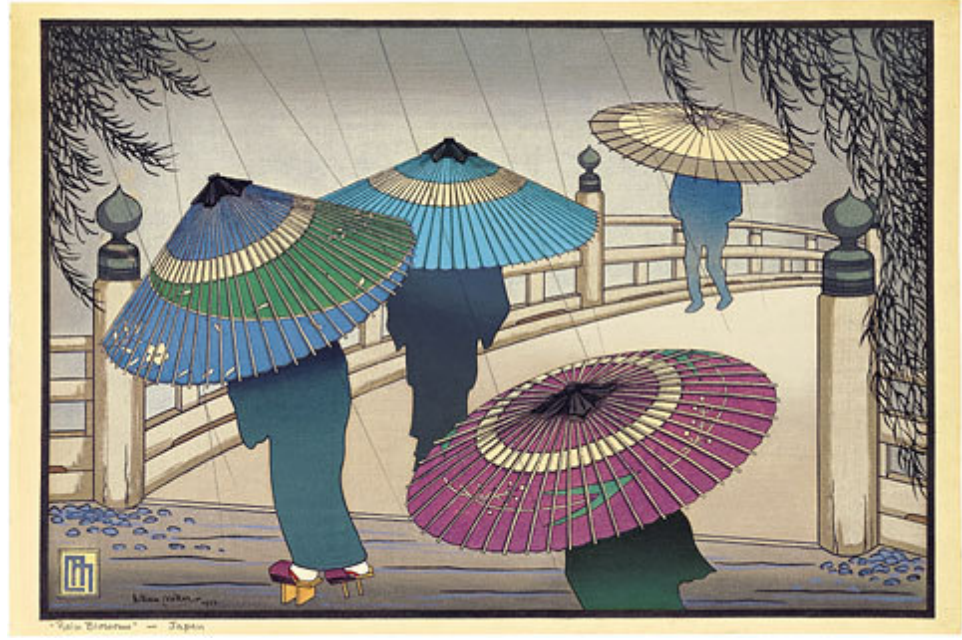

Figure 11: Lilian May Miller "Rain Blossoms", Woodblock Print, 1928

Die Brücke was established in the city of Dresden in 1905 by four German painters under the leadership of Ernst Ludwig Kirchner. This group, which was recognized as the founder organization of the German Expressionist movement, did not use their title at first, but another group of young artists who shared similar opinions was established in Munich titled Der Blaue Reiter (The Blue Rider) in 1911. It was stated the Der Bluae Reiter Painting by Wassilly Kandinsky's painting was named after the group (Barron, 1988). Under the leadership of Kandinsky, Franz Mark, Paul Klee and Auguste Macke, Erch Heckel announced that their title was Die Brücke (Bridge), and they followed footprints of their ancestors. Great German artists of the Renaissance, like Dürer, stated that they were trying to create a combination of the art of the day, with especially those works of art and masterpieces manufactured by great German Renaissance painter's engravings which were all made by competent artists, so as to start a new German Renaissance movement by creating a connective form of art (Spaightwood Galleries, 2019).

Those Expressionists, who depicted the devastating consequences of industrialization and urbanization as well as social problems, were inspired by Medieval woodcuts. To express the disappointment, anxiety felt by people due to the conducts of injustice, they used woodcuts. They printed their works of art by using only black ink so that they can reflect and create a powerful and dramatic effect in their works of art. Those works of art made by German Expressionist Kathe Kollwitz's such as "Weavers" and the "Peasants' War" may be shown as examples of woodcuts which try to reflect social conscious, and sorrows of mankind, motherhood attitude in thematic art of social awareness. (Figure 12). Another sample was "Wordless Novel". The wordless novel is one of the first samples of the German Expressionist Movement which began at the beginning of the 20th century and their first samples of art appeared in the "The 25 Images of A Man's Passion" by Flemish artist Frans Masereel published in 1918. It is stated that German Otto Nückel and some other artists followed Masereel's book after this first sample (Figure 13). 


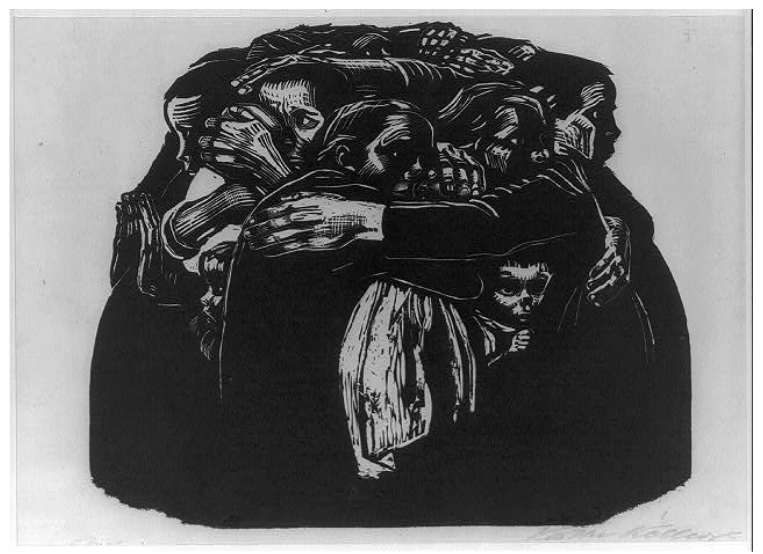

Figure 12: Kollwitz, Käthe, "Die Mütter" (The Mothers), Woodcut, Library of Congress 1922
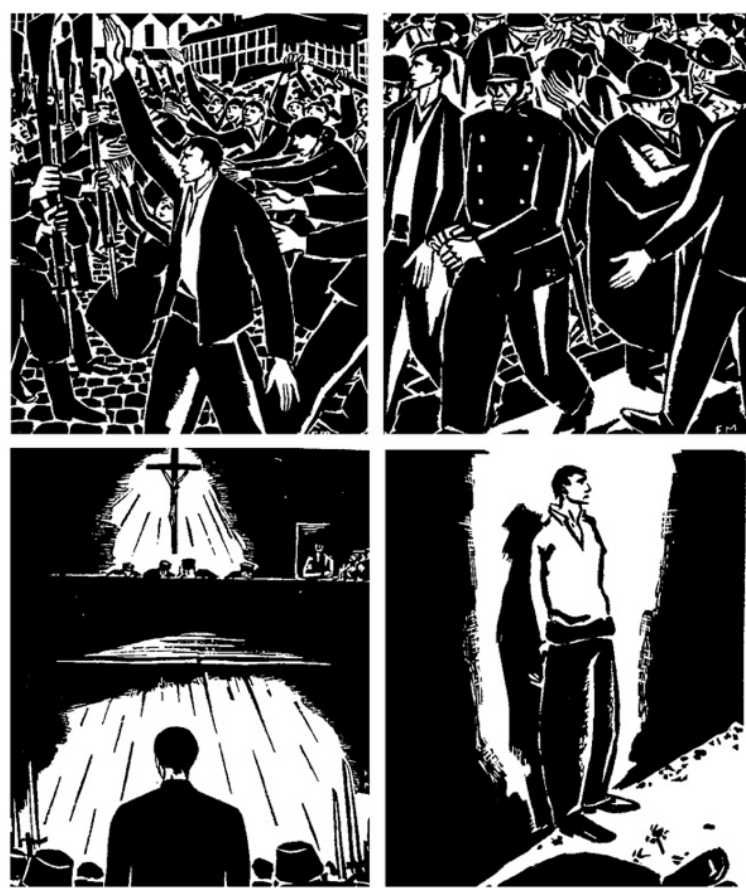

Figure 13: Frans Masereel, Final four panels from the wordless novel 25 Images of a Man's Passion, Frans-Masereel-Foundation, 1918

\section{CONCLUSIONS}

Among the movement of modern art, the movement of Expressionism may be deemed as an important and unique form of art belonging to Europe within the content of pioneers' cultural movement just like the German Expressionist Movement. Samples of those traditional Japanese printmaking which arrived in Europe became a source inspiration for the European artists during their presentations of art by sparing a place to different practices and applications and thus it paved the way to increase co-operations and collaborations. Thanks to this industry and art partnership and collaboration Degas printed "Vingt Dessins" plates just like Dürer and thus he advanced his work of art by making some new arrangements intellectually in his printmaking activities. Manzi's competence and daintiness enabled him to manufacture his works of art without causing any waste and competence of Degas in producing patterns and shapes flawlessly enhanced their co-operation and collaboration while they were trying some new methods of art. Consequently, it turned out to be an efficient partnership which enabled them to boost both their draftsmanship to obtaining perfect printing results by working together with competent printmaker. 
Those Expressionists, who depicted the devastating results of industrialization and urbanization which caused many social unrests and problems, got inspired by those woodcut printing made during the Medieval Age, and they used woodcut printing to express their anxiety and disappointment towards social injustice. Artists created a strong dramatic effect by using only black ink. The effect of power of the single colour woodcut printings and samples of some other forms such as "Wordless Novel" supported German Expressionist Movement. Expressionism, which includes ethical, artistic and philosophical superstructure institutions of that period, affected the modern art to discover its new functions and fields of engagement- and also to create new ways of communication language as well as some new forms (26). Thus, Expressionism proceeds to be an influential art movement with the impulse it gained from the main sources of art as a cultural movement which reflects its effective impact in art even nowadays.

\section{REFERENCES}

[1] Barron, S.: "German Expressionism 1915-1925 the Second Generation", (Prestel Publishing, New York NY, 1988.)

[2] BBC Radio 3 - Sunday Feature: "Albrecht Durer: Printing Press Native", URL: https://www.bbc.co.uk/programmes/b03q59w4 (last request: 2019-11-20).

[3] Claypool, L.: "Feminine Orientalism or Modern Enchantment? Peiping and the Graphic Artists Elizabeth Keith and Bertha Lum, 1920s-1930s", Nan Nü 16 (1), 91-127, 2014. doi: 10.1163/15685268-00161p04.

[4] Duncan P.: "Volume Information", The Kenyon Review 11 (4), 561-566, 1949.

[5] Frost, F.: "Remembering Lilian Miller, The Pioneering Woodblock Arist Caught Between East and West”, URL: https://www.atlasobscura.com/articles/lilian-miller-woodblock-artist-japan (last request: 2017-12-01).

[6] Genc, A.: "Tümel bir varım olarak Alman Ekspresyonizmi" (Hacettepe University Faculty of Fine Arts Publications, Ankara, 1987.), pages 55-61.

[7] Ives C.: "Japonisme.In Heilbrunn Timeline of Art History.", URL: https://www.metmuseum.org/toah/hd/jpon/hd_jpon.htm (last request: 2020-07-20)

[8] Ives C.: "Review: The Nabis and the French Popular Press", Print Quarterly 7 (1), 84-87, 1990.

[9] Kovacs, C. L.: "Degas and Manzi's Vingt Dessins: an experimental collaboration in print", URL: https://scalar.usc.edu/works/vingt_dessins/introduction?path=index (last request: 2016-02-01)

[10] Merritt, H., Yamada, N.: "Guide to Modern Japanese Woodblock Prints: 1900-1975", (University of Hawaii, Honoluli, 1995.)

[11] Newland, A. R.: "The Hotel Encyclopedia of Japanese Woodblock Prints", (Hotei Publishing, Leiden, 2006.)

[12] Russell J.: "An Art School That Also Taught Life", URL: https://www.nytimes.com/1989/03/19/arts/art-view-an-art-school-that-also-taught-life.html (last request: 1989-03-19).

[13] R., C.: "The Passing of Siegfried Bing", Brush and Pencil 16 (5), 161-164, 1905.

[14] Savage, S., Kemble, B. A.: "Printmaking from 1400 to 1700 with a catalogue of the print collection at the Dallas Museum of Art", MSc Thesis, North Texas State University, 1982.

[15] Schenkel. R.: "Edgar Degas (1834-1917): Painting and Drawing", URL: https://www.metmuseum.org/toah/hd/dgsp/hd_dgsp.htm (last request: 2020-07-20).

[16] Spira, F.: "Etcher Sketch: A Conversation with Nadine Orenstein and Freyda Spira About The Renaissance of Etching", Art in Print 9(4), 2019.

[17] Spaightwood Galleries: "German Expressionist Prints and Drawings: Portraits and Self-Portraits",

[18] URL: http://www.spaightwoodgalleries.com/Pages/Exhibitions_German_Exp.html (last request: 2019-06-23).

[19] Verhoogt, R.: "ART in Reproduction: Nineteenth-Century Prints after Lawrence Alma-Tadema, Jozef Israëlsand Ary Scheffer", (Amsterdam University Press, Amsterdam, 2007.)

[20] Wagner, A.: "Ronin Gallery Highlights the Crucial Influence Japanese Art Had on Toulouse-Lautrec", URL: https://www.artsy.net/article/artsy-ronin-gallery-highlights-the-crucial-influence-japanese-arthad-on-toulouse-lautrec (last request: 2016-03-10). 


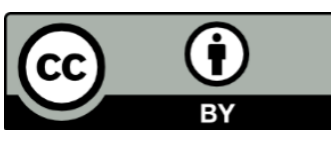

(C) 2020 Authors. Published by the University of Novi Sad, Faculty of Technical Sciences, Department of Graphic Engineering and Design. This article is an open access article distributed under the terms and conditions of the Creative Commons Attribution license 3.0 Serbia

(http://creativecommons.org/licenses/by/3.0/rs/). 
DIGITAL MEDIA

W 



\title{
VISUALIZATION OF THE PROCESS-RESOURCE MODEL FOR WORKFLOWS
}

\author{
Thomas Hoffman-Walbeck ${ }^{1}$ (D), Richard Adams II $^{2}$ \\ ${ }^{1}$ Stuttgart Media University, Stuttgart, Germany \\ ${ }^{2}$ Ryerson University, Toronto, Canada
}

\begin{abstract}
We describe the design of a Javascript prototype that allows the user to visualize an arbitrary production workflow for print production that is based on the Process-Resource Model. The user can create square cards of type "process," "resource" or "resource group." For each card, a name might be chosen out of a list and neighboring relations can be set (input and output). Each card should be positioned on a fixed grid. Finally, the user can check the workflow design according to different reasoning.
\end{abstract}

Key words: Workflow, Process Resource Model, Visualization, JavaScript, JDF

\section{INTRODUCTION}

For the graphic arts industry, automation is the key to reducing human touchpoints in the production process. In very general terms, this can be done by optimizing the organization and improving devices (machines or software modules) that handle one or more production processes. Device optimizations are achieved either by shortening the presetting time or by automating the actual production phase.

Especially for presetting, a device needs data that is generated outside of the device. For example, a printing press needs to know the type, quality, thickness, and dimension of the printing substrates, the primary inks and the printing sequence and so on. Of course, the press also needs physical assets like the actual paper, ink, and printing forms (plates) for conventional printing. Both these physical assets and the data we subsume under the notion "resources." That is, the process "printing" needs input resources, then it generates an output resource (print sheets), which in turn will be inputted by the next process. A "Process-Resource Model" (PRM) is a description of (production) steps via processes and resources in a net topology.

"Workflow automation" denotes the method of providing input resources for processes automatically as well as importing theses resources into a device so that devices can react on them in a self-acting manner. The data formats JDF/JMF (CIP4, 2018a) and XJDF/XJMF (CIP4, 2018b) are based on the PRM.

As a user, one does not pay attention to these formats, just as little as the underlying PRM. For the planning of new production methods or production lines, however, an understanding of PRM is essential. In order to communicate a PRM (e.g., between Print Provider and system integrator), a visualization of PRMs are necessary. Since there is no standard method and no tool of visualizing a PRM, we developed a JavaScript-based interactive tool called "Workflow Arrows."

\section{HOW TO USE THE SCRIPT}

We called the script "Workflow Arrows," because input and output resources are linked to processes by arrows. We hosted the script under:

\section{https://www.ryerson.ca/ wdp/workflow-puzzle/print/Test/Workflow_Arrows.html.}

We encourage you to try it out yourself.

Figure 1 shows the user interface of the script as well as an example of a workflow description for a hardcover book production.

In "Card Type," you can define whether the card should represent a process (yellow), a resource (blue), or process group (gray). Process groups are collections of processes, which can be handled in the tool like a process. The difference is that a process group contains several processes or - in other words - they represent a wider range of the print production, like "Prepress Preps."

Please note, that a resource cannot generate a process and similarly a process cannot generate a process. That is, a processes and resources always have to alternate. 


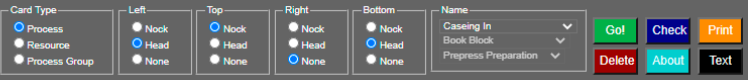

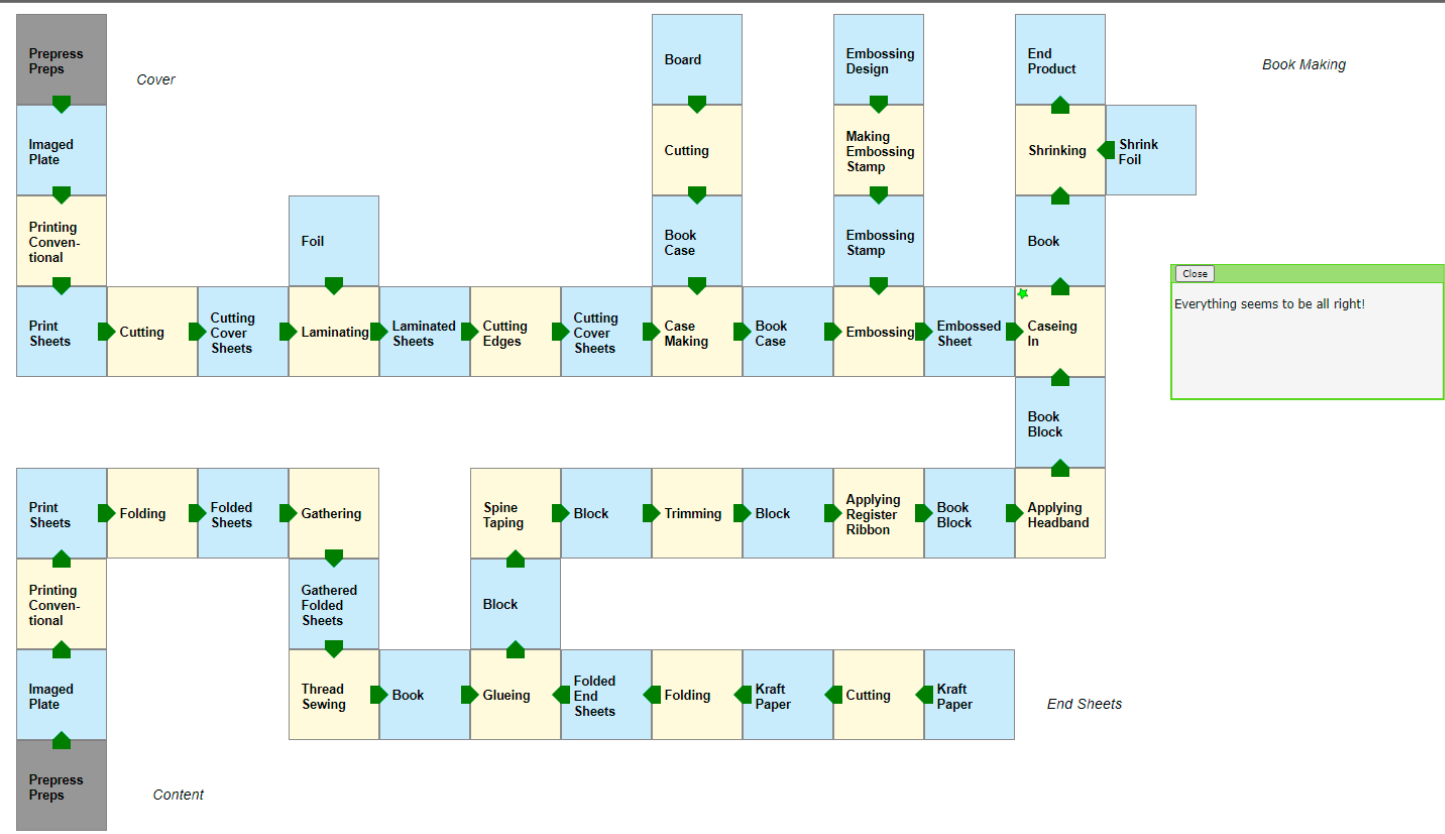

Figure 1: Process-Resource model for the hardcover book production. The small green dialog box on the right shows the result of the "check".

Arrows indicate the connection of resources and processes. Each arrow consists of two parts: The arrow nock (a rectangle) and the arrowhead (a triangle). Each arrow nock needs an arrowhead as a counterpart. For example, in Figure 2 the process card "Folding" has an arrow nock on the right-hand edge, while the resource card "Folded Sheets" has an arrow head on the left-hand edge. For each edge of a card, you may create arrow nocks or arrowheads. You also should choose a specific name of a process, group, or resource from the list.

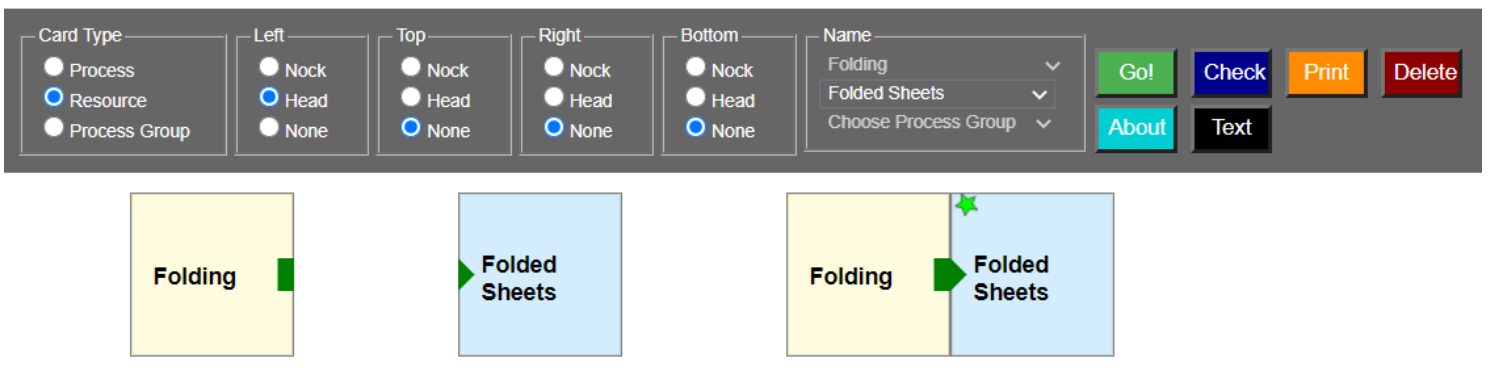

Figure 2: An arrow nock and an arrowhead compose an arrow. On the right-hand side, the two cards are next to each other-building a proper arrow.

After specifying the type, the arrows and the name of a card, clicking on the button "go" will create the HTML element. Next, you need to move the card to its approximate position. It will snap onto an invisible grid. A little green star on the upper left corner of the card indicates the last card you moved to the grid (or the last selected card).

If the user cannot find the card name in the list, she or he can create an own name by clicking on ** Own Process**, ** Own Resource**, or ** Own Process Group** in selection list "Name." In Figure 3, the card "Wand" and "Perform Magic" are generated that way. 


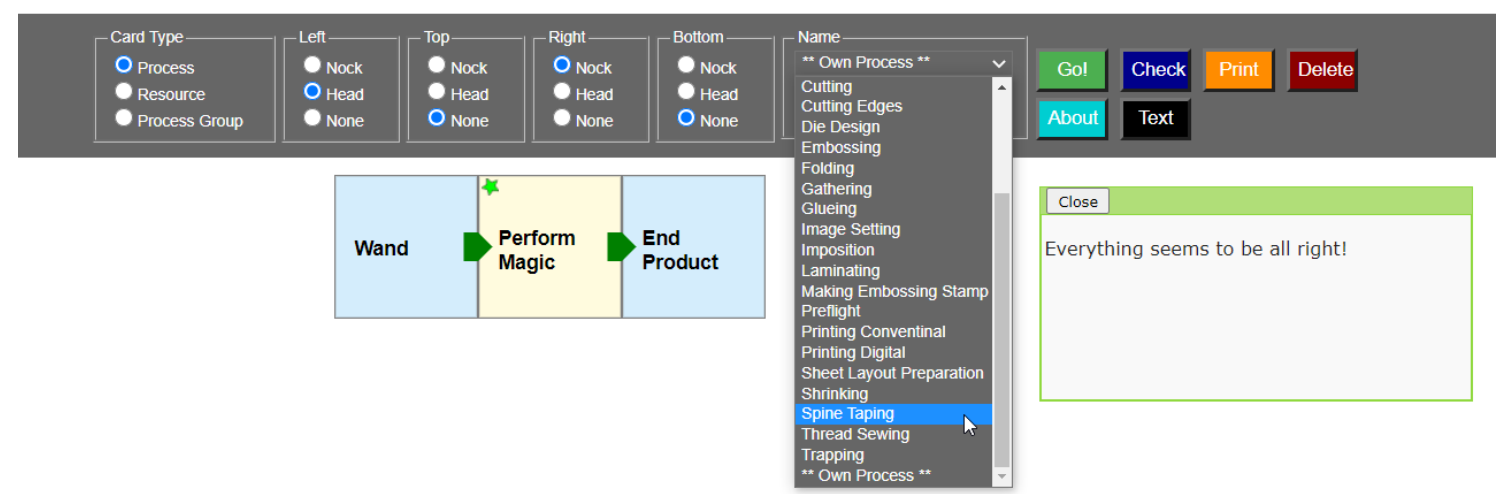

Figure 3: Names of processes, resources or process groups can be defined arbitrarily

Each PRM needs a start and an end. They can be either a process card or a resource card. A start card may not have any input; the end card may not have any output. Typically, the end card represents the final product.

A workflow can be checked by clicking on the button "check." However, only the formal structure of the PRM will be analyzed. For example, it will be checked, if there are at least one start card and one end card available and whether the structure follows the PRM requirements, e.g., alternating processes and resources. However, the user is responsible for laying out the right processes and resources for the production. If no error is found, there will be the message "Everything seems to be all right!" (See Figure 3). If the script finds a mistake, it will be describes accordingly as to be seen in Figure 4.

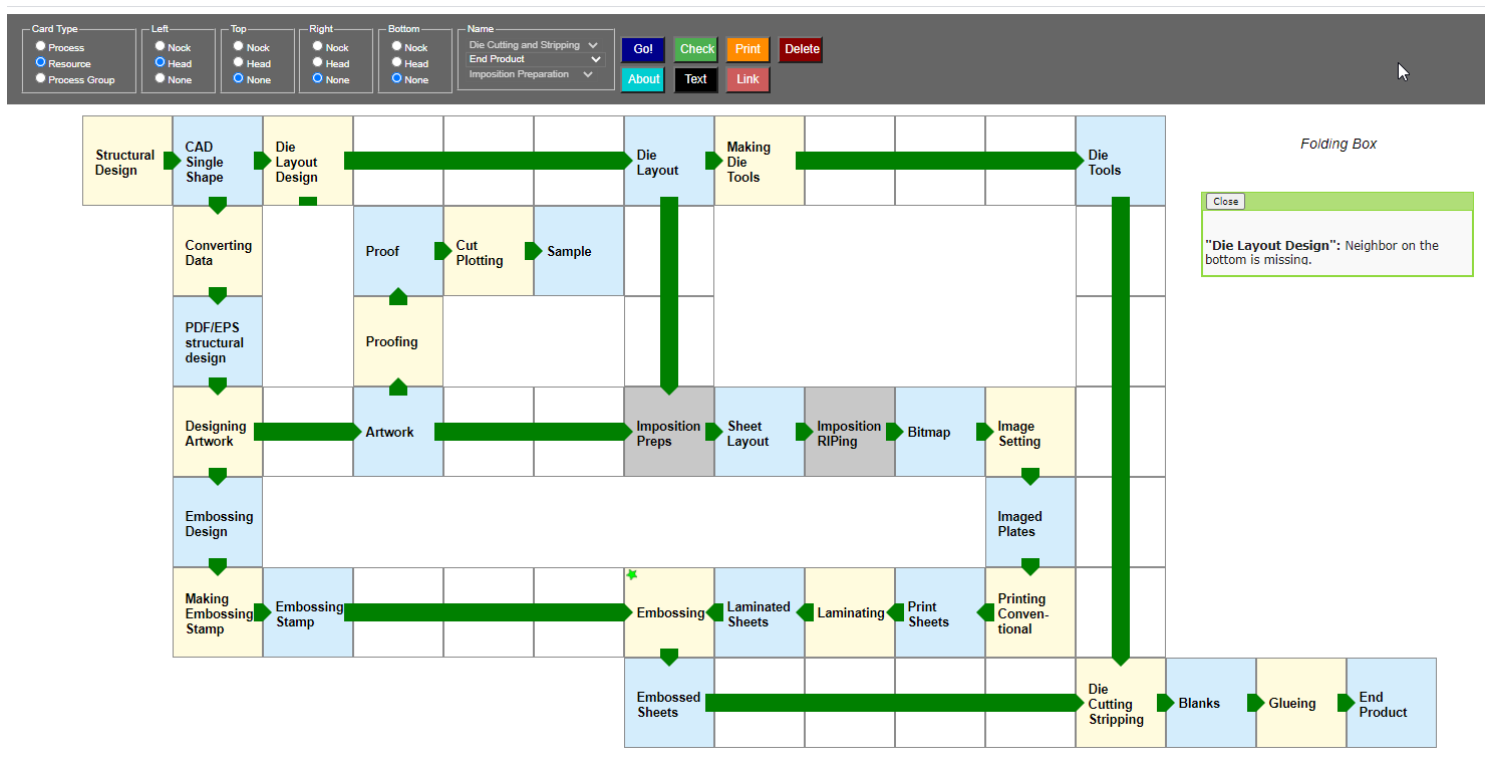

Figure 4: The Workflow describes the production of folding boxes. Please note that the check found an error. There is a mistake in the card "Die Layout Design", which erroneously has an arrow nock at the bottom edge.

In a more complex workflow like shown in Figure 4, it is necessary to combine cards that are not direct neighbors. This can be achieved by using the button "link." Before that the edges have to be specified, whereas is does not make any difference if you click on "nock" or "head."

\section{TOOLS}

We wrote the tool in HTML 5 (W3C, 2017) and JavaScript (W3C, 2020). We deployed the JavaScript libraries jQuery (version 3.5.1) and jQuery UI (version 1.12.1) (JQuery, 2020). Editing the code, we used Brackets (Release 1.14) (Adobe, 2020). For testing and debugging the HTML and JavaScript, we loaded the 
code into Google Chrome (Version 83.0.4103.61) and Mozilla Firefox (version 76.0.1). All of these tools can be downloaded free of charge.

\section{IMPLEMENTATION}

We were using standard JavaScript and jQuery to build the UI. The content of the cards are described in SVG (W3C, 2011), according to the setting of "Card Type", "Name", "Left", "Top", "Right" and "Bottom" in the UI.

In the script, we defined two classes, "Card" and "Cards". With the first one, we can define objects for each card, incorporating the following properties: "card Type", "Name", "Left", "Top", "Right", "Bottom", position (row/column on the grid), id of the HTML element and a Boolean variable, weather the element has been deleted or not.

The instance of class "Cards" incorporates an array of all card objects, that is, it defines the entire topology of the net.

The configuration of the cards can be stored in the local browser employing the web storage API. The data is stored as properties of the storage object, i.e. as key/value pairs. Of course, the data can also be retrieved from there.

\section{DISCUSSION}

Many small enhancements are needed before this prototype could become an application. It would be more challenging, however, to add certain production requirements to be tested concerning rules like "Image Setting must be followed by Imaged Plate," "Imaged Plate must be followed by Conventional Printing," Image Setting is a Prepress process," "folding is a Postpress process," "Prepress process must not be behind a Postpress process" and so on. Possibly, Al method could be employed.

\section{REFERENCES}

[1] Adobe (2020): "Brackets, version 1.14.2", URL: http://brackets.io/ (last request: 2020-08-15.)

[2] CIP4 (2018a): "Cooperation for the Integration of Processes in Prepress, Press, and Postpress (CIP4): "JDF Specification 1.6-final (2018)", URL: https://confluence.cip4.org/display/PUB/JDF (last request: 2020-08-14.).

[3] CIP4 (2018b): "Cooperation for the Integration of Processes in Prepress, Press, and Postpress (CIP4): “XJDF 2.0 (2018) ", URL: https://confluence.cip4.org/display/PUB/XJDF (last request: 2020-08-14.).

[4] JQuery (2020): "Open JS Foundation (Linux Foundation Projects): jQuery 3.5.1", URL: https://jquery.com/ (last request: 2020-08-15.)

[5] W3C (2017): "HTML 5.2 (2017)", URL: https://www.w3.org/TR/html52/ (last request: 2020-08-15.)

[6] W3C (2020): "JavaScript Tutorial", URL: https://www.w3schools.com/js/DEFAULT.asp (last request: 2020-08-16.)

[7] W3C (2011): "Scalable Vector Graphics (SVG) 1.1, Second Edition, 2011", URL: https://www.w3.org/TR/SVG11/ (last request: 2020-08-15.)

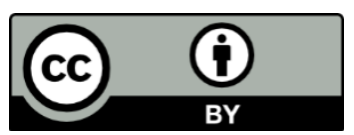

(C) 2020 Authors. Published by the University of Novi Sad, Faculty of Technical Sciences, Department of Graphic Engineering and Design. This article is an open access article distributed under the terms and conditions of the Creative Commons Attribution license 3.0 Serbia (http://creativecommons.org/licenses/by/3.0/rs/). 


\title{
DEVELOPMENT OF CHILDREN'S COGNITIVE ABILITIES THROUGH INTERACTIVE APPLICATIONS
}

\author{
Filip Mauzner, Lidija Mandić (iD), Ana Agić (iD), Jesenka Pibernik (iD) \\ University of Zagreb, Faculty of Graphic Arts, Zagreb, Croatia
}

\begin{abstract}
In this paper we present the development of cognitive abilities in kindergarten children with interactive applications. Practical part includes the design of application prototype used for the development of cognitive abilities in children age three to four. It comprises three categories in which children's cognitive abilities are tested and being developed. The categories are colors, numbers, shapes and sizes.
\end{abstract}

Key words: application, cognitive abbilities, color, numbers, shapes

\section{INTRODUCTION}

Today, children, no matter where they live, will have to face the phenomenon of change. To prepare children, in order to be ready to become persons who will reach new knowledge, it is necessary to develop the basics for learning skills that are key factors in meeting modern challenges.

In principle, in the field of early childhood education and development, there are two basic approaches to the study of children aged three to six (Hansen et al, 2006). The first is the behaviorist approach, which implies that the concepts of learning do not originate from the child himself and do not develop spontaneously. An approach that is fundamentally opposite to the behaviorist one is called a developmental approach. Two lines of development - natural and social - continuously interact with the development of the child's thinking. Cognitive development is initially the result of direct experience from the environment, but as they develop, children become able to transform their own experience through thinking. The pace of individual development depends on the social environment. Cognitive development involves large, qualitative changes in thinking. Piaget believed that children go through different stages as they grow up. The first is sensory motor, which occurs after birth and lasts until the second year (Duran, 1995). The second lasts from the second to the eleventh year and represents the degree of concrete action. The third occurs in early adolescence through the degree of formal actions. Vygotsky changes his mind about when children become able to communicate with the help of speech and when they are instructed to become aware of their own thoughts and master them. Erickson's theory speculates on three phases related to childhood that reflect an individual's relationship to the social environment. Healthy development is the resolution of conflicts typical of a certain age. From birth to the third year, the child develops trust, from the first to the third year the child develops his autonomy, and from the third to the sixth year the individual acquires a sense of initiative.

The Step by Step program is a unique program for children aged three to six and their families (Slunjski et al, 2014). The educational plan and program is such that it combines research practice in early childhood education and strong connections and work with families, in order to individualize the experiences of each child. The program is designed to meet the unique needs of each child, while taking into an account the diversity of cultures and traditions. The program is characterized by an emphasis on 3 basic principles: individualization, independent choice of activities and partnership with parents and other family members. The philosophy of the program is based on the belief that children develop best when they are truly involved in their own learning. Important features that the "Step by Step" program encourages in children are the ability to adequately cope with influence change, to make critical judgments and choices and to detect and solve problems

\section{THE INFLUENCE OF INTERACTIVE MEDIA ON CHILDREN`S DEVELOPMENT}

With so many variations of types games, it is difficult to guess whether the games are generally good or bad. Numerous studies have been conducted on this topic and information on the advantages and disadvantages they can be easily found. Studies have shown a negative impact video games for younger generations. Kids who spend more time playing violent games had faster heartbeats, more often reported dizziness and nausea and showed more aggressive thoughts in a later test than children who played 
nonviolently games (Shapiro, 2014). Another reason for the negative impact of games on children is the impact on their social life. Children prefer to play on a console or mobile phone instead of playing outdoors, on a playground, etc. Children are less likely to enroll in extracurricular activities which prevents them from meeting new people and making new friendships. Positive aspects of games have shown that playing video games can be useful for the development of many cognitive functions and can also be socially beneficial (Venderbilt, 2014). Players can learn strategy and expectations, resource management, recognition samples, quantitative calculations, etc. Players also get used to multitasking (performing multiple actions simultaneously) through tasks that force them to simultaneously deal with multiple elements or ideas in the game. There are advantages: such as the development of hand-eye coordination, fine motor skills and a sense of space. Games also contain social component, stimulate communication and the learning experience. They are often already familiar with downloading applications from service to the device and work with them. Most kids love to download apps that have fun like games, stories, videos, etc. In case parents are the ones downloading apps for their kids, they mostly prefer applications that are educational and creative. These are applications that focus on the development of specific sets skill. Children respond positively to awards and compliments which are good for their self-esteem. Challenging and rewarding applications make a child happy while using the application and thus ensure that you continue to use them.

\section{EXPERIMENT}

In the experimental part, an application was designed and developed for development of cognitive abilities of kindergarten children. The target age group were children from three to four years. The application contains material suitable for more advanced children suitable for the age group of four to five years. After the development, the research was carried out in the kindergarten group in the "Jarun Kindergarten" Medo group. The educators were performed certain aspects of research and participate in the development of games for children. The children were accessed according to the "Step by Step" program. The role of the educator was to respond to the results of solving children's tasks and determine in which areas and why a particular child has problems if the application indicates so.

The name of the application itself is "Cogi". The application is a demo version. („High fidelity” prototype) in which the emphasis is primarily on the functional part of the game in order to test the impact on the development of children's cognitive abilities. The app in the current demo version requires additional engagement a person, who guides the child through play on occasion solving because there is no built-in voice element that would guide the children in solving the game and setting tasks. The advantage of this engagement is the possibility observations of the child's attitude, desire and success of solving tasks.

The tasks are made according to the map of the appropriate development of children from three to four years according to the international program for children's development "Step by step". Advanced tasks are added according to the map of appropriate development of children from four up to five years of age from the same program. The basic things that are in the application from the map of appropriate development are: numbers from 0 to 4, advanced level: up to 7; basic RGB colors and variations of them, advanced level: random added colors and basic shapes and size ratio, advanced level: some shapes added and combinations and size relationships (largest, smallest)

The application contains four menus. The first is a simple game in which they are chosen levels and tasks to be solved. The first menu shows 5 active categories that children can solve. These five categories are gestures, colors, numbers, shapes and sizes and the last category is advanced that combines color numbers and shapes as it is shown in figure 1.

The second menu is the test menu the progress of each child can be monitored individually. The results can show how the child solves the game and progresses in individual categories. The number and result of individual games is visible, so it is from of this easily visible progress.

Next menu is results. The results can show how the child solves the game and progresses in individual categories. The number and result of individual games is visible, so it is from of this easily visible progress. The last menu is options and customizations for the app itself. The adjustments are simple and few: turn sound, voice, and animation on or off, or change of language. 


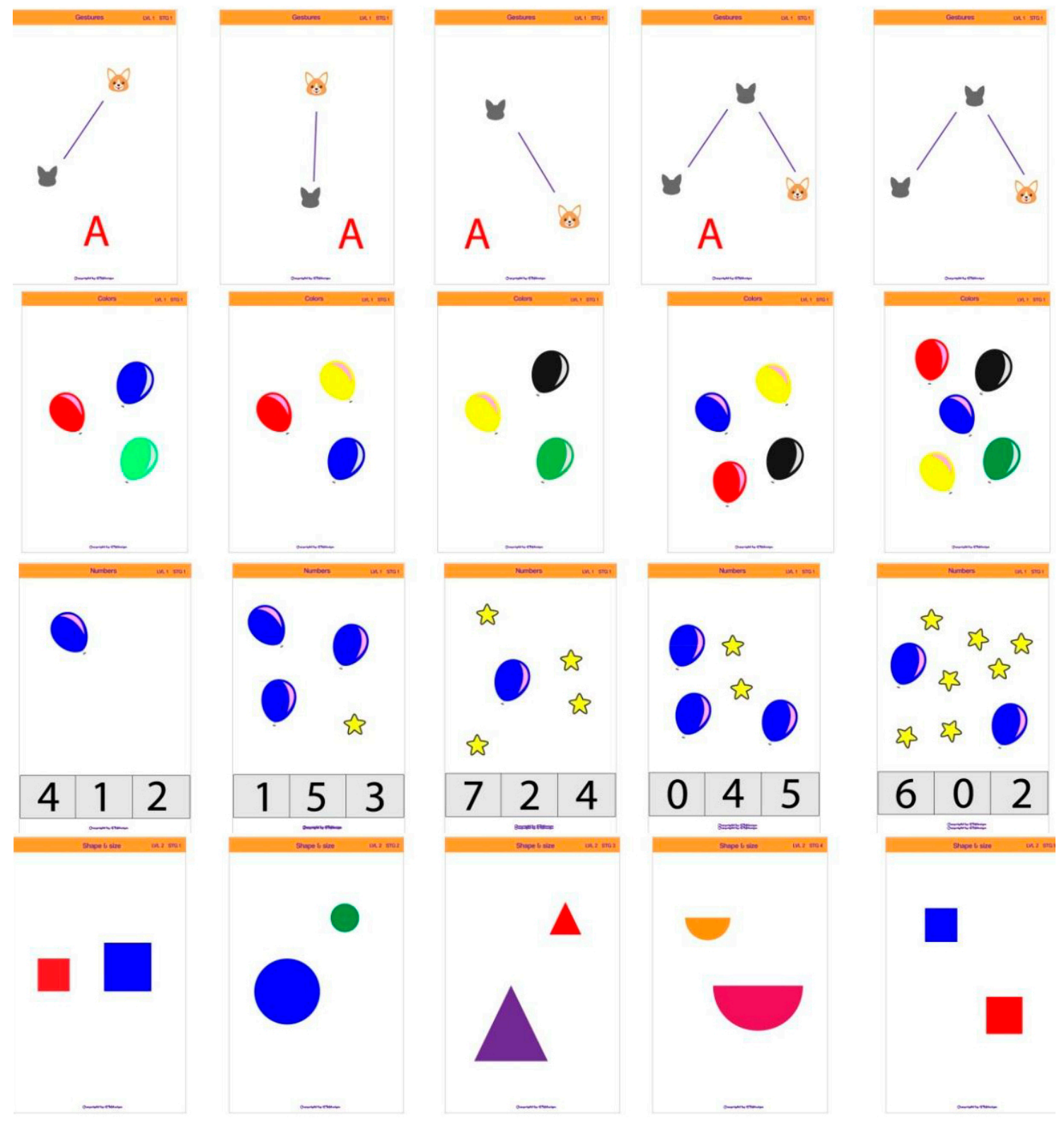

Figure 1: Categories: gestures, colors, numbers and size and shapes

The first category of the application is used to introduce the child to the gestures that operate on touch devices. Basic gestures include "touch", "swipe", drag and drop. The actions are straight, circular, with multiple elements at once to make the child already initially accustomed to different sides of the movement and the possibility of action on the screen. Tasks in which the elements are mixed colors encourage the child to conclude the correct response by elimination. First in tasks in which all the elements are in one color except the one that is the correct answer. Later, the number of multicolored elements increases and thus the number of colors with which a certain element is painted. In solving number tasks it is expected that children from three to four years of age recognize and count from 0 to 4 without major problems. The numbers are pretty represented in children's lives. Children like to count, look for two or three more sweets, etc. As the level increases, children are given tasks with numbers up to 7 and it is important expose the child to a problem where they need to recognize what needs to be counted or if needed count all the elements in the picture. In fourth category it is necessary to distinguish between shapes and sizes. The forms are square, circle, triangle and semicircle. The most important item in this category is that children are slowly getting used to the proper one shape names like squares (not cubes) and to learn the size ratio: larger, largest. Children in the age group of three to 
four recognize which element it is larger but if there are more than two comparable elements they have problems with descriptions larger and largest.

In order to motivate the child and inform him about the success of solving with everyone with the correct answer the message bravo appears with the smiling face of the dog breed corgi and shows the child that he answered correctly. In case of incorrect the answer appears a sad figure of a dog.

Twenty-seven children were tested.

\section{RESULTS}

Three tests were conducted for all categories to see children's progress. From first testing with color the results show that children recognized the colors according to their age. The category with the numbers shows more deviation from the success of solving tasks regardless of the age of the children. Children have no problem recognizing the basics shapes and call them by proper names and compare their sizes and relationships. The interesting thing about the second round of testing is that there are some children who are either rejected whole first testing or given up in the middle of testing ask for playing. In the third testing, 4 children who had difficulty solving tests were tested again in order to find whether they will be more successful after repetitions.

\section{CONCLUSION}

Today, technology has large impact on children. Games have positive and negative impact on children. By concentrating on the positive influence of games we could develop children's cognitive abilities. Creating an application and testing show positive results in learning. Technology is still an element that can complement cognitive abilities but not replace it. Children need physical contact with the world, learn through touch, smell and other senses. Also, if today's technology is used in a coercive way, performance is drastically reduced. The role of parents, educators, friends and enemies no one application can replace. The symbiosis of the real and virtual world could benefit today's children on a larger scale level than ever before in history but only if it is properly implemented.

\section{REFERENCES}

[1] Duran, M.: "Dijete i igra”, (Naklada Slap, Jastrebarsko, 1995.).

[2] Hansen, K., Kauffman, R., Walsh, K.: "Kurikulum za vrtiće, Razvojno primjereni program od 3 do 6 godina", (Pučko otvoreno učilište Korak po Korak, Zagreb, 2006.).

[3] Shapiro, URL: http://www.forbes.com/sites/jordanshapiro/2014/08/27/a-surprisingnew-study-on-howvideo-games-impact-children/ - A surprising new study how video games impact children, (last request: 2019-03-11.).

[4] Slunjski, E., Vujučić, L., Burić, H., Jaman-Čuveljak, K., Pavlic, K., Franko, A., Luetar, M.P., Guštin, D., Drviš, D.: "Nacionalni kurikulum za rani i predškolski odgoj i obrazovanje", (Ministarstvo znanosti, obrazovanja i sporta, Zagreb, 2014.).

[5] Venderbilt, URL: https://my.vanderbilt.edu/developmentalpsychologyblog/2014/04/effect -of-video-games-onchild-development/ - Effect of video games on child development, (last request: 2019-10-11.).

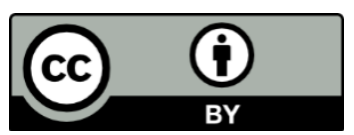

(C) 2020 Authors. Published by the University of Novi Sad, Faculty of Technical Sciences, Department of Graphic Engineering and Design. This article is an open access article distributed under the terms and conditions of the Creative Commons Attribution license 3.0 Serbia (http://creativecommons.org/licenses/by/3.0/rs/). 


\title{
USE OF PREPRESS AUTOMATION IN THE CZECH REPUBLIC AND EXAMPLES OF AUTOMATED PROCESSING FOR SELECTED PREPRESS TASKS
}

\author{
Petr Roudný (D), Markéta Držková \\ University of Pardubice, Faculty of Chemical Technology, Department of Graphic Arts and \\ Photophysics, Pardubice, Czech Republic
}

\begin{abstract}
The work is focused on the prepress and possibilities of its automation. The article provides a brief overview of main prepress operations together with software products available for their automation. The information on problematic areas of prepress processing and current use of software tools and prepress automation in the Czech Republic was gathered via the survey with almost a hundred participating companies. The questions about the type of company, the number of its employees and the number of orders received per day were also included so that the results could be better evaluated. As expected, most of the problems in prepress are connected to the printing data received from customers. The reported frequency of different issues and the time needed for the corrections are presented. The results also show that while almost half of the participating companies use a workflow system, which is the main means of automation, often it is not used to the full extent. Further, different possibilities of automated processing were demonstrated for three common issues selected on the basis of the survey results. The tasks included correction of files with default printer marks and a missing bleed, which belong to the most frequent problems, and adding the missing data for processing steps; this issue does not occur so often, but the participating companies reported they spend more time with its solution. The example PDF files were created in Adobe Illustrator and then processed in Adobe Acrobat, Callas pdfToolbox Desktop, Xerox FreeFlow Core, Enfocus PitStop Pro, and Esko Automation Engine. It was verified that when the given software includes the appropriate editing functions and the automated processing is employed, all the tasks can be accomplished very quickly - in the case of the example printing data, it was in less than a minute, usually in a few seconds. Based on the findings, the applicability and benefits of the alternatives considered are outlined. The comparison of functionality of the software tested and a number of their implementations in the participating companies suggests the important role of local resellers and support.
\end{abstract}

Key words: prepress software utilisation, prepress automation, Czech Republic, survey, automation benefits

\section{INTRODUCTION}

Processing of a print job in the prepress stage can be highly automated thanks to full digitalisation of all operations from layout up to imaging or printing. For each step, it is possible to choose from a wide variety of software, and the same applies for automation of the processing in the workflow. On the other hand, the fact that these options are available does not imply their application in the industry or their effective utilisation. This work presents the main findings of a diploma thesis (Roudný, 2020) exploring the current possibilities and use of prepress automation in the Czech Republic.

Today, the prepress workflow is usually based on PDF (Portable Document Format). Figure 1 illustrates the PDF workflow with other processes related to job management and control. The individual steps can be more or less interconnected, depending on the degree of automation, which is commonly accomplished using rule-based approach and job metadata in a suitable format. Besides reducing the need for human intervention and increasing the speed of processing, the automated workflow also helps to ensure proper communication of specifications both between a customer and a company and across all workflow steps, which is the fundamental prerequisite for achieving the required quality in an efficient way. Almost two decades ago, in the study of the former Graphic Arts Technical Foundation (GATF), $88 \%$ of respondents reported they encounter errors in PDF files received from customers (WhatTheyThink, 2002). The authors of a recent survey by the Ghent Workgroup (GWG) see a positive trend regarding the incoming files containing errors, because only $23 \%$ of respondents answered that more than half files contain errors and $46 \%$ reported errors only in a few received files (to $10 \%$ ); however, only $6 \%$ of respondents answered they encounter no errors (Ghent Workgroup, 2018). This indicates there is still room for improvement. 


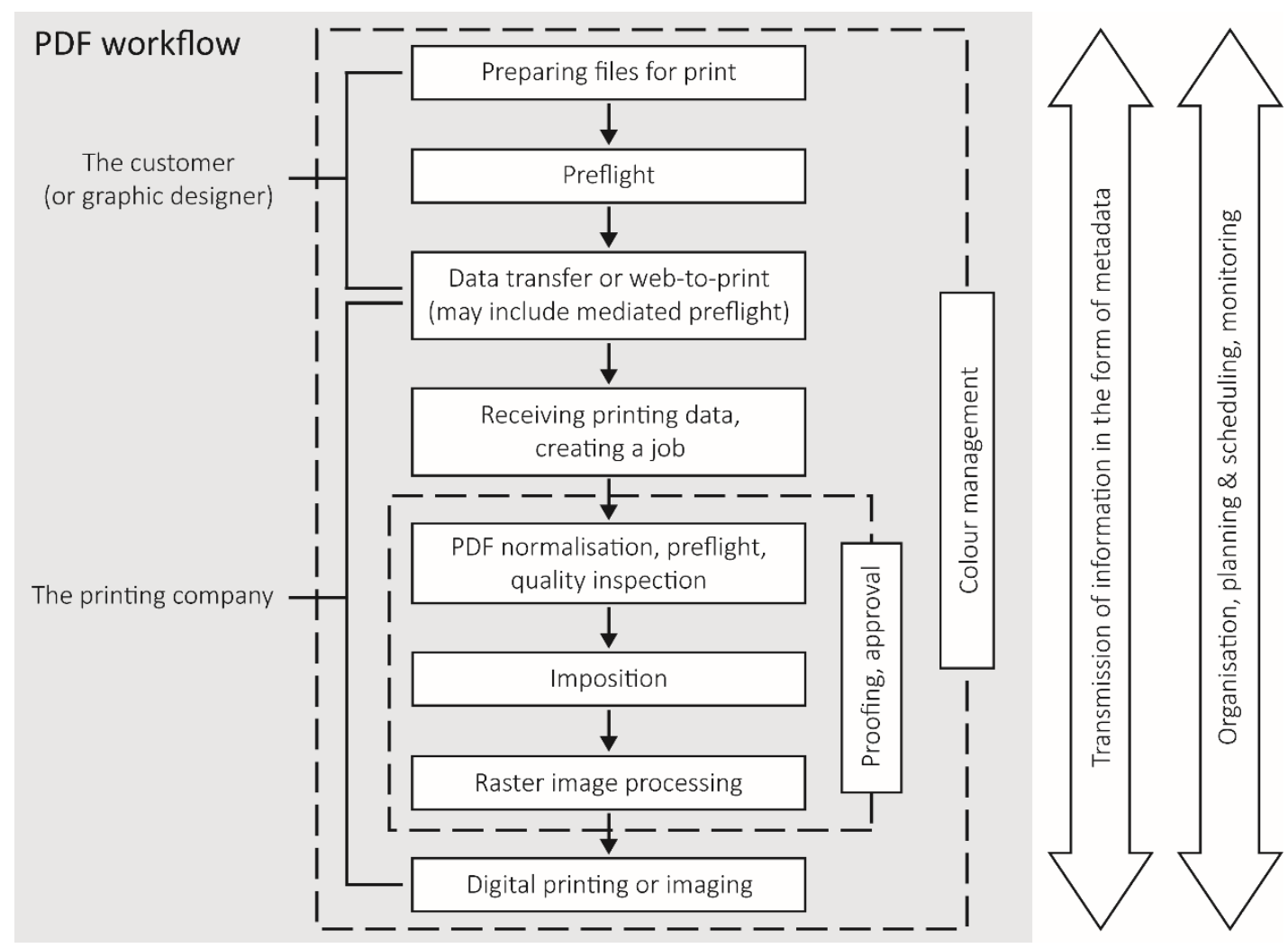

Figure 1: Main steps of PDF workflow and other processes related to job processing before printing

On the customer side, the available prepress solutions helping to produce data conforming to specifications include mainly the preflight tools, either for native files as a built-in feature of a graphic software or using a dedicated plug-in (e.g. Esko DeskPack Packaging Preflight - Esko, 2020a) or application (e.g. Markzware FlightCheck - Markzware, 2020), or for PDF files (e.g. Adobe Acrobat - Adobe, 2020). Data transfer in the next step also can be facilitated by a software, such as Agfa PrintSphere (Agfa, 2018), usually implemented by a printing company. Similarly, it is an integral part of web-to-print solutions (e.g. EFI MarketDirect StoreFront - Electronics for Imaging, 2020a). Enfocus Connect (Enfocus, 2020a) combines data transfer with preflight; more complex solutions further add proofing and approval features (e.g. Kodak InSite Prepress Portal - Kodak, 2018a).

Software for automated preflight and editing of received PDF files used by printing companies ranges from Adobe Acrobat (Adobe, 2020), to applications as Enfocus PitStop Pro (Enfocus, 2020b) and Callas pdfToolbox (Callas software, 2020), up to the tools included in complex workflow systems, usually with built-in Enfocus PitStop or Callas software technology. Some workflow systems offer also their own technology, such as EFI Fiery Preflight (Electronics for Imaging, 2020b), Heidelberg Preflighter (Heidelberg, 2012) and OneVision Asura (OneVision Software, 2020). Further capabilities include the raster preview of separations (e.g. Agfa Apogee - Agfa, 2020), advanced comparison of PDF files (e.g. Kodak Prinergy Workflow - Kodak, 2018b) and other quality control features (e.g. Esko Automation Engine, Esko, 2020b). The 2020 release of Enfocus PitStop employs computer vision techniques to check the visual content of a PDF file (Enfocus, 2020c). Among the software for imposition, automation is supported e.g. by Tilia Labs Phoenix (Tilia Labs, 2019). The final steps, i.e. raster image processing and imaging or digital printing, can be a part of the automated workflow as well. Appropriate colour management features are important across the whole process, which is reflected in all prepress workflow systems and applications.

This outline has listed just a few examples of products available on the market; a comprehensive (but still not exhaustive) overview is in Roudný (2020). The next part of this work presents the survey conducted among printing companies to gain an insight into utilisation of these tools in the industry and identify problematic areas of prepress automation in the Czech Republic. Based on the results, missing data for processing steps (namely varnishing and cutting), problems with bleed and problems with printer marks (crop and registration marks, colour bars, etc.), were chosen as model situations. The last part presents the corresponding source data and example solutions in Adobe Acrobat, Callas pdfToolbox, Enfocus PitStop, Xerox FreeFlow Core, and Esko Automation Engine. 


\section{SURVEY ON PREPRESS AUTOMATION IN THE CZECH REPUBLIC}

The survey among printing companies in the Czech Republic employed an online questionnaire. The introductory questions assessed general information about the involved companies (main type of production, number of employees and average number of jobs per day) to provide a context for evaluation of answers concerning the prepress practices and issues, as well as the software, specifications and standards used by the companies.

\subsection{Survey participants}

The questionnaire was completed by 94 companies from altogether 426 companies randomly selected across all regions of the Czech Republic based on the annually published directory (ISMC, 2018) and information available on the internet.

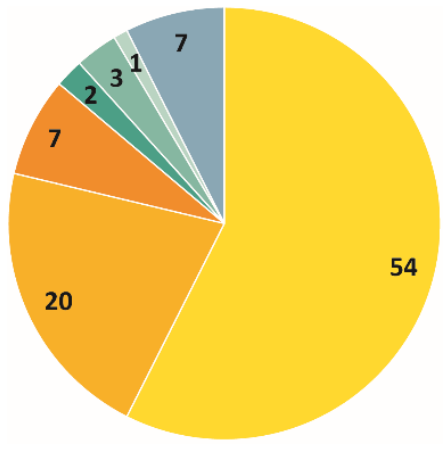

54

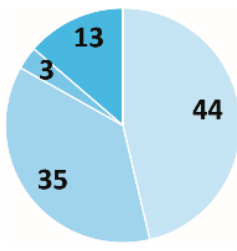

$1-10$

$11-50$

$51-100$

101 and more

(n)
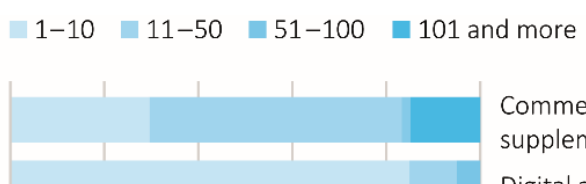

Commercial offset printing (possibly supplemented by digital or other printing)

Digital and/or large format printing

Label and/or packaging printing

Magazine and/or newspaper printing

Textile printing and/or promotional products printing

Publishing

Other

b)

c)

Figure 2: Survey responses to the questions on a) the main type of production and b) the number of employees, with c) percentage representation of the latter according to the main type of production

Figures 2 and 3 show characteristics of the participating companies. Regarding the main type of production, the companies who answered "Other" specified letterpress printing and die-cutting, manufacture of paper packaging, signmaking and orientation systems, screen printing and related services, and printing on digital media; one company combines more sectors. As there is no current and detailed official statistics on the structure of the Czech printing industry available, it is not possible to classify the sample of respondents as representative or not. However, taking into account the production and size of the involved companies, the sample can be considered satisfactory. When looking at the number of employees and jobs per day, the overall pattern in the graphs is similar, with the ratio of jobs and employees higher for digital and large format printers and smaller for large commercial offset, label, packaging, magazine and newspaper printers. 


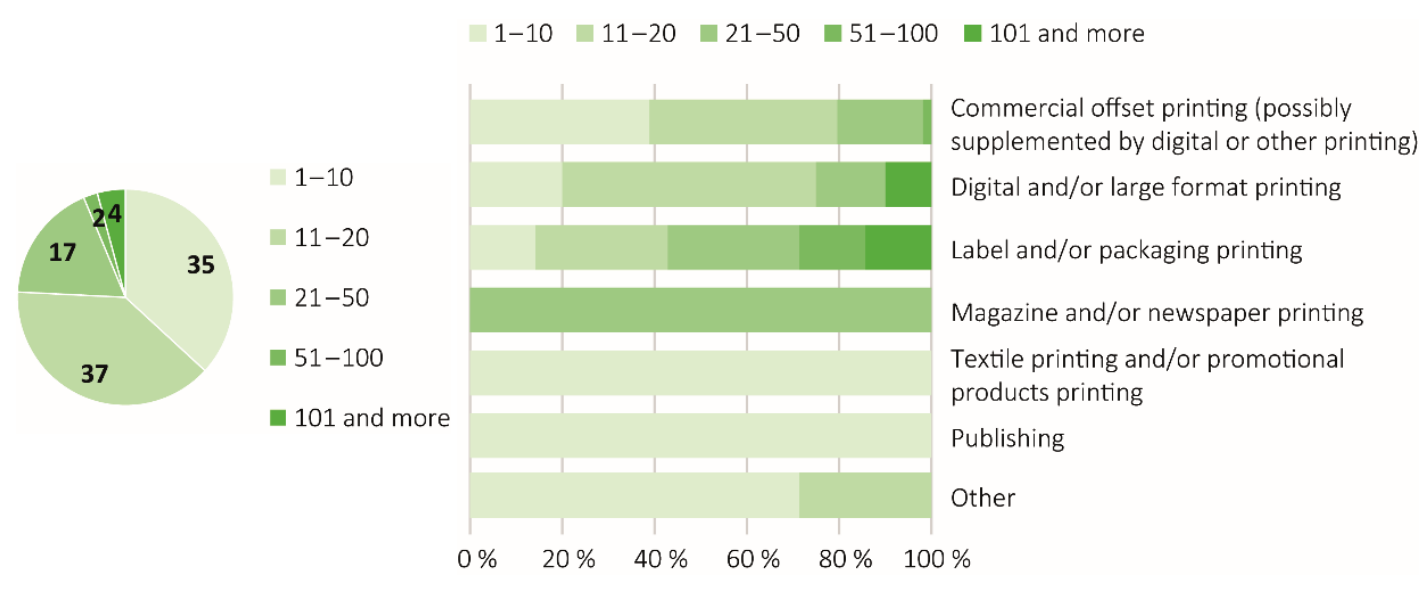

a)

b)

Figure 3: a) Survey responses to the question on the number of jobs per day, with b) their percentage representation according to the main type of production

\subsection{Prepress practices and issues}

The main part of the questionnaire, focused on prepress, started with the question whether and how companies support graphic designers or customers in preparing printing data. Only 6 companies do not provide any support; among the remaining 88 respondents, 50 provide at least some kind of support and the other combine more options. About 80 \% (76 companies) explain their requirements on request, or when it is necessary to correct the received data. But more than a half of them, 40 companies, do not use any other option. Only 29 companies have the requirements regarding printing data specified on their website, and just 4 companies offer free download of preflight profiles, ICC profiles, droplets, etc. In 16 companies, printing data are automatically checked when transferred to the company. With a few exceptions, the results clearly show the overall lack of attention paid to this area, especially when considering the answers to the following question showing that almost all respondents encounter problems with poorly prepared printing data and also the other common problems are related to the communication with clients (Figure 4). When examining how frequently the companies encounter jobs with incorrect printing data, almost half of the respondents reported that it is the case of approx. each third job; for about one third of respondents, it even makes a half of jobs or more. These numbers are higher than reported in the GWG survey participated by 1109 respondents worldwide (Ghent Workgroup, 2018).

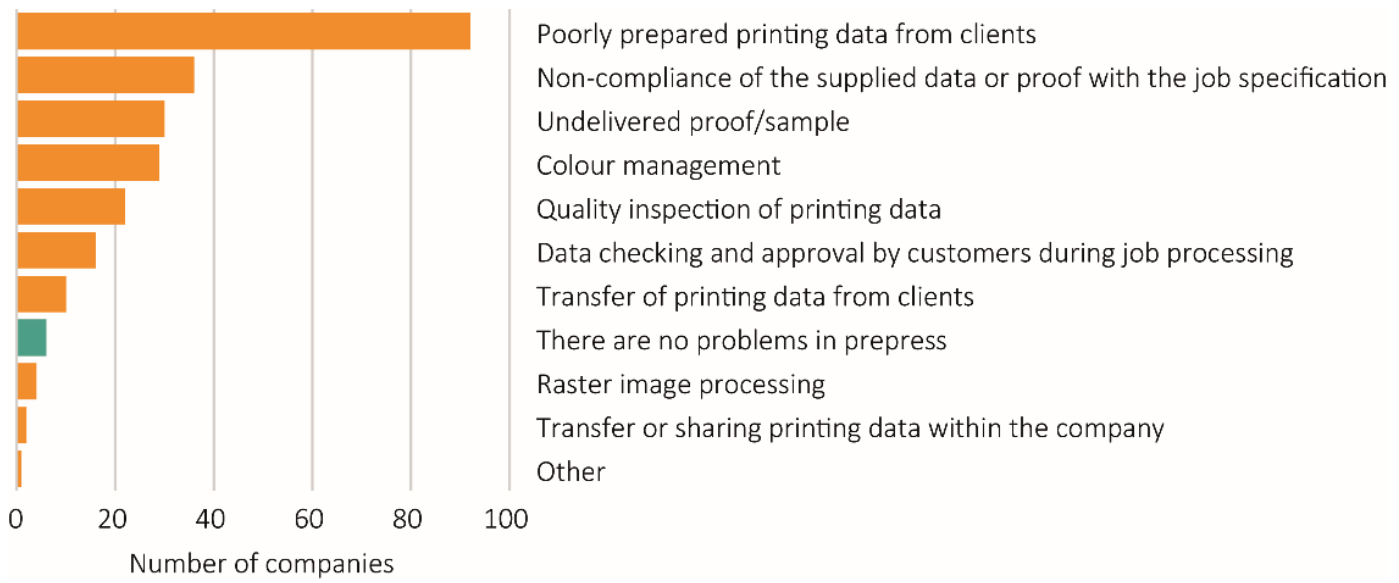

Figure 4: Survey responses to the question in which areas of prepress are encountered problems

Two questions explored the frequency of selected issues in the received printing data and the time typically needed to solve them; the results are presented in Figure 5. The most common problems are bleed issues and wrong resolution or format of raster images. Almost all companies also encounter the problems with $\mathrm{PDF} / \mathrm{X}$ compliance, colour space, fonts and page format, at least occasionally. When analysing how time- 
consuming is to solve individual issues, on average, the highest number of respondents can solve the problems in 1-10 minutes (45\%) and about $20 \%$ need less than 1 minute. On the other hand, about $25 \%$ need 11-59 minutes and $10 \%$ of respondents even more than an hour. Among the individual categories, more time-consuming is to deal with the missing data for processing steps and problems with transparency or its flattening; the largest delays are caused when the printing data do not match with the delivered proof, PDF files cannot be opened or processed, and raster images have wrong resolution or format.

The rather high ratio of answers that indicate solving problems within 1 or 10 minutes suggests the automated or semi-automated processing. However, 53 respondents (56 \%) answered the optional open question allowing to provide more details about the way the most common issues are solved, where 30 respondents reported that they return the data to the customer or graphic designer. It was found out that the majority of these respondents indicated a short time needed to deal with the issues. Therefore, in these companies, the real time needed to completely solve the problems is probably longer than they reported. Only two respondents reported making corrections in an automated workflow.

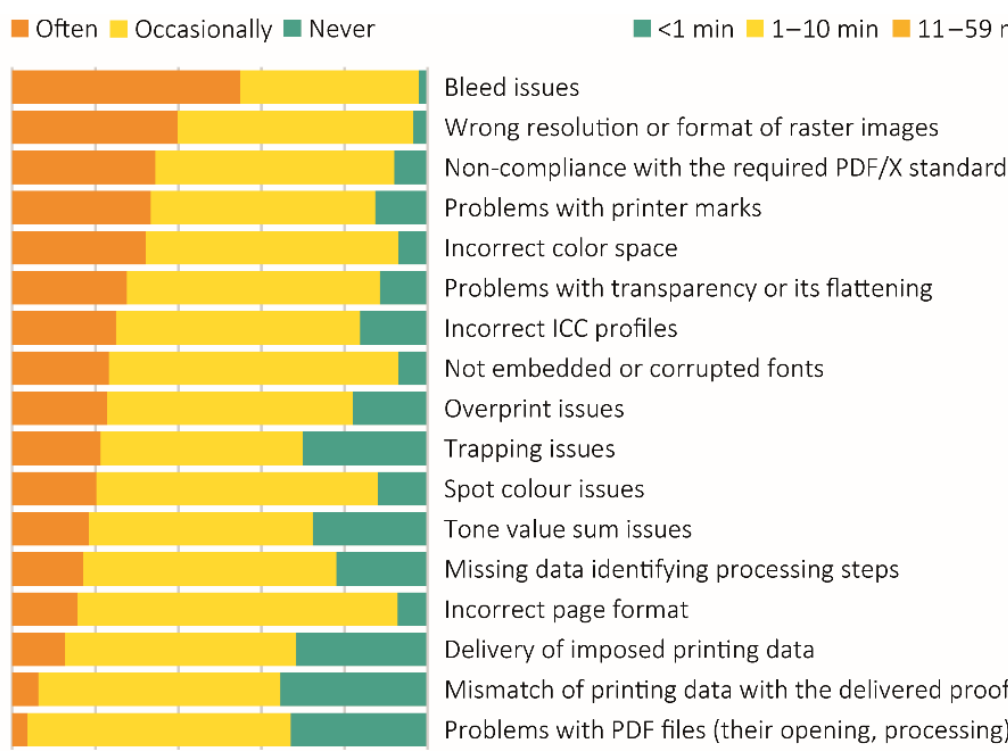

$0 \% \quad 20 \% \quad 40 \% \quad 60 \% \quad 80 \% \quad 100 \%$

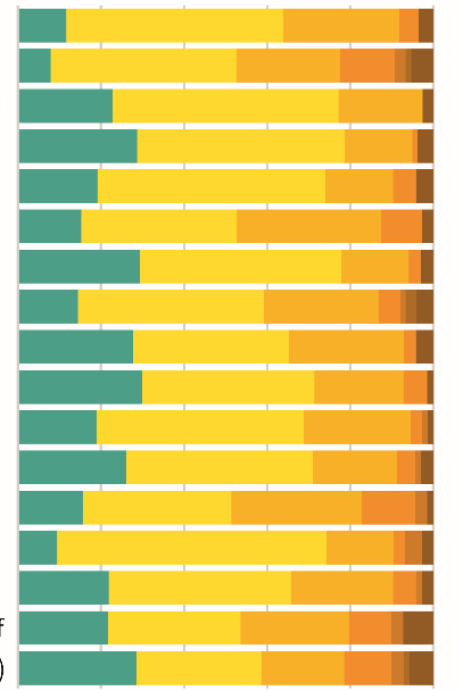

$0 \% \quad 20 \% \quad 40 \% \quad 60 \% \quad 80 \% \quad 100 \%$

Figure 5: Percentage representation of survey responses specifying how often are encountered particular issues in the received printing data (left part) and how long does it typically take to solve these issues (right part)

Another question was how much time does it approximately take to check and process a correctly prepared printing PDF (from its receiving up to raster image processing). Almost two thirds of respondents answered it takes 1-10 minutes and about one third 11-59 minutes; only a few respondents need longer time. These results confirm that the low efficiency in prepress is mostly caused by poorly prepared printing data that need correction, which is often due to the lack of communication between a company and a customer.

\subsection{Prepress software}

The following questions asked about the software solutions used in the companies for prepress operations and their automation.

Concerning the prepress workflow systems, above one third of respondents use only independent applications and modules from different manufacturers, not communicating with each other. About $17 \%$ combine the software from different manufacturers into the workflow and $5 \%$ use the custom-programmed workflow system. The remaining companies listed Caldera Nexio, Enfocus Switch, Esko Automation Engine, Kodak Prinergy, Heidelberg Prinect, Agfa Apogee, Asanti or Arkitex, Fujifilm XMF, Efi Fiery Workflow Suite, OneVision Software solutions, and Xerox FreeFlow Core. Among these, Heidelberg Prinect used by $12 \%$ of respondents is the most common, while the other systems are used by $5 \%$ or less.

Among PDF preflight and editing software, the most commonly used is Adobe Acrobat (53\% of respondents) and Enfocus PitStop Pro (40\%); $14 \%$ use the built-in preflight in a workflow system and only a few respondents use Enfocus PitStop Server or Callas pdfToolbox Desktop. Almost a quarter of respondents check the data only visually and $4 \%$ do not preflight nor correct data. 
When examining software coverage of other prepress areas, about two thirds of respondents use software for raster image processing and imposition and about one third for job management, colour management, job monitoring in production and information system functions. Further, $21 \%$ use software for certified preview or proofing in a company, $16 \%$ for data transfer from a customer, $10 \%$ for approval workflow or certified online soft proofing, and $4 \%$ for mediated automatic preflight on the side of a customer. In general, these numbers are low.

Concerning the ways of simplifying routine work in prepress, predefined actions and batch processing are used by $40 \%$, hot folders by $28 \%$ and JDF (Job Definition Format) by $10 \%$ of respondents, at least; $17 \%$ of respondents answered that they do not know the particular way, because all automated tasks are done by some application or workflow system as set up since implementation. Some respondents noted in the answer other ways, such as definition of keyboard shortcuts, use of templates, plug-ins, appropriate settings, etc. More than a quarter of companies do not use any of these options.

Considering these results, on the one hand, the responses suggest quite satisfying situation among printing companies as almost every second one uses a prepress workflow system and about three quarters automate at least some operations. On the other hand, the high ratio of incorrect files received from customers, the time needed to solve these issues and the low number of companies using automated preflight and other options show that the prepress workflow systems could be utilised more efficiently where available and more automation tools should be implemented overall. At the same time, it is important to stress that the investment into any automation needs to be carefully considered and, even then, it may require further effort to make a full use of it. For example, one company that offers mediated preflight and data upload using Enfocus Connect reported that customers are not interested in this option, in spite of the marketing campaign.

\subsection{PDF standards and specifications}

According to the answers, almost every respondent is familiar with PDF/X standards (96\%), while PDFXready (17\%) and GWG (10\%) specifications are much less known among respondents. This explains the overall weak support provided to graphic designers or customers in preparing printing data. It can be expected that companies will achieve a substantial decrease in error rate for printing data they receive if their knowledge in this area improves.

When analysing the particular PDF standards and specifications used in the involved companies, the most respondents (59\%) use PDF/X-1a:2001. This corresponds with the recent information that it is still the most widespread PDF/X standard in the Czech Republic (Lozan, 2017). The less restricted standard, PDF/X-4, is used by $38 \%$ of companies, often together with PDF/X-1a:2001. Only several respondents use PDFX-ready V1.3, PDFX-ready V2, or GWG2015 specifications. However, about a third of respondents use their own customised settings. About $10 \%$ of respondents do not use any standard or specification or do not know. The former answered that they print whatever the customer sends, without any changes, i.e. with no control of the input data quality. This approach was reported also by some companies from those who otherwise use the standardised settings but leave the responsibility on the customer (15\% of respondents).

\subsection{Further remarks}

The evaluation of the survey was quite complicated due to the inconsistent use of terms, although the questionnaire was in the Czech language. The answers show that some respondents misunderstand or confuse the concepts as preflight, prepress workflow system, PDF standards and specifications, listing the software or formats without the corresponding features. Naturally, when the awareness of the current technology and possibilities is low, it is difficult to achieve any progress or at least to do it efficiently. Besides the education on the side of printing companies, higher expertise of graphic designers would improve the situation as well, since the understanding of the issue can facilitate a large amount of work. As shown in the study of Liao and Lü (2017), which investigated the possibilities to optimise the preflight settings, the complexity of preflight should be adjusted according to the customer situation. The comprehensive preflight settings are recommended only when a graphic designer on a customer side is very well acquainted with the exact requirements of the printing company. However, at least the essential parameters such as document size, transparency, bleed and resolution should be checked in any case. 


\section{AUTOMATED PROCESSING OF MODEL PREPRESS TASKS}

This part deals with the processing of three model tasks to practically examine the current possibilities of prepress automation. The tasks were selected according to the findings from the survey. The printing data with default printer marks and a missing bleed represent the most frequently encountered problems, while the issue with the missing data for processing steps requires more time to be solved (see Figure 5). The example printing data were created in Adobe Illustrator and saved to PDF. One model job is a bookmark (Figure 6), where partial varnishing of the illustration of screen printing is expected. The illustration was also used separately as the second model job, which is expected to be cut after printing, for example in the form of a sticker (Figure 7). The illustration consists of many objects to make its automatic selection more difficult. The default printer marks were deliberately added to the printing data for both jobs; in addition, a second version without bleed and printer marks was created for the bookmark. All objects are vectorbased by default, but versions with rasterised objects were also created and used during testing.

The first aim was to remove the default printer marks and add the required ones. The second aim was to add a bleed when missing. The third aim was to create a new design element either in a spot colour or in a new layer or both and set it to overprint. In the case of the bookmark, it is the filled element in the shape of the illustration to be varnished. In the case of the illustration alone, it is a line around the motif to be cut during finishing. The example PDF files were processed in Adobe Acrobat X Pro, Callas pdfToolbox Desktop 11, Enfocus PitStop Pro 2020, Xerox FreeFlow Core 5.4.1, and Esko Automation Engine 18.1.0. A detailed description of all procedures and settings is in Roudný (2020).

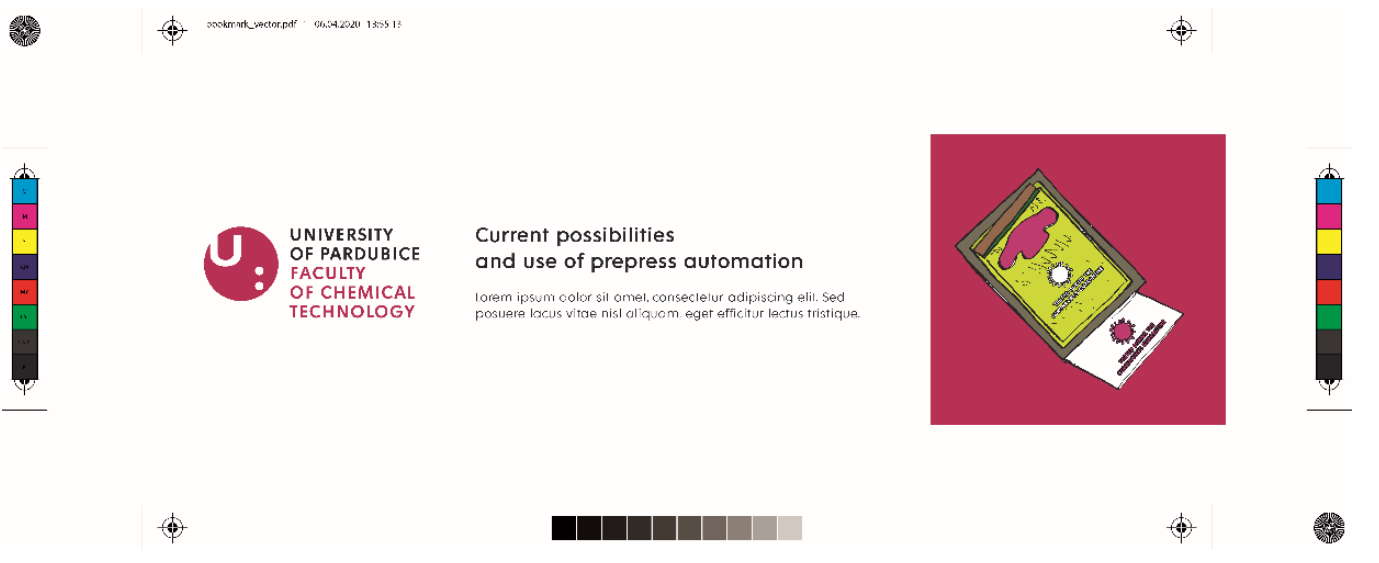

Figure 6: A preview of the first printing data created for testing - the bookmark with the default printer marks and without the data for partial varnishing (scale 1:2); the second printing data comprise the same content but cropped to the TrimBox size (without the printer marks and bleed)

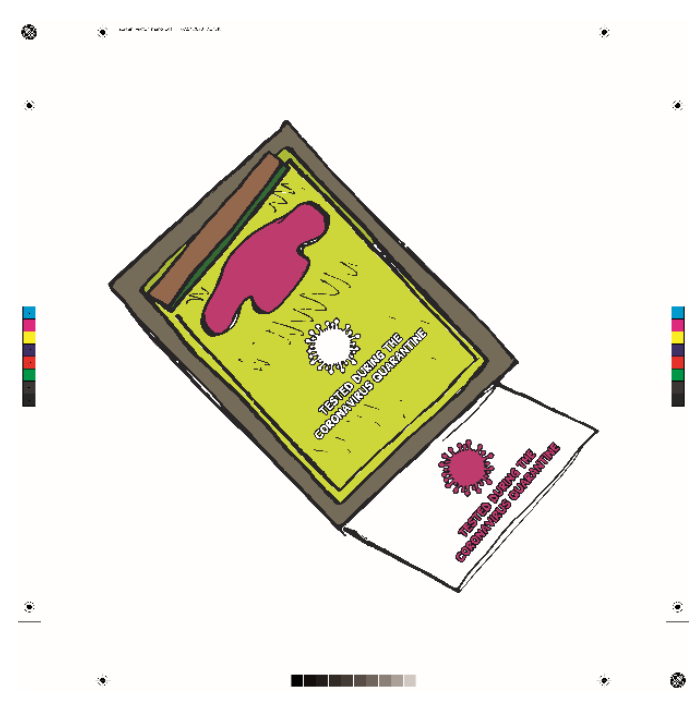

Figure 7: A preview of the third printing data created for testing - the illustration of screen printing with the default printer marks and without the data for cutting (scale 1:4) 


\subsection{Adobe Acrobat}

Adobe Acrobat enables automated processing of PDF files using actions to perform the required operations, including those defined in preflight profiles with appropriate checks and fixups. When the action is executed, all operations run in the background. It is possible to batch-process more files at once. Considering the selected model tasks, this way can be fixed only the issue with the printer marks. The corresponding action involved defining a file or folder with files that should be processed, removing the content outside the BleedBox, adding the correct printer marks, if required, setting the proper CropBox size, and saving the resulting file(s). In some cases, the file with the missing bleed can be also corrected automatically, but only when the content of the bleed area is present in the PDF file and just hidden due to the CropBox size set to that of the TrimBox. Creating or editing objects in the case of missing bleed and technical elements for varnishing or cutting requires manual editing and still the possibilities are very limited.

\subsection{Callas pdfToolbox Desktop and Enfocus PitStop Pro}

The desktop versions of Callas pdfToolbox and Enfocus PitStop Pro offer advanced options for PDF file editing and allow automated processing of all three tested tasks. In general, more approaches can be used to accomplish the given task in both of them. The optimal procedure is derived from the complexity and other features of the particular design and often can be chosen on the basis of the suitable checks.

In Callas pdfToolbox, fixups and checks can be combined into profiles and further into process plans, so that all the required tasks can be completed at once. As in Adobe Acrobat, they can be applied in batch processing. Moreover, the values of parameters can be defined as variables and later, during execution, individually specified by the operator according to the given job. The steps for correcting the printer marks were the same as in Adobe Acrobat. The methods available for adding the missing bleed without changing the content of the TrimBox are "Mirror as images (edges and corners)", "Repeat the last pixel as image" and "Mirror page objects". Only the last one preserves the vector objects in bleed and therefore it was used in the testing; in other cases, the created bleed is a raster image. Another option is to use a fixup "Generate bleed by upscaling". To create the element for varnishing or cutting, the procedure was based on a fixup "Create and apply shapes". It was verified that the selection of the appropriate object(s) can be based on a certain number of nodes in the path or size of the object. For complex illustrations, it might be necessary to choose the options "From tracing page content (including white areas)" (or, on the contrary, excluding white areas), "Render only outside shape" and "Reduce shape to outer borders". It was also possible to create the shape from a defined layer. The size of the resulting shape could be adjusted to account for the manufacturing tolerances. Finally, the created shape was applied as a filled object for varnishing or a stroked object for cutting, with defined properties. Figure 8 shows the example of the resulting data with the path for cutting. In addition, it was possible to define a more complex workflows within the process plans, including not only the described modifications, but also the imposition of both the printed image and the varnishing or cutting element into two separate PDF files.

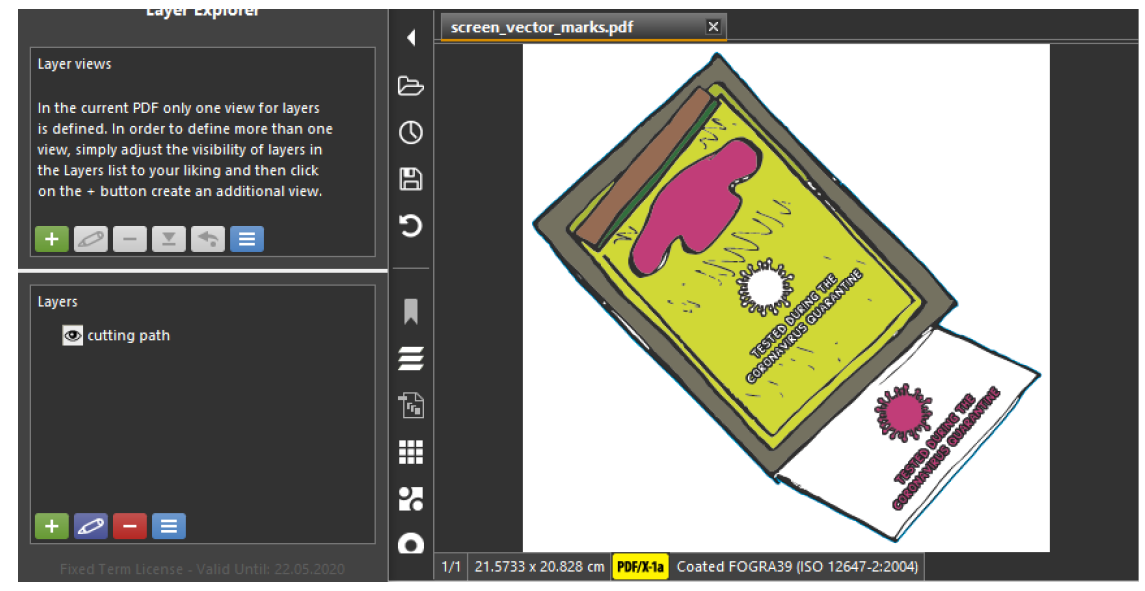

Figure 8: Modified printing data (see Figure 7) with the created layer "cutting path" containing the stroked object in a spot colour set to overprint, in Callas pdfToolbox Desktop 11

In Enfocus PitStop Pro, a plugin for Adobe Acrobat, the automated processing can employ preflight profiles, global changes and action lists, where also the manually performed and recorded operations can be used. 
These all can be combined into the so-called QuickRuns. There is also the possibility to use the variables and logical operators. For correcting the printer marks, the procedure is again similar as in the previous two applications, but in PitStop it is not possible to define the added marks in detail; only the InDesign style (which interferes with the BleedBox) or the QuarkXpress style can be chosen. The missing bleed can be fixed by mirroring or enlarging the content at the TrimBox edges; when generating the bleed in PitStop, the type of data (vector or raster) is preserved. Several options were tested to create the element for varnishing or cutting. For vector objects, it is always based on combining and dividing shapes; in this particular case, the "Unite line art" action was used after selecting the objects by size, with the option to "Keep original objects" to create the new shape. If the resulting shape shows any undesired features (such as occasional holes) that can arise when editing complex illustrations, the action can be used repeatedly. Then, the fill or stroke and overprint properties of the object were defined. As in Callas pdfToolbox, it was also possible to adjust the size and create a dedicated layer. The procedure could be further enhanced by employing the "Select overlapping objects" action. For some designs, the action "Select line art by total number of nodes" may be more appropriate. In the case of raster images, the action "Trace the selected object(s)" with the option to "Ignore white holes" was applied to the selection made using the "Select by image size" action. As an alternative, "Select objects inside region" was used, which can be applied also for vector objects.

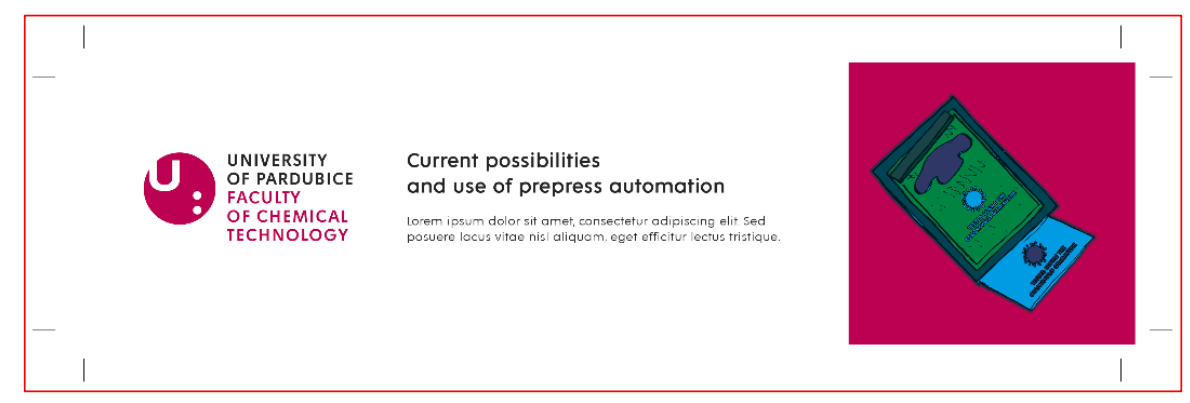

Figure 9: A preview of the printing data (see Figure 6) modified using Enfocus PitStop Pro 2020, with the corrected printer marks and the filled object in a spot colour set to overprint defining the area for partial varnishing (scale 1:2); the CropBox is marked with a red line

Each of these software solutions has some advantages in terms of possibilities, quality, and speed of processing; the comparison of time needed to create the cutting path in dependence on the type of objects is given in Table 1. Therefore, their suitability must be evaluated in the context of particular requirements. While Callas pdfToolbox Desktop offers batch processing, process plans and imposition and thus appears to be more powerful in terms of automation, Enfocus PitStop Pro offers the option of manual editing that can be recorded to Action Lists, which can be indispensable in some cases. In general, the range of functions in Callas pdfToolbox and Enfocus PitStop Pro is still being upgraded.

Table 1: Speed of data processing when creating the cutting path in Callas pdfToolbox Desktop 11 and Enfocus PitStop Pro 2020 (for the data see Figure 7); raster procedure means the use of "Raster selection" and "Add trace path" actions in Enfocus PitStop Pro and "Create shape from tracing page content" in fixup in Callas pdfToolbox Desktop

\begin{tabular}{llll}
\hline Data type & Callas pdfToolbox Desktop & Enfocus PitStop Pro & Comparison \\
\hline Vector data & $1.7 \pm 0.2 \mathrm{~s}$ & $0.9 \pm 0 \mathrm{~s}$ & $\begin{array}{l}\text { Enfocus PitStop Pro } \\
1.9 \text { times faster }\end{array}$ \\
$\begin{array}{l}\text { Vector data, raster procedure } \\
\text { of creating the cutting path }\end{array}$ & $1.5 \pm 0.2 \mathrm{~s}$ & $4.3 \pm 0.2 \mathrm{~s}$ & $\begin{array}{l}\text { Callas pdfToolbox Desktop } \\
2.9 \text { times faster }\end{array}$ \\
Raster data & $5.6 \pm 0.1 \mathrm{~s}$ & $24.6 \pm 0.3 \mathrm{~s}$ & $\begin{array}{l}\text { Callas pdfToolbox Desktop } \\
4.4 \text { times faster }\end{array}$ \\
\hline
\end{tabular}

\subsection{Xerox FreeFlow Core and Esko Automation Engine}

From the two prepress workflow systems tested, Xerox FreeFlow Core includes the built-in Callas pdfToolbox technology; the checks, fixups, preflight profiles, and process plans created in Callas pdfToolbox Desktop can be loaded and used in Xerox FreeFlow Core, but it is not possible to define them directly in Xerox FreeFlow Core. Xerox FreeFlow Core 5.4.1, in particular, has a built-in Callas pdfToolbox 10.2, while the Desktop application was used in version 11; nevertheless, all functions utilised in this work (see 3.2) are available 
also in version 10.2 and thus all the automated procedures defined in Callas pdfToolbox Desktop 11 could be used in the workflow system. When employing the additional features available in Xerox FreeFlow Core and creating more advanced workflow, including e.g. the PDF file optimisation, it was possible to save further work and time compared to batch processing in Callas pdfToolbox Desktop or Adobe Acrobat.

The second prepress workflow system, Esko Automation Engine, offers the most automation features among the software solutions used for testing. However, as its version 18.1.0 has a built-in Enfocus PitStop 2018 and the action lists were prepared in Enfocus PitStop Pro 2020, some features, including the "Add tracing path" action, were missing and only the action lists with supported functions could be imported and used within Esko Automation Engine. On the other hand, it is possible to create user-defined action lists directly in Esko Automation Engine; the Enfocus PitStop licence is not needed. As in Xerox FreeFlow Core, all three model tasks described above were successfully completed in Esko Automation Engine, together with the additional operations included in the more complex workflow, such as the optimisation, imposition and separate processing of the printed image and the varnishing or cutting element.

In general, the workflow systems as such offer the greatest possibilities for the automation of the entire job processing and the efficient use of the metadata available for a particular job. However, it is necessary to take into account that the new versions of the built-in technology are always implemented with some delay. Therefore, in this respect, the available options are limited compared to the latest version of the respective standalone applications.

\section{CONCLUSIONS}

This work helped to gain insight into the current situation in prepress automation in the Czech Republic. Based on the results of the survey among printing industry participants and practical demonstration of possible solutions of the three model prepress tasks, it can be concluded that the time needed to deal with the commonly encountered issues can be significantly reduced through automation using the existing software. The software based on either the Callas pdfToolbox or Enfocus PitStop technology could automatically complete all prepress operations in question. In Adobe Acrobat, the range of functions is more limited and some operations could not be done without the use of an additional software, but still it enables automated batch processing of many tasks. The survey shows that, overall, the awareness of the available options is rather low, which indicates a large room for improvement being possible even without a substantial investment if the companies learn about the automation possibilities in more detail and, based on the process analysis, implement the appropriate solution. On the other hand, some companies are well informed about the current technology and options in prepress and benefit from its automation. Further, it was observed that although Callas pdfToolbox Desktop and Enfocus PitStop Pro are applications with the same purpose and largely with a similar functionality, much higher use of the Enfocus PitStop Pro can be seen among the respondents. This may be because there is no Callas pdfToolbox Desktop reseller on the Czech market, which suggests the important role of local business and technical support.

\section{ACKNOWLEDGMENTS}

The authors thank all respondents for taking part in the survey, Martin Šaněk and Nextar Group for the access to Xerox Free Flow Core, Dominik Štýbr and OTK GROUP for the access to Esko Automation Engine, and Four Pees for the possibility to use Callas pdfToolbox.

\section{REFERENCES}

[1] Adobe: "Acrobat User Guide - Preflight (Acrobat Pro)", URL: https://helpx.adobe.com/acrobat/userguide.html?topic=/acrobat/morehelp/preflight_acrobat_pro_.ug.js (last request: 2020-09-10).

[2] Agfa: "PrintSphere", URL: https://www.agfa.com/printing/wpcontent/uploads/sites/19/2019/09/printsphere-brochure-en-web.pdf (last request: 2020-09-10).

[3] Agfa: "Apogee", URL: https://www.agfa.com/printing/products/apogee/ (last request: 2020-09-10).

[4] Callas software: "pdfToolbox", URL: https://www.callassoftware.com/en/products/pdftoolbox (last request: 2020-09-10).

[5] Electronics for Imaging: "EFI MarketDirect StoreFront", URL: https://www.efi.com/products/productivity-software/efi-marketdirect-customer-engagementplatform/efi-marketdirect-storefront/overview/ (last request: 2020-09-10). 
[6] Electronics for Imaging: "Fiery JobFlow", URL: https://www.efi.com/products/fiery-servers-andsoftware/fiery-workflow-suite/fiery-jobflow/overview/ (last request: 2020-09-10).

[7] Enfocus: "Connect ALL: PDF quality control for job submission", URL: https://www.enfocus.com/en/connect-all (last request: 2020-09-10).

[8] Enfocus: "PitStop Pro: PDF checked, fixed, ready", URL: https://www.enfocus.com/en/pitstop-pro (last request: 2020-09-10).

[9] Enfocus: "PitStop 2020 Released", URL: https://www.enfocus.com/en/news/pitstop-2020-released (last request: 2020-09-10).

[10] Esko: "DeskPack Packaging Preflight for Adobe Illustrator", URL: https://www.esko.com/en/products/deskpack/plugins/packaging-preflight (last request: 2020-0910).

[11] Esko: "Automation Engine", URL: https://www.esko.com/en/products/automation-engine/features (last request: 2020-09-10).

[12] Ghent Workgroup: "GWG 2017 PDF Survey Results", URL: https://www.gwg.org/gwg-2017-pdfsurvey-results/ (last request: 2020-09-10).

[13] Heidelberg: "Prinect Prepress Manager", URL: https://www.heidelberg.com/global/media/en/global_media/products ect_prepress_manager_product_guide.pdf

[14] ISMC: "Polygrafie České republiky 2018 - Kompletní seznam firem z oblasti polygrafie, souvisejících činností a jejich dodavatelü" [2018 Graphic Arts Industry of the Czech Republic - Complete directory of companies from the printing industry and related fields and their suppliers], 23rd edition, (ISMC Bohemia, Brno, 2018).

[15] Kodak: "InSite Prepress Portal", URL: https://www.kodak.com/uploadedFiles/PinergyWorkflow/Insite_Prepress_Portal/InSitePrepressPortalSellSheet.pdf (last request: 2020-09-10).

[16] Kodak: "Prinergy Workflow", URL: https://www.kodak.com/uploadedFiles/PinergyWorkflow/Pinergy-Workflow/PrinergySellSheet.pdf (last request: 2020-09-10).

[17] Liao, Y., Lü, X.: "Optimized three-stage strategy of orderly management of file stream in network printing workflow", Journal of Systems Science and Information 5 (1), 74-87 (2017). doi:10.21078/JSSI-2017-074-14.

[18] Lozan, P.: "Odkládáte implementaci PDF/X-4 na neurčito? Stephan Jaeggi: Je to jen výmluva" [Are you postponing the implementation of PDF/X-4 indefinitely? Stephan Jaeggi: It's just an excuse], URL: http://www.pdf-x.cz/stephan-jaeggi-rozhovor-je-to-jen-vymluva/ (last request: 2020-09-10).

[19] Markzware: "FlightCheck (Preflight for Print)", URL: https://markzware.com/products/flightcheck/ (last request: 2020-09-10).

[20] OneVision Software: "Asura", URL: https://www.onevision.com/solutions/prepress-software/asura/ (last request: 2020-09-10).

[21] Roudný, P.: "Current possibilities and use of prepress automation", MSc thesis, University of Pardubice, Pardubice, 2020. URL:

https://portal.upce.cz/StagPortletsJSR168/CleanUrl?urlid=prohlizeni-prace-detail\&praceldno=37988 (last request: 2020-09-10).

[22] Tilia Labs: "Automation and Integration", URL: https://www.tilialabs.com/phoenix/automation/ (last request: 2020-09-10).

[23] WhatTheyThink: "GATF Studies the Reality of PDF, Top Five Benefits", URL: http://whattheythink.com/news/17122-gatf-studies-reality-pdf-top-five-benefits/ (last request: 2020-09-10).

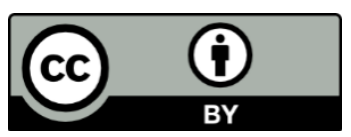

(C) 2020 Authors. Published by the University of Novi Sad, Faculty of Technical Sciences, Department of Graphic Engineering and Design. This article is an open access article distributed under the terms and conditions of the Creative Commons Attribution license 3.0 Serbia (http://creativecommons.org/licenses/by/3.0/rs/). 



\title{
USE OF CODECS IN VIDEO UPLOADS
}

\author{
Andrej Učakar (D), Patricija Selič (D), Raša Urbas (D) \\ University of Ljubljana, Faculty of Natural Sciences and Engineering, Department of Textiles, \\ Graphis Arts and Design, Chair of Information and Graphic Arts Technology, Ljubljana, Slovenia
}

\begin{abstract}
In recent decades, linear communication has largely been replaced by visual depictions that contain not only moving images but also sound, text and other (visible or invisible) data. It is therefore not surprising that video has become so popular, especially among young people. So-called multimedia communication is transmitted via a variety of media. Since there are many ways and means of transmission, we wanted to investigate how the type of encoding that allows efficient file reduction affects the characteristics of the video format. For this purpose, we encoded selected videos using the three most common encoding mechanisms H.264/AVC, MPEG-2 and H.265/HEVC at high and medium bitrate. The newly created video files were then uploaded to three popular platforms - Instagram, YouTube and Gmail. Changes in file size, colour gamut, frame and bitrate, resolution and other visually recognizable details are presented in the paper.
\end{abstract}

Key words: codec, compression, encoding, file format, upload, video

\section{INTRODUCTION}

Video contents have been a part of our daily lives for almost half a century. Since their beginnings in the early 1980s' they have developed not only in terms of content but also in terms of quality. The integration of moving images, text, sound and sometimes other effects has determined the ever-increasing size and consequently the complexity of written files. Improved recording quality, higher frame rate (fps), resolution (ppi) and quality of rendering demand a sophisticated development of different codecs and file types, which enable higher video quality, smaller file size and improved rendering mode.

In order to either share or post videos for viewing on different screens and devices, in small or large dimensions, video content must be recorded in a variety of different formats. In an effort to make video content as realistic as possible, the use of compression and interpolation methods in formatting (without noticeable data loss) is essential (Rippel et al, 2018; Le Tanou and Blestel, 2019; Laude et al, 2017). Optimal results are controlled by the use of codecs (short for coder/decoder), which are stored in more complex containers that properly compress the video content and its components (audio/metadata) in each file. Codecs encode audio and/or video into a stream of bytes. Choosing the right codec is based on several variables - digital storage space, frame and bit rate, encoding mode, resolution, colour gamut and others. Today, different codecs are used, each with its own advantages and disadvantages. The selection of the appropriate codec therefore depends on the type of transmission, either via an external hard drive, by e-mail or by uploading to various websites and platforms. The upload requirements depend on the type of codecs supported by either the devices or platforms. These restrictions condition the use of certain codecs. Until 2013, the market for standardized video codecs was dominated by ISO (International Organization for Standardization), IEC (International Electrotechnical Commission) and ITU-T (Telecommunication Standardization Sector) standardization groups, with most representable codecs such as MPEG-1, MPEG2/H.262, H.263, MPEG-4 Visual and Advanced Video Coding (i.e. AVC, also known as MPEG-4 Part 10 or H.264) (Laude et al, 2017; Zhang and Mao, 2018; The Moving Picture Experts Group, n.d.). These standards have most of the basic functions in common, but differ in detail. In general H.264 provides better compression efficiency and has greater flexibility in compressing, transmitting and storing video than MPEG-1 and MPEG-2. Advances in video coding have resulted in high efficiency video coding (i.e. HEVC), which has been standardized by ISO/IEC as MPEG-H Part 2 and by ITU-T as H.265 (Richardson, 2017).

In this scientific paper we present the differences in the characteristics of selected videos compressed with MPEG-2, H.264/AVC and H.265/HEVC codecs. The aim of the study was to determine how the codec type affects the properties of video recording (i.e. visual presentation (occurrence of unwanted image artifacts), file size, frame and bit rate, resolution, colour gamut and other properties) when displayed on different platforms - Instagram, YouTube, and Gmail. 


\section{VIDEO PREPARATION AND PROCESSING}

Video preparation and processing. For video recording we used the compact system camera Sony Alpha A5000 (Sony, Japan) with 20 megapixel APS-C CMOS (e.g. complementary metal-oxide-semiconductor) image sensor. The device allows maximum video HD resolution of $1920 \times 1080$ pixels, with 50i, 25p or 24p $\mathrm{fps}$. Videos can be saved in two types of video containers - MP4 and AVCHD, both using the same codec H.264/AVC.

For the acquisition of the individual video image frames, the comparison of the histograms and the conversion into different codecs, the Adobe Photoshop and Adobe Media Encoder software were used. The VLC media player was used for verification and comparison of the stored video versions.

Video recording. For the purposes of this study, videos were recorded at maximum camera resolution, aspect ratio $16: 9,25 \mathrm{fps}$ in progressive scan mode, at an average bitrate of $17 \mathrm{Mbps}$, and maximum colour gamut. The video was recorded during the day when there is enough natural light. The decision was to record a video of blooming, colourful flowers, which allowed a wide range of colour shades to be captured. Several different videos were recorded, both from a distance and close up, with the focus object resting or moving in the wind. In addition, the recording time also varied - from a few seconds to a minute - with the aim of selecting the most suitable video for comparison and analysis.

Variations of compared videos. Among the recorded videos we chose the one with the most details and the maximum colour gamut (mainly because of its numerous shades of green). The video had 00011.mts (MPEG-2 Transport Stream; M2TS) and took up 27.1 MB of memory. It was 13 seconds long, recorded at maximum resolution, at the final bitrate of $6.3 \mathrm{Mbps}$ and encoded using the H.264/AVC codec. Three file formats, i.e. codecs, were used with the VBR (variable bitrate) encoding method and different presets that allowed different video storage characteristics i.e. bitrate settings (Table 1).

Table 1: Video conversion properties and corresponding upload platforms

\begin{tabular}{|c|c|c|c|c|c|}
\hline Codec & \multicolumn{2}{|c|}{ H.264/AVC } & \multicolumn{2}{|c|}{ MPEG-2 } & H.265/HEVC \\
\hline Bitrate (Mbps) & $\begin{array}{c}10.0-12.0 \\
\text { (high) }\end{array}$ & $\begin{array}{c}3.0-6.0 \\
\text { (medium) }\end{array}$ & $\begin{array}{c}4.0-18.5 \\
\text { (high) }\end{array}$ & $\begin{array}{c}2.5-6.0 \\
\text { (medium) }\end{array}$ & $\begin{array}{c}\text { 16.0-20.0 } \\
\text { (high) }\end{array}$ \\
\hline Upload platform & $\begin{array}{l}\text { O) } \\
\text { Instagram } \\
\text { YouTube } \\
\text { M }\end{array}$ & $\begin{array}{l}\text { Onstagram } \\
\text { YouTube } \\
\text { Gmail }\end{array}$ & YouTube & $\begin{array}{l}\text { YouTube } \\
\text { Gmail }\end{array}$ & $\begin{array}{l}\text { O } \\
\text { Instagram } \\
\text { YouTube } \\
\text { M }\end{array}$ \\
\hline
\end{tabular}

Video upload. For research purposes, all five videos were uploaded to Instagram, YouTube and Gmail platforms. Due to the fact that all three platforms have individual requirements and limitations, the procedures for uploading videos differed (Table 1).

To upload to Instagram, we first had to create a user profile. Later we transferred the selected videos to the smartphone (Huawei p20 lite) using a USB cable (drag and drop from one file folder to another). Even though the mobile application for video posting does not support screen rotation and the $16: 9$ aspect ratio (it only allows $4: 5$ ), the videos could be uploaded unchanged. Unfortunately, the original video could not be uploaded to the smartphone because the device does not have the codecs to read .mts file formats. Instagram only supports H.264/AVC and H.265/HEVC codecs and not MPEG-2, so the later video conversions were not performed. Size limits are set at $650 \mathrm{MB}$ for videos that last 10 minutes or less and 3.6 GB for videos up to 60 minutes in length (valid for 2020; constraints often change with the development of ICT).

To upload to YouTube, videos were simply uploaded to the platform and published privately. Since they were not published publicly, the videos were only visible in Beta Studio of our YouTube channel. All five videos were uploaded without any problems and later transferred back to the computer. When uploading to YouTube, only the size is limited (128 GB, HD video).

Gmail has a certain size limit for sending files, which cannot exceed $25 \mathrm{MB}$ in a single message. Therefore, only videos encoded using the H.264/AVC and MPEG-2 medium bitrate codecs met this criterion. Both videos were dragged into the application and sent as a new email when uploaded. After receiving the mail, the videos were saved on the computer. Gmail also offers the possibility of sending files larger than $25 \mathrm{MB}$, 
but in this case the files must be uploaded to Google Drive (cloud storage service, limited in size according to the individual user). We wanted to specify if the videos are re-encoded when uploaded to Google Drive. The remaining three videos (encoded with the H.264/AVC and MPEG-2 high bitrate, and H.265/HEVC) were sent with Gmail in the same way as before (although before pre-uploaded to Google Drive), although their size was now larger (26, 28 and $30 \mathrm{MB})$. The received files were then stored on the computer.

Video comparison. The comparison of the selected five videos was based on the resulting changes in video conversions (original and re-encoded), which were reflected in alterations of video file sizes, different bit rates and smaller colour gamut, as well as the occurrence of unwanted artifacts due to compression and interpolation. Since colour changes in the videos (due to movement) could not be observed accurately, we performed this comparison on a defined static part of the videos - video image frame (marked with red square in Figure 1), at high magnification (1300\%).

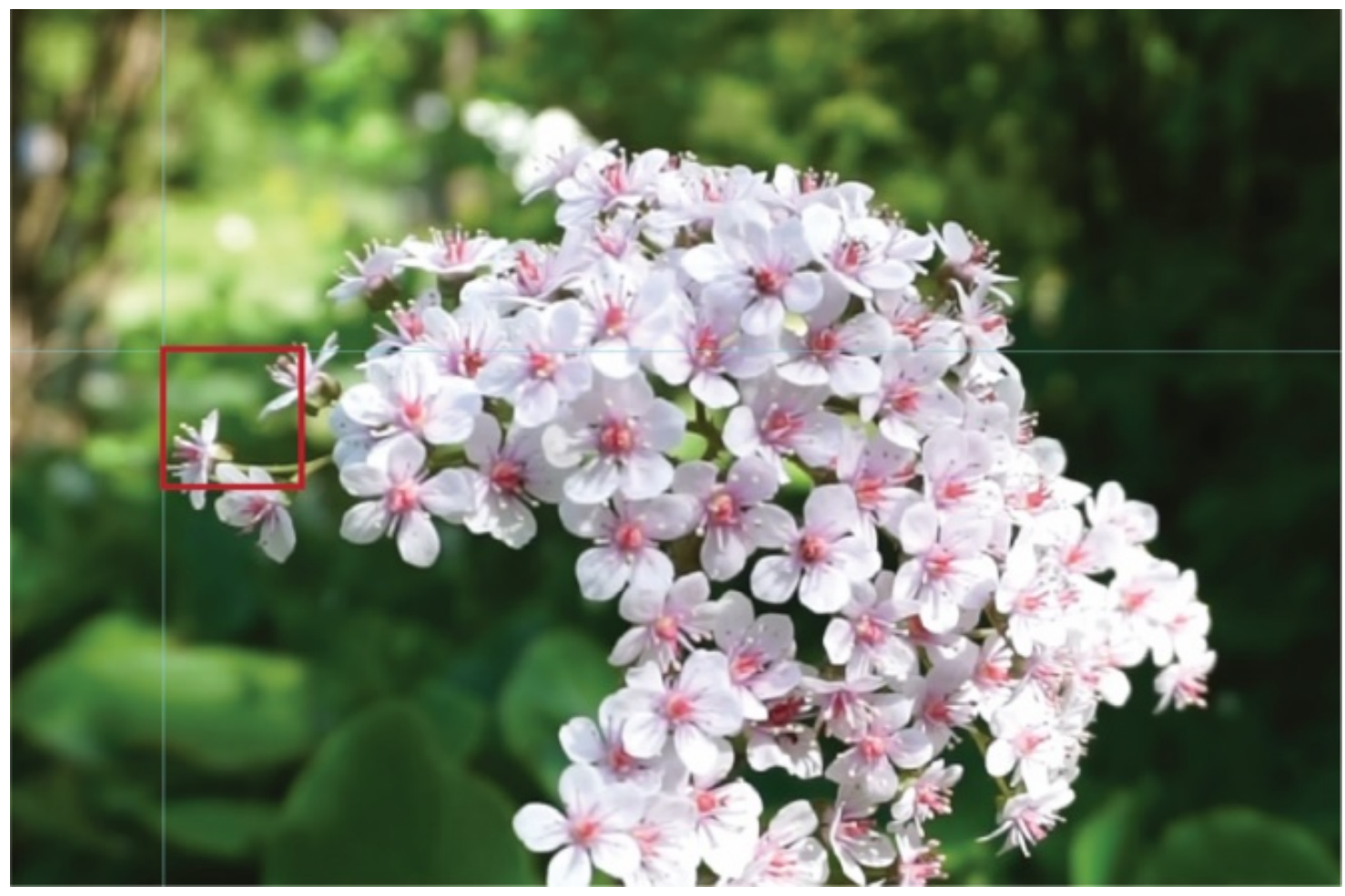

Figure 1: Example of selected video image frame

The colour differences were determined by comparing the histograms of the individual enlarged image frames. For this purpose, Adobe Photoshop was used, where each converted image frame was copied as a separate layer into a new document. By changing the visibility of each layer, we observed differences in the histograms and channel views.

\section{RESULTS AND DISCUSSION}

\subsection{Results of video format data changes}

As expected, the use of different encoding methods (i.e. codecs) had a significant impact on video file properties (Table 2). For high bitrate encoding methods, the file size of H.265/HEVC (10.83\%) and H.264/AVC (6.59\%) codecs increased, while the file size of MPEG-2 codec decreased slightly (3.92 \%). An opposite effect was observed for bitrate data, where all three high bitrate encoding methods increased in size - in the case of MPEG-2 the increase in bitrate was quite significant (11.65\%) and slightly less for H.265/HEVC (8.06 \%), while for H.264/AVC the increase was almost equal (1.55\%).

The use of medium bitrate encoding methods led to more drastic changes in video file properties. Both file size and bitrate decreased significantly for about $69 \%$ (using the medium bitrate encoding method H.264/AVC, file size decreased for $68.17 \%$ and bitrate for $69.19 \%$ ), while using the medium MPEG-2 encoding method resulted in a slightly smaller change of $62 \%$ (file size for $62.76 \%$ and bitrate for $61.92 \%)$. 
The results are rather illogical with regard to selected coding methods. In fact, we expected that video encoded with the H.265/HEVC codec (as the most efficient method) would produce the smallest files, followed by H.264/AVC and MPEG-2 at high and medium bitrate, respectively. Due to the fact that all video conversions were performed in Adobe Media Encoder, with used presets, we are not quite sure which compression mechanisms and interpolation algorithms were used. We assume that this could be the reason for the results. From the above we could therefore conclude that it would be necessary to further analyse and determine the causes of the situation.

As will be shown in the continuation, the differences found led to visible changes in colour transformations (reduction in the number of colour shades and coarser colour transitions) and the occurrence of unwanted artifacts in the form of aliasing, blurring and edge halo.

Interestingly encoding (regardless of bitrate speed) increased the length of the videos by one second, adding a black image frame at the end of videos. The reason for this was not found.

Table 2: Changes in video file properties after using different encoding methods

\begin{tabular}{|c|c|c|c|c|c|}
\hline Codec & \multicolumn{2}{|c|}{ H.264/AVC } & \multicolumn{2}{|c|}{ MPEG-2 } & \multirow{2}{*}{$\begin{array}{c}\text { H.265/HEVC } \\
\begin{array}{c}16.000-20.000 \\
\text { (high) }\end{array}\end{array}$} \\
\hline Bitrate (bps) & $\begin{array}{c}\text { 10.000-12.000 } \\
\text { (high) }\end{array}$ & $\begin{array}{c}3.000-6.000 \\
\text { (medium) }\end{array}$ & $\begin{array}{c}4.000-18.500 \\
\text { (high) }\end{array}$ & $\begin{array}{c}2.500-6.000 \\
\text { (medium) }\end{array}$ & \\
\hline Original container type & \multicolumn{5}{|c|}{.mts } \\
\hline Encoded container & \multicolumn{2}{|c|}{ MP4 } & \multicolumn{2}{|c|}{ MPEG } & MP4 \\
\hline Original video length (s) & \multicolumn{5}{|c|}{13} \\
\hline Encoded video length (s) & 14 & 14 & 14 & 14 & 14 \\
\hline Original file size $(\mathrm{kB})$ & \multicolumn{5}{|c|}{27.100} \\
\hline Encoded file size (kB) & 28.390 & 8.625 & 26.037 & 10.091 & 30.393 \\
\hline Original bitrate $(\mathrm{kb} / \mathrm{s})$ & \multicolumn{5}{|c|}{16.344} \\
\hline Encoded bitrate $(\mathrm{kb} / \mathrm{s})$ & 16.601 & 5.036 & 18.500 & 6.224 & 17.776 \\
\hline
\end{tabular}

\subsection{Results of video format visual changes}

The results of the encoded videos differed from the original video in colour gamut and image quality. These changes were noticeable not only in the histograms, but also in the appearance of unwanted artifacts (mainly jagged details in enlarged video images, blur and reduced saturation (Figure 2 and Figure 3).

The colour differences were not the same for all coding methods used. As expected, these changes were more pronounced in highly compressed video files with smaller file sizes. Good visual results were achieved with the H.265/HEVC codec, which had bright and saturated colours, smooth gradients, and few unwanted artifacts. The jagged edges were less intense than in the original video, especially in the greens (Figure 3). A slightly better quality was achieved with high bitrate H.264/AVC encoding, although histograms show similar colour changes as H.265/HEVC encoded video. The worst results were obtained with videos encoded using medium and high bitrate MPEG-2 codecs, where colour transformations were strongest. The compression mechanisms greatly reduced the number of colour shades (especially in the greens) and the interpolation algorithms caused numerous artefacts that resulted in aliasing and high blur (Figure 3). These artefacts occurred not only in selected video image frames, but also in the video.

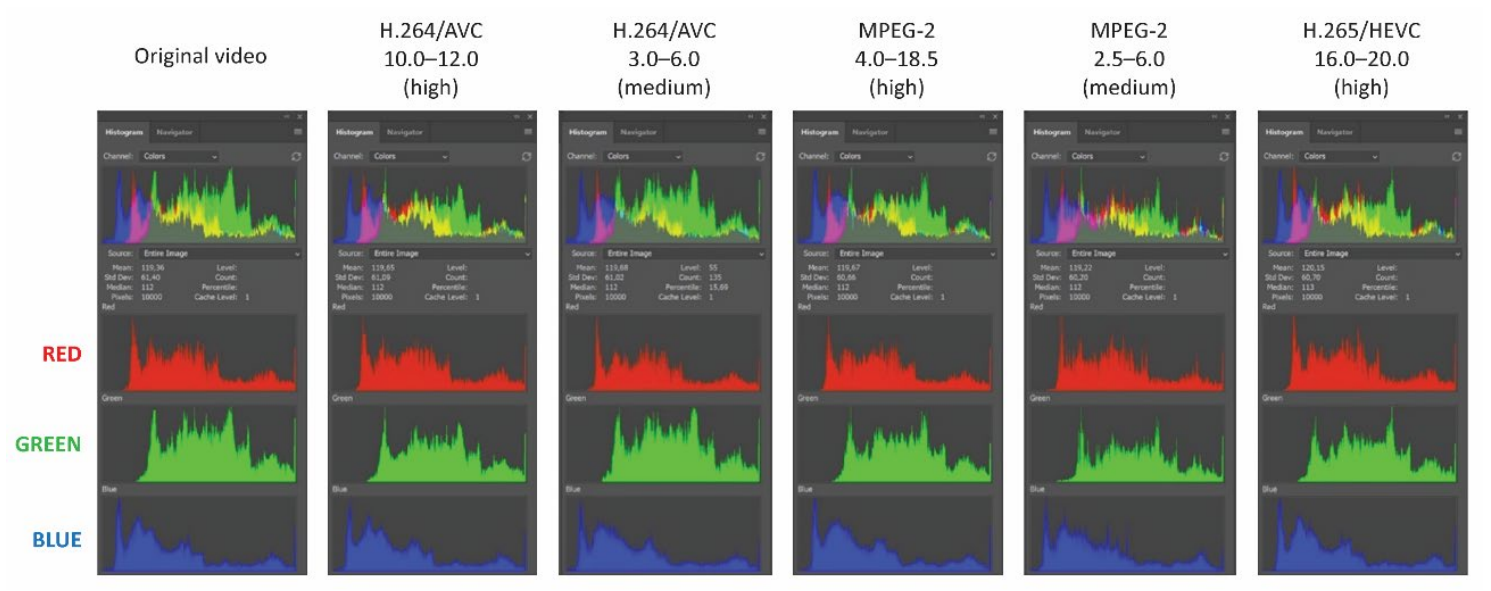

Figure 2: Histograms of original and encoded videos with different high and medium codecs 


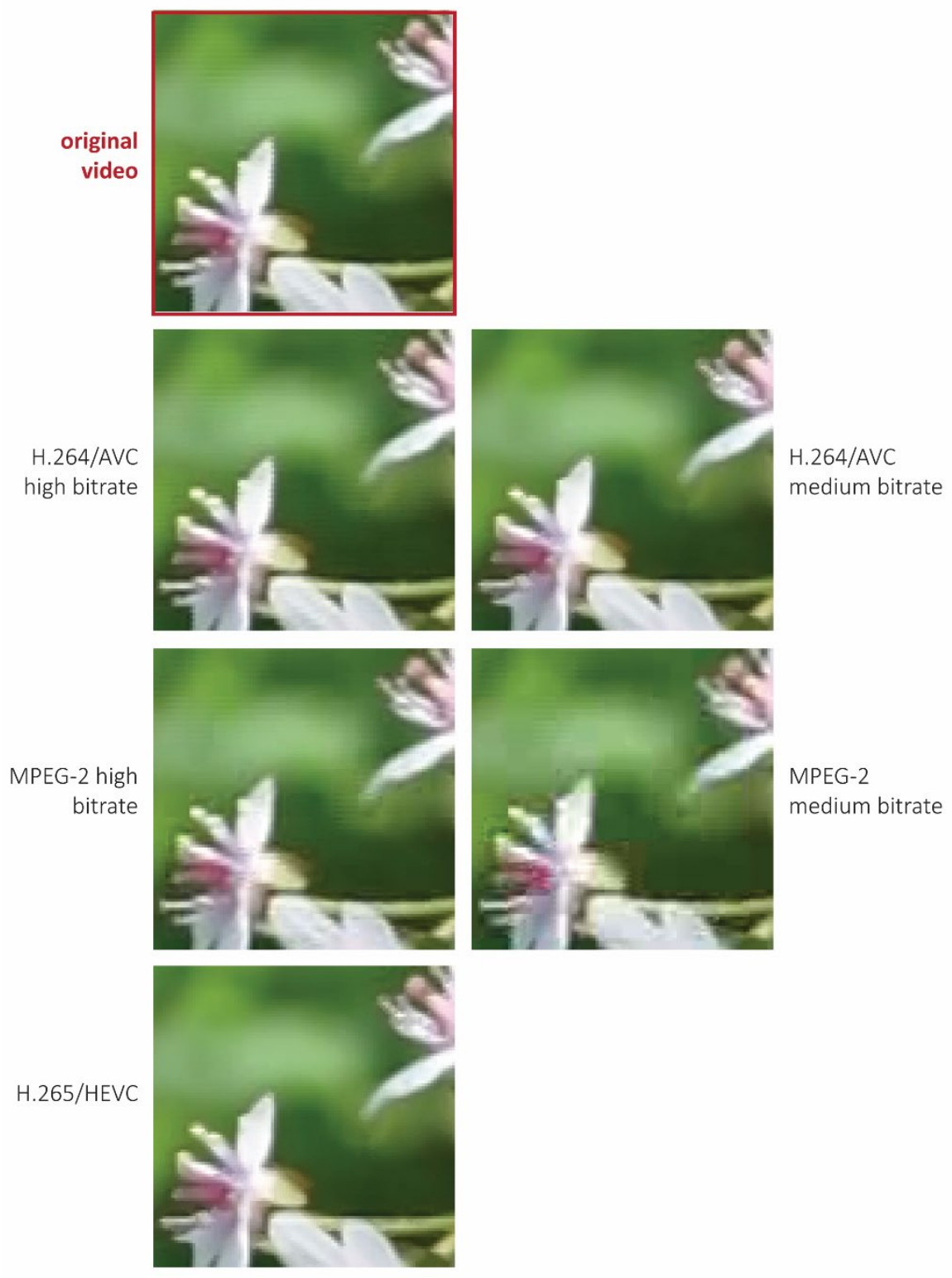

Figure 3: Enlarged details (1300\%) of encoded selected video image frames

\subsection{Results of platforms video uploads}

When uploading content to platforms, each platform uses its own algorithms and settings that determine the properties of the uploaded files (Table 3).

As mentioned above, Instagram uses predefined encoding methods (it only supports the H.264/AVC and H.265/HEVC codecs and changes them to MP4), so uploading with MPEG-2 is not possible) and reduces the resolution while keeping the bitrate unchanged. As the resolution decreases during upload, the file size (at the same bitrate) is reduced accordingly. Since Instagram is primarily a mobile application, we observed the changes in all the videos first on the smartphone and secondly on the computer. The changes in video file sizes were high, most noticeable for the most efficient H.265/HEVC codec (91.05\%), and slightly less for H.264/AVC with high (88.86 \%) and medium bitrate (67.77\%), while the resolution decreased by 62.5 $\%$. The visual changes observed on a smartphone were small but noticeable. As expected, the video encoded with H.264/AVC at medium bitrate had the most flaws. The edges were more jagged due to the lower bitrate and the colour transitions were not as smooth. The other two videos (high bitrate H.264/AVC and H.265/HEVC) looked good, with smooth colour transitions, no aliasing and jagged edges. H.264/AVC encoded video had slightly more saturated colours. The visual changes mentioned were even more noticeable when viewed on a computer due to the larger screen size and aspect ratio and the use of codecs and algorithms adapted for mobile applications. 
Based on the results, we would like to emphasize that when uploading videos to Instagram, it is most advisable to adjust the properties of the files to be uploaded as closely as possible to the characteristics of that platform, and also invert the aspect ratio $(1080 \times 1920 \mathrm{px})$.

We found that all videos uploaded to YouTube were encoded using the H.264/AVC codec, which has been changed to the MP4 container. This platform is one of the few that allows arbitrary selection of viewing resolution, even in full resolution. Despite the above, the resolution in encoded videos decreased (by 33.33 $\%)$, although not as much as in the encoding for Instagram. After uploading all encoded videos, the file size was reduced to about $4.000 \mathrm{~KB}$ at an average bitrate of $128 \mathrm{~kb} / \mathrm{s}$. When we upload the video to YouTube, the compression mechanisms change it regardless of the format and resolution used. It is therefore recommended that we are aware of these changes and keep them to a minimum. Visible changes were the smallest in the high bitrate H.264/AVC codec because the platform uses the same codec for encoding. It is recommended that you choose a slightly larger file size and bitrate when uploding videos so that the platform is able to handle more data that is reduced and changed due to the encoding process. It's also important that we do not encode videos with too much data, as this would require a more extensive encoding, while the quality of the video will not be better. On the other hand, if the amount of data is insufficient, the video quality cannot be restored. When uploading to YouTube, we must also consider the bandwidth of the Internet - if it is too weak, the quality of a video will be in lower resolution.

The study has shown that when uploading to YouTube, we should use an H.264/AVC codec in a high bitrate MP4 container, with the resolution remaining the same as in the original video (in our case: $1920 \times 1080 \mathrm{px})$.

There are two ways to send videos via Gmail. The first way is to share videos as an attachment, with the video file size limited to $25 \mathrm{MB}$, and the second way is to upload the video file to a cloud Google Drive storage first. Sending videos in Gmail requires high compression, which results in high data loss. As the file size decreases, the video quality deteriorates dramatically. We have found that in the case of our encoded videos only two are suitable - H.264/AVC and MPEG-2 at medium bitrate, with encoding resulting in file sizes smaller than $25 \mathrm{MB}$. When comparing the two video qualities, we found that H.264/AVC can provide better visual results. For video encoded with MPEG-2, we noticed jagged edges, blur, and uneven and unnatural colour gradients. Due to the poor quality, this method is therefore only suitable for sending video previews. On the other hand, if we want to share videos in high quality, it is necessary to upload the video files to Google Drive, where the content will remain unchanged, i.e. not re-encoded, while only a link to the video file will be sent by mail. There are (theoretically) no limitations here.

Table 3: Pre- and post-upload properties of video files encoded with different codecs

\begin{tabular}{|c|c|c|c|c|c|c|c|}
\hline \multirow[b]{2}{*}{ Platform } & \multicolumn{2}{|r|}{ Codec } & \multicolumn{2}{|c|}{ H.264/AVC } & \multicolumn{2}{|c|}{ MPEG-2 } & \multirow{2}{*}{$\begin{array}{c}\text { H.265/HEVC } \\
16.000- \\
20.000 \\
\text { (high) } \\
\end{array}$} \\
\hline & $\begin{array}{l}\text { Video } \\
\text { properties }\end{array}$ & $\begin{array}{l}\text { Bitrate } \\
\text { (Mbps) }\end{array}$ & $\begin{array}{c}10.000- \\
12.000 \\
\text { (high) }\end{array}$ & $\begin{array}{c}3.000- \\
6.000 \\
\text { (medium) }\end{array}$ & $\begin{array}{c}4.000- \\
18.500 \\
\text { (high) }\end{array}$ & $\begin{array}{c}2.500- \\
6.000 \\
\text { (medium) }\end{array}$ & \\
\hline \multirow{6}{*}{ Instagram } & \multirow{2}{*}{ File size (kB) } & pre-upload & 28.390 & 8.625 & \multirow{4}{*}{$\begin{array}{c}\text { not } \\
\text { possible }\end{array}$} & \multirow{4}{*}{$\begin{array}{c}\text { not } \\
\text { possible }\end{array}$} & 30.393 \\
\hline & & post-upload & 3.164 & 2.780 & & & 2.719 \\
\hline & \multirow{2}{*}{$\begin{array}{l}\text { Average } \\
\text { bitrate }(\mathrm{kb} / \mathrm{s})\end{array}$} & pre-upload & \multirow{2}{*}{319} & \multirow{2}{*}{126} & & & \multirow{2}{*}{190} \\
\hline & & post-upload & & & & & \\
\hline & \multirow{2}{*}{$\begin{array}{l}\text { Resolution } \\
(p x)\end{array}$} & pre-upload & \multicolumn{5}{|c|}{$1920 \times 1080$} \\
\hline & & post-upload & \multicolumn{5}{|c|}{$720 \times 406$} \\
\hline \multirow{6}{*}{ YouTube } & \multirow{2}{*}{ File size (kB) } & pre-upload & 28.397 & 8.625 & 26.037 & 10.091 & 30.393 \\
\hline & & post-upload & 4.010 & 4.007 & 4.023 & 4.015 & 3.820 \\
\hline & \multirow{2}{*}{$\begin{array}{l}\text { Average } \\
\text { bitrate }(\mathrm{kb} / \mathrm{s})\end{array}$} & pre-upload & 319 & 126 & 284 & 224 & 190 \\
\hline & & post-upload & \multicolumn{5}{|c|}{128} \\
\hline & \multirow{2}{*}{$\begin{array}{l}\text { Resolution } \\
(\mathrm{px})\end{array}$} & pre-upload & \multicolumn{5}{|c|}{$1920 \times 1080$} \\
\hline & & post-upload & \multicolumn{5}{|c|}{$1280 \times 720$} \\
\hline \multirow{3}{*}{ M Gmail } & \multirow{2}{*}{ File size (kB) } & pre-upload & \multirow{3}{*}{$\begin{array}{c}\text { not } \\
\text { possible }\end{array}$} & 8.625 & \multirow{3}{*}{$\begin{array}{c}\text { not } \\
\text { possible }\end{array}$} & 10.091 & \multirow{3}{*}{$\begin{array}{c}\text { not } \\
\text { possible }\end{array}$} \\
\hline & & post-upload & & & & & \\
\hline & $\begin{array}{l}\text { Average } \\
\text { bitrate }(\mathrm{kb} / \mathrm{s})\end{array}$ & $\begin{array}{l}\text { pre-upload } \\
\text { post-upload }\end{array}$ & & 126 & & 224 & \\
\hline \multirow{4}{*}{ M } & \multirow{2}{*}{ File size (kB) } & pre-upload & \multirow{2}{*}{28.397} & \multirow{2}{*}{8.625} & & & \\
\hline & & post-upload & & & 26.037 & 10.091 & 30.393 \\
\hline & Average & pre-upload & 319 & 126 & 284 & 224 & 190 \\
\hline & bitrate $(\mathrm{kb} / \mathrm{s})$ & post-upload & 319 & 126 & 284 & 224 & 190 \\
\hline
\end{tabular}




\section{CONCLUSIONS}

The results showed that the most suitable video codec for video display is H.264/AVC. It allows bitrate and resolution changes and is also generally the most commonly used video encoding method since 2019. As it is a lossy compression method, its transformations are perceived, although they are usually imperceptible to the human eye, especially when displaying video (moving images). Similar results have been achieved with the H.265/HEVC codec, which is somewhat larger in file size. Saving in MPEG-2 codecs (regardless of bitrate) resulted in noticeable unnatural colour gradients and blurred images (aliasing), larger changes in file size and bitrate.

The most suitable video format for uploading to YouTube is the H.264/AVC codec in MP4 format with high bitrate, but when uploading the video file to Instagram we must also take into account the resolution and aspect ratio, which are limited. The least limited is uploading via Gmail, as we can upload the file to the cloud and only send access to it. However, if we only want to send via Gmail, we have to use a lower bitrate, which reduces the file size to a maximum of $25 \mathrm{MB}$.

In this research, the Adobe Media Encoder with coding parameters set as default presets was used. Since the comparison of the video encoding methods led to quite unexpected results, a more detailed analysis is planned with the help of open source programs, which allow manual setting of certain parameters and their control. We hope that their use will help us to answer the question why the file sizes are so large when using the H.265/HEVC codec.

\section{REFERENCES}

[1] Laude, T., Adhisantoso, Y. G., Voges, J., Munderloh, M., Ostermann, J.: "A Comprehensive Video Codec Comparison", SIP 8 (30), 1-16, 2017. doi: 10.1017/ATSIP.2019.23

[2] Le Tanou, J., Blestel, M.: "Analysis of Emerging Video Codecs: Coding Tools, Compression Efficiency and Complexity", Society of Motion Picture \& Television Engineers Technical Conference SMPTE 2018, (SMPTE 2018: Los Angeles CA, USA, 2019).

[3] Richardson, I. E.: "Video compression codecs: a survival guide", IASA - International Association of Sound and Audiovisual Archives Journal 47, 1-8,2017. doi: 10.35320/ij.v0i47.51

[4] Rippel, O., Nair, S., Lew, C., Branson, S., Anderson, G. A., Bourdev, L.: "Learned Video Compression", Electrical Engineering and Systems Science - Image and Video Processing arXiv:1811.06981v1, 1-11, 2018.

[5] The Moving Picture Experts Group: “MPEG”, URL: https://mpeg.chiariglione.org/ (last request: 2020-09-24).

[6] Zhang, T., Mao, S.: "An overview of emerging video coding standards", GetMobile 22 (4), 13-20, 2018. doi: $10.1145 / 3325867.3325873$

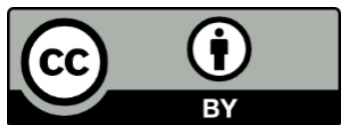

(C) 2020 Authors. Published by the University of Novi Sad, Faculty of Technical Sciences, Department of Graphic Engineering and Design. This article is an open access article distributed under the terms and conditions of the Creative Commons Attribution license 3.0 Serbia (http://creativecommons.org/licenses/by/3.0/rs/). 



\title{
THE ANALYSIS OF GRAPHIC DESIGN PLATFORMS USED IN SOCIAL MEDIA MARKETING
}

\author{
Ksenija Mitrović (D), Anja Jakšić (D), Jelena Spajić (iD) \\ University of Novi Sad, Faculty of Technical Sciences, Department of Industrial Engineering \\ and Management, Novi Sad, Serbia
}

\begin{abstract}
Development of the internet conditioned the evolution of marketing. Nowadays, organizations have relocated their marketing activities on the internet, so digital marketing comes into focus, as the most influential branch of marketing. A progress of digital marketing activities established the appearance of different digital marketing elements, among which social media marketing becomes more prevalent. Social media marketing is an inevitable element of digital marketing strategy and nowadays business. In order to complement social media marketing activities, graphic design is used as a crucial part of a content strategy. This paper focuses on the importance of effective visual content for social media and the usage of different tools that can facilitate and improve its creation. Social media users interact with visual content. In order to achieve higher engagement, social media posts are enriched with compelling visuals. Social media have become a real field for competition in terms of creating competitive content and attracting more users' attention. The aim of this paper is to analyze the effectiveness of online graphic design tools that are used for creating visual content adapted to the requirements of communication on social networks. Given the importance of visuals in social media marketing, an abundance of tools are created with different features in order to support content design. These online platforms offer complete customization options, a wide range of different editing tools and templates and diverse functionalities. Visual content, through social media platforms, boosts user awareness of existing brands and makes it easier for users to associate with the organization. Through a relevant literature review in the field of social media marketing, the importance of visual elements and graphic design in online marketing communication is emphasized. In addition, this paper provides a comparative analysis of the most commonly used online tools and platforms that provide graphic design solutions and increase the effectiveness of online marketing campaigns.
\end{abstract}

Key words: social media marketing, visual communication, content strategy, graphic design tools

\section{INTRODUCTION}

Development of the Internet and social networks led to creating a new business model where a general presence on social media represents a competitive advantage for brands. In such conditions, social media marketing becomes an integral part of digital marketing and one of the vital tools for overall marketing strategy (Ahmad et al, 2016). Social media enables bringing together a large number of people from different backgrounds to design, modify, share and discuss Internet content (Tafesse, 2015). Being competitive on the digital market imposes generating marketing content adjusted for the audience and distributed by the right social networks. Well-designed content is a cornerstone of a brand's online presence (Gunelius, 2010), since visual content drives social media exposure and engagement as well as traffic to websites. In order to make visual communication attractive and effective, the intervention of graphic design in marketing communication is required (Abdel-Rahim and Ali, 2016).

With the purpose of combining technology with art better and facilitating the process of creation of visual content, an abundance of platforms are introduced online. Therefore, this paper analyzes the most commonly used online tools and platforms that provide graphic design solutions and increase the effectiveness of online marketing campaigns. The most relevant of them will be presented and compared. With the intention to examine the usage of these platforms, web analytics is conducted using an online platform for website traffic statistics and analytics, named SimilarWeb. After that, the most visited platforms were analyzed according to their functionalities and features in order to highlight those that are most suitable and effective for social media marketing. 


\section{SOCIAL MEDIA MARKETING}

Since the number of online users and browsing time increase, social networks are recognized as the powerful marketing channels (Chang et al, 2015). Social media represents online publishing and communication tools, sites, and destinations of Web 2.0 (Gunelius, 2010) enabling content sharing, information diffusion, and relationship building (Kim and Ko, 2012). Many forms of social media are familiar (Zarrella, 2009):

- blogs,

- microblogs,

- social networks,

- media-sharing sites,

- social bookmarking and voting sites,

- review sites,

- forums,

- virtual worlds.

Nowadays, it is the fastest way to get information. Appel et al. (2020) assert the practical aspect of social media, describing them as "a collection of software-based digital technologies-usually presented as apps and websites - that provide users with digital environments in which they can send and receive digital content or information over some type of online social network". Considering the presence of these platforms in everyday life, an opportunity to connect with the customer in a new way arose.

Social media gives marketers a voice and a way to communicate with (potential) customers (Neti, 2011). Facebook, Twitter, Instagram and other social networks became the new environment for promoting products and connecting with an audience. Social media is used as a marketing medium (Kapoor et al, 2018). In that way, many marketing objectives can be achieved. According to Ocić (2014), social media enables: fast exchange of information and interactivity, encouragement of influence of direct marketing, improving the branding process, attention direction on specific products, improving the process of loyalty and trust, conducting market research and monitoring competition, considering customer opinions and so forth (Ocić, 2014). 2020 Social Media Marketing Industry Report (Stelzner, 2020) shows the most indicated benefits of the usage of social media marketing: $86 \%$ of respondents consider increased exposure as a result of their efforts. The second major benefit is increased traffic with $78 \%$, followed by generated leads (67\%) and developed loyal fans (60\%).

The ease of finding information online gives customers more options than ever. A presence on social media is now an imperative, but thanks to the social web, brands get more exposure, making it challenging to establish adequate communication with their customers.

\section{CONTENT MARKETING}

Brands use content marketing to create and share their stories (Baltes, 2015). Content Marketing Institute defines it as "a strategic marketing approach focused on creating and distributing valuable, relevant, and consistent content to attract and retain a clearly defined audience - and, ultimately, to drive profitable customer action" (Content Marketing Institute, 2020). It focuses on providing value for the customer in the form of relevant information and ideas (Vinerean, 2017). High-quality content empowers driving the engagement on social media, and has a significant role in the social media marketing campaign (Ahmad et al, 2016).

Brands today face the challenge of creating and sharing content that builds and sustains the recognition of their posts on social media (Chauhan and Pillai, 2013). It is expected from them to provide the content that is able to answer all the customers' queries in a very attractive and creative way (Ahmad et al, 2016). According to Five Software Marketing Trends for 2020 (Gartner, 2019) customers should be guided with attractive content and encouraged for participation through social media, contests and review collection to extend brand exposure across their relevant networks. It is stated that " $91 \%$ of consumers prefer interactive or visual content, such as video, over conventional static media". Graphic design has an important role in generating what customers expect on the network. It is considered as a visual piece that leads customers through intended messages (Tresnic Media, 2020).

When reaching out to people on social media, brands need to prove they have something valuable to say. Thus, an adequate content can position them as an authoritative, contributing member of the social Web 
community (Gunelius, 2010). Social media is very visual which explains the importance of content design (Gancho et al, 2013). Marketing and graphic design together create social media spaces. With the help of graphic design messages are presented through innovative design elements that ultimately give the audience stellar visual experience. Capturing customer's attention is one of the primary factors that drive marketers to integrate graphic design into their content strategy (Abdel-Rahim and Ali, 2016). Design dictates the aesthetics and friendliness of social media networks (Gancho et al, 2013). It is used to execute visual marketing through an array of graphic aspects such as infographics, videos, mailers and animations (Abdel-Rahim and Ali, 2016).

\section{ONLINE VISUAL IDENTITY}

Communication in society today is much more visually oriented. Visual culture is replacing printed or written culture (Rodríguez Estrada and Davis, 2015), giving graphic design a greater significance. Brands try to show their visual statement of who they are. Every time customers interact with a brand, they are exposed to visual stimuli such as logos, shapes, colours, characters, styles and other elements that define the brand's image (McQuarrie and Phillips, 2008). These elements are associated with the brand and help customers to identify it.

Social networks have become an imperative of today's business, so brands need to broaden their online presence. The Internet allows greater involvement of brand experience and brand engagement in the communities through interaction, which consequently leads to brand loyalty, encouraging trust and creating greater value to consumers (Jayasingh, 2019). In the online world, it only takes four to eight seconds to impress the audience, so attractive graphics are important to this process (Gancho et al, 2013). Graphic design can influence the look, ambience, functionality and the message which a brand intends to convey (Abdel-Rahim and Ali, 2016). The aspiration is to create a look and feel that will harmonize visual communication in a way that further represents the brand to the audience.

Visual communication design transforms as people's needs change. Under the influence of digital media, it has been given new features (Zhang, 2018), resulting in a wide range of online tools that facilitate creating compelling visual content. The usage of different design features creates a point of differentiation on the market, strengthens a brand's image and improves customers' loyalty (Magrath and McCormick, 2013). Compelling visuals connect the brand with its audience. They encourage discussion and shares. Also, it is shown that visual appeal can influence the quality of interaction between a customer and online stimuli (Lee et al, 2015).

Since design facilitates the interaction between brands and customers (Gancho et al, 2013), content should be carefully created to be stimulative and interactive (Duffett, 2015). Delivering an engaging experience online will affect customers' buying behaviour (Rowley, 2004) and designing that experience is a challenge. Building a desired image and recognition is supported with adequate reaching to people. Creating distinct and powerful content on a daily basis is supported with different online platforms. They help designers in generating any type of visual content and make the process more efficient. These image-creation and editing tools enable designing custom images, graphs, charts, memes, infographics, making cohesive look across all the channels. Besides producing an appealing visual in a wide range of formats, they offer a possibility to publish and share the design easily.

\section{THE ANALYSIS OF GRAPHIC DESIGN PLATFORMS USED IN SOCIAL MEDIA MARKETING}

As the website Tweak Your Biz is one of the leading global publication and online business communities, we considered it as a relevant source for the list of most important graphic design tools for social media marketing. This web site receives over 50.000 unique views per month and publishes a large amount of articles which cover every aspect of corporate lifestyle (Tweak Your Biz, 2020).

According to Tweak Your Biz, the best online graphic design tools are (Tweak Your Biz, 2020):

1. PhotoADKing;
2. Canva;
3. Befunky;
4. Pixlr;
5. Infogram;
6. Snappa;
7. Pablo;

1. PhotoADKing;

2. Canva;

3. Befunky;

4. Pixlr;

5. Infogram

7. Pablo 

15. Gravit;
16. Venngage;
17. PhotoVisi;
18. TimelineCoverBanner;
19. Landscape;
20. IPICCY.

To verify the validity of this ranking, an online tool for website traffic statistics and analytics, named SimilarWeb was used for web analytics in order to compare and evaluate these online graphic design tools. The SimilarWeb results for website traffic are presented in a Table 1.

Table 1: SimilarWeb traffic analysis of graphic design tools used in social media marketing

\begin{tabular}{|c|c|c|c|c|c|c|c|c|c|}
\hline No. & $\begin{array}{l}\text { Graphic tool } \\
\text { name }\end{array}$ & $\begin{array}{l}\text { Total } \\
\text { visits }\end{array}$ & $\begin{array}{l}\text { Average } \\
\text { visit } \\
\text { duration }\end{array}$ & $\begin{array}{l}\text { Bounce } \\
\text { rate }\end{array}$ & $\begin{array}{l}\text { Traffic } \\
\text { from } \\
\text { Search }\end{array}$ & $\begin{array}{l}\text { Organic } \\
\text { Search }\end{array}$ & $\begin{array}{l}\text { Paid } \\
\text { Search }\end{array}$ & $\begin{array}{l}\text { Traffic } \\
\text { from } \\
\text { Social } \\
\text { Media }\end{array}$ & $\begin{array}{l}\text { Traffic } \\
\text { from } \\
\text { Direct }\end{array}$ \\
\hline 1 & PhotoADKing & $84,68 \mathrm{~K}$ & 00:08:05 & $37,18 \%$ & $68,18 \%$ & $76,08 \%$ & $23,92 \%$ & $6,11 \%$ & $24,04 \%$ \\
\hline 2 & Canva & $146,79 M$ & 00:07:11 & $27,32 \%$ & $21,89 \%$ & $88,81 \%$ & $11,11 \%$ & $3,32 \%$ & $71,40 \%$ \\
\hline 3 & BeFunky & $4,71 \mathrm{M}$ & 00:04:17 & $47,38 \%$ & $54,16 \%$ & $99,98 \%$ & $0,02 \%$ & $0,58 \%$ & $44,08 \%$ \\
\hline 4 & Pixlr & $12,81 \mathrm{M}$ & 00:03:25 & $49,87 \%$ & $31,96 \%$ & $99,98 \%$ & $0,02 \%$ & $2,76 \%$ & $63,90 \%$ \\
\hline 5 & Infogram & $2,32 \mathrm{M}$ & $00: 08: 33$ & $72,10 \%$ & $26,25 \%$ & $99,3 \%$ & $0,07 \%$ & $6,42 \%$ & $50,70 \%$ \\
\hline 6 & Snappa & $1,56 \mathrm{M}$ & 00:03:25 & $58,50 \%$ & $66,91 \%$ & $99,33 \%$ & $0,67 \%$ & $3,92 \%$ & $27,47 \%$ \\
\hline 7 & Pablo & $134,91 \mathrm{~K}$ & $00: 02: 42$ & $62,44 \%$ & $17,91 \%$ & $100 \%$ & $0 \%$ & $1,89 \%$ & $71,14 \%$ \\
\hline 8 & $\begin{array}{l}\text { Quotes } \\
\text { Cover }\end{array}$ & $144,31 \mathrm{~K}$ & 00:06:15 & $44,65 \%$ & $58,21 \%$ & $99,83 \%$ & $0,17 \%$ & $1,46 \%$ & $38,56 \%$ \\
\hline 9 & Fotor & $3,13 \mathrm{M}$ & $00: 04: 25$ & $31,49 \%$ & $60,91 \%$ & $99,98 \%$ & $0,02 \%$ & $2,12 \%$ & $34,13 \%$ \\
\hline 10 & Genially & $6,38 \mathrm{M}$ & 00:08:11 & $49,70 \%$ & $31,22 \%$ & $87,21 \%$ & $12,79 \%$ & $4,85 \%$ & $51,65 \%$ \\
\hline 11 & Easel.ly & $236,51 \mathrm{~K}$ & $00: 12: 45$ & $44,27 \%$ & $28,77 \%$ & $99,61 \%$ & $0,39 \%$ & $2,96 \%$ & $58,95 \%$ \\
\hline 12 & PiZap & $795,06 K$ & 00:05:59 & $25,10 \%$ & $46,31 \%$ & $99,92 \%$ & $0,08 \%$ & $8,86 \%$ & $41,12 \%$ \\
\hline 13 & PicMonkey & $2,88 \mathrm{M}$ & $00: 22: 15$ & $26,96 \%$ & $45,51 \%$ & $76,17 \%$ & $23,28 \%$ & $3,71 \%$ & $46,29 \%$ \\
\hline 14 & Stencil & $161 \mathrm{~K}$ & 00:05:59 & $37,49 \%$ & $22,38 \%$ & $99,67 \%$ & $0,33 \%$ & $4,73 \%$ & $62,00 \%$ \\
\hline 15 & Gravit & $232,57 \mathrm{~K}$ & 00:03:28 & $63,49 \%$ & $60,85 \%$ & $88,58 \%$ & $11,42 \%$ & $7,15 \%$ & $24,41 \%$ \\
\hline 16 & Venngage & $2,48 \mathrm{M}$ & 00:04:17 & $52,26 \%$ & $72,91 \%$ & $93,11 \%$ & $6,89 \%$ & $2,48 \%$ & $21,73 \%$ \\
\hline 17 & Photovisi & $230,55 \mathrm{~K}$ & 06:42:09 & $29,90 \%$ & $71,45 \%$ & $99,98 \%$ & $0,02 \%$ & $1,58 \%$ & $24,73 \%$ \\
\hline 18 & $\begin{array}{l}\text { Timeline } \\
\text { Cover Maker }\end{array}$ & $144,31 \mathrm{~K}$ & 00:06:15 & $44,65 \%$ & $58,21 \%$ & $99,83 \%$ & $0,17 \%$ & $1,46 \%$ & $38,58 \%$ \\
\hline 19 & Landscape & $2,58 \mathrm{M}$ & 00:06:21 & $59,67 \%$ & $58,59 \%$ & $98,15 \%$ & $1,85 \%$ & $1,76 \%$ & $36,17 \%$ \\
\hline 20 & Ipiccy & $998,87 \mathrm{~K}$ & 00:02:41 & $21,87 \%$ & $15,91 \%$ & $100 \%$ & $0 \%$ & $2,36 \%$ & $80,38 \%$ \\
\hline
\end{tabular}

As Table 1 indicates, the most visited site in the past six months of 2020 is Canva,with total visits at $146,79 \mathrm{M}$ visits. It is followed by Pix/r with $12,81 \mathrm{M}$ visits and Genially which recorded 6,38M visits. In the previous six month, lesser visited websites are PhotoADKing which totaled 84,68K visits and it is followed by Timeline Cover Maker with 144,31K and Pablo which amounted 134,91K visits. 
The largest average visit duration has Photovisi with $6 \mathrm{~h}$ and $42 \mathrm{~min}$. Next to it, PicMonkey and Easel.ly have larger average visit duration in comparison with the rest of the tools, respectively 22 minutes 15 seconds and 12 minutes 45 seconds. The shortest average visit duration is noted in case of Ipiccy with 2 minutes 41 seconds and Pablo with 2 minutes 42 seconds.

The highest bounce rate has Infogram with $72,10 \%$, followed by Pablo with $62,44 \%$. The bounce rate represents the number of visitors on the website, which leaves the site instead of surfing on it. The high bounce rate significates that the website is not attracting enough visitors. The lowest bounce rate has Ipiccy with 21,87\%.

Mostly traffic comes from search or direct on the website. From the search the highest level of visits have Venngage (72,91\%) and Photovisi (71,45\%) and on the opposite side, the lowest level is recorded in case of Ipiccy $(15,91 \%)$ and Pablo (17,91\%). The sites with most direct traffic are Ipiccy and Canva with respectively $80,38 \%$ and $71,40 \%$. Venngage is the site with the poorest direct traffic at $21,73 \%$.

Pablo and Ipiccy has $100 \%$ organic search, followed by Photovisi, Fotor,Pix/r and BeFunky at 99,98\% organic search. The websites with the most paid search and traffic are definitely the PhotoAdKing and PicMonkey with $23,92 \%$ and $23,28 \%$.

Social media is not one of the strongest sources of traffic for these websites. The most traffic from social media platforms got PiZap with 8,86\% and the poorest traffic from social media has BeFunky at 0,58\%.

In order to get more detailed insight to the functionalities and features that are most suitable and effective for social media marketing, the second step in this research is content analysis of the most visited platforms for graphic design. Table 2 highlights the main features that these tools offer in the context of creating SMM content.

Table 2: The analysis of functionality of the 5 most visited graphic design tools used in social media marketing

\begin{tabular}{|c|c|c|c|c|c|}
\hline GD platform & \multirow{2}{*}{ Canva } & \multirow{2}{*}{ Pixlr } & \multirow{2}{*}{ Genially } & \multirow{2}{*}{ BeFunky } & \multirow{2}{*}{ Fotor } \\
\hline Functionality & & & & & \\
\hline Basic photo editing & + & + & + & + & + \\
\hline Beauty retouching & - & + & - & + & + \\
\hline Background remover & - & + & - & + & - \\
\hline Collage Maker & + & - & - & + & + \\
\hline Photo Effects & + & + & + & + & + \\
\hline Social media templates & + & - & - & + & + \\
\hline Text editing & + & + & + & + & + \\
\hline Stickers & + & - & + & - & + \\
\hline Photo frames & + & - & - & + & + \\
\hline HDR & + & + & - & + & + \\
\hline Video editing & + & - & + & - & - \\
\hline Animation & + & - & + & - & - \\
\hline Insert audio & + & - & + & - & - \\
\hline Free stock images & + & + & + & + & - \\
\hline Free version & Yes & Yes & Yes & Yes & Yes \\
\hline $\begin{array}{l}\text { Paid version and } \\
\text { pricing }\end{array}$ & $\begin{array}{c}\text { Pro } \\
\text { 9,95\$/user } \\
\text { monthly and } \\
\text { Premium } \\
\text { 30\$/user } \\
\text { monthly }\end{array}$ & $\begin{array}{c}\text { Premium } \\
4,90 \$ \text { and } \\
\text { Professional } \\
14,99 \$\end{array}$ & $\begin{array}{c}\text { Pro, Master } \\
\text { and Team } \\
\text { package } \\
\text { (respectively: } \\
7,49 \$ \\
20,82 \$ \\
79,15 \$ \\
\text { monthly) }\end{array}$ & $\begin{array}{c}6,99 \$ \\
\text { monthly/59,88\$ } \\
\text { annually }\end{array}$ & $\begin{array}{c}8,99 \$ \\
\text { monthly/39,99\$ } \\
\text { annually }\end{array}$ \\
\hline
\end{tabular}


As Table 2 indicates, different types of graphic design online platforms provide different features. For instance, for photo editing the most convenient tools are Pixlr and BeFunky, as for the removing background. All presented tools have option to design text and making special effects on the photos. Video and audio editing have only two of five tools - Canva and Genially. Templates for social media have three of five analyzed tools - Canva, Fotor and BeFunky. The all five of most visited graphic design online tools have free version, but also the paid one. The highest price for the pricing packages has Canva.

\section{CONCLUSION}

Visual communication is the present and the future of digital marketing. Digital marketing strategy cannot be successful without having quality content. This paper analyzed the most used platforms to make the communication process on social media effective and efficient. Conducted research highlighted 20 tools and used digital market intelligence platform to explore their site analytics. The results show that the parameters vary among platforms. Number of total visits proves the wide use of these websites, reaching up to $146,79 \mathrm{M}$ visits. Quick access to personal workspace anytime and everywhere is the actuator of visits. Also, the usage of these platforms is the solid foundation for communicating the ideas and saving them in one place. Some of the mentioned platforms use social media and paid search, but the data show that it is not the strongest source to attract users. Search and direct drive most traffic.

In the context of these tools' functionalities for social media marketing, we can conclude that different tools contribute to different options, and best one cannot be chosen. For advanced editing photos, the great free solutions are Pixlr and BeFunky, but for creating memorable content for social media networks, Canva and Fotor have a huge range of features that can be used for different platforms and public. Genially is a tool which is created with wide range of purposes, but with lack of some important features related with social media marketing. Observing the effectiveness of these tools in the context of creating content for SMM, according to the identified parameters, it can be concluded that Canva meets the largest number of these requirements, however for certain functionalities some of the other observed online tools are more efficient.

Since today's business moved to the online world, it is easiest to find customers on social networks. People are visual beings who spend a lot of time on social media. In order to attract them and draw their attention to the promotional content, it is necessary to create a unique design and differentiate from others. Compelling visual content is needed and marketing communications are greatly supported and empowered by graphic design platforms that are easy and simple to use. Visuals are memorable and relatable. Whether it is used to express the brand, promote a product or convey a message, visual content is the path to get in front of customers in a powerful, interactive, and meaningful way.

\section{REFERENCES}

[1] Abdel-Rahim, F., Ali, M.: "A study on impact of graphic design on marketing in sultanate of Oman", Shanlax International Journal of Arts, Science \& Humanities 4(2), 65-76, 2016.

[2] Ahmad, N. S., Musa, R., Harris, M., Harun, M.: "The Impact of Social Media Content Marketing (SMCM) towards Brand Health", Procedia Economics and Finance 37, 331-336, 2016. doi: 10.1016/S2212-5671(16)30133-2.

[3] Appel, G., Grewal, L., Hadi, R., Stephen, A. T.: "The future of social media marketing", Journal of the Academy of Marketing Science 48, 79-95, 2020. doi: 10.1007/s11747-019-00695-1.

[4] Baltes, L. P.: "Content marketing - the fundamental tool of digital marketing", Bulletin of the Transilvania University of Brasov, Series V: Economic Sciences 8(57), 111-118, 2015.

[5] Chang, Y-T., Yu, H., Wu, H-P.: "Persuasive messages, popularity cohesion, and message diffusion insocial media marketing", Journal of Business Research 68, 777-782, 2015. doi: 10.1016/j.jbusres.2014.11.027.

[6] Chauhan, K., Pillai, A.: "Role of Content Strategy in Social Media Brand Communities: A Case of Higher Education Institutes in India", Journal of Product and Brand Management 22(1), 40-51, 2013. doi: 10.1108/10610421311298687.

[7] Content Marketing Institute: "What is Content Marketing", URL: https://contentmarketinginstitute.com/what-is-content-marketing/ (last request: 2000-08-26).

[8] Duffett, R. G.: "Facebook advertising's influence on intention-to-purchase and purchase amongst millennials", Internet Research 25(4), 498-526, 2015. doi: 10.1108/IntR-01-2014-0020. 
[9] Gancho, S., Cooper, R., Evans, M.: "The impact of Design in social media today", Proceedings of 2nd Cambridge Academic Design Management Conference 2013, (CADMC: Cambridge, UK, 2013), pages 673-686.

[10] Gartner: "Five Software Marketing Trends for 2020", URL: https://www.gartner.com/en/digitalmarkets/insights/five-software-marketing-trends-for-2020 (last request: 2020-08-26).

[11] Gunelius, S.: "30-Minutes Social Media Marketing", (McGraw-Hill Professional, 2010.), page 10.

[12] Jayasingh, S.: "Consumer brand engagement in social networking sites and its effect on brand loyalty", Cogent Business and Management 6(1), 2019. doi: 10.1080/23311975.2019.1698793.

[13] Kapoor, K.K., Tamilmani, K., Rana, N.P., Patil, P., Dwivedi, Y.K., Nerur S.: "Advances in social media research: past, present and future", Information Systems Frontiers 20(3), 531-558, 2018. doi: 10.1007/s10796-017-9810-y.

[14] Kim, A.J., Ko, E.: "Do social media marketing activities enhance customer equity? An empirical study of luxury fashion brands", Journal of Business Research 65(10), 1480-1486, 2012. doi: 10.1016/j.jbusres.2011.10.014.

[15] Lee, J., Ahn, J.-H., Park, B.: "The effect of repetition in Internet banner ads and the moderating role of animation", Computers in Human Behavior 46, 202-209, 2015. doi: 10.1016/j.chb.2015.01.008.

[16] Magrath, V., McCormick, H.: "Branding design elements of mobile fashion retail apps", Journal of Fashion Marketing and Management 17(1), 98-114, 2013. doi: 10.1108/13612021311305164.

[17] McQuarrie, E. F., Phillips, B. J.: "It's not your father's magazine ad: Magnitude and direction of recent changes in advertising style", Journal of Advertising 37, 95-106, 2008.

[18] Neti, S.: "Social media and its role in marketing", International Journal of Enterprise Computing and Business Systems 1 (2), 1-15, 2011.

[19] Ocić, Č.: "Moguće strategije razvoja Srbije”, (SANU, Beograd, 2014.).

[20] Rodríguez Estrada, F.C., Davis, L.S.: "Improving Visual Communication of Science Through the Incorporation of Graphic Design Theories and Practices Into Science Communication", Science Communication 37(1), 2015. doi: 10.1177/1075547014562914.

[21] Rowley, J.: "Online branding", Online Information Review 28 (2), 131-138, 2004. doi: 10.1108/14684520410531637.

[22] Stelzner, M.: "2020 Social Media Marketing Industry Report”, Social Media Examiner, URL: https://www.socialmediaexaminer.com/social-media-marketing-industry-report-2020/ (last request: 2020-08-26).

[23] Tafesse, W.: "Content Strategies and Audience Response on Facebook Brand Pages", Marketing Intelligence \& Planning 33 (6), 927-943, 2015. doi: 10.1108/MIP-07-2014-0135.

[24] Tresnic Media: "3 Ways Graphic Design is Used in Content Marketing", URL: https://tresnicmedia.com/3-ways-graphic-design-is-used-in-content-marketing/ (last request: 202008-26).

[25] Tweak Your Biz: "Best Graphic Design Tools For Social Media Marketing", URL: https://tweakyourbiz.com/marketing/graphic-design-tools-smm (last request: 2020-09-01).

[26] Vinerean, S.: "Content Marketing Strategy. Definitions, Objectives and Tactics", Expert Journal of Marketing 5 (2), 92-98, 2017.

[27] Zarrella, D.: "The Social Media Marketing Book", 1sted. (O'Reilly Media, Inc., Sebastopol, 2009.), page 3.

[28] Zhang, L.: "Design and Research on Visual Communication under the Influence of Digital Media", Proceedings of the 6th International Conference on Social Science, Education and Humanities Research (SSEHR: Jinan, China, 2017), pages 257-260. doi: 10.2991/ssehr-17.2018.60.

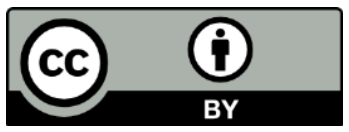

(C) 2020 Authors. Published by the University of Novi Sad, Faculty of Technical Sciences, Department of Graphic Engineering and Design. This article is an open access article distributed under the terms and conditions of the Creative Commons Attribution license 3.0 Serbia (http://creativecommons.org/licenses/by/3.0/rs/). 



\title{
EVALUATION OF THE IMPACT OF AN AWARENESS-BASED ANIMATION ON STUDENTS' KNOWLEDGE ABOUT MENTAL ILLNESS
}

\author{
Mojca Plot ${ }^{1}$ (D), Saška Roškar ${ }^{2}$ (D), Helena Gabrijelčič Tomc ${ }^{1}$ (D) \\ ${ }^{1}$ University of Ljubljana, Faculty of Natural Sciences and Engineering, Department of Textiles, \\ Graphic Arts and Design, Chair of Information and Graphic Arts Technology, Ljubljana, Slovenia \\ ${ }^{2}$ National Institute of Public Health, Ljubljana, Slovenia
}

\begin{abstract}
Animation is an exceptionally good medium for educating and raising awareness of the issues that are more difficult to talk about, such as mental illness. The use of animation and graphics in society awareness and education can improve knowledge and communication about issues related to mental illness. Despite various destigmatization activities, people are still reluctant to directly approach individuals suffering from mental illness, partly because they do not have enough knowledge on the subject. Therefore, the aim of our study was to test whether animation can improve the knowledge about appropriate / inappropriate conversations with a person suffering from depression in a Slovenian student population. We focused on education and awareness-based animation (adapted to the target group) to evoke empathy without arousing pity and to indirectly encourage people in need and others to talk about it. The methodology included the surveying of the participants and their knowledge about appropriate and inappropriate conversations with a person suffering from depression (22 phrases, 11 appropriate and 11 inappropriate). 251 participants aged 19 to 30 completed the survey. Participants were asked to rate each phrase for appropriateness on a 5-point Likert scale before and after being exposed to the animation. The results obtained were analysed using the paired samples t-test. The desired change in knowledge was confirmed by comparing the average scores of the survey responses before and after viewing the animation. A statistically significant result was obtained in 18 of 22 sentences. A change in the desired direction was detected in $81 \%$ of the statements. Our study had some limitations, but we nevertheless conclude that an awareness-based animation can be a useful tool to increase knowledge and subsequently influence behavioural change in the student population.
\end{abstract}

Key words: illustration, animation, stigma, mental disorders, depression

\section{INTRODUCTION}

Web videos or animations are an effective medium for raising awareness, as the ability to remember a message is $58 \%$ higher than when information is provided with an audio clip alone. Recipients of an animated message are more likely to receive and remember the message, and they are also more likely to receive the message faster because the animated message is usually accessible on variable devices (Instruxion, 2014). Yamaguchi et al (2013), in a systematic review of student-centred anti-stigmatism programs, found that video and face-to-face contact are the most effective means of intervention to change attitudes and reduce social distance (Yamaguchi et al, 2013).

The word "stigma" had sometimes been used to denote physical signs that have been cut or burned into the body of a violated person (Goffman, 2008). Today we understand stigma as a social psychological construct that refers to stereotypes, prejudice and discrimination (Pregelj et al, 2013). Stereotypes are apparently well-founded facts (Corrigan and Bink, 2016) that correctly or incorrectly generalize social phenomena, social groups and their members. Stereotypes develop into prejudices when people have negative feelings towards stereotyped people and evaluate them negatively (Corrigan and Bink, 2016). While prejudice is the emotional reaction of an individual to the object of stigmatization, discrimination refers to a behavioural response (different treatment of people) (Corrigan and Bink, 2016). Due to stigma, people with mental disorders do not seek help in time or not at all. Research shows that there is a link between the symptoms of mental illness and adolescence (Pregelj et al, 2013).

The first symptoms of mental illness plaguing adults develop by the mid-twenties. In individuals with mood disorders, $25 \%$ develop the disorder by the age of 18 , anxiety disorders develop by $75 \%$ by the age of 21 , and $75 \%$ of people with a mental disorder develop it by the age of 24 . Studies show that undergraduate students often have mental health problems, but most often do not seek help (Gaddis et al, 2018). Based on the results of a study by Calear et al (2019), which examined the personal and public stigmatisation of depression in Australian youth, it would be useful to develop a general campaign to 
reduce the stigma of youth and a specific campaign to reduce the stigma of young men who have little experience and knowledge of depressive disorders.

In a study (Vidourek and Burbage, 2019) on positive mental health and the stigma of mental health among students, the researchers equated positive mental health with happiness, low stress and a positive attitude. Improved quality of life, better coping with problems and reduced stress were described as positive treatment benefits. In this study, students recognized the benefits of seeking help. By being aware of the perceived benefits and highlighting them, barriers to treatment can be removed as students would have a more acceptable attitude towards seeking treatment for mental health problems. The study found that most students believe that stigma is an obstacle to treatment. They also believe that the search for help needs to be intensified, which can be achieved by reducing stigmatization through education and understanding. A few participants pointed out that media coverage of mental health influences society's perception of what it means to have mental health problems. Education and awareness were identified as key factors in reducing stigma and increasing treatment rates.

People find it easier to identify with a message created by focusing on a specific group of people (Gauss, 2020). The campaign message should be designed so that people can easily understand it. People must be given a clear message that their participation has a positive impact (Esquivel, 2020). The audience is likely to attribute a high level of credibility if they have first-hand experience of the topic; people are also more receptive to resources that are similar to them and embody characteristics such as sympathy, professionalism and trust (Yamaguchi et al, 2013).

The structure and content of a message influences attention, perception, emotions, and intentions. When creating a message, the creator can attract the attention of the audience, improve the memory of the message and trigger emotional reactions by using structural characteristics that function in accordance with people's cognitive and physiological processes. When designing audio and video messages, the audience can be directed to focus on specific moments and specific content by creating messages with structural characteristics that trigger targeted reactions (Yamaguchi et al, 2013). Social marketing is a way to raise interest in the plight of disadvantaged groups and motivate others to take collective action (Summers and Summers, 2017). For communication it uses visual elements that evoke empathy (Grinstein et al, 2019). Because of empathy, the consumers of the message have positive feelings towards stigmatized persons and an increased need for help (Summers and Summers, 2017). Empathy requires identification and perceived need (Grinstein et al, 2019). In a study of the effects of pity on the perception of oneself and other mentally ill people, Fominaya et al (2016) found that pity not only reduces anger but also increases avoidance. The findings of this research were consistent with the model of self-stigmatization, which states that perceived stigmatization is the first step to self-stigmatization. Moreover, the findings suggest that programs meant to remove the stigma of mental illness should avoid messages that pose mental illness in a pitying light.

The purpose of the presented research was to study the factors influencing the message, comprehensibility and effectiveness of 2D illustration and animation, and on the basis of this study to create an animation that provides a good insight into the plight of a person with depression and teaches appropriate and inappropriate communication talking to a person with depression and emphasizing the importance of proper support. In the research, our goal was to prove that watching visual animated images and listening to the phrases (sentences) that are more or less suitable for communication with a person suffering from depression can improve the understanding of the plight of the person suffering from depression and awareness about which phrases are suitable and not suitable in communicating. We hypothesized that after watching the animation with the goal of teaching about appropriate and inappropriate communication with a person with depression, the percentage of sentences that the respondents of the questionnaire would label as suitable for communication with a person with depression would change.

\section{METHODS}

The methodology included the identification of the target group, animation production, the testing of the participants (target group representatives) and the statistical analysis of the results.

The target group were students of the 1st and 2 nd level of higher and university educational study programme of the University of Ljubljana (study programmes of different professional fields). Animation production included: 
- pre-production of animation: determining the message of the animation, writing the script, and creating the story (narrative in the form of a personal confession of the student)

- production and post-production of animation: digital illustration - XP-PEN Artist 22E Pro graphics tablet and Adobe Photoshop CC 2018; sound and narration capture - microphone and Audacity program; illustration animation - Adobe After Effects CC 2018; and editing - Adobe Premiere Pro CC 2018.

The survey of the target group was conducted using the Google Forms tool, and an anonymous survey was sent by e-mail. The online survey was divided into three parts:

- Part 1 of the survey: the participants filled in demographic data, answered a question whether they had personal experiences with a mental disorder and completed a questionnaire consisting of 22 phrases (11 suitable and 11 unsuitable for communicating with a person with depression).

- Part 2 of the survey: The participants watched the animation.

- Part 3 of the survey: Participants answered a questionnaire consisting of 22 phrases with 11 appropriate and 11 inappropriate phrases in communication with a person with depression (the distribution of phrases was different from part 1 of the test), from which participants had to choose phrases again that they thought were appropriate for communication with a person with depression.

- Examples of inappropriate phrases were: "You do not look depressed to me", "Try to get more exercise and eat a healthy diet", "Get yourself together. Be grateful for what you have. "Ah, you do not have to be depressed about anything. You've got it all.", etc., and examples of appropriate phrases: "I am worried about you. Is there anything I can do to help you? "," Whenever you want to share something with me, I am here for you. I am interested in everything you want to tell me. "," I am here for you even in difficult times. I am not going anywhere. "," I want to help you. You are not alone.", etc.

- Each sentence was rated by the participants on a 5-point Likert scale (1 - totally inappropriate; 2 - slightly appropriate, 3 - I do not know; 4 - quite appropriate; 5 - totally appropriate) and marked as appropriate or inappropriate.

The statistical analysis of the results was performed in IBM SPSS Statistics. We were interested in whether the percentage of responses indicating inappropriate communication with a person suffering from depression changes after watching the animation. The mutual comparison of the average values of the selected parameters (the degree of suitability of the sentence) was performed with a paired sample t-test for repeated measurements, i.e. evaluation of the survey responses in twenty-two sentences before and after watching the animation. The value of statistical significance was defined at $p=0.05$; with a confidence interval of $95 \%$. The change in attitude to a more or less appropriate phrase was characterized by a positive or negative difference calculated between the responses resulted before and after watching the animation. If defined statistical conditions were met, it could be argued that the person's attitude has changed, which meant that there had been a relevant change in knowledge about the topic. The relevant change has been confirmed when the response was statistically significant, i.e. in the respondent attitude there was a change to more appropriate or less stigmatizing phrase to address a person with depression.

\section{RESULTS}

Figure 1 shows scenes from the animation, which depicts the personal experience of a student with depression and the support she receives from her environment. The main message is that depression is a curable disease, so the animation urges people to support people, not stigmatise them.

The total number of respondents who filled out the entire survey was 251 . Their age was between 19 and 30 years old (Figure 2a). All questions in the survey were mandatory, so that participants could only submit a fully completed survey. Significantly more women than men took part in the survey, namely 218 women and 33 men. There were several possible answers to the question "Do you have any experience with a mental disorder?". 269 answers were recorded (Figure 2b), indicating that the participants had a personal experience with a mental disorder or knew someone who had an experience with a mental disorder. The participants ticked 86 times that they had no experience with the mental disorder or did not want to say that they had. 


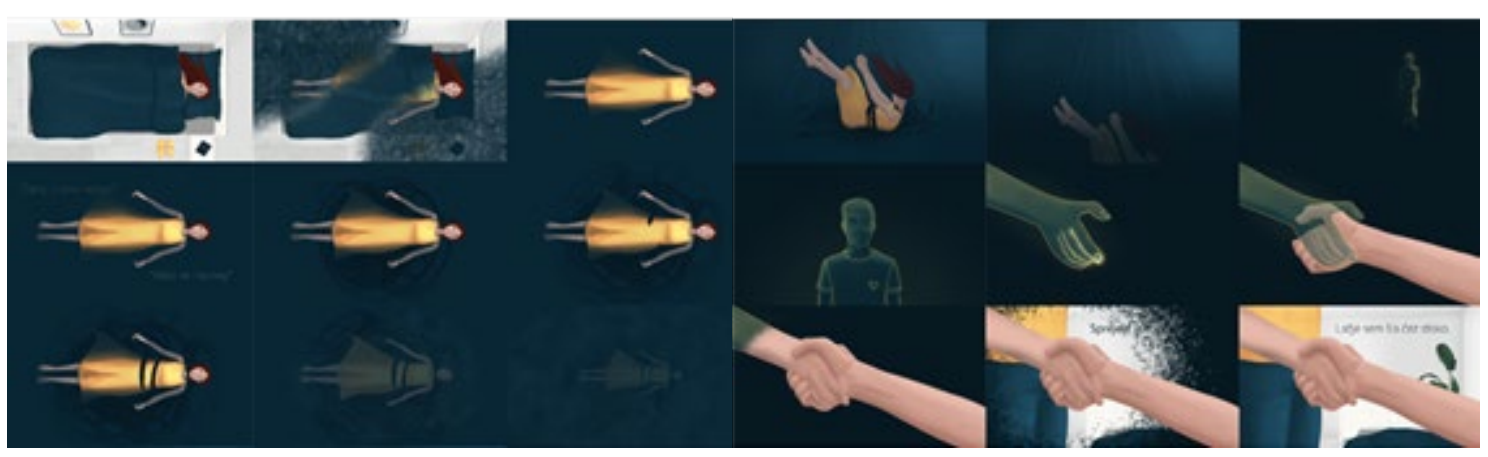

Figure 1: Final animation plans

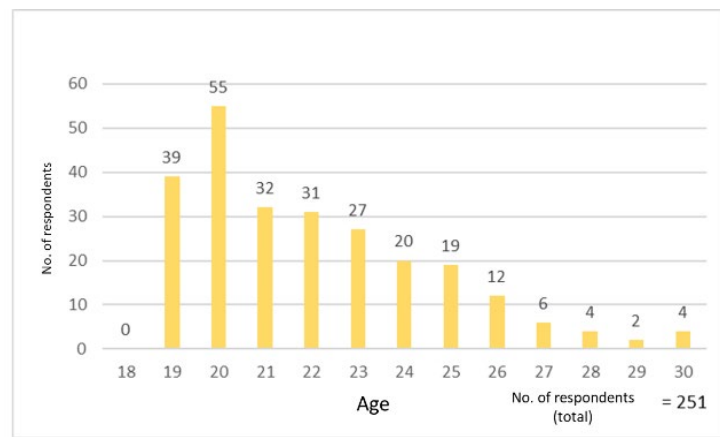

a)

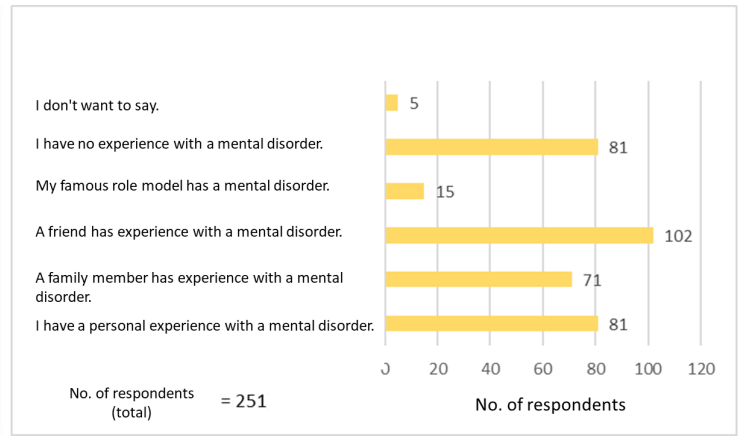

b)

Figure 2: Age structure of respondents and number of respondents who had or did not have experience with a mental disorder

\subsection{Statistical analysis}

The analysed data of the selection of 22 appropriate and inappropriate phrases are presented in Table 1 as mean values and standard errors (SN). The mutual comparison of the mean values of the selected parameters (the degree of suitability of the phrase) was performed with a Paired Sample T-Test for repeated measurements. We used it to evaluate the survey responses in twenty-two sentences before and after watching the animation. Table 1 contains descriptive statistics. The mean values of the answers of all sentences before and after watching the animation and the standard deviation are calculated.

Table 1 (part 1): Descriptive statistical values of the sentences used in both measurements. The letter B indicates the answers before watching the animation and the letter $A$ indicates the answers after watching the animation

\begin{tabular}{|c|c|c|c|c|}
\hline $\begin{array}{c}\text { No. of } \\
\text { phrase }\end{array}$ & $\begin{array}{c}\text { Survey before / after } \\
\text { animation }\end{array}$ & $\begin{array}{c}\text { M - average response } \pm \\
\text { SN }\end{array}$ & N- No. of participants & $\begin{array}{c}\text { SD - standard } \\
\text { deviation }\end{array}$ \\
\hline 1 & B01 & $1,48 \pm 0,048$ & 251 & 0,766 \\
\hline \multirow{2}{*}{2} & A01 & $1,26 \pm 0,040$ & 251 & 0,641 \\
\hline \multirow{2}{*}{3} & B02 & $1,48 \pm 0,048$ & 251 & 0,761 \\
\hline \multirow{2}{*}{4} & A02 & $1,33 \pm 0,045$ & 251 & 0,713 \\
\hline \multirow{2}{*}{5} & B03 & $2,76 \pm 0,072$ & 251 & 1,139 \\
\hline 5 & A03 & $1,97 \pm 0,070$ & 251 & 1,115 \\
\hline & B04 & $1,44 \pm 0,049$ & 251 & 0,769 \\
\hline 6 & A04 & $1,22 \pm 0,036$ & 251 & 0,578 \\
\hline & B05 & $1,25 \pm 0,041$ & 251 & 0,647 \\
\hline & A05 & $1,13 \pm 0,030$ & 251 & 0,476 \\
\hline & B06 & $1,73 \pm 0,061$ & 251 & 0,970 \\
\hline
\end{tabular}


Table 1 (part 2): Descriptive statistical values of the sentences used in both measurements. The letter B indicates the answers before watching the animation and the letter $A$ indicates the answers after watching the animation

\begin{tabular}{|c|c|c|c|c|}
\hline $\begin{array}{l}\text { No. of } \\
\text { phrase }\end{array}$ & $\begin{array}{l}\text { Survey before / after } \\
\text { animation }\end{array}$ & $\begin{array}{c}\text { M - average response } \pm \\
\text { SN }\end{array}$ & $\mathrm{N}$ - No. of participants & $\begin{array}{l}\text { SD - standard } \\
\text { deviation }\end{array}$ \\
\hline \multirow[t]{2}{*}{7} & B07 & $1,61 \pm 0,062$ & 251 & 0,983 \\
\hline & A07 & $1,33 \pm 0,046$ & 251 & 0,735 \\
\hline \multirow[t]{2}{*}{8} & B08 & $2,14 \pm 0,073$ & 251 & 1,162 \\
\hline & A08 & $1,59 \pm 0,059$ & 251 & 0,940 \\
\hline \multirow[t]{2}{*}{9} & B09 & $1,29 \pm 0,040$ & 251 & 0,632 \\
\hline & A09 & $1,22 \pm 0,041$ & 251 & 0,648 \\
\hline \multirow[t]{2}{*}{10} & B10 & $2,05 \pm 0,068$ & 251 & 1,085 \\
\hline & A10 & $1,63 \pm 0,058$ & 251 & 0,917 \\
\hline \multirow[t]{2}{*}{11} & B11 & $1,31 \pm 0,041$ & 251 & 0,645 \\
\hline & A11 & $1,18 \pm 0,037$ & 251 & 0,583 \\
\hline \multirow[t]{2}{*}{12} & B12 & $4,27 \pm 0,057$ & 251 & 0,903 \\
\hline & A12 & $4,43 \pm 0,060$ & 251 & 0,958 \\
\hline \multirow[t]{2}{*}{13} & B13 & $4,46 \pm 0,050$ & 251 & 0,796 \\
\hline & A13 & $4,64 \pm 0,044$ & 251 & 0,692 \\
\hline \multirow[t]{2}{*}{14} & B14 & $4,54 \pm 0,048$ & 251 & 0,754 \\
\hline & A14 & $4,78 \pm 0,040$ & 251 & 0,629 \\
\hline \multirow[t]{2}{*}{15} & B15 & $4,73 \pm 0,037$ & 251 & 0,585 \\
\hline & A15 & $4,74 \pm 0,042$ & 251 & 0,670 \\
\hline \multirow[t]{2}{*}{16} & B16 & $4,56 \pm 0,045$ & 251 & 0,721 \\
\hline & A16 & $4,75 \pm 0,034$ & 251 & 0,547 \\
\hline \multirow[t]{2}{*}{17} & B17 & $4,05 \pm 0,061$ & 251 & 0,966 \\
\hline & A17 & $4,56 \pm 0,048$ & 251 & 0,759 \\
\hline \multirow[t]{2}{*}{18} & B18 & $4,55 \pm 0,044$ & 251 & 0,705 \\
\hline & A18 & $4,63 \pm 0,045$ & 251 & 0,705 \\
\hline \multirow[t]{2}{*}{19} & B19 & $4,35 \pm 0,052$ & 251 & 0,823 \\
\hline & A19 & $4,49 \pm 0,051$ & 251 & 0,812 \\
\hline \multirow[t]{2}{*}{20} & B20 & $4,15 \pm 0,060$ & 251 & 0,943 \\
\hline & A20 & $4,25 \pm 0,061$ & 251 & 0,967 \\
\hline \multirow[t]{2}{*}{21} & B21 & $4,18 \pm 0,054$ & 251 & 0,857 \\
\hline & A21 & $4,48 \pm 0,051$ & 251 & 0,802 \\
\hline \multirow[t]{2}{*}{22} & B22 & $4,64 \pm 0,044$ & 251 & 0,704 \\
\hline & A22 & $4,72 \pm 0,043$ & 251 & 0,683 \\
\hline
\end{tabular}

Table 2 shows the t-test values for repeated measurements (comparison of mean values before and after the animation) and the corresponding characteristic levels. As shown in Table 2, statistically significant differences occurred in 18 sentences out of 22 (1-8, 10-14, 16, 17, 19-21). 
Table 2: T-test values, comparisons of differences in mean values between the two measurements

\begin{tabular}{|c|c|c|c|c|c|}
\hline \multirow{2}{*}{$\begin{array}{l}\text { No. of the } \\
\text { phrase }\end{array}$} & \multirow[t]{2}{*}{$\mathrm{t}$} & \multirow{2}{*}{$\begin{array}{l}\mathrm{df} \text { - degree } \\
\text { of freedom }\end{array}$} & \multirow[t]{2}{*}{$\mathrm{p}$ - significance } & \multicolumn{2}{|c|}{$\mathrm{Cl}-95 \%$ confidence interval } \\
\hline & & & & lower & upper \\
\hline 1 & 5,076 & 250 & 0,000 & 0,134 & 0,304 \\
\hline 2 & 3,612 & 250 & 0,000 & 0,069 & 0,234 \\
\hline 3 & 11,306 & 250 & 0,000 & 0,648 & 0,922 \\
\hline 4 & 5,076 & 250 & 0,000 & 0,134 & 0,304 \\
\hline 5 & 3,284 & 250 & 0,001 & 0,046 & 0,185 \\
\hline 6 & 8,099 & 250 & 0,000 & 0,286 & 0,471 \\
\hline 7 & 5,452 & 250 & 0,000 & 0,181 & 0,385 \\
\hline 8 & 9,241 & 250 & 0,000 & 0,433 & 0,667 \\
\hline 9 & 1,635 & 250 & 0,103 & $-0,015$ & 0,158 \\
\hline 10 & 6,694 & 250 & 0,000 & 0,295 & 0,541 \\
\hline 11 & 4,016 & 250 & 0,000 & 0,069 & 0,202 \\
\hline 12 & $-2,400$ & 250 & 0,017 & $-0,283$ & $-0,028$ \\
\hline 13 & $-3,810$ & 250 & 0,000 & $-0,272$ & $-0,087$ \\
\hline 14 & $-5,520$ & 250 & 0,000 & $-0,324$ & $-0,154$ \\
\hline 15 & $-0,317$ & 250 & 0,751 & $-0,086$ & 0,062 \\
\hline 16 & $-5,141$ & 250 & 0,000 & $-0,264$ & $-0,118$ \\
\hline 17 & $-9,555$ & 250 & 0,000 & $-0,615$ & $-0,405$ \\
\hline 18 & $-1,882$ & 250 & 0,061 & $-0,179$ & 0,004 \\
\hline 19 & $-2,567$ & 250 & 0,011 & $-0,232$ & $-0,031$ \\
\hline 20 & $-2,031$ & 250 & 0,043 & $-0,204$ & $-0,003$ \\
\hline 21 & $-6,225$ & 250 & 0,000 & $-0,393$ & $-0,204$ \\
\hline 22 & $-1,952$ & 250 & 0,052 & $-0,168$ & 0,001 \\
\hline
\end{tabular}

\section{DISCUSSION}

The completion of the survey depended on people's willingness to participate and interest in the topic, as the survey was conducted online and was not mandatory. The link to the survey was distributed by email from various faculties and their social networks, so we could not predict how many women or men the survey would be forwarded to. Women suffer from depression twice as often as men (Dernovšek et al, 2006). Therefore, it is possible that they were more attracted to the topic and as a result participated in the survey more $(87 \%)$ than men $(13 \%)$.

By comparing the average values of the survey answers before and after watching the animation, we confirmed the change in knowledge about depression among students aged 19-30 years. The survey measured the participants knowledge of the appropriateness and inappropriateness of phrases that can be used in a conversation with a person suffering from depression. A statistically significant result was obtained for 18 of 22 sentences (1-8, 10-14, 16, 17, 19-21). If we convert this into percentages, we can conclude that the watching of the animation resulted in an $81.8 \%$ change in students thinking. The responses obtained from the survey indicate that the participants were able to correctly assess the appropriateness or inappropriateness of the sentences before watching the animation. Most of the participants had a personal experience with a mental disorder or know someone who had an experience with a mental disorder. According to the results, the animation further strengthened the participants' knowledge and convinced them of the appropriateness or inappropriateness of the sentences. This is indicated by lower averages of responses after watching the animation in sentences 1-11 and higher 
averages of responses after watching the animation in sentences $12-22$. The results after watching the animation were even closer to grade 1 - completely inappropriate, which is the desired result in sentences 1-11, or closer to grade 5 - completely appropriate, which is the desired result in sentences 1222. These results mean that the participants have understood the message of the animation. The message of the illustrations and the animation, in conjunction with the colour scheme and the narrative, was appropriate to convey the message and to raise awareness of the depression.

\section{CONCLUSIONS}

Mental disorders are diseases such as diabetes or various forms of cancer, but mental illnesses are much more stigmatized. One of the consequences of stigma is that it is difficult to seek help. Students often have mental health problems, but usually do not seek help (Gaddis et al, 2018). Campaigns that use the principles of social marketing are therefore important to combat the stigma of mental health problems, and they can use print and digital media, including animation, to present a variety of topics. Our aim was to use animation to introduce students to depression from the students' perspective, to teach them about appropriate and inappropriate communication that can be used in a conversation with a person with depression, and to demonstrate the importance of appropriate support.

We confirmed the hypothesis that animation is statistically relevant in changing students' beliefs about the appropriateness or inappropriateness of communication that can be used in a conversation with a person with depression, towards less stigma. A change in the desired direction was found in $81 \%$ of the claims. We found that animation as a visual and auditory stimulus had a positive effect on the change in thinking in students aged 19-30 years. Thus, the message of the illustrations and animations helped to facilitate understanding and awareness of depression, as we successfully conveyed the message to students, as the results of the survey show. By confirming the hypothesis, we proved the effectiveness of animation as an awareness-raising and educational material for presenting more difficult issues in destigmatisation campaigns. The survey showed that most people have a personal experience with a mental disorder or know someone who has experience with a mental disorder. With this in mind, the animation could be used as supporting material in a destigmatisation campaign, as it effectively presents the plight of a student with a depression and shows the right support or the importance of support from the environment and shows the acceptance of support as something positive. This would encourage discussion of more difficult issues between students and their families, which in turn could contribute to a greater search for or acceptance of help.

\section{REFERENCES}

[1] Calear, A. L., Griffiths, K. M., Christensen, H.: "Personal and perceived depression stigma in Australian adolescents: magnitude and predictors", Journal of Affective Disorders 129 (1-3), 104108, 2019. doi: 10.1016/j.jad.2010.08.019.

[2] Corrigan, P. W., Bink, A. B.: "The stigma of mental illness", Encyclopedia of Mental Health 4, 230234, 2016. doi: 10.1016/B978-0-12-397045-9.00170-1.

[3] Dernovšek, M. Z., Gorenc, M., Jeriček, H.: "Ko te strese stres: kako prepoznati in zdraviti stresne, anksiozne in depresivne motnje", (Inštitut za varovanje zdravja Republike Slovenije, Ljubljana, 2006.), page 54.

[4] Esquivel, M.: "How to start a standout awareness campaign", URL: https://www.wholewhale.com/tips/awareness-campaign-how-to/ (last request: 2020-07-02), 2020.

[5] Fominaya, A. W., Corrigan, P. W., Rüsch, N.: "The effects of pity on self- and other-perceptions of mental illness", Psychiatry Research 241, 159-164, 2016. doi: 10.1016/j.psychres.2016.04.058.

[6] Gaddis, S. M., Ramirez, D., Hernandez, E. L.: "Contextualizing public stigma: endorsed mental health treatment stigma on college and university campuses", Social Science \& Medicine 197, 183-191, 2018. doi: 10.1016/j.socscimed.2017.11.029.

[7] Gauss, A.: "A beginner's guide to scaling an awareness campaign", URL: https://www.classy.org/blog/a-beginners-guide-to-scaling-an-awareness-campaign/ (last request: 2020-07-02), 2020.

[8] Goffman, E.: "Stigma: Zapiski o upravljanju poškodovane identitete", (Založba Aristej, Maribor, 2008.), page 128. 
[9] Grinstein, A., Hagtvedt, H., Kronrod, A.: "Aesthetically (dis)pleasing visuals: a dual pathway to empathy and prosocial behavior", International Journal of Research Marketing 36 (1), 83-99, 2019. doi: 10.1016/j.ijresmar.2018.09.003.

[10] Instruxion: "How to use an animated video to create awareness of sensitive topics", URL: https://www.instruxion.com/how-to-use-an-animated-video-to-create-awareness-of-sensitivetopics/ (last request: 2020-04-02), 2014.

[11] Pregelj, P., Kores Plesničar, B., Tomori, M., Zalar, B., Ziherl, S.: “Psihiatrija”, (Psihiatrična klinika, Ljubljana, 2013.), pages 422-423.

[12] Summers, J., Summers, J.: "Motivating intention to take action on behalf of an out-group: implications for the use of advocacy messages in social marketing strategies", Journal of Marketing Management 33, 973-1002, 2017. doi: 10.1080/0267257X.2017.1311933.

[13] Vidourek, R. A., Burbage, M.: "Positive mental health and mental health stigma: a qualitative study assessing student attitudes", Mental Health \& Prevention 13, 1-6, 2019. doi: 10.1016/j.mhp.2018.11.006.

[14] Yamaguchi, S., Wu, S.-I., Biswas, M., Yate, M.: "Effects of Short-Term Interventions to Reduce Mental Health-Related Stigma in University or College Students A Systematic Review", The Journal of nervous and mental disease 201 (6), 490-503, 2013. doi: 10.1097/NMD.0b013e31829480df.

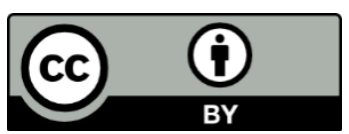

(C) 2020 Authors. Published by the University of Novi Sad, Faculty of Technical Sciences, Department of Graphic Engineering and Design. This article is an open access article distributed under the terms and conditions of the Creative Commons Attribution license 3.0 Serbia (http://creativecommons.org/licenses/by/3.0/rs/). 


\title{
ANALYSIS OF THE LOADING ANIMATION PERFORMANCE AND VIEWER PERCEPTION
}

\author{
Gojko Vladić (D), Selena Mijatović, Gordana Bošnjaković (D), \\ Ivana Jurič (D), Vladimir Dimovski (iD) \\ University of Novi Sad, Faculty of Technical Sciences, \\ Department of Graphic Engineering and Design, Novi Sad, Serbia
}

\begin{abstract}
Digital content presented to the viewer usually has to be processed by the device on which is displayed, in case of internet content processing is done by hosting server and user device with additional download time. Time elapsed for these tasks differs depending on the quantity of the data and complexity of the processing needed. Waiting time for content to be displayed can have significant influence on the user experience. Loading animations are often used to divert viewers' attention or to provide viewer with the information about the process progress, estimated time, etc. Performance of these animation can differ depending on their type, elements or even a story. This paper presents analysis of the performance and viewer perception of different loading animations. Survey and eye tracking were used to gain insight in to the viewer's perception of the loading animation. Results show noticeable differences caused by loading animation type.
\end{abstract}

Key words: Loading animation, User experience, Perceived Performance

\section{INTRODUCTION}

Many of everyday human tasks are infused with digital content. It can be argued that whole humanity today, with some exemptions, is highly accustomed to digital content consumption. Digital content has to be processed by the user device. If the content is distributed through the internet the content is processed by the provider servers and users device. All of these processing tasks take time, additionally internet transfer of the data takes time too. Sum of time that all of these tasks take is called loading time. User experience can be influenced by the digital content loading time. User experience (UX) is how the user interacts with a product, and the emotion and experiences this interaction creates (Persson, 2019). Google published a study in 2017 establishing relation between loading time and bounce rate by the web site viewers.

Results of this study reveal that (Google, 2020):

- $1-3$ seconds load time increase the bounce rate probability by $32 \%$

- $1-5$ seconds load time increase the bounce rate probability by $90 \%$

- 1-6 seconds load time increase the bounce rate probability by $106 \%$

- $1-10$ seconds load time increase the bounce rate probability by $123 \%$

This Google's study confirmed facts about human perceptual abilities, first established by Miller 1968, and others later (Card et al, 1991; Miller, 1968; Nielsen, 1993).

There are 3 main human perceptual time limits:

- 0.1 second makes users feel instantaneous,

- $\quad 0.1-1$ second makes users realize the delay and feel of non-operating directly,

- $\quad 1-10$ seconds need to provide feedback for users to reduce impatience.

There is a significant difference between loading time and perceived loading time. It is well known that people perceive time differently while waiting compared to when performing an action. Action can be anything that occupies viewers' attention. One of the most used tools for occupying viewers' attention is loading animation, although a simple game or some other activity can be used also.

Animation today is not limited to only animated series and movies. It is often used in applications, websites and other various digital services and tools in order to improve the appeal, usability, or to indicate a change. However, there is currently a lack of well-regarded guidelines for animation in relation to user interfaces (UI) on the different digital platforms (i.e. any type of computers, including smartphones and tablets) (Persson, 2019). 
Loading animation can inform users about the expected wait time, explanation of the process, reason for waiting, indicate status, such as downloading, uploading or saving data. There are several approaches to the loading animation design. Progress indicators inform the user that an operation is in progress. They can be classified as determinate and indeterminate progress indicators, depending on whether they present how long a process will take, or just inform the viewer that process is in progress with uncertain amount of wait time. Graphic presentation of the progress indicator is limited only by the creativity of the designer and the technology used for loading animation production (Hao, 2020). Usual and well known approaches to loading animation design is circular or linear progress indicator, Figure 1.
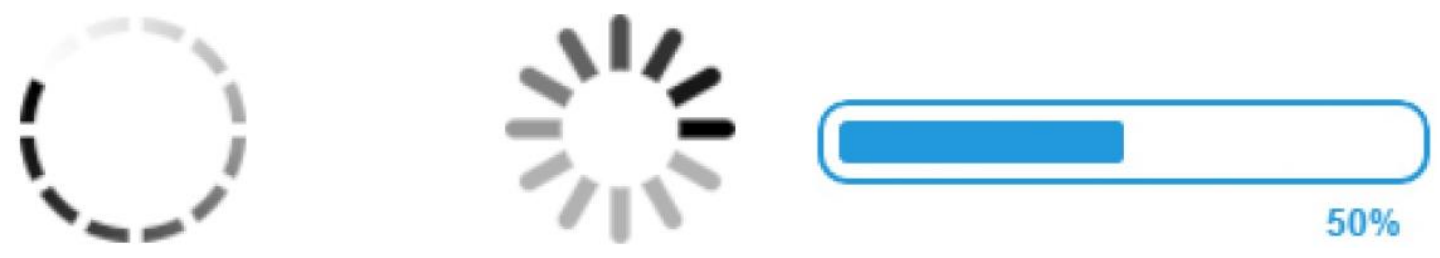

Figure 1: Circular and linear progress indicator

On the other hand they are not too useful for occupying viewer attention for a long time, as they are repetitive and simple. Loading animation with the "story", shown in figure 2, are far more engaging for the viewer, resulting in different perception of the time elapsed.
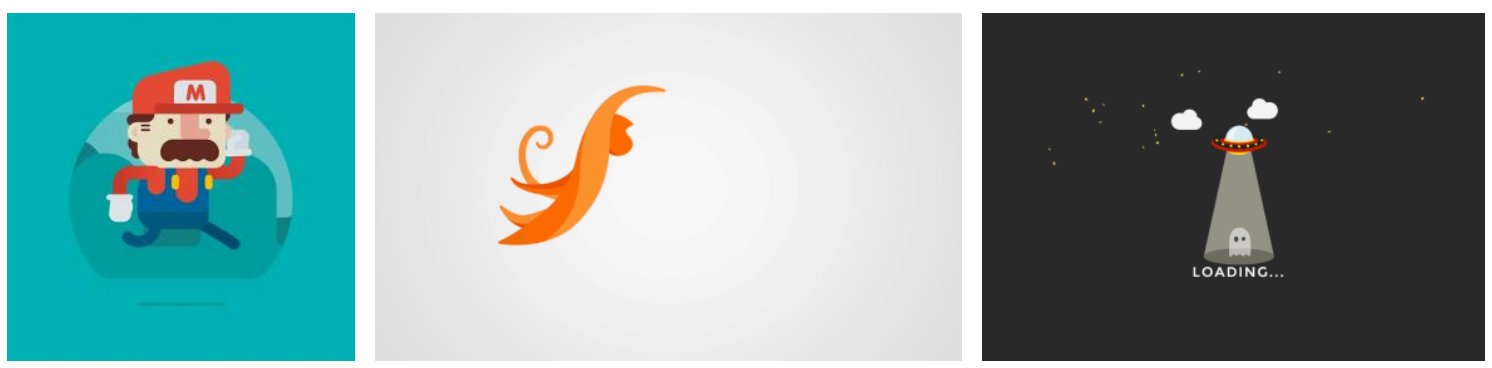

Figure 2: Loading animations with the "story"

This paper aims to examine influence of the loading animation complexity, used elements and variations of those elements on the viewer's perception of the loading animation.

\section{METHODS}

In order to determine influence of loading animation content and variations of its elements, 17 different animations were prepared using Adobe After Effects and Cinema 4D. There were 2D animation (figure 3), faux 3D animations (2D animation that look like 3D, figures 4-8) and real 3D animation (figure 9). Animations had variations concerning shape of the elements, color, content (text, loading bar), and complexity. All animations were shown in the same duration, 10 seconds, where some of them repeated several times depending on the cycle length (loop animation), while other run only once,

Survey was conducted in order to gather insight in to viewer's perception of selected animations. Animations were shown in randomized order with accompanying question about subjective perception of the duration. Aside the survey, eye tracking experiment was done in order to observe participants viewing patterns of different animations. Gaze Point GP3 device and 24" computer monitor were used for this part of the research.

138 participants submitted their opinion on the shown animations trough the survey, while 10 new participants were included in the eye tracking part of the experiment. $64 \%$ were female and $36 \%$ male participants. Majority of them were 25 to 50 years old.

All participants were instructed to give their unbiased opinion, without using any strategies in their answers. 


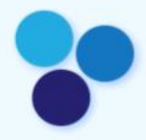

a)

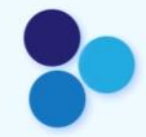

LOADING...

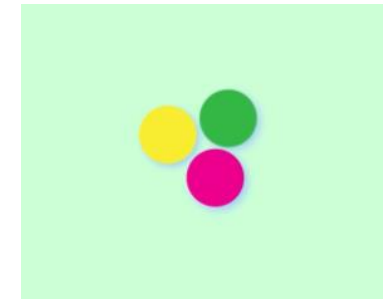

c)

Figure 3: 2D animation: a) circles in circular motion, b) added text, c) color variation

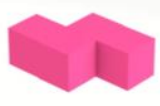

a)

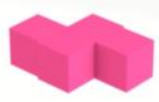

RQDDIEGoes

b)

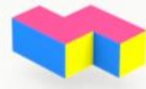

c)

Figure 4: Faux 3D animation: a) rotating bricks, b) added text, c) color variation

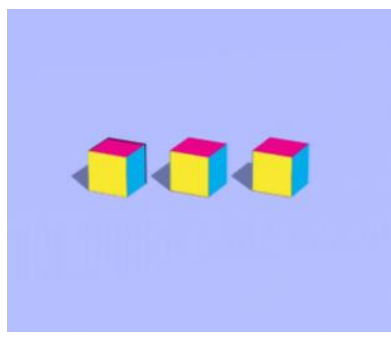

a)

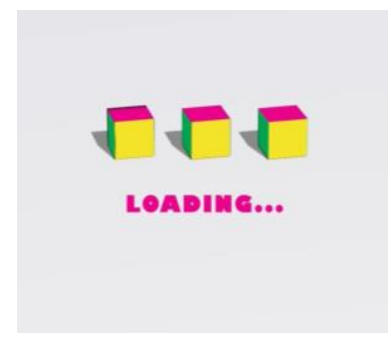

b)

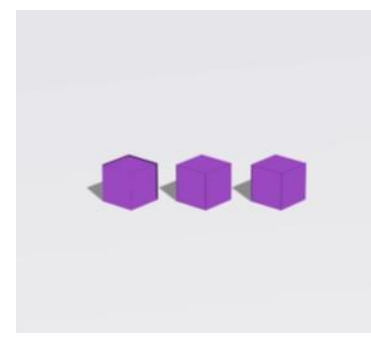

c)

Figure 5: Faux 3D animation: a) circulating boxes, b) added text, c) color variation

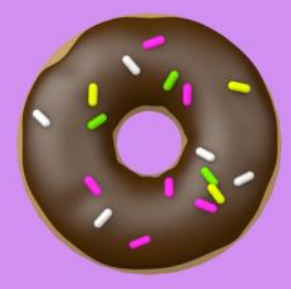

a)

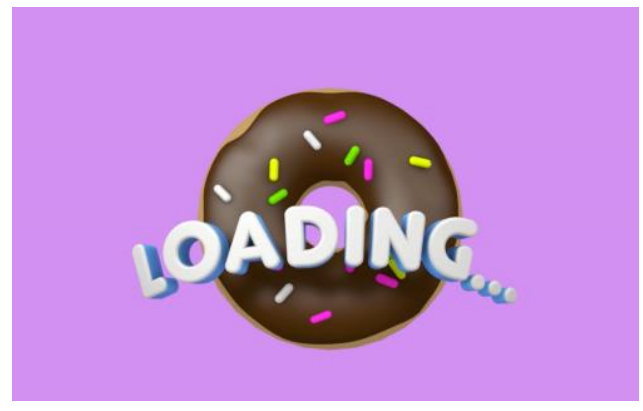

c)

Figure 6: 3D animation appearing donut: a) without text, b) with text 


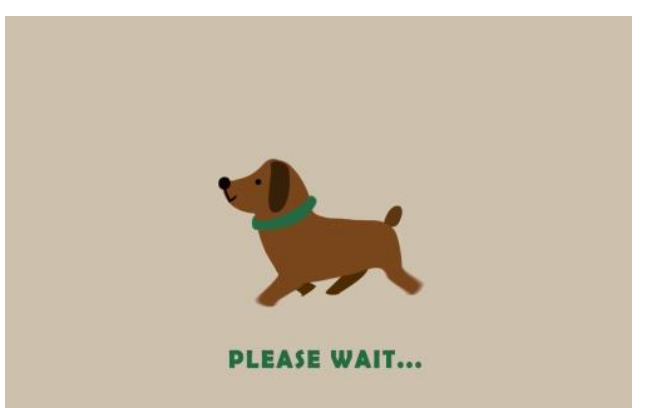

a)

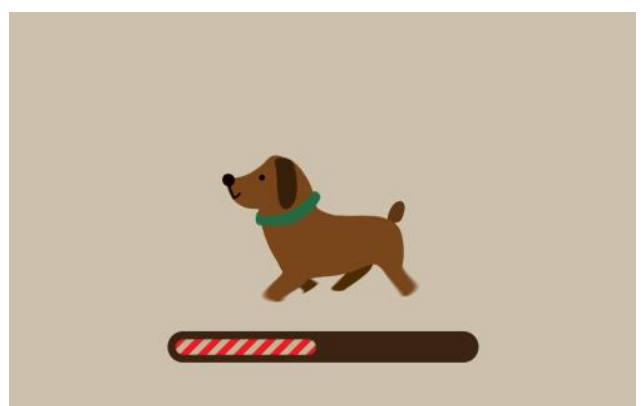

c)

Figure 7: 2D animation of walking dog: a) with text, b) with progress bar

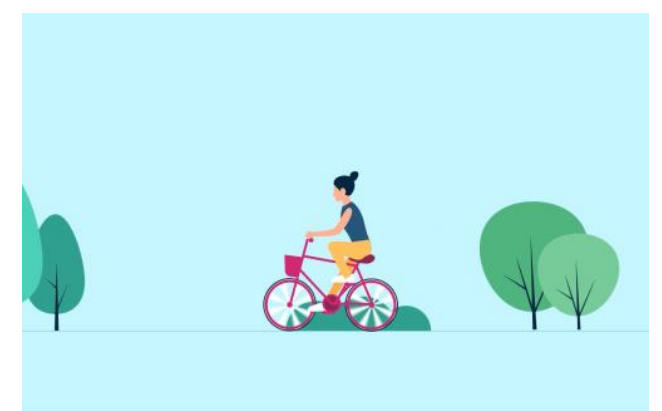

a)

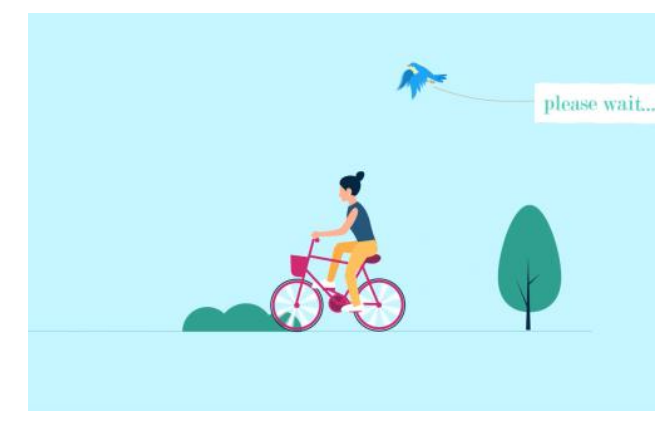

c)

Figure 8: 2D animation of bicycle ride: a) without text, b) with text

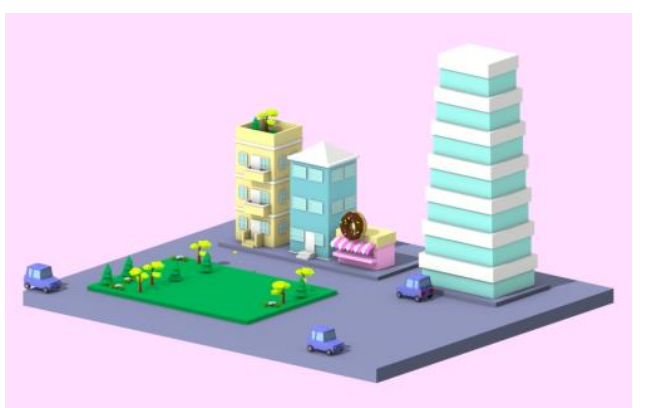

a)

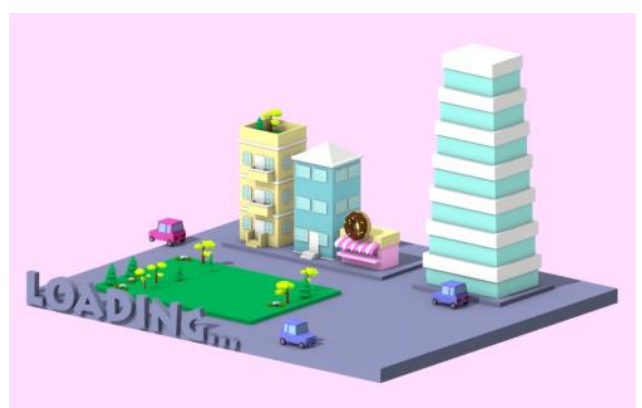

c)

Figure 9: 3D animation of appearing city: a) without text, b) with text

\section{RESULTS AND DISCUSSION}

\subsection{Perceived duration of the animation / loading speed}

Results of the survey revealed that simple loop animations were judged as not slow or fast loading (duration of animation / speed of loading) by majority of the participants. Figure 10 shows results for the simple 2D animation with circles in circular motion. All the simple geometrical animations showed similar pattern with small deviations. Differences in the animation elements (text and color) did not influence perceived duration of the animation. 


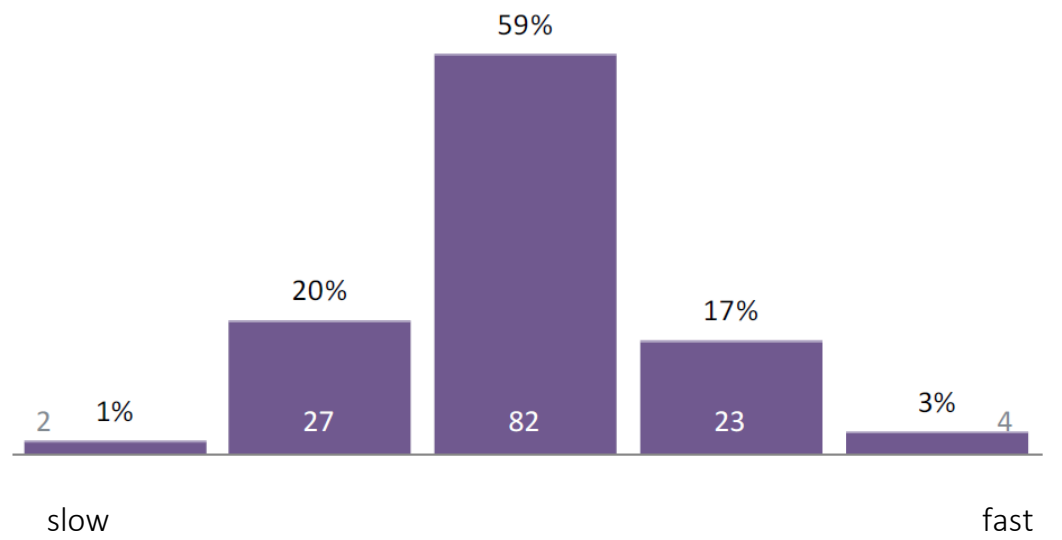

Figure 10: Results for the simple 2D animation with circles in circular motion duration of animation /speed of loading

Variations in the 2D animation of walking dog with text and with progress bar showed a difference in the perceived duration. Animation with text was perceived as longer. This could be explained by the fact that progress bar offered viewers additional information which occupied their attention and as a result the animation with progress bar was perceived as shorter. Figure 11 presents the differences in perceived duration.

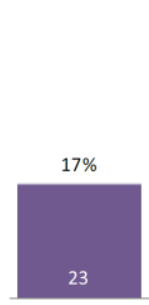

slow

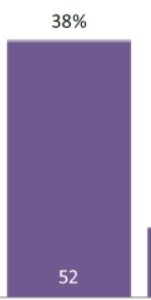

a)

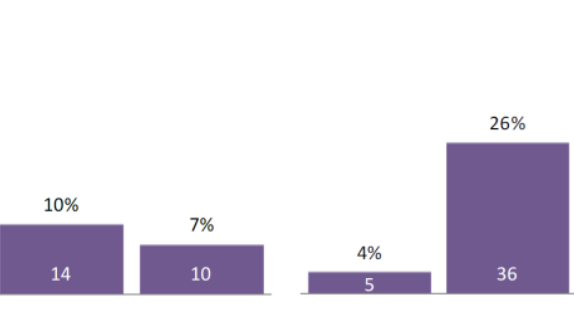

fast slow
$46 \%$
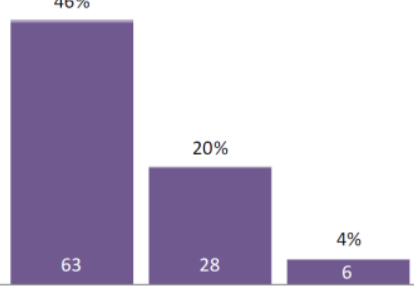

fast

b)

Figure 11: Results for the duration of animation/speed of loading 2D animation of walking dog:

a) with text, b) with progress bar

Similarly, but to lesser extent, as addition of progress bar in the previous case, addition of the text to the 3D animation appearing donut offered more content to the viewer. This in turn resulted in shorter perceived time of the animation with additional text message. Animation of bicycle ride with and without text showed the similar pattern. To be specific, the animation with text was perceived as shorter in duration. Perceived duration of the animation without and with text is shown in Figure 12 for animation appearing donut and Figure 13 for animation bicycle ride.

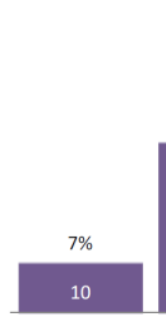

slow
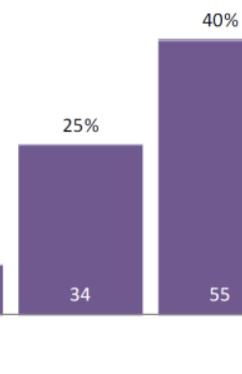

a)

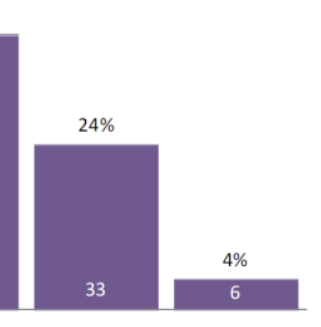

fast

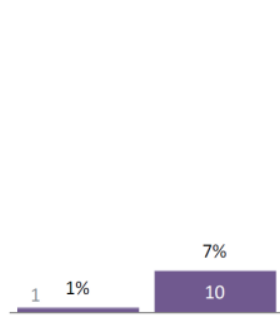

slow

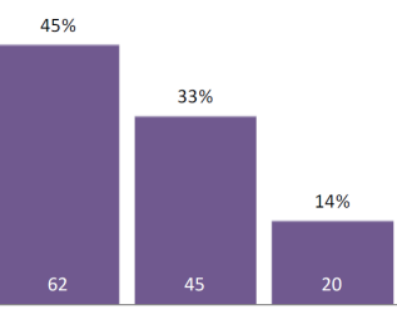

fast

b)

Figure 12: Results for the duration of animation /speed of loading 3D animation of appearing donut: a) without text, b) with text 


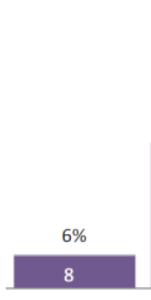

slow

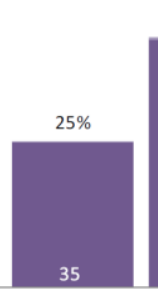

60

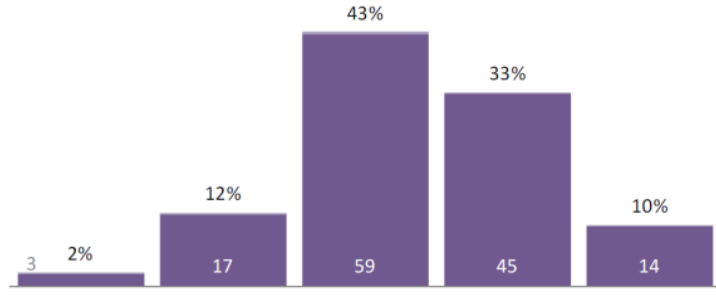

slow

b)

Figure 13: Results for the duration of animation/speed of loading 2D animation of bicycle ride: a) without text, b) with text

Presence of the text in the 3D animation of appearing city did not produce any differences in the perceived duration of the animation. Possibly due to the overall complexity of the animation.

\subsection{Eye tracking results}

Eye tracking recording offered insight in to viewing pattern of the participants. Figures 14-20 show heat map visualization of the viewing pattern of one participant, which was selected as a typical representative. Each participant has unique viewing pattern and in this case summary heat map did not offer good presentation. Figures 13-16 show results for simple animations with variations in the elements. Even though there was no reported difference in the perceived duration, differences in the viewing pattern are obviously present and influenced by the animation elements. In all three simple geometrical animations gaze fixations are much more concentrated in the case of animations with text and scattered in case of animations with just objects moving. Variation of color did not have any influence. In case of these simple animations order in which they are shown to the viewer also had influence. As animations are simple, viewer had more concentrated gaze fixation first time he/she saw the animation. The next time similar animation was shown to the participant gaze fixations were more scattered as if viewer was searching the screen for some information.

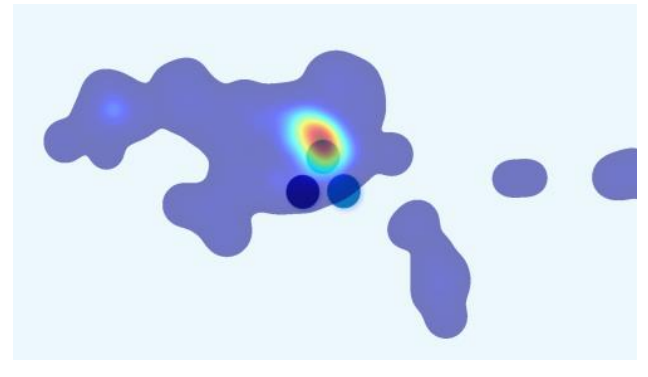

a)

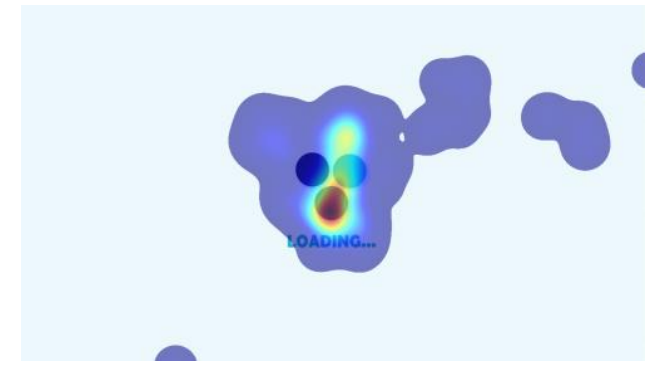

b)

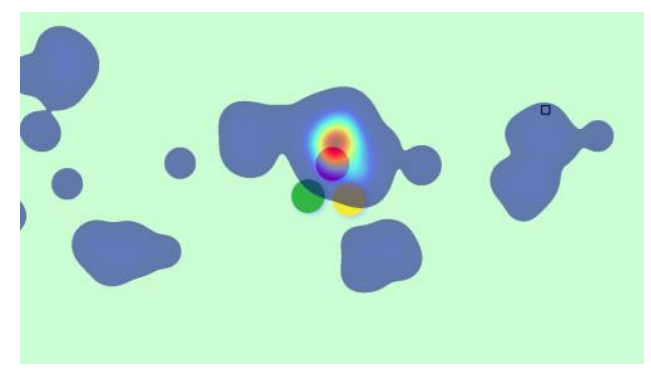

c)

Figure 14: Eye tracking heat map for 2D animation: a) circles in circular motion, b) added text, c) color variation 


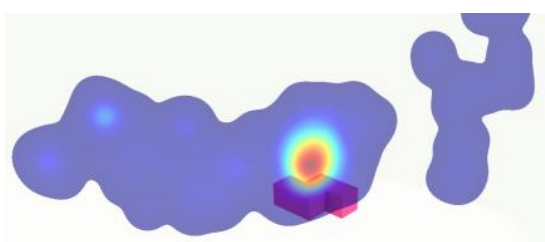

a)

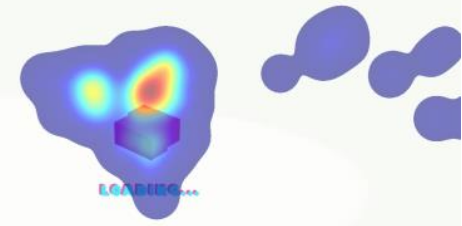

b)

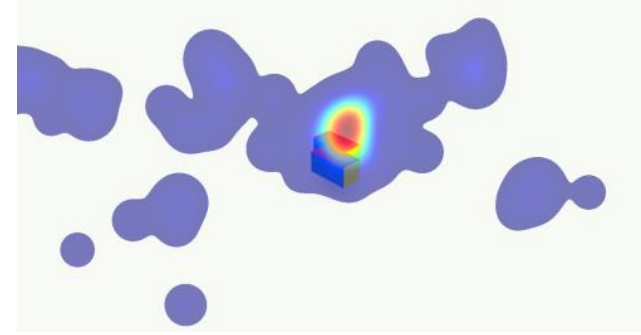

d)

Figure 15: Eye tracking heat map for Faux 3D animation: a) rotating bricks, b) added text, c) color variation

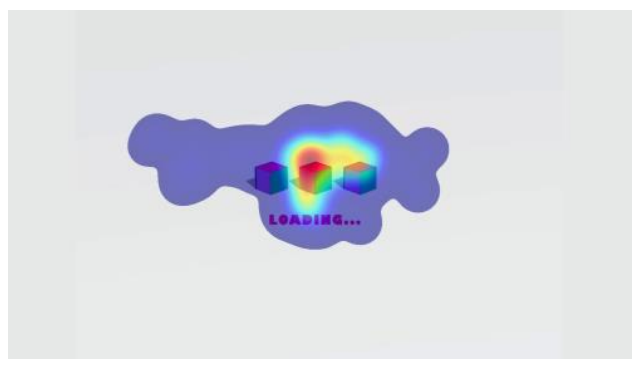

a)

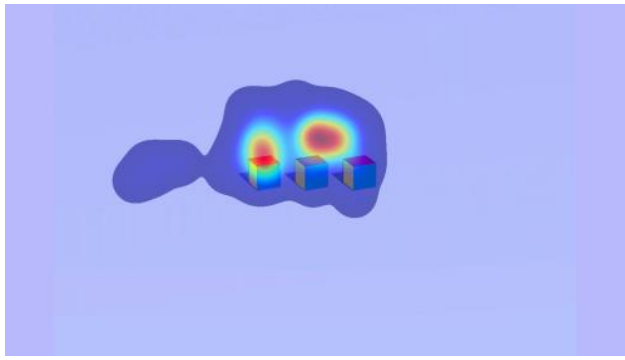

b)

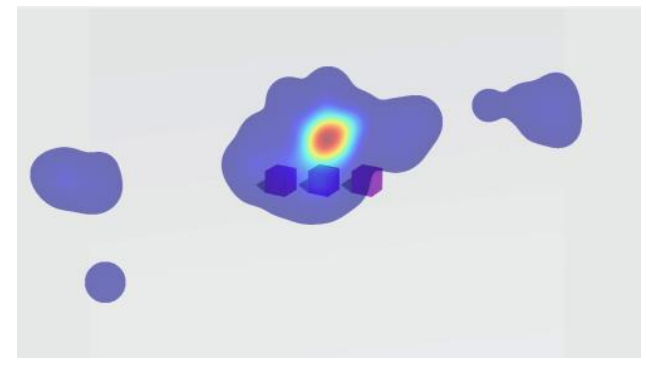

c)

Figure 16: Eye tracking heat map for Faux 3D animation: a) circulating boxes, b) added text, c) colorvariation

Similarly as in the case of simple animations, Figure 17 shows that presence of text concentrates gaze fixations on the animation and viewers are not searching throughout the screen for more information.

Figure 18 shows that presence of the progress bar has a similar effect as the text, as gaze fixations are concentrated. Looking at the heat map Figure 18a, could lead to the conclusion that effect is stronger with progress bar than with text, but results of other participants do not support that clearly. More specialized experiment would be advised.

Eye tracking the viewing of the bicycle ride and appearing city animations show that participants were observing all of the elements of the animations. Whether those elements are distributed all over the screen of concentrated in one area did not make any difference. More complex animations, as these two examples, are packed with elements for the viewer to analyze thru whole duration of the animation. 


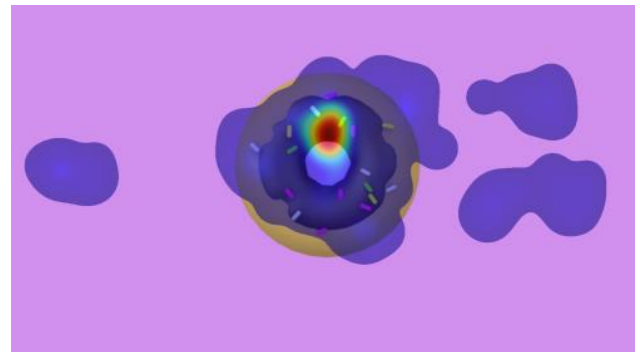

a)

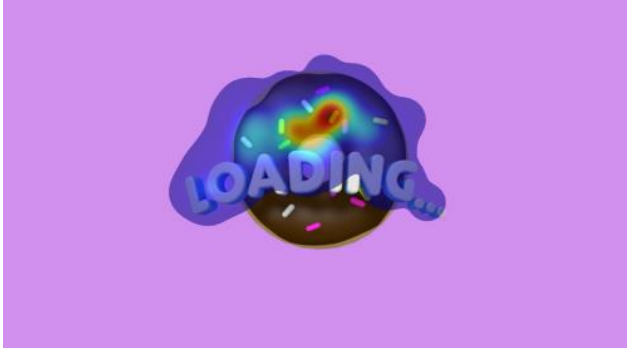

b)

Figure 17: Eye tracking heat map for 3D animation: a) appearing donut, b) added text

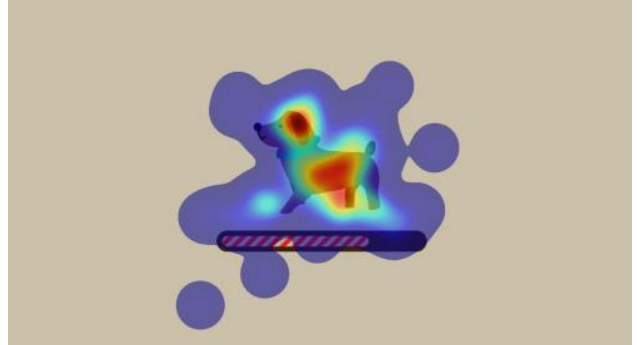

a)

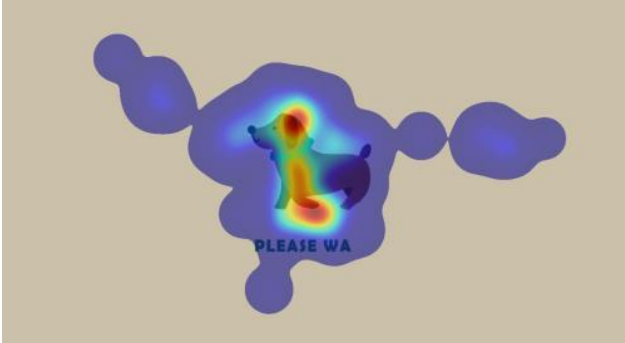

b)

Figure 18: Eye tracking heat map for 2D animation of walking dog: a) with text, b) with progress bar

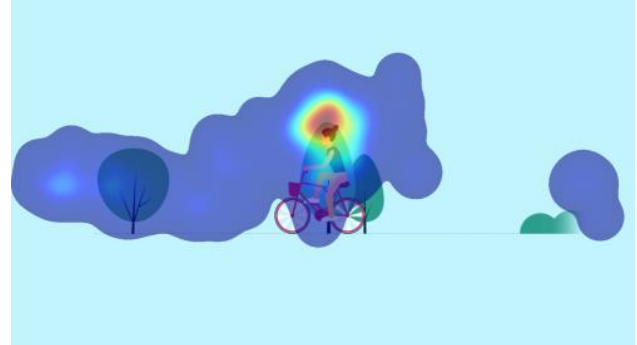

a)

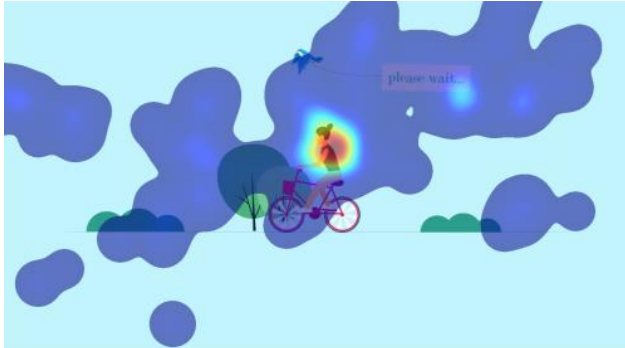

b)

Figure 19: Eye tracking heat map for 2D animation of bicycle ride: a) without text, b) with text

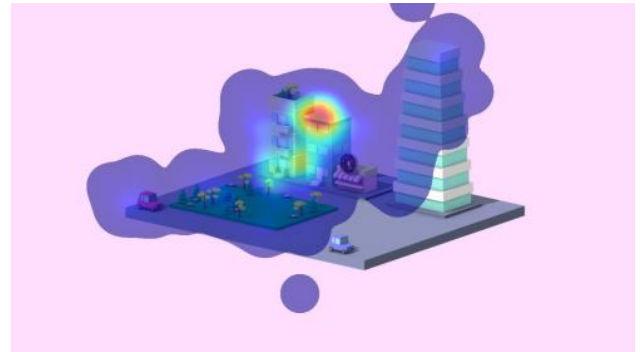

a)

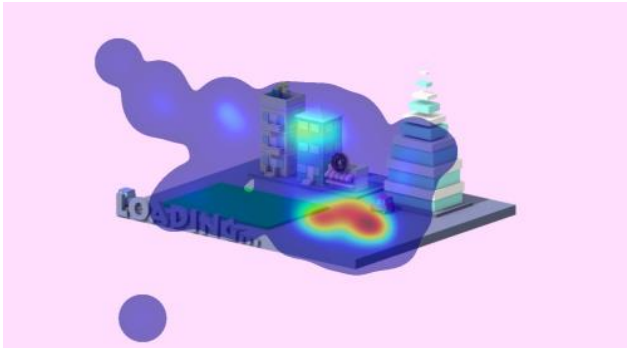

b)

Figure 20: 3D animation of appearing city: a) without text, b) with text 


\section{CONCLUSIONS}

Loading animations play important role in UX design, and must be taken in to consideration if users are waiting longer than 1 second while using the mobile or computer application, web site, etc. Even if waiting is unavoidable it should be made as pleasant as possible for the user. Results of the survey showed that perception of animation duration could be manipulated. Displaying text or progress bar could be used as assets in achieving perception of shorter wait time. The Eye tracing part of the experiment revealed that viewer will search the screen for additional information if animation is offering the same content in a loop. This could be countered by using text which holds the attention of the user for the longer time. Using text or progress bar showed effectiveness in both simple and complex animations. Differences between effects of using progress bar and text were not conclusive and should be examined in more details in future experiments.

\section{ACKNOWLEDGMENTS}

This research (paper) has been supported by the Ministry of Education, Science and Technological Development through the project no. 451-03-68/2020-14/200156: "Innovative scientific and artistic research from the FTS (activity) domain".

\section{REFERENCES}

[1] Card, S. K., Robertson, G. G., Mackinlay, J. D.: "The information visualizer: An information workspace", Proceedings of ACM CHI'91 Conference 1991, (ACM CHI'91: New Orleans, LA, 1991), pages 181-188. doi: 10.1145/108844.108874.

[2] Google API: "Find Out How You Stack Up to New Industry Benchmarks for Mobile Page Speed", URL: https://think.storage.googleapis.com/docs/mobile-page-speed-new-industry-benchmarks.pdf (last request: 2020-09-15).

[3] Hao, Y.: "Understanding loading animations - types and applications", URL: https://uxdesign.cc/understanding-loading-animation-types-and-its-application-e41ba914b847 (last request: 2020-10-14).

[4] Miller, R.: "Response time in man-computer conversational transactions", Proceedings of AFIPS Fall Joint Computer Conference 1968, (AFIPS/ACM/Thomson Book Company, Washington D.C., 1968), pages 267-277, URL:

http://yusufarslan.net/sites/yusufarslan.net/files/upload/content/Miller1968.pdf (last request: 2020-10-14).

[5] Nielsen, J.: "Response times: the three important limits, Excerpt from Chapter 5 of Usability Engineering by Jakob Nielsen", Academic Press, 1993., URL: http://www.useit.com/papers/responsetime.html (last request: 2020-09-15).

[6] Persson, S.: "Improving perceived performance of loading screens through animation", Bachelor thesis, Linnaeus University, Sweden, 2019. URL: https://www.divaportal.org/smash/get/diva2:1333185/FULLTEXT01.pdf (last request: 2020-10-14).

[7] Preece, J., Rogers, Y., Sharp, H.: "Interaction Design: Beyond human-computer interaction", 4th edition, (Wiley: Chichester, 2015.).

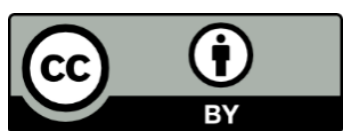

(C) 2020 Authors. Published by the University of Novi Sad, Faculty of Technical Sciences, Department of Graphic Engineering and Design. This article is an open access article distributed under the terms and conditions of the Creative Commons Attribution license 3.0 Serbia (http://creativecommons.org/licenses/by/3.0/rs/). 



\title{
THE RELATIONSHIP BETWEEN SOCIAL ROLES OF CONTEMPORARY ART MUSEUMS AND DIGITALIZATION
}

\author{
Atiye Güner $^{1}$ (D), ismail Erim Gülaçtı² ${ }^{2}$ \\ ${ }^{1}$ Yıldiz Technical University, Student in Art and Design PhD Programme, Istanbul Turkey \\ Hasan Kalyoncu University, Faculty of Communication, Visual Communication Design \\ Department, Gaziantep, Turkey \\ ${ }^{2}$ Yıldiz Technical University, Faculty of Art and Design, Department of Art, istanbul Turkey
}

\begin{abstract}
This paper was adapted from the author's PhD dissertation named "The Effects of Digitalization on Contemporary Art Museums and Galleries".

The digital age has started with the digitalization of information and information communication. The digitalization processes that accelerated with the rapid developments in information and communication technologies have deeply affected museums. Museums are information-based organizations, their primary functions are to protect and spread information. Digitalized information and information communication have obligated contemporary art museums to follow digitalization processes. In this process, technological convergence is another factor that accelerates digitalization of contemporary art museums.

ICOM has defined a contemporary museum as a polyphonic platform including participatory, inclusive and democratizing elements. When all these concepts are considered, the importance of communication between museum-community becomes apparent. Today, contemporary art museums have taken communication to their focal points. Museum-society communication is experienced in contemporary art museums through artistic activities as well as institution's communication-oriented strategies. Contemporary art activities using digital technologies and multimedia technologies generally require audience participation. Global access and various digital platforms provide the society with equal access to museums and art events, as well as making the arts of various countries and identities more visible. In the field of education, contemporary art museums develop projects by cooperating with various institutions. The effective use of digital platforms and institutional pages serves as a catalyst in the realization of these roles that museums undertake. Innovations in information and communication technologies accelerate the digitalization processes and serve as a mediator in maintaining the social roles of museums. For example, it can be said that technological convergence increases the number of museum visitors, therefore, it is the mediator of the social roles of museums. Technologies such as virtual reality, augmented reality and artificial intelligence, which are used in exhibition design in museums, require audience interaction. Digital art based on digital technology takes its place in contemporary art museums. In this study, it was aimed to reveal that social roles undertaken by contemporary art museums, such as participatory, inclusive, democratizing and polyphonic roles, are closely related to the digitalization of institutions and that digitalization acts as a catalyst for these roles.
\end{abstract}

Key words: Contemporary Art Museums, Social Roles of Museums, Communication Function in Museums, Digitalization Process

\section{INTRODUCTION}

Today, the rapid digitalization of communication technology affects contemporary art institutions in the direction of digitalization. Information/data was the first units that were digitalized in the digital age. The fact that digitalized information can be easily stored, transferred, online and quickly accessed has transformed museums from being static spaces to a state where virtual exhibitions and collections are easily accessible in high-resolution image format. The online, accessibility and virtual feature of information communication and digital technology affects not only the functions of storing and preserving the information but also the social functions of museums in the direction of digitalization; the social process called digitalization transforms the functioning and purposes of art institutions as well as the various areas of life.

As mentioned in the section of Contemporary Art Museums and Their Social Roles, museums that have changed since the 1970s have been redefined and their functions have shifted from object-focused to human-focused (table1). Thus, for museums, strong communication with the society means being a strong social institution. 
Table 1: The changing functions of museums

\begin{tabular}{|l|l|l|}
\hline functional & $\begin{array}{l}\text { Museums acquires, preserves, communicates, exhibits for educational and } \\
\text { artistic purposes. }\end{array}$ & object-based \\
\hline purposeful & $\begin{array}{l}\text { Museums are places where people can have fun and learn from collections } \\
\text { that have reliable information and have equal access. }\end{array}$ & human-based \\
\hline
\end{tabular}

Adopted from Rentschler Ruth. Museum Marketing: Understanding Different Types Of Audience (Arts Marketing, London: Routledge 2004).

Digital platforms that function as socialization areas have become platforms where contemporary art museums communicate with the society and with each other. In contemporary art museums, digital technologies have been an instrument for ensuring social participation by creating different spatial perceptions. Thus, the concept of the audience, which is both the source and the receiver of information, has also been transformed.

\section{METHOD}

In this paper, the relationship between the social functions of contemporary art museums for public interest and digital technology has been questioned. The main problem of the study is the question of whether digital technology and digital platforms will cause a change in the social functions of a contemporary art museum because in the digitalization process, we can mention existence of cyberspace as an environment. Cyber space is a virtual environment that have all kinds of information which get electronized through connections such as telephone cables, internet, connection cables, and fiber optic lines. The reality perceptions of the society undergo a change of paradigm towards virtualization. With these effects, the characteristics of each organism and institution are being reshaped in cyberspace. Within the framework of this basic problem, data were collected from the literature, printed and accessible sources, related pages and videos that has been accessed on the internet.

In this article; Contemporary Art Museums and Their Social Roles, Digitalization and Use of Digital Technology in Contemporary Art Museums are examined in two main sections and then concluded.

\section{CONTEMPORARY ART MUSEUMS AND THEIR SOCIAL ROLES}

The museums that emerged for scientific purposes continued their existence for the same purposes during the Renaissance and Enlightenment. In the 18th century, royal collections were transformed into modern museums in Europe. Thus, museums played a role in the construction of nation states as a public space (Artun, 2006). Art museums have been seen as institutions in which autonomy in art is structured since this era. In the 20th century, the attitude of avant-garde art towards the autonomization and institutionalization of art and the questioning of the museum institution by the avant-garde and post-art movements in this context caused art museums to reach a different consciousness with contemporary understanding. Thus, a new understanding of museology has dominated since the 1970s.

The 1980s point out the one important development in terms of museology. With the globalization that reached a peak in this period, ethnic identities were questioned and multicultural understanding prevailed. For this reason, museums are also questioned with support of postmodernist ideas. Identities and societies that had not been adequately represented until then, were embraced both politically and culturally, and their works were included in contemporary art museums. During this period, the business culture which is created by neoliberalism also affected museums (Yücel, 2012b). Thus, the effect of business culture, postmodernist inquiries and the change in understanding of representation in museums in this context have developed the understanding of contemporary museology. In the contemporary understanding of museology, emphasis on the social functions of museums has increased. The public interest has emerged as an important function of museums.

The International Council of Museums ICOM shares an alternative definition for voting at the ICOM Extraordinary General Congress held in Kyoto, Japan on 7.09.2019

Museums are democratising, inclusive and polyphonic spaces for critical dialogue about the pasts and futures. Acknowledging and addressing the conflict and challenges of the present, they hold artefacts and specimens in trust for society, safeguard diverse memories for future generations and guarantee equal 
rights and equal access to heritage for all people. Museums non for profit. They are participatory and transparent, and work in active partnership with and for diverse communities to collect, preserve, research, interpret, exhibit and enhance understandings of the world, aiming to contribute to human dignity and social justice, global equality and planetary wellbeing (ICOM, 2019).

This definition agrees that museums are non-profit institutions, just like the definition in the current ICOM statute which is adopted by the 22nd general assembly in Vienna on 24 August 2007. The permanence emphasized by the current definition has changed with the alternative definition in 2019 that museums are polyphonic organizations that cooperate with active partnerships to achieve their transparent, participatory, inclusive goals at the level of global equality and prosperity. As seen in the definition, social roles of museums are emphasized as well as preservation, research, exhibition and communication. The democratizing, participatory and inclusive social roles of museums and in this context, their communication with their internal and external environments have been prominent values.

\subsection{Social Functions of Contemporary Art Museums}

The factors that increase the power of contemporary art museums are that museums develop face-toface communication opportunities, they are responsible for creating their own resources; they collaborate with various institutions and communities to develop their curatorial work, they apply creative solutions regarding technology and design, and they prioritize communication in planning exhibitions and events (Ertürk and Uralman, 2012). The museums, which previously take responsibility only for their collections and which adopt an object-centered approach, today are based on social sharing. They aim to integrate with the society through a visitor and communication-based approach. For these reasons, the fact that museums are inclusive, democratizing and polyphonic platforms is closely linked to the improvement of their communication with the society.

Social responsibility undertaken by contemporary art museums brings prestige to companies and groups. In this context, museums have taken care to be transparent and accessible due to the sanctions of the laws, non-governmental organizations and the prestige they will gain. For example, even though the private sector supports the museums in the USA, they are operated as a public institution and take social responsibility. American Associations of Museums (AAM), a private institution that inspects museums in the United States, publishes an accreditation list every year based on the compliance of museums with ethical rules in the public sense (Köksal, 2016). Being included in this list is important for museums since according to this variable the number of viewers, donors and membership increases.

The social functions of museums can be listed under the titles of democratization and inclusiveness. Education and participation functions can also be examined within the functions of inclusiveness and democratization. The education and training programs organized by museums serve a democratizing function by ensuring the equal distribution of knowledge. The increase in social functions of today's museums and the museums' caring for public interest, as Atagök says (2012, 172-173), starts with museums seeing themselves as an educational institution. Thus, museums ceased to be an authoritarian institution, and gained the characteristic of being a participatory institution serving the values of the society, questioning historical and cultural values, activating the audience who questioned them.

Contemporary art museums play a role in creating public space in the context of inclusive museology. The organized exhibitions, events and projects are social functions in terms of creating a public, i.e., critical space. The inclusiveness and democratization function defines the place of a contemporary museum in the globalizing world. According to Maleuvre $(2012,112)$, the inclusive understanding of museology makes cultural institutions sensitive to the public and this specific understanding ensures the democratization of the culture. Inclusivity has brought the approach that the museum provides equal access to information, as well as keeping different cultures together, causing museums to become polyphonic platforms. Thus, an inclusive museum provides access to information by revealing overlooked information and provides equality with the representation of underrepresented identities.

The concept of inclusive museology, which emphasizes the social functions of museums, means much more than being accessible for a large group. The strategies to attract masses who are not in the habit of visiting the museum reflect the understanding of inclusive museology. As stated by Özalp Birol (Birol, 2018), General Manager of Suna and Inan Kıraç Foundation Culture and Art Enterprise, this understanding transforms contemporary art museums into places in which various curatorial projects organized for education, training, entertainment, guided tours, screenings, conferences, performances, etc. and in which the audience is included in art events. It has also transformed it into multifunctional show venues where products are marketed, such as commercial businesses. 
The Center Pompidou, founded in Paris in 1977, can be cited as the first example of the transformation of contemporary art museums into a multifunctional and targeted state. Center Pompidou is a new cultural center project on a private estate in Paris, consisting of a large public library, a museum with a national modern art collection, large halls for design, music research, permanent exhibition galleries, theater, seminar, concert film screening. It is a cultural project announced by President Georges Pompidou in 1969, which he thinks will make Paris superior in international art (Lorente, 2016). It reached immense popularity after its official opening on January 31, 1977. The detection of Lorente for Pompidou, which spans an area of 65,000 square meters with about seven million visitors a year, is interesting. Four-fifths of the people who visit the museum in a year are people who have never been interested in the museum section. This determination shows that the concept of inclusive museology has increased the museum audience, and in the 21st century, museums are not only institutions that convey information, but show centers focusing on the public good, as in the 19th century.

Fulfilling the social functions of museums also requires a participation factor. British Museum Object Journeys Project Manager Kayte McSweeney (McSweeney, 2018) states that contemporary museums are not detached from the public but they show a participatory attitude towards the public. The participatory approach that developed in the 1990s is necessary for the democratization of culture and heritage, and it requires audience cooperation as well as partnerships and the multiplication of stakeholders. The participatory approaches of museums aim not only for the passive participation of people in museum activities but also for active participation in a wide variety of ways. Participation in the field of culture is a concept that includes people attending cultural events, participating in artistic and intellectual creation processes, cooperating with cultural institutions, taking part in decision-making processes in the field of culture and interacting with each other.

\section{DIGITALIZATION AND THE USE OF DIGITAL TECHNOLOGIES IN CONTEMPORARY ART MUSEUMS}

Neoliberal economies that have developed with the effects of globalization since the 1980s have turned art into an investment tool. Contemporary art institutions have turned into an element of power on an international scale. One of the factors that prepared this situation is the changes in information communication technologies (ICT) and the rapid spread of the internet.

Information communication technologies and internet carry out all kinds of information / data communication in a very short time. Thus, the perceptions of speed, time and space have also transformed, causing changes in communication, finance, production, consumption, social structures and the functioning of institutions. For example, according to Manuel Castells (Castells, 2000), all processes of our individual and common existence are directly determined by new technology, the raw material of which is knowledge. After a while, Alvin Toffler defines highly electronic third-wave civilization whose basic raw material is knowledge and imagination (Toffler, 2018). During the same period (1980s) Japanese sociologist Yoneji Masuda emphasizes that the driving force behind contemporary society is not material values as in industrial society, but digitalized knowledge (Masuda, 2004). The new social framework in which the information society is established is based on the analysis of computer and communication technology. As communication shifts from analog technologies to digital ones like information (e-mail, chat, social media), both business and social life become digital.

Digitalization is done by digitalizing the data taken from analog life. Feldman (Feldman, 1997) defines the properties of digital data as the keys to their potential effects on our lives. These features of the data are that; they are manipulable (changeable), networkable (networkable), dense (dense), compressible (compressible), impartial (neutral). According to Atabek (Atabek, 2001), the difference between analog and digital technologies can be explained by the definition that the analog is real and the digital one simulates the reality.

Information / data can be changed, compressed, recorded, copied and reproduced, its rapid dissemination has brought forward information / data communication in the 21st century. For these reasons, museums, which are basically knowledge-based institutions, attach great importance to their interaction and communication with the society in order to compete on a global scale and to maintain their existence and power. In addition to its basic functions such as storing, preserving and transferring information, ICT and internet usage is very important in fulfilling the display, public and institution communication, promotion, marketing and social functions that can be examined under communication functions. 


\subsection{Examples of Social Functions of Museums Performed by Digital Technology}

Digitalization has made it possible for museum / gallery collections to be displayed on the internet since the 1990s and brought the concept of virtual museum / gallery created in a digital environment to the agenda (Yücel, 2012a). A virtual museum is more than digitalizing collections and having a web page. For example, according to Schweibenz (Schweibenz, 2004), a virtual museum is not just a museum that has a web page and makes its collections accessible. Schweibenz, in his article The Development of Virtual, described the virtual museum as the highest level of internet applications implemented in a museum. This stage is the virtual museum that offers visitors easily accessible connected digital objects and information, and can be opened to an interactive dialogue using multi-media technologies.

"For me, Twitter was a great thing to discover. I opened my work and went beyond Kiasma's walls and expanded my work in the outside world. "Senior Planning Officer, Public Programs Department of Kiasma Museum Sanna Hirvonen summarizes the relationship between social media and contemporary art museums in this way (Project-musa, 2020). Social networks created with Web 2.0 technology, which has features such as mutual interaction and content management, developed after the 2000s, have been one of the platforms where museums communicate with the public. Social media platforms such as blocks, micro blogs, RSS feeds, forums, communication sites, picture-video sharing sites are the visible face of contemporary art museums in society.

Live broadcasts on social media and digital platforms have become a tool for contemporary art museums to create a public space and defend global problems and the rights of oppressed and different identities. Thus, contemporary art museums fulfill their social functions by highlighting social problems and creating platforms for public criticism. For example, Tate has been broadcasting live streams on Facebook since June 2016 and on Instagram since March 2017. In 2018, before the Deaf Awareness Week, he published a live exhibition tour on Facebook with the first British Sign Language (BSL) in the UK cultural sector, and he examined three works of Picasso in detail. Instagram live streams were posted as a number around LGBTQ + themes (Tate, 2019). Tate, 2019 ' Emphasizing that women were not sufficiently represented in art during the Women's History Month, she made live broadcasts on Facebook and Instagram. According to the latest annual (2018-2019) report shared by Tate, Tate Modern was among the top three museums in the world geotagged by the Instagram community in 2018, and its Instagram followers grew by thirty-two percent.

The highly developed virtual exhibition platform offered by Google Art Project and Google's Open Gallery software are advanced examples of virtual museums / galleries. Google Art Project is a virtual museum project and museums participating in this platform have the opportunity to add visuals and develop applications for various works. Technologies such as Google Street View Street View are used to provide 3D images. Through "Create an Artwork Collection" offered by the Create an Art Collection feature, viewers can create and comment on their virtual collections (A Single Museum on the Internet: Google Art Project, 2012). Google Art and similar projects reveal the importance of contemporary museums' communication with each other and common platforms.

A traditional art museum informs the public by displaying certain objects and images and opening them to historical comparisons, analysis and theoretical thinking. This position based on interpretation in the face of art keeps the viewer's gaze in the work of art (Groys, 2017). In the contemporary art museum, with the effect of technology, the viewer's gaze has turned to the process of documenting the art event from inside and outside, the positioning of this process in the media space, in other words, the spatial boundaries of the event. Thus, the perception of the museum space has transformed as the processes of obtaining and spreading information are transformed with communication technology. The audience was included in the artistic activity and projects and took part in the co-creation function of a participatory museum.

The fact that digital technologies facilitate access and create the interaction feature in the implementation of projects, and the advantages of technological convergence in all kinds of virtual, visual and audio participation are a factor that increases the participation of a contemporary museum. For example, the Louvre Museum presented its first virtual reality (VR) application between October 24, 2019 and February 24, 2020 at Napoleon Hall with the project named Mona Lisa: Beyond the Glass. In a virtual reality room, the project realized by Louvre in collaboration with HTC VIVE Arts, was experienced by a virtual reality glasses developed by HTC and SteamVR. Besides, the project was experienced worldwide through mobile phones having iOS, Android and other operating systems (VIVE Arts, 2020). Digital viewers also had a virtual visit to the Louvre Museum and they access to the Louvre's permanent collection. According to research, Mona Lisa is seen by more than 20,000 people every day. Due to the 
large number of visitors and its fragility, each visitor can see the work for 30 seconds from a certain distance. Therefore, the virtual reality experience created by combining moving image, sound and interactive design has facilitated access to information and democratized access to the artwork.

Augmented Reality (AR) technology is an important digital tool in carrying out the mission of museums to dialogue and inform the public and encourages greater participation. For example, in July 2017, Art Gallery of Toronto (AGO) launches an AR installation called ReBlink with digital artist Alex Mayhew (Coates, 2020). Viewers use a tablet or mobile phone, and in Mayhew's exhibition, they see different versions of the paintings, along with their originals, in which industrial and technological visual images are placed and animated. In AGO's survey with the audience, museum visitors have an average of only 2.31 in front of each painting. It was determined that he spent seconds. Reproducing the time and participation of the audience in the museum, providing information transfer AR and VR technologies.

Museums know how to use digital Technologies and platforms and turn them into advantages in accordance with the requirements of the age. During the pandemic in 2020, many museums attracted the audience with contactless information and visits with QR codes displayed in the venue. When viewers take a picture of the code with their smartphones, they are directed to a specific site that can provide information about exhibitions and artists. Information about current and future exhibitions and events, as well as museum-specific apps, maps and programs can be provided to the viewers. They can also link to visitor surveys that provide museums with valuable information about guest experiences. For example, the Detroit Institute of Arts has launched a mobile tour called Lumin that uses videos, photos, animations and sounds, as well as AR and 3D Mapping, to provide its audience with more information about exhibits through their personal smart devices (Spencer, 2020). The Toledo Art Museum offered visitors a free downloadable application with multimedia guides and audio commentary. Life-changing phone features for the disabled, voice control features, applications that convert speech to text and applications that explain text in a photo to visually impaired users are available in this application. These applications for touch screens encouraged the audience to participate during the pandemic and provided democratic access to artworks for those with visual and hearing impairments.

Kati Price (Price, 2014), head of the digital media department of the Victoria Albert Museum, states that the future museums will put more emphasis on the social functions, and newer generation technologies such as the Internet of Things (IOT) can be used to create personalized experiences.

\section{CONCLUSION}

Today, Museums of contemporary art have features that pursue the public good, collaborate mor with the community and steakholders, focus on participation rather than presentation, and develop online (as well as physical) experiences. It can be said that the use of digital technology has created an acceleration in the diversification of the service areas of museums, in the fulfillment of their increasing social responsibilities including education and training, and in ensuring community participation.

Contemporary art museums make use of all the possibilities of digital technology by establishing public space, spreading information, preserving and transmitting culture through web pages and social networks they use. Analyzes to be made with digital measurements constitute an important part of communication strategies. Viewers are also content producers. For the social values that museums create interactively and for their own values that they will create in this context, national and international accessibility is important in the projects they will realize with correct communication.

"Museums have no borders, they have a network" This discourse on ICOM's Web landing page is an emphasis on the networking of contemporary museums relationships with each other, their stakeholders and society, and is a reference to digital network technology.

Contemporary art museums are part of the scientific, cultural and international relations network. In the understanding of contemporary museology, where communication and social roles come to the fore, contemporary art museums, which add the influence and attraction of art, have turned into a global power factor. The possibilities of digital technology and digital platforms have become a catalyst by accelerating, diversifying and making the relationship of contemporary art museums transparent with society.

In addition, digital communication technologies have turned into an artistic tool and even a method, making the digitalization processes of contemporary art museums obligatory. 


\section{REFERENCES}

[1] Artun, A.: "Art at the Border of Modernity- Criticism, Autonomy, Politics", URL: http://www.aliartun.com/yazilar/modernligin-sinirinda-sanat-sanat-ve-elestiri/ (last request: 202008-10).

[2] Atabek, Ü.: "Communication and Technology", (Seçkin Publishing, Ankara, 2001.), page 37.

[3] Atagök, T.: "The ABC of Museology", (Ege Publications, Istanbul, 2012.), pages 171-176.

[4] Birol, Ö.: "Museology and Marketing in Pera Museum", URL: https://www.youtube.com/watch?v=LOmHRmVdgVs\&t=669s (last request: 2020-08-10).

[5] Castells, M.: "The Rise of Network Society", (Wiley-Blackwell, Hoboken NJ, 2000), page 70.

[6] Coates, C.: "How Museums are using Augmented Reality", URL: https://www.museumnext.com/article/how-museums-are-using-augmented-reality/ (last request: 2020-09-20).

[7] Ertürk, N., Uralman, H.: "The ABC of Museology", (Ege Publications, Istanbul, 2012.), pages 191-193.

[8] Feldman, T.: "An Introduction to Digital Media", (Routledge, New York, 1997.), page 3.

[9] Groys, B.: "Art in the Internet Age in Streaming", (Koç University Publications, Istanbul, 2017.), pages 20-21.

[10] ICOM, “Museum Definition”, URL: https://icom.museum/en/resources/standardsguidelines/museum-definition/, (last request: 2020-08-10).

[11] Köksal, A, H.: “Contemporary Art Talks", (Okan University Publications, Istanbul, 2016.), pages 118-135.

[12] Lorente, J, P.: "Contemporary Art Museums", (Koç University Publications, Istanbul, 2016.), pages 197-210.

[13] Masuda, Y.: "The Information Society Reader", (Routledge, London, 2004.), pages 15-20.

[14] McSweeney, K.: “Open Museum: Approaches to Participation", URL: https://www.youtube.com/watch?v=xolyfoih1xs\&t=294s, (last request: 2020-08-10), 2018.

[15] Price, K.: "How can technology improve the museum experience?", URL: https://www.vam.ac.uk/blog/digital/how-can-technology-improve-the-museum-experience, (last request: 2020-08-10).

[16] Project-musa: "Museum of the Future", URL: http://www.project-musa.eu/wpcontent/uploads/2017/03/MuSA-Museum-of-the-future.pdf, (last request: 2020-08-10).

[17] Schweibenz, W.: "The Development Virtual Museums", URL: http://archives.icom.museum/pdf/E_news2004/p3_2004-3.pdf, (last request: 2020-08-10).

[18] Spencer, K.: "Leveraging Smartphone Technology to Protect Museum Visitors", URL: https://www.aam-us.org/2020/07/03/leveraging-smartphone-technology-to-protect-museumvisitors/ (last request: 2020-08-10).

[19] Tate: "Tate Reports", URL: https://www.tate.org.uk/about-us/tate-reports (last request: 2020-08-10).

[20] Toffler, A.: "Third wave A Classic of Futuristic Economic Analysis", (Koridor Publishing, Istanbul, 2018), pages 436-438.

[21] VIVE Arts: "Mona Lisa: Beyond the Glass", URL: https://arts.vive.com/us/articles/projects/artphotography/mona_lisa_beyond_the_glass/ (last request: 2020-08-10).

[22] Yücel, D.: "Changing Arts And Institutions In The Axis Of Digital Technologies", Genç Sanat, (202), 32-39, 2012b

[23] Yücel, D.: "New Media Art and New Museology: Evaluation of Digital Art Practices in a Museological Context", (Anahtar Books Publishing House, Istanbul, 2012a.), pages 134-152.

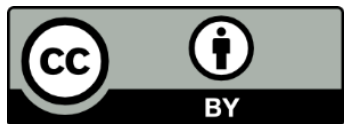

(C) 2020 Authors. Published by the University of Novi Sad, Faculty of Technical Sciences, Department of Graphic Engineering and Design. This article is an open access article distributed under the terms and conditions of the Creative Commons Attribution license 3.0 Serbia (http://creativecommons.org/licenses/by/3.0/rs/). 



\title{
ELECTRONIC PUBLISHING AS A GRAPHIC PRODUCT
}

\author{
Željko Zeljković (D), Dragoljub Novaković (D), Saša Petrović \\ Neda Milić Keresteš (D), Stefan Đurđević (iD) \\ University of Novi Sad, Faculty of Technical Sciences, \\ Department of Graphic Engineering and Design, Novi Sad, Serbia
}

\begin{abstract}
Electronic publishing has a particularly significant application as a graphic product in the publication of some products such as books and newspapers that have traditionally been essential products of newspaper printing, book printing and the like. In the electronic publication of newspapers, there are certain templates that are related to the identity of the publisher. There is a number of published and printed editions of newspapers that were published before the introduction of electronic editions. Newspapers stick to tradition and try to transfer printed editions to electronic ones, that is, to do the so-called digitalization. The process of digitization is a complex and extensive work consisting of analysis and proper preparation of the transformation into a bit of a mapped image with the help of reproduction devices, rearranging and arranging data with OCR software, creating metadata, database management and web application development. As current products of graphic production, multimedia appears as a set of different media that affect the human senses. Procedures for digitalization of graphic products with essential elements are necessary, and various software tools are needed for the realization of the process. This paper points out the most important segments of previously mentioned procedures.
\end{abstract}

Keywords: digitalization, printed media, electronic media, multimedia, metadata, electronic publishing

\section{INTRODUCTION}

Digitalization, by definition, is the conversion of an analogue input into a digital form. In the case of graphic products, the goal is not to lose the quality of the input material by digitalizing the archive. Digitalization is a planned and expensive process, which should be conducted following known principles and priorities and according to established rules. The paper analyzes multimedia, modern software tools, metadata, based on which the concept of metadata is set. Metadata is "data about data" with a description of the content of electronic publications used during the search. Effective access to the required content means that these contents are well described using the metadata. When publishing some graphic products, such as newspapers and books, the problem is not in the use of technology, but in the organization of work. The advantage of digitalized media is that they can be easily and quickly reproduced without damaging the original, a large number of users have access to the material regardless of time and geographical limitations, the content is not damaged during the use, digital content can be searched and modified. Disadvantages include digital protection, digitalization converts images into bits that must then be reconstructed in order for images to be displayed, and shaded transitions in images can be transformed into sharp contrasts. In order to read an electronic document, it is necessary to have additional equipment and considerable financial resources needed for digitalization. Publishing graphic products such as newspapers is a complex process where certain attributes of advantages and disadvantages of electronic media in relation to print media get highlighted. The main difference between printed and electronic newspaper media is in accessibility and coverage. These differences can be compared using the basis of comparison (IFLA, 2002). In terms of the characteristics of the transfer of newspaper data, the printed media is a material form that delivers news and information through printed newspaper publications in relation to the electronic medium that creates, delivers and accesses news and information through electronic devices. To understand the print media, one needs to be literate in order to read certain content. In contrast, in the case of electronic media, this is not the primary requirement because it can be watched and listened to on presentation devices. The lifetime of the data in printed media is unchanged because what is printed remains on the substrate, while in electronic media, it can be changed and updated. It is not possible to exchange comments using printed media, while there are no restrictions with electronic media. The distribution of printed media has many limitations, while electronic media have no limitations. The language of the printed media is related to the publication, while the electronic media has the possibility of rapid change. E.g. newspaper print is available in all places where the reader brings it, while electronic editions of newspapers are dependent on the Internet. Printed newspapers can be archived and available 
in the future, while the electronic ones are tied to server capacity and data storage. Visualization is on the side of electronic media through video content (Lukačević et al, 2015).

Printed newspaper media can be described as a mean of mass communication used to inform the general public through printed publications - newspapers, magazines, books, etc. Electronic news media is a newer form of mass media in which electronic devices are used to create and spread news and information. In both printed and electronic media, there is a connection between the generation and transmission of information, which depends on the current specific content of the media. Presentations in electronic media have certain specifics of displaying that must be taken to account in their design. A limitation of the display format can be noticed when compared to the printed media. For the printed media, paper formats act as a display, while for electronic media, this depends on the size of the device display. The quality of both is related to the display resolution, for printed ones it is the resolution in lines per inch and for electronic ones it is the screen resolutions. Printed and electronic media have common elements in data archiving devices. A unique feature is their recording capacity. Recording capacity is characterized by data compression procedures, which allow the reduction of a certain amount of data without a visible reduction in quality. An essential characterization of compressed data is its ability to be transferred to different media. Modern ways of data transfer are realized using various techniques such as the Internet, satellite transmission, high-speed cable connections to receiving devices that can reproduce them. These devices are various systems for the presentation of transferred data such as computer monitors, projection devices, audio playback systems and other devices. The control systems of these devices are various hardware elements and software applications. The use and distribution of printed and electronic media is regulated by the copyright protection of the media authors. A significant segment of digital media development is the field of cryptography, which deals with the protection of digital data. Another important area of development is data compression. Both of these areas will occupy a significant place in the future development of digital media.

The initial phase of media creation is media preparation. Further phases include tools and software for creating printed or electronic media. These media can be distributed in the created form as electronic or printed media. Their integration results in multimedia.

\section{ELECTRONIC MEDIA}

Electronic media can be characterized as time-dependent in terms of their monitoring, while printed media can be characterized as static. Ideas, content and their form from information sources are the basis for output. This data belongs to the field of media preparation. Data from the preparation are further directed, depending on the need, to the printed media or the electronic media in order to process or create products intended for end-users. Processing in the production process of electronic or printed media results in media products, electronic information from electronic media and printed products from printing media. Together they make up multimedia. The structure for the production of electronic media, print media, and multimedia is given in Figure 1.

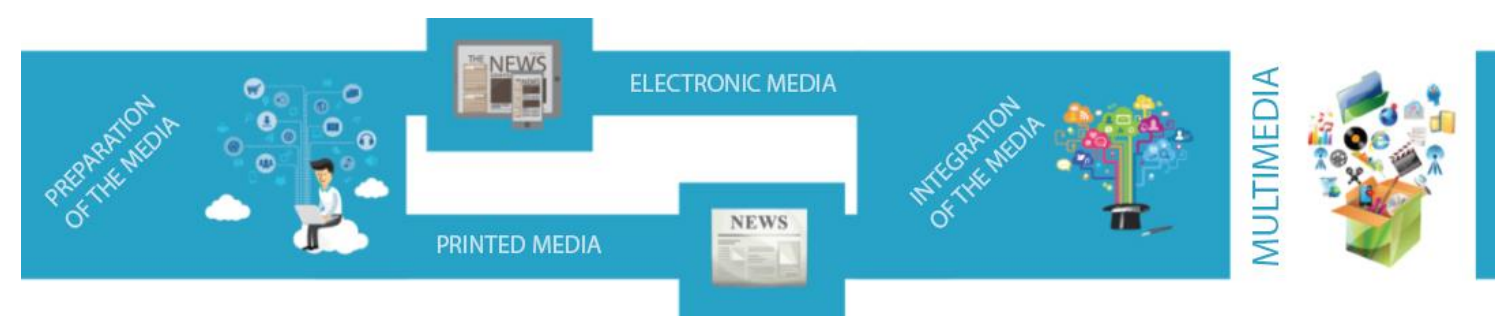

Figure 1: Flow for the production of electronic media, print media and multimedia

People encounter multimedia every day. It is all around, on the Internet, computing, education, telecommunications, the world of games, advertising, e-commerce. Figure 2 shows the possible media combining which the multimedia gets created. 


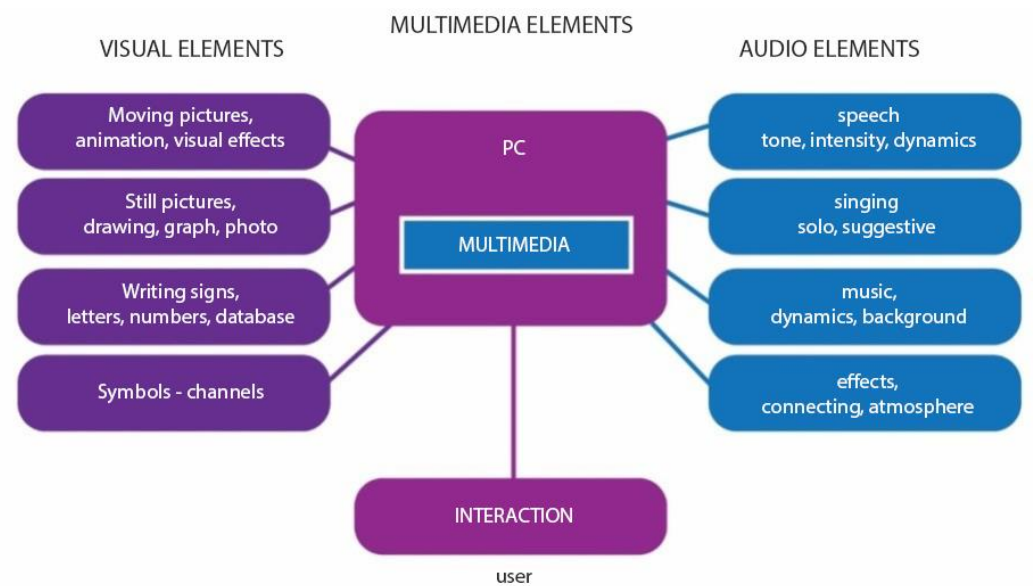

Figure 2: The possible media combining which the multimedia gets created

Planning and development of multimedia content consist of three main steps, them beeing:

- analysis,

- planning,

- realization.

Each of these steps can be further broken down into smaller steps as shown in Figure 3.

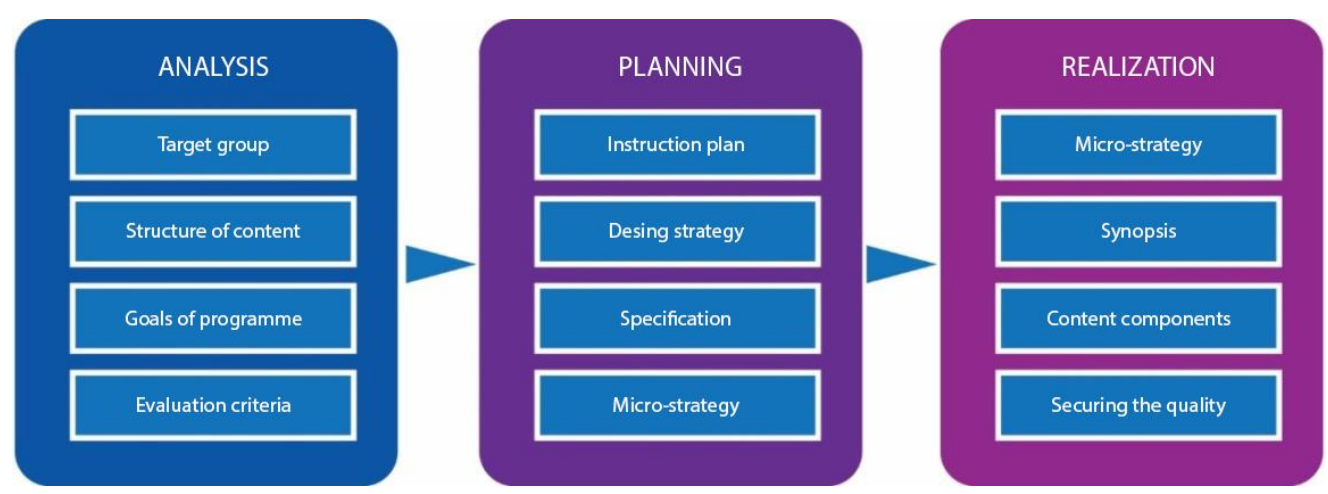

Figure 3: Content planning and development steps

Multimedia affects different senses of a person. Figure 4 shows all the human senses that are affected by multimedia content and the senses which will be affected in the near future.

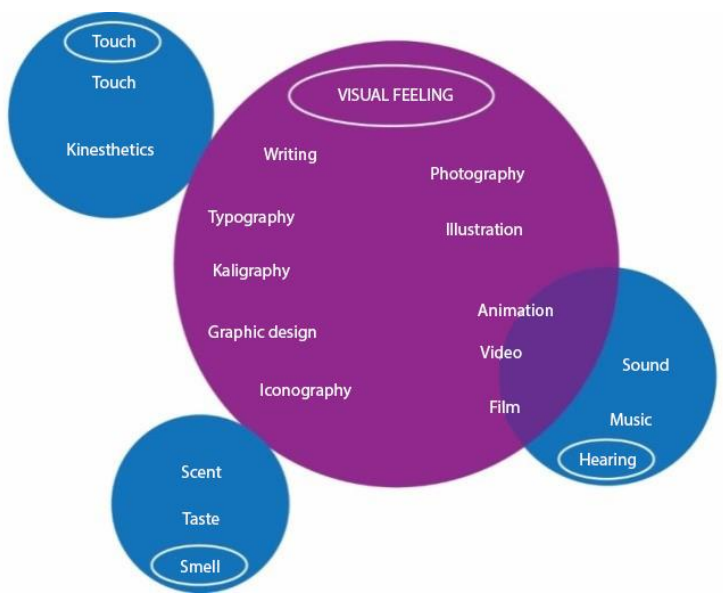

Figure 4: Multimedia and its influence on the human senses 
There is a tendency for the sense of smell and touch to be included in multimedia applications. It may still seem unthinkable from today's point of view, but it will soon become generally accepted. In the future, these devices will be able to connect to a PC and will have one special chip for scents.

Typography also has a long tradition in the printed media. When designing educational materials, their influence on the emotions of the recipient must not be neglected. Every sensory detail of the project needs to be carefully planned. The first impression of a multimedia content depends on the creativity of the designer, i.e. from the harmony of letters, colours and graphic elements.

When creating multimedia, in addition to hardware and software knowledge, it is also necessary to be familiar with design, didactics, psychology, communications, marketing. Media is an integral part of communication. They are an essential part of communication in society and among people. The media are used to make communication successful, both in individual and public communication. The media are always closely connected with the issue of communication. Every communication requires a medium, a mean by which a message is exchanged between communication partners and which is the basis for mediation between partners. The same goes for direct communication. The fundamental importance of media lies in the fact that they achieve an effect that contributes to the success of communication.

A successful presentation or performance is often labelled multimedia, thus emphasizing the robust, multifaceted and simultaneous flow of information between performers and participants in events. The multimedia information system should, in interactive communication with the user, simultaneously use various forms of information, such as text, graphics, animation, static or moving images, music and speech. Therefore, multimedia technology includes new input/output units for automated data acquisition from the environment. Such units are television camera, microphone, scanner. They generate multimedia entities: video, audio, images that are only partially interpreted via programs because they are insufficiently structured. Figure 5 shows the concept of multimedia as an integration of different media.

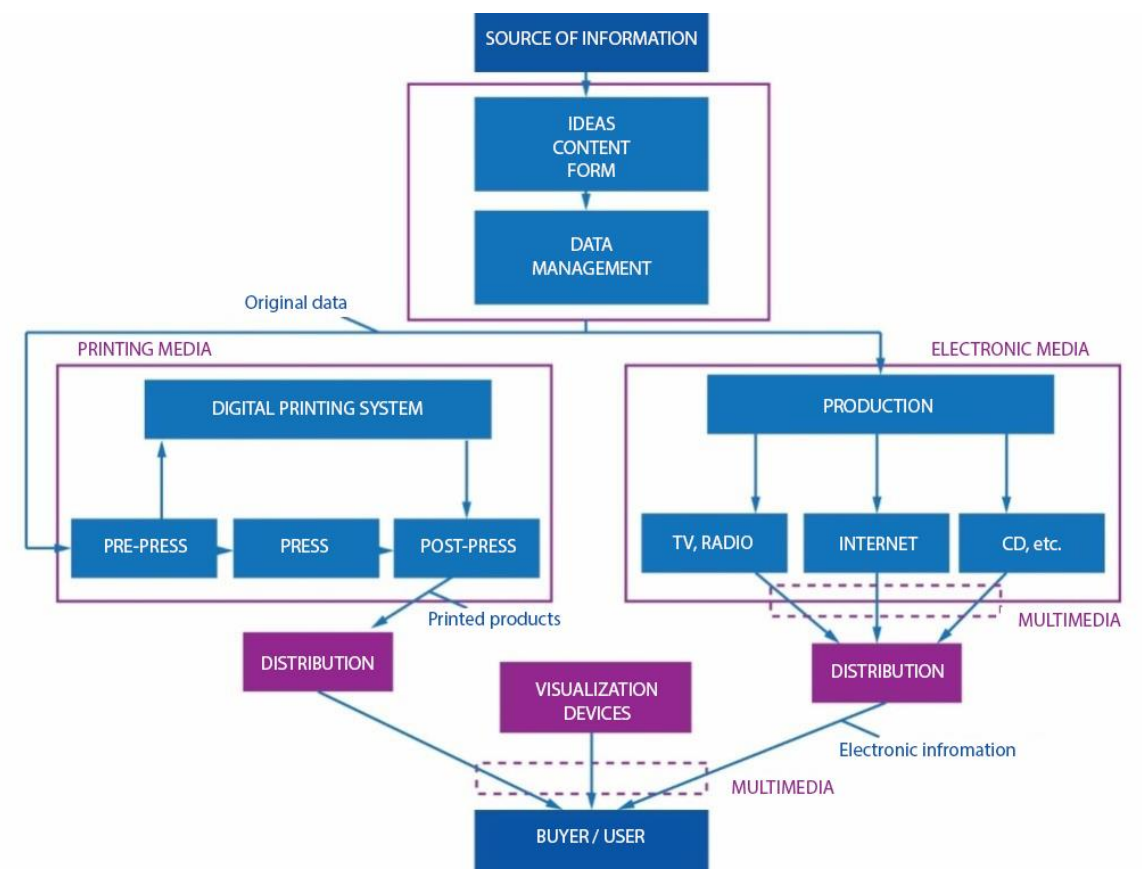

Figure 5: Multimedia as an integration of different media

Distributed multimedia information systems should enable the transfer of multimedia data from one or more sources located inside or outside of the workstation. Multimedia technology, which is changing rapidly, includes machines that transmit experience not only through text and equations but also by acting on human senses, through sound as well as moving images. Besides, multimedia still do not have an adequate way of management, and it is difficult to predict their development. What makes all this possible is a digital and optical technology that is evolving rapidly, enabling efficiency in the processing, storage, maintenance and addition of new information.

Multimedia combines text, image, sound, animation and video, and very different means have been used to play them before, although lately a multimedia computer has been used to play multimedia, and a CDROM or the Internet to store data. 
In the interpretation of the media, various software can be used to interpret the solutions. The suitability of such an interpretation belongs to (Poliščuk, 2004):

- artificial intelligence,

- $\quad$ expert systems,

- neural networks,

- fuzzy logic,

- genetic algorithms,

- hybrid systems,

- distance learning,

- multimedia,

- general-purpose software systems,

- $\quad$ other application systems.

Artificial intelligence - artificial intelligence can be defined as a computer technique. The technique of artificial intelligence consists of the development of software applications, the execution of which can be characterized by an intelligent process similar to the decision-making process of humans. Research in the field of artificial intelligence begins and follows the development of computer systems. Expert systems are one of the parts of development in artificial intelligence that are based on the logic of expert thinking in a particular area where expert decisions are realized in the form of programming systems with special software tools.

Expert systems are intelligent computer programs that emulate problem-solving in the way that experts do and represent one of the most important areas of artificial intelligence research. The systems solve real problems from different areas, which would otherwise require human expertise. The goal is that the computer program always gives correct answers, in a given area, not worse than an expert, but that is difficult to achieve. An expert is an expert in a field who possesses and effectively uses certain knowledge, understanding of problems and tasks, skills and experience. Experts also have the ability to recognize a typical task in a specific problem they solve. Figure 6 shows the areas that define expert systems.

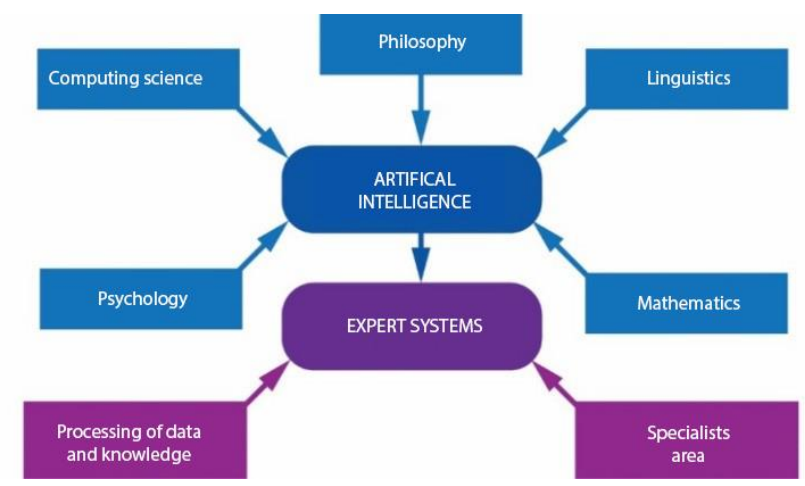

Figure 6: Areas that determine expert systems (Kukolj, 2007)

It is challenging to classify the tools for the development of ES into certain groups since the boundary between them is not strictly defined. It is often the case that individual tools can be classified into several groups according to their characteristics. Programming languages had a specific developmental course. Figure 7 shows the evolution of programming languages.

Artificial neural networks are a form of artificial intelligence that tries to mimic the function of the human brain and nervous system. Neural networks are being used to solve an increasing number of everyday problems of significant complexity. In programming, they can be used as a "generator" that is able to perform various recognizations and classifications, which also has the ability to generalize when deciding on unstructured input data.

Fuzzy logic is multivalued logic developed from phase set theory, as an extension of set theory. Fuzzy logic does not mean that it is imprecise logic. The term "fuzzy" means that logic describes vague concepts, such as human knowledge. In the logic phase, the degree of truth or the degree of membership represents the degree to which an element belongs to a particular phase of a set. 
Genetic algorithms and genetic programming belong to the class of automatic methods for creating a computer program or other complex problem-solving structure. The idea of genetic algorithms is based on the processes of imitation of natural selection.

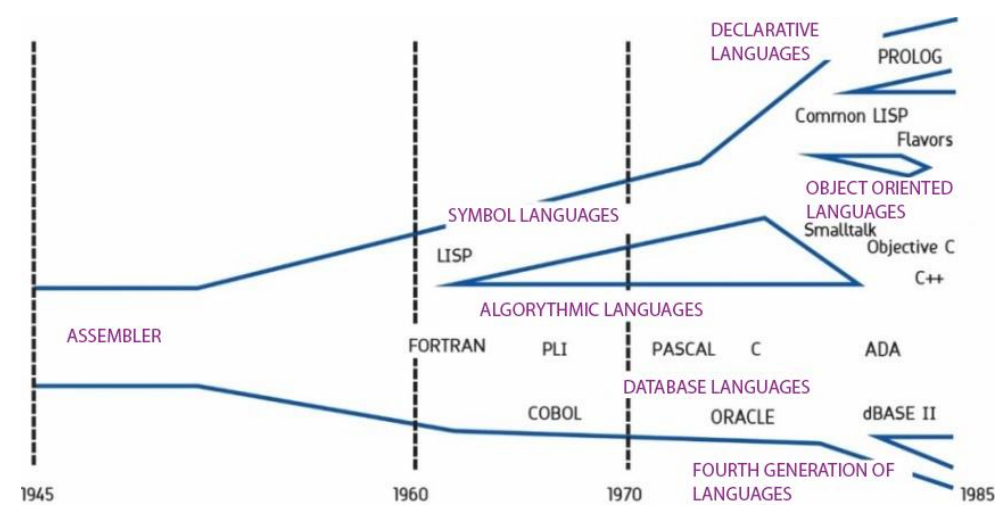

Figure 7: The evolution of programming languages(Lisjak, 2004)

Hybrid systems - most of the traditional information systems, which are based on knowledge, are developed as independent systems, with minimal interconnection. Increasing the amount of information requires the development of more complex systems, which integrate knowledge and traditional processing. One generation of intelligent systems is being developed with the help of hybrid techniques. Hybrid systems are suitable for solving various application problems

Distance learning - in the conditions of rapid technological changes and changing market conditions, the educational system must provide increased educational opportunities without increasing material resources. Many educational institutions are responding to this challenge with the development of distance learning programs, which have become a vital need today due to the pandemic. Content delivery methods used in e-learning are shown in Figure 8.

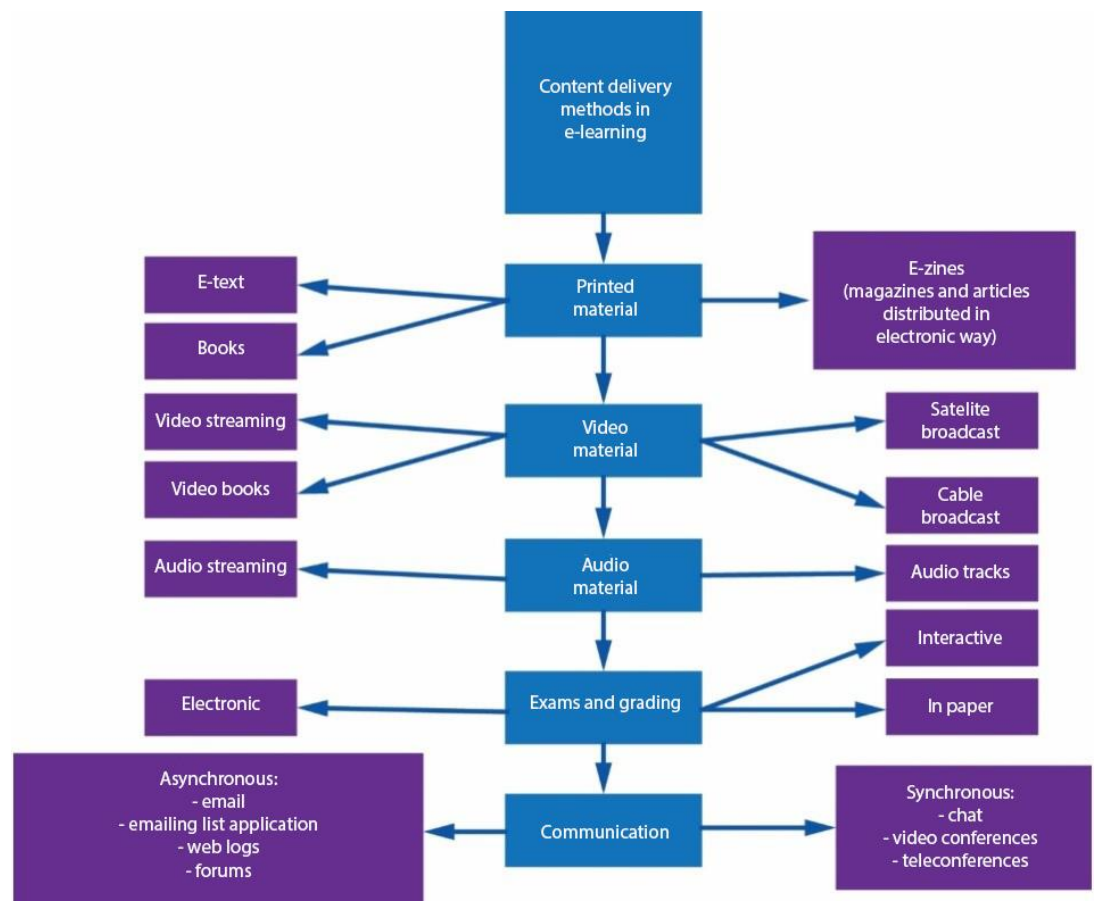

Figure 8: Content delivery methods in e-learning

Multimedia in the process of education is primarily set on influencing sight and hearing. The learning process is realized through the media transfer of information in the relation of knowledge transfer "knowledge giver - user of knowledge" or "lecturer-user", "professor-student", "teacher-student", etc. or 
different executors as providers of knowledge and different categories of recipients of knowledge. Significant conditions and contribution to the progress of distance learning have been made possible by the development of information and communication technologies.

General-purpose software systems are software applications of a universal character. Application systems are dedicated applications developed to solve specific problems.

\section{DIGITALIZATION OF PRINTED MEDIA}

Over time, news outlets have realized the need for modern digitalization of earlier print editions. This process is preceded by technical requirements and the implementation of digitalization. A digital image is an electronic photograph mapped in the form of a series of image elements, pixels and arranged following a previously defined ratio of horizontal and vertical. In the process of digitalization, the original documents are translated into bitmapped images with the help of a scanner or camera. The scanned document is stored as a digital image record without data compression (e.g. TIFF format) or with compression (JPEG format). Such images can be subsequently processed on a computer, where their brightness, contrast, colour intensity, sharpness, etc. can be increased or decreased. Reasons behind image compression are high memory space requirements, slow devices that are unable to display an uncompressed image in realtime, network bandwidth that does not allow real-time image transfer.

Media microfilming was a commonly used archiving process. Microfilming is one of the most efficient, economical and most straightforward ways to store large amounts of information on different types of films: silver halide, visual and diazo film. Advantages of microfilming: the document on film is an identical copy of the original, it is possible to save large format documents in the overall perspective of the image, connected to compatible output devices, can be printed, faxed and e-mailed, the cheapest way to obtain archival information, availability is not limited to electronic devices, a lot of information can be stored in a smaller space than needed for the printed material, it can be scanned and thus provide an identical copy that can be stored permanently. Disadvantages of microfilm are: the use of film is limited to one person, users must have reading devices, it is necessary to have a suitable printer or copier in order to reproduce it, pages must be read in order, there is no possibility to search specific information, microfilm records cannot be updated without the use of microfiche technologies, durability and usability of the film are regulated by many factors (film quality, proper processing control, appropriate storage conditions and handling) (Lukačević et al, 2015).

OCR software is needed to allow extracting, editing and rearranging data from scanned documents, camera images, PDFs, or in general - original documents. The OCR software must have dictionary support in the language in which the source document is written. How the OCR software works: the program analyzes the structure of the document image, after that the program divides the page into elements such as blocks of texts, tables, images, etc. The lines are divided into words and then into signs. After the extraction of the scanned images, the program compares them with a set of sample images. It advances several hypotheses about the possibilities of scanned images. Based on these hypotheses, the program analyzes different variants of breaking lines into words and words into signs. After processing a vast number of such probability hypotheses, the program finally makes a decision, presenting a recognizable text. When converting materials, it is very important to:

- Choose scanners that can be adjusted to the physical dimensions of the original document, the type of media, the range of details, tones and colours on the documents, as well as the physical condition of the documents

- Choose a resolution, bit depth that is sufficient to convey the finest essential details in the newspaper which are to be scanned and to apply newspaper improvement procedures very carefully.

- Use standard compression techniques "lossless" for the parent, i.e. master files

- Try to strike a balance between the visual quality acceptable to users and the file size that the computer can access with an acceptable delay.

Metadata is structured information that describes, explains, locates, or otherwise makes it easier to find, use, or manage a source of information. Metadata is often defined as data about data or information about information.

Metadata can be descriptive, structural, and administrative. Metadata can be embedded in a digital object and can be stored separately. Metadata is often embedded in HTML documents and image file headers. Storing metadata together with an object ensures that it will not be lost, avoids the problems of linking 
data and metadata, and provides security that metadata and the object will be updated together. Flaws of metadata: creating metadata is expensive and time-consuming, metadata is complicated (especially for end-users), metadata is subjective and context-dependent, there is no exact limit to the level of detail up to which metadata is useful, metadata is useless (given the fulltext of the browser such as Google) (Mirosavljević et al, 2018).

Format Metadata in librarianship - Formats for machine-readable bibliographic data recording: MARC21 and UNIMARC. The two largest library systems in Serbia, COBISS and BISIS, operate on the UNIMARC platform. The role of metadata in librarianship is to find the source of the data according to the relevant criteria; to organize and manage various archives; to enable the exchange of information and content between different systems, data structures and interfaces with minimal loss of content and functionality; then digital identification (via permanent identifiers such as URLS or DOI numbers); and finally archiving and protection of digital information. Metadata schemes: Dublin Core, TEI (Text Encoding Initiative), METS (Metadata Encoding and Transmission Standard), MODS (Metadata Object Description Schema), LOM (Learning Object Metadata) (Mirosavljević et al, 2018).

Dublin Core - The basic characteristics of Dublin Core are: simple, adaptable, international, expandable, the elements themselves are optional, repeatable, can appear in any order, contains a codebook and its application is recommended.

Data models - Many different data models have been developed over the last fifty years. Some of them were just an attempt or a step in the development of other data models, while others came to life and left a mark both in the theory and in the practice of databases. Some of the models that have been used, or are still used in practice today, are:

- network data model,

- hierarchical data model,

- relational data model,

- model of entity and link types,

- object-oriented data model and

- XML data model.

Hierarchical and networked data models emerged in the second half of the 1960s. Database management systems based on a hierarchical and networked data model were soon introduced into everyday use. However, these database management systems did not lead to the expected increase in productivity of either programmers or users. This is due to the fact that the logical and physical aspects of the database were not sufficiently separated, data structures were complex, and procedural languages were used as operational components.

The relational data model originated in the 1970s, and the main reasons for its introduction were the introduction of a clear distinction between the logical and physical aspects of the database, structural simplicity and the existence of declarative language for defining and using the database. In previous data models, information about the physical structure was built into the programs themselves. If the physical structure of the database were to change, the programs affected by that change would also have to change. In the relational data model, the largest organizational unit of data is the $\mathrm{n}$-array relation, which contains a set of n-torques.

XML data model - XML (eXtensible Markup Language) is a standard set of rules for defining data in electronic form. It is prescribed by the W3C organization. Its main advantage is that software for working with XML documents exists on all computer platforms (PC / Mac, Windows / Linux / Unix / macOS). It gives full results only when used with related technologies, some of them being: DTD, XML schema, XPath, XQuery, XSL transformations.

The XML data model has been in use for more than a decade. Although not new, it has not been sufficiently researched, especially compared to the relational data model. The XML data model, like other data models, has a structural, integrity, and operational component. The structural component of the XML data model is based on the concept of an XML document, at the extension level. At the intension level, an XML Schema document or DTD document is used. The XML data model is specific compared to other data models in that the $X M L$ extension can exist without the XML intension. This is due to the self-explanatory nature of the $\mathrm{XML}$ extension. However, if there is no schema according to which the XML document was formed, one cannot speak of an XML database, in the real sense of the term database) (Mirosavljević et al, 2018).

The XML language has made a real revolution in the field of data storage and transfer in the past decade, with a tendency to spread further. The language is human and machine-readable at the same time, with 
an emphasis on scalability and simplicity. A large number of formally defined languages have been developed on its basis.

$\mathrm{XML}$ is a meta-language for tagging text documents. The language is standardized by the international organization W3C (World Wide Web Consortium) for the development of Internet standards. Many formally defined markup languages are based on XML syntax. An XML document is a text document that can contain only textual content, while binary-type data cannot appear in it.

$\mathrm{XML}$ notation is used to describe structured documents. Extensible Markup Language $(\mathrm{XML})$ is a family of document specification languages, which gained great popularity soon after its introduction in 1998. XML is easy to understand and easy to learn, standardized and open to further extensions. XML is used to store, publish, and share information, and allows communicating parties to compile their language with welldefined semantics, syntax, and structuring rules.

Using the XML language to form documents helps to avoid keeping documents in a private format. XML documents are said to be self-explanatory because they contain both data and metadata. In addition to exchanging XML documents, it is necessary to define how to store, search and update XML documents. In order for all parties to the communication to use the same type of XML documents, it is necessary to define the semantics, syntax and rules of document structuring. Intensive data exchange via XML documents has created the need to store, search and update them. This has led to the development of database management systems based on XML technology. They are used in building XML database systems. XML has languages and concepts that can be used in the role of data models with its structural, integrity and operational component, thus providing all the necessary conditions for expressing the XML database schema in a formal way. The XML data model is in intensive development.

The Database Management System (DBMS) is software introduced as a link between users (user programs, applications) and database records on disk. User programs do not access the data directly, but communicate with this program, through an interface close to the user. Figure 9 provides an overview of software that currently represents the state of the art and have a significant share of the world market. Databases are usually implemented using one of the tested software packages (Zeljković, 2016).

\begin{tabular}{|l|l|l|l}
\hline Producer & Product & Operating System & Languages \\
\hline IBM Corporation & DB2 & $\begin{array}{l}\text { Linux, UNIX (razni), MS } \\
\text { Windows NT/2000/XP, } \\
\text { VMS, MVS, VM, OS/400 }\end{array}$ & $\begin{array}{l}\text { SQL, COBOL, Java, } \\
\text { etc. }\end{array}$ \\
\hline Oracle Corporation & Oracle & $\begin{array}{l}\text { MS Windows (various), } \\
\text { Mac OS, UNIX (various), } \\
\text { Linux, etc. }\end{array}$ & SQL, Java, etc. \\
\hline $\begin{array}{l}\text { IBM Corporation } \\
\text { (pre: Informix Software Inc.) }\end{array}$ & Informix & $\begin{array}{l}\text { UNIX (various), Linux, MS } \\
\text { Windows NT/2000/XP }\end{array}$ & SQL, Java, etc. \\
\hline Microsoft & MS SQL Server & MS Windows NT/2000/XPP SQL, C++, etc. \\
\hline MySQL AB & MySQL & $\begin{array}{l}\text { Linux, UNIX (various), MS } \\
\text { Windows (various), Mac OS }\end{array}$ & SQL, C, PHP, etc. \\
\hline Sybase Inc. & Sybase SQL Server & $\begin{array}{l}\text { MS Windows NT/2000, } \\
\text { OS/2, Mac, UNIX (various), } \\
\text { UNIXWare }\end{array}$ & SQL, COBOL, etc. \\
\hline Mewlett Packard Co. & Allbase/SQL & UNIX (HP-UX) & SQL,4GL, C, etc. \\
\hline Cicom System Inc. & Supra & $\begin{array}{l}\text { MS Windows NT/2000, } \\
\text { Linux, UNIX (various), } \\
\text { VMS, MVS, VM }\end{array}$ & SQL, COBOL, etc. \\
\hline MS Windows (various)
\end{tabular}

Figure 9: Software tools for working with databases 


\section{CONCLUSION}

As a consequence of the growing automation of all phases of the printing process, strong innovation potential in the fields of machines, devices and processes will be released in the coming years. This can be best seen on the basis of technical development in the preparation of printing with short periods of change of the device on which the preparation is realized. The control electronics enable high-quality retention and higher productivity.

Today, the field of press preparation is, as a rule, in digital form. Only in this way is it possible to shorten the delivery time of printed products and meet the high demands of customers related to quality.

Basically, all printing plants are expected to be more flexible in the production of various printed products. In accidental printing, more than half of the orders are already in digital form. The trend towards multicolour as well as towards decorative and special colours is growing. The volume of editions is decreasing, which opens the perspective for small short-term editions. According to expert opinion, such publications have the greatest chance of growth.

Positive impulses for the entire printing industry are expected from the information and communication sector.

In addition to the classic areas of work, media production will gain in importance in the future. Thus, the needs for the design of printed media and the creation of multimedia products, Internet sites, printed media in combination with electronic media, etc. will grow more intensively. The additional capability of electronic media, especially the Internet, will increase the competitive pressure on printed media and will partially replace printed products, but will also create new requirements for printing.

The market for printed products remains, despite the growth of electronic media, as a further attractive and an extensively strong market, as a large part of the ever-growing advertising fees flows into the print media with the widespread growth of the needs for printed and electronic media.

With the spreading of the Internet, the sale of goods and services over the Internet by many companies is expanding as a new form of sales. The Internet is inevitably changing traditional media.

The digitalization of our cultural heritage connects different sectors of the global community in a whole new way. Due to the great use of the Internet, user groups of library structures have been transformed. Newspaper publishers integrate print and online publications to reach a broader range of readers.

Interactive Internet techniques provide libraries and archives with a new opportunity to develop a global community of users, so the newspapers also need to follow this trend in order to survive. The old archive needs to be digitalized, and the new editions need to be properly preserved and organized.

\section{ACKNOWLEDGEMENTS}

This research (paper) has been supported by the Ministry of Education, Science and Technological Development through the project no. 451-03-68/2020-14/200156: "Innovative scientific and artistic research from the FTS (activity) domain".

\section{REFERENCES}

[1] IFLA, "Smjernice za projekte digitalizacije", (Nacionalna biblioteka Crne Gore - Đurđe Crnojević, Cetinje, 2002.), page 29.

[2] Kukolj, D.: „Sistemi zasnovani na racunarskoj inteligenciji”, (Fakultet tehničkih nauka, Novi Sad, 2007.)

[3] Lisjak, D.: „Primjena metoda umjetne inteligencije pri izboru materijala“, PhD thesis, Faculty of Mechanical Engineering and Naval Architecture, 2004.

[4] Lukačević, S., Buljević, J., Mokriš, S.: "Formati digitalnih sadržaja za čuvanje i zaštitu novina u knjižnicama", Knjižničarstvo: glasnik Društva knjižničara Slavonije, Baranje i Srijema 19 (1-2),104, 2015.

[5] Milosavljević, B., Zaric, M., Zeljković, Ž.: „Elektronsko izdavaštvo materijal sa predavanja“, URL: https://www.grid.uns.ac.rs/predmet2.html?predmet=88 (last request: 2020-08-10), 2018.

[6] Poliščuk, J.: „Ekspertni sistemi“, (ETF Podgorica, Podgorica, 2004.)

[7] Zeljković, Ž.: „System for identification of printing process parameters“, PhD thesis, University of Novi Sad, Faculty of Technical Sciences, 2016. 


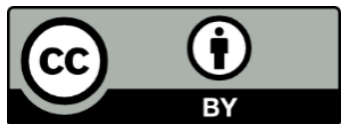

(C) 2020 Authors. Published by the University of Novi Sad, Faculty of Technical Sciences, Department of Graphic Engineering and Design. This article is an open access article distributed under the terms and conditions of the Creative Commons Attribution license 3.0 Serbia

(http://creativecommons.org/licenses/by/3.0/rs/). 

TYPOGRAPHY

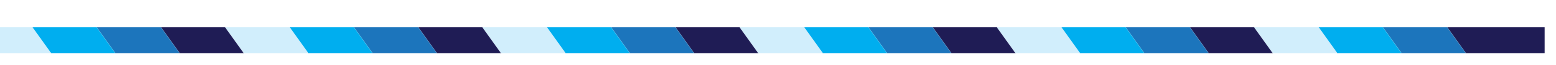





\title{
INFLUENCE OF WHITE SPACE ON TEXT SCANNING
}

\author{
Kata Jovančić (iD, Neda Milić Keresteš (D), Uroš Nedeljković (iD) \\ University of Novi Sad, Faculty of Technical Sciences, \\ Department of Graphic Engineering and Design, Novi Sad, Serbia
}

\begin{abstract}
Among its many roles, typography also serves to make a text more legible and readable, allowing the reader to follow the content flow with more ease. Typographic hierarchy, in turn, with its use of different logical and visual tools, serves to establish an order of importance of different text elements. To emphasize certain elements - i.e. create eye-catchers, typographers usually resort to making bigger and bolder items. In this paper we wish to examine whether white space can also serve as a means of emphasis. While several studies have already proven that white space influences consumer perception in advertising, no one has yet investigated the effects of white space on text scanning. With that in mind, we examined whether white space could contribute to the effectiveness and speed of text scanning. We used eye-tracking technology to collect accurate quantitative and visual data. Although the results did not show that white space has a positive effect on scanning speed or text structure memorability, we have noted a difference in the eye-movement pattern, which raises hope and leads us to believe that further research is needed.
\end{abstract}

Key words: typography, typographic hierarchy, white space, text scanning, eye-tracking

\section{INTRODUCTION}

Typography is a refined craft that makes language visible (Cullen, 2012). It uses type to communicate (Black et al, 1992) and interpret a message (Bringhurst, 2018). Typographers cannot force anyone to read, but they can make a document clear, accessible, and adaptable (Black et al, 1992). Except it should attract attention, reveal content and meaning of a text, connect the text with other elements and provide reading comfort, typography should also explain structure and framework of a text, i.e. enables navigation through the content flow (Black et al, 1992; Lupton, 2010; Bringhurst, 2018).

Although the purpose of typography is mostly defined as the readability improvement, "one of design's most humane functions is, in actuality, to help readers avoid reading (Lupton, 2010)." Apart from novels, readers rarely read documents from beginning to end (Black et al, 1992). Before processing on a wordlevel, a reader is scanning a text by identifying its physical appearance: format, size and complexity; reader recognises different degrees of information on a global level, by finding and collecting structural signs and characteristics (Black et al, 1992), which helps him/her in processing content quickly to extract elements for immediate use (Lupton, 2010). The documents must be adapted to this purpose of the text (Black et al, 1992), and this is where the hierarchy comes into play.

Typographic hierarchy makes the content easy to scan, helps the composition to be unambiguous, clean, clear and understandable (Ambrose and Harris, 2006; Lupton, 2010; Samara, 2014). "Hierarchy is a logical and visual way to express the relative importance of different text elements by providing a visual guide to their organisation (Ambrose and Harris, 2006)." Content should be organised logically rather than stylistically (Lupton, 2010), because so-designed messages are not just more comfortable and quicker read, but remain remembered (Müller-Brockmann, 1996). "Designers conduct hierarchy with typographic, spatial, and graphic factors (Cullen, 2012)." The human eye experiences bigger and bolder items as more important than smaller and lighter ones. Still, typographic distinction alone is sometimes insufficient to discern hierarchy levels but is achieved using the space (Black et al, 1992). When it comes to the use of space, there are two opposing opinions.

One advocates that both black and white space are equally important because disposition and amount of area which surrounds text also convey information. The other opinion is coming from the fierce proponents of visual density. They claim that one page full of well-organised information is better than multiple ones with plenty of white space (Lupton, 2010).

Research in the field of typography mostly focuses on the printed elements of a page, leaving white space both literally and metaphorically on the margins. Where the influence of white space on the perception of the advertised product has been proven in several studies (Pracejus et al, 2006; Jacobs and Poillon, 2012; Olsen et al, 2012; Loh, 2013; Kwan et al, 2017), its effect on text scanning has not been examined. 
This paper aims to fill that gap, investigating whether white space has an impact on the speed and effectiveness of text scanning.

\section{METHODS}

The goal of this study is to see if white space contributes to text scanning speed and effectiveness, i.e. can white space be applied as an eye-catcher. Additionally, we will check whether white space will impact answer accuracy, text's structure awareness and memorability. Therefore we formulated the hypotheses. $\mathrm{H}_{0}$ : White space does not have a significant impact on text scanning speed and effectiveness.

$\mathrm{H} 1$ : White space does have a significant impact on text scanning speed.

$\mathrm{H} 2$ : White space does have a significant impact on text scanning effectivity.

H3: White space does have a significant impact on the text's structure awareness.

H4: White space does have a significant impact on the memorability.

For this purpose, two layouts were designed: control and experimental one. We chose two different texts ( $A$ and $B$ ) with the same number of words and an approximately equal number of characters. The two texts were prepared as both control and experimental stimuli, which form four different stimuli. According to the experimental 2x2 design (Novaković et al, 2013) participants were assigned to one of the following four groups: Group 1: reads the text Ac, then Be; Group 2: reads the text Ae, then Bc; Group 3: reads the text $B c$, then $A e$; Group 4: reads the text $B e$, then $A c$.

\subsection{Tools}

We used Lenovo Z51 laptop PC, Eizo Color Edge CG241W LCD monitor, Gazepoint GP3 eye-tracking device, Gazepoint Analysis 3.5.0 and Gazepoint Control 3.5.0 software. According to Gazepoint official recommendation, the experimental room was shaded, excluding both direct and indirect light sources. During the experiment, PC was connected to the monitor (which projected stimuli) and to the eyetracking device, which was set under the monitor. Gazepoint GP3 eye-tracking device contains a $60 \mathrm{~Hz}$ frequency camera, which is limited in reading text tasks, but it is sufficient for visual search ones.

\subsection{Participants}

Twenty-nine students and assistants from the Faculty of Technical Sciences, University of Novi Sad began the experiment session. Due to the impossibility of calibration or data analysis, data on 20 respondents was collected. The selection of respondents was random, and participation in the experiment on a voluntary basis. Respondents were randomly assigned to one of four groups.

\subsection{Design of stimuli}

This experiment manipulates white space, while other text parameters remain constant. Both stimuli have two hierarchy levels, where the first one (subtitles) is set in bold, and the second one in a regular cut. The stimulus control (c) follows an essay layout, containing familiar white space. Experimental stimulus (e) is set in two columns, where the first hierarchy level is surrounded by a greater amount of white space. Other parameters of the stimuli layout were designed in accordance with the researched literature. Therefore, the type was set in Arial Regular, because of its familiarity and wide-spread use. A gradation of $11 \mathrm{pt}$ was selected, with a spacing of $13.2 \mathrm{pt}$. All stimuli were arranged without hyphenation. Line density was between 75 and 90 characters per line. Figures 1 and 2 show the layout of the control and experimental stimuli, respectively.

For textual content of the stimuli, popular science articles were selected, which were filled with a lot of information that is not generally known, nor does it fall under the engineering profession. The two articles "Why do we drink cow's milk?" and "Invasion of Bamboo" were taken from the platform naukakrozprice.rs. To achieve the same number of characters and an approximate number of words in both texts (3681 characters; 616 words in text A and 607 words in text B), some of the sentences are reformulated or moved, without changing the content and context. The subheadings were arbitrarily chosen so that they refer to the paragraph and guide participant clearly in answer search. In order to make a difference in the number of sections, text $A$ is adjusted to four, and for text $B$ to five paragraphs. Texts $A$ and $B$ are entirely independent and can be read in any order. By combining two texts and two formatting modes, four stimuli were prepared: (1) Control $A(A c)$, (2) Control B (BC), (3) Experimental $A$ (Ae) and (4) Experimental B (Be). 


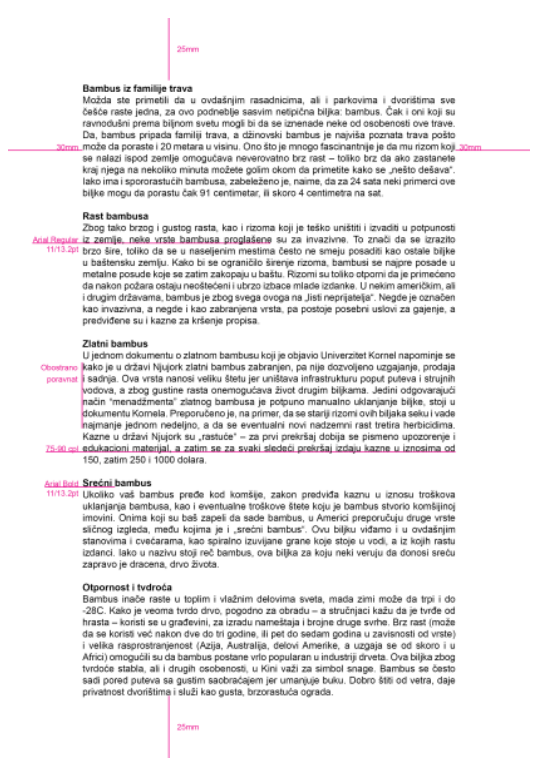

Figure 1: Stimuli control layout

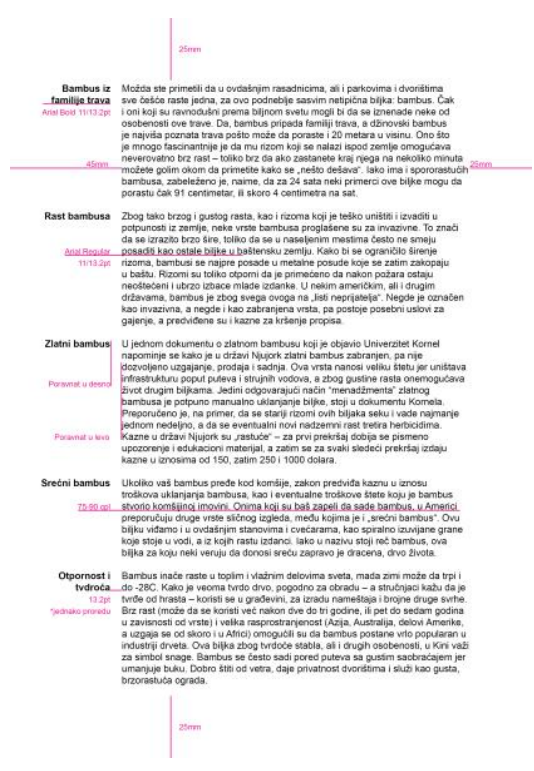

Figure 2: Experimental stimuli layout

In addition to these primary stimuli, two more were prepared, with questions for text $A$ and $B$. The stimuli with questions were also set in 11 pt Arial, centrally aligned, in the middle of the observed surface. The questions are formulated so that they have a term that corresponds to one of the subheadings so that the respondents first find it, and then continue reading the matching paragraph, find the required information and give the answer. The question for text A was: "When did the mutation of milk intolerance occur?"; for text B: "In which country is golden bamboo banned?" In the former they were supposed to find the subtitle "Mutation of intolerance", and then in the paragraph "about 7500 years ago", and in the later, subtitle "Golden Bamboo", followed by "in the state of New York."

Gazepoint Analysis 3.5.0 offers video, web page, screen, text file in .txt format, and image analyse option but does not provide one for a .pdf extension file. Therefore, the stimuli were prepared as images in .png format.

\subsection{Procedure}

To avoid individual differences between the participants, each of them had to encounter both texts and both ways of stimuli design. Additionally, to collect the observed variables for each participant in both control and experimental conditions, avoiding the influence of both the order of the texts and the order of the design, four groups were formed, into which the participants were randomly assigned: Group 1 reads text $A c$, then $B e$; Group 2 reads text $A e$, then $B c$, Group 3 reads text $B c$, then $A e$, group 4 reads text Be, then Ac.

At the beginning of each experimental session, every participant was informed about the experimental procedure. A 9-point calibration followed the explanation, afterwards data collection of eye movements began. After the experiment sessions with all subjects were completed, AOls (areas of interest) for each subheading and the part of the paragraph that contains the answer were defined.

\section{RESULTS}

Before performing a statistical test, we checked whether the continuous variables, which are the focus of the research, were normally distributed. Since the sample is smaller than 50 , we used the Shapiro-Wilk normality test. 
Table 1: Results of examing variables normal distribution

\begin{tabular}{|l|l|l|l|l|l|l|}
\hline & $\begin{array}{l}\text { Answer time } \\
{[\mathrm{sec}]}\end{array}$ & $\begin{array}{l}\text { AOI answer } \\
\text { time to 1st } \\
\text { view [sec] }\end{array}$ & $\begin{array}{l}\text { AOI answer } \\
\text { time viewed } \\
{[\mathrm{sec}]}\end{array}$ & $\begin{array}{l}\text { AOl answer } \\
\text { time viewed } \\
{[\%]}\end{array}$ & $\begin{array}{l}\text { AOl number of } \\
\text { fixations }\end{array}$ & $\begin{array}{l}\text { AOI answer } \\
\text { revisits }\end{array}$ \\
\hline $\mathrm{A}$ & $\mathrm{p}_{\mathrm{c}}<0.01$, & $\begin{array}{l}\mathrm{p}_{\mathrm{c}}<0.01, \\
\mathrm{p}_{\mathrm{e}}<0.01\end{array}$ & $\begin{array}{l}\mathrm{p}_{\mathrm{c}}>0.05, \\
\mathrm{p}_{\mathrm{e}}<0.05\end{array}$ & $\begin{array}{l}\mathrm{p}_{\mathrm{c}}>0.05, \\
\mathrm{p}_{\mathrm{e}}<0.05\end{array}$ & $\begin{array}{l}\mathrm{p}_{\mathrm{c}}>0.05, \\
\mathrm{p}_{\mathrm{e}}>0.05\end{array}$ & $\begin{array}{l}\mathrm{pc}>0.05, \\
\text { pe }>0.05\end{array}$ \\
\hline $\mathrm{p}<0.01$ & $\mathrm{p}_{\mathrm{c}}>0.05$, & $\begin{array}{l}\mathrm{p}_{\mathrm{c}}<0.01, \\
\mathrm{p}_{\mathrm{e}}<0.01\end{array}$ & $\begin{array}{l}\mathrm{p}_{\mathrm{c}}>0.05, \\
\mathrm{p}_{\mathrm{e}}<0.01\end{array}$ & $\begin{array}{l}\mathrm{p}_{\mathrm{c}}>0.05, \\
\mathrm{p}_{\mathrm{e}}<0.01\end{array}$ & $\begin{array}{l}\mathrm{p}_{\mathrm{c}}>0.05, \\
\mathrm{p}_{\mathrm{e}}<0.01\end{array}$ & $\begin{array}{l}\mathrm{pc}=0.05, \\
\mathrm{pe}<0.05\end{array}$ \\
\hline
\end{tabular}

As Table 1 shows, the observed variables are generally not normally distributed. Therefore we used a nonparametric test of independent groups to compare continuous variables between groups, i.e. ManWhitney U test.

Table 2: Results of the Man-Whitney $U$ test for continuous variables, text $A$

\begin{tabular}{|l|l|l|l|l|}
\hline & $\begin{array}{l}\text { Mann- } \\
\text { Whitney U }\end{array}$ & Z & $\begin{array}{l}\text { Asymp. Sig. } \\
\text { (2-tailed) }\end{array}$ & r \\
\hline Answer time & 33.000 & -1.285 & 0.199 & \\
\hline Answer AOI_timetofirstview & 37.000 & -0.983 & 0.326 & \\
\hline Answer AOI_timeviewed* & 18.000 & -2.419 & 0.016 & 0.5409 \\
\hline Answer AOI_timeviewedpercent* & 18.000 & -2.419 & 0.016 & 0.5409 \\
\hline Answer AOI_fixations & 29.500 & -1.563 & 0.118 & \\
\hline Answer AOI_answerrevisits & 42.000 & -0.609 & 0.542 & \\
\hline Subtitle AOI_timetofirstview & 42.000 & -0.605 & 0.545 & \\
\hline Subtitle AOI_timeviewed & 26.000 & -1.814 & 0.070 & \\
\hline Subtitle AOI_timeviewedpercent & 26.000 & -1.814 & 0.070 & \\
\hline Subtitle AOI_fixations* & 15.500 & -2.666 & 0.008 & 0.59607 \\
\hline Subtitle AOI_revisits* & 22.500 & -2.143 & 0.032 & 0.47929 \\
\hline
\end{tabular}

The results of the Mann-Whitney $U$ test show differences between the groups. In Table 2 we note that statistically significant differences are present in the absolute and relative time viewed of the Answer AOI, as well as in the number of fixations and the number of revisits to the Subtitle AOI. In all differences between the groups, Cohen's criteria are large $(r \sim 0.5)$. For all the mentioned differences, the lower median values refer to the experimental group.

Table 3: Results of the Man-Whitney $U$ test for continuous variables, text $B$

\begin{tabular}{|l|l|l|l|l|}
\hline & $\begin{array}{l}\text { Mann- } \\
\text { Whitney U }\end{array}$ & $Z$ & $\begin{array}{l}\text { Asymp. Sig. } \\
\text { (2-tailed) }\end{array}$ & r \\
\hline Answer time & 39.500 & -0.794 & 0.427 & \\
\hline Answer AOI_timetofirstview & 44.000 & -0.460 & 0.646 & \\
\hline Answer AOI_timeviewed & 42.000 & -0.605 & 0.545 & \\
\hline Answer AOI_timeviewedpercent & 42.000 & -0.605 & 0.545 & \\
\hline Answer AOI_fixations & 37.000 & -0.985 & 0.325 & \\
\hline Answer AOI_answerrevisits & 46.000 & -0.304 & 0.761 & \\
\hline Subtitle AOI_timetofirstview & 39.500 & -0.794 & 0.427 & \\
\hline Subtitle AOI_timeviewed* & 24.500 & -1.928 & 0.054 & 0.43119 \\
\hline $\begin{array}{l}\text { Subtitle AOI } \\
\text { timeviewedpercent* }\end{array}$ & 24.500 & -1.928 & 0.054 & 0.43119 \\
\hline Subtitle AOI_fixations* & 13.000 & -2.857 & 0.004 & 0.63876 \\
\hline Subtitle AOI_revisits* & 15.000 & -2.713 & 0.007 & 0.60662 \\
\hline
\end{tabular}


In Table 3, we notice that statistically significant differences are present in the absolute and relative time viewed, as well as in the number of fixations and the number of revisits to the Subtitle AOI. In all differences between the groups, Cohen's criteria shows medium to large $(0.3<r<0.5)$ and large $(r>0.5)$ value. For all the above differences, the experimental group of stimuli has a lower median value.

The Chi-square test was used to test the differences between groups for categorical variables. Since all participants gave the correct answer for both text A and text B, without a statistical test, we conclude that there is no difference between the control and experimental group. Neither subtitles number accuracy, nor subtitles memory accuracy show differences between the groups, which we see in Table 4.

Table 4: Results of the Chi-square test

\begin{tabular}{|l|l|l|}
\hline & Text A & Text B \\
\hline Subtitles number accuracy & $\chi^{2}=0, p=1.000$ & $\chi^{2}=0.833, p=0.361$ \\
\hline Subtitles memory accuracy & $\chi^{2}=2.343, p=0.673$ & $\chi^{2}=0.933, p=0.817$ \\
\hline
\end{tabular}

\section{DISCUSSION}

The first issue we encountered in data analysis is the inefficient sample size for the two-factor ANOVA test. Therefore we used a more robust, nonparametric, Man-Whitney $U$ test. In categorical variables (answer accuracy, subtitles number accuracy and subtitles memory accuracy) differences between groups were not statistically significant. The primary observed continuous variable (answer time) hasn't shown a statistically significant difference between control and experimental groups. However, some other variables did. The number of fixations and of revisits to the subtitle AOI is significantly smaller in the experimental group in both texts. According to all the above, the formulated hypothesis $\mathrm{H}_{0}$ (The use of whiteness does not have a significant influence on speed and effectivity of visual search of the text) cannot be rejected.

\subsection{Heat Map analysis}

The Heat Map visualises the length of the fixations with a range of colours from light blue, through dark, orange and red, where light blue corresponds to the shortest fixation and red to the longest. If there is no colour, it means that there was no fixation in that part of the screen at a particular moment. The following figures (3-10) show the heat maps for every group, in five representative moments.
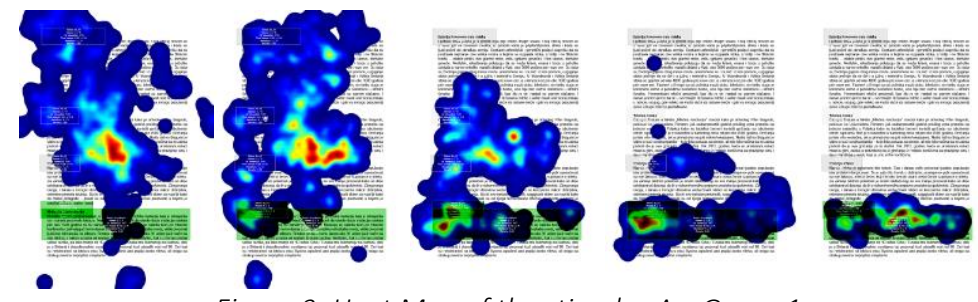

Figure 3: Heat Map of the stimulus Ac, Group 1
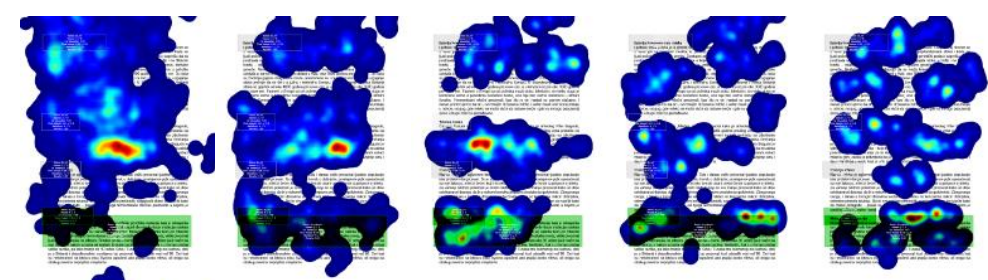

Figure 4: Heat Map of the stimulus Ac, Group 4 

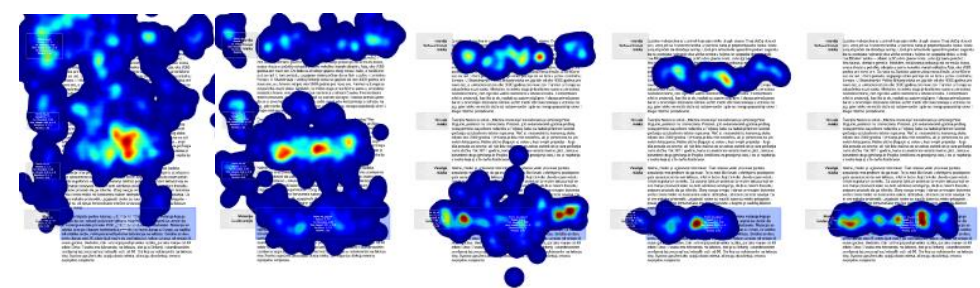

Figure 5: Heat Map of the stimulus Ae, Group 2
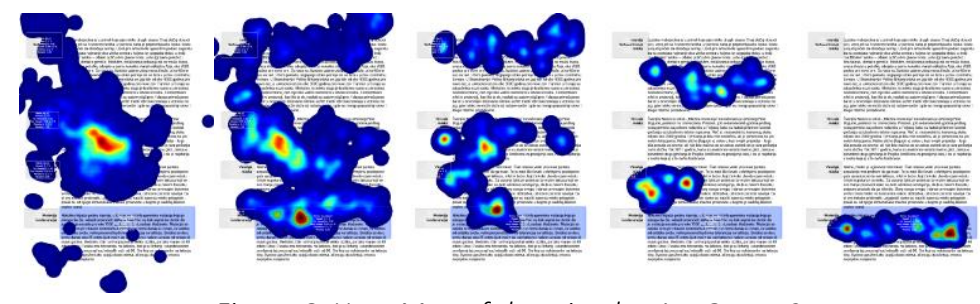

Figure 6: Heat Map of the stimulus Ae, Group 3
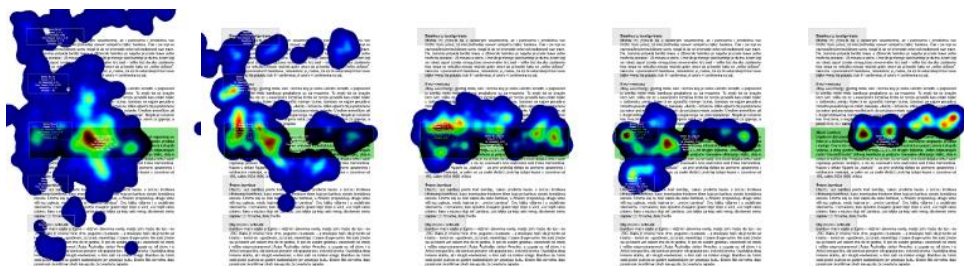

Figure 7: Heat Map of the stimulus Bc, Group 3
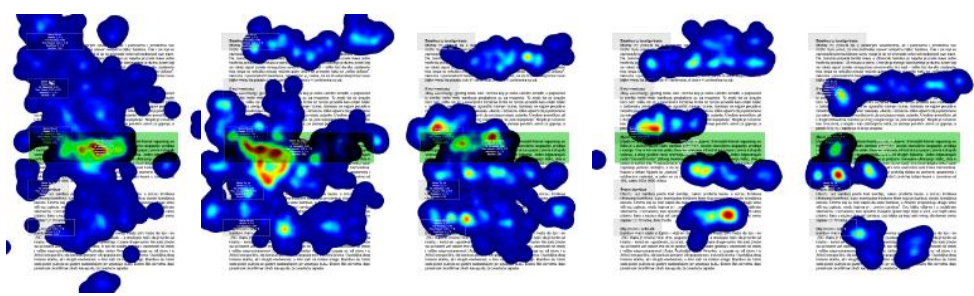

Figure 8: Heat Map of the stimulus Bc, Group 2
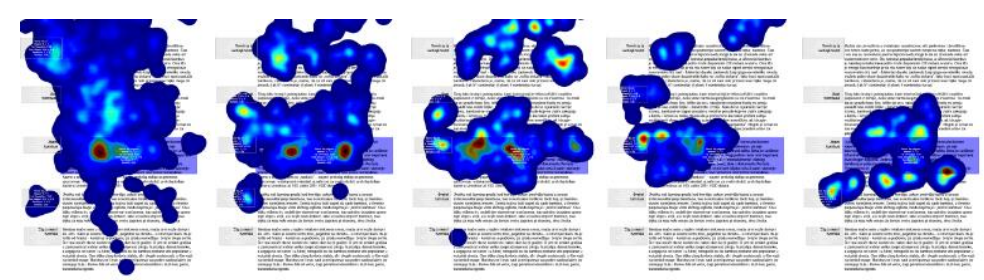

Figure 9: Heat Map of the stimulus Be, Group 4

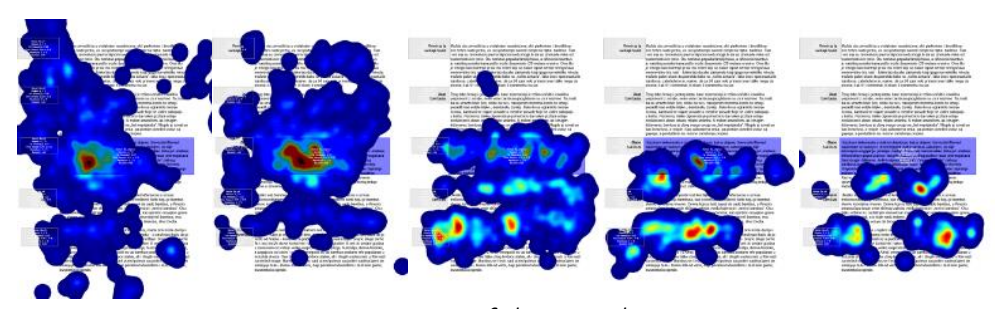

Figure 10: Heat Map of the stimulus Be, Group 1

At the beginning of each collective observation, we notice established movements from the upper-left edge of the page to the field of interest. We also notice that on the experimental stimulus, observed in relative time, the gaze is directed faster towards the field of interest, while on the control stimulus, it is more distracted. At certain moments, we also notice completely separate concentrations of fixations 
(some respondents searched for the region of interest longer than others), which confirms the scattering of the distribution of the time of finding the answer.

\section{CONCLUSIONS}

The typographic hierarchy inevitably has a role in page navigation, i.e. more efficient text scanning. Among the many ways to achieve typographic hierarchy, the influence of white space is not extensive in empirical research. However, design practice claims that white space contributes to a certain extent to the perception of the visual hierarchy. This claim has been experimentally tested, by designing control and experimental stimuli, with the usual and unconventional use of white space, respectively. The eyetracking method has proven to be very useful in the visual search experiment, as it offers plenty of quantitative and visual data, providing a very detailed analysis of the human eye movements. In the quantitative data analysis, the biggest obstacle was the small sample size, as well as the non-normal distribution of variables. Therefore nonparametric tests were used, which are more robust than parametric ones.

The results of the experiment did not show that white space impacts answer time, answer correctness, nor text structure memory. Therefore the null hypothesis was not rejected. However, results noted a significantly less number of fixations and $\mathrm{AOI}$ revisits for the experimental stimuli. From both quantitative and visual data, we notice that there is no difference in the first subtitle AOI. This phenomenon can be explained by the habit of Western civilizations to start reading or scanning the text from the upper left page area. This notice also shows that eye-catchers that use white space are not strong enough, because they do not draw attention to themselves first, but allow the eye to start moving through the text by inertia. However, the results showed that other subheadings surrounded by white space generally require fewer fixations and fewer eye revisits. This observation provides a basis for additional, more thoroughly prepared experiments to prove that white space contributes to more efficient text scanning and memory.

\section{ACKNOWLEDGMENTS}

This research (paper) has been supported by the Ministry of Education, Science and Technological Development through the project no. 451-03-68/2020-14/200156: "Innovative scientific and artistic research from the FTS (activity) domain".

\section{REFERENCES}

[1] Ambrose, G., Harris, P.: "The Fundamentals of Typography", (AVA Publishing, Lausanne SA, 2006.).

[2] Black, A., Stiff, P., Waller, R.: "Designing Business Documents", (Redhill: Monotype Typography Ltd, 1992.).

[3] Bringhurst, R.: "Elementi tipografskog stila", (Hrvatsko dizajnersko društvo, Zagreb, 2018.).

[4] Cullen, K.: "Design elements typography fundamentals: a graphic style manual for understanding how typography affects design", (Rockport MA, Beverly, 2012.).

[5] Jacobs, L., Poillon, C.L.: "White Space in Newspaper Grocery Advertising: Some New Findings", Journal of Current Issues \& Research in Advertising 14, 69-75, 2012. doi: 10.1080/10641734.1992.10504990.

[6] Kwan, C.M.C., Dai, X., Wyer, R.S.: "Contextual Influences on Message Persuasion: The Effect of Empty Space", Journal of Consumer Research 44, 448-464, 2017. doi: 0.1093/jcr/ucx051.

[7] Loh, S.L.: "Effects of White Space on Consumer Perceptions", MSc thesis, University of San José, 2013.

[8] Lupton, E.: "Thinking with type: a critical guide for designers, writers, editors, \& students", (Princeton Architectural Press, New York, 2010.).

[9] Müller-Brockmann, J.: "Grid systems. ", (Niggli Verlag, 1996.).

[10] Novaković, D., Milić, N., Milosavljević, B.: "Animated vs. Illustrated Software Tutorials: Screencasts for acquisition and Screenshots for Recalling", International Journal of Engineering Education, 29, 1013-1023, 2013.

[11] Olsen, G.D., Pracejus, J.W., O'Guinn, T.C.: "Print advertising: White space", Journal of Business Research 65, 855-860, 2012. doi: 10.1016/j.jbusres.2011.01.007. 
[12] Pracejus, J., Olsen, D., O'Guinn, T.: "How Nothing Became Something: White", Journal of Consumer Research 33, 82-90, 2006. doi: 10.1086/504138.

[13] Samara, T.: "Design Elements: Understanding the Rules and Knowing When to Break Them", (Second ed. Gloucester: Rockport Publishers, 2014.).

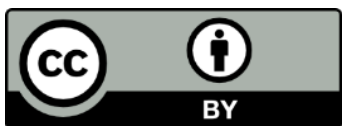

(C) 2020 Authors. Published by the University of Novi Sad, Faculty of Technical Sciences, Department of Graphic Engineering and Design. This article is an open access article distributed under the terms and conditions of the Creative Commons Attribution license 3.0 Serbia

(http://creativecommons.org/licenses/by/3.0/rs/). 


\title{
THE EFFECT OF CONTROLLING THE WEIGHT VARIABLE ON THE TYPEFACE ATTRIBUTE ASSESSMENT
}

\author{
Jelena Žarko (D), Uroš Nedeljković \\ University of Novi Sad, Faculty of Technical Sciences, Department of Graphic Engineering and \\ Design, Novi Sad, Serbia
}

\begin{abstract}
Certain characteristics specific for typeface design initiate different impressions on observers, but here arises a research problem where we cannot identify what specific or universal characteristics of the typeface initiate the impressions on certain attributes. A common problem encountered in previous researches is that fonts may vary in many variables and at the same time differ in width, weight, contrast, and structure. Therefore, it is difficult to determine and isolate which universal and specific characteristics of the typeface affect the impression. The subject of this paper is the isolation of the weight variable and the investigation of its relationship with typeface personality attributes. The main goal of this paper is to provide empirical support for theoretical assumptions, building on previous researches on the typeface personality and typographic rhetoric to show how specific typographic characteristics influence the experience of writing itself.
\end{abstract}

Keywords:Typeface personality, Visual rhetoric, Universal structure

\section{INTRODUCTION}

According to Aristotle's theory of rhetoric, people are affected through reason (logos), through feelings (pathos) and personality, morals, ethics (ethos). Logos, Pathos and Ethos are key dimensions for communication efficiency. Rhetoric is a skill (ars techne), and skill is a set of rules that arose from experience and was subsequently thought out (Aristotele, et al., 1954). Typography as well as rhetoric insists on order, symmetry, limitations, structure and composition of parts as a whole. Beauty is the subject of both rhetoric and typography. The activities of typographers are similar to the activities of rhetoricians. Just like a rhetorician, a typographer applies rules of conduct to his art to ultimately lead his audience to see as he sees. Typography encompasses not only the visual impression of the typeface but also the relationship between the image we perceive and the statement we want to express. This harmony can only be successfully achieved through creative interpretation between rhetorician and typographer (Trummel, 1988).

Typeface design is an important visual tool for achieving the goals of communication in general, and today, in particular, technical communication. The design of the typeface affects the impressions of the observer, but the nature of that effect is still unknown. The personality of the typeface is an important aspect of technical documents and the education of administrative staff. By selecting the appropriate font, the visual tone and character of the text can be determined. This lack of guidance led McCarthy and Mothersbaugh (McCarthy and Mothersbaugh, 2002) to conduct research and create a set of principles that link the characteristics of the typeface to the impressions they create. Part of this model has been empirically tested by researching how common typographic characteristics can affect the perception of an advertisement. Although this study does not link the effect of the typeface on conviction (e.g. attitude towards a brand), it in itself indicates that typography has a significant impact on the ability of consumers to read the advertising copy/advertisement. Designers support the idea that typefaces have expressive personalities, suggesting that even a typeface destined to be free from historical and cultural associations cannot be completely free from rhetorical influence (Kinros, 1985; Nedeljković, 2012). Initial research, research by Henderson (Henderson et al, 2004), Childers (Childers, and Jass 2002), Doyle and Bottomley (Doyle and Bottomley, 2006) show that typeface design affects the perception of advertising brands, affects the readability and memory of advertisements, creates strategically important impressions, affects the suitability of the typeface for different products and therefore there is an assumption that it can affect the financial results of the company. Design practitioners had different opinions about the personalities of the typeface. They believe that each typeface has a special personality (Shushan and Wright, 1994; Kostelnick and Roberts, 1998; Brumberger, 2003a), can convey and evoke different feelings and moods, communicate with a certain attitude and adjust the visual tone (Strizver, 2001; Parker and Parker, 1997). These conclusions were further deepened by research where the comparison was made based on the characteristics specific to the typeface. Kastl and Child (Kastl and Child, 1968) concluded 
that there is a connection between certain typeface characters and certain typeface-specific characteristics. While Davis and Smith (Davis and Smith, 1933), striving to find out how specific characteristics affect the impression, concluded that the most extreme differences in size, width and contrast leave the greatest impression on the observer. Exploring the differences between serif and sansserif typefaces, Benson (Benson, 1985) concluded that sans-serif typefaces were cleaner and had a more modern look than sans-serif, while Kostelnick and Roberts (Kostelnick and Roberts, 1998) concluded that sans-serif typefaces were more technical than serif, because of the clean, machine-like looks of modernism. Parker (Parker and Parker 1997) further deepened the research according to the shape of the serif, concluding that rounded, round serifs are more friendly, while the square, slab serifs are more businesslike, i.e. more official. By analyzing the very form of the typeface, it was concluded that thinner strokes are more delicate, gentle, feminine, while thicker strokes are strong, aggressive and masculine (White, 1988; Baylis, 1955), and that smoother flowing strokes with longer ascending and descending strokes give a childlike and friendly atmosphere (Sassoon, 1993). None of the authors mentioned above explains why these typefaces convey these impressions (Mackiewicz and Moeller, 2004). A lot of previous research has been initiated by researchers who do not have academic experience related to typeface design and thus do not have an adequate and professional understanding of typography. This can affect the very setting of the research and its analysis, because due to the lack of understanding of the differences in the formal attributes of each typeface, from weight, skeleton, to the shape and style of the serif.

Recent research (Dyson, 2011; Beier and Larson, 2010; Morris et al, 2002), freed from the technical limitations of the pre-digital design era, can design and control (un)desired variables on a test stimulus, specific to given research.

\section{RESEARCH PROBLEM AND RESEARCH QUESTION}

Based on the review of existing research that attempts to quantify the psychological effects of typographic design, it can be concluded that most research on typography has dealt only with legibility. Typography, in itself, was not considered a semiotic model. In Thames and Hudson's Handbook of Typography, first published in 1980, McLean (Van Leeuwen, 2006) says that "to a very limited extent, typefaces can help express feelings or moods that are consistent with the meaning of the word," but for the most part "typefaces and calligraphic writing are abstract arts"(van Leeuwen, 2006).

Several empirical studies have directly investigated the relationship between typefaces and response. Tantillo, DiLorenzo-Ais and Madison (Rowe, 1982) investigated the influence of different typeface style on selected impressions (e.g., happy/sad and young/old) and found numerous differences between sansserif and serif typefaces while, in a similar study Rowe (Rowe, 1982) found very little difference. Although each of these studies made a worthy initial effort, these studies failed to research the causes of typefaces that have a representative range of design features. This research has also neglected a whole range of responses.

Certain characteristics specific to typeface design leave different impressions on observers, but here a research problem arises in which we cannot see which specific or universal characteristics of typeface affect our perception of the typeface personality itself, and linking it to certain personality attributes. A common problem that has arisen in previous research is that typefaces vary in many variables, and at the same time differ in width, weight, contrast, and skeleton. Therefore, it is difficult to determine specifically which universal and specific characteristics of the typeface affect the very impression of the typeface.

Based on this isolated research problem, we can form a research question:

- $\quad \mathrm{RQ}$ : To what extent and in what way the typeface weight as a factor affects the personality of the typeface?

Guided by this question, we start from two hypotheses:

- $\quad \mathrm{H} 1$ : Based on the estimates of the typeface personality attributes, it is possible to single out the specific typeface personality attributes that are related to the weight variable of the typeface.

- $\quad \mathrm{H} 2$ : Based on the weight variable of the typeface, it is possible to single out specific typeface personality attributes that describe the best and the worst specific typeface weight. 


\section{METHOD}

For the purposes of the research, stimuli were designed with the help of which hypotheses were tested in an experiment with the subjects.

\subsection{Subjects}

Participants in this research are a group of 60 students from the Faculty of Technical Sciences. In preliminary research (Žarko and Nedeljković, 2014), it was noted that there are no significant differences in assessments of the typeface personality attributes between male and female subjects, regardless of whether they are of graphic profession or laymen, so these factors were neglected in this study.

\subsection{Stimuli}

A string of letters, 'Hafonurmtgesbiv', was formed for testing purposes. This string was taken in order not to make any form of suggestion related to the content of the text, while the selection of letters that make up the string contains all the important forms of letters, by which typefaces can be recognized and differentiated.

\subsubsection{Stimulus design}

A prototype of a string of letters is formed, which varies only according to the typeface weight. In this way, one specific characteristic is isolated and its influence on perception will be monitored.

This prototype is defined according to Adrian Frutiger's model (Frutiger, 1998; Frutiger, 2009) of the "common skeleton", which represents a neutral letter shape because its properties are identical to the properties of the fonts used. Frutiger used eight popular fonts (Garamond, Baskerville, Bodoni, Excelsior, Times, Palatino, Optima and Helvetica) in his model. The "common skeleton" was obtained as a crosssection of all the layered fonts used.

The prototype, for the purposes of this research, was formed from Lineal (linéales) typefaces, according to the Vox - Atyp/ classification, where Franklin Gothic was taken as the representative of the Grotesque group; Helvetica was taken for Neo-Grotesque; Futura was taken for Geometry and Gill Sans was taken as Humanistic (Figure 1).

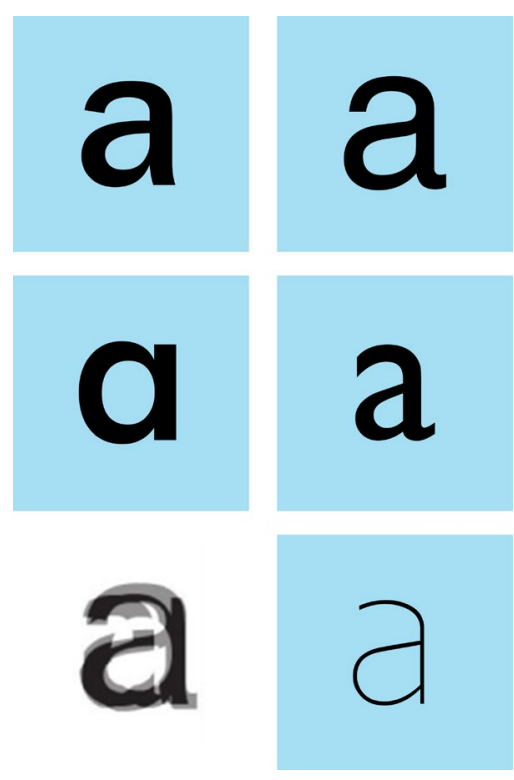

Figure 1: Designing a stimulus based on Frutiger's "common skeleton" model

This string was designed in the program FontLab Studio 5.1 using the option Multiply Master for 10 different typeface weights that follow Panose classification and go in the following order: Ultra Light, Thin, Light, Book, Regular, Medium, Bold, Heavy, Black and Extra Black (Figure 2). 


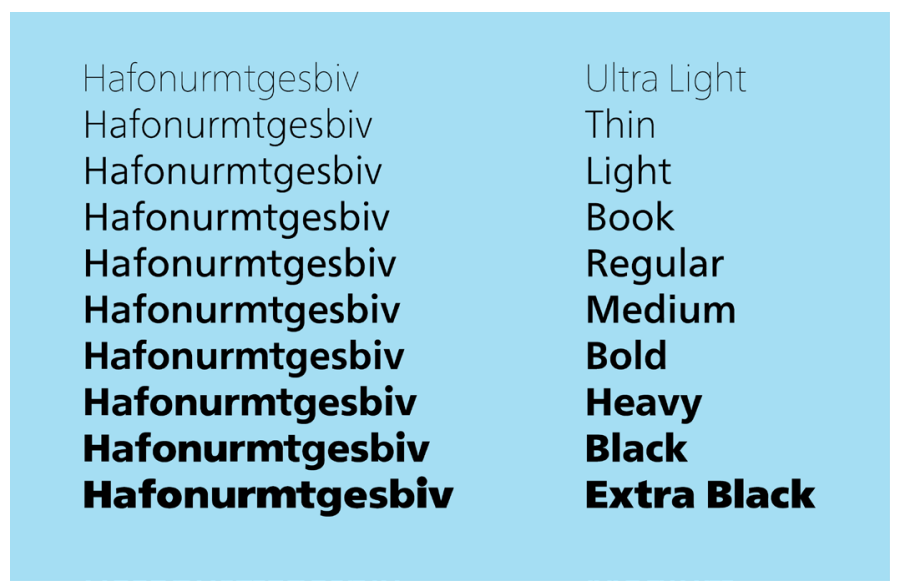

Figure 2: Stimulus model created for 10 different typeface weights

Panose is a classification system for visual attributes of type only. It was originally developed by Benjamin Bauermeister. The premise of Panose is that, by determining the characteristics of the font according to this system, we can identify the closest font match in the group.

The families of the typeface are described with two main characteristics: the manuscript type and the genre type. There are four main categories of manuscript type: Latin, Kanji, Hebrew, and "etc.", which encompasses all fonts that are not included in the first three categories. Genres further classify fonts within the manuscript type. Latin fonts are subclassified as "text", "decorative", "handwritten" or "symbols".

The Latin category represents most Western fonts. Within this family, the font is described using ten digits. The first specifies a subcategory (text, decorative, handwritten, or symbol), and the remaining nine digits indicate a number of additional attributes. For each of these attributes, a number is used to describe a feature. They are predefined in the Panose system. For example, there are fifteen options for a serif attribute. Some of them are: 0 - any, 1 - does not match, 2 - round (cove), 3 - blunt round, 4 rectangular round, 5 - blunt rectangular round. This similar division applies to all nine features. There are thirteen options for the character brightness attribute. 0 - any, 1 - do not match, 2 -Very Light, 3 - Light, 4 - Thin, 5 - Book, 6 - Medium, 7 - Demi, 8 - Bold, 9 - Heavy, 10 - Black n 11 - Extra Black.

In order to create a functional stimulus model for ten typeface weights, it was necessary to make additional perceptual adjustments, however, these methods do not represent a scientific principle in which all character strokes change according to the same mathematical formula.

In order to maintain the same level of contrast of strokes that is predefined in the skeleton, all strokes must have the same weight. However, when weight is added in this way, certain letters, such as "e", " $a$ " and "s", will be congested and closed in the interior. Accordingly, the added weight may not be the same for all letters. The next problem that arises is related to horizontal and vertical strokes. To make vertical and horizontal strokes look equal in weight, horizontal strokes should be lighter in weight than vertical strokes. This problem is best seen with the letter " $H "$ ". This is a consequence of our perceptual understanding, where we do not see all shapes and forms in their mathematically correct dimensions (Gates, 1969; Beier, 2013).

\subsubsection{Binary code matrix analysis}

The validity of the designed stimuli was further tested through digital image analysis in digital image processing software, ImageJ. Ratio and range validation were measured using mean grey value and structural similarity analysis - SSIM (The Structural Similarity Index).

\subsubsection{Mean grey value}

The analysis of the mutual relationship between the ten different typeface weights was done by determining their mean grey value. Mean grey value analysis is often used during the analysis of raster digital images. The advantage of this procedure is image segmentation, as well as limiting the influence of filters in the very process of image processing. The mean grey value is defined as the sum of the intensity values of all pixels present in the image divided by the total number of pixels. The formula used to calculate the value of the mean grey is (Nedeljković et al, 2012): 


$$
P_{\text {avg }}=\frac{1}{M \times N} \sum_{i=1}^{M} \sum_{j=1}^{N} I_{m a t}(i, j)
$$

where $\mathrm{M}$ and $\mathrm{N}$ represent the number of rows and columns digitized, Imat $(i, j)$ are mean grey values on position $(i, j)$.

Ten measuring samples with the dimensions of $2262 \times 394$ pixels with the presented string of letters 'Hafonurmtgesbiv' were created. The results of mean grey measurements are given in Table 1.

Table 1: Mean grey value

\begin{tabular}{|c|c|c|c|}
\hline & Mean grey value & \% of decrease of the mean grey value & Std. Dev \\
\hline Ultra Light & 249,70 & $0 \%$ & 34,86 \\
\hline Thin & 243,85 & $-2 \%$ & 51,13 \\
\hline Light & 239,47 & $-2 \%$ & 60,12 \\
\hline Book & 236,07 & $-1 \%$ & 65,96 \\
\hline Regular & 232,96 & $-1 \%$ & 70,88 \\
\hline Medium & 229,53 & $-1 \%$ & 75,76 \\
\hline Bold & 225,80 & $-2 \%$ & 80,51 \\
\hline Heavy & 221,10 & $-2 \%$ & 85,93 \\
\hline Black & 216,61 & $-2 \%$ & 90,59 \\
\hline Extra Black & 209,82 & $-3 \%$ & 96,76 \\
\hline
\end{tabular}

\subsubsection{Structural similarity analysis SSIM}

After the analysis of the mean grey value, using the same measurement samples, the analysis of structural similarity (SSIM) was conducted. SSIM measures the similarity between two images using three essential factors: brightness, contrast, and structure. The SSIM index is calculated through the formula (Wang et al., 2003):

$\operatorname{SSIM}(x, y)=\frac{\left(2 \mu_{x} \mu_{y}+c_{1}\right)\left(2 \sigma_{x y}+c_{2}\right)}{\left(\mu_{x}^{2}+\mu_{y}^{2}+c_{1}\right)\left(\sigma_{x}^{2}+\sigma_{y}^{2}+c_{2}\right)}$

where $x, y$ are the images on which we examine similarity, $\mu x$ - the average value of $x ; \mu y$ - the average value of $\mathrm{y} ; \sigma_{x}^{2}$ - variance of $\mathrm{x} ; \sigma_{y}^{2}$ - variance of $\mathrm{y} ; \sigma_{\mathrm{xy}}$ - covariance of $\mathrm{x}$ and $\mathrm{y} ; \mathrm{c}_{1}$ and $\mathrm{c}_{2}-$ are variables that serve to stabilize the negative denominator in the fraction.

The $\operatorname{SSIM}$ index satisfies the symmetry condition $\operatorname{SSIM}(x, y)=\operatorname{SSIM}(y, x)$. The $\operatorname{SSIM}$ index result is represented as a decimal value from -1 to 1 . A value of 1 is only possible in the case of two identical data sets. Ten measuring samples of the letter string 'Hafonurmtgesbiv' with different typeface weight were compared with each other. The results obtained in this way show how different a specific typeface weight is compared to the others (Table 2).

Table 2: SSIM index value

\begin{tabular}{|c|c|c|c|c|c|c|c|c|c|c|}
\hline & Ultra Light & Thin & Light & Book & Regular & Medium & Bold & Heavy & Black & $\begin{array}{c}\text { Extra } \\
\text { Black }\end{array}$ \\
\hline Ultra Light & 1 & $/$ & $/$ & $/$ & $/$ & $/$ & $/$ & $/$ & $/$ & $/$ \\
\hline Thin & 0,956 & 1 & $/$ & $/$ & $/$ & $/$ & $/$ & $/$ & $/$ & $/$ \\
\hline Light & 0,953 & 0,955 & 1 & $/$ & $/$ & $/$ & $/$ & $/$ & $/$ & $/$ \\
\hline Book & 0,952 & 0,952 & 0,950 & 1 & $/$ & $/$ & $/$ & $/$ & $/$ & $/$ \\
\hline Regular & 0,950 & 0,950 & 0,950 & 0,952 & 1 & $/$ & $/$ & $/$ & $/$ & $/$ \\
\hline Medium & 0,950 & 0,950 & 0,949 & 0,947 & 0,948 & 1 & $/$ & $/$ & $/$ & $/$ \\
\hline Bold & 0,948 & 0,948 & 0,947 & 0.946 & 0,947 & 0,947 & 1 & $/$ & $/$ & $/$ \\
\hline Heavy & 0,943 & 0,943 & 0,944 & 0,945 & 0,945 & 0,947 & 0,949 & 1 & $/$ & $/$ \\
\hline Black & 0,942 & 0,942 & 0,942 & 0,942 & 0,942 & 0,943 & 0,943 & 0,946 & 1 & $/$ \\
\hline Extra Black & 0,935 & 0,935 & 0,936 & 0,936 & 0,936 & 0,937 & 0,940 & 9,40 & 0,941 & 1 \\
\hline
\end{tabular}




\subsection{Test instrument}

20 typeface personality attributes were examined for 10 typeface weights of the string 'Hafonurmtgesbiv'. Typeface personality attributes consist of 20 descriptors collected from previous research (Brumberger, 2003b; Davis and Smith, 1933; Henderson, 2004; Mackiewicz and Moeller, 2004; Nedeljković et al, 2012; Rowe, 1982): Cheap, Cold, Reliable, Dignified, Elegant, Feminine, Formal, Friendly, Attractive, Loud, Masculine, Contemporary, Pretentious, Professional, Relaxed, Academic, Serious, Technical, Direct and Warm. They were rated on the Likert scale ranging from 1 to 7 . Subjects were not given any explanation or description of the research method, as such explanations could influence subjects' decisions to respond in a certain way.

For the purposes of the examination, a booklet was formed consisting of 10 wired pages containing the string of letters 'Hafonurmtgesbiv'. The pages were randomly shuffled so that the continuity of the typeface weight change is not obvious.

\section{RESULT ANALYSIS AND DISCUSSION}

Data collected by the conducted experiment with the subjects were analyzed using the program SPSS 20.

\subsection{Results of research with subjects}

The impact of the typeface personality attribute variable was analyzed using arithmetic means as the mean values of the subjects' estimates for all presented descriptors. Based on the results, certain rules in the perception of the typeface can be noted. As the typeface weight increases, the feeling of Femininity and Elegance is decreasing (Figure 3a). Contrary to the typeface personality attribute Feminine, it can be noted that with the increase in the typeface weight, the influence of Loudness and Masculinity typeface personality attribute increases (Figure $3 b$ ).

A similar trend was noted in typeface personality attributes Professional, Academic, Serious and Technical (Figure 4), while with the typeface personality attributes Direct and Pretentious no trend was noted (Figure 5).

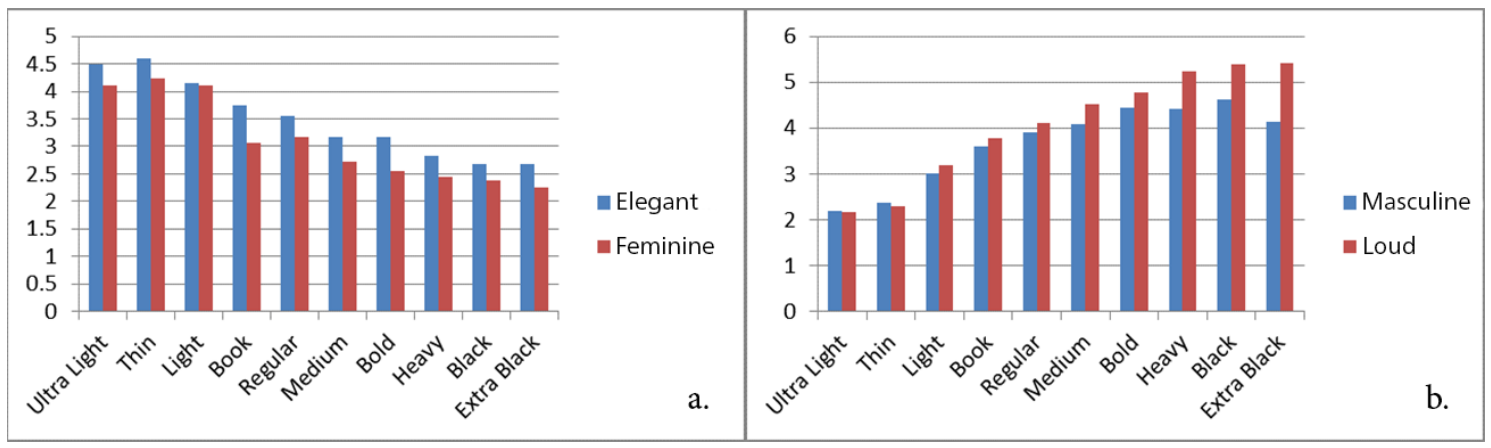

Figure 3: a. Comparison of results for the attributes Feminine and Elegant;

b. Comparison of results for the attributes Masculine and Loud

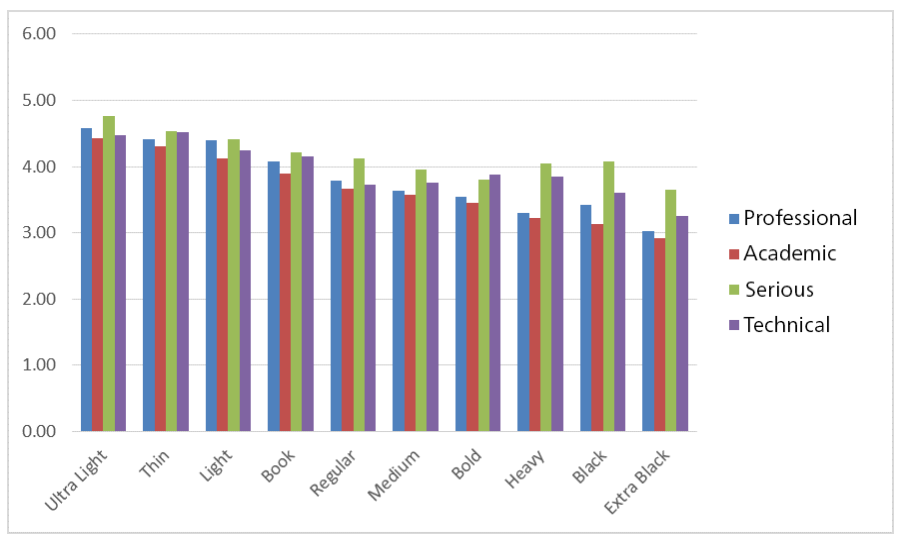

Figure 4: Comparison of results for the attributes Professional, Academic, Serious and Technical 


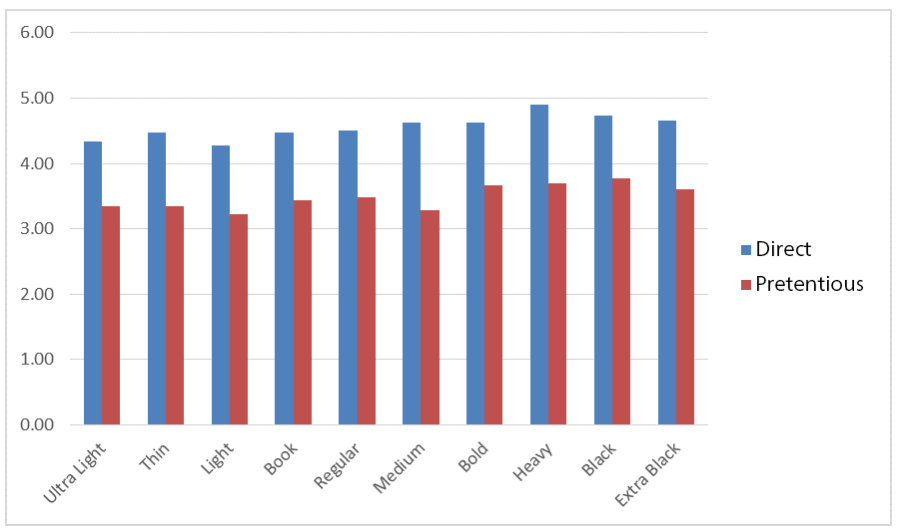

Figure 5: Comparison of results for the attributes Direct and Pretentious

\subsubsection{Factor analysis of the main components on the typeface weights}

To examine the possibility of a grouping of the weights and possible identification of common factors, a factor analysis of the main components with Varimax rotation and Kaiser normalization was performed. When Factor includes only the sums on the typeface weights, three factors stand out that describe $71 \%$ of the variance. The first factor consists of the following weights: Medium, Bold, Heavy, Black and Extra Black. The second factor consists of the following weights: Thin, Light, Book and Regular. The third factor consists of the following weight: Ultra Light. The first factor is best defined with the typeface personality attributes Loud, Masculine and Direct. It is least defined with typeface personality attributes Feminine, Elegant and Academic. The second factor is best defined with typeface personality attributes Elegant, Academic, Professional and Serious, and the least with typeface personality attribute cheap. The third factor is best defined with typeface personality attributes Professional, Formal and Elegant, and the least by the typeface personality attributes loud and masculine.

Since the distributions of subjects' responses do not follow statistical normality, a nonparametric KruskalWallis Test was used to compare several groups. Looking at the statistically significant differences, they are shown on several typeface personality attributes. The typeface personality attributes where there is statistically significant difference are Dignified, Elegant, Feminine, Formal, Friendly, Attractive, Loud, Masculine, Professional, Academic, Serious, Technical and Warm.

\subsubsection{Factor analysis of the main components on the typeface personality attributes}

Factor analysis was performed on the selected typeface personality attributes. Prior to the analysis, the possibility of applying factor analysis (KMO test and Bartlett test) was tested. According to Scree Plot (Figure 6), it is possible to single out one most important factor, or three significant ones. The first factor describes $37.12 \%$ of the variance, while all three factors together describe $66 \%$ of the variance.

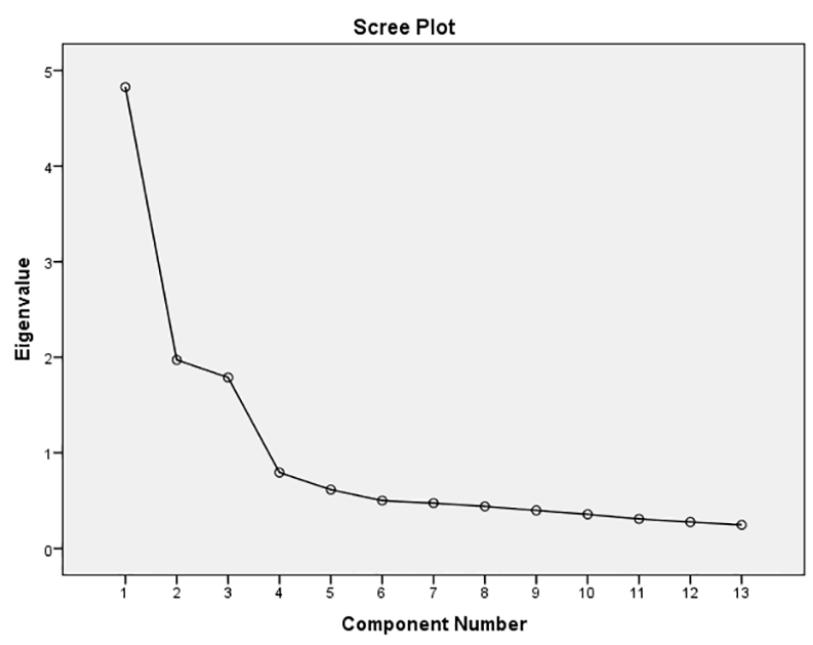

Figure 6: Scree plot of the factor analysis 
When only one factor is singled out, it is best described by the typeface personality attributes: Professional, Elegant, Formal, Dignified, Academic and Attractive. On the other hand, this factor excludes the typeface personality attributes such as Warm, Loud and Masculine. The excluded typeface personality attributes contribute very little or nothing to the factor.

When three factors are analyzed, the first factor includes the typeface personality attributes Professional, Serious, Academic, Formal, Technical and Dignified. The second factor includes the typeface personality attributes Attractive, Friendly, Elegant, Feminine and Warm. The third factor is described by the typeface personality attributes Masculine and Loud. These factors, with the typeface personality attributes that define them, follow the changing trend of the typeface weight. The most prevalent is certainly the first factor, but all three factors are statistically significant. To confirm that the isolated factors are correlated, the Promax rotation was used. Promax rotation analysis confirmed that the first and the second factors correlate statistically significantly in the positive direction $(r=0.456)$, while the third factor correlates slightly and in a negative direction.

To observe which of these factors best describes which group of typeface weights, a one-way analysis of variance was performed. The independent variable was the typeface, while the dependent variables were isolated factors. According to the applied statistical analysis, it can be said that the typeface weights differ statistically significant from each other according to each of the factors. This is shown by the size of $f$ test and significance. The Post hoc test (Sheffe's) was used to show on which factors are statistically significant differences. It is necessary to emphasize that Sheffe's post hoc test is stricter in its criteria compared to the applied one-way analysis of variance.

The first factor divides the typeface weights into four groups, within which there are no statistically significant differences, and yet it exists with the next group. The noticeable trend is that the lighter the typeface weight is, the more pronounced this factor is, while the darker typeface weight is negative. No statistically significant difference was noted for the second factor. But it is noticeable how the typeface weights are arranged according to this factor. From weights which describe it in a negative direction (Extra Black), to weights which have a highly positive trend towards it (Light). The third factor divides the typeface weights into five groups, within which there are no statistically significant differences, yet it exists with the next group. It is noticeable that the lighter the typeface weight, the more negative is the factor, while the darker typeface weight is the most pronounced is the factor.

Based on these results, it is noticeable that the first factor, which includes the typeface personality attributes Professional, Serious, Academic, Formal, Technical and Dignified, best describes the weights Ultra Light, Thin, Light and Book. The second factor, which includes the typeface personality attributes Attractive, Friendly, Elegant, Feminine and Warm, best describes the weights Ultra Light, Thin, Light, Book and Regular. The third factor, which includes the typeface personality attributes Male and Loud, best describes the weights Extra Black, Black, Heavy, Bold and Medium. It can be noted that in all three groups of factors, with the increase in the typeface weight also increases the attitude towards the given typeface personality attribute. In the case of the first factor, which includes the typeface personality attributes Professional, Serious, Academic, Formal, Technical and Dignified, these attributes are most pronounced in the weight Ultra Light and their expression decreases linearly with the increase of the weight, where it is least pronounced in the weight Extra Black. The same case is with the second factor, which includes the typeface personality attributes Attractive, Friendly, Elegant, Feminine and Warm, these are most pronounced in lighter weights and their expression decreases linearly with the increase of the weight. In case of the third factor, which includes the typeface personality attributes Masculine and Loud, the expression of these attributes increases linearly with the increase of weight, i.e. they are most pronounced in the weight Extra Black and least in the weight Ultra Light.

\section{CONCLUSION}

Researching the topic of the typeface personality, it is noticeable that the previous research on this topic are incomplete. They do not provide answers to all questions and do not take into account all possible aspects that could affect the impressions that the typefaces leave. This research was conducted with the goal to make a functional classification of the typefaces that connects all aspects of the typeface personality attributes and visual rhetoric in such a way that will be functional, understandable and accessible to the public regardless of the level of education. The results showed that the participants consistently attribute certain typeface personality attributes to certain typeface weights.

The results also confirmed the assumptions that there are significant differences between typeface personality attributes. Factor analysis of the main components, which includes only the typeface weights, 
shows that typeface weights were grouped into three factors that differentiate for each typeface weight (Figure 7). The results showed which typeface personality attributes describe each group of typeface weights. It is noticeable that the typeface weights were grouped according to the weights between which are lower percentage contrast, which matches the results of the mean grey values (Table 1 ).

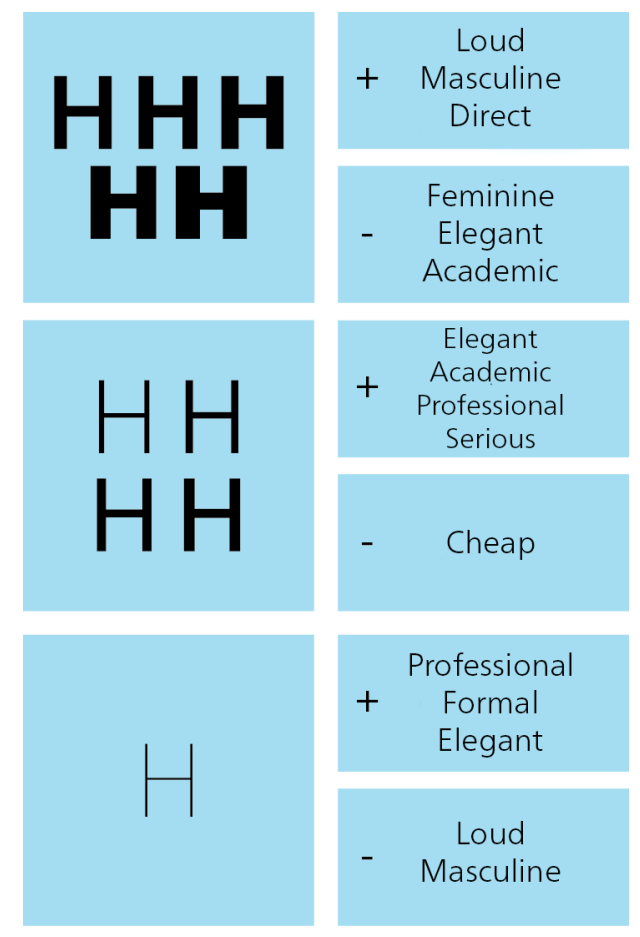

Figure 7: Results of factor analysis of the main components on the typeface weights

Besides, based on the results of factor analysis of the main components on the typeface personality attributes, it is noted that they form three groups of factors in which increasing/decreasing the typeface weight affects the increase/decrease of attitude towards the typeface personality attributes. The first factor, which consists of the typeface personality attributes Professional, Serious, Academic, Formal, Technical and Dignified, are most pronounced in the weight Ultra Light and their expression decreases linearly with increase of the weight, and it is least pronounced in the weight Extra Black. The same case is with the second factor, which includes the typeface personality attributes Attractive, Friendly, Elegant, Feminine and Warm, these attributes are most pronounced in lighter weights and their expression decreases linearly with increasing of weight. The third factor, which includes the typeface personality attribute Masculine and Loud, where the expression of these attributes increases linearly with the increase of weight, i.e. they are most pronounced in the weight Extra Black and least pronounced in the weight Ultra Light.

Based on results, we can conclude that the typeface weight is an important factor, which should be paid attention to when choosing a typeface. Proper choice of weight affects the tone and attitude towards the text itself.

A new research question arises here, to what extent and in what way does the typeface weight as a factor can affect the personality in serif letters? For this kind of research, it will be necessary to create a new set of typeface weights with serifs as an additional feature.

\section{ACKNOWLEDGMENTS}

I would like to express my gratitude and appreciation for Uroš Nedeljković whose guidance, support and encouragement have been invaluable throughout this research.

Also, I would like to thank my mother Dragica, sister Ana and my love Vladimir for their wise counsel and sympathetic ear. You are always there for me. I could not have completed this research without the support of my friends, Mitar and Borjana, who provided stimulating discussions as well as happy distractions to rest my mind outside of my research. 
Finally, many thanks to all participants that took part in the study and enabled this research to be possible.

\section{REFERENCES}

[1] Aristotele, Roberts, W. R., Bywater, I. Solmsen, F.: "Rhetoric", (Modern Library, New York, 1954.)

[2] Baylis, C.: "Trends in typefaces", Printer's ink 252 (5), 44-46, 1955.

[3] Beier, S., Larson, K.: "Design Improvements for Frequently Misrecognized Letters", Information Design Journal 18 (2), 118-137, 2010.

[4] Beier, S.: "Legibility Investigations: Controlling Typeface Variables", Praxis and Poetics: Research Through Design 2013 Conference Proceedings, (Northumbria University: New Castle, United Kingdom, 2013), pages 92-95.

[5] Benson, P.: "Writing visually: Design considerations in technical publications", Technical communication 32 (4), 35-39, 1985. doi: 10.1177/1050651994008001004

[6] Brumberger, E.: "The rhetoric of typography: The persona of typeface and text", Technical Communication 50 (2), 206-223, 2003.

[7] Brumberger, E.: "The rhetoric of typography: The awareness and impact of typeface appropriateness", Technical Communication 50 (2), 224-231, 2003.

[8] Childers T., Jass J.: "All Dressed Up with Something to Say: Effects of Typeface Semantic Associations on Brand Perceptions and Consumer Memory", Journal of Consumer Psychology 12 (2), 93-106, 2002. doi: 10.1207/S15327663JCP1202_03

[9] Davis, R. C., Smith, H. J.: "Determinants of Feeling Tone in Type Faces", Journal of Applied Psychology 17, 742-764, 1933. doi: 10.1037/h0074491

[10] Dyson, M. C.: “Do Designers Show Categorical Perception of Typefaces?", Visible Language 45 (3), 193-220, 2011

[11] Doyle J., Bottomley P.: "Dressed for the Occasion: Font-Product Congruity in the Perception of Logotype", Journal of consumer psychology 16 (2), 112-123, 2006. doi: 10.1207/s15327663jcp1602_2

[12] Frutiger, A.: "Signs and Symbols: Their Design and Meaning", (Ebury Press, London, 1998.)

[13] Frutiger A.: "Typefaces: The Complete Works", (Springer Verlag, New York, 2009.), ISBN $3764385812,9783764385811$.

[14] Gates, D.: "Lettering for Reproduction", (Watson-Guptill Publication, New York, 1969.)

[15] Henderson, P.W., Giese, J.L., Cote, J.A.: "Impression management using typeface design", Journal of Marketing 68 (4), 60-72, 2004. doi: 10.1509/jmkg.68.4.60.42736

[16] Kastl, A. J., Child, I. L.: "Emotional meaning of four typographical variables.", Journal of Applied Psychology 52 (6), 440, 1968. doi: 10.1037/h0026506

[17] Kinross, R.: "The rhetoric of neutrality", Design Issues 2 (2), 18-30, 1985. doi: 10.2307/1511415

[18] Kostelnick, C., Roberts, D.: "Designing visual language: Strategies for professional communicators", (Allyn and Bacon, Needham Heights, 1998.)

[19] Mackiewicz, J., Moeller, R.: "Why people perceive typefaces to have different personalities", Proceedings: Communication Frontiers: IPCC 2004, (IEEE: Minneapolis, USA, 2004), pages 304-313.

[20] McLean R.: "Manual of Typography", (Thames \& Hudson Ltd, London, 1980), ISBN-10: 0500670226.

[21] McCarthy, M., Mothersbaugh, D.: "Effects of typographic factors in advertising-based persuasion: A general model and initial empirical tests", Psychology \& Marketing 19 (7-8), 663-691, 2002. doi: 10.1002/mar.10030

[22] Morris, R. A., Aquilante, K., Yager, D., Bigelow, C.: "P-13: Serifs Slow RSVP Reading at Very Small Sizes, but Don't Matter at Larger Sizes", SID Symposium Digest of Technical Papers 33 (1), (Blackwell Publishing Ltd: Oxford, United Kingdom, 2002), pages 244-247.

[23] Nedeljković U., Novaković D., Pinćjer I.: "Detecting Universal Structure and Effects of Typefaces", Technical Gazette 19 (4), 709-715, 2012. doi: 10.17559/TV-20150831131738

[24] Parker, C. R., Parker R.: "Looking good in print", (Ventana Communications Group Inc, Research Triangle Park NC, 1997.)

[25] Rowe, Camille L.: "The connotative dimensions of selected display typefaces", Information design journal 3 (1), 30-37, 1982. doi: 10.1075/idj.3.1.03row

[26] Sassoon, R.: "Through the eyes of a child - Perception and type design" In Computers and typography, (IntellectBooks, Oxford UK, 1993.), pages 178-201.

[27] Shushan, R., Wright, D.: "Desktop publishing by design", (Microsoft Press, Redmond WA, 1994.) 
[28] Strizver, I.: "Type Rules: The designer's guide to professional typography", (John Wiley \& Sons, Hoboken NJ, 2001.)

[29] Trummel, P.: "Rhetoric+typography: creative interaction in modern communication", IEEE transactions on professional communication 31 (3), 124-129, 1988.

[30] Van Leeuwen, T.: "Towards a semiotics of typography", Information design journal 14 (2), 139-155, 2006. doi: 10.1075/idj.14.2.06lee

[31] Wang, Z., Simoncelli, E. P., Bovik, A. C.: "Multiscale structural similarity for image quality assessment", The Thrity-Seventh Asilomar Conference on Signals, Systems \& Computers 2003, (IEEE: Pacific Grove CA, USA, 2003)

[32] White, J.: "Graphic design for the electronic age: The manual for traditional and desktop publishing", (NYT: Watson-Guptill Publications and Xerox Press, New York, 1988.)

[33] Žarko, J., Nedeljković, U.: “Efekti svetline lika na procenu atributa ličnosti tipografskog pisma”, Zbornik radova Fakulteta tehničkih nauka 29 (12), 2577-2580, 2014.

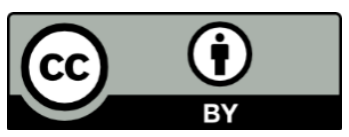

(C) 2020 Authors. Published by the University of Novi Sad, Faculty of Technical Sciences, Department of Graphic Engineering and Design. This article is an open access article distributed under the terms and conditions of the Creative Commons Attribution license 3.0 Serbia (http://creativecommons.org/licenses/by/3.0/rs/). 



\title{
KINETIC TYPOGRAPHY - FIGURATION AND TECHNOLOGY
}

\author{
Nikolina Stanić Loknar (D), Diana Bratić (D), Ana Agić \\ University of Zagreb, Faculty of Graphic Arts, Zagreb, Croatia
}

\begin{abstract}
Kinetic typography - text in motion is an animation method of characters that has a video form instead of some "static" form such as picture, poster or book. The most important element for figuration of kinetic typography is the choice of font. Furthermore, one should think about the letter cut, the size and color of the characters, and the background color on which the animation takes place. It can be created in various ways, most often using software that applies a multitude of effects to the text or letter character, creating dynamic solutions. The effects vary from the simplest such as "fade-in" and "fade-out" (entering and exiting text in and out of the frame). Static characters can expand, narrow, move slowly or rapidly, grow and change in a variety of ways to very complex ones in which the author builds an entire story or promotional video by carefully combining software capabilities. However, each software has its limitations and for this reason the kinetic typography presented in this paper is programmed using codes. In a wide range of available programming languages due to the simple interface that does not require advanced programming concepts and gives exceptional results in the field of kinetic typography, Processing was chosen. The Processing programming language is intended for generating and modifying graphics and is based on the Java programming language. The most important difference between Processing and Java is that Processing offers a simple programming interface that does not require advanced levels of programming such as classes, objects, or animations. It also allows advanced users to use them. Processing uses a variety of typography rendering approaches such as raster and vector solutions and allows typography to be programmed and displayed on the Web independently of the user's Web browser and font database. Processing enables the use of visual elements in animation, including typographic ones, by introducing interaction to the user. The user is no longer a passive observer but actively participates in the performance of the application whose final appearance is not predefined but arises from the actions of each individual user.

For the purposes of this paper, individual letters were created in a font-making program. The letters made are of various written classifications and cuts, which with their variety contribute to the attractiveness of the animation. In the creating of motion typography in this paper, the programming language Processing was used. Written program codes that manipulate words, letters, or parts of characters to create interesting visual effects for the viewer that aim to hold the viewer's attention and convey the desired message or emotion. There are no strict rules and patterns when making kinetic typography. In kinetic typography, each author determines his own rules, method of production, and there are no same solutions.
\end{abstract}

Key words: kinetic typography, Processing, coding, character

\section{INTRODUCTION}

One of the greatest inventions in human history is the letter or what it enables and that is the transmission of written words. Typography is what communication looks like. But it is almost impossible to look and read at the same time because they are different perceptions. There is beauty in the language and beauty in the way it is presented. It all started about two millennia ago. The rules of typography are centuries old, and although the technologies have changed, the goal has always remained the same: a beautiful setting in the service of a pleasant and fruitful reading experience (Felici, 2012).

With the advent of film and graphic animation, the possibility of matching text and motion emerged. Researchers at the Human Computer Interaction Institute and School of Design at Carnegie Mellon University have traced the first use of kinetic typography to the 1959 Alfred Hitchcock's 1959 film "North by Northwest." In the opening credits, type is used in a movable format. A year later, the effect was used again in "Psycho." "This work stemmed in part from a desire to have the opening credits set the stage for the film by establishing a mood, rather than simply conveying the information of the credits," researchers wrote (Lee, 2015).

Today, kinetic typography is considered as a trend in web design development. Kinetic typography implies letters in motion. It is an animation technique used to make letters shrink, expand, fly, move slowly, and change in a number of ways for the user. The effect can be simple and short with small modifications or quite complex and long lasting. The use of kinetic typography has exploded recently due to the greater use 
of the technique in web design. Kinetic typography is gaining in popularity as a background effect on websites and in web-based videos. All this was made possible by a larger broadband network and increased speed of surfing the Internet and the web. Kinetic typography is used for several reasons because it can add emphasis to a particular content. It can help convey tone and feelings. This can be an affordable option for those on a limited budget. Given the popularity of kinetic typography, today there are various tools and software that allow the creation of moving text. Professional programs with a multitude of tools are available, but also free programs that offer a wide range of tools and templates for creating interesting solutions in the field of kinetic typography. Some software is easier to use, so it is easy for beginners to master (Windowsreport, 2020).

A group of authors from the National Institute of Advanced Industrial Science and Technology (AIST), Tsukuba, Japan introduced a web-based integrated design environment named "TextAlive Online" that supports creating Kinetic Typography videos synchronized with songs available online. Experienced users create Java codes themselves and create kinetic typography while those less skilled use the templates offered (Kato et al, 2015).

In this paper we have chosen Processing because it is an open source programming language, and its environment has been built for the electronic arts and visual design community. Processing files have a .pde extension at the end of every file. They can be easily exported as Java applets and uploaded to the Internet. Also the files can be opened in Adobe Illustrator and saved as an vector .eps file which can be printed in high resolution (Ahn and Cordova, 2008). Processing is real programming. It is not some pretend language to help you get started; it has all the fundamentals and core concepts that all languages have (Shiffman, 2008).

\section{EXPERIMENTAL}

In this paper, several examples of kinetic typography made in Processing are presented. The characters are designed to simulate handwriting and follow the typographic rules in Fontlab. Fonts are generated and installed in a computer so that Processing can use them in program codes that create kinetic typography. Processing displays fonts using the .vlw font format, which uses images for each letter, rather than defining them through vector data. The loadFont() function constructs a new font and textFont() makes a font active (Reas and Fry, 2007). The Processing development environment is a simplified environment for writing computer code. All examples use the abbreviation of the name of GRID symposium and are shown below.

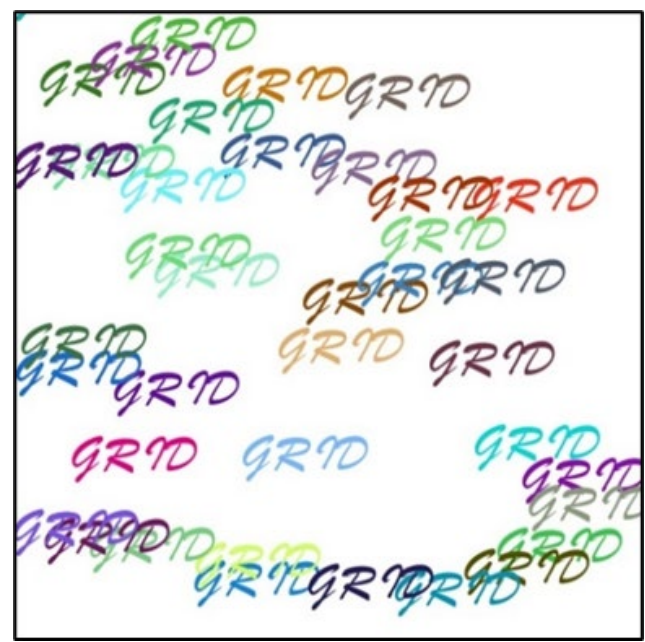

Figure 1: Sketch FrameRate 5

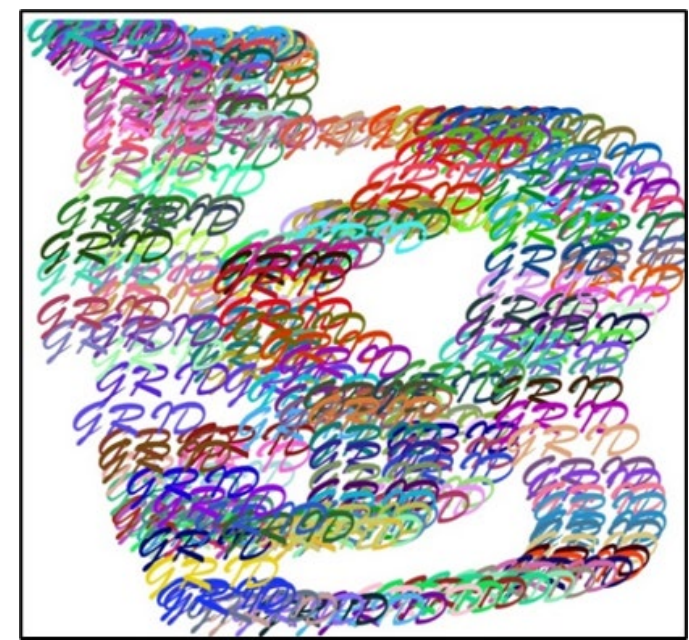

Figure 2: Sketch FrameRate 30

Example 1 shows the printing of "GRID" text in interaction with the user. Printing is repeated regardless of the movement of the mouse position on the screen. The frameRate command specifies the number of frames displayed per second. The default rate is 60 frames per second. In a figure 1, frameRate is set to 5, so that the text is clearly visible and legible. Figure 2 shows a frameRate 30, which is too high for this example because it increased the number of views in a few seconds, which significantly complicates readability and destroys the beauty of the display. The background color is white, while the text changes color with each imprint. The color range is whole RGB spectrum, i.e. a random range of valuable $R, G$, and 
B components ranging from 0 to 255 which is maximum value range in Processing. A very short program code shows an interesting solution that attracts the user's attention and keeps just in order to interactions achieved by the mousex and mousey commands. $X$ and $y$ are the values of the mouse position in the coordinate system on the screen. By moving the mouse, the user changes the values of $x$ and $y$, and in these places a imprint is made in a different color each time.

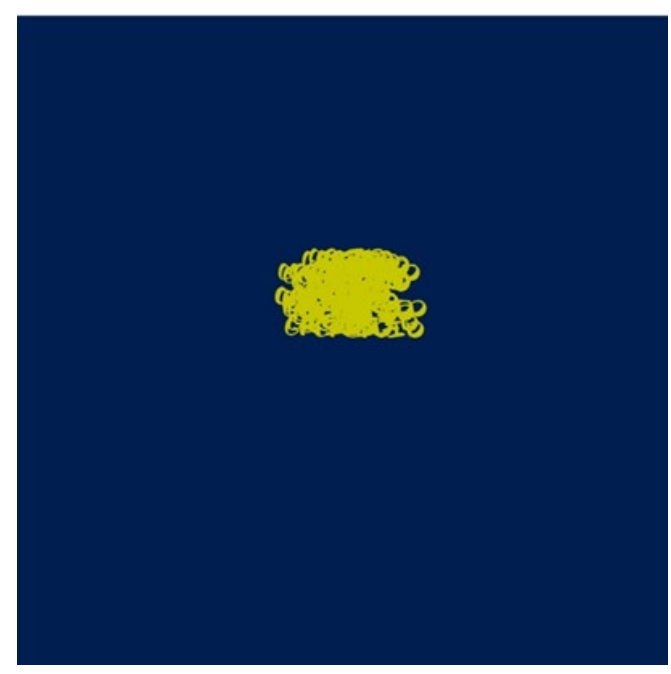

Figure 3: Sketch after click

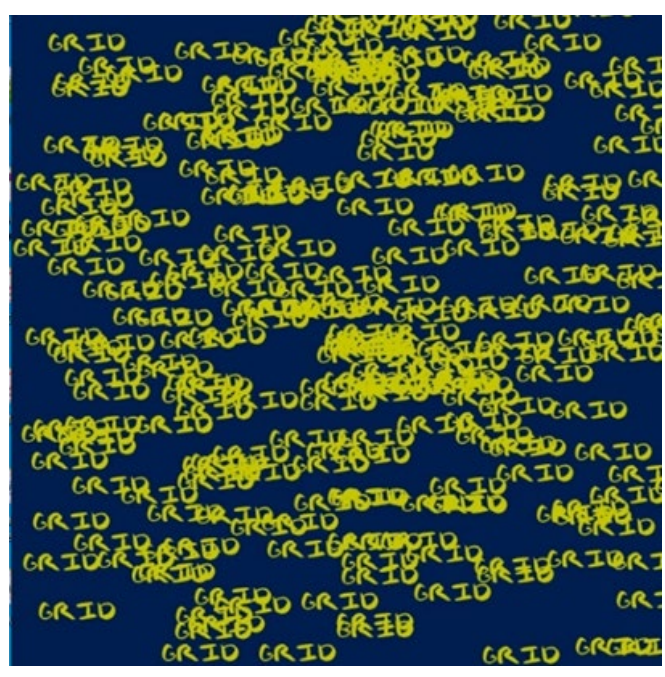

Figure 4: Sketch after four different click

Second example shows a "GRID" text printed in yellow on a blue background. A handwritten font from own font database is used. The program works in way that each mouse clicks at the position it is in, generates 50 imprints of "GRID" text which are further scattered over the entire given area on the screen. The speed and direction of each imprint is different. The difference in the directions of movement is achieved by introducing pseudo-random numbers that within the given end values determine the speed and direction of movement on the screen from the initial position of the click towards the edges. The random numbers we get from the random () function are not truly random; therefore, they are known as "pseudo-random." They are the result of a mathematical function that simulates randomness. This function would yield a pattern over time, but that time period is so long that for us, it is just as good as pure randomness (Shiffman, 2012). Figure 3 shows the moment immediately after the first mouse click where the "explosion" of imprinting begins from that position. Figure 4 shows the moment when 4 mouse clicks were made in different positions so the screen shows 200 "GRID" inscriptions scattered in all directions and moving further towards the edges until they come out of the screen and in the end only the blue background remains. This program works in interaction with the user in such a way that no matter how many times the user clicks the mouse, a new explosion of text printing is created each time. In a few seconds, all the text comes out of the sketch and only the dark blue background remains visible. This code is a bit more demanding than example 1 because the action being triggered by a mouse click, but the speed and direction of movement of the letters on the screen should be programmatically determined using the conditions in the loop. In Processing setup () is executed once when the sketch starts and draw () loops forever and ever until the user quit.

Part of the animation of the third example of kinetic typography in Processing is shown in Figures 5 and 6. Opening the sketch starts a program that has a frameRate set to 5 , which means that it displays 5 imprints of the text "GRID" in one second. The $X$ and $Y$ values that determine the position of each imprint in Sketch, are in the range from 0 to 300, and generates randomly, which is clearly visible in Figure 5.

Also, with each display of text, R G B color values are generated pseudo-randomly, which is especially emphasized in Figure 6. That's way each print has its own shade. The code execution lasts until the user click the mouse. The code defines that the mousePressed command stops the performans of the program, i.e. only the black background color is visible on the screen. Immediately after the click, the program starts running again and very fast we have a full sketch of the text "GRID" in various colors. Regarding a parameters defined pseudorandomly, each image is actually unique. And in this example, a handwritten font from its own database of monoline strokes was used. And in this example, there is an interaction with the user where he participates in image creation. 


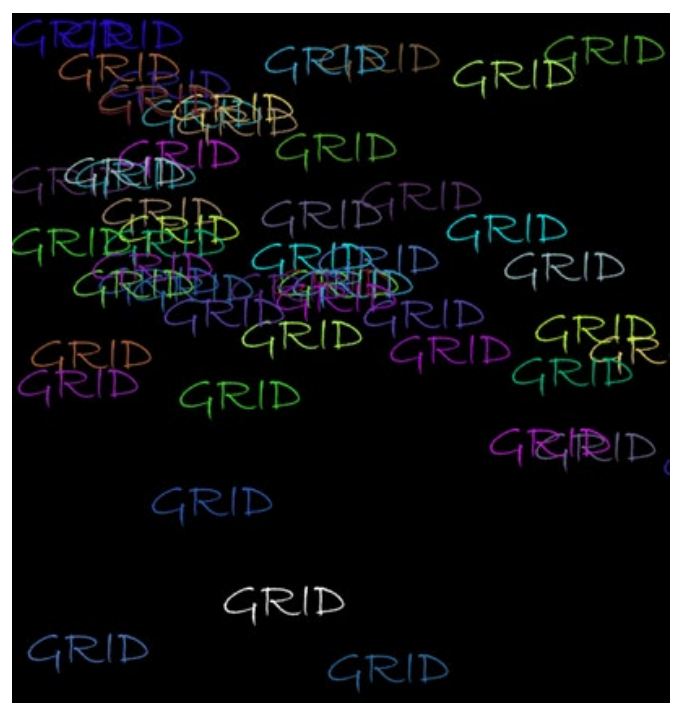

Figure 5: Sketch after start

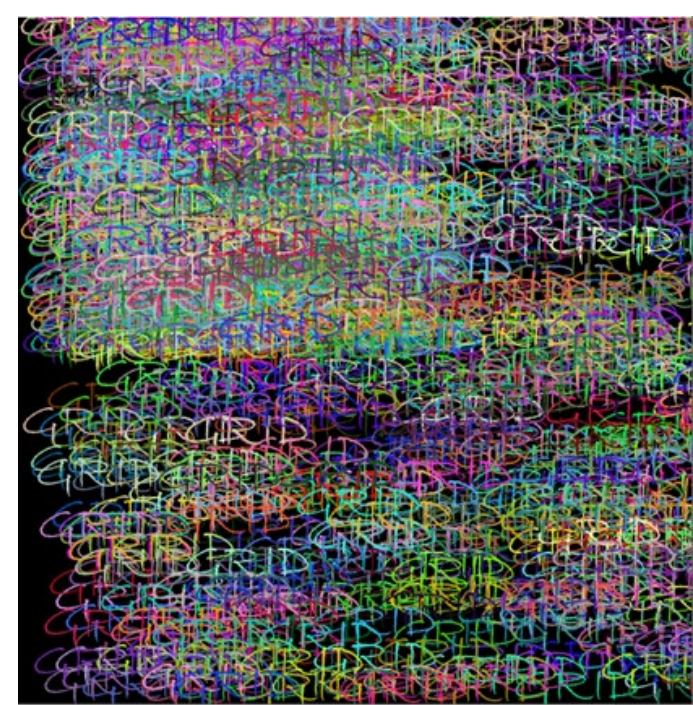

Figure 6: Sketch after few seconds

The fourth example shows a combination of computer graphics and typography in Processing. Using a for loop and Bezier curves, a rosette is programmed, and each "leaf" has its own color. In the same for loop there are also individual letter characters that form the text "GRID". In previous examples, the program understood the "GRID" text as a whole and the color or display position change, applied to all letters at once. Here each letter character has its own position, its own angle of rotation, and its own color. In this example, the dynamism is achieved by changing the color on the rosette leaves so that the impression of rotation is created which is visible in Figures 7 and 8 . The letters GRID change color quickly, so that our eyes seem to flicker which further emphasizes the dynamics and movement which really no exist. The generation of letters and rosette curves occurs at the same position.

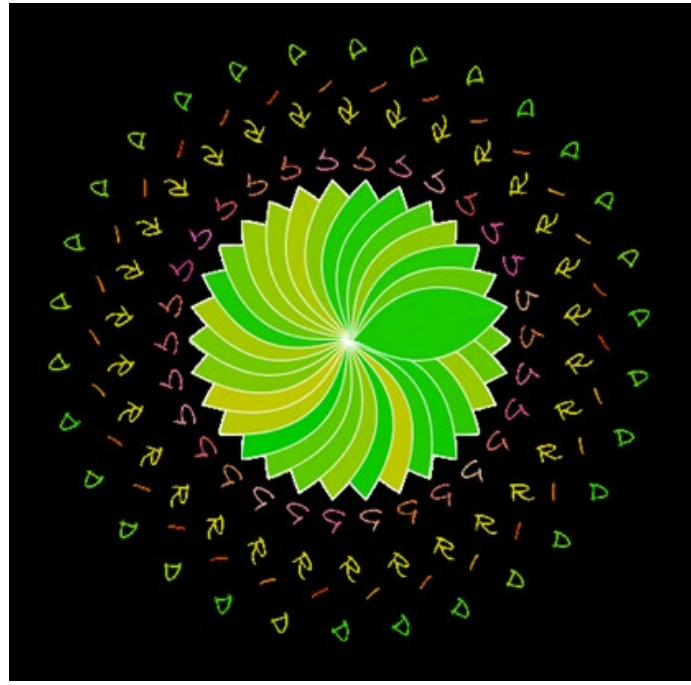

Figure 7: After start

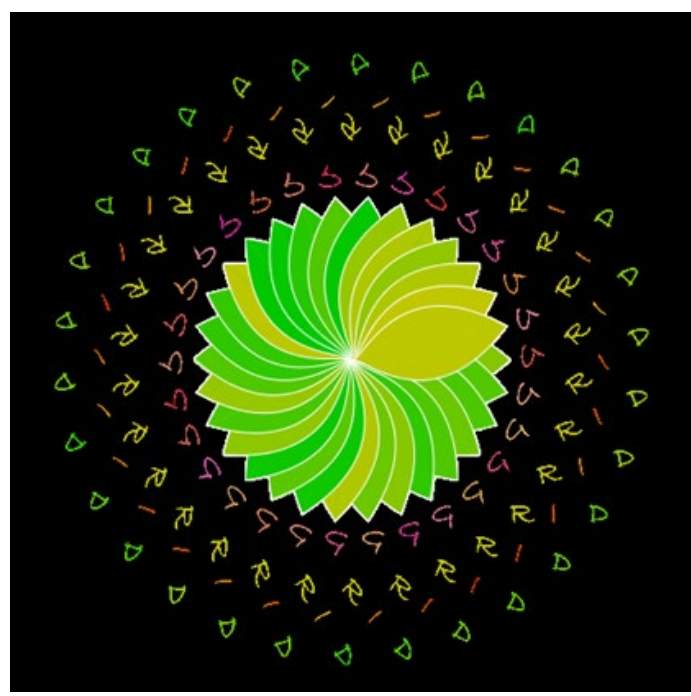

Figure 8: After few seconds

\section{DISCUSSION}

Kinetic typography programming offers unlimited possibilities of expression depending on context. In today's digital world, it is not enough to have a static display, but it is dynamism that captures the viewer's attention. In this paper, the dynamics are presented in several ways within the sketch according to the set limit values of program loops. The program affects the position of the text, color change, rotation angle, number of repetitions, speed of movement, etc. Using the Processing programming language, dynamism gets another important segment, and that is interactivity. As shown in the examples, the user becomes an 
active participant who, through his actions, generates a display in a certain way, which certainly keeps him on that website longer, which is the goal of all advertisers.

\section{CONCLUSIONS}

Processing is a programming language that offers various interactive solutions either in computer graphics or typography. Kinetic typography, i.e. text in motion, attracts the viewer's attention and keeps it much longer than a static image. This paper shows through several examples the possibilities of programming typography in motion. The use of the Processing programming language enables interactivity with the user in such a way that the user, by changing the position or clicking the mouse, on his own determines on which parts of the screen the mobile typography will be created. Likewise, the user controls the text display density which depends on the speed of the mouse movement. The introduction of random numbers increases the attractiveness of the obtained moving graphics because each mouse clicks made by the user generates different movements of letter elements on the screen. The described examples show only a small part of the possibilities provided by Processing in mobile typography programming. Such solutions contribute to the attractiveness of the content, also more impressively convey the message to consumers if they are used for marketing purposes. Mobile typography also finds its application in augmented reality with, for example, exhibits in museums, education, and entertainment.

Processing is relatively easy to learn, so even beginners with knowledge of another programming language can easily manage and with a little effort to program interesting interactive solutions either in computer graphics or typography.

\section{REFERENCES}

[1] Ahn, Y., Cordova, V.: "Type+Code Processing for Designers", (Center for Design Thinking - Maryland Institute College of Art, Maryland, 2008.), page 26.

[2] Felici, J.: "The Complete Manual of Typography, A guide to setting perfect type", (Peachpit, Berkley CA, 2012.), page 11

[3] Kato, J., Nakano, T., Goto, M.: "TextAlive: Integrated Design Environment for Kinetic Typography" Proceedings of the 33rd Annual ACM Conference on Human Factors in Computing Systems 2015. (Association for Computing Machinery: New York, New York, 2015), pages 3403-3412.

[4] Kato, J., Nakano, T., Goto, M. "TextAlive Online: Live Programming of Kinetic Typography Videos with Online Music", Proceedings of the First International Conference on Live Coding 2015,

(AIST: Tsukuba, Japan, 2015), pages 199-205.

[5] Lee, J. C., Forlizzi, J., Hudson, S. E.: "The Kinetic Typography Engine: An Extensible System for Animating Expressive Text", URL: https://www.cs.cmu.edu/ johnny/kt/dist/files/Kinetic_Typography.pdf_(last request: 2020-10-08).

[6] Reas, C., Fry, B.: "Processing: a Programming Handbook for Visual Designers and Artists", (The MIT Press Cambridge, Massachusetts, 2007.), pages 112, 702.

[7] Shiffman, D.: "Learning Processing A Beginner's Guide to Programming Images, Animation, and Interaction" (Elsevier, Burlington MA, 2008.), page 17.

[8] Shiffman, D.: "The Nature of Code: Simulating Natural Systems with Processing", (The Nature of Code, Boston MA, 2012.), page 7.

[9] Stanojevic, M.: "Best kinetic typography software", URL: https://windowsreport.com/kinetictypography-software/ (last request: 2020-10-10).

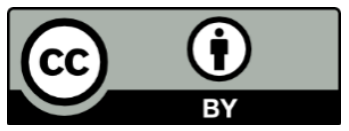

(C) 2020 Authors. Published by the University of Novi Sad, Faculty of Technical Sciences, Department of Graphic Engineering and Design. This article is an open access article distributed under the terms and conditions of the Creative Commons Attribution license 3.0 Serbia (http://creativecommons.org/licenses/by/3.0/rs/). 



\title{
AI DRIVEN OCR: RESOLVING HANDWRITTEN FONTS RECOGNIZABILITY PROBLEMS
}

\author{
Diana Bratić (iD), Nikolina Stanić Loknar \\ University of Zagreb, Faculty of Graphic Arts, Zagreb, Croatia
}

\begin{abstract}
Optical Character Recognition (OCR) is the electronic or mechanical conversion of images of typed, handwritten, or printed text into machine-encoded text. Advanced systems are capable to produce a high degree of recognition accuracy for most technic fonts, but when it comes to handwritten forms there is a problem occur in recognizing certain characters and limitations with conventional OCR processes persist. It is most pronounced in ascenders $(k, b, l, d, h, t)$ and descenders $(g, j, p, q, y)$. If the characters are linked by ligatures, the ascending and descending strokes are even less recognizable to the scanners. In order to reduce the likelihood of a recognition error, it is a necessary to create a large database of stored characters and their glyphs. Feature extraction decomposes glyphs into features like lines, closed loops, line direction, and line intersections. A Multilayer Perceptron (MLP) neural network based on Back Propagation Neural Network (BPNN) algorithm as a method of Artificial Intelligence (Al) has been used in text identification, classification and recognition using various methods: image pattern based, text-based, mark-based etc. Also, the application of Al generates of a large database of different letter cuts, and modifications, and variation of the same letter character structure. For this purpose, the recognizability test of handwritten fonts was performed. Within main group, subgroups of independent letter characters and letter characters linked by ligatures are created, and reading errors were observed. In each subgroup, four different font families (bold stroke, alternating stroke, monoline stroke, and brush stroke) were tested. In subgroup of independent letter characters, errors were observed in similar rounded lines such as the characters a, and e. In the subgroup of letter characters linked by ligatures, errors were also observed in similar rounded lines such as the letter characters $a$ and $e, m$ and $n$, but also in ascenders $b$ and $I$, and descenders $g$ and $q$. Furthermore, seven letter cuts were made from each basic test letters, and up to are thin, ultra-light, light, regular, semi-bold, bold, and ultra-bold, and stored in the existing EMNIST database. The scanning test was repeated, and recently obtained results showed a decrease in the deviation rate, i.e. higher accuracy. Reducing the number of deviations shows that the neural network gives acceptable answers but requires creation of a larger database within about 56,000 different characters.
\end{abstract}

Key words: OCR, handwritten font, letter character, artificial intelligence, MLP BPNN arhitecture

\section{INTRODUCTION}

Handwritten script typefaces are based upon the varied and often fluid stroke created by handwriting or software. Thanks to the available digital technology, there are countless variants of handwritten fonts today. Because of their diversity, the are interesting to designers and are increasingly used. However, the problem arises with their optical readability and recognizability. Handwriting recognition is ability of a computer to receive and interpret intelligible handwritten input from different sources (Grzelak et al, 2019).

Many authors point to the problem of recognizability of handwritten fonts or some specific letter characters significant for certain languages and try to offer different Al solutions for problem resolving.

Rao and his team (2016) in their study presents a modified back propagation-based method for optical character recognition. Authors in their proposed method successfully computes error rate with promising accuracy of $100 \%$ OCR.

Phangtriastu, Harefa and Tanoto (2017) uses several techniques as a comparison for some extracted features, such as zoning algorithm, projection profile, Histogram of Oriented Gradients (HOG) and combination of those feature extractions. Their experiment achieves the highest accuracy of $94.43 \%$.

Desai, Bhavikatti and Patil (2013) proposed approach for handwriting recognition system processing, segmentation, and feature extraction with neural network for character recognition with $99.9 \%$ accuracy for separate character written documents, and $70-80 \%$ accuracy for handwriting text.

Maitra, Bhattacharya and Parui (2015) described Convolutional Neural Network (CNN) based common approach to handwritten character recognition of multiple scripts with accuracy between 95.6 and $99.1 \%$. Also, Zheng, Iwana and Uchida (2019) explained a mining the displacement of max pooling for text 
recognition. D'Souza and Mascarenhas in their paper (2018) proposed an idea to recognize offline Handwritten Mathematical Expression and symbols (HME) using CNN for classification.

Driss et al. (2017) made a comparison study between MLP and Convolutional Neural Network models for character recognition.

As can be seen from a brief overview of the researches, an Artificial Neural Network (ANN) is commonly used for searching for dependencies between data that are not in a linear correlation, and yet can be combined into one complex input set. Generally, a network processes a set of input data in parallel, and different priorities and assigned to these values, which can be changed and processed differently according to a specific scheme during learning (Grzelak et al, 2019).

The main goal of this research was to determinate AI driven OCR system effectiveness in recognizability of handwritten fonts. The research was based of adding two main sets of letters in existing the EMNIST dataset of letters.

To the purpose of this research a Multilayer Perceptron (MLP) neural network based on Back Propagation Neural Network (BPNN) algorithm has been used. MLP is a class of feedforward artificial neural network (ANN). An MLP consist of at least three layers of nodes: an input layer, a hidden layer, and an output layer. Except for the input nodes, each node is a neuron that uses a nonlinear activation function.

The results obtained from the experiment are summarized and presented with concluding remarks and recommendations for further research.

\section{METHODS}

In order to make the methodology of making this paper clearer, the basic concepts related to typography will be briefly explained.

Classification in typography is very important for easier navigation in many different letter cuts, so the letters are divided into several basic forms.

A certain stylization of a letter is called a letter cut. The letter cut is classified as thin, ultra-light, light, regular, semi-bold, bold, and ultra-bold according to the ration of whiteness and blackness.

In letter characters, common forms can be found, i.e. elements that form one letter character. Different letter characters have different element connections, and the basic move, ascending line or move, and descending line or move are some of them. Ascender or ascending move is the part on the current letters $k, b, l, d, h, t$ that rises above the line defined by the current letters $a, c, e, m, n$, etc. A descender of descending stroke is a part of a letter character that descends below the basic letter line (e.g. g, j, p, q, y).

Only handwritten forms will be used in this paper due to their anatomy which is a problem in optical character recognition.

This research was carried out using artificial neural network and machine learning. For this purpose, was used the EMNIST dataset of letters (Cohen et al, 2017). In first step specific dataset of different examples of handwriting test photos is defined. This dataset consists set of English letter characters from A to Z. It contains separated letter characters for every font type of each test group.

Within the group of handwritten forms, two subgroups of fonts were created, namely independent letter characters and letter characters linked by ligatures. Furthermore, four types of font families were created in each basic cut group: bold stroke, alternating stroke, monoline stroke, and brush stroke. Finally, seven letter cuts were made for each of the four font families: thin, ultra-light, light, regular, semi-bold, bold, and ultra-bold. Thus, for testing for each group, 28 fonts were made, i.e. 56 overall. All tested fonts are made by software Fontographer 5.2.

New created letter characters have been added to existing the EMNIST dataset, and using MLP BPNN architecture, the effectiveness of recognition of added characters in the prepared dataset was measured. All calculations were made in Statistica 13.5.0.17.

\subsection{Handwritten fonts with independent letter characters}

First subgroup of tested fonts was handwritten independent letter characters in four basic font families (bold stroke, alternating stroke, monoline stroke, and brush stroke) (Table 1). 
Table 1: An overview of handwritten fonts with independent letter characters

\begin{tabular}{|l|l|l|l|l|}
\hline & \multicolumn{1}{|c|}{ Bold stroke } & \multicolumn{1}{|c|}{ Alternating stroke } & \multicolumn{1}{|c|}{ Monoline stroke } & \multicolumn{1}{c|}{ Brush stroke } \\
\hline Thin cut & Tangerine Thin & Modeschrift Thin & Daily Life Thin & Konichiwa Thin \\
\hline Ultra-Light cut & $\begin{array}{l}\text { Tangerine Ultra- } \\
\text { Light }\end{array}$ & $\begin{array}{l}\text { Modeschrift Ultra- } \\
\text { Light }\end{array}$ & $\begin{array}{l}\text { Daily Life Ultra- } \\
\text { Light }\end{array}$ & $\begin{array}{l}\text { Konichiwa Ultra- } \\
\text { Light }\end{array}$ \\
\hline Light cut & Tangerine Light & Modeschrift Light & Daily Life Light & Konichiwa Light \\
\hline Regular cut & Tangerine Regular & $\begin{array}{l}\text { Modeschrift } \\
\text { Regular }\end{array}$ & Daily Life Regular & Konichiwa Regular \\
\hline Semi-Bold cut & $\begin{array}{l}\text { Tangerine Semi- } \\
\text { Bold }\end{array}$ & $\begin{array}{l}\text { Modeschrift Semi- } \\
\text { Bold }\end{array}$ & Daily Life Semi-Bold & $\begin{array}{l}\text { Konichiwa Semi- } \\
\text { Bold }\end{array}$ \\
\hline Bold cut & Tangerine Bold & Modeschrift Bold & Daily Life Bold & Konichiwa Bold \\
\hline Ultra-Bold cut & $\begin{array}{l}\text { Tangerine Ultra- } \\
\text { Bold }\end{array}$ & $\begin{array}{l}\text { Modeschrift Ultra- } \\
\text { Bold }\end{array}$ & Daily Life Ultra-Bold & $\begin{array}{l}\text { Konichiwa Ultra- } \\
\text { Bold }\end{array}$ \\
\hline
\end{tabular}

Regarding list of handwritten fonts with independent letter characters, tested samples are presented in Figure 1.

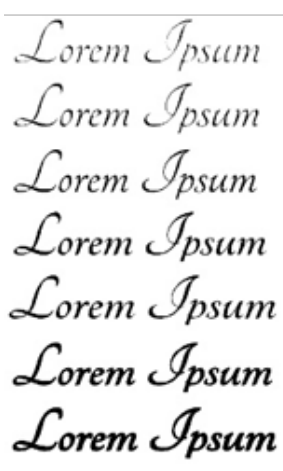

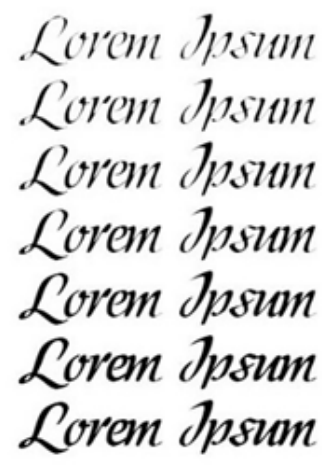

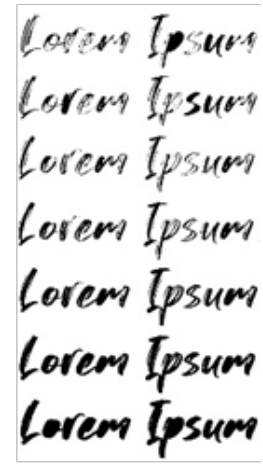

Figure 1: Sample of tested handwritten fonts with independent letter characters

\subsection{Handwritten fonts with letter characters linked by ligatures}

Second subgroup of tested fonts was handwritten letter characters linked by ligatures in four basic letter cuts (bold stroke, alternating stroke, monoline stroke, and brush stroke (Table 2).

Table 2: An overview of handwritten fonts with letter characters linked by ligatures

\begin{tabular}{|l|l|l|l|l|}
\hline & \multicolumn{1}{|c|}{ Bold stroke } & \multicolumn{1}{|c|}{ Alternating stroke } & \multicolumn{1}{|c|}{ Monoline stroke } & \multicolumn{1}{c|}{ Brush stroke } \\
\hline Thin cut & Brightlast Thin & Shelley LTS Thin & Abecedary Thin & Someone Thin \\
\hline Ultra-Light cut & Brightlast Ultra-Light & $\begin{array}{l}\text { Shelley LTS UItra- } \\
\text { Light }\end{array}$ & $\begin{array}{l}\text { Abecedary Ultra- } \\
\text { Light }\end{array}$ & $\begin{array}{l}\text { Someone Ultra- } \\
\text { Light }\end{array}$ \\
\hline Light cut & Brightlast Light & Shelley LTS Light & Abecedary Light & Someone Light \\
\hline Regular cut & Brightlast Regular & Shelley LTS Regular & Abecedary Regular & Someone Regular \\
\hline Semi-Bold cut & Brightlast Semi-Bold & $\begin{array}{l}\text { Shelley LTS Semi- } \\
\text { Bold }\end{array}$ & Abecedary Semi-Bold & $\begin{array}{l}\text { Someone Semi- } \\
\text { Bold }\end{array}$ \\
\hline Bold cut & Brightlast Bold & Shelley LTS Bold & Abecedary Bold & Someone Bold \\
\hline Ultra-Bold cut & Brightlast Ultra-Bold & $\begin{array}{l}\text { Shelley LTS Ultra- } \\
\text { Bold }\end{array}$ & $\begin{array}{l}\text { Abecedary Ultra- } \\
\text { Bold }\end{array}$ & $\begin{array}{l}\text { Someone Ultra- } \\
\text { Bold }\end{array}$ \\
\hline
\end{tabular}

Regarding list of handwritten fonts with letter characters linked by ligatures, tested samples are presented in Figure 2. 

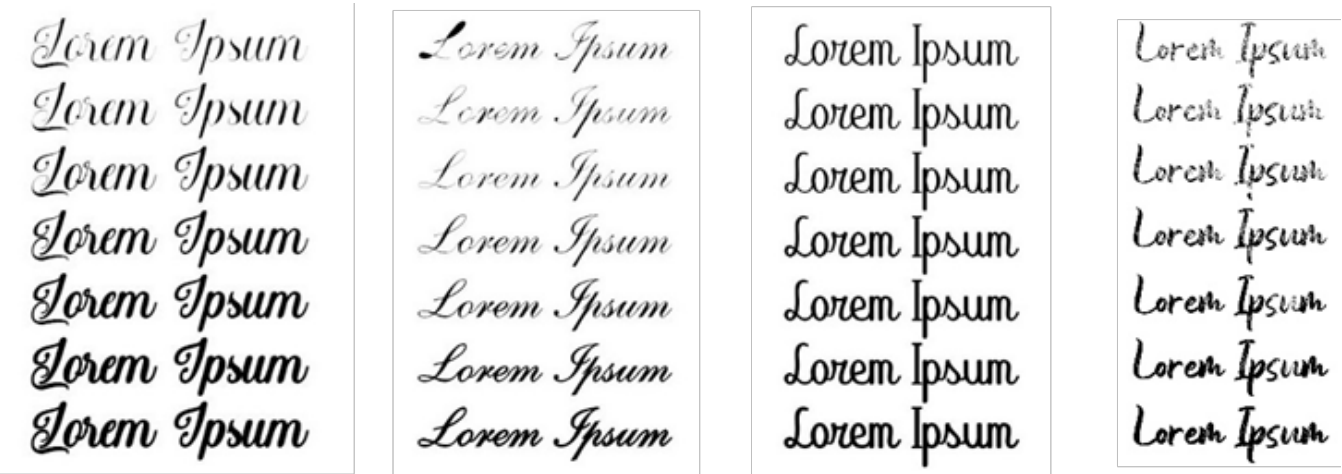

Figure 2: Sample of tested handwritten fonts with letter characters linked by ligatures

\subsection{Artificial intelligence and OCR}

A Multilayer Perceptron (MLP) is a class of feedforward Artificial Neural Network (ANN) (Rao et al, 2016). An MLP consist multiple layers of perceptrons with threshold activation, i.e. a least three layers of nodes: an input layer, a hidden layer and output layer. Except for the input nodes, each node is a neuron that uses a nonlinear activation function. MLP utilizes a supervised learning technique call Back Propagation for training.

The algorithm used in this experiment is Back Propagation Network (BPNN). This algorithm generates an appropriate model that can be used to map the output based on the input data (Jafri and Arabnia, 2009). Figure 3 shows three layers of BPNN structure for this experiment. The input features are based on the feature extraction methods. The number of hidden nodes is obtained from input features and output total classes in experiment, i.e. 56 classes.

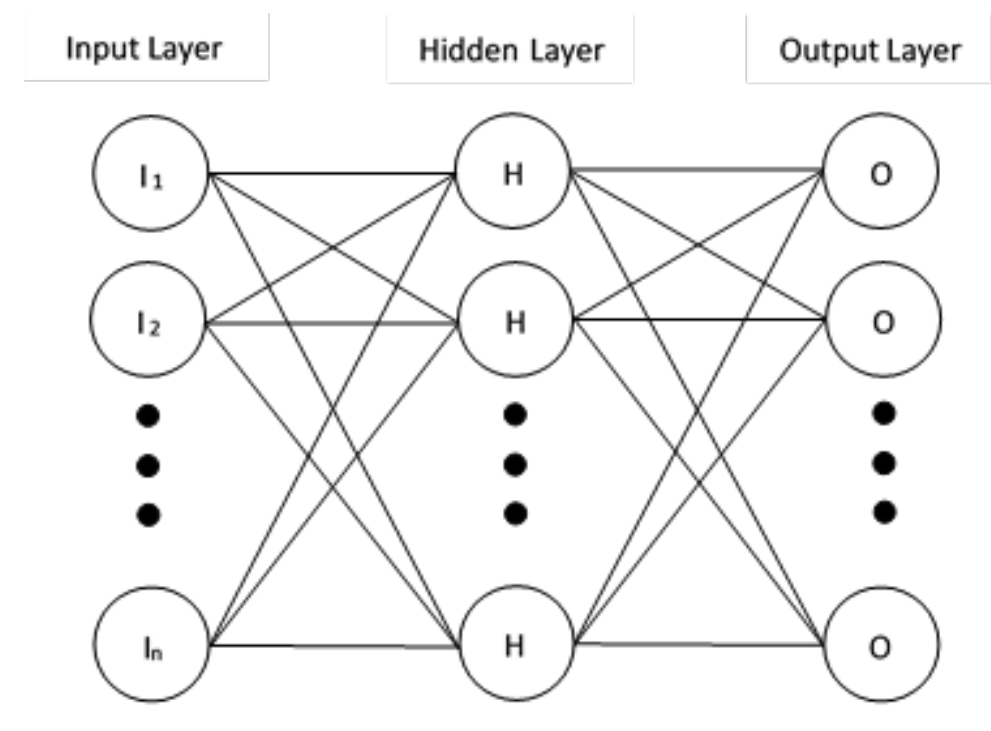

Figure 3: Architecture of Back Propagation Neural Network of experiment

The training algorithm (digital handwritten font from the EMNIST dataset) was used as a tool for training in this research. Expanded testing dataset are digital dataset of 1.456 created letter characters.

\section{RESULTS AND DISCUSSION}

This experiment used the EMNIST dataset of handwritten characters derived from the NIST Special Database 19. Original the EMNIST dataset contains several hundred thousand photos of handwritten alphanumeric characters divided in into six different subgroups.

Total images of Lorem Ipsum words that used in this experiment is 5.600, which mean 100 images for every single created font type. Both letter characters been added to the existing the EMNIST dataset and using of above described Neural Network Architecture, the effectiveness of recognition of these letter characters 
in the prepared dataset was tested. The task was to determine how the network handles the identification of handwritten letter characters in some specific order in word such as maecenas, aliquam, vulputate, fringilla, aenean, fermentum, laoreet, eleifend etc.

Table 3 shows the results of testing of first subgroup of four font families with independent letter characters in seven different letter cuts by standard OCR. The highest accuracy score is achieved by the sets of monoline stroke font family, regular cut with $94.21 \%$. Then follows bold stroke font family, semi bold cut with $93.66 \%$, alternating stroke font family, regular cut with $90.21 \%$, and brush stroke font family, semi bold cut with $87.98 \%$.

The lowest accuracy score is achieved by the sets of brush stroke family, ultra-bold cut with $84.21 \%$, than alternating stroke, thin cut with $88.43 \%$, bold stroke font family, ultra-bold cut with $90.36 \%$, and finally monoline stroke family, also ultra-bold cut with $91.63 \%$.

Table 3: Accuracy results for independent handwritten letter characters in percentage, standard OCR

\begin{tabular}{|c|c|c|c|c|c|}
\hline $\begin{array}{l}\text { Training EMNIST } \\
\text { dataset }\end{array}$ & $\begin{array}{l}\text { Expanded Testing } \\
\text { Dataset }\end{array}$ & $\begin{array}{l}\text { Bold stroke } \\
\text { (indep. } \\
\text { characters) }\end{array}$ & $\begin{array}{l}\text { Alternating } \\
\text { stroke } \\
\text { (indep. } \\
\text { characters) }\end{array}$ & $\begin{array}{l}\text { Monoline } \\
\text { stroke } \\
\text { (indep. } \\
\text { characters) }\end{array}$ & $\begin{array}{l}\text { Brush stroke } \\
\text { (indep. } \\
\text { characters) }\end{array}$ \\
\hline $\begin{array}{l}\text { Digital } \\
\text { handwritten font }\end{array}$ & $\begin{array}{l}\text { Sets of thin cut } \\
\text { Digital handwritten } \\
\text { font }\end{array}$ & $\begin{array}{l}91.92 \\
97.21\end{array}$ & $\begin{array}{l}88.43 \\
96.97\end{array}$ & $\begin{array}{l}92.76 \\
97.44\end{array}$ & $\begin{array}{l}87.22 \\
94.97\end{array}$ \\
\hline $\begin{array}{l}\text { Digital } \\
\text { handwritten font }\end{array}$ & $\begin{array}{l}\text { Sets of ultra-light cut } \\
\text { Digital handwritten } \\
\text { font }\end{array}$ & $\begin{array}{l}91.07 \\
97.72\end{array}$ & $\begin{array}{l}88.92 \\
97.51\end{array}$ & $\begin{array}{l}93.51 \\
97.98\end{array}$ & $\begin{array}{l}87.93 \\
96.58\end{array}$ \\
\hline $\begin{array}{l}\text { Digital } \\
\text { handwritten font }\end{array}$ & $\begin{array}{l}\text { Sets of light cut } \\
\text { Digital handwritten } \\
\text { font }\end{array}$ & $\begin{array}{l}91.84 \\
98.55\end{array}$ & $\begin{array}{l}89.82 \\
97.87\end{array}$ & $\begin{array}{l}93.90 \\
99.43\end{array}$ & $\begin{array}{l}88.28 \\
97.47\end{array}$ \\
\hline $\begin{array}{l}\text { Digital } \\
\text { handwritten font }\end{array}$ & $\begin{array}{l}\text { Sets of regular cut } \\
\text { Digital handwritten } \\
\text { font }\end{array}$ & $\begin{array}{l}93.01 \\
99.17\end{array}$ & $\begin{array}{l}90.21 \\
98.46\end{array}$ & $\begin{array}{l}94.21 \\
99.51\end{array}$ & $\begin{array}{l}87.52 \\
97.96\end{array}$ \\
\hline $\begin{array}{l}\text { Digital } \\
\text { handwritten font }\end{array}$ & $\begin{array}{l}\text { Sets of semi-bold cut } \\
\text { Digital handwritten } \\
\text { font }\end{array}$ & $\begin{array}{l}93.66 \\
99.12\end{array}$ & $\begin{array}{l}89.03 \\
97.98\end{array}$ & $\begin{array}{l}93.92 \\
98.22\end{array}$ & $\begin{array}{l}87.98 \\
97.01\end{array}$ \\
\hline $\begin{array}{l}\text { Digital } \\
\text { handwritten font }\end{array}$ & $\begin{array}{l}\text { Sets of bold cut } \\
\text { Digital handwritten } \\
\text { font }\end{array}$ & $\begin{array}{l}91.97 \\
97.41\end{array}$ & $\begin{array}{l}88.56 \\
96.41\end{array}$ & $\begin{array}{l}92.45 \\
98.78\end{array}$ & $\begin{array}{l}86.03 \\
96.58\end{array}$ \\
\hline $\begin{array}{l}\text { Digital } \\
\text { handwritten font }\end{array}$ & $\begin{array}{l}\text { Sets of ultra-bold cut } \\
\text { Digital handwritten } \\
\text { font }\end{array}$ & $\begin{array}{l}90.36 \\
97.02\end{array}$ & $\begin{array}{l}88.62 \\
96.22\end{array}$ & $\begin{array}{l}91.63 \\
98.08\end{array}$ & $\begin{array}{l}84.21 \\
96.92\end{array}$ \\
\hline
\end{tabular}

In Table 4 are represented the results of testing of first subgroup of four font families with independent letter characters in seven different letter cuts by AI driven OCR. The highest accuracy score is achieved by the sets of bold stroke font family, semi-bold cut with $97.92 \%$. Then follows monoline stroke font family, regular cut with $97.63 \%$, alternating stroke font family, also regular cut with $96.43 \%$, and brush stroke font family, semi-bold cut with $96.12 \%$.

The lowest accuracy is score achieved by the sets of brush stroke family, ultra-bold cut with $92.44 \%$, than alternating stroke, thin cut with $94.41 \%$, monoline stroke font family, ultra-bold cut with $95.83 \%$, and the last one is monoline stroke family, also ultra-bold cut with $95.88 \%$.

Figure 4 shows average percentage increase in recognizability of independent handwritten letter characters using Al driven OCR compared to standard OCR. The biggest increasing rate is for brush stroke font family and amounts $7.79 \%$. The smallest increasing is noted for monoline stroke font family, $3.46 \%$. Bold stroke font family records an increase rate of $4.94 \%$, and alternating stroke font family of $6.59 \%$. Average percentage for subgroup of independent handwritten characters is $5.70 \%$.

Individually speaking it is $2.35 \%$ for monoline stroke font family, regular cut, and $9.80 \%$ for brush stroke font family set, bold cut. 
Table 4: Accuracy results for independent handwritten letter characters in percentage, Al driven OCR

\begin{tabular}{|c|c|c|c|c|c|}
\hline $\begin{array}{l}\text { Training EMNIST } \\
\text { dataset }\end{array}$ & $\begin{array}{l}\text { Expanded Testing } \\
\text { Dataset }\end{array}$ & $\begin{array}{l}\text { Bold stroke } \\
\text { (indep. } \\
\text { characters) }\end{array}$ & $\begin{array}{l}\text { Alternating } \\
\text { stroke (indep. } \\
\text { characters) } \\
\end{array}$ & $\begin{array}{c}\text { Monoline } \\
\text { stroke (indep. } \\
\text { characters) }\end{array}$ & $\begin{array}{l}\text { Brush stroke } \\
\text { (indep. } \\
\text { characters) }\end{array}$ \\
\hline $\begin{array}{l}\text { Digital } \\
\text { handwritten font }\end{array}$ & $\begin{array}{l}\text { Sets of thin cut } \\
\text { Digital handwritten } \\
\text { font }\end{array}$ & $\begin{array}{l}96.52 \\
97.21\end{array}$ & $\begin{array}{l}94.41 \\
96.97\end{array}$ & $\begin{array}{l}96.02 \\
97.44\end{array}$ & $\begin{array}{l}93.98 \\
94.97\end{array}$ \\
\hline $\begin{array}{l}\text { Digital } \\
\text { handwritten font }\end{array}$ & $\begin{array}{l}\text { Sets of ultra-light cut } \\
\text { Digital handwritten } \\
\text { font }\end{array}$ & $\begin{array}{l}96.10 \\
97.72\end{array}$ & $\begin{array}{l}95.92 \\
97.51\end{array}$ & $\begin{array}{l}96.44 \\
97.98\end{array}$ & $\begin{array}{l}94.86 \\
96.58\end{array}$ \\
\hline $\begin{array}{l}\text { Digital } \\
\text { handwritten font }\end{array}$ & $\begin{array}{l}\text { Sets of light cut } \\
\text { Digital handwritten } \\
\text { font }\end{array}$ & $\begin{array}{l}97.03 \\
98.55\end{array}$ & $\begin{array}{l}96.21 \\
97.87\end{array}$ & $\begin{array}{l}97.21 \\
99.43\end{array}$ & $\begin{array}{l}95.49 \\
97.47\end{array}$ \\
\hline $\begin{array}{l}\text { Digital } \\
\text { handwritten font }\end{array}$ & $\begin{array}{l}\text { Sets of regular cut } \\
\text { Digital handwritten } \\
\text { font }\end{array}$ & $\begin{array}{l}97.89 \\
99.17\end{array}$ & $\begin{array}{l}96.43 \\
98.46\end{array}$ & $\begin{array}{l}97.63 \\
99.51\end{array}$ & $\begin{array}{l}94.99 \\
97.96\end{array}$ \\
\hline $\begin{array}{l}\text { Digital } \\
\text { handwritten font }\end{array}$ & $\begin{array}{l}\text { Sets of semi-bold cut } \\
\text { Digital handwritten } \\
\text { font }\end{array}$ & $\begin{array}{l}97.92 \\
99.12\end{array}$ & $\begin{array}{l}96.19 \\
97.98\end{array}$ & $\begin{array}{l}96.26 \\
98.22\end{array}$ & $\begin{array}{l}96.12 \\
97.01\end{array}$ \\
\hline $\begin{array}{l}\text { Digital } \\
\text { handwritten font }\end{array}$ & $\begin{array}{l}\text { Sets of bold cut } \\
\text { Digital handwritten } \\
\text { font }\end{array}$ & $\begin{array}{l}97.42 \\
97.41\end{array}$ & $\begin{array}{l}95.77 \\
96.41\end{array}$ & $\begin{array}{l}96.32 \\
98.78\end{array}$ & $\begin{array}{l}95.83 \\
96.58\end{array}$ \\
\hline $\begin{array}{l}\text { Digital } \\
\text { handwritten font }\end{array}$ & $\begin{array}{l}\text { Sets of ultra-bold cut } \\
\text { Digital handwritten } \\
\text { font }\end{array}$ & $\begin{array}{l}95.88 \\
97.02\end{array}$ & $\begin{array}{l}94.97 \\
96.22\end{array}$ & $\begin{array}{l}95.83 \\
98.08\end{array}$ & $\begin{array}{l}92.44 \\
96.92\end{array}$ \\
\hline
\end{tabular}

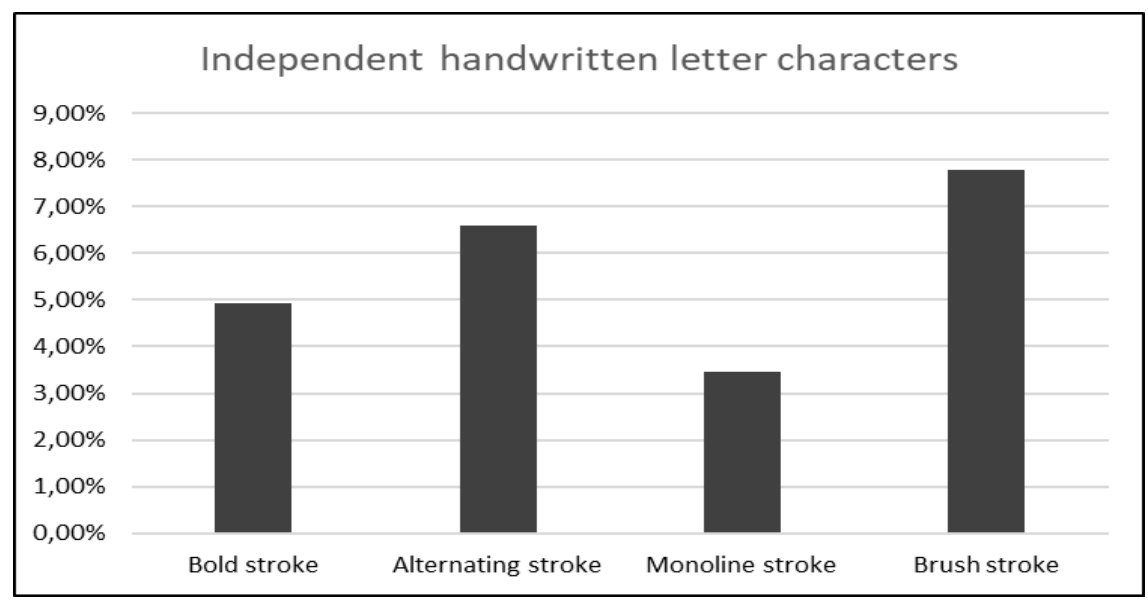

Figure 4: Average percentage increase in recognizability of independent handwritten letter characters using Al driven OCR

Table 5 gives the results of testing of second subgroup of four font families with linked letter characters in seven different letter cuts by standard OCR. The highest accuracy score here is achieved by the sets od monoline stroke font family, bold cut with $88.93 \%$. Then follows brush stroke font family, semi bold cut with $88.44 \%$, bold stroke font family, semi bold cut with $87.12 \%$, and alternating stroke font family, bold cut with $84.88 \%$.

The lowest accuracy score is achieved by the sets of alternating stroke family, thin cut with $82.89 \%$, than brush stroke, ultra-bold cut with $84.49 \%$, bold stroke font family, ultra-bold cut with $85.03 \%$, and lastly monoline stroke family, ultra-light cut with $87.02 \%$.

Table 6 represents the results of testing of second subgroup of four font families with linked letter characters in seven different letter cuts by AI driven OCR. Here the highest accuracy score is achieved by the sets of brush stroke font family, semi-bold cut with $97.92 \%$. Then follows monoline stroke font family, ultra-light cut with $96.43 \%$, alternating stroke font family, bold cut with $96.13 \%$, and bold stroke font family, semi-bold cut with $95.02 \%$. 
The lowest accuracy score is achieved by the sets of alternating stroke family, thin cut with $92.41 \%$, than bold stroke, ultra-bold cut with $93.02 \%$, brush stroke font family, also ultra-bold cut with $94.07 \%$, and finally monoline stroke family, bold cut with $95.21 \%$.

Table 5: Accuracy results for linked handwritten letter characters in percentage, standard OCR

\begin{tabular}{|c|c|c|c|c|c|}
\hline $\begin{array}{l}\text { Training EMNIST } \\
\text { dataset }\end{array}$ & $\begin{array}{l}\text { Expanded Testing } \\
\text { Dataset }\end{array}$ & $\begin{array}{l}\text { Bold stroke } \\
\text { (linked } \\
\text { characters) }\end{array}$ & $\begin{array}{l}\text { Alternating } \\
\text { stroke (linked } \\
\text { characters) }\end{array}$ & $\begin{array}{c}\text { Monoline } \\
\text { stroke (linked } \\
\text { characters) }\end{array}$ & $\begin{array}{l}\text { Brush stroke } \\
\text { (linked } \\
\text { characters) }\end{array}$ \\
\hline $\begin{array}{l}\text { Digital } \\
\text { handwritten font }\end{array}$ & $\begin{array}{l}\text { Sets of thin cut } \\
\text { Digital handwritten } \\
\text { font }\end{array}$ & $\begin{array}{l}85.28 \\
96.47\end{array}$ & $\begin{array}{l}82.89 \\
96.97\end{array}$ & $\begin{array}{l}87.93 \\
96.51\end{array}$ & $\begin{array}{l}86.49 \\
97.61\end{array}$ \\
\hline $\begin{array}{l}\text { Digital } \\
\text { handwritten font }\end{array}$ & $\begin{array}{l}\text { Sets of ultra-light cut } \\
\text { Digital handwritten } \\
\text { font }\end{array}$ & $\begin{array}{l}85.39 \\
97.89\end{array}$ & $\begin{array}{l}83.56 \\
97.51\end{array}$ & $\begin{array}{l}87.02 \\
97.02\end{array}$ & $\begin{array}{l}86.63 \\
95.58\end{array}$ \\
\hline $\begin{array}{l}\text { Digital } \\
\text { handwritten font }\end{array}$ & $\begin{array}{l}\text { Sets of light cut } \\
\text { Digital handwritten } \\
\text { font }\end{array}$ & $\begin{array}{l}86.21 \\
97.58\end{array}$ & $\begin{array}{l}83.92 \\
97.87\end{array}$ & $\begin{array}{l}87.48 \\
97.74\end{array}$ & $\begin{array}{l}86.02 \\
96.03\end{array}$ \\
\hline $\begin{array}{l}\text { Digital } \\
\text { handwritten font }\end{array}$ & $\begin{array}{l}\text { Sets of regular cut } \\
\text { Digital handwritten } \\
\text { font }\end{array}$ & $\begin{array}{l}86.93 \\
98.73\end{array}$ & $\begin{array}{l}84.53 \\
98.46\end{array}$ & $\begin{array}{l}88.22 \\
98.29\end{array}$ & $\begin{array}{l}87.91 \\
97.44\end{array}$ \\
\hline $\begin{array}{l}\text { Digital } \\
\text { handwritten font }\end{array}$ & $\begin{array}{l}\text { Sets of semi-bold cut } \\
\text { Digital handwritten } \\
\text { font }\end{array}$ & $\begin{array}{l}87.12 \\
97.91\end{array}$ & $\begin{array}{l}84.51 \\
97.98\end{array}$ & $\begin{array}{l}88.01 \\
98.03\end{array}$ & $\begin{array}{l}88.44 \\
98.23\end{array}$ \\
\hline $\begin{array}{l}\text { Digital } \\
\text { handwritten font }\end{array}$ & $\begin{array}{l}\text { Sets of bold cut } \\
\text { Digital handwritten } \\
\text { font }\end{array}$ & $\begin{array}{l}86.49 \\
96.25\end{array}$ & $\begin{array}{l}84.88 \\
96.41\end{array}$ & $\begin{array}{l}88.93 \\
98.66\end{array}$ & $\begin{array}{l}85.93 \\
95.78\end{array}$ \\
\hline $\begin{array}{l}\text { Digital } \\
\text { handwritten font }\end{array}$ & $\begin{array}{l}\text { Sets of ultra-bold cut } \\
\text { Digital handwritten } \\
\text { font }\end{array}$ & $\begin{array}{l}85.03 \\
96.98\end{array}$ & $\begin{array}{l}83.98 \\
96.22\end{array}$ & $\begin{array}{l}87.87 \\
97.01\end{array}$ & $\begin{array}{l}84.49 \\
95.04\end{array}$ \\
\hline
\end{tabular}

Table 6: Accuracy results for linked handwritten letter characters in percentage, Al driven OCR

\begin{tabular}{|c|c|c|c|c|c|}
\hline $\begin{array}{l}\text { Training EMNIST } \\
\text { dataset }\end{array}$ & $\begin{array}{l}\text { Expanded Testing } \\
\text { Dataset }\end{array}$ & $\begin{array}{l}\text { Bold stroke } \\
\text { (linked } \\
\text { characters) }\end{array}$ & $\begin{array}{l}\text { Alternating } \\
\text { stroke (linked } \\
\text { characters) }\end{array}$ & $\begin{array}{c}\text { Monoline } \\
\text { stroke (linked } \\
\text { characters) }\end{array}$ & $\begin{array}{l}\text { Brush stroke } \\
\text { (linked } \\
\text { characters) }\end{array}$ \\
\hline $\begin{array}{l}\text { Digital } \\
\text { handwritten font }\end{array}$ & $\begin{array}{l}\text { Sets of thin cut } \\
\text { Digital handwritten } \\
\text { font }\end{array}$ & $\begin{array}{l}93.22 \\
96.47\end{array}$ & $\begin{array}{l}92.41 \\
96.97\end{array}$ & $\begin{array}{l}93.19 \\
96.51\end{array}$ & $\begin{array}{l}94.42 \\
97.61\end{array}$ \\
\hline $\begin{array}{l}\text { Digital } \\
\text { handwritten font }\end{array}$ & $\begin{array}{l}\text { Sets of ultra-light cut } \\
\text { Digital handwritten } \\
\text { font }\end{array}$ & $\begin{array}{l}93.97 \\
97.89\end{array}$ & $\begin{array}{l}93.63 \\
97.51\end{array}$ & $\begin{array}{l}96.43 \\
97.02\end{array}$ & $\begin{array}{l}96.29 \\
95.58\end{array}$ \\
\hline $\begin{array}{l}\text { Digital } \\
\text { handwritten font }\end{array}$ & $\begin{array}{l}\text { Sets of light cut } \\
\text { Digital handwritten } \\
\text { font }\end{array}$ & $\begin{array}{l}93.46 \\
97.58\end{array}$ & $\begin{array}{l}94.06 \\
97.87\end{array}$ & $\begin{array}{l}96.29 \\
97.74\end{array}$ & $\begin{array}{l}97.71 \\
96.03\end{array}$ \\
\hline $\begin{array}{l}\text { Digital } \\
\text { handwritten font }\end{array}$ & $\begin{array}{l}\text { Sets of regular cut } \\
\text { Digital handwritten } \\
\text { font }\end{array}$ & $\begin{array}{l}95.83 \\
98.73\end{array}$ & $\begin{array}{l}95.43 \\
98.46\end{array}$ & $\begin{array}{l}96.17 \\
98.29\end{array}$ & $\begin{array}{l}97.62 \\
97.44\end{array}$ \\
\hline $\begin{array}{l}\text { Digital } \\
\text { handwritten font }\end{array}$ & $\begin{array}{l}\text { Sets of semi-bold cut } \\
\text { Digital handwritten } \\
\text { font }\end{array}$ & $\begin{array}{l}95.02 \\
97.91\end{array}$ & $\begin{array}{l}95.99 \\
97.98\end{array}$ & $\begin{array}{l}95.87 \\
98.03\end{array}$ & $\begin{array}{l}97.92 \\
98.23\end{array}$ \\
\hline $\begin{array}{l}\text { Digital } \\
\text { handwritten font }\end{array}$ & $\begin{array}{l}\text { Sets of bold cut } \\
\text { Digital handwritten } \\
\text { font }\end{array}$ & $\begin{array}{l}93.29 \\
96.25\end{array}$ & $\begin{array}{l}96.13 \\
96.41\end{array}$ & $\begin{array}{l}95.21 \\
95.66\end{array}$ & $\begin{array}{l}94.93 \\
95.78\end{array}$ \\
\hline $\begin{array}{l}\text { Digital } \\
\text { handwritten font }\end{array}$ & $\begin{array}{l}\text { Sets of ultra-bold cut } \\
\text { Digital handwritten } \\
\text { font }\end{array}$ & $\begin{array}{l}93.02 \\
96.98\end{array}$ & $\begin{array}{l}93.17 \\
96.22\end{array}$ & $\begin{array}{l}95.73 \\
97.01\end{array}$ & $\begin{array}{l}94.07 \\
95.04\end{array}$ \\
\hline
\end{tabular}

Figure 5 shows average percentage increase in recognizability of linked handwritten letter characters using Al driven OCR compared to standard OCR. The biggest increasing rate is for alternating stroke font family 
and amounts $10.36 \%$. The smallest increasing is noted for monoline stroke font family, $7.63 \%$. Bold stroke font family records an increase rate of $7.91 \%$, and brush stroke font family of $9.58 \%$. Average percentage for subgroup of independent handwritten characters is $8.87 \%$.

Individually speaking it is $5.26 \%$ for monoline stroke font family, thin cut, and $11.36 \%$ for brush stroke font family set, light cut.

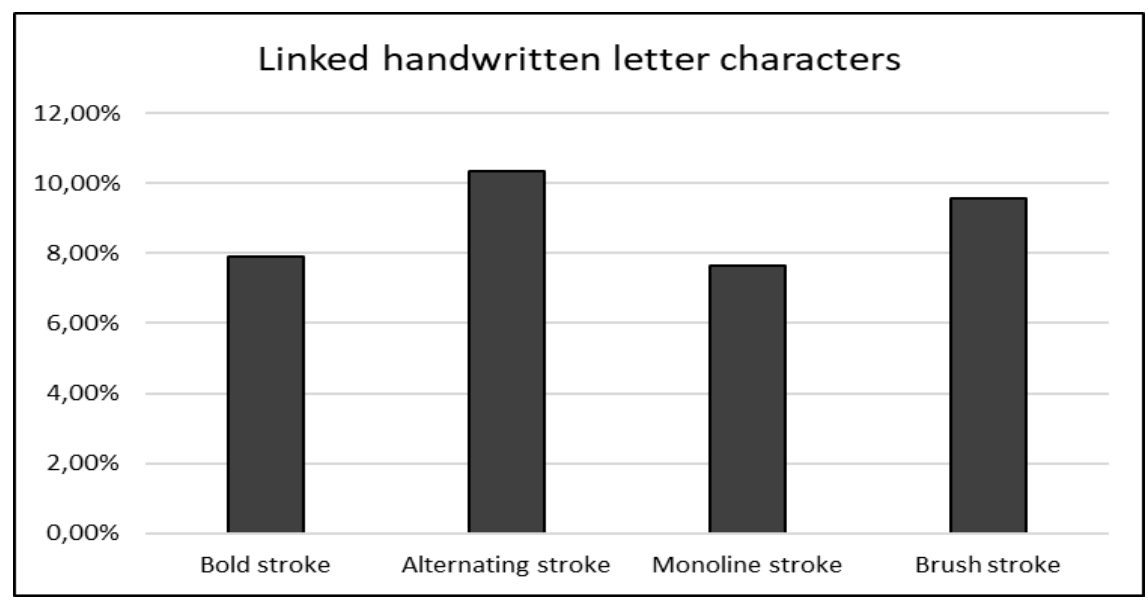

Figure 5: Average percentage increase in recognizability of linked handwritten letter characters using Al driven OCR

An increase in all values was observed, which means that the application of Al driven OCR increased the recognizability of the characters in the sample.

The increase in recognizability using Al driven OCR was expected to bi higher in the subgroup of linked handwritten letter characters because the initial results were lower for this subgroup when using standard OCR.

Analysis of the samples determined that they were deviations are the most pronounced in words with two or more ascenders $(k, b, l, d, h, t)$ and descenders $(g, j, p, q, y)$. If the letter characters are linked by ligatures, the ascending and descending strokes are even less recognizable to the scanners.

In subgroup of independent letter characters, errors were observed in similar rounded lines such as the letter characters $a$, and $e$. In the subgroup of letter characters connected by ligatures, errors were also observed in similar rounded lines such as the letter characters a and e, $m$ and $n$, but also in ascenders $b$ and $\mathrm{I}$, and descenders $\mathrm{g}$ and $\mathrm{q}$.

Here results are based on a small number of tested samples. In future work can be extend to a larger batch pool and for other specific letter characters, and numbers as well. Because OCR is very sensitive, and any disorder can easily confuse similar letter characters it would be good to make software distortion of letter characters in order to increase the number of letter characters and different variations in the database.

Reducing the number of deviations shows that the neural network gives acceptable answers but requires creation of a larger database within about 56,000 different letter characters.

\section{CONCLUSIONS}

Handwritten documents are increasingly being digitized. Therefore, it is important that the base of fonts and individual letter characters be as large as possible. For this purpose, it is useful to create as many digital handwriting fonts as possible. Artificial intelligence helps in the process of identification and classification within a complex database of fonts. This paper describes the application of Al driven OCR based on MLP (Multilayer Perceptron) BPNN (Back Propagation Network) algorithm.

Non-linear increase of $5.70 \%$ for the subgroup of fonts with unrelated characters, and $8.87 \%$ for the subgroup of fonts with ligatures associated with characters. It is therefore indicative of the development of Al driven OCR.

Also, experiment indicates that original the EMNIST dataset could be improved adding a new letter character sets which enable to neural networks for recognition to be more accurate.

There are several areas for future work. The results need to be verified with extended dataset and different kind of algorithm. 


\section{REFERENCES}

[1] Cohen, G., Afshar, S., Tapson, J., van Schaik, A.: "EMNIST: an extension of MNIST to handwritten letters", URL: http://arxiv.org/abs/1702.05373 (last request: 2020-07-13).

[2] Desai, P. A., Bhavikatti, S. N., Patil, R.: "Design and Simulation of Handwritten Text Recognition System", International Journal of Current Engineering and Technology 1, 259-262, 2013.

[3] Driss, S. B., Soua, M., Kachouri, R., Akil, M.: "A comparison study between MLP and Convolutional Neural Network models for character recognition", Proceedings of SPIE Conference on Real-Time Image and Video Processing 2017, (SPIE: Anaheim, California, 2017), pages 1-12.

[4] D’Souza, L., Mascarenhas, M.: “Offline Handwritten Mathematical Expression Recognition using Convolutional Neural Network", Proceedings of International Conference on Information, Communication, Engineering and Technology 2018, (ICICET: Narhe, Pune, India, 2018), pages 1-3.

[5] Grzelak, D., Podlaski, K., Wiatrowski, G.: "Analyze the effectiveness of an algorithm for identifying Polish characters in handwritting based on neural machine learning technologies", Journal of King Saud University - Computer and Information Sciences 08 (1-7), 2019. doi: https://doi.org/10.1016/j.jksuci.2019.08.001.

[6] Jafri, R., Arabnia, H. R.: "A Survey of Face Recognition Techniques", Journal of Information Processing Systems 5 (2), 41-68, 2009. doi: https://doi.org/10.1016/j.jksuci.2019.08.001.

[7] Maitra, D. S., Bhattacharya, U., Parui, K.: "CNN Based Common Approcah to Handwritten Character Recognition of Multiple Scripts", Proceedings of $13^{\text {th }}$ International Conference on Document Analysis and Recognition 2015, (ICDAR: Tunis, Tunisia, 2015), pages 1021-1025.

[8] [8] Phangtriastu, M. R., Harefa, J., Tanoto, D. F.; "Comparison between neural network and support vector machine in optical character recognition", Proceedings of $2^{\text {nd }}$ International Conference on Computer and Computational Intelligence 2017, (ICCSCI: Bali, Indonesia, 2017), pages 351-357.

[9] Rao, N. V., Sastry, A. S. C. S., Chakravarthy, A. S. N., Kalyanchakravarthi, P.: “Optical Character Recognition Technique Algorithms", Journal of Theoretical and Applied Information Technology 83 (2), 275-282, 2016.

[10] Zheng, Y., Iwana, B. K., Uchida, S.: "Mining the Displacement of Max-pooling for Text recognition", Pattern Recognition 93, 558-569, 2019. doi: 10.1016/j.patcog.2019.05.014.

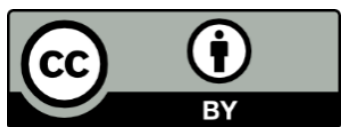

(C) 2020 Authors. Published by the University of Novi Sad, Faculty of Technical Sciences, Department of Graphic Engineering and Design. This article is an open access article distributed under the terms and conditions of the Creative Commons Attribution license 3.0 Serbia (http://creativecommons.org/licenses/by/3.0/rs/). 


\section{AUTHOR INDEX - GRID 2020}

A

Adamović S. // 199, 261, 457

Arman Kandirmaz E. // 221, 387

Agbaba J. // 243

Attia M. // 355

Asrizal Razali M. // 525

Aidinli K. // 531

Adams || R. // 623

Agić A. // 627, 719

B

Bates I. // 57

Buben V. // 93

Birtane H. // 169

Banjanin B. // 199, 269, 457

Bečelić-Tomin M. // 205, 235, 289

Bunyamin Zelzele 0. // 221, 387

Bolanča Mirković I. // 251

Bešlić M. // 251

Bošnjaković G. // 269, 335, 667

Bota J. // 299

Beyler Çigil A. // 363

Bauk S. // 421

Boeva R. // 429

Bizjak M. // 499

Brozović M. // 571

Banić D. // 571

Beris Y. // 609

Bratić D. // 719, 725

C

Cigula T. // 101, 119

Czene T. // 147

Caglar T. // 153

$\check{C}$

Čuk M. // 499, 507

Čavić M. // 597

Čavić D. // 597

D

Durnyak B. // 93, 379

Dedijer S. // 131, 269, 281

Dragić M. // 437
Dimovski V. // 457, 667

Dujmović A. // 545

Držková M. // 631

$\bigoplus$

Đurđević S. // 199, 537, 685

Dž

Džimbeg-Malčić V. // 57

E

Efkolidis N. // 531

F

Franken G. // 347

G

Golik Krizmanić M. // 101

Gvoić V. // 235, 243, 289

Gregor-Svetec D. // 307

Gegeckiene L. // 313

Grujić D. // 437

Gabrijelčič Tomc H. // 485, 561, 659

Gülaçti I. E. // 609, 677

Güner A. // 677

$\mathrm{H}$

Hudika T. // 101, 119

Horváth C. // 413

Hassim N. // 525

Hoffman-Walbeck T. // 623

I

Ivanišević A. // 475

Iskra A. // 485, 493

Ismail N. // 525

J

Jamnicki Hanzer S. // 109

Jurič I. // 131, 281, 667 
Janicki P. // 229

Janković B. // 437

Jakšić A. // 651

Jovančić K. // 699

K

Karlovits I. // 39, 177, 191

Katana M. // 101

Kulčar R. // 109, 161

Kašiković N. // 131, 139, 443

Kukuruzović D. // 139

Koltai L. // 147, 413

Krajnović I. // 161

Kulić Mandić A. // 205, 235, 289

Kerkez Đ. // 205, 235, 289

Komarov S. // 229

Klančar K. // 327

Khokhlova M. // 407

Katić M. // 469

Katić I. // 475

Košak K. // 507

Kyratsis P. // 531, 591

Kovačević D. // 571

Khloud Khaled A. // 577

Kolarov R. // 585

Knežević I. // 597

Kuzmanović S. // 597

L

Lutskiv M. // 93, 379

Lavrič G. // 177

Lužanin 0. // 235

Lončarski M. // 243

Leovac Maćerak A. // 289

Lilić A. // 457

Lošonc A. // 475

Lakićević M. // 585

M

Miketić N. // 63, 199, 261

Milošević R. // 139, 443

Milić Keresteš N. // 281, 685, 699

Mahović Poljaček S. // 317

Madžar A. // 317

Mohamed N. // 355

Maňúrová K. // 413

Mustač S. // 421
Majnarić I. // 421

Miloš S. // 421

Milkov A. // 429

Muck D. // 499, 507, 515

Minaoglou P. // 531

Manavis A. // 591

Mauzner F. // 627

Mandić L. // 627

Mitrović K. // 651

Mijatović S. // 667

N

Novaković D. // 131, 537, 685

Nuša Kočevar T. // 499, 507, 561

Nazlidou I. // 591

Nedeljković U. // 699, 707

0

Ozcan A. // 21, 153, 387

P

Plazonić I. // 57

Pinćjer I. // 63, 199, 261

Pavlova N. // 81

Petriaszwili G. // 93, 229, 379

Pavlović Ž. // 139, 243, 281

Petrović S. // 139, 443, 685

Pucar Milidrag G. // 205, 289

Prica M. // 235, 243

Petković G. // 251, 299

Pál M. // 269, 281, 457

Poljak S. // 281

Pibernik J. // 317, 627

Pukhova E. // 373, 407

Politis A. // 395

Pivar M. // 515

Pušnik N. // 545

Penčić M. // 597

Plot M. // 659

$\mathrm{R}$

Rožić M. // 161

Ružičić B. // 437

Rackov M. // 597

Roudný P. // 631

Roškar S. // 659 
Shepita P. // 93, 379

Yilan G. // 153

Strižić Jakovljević M. // 119

Yordanov S. // 429

S. Hussein M.A. // 355

Spiridonov I. // 429

Z

Stančić M. // 437

Simić I. // 585

Spahiu T. // 591

Selič P. // 643

Spajić J. // 651

Stanić Loknar N. // 719, 725

$\check{S}$

Zeljković Ž. // 443, 537, 685

Zivlak J. // 469

$\dot{Z}$

Żołek-Tryznowska Z. // 93, 185

Širol P. // 109

Šumiga B. // 191

Šumiga B. // 191

Šumrada T. // 307

Šafranj J. // 469

$\check{Z}$

Žličarić M. // 119

Žarko J. // 707

T

Tomić I. // 63, 261, 281

Todorova D. // 69, 81

Tomašegović T. // 101, 317

Trematerra P. // 213

Tomašević Pilipović D. // 235, 289

Tubić A. // 243

Trochoutsos C. // 395

U

Urbas R. // 139, 643

Učakar A. // 643

V

Vrabič Brodnjak U. // 69, 213, 327

Vukoje M. // 109, 161, 251

Vasiljević S. // 243

Vladić G. // 269, 335, 667

Venyte I. // 313

Vereshchagin V. // 373, 407

Vujčić Đ. // 437

W

Więcek M. // 185 



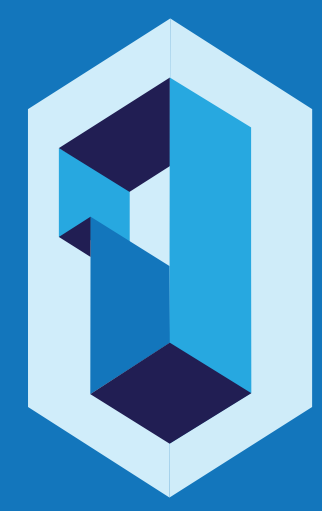

10. INTERNATIONAL SYMPOSIUM

GRAPHIC ENGINEERING AND DESIGN

12-14. NOVEMBER 2020

\section{GR ID \\ 2020}

UNIVERSITY OF NOVI SAD

FACULTY OF TECHNICAL SCIENCES

DEPARTMENT OF GRAPHIC ENGINEERING AND DESIGN 